\title{
Oceanography and
}

Marine Biology AN ANNUAL REVIEW

\section{Volume 55}

\author{
Editors \\ S. J. HAWKINS \\ A. J. EVANS \\ A.C. DALE \\ L. B. FIRTH \\ D. J. HUGHES \\ I. P. SMITH \\ Founder Editor \\ HAROLD BARNES
}

CRC $\underset{\text { Daslor S Prancis Group }}{\mathrm{CRC} \text { Press }}$ 


\section{OCEANOGRAPHY and \\ MARINE BIOLOGY AN ANNUAL REVIEW \\ Volume 55}




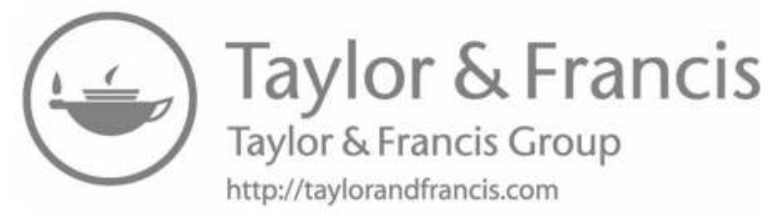




\title{
OCEANOGRAPHY and
}

MARINE BIOLOGY AN ANNUAL REVIEW

Volume 55

\section{Editors}

\author{
S. J. Hawkins
}

Ocean and Earth Science, University of Southampton, National Oceanography Centre, UK

and

The Marine Biological Association of the UK, The Laboratory, Plymouth, UK

\section{A. J. Evans}

Ocean and Earth Science, University of Southampton,

National Oceanography Centre, UK

and

The Marine Biological Association of the UK, The Laboratory, Plymouth, UK

A. C. Dale

Scottish Association for Marine Science, Argyll, UK

L. B. Firth

School of Biological and Marine Sciences, Plymouth University, UK

D. J. Hughes

Scottish Association for Marine Science, Argyll, UK

I. P. Smith

School of Biological Sciences, University of Aberdeen, United Kingdom
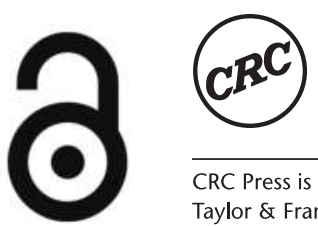

CRC Press

Taylor \& Francis Group

Boca Raton London New York

CRC Press is an imprint of the

Taylor \& Francis Group, an informa business 


\author{
CRC Press \\ Taylor \& Francis Group \\ 6000 Broken Sound Parkway NW, Suite 300 \\ Boca Raton, FL 33487-2742
}

(c) 2017 by S.J. Hawkins, A.J. Evans, A.C. Dale, L.B. Firth, D.J. Hughes, and I.P. Smith

CRC Press is an imprint of Taylor \& Francis Group, an Informa business

No claim to original U.S. Government works

Printed on acid-free paper

Version Date: 20170206

International Standard Book Number-13: 978-1-138-19786-2 (Hardback)

This book contains information obtained from authentic and highly regarded sources. Reasonable efforts have been made to publish reliable data and information, but the author and publisher cannot assume responsibility for the validity of all materials or the consequences of their use. The authors and publishers have attempted to trace the copyright holders of all material reproduced in this publication and apologize to copyright holders if permission to publish in this form has not been obtained. If any copyright material has not been acknowledged please write and let us know so we may rectify in any future reprint.

With the exceptions of chapters 3, 4, 5, and 6, no part of this book may be reprinted, reproduced, transmitted, or utilized in any form by any electronic, mechanical, or other means, now known or hereafter invented, including photocopying, microfilming, and recording, or in any information storage or retrieval system, without written permission from the publishers.

Chapters 3, 4, 5, and 6 are available for free in PDF format as Open Access at www.crcpress.com. They have been made available under a Creative Commons Attribution - Non Commercial - No Deriviatives 4.0 license.

For permission to photocopy or use material electronically from this work, please access www.copyright.com (http:// www.copyright.com/) or contact the Copyright Clearance Center, Inc. (CCC), 222 Rosewood Drive, Danvers, MA 01923, 978-750-8400. CCC is a not-for-profit organization that provides licenses and registration for a variety of users. For organizations that have been granted a photocopy license by the CCC, a separate system of payment has been arranged.

Trademark Notice: Product or corporate names may be trademarks or registered trademarks, and are used only for identification and explanation without intent to infringe.

Visit the Taylor \& Francis Web site at

http://www.taylorandfrancis.com

and the CRC Press Web site at

http://www.crcpress.com 


\section{Contents}

$\begin{array}{lll}\text { Preface } & \text { vii }\end{array}$

Introduction to the Special Issue ix

Ally J. Evans, Louise B. Firth, Andrew Dale, David Hughes, I. Philip Smith

\& Stephen J. Hawkins

Filling in the Grazing Puzzle: A Synthesis of Herbivory in Starfish

Aline S. Martinez, Maria Byrne \& Ross A. Coleman

Intertidal Boulder-Fields: A Much Neglected, but Ecologically Important, Intertidal Habitat M.G. Chapman

Ecological Dominance along Rocky Shores, with a Focus on Intertidal Ascidians

Marc Rius, Peter R. Teske, Patricio H. Manríquez, Rocío Suárez-Jiménez, Christopher D.

McQuaid \& Juan Carlos Castilla

Giant Clams (Bivalvia: Cardiidae: Tridacninae): A Comprehensive Update of Species

and Their Distribution, Current Threats and Conservation Status

Mei Lin Neo, Colette C.C. Wabnitz, Richard D. Braley, Gerald A. Heslinga, Cécile Fauvelot, Simon Van Wynsberge, Serge Andréfouët, Charles Waters, Aileen Shau-Hwai Tan, Edgardo

D. Gomez, Mark J. Costello \& Peter A. Todd

How Anthropogenic Activities Affect the Establishment and Spread of Non-Indigenous

Species Post-Arrival

Emma L. Johnston, Katherine A. Dafforn, Graeme F. Clark, Marc Rius \& Oliver Floerl

A Review of Herbivore Effects on Seaweed Invasions

Swantje Enge, Josefin Sagerman, Sofia A. Wikström \& Henrik Pavia

Author Index

Systematic Index

Subject Index 


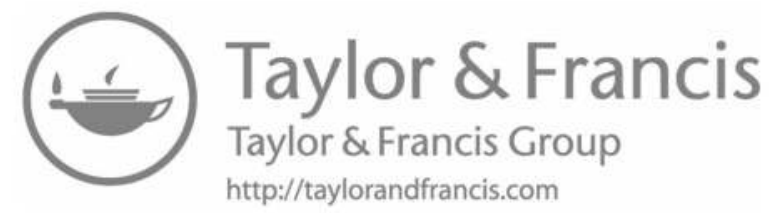




\section{Preface}

The 55th volume of Oceanography and Marine Biology: An Annual Review (OMBAR) contains six reviews that cover a range of topics, reflecting the wide readership of the series. A brief introductory comment outlines the inspiration for review articles in this special issue that stemmed from contributions to and discussions at the 2015 Aquatic Biodiversity \& Ecosystems conference in Liverpool, UK.

OMBAR welcomes suggestions from potential authors for topics that could form the basis of appropriate reviews. Contributions from physical, chemical and biological oceanographers that seek to inform both oceanographers and marine biologists are especially welcome. Because the annual publication schedule constrains the timetable for submission, evaluation and acceptance of manuscripts, potential contributors are advised to contact the editors at an early stage of manuscript preparation. Contact details are listed on the title page of this volume.

The editors gratefully acknowledge the willingness and speed with which authors complied with the editors' suggestions and requests and the efficiency of CRC Press, especially Jennifer Blaise, Marsha Hecht and John Sulzycki, in ensuring the timely appearance of this volume. 


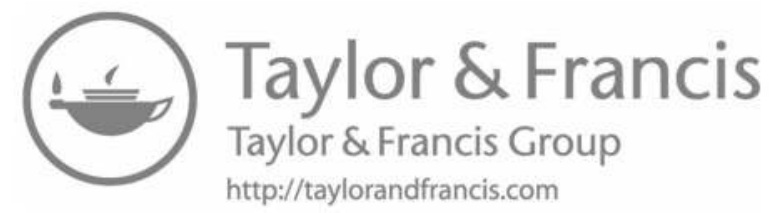




\title{
Introduction to the Special Issue
}

\author{
ALLY J. EVANS ${ }^{1,2}$, LOUISE B. FIRTH ${ }^{3}$, ANDREW DALE ${ }^{4}$, \\ DAVID HUGHES ${ }^{4}$, I. PHILIP SMITH ${ }^{5} \&$ STEPHEN J. HAWKINS ${ }^{1,2}$ \\ ${ }^{1}$ Ocean and Earth Science, National Oceanography Centre \\ Southampton, Southampton, SO14 3ZH, UK \\ ${ }^{2}$ The Marine Biological Association of the UK, The Laboratory, \\ Citadel Hill, Plymouth, PL1 2PB, UK \\ ${ }^{3}$ School of Biological and Marine Sciences, Plymouth University, Plymouth, PL4 8AA, UK \\ ${ }^{4}$ Scottish Association for Marine Science, Scottish Marine \\ Institute, Oban, Argyll, Scotland, PA37 1QA, UK \\ ${ }^{5}$ School of Biological Sciences, University of Aberdeen, Aberdeen, Scotland, AB24 2TZ, UK
}

In this 55th volume of Oceanography and Marine Biology: An Annual Review (OMBAR), we present a special issue stemming directly and indirectly from contributions and discussions at the 2015 Aquatic Biodiversity \& Ecosystems Conference in Liverpool, UK, plus related work from research teams represented at that conference.

The Aquatic Biodiversity \& Ecosystems Conference was organised by Dr Louise Firth at the University of Liverpool in August-September 2015. The overarching theme was "evolution, interactions and global change in aquatic ecosystems", with a number of subthemes, within which over 250 papers were presented to delegates from 30 different countries. The meeting partially followed up on the 1990 Plant-Animal Interactions in the Marine Benthos Conference hosted by Professor Stephen Hawkins 25 years previously, which itself was prompted by a 1983 OMBAR review on grazing of intertidal algae by marine invertebrates (Hawkins \& Hartnoll 1983).

Through structured workshops and informal discussions at the 2015 conference, suggestions were garnered for review articles for this special OMBAR issue, and for chapters in the forthcoming book Interactions in the Marine Benthos-A Regional and Habitat Perspective, a follow-up to Plant-Animal Interactions in the Marine Benthos (John et al. 1992) (which was inspired by the 1990 conference), to be published by Cambridge University Press. The neglected fields of herbivory in starfish (Martinez et al. 2017) and intertidal boulder-fields (Chapman 2017) are synthesized to stimulate further interest in these topics. Ecological dominance along rocky shores is discussed, focussing on ascidians (Rius et al. 2017). Neo et al. (2017) review the ecology of giant clams. Johnston et al. (2017) consider the spread of non-indigenous species. Enge et al. (2017) take this theme further by discussing defences against herbivory of invasive seaweeds. The themes of the conference-evolution, interactions and global change - are all explored in these contributions.

We hope that this special issue will be of value to oceanographers and marine biologists alike, and will inspire further research where knowledge gaps have been identified. We look forward to working with new contributors and welcome suggestions for reviews for future volumes. We would especially value contributions from oceanographers for coming issues.

We sadly heard of the passing away of Professor Roger Hughes at the conference in August 2015. As the then Editor in Chief of OMBAR, this special issue was planned with Roger. We dedicate this volume to his memory as a superb scientist, excellent editor, fine and fanatical fisherman and great guitarist. 


\section{INTRODUCTION TO THE SPECIAL ISSUE}

\section{References}

Chapman, M.G. 2017. Intertidal boulder-fields: a much neglected, but ecologically important, intertidal habitat. Oceanography and Marine Biology: An Annual Review 55, 35-53.

Enge, S., Sagerman, J., Wikström, S.A. \& Pavia, H. 2017. A review of herbivore effects on seaweed invasions. Oceanography and Marine Biology: An Annual Review 55, 421-440.

Hawkins, S.J. \& Hartnoll, R.G. 1983. Grazing of intertidal algae by marine invertebrates. Oceanography and Marine Biology: An Annual Review 21, 195-282.

John, D.M., Hawkins, S.J. \& Price, J.H. 1992. Plant-Animal Interactions in the Marine Benthos. Oxford: Clarendon Press on behalf of the Systematics Association.

Johnston, E.L., Dafforn, K.A., Clark, G.F., Rius, M. \& Floerl, O. 2017. How anthropogenic activities affect the establishment and spread of non-indigenous species post-arrival. Oceanography and Marine Biology: An Annual Review 55, 389-419.

Martinez, A.S., Byrne, M. \& Coleman, R.A. 2017. Filling in the grazing puzzle: a synthesis of herbivory in starfish. Oceanography and Marine Biology: An Annual Review 55, 1-34.

Neo, M.L., Wabnitz, C.C.C., Braley, R.D., Heslinga, G.A., Fauvelot, C., Van Wynsberge, S., Andréfouët, S., Waters, C., Tan, A.S.-H., Gomez, E.D., Costello, M.J. \& Todd, P.A. 2017. Giant clams (Bivalvia: Cardiidae: Tridacninae): a comprehensive update of species and their distribution, current threats and conservation status. Oceanography and Marine Biology: An Annual Review 55, 87-390.

Rius, M., Teske, P.R., Manríquez, P.H., Suárez-Jiménez, R., McQuaid, C.D. \& Castilla, J.C. 2017. Ecological dominance along rocky shores, with a focus on intertidal ascidians. Oceanography and Marine Biology: An Annual Review 55, 55-84. 


\title{
FILLING IN THE GRAZING PUZZLE: A SYNTHESIS OF HERBIVORY IN STARFISH
}

\author{
ALINE S. MARTINEZ 1 , MARIA BYRNE ${ }^{1} \&$ ROSS A. COLEMAN ${ }^{*}$ \\ ${ }^{1}$ Coastal and Marine Ecosystems Group, Marine Ecology Laboratories (A11), \\ School of Life and Environmental Sciences, The University of Sydney \\ New South Wales 2006, Australia \\ *Corresponding author: Ross A. Coleman \\ e-mail: ross.coleman@sydney.edu.au
}

Herbivory is an important ecological process controlling community structure and function in almost all ecosystems. The effects of herbivores on algal assemblages depend primarily on consumer and algal traits, but the strength of this interaction is contingent on physical and biological processes. Marine herbivory is particularly intense, where grazers can remove around $70 \%$ of primary production. Present understanding of marine herbivory is largely based on well-studied groups including herbivorous fishes, gastropods, crustaceans and sea urchins. Herbivory in other marine taxa is poorly understood, but nonetheless important. For instance, grazing by starfish has the potential to strongly affect algal assemblages. Most starfish feed by extruding their stomach and digesting their food externally. This feeding mechanism is distinctive and complex, and evolutionarily advantageous as it allows individuals to explore many different food sources. Variation in the feeding habits of herbivorous starfish is intriguing because some species are very specialized whereas others are more generalist, and the reasons for those variations are not well understood. Some herbivorous starfish are obligate herbivores while others vary from herbivory to carnivory between life stages or between populations within the same species. The question that then arises is how well we are able to predict grazing pressure from complex feeding habits on benthic systems? This review provides a synthesis of herbivory in starfish showing that: the majority of species forage on microalgae and soft tissue macroalgae; fidelity to an algal diet appears to be related to the size of individuals; and, feeding habits are likely to change with variation in food availability. Directions for future studies on the biology and ecology of herbivorous starfish are suggested to better understand variation in species feeding behaviour. Elucidating the mechanisms that contribute to variation in the behaviour of herbivorous starfish is crucial to predict the effects that these species exert on the structure of marine benthic communities. The influence of omnivorous species also warrants more detailed study. Such investigations are important in the context of climate change, given the potential for species invasions associated with range expansions.

\section{Introduction}

Herbivores play a key role in the world's ecosystems by consuming primary production and altering habitat structure. Mammalian herbivory, including inter alia grazing and browsing, is well known to directly affect the distribution of plants in terrestrial systems (Hempson et al. 2015), whereas the most important herbivores in structuring benthic communities in freshwater aquatic systems are 
snails, insects, crustaceans and small vertebrates (Huntly 1991, Steinman 1996). In marine ecosystems, fish, molluscs, small crustaceans and sea urchins have been shown to dramatically affect the structure of marine benthic communities (Hawkins \& Hartnoll 1983, Hawkins et al. 1992, Coleman et al. 2006, Poore et al. 2012, Poore et al. 2014). Thus far, the strongest known impact on a marine habitat, in terms of change in marine algal/macrophyte canopy in the absence of a herbivore, is for molluscs in rocky intertidal habitats (Poore et al. 2012).

The effects of herbivores on marine plants or microalgal assemblages depend primarily on the feeding apparatus of the consumer and the interactions of these with the susceptibility of the primary producer to grazing (Hawkins et al. 1992). The feeding mechanism determines what resources herbivores can exploit (Steneck \& Watling 1982, Hawkins et al. 1989, Kennish \& Williams 1997), whereas food traits (e.g. detectability, toughness, palatability and digestibility etc.) will affect the intake or intensity of consumption (Lubchenco \& Cubit 1980, Lubchenco \& Gaines 1981, Duffy \& Hay 1990, Norton et al. 1990, Paul et al. 2001, Dolecal \& Long 2013). Variation in grazing pressure is also associated with the size and mobility of herbivores. Small and/or sedentary herbivores (e.g. amphipods, limpets) are likely to have local impacts on the assemblage while bigger and/or more mobile species (e.g. fish, sea urchins) require a broader foraging range and can affect assemblages at larger scales (Lawrence 1975, Hay 1984, Norton et al. 1990, Duffy \& Hay 1991, Vergés et al. 2009). Apart from size and mobility of herbivores, abundance and composition of herbivores will together play an important role in the magnitude of the effects of grazing, thereby affecting the spatial heterogeneity and diversity of algal assemblages (Lubchenco \& Gaines 1981, BenedettiCecchi et al. 2005, Jenkins et al. 2008, Griffin et al. 2010).

Although there is a vast literature on the ecology of plant-animal interactions, knowledge from marine systems is concentrated on a few groups of herbivores, i.e. fish, sea urchins, crabs, amphipods and gastropod grazers (Poore et al. 2012). There are a few gaps that need to be addressed in order to clarify grazing pressure by different herbivores. This is the case for starfish species, which are abundant and distributed worldwide. Research on the feeding behaviour of starfish has largely focused on predatory species (e.g. Brun 1972, Paine 1974, 1976, Town 1980, Keesing \& Lucas 1992, Keesing 1995, Himmelman et al. 2005, Scheibling \& Lauzon-Guay 2007, Estes et al. 2011, Mueller et al. 2011, Menge \& Sanford 2013). This is because numerous large and non-cryptic starfish species are carnivores and play an important role in controlling densities of prey (Chesher 1969, Porter 1972, Paine 1974, Gaymer \& Himmelman 2008, Kenyon \& Aeby 2009, Pratchett et al. 2009, Uthicke et al. 2009; Kayal et al. 2012, Baird et al. 2013, Pratchett et al. 2014). Several species of starfish have been reported to also feed on other resources such as detritus, dead animals, and macroand microalgae (for a review, see Sloan 1980, Jangoux 1982b). These species have been considered to be omnivores, however their diet is poorly known because of the difficulty in identification of gut contents, especially because of their peculiar extra-oral feeding mechanism.

Most starfish feed by everting their cardiac stomach and directly secreting enzymes from the epithelium onto the food item and thereby digest their food externally. This feeding mechanism is rare among other animals and allows starfish to utilize many different food types. Despite using the same extra-oral feeding mechanism, diet varies among starfish species, ranging from carnivores feeding on specific prey items to omnivorous feeders and herbivores (for a review, see Sloan 1980, Jangoux 1982b).

The variation in feeding biology among starfish species is related to digestive tract anatomy and tube foot morphology (Jangoux 1982a). There is, however, poor knowledge of the causes of variation in feeding habits among starfish species and populations. This is a particular concern for our understanding of those starfish recorded as feeding on plant or microphyte resources because of the lack of information on their ecological role as herbivores. Understanding the mechanisms involved with a herbivorous diet in starfish is important to predict the potential impacts of grazing by these animals on the structure of benthic assemblages. Therefore the aim of this review is to identify the main findings and the fundamental gaps in knowledge on the ecology of herbivorous starfish, using 
a systematic review of the literature. We compile information of starfish species that forage on any source of plant or microphytes and present a synthesis on the different aspects of the ecology of herbivory in starfish. We describe the food source exploited by herbivorous starfish, the changes in time and space on the use of food resource, and discuss the possible mechanisms driving these variations. We also highlight the potential function of herbivorous starfish in controlling the distribution of algal assemblages and the limited studies on interactions between herbivorous starfish and other herbivores. We expect that this synthesis will encourage researchers to investigate in detail the functional ecology of herbivorous starfish in marine benthic ecosystems.

\section{Data collection and definition of terminology}

Literature on starfish that forage on algae and/or marine macrophytes was compiled by searching the ISI Web of Science database (Jan 1900-Jan 2015) using the following criteria: TOPIC: (starfish or "sea star" or seastar or asteroidea) AND TOPIC: (herb* or graz*) AND TOPIC: (macrophyte* or alga* or seagrass* or eelgrass* or seaweed*). We selected every article that cited or described algal or vascular plant material in the feeding or diet of starfish species. The compilation was supplemented by subsequently searching material cited within those articles including published journal articles and unpublished theses. We also gathered information from published reviews on starfish diet (Sloan 1980, Jangoux 1982b) and searched the references cited therein. The information extracted from the literature included species name, food resource exploited, foraging behaviour, distribution (habitat and region) and size of starfish. Any detailed or more relevant information on feeding habits of a starfish was noted where appropriate. Starfish scientific names are presented as the current accepted species name according to the world Asteroidea database (accessed at http://www.marinespecies.org/asteroidea on Jan 7th, 2015). Previous species names in some of the references cited in this review can be found in Appendix 1.

Hereafter true macrophytes are referred to as "plants". Macroalgae and microalgae are used to distinguish multi- and unicellular algae. We consider that microalgae correspond to any biofilm assemblage (largely prokaryotes and microalgae). Algae are also considered in functional groups according to the classification of Steneck \& Dethier (1994). Finally, it is important to keep in mind that all data of starfish presented as foraging on macroalgae or plant does not necessarily mean that the starfish is feeding on the macroalgae or plant per se, but may be consuming associated epiphytic organisms.

\section{Composition of diet}

Identifying the target plant or algal food source exploited by starfish species was used to detect components of the benthos that are likely to be affected by asteroid grazing. We found 57 species whose diet consisted entirely or partially of algae across a variety of habitats and ecosystems (Table 1). The great majority of starfish (90\%) that consume any source of plant/algae are found on hard-bottom ecosystems, where $30 \%$ are exclusive to coral reefs and $32 \%$ to rocky shores (mostly temperate). The remaining $28 \%$ of species are found in hard and soft bottom systems, including seagrass beds. Only $10 \%$ are exclusive to seagrass and sand/mud sediments. The information on the feeding habits of starfish within different habitats is often descriptive and lacked accurate evidence of diet especially for those species that are found on sediments. After compiling information from the literature, however, a clear pattern of diet emerged for starfish that forage on algal/plant resources.

The most frequently documented algal group exploited by starfish were those that comprise biofilms. Biofilms usually contain a mix of diatoms, cyanobacteria, bacteria, spores of macroalgae and other microorganisms embedded in a matrix of extra-polymer substances (Anderson 1995, Decho 2000). The majority of the species (77\%, 44 out of $57 \mathrm{spp}$.) were reported feeding on epibenthic biofilms on different substrata (Table 1). Thus, starfish feeding on biofilm were identified 


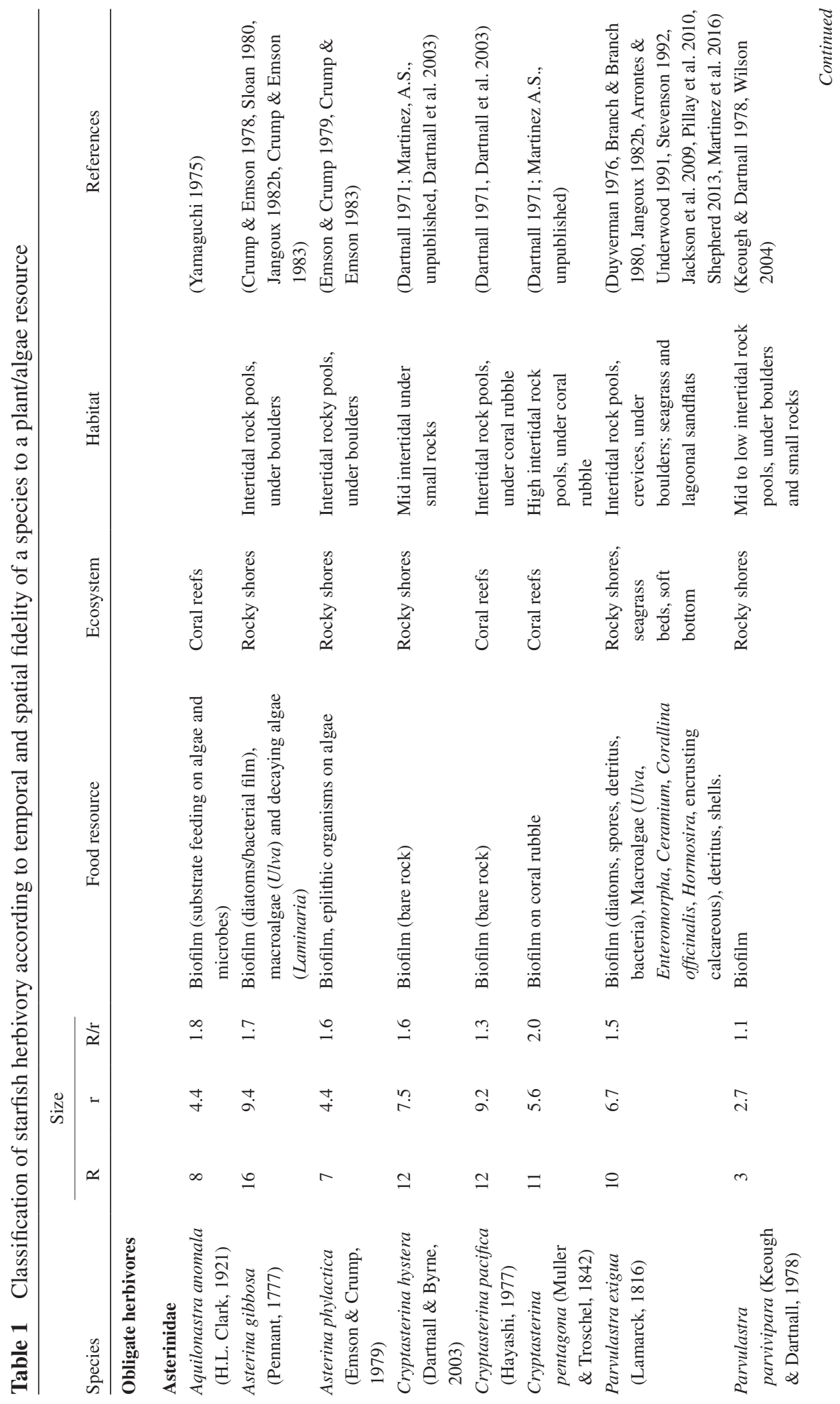




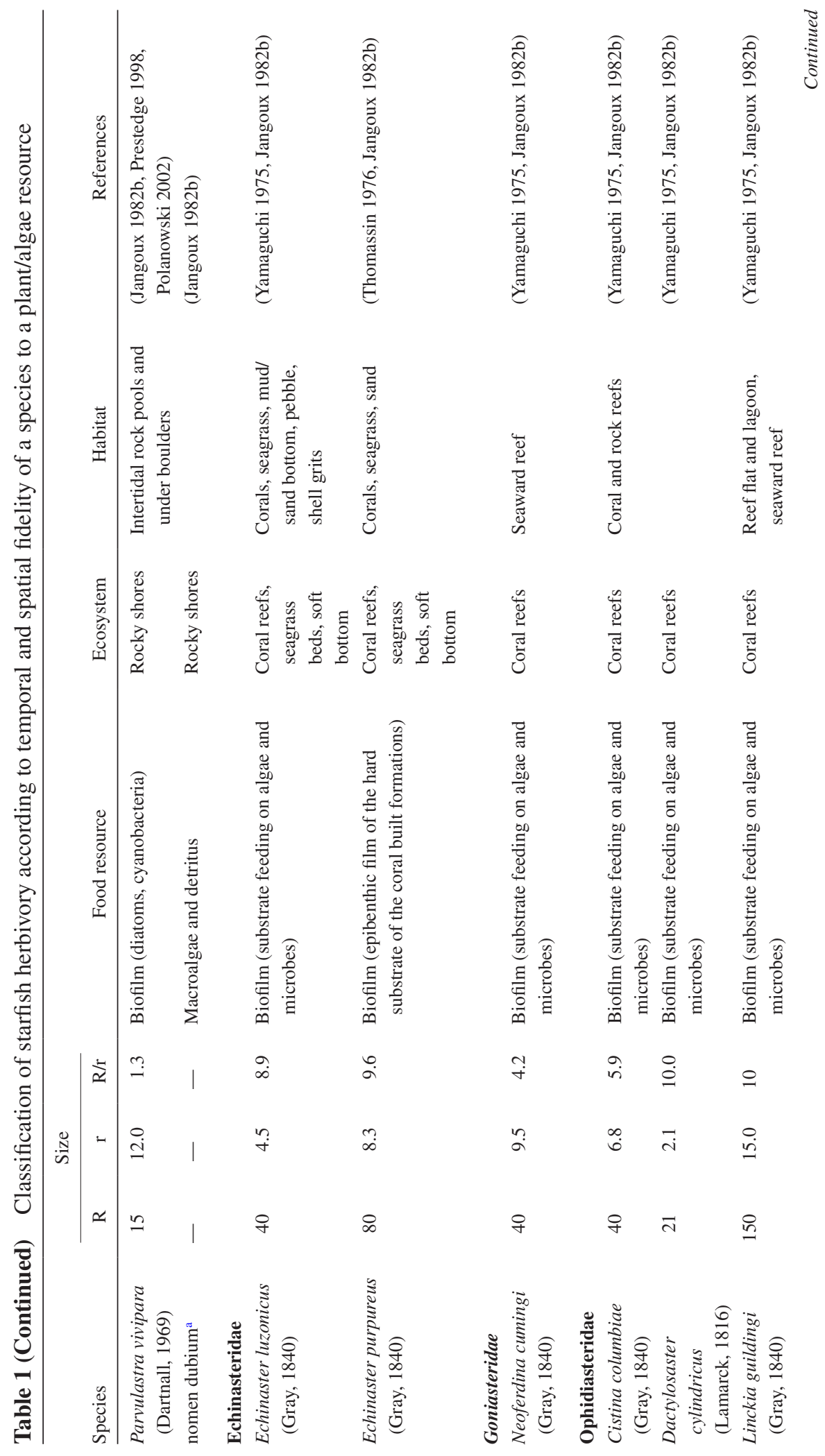




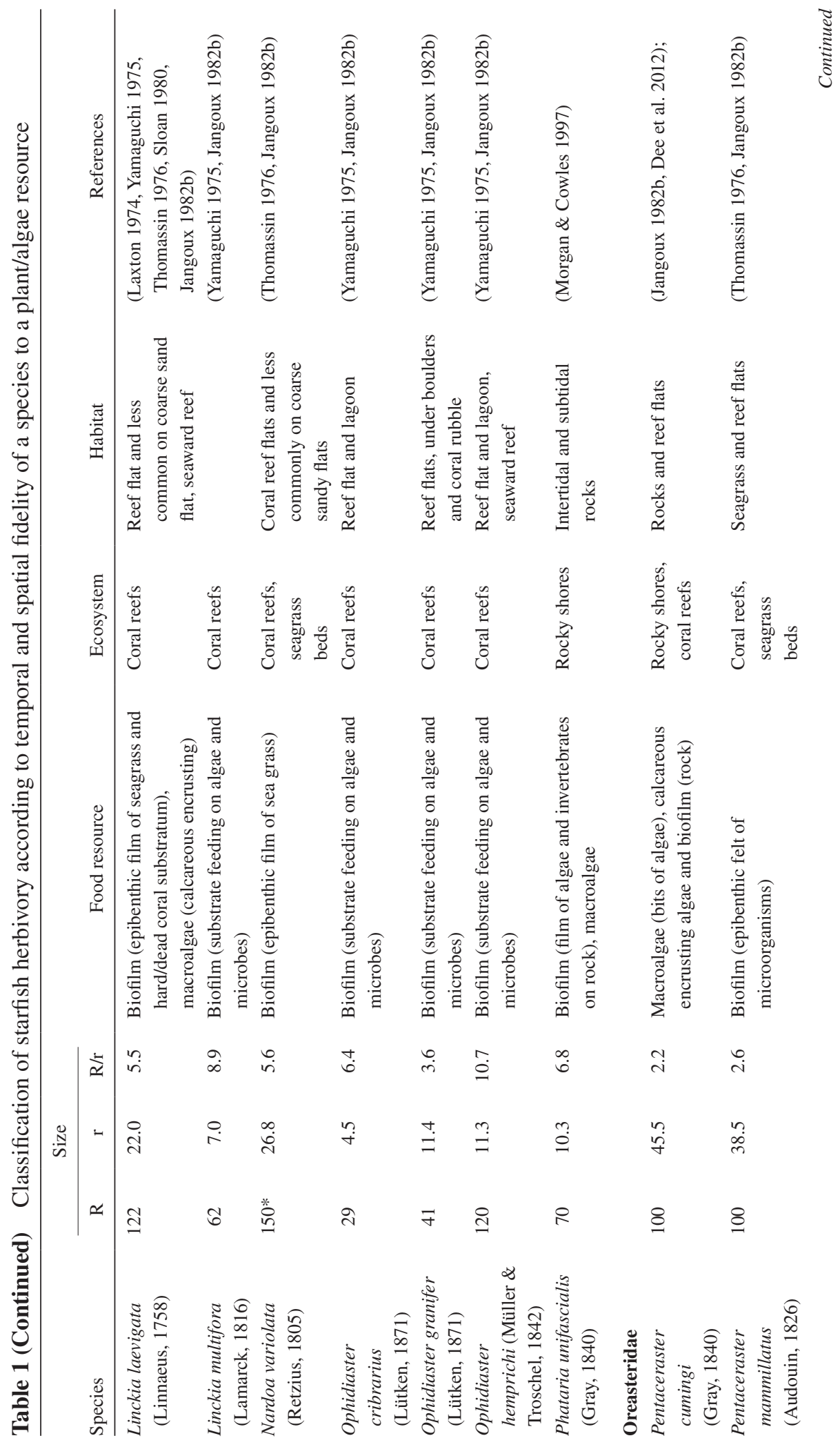




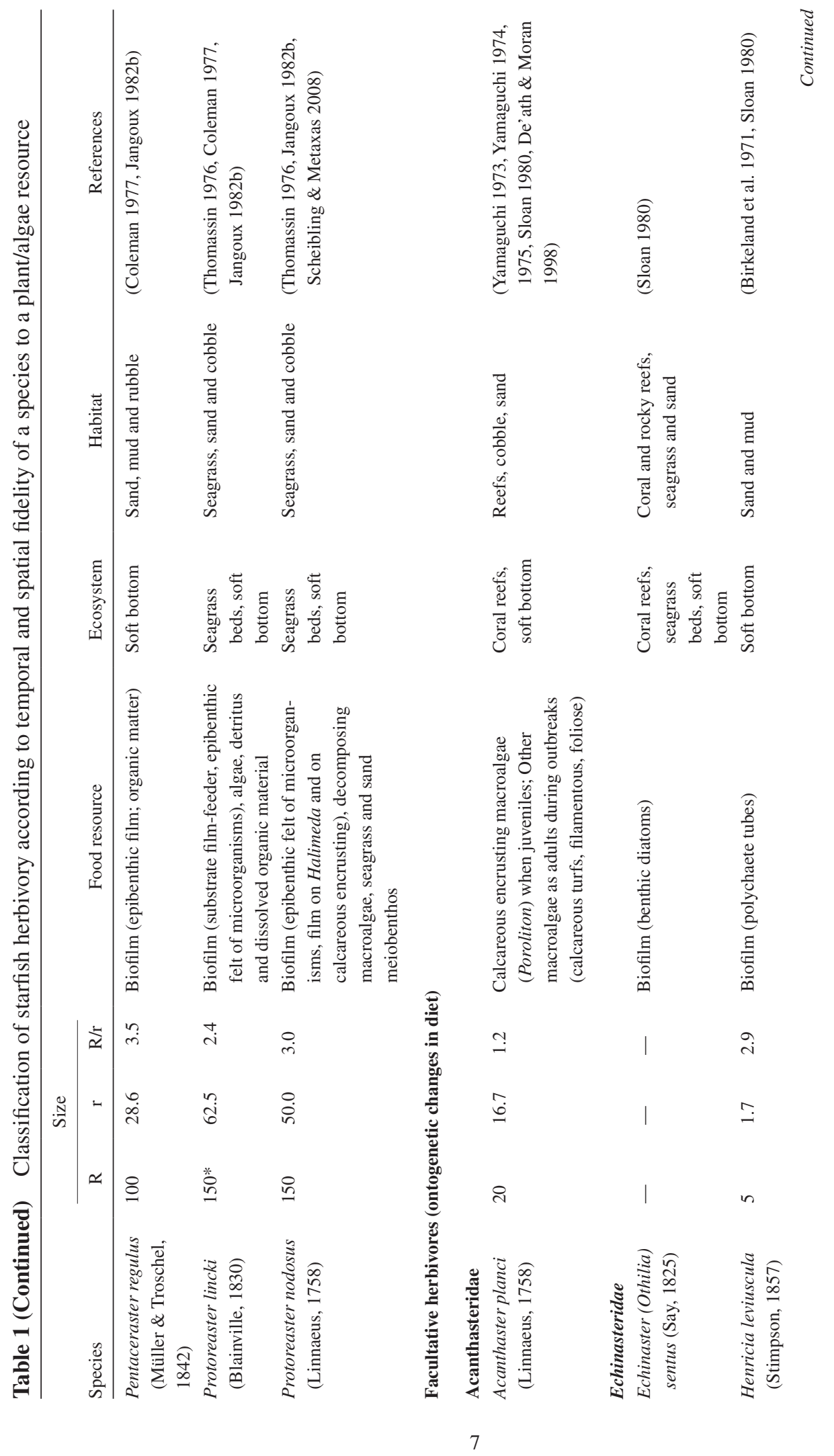




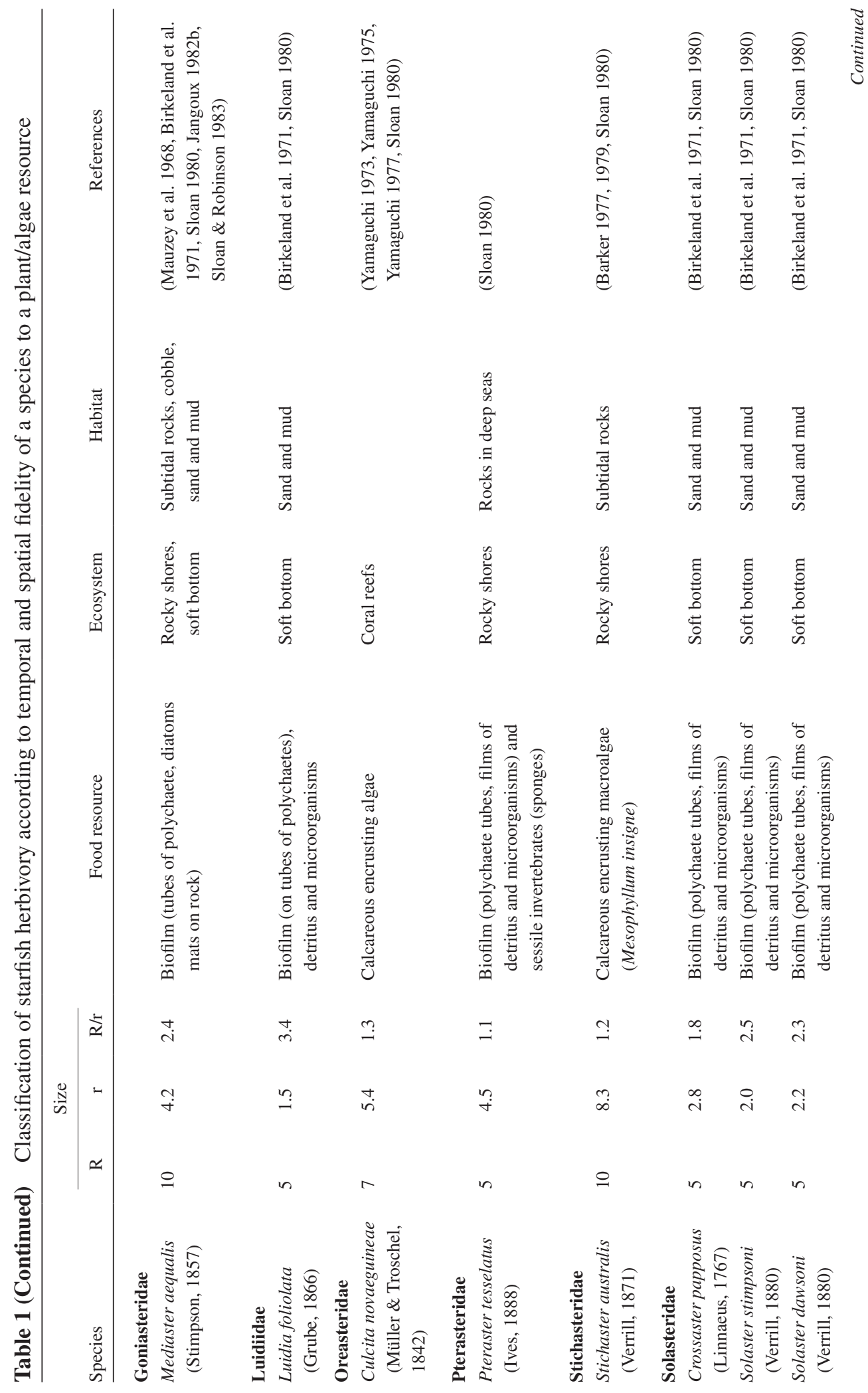


FILLING IN THE GRAZING PUZZLE: A SYNTHESIS OF HERBIVORY IN STARFISH

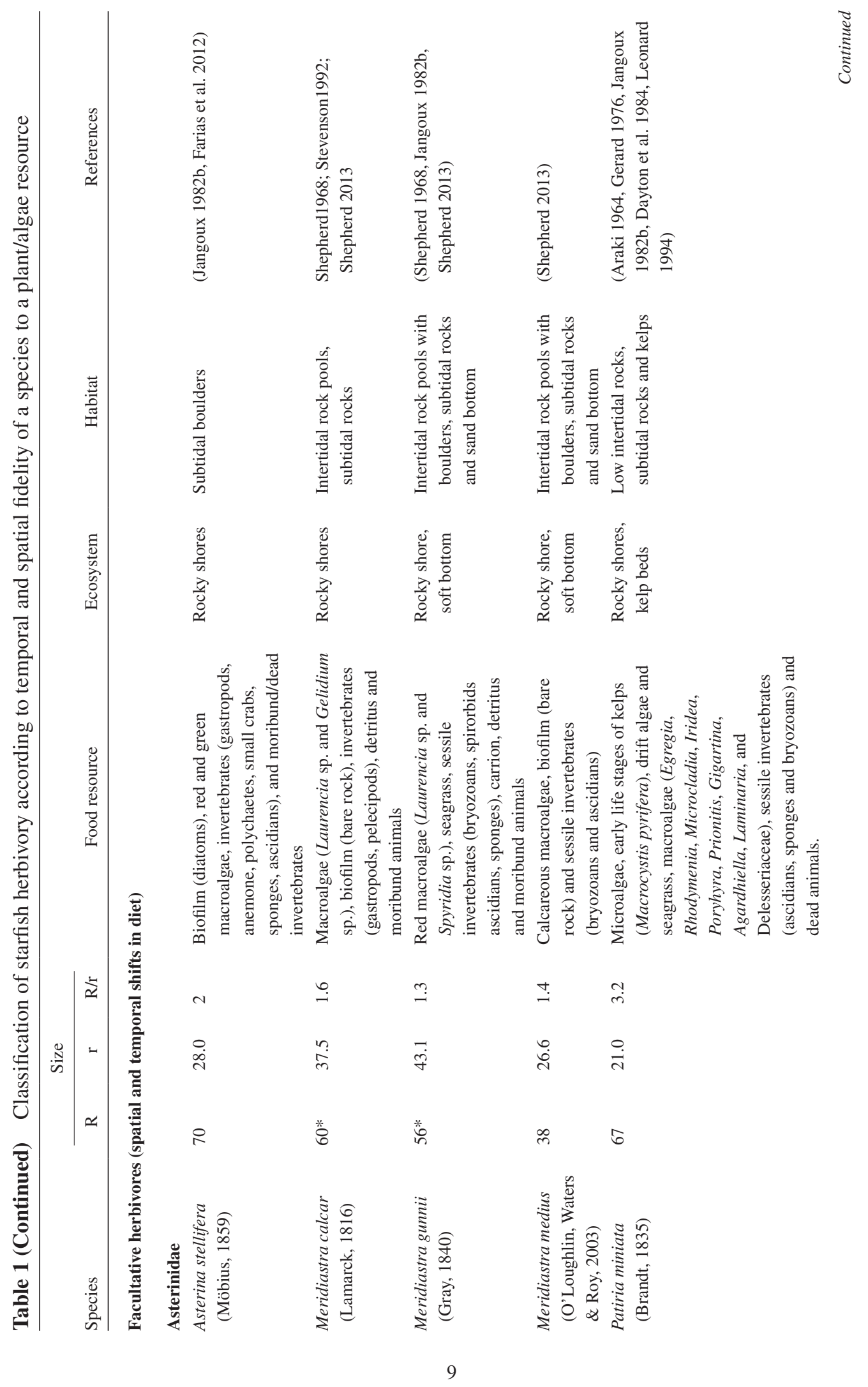




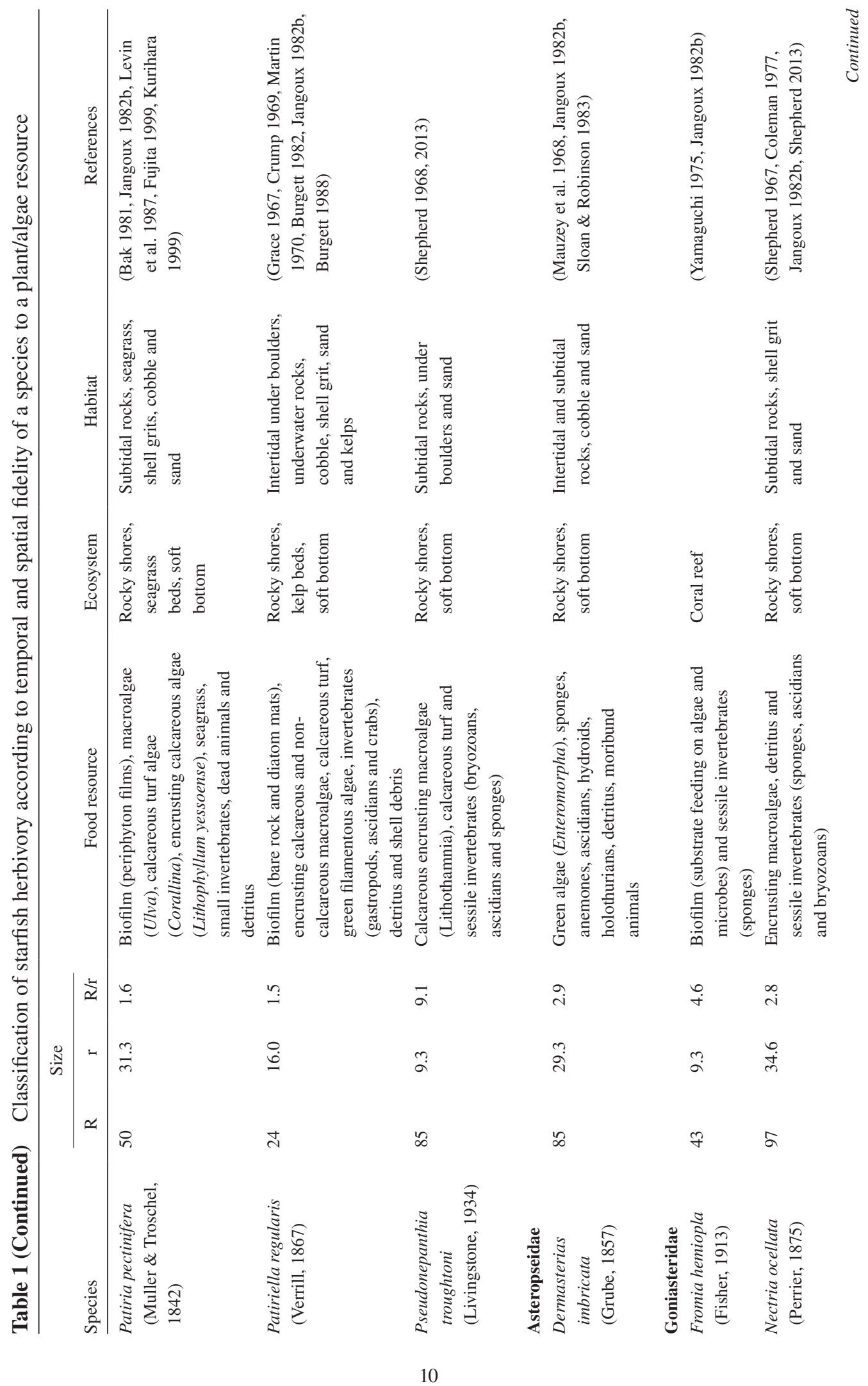




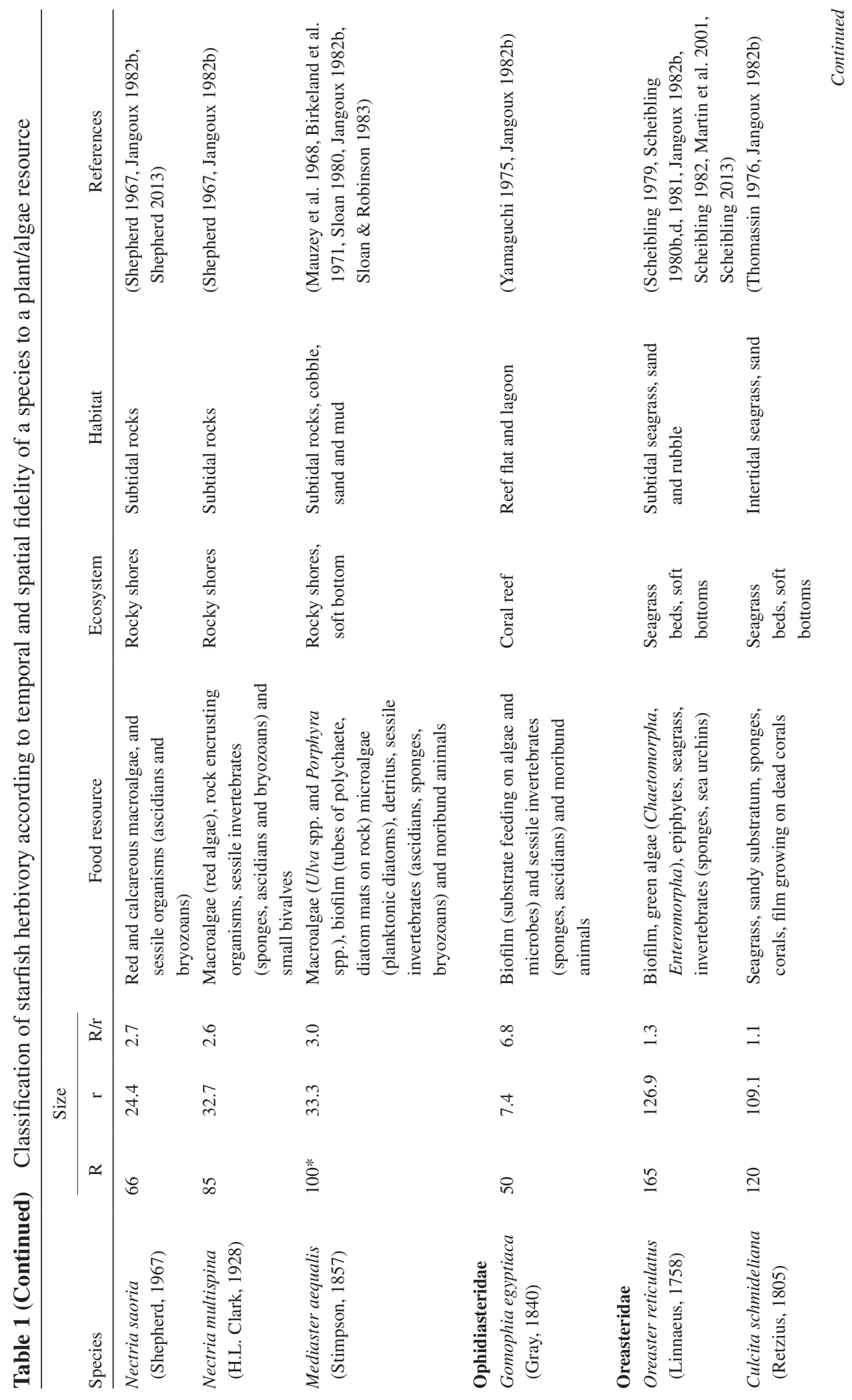




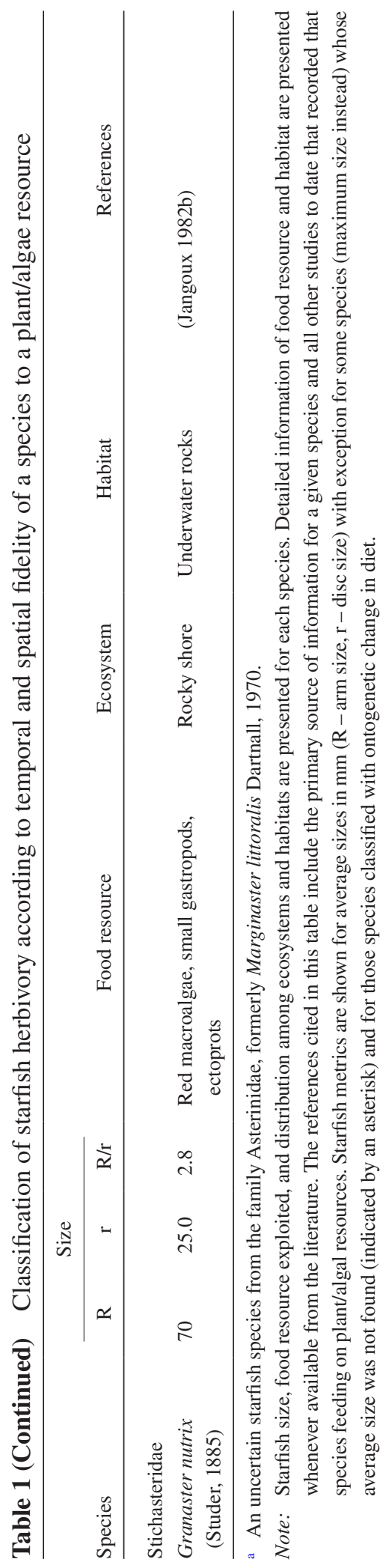


as species feeding on "bare rock", "diatoms", "diatom mats on rock", "films of dead corals, detritus, tubes of polychaetes, shells, macroalgae, seagrass", "microalgae", "epibenthic film", "bacterial film", "epilithic organisms on algae" and "epibenthic felt of microorganisms"; or characterized as "substratal film-feeder" and "substratal feeding on algae and microbes".

Biofilms are one of the main food resources that are also exploited by several grazing gastropods. One of the reasons that gastropods forage on this food resource is that their feeding abilities are limited by the physical characteristics of their radular feeding apparatus (Steneck \& Watling 1982, Hawkins et al. 1989). Asteroids do not have any feeding apparatus such as radulae, Aristotle's lantern in sea urchins or teeth (e.g. fish) that can mechanically rasp, cut or bite the algae from the substratum. The algal food resource utilized by herbivorous starfish relies on the digestive capacity of their stomach. Feeding on biofilms could be a cost-efficient source of food for starfish, since diatoms, bacteria and algal sporelings are protected only by individual cell walls, which are easier to break down compared to the structures of multicellular macrophytes. Macrophytes not only have thick walls, but also exhibit complex chemical defences (Hay 2009).

The enzymes produced in the pyloric ceca of some starfish (e.g. Oreaster reticulatus, Patiria miniata, Patiriella regularis), are capable of digesting some oligosaccharides and polysaccharides that are the sugar reserves of plants and algae (e.g. sucrose, trehalose, amylose, and laminarinose), but they have a weak effect on, or failed to break down, the structural components of plant/algal cell walls such as cellulose, alginate, agar, and carrageenan (Araki 1964, Araki \& Giese 1970, Martin 1970, Scheibling 1980c). This suggests that starfish are potentially capable of digesting macroalgae, but that feeding on these algae with thick cell walls might not be cost-effective. Still some starfish seem to feed on macroalgae, but on less structured thalli forms. Soft-structured macrophytes such as soft foliose (e.g. Ulva spp.) and filamentous algae (e.g. Ceramium, Chaetomorpha, etc.) appear to constitute the main group of macroalgae in the diet of some herbivorous starfish. These algae can be intensively grazed by several herbivores including snails, amphipods, isopods, crabs, and fish (e.g. Choat 1982, Hawkins \& Hartnoll 1983, Arrontes 1990, Poore 1994, Kennish \& Williams 1997). This is because soft filamentous and foliose algae are generally easy to digest, have rapid growth rates and energy intake, and do not offer strong resistance to herbivory (Littler \& Littler 1980, Littler \& Arnold 1982, Steneck \& Dethier 1994). The cell walls of soft and thin thalli algae are generally structured in a simple uni- or multiseriate cell configuration, which are not differentiated and heavily corticated unlike those of thick leathery or calcareous or crustose algae (Steneck \& Dethier 1994). Thus, starfish could benefit from feeding on those soft algae by disrupting their simple cell walls with their enzymes and accessing the digestible cell content (Kristensen 1972, Scheibling 1980a). This hypothesis needs to be addressed through investigation of the digestive capacity of herbivorous species.

The fact that starfish are not able to readily break down the cell walls of plants/macroalgae raises the question of whether asteroids are able to feed on these more complex-structured primary producers. The diet of Asterina gibbosa, Patiria miniata and Protoreaster nodosus includes macroalgal detritus (Gerard 1976, Crump \& Emson 1978, Scheibling \& Metaxas 2008), and it is reasonable that these starfish species can eat decaying algae as the cell walls are already damaged. Indeed, feeding on decomposing macroalgae by Patiria miniata enhanced the nutritional value of the food source compared to intact layers of the algae (Gerard 1976). Some starfish species, however, were described as feeding on calcareous turf algae, calcareous and non-calcareous encrusting algae, red corticated algae and seagrass (Table 1). There is no certainty whether those starfish were actually feeding on the macroalgae itself or on the epiphytes or biofilm on those macrophytes. Some authors argue that starfish probably eat the epilithic organisms that grow on the macroalgae, but many authors noted that the plant/algae area on which a starfish had their stomach extruded became discoloured (Araki 1964, Crump 1969, Yamaguchi 1973, Scheibling 1979, Scheibling 1982, Levin et al. 1987, Leonard 1994, Farias et al. 2012). This is notably visible in calcareous algae, which may look bright orange or white after starfish feeding (Figure 1A,B). The physical structure of 

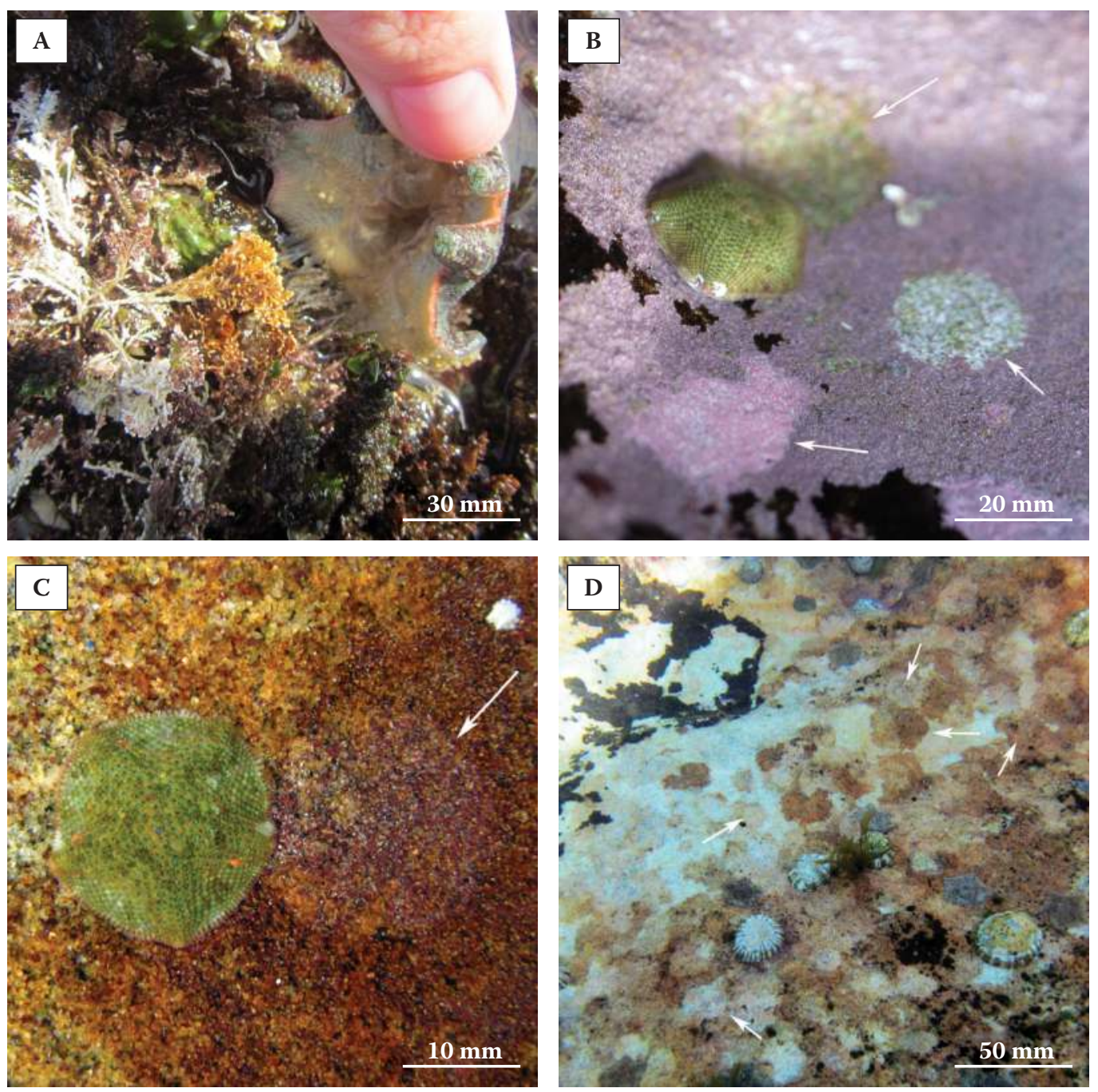

Figure 1 Discolouration of algae and scars caused by starfish herbivory: (A) Calcareous turf discoloured (bright orange) by Meridiastra calcar feeding (Photo: Aline Martinez); (B-D) Feeding scars of Parvulastra exigua on (B) encrusting calcareous algae (Photo: Ross Coleman), on (C) bare rock, in detail (Photo: Aline Martinez), and (D) around rock pools on open rock (Photo: Aline Martinez).

those macrophytes, however, seems to not be affected by the starfish feeding. Indeed, studies of the effects of starfish grazing on calcareous algae showed that the top layer of live tissue on the algae was removed after being grazed, but the structure of the cell walls remained intact (Barker 1979, Burgett 1982, Fujita 1999). Hence it is more likely that starfish are targeting epiphytic organisms growing on the macroalgae than the macroalgae itself, although Bak (1981) showed that Patiria pectinifera intensely consumed eelgrass.

In summary, it seems that the plant/algal resources exploited by starfish are limited by their digestive enzymes. These enzymes can break down unicellular components of the biofilm and might be able to disrupt the cell walls of soft filamentous and foliose algae to readily digest and assimilate material from these macrophytes. Moreover, it is likely that starfish foraging on more robust macroalgae are eating epiphytes and other organisms growing on the thalli. Whether or not the starfish benefits from the apparently digested (discoloured) area on these macrophytes is not known. 


\section{Categories of herbivory}

The definition of trophic guilds (e.g. carnivores, herbivores, omnivores etc.) in asteroid echinoderms is often convoluted and not clear for species that are not strictly carnivores. Trying to distinguish between herbivorous and omnivorous starfish becomes complicated because the behaviour of herbivorous species can vary across time (amount or type of plant/algae consumed by individuals varies at different times) and space (individuals at different places have different diets). There are also species that are herbivorous only during a specific life stage, usually the juvenile stage (e.g. Yamaguchi 1973, Barker 1977, 1979, Sloan 1980; Kamya et al. 2016) whereas other species might forage for their entire life on algae (e.g. Laxton 1974, Arrontes \& Underwood 1991, Prestedge 1998, Wilson 2004, Jackson et al. 2009). Differentiating herbivorous behaviour becomes more complicated when the same species displays different feeding habits between populations, locations or seasons (e.g. Araki 1964, Mauzey et al. 1968, Shepherd 1968, Leonard 1994, Scheibling 2013). Therefore, we approached this review by classifying starfish into different herbivore status depending on temporal and spatial fidelity of a species to an algal resource. Thus, starfish species were classified into obligate and facultative herbivores (Table 1).

\section{Obligate herbivores}

Starfish species that primarily feed on algae were classified as obligate herbivores and are considered herbivorous starfish sensu stricto. Some species were noted to feed on detritus in addition to algae and were also included in the obligate herbivorous category. While detritus may be a range of decaying material, it is unlikely to include dead animals because starfish foraging on dead or decomposing animals are clearly identified in the literature. Obligate herbivores also include some species that, while foraging primarily on algae, on very rare occasions are reported to feed on animal-derived food resources, which was the case for Parvulastra exigua and Pentaceraster cumingi (Branch \& Branch 1980, Dee et al. 2012).

Most herbivorous starfish (70\%) belong to the family Asterinidae and Ophidiasteridae. The Asterinidae includes, Aquilonastra anomala, Asterina gibbosa, A. phylactica, Cryptasterina hystera, C. pentagona, Parvulastra exigua, P. parvivipara and P. vivipara (Dartnall 1971, Yamaguchi 1975, Duyverman 1976, Crump \& Emson 1978, Keough \& Dartnall 1978, Emson \& Crump 1979, Jangoux 1982b, Chen \& Chen 1992, Prestedge 1998; Dartnall et al. 2003). These herbivores are small (average radius varies from 3 to $15 \mathrm{~mm}$; see Figure 2A for example) and many occur in intertidal pools on temperate rocky shores. There are also tropical species that occur in intertidal pools of coral reefs (Aquilonastra anomola and Cryptasterina pentagona). These herbivorous asterinids feed on surficial biofilms on rocks and coral rubble. Parvulastra exigua and Asterina gibbosa may also feed on macroalgae (encrusting algae, soft filamentous and foliose algae, and decaying algae), but these contribute a small portion of their diet (Crump \& Emson 1978, Branch \& Branch 1980).

The species from the Ophidiasteridae are nearly 10 orders of magnitude bigger (average radius varies from 30 to $160 \mathrm{~mm}$ ) than those in the Asterinidae. Herbivorous ophidiasterids include species from the genera Cistina, Dactylosaster, Linckia, Nardoa, Ophidiaster and Phataria and occur mostly in tropical coral reef flats and lagoons. Although they are bigger than the asterinids, the extruded stomach (ca. 5-20 mm radius) of the biggest ophidiasterids (i.e. Linckia spp.; Figure 2B) is similar in size to that of the small asterinids.

The other eight herbivorous starfish are distributed within the families Echinasteridae (2 spp. from the genus Echinaster), Goniasteridae (Neoferdina cumingi) and Oreasteridae ( $2 \mathrm{spp}$. from the genus Pentaceraster and 3 spp. from the genus Protoreaster). The Echinaster spp. and Neoferdina cumingi are as big and similar in shape (i.e. long arms and small central disk) as Linckia spp. These starfish inhabit coral reef flats and seagrass beds where they feed on the biofilms on hard substrata and on epibenthic films of the sediment. The oreasterids are big starfish (average radius 

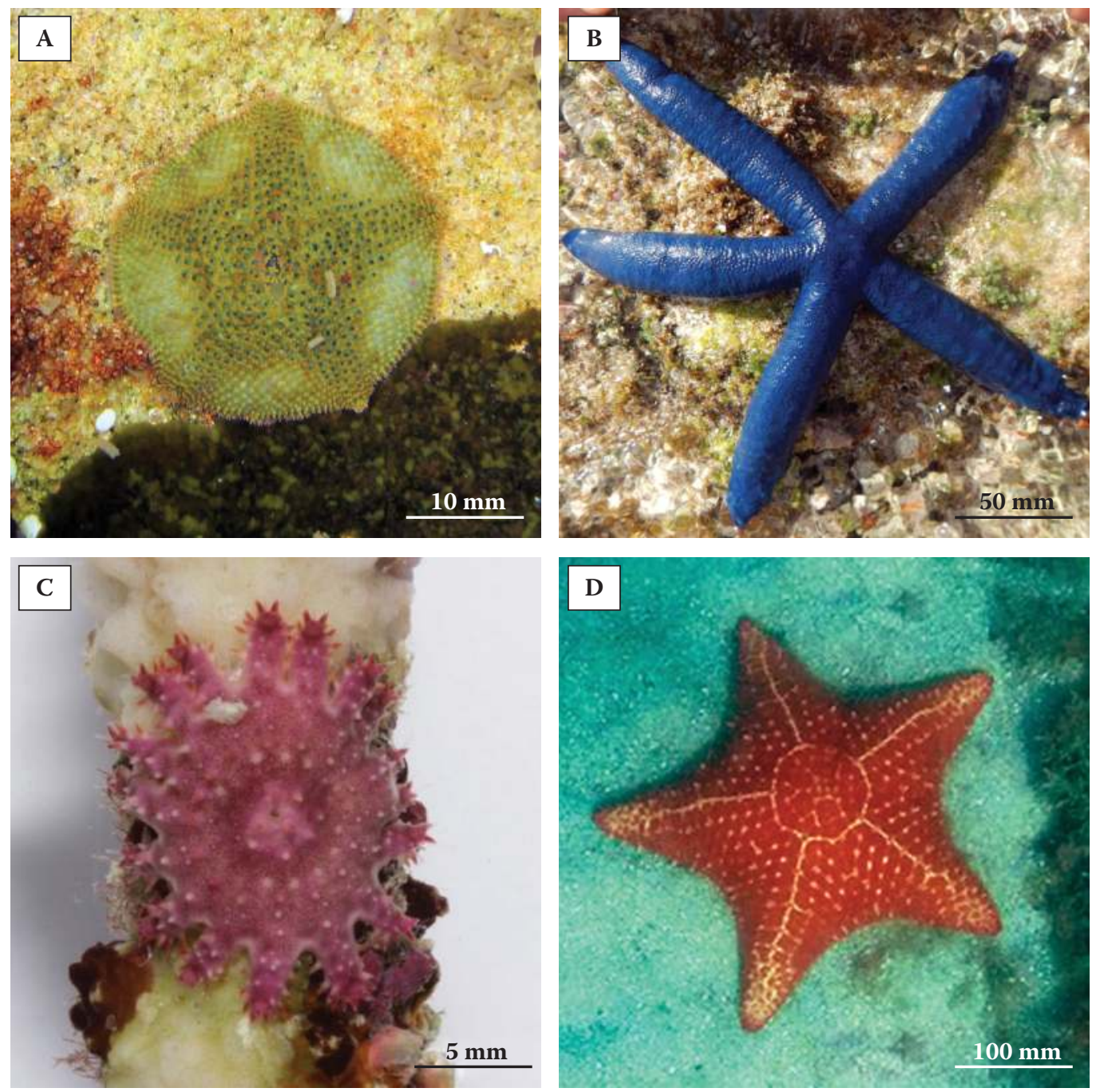

Figure 2 Aboral view of different categories of herbivorous starfish: Obligate herbivores. (A) Parvulastra exigua in a feeding mode shape (round; Photo: Aline Martinez), (B) Linckia laevigata (Maria Byrne); and facultative herbivores, (C) Acanthaster planci at juvenile stage (Photo: Phil Mercurio) and (D) Oreaster reticulatus (Photo: Marcela Rosa).

$100-150 \mathrm{~mm}$ ) and typically inhabit soft bottoms; foraging on seagrass, sand, and among cobbles. Pentaceraster cumingi is the only oreasterid species restricted to hard bottoms where it feeds mostly on biofilms and calcareous encrusting algae (Dee et al. 2012). Oreasterids exploit a broad range of plant/algal resources including biofilm, macroalgae, decomposing algae and seagrass.

It appears that eating plant/algal resources by obligate herbivores is associated with the lack of ability to catch or manipulate animal resources as predatory starfish do. Pentaceraster cumingi consumes small sea urchins (corresponding to $1 \%$ of their diet), but feeding was observed on tethered sea urchins (Dee et al. 2012). Whether the starfish actively captured live sea urchins or was attracted by a moribund sea urchin already attacked by other predators (e.g. fish) is not clear. Other herbivorous species such as Protoreaster nodosus might not primarily forage on animal-derived resources, but benefit from ingesting small invertebrates (i.e. meiofauna) when foraging on plant/ algal food (Thomassin 1976, Scheibling 1982, Scheibling \& Metaxas 2008). Complementing an 
algal diet with animal resource can benefit animal growth as demonstrated for herbivorous crabs (Wolcott \& O'Connor 1992). An explanation for this is that animal food is much richer in essential amino acids, vitamins and sterols compared to plant/algal resource (Phillips 1984).

Interestingly, obligate herbivorous starfish do not forage, or rarely forage, on soft sessile invertebrates such as sponges, bryozoans or ascidians, even though there is no need to handle these organisms. Possible causes for this feeding behaviour include feeding preferences, chemical defences of sessile invertebrates, especially sponges and ascidians, physical prey defences and/or digestive capabilities of starfish. This is an unexplored subject in herbivorous starfish that needs to be addressed to better understand their feeding behaviour.

\section{Facultative herbivores}

Many starfish species that forage on algae also feed on animal-derived material and this is quite variable among and within species, individual lifespan, seasons and location of populations. These species are classified as facultative herbivores, as their algal/plant diet changes in time or space.

\section{Ontogenetic changes in diet}

Herbivory in starfish that display ontogenetic changes in diet is reported from the early life stages of carnivorous or omnivorous species (e.g. Yamaguchi 1973, Barker 1977, 1979, Barker \& Nichols 1983). Only a few species have been described as herbivores when juvenile and carnivores when adult (Table 1). The lack of information on the feeding behaviour of juvenile starfish is due to the difficulty in finding newly-settled or post-metamorphosed starfish in situ (Yamaguchi 1975, 1977). Juveniles are small and often cryptic. Despite the lack of detailed studies, there is evidence that some predatory starfish are herbivores when young (for a review, see Sloan 1980), for example Acanthaster planci (Yamaguchi 1973, Yamaguchi 1975; Kamya et al. 2016), Mediaster aequalis (Birkeland et al. 1971) and Stichaster australis (Birkeland et al. 1971, Yamaguchi 1973, Barker 1977, Sloan 1980).

The feeding behaviour of juveniles of the predatory starfish Acanthaster planci is well documented. Encrusting calcareous and coral rubble substrata induce settlement and metamorphosis of A. planci (Johnson et al. 1991). After metamorphosis, juveniles feed on calcareous encrusting algae for around 18 weeks (radius ca. $20 \mathrm{~mm}$; Figure 2C), after which, they start foraging on small coral polyps (Henderson \& Lucas 1971, Yamaguchi 1973, Yamaguchi 1975). Similarly, the coral reef starfish Culcita novaeguineae settles on encrusting calcareous algae and spends at least 12 months on this substratum (radius reaches ca. $3.5 \mathrm{~mm}$ ) (Yamaguchi 1973, Yamaguchi 1975), but whether further feeding and growth rely on such algae is not known. Adult $C$. novaeguineae forage on sessile invertebrates including coral, but still eat algae. Similar to these tropical species, the temperate starfish Stichaster australis uses the coralline alga Mesophyllum insigne as a nursery area. Juvenile Stichaster australis remain in this habitat and feed on the algae for 15 to 18 months (until ca. $6.5 \mathrm{~mm}$ radius) and then switch to juvenile mussels (Perna canaliculus) (Barker 1977, 1979). The larvae of Mediaster aequalis settle and feed on the biofilm that grows on tubes of the polychaete Phyllochaetopterus prolifica, until the juvenile reaches around 5 to $10 \mathrm{~mm}$ radius and then feeds on animal prey and algae (Birkeland et al. 1971). In a survey of the feeding behaviour of juvenile starfish, Birkeland et al. (1971) noted that individuals smaller than $5 \mathrm{~mm}$ radius (Henricia leviuscula, Luidia foliolata, Pteraster tesselatus, Crossaster papposus, Solaster stimpsoni and S. dawsoni) feed on the tubes of Phyllochaetopterus prolifica. It appears that a period of herbivory in the early juvenile stage may be a common feature of carnivorous starfish, although not all juveniles studied were observed feeding on biofilm. Juvenile Asterias rubens and Marthasterias glacialis eat small encrusting invertebrates as soon as metamorphosis occurs, although these starfish settle in a variety of substrata covered with biofilm (Barker \& Nichols 1983). 
The extent to which herbivory occurs in young starfish appears to be influenced by the growth patterns of a given species. Newly-settled starfish only have one to two pairs of tube feet and so feeding depends on extruding the stomach (Sloan 1980). Juveniles of predatory starfish pass through a phase during which young starfish start foraging on small animals as soon as they are big enough to catch prey. At this stage the juveniles stop feeding on algae. When adult, many predatory species use their disc-ending tube feet to hold prey and open shells (Hennebert et al. 2013). These starfish may also have extensive batteries of specialized pedicellariae (jaw-like structures) that the adults use to ensnare large prey, including fishes (e.g. Stylasterias forreri, Chia \& Amerongen 1975). For predatory starfish, it appears that morphological changes are required as a juvenile develops into a competent predator. However, ecological-morphological studies of diet change through growth of juveniles are necessary to test this hypothesis.

In addition to the intrinsic biology of asteroids, external factors such as availability of resource and predation risk might influence diet shifts in starfish, as has been shown for crabs. Juvenile crabs inhabit macrophyte habitats where they are safe from predators and forage on the available food (i.e. plant/algal resources) until they achieve a certain size at which they are less vulnerable to predation and then move to open areas (Laughlin 1982, Alexander 1986, Orth \& Vanmontfrans 1987, Williams et al. 1990). In a similar way, Yamaguchi (1975) argued that the cryptic behaviour of tropical juvenile starfish is associated with the risk of predation, which has been shown to be high in the early life stage (Keesing \& Halford 1992). Foraging on encrusting algae exploits a highly abundant algal resource available within sheltered-cryptic habitat in coral reefs. When animals become big enough to escape predation, starfish would then start foraging on open areas on the reefs, as demonstrated for Acanthaster planci (Yamaguchi 1973, Yamaguchi 1975). These observations suggest that herbivorous behaviour may have evolved in these species through a predator-prey interaction with the juvenile stages remaining in cryptic algal dominated habitat until they grow to a size where they are less vulnerable to predation.

It is clear that the ontogenetic change in starfish diet is related to starfish size (Birkeland 1989). Thus, investigations of feeding habits associated with morphological changes in post-metamorphosed juvenile starfish, as well as feeding behaviour associated with available food resources and predation risk, would be of great interest to understand the shifts from a herbivorous to a carnivorous diet in asteroids. This may help in understanding the mechanisms that drive different feeding behaviours in starfish, a taxon where feeding is not constrained by possession of a complex feeding apparatus.

\section{Spatial and seasonal changes in diet}

Most asteroids are considered to be opportunistic with feeding habits reflecting the availability of resources (for a review, see Sloan 1980, Jangoux 1982b). A more detailed examination of the literature indicates that several species classified as omnivores or even carnivores, display herbivorous behaviours linked to the variability of food between locations and seasons. Species are referred to here as facultative herbivores. Eighteen species were included in this category belonging to the families Asterinidae (8 spp.), Goniasteridae (5 spp.), Oreasteridae (2 spp.), Asteropseidae (1 sp.), Ophidiasteridae (1 sp.) and Stichasteridae (1 sp.). The most evident aspect of the feeding behaviour of facultative herbivorous starfish is that the proportion of algae eaten by a population varies according to spatial and temporal fluctuations in density of food resources.

A well-studied species is the red cushion star Oreaster reticulatus (Figure 2D), a species that inhabits soft bottoms around reef areas such as sand, seagrass and cobble. Populations of this species vary in their food selection, being either microphagous grazers or macrophagous predators, and the proportion of the food sources utilized changes with respect to the availability of macrofaunal prey (Scheibling 2013). Oreaster reticulatus forages on biofilms (microalgae and other microscopic organisms), detritus, filamentous algae and seagrass in locations where animal prey (sea urchins and sponges) is absent (Scheibling 1980d, 1982, Wulff 1995). Similarly, feeding by 
Dermasterias imbricata varies between carnivory and herbivory depending on local variation in food resource (Mauzey et al. 1968). As a predator, this species forages on anemones in rocky habitats, and on anemones, sponges and ascidians on cobbles and sandy bottoms. When their primary prey is absent, most of the D. imbricata population (ca. 70\%) concentrated their feeding on filamentous green algae (Mauzey et al. 1968). Changes in feeding behaviour across habitats or locations were also observed in the bat star Patiria miniata, which can intensively forage on kelp sporelings in kelp beds (Leonard 1994), but also forages on other macroalgae or invertebrates in rocky shores (Araki 1964). In Meridiastra medius the percentage of algae consumed varies between locations (Shepherd 2013), but it is not clear whether this is associated with resource availability. Other species (e.g. Meridiastra gunnii, M. calcar, Nectria spp., Culcita schmideliana, Pseudonepanthia troughtoni, Granaster nutrix) have a highly variable diet within locations that include both algae and invertebrates (Yamaguchi 1975, Jangoux 1982b, Shepherd 2013). These observations suggest that facultative herbivores may behave as opportunistic species, where prey items consumed may be proportional to the amount of resource available. It is not possible, however, to clarify whether these observations are related to resource availability because the variability of food resources within habitats was not evaluated.

Whilst herbivory in many facultative herbivores seems to be associated with absence of animal prey, some species display a different behaviour in which algal resources appear to be the main target resource when available. For example, Mediaster aequalis feeds on a great range of food resources that vary across habitats and season (Mauzey et al. 1968, Sloan 1980, Sloan \& Robinson 1983). This starfish forages on sponges, hydroids, bryozoans and diatoms on rocky shores, whereas on sandy bottoms it predominantly feeds on sea pens (i.e. $62 \%$ of its diet) and also captures drift algae (2\% of its diet; mostly Ulva and Porphyra spp.) (Mauzey et al. 1968). Alternatively, Mediaster aequalis consumes detritus and biofilm on muddy bottoms. The proportion of the algal resource exploited by this species in sandy habitats varies seasonally. In spring, when Ulva forms dense mats on the seafloor, Mediaster aequalis switches to an algae-dominated diet (51\%) with sea pens being less important (17\%), despite their year-round abundance (Mauzey et al. 1968).

In summary, herbivory appears to be driven by the lack of animal food resources in facultative herbivores, where the proportion of food consumed will depend on variation in prey availability within a location, a habitat, or among seasons. Perhaps the fact that Acanthaster planci intensively forages on macroalgae at the end of an outbreak event when corals were scarce (De'ath \& Moran 1998) is strong evidence that algae might be targeted whenever animal resources are not available. This hypothesis, however, is not conclusive since there is a lack of manipulative studies on the relationships between feeding behaviour, availability of food resource and food preference in starfish that forage on animal and plant/algal resources.

\section{Herbivory and starfish body metrics}

Unlike virtually all other invertebrate taxa, starfish lack a specialized feeding structure. Instead, they have evolved extra-oral digestion of food due to their unusual ability to extrude their stomach. The feeding ecology of starfish has evolved independently of acquisition of specialized feeding structures. It seems that trophic modes among starfish may be influenced by other more general traits such as body size (Figure 3). Most obligate herbivorous starfish have short arm length (R) or in species with long arms, have a small disc size (r) (Figure 2A,B). This is also the case for juvenile individuals of carnivorous species (Figure 2C). Adult carnivores are generally bigger than the adults of herbivorous species. Large animals with larger disc size increase the area on which a starfish can extrude its stomach (Lawrence 2012, Lawrence 2013), which allows the starfish to feed on larger food resources and could facilitate the capture of mobile prey. On the other hand, feeding by species with small disc size regardless of arm length is restricted to a small surface area (Jangoux 1982a, Lawrence 2012, Lawrence 2013). 


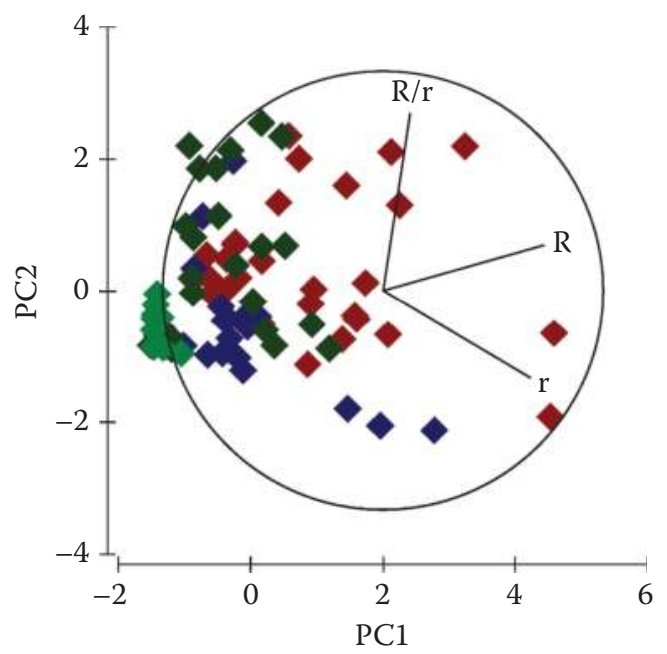

Figure 3 Exploratory analysis (PCA) of starfish body metrics: arm length (R), disc radius (r) and the ratio between arm length and disc radius (R/r). Arm length $(\mathrm{R})$ is the distance between the centre of the starfish disc and the arm tip, and disc radius (r) is the distance between the centre of the starfish disc and the intercept between two arms or interradius. The different colours of diamond symbols represent the data of obligate herbivores (green), herbivores at juvenile stage (light green), facultative herbivores (blue) and random carnivorous species (red).

Another interesting observation is that small herbivorous species and some larger ones have a ratio of arm length and disc size (R/r) close to 1 . The greater the ratio, the greater is the difference between arm length and the arm intercepts. Thus, ratios close to 1 may be indicative of lower arm flexibility compared with species that have greater ratios. A small $\mathrm{R} / \mathrm{r}$ ratio may constrain the capacity to capture mobile or large prey. This hypothesis also supports the observation that carnivorous species have a distinct five-rayed or multi-rayed profile, so have a greater R/r (Figure 3). They are also larger and often have highly dexterous arms (e.g. Asterias, Acanthaster). The fact that some herbivorous and carnivorous species overlap in the $\mathrm{R} / \mathrm{r}$ ratio is not explained, however. Regardless of the ratio, flexibility is contingent on the degree of connection and development of the arm ossicles (Blake 1989, Lawrence 2013). Thus, herbivorous starfish often have a pentagonal cushion-shape where the arms are not distinct from the disc or have arms that are not highly dexterous. In contrast, carnivorous species tend to have a stellate profile with flexible arms, with the exception perhaps of Pisaster ochraceus, which has stiff arms.

Other traits associated with starfish size may also influence starfish feeding habits. A possible explanation for starfish with similar metric sizes, but different feeding guilds, may be associated with the muscular strength of the arms and tube feet, as well as the ability of mutable connective tissue to "lock" the starfish in place (Eylers 1976, Hennebert et al. 2010). Some facultative herbivorous starfish, for example Patiriella regularis, do not appear to be capable of preying on bivalves, species that have strong adductor muscles capable of holding valves shut (Crump 1969). Indeed a few studies note the relative ease of removing herbivorous starfish by hand from the substratum compared to carnivorous species. Strength in starfish depends on the type and number of tube feet, which are used to adhere to the substratum, move and capture prey (Hennebert et al. 2013). Thus, it is likely that herbivorous starfish may have fewer tube feet that have less adhesion power than predatory species, which makes it difficult, if not impossible, to capture mobile or big prey.

Based on these observations, it is suggested that herbivory in starfish is more likely to occur in species with a low R/r or a small disc. The arms may be less dexterous than those of predatory species and their tube feet may not be as muscular. Studies of the relationship between feeding guild, 
starfish body profile (e.g. pentagonal vs. stellate), arm flexibility and strength would be needed to test these hypotheses.

\section{Phylogeny and associated feeding habits}

Asteroid phylogeny has been in a state of flux for decades with strong disagreement among morphologists (e.g. Blake 1989, Gale 2011) with many attempts to resolve species' and family relationships using molecular data (Mah \& Foltz 2011a,b, Feuda \& Smith 2015). Application of new molecular and statistical methods is starting to clarify the relationships between the different asteroid families and their morphological evolution (Mah \& Blake 2012, Feuda \& Smith 2015). Evolution of discending tube feet and an eversible stomach are ancient features of the Asteroidea, with loss of both features in some soft sediment burrowing starfish (e.g. Astropecten; Feuda \& Smith 2015). The pattern of extra-oral digestion using an eversible stomach is a near-uniform characteristic of starfish. Variations of the digestive system among starfish taxa, however, could be informative with respect to herbivorous habits. Many obligate herbivores belong to the Asterinidae, a family that has a welldeveloped cardiac stomach (Jangoux 1982a). Similarly, some other starfish described here, such as Oreaster reticulatus (Oreasteridae), have a relatively larger and expandable cardiac stomach, which has been associated with efficient feeding behaviour on biofilms (Jangoux 1982a,b). For an animal that feeds by digesting the food underneath its stomach, a greater expansion ability of the cardiac stomach would provide a greater feeding surface area. The potential relationship between digestive tract structure and herbivorous starfish feeding behaviour deserves further investigation.

In addition to differences in body profile discussed above (pentagonal vs. stellate) there are other features that separate herbivorous and predatory starfish. Major predatory starfish that are able to manipulate their prey, those in the order Forcipulatida (e.g. Asterias and Coscinasterias), have maximally developed disc-ending tube feet and complex pedicellariae (Feuda \& Smith 2015). The presence of these pedicellariae is an important evolutionary innovation that sets aside these starfish. Forcipulate pedicellariae are intricate jaw-like structures that are used to catch and secure motile prey, including fish. The prey is then delivered to the mouth. In contrast in the order Valvatida, which includes the largely herbivorous asterinids (e.g. Parvulastra) as well as the oreasterids (e.g. Oreaster) and ophidiasterids (e.g. Linckia), pedicellariae are absent or less complex. When present, they are largely used to defend the surface from interfering objects. The tube feet of the valvatids are also less muscular than in the forcipulatids. Pedicellariae are absent in the order Spinulosida (e.g. Echinaster) (Feuda \& Smith 2015).

While the taxonomic development of disc-ending tube feet and pedicellariae are morphological features along with body profile that can be used to separate some predatory starfish from herbivorous species, there remains considerable overlap in feeding behaviour in the carnivory-herbivory dichotomy, as detailed above. It is likely that other differences between carnivorous and herbivorous starfish will be discerned with investigation of digestive physiology and biology (e.g. enzyme biochemistry and internal digestive structure) and details of the skeleton of the mouth frame (e.g. Gale 2011).

\section{Effects of starfish herbivory on benthic assemblages}

The impacts of feeding by herbivorous starfish on benthic communities may be less predictable than by other herbivores because of the mechanism by which starfish feed. Not many studies have investigated the effects of starfish herbivory on benthic communities, but the potential of starfish to modify the structure of algal assemblages has been recognized (Burgett 1982, 1988, Leonard 1994, Fujita 1999, Jackson et al. 2009, Pillay et al. 2010, Dawson \& Pillay 2011).

One of the first studies to document that algal distribution could be affected by starfish grazing was done by Burgett (1982), who showed that Patiriella regularis could inhibit establishment of 
some macroalgal species on rocky shores in New Zealand by eating spores and germlings of newlysettled algae. Likewise, Patiria miniata was shown to control recruitment of giant kelp (Macrocystis pyrifera) along the coast of California by intensively grazing on young sporophytes when they were microscopic (Leonard 1994). Due to the low densities of Patiria miniata, however, this affect may be limited to small spatial scales and areas with low kelp recruitment (Leonard 1994). This study also showed that the starfish increased survival of macroscopic juvenile kelp in the surroundings of the grazed kelp. These observations suggest that grazing by starfish may play an important role in the dynamic of benthic communities on kelp forests and rocky shores.

The most studied starfish, in terms of grazing impacts, is Parvulastra exigua, which is abundant on intertidal rocky shores of South and South Eastern Australia and South Africa where it forages mostly on biofilms (Branch \& Branch 1980, Arrontes \& Underwood 1991, Stevenson 1992, Hart et al. 2006, Martinez et al. 2016). Previously it was demonstrated that $P$. exigua decreased the standing stock of algae, but did not suppress growth of macroalgae (Branch \& Branch 1980, Arrontes \& Underwood 1991). The strength of the grazing impact of P. exigua, however, could not be conclusively determined since both studies had problems with experimental artefacts from the caging methods used, in that the starfish would either escape (Branch \& Branch 1980) or feed on the biofilm growing on the cages (Arrontes \& Underwood 1991). More recently, experiments have demonstrated that $P$. exigua can consume 40 to $70 \%$ of the available biofilm on rocks during one period of low tide (Jackson et al. 2009). This calculation was based on natural densities of starfish in the field using measurements of area grazed and time spent per feeding event as well as the frequency of feeding events per hour.

A key question that arises is how grazing pressure by Parvulastra exigua is affected by other factors such as competition, predation, tides etc. Alteration of the composition of algal assemblages by herbivorous starfish has been recently demonstrated on intertidal sand flats and rocky shores. Grazing by $P$. exigua increases the richness and diversity of microalgal assemblages on sand flats (Pillay et al. 2010, Dawson \& Pillay 2011). This was associated with the increase in extra-polymeric substances (EPS) from $P$. exigua, substances that are an important component for settlement and growth of organisms in biofilms (Wotton 2004). The consumption of dominant competing species in the biofilm matrix by P. exigua was another factor that may contribute to the increase in biofilm diversity (Pillay et al. 2010, Dawson \& Pillay 2011). Moreover, the disturbance caused by starfish feeding on rocky shores resulted in successional changes in algal composition due to the different ages of starfish feeding marks (Figure 1C,D), which may cause local spatial variation in algal diversity (Jackson et al. 2009). More recently, Martinez (2016) demonstrated that $P$. exigua has a grazing impact within rock pools as strong as that of the key grazing limpet Cellana tramoserica on open rocks. This starfish also reduced abundance of primary producers on open rock, but the magnitude of the effect was weaker. The results from this research also showed that Parvulastra exigua may promote the development of red microalgae within rock pools and it was suggested that the starfish could increase the productivity of biofilm. Based on the foraging behaviour of $P$. exigua during high tide, the spatial grazing effects by $P$. exigua will depend on the availability of shelters (i.e. refugia at low tide) on rocky shores (Martinez 2016).

Grazing by starfish has also been shown to impact benthic assemblages on seagrass beds. Oreaster reticulatus significantly decreases chlorophyll concentrations on the surface of sediments in grazed areas (Scheibling 1980d, 2013). This impact can be intensified and occur over a great spatial extent when individuals aggregate and form dense grazing fronts (Scheibling 1980b,d). As $O$. reticulatus and Protoreaster nodosus accumulate sediment under their mouth during feeding and extrude their stomach to ingest associated biofilm and meiofauna, they constantly disturb the surficial sediment (Scheibling 1980b, d, 1982, Scheibling \& Metaxas 2008). Thus, it appears that oreasterids in soft sediment systems have an important role in altering the structure of benthic communities as well as in nutrient recycling. 
While there is evidence for negative and positive effects of starfish herbivory on benthic assemblages, the interactions between starfish grazing and algae are not well understood. Many starfish forage on calcareous algae and the discoloration of the algae in the grazed area is reported across studies (Barker 1979, Burgett 1982, 1988, Arrontes \& Underwood 1991, Fujita 1999). Investigations of the effects of grazing on calcareous algae show that the starfish can damage the top layer of encrusting and turf calcareous algae (Figure 1A,B). It is not known, however, if starfish grazing causes macroalgal mortality (Barker 1979, Burgett 1982, Fujita 1999). It is suggested that grazing on calcareous turf by Patiriella regularis may negatively affect the growth of new branches on the apex of the algae because the enzymes secreted by the starfish attack meristematic tissues (Burgett 1982). In addition, following grazing by starfish, epiphytic organisms colonize the damaged areas on turf algae (Burgett 1982). This probably has a negative effect on the photosynthetic activities of the grazed area on the calcareous algae. On the other hand, calcareous algae might be able to recover from the damage if grazing does not persist (Burgett 1982). Fujita (1999) showed that grazing by Patiria pectinifera stimulated deep-layer sloughing on encrusting calcareous algae. This process can compensate for grazing damage by regenerating new cover cells. Thus, for calcareous algae grazing by starfish may promote growth, although it can cause some damage to the tissue. Grazing effects on the tissue of non-calcareous algae is not known, although some authors suggest that the grazed area might cause tissue death (Araki 1964, Bak 1981, Levin et al. 1987). Further investigations are required to elucidate the effects of starfish grazing on the tissue of different groups of algae.

The impact of starfish herbivory on algal assemblages indicates that starfish might play an important role in altering the structure of benthic communities. By foraging on biofilm, it is well known that molluscan grazers can control the distribution of algal assemblages as well as of some sessile macrofauna (e.g. barnacles, bivalves) as those grazers ingest not only spores of macroalgae, but also other unicellular microorganisms and newly-settled invertebrates (Hawkins \& Hartnoll 1983, Hawkins et al. 1992, Poore et al. 2012). Starfish grazing might have a similar impact, as demonstrated for Parvulastra exigua (Martinez 2016). Thus, studies on grazing by herbivorous starfish linked to changes in benthic assemblages are of great importance to elucidate the ecological niche of starfish herbivory in the diverse ecosystems that they inhabit.

\section{Interactions between starfish and herbivores}

Competitive interactions can influence spatial distribution and foraging activity of grazers, which may result in spatial and temporal variability in grazing pressure on algae (e.g. Branch 1981, Chapman \& Underwood 1992, Johnson et al. 2008, Aguilera \& Navarrete 2011). There is, however, a lack of knowledge on the interactions between herbivorous starfish and other herbivorous taxa.

There are only 3 studies to date where hypotheses of competitive interactions have been tested, all investigating the putative competitive interaction between Parvulastra exigua and the limpet Cellana tramoserica on intertidal rocky shores (Branch \& Branch 1980, Arrontes \& Underwood 1991, Martinez 2016). The motivation for these studies was that $C$. tramoserica is a strong competitor for food compared to other gastropod grazers and it was expected that the limpet would outcompete the starfish for food resources (Underwood 1978, Underwood \& Jernakoff 1981, Steneck $\&$ Watling 1982). The results of these early studies, however, were far from conclusive. According to Branch \& Branch (1980) Parvulastra exigua appears to be a weak competitor when competing with the limpet Cellana tramoserica, while the results from Arrontes \& Underwood (1991) indicate that competition was not evident. The results from these studies are not only contradictory, but also confounded by experimental artefacts. Branch \& Branch (1980) reported issues in caging the starfish because individuals escaped from the cages whereas Arrontes \& Underwood (1991) observed starfish feeding on biofilms/microalgae growing on the cages. The recent study of Martinez (2016) 
eliminated the confounding effects of caging the starfish on her experiment and provided evidence of competition between these grazers. Parvulastra exigua was shown to be as strong a competitor as Cellana tramoserica with the two species having similar effects on each other. This finding may change our view of the dynamics of rocky shores, since the dominance of limpets in this system is a well-established concept (Branch 1984, Underwood 1992).

Many other benthic grazers, especially of intertidal rocky shores, forage on biofilm or soft foliose and filamentous algae (e.g. Hawkins \& Hartnoll 1983, Kennish \& Williams 1997, Coleman et al. 2006). The habitat and food resources exploited overlap with the distribution and feeding habits of most obligate herbivorous starfish (see above). This suggests that starfish might compete for food resources with other herbivores, the outcomes of which may affect the structure of benthic communities. The potential competitive interactions between herbivorous starfish and other herbivores are new, open areas of investigation. This information is relevant to understanding the effects of interaction between different groups of herbivores (e.g. starfish, gastropods) on foraging behaviour, growth and distribution of species in benthic communities.

\section{Overview and future directions}

There is strong evidence that grazing by starfish plays an important role in modifying the structure of algal/plant assemblages in some systems, e.g. biofilm on rocky and sandy shores (Jackson et al. 2009, Pillay et al. 2010, Dawson \& Pillay 2011, Martinez 2016), kelp beds (Leonard 1994), coralline algae on coral reefs (Laxton 1974) and seagrass beds (Scheibling 1980b, d). There are many gaps, however, that need to be investigated to understand the ecological niche of herbivorous starfish in different ecosystems.

First, detailed information on the diet of starfish is required. Most reports of starfish feeding on algae include obligate herbivores as well as omnivores and lack details of prey items. Part of this problem may be the difficulty to actually identify the food item, as most starfish evert their stomach and digest externally. Application of techniques such as stable isotope analysis (e.g. Alfaro 2008), comparison of fatty acid profiles (e.g. Alfaro 2008, Wessels et al. 2012) and even genetic comparisons of stomach contents with the genomes of potential food items (e.g. Pompanon et al. 2012) would be helpful in correctly assigning food types to the diet of these organisms. Also traditional methods such as collecting samples of material under the extruded stomach of starfish might be useful to gather information on starfish diet as long as these data are collected in a systematic way.

Determining the dietary composition of herbivorous starfish species will prompt questions on the factors that might affect their feeding habits. It has been shown that many starfish forage on biofilm, but some species may also forage on macroalgae (e.g. Scheibling 1979, Bak 1981, Stevenson 1992). Investigations of starfish nutritional ecology might be of great importance to elucidate intrinsic characteristics of herbivory in starfish that will give insights into the type of food that different species are likely to exploit. Further studies should focus on the relationships among digestibility of different components of plant/algal resources, morphological and physiological adaptations of starfish species to forage on plant/algae, and herbivore tolerance to chemical defences of primary producers.

It appears that digestive enzymes play an important role in the ability of starfish to forage on algae, such that starfish might forage on algae that are easier to digest e.g. microalgae and soft filamentous / foliose algae (Steneck \& Dethier 1994). It has also been shown that starfish can partially digest more robust algae and it is suggested that those might require a longer digestion time (Kristensen 1972, Scheibling 1980a). Thus, feeding on tough macroalgae might be more energetically costly than soft algae or microalgae. It is also possible that starfish respond to algal chemical defences. Digestive enzymes could induce the production of chemical defences in the macroalgae (Amsler 2001), thus starfish would graze less on algae. Alternatively, starfish could be responding negatively to inherently chemically-defended macroalgae. It is well known that chemical defences 
and palatability of algae are important components of algae-herbivore interactions, which can affect feeding choices and behaviour of herbivores (Hay 1996). There is no information, however, on how algal traits affect herbivory in starfish. Thus, studies should give priority to investigating the ability of different species of starfish to digest different groups of algae and explore the relationship between algal chemical defences and feeding by starfish.

Digestive capabilities, however, would not solely explain why some species feed on algae instead of animal resources because many starfish, including carnivores, possess carbohydrases and proteinases that are potentially capable of breaking down animal or plant/algal material (Araki 1964, Araki \& Giese 1970, Kristensen 1972, Scheibling 1980a). Theoretically starfish should be able to exploit any available resource. That said, some species have specialized digestive enzyme systems, as evident for Acanthaster planci, which is able to avail of the wax esters produced by its coral prey (Benson et al. 1975, Brahimi-Horn et al. 1989). Detailed comparison of the digestive physiology of herbivorous and predatory starfish may reveal diet-related differences in enzyme biochemistry.

Even though starfish do not have specialized morphological structures related to exploitation of a specific food type, in contrast to other herbivores, there may be some morphological features/ traits associated with body size that influence food selection. Herbivory appears to be influenced by starfish size and shape, since starfish feeding on algae are often of similar size or with the same size of stomach (i.e. small disc sizes). It is also suggested that herbivorous species lack the ability and strength to attack or manipulate more mobile or shelled prey (Birkeland et al. 1971, Sloan 1980). The fact that many starfish that forage on algae might opportunistically eat moribund or dead animals may support this hypothesis. If this is true, herbivory is likely to be more common in starfish than thought and would occur in all small species such as in many asterinid starfish, including at least 25 species of the genus Aquilonastra (O'Loughlin \& Rowe 2006), species with small oral discs. Juveniles of carnivorous species also appear to be initially herbivorous. Thus, comparative morphological studies between herbivorous, carnivorous and omnivorous starfish linked to feeding habits are an important area for future research.

Factors other than the intrinsic characteristics of starfish must also influence their foraging behaviour. According to the studies on feeding habits of facultative herbivores, foraging on algae seems to be a response to the availability of animal resources and predation risk. It seems that herbivory will occur in the absence or low availability of animal prey or when accessing animal resource incurs a high risk of being preyed on (e.g. Mauzey et al. 1968, Yamaguchi 1973, De'ath \& Moran 1998, Scheibling 2013). These arguments would explain the great variability in diet (algal/ animals proportion consumed) across different locations and seasons. Manipulative experiments are needed to test these hypotheses.

In addition to predation risk, competitive interactions can strongly affect foraging behaviour of herbivores and consequently the structure of algal assemblages within benthic communities (Lawrence 1975, Underwood \& Denley 1984, Underwood 1992). Because starfish have the potential to forage on any food resource, they may avoid competition by foraging on resources not used by competitors (Arrontes \& Underwood 1991). Otherwise, if starfish select a specific food resource, it is likely that competition might take place (Martinez 2016). Due to the paucity of studies, it is not possible to make inferences about competitive interactions between herbivorous starfish and other herbivorous taxa and the consequent outcomes on foraging behaviour and changes in algal assemblages.

In general, the knowledge of herbivory in starfish is currently limited to descriptive investigations of starfish diet and to a few studies of food digestion, changes in diet and grazing effects of starfish on algal assemblages. Future studies on starfish herbivory should investigate feeding habits in more detail and especially expand investigations to areas with a paucity of information, such as foraging behaviour related to algal chemical defences, competitive interactions and predation risk. Discovering the mechanisms that modulate herbivory in starfish is particularly important in consideration of current changes in species ranges and distribution in response to climate change 
(García Molinos et al. 2015). There is already evidence that natural invasions of herbivorous species in new habitats in the marine environment are causing strong modifications in habitat structure (Johnson et al. 2011, Vergés et al. 2014a,b, Ling et al. 2015). For example there is evidence that tropical herbivorous fish, which disperse to higher latitudes during summer, are now surviving over winter and their grazing is probably causing changes in algal assemblages (Vergés et al. 2014b). The kelp beds that are usually grazed by sea urchins during warm seasons are not being able to recover during winter, probably because tropical fishes are feeding on young, settled kelp, and therefore kelp beds are being replaced by turf algae assemblages (Vergés et al. 2014b).

Changes in the distribution of herbivorous species are also predicted to affect economic activities, such as fisheries, since changes in the structure of assemblages can cause declines in the stocks of target species (Johnson et al. 2011). Perhaps this is already a concern for abalone fisheries in Eastern Tasmania. Due to the expansion and intense grazing of the sea urchin Centrostephanus rodgersii, kelp beds are declining and abalones are losing their habitat as a consequence (Johnson et al. 2011, Ling et al. 2015).

Therefore, there is an urge to investigate the ecology of some groups of herbivores, such as starfish species, that are poorly understood compared to other marine herbivores (Poore et al. 2012). As starfish have no apparent specialized structures adapted to forage on specific food resources, understanding the mechanism that affects their feeding behaviour towards herbivory can be crucial to predict the effects of species expansion on native benthic communities in different ecosystems.

\section{Acknowledgements}

We would like to thank Alistair Poore for helping with the organization of the review structure, and Augustine Porter and Rebecca Morris for comments and critique during the production of this review. AM was funded by an Endeavour Award from the Australian Government and a CNPq (Science without Borders scholarship) from the Brazilian Government. Thanks to Phil Mercurio and Marcela Rosa for providing images. This is contribution number 196 of the Sydney Institute of Marine Science.

\section{References}

Aguilera, M.A. \& Navarrete, S.A. 2011. Distribution and activity patterns in an intertidal grazer assemblage: influence of temporal and spatial organization on interspecific associations. Marine Ecology Progress Series 431, 119-136.

Alexander, S.K. 1986. Diet of the blue crab, Callinectes sapidus Rathbun, from nearshore habitats of Galveston Island, Texas. Texas Journal of Science 38, 85-89.

Alfaro, A.C. 2008. Diet of Littoraria scabra, while vertically migrating on mangrove trees: gut content, fatty acid, and stable isotope analyses. Estuarine Coastal and Shelf Science 79, 718-726.

Amsler, C.D. 2001. Induced defenses in macroalgae: the herbivore makes a difference. Journal of Phycology 37, 353-356.

Anderson, M.J. 1995. Variations in biofilms colonizing artificial surfaces: seasonal effects and effects of grazers. Journal of the Marine Biological Association of the United Kingdom 75, 705-714.

Araki, G.S. 1964. On the physiology of feeding and digestion in the sea star, Patiria miniata. PhD thesis. Stanford University, United States.

Araki, G.S. \& Giese, A.C. 1970. Carbohydrases in sea stars. Physiological Zoology 43, 296-305.

Arrontes, J. 1990. Diet, food preference and digestive efficiency in intertidal isopods inhabiting macroalgae. Journal of Experimental Marine Biology and Ecology 139, 231-249.

Arrontes, J. \& Underwood, A.J. 1991. Experimental studies on some aspects of the feeding ecology of the intertidal starfish Patiriella exigua. Journal of Experimental Marine Biology and Ecology 148, 255-269.

Baird, A.H., Pratchett, M.S., Hoey, A.S., Herdiana, Y. \& Campbell, S.J. 2013. Acanthaster planci is a major cause of coral mortality in Indonesia. Coral Reefs 32, 803-812. 
Bak, H.P. 1981. Feeding habits of the sea star Asterina pectinifera (Muller et Troshel) and its grazing effect on the eelgrass Zostera marina L. Publications from the Amakusa Marine Biological Laboratory Kyushu University 6, 1-8.

Barker, M.F. 1977. Observations on the settlement of Brachiolaria larvae of Stichaster australis (Verrill) and Coscinasterias calamaria (Gray) (Echinodermata: Asteroidea) in laboratory and on the shore. Journal of Experimental Marine Biology and Ecology 30, 95-108.

Barker, M.F. 1979. Breeding and recruitment in a population of the New Zealand starfish Stichaster australis (Verrill). Journal of Experimental Marine Biology and Ecology 41, 195-211.

Barker, M.F. \& Nichols, D. 1983. Reproduction, recruitment and juvenile ecology of the starfish, Asterias rubens and Marthasterias glacialis. Journal of the Marine Biological Association of the United Kingdom 63, 745-765.

Benedetti-Cecchi, L., Vaselli, S., Maggi, E. \& Bertocci, I. 2005. Interactive effects of spatial variance and mean intensity of grazing on algal cover in rock pools. Ecology 86, 2212-2222.

Benson, A.A., Patton, J.S. \& Field, C.E. 1975. Wax digestion in a crown-of-thorns starfish. Comparative Biochemistry and Physiology 52, 339-340.

Birkeland, C. 1989. The influence of echinoderms on coral-reef communities. Echinoderm Studies 3, 1-79.

Birkeland, C., Chia, F.-S. \& Strathmann, R.R. 1971. Development, substratum selection, delay of metamorphosis and growth in the seastar, Mediaster aequalis Stimpson. Biological Bulletin 141, 99-108.

Blake, D.B. 1989. Asteroidea: Functional morphology, classification and phylogeny. Echinoderm Studies 3, 179-223.

Brahimi-Horn, M.C., Guglielmino, M.L., Sparrow, L.G., Logan, R.I. \& Moran, P.J. 1989. Lipolytic enzymes of the digestive organs of the crown-of-thorns starfish (Acanthaster planci): comparison of the stomach and pyloric caeca. Comparative Biochemistry and Physiology 92, 637-643.

Branch, G.M. 1981. The biology of limpets: physical factors, energy flow, and ecological interactions. Oceanography and Marine Biology: An Annual Review 19, 235-380.

Branch, G.M. 1984. Competition between marine organisms: ecological and evolutionary implications. Oceanography and Marine Biology: An Annual Review 22, 429-593.

Branch, G.M. \& Branch, M.L. 1980. Competition between Cellana tramoserica (Sowerby) (Gastropoda) and Patiriella exigua (Lamarck) (Asteroidea), and their influence on algal standing stocks. Journal of Experimental Marine Biology and Ecology 48, 35-49.

Brun, E. 1972. Food and feeding habits of Luidia ciliaris Echinodermata: Asteroidea. Journal of the Marine Biological Association of the United Kingdom 52, 225-236.

Burgett, J.M. 1982. The feeding ecology of Patiriella regularis (Verrill) in the rocky intertidal. MSc thesis. University of Auckland, New Zealand.

Burgett, J.M. 1988. Effects of digestive grazing by the sea star Patirella regularis on communities of coralline algae. Pacific Science 42, 116.

Chapman, M.G. \& Underwood, A.J. 1992. Foraging behaviour of marine benthic grazers. in D.M. John et al. (eds). Plant-Animal Interactions in the Marine Benthos. United Kingdom: Oxford University, 289-317.

Chen, B.Y. \& Chen, C.P. 1992. Reproductive cycle, larval development, juvenile growth and population dynamics of Patiriella pseudoexigua (Echinodermata: Asteroidea) in Taiwan. Marine Biology 113, 271-280.

Chesher, R.H. 1969. Destruction of pacific corals by sea star Acanthaster planci. Science 165, doi:10.1126/ science.1165.3890.1280.

Chia, F.-S. \& Amerongen, H. 1975. On the prey-catching pedicellariae of a starfish, Stylasterias forreri (de Loriol). Canadian Journal of Zoology 53, 748-755.

Choat, J.H. 1982. Fish feeding and the structure of benthic communities in temperate waters. Annual Review of Ecology and Systematics 13, 423-449.

Coleman, N. 1977. A Field Guide to Australian Marine Life. Australia: Rigby Limited.

Coleman, R.A., Underwood, A.J., Benedetti-Cecchi, L., Aberg, P., Arenas, F., Arrontes, J., Castro, J., Hartnoll, R.G., Jenkins, S.R., Paula, J., Della Santina, P. \& Hawkins, S.J. 2006. A continental scale evaluation of the role of limpet grazing on rocky shores. Oecologia 147, 556-564.

Crump, R.G. 1969. Aspects of the biology of some New Zealand echinoderms: feeding, growth and reproduction in the asteroids, Patiriella regularis (Verrill, 1867) and Coscinasterias calamaria (Gray, 1840). $\mathrm{PhD}$ thesis. University of Otago, New Zealand. 
Crump, R.G. \& Emson, R.H. 1978. Some aspects of the population dynamics of Asterina gibbosa (Asteroidea). Journal of the Marine Biological Association of the United Kingdom 58, 451-466.

Crump, R.G. \& Emson, R.H. 1983. The natural history, life history and ecology of the two British species of Asterina. Field Studies 5, 867.

Dartnall, A.J. 1971. Australian sea-stars of the genus Patiriella (Asteroidea, Asterinidae). Proceedings of the Linnean Society of New South Wales 96, 39-49.

Dartnall, A.J., Byrne, M., Collins J. \& Hart, M.W. 2003. A new viviparous species of asterinid (Echinodermata, Asteroidea, Asterinidae) and a new genus to accommodate the species of pan-tropical exiguoid sea stars. Zootaxa 359, 1-14.

Dawson, J. \& Pillay, D. 2011. Influence of starfish grazing on lagoonal microalgal communities: noncompetitive mechanisms for unimodal effects on diversity. Marine Ecology Progress Series 435, 75-82.

Dayton, P.K., Currie, V., Gerrodette, T., Keller, B.D., Rosenthal, R. \& Tresca, D.V. 1984. Patch dynamics and stability of some California kelp communities. Ecological Monographs 54, 254-289.

De'ath, G. \& Moran, P.J. 1998. Factors affecting the behaviour of crown-of-thorns starfish (Acanthaster planci L.) on the Great Barrier Reef: 1: patterns of activity. Journal of Experimental Marine Biology and Ecology 220, 83-106.

Decho, A.W. 2000. Microbial biofilms in intertidal systems: an overview. Continental Shelf Research 20, 1257-1273.

Dee, L.E., Witman, J.D. \& Brandt, M. 2012. Refugia and top-down control of the pencil urchin Eucidaris galapagensis in the Galápagos Marine Reserve. Journal of Experimental Marine Biology and Ecology 416-417, 135-143.

Dolecal, R.E. \& Long, J.D. 2013. Ephemeral macroalgae display spatial variation in relative palatability. Journal of Experimental Marine Biology and Ecology 440, 233-237.

Duffy, J.E. \& Hay, M.E. 1990. Seaweed adaptations to herbivory. Bioscience 40, 368-375.

Duffy, J.E. \& Hay, M.E. 1991. Food and shelter as determinants of food choice by an herbivorous marine amphipod. Ecology 72, 1286-1298.

Duyverman, H. 1976. Factors influencing the local distribution of the sea star Patiriella exigua L. MSc thesis. Flinders University of South Australia, Australia.

Emson, R.H. \& Crump, R.G. 1979. Description of a new species of Asterina (Asteroidea), with an account of its ecology. Journal of the Marine Biological Association of the United Kingdom 59, 77-94.

Estes, J.A., Terborgh, J., Brashares, J.S., Power, M.E., Berger, J., Bond, W.J., Carpenter, S.R., Essington, T.E., Holt, R.D., Jackson, J.B.C., Marquis, R.J., Oksanen, L., Oksanen, T., Paine, R.T., Pikitch, E.K., Ripple, W.J., Sandin, S.A., Scheffer, M., Schoener, T.W., Shurin, J.B., Sinclair, A.R.-E., Soule, M.E., Virtanen, R. \& Wardle, D.A. 2011. Trophic downgrading of planet earth. Science 333, 301-306.

Eylers, J.P. 1976. Aspects of skeletal mechanics of the starfish Asterias forbesii. Journal of Morphology 149, 353-367.

Farias, N.E., Meretta, P.E. \& Cledón, M. 2012. Population structure and feeding ecology of the bat star Asterina stellifera (Möbius, 1859): omnivory on subtidal rocky bottoms of temperate seas. Journal of Sea Research 70, 14-22.

Feuda, R. \& Smith, A.B. 2015. Phylogenetic signal dissection identifies the root of starfishes. PloS ONE 10, e0123331; doi:0123310.0121371/journal.pone.0123331.

Fujita, D. 1999. The sea star Asterina pectinifera causes deep-layer sloughing in Lithophyllum yessoense (Corallinales, Rhodophyta). Hydrobiologia 398-399, 261-266.

Gale, A.S. 2011. The Phylogeny of Post-Palaeozoic Asteroidea (Neoasteroidea, Echinodermata). Wales, UK: John Wiley and Sons.

García Molinos, J., Halpern, B.S., Schoeman, D.S., Brown, C.J., Kiessling, W., Moore, P.J., Pandolfi, J.M., Poloczanska, E.S., Richardson, A.J. \& Burrows, M.T. 2015. Climate velocity and the future global redistribution of marine biodiversity. Nature Climate Change, doi:10.1038/nclimate2769.

Gaymer, C.F. \& Himmelman, J.H. 2008. A keystone predatory sea star in the intertidal zone is controlled by a higher-order predatory sea star in the subtidal zone. Marine Ecology Progress Series 370, 143-153.

Gerard, V.A. 1976. Some aspects of material dynamics and energy flow in a kelp forest in Monterey Bay, California. PhD thesis. University of California, United States.

Grace, R.V. 1967. An underwater survey of two starfish species in the entrance to the Whangateau harbour. Tane 13, 13-19. 
Griffin, J.N., Noel, L., Crowe, T.P., Burrows, M.T., Hawkins, S.J., Thompson, R.C. \& Jenkins, S.R. 2010. Consumer effects on ecosystem functioning in rock pools: roles of species richness and composition. Marine Ecology Progress Series 420, 45-56.

Hart, M.W., Keever, C.C., Dartnall, A.J. \& Byrne, M. 2006. Morphological and genetic variation indicate cryptic species within Lamarck's little sea star, Parvulastra (=Patiriella) exigua. Biological Bulletin 210, 158-167.

Hawkins, S.J. \& Hartnoll, R.G. 1983. Grazing of intertidal algae by marine invertebrates. Oceanography and Marine Biology: An Annual Review 21, 195-282.

Hawkins, S.J., Hartnoll, R.G., Kain, J.M. \& Norton, T.A. 1992. Plant-animal interactions on hard substrata in the North-East Atlantic, in D.M. John et al. (eds). Plant-Animal Interactions in the Marine Benthos. United Kingdom: Clarendon Press, 1-32.

Hawkins, S.J., Watson, D.C., Hill, A.S., Harding, S.P., Kyriakides, M.A., Hutchinson, S. \& Norton, T.A. 1989. A comparison of feeding mechanisms in microphagous, herbivorous, intertidal, prosobranchs in relation to resource partitioning. Journal of Molluscan Studies 55, 151-165.

Hay, M.E. 1984. Patterns of fish and urchin grazing on Caribbean coral reefs: are previous results typical? Ecology 65, 446-454.

Hay, M.E. 1996. Marine chemical ecology: what's known and what's next? Journal of Experimental Marine Biology and Ecology 200, 103-134.

Hay, M.E. 2009. Marine chemical ecology: chemical signals and cues structure marine populations, communities, and ecosystems. Annual Review of Marine Science 1, 193-212.

Hempson, G.P., Archibald, S., Bond, W.J., Ellis, R.P., Grant, C.C., Kruger, F.J., Kruger, L.M., Moxley, C., Owen-Smith, N., Peel, M.J.S., Smit, I.P.J. \& Vickers, K.J. 2015. Ecology of grazing lawns in Africa. Biological Reviews 90, 979-994.

Henderson, J.A. \& Lucas, J.S. 1971. Larval development and metamorphosis of Acanthaster planci (Asteroidea). Nature 232, 655-657.

Hennebert, E., Haesaerts, D., Dubois, P. \& Flammang, P. 2010. Evaluation of the different forces brought into play during tube foot activities in sea stars. Journal of Experimental Biology 213, 1162-1174.

Hennebert, E., Jangoux, M. \& Flammang, P. 2013. Functional biology of asteroid tube feet, in J.M. Lawrence (ed.). Starfish: Biology and Ecology of the Asteroidea. United States: The Johns Hopkins University Press, 24-36.

Himmelman, J.H., Dutil, C. \& Gaymer, C.F. 2005. Foraging behavior and activity budgets of sea stars on a subtidal sediment bottom community. Journal of Experimental Marine Biology and Ecology 322, $153-165$.

Huntly, N. 1991. Herbivores and the dynamics of communities and ecosystems. Annual Review of Ecology and Systematics 22, 477-503.

Jackson, A.C., Murphy, R.J. \& Underwood, A.J. 2009. Patiriella exigua: grazing by a starfish in an overgrazed intertidal system. Marine Ecology Progress Series 376, 153-163.

Jangoux, M. 1982a. Digestive systems: Asteroidea, in M. Jangoux \& J.M. Lawrence (eds). Echinoderm Nutrition. Netherlands: A.A. Balkema, 235-272.

Jangoux, M. 1982b. Food and feeding mechanisms: Asteroidea, in M. Jangoux \& J.M. Lawrence (eds). Echinoderm Nutrition. Netherlands: A.A. Balkema, 117-159.

Jenkins, S.R., Moore, P., Burrows, M.T., Garbary, D.J., Hawkins, S.J., Ingólfsson, A., Sebens, K.P., Snelgrove, P.V.R., Wethey, D.S. \& Woodin, S.A. 2008. Comparative ecology of North Atlantic shores: do differences in players matter for process? Ecology 89, S3-S23.

Johnson, C.R., Banks, S.C., Barrett, N.S., Cazassus, F., Dunstan, P.K., Edgar, G.J., Frusher, S.D., Gardner, C., Haddon, M., Helidoniotis, F., Hill, K.L., Holbrook, N.J., Hosie, G.W., Last, P.R., Ling, S.D., MelbourneThomas, J., Miller, K., Pecl, G.T., Richardson, A.J., Ridgway, K.R., Rintoul, S.R., Ritz, D.A., Ross, D.J., Sanderson, J.C., Shepherd, S.A., Slotwinski, A., Swadling, K.M. \& Taw, N. 2011. Climate change cascades: shifts in oceanography, species' ranges and subtidal marine community dynamics in eastern Tasmania. Journal of Experimental Marine Biology and Ecology 400, 17-32.

Johnson, C.R., Sutton, D.C., Olson, R.R. \& Giddins, R. 1991. Settlement of crown-of-thorns starfish: role of bacteria on surfaces of coralline algae and a hypothesis for deepwater recruitment. Marine Ecology Progress Series 71, 143-162.

Johnson, M.P., Hanley, M.E., Frost, N.J., Mosley, M.W.J. \& Hawkins, S.J. 2008. The persistent spatial patchiness of limpet grazing. Journal of Experimental Marine Biology and Ecology 365, 136-141. 
Kamya, P.Z., Byrne, M., Graba-Landry, A. \& Dworjanyn, S.A. 2016. Near future ocean acidification enhances the feeding rate and development of the herbivorous juveniles of the Crown of Thorns Starfish, Acanthaster planci. Coral Reefs DOI 10.1007/s00338-016-1480-6

Kayal, M., Vercelloni, J., de Loma, T.L., Bosserelle, P., Chancerelle, Y., Geoffroy, S., Stievenart, C., Michonneau, F., Penin, L., Planes, S. \& Adjeroud, M. 2012. Predator crown-of-thorns starfish (Acanthaster planci) outbreak, mass mortality of corals, and cascading effects on reef fish and benthic communities. PloS ONE 7, doi:10.1371/journal.pone.0047363.

Keesing, J.K. 1995. Temporal patterns in the feeding and emergence behaviour of the crown-of-thorns starfish Acanthaster planci. Marine and Freshwater Behaviour and Physiology 25, 209-232.

Keesing, J.K. \& Halford, A.R. 1992. Field measurement of survival rates of juvenile Acanthaster planci: techniques and preliminary results. Marine Ecology Progress Series 85, 107-114.

Keesing, J.K. \& Lucas, J.S. 1992. Field measurement of feeding and movement rates of the crown-of-thorns starfish Acanthaster planci (L.). Journal of Experimental Marine Biology and Ecology 156, 89-104.

Kennish, R. \& Williams, G.A. 1997. Feeding preferences of the herbivorous crab Grapsus albolineatus: the differential influence of algal nutrient content and morphology. Marine Ecology Progress Series 147, $87-95$.

Kenyon, J.C. \& Aeby, G.S. 2009. Localized outbreak and feeding preferences of the crown-of-thorns seastar Acanthaster planci (Echinodermata, Asteroidea) on reefs off Oahu, Hawaii. Bulletin of Marine Science 84, 199-209.

Keough, M.J. \& Dartnall, A.J. 1978. A new species of viviparous asterinid asteroid from Gyre Peninsula, South Australia. Records of the South Australian Museum 17, 407-416.

Kristensen, J.H. 1972. Carbohydrases of some marine invertebrates with notes on their food and on natural occurrence of carbohydrates studied. Marine Biology 14, 130-142.

Kurihara, T. 1999. Effects of sediment type and food abundance on the vertical distribution of the starfish Asterina pectinifera. Marine Ecology Progress Series 181, 269-277.

Laughlin, R.A. 1982. Feeding habits of the blue crab, Callinectes sapidus Rathbun, in the Apalachicola Estuary, Florida. Bulletin of Marine Science 32, 807-822.

Lawrence, J.M. 1975. On the relationships between marine plants and sea urchins. Oceanography and Marine Biology: An Annual Review 13, 213-286.

Lawrence, J.M. 2012. Form, function, food and feeding in stellate echinoderms. In Echinoderm Research 2010: Proceedings of the Seventh European Conference on Echinoderms, A. Kroh \& M. Reich (eds). Auckland: Magnolia Press, 33-42.

Lawrence, J.M. 2013. The asteroid arm, in J.M. Lawrence (ed.). Starfish: Biology and Ecology of Asteroidea. United States: The Johns Hopkins University Press, 15-23.

Laxton, J.H. 1974. A preliminary study of the biology and ecology of the blue starfish Linckia laevigata (L.) on the Australian Great Barrier Reef and an interpretation of its role in the coral reef ecosystem. Biological Journal of the Linnean Society 6, 47-64.

Leonard, G.H. 1994. Effect of the bat star Asterina miniata (Brandt) on recruitment of the giant kelp Macrocystis pyrifera C. Agardh. Journal of Experimental Marine Biology and Ecology 179, 81-98.

Levin, V.S., Ivin, V.V. \& Fadeev, V.I. 1987. Ecology of the starfish Patiria pectinifera (Mueller et Troschel) in Possiet Bay, Sea of Japan. Asian Marine Biology 4, 49-60.

Ling, S.D., Scheibling, R.E., Rassweiler, A., Johnson, C.R., Shears, N., Connell, S.D., Salomon, A.K., Norderhaug, K.M., Pérez-Matus, A., Hernández, J.C., Clemente, S., Blamey, L.K., Hereu, B., Ballesteros, E., Sala, E., Garrabou, J., Cebrian, E., Zabala, M., Fujita, D. \& Johnson, L.E. 2015. Global regime shift dynamics of catastrophic sea urchin overgrazing. Philosophical Transactions of the Royal Society of London B: Biological Sciences 370, doi:10.1098/rstb.2013.0269.

Littler, M.M. \& Arnold, K.E. 1982. Primary productivity of marine macroalgal functional-form groups from Southwestern North America. Journal of Phycology 18, 307-311.

Littler, M.M. \& Littler, D.S. 1980. The evolution of thallus form and survival strategies in benthic marine macroalgae: field and laboratory tests of a functional form model. American Naturalist 116, 25-44.

Lubchenco, J. \& Cubit, J. 1980. Heteromorphic life histories of certain marine algae as adaptations to variations in herbivory. Ecology 61, 676-687.

Lubchenco, J. \& Gaines, S.D. 1981. A unified approach to marine plant-herbivore interactions. I. Populations and communities. Annual Review of Ecology and Systematics 12, 405-437. 
Mah, C. \& Foltz, D. 2011a. Molecular phylogeny of the Forcipulatacea (Asteroidea: Echinodermata): systematics and biogeography. Zoological Journal of the Linnean Society 162, 646-660.

Mah, C. \& Foltz, D. 2011b. Molecular phylogeny of the Valvatacea (Asteroidea: Echinodermata). Zoological Journal of the Linnean Society 161, 769-788.

Mah, C.L. \& Blake, D.B. 2012. Global diversity and phylogeny of the Asteroidea (Echinodermata). PloS ONE 7, e35644. doi:35610.31371/journal.pone.0035644.

Martin, R.B. 1970. Asteroid feeding biology. MSc thesis. The University of Auckland, New Zealand.

Martin, A., Penchaszadeh, P. \& Atienza, D. 2001. Population density and feeding habits of Oreaster reticulatus (Linnaeus, 1758) (Echinodermata, Asteroidea) living in seagrass beds off Venezuela. Boletin Instituto Espanol de Oceanografia 17, 203-208.

Martinez, A.S. 2016. Reevaluating the dynamics of intertidal rocky ecosystems: the foraging and behavioural ecology of an understudied grazer and its effects on benthic assemblages. $\mathrm{PhD}$ thesis. The University of Sydney, Australia.

Martinez, A.S., Byrne, M. \& Coleman, R.A. 2016. What and when to eat? Investigating the feeding habits of an intertidal herbivorous starfish. Marine Biology 163, 1-13.

Mauzey, K.P., Birkelan.C \& Dayton, P.K. 1968. Feeding behavior of asteroids and escape responses of their prey in Puget Sound region. Ecology 49, 603-619.

Menge, B.A. \& Sanford, E. 2013. Ecological role of sea stars from populations to meta-ecosystems, in J.M. Lawrence (ed.). Starfish: Biology and Ecology of Asteroidea. United States: The Johns Hopkins University Press, 67-80.

Morgan, M.B. \& Cowles, D.L. 1997. The effects of temperature on the behaviour and physiology of Phataria unifascialis (Gray) (Echinodermata, Asteroidea) implications for the species' distribution in the Gulf of California, Mexico. Journal of Experimental Marine Biology and Ecology 208, 13-27.

Mueller, B., Bos, A.R., Graf, G. \& Gumanao, G.S. 2011. Size-specific locomotion rate and movement pattern of four common Indo-Pacific sea stars (Echinodermata; Asteroidea). Aquatic Biology 12, 157-164.

Norton, T.A., Hawkins, S.J., Manley, N.L., Williams, G.A. \& Watson, D.C. 1990. Scraping a living: a review of littorinid grazing. Hydrobiologia 193, 117-138.

O’Loughlin, P.M. \& Rowe, F.W.E. 2006. A systematic revision of the asterinid genus Aquilonastra O'Loughlin, 2004 (Echinodermata: Asteroidea). Memoirs of Museum Victoria 63, 257-287.

Orth, R.J. \& Vanmontfrans, J. 1987. Utilization of a seagrass meadow and tidal marsh creek by blue crabs Callinectes sapidus. 1. Seasonal and annual variations in abundance with emphasis on post-settlement juveniles. Marine Ecology Progress Series 41, 283-294.

Paine, R.T. 1974. Intertidal community structure: experimental studies on relationship between a dominant competitor and its principal predator. Oecologia 15, 93-120.

Paine, R.T. 1976. Size-limited predation: an observational and experimental approach with Mytilus-Pisaster interaction. Ecology 57, 858-873.

Paul, V.J., Cruz-Rivera, E. \& Thacker, R.W. 2001. Chemical mediation of macroalgal-herbivore interactions: ecological and evolutionary perspectives. Marine Chemical Ecology, 227-265.

Phillips, N.W. 1984. Role of different microbes and substrates as potential suppliers of specific, essential nutrients to marine detritivores. Bulletin of Marine Science 35, 283-298.

Pillay, D., Branch, G.M. \& Steyn, A. 2010. Unexpected effects of starfish grazing on sandflat communities following an outbreak. Marine Ecology Progress Series 398, 173-182.

Polanowski, A. 2002. The feeding behaviour, distribution and population genetics of the endangered sea star Patiriella vivipara. Hons thesis. University of Tasmania, Australia.

Pompanon, F., Deagle, B.E., Symondson, W.O.C., Brown, D.S., Jarman, S.N. \& Taberlet, P. 2012. Who is eating what: diet assessment using next generation sequencing. Molecular Ecology 21, 1931-1950.

Poore, A.B., Gutow, L., F. Pantoja, J., Tala, F., Jofré Madariaga, D. \& Thiel, M. 2014. Major consequences of minor damage: impacts of small grazers on fast-growing kelps. Oecologia 174, 789-801.

Poore, A.G.B. 1994. Selective herbivory by amphipods inhabiting the brown alga Zonaria angustata. Marine Ecology Progress Series 107, 113-123.

Poore, A.G.B., Campbell, A.H., Coleman, R.A., Edgar, G.J., Jormalainen, V., Reynolds, P.L., Sotka, E.E., Stachowicz, J.J., Taylor, R.B., Vanderklift, M.A. \& Emmett Duffy, J. 2012. Global patterns in the impact of marine herbivores on benthic primary producers. Ecology Letters 15, 912-922. 
Porter, J.W. 1972. Predation by Acanthaster and its effect on coral species diversity. The American Naturalist 106, 487-492.

Pratchett, M.S., Caballes, C.F., Rivera-Posada, J.A. \& Sweatman, H.P.A. 2014. Limits to understanding and managing outbreaks of crown-of-thorns starfish (Acanthaster spp.). Oceanography and Marine Biology: An Annual Review 52, 133-199.

Pratchett, M.S., Schenk, T.J., Baine, M., Syms, C. \& Baird, A.H. 2009. Selective coral mortality associated with outbreaks of Acanthaster planci L. in Bootless Bay, Papua New Guinea. Marine Environmental Research 67, 230-236.

Prestedge, G.K. 1998. The distribution and biology of Patiriella vivipara (Echinodermata: Asteroidea: Asterinidae) a sea star endemic to southeast Tasmania. Records of the Australian Museum 50, 161-170.

Scheibling, R. \& Lauzon-Guay, J.-S. 2007. Feeding aggregations of sea stars (Asterias spp. and Henricia sanguinolenta) associated with sea urchin (Strongylocentrotus droebachiensis) grazing fronts in Nova Scotia. Marine Biology 151, 1175-1183.

Scheibling, R.E. 1979. The ecology of Oreaster reticulatus (L.) (Echinodermata: Asteroidea) in the Caribbean. $\mathrm{PhD}$ thesis. McGill University, Canada.

Scheibling, R.E. 1980a. Carbohydrases of the pyloric ceca of Oreaster reticulatus (L) (Echinodermata: Asteroidea). Comparative Biochemistry and Physiology B-Biochemistry \& Molecular Biology 67, 297-300.

Scheibling, R.E. 1980b. Dynamics and feeding activity of high-density aggregations of Oreaster reticulatus (Echinodermata: Asteroidea) in a sand patch habitat. Marine Ecology Progress Series 2, 321-327.

Scheibling, R.E. 1980c. Homing movements of Oreaster reticulatus (L.) (Echinodermata: Asteroidea) when experimentally translocated from a sand patch habitat. Marine Behaviour and Physiology 7, 213-223.

Scheibling, R.E. 1980d. The microphagous feeding behavior of Oreaster reticulatus (Echinodermata: Asteoridea). Marine Behaviour and Physiology 7, 225-231.

Scheibling, R.E. 1981. Optimal foraging movements of Oreaster reticulatus (L.) (Echinodermata: Asteroidea). Journal of Experimental Marine Biology and Ecology 51, 173-185.

Scheibling, R.E. 1982. Feeding habits of Oreaster reticulatus (Echinodermata: Asteroidea). Bulletin of Marine Science 32, 504-510.

Scheibling, R.E. 2013. Oreaster reticulatus, in J.M. Lawrence (ed.). Starfish: Biology and Ecology of Asteroidea. United States: The Johns Hopkins University Press, 142-152.

Scheibling, R.E. \& Metaxas, A. 2008. Abundance, spatial distribution, and size structure of the sea star Protoreaster nodosus in Palau, with notes on feeding and reproduction. Bulletin of Marine Science 82, 221-235.

Shepherd, S.A. 1967. A review of the starfish genus Nectria (Asteroidea; Goniasteridae). Records of the South Australian Museum 15, 463-482.

Shepherd, S.A. 1968. The shallow water echinoderm fauna of South Australia - Part I: the asteroids. Records of the South Australian Museum 15, 729-756.

Shepherd, S.A. 2013. Echinoderms, in S.A. Shepherd \& G.J. Edgar (eds). Ecology of Australian Temperate Reefs: The Unique South. Australia: CSIRO, 233-258.

Sloan, N.A. 1980. Aspects of the feeding biology of asteroids. Oceanography and Marine Biology: An Annual Review 18, 57-124.

Sloan, N.A. \& Robinson, S.M.C. 1983. Winter feeding by asteroids on a subtidal sandbed in British Columbia. Ophelia 22, 125-141.

Steinman, A.D. 1996. Effects of grazers on freshwater benthic algae, in R.J. Stevenson et al. (eds). Algal Ecology: Freshwater Benthic Ecosystem. United States: Elsevier, 341-374.

Steneck, R.S. \& Dethier, M.N. 1994. A functional group approach to the structure of algal-dominated communities. Oikos 69, 476-498.

Steneck, R.S. \& Watling, L. 1982. Feeding capabilities and limitation of herbivorous mollusks: a functional group approach. Marine Biology 68, 299-319.

Stevenson, J.P. 1992. A possible modification of the distribution of the intertidal seastar Patiriella exigua (Lamarck) (Echinodermata: Asteroidea) by Patiriella calcar (Lamarck). Journal of Experimental Marine Biology and Ecology 155, 41-54.

Thomassin, B.A. 1976. Feeding behaviour of the felt-, sponge-, and coral-feeder sea stars, mainly Culcita schmideliana. Helgoländer wissenschaftliche Meeresuntersuchungen 28, 51-65. 
Town, J.C. 1980. Movement, morphology, reproductive periodicity, and some factors affecting gonad production in the seastar Astrostole scabra (Hutton). Journal of Experimental Marine Biology and Ecology 44, 111-132.

Underwood, A.J. 1978. Experimental evaluation of competition between three species of intertidal prosobranch gastropods. Oecologia 33, 185-202.

Underwood, A.J. 1992. Competition and marine-plant interactions, in D.M. John \& S.J. Hawkins (eds). Plantanimal Interactions in the Marine Benthos. United Kingdom: Oxford University, 443-475.

Underwood, A.J. \& Denley, E.J. 1984. Paradigms, explanations and generalizations in models for the structure of intertidal communities on rocky shores, in D.R. Strong, Jr. et al. (eds). Ecological Communities: Conceptual Issues and the Evidence. United States: Blackwell Scientific, 151-180.

Underwood, A.J. \& Jernakoff, P. 1981. Effects of interactions between algae and grazing gastropods on the structure of a low-shore intertidal algal community. Oecologia 48, 221-233.

Uthicke, S., Schaffelke, B. \& Byrne, M. 2009. A boom and bust phylum? Ecological and evolutionary consequences of large population density variations in echinoderms. Ecological Monographs 79, 3-24.

Vergés, A., Alcoverro, T. \& Ballesteros, E. 2009. Role of fish herbivory in structuring the vertical distribution of canopy algae Cystoseira spp. in the Mediterranean Sea. Marine Ecology Progress Series 375, 1-11.

Vergés, A., Steinberg, P.D., Hay, M.E., Poore, A.G.B., Campbell, A.H., Ballesteros, E., Heck, K.L., Booth, D.J., Coleman, M.A., Feary, D.A., Figueira, W., Langlois, T., Marzinelli, E.M., Mizerek, T., Mumby, P.J., Nakamura, Y., Roughan, M., van Sebille, E., Gupta, A.S., Smale, D.A., Tomas, F., Wernberg, T. \& Wilson, S.K. 2014a. The tropicalization of temperate marine ecosystems: climate-mediated changes in herbivory and community phase shifts. Proceedings of the Royal Society B: Biological Sciences 281, doi:10.1098/rspb.2014.0846.

Vergés, A., Tomas, F., Cebrian, E., Ballesteros, E., Kizilkaya, Z., Dendrinos, P., Karamanlidis, A.A., Spiegel, D. \& Sala, E. 2014b. Tropical rabbitfish and the deforestation of a warming temperate sea. Journal of Ecology 102, 1518-1527.

Wessels, H., Karsten, U., Wiencke, C. \& Hagen, W. 2012. On the potential of fatty acids as trophic markers in Arctic grazers: feeding experiments with sea urchins and amphipods fed nine diets of macroalgae. Polar Biology 35, 555-565.

Williams, A.H., Coen, L.D. \& Stoelting, M.S. 1990. Seasonal abundance, distribution, and habitat selection of juvenile Callinectes sapidus (Rathbun) in the northern Gulf of Mexico. Journal of Experimental Marine Biology and Ecology 137, 165-183.

Wilson, C. 2004. Population ecology and nocturnal foraging patterns of the seastar Paritriella parvivipara (Keough \& Dartnall) (Echinodermata: Asteroidea: Asterinidae). Hons thesis. University of Adelaide, Australia.

Wolcott, D.L. \& O'Connor, N.J. 1992. Herbivory in crabs: adaptations and ecological considerations. American Zoologist 32, 370-381.

Wotton, R.S. 2004. The essential role of exopolymers (EPS) in aquatic systems. Oceanography and Marine Biology: An Annual Review 42, 57-94.

Wulff, J.L. 1995. Sponge-feeding by the Caribbean starfish Oreaster reticulatus. Marine Biology 123, 313-325.

Yamaguchi, M. 1973. Early life histories of coral reef asteroids, with special reference to Acanthaster planci (L.), in O.A. Jones \& R. Endean (eds). Biology and Geology of Coral Reefs. United States: Academic Press, 369-387.

Yamaguchi, M. 1974. Growth of juvenile Acanthaster planci (L.) in the laboratory. Pacific Science 28, $123-138$.

Yamaguchi, M. 1975. Coral-reef asteroids of Guam. Biotropica 7, 12-23.

Yamaguchi, M. 1977. Estimating the length of the exponential growth phase: growth increment observations on the coral-reef asteroid Culcita novaeguineae. Marine Biology 39, 57-59.

Yamaguchi, M. 1977. Population structure, spawning, and growth of the coral reef asteroid Linckia laevigata (Linnaeus). Pacific Science 31, 13-30. 


\section{Appendix 1 Current accepted name of species cited in the review and previous species name that may be found in the references cited}

\begin{tabular}{|c|c|c|}
\hline Family & Current species name & Previous species name \\
\hline \multirow[t]{12}{*}{ Asterinidae } & Aquilonastra anomala (H.L. Clark, 1921) & Asterina anomala \\
\hline & Asterina stellifera (Möbius, 1859) & Patiria stellifera \\
\hline & Cryptasterina pacifica (Hayashi, 1977) & Patiriella pseudoexigua pacifica \\
\hline & Cryptasterina hystera (Dartnall \& Byrne, 2003) & Patiriella pseudoexigua \\
\hline & Cryptasterina pentagona (Muller \& Troschel, 1842) & $\begin{array}{l}\text { Patiriella pseudoexigua pseudoexigua, } \\
\text { Patiriella obscura }\end{array}$ \\
\hline & Meridiastra calcar (Lamarck, 1816) & Patiriella calcar \\
\hline & Meridiastra gunnii (Gray, 1840) & Patiriella brevispina \\
\hline & Parvulastra parvivipara (Keough \& Dartnall, 1978) & Patiriella parvivipara \\
\hline & Parvulastra exigua (Lamarck, 1816) & Patiriella exigua \\
\hline & Parvulastra vivipara (Dartnall, 1969) & Patiriella vivipara \\
\hline & Patiria miniata (Brandt, 1835) & Asterina miniata \\
\hline & Patiria pectinifera (Muller \& Troschel, 1842) & Asterina pectinifera \\
\hline \multirow[t]{2}{*}{ Ophidiasteridae } & Ophidiaster cribrarius (Lütken, 1871) & Ophidiaster robillardi \\
\hline & Ophidiaster hemprichi (Müller \& Troschel, 1842) & Ophidiaster squameus \\
\hline Oreasteridae & Pentaceraster cumingi (Gray, 1840) & Oreaster occidentalis \\
\hline
\end{tabular}




\title{
INTERTIDAL BOULDER-FIELDS: A MUCH NEGLECTED, BUT ECOLOGICALLY IMPORTANT, INTERTIDAL HABITAT
}

\author{
M.G. CHAPMAN \\ School of Life and Environmental Sciences, University of Sydney, NSW 2006, Australia \\ E-mail: gee.chapman@sydney.edu.au
}

Intertidal boulder-fields form important habitat because they support a wide range of fauna, many species of which are rare or not found in other habitats. Over many decades, they have been studied to test general ecological theories, such as effects of disturbance, succession and species-area relationships, because of the ease with which the habitats themselves and their biota can be manipulated experimentally. Much less is known about their unique characteristics and biota. Experimental studies are limited to few parts of the world, primarily south-eastern Australia. Intertidal boulder-fields support a diverse biota of often related rare and common species, which typically show extremely aggregated patterns of dispersion, but little consistent association among different species. This review summarizes experimental research in these habitats, which has led to current understanding of factors affecting spatial and temporal patterns of species living in boulder-fields, in addition to the contributions that have been made to broader ecological concepts. Finally, directions for future research are suggested, particularly with respect to conservation and restoration of intertidal boulder-fields in a rapidly changing world.

\section{Introduction}

Intertidal boulder-fields are important habitats worldwide. They can occur overlying soft sediments and, in places, grade into cobble shores. Elsewhere they lie adjacent to rocky platforms. Boulderfields can be extensive (kilometres long), or only occupy tens of metres of shoreline. They can occur on shores that are very exposed or those that are very sheltered, and from highshore levels down to low on the shore where they extend into subtidal areas. They can be natural areas or created by anthropogenic activities, either intentionally to create new habitat (Chapman 2012), or unintentionally through the disposal of waste (Chapman 2006).

The boulders themselves are used as habitats by a mix of widespread, common marine invertebrates and algae and by a suite of specialist, rare species, particularly invertebrates (Chapman 2002a, 2005). Nevertheless, boulder-fields have not been extensively studied by ecologists. A preliminary search of Web of Science 2005-2015 for the numbers of published papers describing research in intertidal habitats gave more than 46,000 records. Of these, fewer than $0.1 \%$ described research in boulder-fields (Figure 1) and not all of these were ecological studies. The ecology of this habitat is thus poorly described compared to many other intertidal habitats. Boulder-fields are susceptible to many natural and anthropogenic disturbances, including wave action (Lieberman et al. 1979, Sousa 1979a), burial by sand (McGuinness 1987a,b, Kurihara et al. 2001) and harvesting (Cryer et al. 1987, Addessi 1994). Many of these perturbations are expected to increase with both climatic change and urbanization of the coast. 


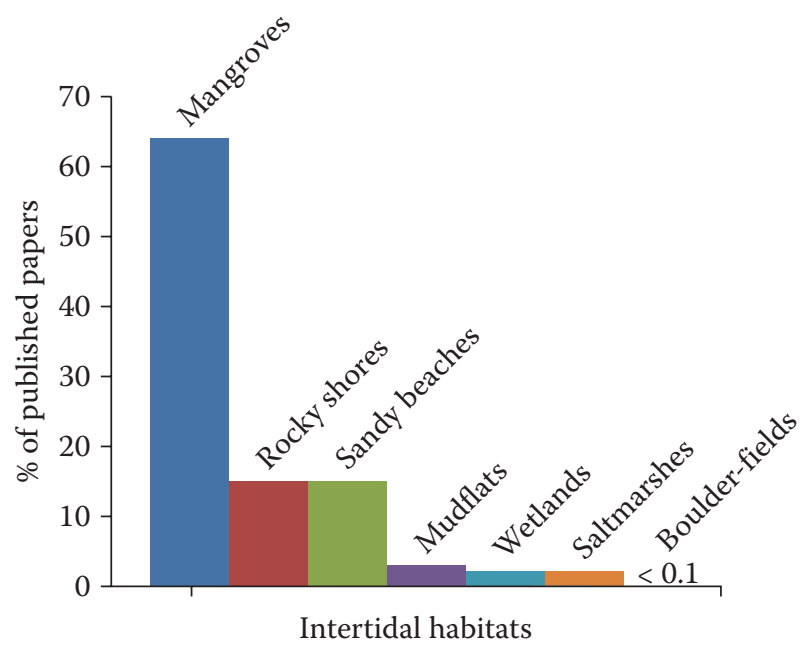

Figure 1 The proportion of more than 46,000 scientific publications between 2005 and 2015 categorized as reporting research in different intertidal habitats.

Boulder-fields contain at least four types of microhabitats, three of which are unique to this habitat. The exposed tops and sides of intertidal boulders have many biota in common with intertidal rock platforms; although the boulders are small isolated patches of habitat, rather than an extensive patch of similar habitat (Figure 2A). The undersurfaces of the boulders, the rocky or sedimentary substratum lying immediately below a boulder and the crevices created between adjacent boulders are, however, microhabitats unique to these habitats, which are composed of movable, isolated units. They tend to support a very different biota to those living on their upper surfaces (Figure 2B). The number of unique microhabitats in boulder-fields has been extended to eight by some authors (Le Hir \& Hily 2005), and are distinguished by subtle differences in the degree of shelter offered by the boulders. Many of these additional microhabitats are occupied by very similar biota.

Because boulders are natural patches of isolated habitat, which can be relatively easily manipulated in the field, they have proved ideal units for experimental manipulations to test general ecological ideas. Here, I briefly review the more important early studies in boulder-fields, where boulders were used primarily to investigate general ecological theories, often in conjunction with or parallel to similar studies on rocky shores. Their uniqueness, in being composed of isolated patches of habitat of different size and structure, which could be experimentally manipulated in the field, added considerable insight to current knowledge. I then follow this by describing studies of the general ecology of intertidal boulder-fields themselves, where the primary focus has been on understanding how their ecology differs from that of rocky shores and how we can best ensure the persistence of these habitats in a rapidly changing world.

\section{A brief history of ecological studies in boulder-fields}

\section{Using boulder-fields to develop general ecological theories}

Many of the early ecological studies in boulder-fields used boulders as natural units of intertidal habitat to test models about general ecological processes, such as the establishment and succession of faunal (Osman 1977) or algal (Sousa 1979b) assemblages. Especially important were investigations into the role of physical disturbance, due to the vulnerability of boulders to movement and overturning, in resetting an assemblage to an earlier successional stage (Sousa 1979a). Sousa (1979b) demonstrated a successional sequence from quick-growing, rapidly-reproducing species, 

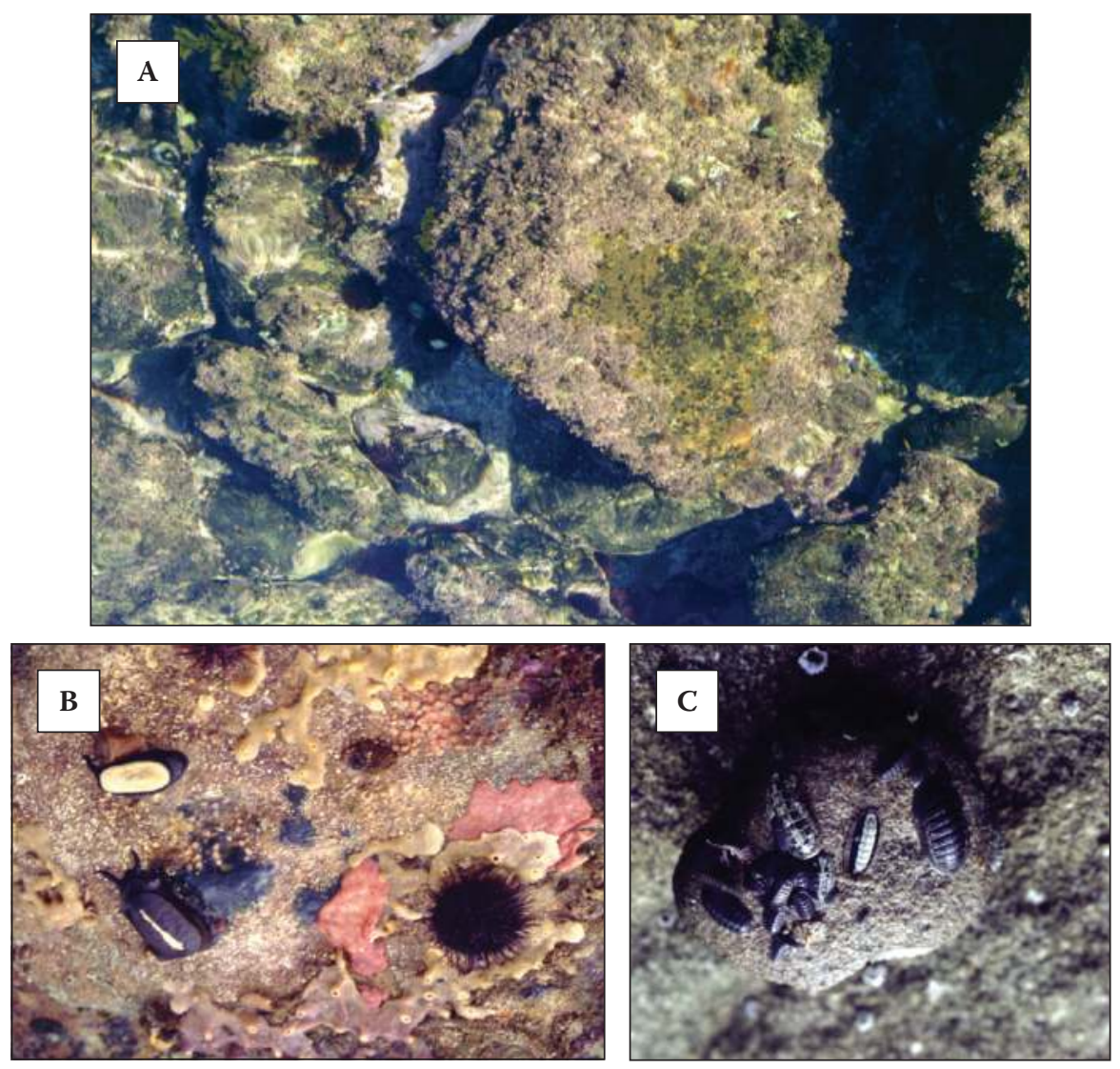

Figure 2 (A) Diverse assemblages on the tops of boulders resemble those living on rocky shores, whereas those species living under boulders (B) are not generally found together in other intertidal habitats. (C) Many of the species are very overdispersed, being crowded onto relatively few of the available boulders. (Photos: M.G. Chapman)

such as the green alga, Ulva lactuca, and barnacles, which were gradually replaced by a range of green and red algae, before the boulders became dominated by the red alga, Chondracanthus canaliculatus (=Gigartina canaliculata). Despite this general pattern, there was considerable local variation, depending on the season and the size of area (created on the substratum by various forms and intensities of disturbance) available for colonization at different successional stages. The successional stage found on a boulder was related to its size, with early successional species common on small, easily-disturbed boulders and large boulders dominated by Chondracanthus canaliculatus. Medium-sized boulders supported a range of algae. Although each small boulder only supported a few species, a set of such boulders could support more species than a similar set of larger stable boulders, because each small boulder was not necessarily occupied by the same species, whereas large boulders tended each to be dominated by the same set of few species (Sousa 1979a; but see Douglas \& Lake 1994 for different patterns on boulders in streams). This work was very important in providing experimental evidence for the 'Intermediate Disturbance Hypothesis' (Connell 1978).

A few years later, McGuinness (1984) used boulders of different sizes to investigate hypotheses derived from four models that were currently being used to explain species-area relationships. Using boulders allowed him to examine abundances of species of marine organisms across natural patches of habitat of different sizes. This was in contrast to studies that examined accumulation of species when patches of similar sizes of a shore were summed to create larger areas (Hawkins \& Hartnoll 
1980). McGuinness (1984) also tested these hypotheses using the mobile and sessile components of assemblages on boulders at different shore levels and in different sites to test for generality of any patterns. Each of the models examined (Random Placement, Intermediate Disturbance, Habitat Diversity, Equilibrium Theory) could explain the number of species on boulders of different sizes and relative to similarly-sized patches of adjacent rock platforms. This, however, depended on the site, shore height and the assemblage examined, thus emphasizing the danger of generalizing ecological concepts from limited data. This contrasts with boulders in rivers, where small boulders were always depauperate, even when their areas were summed to equal that of larger boulders (Douglas \& Lake 1994, Downes et al. 1998).

In some terrestrial habitats, boulders have been considered inappropriate to test theories such as island biogeography, because of small-scale disturbances interrupting succession (Kimmerer \& Driscoll 2000). Similar patchy disturbances may have contributed to the variable results described by McGuinness (1984), but spatially-variable disturbances are natural features of most habitats. In a smaller study, Londoño-Cruz \& Tokeshi (2007) showed a linear relationship between species diversity of molluscs and sizes of boulders, but the abundance-area relationships were dominated by very large abundances on only a few large boulders. It is likely, however, that had this study been replicated under many conditions, as was done by McGuinness (1984), then similar spatial variability in the patterns would have been found.

This research was later extended by McGuinness \& Underwood (1986) in their experimental study of the importance of habitat complexity in determining diversity of species on boulders, standardizing habitat by using concrete blocks of different thickness with added pits and/or grooves in place of natural boulders (see also Douglas \& Lake 1994, Downes et al. 1998 for similar studies in streams). McGuinness \& Underwood (1986) demonstrated considerable spatial variability in patterns of colonization and increased habitat complexity did not consistently lead to increased diversity as predicted by theory. Its importance varied with the types of species examined (algae, sessile fauna, mobile fauna), the height on the shore (which influences the types and intensities of disturbances) and individual sites in complex and unpredictable ways.

Because of the sparse distribution of many taxa living under boulders and the common pattern of extreme overdispersion shown by both rare and common taxa (e.g. chitons, Figure 2C), it can be necessary (depending on local conditions) to sample a large number of boulders to measure temporal and spatial patterns with any degree of precision (Chapman 2002a, 2005). Such data can be used to test more general ideas. Such a dataset of sessile and mobile animals on 100 boulders from each of six locations in the Sydney region of New South Wales (NSW), Australia, allowed a powerful evaluation of the accuracy and precision of six non-parametric methods and five regression models used for deriving species estimates from samples (Chapman \& Underwood 2009). This extensive study (which also included samples of species living on rock platforms and small invertebrates colonizing artificial units of habitat), tested how well random samples of different sizes estimated the known number of species from all samples combined. Analyses showed that many of the commonly-used methods estimated the species number very poorly (Table 1). In addition, the accuracy (how close was the predicted total number of species to the true measured number) and the precision (what percentage of the estimated values lay within $10 \%$ of the measured value) differed among the different metrics according to site, the sample size and whether one was examining the sessile or mobile component of the assemblage on the boulders (details in Chapman \& Underwood 2009). This comparison raises questions about using any single metric to estimate the number of species in an area from a single sample, especially in cases with small replication.

Using the same extensive dataset, Chapman et al. (2009) developed indices for ranking sites for conservation, under conditions where the objective is to choose which sites to conserve among a number of sites for which there are quantitative data on abundances of organisms. Individual species are given scores for each site, according to the proportion of sites that each species is found in, the proportion of patches of habitat (or samples) in which it is found in each site and the proportion 
Table 1 Total number of species on 100 boulders in six sites (LR, LB, CB, CH, BH, RB), the mean number of species estimated for 100 boulders from 500 random samples, each of 20 boulders and (in parentheses) the percentage of the 500 estimates that were within $10 \%$ of the true value for mobile and sessile species

\begin{tabular}{|c|c|c|c|c|c|c|c|c|c|c|c|c|}
\hline \multirow[b]{2}{*}{ Site } & \multirow[b]{2}{*}{$\begin{array}{l}\text { Total } \\
\text { spp. }\end{array}$} & \multicolumn{5}{|c|}{ Non-parametric estimators } & \multicolumn{6}{|c|}{ Regression models } \\
\hline & & $\mathrm{HF}$ & SB & $\mathrm{J}_{2}$ & $\mathrm{SJ}_{1}$ & $\mathrm{SJ}_{2}$ & Chao 2 & Power & Exp. & $\begin{array}{l}\text { Neg. } \\
\text { Exp. }\end{array}$ & Asymp. & Rational \\
\hline \multicolumn{13}{|c|}{ Mobile species } \\
\hline LR & 53 & $44(26)$ & $37(<1)$ & $51(43)$ & $35(<1)$ & $48(36)$ & $50(24)$ & $88(<1)$ & $44(30)$ & $33(0)$ & $36(2)$ & $44(25)$ \\
\hline LB & 54 & $45(30)$ & $39(<1)$ & $53(43)$ & $36(0)$ & $47(34)$ & $55(28)$ & $79(4)$ & $47(46)$ & $33(0)$ & $36(<1)$ & 43 (19) \\
\hline $\mathrm{CB}$ & 48 & $39(22)$ & $33(<1)$ & $45(44)$ & $32(<1)$ & $40(23)$ & $45(25)$ & $77(<1)$ & $42(38)$ & $30(0)$ & $32(<1)$ & $38(17)$ \\
\hline $\mathrm{CH}$ & 47 & $35(11)$ & $28(<1)$ & $42(29)$ & $28(<1)$ & $38(21)$ & $49(21)$ & $68(10)$ & $34(7)$ & $26(<1)$ & $28(3)$ & $34(11)$ \\
\hline $\mathrm{BH}$ & 34 & $23(7)$ & $19(0)$ & $29(30)$ & $20(2)$ & $29(20)$ & 35 (12) & $53(5)$ & $21(1)$ & $20(3)$ & $22(8)$ & $13(<1)$ \\
\hline $\mathrm{RB}$ & 35 & $26(13)$ & $21(0)$ & $32(34)$ & $22(3)$ & $30(24)$ & $34(16)$ & $60<1)$ & $25(5)$ & $22(4)$ & $23(8)$ & $15(2)$ \\
\hline \multicolumn{13}{|c|}{ Sessile species } \\
\hline LR & 49 & $46(62)$ & 41 (17) & 49 (49) & $38(2)$ & $46(55)$ & 48 (39) & $75(0)$ & $51(71)$ & $36(0)$ & $37(<1)$ & $44(45)$ \\
\hline LB & 36 & $32(45)$ & $27(6)$ & $36(45)$ & $25(<1)$ & $34(44)$ & $37(30)$ & $48(8)$ & $33(56)$ & $23(0)$ & $26(5)$ & $31(36)$ \\
\hline $\mathrm{CB}$ & 51 & $49(70)$ & $44(30)$ & $52(49)$ & $41(4)$ & $49(63)$ & 49 (44) & $81(0)$ & $56(57)$ & $38(0)$ & $41(4)$ & 48 (69) \\
\hline $\mathrm{CH}$ & 52 & $50(72)$ & $45(31)$ & $53(61)$ & $43(4)$ & $48(56)$ & $50(47)$ & $75(0)$ & $57(56)$ & $39(0)$ & $42(2)$ & $47(59)$ \\
\hline $\mathrm{BH}$ & 44 & $41(60)$ & 37 (16) & $44(48)$ & $34(1)$ & $39(38)$ & $43 \# \$)$ & $62(<1)$ & $45(76)$ & $31(0)$ & $34(2)$ & $39(36)$ \\
\hline $\mathrm{RB}$ & 65 & $60(64)$ & $55(14)$ & $63(65)$ & $52(2)$ & $57(31)$ & $61(43)$ & $94(0)$ & $70(62)$ & $48(0)$ & $51(0)$ & $57(31)$ \\
\hline
\end{tabular}

Note: Estimates were made from six non-parametric estimates ( $\mathrm{HF}, \mathrm{SB}, \mathrm{J}_{2}, \mathrm{SJ}_{1}, \mathrm{SJ}_{2}$ and Chao 2) and five regression models (Power, Exponential, Negative exponential, Asymptotic and Rational). Details of the metrics used, sites and methods are in Chapman and Underwood (2009).

of individuals in each site. This information is used to create an index which identifies those species with very limited distributions within and among sites and, when summed across species, identifies those sites containing a large proportion of such species. Although developed for assemblages in boulder-fields, the results are applicable to any conservation issue where sites need to be ranked, using quantitative data from diverse assemblages.

There have thus been many studies in boulder-fields in which the boulders simply represented intertidal habitat, with no questions about their features as boulders (e.g. testing interactions among grazers, barnacles and algae; Van Tamelen 1987). This has contributed to and extended the well-documented early research on rocky shores in the UK (Hawkins \& Hartnoll 1982, Hawkins 1983), Australia (Underwood \& Jernakoff 1981, Underwood 1984), South Africa (Branch 1975) and in the USA (Dayton 1971, Menge 1976), increasing our understanding of the complexity of interactions among rocky shore assemblages. Green \& Crowe (2014) examined the effects of the invasive oyster, Magallana gigas (=Crassostrea gigas), on intertidal biodiversity, using manipulations of oysters on individual boulders. The questions being addressed, however, regarded the invasive oyster, not the boulder habitat per se. Similarly, Altieri et al. (2010) used intertidal cobble beaches that were colonized by cordgrass and mussels to investigate relationships between abiotic stress, species diversity and invasibility.

\section{Understanding the ecology of the biota living under boulders}

The upper surfaces of intertidal boulders tend to have much bare space or be dominated by common algae or sessile invertebrates depending on the exposure of the site and the sizes of the boulders. In contrast, the undersurfaces tend to be dominated by encrusting algae and sessile animals, including sponges, bryozoans and tube worms (described by McGuinness 1987a,b, Chapman 2002a, 2005) (Figure 2B). Even in extremely harsh environments, where the tops of boulders are bare, the 
undersurfaces support a few common epifauna, particularly bryozoans and polychaetes (Barnes et al. 1996, Kuklinski et al. 2006, Waller 2012). Where boulders are colonized by species that provide biogenic habitat (e.g. plants or sessile species, such as mussels), species diversity is increased in such harsh environments, due to amelioration of these environmental stresses (Altieri et al. 2010).

In more benign environments, the undersurfaces of boulders and any rocky substratum on which they rest, support a diverse sessile assemblage of invertebrates and many mobile species, particularly molluscs and echinoderms. Many of these are widespread species, but others appear to be habitat-specialists and can be relatively rare under boulders and even sparser in other habitats (McGuinness 1987a, Chapman 2002a, 2005). Chitons are particularly speciose and abundant, most notably species of the genus Ischnochiton (Kangas \& Shepherd 1984, Grayson \& Chapman 2004). McGuinness (1987a) showed that although the abundances of individual species were sometimes related to size of the boulder, patterns were very variable, with increases in abundance with size on one shore (NSW, Australia), but the opposite pattern found on another nearby shore. This result was, however, confounded by the rock-type differing between the two shores. Most studies of biota living under boulders in NSW have shown no relationship between either abundances of individual species or numbers of species with the size of the boulder (Smith \& Otway 1997, Chapman 2002a, 2005, Grayson \& Chapman 2004, Palmer 2012).

An obvious characteristic of many species living under boulders is their extreme overdispersion at a number of spatial scales. In any location, many boulders are unoccupied by any particular species and many individuals of that species are crowded on to few boulders (described by Smith \& Otway 1997, Chapman 2002a, Grayson \& Chapman 2004, Smoothey \& Chapman 2007) (Figures 2C and 3). Nevertheless, very few boulders are completely devoid of species (as few as 5\%; Chapman 2005) in many locations and the mix of species co-existing on boulders in a location is very variable (shown for a sample of boulders from Cape Banks, NSW, Australia in Figure 4), indicating that many more boulders may be suitable habitat than are actually occupied by any particular species. Up to $90 \%$ of the spatial variation at multiple scales, from individual boulders to locations hundreds of kilometres apart, is found at the scale of metres, among individual boulders. Assemblages in adjacent sites in one location can differ more than assemblages that are kilometres apart in different boulder-fields (Chapman 2005). In addition, the species that most contribute to variability among boulders also vary spatially, with different species showing quite different degrees of overdispersion in different places, in quite unpredictable ways.

Palmer (2012) compared the spatial patterns of a brooding chiton and one which was a broadcast fertilizer in a number of boulder-fields in NSW, Australia, expecting that the brooding species would be more aggregated than the broadcast fertilizer. Each species was overdispersed, but the brooder was not more aggregated and did not show greater genetic relationships among animals under individual boulders than did the broadcast fertilizer. In fact, there was a very large amount of genetic variability among individuals for both breeding types, under individual boulders and within patches of a boulder-field. This suggests large amounts of dispersal among boulders by both species, probably as small juveniles or adults, despite their apparent 'preference' for certain boulders.

Patterns of overdispersion are established very early in the development of an assemblage. Chapman (2002b) examined colonization of newly quarried rocks (thus, with no biofilm, which might act as an attractant for some species) placed on a sandy or algal/rocky substratum in replicate areas. Many species that rapidly colonized these boulders-68 taxa within five days-are generally only seen under boulders or in biogenic habitat and not on the substratum among the boulders (e.g. the chitons, Ischnochiton australis and I. smaragdinus), although other early colonizers were common and widespread species (e.g. the gastropod, Austrocochlea porcata). From relatively early in the experiment, however, common and rare species were each aggregated on to some of the new boulders, but all species did not colonize the same subset of boulders. Therefore, nearly all boulders had some species aggregated under them, with different species colonizing a different subset of boulders. It was never clear how or why they located those particular boulders, why they moved on 


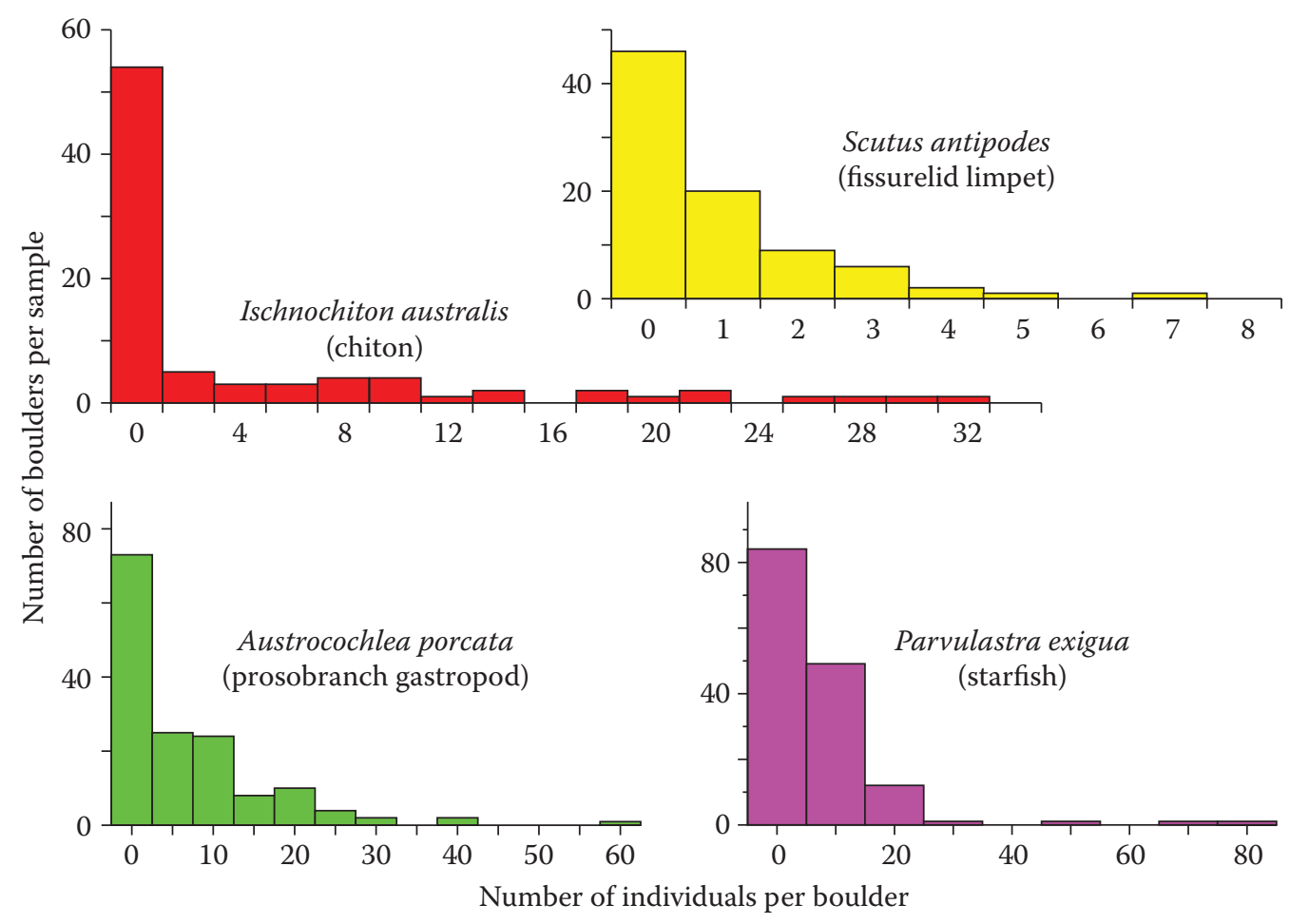

Figure 3 Overdispersion among boulders illustrated for a species of chiton (Ischnochiton australis), fissurelid limpet (Scutus antipodes), starfish (Parvulastra exigua) and prosobranch gastropod (Austrocochlea porcata) sampled in NSW, Australia. Most boulders are not occupied by any particular species, with many individuals crowded onto a few boulders, which differ among the different species. (Chapman, unpublished data.)

to the novel habitat, nor the mechanisms by which they dispersed among boulders. Some species (e.g. Ischnochiton australis and the gastropod, Stomatella impertusa) detach from the surfaces of boulders into the water column when the boulders are disturbed. They are rapidly washed away with the moving water, although $S$. impertusa appears to readily adhere to new substratum that it encounters while carried in the water column (G. Chapman, pers. obs).

Aggregation also occurs at scales larger than among individual boulders. This may occur because different species tend to live at different shore heights (e.g. porcelain crabs, Emparanza 2007; chitons, Palmer 2012), but patchiness is often not related to height, with large and, so far, unexplained variability in assemblages among patches of apparently similar boulders at the same height (Chapman 2005). At a smaller scale, different species distribute themselves non-randomly on individual boulders. For example, in Australia and South Africa, chitons were more common near the edges than the centres of undersurfaces of boulders lying over fine sediments (Liversage et al. 2012), and the distribution of coralline crusts under boulders depends on their shape (Liversage 2016). Experiments in which sediments under the boulders were altered showed increased movement of chitons towards the edges when boulders were placed on fine sediment, perhaps because the centres of boulders tended to bury more deeply in fine than in coarse sediment. Choi \& Ginsberg (1983) similarly showed greater densities of coelobites towards the edges of coral rubble rather than towards the middle of the undersurfaces.

Temporal variation of assemblages in boulder-fields is also very difficult to explain, because there are often no clear seasonal or annual patterns of abundance nor recruitment, with both shortand long-term temporal variability in numbers of most species interacting with numerous spatial 

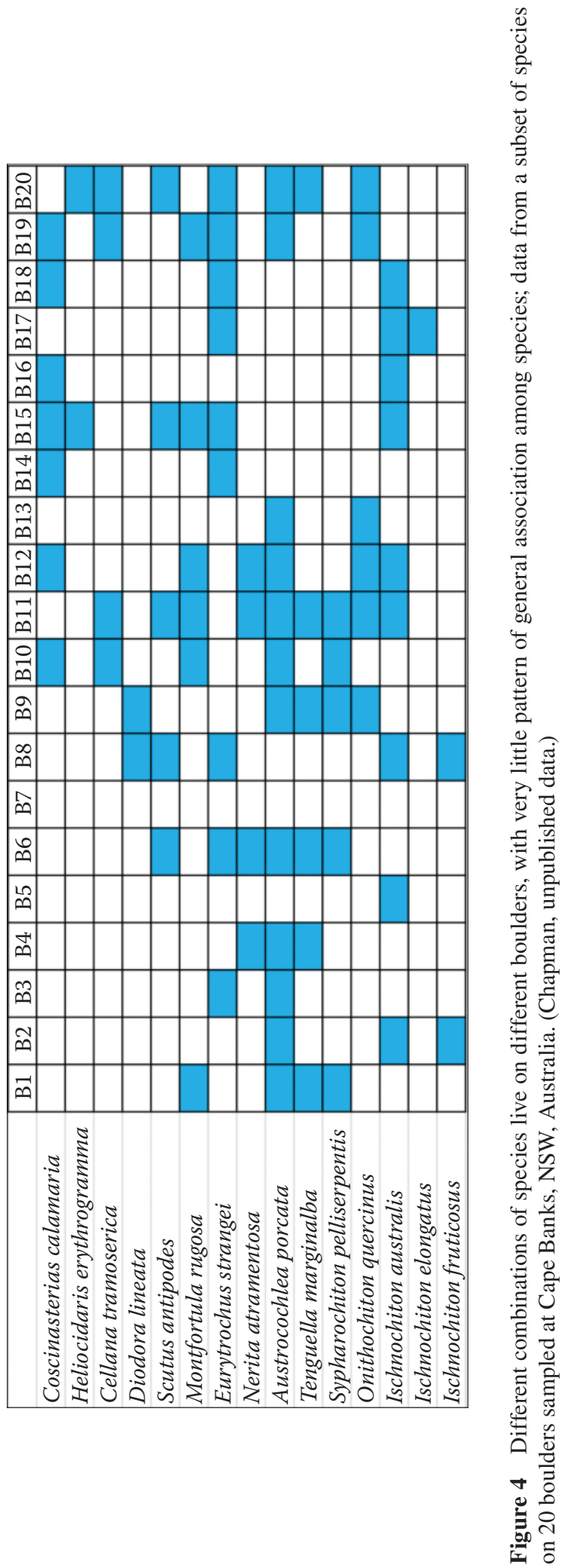

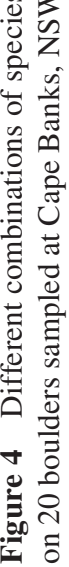


scales, from metres to kilometres (Chapman 2005). In areas where seasons are more extreme, there may, however, be seasonal patterns in abundance which are more predictable (Gianguzza et al. 2013).

\title{
Rarely studied microhabitats in boulder-fields
}

Some specific microhabitats found in boulder-fields have been little studied. In the spaces between adjacent boulders, crevices can be used as refuges by invertebrates, such as sea urchins (Smoothey \& Chapman 2007) or fish, many of which are quite rare (Kovačič et al. 2012). Female blue-ringed octopuses, Hapalochlaena lunulata, lay egg masses in the crevices among boulders, which they brood until hatching (G. Chapman, pers. obs.). Similarly, freshwater crayfish, Cambarus chasmodactylus, maintain territories in such crevices and under boulders in rivers in Florida, USA (Loughman et al. 2013).

The presence of boulders may also affect species living in soft-sedimentary intertidal habitats, for example in saltmarshes, where patches of boulders protect rare forbs from wave action (Bruno 2000), or in mangroves where boulders provide hard substrata for settlement and grazing (Underwood \& Barrett 1990). Where boulders overlay sediment, they lead to altered grain-size and increased amounts of organic matter in the sediment (Cruz-Motta et al. 2003). Either these changes or other factors associated with the presence of boulders can affect the infauna in the sediment directly under the boulders. Again, such influences are spatially variable, although they can be strongly influenced by the state of the tide (Cruz-Motta 2005).

\section{Factors affecting diversity and abundances of biota on boulders}

\author{
Abiotic factors
}

\section{Disturbances}

Individual boulders are vulnerable to numerous disturbances, both anthropogenic and natural. Small boulders in dynamic environments are overturned by wave action (Osman 1977, Sousa 1979a, McGuinness 1987a,b), or scoured (Littler \& Littler 1984) or buried by sediment (McGuinness 1987a). These boulders support few species compared to more stable boulders. Sousa (1979a) showed experimentally, by stabilizing small boulders, that the numbers of species occupying boulders was directly related to the frequency and extent of disturbance. McGuinness (1987b) similarly used experimentally-stabilized or buried boulders of different sizes to illustrate the effects of disturbance on species diversity. In contrast to Sousa (1979a), he showed no effects of the experimental treatments on algal diversity on the tops of boulders, probably because his sites were comparatively undisturbed and/or grazers had strong effects on diversity of algae in some areas. These disturbances did, however, affect some species living under the boulders. In the absence of such disturbances, assemblages under boulders were dominated by ascidians and sponges, which readily overgrow other taxa.

In some areas, boulders are overturned by humans while harvesting (Cryer et al. 1987), which can kill the biota on the upper and lower surfaces (Addessi 1994) and reduces abundances of harvested species, such as urchins and crabs. Harvested species can, but do not always, increase in areas with intermediate amounts of such disturbance (Addessi 1994), although crabs can rapidly move on to boulders from which individuals have been removed by harvesters (Cryer et al. 1987). If boulders are not left overturned, but are replaced in their normal orientation, then as long as disturbances are not too frequent, both mobile and sessile assemblages are likely to be unaltered by the disturbance (Chapman \& Underwood 1996). When boulders are overturned on sequential days, however, even if they are replaced each time, abundances of many taxa are likely to decrease as mobile species apparently move away from the disturbed area. This is an important consideration 
when sampling organisms that live under boulders, because boulders must be overturned before the undersurfaces can be sampled. Nevertheless, this form of disturbance has not received a lot of attention from ecologists working in this habitat (but see Chapman \& Underwood 1996).

There are also potential cascading effects of harvesting on other species living under boulders. For example, in NSW, Australia, people frequently harvest sea urchins from under boulders (G. Chapman, pers. obs.). The chiton, Ischnochiton australis, is very strongly associated with urchins, being more abundant on boulders with urchins and, on the surface of the boulder, being crowded into the areas under the spines of the urchins (Chapman \& Smoothey 2014). Experiments showed that the chitons left boulders from which urchins had been removed at a faster rate than from boulders with urchins, but removal of chitons did not affect numbers of urchins. This suggests that urchins provide important habitat for the chitons, but it is not known what particular resources they provide, considering that the boulder itself appears to protect the chitons from predation or strong water movement. Whatever these resources are, they appear to be removed by removal of urchins.

\section{Features of the boulders or their immediate surroundings}

In experiments to try to identify features of the habitat that affect dispersal of animals on to and among boulders, most species that colonized newly quarried boulders aggregated rapidly on some boulders and not others, despite the lack of a sessile assemblage that could influence dispersal (Chapman 2002b). Overdispersion for most species was established very early-within days. These patterns were mainly due to dispersal, not settlement, because most colonizers were not new recruits. Later work compared colonization on to denuded natural boulders or sandstone blocks (which provided reduced complexity of habitat). The blocks had either no or one of two ages of established sessile assemblages (thus providing different levels of biotic complexity). These treatments were either placed adjacent to or away from a natural boulder, with the latter treatments placed in a position from which a boulder was removed, or in a position where there was no natural boulder (potentially influencing proximity to a pool of potential colonizers). Colonization was measured after the first week to nine months after deployment of the treatments. There was rapid colonization of all habitats, with no effects of either features of boulder, nor its position (Chapman 2003a) and assemblages on all habitats converged within six months (development of the mobile assemblage shown as trends in the centroids calculated at each time of sampling for selected treatments in Figure 5). Again, most species were overdispersed, with the detailed patterns showing no similarity among species. Later research showed that neither size of sandstone block, time of deployment, nor length of deployment showed clear effects on animals colonizing the experimental units, although there was some suggestion that the position in the boulder-field may be more important than the habitat itself (Chapman 2007).

The most obvious feature of a boulder that would be expected to affect diversity of species occupying it is its size, but generally, neither abundances of individual taxa nor numbers of species appear related to size of the boulder (Smith \& Otway 1997, Chapman 2002a, 2005, Grayson \& Chapman 2004), or results are very spatially variable (McGuinness 1984, 1987a,b). In contrast to much of the unexplained variation, experiments have shown that rock-type may be important (McGuinness \& Underwood 1986, Green et al. 2012), but it cannot explain patterns of distribution for all species. Liversage \& Benkendorff (2013) sampled limestone and basalt boulder-fields and showed species were most abundant in areas with basalt shores and that some species (e.g. Ischnochiton australis) were never found on limestone boulders. Patterns of overdispersion for some species also varied with rock-type, but this was not consistent among locations for the different species.

In addition, neither abundances nor diversity may be related to the characteristics of the substratum on which the boulders lie (e.g. the grain-size of the sediments; Smith \& Otway 1997), although in a comparative study between Australia and South Africa, Liversage et al. (2012) showed more chitons under boulders lying on fine than on coarse sediment. Changing the sediment showed more immigration to boulders lying on fine sediment, but densities were not controlled in the experimental treatments, so the results were confounded. Chapman (2002b) also showed differences in developing 

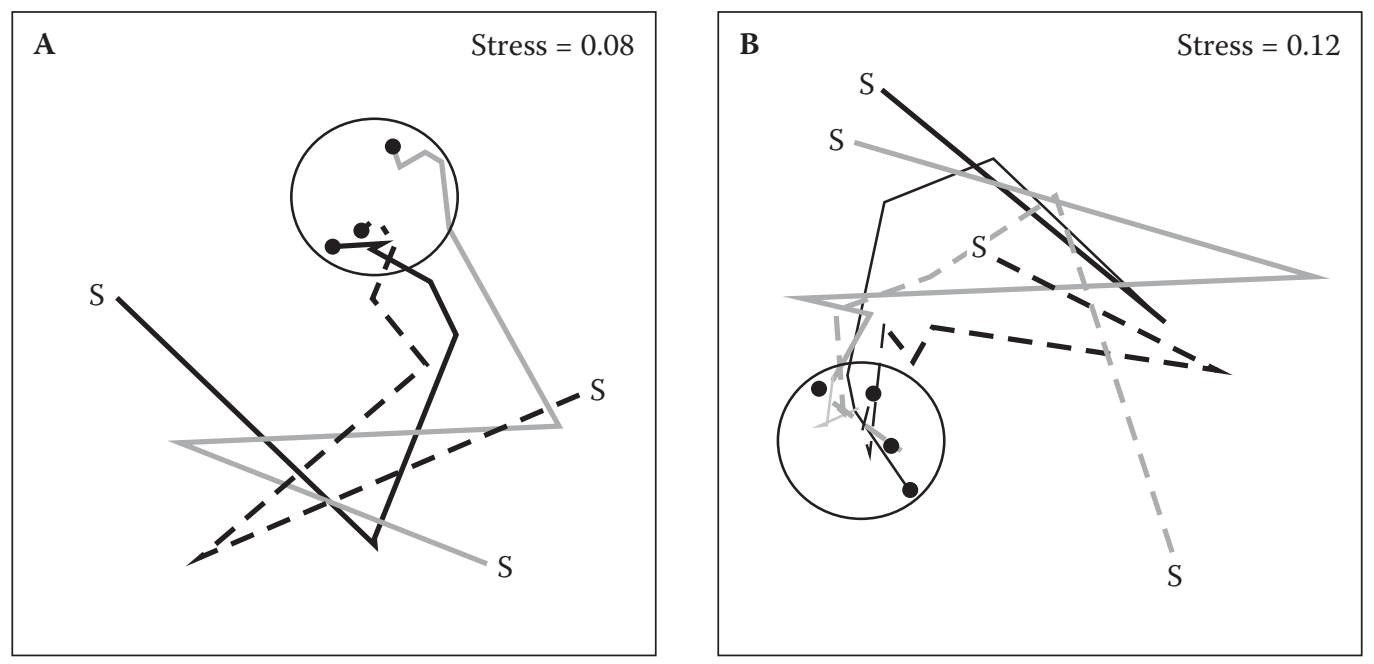

Figure 5 Convergence of the mobile assemblage over nine months from one week after plates and boulders were deployed at the start of the experiment (S). Trends are shown by the centroids calculated from independent samples of each treatment at each time of sampling. (A) Artificial plates with no biofilm, placed at the start of the experiment adjacent to an existing boulder (black dashed line), at least $1 \mathrm{~m}$ away from an existing boulder (gray solid line) or in a position where there was originally a natural boulder (black solid line). (B) Treatment placed adjacent to an existing boulder; samples of new plates with no biofilm (gray dashed line), plates with a six-month-old sessile assemblage (black solid line), plates with a nine-month-old sessile assemblage (gray solid line), denuded natural boulder with existing sessile assemblage (black dashed line). (From Chapman 2003a.)

assemblages depending on whether the underlying substratum was sand or algal/rocky, but patterns varied between replicate areas and few general patterns could be identified (Chapman 2003a).

\section{Combinations of abiotic stresses}

Cobbles on semi-sheltered beaches in New England, USA, can be colonized by large areas of cord grass and mussels. Experiments have shown that the former provide shade and the latter stabilize the cobbles (Altieri et al. 2010). Both of these mechanisms ameliorate abiotic stresses, increasing the number of species and abundances of the invasive crab, Hemigrapsus sanguineus, associated with the cobble beds (Altieri et al. 2010). Similarly, disturbances due to wave action or water movement can vary with the depth of the water or distance off shore, altering the size-range of subtidal boulders that are frequently overturned (Osman 1977). Intertidally, the small-scale configuration of the shoreline and presence of offshore shallow reefs similarly reduce disturbance on intertidal boulders, although these reductions do not occur in very stormy conditions (G. Chapman, pers. obs.). Exposure to waves has been shown to influence disturbance to intertidal coral rubble, directly in relationship to size of the boulders and the height on the shore (Walker et al. 2008). This did not directly relate to the numbers of species under the boulders, which, it was suggested, may also be affected by competition. Experiments are needed, however, to unravel the complexity of interacting abiotic factors, such as height on the shore, wave exposure and size of boulders on the richness of species. Such experiments are still, unfortunately, relatively rare.

\section{Biotic factors}

\section{Recruitment}

Initial patterns of recruitment can be very important in determining later assemblages on boulders (Osman 1977). Recruitment can be affected by the composition of the rock, as shown by 
McGuinness \& Underwood (1986), who used a reciprocal transplant of sandstone or shale rocks between two shores to test the hypotheses that differences in the distribution of the alga, Ulva lactuca, and spirorbid polychaetes between shores could be explained by recruitment in response to rock-type. As predicted, the alga colonized more onto sandstone than onto shale boulders, with spirorbids showing the opposite pattern. At a larger scale, Green et al. (2012) showed more foliose algae colonizing sandstone boulders and more barnacles colonizing granite boulders in artificial boulder-fields created at the bases of sea walls.

An experimental extension of the research by McGuinness \& Underwood (1986), where upper and lower surfaces of the two types of rocks were painted different colours to match different rock-types, showed that spirorbids recruited in response to a dark lower surface, irrespective of the type of rock or the colour of the upper surface (James \& Underwood 1994). Colour alone was not, however, adequate to explain all of the variation and on natural boulders, both the upper and lower surfaces tend to be multicoloured, depending on the sessile assemblages that they support. Recruitment in response to rock-type could not explain patterns of distribution in the coexisting common polychaete, Galeolaria caespitosa (McGuinness 1988).

\section{Competition}

There have been few studies of competition in assemblages on or under boulders, largely because, other than on the tops of stable boulders (Sousa 1979b), there is often considerable free space (McGuinness 1987a,b). Despite available free space, species may, however, be crowded into very small areas of the boulders, as described above for chitons under boulders lying on fine sediments (Liversage et al. 2012). Barnes \& Lehane (2001), however, showed strong competitive interactions, including overgrowth, by numerous sessile species of invertebrates under boulders on South Atlantic islands, where the fauna are crowded into the central areas of the undersurfaces. There was, thus, strong competition for space, despite most of the boulders being unoccupied and abundant space being available.

Extreme aggregation of many mobile species among individual boulders (Smith \& Otway 1997, Chapman 2002a, 2005) and overdispersion on the undersurfaces of individual boulders themselves (Chapman \& Smoothey 2014) suggests that space under boulders may be limiting for attachment and feeding by mobile species, even when many boulders in the vicinity are sparsely or unoccupied. The chiton, Ischnochiton australis, can occur in large abundances under some boulders and are often lying in layers on top of each other (Palmer 2012), or crowded under other species, such as urchins (Chapman \& Smoothey 2014). This suggests that there could be strong local competition for space or food, but neither intra- nor interspecific competition has been examined in these overdispersed species living under boulders, so this question remains unanswered.

\section{Grazing and predation}

Grazers may not be as important as are physical disturbances in controlling cover of algae on boulders, which contrasts to its importance on many rocky shores (Underwood 1980, Hawkins \& Hartnoll 1983). Nevertheless, grazing may explain the lack of relationship between algal cover and size of boulders in some lowshore areas, where grazers are more abundant on larger boulders. They may reduce algal cover on these boulders in a similar way that physical disturbance controls cover of algae on smaller or highshore boulders (McGuinness 1987b), thus disrupting the expected species-area relationship.

It is not clear on what and where many of the species that live under boulders feed. Many molluscs, including those living under boulders, are algal grazers, but measures of micro- or macroalgal food under boulders are lacking. Other species, such as Ischnochiton smaragdinus, feed on bryozoans and sponges that are common under boulders, and Loricella angasi can catch and eat amphipods (Kangas \& Shepherd 1984). Some species have been seen to move on to the upper surfaces to feed (e.g. Ischnochiton australis; Kangas \& Shepherd 1984) and others migrate into the surrounding 
area at night before returning to boulders during daylight (J. Grayson, pers. comm.). It is assumed, but not known, that these animals are feeding.

There have been few studies of predation in intertidal boulder-fields, other than human harvesting, although Rogers \& Elliott (2013) examined predation of starfish by gulls in numerous intertidal habitats in Puget Sound, USA. Small starfish were only found in the boulder-fields, where there was also the largest incidence of predation, with gulls observed pulling small starfish out from under the boulders. Experiments showed that gulls tended to feed only on the small starfish. These may have been eaten in parts of the shore where they are easily visible and were, thus, only found under boulders, or they may not have recruited to those other habitats. Thus, gulls concentrated their predation in the only habitat where young starfish lived.

\section{Post-settlement dispersal}

Some experiments on dispersal of organisms among boulders have shown strong behavioural responses for some species. For example, Cryer et al. (1987), in an experimental study of the effects of harvesting, showed that boulders which originally had crabs sheltering under them, were more likely to be recolonized by crabs, even after the crabs had been removed. The colonizing crabs were presumably responding to some features of the boulders (or possibly cues remaining after removal of the crabs), but what these were is unknown. Smoothey \& Chapman (2007) showed similar behaviour for sea urchins: more dispersal to boulders under which there were originally urchins, even after the urchins had been removed, than to boulders without urchins at the start of the experiment.

In experiments to try to identify what are the features of boulders or their surroundings that affect dispersal of animals, newly quarried boulders were deployed within boulder-fields (Chapman 2002b). These boulders had no biota or biofilm at the start of the experiment. Nevertheless, they were quickly colonized with most animals arriving as adults or juveniles, rather than settling larvae. They apparently moved under the new boulders from the surrounding habitat (Chapman 2002b, 2003a). An overdispersed pattern of distribution among individual units of habitat was established very quickly—within days or weeks.

\section{Restoration of boulder-fields in response to degradation or loss}

Because boulders support a wide diversity of biota and create complex habitat that changes rates of water movement and sediment deposition (Cruz Motta 2005), they have been deployed in streams and rivers as part of restoration programmes, often in conjunction with the addition of vegetation and removal of channelization. The aim has been to increase local biodiversity or improve habitat for fish (Roni et al. 2006, Branco et al. 2013) because boulders are effective at retaining floating vegetation at relatively low rates of discharge (Koljonen et al. 2012), thus increasing the availability of local patches of complex habitat and resources.

Boulders, or artificial surrogates such as concrete blocks, are similarly used to build artificial reefs in subtidal areas to mitigate for loss of habitat, predominantly to provide habitat for exploited or charismatic species, or to increase habitat for fish (reviewed by Baine 2001). Such reefs, however, frequently support unique assemblages and do not form surrogates for any loss of natural habitats. For example, a 5-year-long comparison of a built boulder-reef and natural reef in Florida, USA, showed that the former consistently had larger abundances of fish and supported a different assemblage to that found on the natural reef (Kilfoyle et al. 2013).

Intertidally, there has been little research on the restoration of boulder-fields, with most intertidal restoration efforts focused on mangroves and wetlands. Because boulder-fields are vulnerable to so many disturbances and support such a diverse and specialized fauna, consideration should be given to the possibility of creating novel boulder-fields to replace those that have been lost or are under threat (e.g. due to urban development or potentially through a rise in sea level). The sessile assemblages that naturally inhabit boulders often include many fouling species that readily colonize 
bare space, but characteristics of the sessile assemblage do not seem important in influencing colonization by the mobile species, many of which are habitat-specialists (Chapman 2002b). When novel habitat, such as sandstone blocks, are placed within boulder-fields, they are rapidly colonized (Chapman 2003a), suggesting that boulder-fields may be easy to duplicate if there is a nearby source of colonists, and boulders or their surrogates can be deployed with minimal disturbances. This view is supported by examining the small artificial boulder-fields that are created from building rubble at the base of many intertidal sea walls. These support many species which do not live on the walls themselves, thus increasing local diversity of species (Chapman 2006). Stony rubble, if left in place, may therefore compensate to some extent for the negative effects on native biodiversity of armoring shorelines by replacing natural habitat with sea walls (Chapman 2003b). This is not to suggest, however, that it is acceptable to simply discard waste materials in the sea and call them artificial reefs or surrogate habitat (Chou 1997).

Research in NSW, Australia, has created new, relatively small boulder-fields from quarried rock in areas near to, but not within, natural boulder-fields (Chapman 2012). Sessile assemblages colonized these patches very slowly and variably and had not reached the equivalence of natural boulders within a year. Nevertheless, both rare and common mobile animals, primarily molluscs and echinoderms which are the main taxa that occupy natural boulders, rapidly colonized these patches. There was no clear successional sequence, with colonization patchy at the scales of individual boulders, among patches of boulders $20 \mathrm{~m}$ apart, between sites $500 \mathrm{~m}$ apart and between locations $2 \mathrm{~km}$ apart, although diversities and abundances of some species matched those of natural boulders within a few months. Both rare and common animals mainly colonized as adults from surrounding areas, despite the fact that there were no visible individuals of many of the rare species in these areas. The size of the newly created patches, composed of 50 or 100 large boulders, showed no effect of patch size on either rates of colonization, or the suite of species that colonized the different patches (Chapman 2013). Most species were randomly distributed between the two patch sizes, some species were more abundant on the larger patches, but other closely-related species showed the opposite pattern. After a few weeks, most species were as abundant in these patches as on natural boulders; colonization was rapid.

\section{Future research directions}

Intertidal boulder-fields have many characteristics which make them ideal for experimental studies to further our understanding of ecology. A fertile field for further research is the causes for the extreme patterns of overdispersion that are found in this habitat. Despite considerable research into responses of biota to different features of habitat associated with the boulders themselves, these strong patterns of overdispersion are still little understood. Because the fauna occupy and move among discrete patches of habitat (the boulders), which can be experimentally manipulated with respect to their features (size, complexity, sessile assemblage), their positions relative to each other, and the timing of manipulations relative to timing of settlement, weather, etc., they are ideal habitats in which to test experimentally complex ecological models of dispersal and habitat requirements. In addition, because many of the more common species are also found on continuous rocky shores, they are ideally placed to compare dispersal and recolonization of denuded areas in continuous versus patchy habitats. With increased disturbances on natural rocky shores potentially disrupting and fragmenting natural populations, such information could be invaluable in determining how best to manage such populations.

Despite the well-documented species-area relationship for many habitats, size of boulders appears to have little consistent effect on either abundances or numbers of species found on them. Because this theory is a cornerstone of much ecological theory, this habitat is an ideal arena in 
which to explore this relationship (or lack thereof) because the habitat itself can be easily experimentally manipulated.

There is still much to learn about the persistence of rare species because their spatial and temporal dynamics, responses to habitat, body-size abundance patterns and many other characteristics of life history are all thought to differ fundamentally from those of common species (Gaston 1994). Because boulder-fields support a number of species which are closely related, which are functionally similar, or which have differing modes of reproduction, they and their habitat can be manipulated in the field with relatively little disturbance (Chapman \& Underwood 1996). This makes them ideal for investigating many of the questions raised by Gaston (1994) and others who attempt to understand the dynamics of rare species.

Finally, there is still much to understand in order to manage, restore or recreate these habitats for the conservation of their biota, both with respect to repairing damage to existing boulder-fields, or building new habitat in mitigation for that lost or threatened. In addition, it has been suggested that boulder-fields may be built to compensate for loss of alternative habitat, such as seagrasses through urban development (Iversen \& Bannerot 1984). Boulder-fields are being built to protect shorelines (Green et al. 2012) as part of softening armoured shores to create hybrid designs. Yet, to date, there has been little research into the ecological value of such created habitat relative to that lost by urbanization and shoreline development.

\section{Conclusions}

Despite their prevalence along some coastlines and the large number of species that live in intertidal boulder-fields, they have been little studied compared to habitats such as mangrove forests or intertidal rock platforms. Yet, because boulder-fields are composed of natural units of habitat (the boulders), which can be transplanted among sites (with or without their very diverse sessile and mobile assemblages), and in addition, experimentally manipulated in many different ways to test a variety of hypotheses, they have been very rich areas of research for tests of such ecological concepts as succession, the role of disturbance, species-area relationships, and the effects of habitat complexity on diversity. As such, research in boulder-fields has added important data to the generality of many ecological theories.

In addition, the undersurfaces of boulders, especially in relatively sheltered areas, are habitat for a wide range of species, particularly of molluscs, many of which are seldom or not found in other habitats. Many of these are rare species, with limited range and/or small abundances. As such, they are vulnerable to many current and predicted disturbances. Most species have extremely strong patterns of habitat association, but in general, the factors causing these overdispersed patterns of abundance, at scales of metres to kilometres, are not known. With few exceptions, animals do not appear to respond to obvious features of the boulders, or to the other biota inhabiting the boulders, but they aggregate on to a limited number of boulders at the stage of initial colonization. To maximize our potential to protect these fauna, it is important to generate better understanding of the responses to habitat of these species, especially the rare species. This requires careful, well thought-out experiments that minimize disturbance to the habitat (Chapman \& Underwood 1996) and the rare species (Chapman \& Smoothey 2014).

\section{References}

Addessi, L. 1994. Human disturbance and long-term changes on a rocky intertidal community. Ecological Applications 4, 786-797.

Altieri, A.H., Van Wesenbeeck, B.K., Bertness, M.D. \& Silliman, B.R. 2010. Facilitation cascade drives positive relationship between native biodiversity and invasion success. Ecology 91, 1269-1275. 


\section{M.G. CHAPMAN}

Baine, M. 2001. Artificial reefs: a review of their design, application, management and performance. Ocean \& Coastal Management 44, 241-259.

Barnes, D.K.A. \& Lehane, C. 2001. Competition, mortality and diversity in South Atlantic coastal boulder communities. Polar Biology 24, 200-208.

Barnes, D.K.A., Rothery, P. \& Clarke, A. 1996. Colonisation and development in encrusting communities from the Antarctic intertidal and sublittoral. Journal of Experimental Marine Biology and Ecology 196, 251-265.

Branch, G.M. 1975. Mechanisms reducing intraspecific competition in Patella species: migration, differentiation and territorial behavior. Journal of Animal Ecology 44, 575-600.

Branco, P., Boavida, I., Santos, J.M., Pinheiro, A. \& Ferreira, M.T. 2013. Boulders as building blocks: improving habitat and river connectivity for stream fish. Ecohydrology 6, 627-634.

Bruno, J.F. 2000. Facilitation of cobble beach plant communities through habitat modification by Spartina alterniflora. Ecology 81, 1179-1192.

Chapman, M.G. 2002a. Patterns of spatial and temporal variation of macrofauna under boulders in a sheltered boulder field. Austral Ecology 27, 211-228.

Chapman, M.G. 2002b. Early colonization of shallow subtidal boulders in two habitats. Journal of Experimental Marine Biology and Ecology 275, 95-116.

Chapman, M.G. 2003a. The use of sandstone blocks to test hypotheses about colonization of intertidal boulders. Journal of the Marine Biological Association of the United Kingdom 83, 415-423.

Chapman, M.G. 2003b. Paucity of mobile species on constructed seawalls: effects of urbanization on biodiversity. Marine Ecology Progress Series 264, 21-29.

Chapman, M.G. 2005. Molluscs and echinoderms under boulders: tests of generality of patterns of occurrence. Journal of Experimental Marine Biology and Ecology 325, 65-83.

Chapman, M.G. 2006. Intertidal seawalls as habitats for molluscs. Journal of Molluscan Studies 72, 247-257.

Chapman, M.G. 2007. Colonization of novel habitat: tests of generality of patterns in a diverse invertebrate assemblage. Journal of Experimental Marine Biology and Ecology 348, 97-110.

Chapman, M.G. 2012. Restoring intertidal boulder-fields as habitat for "specialist" and "generalist" animals. Restoration Ecology 20, 277-285.

Chapman, M.G. 2013. Constructing replacement habitat for specialist and generalist molluscs - the effect of patch size. Marine Ecology Progress Series 473, 201-214.

Chapman, M.G. \& Smoothey, A.F. 2014. Sea urchins provide habitat for rare chitons in intertidal boulderfields. Journal of Experimental Marine Biology and Ecology 459, 31-37.

Chapman, M.G. \& Underwood, A.J. 1996. Experiments on effects of sampling on biota under intertidal and shallow subtidal boulders. Journal of Experimental Marine Biology and Ecology 207, 103-126.

Chapman, M.G. \& Underwood, A.J. 2009. Evaluating accuracy and precision of species-area relationships for multiple estimators and different marine assemblages. Ecology 90, 754-766.

Chapman, M.G., Underwood, A.J. \& Clarke, K.R. 2009. New indices for ranking conservation sites using 'relative endemism'. Biological Conservation 142, 3154-3162.

Choi, D.R \& Ginsberg, R.N. 1983. Distribution of coelobites (cavity-dwellers) on coral rubble across a Florida reef tract. Coral Reefs 2, 165-172.

Chou, L.M. 1997. Artificial reefs of Southeast Asia - do they enhance or degrade the marine environment? Environmental Monitoring and Assessment 44, 45-52.

Connell, J.H. 1978. Diversity in tropical rainforests and coral reefs. Science 199, 1302-1310.

Cruz Motta, J.J. 2005. Diel and tidal variations of benthic assemblages in sediments associated with boulder fields. Marine Ecology Progress Series 290, 97-107.

Cruz Motta, J.J., Underwood, A.J., Chapman, M.G. \& Rossi, F. 2003. Benthic assemblages in sediments associated with intertidal boulder-fields. Journal of Experimental Marine Biology and Ecology 285-286, 383-401.

Cryer, M., Whittle, G.N. \& Williams, R. 1987. The impact of bait collection by anglers on marine intertidal invertebrates. Biological Conservation 42, 83-93.

Dayton, P.K. 1971. Competition, disturbance, and community organization: the provision and subsequent utilization of space in a rocky intertidal community. Ecological Monographs 41, 351-389.

Douglas, M. \& Lake, P.S. 1994. Species richness of stream stones: an investigation of the mechanisms generating the species-area relationship. Oikos 69, 387-396. 
Downes, B.J., Lake, P.S., Schreiber, E.S.G. \& Glaister, A. 1998. Habitat structure and regulation of local species diversity in a stony, upland stream. Ecological Monographs 68, 237-257.

Emparanza, E.J.M. 2007. Patterns of distribution of dominant porcelain crabs (Decapoda: Porcellamidae) under boulders in the intertidal of northern Chile. Journal of the Marine Biological Association of the United Kingdom 87, 523-531.

Gaston, K.J. 1994. Rarity. London: Chapman \& Hall.

Gianguzza, P., Jensen, K.R., Bonaviri, C., Agnetta, D. \& Chemello, R. 2013. Hiding behavior of Oxynoe olivacea (Mollusca: Opisthobranchia: Sacoglossa) in the invasive seaweed Caulerpa taxifolia. Italian Journal of Zoology 3, 437-442.

Grayson, J.E. \& Chapman, M.G. 2004. Patterns of distribution and abundance of chitons of the genus Ischnochiton in intertidal boulder fields. Austral Ecology 29, 363-373.

Green, D.S., Chapman, M.G. \& Blockley, D.J. 2012. Ecological consequences of the type of rock used in the construction of artificial boulder-fields. Ecological Engineering 46, 1-10.

Green, D.S. \& Crowe, T.P. 2014. Physical and biological effects of introduced oysters on biodiversity in an intertidal boulder field. Marine Ecology Progress Series 482, 119-132.

Hawkins, S.J. 1983. Interactions of Patella and macroalgae with settling Semibalanus balanoides (L.). Journal of Experimental Marine Biology and Ecology 71, 55-72.

Hawkins, S.J. \& Hartnoll, R.G. 1980. A study of the small-scale relationship between species number and area on a rocky shore. Estuarine and Coastal Marine Science 10, 201-214.

Hawkins, S.J. \& Hartnoll, R.G. 1982. The influence of barnacle cover on the numbers, growth and behavior of Patella vulgata on a vertical pier. Journal of the Marine Biological Association of the United Kingdom 62, 855-868.

Hawkins, S.J. \& Hartnoll, R.G. 1983. Grazing of intertidal algae by invertebrates. Oceanography and Marine Biology: An Annual Review 21, 195-282.

Iversen, E.S. \& Bannerot, S.P. 1984. Artificial reefs under marine docks in southern Florida. North American Journal of Fisheries Management 4, 294-299.

James, R.L. \& Underwood, A.J. 1994. Influence of colour of substratum on recruitment of spirorbid tubeworms to different types of intertidal boulders. Journal of Experimental Marine Biology and Ecology 181, 105-115.

Kangas, M. \& Shepherd, S.A. 1984. Distribution and feeding of chitons in a boulder habitat at West Island, South Australia. Journal of the Malacological Society of Australia 6, 101-111.

Kilfoyle, A.K., Freeman, J., Jordan, L.K.B., Quinn, T.P. \& Spieler, R.E. 2013. Fish assemblages on a mitigation boulder reef and neighbouring hardbottom. Ocean \& Coastal Management 75, 53-62.

Kimmerer, R.W. \& Driscoll, M.J.L. 2000. Bryophyte species richness on insular boulder habitats: the effect of area, isolation, and microsite diversity. The Bryologist 103, 748-756.

Koljonen, S., Louhi, A., Mäki-Petäys, A., Huusko, A. \& Muotka, T. 2012. Quantifying the effects of instream habitat structure and discharge on leaf retention: implications for stream restoration. Freshwater Science 31, 1121-1130.

Kovačič, M., Patzner, R.A. \& Schliewen, U. 2012. A first quantitative assessment of the ecology of cryptobenthic fishes in the Mediterranean Sea. Marine Biology 159, 2731-2742.

Kuklinski, P., Barnes, D.K.A. \& Taylor, P.D. 2006. Latitudinal patterns of diversity and abundance in North Atlantic intertidal boulder-fields. Marine Biology 149, 1577-1583.

Kurihara, T., Kosuge, T., Kobayashi, M., Katoh, M. \& Mito, K.-I. 2001. Spatial and temporal fluctuations in densities of gastropods and bivalves on subtropical cobbled shores. Bulletin of Marine Science $\mathbf{6 8}$, 409-426.

Le Hir, M. \& Hily, C. 2005. Macrofaunal diversity and habitat structure in intertidal boulder fields. Biodiversity and Conservation 14, 233-250.

Lieberman, M., John, D.M. \& Lieberman, D. 1979. Ecology of subtidal algae on seasonally devastated cobble substrates off Ghana. Ecology 60, 1151-1161.

Littler, M.M. \& Littler, D.S. 1984. Relationships between macroalgal functional form groups and substrata stability in a subtropical rocky-intertidal system. Journal of Experimental Marine Biology and Ecology 74, 13-34.

Liversage, K. 2016. The influence of boulder shape on the spatial distribution of crustose coralline algae (Corallinales, Rhodophyta). Marine Ecology 37, 459-462. 


\section{M.G. CHAPMAN}

Liversage, K. \& Benkendorff, K. 2013. A preliminary investigation of diversity, abundance and distributional patterns of chitons in intertidal boulder fields of differing rock type in South Australia. Molluscan Research 33, 24-33.

Liversage, K., Cole, V.J., McQuaid, C.D. \& Coleman, R.A. 2012. Intercontinental tests of the effects of habitat patch type on the distribution of chitons within and among patches in intertidal boulder field landscapes. Marine Biology 159, 2777-2786.

Londoño-Cruz, E. \& Tokeshi, M. 2007. Testing scale variance in species-area and abundance-area relationships in a local assemblage: an example from a subtropical boulder shore. Population Ecology 49, 275-285.

Loughman, Z.J., Skalican, K.T. \& Taylor, N.D. 2013. Habitat selection and movement of Cambarus chasmodactylus (Decapoda: Cambaridae) assessed via radio telemetry. Freshwater Science 32, 1288-1297.

McGuinness, K.A. 1984. Species-area relations of communities on intertidal boulders: testing the null hypothesis. Journal of Biogeography 11, 439-456.

McGuinness, K.A. 1987a. Disturbance and organisms on boulders. I. Patterns in the environment and the community. Oecologia 71, 409-419.

McGuinness, K.A. 1987b. Disturbance and organisms on boulders. II. Causes in patterns of diversity and abundance. Oecologia 71, 420-430.

McGuinness, K.A. 1988. Explaining patterns in abundances of organisms on boulders: the failure of 'natural' experiments. Marine Ecology Progress Series 48, 199-204.

McGuinness, K.A. \& Underwood, A.J. 1986. Habitat structure and the nature of communities on intertidal boulders. Journal of Experimental Marine Biology and Ecology 104, 97-123.

Menge, B.A. 1976. Organization of the New England rocky intertidal community: role of predation, competition and environmental heterogeneity. Ecological Monographs 46, 355-393.

Osman, R.W. 1977. The establishment and development of a marine epifaunal community. Ecological Monographs 47, 37-63.

Palmer, A.N.S. 2012. Spatial and genetic investigation of aggregation in Ischnochiton (Polyplacophora; Neoloricata; Ischnochitonina; Ischnochitonida; Ischnochitoninae) species with different larval development. Austral Ecology 37, 110-124.

Rogers, T.L. \& Elliott, J.K. 2013. Differences in relative abundance and size structure of the sea stars Pisaster ochraceus and Evasterias trochelii among habitat types in Puget Sound, Washington, USA. Marine Biology 160, 835-865.

Roni, P., Bennett, T., Morley, S., Pess, G.R., Hanson, K., Van Slyke, D. \& Olmstead, P. 2006. Rehabilitation of bedrock stream channels: the effect of boulder weir placement on aquatic habitat and biota. River Research and Applications 22, 967-980.

Smith, K.A. \& Otway, N.M. 1997. Spatial and temporal patterns in abundance and the effects of disturbance on under-boulder chitons. Molluscan Research 18, 43-57.

Smoothey, A.F. \& Chapman, M.G. 2007. Small-scale variability in the dispersion of the sea urchin Heliocidaris erythrogramma among boulders. Marine Ecology Progress Series 340, 89-99.

Sousa, W.P. 1979a. Disturbance in marine intertidal boulder fields: the nonequilibrium maintenance of species diversity. Ecology 60, 1225-1239.

Sousa, W.P. 1979b. Experimental investigations of disturbance and ecological succession in a rocky intertidal algal community. Ecological Monographs 49, 227-254.

Underwood, A.J. 1980. The effects of grazing by gastropods and physical factors on the upper limits of distribution of intertidal macroalgae. Oecologia 46, 201-213.

Underwood, A.J. 1984. Vertical and seasonal patterns in competition for microalgae between intertidal gastropods. Oecologia 64, 211-222.

Underwood, A.J. \& Barrett, G. 1990. Experiments on the influence of oysters on the distribution, abundance and sizes of the gastropod Bembicium auratum in a mangrove swamp in New South Wales, Australia. Journal of Experimental Marine Biology and Ecology 137, 25-45.

Underwood, A.J. \& Jernakoff, P. 1981. Effects of interactions between algae and grazing gastropods on the structure of a lowshore algal community. Oecologia 48, 221-233.

Van Tamelen, P.G. 1987. Early successional mechanisms in the rocky intertidal: the role of direct and indirect interactions. Journal of Experimental Marine Biology and Ecology 112, 39-48. 


\section{INTERTIDAL BOULDER-FIELDS}

Walker, S.J., Degnan, B.M., Hooper, J.N.A. \& Skilleter, G.A. 2008. Will increased storm disturbance affect the biodiversity of intertidal, nonscleractinian sessile fauna on coral reefs? Global Change Biology 14, $1-16$.

Waller, C.L. 2012. Zonation in a cryptic Antarctic intertidal macrofaunal community. Antarctic Science 25, 62-66. 


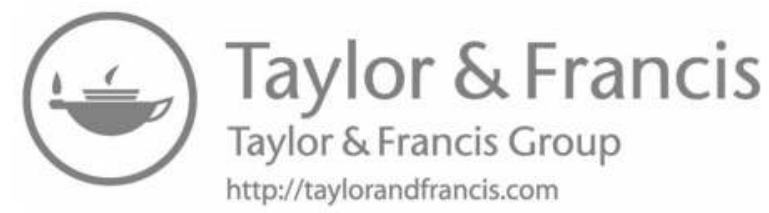




\title{
ECOLOGICAL DOMINANCE ALONG ROCKY SHORES, WITH A FOCUS ON INTERTIDAL ASCIDIANS
}

\author{
MARC RIUS ${ }^{1,2 *}$, PETER R. TESKE ${ }^{2}$, PATRICIO H. MANRÍQUEZ ${ }^{3}$, \\ ROCÍO SUÁREZ-JIMÉNEZ ${ }^{4}$, CHRISTOPHER D. MCQUAID ${ }^{5} \&$ JUAN CARLOS CASTILLA $^{6}$
}

${ }^{1}$ Ocean and Earth Science, University of Southampton, National Oceanography Centre, European Way, Southampton, SO14 3ZH, United Kingdom

${ }^{2}$ Centre for Ecological Genomics and Wildlife Conservation, Department of Zoology, University of Johannesburg, Auckland Park, 2006, South Africa

${ }^{3}$ Laboratorio de Ecología y Conducta de la Ontogenia Temprana (LECOT),

Centro de Estudios Avanzados en Zonas Áridas (CEAZA),

Coquimbo, Avenida Ossandón 877, Coquimbo, Chile

${ }^{4}$ Department of Botany, University of Otago, Dunedin 9054, New Zealand

${ }^{5}$ Coastal Research Group, Department of Zoology and Entomology,

Rhodes University, Grahamstown, South Africa

${ }^{6}$ Centro de Conservación Marina, Estación Costera de Investigaciones Marinas (ECIM), Núcleo de Conservación Marina. Iniciativa Científica Milenio. Facultad de Ciencias Biológicas, Pontificia Universidad Católica de Chile, Santiago, Chile

*Corresponding author: Marc Rius

e-mail: M.Rius@soton.ac.uk

The role of dominant species is of central importance in ecology. Such species play a key role in ecosystem structure, stability and function, regulating resource allocation across trophic levels and overall ecosystem productivity. Although ecological interactions between dominant and subordinate species are often considered to influence the latter negatively, the presence of dominant species can also be beneficial. These species commonly act as ecosystem engineers and enhance biodiversity by creating habitat for other species. Along rocky coastlines, dominant species are often sessile suspension-feeding organisms that can monopolize all available substrata. This is particularly noticeable in intertidal and shallow subtidal habitats where the number of species that achieve ecological dominance is limited. Here, we review the ecological and evolutionary mechanisms that facilitate dominance along rocky coastlines. We then focus on a prominent example, the members of the Pyura stolonifera species complex (Tunicata), which are an emerging model system for studying ecological dominance. These ascidians achieve the highest biomass levels ever reported in rocky intertidal habitats and, when invasive, can fundamentally transform entire ecosystems. Finally, we discuss conservation implications and conclude with directions for future research.

\section{Introduction}

Ecological dominance can be defined as "the exertion of a major controlling influence of one or more species upon all other species by virtue of their number, size, productivity or related activities" (United Nations 1997). Interest in ecological dominance extends across a wide range of fields including, for example, paleontology (Clapham et al. 2006) and anthropology (Flinn et al. 2005). 
In ecology, dominance describes the opposite of ecosystem evenness (Hillebrand et al. 2008) and dominant species are generally the most abundant components of natural communities as a result of their competitive superiority. These species have the ability to structure communities in terms of species composition, diversity, biomass, spatial arrangement and occupancy. Additionally, dominant species often function as ecosystem engineers or bioengineer species (Jones et al. 1994, 1997, Nilsson \& Wardle 2005) as they provide habitat for, and regulate the distribution and abundance of other species. Ecological dominance could be construed as including keystone predators or habitatforming seaweeds, but within the context of this chapter we limit it to spatial dominance by sessile or sedentary animals. The persistence of dominant species may depend on certain levels of environmental stochasticity (e.g. disturbance), which maintain stable levels of species diversity and hierarchy (Connell 1978, but see Fox 2013). Consequently, dominant species and disturbance may collectively determine ecosystem stability and levels of functional diversity (Loreau et al. 2001, Smith \& Knapp 2003).

In marine benthic ecosystems, dominant species are often sessile suspension-feeders. These organisms are able to gather and incorporate allochthonous pelagic energy into benthic communities with remarkable efficiency (Gili \& Coma 1998) and monopolize food and spatial resources (Sarà 1986). This is especially noticeable in rocky intertidal and shallow subtidal ecosystems where dominance is often achieved by one or a few suspension-feeding species (e.g. Dayton 1971, Paine 1971, Sousa 1979, Paine et al. 1985, Underwood et al. 1991, Castilla et al. 2000). Dominant suspension-feeders are ecosystem engineer species (Wright \& Jones 2006) and are present in most marine ecosystems around the world (Jones et al. 1994, Crooks 2002, Gutiérrez et al. 2003).

Here, we review the literature to unravel the ecological and evolutionary mechanisms that facilitate dominance. We then focus on a specific group of dominant marine invertebrate species that are of considerable ecological importance in rocky shore communities of the southern hemisphere, the members of the Pyura stolonifera species complex. We conclude with the role of ecological dominance in conservation efforts and outline future directions for research on dominant species.

\section{The theory behind ecological dominance}

Ecological dominance is strongly linked to competitive ability (e.g. Dayton 1975, Steneck et al. 1991, Baird \& Hughes 2000), which is often seen as having negative effects on species richness as competing species work towards eliminating one another. In order to understand how ecological dominance can influence overall community structure, it is important to recognize that competition can take various forms. Theoretically, competition only occurs if specific resources are in limited supply and, in the case of competition for food or space, it can take the form of either exploitation or interference competition (Schoener 1983, Yodzis 1989). Competition for renewable resources such as food often exclusively involves interference, whereas competition for space has two components that operate across different spatial scales and interact with one another: actual competition for space, which operates at small scales through interference, and exploitation competition (Steinwascher 1978) through dispersal, which takes place at larger scales. Dispersal is required to find and to monopolize available space.

In the marine realm, organisms exhibit markedly different scales of propagule dispersal (Kinlan \& Gaines 2003), and this has important consequences for the likelihood of coexistence of competing (and potentially dominant) species (Berkley et al. 2010, Aiken \& Navarrete 2014). When dispersal is minimal, two species can theoretically coexist, as patches of habitat often operate independently of one another (Leibold et al. 2004, Tilman 1994). If dispersal scales are very large, however, the distinction among patches of habitat is lost and coexistence is less likely. Therefore, it is important to measure and define scales carefully when describing the effects of dispersal and 
to recognize that ecological processes are affected by dispersal type (Kinlan et al. 2005, Aiken \& Navarrete 2014). Nevertheless, there are clearly different implications for space occupiers that are assumed to have the potential to disperse over scales of hundreds of kilometres, such as mussels or barnacles (Tapia \& Pineda 2007, Teske et al. 2016) as opposed to those with abbreviated larval development, such as ascidians (Millar 1971, Clarke et al. 1999). Scales of dispersal also have implications for the type of guild responsible for dominating space. Where species are capable of outcompeting others through functional dominance, as is often the case for intertidal communities (e.g. Dayton 1975, Lubchenco \& Menge 1978), the guild is composed of dominant space occupiers. In this case, weakening of dominance results in an increase in the number of species that can coexist so that non-selective mortality, common in cases of mass mortality due to wave or heat stress (e.g. Tsuchiya 1983, Erlandsson et al. 2006, Garrabou et al. 2009), has a positive effect on species richness. In contrast, in ecosystems without clear competitive dominance, the system is shaped by dispersal and colonization events and is considered to be founder-controlled. Such systems include coral reef fish communities (e.g. Sale 1977, 1979, Almany et al. 2007) and in this case, mortality will decrease richness (Paine 1966, Sousa 1979, Yodzis 1989).

There is a vast body of both theoretical and empirical literature on resource-mediated interactions in communities dominated by superior competitors, including the implications for the control of species richness, the persistence of subordinate species (Dayton 1975), shifting competitive dominance (Paine 1969, Lubchenco 1978) and ecological consequences of body size (Brown \& Maurer 1986). Of course, dominant species interact with other drivers of community structure, including keystone species (Paine 1969, Paine \& Suchanek 1983, Menge et al. 1994, Castilla 1999), recruitment limitation (Connolly \& Roughgarden 1999) and disturbance (Lubchenco \& Menge 1978, Sousa 1979). Importantly, and partly through their effects on other species, dominant species can regulate ecosystem function, trophic complexity and community stability (Paine 1969, Smith \& Knapp 2003), which leads to community-level impacts (Harley 2006). More recently, it has been recognized that species that occupy primary space interact not only with other space-occupiers, but also have a key role in enhancing species richness through facilitation. The inclusion of facilitation in ecological models can completely alter predictions of the effects of environmental stress, disturbance or predation on species richness and the probability of success of biological invasions (Bruno et al. 2003). This builds on the recognition of the importance of within-species group effects for space-occupiers (Bertness \& Leonard 1997) and their role as ecological engineers (Jones et al. 1994). Dominant species can provide habitat for associated species, offer protection from predation (Stachowicz \& Hay 1999, Crain \& Bertness 2006), mitigate environmental stress (Rius \& McQuaid 2006, 2009) and enhance recruitment success of conspecifics (Erlandsson \& McQuaid 2004) as well as other species. For example, successful settlement of mussel recruits can be enhanced by the presence of macroalgae (Bayne 1964, McQuaid \& Lindsay 2005).

Resource availability is a critical mechanism modulating ecosystems. It determines community structure, ecological interactions and phenotypic traits (Coley et al. 1985), and it shapes levels of energy transfer across trophic levels that are required to maintain niche differentiation and functional diversity. Along rocky coastlines, the primary limiting factor for benthic organisms is space, which in the intertidal zone can be dominated by both sessile animals and algae. However, the balance between faunal and algal dominance is often mediated by wave action (McQuaid \& Branch 1984). At the subtidal fringe, space is mostly dominated by suspension-feeders, with ascidians dominating many temperate coastlines, especially in the Southern Hemisphere (see below).

The monopolization of a specific resource by a single species is generally ascribed to certain attributes (Paine \& Suchanek 1983, Guiñez \& Castilla 2001). Accordingly, it is expected that competitive dominance will positively correlate with degree of gregariousness and the species' ability to occupy space (Figure 1). Among the species traits that enhance ecological dominance (Figure 2), gregariousness and a sessile or sedentary life strategy are tightly linked (i.e. it is difficult to have one trait without the other), and collectively lead to a specific ecological trade-off. A gregarious 
Figure 1 Drivers and consequences of ecological dominance in benthic animals. Nested ellipsoids represent isobars of likelihood of becoming a dominant species.
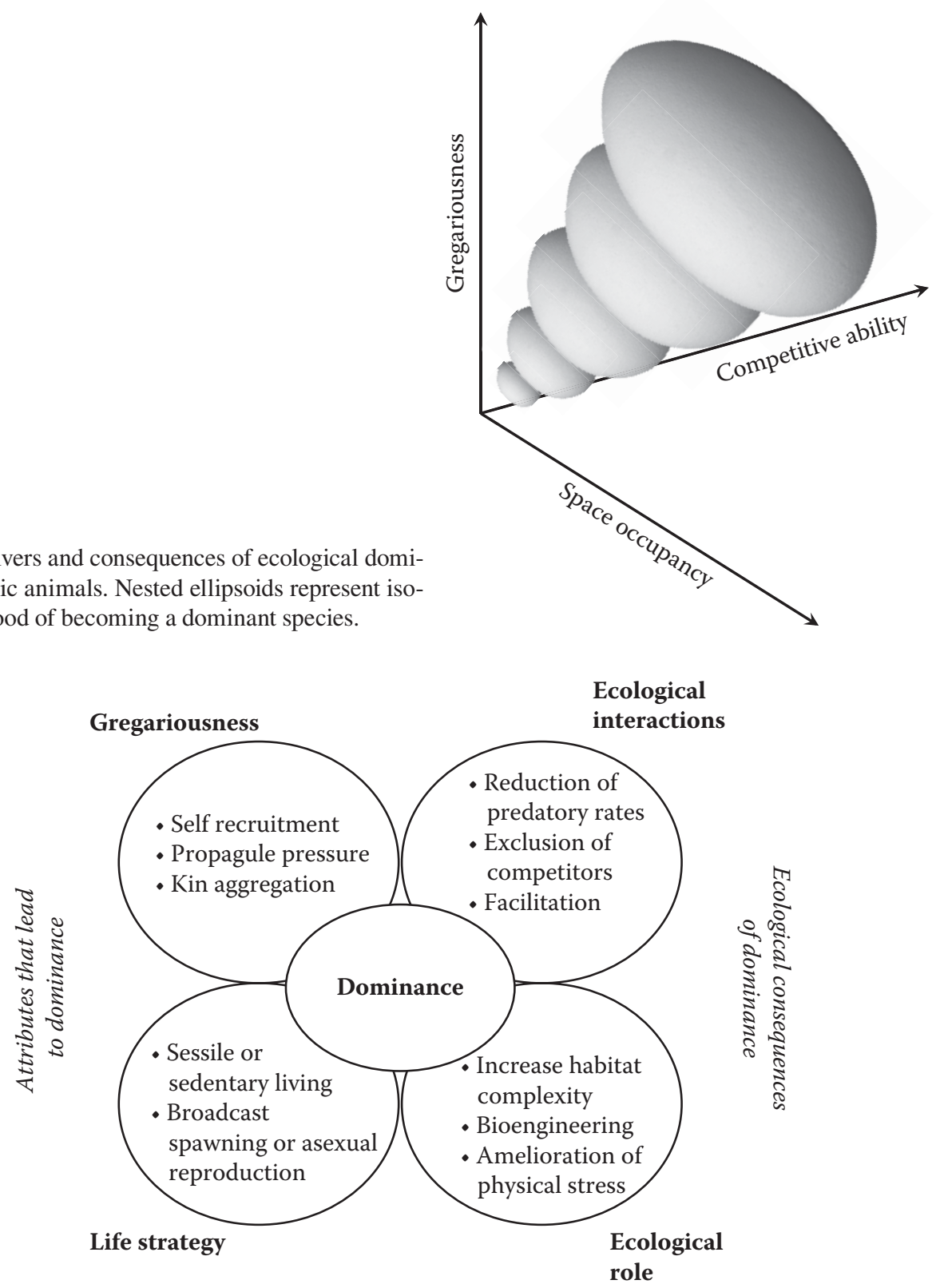

Figure 2 Drivers and consequences of ecological dominance in benthic animals. Shown are main attributes leading to dominance, together with consequences of the presence of dominant species.

species can act as a bioengineer and occupy space while the ability of its predators or competitors to fulfil their roles diminishes. A key aspect for dominance is to maximize the extent and duration of resource monopolization. Species such as ephemeral algae are rarely considered dominant species as they are short-lived and space occupancy is only transient.

The monopolization of resources, particularly space, can be mitigated by compensatory mortality, with dominant species suffering higher rates of mortality through disturbance (e.g. Connell 
1978, Paine 1979, Sousa 1979, Erlandsson et al. 2006) or predation (Paine 1976, Symondson et al. 2002). The effects of predation can depend on timing in terms of ecological succession (Vieira et al. 2012) and recruitment rates high enough to swamp predators can ultimately allow monopolization (Navarrete \& Berlow 2006). Thus, disturbance and predation generally tend to free resources and ameliorate the subordination of inferior species. This reduces interference competition and allows species to exploit spatial and temporal variability in resources, minimizing dominance by a particular species.

\section{Evolutionary implications of ecological dominance}

The formation of aggregations by propagules that disperse freely in a particular environment requires certain behavioural abilities. For example, behaviour-mediated recruitment has been reported in many taxa (Toonen \& Pawlik 1994) and is often a response to the presence of conspecific adults (Toonen \& Pawlik 1996, Alvarado et al. 2001). However, other external stimuli such as light, biofilm, substratum orientation or flow conditions may be more relevant (Pawlik et al. 1991, Keough \& Raimondi 1995, Wieczorek \& Todd 1997, Rius et al. 2010a). In addition, evolutionary mechanisms such as Allee effects may be critical for understanding ecological dominance. Allee effects normally appear when there is a decline in population size or density that leads to a loss of overall fitness (Courchamp et al. 1999, Berec et al. 2007). These effects can operate through increased difficulty in finding mates (e.g. Kuussaari et al. 1998) or susceptibility to predators (e.g. Bertness \& Grosholz 1985). Additionally, because most broadcast-spawning benthic suspension-feeders are sessile (e.g. ascidians) or near-sessile (e.g. mussels), populations often exhibit Allee effects because the likelihood of gamete encounters resulting in fertilization is significantly lower when adults are present at low densities (Levitan 1991, Babcock \& Keesing 1999).

For many organisms, ecological dominance is largely a consequence of the behaviour of their dispersive larvae, which enables the formation of long-lasting aggregations. Aggregated settlement can be facilitated by conspecific cues following successful colonization by a founder (Toonen \& Pawlik 1994). Indeed, a possible evolutionary consequence of Allee effects is conspecific attraction. Although the idea of linking Allee effects, recruitment and conspecific attraction was developed in the context of vertebrates, especially colonial- and non-colonial-nesting birds (Reed \& Dobson 1993), the insights gained are applicable to species with external fertilization. Stephens \& Sutherland (1999) regard conspecific attraction as a "direct product" of Allee effects and Donahue (2006) suggests that conspecific cues and Allee effects jointly lead to conspecific attraction. Another aspect that may be relevant is kin aggregation (Grosberg \& Quinn 1986, Veliz et al. 2006), although the reverse situation (kin avoidance) has also been reported (Johnson \& Woollacott 2010) and thus requires further investigation.

Propagule attraction to conspecifics can be facilitated by increased habitat complexity. For example, studies have shown increased settlement rates in structurally-complex mussel beds (Alvarado \& Castilla 1996, Alvarado 2004), though there is responsiveness to conspecifics in the absence of structural complexity that can change with settler age (von der Meden et al. 2010). Attraction to adult conspecifics can have negative consequences in the case of suspension-feeders that feed indiscriminately, such as adult mussels which are able to consume $>70 \%$ of potential settlers, including conspecifics, through larviphagy (Lehane \& Davenport 2004, Porri et al. 2008, Troost et al. 2008). In addition, self-recruitment (i.e. recruitment of progeny to the parental population or patch) may increase levels of inbreeding (potentially promoting low levels of genetic diversity), which is known to negatively affect population persistence (Keller \& Waller 2002). Despite the potential negative effects, settling close to parents seems to have remarkable fitness benefits in some taxa. The positive aspects of attraction of settling larvae to adults are chiefly due to the enhancement of fertilization success via adult aggregation. In the case of broadcast spawners, fertilization success is often correlated with the degree of aggregation (Levitan et al. 1992, Downing et al. 1993). In addition, aggregations can have evolutionary benefits by providing group defence against predators. For example, mussels use byssal 
threads to trap predatory whelks (Day et al. 1991, Farrell \& Crowe 2007) and to mutually protect conspecifics from wave action (van de Koppel et al. 2005). The latter can also involve facilitative interspecific effects between ecologically homologous species (e.g. Rius \& McQuaid 2009).

\section{Ecological dominance on rocky shores}

Intertidal habitats have long been model systems for the study of ecological dynamics and principles (Paine 1966, 1969, Stephenson \& Stephenson 1972, Lubchenco \& Gaines 1981, Hawkins \& Hartnoll 1983b, Branch 1984, Castilla \& Durán 1985, Menge \& Sutherland 1987, Menge et al. 1994, Underwood 2000, Navarrete \& Castilla 2003). They can support sessile consumers because food can be transported through the aquatic medium itself, and in many systems, suspension-feeders maintain extremely dense populations (Monteiro et al. 2002, Castilla et al. 2004b). These species dominate overall biomass (e.g. McQuaid \& Branch 1984, Castilla et al. 2000) and energy flow (Newell et al. 1982) because of their high rates of secondary production (Baird et al. 2004). Dominant rocky shore species filter large volumes of water and suspended particles (mainly originating from primary production), creating a habitat for diverse associated biota. This gives such species a number of critical roles in ecosystem functioning. Firstly, they act as primary consumers, linking primary production and secondary consumers (Gili \& Coma 1998), critically contributing to remineralization (Eriksson et al. 2010) and benthic-pelagic coupling. This creates a two-way interaction between the water column and the benthos through both the consumption of suspended particles (McQuaid \& Branch 1985, Loo \& Rosenberg 1989, 1996) and the benthic recruitment of planktonic larvae (Navarrete et al. 2005). Secondly, dominant rocky shore species can act as autogenic ecological engineers (sensu Lawton \& Jones 1995), occupying all available primary space (e.g. Castilla et al. 2004a), and in doing so increasing architectural complexity (Hughes \& Griffiths 1988, Guiñez \& Castilla 1999, 2001), which enhances species richness (Cerda \& Castilla 2001, Cole \& McQuaid 2010). All these characteristics make this group a unique and important component of benthic communities.

Mass mortalities of dominant suspension-feeding species as a result of extreme environmental stress or disease (e.g. Hanekom et al. 1999), can have important implications for the entire rocky shore ecosystem. One direct consequence is the loss of ecological networks and function. For example, drastic reductions of intertidal suspension-feeding species directly modify the intertidal community structure and zonation, impacting on key ecosystem services (Castilla et al. 2014, Manríquez et al. 2016). Another consequence of major disturbance events is the decrease of structural complexity upon which other species depend. This is particularly critical when the spatially-dominant species lack a hard calcareous skeleton, such as ascidians (Cerrano \& Bavestrello 2009). However, in the case of calcareous species such as barnacles, habitat complexity can persist after mortality. Patch fragmentation as a result of disturbance has major effects on dominant suspension-feeding species and associated communities, contributing to a non-random community assembly in intertidal areas.

Ecological dominance along rocky shores is achieved by a small, taxonomically-diverse group of species. Some examples include bivalves, tubeworms, bryozoans and solitary ascidians (Figure 3), all broadcast-spawning organisms with well-studied life histories (Marshall \& Keough 2008, Marshall et al. 2012). These taxa have a wide variety of dissimilar characteristics (Figure 3), indicating that ecological dominance is not due to analogous combinations of traits.

\section{The Pyura stolonifera species complex: A model system for studying ecological dominance}

Members of the Pyura stolonifera species complex (sensu Rius \& Teske 2011, Phylum Chordata, Subphylum Tunicata) (hereafter the P.s.s.c.) are amongst the few intertidal solitary ascidian species that form extensive and dense monospecific aggregations, dominating all available substrata. These 


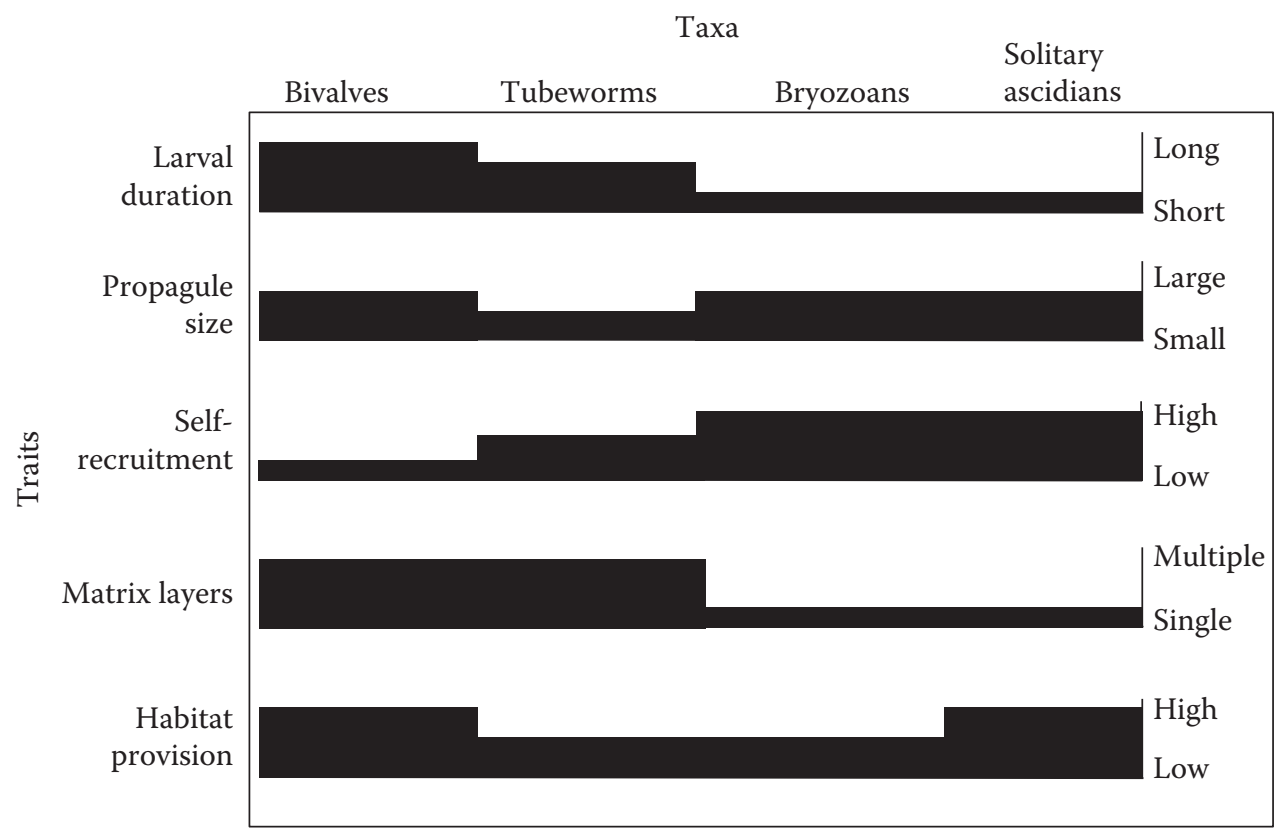

Figure 3 Generalized trait variation of four sessile or sedentary suspension-feeding taxa that are able to dominate rocky shores. The selected traits are all key for understanding ecological dominance and they influence different life-history stages, from early ontogenetic life stages (top) to adulthood (bottom). The right $\mathrm{x}$-axis provides a general idea of rankings and allows overall comparison. Propagule size refers to the size of motile early life-history stages, which in broadcast spawning species is generally correlated with the size of the juvenile and adult stages (Rius et al. 2010b). Self-recruitment refers to recruitment of progeny to the parental population or patch. Matrix layers refer to the ability of dominant species to form multilayer assemblages, which provide secondary habitat for other species.

species are roughly barrel-shaped tunicates that can grow to $>30 \mathrm{~cm}$ in height (Paine \& Suchanek 1983, Fielding et al. 1994, Castilla et al. 2000). They form extensive cemented aggregations or 3-dimensional matrices (Guiñez \& Castilla 2001) in the form of collective packed units, although isolated individuals also occur (Castilla \& Camaño 2001, Monteiro et al. 2002). Members of the P.s.s.c. produce the highest intertidal biomass per unit surface area ever reported in the literature, with dry tissue biomass of $>20 \mathrm{~kg} \mathrm{~m}^{-2}$ and densities of up to 1800 individuals $\mathrm{m}^{-2}$ (Fielding et al. 1994, Castilla et al. 2000). Such biomass is an order of magnitude higher than the maximum values reported for other suspension-feeding species along rocky shores (e.g. McQuaid \& Branch 1985). Ecological theory predicts that the area on either side of the Low Water Springs level is dominated by highly competitive species that are generally free from predators (Hawkins \& Hartnoll 1983). Accordingly, intertidal populations of the members of the P.s.s.c. achieve the highest densities and biomass in this particular area (Castilla et al. 2000). The members of the P.s.s.c. each present unique bioengineer habitat architectures in terms of the number, size and shape of individuals and the arrangements of habitable secondary space. Overall, these ascidians represent good models for the study of ecological dominance in benthic communities (Monteiro et al. 2002, Castilla et al. 2004b, Teske et al. 2011, Manríquez et al. 2016).

Information on the P.s.s.c. has been accumulating over the past 130 years or so, from taxonomic (Heller 1878, Van Name 1945, Millar 1955, 1966, Monniot \& Bitar 1983, Rius \& Teske 2011) and ecological studies (Guiler 1959, Stephenson \& Stephenson 1972, Paine \& Suchanek 1983, Clarke et al. 1999, Castilla et al. 2000, Monteiro et al. 2002, Castilla et al. 2004a, Castilla et al. 2004b, Knott et al. 2004, Rius et al. 2010a) to recent studies of its physiology (Rius et al. 2014a), genetics 
(Castilla et al. 2002, Astorga et al. 2009, Teske et al. 2011, Rius \& Teske 2013), invasion biology (Castilla et al. 2004a, Hayward \& Morley 2009, Teske et al. 2011, Rius \& Teske 2013) and exploitation by humans (Kyle et al. 1997, Castilla et al. 2014, Manríquez et al. 2016). Below, we analyze the biological attributes that have allowed this group to become successful in dominating rocky shores.

\section{Biogeography and evolutionary history of the species complex}

Despite the conspicuous nature of the members of the P.s.s.c. in both intertidal and subtidal environments, the taxonomy of the group has been fiercely contested until very recently (Kott 2006, Rius \& Teske 2011). Many papers referred to all the members of the P.s.s.c. as Pyura stolonifera (e.g. Kott 1985, Marshall et al. 2000) despite taxonomic (Millar 1962, Monniot \& Bitar 1983, Monniot et al. 2001), ecological (Dalby 1997) and genetic (Castilla et al. 2002) evidence pointing to the existence of multiple species. Recent studies employing a combination of morphological and genetic analyses (Rius \& Teske 2011, 2013, Teske et al. 2011) have revealed that Pyura stolonifera (Heller, 1878) as defined by Kott (2006) is a species complex that in fact represents at least five distinct species. The species presently accepted as valid are the African representatives $P$. stolonifera and $P$. herdmani (Drasche, 1884), and the Australian P. praeputialis (Heller, 1878), P. dalbyi (Rius \& Teske, 2011) and $P$. doppelgangera (Rius \& Teske, 2013).

Members of the P.s.s.c. are predominantly found along temperate rocky shores of the Southern Hemisphere. In particular, most species are distributed along southern African (Millar 1955, Monniot \& Monniot 2001) and Australian (Kott 1985) coasts, but one member of the P.s.s.c. (Pyura herdmani) is also present in the Northern Hemisphere (Monniot \& Bitar 1983, Lafargue \& Wahl 1986-1987, Teske et al. 2011). The different species are typically allopatric and some exhibit disjunct distributions, with populations that are separated by large geographic distances (Castilla \& Guiñez 2000, Rius \& Teske 2013), but there are also instances of sympatric distributions in southern Africa and Australia (Figure 4). Reports from South America (Clarke et al. 1999) and New Zealand (Hayward \& Morley 2009) that are corroborated by genetic evidence (Teske et al. 2011), as well as recent sightings in Europe (see further details below), suggest that the species found in these regions originated from elsewhere and were most likely introduced through human activities.

Temperate coastlines characterized by upwelling systems are often preferred habitats for members of the P.s.s.c. (Figure 4). Some species, such as Pyura herdmani in Africa, are widespread and occur across several biogeographic provinces of differing temperature regimes, providing an interesting system to study population connectivity and physiological tolerance across ecoregions. Another interesting case is $P$. dalbyi, which shows a large distribution gap between the southwestern and southeastern coasts of Australia (Figure 4). However, much of the intermediate region is part of the Great Australian Bight, which is highly inaccessible to study, so this species may be more widespread.

The presence of members of the P.s.s.c. on land masses that formed part of the former supercontinent of Gondwanaland (Africa, Australasia and South America) suggests that the present species shared a common ancestor during the Mesozoic. Interestingly, despite treating all as a single species, Kott $(1985,2006)$ favoured a Gondwanan origin for the group, notwithstanding the fact that tens of millions of years are ample time for speciation to occur. While it is now believed that the populations in South America and New Zealand are the product of recent anthropogenic introductions from Australia (see below), phylogenetic work indicates that there is an ancient split between evolutionary lineages comprising the African species (Pyura stolonifera and P. herdmani) on one hand, and two of the Australian (P. praeputialis and P. doppelgangera) species on the other (Teske et al. 2011). This split has not yet been dated, and a shared Gondwanan ancestry of these two lineages thus remains a possibility. However, such a scenario would have involved extinctions on all of the remaining Gondwanan land masses (Madagascar, India, South America, New Zealand and 


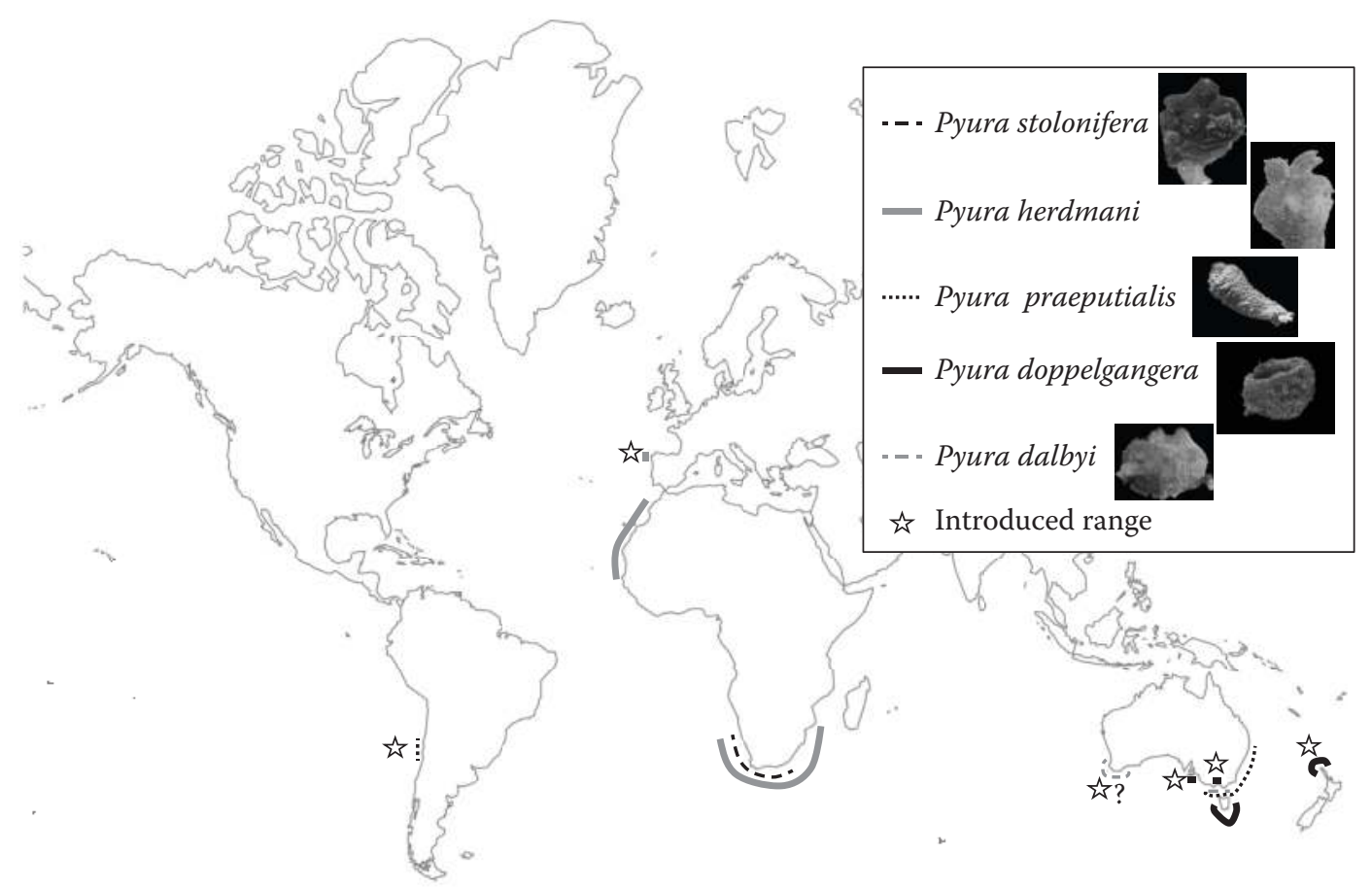

Figure 4 Global distribution of the members of the Pyura stolonifera species complex, with the introduced ranges of the different species indicated.

Antarctica), which is a less parsimonious solution than a single long-distance colonization event (e.g. from Africa to Australia via the West Wind Drift). The gametes and larvae of ascidians are unable to disperse over greater distances because of their very short planktonic propagule durations (Millar 1971, Clarke et al. 1999, Rius et al. 2010b), but it is well known that the adults can travel attached to vessels or other floating objects (Lambert 2007, Locke 2009). There is thus little reason to rule out the possibility that the disjunct distribution of the African and Australian lineages was the result of an ancient long-distance colonization event.

\section{Reproductive cycle, early life-history stages, settlement and fertilization}

The members of the P.s.s.c. have a multiphasic life-cycle (Figure 5) and are broadcast-spawning simultaneous hermaphrodites, releasing male and female gametes mainly during low tides (Marshall 2002, Manríquez \& Castilla 2010). After release, currents disperse the gametes, reducing the likelihood of inbreeding. In addition, members of the P.s.s.c. have blocks to self-fertilization since eggs of Pyura praeputialis fertilized with self-sperm fail to complete development (Manríquez \& Castilla 2010). As a result, fertilization and developmental success rely mainly on allogametes encountering one another, which in turn depends on the concentration of allosperm and the viability of eggs (see Marshall 2002, Manríquez \& Castilla 2010). Fertilization success in P. praeputialis is at its highest with newly-shed sperm and declines as sperm and eggs age (Manríquez \& Castilla 2010). Since allogamete limitation as a result of the rapid dispersion of gametes may occur along exposed rocky shores, some members of the P.s.s.c. have developed strategies to counteract gamete dilution and mitigate the difficulties of fertilization in such environments. Gamete retention close to the parents following spawning has been observed in P. praeputialis both in Australia (Marshall 2002) and Chile (Manríquez \& Castilla 2010) and, although this has not yet been described in other members 


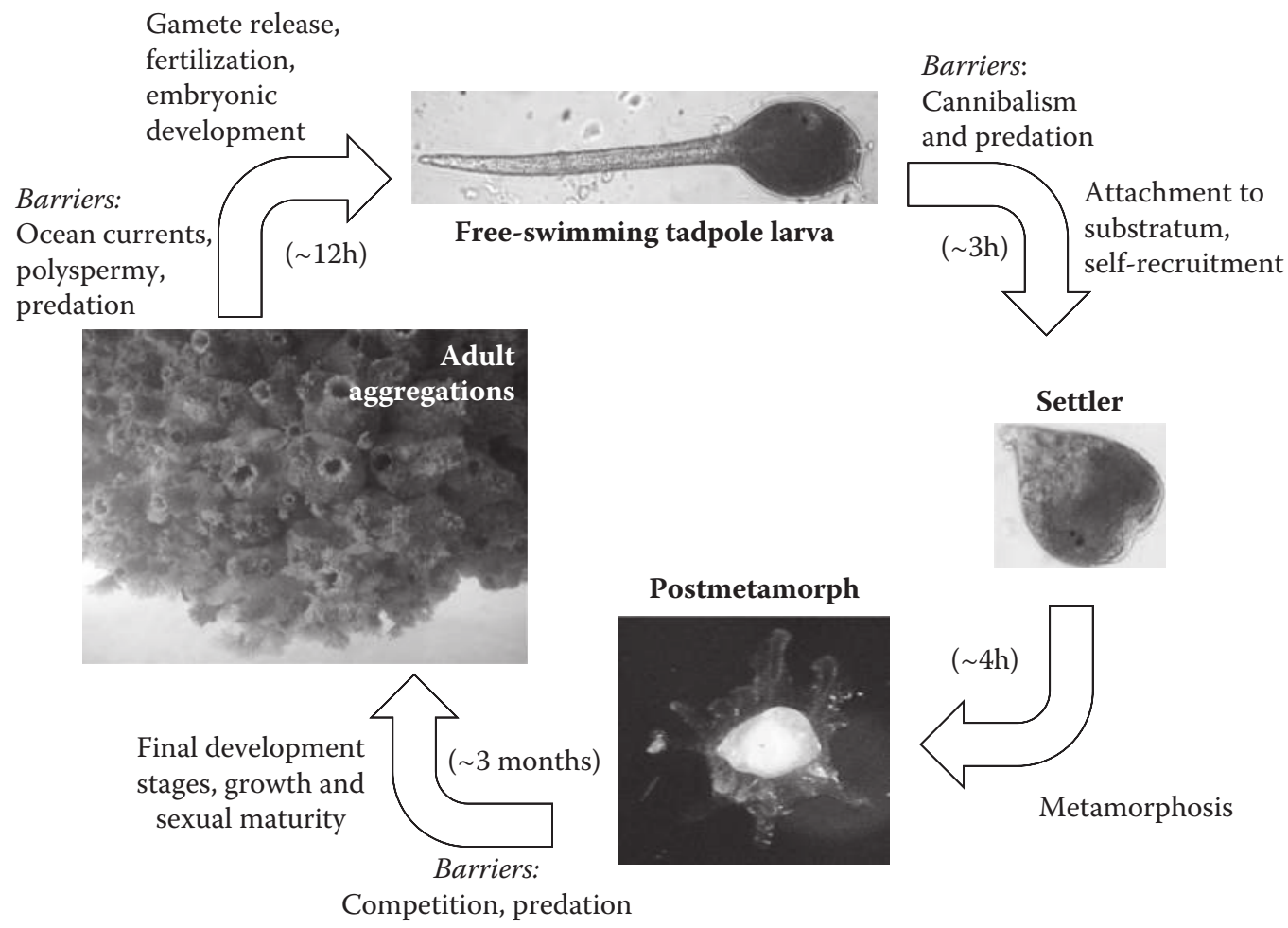

Figure 5 Life cycle of Pyura herdmani depicting different life-history stages and key barriers that may preclude ecological dominance. Early life-history stages were obtained via artificial fertilization in the laboratory (see details in Rius et al. 2010a). All photographs were taken in South Africa.

of this complex, it is highly plausible that it occurs. The gametes of $P$. praeputialis are often shed in a viscous matrix (Marshall 2002, Castilla et al. 2007b, Manríquez \& Castilla 2010) and once they come into contact with seawater a biofoam is formed (Castilla et al. 2007b, Manríquez \& Castilla 2010). Such biofoam also retains a high concentration of developing embryos and larvae of $P$. praeputialis (Castilla et al. 2007b, Manríquez \& Castilla 2010). This suggests that biofoam formation may be an adaptive mechanism that enhances fertilization success and self-recruitment.

After fertilization, embryonic development occurs rapidly (see details in Rius et al. 2010a) and results in tadpole-like larvae that have a very short swimming period (Figure 5). The larvae are lecithotrophic and dependence on limited yolk-reserves limits dispersal range. As a result of the short pelagic duration of gametes, embryos and larvae, settlement will occur in the vicinity of the parental habitat, and colonization of new areas (away from the parental populations) requires the dispersal of adults that have settled on moving objects, such as boats or floating debris (Teske et al. 2015). Since direct observation of pelagic dispersal is challenging, genetic tools are often used to estimate population connectivity (e.g. Teske 2014) and confirm that levels of self-recruitment are high (Teske et al. 2015).

Although experimental trials using Pyura stolonifera and P. herdmani larvae showed that settlement occurs irrespective of the presence of adult tunic extracts (Rius et al. 2010a), the highest recruitment in the field is consistently reported on the tunics of adults or on substrata in the immediate vicinity (Alvarado et al. 2001, Marshall 2002, Monteiro et al. 2002, Castilla et al. 2014, Manríquez et al. 2016). More studies are however needed to confirm if self-recruitment is consistently present in aggregations of these ascidians. Taken together, gamete release synchrony, as well as strategies to retain early life-history stages, facilitate ecological dominance by members of the P.s.s.c. along rocky shores. 


\section{Suspension-feeding and diet}

Species of the P.s.s.c. are, like the great majority of ascidians, ciliary-mucus active sieving suspension-feeders (Bone et al. 2003). Water filtration is extremely efficient, even for particles as small as 2-3 $\mu \mathrm{m}$, with food items including detrital organic matter, diatoms and other phytoplankton, and suspended bacteria (Millar 1971, Monniot et al. 1991, Bak et al. 1998, Tyree 2001, Lambert 2005). Although no evidence of particle selection has yet been reported (Randløv \& Riisgård 1979), studies of the gut of Pyura stolonifera suggest that phytoplankton is a much more important energy source than macroalgal detritus (Seiderer \& Newell 1988). Other potential food items include developing stages and larvae of other invertebrate species, including self- and allogametes. Gut content analysis of adult individuals of $P$. praeputialis shows the presence of annelid, crustacean and mollusc larvae (Table 1). In addition, faecal pellets of $P$. praeputialis collected in the field contained tadpole larvae of $P$. praeputialis, mytilid larvae and newly hatched veliger larvae of the gastropod Concholepas concholepas (Table 2). Regardless of whether or not these items are digested, the available information suggests that members of the P.s.s.c. interact with other species inhabiting the same area by reducing food availability and by directly consuming early life-history stages.

The rates of filtration by ascidians generally depend on body size (Monniot et al. 1991) and seawater temperature (Fiala-Médioni 1978, Petersen \& Riisgård 1992, Ribes et al. 1998). For Pyura stolonifera, filtration rates increase with the size of the branchial sacs (Klumpp 1984) and ciliary bands lining the stigmatal openings (Petersen \& Svane 2002). Large individuals of P. stolonifera can filter up to 18 litres seawater $h^{-1}$ (Klumpp 1984).

Table 1 Stomach content (mean number of individual food items counted \pm SE) of Pyura praeputialis collected at two sampling sites in Antofagasta Bay, Chile

\begin{tabular}{|c|c|c|}
\hline & El Way $(n=21)$ & Las Conchitas $(\mathrm{n}=20)$ \\
\hline Foraminifera ${ }^{(\mathrm{j}, \mathrm{a})}$ & $11.67 \pm 1.67$ & $3.40 \pm 1.02$ \\
\hline Tintinnida $(\mathrm{j}, \mathrm{a})$ & $1.00 \pm 10.29$ & 0 \\
\hline Nematoda $(\mathrm{j}, \mathrm{a})$ & $0.10 \pm 0.07)$ & $0.10 \pm 0.10$ \\
\hline Gastropoda $^{(j)}$ & $2.10 \pm 0.48$ & $2.05 \pm 0.84$ \\
\hline Mytilidae $^{(1, j)}$ & $1.38 \pm 0.30$ & $18.25 \pm 10.23$ \\
\hline Annelida ${ }^{(1, j)}$ & $0.10 \pm 0.10$ & 0 \\
\hline Crustacea (unidentified) & $0.29 \pm 0.20$ & $0.40 \pm 0.24$ \\
\hline Nauplii & $1.86 \pm 0.46$ & $0.60 \pm 0.60$ \\
\hline Cyprids & $1.48 \pm 0.35$ & $0.25 \pm 0.16$ \\
\hline \multicolumn{3}{|l|}{ Copepoda } \\
\hline Harpacticoida (j, a) & $0.38 \pm 0.13$ & $0.40 \pm 0.23$ \\
\hline Calanoida $^{(\mathrm{j}, \mathrm{a})}$ & $0.67 \pm 0.17$ & $1.60 \pm 0.60$ \\
\hline Cyclopoida $^{(\mathrm{j}, \text { a) }}$ & $0.33 \pm 0.17$ & $0.15 \pm 0.08$ \\
\hline Bacillariophyceae & $3.33 \pm 0.87$ & $0.55 \pm 0.17$ \\
\hline \multicolumn{3}{|l|}{ Dinoflagellata } \\
\hline Protoperidinium sp. & $0.81 \pm 0.25$ & $0.70 \pm 0.47$ \\
\hline Ceratium sp. & $0.14 \pm 0.10$ & $0.20 \pm 0.20$ \\
\hline Algal detritus & $\mathrm{p}$ & $\mathrm{p}$ \\
\hline Silt & $\mathrm{p}$ & $\mathrm{p}$ \\
\hline Faecal pellets & $\mathrm{p}$ & $\mathrm{p}$ \\
\hline \multicolumn{3}{|c|}{$\begin{array}{l}\text { Sampling was conducted between February and May } 1998 \text { (El Way, } \\
23^{\circ} 45^{\prime} \mathrm{S} ; 70^{\circ} 26^{\prime} \mathrm{W} \text { ) and March and May } 1998 \text { (Las Conchitas, } \\
23^{\circ} 31^{\prime} \mathrm{S} ; 70^{\circ} 32^{\prime} \mathrm{W} \text { ). Key: } \mathrm{p}=\text { present but not quantified, }{ }^{1}=\text { larvae, } \\
\mathrm{j}^{\mathrm{j}}=\text { juveniles, }{ }^{\mathrm{a}}=\text { adults. }\end{array}$} \\
\hline
\end{tabular}


Table 2 Pyura praeputialis consumption of embryos and larvae when biofoam is present and absent

\begin{tabular}{lcc}
\hline & Pools with biofoam $(\mathrm{n}=15)$ & Pools without biofoam $(\mathrm{n}=17)$ \\
\hline Developing embryos $^{\mathrm{a}}$ & $0.83 \pm 0.21$ & 0 \\
Tadpole larvae $^{\mathrm{a}}$ & $0.41 \pm 0.13$ & $0.03 \pm 0.03$ \\
Mytilidae larvae $^{\mathrm{b}}$ & $0.84 \pm 0.22$ & $0.10 \pm 0.06$ \\
Gastropod larvae $^{\mathrm{c}}$ & $0.15 \pm 0.21$ & $0.03 \pm 0.21$ \\
\hline
\end{tabular}

Note: The abundance (mean $\pm \mathrm{SE}$ ) of developing embryos or larvae per unit length of the faecal pellet is indicated. Faecal pellets were collected from the field in May 2004 at El Way (23 $45^{\prime}$ S, $\left.70^{\circ} 26^{\prime} \mathrm{W}\right)$ in Antofagasta Bay, Chile, approximately two hours after a spawning of Pyura praeputialis. They were collected from the vicinity of the exhalant siphon of individuals present in small rocky intertidal pools. Faecal pellets were collected from several pools with $(n=50$ pellets) and without $(n=50$ pellets) surface biofoam.

a Embryonic stages (ca. $200 \mu \mathrm{m}$, total length) and hatched Pyura praeputialis tadpole larvae $(120 \times 1200 \mu \mathrm{m}$; trunk and total length) (see Clarke et al. 1999).

b Prodisoconch and disoconch larvae, presumably Perumytilus purpuratus with sizes ranging from 100-180 $\mu \mathrm{m}$ (see Ramorino \& Campos 1983).

c Newly hatched larvae of Concholepas concholepas of about $250 \mu \mathrm{m}$ in size (see Manríquez et al. 2014).

Laboratory studies of Pyura stolonifera showed $100 \%$ retention efficiency when individuals were offered cells of the alga Dunaliella primolecta of sizes ranging from 4 to $6.35 \mu \mathrm{m}$ (Stuart \& Klumpp 1984). The same was found by Klumpp (1984) when food particles from the field were analyzed. These studies suggest that Pyura stolonifera is a non-selective suspension-feeder and that this may contribute to their competitive superiority over coexisting species, such as bivalves and sponges (Stuart \& Klumpp 1984).

The risk of predation is a major selective pressure driving the evolution of larval settlement strategies in marine invertebrates (Thorson 1950). Young (1988) reported that gregarious species such as Pyura haustor rejected their own eggs and larvae as food, which can be seen as an adaptive strategy to avoid cannibalism. The large inhalant siphon of the members of the P.s.s.c. (diameter up to $1.5 \mathrm{~cm}$ ) does not allow discrimination among suspended particles, and high levels of consumption of conspecific offspring have been reported (see Table 2). In addition, rates of cannibalism of larvae are extremely high when mechanisms of gamete and larval retention (e.g. biofoam) are present (Castilla et al. 2007b, Manríquez \& Castilla 2010). This suggests that in the absence of biofoam the gametes spawned are not present or are considerably diluted, so there is little or no opportunity for cannibalism.

\section{Community structure and ecological interactions}

Members of the P.s.s.c. are fierce competitors for space, outcompeting individuals at intra-specific (Dalby 1995, Guiñez \& Castilla 2001) and inter-specific (Castilla et al. 2004a, Caro et al. 2011, Manríquez et al. 2016) levels. Experimental studies of intertidal aggregations of Pyura praeputialis in Antofagasta Bay, Chile (where this species is invasive), showed that as aggregates reach high population densities, a negative relationship exists between the number of individuals per unit area and mean individual mass (Guiñez \& Castilla 2001). As a result, competition in the form of severe crowding affects the morphological characteristics and the energy/tissue allocation of $P$. praeputialis (Guiñez \& Castilla 2001). Experiments analyzing competition for space between the introduced $P$. praeputialis and the native mussel Perumytilus purpuratus in Antofagasta Bay have shown that the tunicate significantly affects native rocky intertidal biota, as well as several ecological processes. 


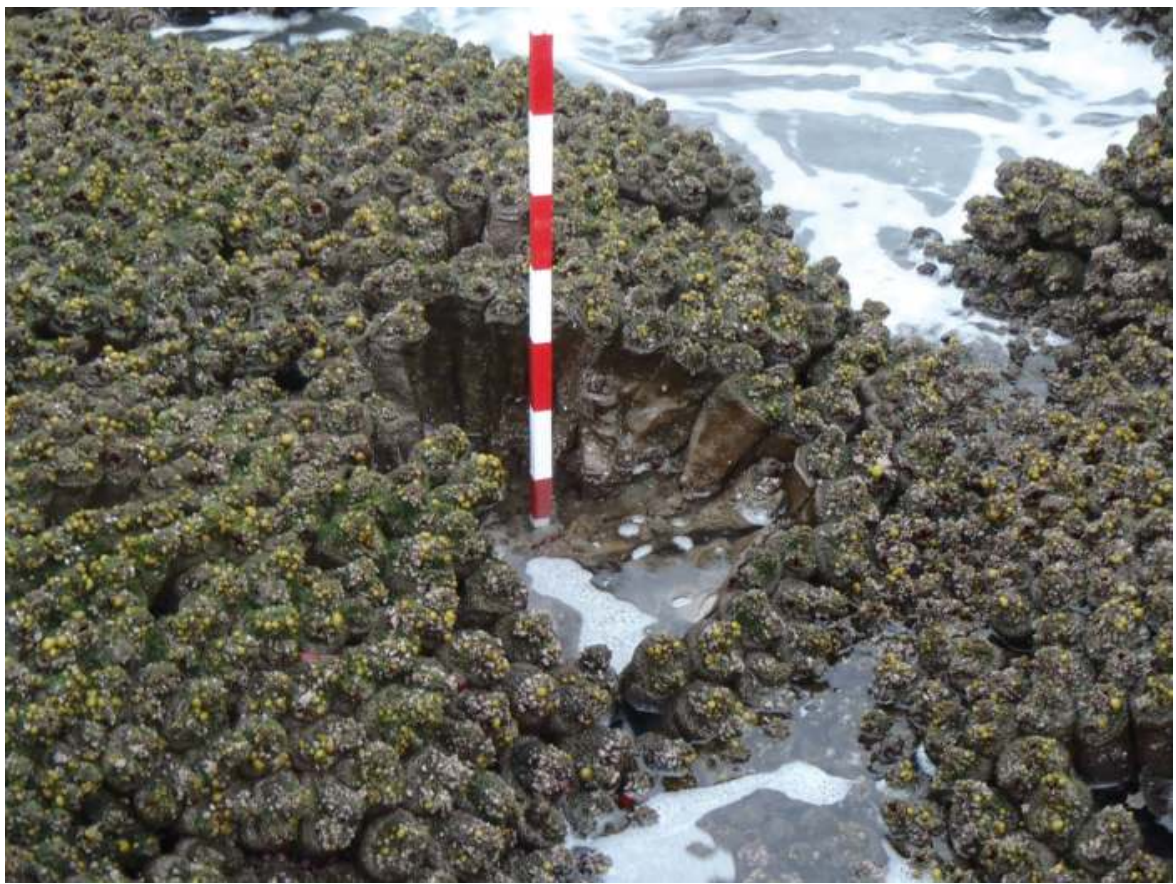

Figure 6 Dense aggregations of Pyura praeputilalis in La Rinconada (23⒉ $\left.8^{\prime} 16.41^{\prime \prime} \mathrm{S}, 70^{\circ} 30^{\prime} 47.83^{\prime \prime} \mathrm{W}\right)$, Chile. A bar with red and white sections (10 centimetres each) was positioned for scale.

For example, Pyura praeputialis has completely modified the intertidal zonation pattern of the bay by monopolizing the low and mid rocky intertidal zones, constraining the distribution of the native mussel to the mid-upper intertidal fringe (Castilla et al. 2004a, Caro et al. 2011, Manríquez et al. 2016). In Antofagasta Bay, Ortiz et al. (2013), analized rocky intertidal communities using Ecopath, Ecosim and Loop Analysis (Levins, 1974) to better understand the properties of keystone species (e.g. biomass, food consumption) and concluded that $P$. praeputialis is not a superior bioengineer compared to the kelp Lessonia nigrescens. In fact, the model indicated that these two bioengineer species hosted ecologically-similar species but relied on different ecological processes to carry out their ecosystem role.

Another consequence of dominance by members of the P.s.s.c. is the creation of habitat structure that allows a diverse associated community to thrive. In South Africa, 64 intertidal and 61 subtidal taxa of benthic macroinvertebrates, representing 10 phyla, were associated with aggregations of Pyura stolonifera (Fielding et al. 1994). Similar research on aggregations of $P$. praeputialis in Antofagasta Bay reported 96 associated benthic invertebrate species (Castilla et al. \& Camaño 2001), with polychaetes, decapods and bivalves being the most speciose (see Cerda \& Castilla 2001). In addition to epifauna, amphipods, copepods and nemerteans may be present inside the branchial sac of large individuals (e.g. Oldewage 1994, Dalby 1996). Van Driel \& Steyl (1978) showed that in Algoa Bay (South Africa), the composition of communities associated with P. stolonifera was determined by levels of wave exposure. Similarly, Ramírez \& Mena (1984) found differences in the distribution and abundance of macroalgae that grow on top of Pyura praeputialis aggregations in Antofagasta Bay across different levels of wave exposure. Although high densities of Ulva spp. are frequently observed growing on top of $P$. praeputialis (see Castilla et al. 2014), the presence of algae does not appear to affect the ascidian (Castilla et al. 2004b). The density of P. praeputialis individuals also affects the composition of associated communities, with clumped and sparse $P$. praeputialis individuals having different alga- and invertebrate-associated assemblages 


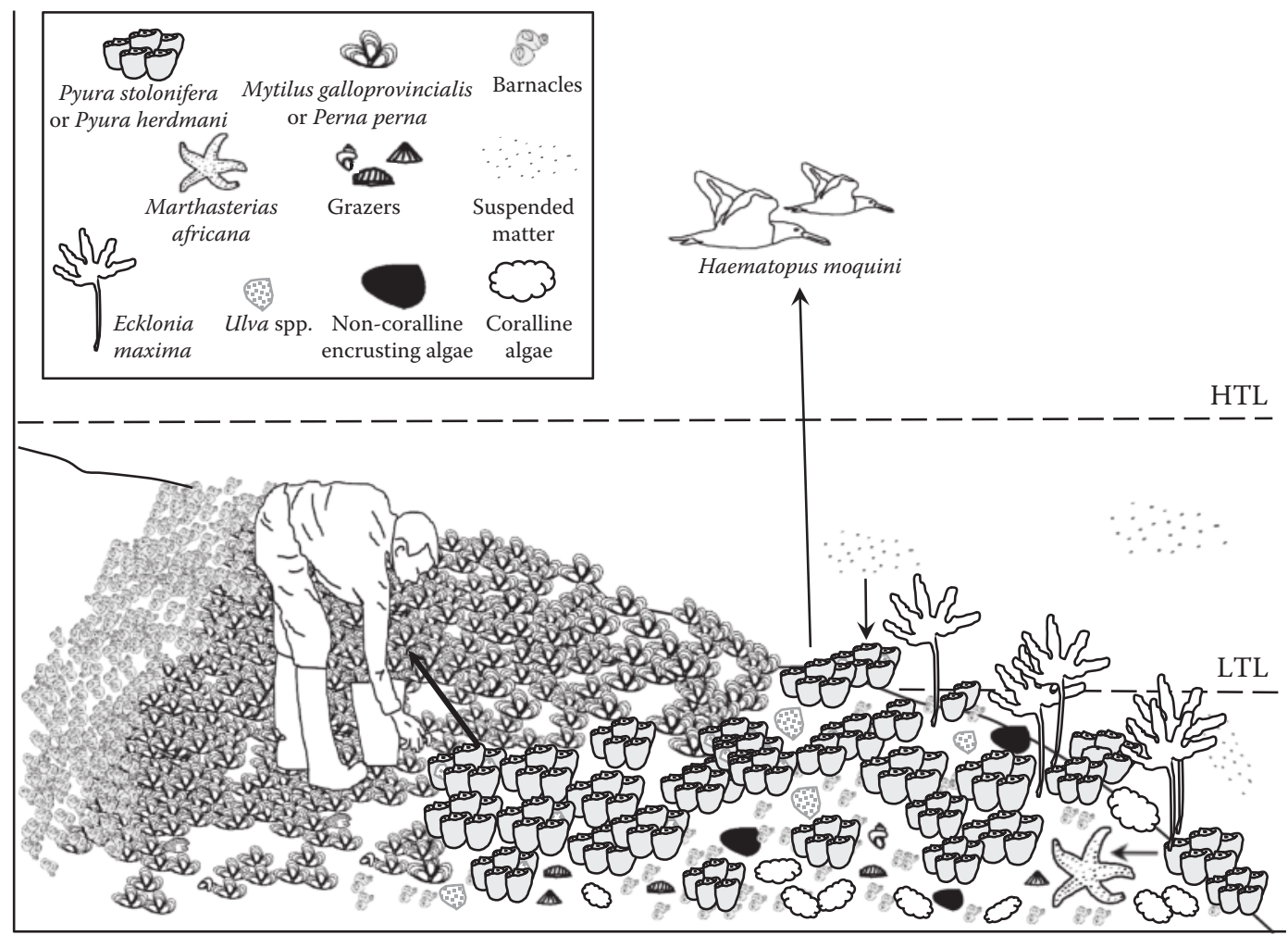

Figure 7 Food web and energy transfer on intertidal rocky shores in South Africa (southwestern coast, native range) where members of the Pyura stolonifera species complex can be found. Low tidal level (LTL) and high tidal level (HTL) are indicated. (Continued)

(Monteiro et al. 2002). Coralline algae and the limpet Cellana sp. are typically found in low-density aggregations of Pyura praeputialis, whereas species of whelks are more common in denser aggregations (Monteiro et al. 2002).

Predation upon members of the P.s.s.c. has rarely been studied (see Alvarado 2004). In Chile, apart from human harvesting (see below), the main intertidal predators are the sunstar Heliaster helianthus (Castilla et al. 2013) and the muricid gastropod Concholepas concholepas (Alvarado 2004), which both appear to regulate populations of Pyura praeputialis in the lower intertidal zone (Castilla et al. 2004a) (Figure 7). Further, the oystercatcher Haematopus palliatus pitanay is also an active predator of Pyura praeputialis in Chile (Pacheco \& Castilla 2001, Goss-Custard et al. 2006) (Figure 7). In Australia, the triton shell Cabestana spengleri and the sooty oystercatcher Haematopus fuliginosus have been reported as preying on Pyura praeputialis (Schultz 1989, Fairweather 1991, Chafer 1992). Finally, in South Africa, known predators include the oystercatcher Haematopus moquini and the seastar Marthasterias africana (Wright et al. 2016) (Figure 7), but more work is needed to determine the extent of their predatory role in intertidal communities.

Apart from competition and predation, two additional factors can negatively affect the population dynamics of the P.s.s.c.. The first is mass mortality, as reported for Pyura stolonifera along the South African coast (Hanekom et al. 1999, Hanekom 2013). Such mortalities were suspected to occur as a result of infection by an unidentified microbe, potentially as an indirect result of abnormally high temperatures (Hanekom 2013). The second factor is patch dynamics that are directly influenced by mechanical forces. Intertidal and subtidal aggregations of $P$. praeputalis are 


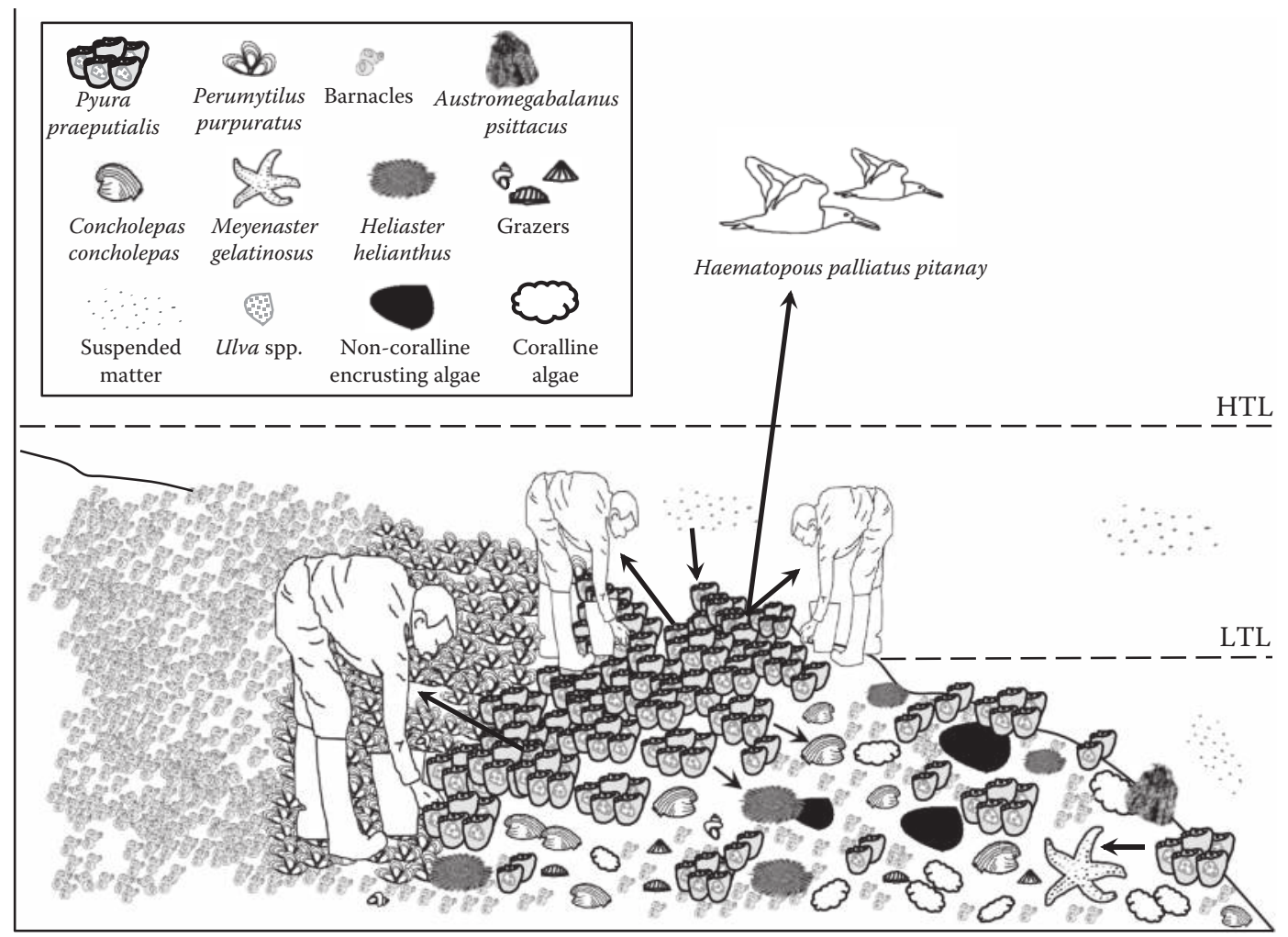

Figure 7 (Continued) Food web and energy transfer on intertidal rocky shores in Chile (Antofagasta Bay, introduced range) where members of the Pyura stolonifera species complex can be found. Low tidal level (LTL) and high tidal level (HTL) are indicated.

constantly exposed to removal by wave action. An important patch-filling mechanism is propagule retention, which increases recruitment in the patch-border zone next to adults (Alvarado et al. 2001).

\section{Invasion biology and the Pyura stolonifera species complex}

Species that are dominant in their native habitat are expected to have a particularly high likelihood of becoming invasive once established elsewhere (Simberloff 2010). Therefore, understanding dominance is particularly important for predicting the changes in ecosystem structure and function caused by biological invasions. Members of the P.s.s.c. dominate intertidal and subtidal areas in their native ranges, and when these species are introduced to new areas, they can strongly alter local communities. Introductions of members of the P.s.s.c. are being reported with increasing frequency, including the colonization of the northern part of New Zealand's North Island by Pyura doppelgangera (Hayward \& Morley 2009, Fletcher 2014) and the recent introduction of P. herdmani to northwestern Spain (X. Turon, personal communication).

A growing debate exists in the literature around the concept of invasiveness and the impact of invasive species on recipient communities (see Cronon 1983, Katz 1992, Soulé 1995, Jordan 2000, Katz 2000, Cafaro 2001, Castilla \& Neill 2009, Simberloff 2012, Simberloff \& Vitule 2014). This debate includes conceptual aspects such as understanding what is 'native', 'harmful' or 'wild', and even philosophical aspects; for example whether non-indigenous sentient (vertebrate) or nonsentient species (e.g. invertebrates, plants, fungi) have intrinsic value (see Varner 1990, 1998, Justus et al. 2009). Some non-indigenous species are considered to be innocuous, while others can have 
dramatic ecological effects (although the latter may have critical economic value for humans, e.g. in terms of food security). Non-indigenous marine organisms can have positive, neutral or negative impacts on humans (Castilla \& Neill 2009, Manríquez et al. 2016). For example, the non-indigenous intertidal macroalgae Porphyra linearis, Pyropia pseudolinearis (=Porphyra pseudolinearis) and Mastocarpus papillatus are commercially important resources in Chile, as they are extracted by small-scale (artisanal) fishermen, and as yet no negative ecological impact has been reported. Similarly, both Pyura praeputialis and subtidal red algae of the genus Gracilaria are introduced species in Chile but have not yet caused adverse economic effects (Castilla et al. 2002, Castilla et al. 2014, Manríquez et al. 2016). In South Africa, the introduced mussel Mytilus galloprovincialis has been farmed for decades (Heasman et al. 1998), but even though this species is now of considerable economic importance it dominates extensive stretches of the South African coastline, causing drastic ecological changes to native communities (Robinson et al. 2005). Another example of dominant non-indigenous species causing harm to natural communities is Pyura praeputialis in Antofagasta Bay. This species has reduced the abundance of native species of mussels through displacement by competition for space (Castilla 1998, Castilla \& Guiñez 2000, Castilla et al. 2004a, Castilla 2008, Caro et al. 2011, Castilla et al. 2014, Manríquez et al. 2016). In turn, however, the presence of this introduced species has resulted in an increase of overall local biodiversity (i.e. an increase in macroinvertebrate richness) via the provision of a new habitat (Castilla et al. 2004b, Castilla et al. 2005).

Once a new geographic area is colonized, establishment success depends on the inability of the resident community to repel newcomers (Rius et al. 2014b). Specifically, certain types of habitats (e.g. marine hard infrastructure, Airoldi et al. 2015) and community attributes (e.g. levels of native species diversity, Crutsinger et al. 2008) may facilitate biological invasions in some regions but not others. This is illustrated by considerable differences in the colonization success of the nonindigenous populations of Pyura doppelgangera (Teske et al. 2014). In the North Island of New Zealand this species was introduced less than 20 years ago (Hayward \& Morley 2009) and has now spread along $100 \mathrm{~km}$ of exposed rocky shores (Fletcher 2014). In contrast, introduced populations of the same species in two regions of the Australian mainland (Adelaide in South Australia, and Corner Inlet in Victoria) have failed to expand their ranges beyond the immediate points of introduction. Taxonomic and genetic evidence suggests that this species has recently been introduced to mainland Australia (Kott 1952, Teske et al. 2014) from northern Tasmania. Both Adelaide and Corner Inlet lack rocky shores and are dominated by sandy shores (Bowman \& Harvey 1986), with artificial structures such as jetties and piers representing the only habitat suitable for settlement. Such marine infrastructures are spaced a few kilometres apart and thus large gaps of sandy beach seem to limit connectivity among suitable habitats. Small-scale dispersal has been assessed in the $P$. doppelgangera population of the Adelaide metropolitan area and revealed high levels of selfrecruitment, with most larvae settling on the structure occupied by their parents (Teske et al. 2015). This is also consistent with findings suggesting effective gamete retention mechanisms and spawning synchrony of P. praeputialis in southeastern Australia (Marshall 2002).

The short larval duration typical of solitary ascidians (Figure 5) considerably reduces colonization success when substrata suitable for settlement are located far from one another, and suggests that Pyura doppelgangera will only spread rapidly where habitat is more continuous. In New Zealand, the sea star Stichaster australis and a whelk of the genus Cabestana prey upon the abundant new food resource provided by Pyura doppelgangera (Fletcher 2014). However, such biotic resistance effects are clearly insufficient to counteract the invasion of this ascidian species. Localized removal of $P$. doppelgangera patches have been conducted by local communities, but it is likely to prove too late for the complete eradication of this invasive species.

Cases of naturalization (i.e. species that are able to self-sustain populations but that have failed to spread beyond the immediate point of introduction, Richardson et al. 2000) have also been reported in the P.s.s.c. For example, while Pyura praeputialis is found along thousands of kilometres of rocky shore in its native habitat in Australia, the Chilean distribution is restricted to a single 
bay (Clarke et al. 1999, Castilla \& Guiñez 2000, Castilla et al. 2002). Other examples of limited distribution include those of $P$. dalbyi in Western Australia (Teske et al. 2011) and $P$. doppelgangera in mainland Australia (Teske 2014, Teske et al. 2015).

\section{Human exploitation and conservation of the Pyura stolonifera species complex}

Human activities such as rocky intertidal harvesting and trampling are well-known stressors of several marine taxa including algae (Bally \& Griffiths 1989, Castilla \& Bustamante 1989, Castilla et al. 2007a) and various invertebrates (Castilla \& Durán 1985, Roy et al. 2003, Smith \& Murray 2005, Rius et al. 2006). Although human exploitation of intertidal resources targets a wide range of species (Moreno et al. 1984, Lasiak 1991, Keough et al. 1993, Castilla 1999), dominant species (e.g. mussels and tunicates) are often an important proportion of the overall catch (Kyle et al. 1997, Rius \& Cabral 2004). This is not surprising as the gregarious nature of these organisms allows maximization of the catch. The selective removal of large adults in limited quantities may allow sustainable exploitation of intertidal resources (as is sometimes seen in subsistence exploitation, Castilla et al. 2014), but human harvesting is often unrestrained and can be a major conservation threat to intertidal communities.

Humans harvest members of the P.s.s.c. for subsistence exploitation and/or recreational activities (e.g. bait collection). Such activities have been reported in Australia (Otway 1989, Fairweather 1991, Kingsford et al. 1991, Chapman \& Underwood 1994, Monteiro et al. 2002), South Africa (Kyle et al. 1997) and Chile (Castilla et al. 2004a, Castilla et al. 2014, Manríquez et al. 2016). Fairweather (1991) studied the exploitation of Pyura praeputialis at seven intertidal sites in New South Wales, Australia, showing that changes in density of $P$. praeputialis were temporally asynchronous among sites but that $P$. praeputialis recovery was consistently slow. The study concluded that the population dynamics of $P$. praeputialis are modulated by human harvesting, episodic storms and recruitment patterns. Monteiro et al. (2002) studied habitat structure in patches of P. praeputialis in Sydney, Australia, where fishermen collect this species for bait, and found that changes to the structure of these patches resulted in changes in the composition of associated biota. The authors identified 19 algal and 45 invertebrate species in habitats provided by $P$. praeputialis, and species assemblages differed significantly between sparse and dense patches. In South Africa, P. herdmani is heavily exploited by intertidal food-gatherers (Fielding et al. 1994), as well as anglers who collect this species for bait. Along some parts of the South African coast $P$. herdmani is the second most important harvested species (after mussels) (Kyle et al. 1997). In Chile, P. praeputialis is considered a delicacy and has a high market value, and studies indicate that the rate of extraction by professional tunicate gatherers can be up to 750 individuals $\mathrm{h}^{-1}$ during low tide (Castilla et al. 2014, Manríquez et al. 2016). The harvesting of $P$. praeputialis is in fact so continuous and intense that it impairs recruitment. The shrinking of $P$. praeputialis aggregations in certain sites has allowed mussels to recover intertidal dominance (Castilla et al. 2014, Manríquez et al. 2016).

Reductions of intertidal aggregations of members of the P.s.s.c. can significantly affect the associated intertidal community (Fielding et al. 1994, Cerda \& Castilla 2001, Monteiro et al. 2002, Castilla et al. 2004b, Manríquez et al. 2016). In Chile, the crevices and gaps between individuals of Pyura praeputialis create microhabitats for the settlement of the species Concholepas concholepas, a commercially important gastropod (Castilla \& Jerez 1986, Castilla et al. 1998, Castilla 1999, Castilla \& Defeo 2001, Manríquez et al. 2008, Gelcich et al. 2017), and they are used by females of C. concholepas to lay thousands of egg capsules during the reproductive season (authors' unpublished data). In addition, individuals of $C$. concholepas and Octopus mimus have traditionally been collected from aggregations of Pyura praeputialis during low tide. However, overexploitation of 
$P$. praeputialis during the past decade has resulted in a considerable decrease in the number of these associated species (authors' unpublished data). Similarly, the scarcity of $P$. stolonifera and $P$. herdmani along some sections of the South African coast may be an indication of overharvesting (e.g. Kyle et al. 1997, Majiza \& Lasiak 2010). Future repopulation initiatives may be key for restoring ecosystem functioning, as these aggregations play an important role as bioengineers (Castilla et al. 2001, Castilla et al. 2004b). Considering that ecological dominance influences many fundamental aspects of ecosystem health, such as coexistence and metacommunity dynamics (Hillebrand et al. 2008), human activities reducing the dominance of members of the P.s.s.c. are likely to result in alterations of biodiversity patterns.

\section{Conclusions and future research directions}

Dominant species are superior competitors that often generate exceptional levels of biomass. Although many attributes (e.g. gregariousness, sessile life strategy, broadcast spawning) may be linked to ecological dominance (Figure 2), it cannot be readily explained by any specific combination of traits (Figure 3). The presence of dominant sessile invertebrates generally increases habitat complexity, directly benefiting a wide range of associated biota. Therefore, dominant species are key components for the conservation of biodiversity and ecosystem functioning along rocky shores.

Although knowledge of ecological dominance has been accumulating for decades, more research is needed to understand fully some of the underlying ecological and evolutionary mechanisms. For example, little is known about how kin selection affects gregariousness, and there is limited information on possible links between Allee effects and ecological dominance. To date, there is little empirical evidence for Allee effects in natural populations (Gascoigne \& Lipcius 2004), and studies are particularly scarce in the context of dominant species.

This review focused on members of the P.s.s.c. as a key example for the study of ecological dominance. Among many consequences that derive from the presence of these dominant species, creation of architectural complexity is one of the most striking, as it influences the hydrodynamics of intertidal zones, ameliorates physical stress and creates habitat for a wide range of associated species. Other aspects remain largely unexplored, however. For example, there is as yet no information on the impact of the P.s.s.c. on planktonic communities. The high rates of filtration and particle retention achieved by the members of the P.s.s.c. suggest that they may extract massive amounts of suspended particles from seawater (Klumpp 1984, Seiderer \& Newell 1988). This, together with their aggregated nature and large adult size, strongly suggest that these species have an important role in ecosystems. High clearance rates that significantly alter seston composition and reduce food availability may directly affect adult survival, growth and reproductive potential of competing or subordinate species, such as mussels and barnacles. Another unexplored consequence of such high filtration capacity is the consumption of heterospecific gametes and larvae. Studies have assessed the role of cannibalism by members of the P.s.s.c. and found that it reduces the conspecific larval pool. However, little is known about how such feeding may influence the abundance and distribution of heterospecific gametes and larvae. Species that could be directly displaced include suspension-feeders but also primary producers (e.g. seaweeds). Thus, possible impacts of the presence of these dominant ascidians could go beyond a specific trophic level, and influence entire food chains. A negative association between tunicate abundance and the settlement of mussel larvae has been found (LeBlanc et al. 2007), which suggests tunicate predation on mussel larvae, as well as a reduction of available food particles. This may have been the mechanism through which the invasive population of Pyura praeputialis in Antofagasta Bay outcompeted the native mussel species Perumytilus purpuratus (Castilla et al. 2004a, Castilla et al. 2014). Finally, the multiphasic life cycle of the members of the P.s.s.c. (Figure 5) implies that the size and type of particles consumed by each life-history stage (i.e. postmetamorph, juvenile and adult) vary, so the study of dietary shifts (see Sherrard \& LaBarbera 2005) may reveal important insights into this possible form of food 
competition. Taken together, filtration capacity, when fully investigated, may reveal key aspects facilitating the establishment and maintenance of dense aggregations of these dominant species.

Comprehensive information is available on the intertidal distribution, population structure, biomass, energy/tissue allocation and phenotypic traits of the members of the P.s.s.c., especially from Antofagasta Bay, Chile (e.g. Clarke et al. 1999, Castilla et al. 2000). The restricted distribution of Pyura praeputialis in South America (a range of only about $70 \mathrm{~km}$; Castilla et al. 2002) and the high densities attained there (intertidal belts over $10 \mathrm{~m}$ wide, with the highest densities towards the centre of the belt) makes Antofagasta Bay a unique location to study ecological aspects of this species. However, our present ecological knowledge is limited to studies of $P$. praeputialis and $P$. stolonifera. Further research is therefore required to study the ecology of the remaining members of the P.s.s.c., as well as to understand the influence of coastal geography and oceanography on ecological dominance. Nearshore larval retention of $P$. praeputialis has been reported in Antofagasta Bay (Castilla \& Largier 2002), but similar studies are needed in the native range. Distances between suitable habitats may be too large to be crossed by larval transport, particularly when oceanographic conditions are not favourable, and consequently, self-recruitment seems to be the norm (Teske et al. 2015). Regions where the effects of geography and oceanography could be tested include False Bay in South Africa and the coastline around Adelaide in Australia. Taken together, it remains uncertain how geographic and oceanographic singularities affect ecological dominance.

In order to study ecological dominance, a detailed understanding of the taxonomy and evolutionary history of the studied organism is required. For example, failing to correctly identify cryptic species or hybrids could lead to erroneous interpretation of ecological data. For the members of the P.s.s.c., the combined study of morphological and genetic data has greatly facilitated the resolution of phylogenetic relationships (Teske et al. 2011, Rius \& Teske 2013). However, numerous challenges remain. First, it is presently not established whether the species complex is reciprocally monophyletic. Thus, more work is needed to understand whether all its members have arisen from a single ancestor, or whether the inclusion of some species is merely an artefact of similar morphology. For example, the phylogenetic placement of Pyura dalbyi is poorly resolved (Teske et al. 2011), and it is possible that this species is more closely related to the morphologically very different $P$. spinifera (Quoy \& Gaimard 1834). It is also uncertain whether any of the presently-accepted species comprise additional 'cryptic' species that should be scientifically described. Phylogenetic data based on mitochondrial DNA sequences indicate that $P$. herdmani comprises four reciprocally monophyletic genetic lineages (Teske et al. 2011). One lineage occurs in northwestern Africa, one in subtropical/ tropical southern Africa, and two lineages have overlapping ranges in temperate southern Africa. While these lineages may be morphologically difficult to distinguish, different geographical ranges or habitat preferences support the hypothesis that they may be different species (see Rius \& Teske 2011). Of the temperate southern African populations, one has a sister-taxon relationship with the northwest African population of $P$. herdmani and has so far been exclusively found on rocky shores, while the other also occurs on sandy sediments. Given that $P$. herdmani can hybridize with $P$. stolonifera (Rius \& Teske 2013), it cannot be ruled out that hybridization is also common among the individual southern African lineages of $P$. herdmani, which would considerably complicate attempts at resolving their taxonomy. The existence of hybrids in regions where multiple species coexist (i.e. southern Africa and southeastern Australia) could provide important insights into understanding recent range expansions. Human activities are known to facilitate interbreeding among divergent lineages (Chunco 2014, Vallejo-Marín \& Hiscock 2016), which may create hybrids with enhanced ability to colonize new habitats (Ruis \& Darling 2014).

Genetic data have been particularly useful in confirming the non-indigenous status of populations of the members of the P.s.s.c. Genetic evidence often falls into two categories: 1) lack of genetic differentiation among non-indigenous populations that contrasts with well-defined native population structure, and 2) recent divergence between native and introduced ranges (on the basis of molecular dating) since the start of human-mediated transoceanic transport. In addition, circumstantial 
evidence for the non-indigenous status of a particular population could include small distribution ranges (e.g. limited to harbours as most likely points of introduction, Carlton \& Geller 1993) and settlement on marine infrastructures in regions that lack rocky shores. DNA sequence data have been used to identify the lack of genetic differentiation among introduced populations that are separated by vast distribution gaps. For example, a genetic study of Pyura praeputialis samples collected in Chile revealed that these were genetically indistinguishable from eastern Australian populations (Castilla et al. 2002), and all mtDNA haplotypes found in the single Western Australian population of $P$. dalbyi were also found in southeastern Australia (Teske et al. 2011). The use of polymorphic microsatellites can be much more informative than sequence data in revealing the colonization history of non-indigenous populations (e.g. Rius et al. 2012). The high mutation rate of these genetic markers make them suitable for distinguishing ancient natural colonization events from introductions that have occurred since humans started navigating the seas. For example, microsatellite data confirmed that all non-Tasmanian populations of $P$. doppelgangera diverged from closely related northern Tasmanian populations no more than a few hundred years ago (Teske et al. 2014). Genetic data able to provide information on recent changes are thus required for understanding recent colonization events by these dominant species. For example, many uncertainties remain concerning the introduction of P. praeputialis from Australia to Chile. Fine-scale and temporal genetic studies have the potential to not only reveal important information on the colonization history of this species, but also to provide key insights into the community effects of this species over time.

Members of the P.s.s.c. are often reported as introduced species around the world (Figure 4) but few studies have focused on reconstructing invasion routes or identifying source populations or the presence of recurrent introductions. A particularly interesting example is the recent introduction of Pyura doppelgangera in New Zealand (Hayward \& Morley 2009), where it has spread across continuous rocky shores, replacing native assemblages. Since limited information is available to date (Rius \& Teske 2013), a multilocus genetic or genomic study would help to explain why and how this invasion is particularly successful. New introductions by members of the P.s.s.c. provide unplanned replicated experiments to study the consequences of ecological dominance for rocky shore ecosystems.

\section{Acknowledgements}

We are grateful to Steve Hawkins, Louise Firth and Hanna Schuster for inviting us to submit this review, as well as an anonymous reviewer for insightful comments that helped improve the final version. We are grateful to John Largier for discussion during the early planning of this review. MR acknowledges ASSEMBLE (an EU FP7 research infrastructure initiative comprising a network of marine research stations) for awarding a grant to conduct research at the 'Estación Costera de Investigaciones Marinas-Las Cruces', Chile. JCC is grateful for support from the project entitled 'Núcleo Milenio en Conservación Marina CCM RC 130004, Iniciativa Científica Milenio, Ministerio de Economía' de Chile and the 'Minera Escondida Ltda' for long-term logistic and financial support. PHM acknowledges the National Fund for Scientific and Technological Development (FONDECYT) of Chile for the financial support that has allowed him to conduct, through several grants, research activities in Antofagasta Bay from year 2000. This work is based upon research supported by the South African Research Chairs Initiative of the Department of Science and Technology and the National Research Foundation.

\section{References}

Aiken, C.M. \& Navarrete, S.A. 2014. Coexistence of competitors in marine metacommunities: environmental variability, edge effects, and the dispersal niche. Ecology 95, 2289-2302.

Airoldi, L. Turon, X., Perkol-Finkel, S. \& Rius, M. 2015. Corridors for aliens but not for natives: effects of marine urban sprawl at a regional scale. Diversity and Distributions 21, 755-768. 
Almany, G.R., Berumen, M.L., Thorrold, S.R., Planes, S. \& Jones, G.P. 2007. Local replenishment of coral reef fish populations in a marine reserve. Science 316, 742-744.

Alvarado, J.L. 2004. Patrones de distribución de organismos intermareales en la Bahía de Antofagasta: patrones simples y causas complejas. PhD thesis, Pontificia Universidad Católica de Chile.

Alvarado, J.L. \& Castilla, J.C. 1996. Tridimensional matrices of mussels Perumytilus purpuratus on intertidal platforms with varying wave forces in central Chile. Marine Ecology Progress Series 133, 135-141.

Alvarado, J.L., Pinto, R., Marquet, P., Pacheco, C., Guiñez, R. \& Castilla, J.C. 2001. Patch recolonization by the tunicate Pyura praeputialis in the rocky intertidal of the Bay of Antofagasta, Chile: evidence for self-facilitation mechanisms. Marine Ecology Progress Series 224, 93-101.

Astorga, M.P., Guiñez, R. \& Castilla, J.C. 2009. Genetic divergence in the ascidian Pyura praeputialis (= Pyura stolonifera) (Heller, 1878) from mainland Australia and Tasmania. Papers and Proceedings of the Royal Society of Tasmania 143, 101-104.

Babcock, R. \& Keesing, J. 1999. Fertilization biology of the abalone Haliotis laevigata: laboratory and field studies. Canadian Journal of Fisheries and Aquatic Sciences 56, 1668-1678.

Baird, A.H. \& Hughes, T.P. 2000. Competitive dominance by tabular corals: an experimental analysis of recruitment and survival of understorey assemblages. Journal of Experimental Marine Biology and Ecology 251, 117-132.

Baird, D., Asmus, H. \& Asmus, R. 2004. Energy flow of a boreal intertidal ecosystem, the Sylt-Rømø Bight. Marine Ecology Progress Series 279, 45-61.

Bak, R.P.M., Joenje, M., de Jong, I., Lambrechts, D.Y.M. \& Nieuwland, G. 1998. Bacterial suspension feeding by coral reef benthic organisms. Marine Ecology Progress Series 175, 285-288.

Bally, R. \& Griffiths, C.L. 1989. Effects of human trampling on an exposed rocky shore. International Journal of Environmental Studies 34, 115-125.

Bayne, B.L. 1964. Primary and secondary settlement in Mytilus edulis L. (Mollusca). Journal of Animal Ecology 33, 513-523.

Berec, L., Angulo, E. \& Courchamp, F. 2007. Multiple Allee effects and population management. Trends in Ecology \& Evolution 22, 185-191.

Berkley, H.A., Kendall, B.E., Mitarai, S. \& Siegel, D.A. 2010. Turbulent dispersal promotes species coexistence. Ecology Letters 13, 360-371.

Bertness, M.D. \& Grosholz, E. 1985. Population dynamics of the ribbed mussel, Geukensia demissa: the costs and benefits of an aggregated distribution. Oecologia 67, 192-204.

Bertness, M.D. \& Leonard, G.H. 1997. The role of positive interactions in communities: lessons from intertidal habitats. Ecology 78, 1976-1989.

Bone, Q., Carré, C. \& Chang, P. 2003. Tunicate feeding filters. Journal of the Marine Biological Association of the UK 83, 907-919.

Bowman, G. \& Harvey, N. 1986. Geomorphic evolution of a Holocene beach-ridge complex, LeFevre Peninsula, South Australia. Journal of Coastal Research 2, 345-362.

Branch, G.M. 1984. Competition between marine organisms: ecological and evolutionary implications. Oceanography and Marine Biology: An Annual Review 22, 429-593.

Brown, J.H. \& Maurer, B.A. 1986. Body size, ecological dominance and Cope's rule. Nature 324, 248-250.

Bruno, J.F., Stachowicz, J.J. \& Bertness, M.D. 2003. Inclusion of facilitation into ecological theory. Trends in Ecology \& Evolution 18, 119-125.

Cafaro, P. 2001. For a grounded conception of wilderness and more wilderness on the ground. Ethics and the Environment 6, 1-17.

Carlton, J.T. \& Geller, J.B. 1993. Ecological roulette: the global transport of nonindigenous marine organisms. Science 261, 78-82.

Caro, A.U., Guiñez, R., Ortiz, V. \& Castilla, J.C. 2011. Competition between a native mussel and a nonindigenous invader for primary space on intertidal rocky shores in Chile. Marine Ecology Progress Series 428, 177-185.

Castilla, J.C. 1998. Las comunidades intermareales de la Bahía San Jorge: estudios de linea base y el programa ambiental de Minera Escondida Ltda. en Punta Coloso. In Mineria del Cobre, Ecologia y Ambiente Costero, D. Arcos (ed.). Editorial Anibal Pinto SA, 221-244.

Castilla, J.C. 1999. Coastal marine communities: trends and perspectives from human exclusion experiments. Trends in Ecology \& Evolution 14, 280-283. 
Castilla, J.C. 2008. Fifty years from the publication of the first two papers on Chilean rocky intertidal assemblages: honoring Professor Eric R. Guiler. Revista de Biología Marina y Oceanografía 43, 457-467.

Castilla, J.C. \& Bustamante, R.H. 1989. Human exclusion from rocky intertidal of Las Cruces, central Chile: effects on Durvillaea antarctica (Phaeophyta, Durvilleales). Marine Ecology Progress Series 50, 203-214.

Castilla, J.C., \& Camaño, A. 2001. El piure de Antofagasta, Pyura praeputialis (Heller, 1878): un competidor dominante e ingeniero de ecosistemas. In Sustentabilidad de la Biodiversidad. K. Alveal \& T. Antezana (eds). Universidad de Concepcíon, Chile, 719-729.

Castilla J.C., Campos, M.A. \& Bustamante, R.H. 2007a. Recovery of Durvillaea antarctica (Durvilleales) inside and outside Las Cruces Marine Reserve. Ecological Applications 17, 1511-1522.

Castilla, J.C., Collins, A.G., Meyer, C.P., Guiñez, R. \& Lindberg, D.R. 2002. Recent introduction of the dominant tunicate, Pyura praeputialis (Urochordata, Pyuridae) to Antofagasta, Chile. Molecular Ecology 11, 1579-1584.

Castilla, J.C. \& Defeo, O. 2001. Latin-American benthic shellfisheries: emphasis on co-management and experimental practices. Reviews in Fish Biology and Fisheries 11, 1-30.

Castilla, J.C. \& Durán, L.R. 1985. Human exclusion from the rocky intertidal zone of central Chile: the effects on Concholepas concholepas (Gastropoda). Oikos 45, 391-399.

Castilla, J.C. \& Guiñez, R. 2000. Disjoint geographical distribution of intertidal and nearshore benthic invertebrates in the Southern Hemisphere. Revista Chilena de Historia Natural 73, 585-603.

Castilla, J.C., Guiñez, R., Alvarado, J.L., Pacheco, C. \& Varas, M. 2000. Distribution, population structure, population biomass and morphological characteristics of the tunicate Pyura stolonifera in the Bay of Antofagasta, Chile. Marine Ecology 21, 161-174.

Castilla, J.C., Guiñez, R., Caro, A.U. \& Ortiz, V. 2004a. Invasion of a rocky intertidal shore by the tunicate Pyura praeputialis in the Bay of Antofagasta, Chile. Proceedings of the National Academy of Sciences of the USA 101, 8517-8524.

Castilla, J.C. \& Jerez, G. 1986. Artisanal fishery and the development of a data base for managing the loco (Concholepas concholepas) in Chile. Canadian Journal of Fisheries and Aquatic Sciences 92, 133-139.

Castilla, J.C., Lagos, N.A. \& Cerda, M. 2004b. Marine ecosystem engineering by the alien ascidian Pyura praeputialis on a mid-intertidal rocky shore. Marine Ecology Progress Series 268, 119-130.

Castilla, J.C. \& Largier, J. 2002. The Oceanography and Ecology of the Nearshore and Bays in Chile. Ediciones Universidad Católica de Chile.

Castilla, J.C., Manríquez, P., Alvarado, J., Rosson, A., Pino, C., Soto, R., Oliva, D. \& Defeo, O. 1998. Artisanal caletas as units of production and co-managers of benthic invertebrates in Chile. Canadian Journal of Fisheries and Aquatic Sciences 125, 407-413.

Castilla, J.C., Manríquez, P.H., Delgado, A., Ortiz, V., Jara, M.E. \& Varas, M. 2014. Rocky intertidal zonation pattern in Antofagasta, Chile: invasive species and shellfish gathering. PLOS ONE 9, e110301.

Castilla, J.C., Manríquez, P.H., Delgado, A.P., Gargallo, L., Leiva, A. \& Radic, D. 2007b. Bio-foam enhances larval retention in a free-spawning marine tunicate. Proceedings of the National Academy of Sciences of the USA 104, 18120-18122.

Castilla, J.C., Navarrete, S.A., Manzur, T. \& Barahona, M. 2013. Heliaster helianthus. In Starfish, J.M. Lawrence (ed.). Baltimore, USA: Johns Hopkins University Press, 153-160.

Castilla, J.C. \& Neill, P.E. 2009. Marine bioinvasions in the southeastern Pacific: status, ecology, economic impacts, conservation and management. In Biological Invasions in Marine Ecosystems, G. Rilov \& J.A. Crooks (eds). Berlin \& Heidelberg: Springer-Verlag, 439-457.

Castilla, J.C., Uribe, M., Bahamonde, N., Clarke, M., Desqueyroux-Faúndez, R., Kong, I., Moyano, H., Rozbaczylo, N., Santelices, B., Valdovinos, C. \& Zavala, P. 2005. Down under the southeastern Pacific: marine non-indigenous species in Chile. Biological Invasions 7, 213-232.

Cerda, M. \& Castilla, J.C. 2001. Diversity and biomass of macro-invertebrates in intertidal matrices of the tunicate Pyura praeputialis (Heller, 1878) in the Bay of Antofagasta, Chile. Revista Chilena de Historia Natural 74, 841-853.

Cerrano, C. \& Bavestrello, G. 2009. Mass mortalities and extinctions. In Marine Hard Bottom Communities, M. Wahl (ed.). Berlin \& Heidelberg: Springer-Verlag, 295-307.

Chafer, C.J. 1992. Ascidian predation by the sooty oystercatcher Haematopus fuliginosus: further observation. Stilt 20, 20-21. 
Chapman, M.G. \& Underwood, A.J. 1994. Dispersal of the intertidal snail, Nodilittorina pyramidalis, in response to the topographic complexity of the substratum. Journal of Experimental Marine Biology and Ecology 179, 145-169.

Chunco, A.J. 2014. Hybridization in a warmer world. Ecology and Evolution 4, 2019-2031.

Clapham, M.E., Bottjer, D.J., Powers, C.M., Bonuso, N., Fraiser, M.L., Marenco, P.J., Dornbos, S.Q. \& Pruss, S.B. 2006. Assessing the ecological dominance of Phanerozoic marine invertebrates. Palaios 21, 431-441.

Clarke, M., Ortiz, V. \& Castilla, J.C. 1999. Does early development of the chilean tunicate Pyura praeputialis (Heller, 1878) explain the restricted distribution of the species? Bulletin of Marine Science $\mathbf{6 5}, \mathbf{7 4 5 - 7 5 4 .}$

Cole, V.J. \& McQuaid, C.D. 2010. Bioengineers and their associated fauna respond differently to the effects of biogeography and upwelling. Ecology 91, 3549-3562.

Coley, P.D., Bryant, J.P. \& Chapin, F.S. 1985. Resource availability and plant antiherbivore defense. Science 230, 895-899.

Connell, J.H. 1978. Diversity in tropical rain forests and coral reefs. Science 199, 1302-1310.

Connolly, S.R. \& Roughgarden, J. 1999. Theory of marine communities: competition, predation, and recruitment-dependent interaction strength. Ecological Monographs 69, 277-296.

Courchamp, F., Clutton-Brock, T. \& Grenfell, B. 1999. Inverse density dependence and the Allee effect. Trends in Ecology \& Evolution 14, 405-410.

Crain, C.M. \& Bertness, M.D. 2006. Ecosystem engineering across environmental gradients: implications for conservation and management. BioScience 56, 211-218.

Cronon, W. 1983. Changes in the Land: Indians, Colonists and the Ecology of New England. New York: Hill and Wang.

Crooks, J.A. 2002. Characterizing ecosystem-level consequences of biological invasions: the role of ecosystem engineers. Oikos 97, 153-166.

Crutsinger, G.M., Souza, L. \& Sanders, N.J. 2008. Intraspecific diversity and dominant genotypes resist plant invasions. Ecology Letters 11, 16-23.

Dalby, J.E.J. 1996. Nemertean, copepod, and amphipod symbionts of the dimorphic ascidian Pyura stolonifera near Melbourne, Australia: specificities to host morphs, and factors affecting prevalences. Marine Biology 126, 231-243.

Dalby, J.E.J. 1997. Dimorphism in the ascidian Pyura stolonifera near Melbourne, Australia, and its evaluation through field transplant experiments. Marine Ecology 18, 253-271.

Day, R.W., Barkai. A. \& Wickens, P.A. 1991. Trapping of three drilling whelks by two species of mussel. Journal of Experimental Marine Biology and Ecology 149, 109-122

Dayton, P.K. 1971, Competition, disturbance, and community organization - provision and subsequent utilization of space in a rocky intertidal community. Ecological Monographs 41, 351-389.

Dayton, P.K. 1975. Experimental evaluation of ecological dominance in a rocky intertidal algal community. Ecological Monographs 45, 137-159.

Donahue, M.J. 2006. Allee effects and conspecific cueing jointly lead to conspecific attraction. Oecologia $149,33-43$.

Downing, J.A., Rochon, Y., Pérusse, M. \& Harvey, H. 1993. Spatial aggregation, body size, and reproductive success in the freshwater mussel Elliptio complanata. Journal of the North American Benthological Society 12, 148-156.

Eriksson, B.K., van der Heide, T., van de Koppel, J., Piersma, T., van der Veer, H.W. \& Olff, H. 2010. Major changes in the ecology of the Wadden Sea: human impacts, ecosystem engineering and sediment dynamics. Ecosystems 13, 752-764.

Erlandsson, J. \& McQuaid, C.D. 2004. Spatial structure of recruitment in the mussel Perna perna at local scales: effects of adults, algae and recruit size. Marine Ecology Progress Series 267, 173-185.

Erlandsson, J., Pal, P. \& McQuaid, C.D. 2006. Re-colonisation rate differs between co-existing indigenous and invasive intertidal mussels following major disturbance. Marine Ecology Progress Series 320, 169-176.

Fairweather, P.G. 1991. A conceptual framework for ecological studies of coastal resources: an example of a tunicate collected for bait on Australian Seashores. Ocean and Shoreline Management 15, 125-142.

Farrell, E.D. \& Crowe, T.P. 2007. The use of byssus threads by Mytilus edulis as an active defence against Nucella lapillus. Journal of the Marine Biological Association of the United Kingdom 87, 559-564. 
Fiala-Médioni, A. 1978. Filter-feeding ethology of benthic invertebrates (ascidians). IV. Pumping rate, filtration rate, filtration efficiency. Marine Biology 48, 243-249.

Fielding, P.J, Weerts, K.A. \& Forbes, A.T. 1994. Macroinvertebrate communities associated with intertidal and subtidal beds of Pyura stolonifera (Heller) (Tunicata: Ascidiacea) on the Natal coast. South African Journal of Zoology 29, 46-53.

Fletcher, L. 2014. Background information on the sea squirt Pyura doppelgangera to support regional response decisions. Cawthron Institute, report prepared for Marlborough District Council, Nelson, New Zealand.

Flinn, M.V., Geary, D.C. \& Ward, C.V. 2005. Ecological dominance, social competition, and coalitionary arms races. Evolution and Human Behavior 26, 10-46.

Fox, J.W. 2013. The intermediate disturbance hypothesis should be abandoned. Trends in Ecology \& Evolution 28, 86-92.

Garrabou, J., Coma, R., Bensoussan, N., Bally, M., Chevaldonné, P., Cigliano, M., Diaz, D., Harmelin, J.G., Gambi, M.C., Kersting, D.K., Ledoux, J.B., Lejeusne, C., Linares, C., Marschal, C., Pérez, T., Ribes, M., Romano, J.C., Serrano, E., Teixido, N., Torrents, O., Zabala, M., Zuberer, F. \& Cerrano, C. 2009. Mass mortality in Northwestern Mediterranean rocky benthic communities: effects of the 2003 heat wave. Global Change Biology 15, 1090-1103.

Gascoigne, J. \& Lipcius, R.N. 2004. Allee effects in marine systems. Marine Ecology Progress Series 269, $49-59$.

Gelcich, S., Cinner, J., Donlan, C.J., Tapia-Lewin, S., Godoy, N. \& Castilla, J.C. 2017. Fishers' perceptions on the Chilean coastal TURF system after two decades: problems, benefits, and emerging needs. Bulletin of Marine Science 93, 53-67.

Gili, J.-M. \& Coma, R. 1998. Benthic suspension feeders: their paramount role in littoral marine food webs. Trends in Ecology \& Evolution 13, 316-321.

Goss-Custard, J.D., West, A.D., Yates, M.G., Caldow, R.W., Stillman, R.A., Bardsley, L., Castilla, J., Castro, M., Dierschke, V., Durell, S.E., Eichhorn, G., Ens, B.J., Exo, K.M., Udayangani-Fernando, P.U., Ferns, P.N., Hockey, P.A., Gill, J.A., Johnstone, I., Kalejta-Summers, B., Masero, J.A., Moreira, F., Nagarajan, R.V., Owens, I.P., Pacheco, C., Perez-Hurtado, A., Rogers, D., Scheiffarth, G., Sitters, H., Sutherland, W.J., Triplet, P., Worrall, D.H., Zharikov, Y., Zwarts, L. \& Pettifor, R.A. 2006. Intake rates and the functional response in shorebirds (Charadriiformes) eating macro-invertebrates. Biological Reviews 81, 501-529.

Grosberg, R.K. \& Quinn, J.F. 1986. The genetic control and consequences of kin recognition by the larvae of a colonial marine invertebrate. Nature 322, 456-459.

Guiler, E.R. 1959. Intertidal belt-forming species on the rocky coasts of northern Chile. Papers and Proceedings of the Royal Society of Tasmania 93, 33-58.

Guiñez, R. \& Castilla, J.C. 1999. A tridimensional self-thinning model for multilayered intertidal mussels. American Naturalist 154, 341-357.

Guiñez, R. \& Castilla, J.C. 2001. An allometric tridimensional model of self-thinning for a gregarious tunicate. Ecology 82, 2331-2341.

Gutiérrez, J.L., Jones, C.G., Strayer, D.L. \& Iribarne, O.O. 2003. Mollusks as ecosystem engineers: the role of shell production in aquatic habitats. Oikos 101, 79-90.

Hanekom, N. 2013. Environmental conditions during mass mortalities of the ascidian Pyura stolonifera (Heller) in the Tsitsikamma Marine Protected Area. African Zoology 48, 167-172.

Hanekom, N., Harris, J.M., Branch, G.M. \& Allen, J.C. 1999. Mass mortality and recolonization of Pyura stolonifera (Heller) on the south coast of South Africa. South African Journal of Marine Science 21, $117-133$.

Harley, C.D.G. 2006. Effects of physical ecosystem engineering and herbivory on intertidal community structure. Marine Ecology Progress Series 317, 29-39.

Hawkins, S.J. \& Hartnoll, R.G. 1983. Grazing of intertidal algae by marine invertebrates. Oceanography and Marine Biology: An Annual Review 21, 195-282.

Hayward, B.W. \& Morley, M.S. 2009. Introduction to New Zealand of two sea squirts (Tunicata, Ascidiacea) and their subsequent dispersal. Records of the Auckland Museum 46, 5-14.

Heasman, K.G., Pitcher, G.C., McQuaid, C.D. \& Hecht, T. 1998. Shellfish mariculture in the Benguela system: raft culture of Mytilus galloprovincialis and the effect of rope spacing on food extraction, growth rate, production, and condition of mussels. Journal of Shellfish Research 17, 33-39.

Heller, C. 1878. Beiträge zur näheren Kenntniss der Tunicaten. Sitzungsberichte der Academie der Wissenschaften in Wien 77, 83-109. 
Hillebrand, H., Bennett, D.M. \& Cadotte, M.W. 2008. Consequences of dominance: a review of evenness effects on local and regional ecosystem processes. Ecology 89, 1510-1520.

Hughes, R.N. \& Griffiths, C.L. 1988. Self-thinning in barnacles and mussels: the geometry of packing. American Naturalist 132, 484-491.

Johnson, C.H. \& Woollacott, R.M. 2010. Larval settlement preference maximizes genetic mixing in an inbreeding population of a simultaneous hermaphrodite (Bugula stolonifera, Bryozoa). Molecular Ecology 19, 5511-5520.

Jones, C.G., Lawton, J.H. \& Shachak, M. 1994. Organisms as ecosystem engineers. Oikos 69, 373-386.

Jones, C.G., Lawton, J.H. \& Shachak, M. 1997. Positive and negative effects of organisms as physical ecosystem engineers. Ecology 78, 1946-1957.

Jordan, W.R. 2000. Restoration, community, and wilderness. In Restoring Nature. Perspectives from the Social Sciences and Humanities, P.H. Gobster \& R.B. Hull (eds). Washington, DC: Island Press, 21-36.

Justus, J., Colyvan, M., Regan, H. \& Maguire, L. 2009. Buying into conservation: intrinsic versus instrumental value. Trends in Ecology \& Evolution 24, 187-191.

Katz, E. 1992. The big lie: human reconstuction of nature. Research in Philosophy and Technology 12, 231-241.

Katz, E. 2000. Another look at restoration: technology and artificial nature. In Restoring Nature. Perspectives from the Social Sciences and Humanities, P.H. Gobster \& R.B. Hull (eds). Washington, DC: Island Press, 37-48.

Keller, L.F. \& Waller, D.M. 2002. Inbreeding effects in wild populations Trends in Ecology \& Evolution 17, 230-241.

Keough, M.J., Quinn, G.P. \& King, A. 1993. Correlations between human collecting and intertidal mollusc populations on rocky shores. Conservation Biology 7, 378-390.

Keough, M.J. \& Raimondi, P.T. 1995. Responses of settling invertebrate larvae to bioorganic films: effects of different types of films. Journal of Experimental Marine Biology and Ecology 185, 235-253.

Kingsford, M.J., Underwood, A.J. \& Kennelly, S.J. 1991. Humans as predators on rocky reefs in New South Wales, Australia. Marine Ecology Progress Series 72, 1-14.

Kinlan, B.P. \& Gaines, S. 2003. Dispersal in marine and terrestrial environments: a community perspective. Ecology 84, 2007-2020.

Kinlan, B.P., Gaines, S.D. \& Lester, S.E. 2005. Propagule dispersal and the scales of marine community process. Diversity and Distributions 11, 139-148.

Klumpp, D.W. 1984. Nutritional ecology of the ascidian Pyura stolonifera: influence of body size, food quantity and quality on filter-feeding, respiration, assimilation efficiency and energy balance. Marine Ecology Progress Series 19, 269-284.

Knott, N.A., Davis, A.R. \& Buttemer, W.A. 2004. Passive flow through an unstalked intertidal ascidian: orientation and morphology enhance suspension feeding in Pyura stolonifera. Biological Bulletin 207, 217-224.

Kott, P. 1952. The ascidians of Australia I. Stolidobranchiata lahille and Phlebobranchiata lahille. Australian Journal of Marine and Freshwater Research 3, 205-333.

Kott, P. 1985. The Australian Ascidiacea, Part 1. Phlebobranchia and Stolidobranchia. Memoirs of the Queensland Museum 23, 1-440.

Kott, P. 2006. Observations on non-didemnid ascidians from Australian waters. Journal of Natural History 40, 169-234.

Kuussaari, M., Saccheri, I., Camara, M. \& Hanski, I. 1998. Allee effect and population dynamics in the Glanville fritillary butterfly. Oikos 82, 384-392.

Kyle, R., Pearson, B., Fielding, P.J., Robertson, W.D. \& Birnie, S.L. 1997. Subsistence shellfish harvesting in the Maputaland marine reserve in northern Kwazulu-Natal, South Africa: rocky shore organisms. Biological Conservation 82, 183-192.

Lafargue, F. \& Wahl, M. (1986-1987) Contribution to the knowledge of littoral ascidians (Ascidiacea, Tunicata) of the Senegalese coast. Bulletin de l'IFAN 46, 385-402.

Lambert, G. 2005. Ecology and natural history of the protochordates. Canadian Journal of Zoology 83, $34-50$.

Lambert, G. (2007) Invasive sea squirts: a growing global problem. Journal of Experimental Marine Biology and Ecology 342, 3-4. 
Lasiak, T. 1991. The susceptibility and/or resilience of rocky littoral molluscs to stock depletion by the indigenous coastal people of Transkei, Southern Africa. Biological Conservation 56, 245-264.

Lawton, J.H. \& Jones, C.G. 1995. Linking species and ecosystems: organisms as ecosystem engineers. In Linking Species and Ecosystems, C.G. Jones \& J.H. Lawton (eds). Springer, 141-150.

LeBlanc, N., Davidson, J., Tremblay, R., McNiven, M. \& Landry, T. 2007. The effect of anti-fouling treatments for the clubbed tunicate on the blue mussel, Mytilus edulis. Aquaculture 264, 205-213.

Lehane, C. \& Davenport, J. 2004. Ingestion of bivalve larvae by Mytilus edulis: experimental and field demonstrations of larviphagy in farmed blue mussels. Marine Biology 145, 101-107.

Leibold, M.A., Holyoak, M., Mouquet, N., Amarasekare, P., Chase, J.M., Hoope, M.F., Holt, R.D., Shurin, J.B., Law, R., Tilman, D., Loreau, M. \& Gonzalez, A. 2004. The metacommunity concept: a framework for multi-scale community ecology. Ecology Letters 7, 601-613.

Levins, R. 1974. The qualitative analysis of partially specified systems. Annals of the New York Academy of Sciences 231, 123-138.

Levitan, D.R. 1991. Influence of body size and population density on fertilization success and reproductive output in a free-spawning invertebrate. Biological Bulletin 181, 261-268.

Levitan, D.R., Sewell, M.A. \& Chia, F.-S. 1992. How distribution and abundance influence fertilization success in the sea urchin Strongylocentotus franciscanus. Ecology 73, 248-254.

Locke, A. 2009. A screening procedure for potential tunicate invaders of Atlantic Canada. Aquatic Invasions 4, 71-79.

Loo, L.-O. \& Rosenberg, R. 1989. Bivalve suspension-feeding dynamics and benthic-pelagic coupling in an eutrophicated marine bay. Journal of Experimental Marine Biology and Ecology 130, 253-276.

Loo, L.-O. \& Rosenberg, R. 1996. Production and energy budget in marine suspension feeding populations: Mytilus edulis, Cerastoderma edule, Mya arenaria and Amphiura filiformis. Journal of Sea Research 35, 199-207.

Loreau, M., Naeem, S., Inchausti, P., Bengtsson, J., Grime, J.P., Hector, A., Hooper, D.U., Huston, M.A., Raffaelli, D., Schmid, B., Tilman, D. \& Wardle, D.A. 2001. Biodiversity and ecosystem functioning: current knowledge and future challenges. Science 294, 804-808.

Lubchenco, J. 1978. Plant species diversity in a marine intertidal community: importance of herbivore food preference and algal competitive abilities. American Naturalist 112, 23-39.

Lubchenco, J. \& Gaines, S.D. 1981. A unified approach to marine plant-herbivore interactions. I. Populations and communities. Annual Review of Ecology and Systematics 12, 405-437.

Lubchenco, J. \& Menge, B.A. 1978. Community development and persistence in a low rocky intertidal zone. Ecological Monographs 48, 67-94.

Majiza, V.N. \& Lasiak, T.A. 2010. The influence of site, season and day of the week on exploitation of rocky intertidal biota in central Transkei, South Africa. South African Journal of Marine Science 24, 57-64.

Manríquez, P.H. \& Castilla, J.C. 2010. Fertilization efficiency and gamete viability in the ascidian Pyura praeputialis in Chile. Marine Ecology Progress Series 409, 107-119.

Manríquez, P.H., Castilla, J.C., Ortiz, V. \& Jara, M.E. 2016. Empirical evidence for large-scale human impact on intertidal aggregations, larval supply and recruitment of Pyura praeputialis around the Bay of Antofagasta, Chile. Austral Ecology 41, 701-714.

Manríquez, P.H., Delgado, A.P., Jara, M.E. \& Castilla, J.C. 2008. Field and laboratory pilot rearing experiments with early ontogenic stages of Concholepas concholepas (Gastropoda: Muricidae). Aquaculture 279, 99-107.

Manríquez, P.H., Jara, M.E., Mardones, M.L., Torres, R., Lagos, N.A., Lardies, M.A., Vargas, C.A., Duarte, C. \& Navarro, J.M. 2014. Effects of ocean acidification on larval development and early post-hatching traits in Concholepas concholepas (loco). Marine Ecology Progress Series 514, 87-103.

Marshall, D.J. 2002. In situ measures of spawning synchrony and fertilization success in an intertidal, freespawning invertebrate. Marine Ecology Progress Series 236, 113-119.

Marshall, D.J. \& Keough, M.J. 2008. The evolutionary ecology of offspring size in marine invertebrates. Advances in Marine Biology 53, 1-60.

Marshall, D.J., Krug, P.J., Kupriyanova, E.K., Byrne, M. \& Emlet, R.B. 2012. The biogeography of marine invertebrate life histories. Annual Review of Ecology, Evolution, and Systematics 43, 97-114.

Marshall, D.J., Styan, C.A. \& Keough, M.J. 2000. Intraspecific co-variation between egg and body size affects fertilisation kinetics of free-spawning marine invertebrates. Marine Ecology Progress Series 195, 305-309. 
McQuaid, C.D. \& Branch, G.M. 1984. The influence of sea temperature, substratum and wave exposure on rocky intertidal communities: an analysis of faunal and floral biomass. Marine Ecology Progress Series 19, 145-151.

McQuaid, C.D. \& Branch, G.M. 1985. Trophic structure of rocky intertidal communities: response to wave action and implications for energy flow. Marine Ecology Progress Series 22, 153-161.

McQuaid, C.D. \& Lindsay, J.R. 2005. Interacting effects of wave exposure, tidal height and substratum on spatial variation in densities of mussel Perna perna plantigrades. Marine Ecology Progress Series 301, 173-184.

McQuaid, C.D. \& Phillips, T.E. 2000. Limited wind-driven dispersal of intertidal mussel larvae: in situ evidence from the plankton and the spread of the invasive species Mytilus galloprovincialis in South Africa. Marine Ecology Progress Series 201, 211-220.

Menge, B.A., Berlow, E.L., Blanchette, C.A., Navarrete, S.A. \& Yamada, S.B. 1994. The keystone species concept - variation in interaction strength in a rocky intertidal habitat. Ecological Monographs 64, 249-286.

Menge, B.A. \& Sutherland, J.P. 1987. Community regulation - variation in disturbance, competition, and predation in relation to environmental-stress and recruitment. American Naturalist 130, 730-757.

Millar, R.H. 1955. On a collection of ascidians from South Africa. Proceedings of the Zoological Society of London 125, 169-221.

Millar, R.H. 1962. Further descriptions of South African ascidians. Annals of the South African Museum 46, $113-221$.

Millar, R.H. 1966. Port Phillip survey 1957-1963. Ascidiacea. Memoirs of the National Museum of Victoria 27, 357-384.

Millar, R.H. 1971. The biology of ascidians. Advances in Marine Biology 9, 1-100.

Monniot, C. \& Bitar, G. 1983. Sur la présence de Pyura stolonifera (Tunicata, Ascidiacea) à Ras Achaccar (côte nord atlantique marocaine). Comparaison anatomique distinctive avec Pyura praeputialis. Bulletin de l'Institut Scientifique, Rabat 7, 83-91.

Monniot, C., Monniot, F., Griffiths, C.L. \& Schleyer, M. 2001. South African ascidians. Annals of the South African Museum 108, 1-141.

Monniot, C., Monniot, F. \& Laboute, P. 1991. Coral Reef Ascidians of New Caledonia. Paris: Éditions de L'Orstom.

Monniot, F. \& Monniot, C. 2001. Ascidians from the tropical western Pacific. Zoosystema 23, 201-383.

Monteiro, S.M., Chapman, M.G. \& Underwood, A.J. 2002. Patches of the ascidian Pyura stolonifera (Heller, 1878): structure of habitat and associated intertidal assemblages. Journal of Experimental Marine Biology and Ecology 270, 171-189.

Moreno, C.A., Sutherland, J.P. \& Jara, H.F. 1984. Man as a predator in the intertidal zone of southern Chile. Oikos 42, 155-160.

Navarrete, S.A. \& Berlow, E.L. 2006. Variable interaction strengths stabilize marine community pattern. Ecology Letters 9, 526-536.

Navarrete, S.A. \& Castilla, J.C. 2003. Experimental determination of predation intensity in an intertidal predator guild: dominant versus subordinate prey. Oikos 100, 251-262.

Navarrete, S.A., Wieters, E.A., Broitman, B.R. \& Castilla, J.C. 2005. Scales of benthic-pelagic coupling and the intensity of species interactions: from recruitment limitation to top-down control. Proceedings of the National Academy of Sciences of the USA 102, 18046-18051.

Newell, R.C., Field, J.G. \& Griffiths, C.L. 1982. Energy balance and significance of microorganisms in a kelp bed community. Marine Ecology Progress Series 8, 103-113.

Nilsson, M.-C. \& Wardle, D.A. 2005. Understory vegetation as a forest ecosystem driver: evidence from the northern Swedish boreal forest. Frontiers in Ecology and the Environment 3, 421-428.

Oldewage, W.H. 1994. Description of Doropygus pyurus n.sp. (Copepoda, Notodelphyidae) from Pyura stolonifera (Echinodermata, Ascidiacea) in South Africa. South African Journal of Zoology 29, 212-216.

Ortiz, M., Campos, L., Berrios, F., Rodriguez, F., Hermosillo, B. \& González, J. 2013. Network properties and keystoneness assessment in different intertidal communities dominated by two ecosystem engineer species (SE Pacific coast): a comparative analysis. Ecological Modelling 250, 307-318.

Otway, N.M. 1989. The effects of grazing by chitons on mid and low shore intertidal communities. PhD thesis, University of Sydney, Australia. 
Pacheco, C.J. \& Castilla, J.C. 2001. Foraging behavior of the American oystercatcher Haematopus palliatus pitanay (Murphy 1925) on the intertidal ascidian Pyura praeputialis (Heller 1878) in the Bay of Antofagasta, Chile. Journal of Ethology 19, 23-26.

Paine, R.T. 1966. Food web complexity and species diversity. American Naturalist 100, 65-75.

Paine, R.T. 1969. A note on trophic complexity and community stability. American Naturalist 103, 91-93.

Paine, R.T. 1971. Short-term experimental investigation of resource partitioning in a New Zealand rocky intertidal habitat. Ecology 52, 1096-1106.

Paine, R.T. 1976. Size-limited predation: an observational and experimental approach with the MytilusPisaster interaction. Ecology 57, 858-873.

Paine, R.T. 1979. Disaster, catastrophe, and local persistence of the sea palm Postelsia palmaeformis. Science 205, 685-687.

Paine, R.T., Castilla, J.C. \& Cancino, J. 1985. Perturbation and recovery patterns of starfish-dominated intertidal assemblages in Chile, New Zealand, and Washington State. American Naturalist 125, 679-691.

Paine, R.T. \& Suchanek, T.H. 1983. Convergence of ecological processes between independently evolved competitive dominants: a tunicate-mussel comparison. Evolution 37, 821-831.

Pawlik, J.R., Butman, C.A. \& Starczak, V.R. 1991. Hydrodynamic facilitation of gregarious settlement of a reef-building tube worm. Science 251, 421-423.

Petersen, J.K. \& Riisgård, H.U. 1992. Filtration capacity of the ascidian Ciona intestinalis and its grazing impact in a shallow fjord. Marine Ecology Progress Series 88, 9-17.

Petersen, J.K. \& Svane, I. 2002. Filtration rate in seven Scandinavian ascidians: implications of the morphology of the gill sac. Marine Biology 140, 397-402.

Porri, F., Jordaan, T. \& McQuaid, C.D. 2008. Does cannibalism of larvae by adults affect settlement and connectivity of mussel populations? Estuarine, Coastal and Shelf Science 79, 687-693.

Quoy, J. \& Gaimard, A. 1834. Animaux Mollusques. In Voyages de Decouvertes de l'Astrolabe Executes par Orde du Roi, Pendant les Annees 1826-29, sous le Commandement de M.J. Dumont d'Urville, Zoologie, Vol 3, 559-625.

Ramírez, M.E. \& Mena, O. 1984. Distribucion, abundancia y estructuras de las comunidades de algas que crecen sobre Pyura praeputialis Heller, 1878 en Caleta Coloso (Antofagasta). Boletin Museo Nacional Historia Nacional Chile 40, 7-21.

Ramorino, L. \& Campos, B. 1983. Larvas y postlarvas de Mytilidae de Chile (Mollusca: Bivalvia). Revista de Biología Marina 19, 143-192.

Randløv, A. \& Riisgård, H.U. 1979. Efficiency of particle retention and filtration rate in four species of ascidians. Marine Ecology Progress Series 1, 55-59.

Reed, J.M. \& Dobson, A.P. 1993. Behavioural constraints and conservation biology: conspecific attraction and recruitment. Trends in Ecology \& Evolution 8, 253-256.

Ribes, M., Coma, R. \& Gili, J.M. 1998. Seasonal variation of in situ feeding rates by the temperate ascidian Halocynthia papillosa. Marine Ecology Progress Series 175, 201-213.

Richardson, D.M., Pyšek, P., Rejmánek, M., Barbour, M.G., Panetta, F.D. \& West, C.J. 2000. Naturalization and invasion of alien plants: concepts and definitions. Diversity and Distributions 6, 93-107.

Rius, M., Branch, G.M., Griffiths, C.L. \& Turon, X. 2010a. Larval settlement behaviour in six gregarious ascidians in relation to adult distribution. Marine Ecology Progress Series 418, 151-163.

Rius, M. \& Cabral, H.N. 2004. Human harvesting of Mytilus galloprovincialis Lamarck, 1819, in the central coast of Portugal. Scientia Marina 68, 545-551.

Rius, M., Clusella-Trullas, S., McQuaid, C.D., Navarro, R.A., Griffiths, C.L., Matthee, C.A., von der Heyden, S. \& Turon, X. 2014a. Range expansions across ecoregions: interactions of climate change, physiology and genetic diversity. Global Ecology and Biogeography 23, 76-88.

Rius, M. \& Darling, J.A. 2014. How important is intraspecific genetic admixture to the success of colonising populations? Trends in Ecology \& Evolution 29, 233-242.

Rius, M., Kaehler, S. \& McQuaid, C.D. 2006. The relationship between human exploitation pressure and condition of mussel populations along the south coast of South Africa. South African Journal of Science 102, 130-136.

Rius, M. \& McQuaid, C.D. 2006. Wave action and competitive interaction between the invasive mussel Mytilus galloprovincialis and the indigenous Perna perna in South Africa. Marine Biology 150, 69-78.

Rius, M. \& McQuaid, C.D. 2009. Facilitation and competition between invasive and indigenous mussels over a gradient of physical stress. Basic and Applied Ecology 10, 607-613. 
Rius, M., Potter, E.E., Aguirre, J.D. \& Stachowicz, J.J. 2014b. Mechanisms of biotic resistance across complex life cycles. Journal of Animal Ecology 83, 296-305.

Rius, M. \& Teske, P.R. 2011. A revision of the Pyura stolonifera species complex (Tunicata, Ascidiacea), with a description of a new species from Australia. Zootaxa 2754, 27-40.

Rius, M. \& Teske, P.R. 2013. Cryptic diversity in coastal Australasia: a morphological and mitonuclear genetic analysis of habitat-forming sibling species. Zoological Journal of the Linnean Society 168, 597-611.

Rius, M., Turon, X., Dias, G.M. \& Marshall, D.J. 2010b. Propagule size effects across multiple life-history stages in a marine invertebrate. Functional Ecology 24, 685-693.

Rius, M., Turon, X., Ordóñez, V. \& Pascual, M. 2012. Tracking invasion histories in the sea: facing complex scenarios using multilocus data. PLoS ONE 7, e35815.

Robinson, T.B., Griffiths, C.L., McQuaid, C.D. \& Rius, M. 2005. Marine alien species of South Africa - status and impacts. African Journal of Marine Science 27, 297-306.

Roy, K., Collins, A.G., Becker, B.J., Begovic, E. \& Engle, J.M. 2003. Anthropogenic impacts and historical decline in body size of rocky intertidal gastropods in southern California. Ecology Letters 6, 205-211.

Sale, P.F. 1977. Maintenance of high diversity in coral reef fish communities. American Naturalist 111, 337-359.

Sale, P.F. 1979. Recruitment, loss and coexistence in a guild of territorial coral reef fishes. Oecologia 42, $159-177$.

Sarà, M 1986. Sessile macrofauna and marine ecosystem. Bolletino di Zoologia 53, 329-337.

Schoener, T.W. 1983. Field experiments on interspecific competition. American Naturalist 122, 240-285.

Schultz, M. 1989. Sooty oystercatcher feeding on washed-up cunjevoi. Stilt 14, 66-67.

Seiderer, L.J. \& Newell, R.C. 1988. Exploitation of phytoplankton as a food resource by the kelp bed ascidian Pyura stolonifera. Marine Ecology Progress Series 50, 107-115.

Sherrard, K.M. \& LaBarbera, M. 2005. Form and function in juvenile ascidians II. Ontogenetic scaling of volumetric flow rates. Marine Ecology Progress Series 287, 139-148.

Simberloff, D. 2010. Invasive species. In Conservation Biology for All, N.S. Sodhi \& P.R. Ehrlich (eds). Oxford: Oxford University Press, 131-152.

Simberloff, D. 2012. Nature, natives, nativism, and management: Worldviews underlying controversies in invasion biology. Environmental Ethics 34, 5-25.

Simberloff, D. \& Vitule, J.R.S. 2014. A call for an end to calls for the end of invasion biology. Oikos 123, 408-413.

Smith, J.R. \& Murray, S.N. 2005. The effects of experimental bait collection and trampling on a Mytilus californianus mussel bed in southern California. Marine Biology 147, 699-706.

Smith, M.D. \& Knapp, A.K. 2003. Dominant species maintain ecosystem function with non-random species loss. Ecology Letters 6, 509-517.

Soulé, M. 1995. The social siege of nature. In Reinventing Nature? Responses to Postmodern Deconstruction. M. Soulé \& G. Lease (eds). Washington DC, Island Press, 137-170.

Sousa, W.P. 1979. Experimental investigations of disturbance and ecological succession in a rocky intertidal algal community. Ecological Monographs 49, 227-254.

Stachowicz, J.J. \& Hay, M.E. 1999. Reducing predation through chemically mediated camouflage: indirect effects of plant defenses on herbivores. Ecology 80, 495-509.

Steinwascher, K. 1978. Interference and exploitation competition among tadpoles of Rana utricularia. Ecology 59, 1039-1046.

Steneck, R.S., Hacker, S.D. \& Dethier, M.N. 1991. Mechanisms of competitive dominance between crustose coralline algae: an herbivore-mediated competitive reversal. Ecology 72, 938-950.

Stephens, P.A. \& Sutherland, W.J. 1999. Consequences of the Allee effect for behaviour, ecology and conservation. Trends in Ecology \& Evolution 14, 401-405.

Stephenson, T.A. \& Stephenson, A. 1972. Life Between Tidemarks on Rocky Shores. San Francisco: W.H. Freeman and Company.

Stuart, V. \& Klumpp, D.W. 1984. Evidence for food-resource partitioning by kelp-bed filter feeders. Marine Ecology Progress Series 16, 27-37.

Symondson, W.O.C., Sunderland, K.D. \& Greenstone, M.H. 2002. Can generalist predators be effective biocontrol agents? Annual Review of Entomology 47, 561-594.

Tapia, F.J. \& Pineda, J. 2007. Stage-specific distribution of barnacle larvae in nearshore waters: potential for limited dispersal and high mortality rates. Marine Ecology Progress Series 342, 177-190. 
Teske, P.R. 2014. Connectivity in solitary ascidians: is a 24-h propagule duration sufficient to maintain largescale genetic homogeneity? Marine Biology 161, 2681-2687.

Teske, P.R., Rius, M., McQuaid, C.D., Styan, C.A., Piggott, M.P., Benhissoune, S., Fuentes-Grünewald, C., Walls, K., Page, M., Attard, C.R.M., Cooke, G.M., McClusky, C.F., Banks, S.C., Barker, N.P. \& Beheregaray, L.B. 2011. "Nested" cryptic diversity in a widespread marine ecosystem engineer: a challenge for detecting biological invasions. BMC Evolutionary Biology 11, 176.

Teske, P.R., Sandoval-Castillo, J., Sasaki, M. \& Beheregaray, L.B. 2015. Invasion success of a habitat-forming marine invertebrate is limited by lower-than-expected dispersal ability. Marine Ecology Progress Series 536, 221-227.

Teske, P.R., Sandoval-Castillo, J., van Sebille, E., Waters, J. \& Beheregaray, L.B. 2016. Oceanography promotes self-recruitment in a planktonic larval disperser. Scientific Reports 6, 34205.

Teske, P.R., Sandoval-Castillo, J., Waters, J.M. \& Beheregaray, L.B. 2014. Can novel genetic analyses help to identify low-dispersal marine invasive species? Ecology and Evolution 4, 2848-2866.

Thorson, G. 1950. Reproductive and larval ecology of marine bottom invertebrates. Biological Reviews 25, $1-45$.

Tilman, D. 1994. Competition and biodiversity in spatially structured habitats. Ecology 75, 2-16.

Toonen, R.J. \& Pawlik, J.R. 1994. Foundations of gregariousness. Nature 370, 511-512.

Toonen, R.J. \& Pawlik, J.R. 1996. Settlement of the tube worm Hydroides dianthus (Polychaeta: Serpulidae): cues for gregarious settlement. Marine Biology 126, 725-733.

Troost, K., Kamermans, P. \& Wolff, W.J. 2008. Larviphagy in native bivalves and an introduced oyster. Journal of Sea Research 60, 157-163.

Tsuchiya, M. 1983. Mass mortality in a population of the mussel Mytilus edulis L. caused by high temperature on rocky shores. Journal of Experimental Marine Biology and Ecology 66, 101-111.

Tyree, S. 2001. The Ascidians (Sea Squirts). Their Biology, Physiology and Natural Filtration Integration. Rancho Cucamonga: DE Publishing.

Underwood, A.J. 2000. Experimental ecology of rocky intertidal habitats: what are we learning? Journal of Experimental Marine Biology and Ecology 250, 51-76.

Underwood, A.J., Kingsford, M.J. \& Andrew, N.L. 1991. Patterns in shallow subtidal marine assemblages along the coast of New South Wales. Australian Journal of Ecology 16, 231-249.

United Nations 1997. Glossary of Environment Statistics. New York.

Vallejo-Marín, M. \& Hiscock, S.J. 2016. Hybridization and hybrid speciation under global change. New Phytologist 211, 1170-1187.

van de Koppel, J., Rietkerk, M., Dankers, N. \& Herman, P.M.J. 2005. Scale-dependent feedback and regular spatial patterns in young mussel beds. American Naturalist 165, E66-E77.

Van Driel, C.D. \& Steyl, C.D. 1978. A quantitative similarity analysis of fauna associated with growth forms of red bait (Pyura stolonifera) in Algoa Bay. In Proceedings of the First Interdisciplinary Conference on Marine and Freshwater Research in Southern Africa, 5-10 July 1976, University of Port Elizabeth, Summerstrand Campus, Port Elizabeth, South Africa. South African National Committee for Oceanographic Research.

Van Name, W.G. 1945. The North and South American ascidians. Bulletin of the American Museum of Natural History 84, 1-476.

Varner, G. 1990. Biological functions and biological interests. Southern Journal of Philosophy 17, 251-270.

Varner, G. 1998. In Nature's Interest? Interest, Animal Rights and Environmental Ethics. Oxford: Oxford Univeristy Press.

Veliz, D., Duchesne, P., Bourget, E. \& Bernatchez, L. 2006. Genetic evidence for kin aggregation in the intertidal acorn barnacle (Semibalanus balanoides). Molecular Ecology 15, 4193-4202.

Vieira, E.A., Duarte, L.F.L. \& Dias, G.M. 2012. How the timing of predation affects composition and diversity of species in a marine sessile community? Journal of Experimental Marine Biology and Ecology 412, 126-133.

von der Meden, C.E.O., Porri, F., McQuaid, C.D., Faulkner, K. \& Robey, J. 2010. Fine-scale ontogenetic shifts in settlement behaviour of mussels: changing responses to biofilm and conspecific settler presence in Mytilus galloprovincialis and Perna perna. Marine Ecology Progress Series 411, 161-171.

Wieczorek, S.K. \& Todd, C.D. 1997. Inhibition and facilitation of bryozoan and ascidian settlement by natural multi-species biofilms: effects of film age and the roles of active and passive larval attachment. Marine Biology 128, 463-473. 
Wright, A., Pérez-Portela, R. \& Griffiths, C.L. 2016. Determining the correct identity of South African Marthasterias (Echinodermata: Asteroidea). African Journal of Marine Science 38, 443-455.

Wright, J.P. \& Jones, C.G. 2006. The concept of organisms as ecosystem engineers ten years on: Progress, limitations, and challenges. BioScience 56, 203-209.

Yodzis, P. 1989. Introduction to Theoretical Ecology. New York: Harper and Row.

Young, C.M. 1988. Ascidian cannibalism correlates with larval behavior and adult distribution. Journal of Experimental Marine Biology and Ecology 117, 9-26. 


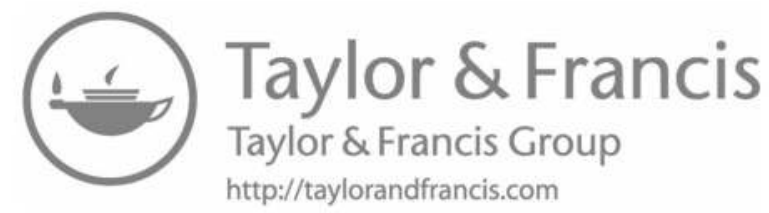




\title{
GIANT CLAMS (BIVALVIA: CARDIIDAE: TRIDACNINAE): A COMPREHENSIVE UPDATE OF SPECIES AND THEIR DISTRIBUTION, CURRENT THREATS AND CONSERVATION STATUS
}

\author{
MEI LIN NEO ${ }^{1,11 *}$, COLETTE C.C. WABNITZ2,3, RICHARD D. BRALEY ${ }^{4}$, \\ GERALD A. HESLINGA ${ }^{5}$, CÉCILE FAUVELOT ${ }^{6}$, SIMON VAN WYNSBERGE ${ }^{7}$, \\ SERGE ANDRÉFOUËT ${ }^{6}$, CHARLES WATERS $^{8}$, AILEEN SHAU-HWAI TAN ${ }^{9}$, \\ EDGARDO D. GOMEZ ${ }^{10}$, MARK J. COSTELLO ${ }^{8} \&$ PETER A. TODD $^{11 *}$
}

${ }^{1}$ St. John's Island National Marine Laboratory, c/o Tropical Marine Science Institute, National University of Singapore, 18 Kent Ridge Road, Singapore 119227, Singapore

${ }^{2}$ The Pacific Community (SPC), BPD5, 98800 Noumea, New Caledonia

${ }^{3}$ Changing Ocean Research Unit, Institute for the Oceans and Fisheries,

The University of British Columbia, AERL, 2202 Main Mall, Vancouver, BC, Canada ${ }^{4}$ Aquasearch, 6-10 Elena Street, Nelly Bay, Magnetic Island, Queensland 4819, Australia

${ }^{5}$ Indo-Pacific Sea Farms, P.O. Box 1206, Kailua-Kona, HI 96745, Hawaii, USA

${ }^{6}$ UMR ENTROPIE Institut de Recherche pour le développement, Université de La Réunion,

CNRS; Centre IRD de Noumea, BPA5, 98848 Noumea Cedex, New Caledonia

${ }^{7} U M R$ ENTROPIE Institut de Recherche pour le développement,

Université de La Réunion, CNRS; Centre IRD de Tahiti,

BP529, 98713 Papeete, Tahiti, French Polynesia

${ }^{8}$ Institute of Marine Science, University of Auckland, P. Bag 92019, Auckland 1142, New Zealand

${ }^{9}$ School of Biological Sciences, Universiti Sains Malaysia, Penang 11800, Malaysia

${ }^{10}$ Marine Science Institute, University of the Philippines, Diliman,

Velasquez Street, Quezon City 1101, Philippines

${ }^{11}$ Experimental Marine Ecology Laboratory, Department of Biological Sciences,

National University of Singapore, 14 Science Drive 4, Singapore 117557, Singapore

*Corresponding authors:

Mei Lin Neo

e-mail: tmsnml@nus.edu.sg

Peter A. Todd

e-mail: dbspat@nus.edu.sg

Giant clams, the largest living bivalves, play important ecological roles in coral reef ecosystems and provide a source of nutrition and income for coastal communities; however, all species are under threat and intervention is required. Here, we re-examine and update their taxonomy, distribution, abundance and conservation status as a contribution to the protection, rebuilding and management of declining populations. Since the first comprehensive review of the Tridacnidae by Rosewater (1965), the taxonomy and phylogeny of giant clams have evolved, with three new species descriptions and rediscoveries since 1982 represented by Tridacna squamosina (formerly known as T. costata), T. noae and T. lorenzi. Giant clams are distributed along shallow coasts and coral reefs from South 
Africa to the Pitcairn Islands $\left(32^{\circ} \mathrm{E}\right.$ to $\left.128^{\circ} \mathrm{W}\right)$, and from southern Japan to Western Australia $\left(24^{\circ} \mathrm{N}\right.$ to $15^{\circ} \mathrm{S}$ ). Geographic distribution of the 12 currently recognized species is not even across the 66 localities we review here. Tridacna maxima and T. squamosa are the most widespread, followed by the intermediate-range species, T. gigas, T. derasa, T. noae, T. crocea and Hippopus hippopus, and the restricted-range species, Tridacna lorenzi, T. mbalavuana, T. squamosina, T. rosewateri and Hippopus porcellanus. The larger species, Tridacna gigas and T. derasa are the most endangered, with $>50 \%$ of wild populations either locally extinct or severely depleted. The smaller and boring species, such as T. maxima and T. crocea, remain relatively abundant despite ongoing fishing activities. Population density also varies across localities. Areas with the lowest densities generally correspond with evidence of high historical exploitation intensity, while areas with the highest densities tend to be within marine reserves, remote from human populations or have low historical fishing pressures. Exploitation continues to be the main threat and conservation challenge for giant clams. Harvesting for subsistence use or local sale remains an important artisanal fishery in many localities; however, increased commercial demand as well as advances in fishing, transport and storage practices, are in large part responsible for the ongoing loss of wild populations. Habitat loss and a suite of other anthropogenic stressors, including climate change, are potentially accelerating stock depletions. Despite these challenges, global efforts to protect giant clams have gained momentum. CITES Appendix II listings and IUCN conservation categories have raised awareness of the threats to giant clams and have contributed to stemming their decline. The continued development of mariculture techniques may also help improve stock numbers and lend populations additional resilience. However, more effective implementation of conservation measures and enforcement of national and international regulations are needed. It is clear that active management is necessary to prevent the extinction of giant clam species as they continue to face threats associated with human behaviours.

\section{Introduction}

Giant clams ('tridacnines', of the subfamily Tridacninae) are the largest and most conspicuous sessile molluscs on coral reefs, where their presence can be traced back to possibly the Upper Cretaceous (Keen 1969), and from the late Eocene and Oligocene (Oppenheim 1901, Cox 1941, Harzhauser et al. 2008). These highly specialized bivalves have the ability to both filter feed and photosynthesize via symbionts (zooxanthellae, Symbiodinium spp.) living within their mantle tissues (Yonge 1936, 1982, Fankboner 1971, Fitt 1988). All species of giant clams are considerably larger than most other bivalves, from the smallest species, Tridacna crocea, that measures up to $15 \mathrm{~cm}$, to the largest, $T$. gigas, that can grow to over $1 \mathrm{~m}$ long and weigh over $300 \mathrm{~kg}$ (Rosewater 1965). Tridacnines are effective ecosystem engineers that play numerous ecological roles on coral reefs (Neo et al. 2015a). For example, the high tissue biomass of giant clams makes them attractive to a wide range of predators (Perron et al. 1985, Alcazar 1986, Cumming 1988, Heslinga et al. 1990, Govan 1992), while opportunistic feeders exploit their expelled zooxanthellae, gametes and faeces (Ricard \& Salvat 1977, Maboloc \& Mingoa-Licuanan 2011). Tridacnine shells provide extensive surfaces for epibiont colonization (Vicentuan-Cabaitan et al. 2014), and their large mantle cavities host a diversity of reef fish, as well as commensal and parasitic organisms (Rosewater 1965, Bruce 2000). Collectively, giant clams can increase topographic relief of coral reefs (Cabaitan et al. 2008), act as reservoirs of zooxanthellae (DeBoer et al. 2012), and potentially counteract eutrophication via water filtering (Klumpp \& Griffiths 1994). Finally, dense populations of tridacnines produce large quantities of calcium carbonate shell material that may eventually become incorporated into the reef framework (Gilbert et al. 2006a). Given the wide range of ecological contributions giant clams make to coral reefs, they are unique among reef organisms and their conservation yields benefits beyond the preservation of a single taxon.

Giant clams have been utilized by humans for millennia. Human artefacts (at least 2500 years old) made from their shells, such as adzes and engraved shell discs, have featured strongly in 
numerous excavation finds in the Middle East, Italy and Japan (Reese 1988, Asato 1991, Reese \& Sease 1993). In modern times, tridacnine shells have been used to make terrazzo/terasa tiles (Brown \& Muskanofola 1985, Juinio et al. 1989), domestic tools (Hviding 1993, Richards \& Roga 2004), beads and other craft ware (Lai 2015, Gomez 2015a). Tridacnines are also commercially valuable in the aquarium trade (Brown \& Muskanofola 1985, Teitelbaum \& Friedman 2008) and the flesh is a popular food (Hviding 1993). During the past few decades, the increase in demand for their adductor muscles as an ingredient in Asian gastronomy, and their shells for carving and for the preparation of seed used in the freshwater pearl-farming industry have made giant clams highly valuable (Dawson \& Philipson 1989, Shang et al. 1991, Heslinga 1995, Kinch \& Teitelbaum 2010, Hambrey Consulting 2013, Larson 2016). This has resulted in a period of intensive exploitation by locals and illegal harvesting by foreign fishers, and has been responsible for rapid stock reductions across the Indo-Pacific (Bryan \& McConnell 1976, Pearson 1977, Gomez 2015a, Larson 2016). Increased fishing pressure can result in tridacnine densities below levels required for successful reproduction and recruitment (Lucas 1988, Munro 1992), thereby impeding natural recovery of stocks and the possible collapse of entire populations (Neo et al. 2013a).

Early concerns over the heavy exploitation of giant clams and their threatened status throughout the Indo-Pacific fuelled scientific interest, particularly in the development of mariculture techniques to assist in their conservation (Jameson 1976, Yamaguchi 1977, Beckvar 1981, Heslinga et al. 1984, 1990, Crawford et al. 1987, Heslinga \& Fitt 1987, Braley et al. 1988), symbiosis as a biological phenomenon (Fitt \& Trench 1981, Trench et al. 1981, Norton et al. 1992, Maruyama \& Heslinga 1997), physiology (Yonge 1936, Morton 1978) and biochemistry (Baldo \& Uhlenbruck 1975, Reid et al. 1984). Yamaguchi (1977) was the first to mention the lack of conservation measures to curb extensive exploitation of giant clams. The International Union for Conservation of Nature (IUCN) first engaged with this issue in 'The IUCN Invertebrate Red Data Book' (Wells et al. 1983), which highlighted the various human pressures on tridacnine populations, and how each species was threatened worldwide. The IUCN Red List of Threatened Species then re-assessed nine species in 1996 and listed them as either 'Least Concern' or 'Vulnerable'. The IUCN status of tridacnine species, however, is in need of updating. The first giant clams to be listed in Appendix II of the Convention on International Trade in Endangered Species of Wild Fauna and Flora (CITES) were Tridacna derasa and T. gigas in 1983. The other species, Hippopus hippopus, H. porcellanus, Tridacna squamosa, T. maxima and T. crocea, were listed in 1985-regulating international trade in any of their parts (shells, tissues, alive or dead). In 1988, CITES re-examined whether trade levels could pose problems for wild populations (Wells 1997). Key literature reviews on giant clams reiterated their threatened status, and highlighted the role that mariculture could play in sustainable exploitation and restocking (Munro \& Heslinga 1983, Heslinga \& Fitt 1987, Munro 1989, Lucas 1994, 1997, Braley 1996, Bell et al. 2005). Based on results from earlier hatchery programmes in the Pacific Islands (Heslinga et al. 1990), Australia (Braley 1992) and the Philippines (Calumpong \& SolisDuran 1993), these studies emphasized domestication as an aid to giant clam conservation.

Despite the efforts to promote the sustainable exploitation and conservation of giant clams outlined above, Lucas (2014, p. R184) highlighted that "giant clams species are extinct or in danger of extinction in many parts of their distributions". Othman et al. (2010) published the most recent review on the status of giant clams worldwide but, while cited widely, it requires significant updates. Moreover, there remains a paucity of published data on tridacnines from lesser-known regions such as East Asia, the Indian Ocean and East Africa. Here we synthesize the recent taxonomy of giant clams and their global distribution, collate the information available on their exploitation and the laws that protect them, review the impacts that harvesting rates may have on wild populations, and summarize the outcomes of past and ongoing mariculture programmes. We also re-examine the current conservation approaches for all tridacnine species and identify key knowledge gaps for future research. 


\section{Taxonomy}

Giant clams are morphologically derived cardiids (true cockles) which have evolved an obligate symbiotic association with photosynthetic dinoflagellate algae (Schneider 1998, Morton 2000). The current, and most widely accepted, scientific classification of giant clams is: Order Venerida Gray, 1854, Family Cardiidae Lamarck, 1809, Subfamily Tridacninae Lamarck, 1819, and two genera: Hippopus Lamarck, 1799 and Tridacna Bruguière, 1797 (Rosewater 1965, 1982, Schneider 1998, Schneider \& Ó Foighil 1999). Giant clams, however, were formerly regarded as a distinct family, Tridacnidae Lamarck, 1819, within the Order Venerida. Lamarck (1809) was the first to recognize a close relationship between cardiids and giant clams. Yonge (1936) and Stasek (1962), using anatomical characters, similarly proposed that the ancestry of Tridacna, was close to that of Cerastoderma Poli, 1795, which is the least derived of the Lymnocardiinae Stoliczka, 1870. The results of successive cladistic analyses of shell, anatomical, sperm ultrastructural, and molecular characters have revealed that giant clams indeed form a monophyletic group within the Cardiidae (Schneider 1992, 1998, Braley \& Healy 1998, Maruyama et al. 1998, Schneider \& Ó Foighil 1999, Keys \& Healy 2000, Herrera et al. 2015). Tree topologies by Schneider $(1992,1998)$ also suggested sister taxa relationships between the azooxanthellate Lymnocardiinae (Cerastoderma) and the zooxanthellate Tridacninae (Hippopus and Tridacna) and Fragiinae Stewart, 1930 (Fragum Röding, 1798), although Herrera et al. (2015) cast some doubts over this possibility as only a single representative and a single genetic marker (18S rRNA) were used for the analysis. In general, evidence over the last two decades supports earlier proposals that giant clams should be considered a subfamily (Tridacninae) of the Cardiidae, but the sister taxa relationships within cardiids still need to be resolved. It must be noted that others have argued to maintain Tridacnidae as a full family, based mainly on its highly distinct morphology (Huber 2010, Huber \& Eschner 2011, Penny \& Willan 2014).

The number of described tridacnine species continues to expand with some new additions since Rosewater's (1965) seminal paper listing Hippopus hippopus, Tridacna gigas, T. derasa, T. squamosa, T. maxima and T. crocea. In 1982, a new Hippopus species, H. porcellanus, was described from the Sulu Archipelago, Philippines (Rosewater 1982) and in 1991, a new Tridacna species, T. rosewateri was described from the Saya de Malha Bank, Indian Ocean (Sirenko \& Scarlato 1991). Lucas et al. (1990, 1991) also discovered and described a new species 'Tridacna tevoroa' in 1991, apparently unaware of an earlier description of the same species as Tridacna mbalavuana. T. mbalavuana was first described from fossils on Viti Levu, Fiji (Ladd 1934), and was already commonly known to the locals as 'tevoro', the devil clam. After closer examination of their morphological characters the two species are now considered synonymous, with T. tevoroa the junior synonym of T. mbalavuana (Newman \& Gomez 2000). In the late 2000s, Richter et al. (2008) discovered a new Red Sea species 'Tridacna costata'. A subsequent morphological comparison of T. squamosina of Sturany (1899) and T. costata of Richter et al. (2008) suggest, however, that the two species are identical (Huber \& Eschner 2011). Hence, T. squamosina is now recognized as the lectotype and T. costata as a junior synonym.

Finally, the recent use of molecular tools has led to the rediscovery of a cryptic species: Tridacna noae (Su et al. 2014, Borsa et al. 2015a). Tridacna noae was previously relegated as one of the many variants of T. maxima (McLean 1947, Rosewater 1965) owing to morphological similarity. However, McLean (1947) pointed out that T. noae had well-spaced scutes on the upper (i.e. ventral) shell compared to the close-set scutes of T. maxima. Moreover, in living specimens T. noae can also generally be distinguished from T. maxima through the presence of discrete teardrop-shaped markings on the mantle, typically bounded by white margins (Wabnitz \& Fauvelot 2014). Furthermore, genetic analyses showed that T. noae and T. maxima are distinct (Su et al. 2014). Another newly described species, 'Tridacna ningaloo' from Western Australia (Penny \& Willan 2014), is similar in appearance to T. maxima and T. noae, and Borsa et al. (2015a) established that T. noae and T. ningaloo have no apparent genetic or morphological differences (except, possibly, in mantle patterns). Hence, 
T. ningaloo should be regarded as a junior synonym of T. noae. Lastly, the most recent species to be described, based purely on morphology, is T. lorenzi. Tridacna lorenzi is so far recorded only from the outlying territories of Mauritius (Monsecour 2016). It is morphologically similar to T. maxima and $T$. rosewateri, but can still be distinguished from both species by its triangular primary ribs and more globose shell (Monsecour 2016). However, considering the high variation typically observed in tridacnine shell morphology, future studies should include genetic comparisons when delimiting Tridacninae species.

Both genera, Hippopus and Tridacna, were thought to have evolved independently from a nowextinct Byssocardium-like ancestor in the early Miocene. Hippopus is considered more primitive as it has retained more Byssocardium-like ancestral characters than Tridacna (Stasek 1962, Schneider 1998). Hippopus and Tridacna are reciprocally monophyletic sister taxa (Benzie \& Williams 1998, Herrera et al. 2015). Tridacna is subdivided into three subgenera: Tridacna (comprising T. gigas), Persikima Iredale, 1937 (comprising Tridacna derasa and T. mbalavuana), and Chametrachea Herrmannsen, 1846 (comprising Tridacna squamosa, T. maxima, T. crocea, T. squamosina and T. noae) (Rosewater 1965, 1982, Lucas et al. 1991, Benzie \& Williams 1998, Schneider \& Ó Foighil 1999, Nuryanto et al. 2007, Richter et al. 2008, Lizano \& Santos 2014, Su et al. 2014, Borsa et al. 2015b). While the phylogenetic relationships among the subgenera remain equivocal, most tree topologies suggest that T. gigas is an intermediate between Chametrachea and Persikima on the basis of morphological characters and genetic markers (Benzie \& Williams 1998, Herrera et al. 2015). In addition, the relationship within Chametrachea for Tridacna squamosa, T. maxima and T. crocea has been inconsistent across studies using different genetic markers (Benzie \& Williams 1998, Maruyama et al. 1998, Schneider \& Ó Foighil 1999, Nuryanto et al. 2007, Herrera et al. 2015, see Table 1 for details). However, the latest molecular analysis (using $16 \mathrm{~S}$ gene sequences), including all five known species from the subgenus Chametrachea, place Tridacna squamosa and T. crocea as sister taxa with a high degree of statistical confidence (Huelsken et al. 2013, DeBoer et al. 2014, Lizano \& Santos 2014, Su et al. 2014, Borsa et al. 2015b). These ongoing updates and debates illustrate the need for more robust datasets and analyses (Herrera et al. 2015).

Table 1 Chronology of giant clam taxonomic changes

\begin{tabular}{|c|c|c|c|c|}
\hline Year & Description & Character traits & $\begin{array}{l}\text { Taxonomic } \\
\text { level }\end{array}$ & Reference \\
\hline 1809 & $\begin{array}{l}\text { Recognized a close relationship between cardiids and } \\
\text { giant clams }\end{array}$ & Morphology & Familial & Lamarck (1809) \\
\hline 1921 & Classified giant clams as family Tridacnidae & Morphology & Familial & Hedley (1921) \\
\hline 1936 & $\begin{array}{l}\text { Proposed that the ancestry of Tridacna was close to } \\
\text { that of Cerastoderma (family Cardiidae) }\end{array}$ & Morphology & Familial & Yonge (1936) \\
\hline 1947 & Classified giant clams as family Tridacnidae & Morphology & Familial & McLean (1947) \\
\hline 1962 & $\begin{array}{l}\text { Proposed that the ancestry of Tridacna was close to } \\
\text { that of Cerastoderma (family Cardiidae) }\end{array}$ & Morphology & Familial & Stasek (1962) \\
\hline 1965 & Classified giant clams as family Tridacnidae & Morphology & Familial & Rosewater (1965) \\
\hline 1969 & Proposed superfamily Tridacnoidea & Morphology & Familial & Keen (1969) \\
\hline 1982 & New species described, Hippopus porcellanus & Morphology & Species & Rosewater (1982) \\
\hline 1991 & New species described, Tridacna tevoroa & Morphology & Species & Lucas et al. (1991) \\
\hline 1991 & New species described, Tridacna rosewateri & Morphology & Species & $\begin{array}{l}\text { Sirenko \& } \\
\text { Scarlato (1991) }\end{array}$ \\
\hline 1992 & Giant clams formed a monophyletic group within & Morphology & Familial & Schneider (1992) \\
\hline
\end{tabular}


Table 1 (Continued) Chronology of giant clam taxonomic changes

\begin{tabular}{|c|c|c|c|c|}
\hline Year & Description & Character traits & $\begin{array}{l}\text { Taxonomic } \\
\text { level }\end{array}$ & Reference \\
\hline 1998 & $\begin{array}{l}\text { Giant clams formed a monophyletic group within } \\
\text { family Cardiidae }\end{array}$ & Morphology & Familial & Schneider (1998) \\
\hline 1998 & $\begin{array}{l}\text { Proposed relationship within subgenus } \\
\text { Chametrachea: (Tridacna squamosa }(\text { T. crocea }+ \\
\text { T. maxima)), (T. maxima }(T . \text { crocea }+ \\
\text { T. squamosa) }),(\text { T. crocea }(T . \text { squamosa }+ \\
\text { T. maxima) })\end{array}$ & $\begin{array}{l}\text { Genetic markers } \\
(18 \mathrm{~S})\end{array}$ & Genus & $\begin{array}{l}\text { Maruyama et al. } \\
\text { (1998) }\end{array}$ \\
\hline 1998 & $\begin{array}{l}\text { Proposed relationship within subgenus } \\
\text { Chametrachea: (Tridacna squamosa (T. crocea }+ \\
\text { T. maxima)) }\end{array}$ & $\begin{array}{l}\text { Allozyme } \\
\text { variations }\end{array}$ & Genus & $\begin{array}{l}\text { Benzie \& } \\
\text { Williams (1998) }\end{array}$ \\
\hline 1999 & $\begin{array}{l}\text { Proposed relationship within subgenus } \\
\text { Chametrachea: (Tridacna maxima (T. crocea }+ \\
\text { T. squamosa)) }\end{array}$ & $\begin{array}{l}\text { Genetic markers } \\
\text { (partial 16S) }\end{array}$ & Genus & $\begin{array}{l}\text { Schneider \& } \\
\text { Ó Foighil (1999) }\end{array}$ \\
\hline 2000 & $\begin{array}{l}\text { Giant clams formed a monophyletic group within } \\
\text { family Cardiidae }\end{array}$ & $\begin{array}{l}\text { Sperm } \\
\text { ultrastructure }\end{array}$ & Familial & $\begin{array}{l}\text { Keys \& Healy } \\
(2000)\end{array}$ \\
\hline \multirow[t]{2}{*}{2000} & $\begin{array}{l}\text { Proposed that Tridacna rosewateri belong to } \\
\text { subgenus Chametrachea }\end{array}$ & Morphology & Genus & $\begin{array}{l}\text { Newman \& } \\
\text { Gomez (2000) }\end{array}$ \\
\hline & Tridacna tevoroa a junior synonym of $T$. mbalavuana & Morphology & Species & \\
\hline 2007 & $\begin{array}{l}\text { Discovered a 'Tridacna maxima' lookalike in Japan } \\
\text { waters but did not identify species }\end{array}$ & Morphology & Species & $\begin{array}{l}\text { Kubo \& Iwai } \\
\text { (2007) }\end{array}$ \\
\hline 2007 & $\begin{array}{l}\text { Proposed relationship within subgenus } \\
\text { Chametrachea: (Tridacna maxima (T. crocea }+ \\
\text { T. squamosa)) }\end{array}$ & $\begin{array}{l}\text { Genetic markers } \\
\text { (CO1) }\end{array}$ & Genus & $\begin{array}{l}\text { Nuryanto et al. } \\
\text { (2007) }\end{array}$ \\
\hline 2008 & New species described, Tridacna costata & $\begin{array}{l}\text { Morphology, } \\
\text { Genetic markers } \\
(16 S)\end{array}$ & Species & $\begin{array}{l}\text { Richter et al. } \\
\text { (2008) }\end{array}$ \\
\hline 2011 & Tridacna costata a junior synonym of $T$. squamosina & Morphology & Species & $\begin{array}{l}\text { Huber \& Eschner } \\
\text { (2011) }\end{array}$ \\
\hline 2014 & Rediscovered species, Tridacna noae & $\begin{array}{l}\text { Morphology, } \\
\text { Genetic markers } \\
(\mathrm{CO} 1,16 \mathrm{~S}, 18 \mathrm{~S})\end{array}$ & Species & Su et al. (2014) \\
\hline 2014 & $\begin{array}{l}\text { Proposed that Tridacna noae and T. squamosina } \\
\text { belong to subgenus Chametrachea }\end{array}$ & $\begin{array}{l}\text { Genetic markers } \\
(\mathrm{CO} 1,16 \mathrm{~S})\end{array}$ & Species & $\begin{array}{l}\text { Lizano \& Santos } \\
\text { (2014) }\end{array}$ \\
\hline 2014 & New species described, Tridacna ningaloo & $\begin{array}{l}\text { Morphology, } \\
\text { Genetic markers } \\
(\mathrm{CO} 1,16 \mathrm{~S})\end{array}$ & Species & $\begin{array}{l}\text { Penny \& Willan } \\
(2014)\end{array}$ \\
\hline 2015 & Tridacna ningaloo a junior synonym of $T$. noae & $\begin{array}{l}\text { Genetic markers } \\
\text { (CO1) }\end{array}$ & Species & $\begin{array}{l}\text { Borsa et al. } \\
\text { (2015a) }\end{array}$ \\
\hline \multirow[t]{2}{*}{2015} & $\begin{array}{l}\text { Giant clams formed a monophyletic group within } \\
\text { family Cardiidae }\end{array}$ & $\begin{array}{c}\text { Genetic markers } \\
(\mathrm{H} 3,16 \mathrm{~S}, 28 \mathrm{~S})\end{array}$ & Familial & $\begin{array}{l}\text { Herrera et al. } \\
(2015)\end{array}$ \\
\hline & $\begin{array}{l}\text { Proposed relationship within subgenus } \\
\text { Chametrachea: (Tridacna maxima (T. crocea }+ \\
\text { T. squamosa)) }\end{array}$ & & Genus & \\
\hline 2016 & New species described, Tridacna lorenzi & Morphology & Species & Monsecour (2016) \\
\hline
\end{tabular}




\section{Distribution of giant clam species}

Since Rosewater's (1965) paper, only a few publications have attempted to consolidate global distribution data for giant clams. Early surveys by Dawson (1986) and Munro (1989) list the presence or absence of tridacnine species in 18 and 32 countries, respectively (Table 2), while others provide broad geographic descriptions for individual species (e.g. Wells 1996, Lucas 1997). Othman et al. (2010) compiled the geographic ranges and densities for ten species in 15 countries, but did not discuss the status of tridacnines in certain ranges (i.e. Red Sea, East Africa and the Indian Ocean). Van Wynsberge et al. (2016) extensively reviewed the status of Tridacna maxima using 59 studies that reported density estimates for 172 sites across 26 countries in the Indo-Pacific and Red Sea. The present study has identified 66 localities (defined as either countries or regions) globally where giant clams are present or have been present (Table 2, see Supplementary Tables A1 \& A2). Tridacnines generally inhabit shallow coastal waters and coral reefs from South Africa to the Pitcairn Islands $\left(32^{\circ} \mathrm{E}\right.$ to $\left.128^{\circ} \mathrm{W}\right)$, and from southern Japan to Western Australia $\left(24^{\circ} \mathrm{N}\right.$ to $\left.15^{\circ} \mathrm{S}\right)$. The extent of the geographic range differs among the 12 known species, with the highest diversity (nine species) within the Coral Triangle (Figure 1). The most widespread species, T. maxima and T. squamosa, can be found in almost all of the 66 localities reviewed. These are followed by the species with an intermediate geographic range: T. gigas, T. derasa, T. noae, T. crocea and Hippopus hippopus, while the rare species Tridacna lorenzi, T. mbalavuana, T. squamosina, T. rosewateri and Hippopus porcellanus are each recorded from only one or a few locations.

In most surveyed areas, the density of tridacnine species typically ranges from $10^{-4}$ to $10^{-5}$ individuals per metre squared $\left(\mathrm{m}^{-2}\right)$, equivalent to $1-10 \mathrm{ha}^{-1}$, with occasional exceptions of $>10 \mathrm{~m}^{-2}$ (see Supplementary Table A3). Such exceptions include atolls of the Eastern Tuamotu in French Polynesia that are characterized by natural densities of Tridacna maxima of up to $500 \mathrm{~m}^{-2}$ in the early 2000s (Andréfouët et al. 2005, Gilbert et al. 2006b). Reef Check surveys often report densities of $10^{-3} \mathrm{~m}^{-2}$ to $1 \mathrm{~m}^{-2}\left(10-10,000 \mathrm{ha}^{-1}\right)$ (Reef Check Foundation 2016, see Supplementary Table A4), but these surveys group all Tridacna species together. In general, areas with the lowest densities correspond with evidence of high historical exploitation intensity, whereas areas with the highest densities tend to correspond to marine reserves, remoteness from human populations, or low historical fishing pressures (Table 3, see Supplementary Tables A3 and A4).

The following sections examine the 12 known giant clam species and their characteristics, with a summary of their individual geographic distribution, exploitation and conservation status. Table 4 presents species status, exploitation and conservation efforts (if any) by locality.

Table 2 A comparison of survey information on the global status of giant clam stocks provided by the current and past reviews that have considered all species

\begin{tabular}{llcc}
\hline Study & \multicolumn{1}{c}{ Species list } & $\begin{array}{c}\text { Number of localities } \\
\text { examined }\end{array}$ & $\begin{array}{c}\text { Density } \\
\text { data? }\end{array}$ \\
\hline Dawson (1986) & Hh, Hp, Tg, Td, Ts, Tm (6) & 18 & $\times$ \\
Munro (1989) & Hh, Hp, Tg, Td, Ts, Tm (6) & 32 & $\times$ \\
Wells (1996)_IUCN & Hh, Hp, Tg, Td, Tmb, Ts, Tr, Tm, Tc (9) & 46 & $\times$ \\
Othman et al. (2010) & Hh, Hp, Tg, Td, Tmb, Ts, Tsi, Tr, Tm, Tc (10) & 15 & $\checkmark$ \\
Present study & Hh, Hp, Tg, Td, Tmb, Ts, Tsi, Tm, Tno, Tr, Tlz, Tc (12) & 66 & $\checkmark$ \\
\hline
\end{tabular}

Note: Abbreviations for species: Tg-Tridacna gigas, Td—T. derasa, Tmb-T. mbalavuana (previously T. tevoroa), Ts-T. squamosa, Tsi-T. squamosina (previously T. costata), $\mathrm{Tr}-T$. rosewateri, Tlz-T. lorenzi, $\mathrm{Tm}-T$. maxima, Tno-T. noae, Tc-T. crocea, $\mathrm{Hh}-$ Hippopus hippopus, $\mathrm{Hp}-H$. porcellanus. A specific review on Tridacna maxima is provided by Van Wynsberge et al. (2016). 


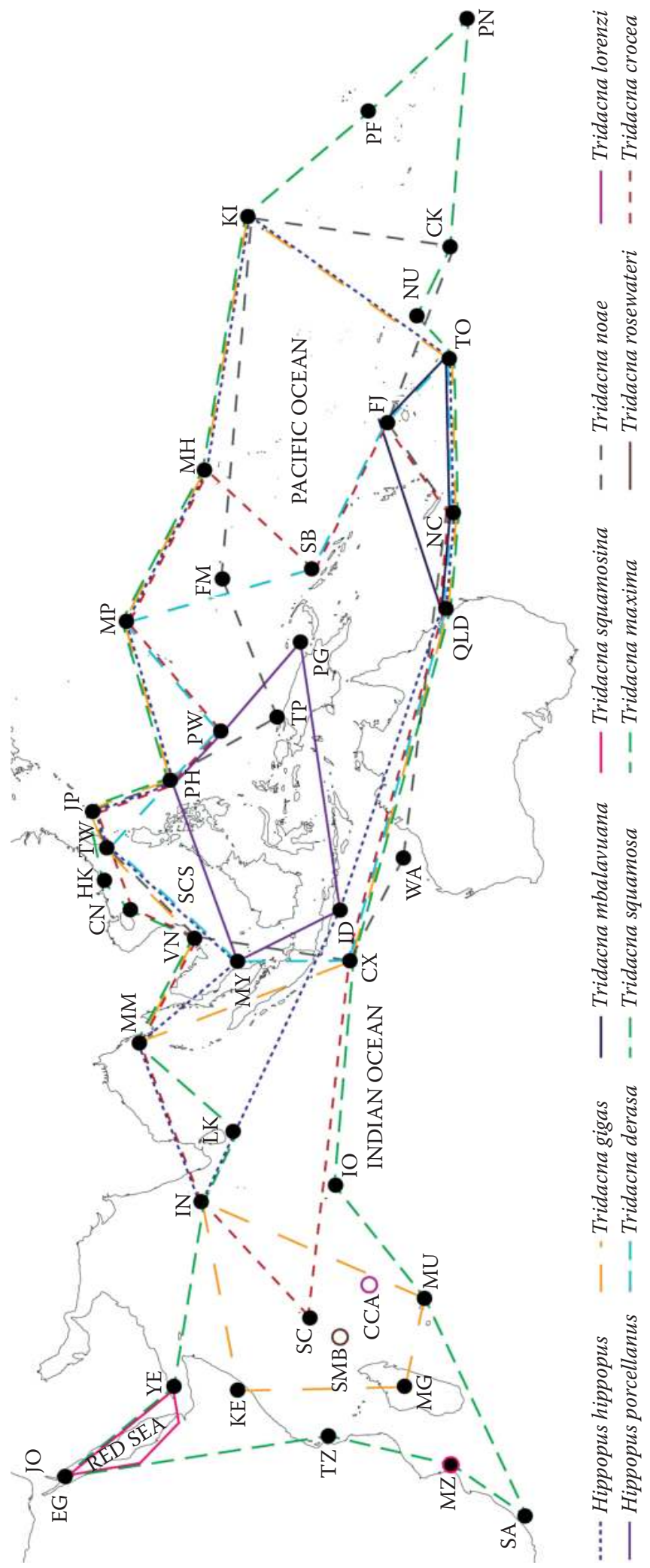

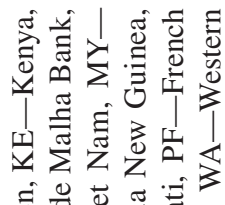

बี

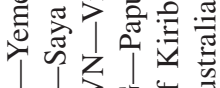

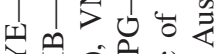

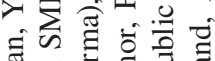

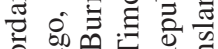

하요

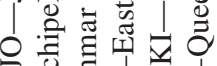

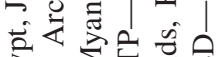

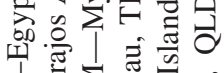

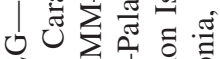

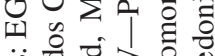

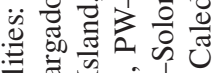

ठํำ

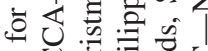

क क

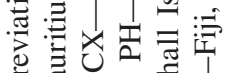

究

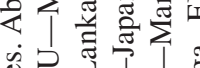

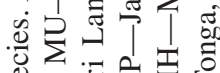

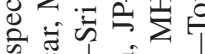

๑)

要

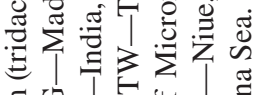

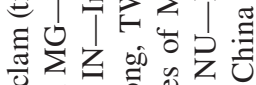

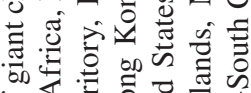

눙

क 言

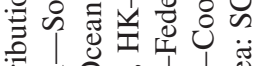

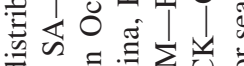

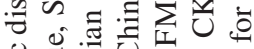

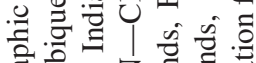

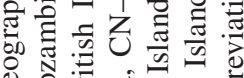

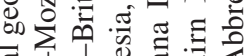

可丁 1

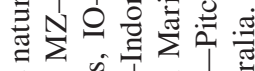

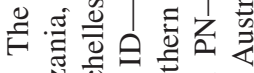

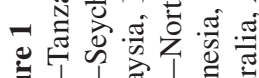

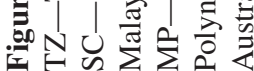


Table 3 An overview of global records of population density, presenting the highest and lowest densities recorded for all 12 tridacnine species

\begin{tabular}{|c|c|c|c|c|c|}
\hline Species & Record & Locality & Year & Density $\left(\mathrm{ha}^{-1}\right)$ & Reference \\
\hline \multirow[t]{2}{*}{$\begin{array}{l}\text { Hippopus } \\
\text { hippopus }\end{array}$} & Lowest & $\begin{array}{l}\text { Tarawa Atoll, Central Gilbert } \\
\text { Islands Group, Republic of } \\
\text { Kiribati }\end{array}$ & 1985 & 0.2 & Munro (1988) \\
\hline & Highest & $\begin{array}{l}\text { Helen Reef, Western Caroline } \\
\text { Islands, Palau }\end{array}$ & 1976 & 40.7 & Hirschberger (1980) \\
\hline \multirow[t]{2}{*}{$\begin{array}{l}\text { Hippopus } \\
\text { porcellanus }\end{array}$} & Lowest & $\begin{array}{l}\text { Engineer and Conflict Group } \\
\text { Islands, Papua New Guinea }\end{array}$ & 1996 & 0.3 & Kinch (2001) \\
\hline & Highest & $\begin{array}{l}\text { Tubbataha Reefs, Cagayancillo, } \\
\text { Philippines }\end{array}$ & 2008 & 97.6 & $\begin{array}{l}\text { Dolorosa \& Jontila } \\
\text { (2012) }\end{array}$ \\
\hline \multirow[t]{2}{*}{$\begin{array}{l}\text { Tridacna } \\
\text { gigas }\end{array}$} & Lowest & $\begin{array}{l}\text { Tarawa Atoll, Central Gilbert } \\
\text { Islands Group, Republic of } \\
\text { Kiribati }\end{array}$ & 1985 & 0.2 & Munro (1988) \\
\hline & Highest & $\begin{array}{l}\text { Michaelmas Reef, Great Barrier } \\
\text { Reef, Australia }\end{array}$ & 1978 & 431.9 & $\begin{array}{l}\text { Pearson \& Munro } \\
\text { (1991) }\end{array}$ \\
\hline \multirow[t]{3}{*}{$\begin{array}{c}\text { Tridacna } \\
\text { derasa }\end{array}$} & Lowest & $\begin{array}{l}\text { Milne Bay Province, Papua New } \\
\text { Guinea }\end{array}$ & 2001 & 0.3 & Kinch (2002) \\
\hline & & $\begin{array}{l}\text { North Eastern Lagoon (Poeubo } \\
\text { to Hienghène), New Caledonia }\end{array}$ & 2004 & 0.3 & McKenna et al. (2008) \\
\hline & Highest & $\begin{array}{l}\text { Meara Island, Palawan, } \\
\text { Philippines }\end{array}$ & 2004 & 250 & Gonzales et al. (2014) \\
\hline $\begin{array}{l}\text { Tridacna } \\
\text { mbalavuana }\end{array}$ & Data Deficient & & & & \\
\hline \multirow[t]{2}{*}{$\begin{array}{l}\text { Tridacna } \\
\text { squamosa }\end{array}$} & Lowest & $\begin{array}{l}\text { Helen Reef, Western Caroline } \\
\text { Islands, Palau }\end{array}$ & 1972 & 0.2 & Hester \& Jones (1974) \\
\hline & Highest & $\begin{array}{l}\text { Chiriyatapu, Andaman and } \\
\text { Nicobar Island (S), India }\end{array}$ & $?$ & 10,000 & Ramadoss (1983) \\
\hline \multirow[t]{2}{*}{$\begin{array}{l}\text { Tridacna } \\
\text { squamosina }\end{array}$} & Lowest & Fayrouza, Nuweiba, Egypt & $?$ & 2.9 & Richter et al. (2008) \\
\hline & Highest & Marsa Abu Kalawa, Egypt & $?$ & 62.2 & Richter et al. (2008) \\
\hline $\begin{array}{l}\text { Tridacna } \\
\text { rosewateri }\end{array}$ & Data Deficient & & & & \\
\hline \multirow{2}{*}{$\begin{array}{r}\text { Tridacna } \\
\text { maxima }\end{array}$} & Lowest & Pari Island, Indonesia & 2003 & 0.3 & Eliata et al. (2003) \\
\hline & Highest & $\begin{array}{c}\text { Tatakoto Atoll, Eastern Tuamotu } \\
\text { Archipelago, French Polynesia }\end{array}$ & 2004 & $5.44 \times 10^{6}$ & Gilbert et al. (2005) \\
\hline \multirow[t]{2}{*}{$\begin{array}{l}\text { Tridacna } \\
\text { noae }\end{array}$} & Lowest & $\begin{array}{l}\text { Kavieng lagoonal system, New } \\
\text { Ireland Province, Papua New } \\
\text { Guinea }\end{array}$ & 2015 & 27.3 & Militz et al. (2015) \\
\hline & Highest & $\begin{array}{l}\text { Mandu Mandu, Ningaloo } \\
\text { Marine Park, WA }\end{array}$ & 2014 & 2,800 & Johnson et al. (2016) \\
\hline $\begin{array}{c}\text { Tridacna } \\
\text { lorenzi }\end{array}$ & Data Deficient & & & & \\
\hline \multirow{2}{*}{$\begin{array}{l}\text { Tridacna } \\
\text { crocea }\end{array}$} & Lowest & Mare, New Caledonia & 2010 & 0.2 & Dumas et al. (2011) \\
\hline & Highest & $\begin{array}{l}\text { Cau Island, Con Dao } \\
\text { Archipelago, Viet Nam }\end{array}$ & 2011 & 250,000 & Selin \& Latypov (2011) \\
\hline
\end{tabular}

Note: Densities originally published as number of individuals per metre squared have been converted into number of individuals per hectare $\left(\mathrm{ha}^{-1}\right)$. For more information, please see Supplementary Table A3. 
MEI LIN NEO ET AL.

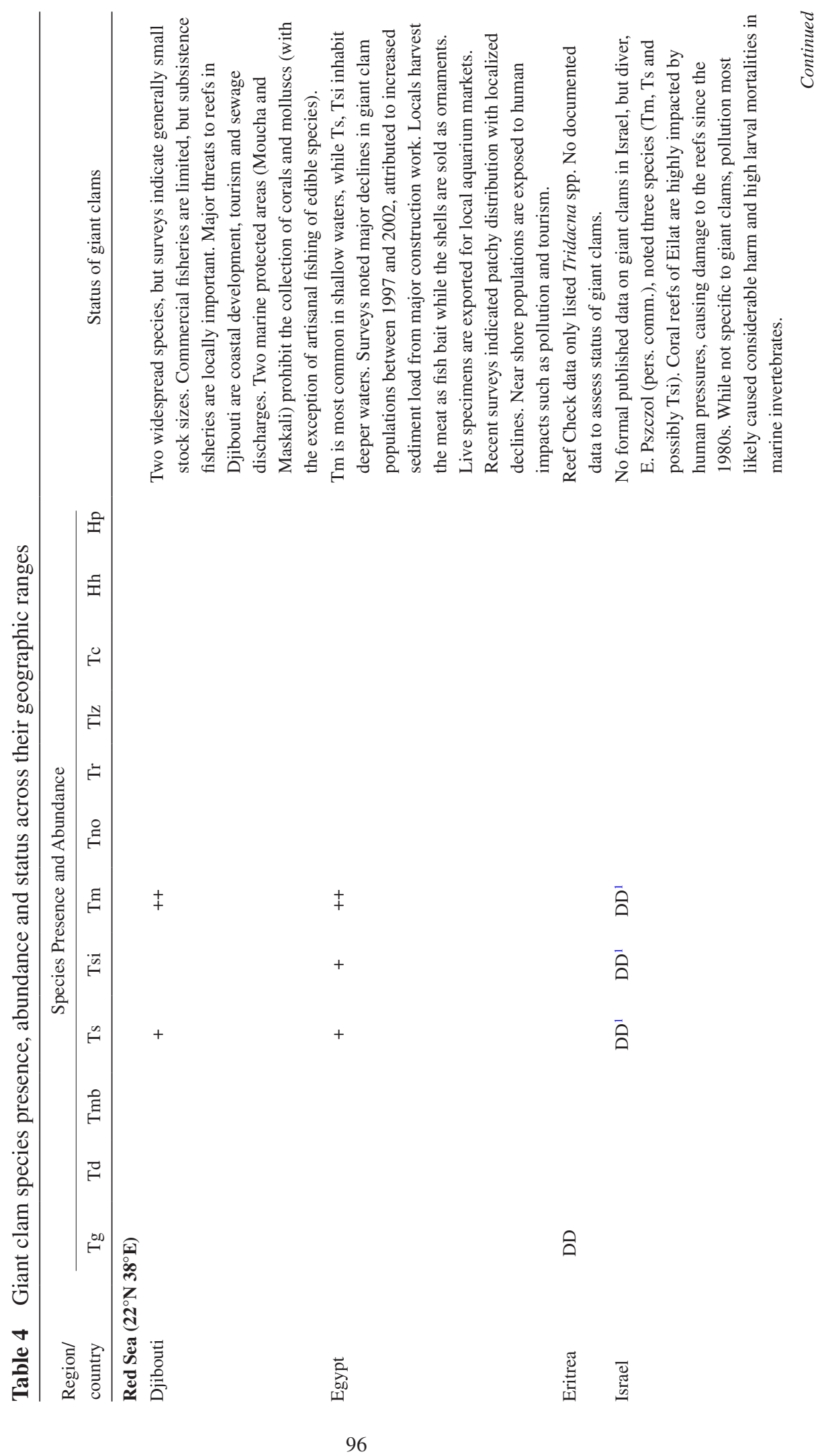


GIANT CLAMS (BIVALVIA: CARDIIDAE: TRIDACNINAE)

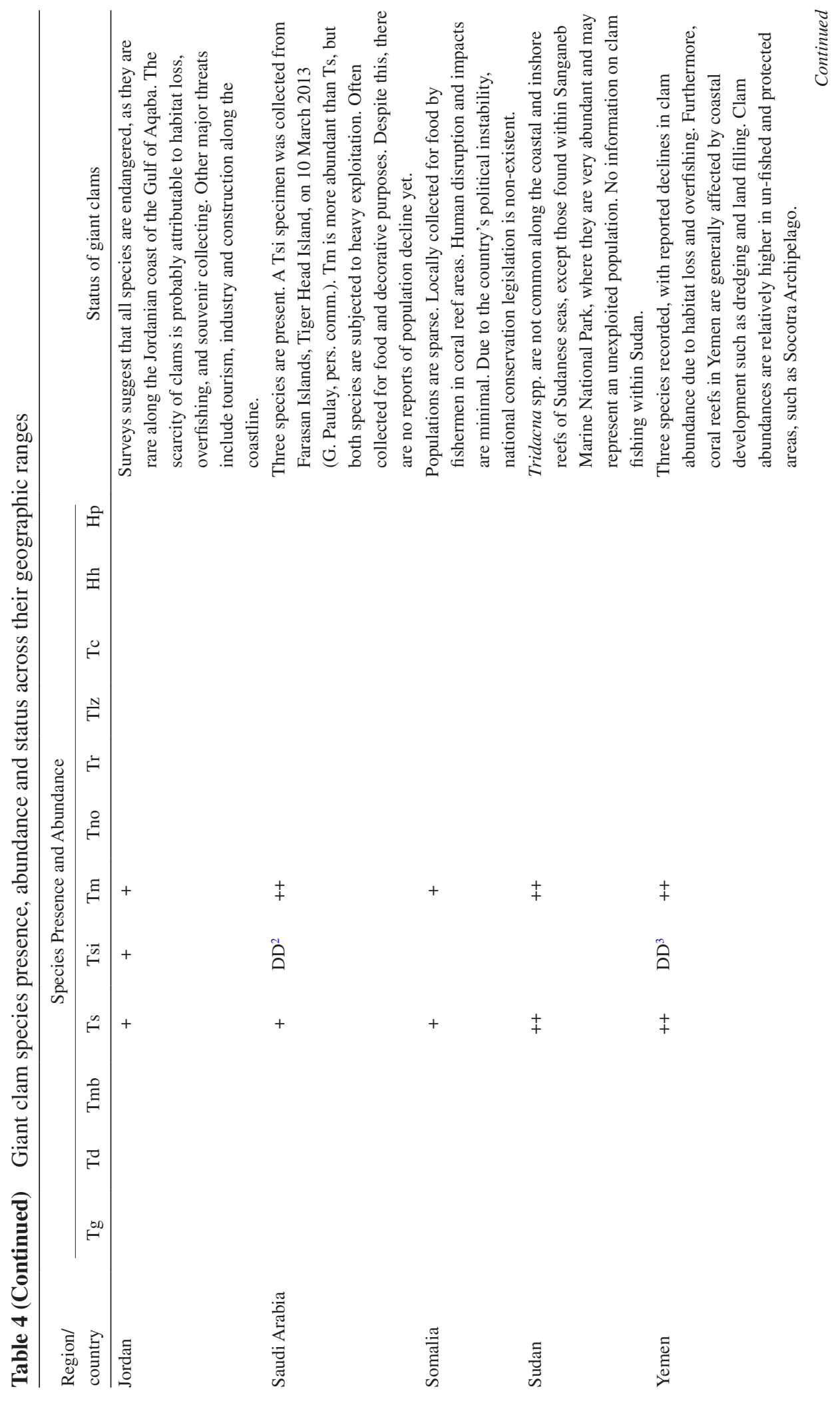


MEI LIN NEO ET AL.

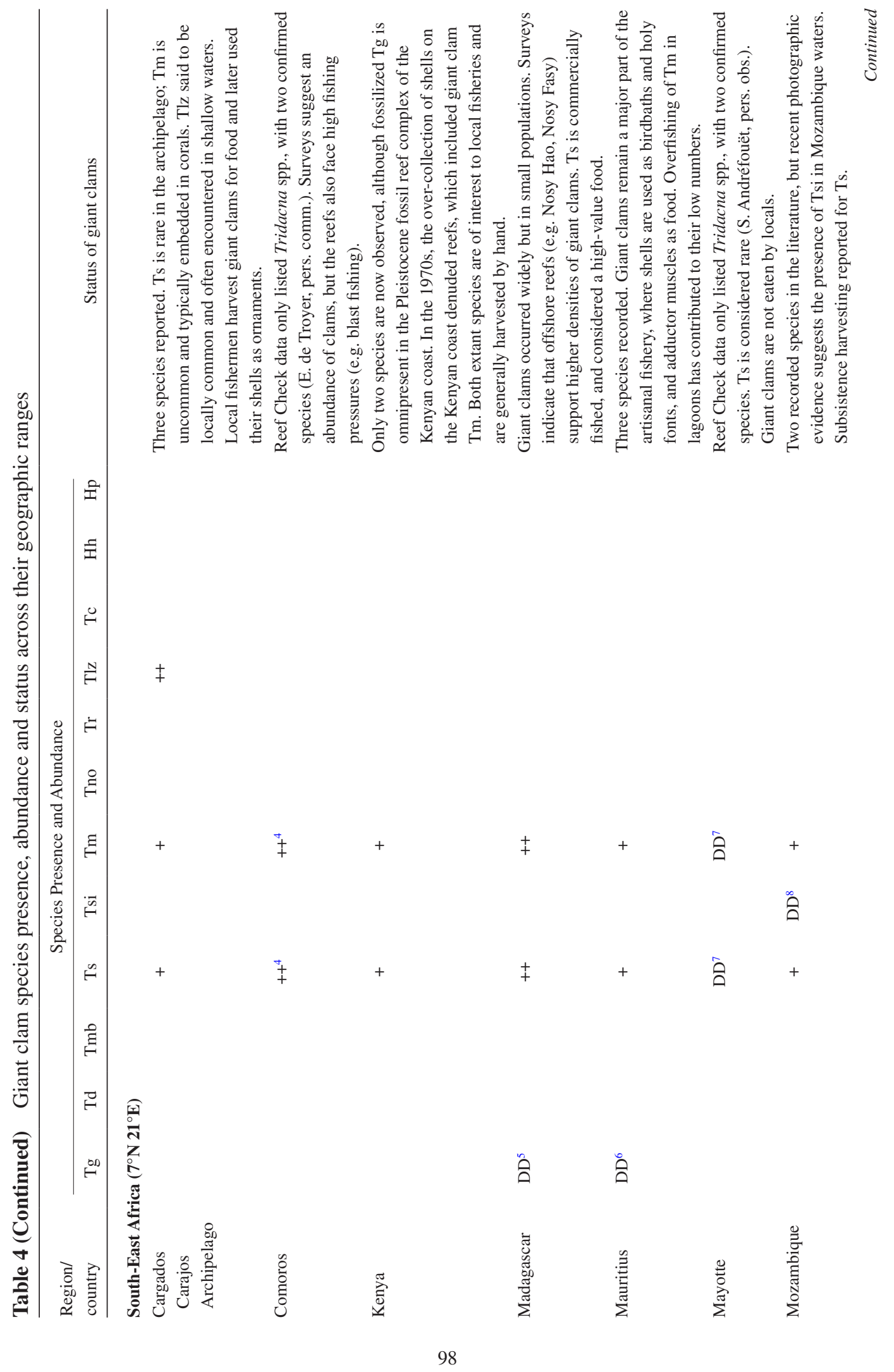




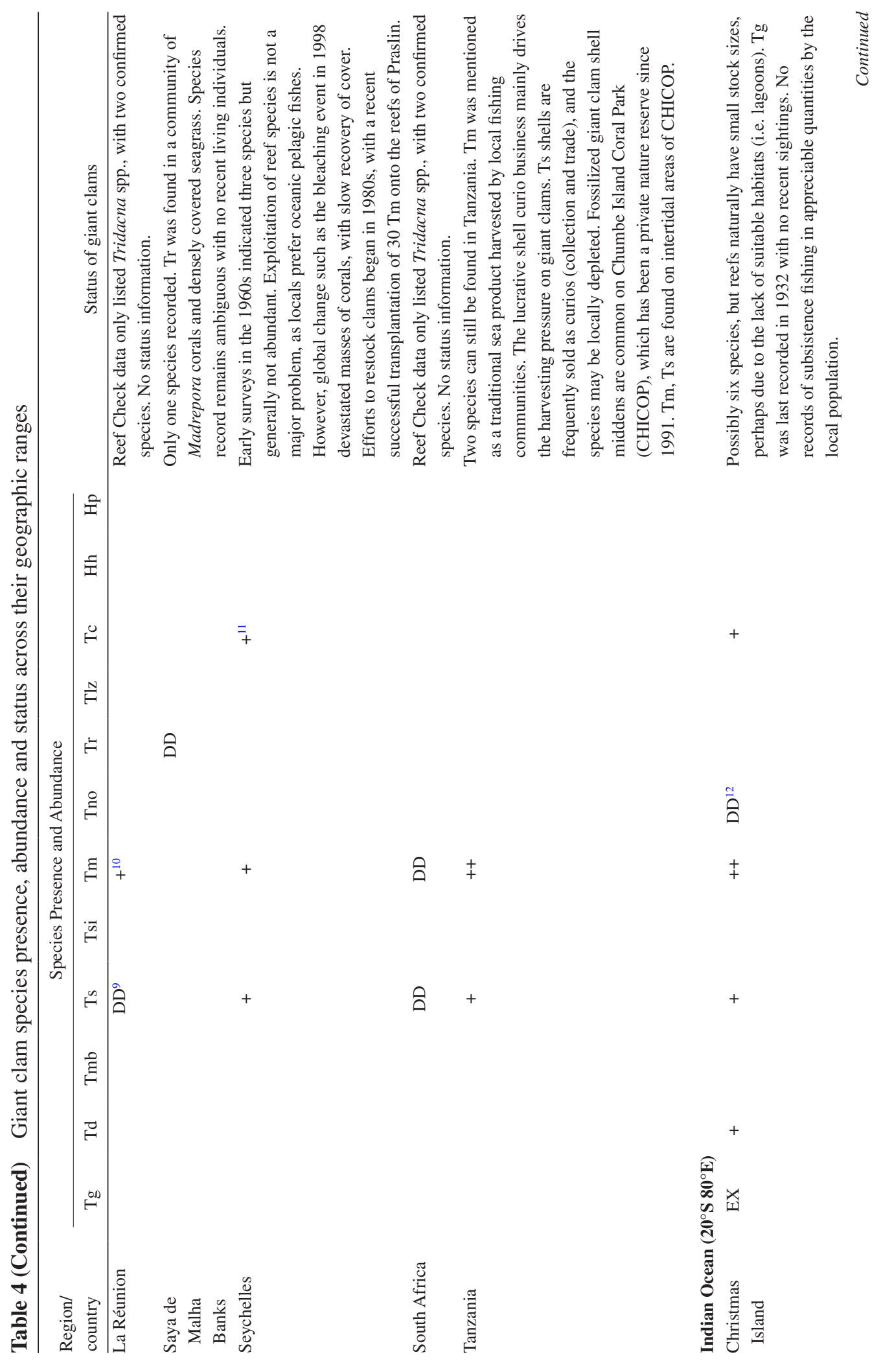




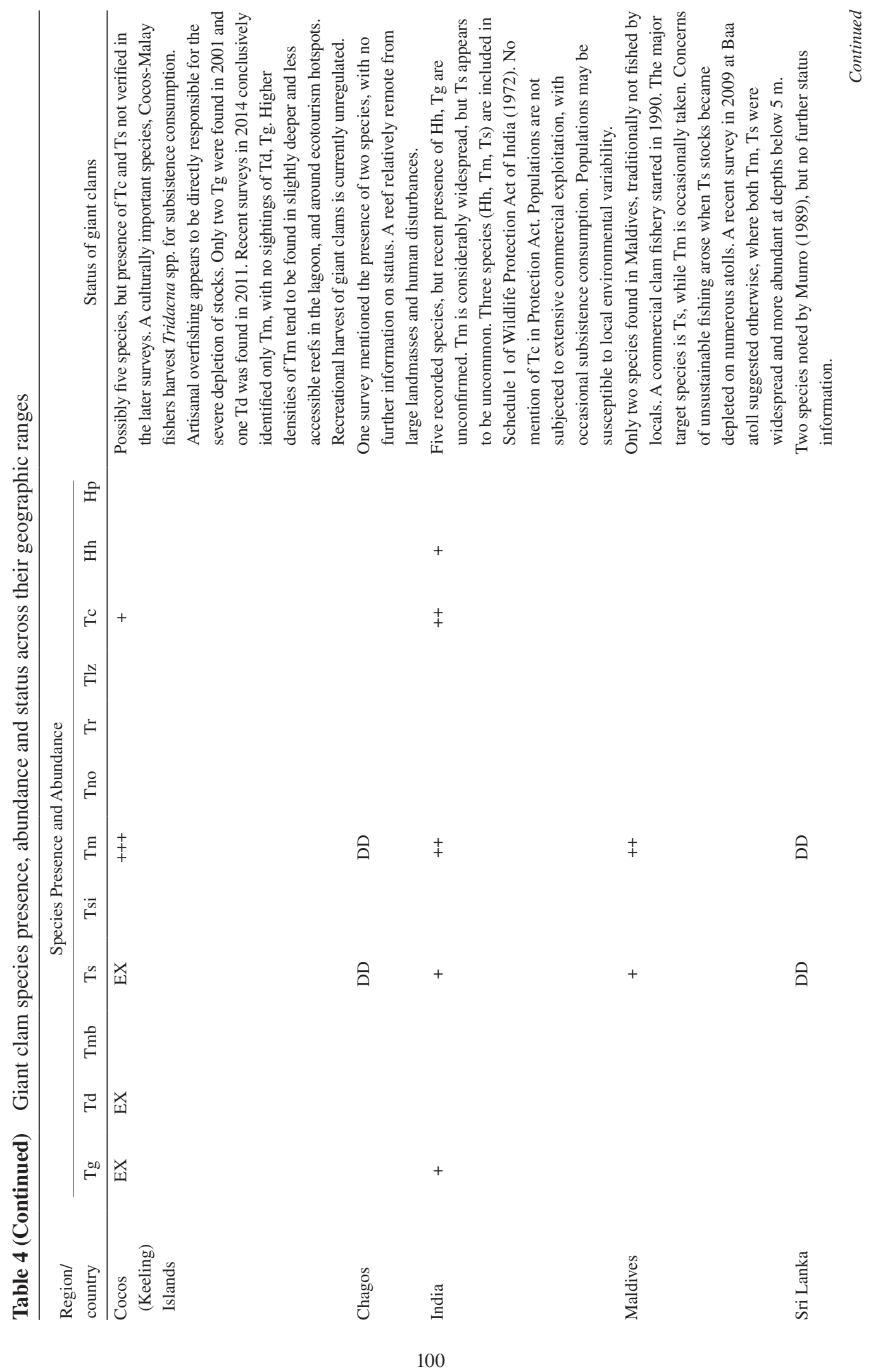




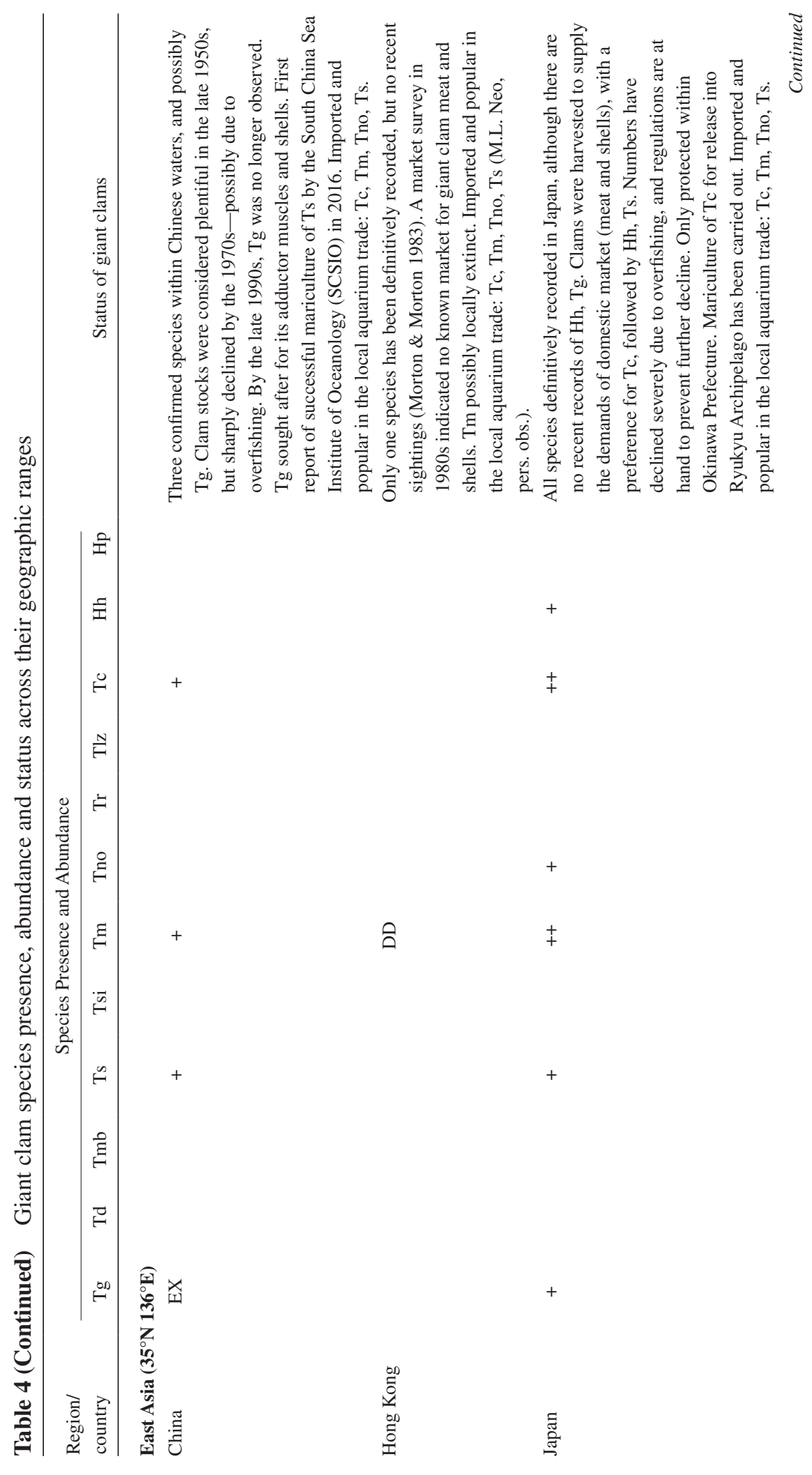




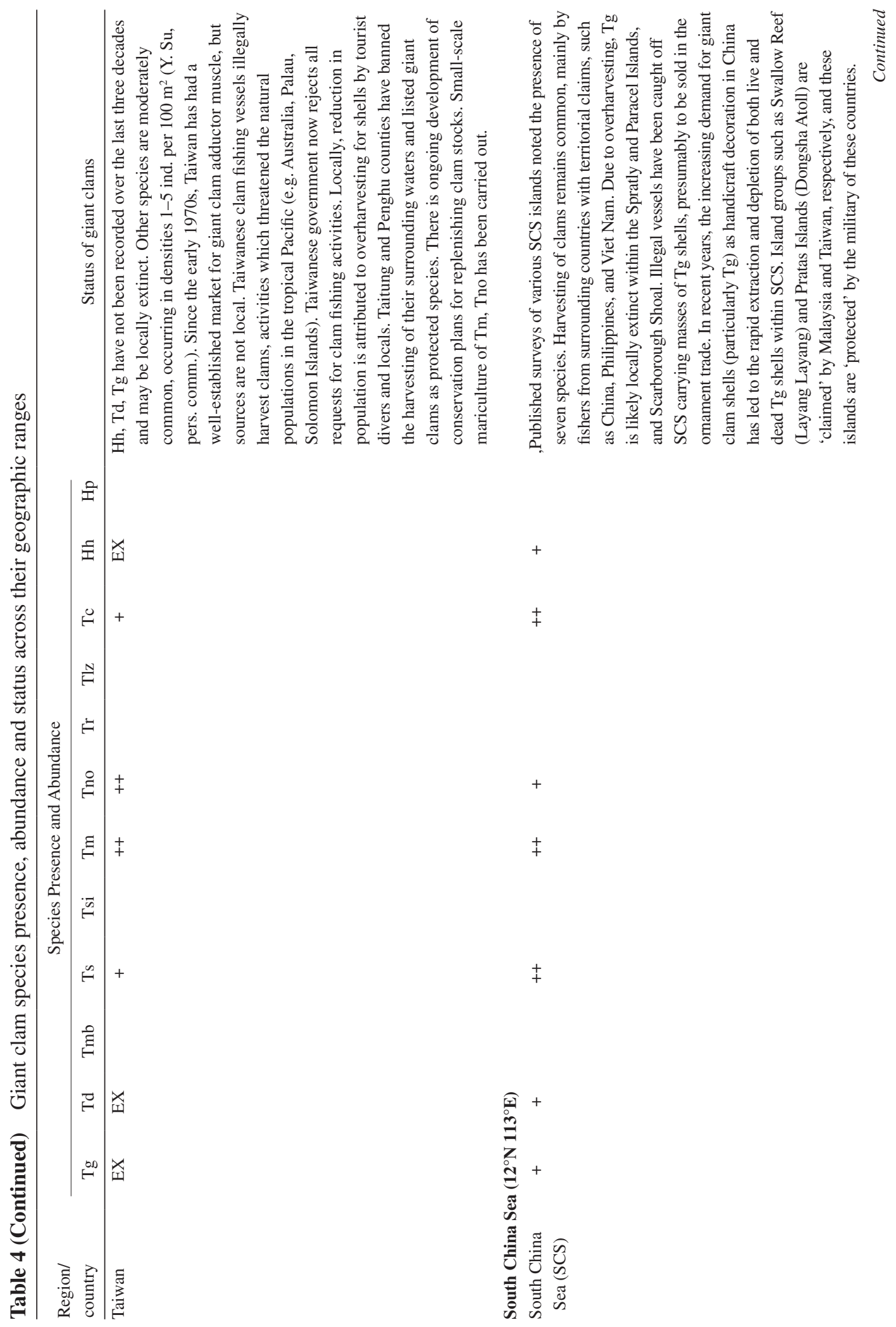


GIANT CLAMS (BIVALVIA: CARDIIDAE: TRIDACNINAE)

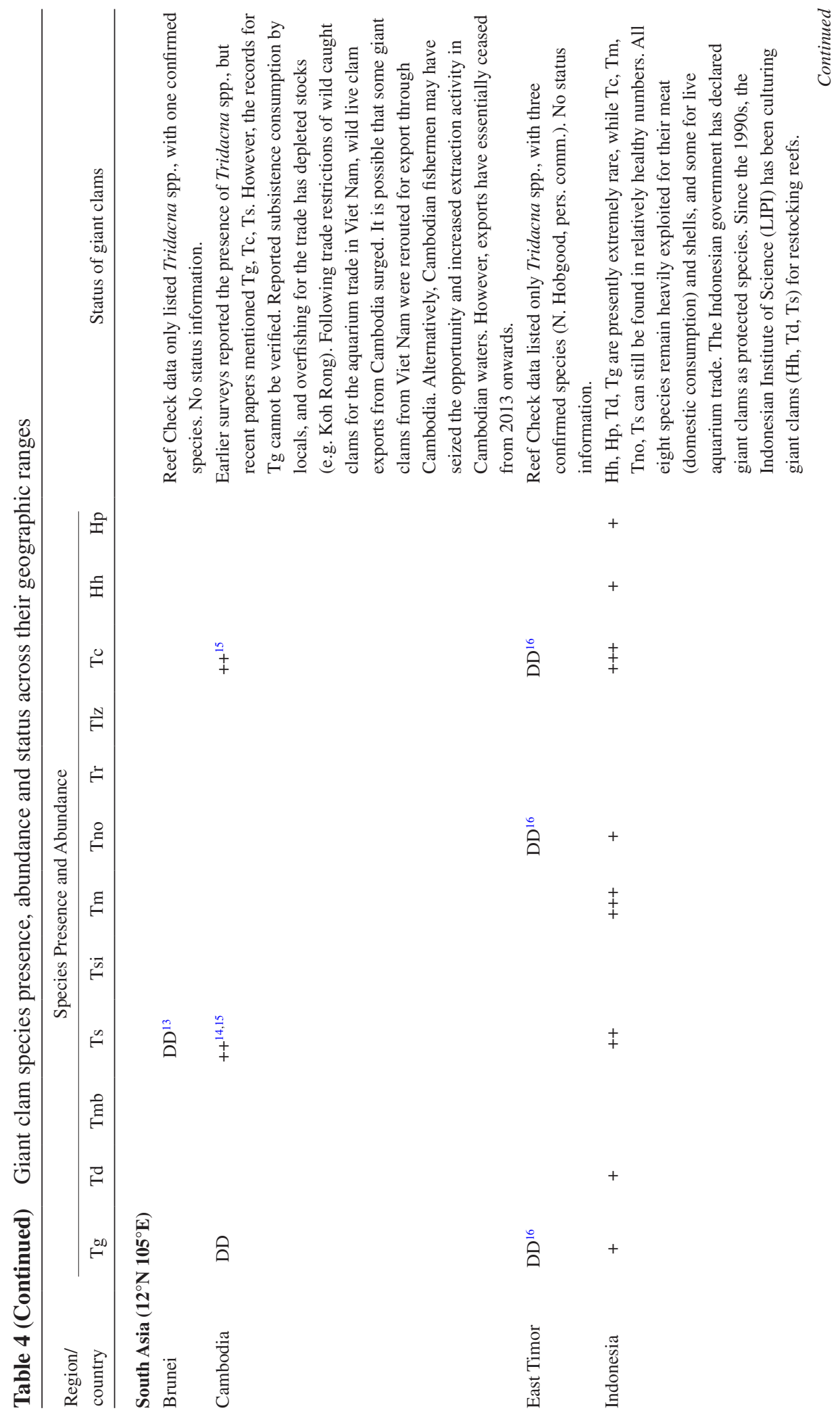


MEI LIN NEO ET AL.

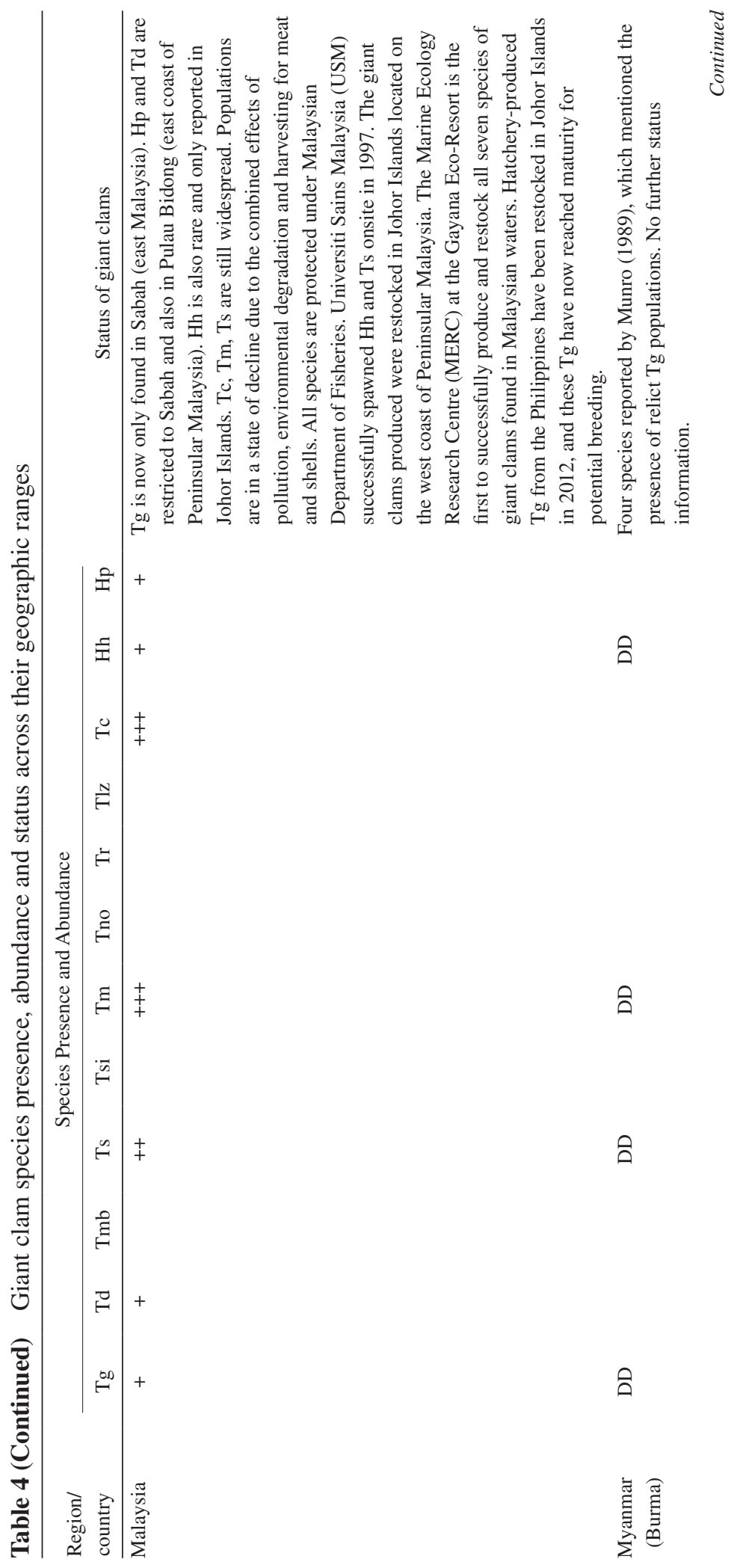


GIANT CLAMS (BIVALVIA: CARDIIDAE: TRIDACNINAE)

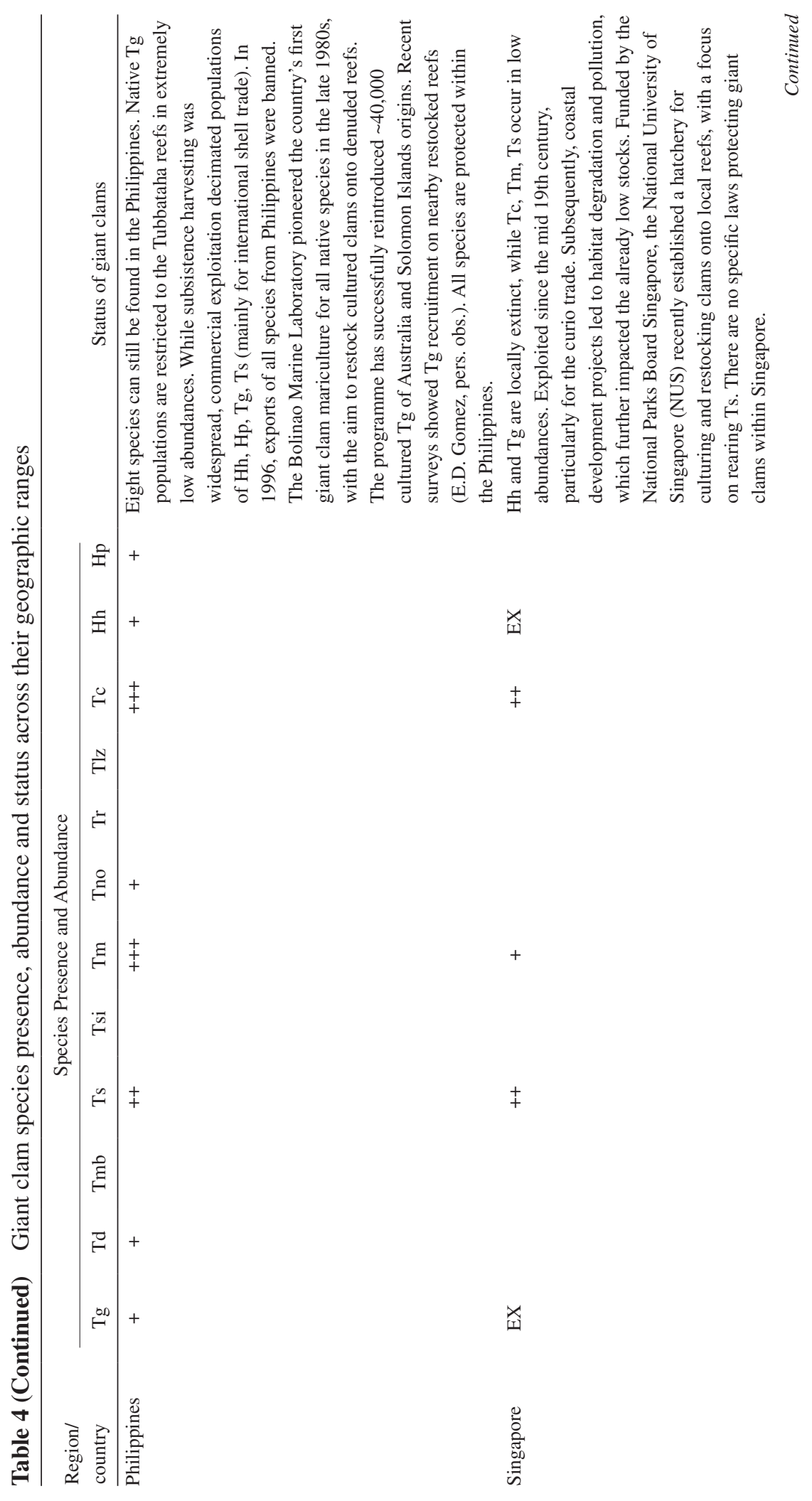




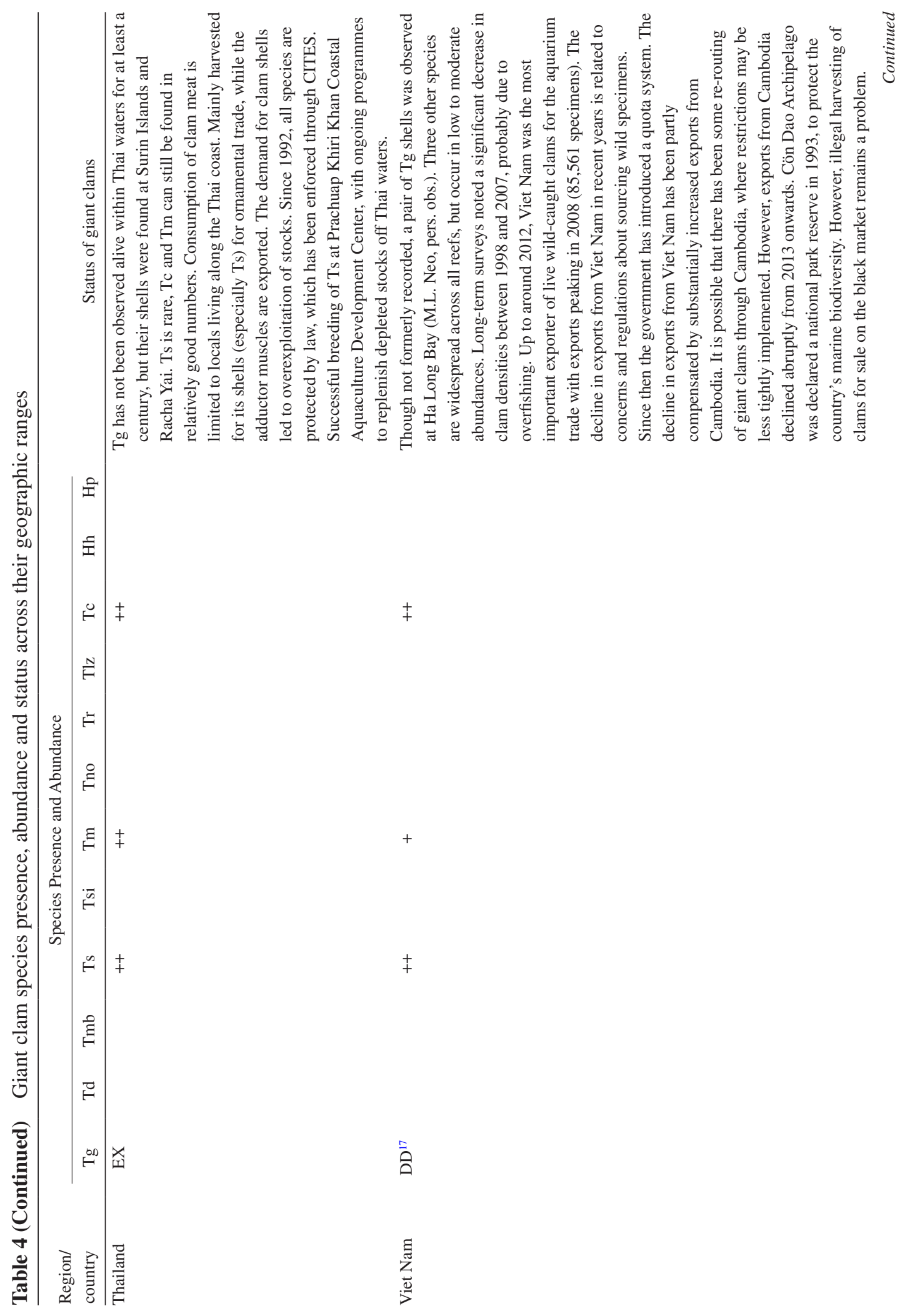


GIANT CLAMS (BIVALVIA: CARDIIDAE: TRIDACNINAE)

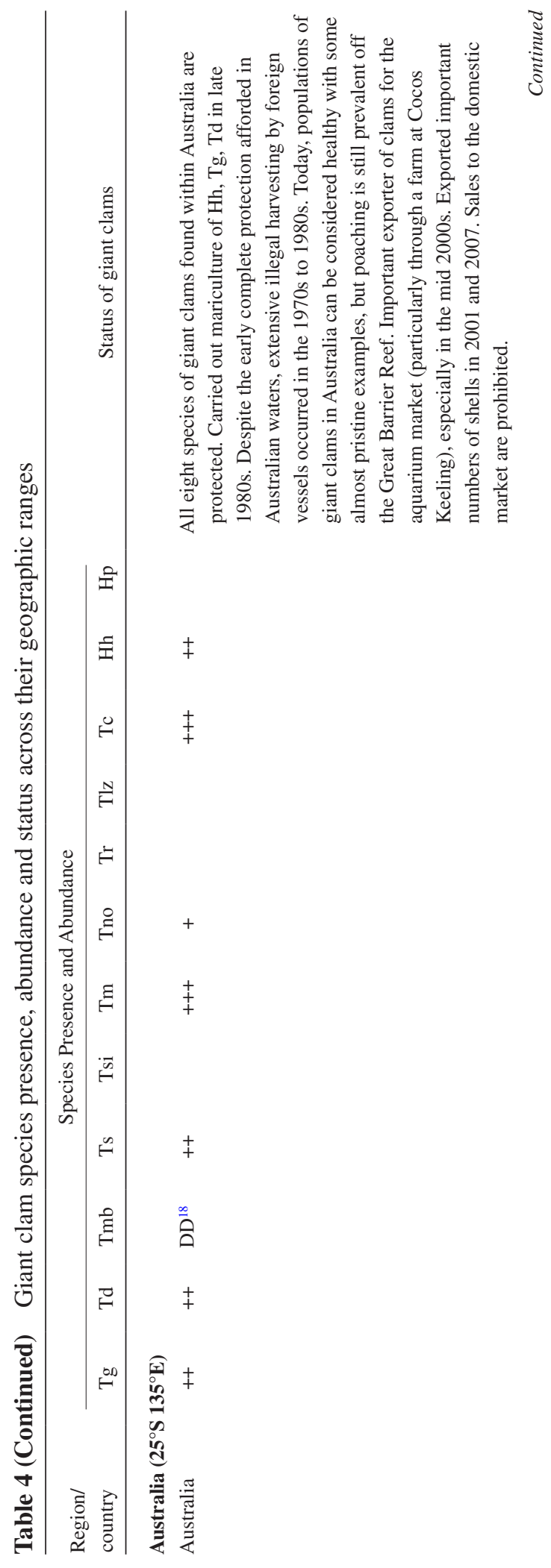




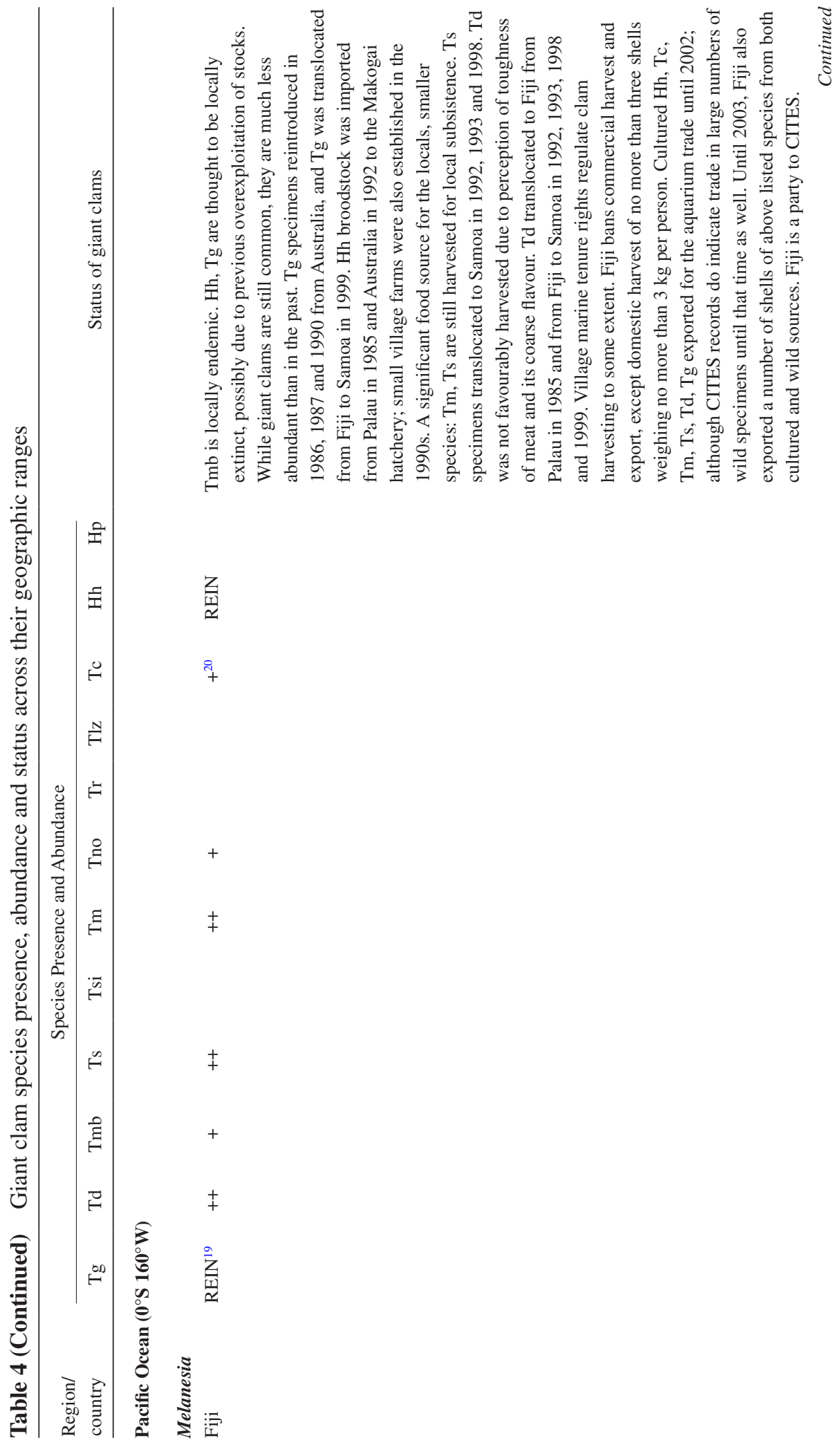




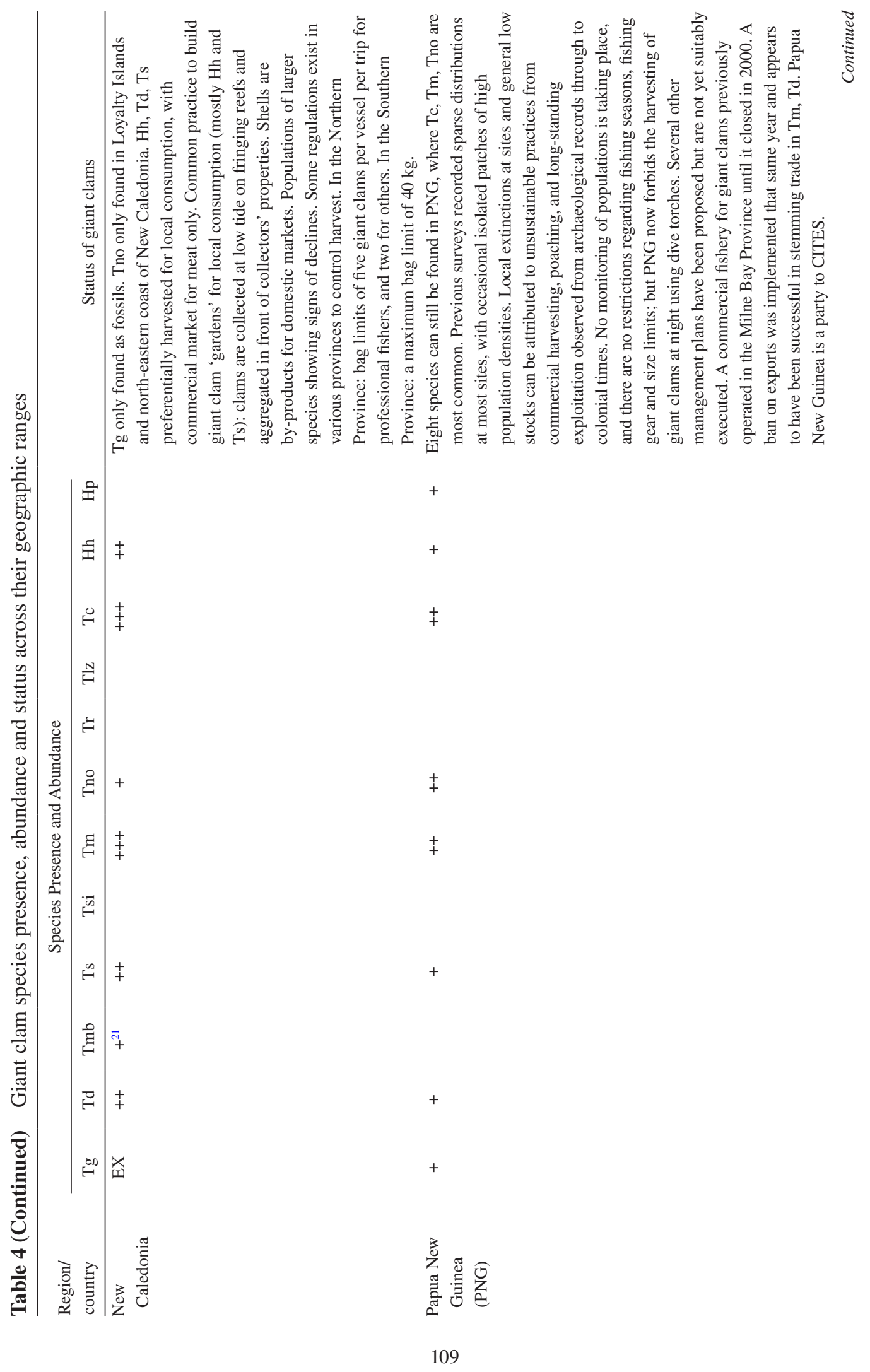




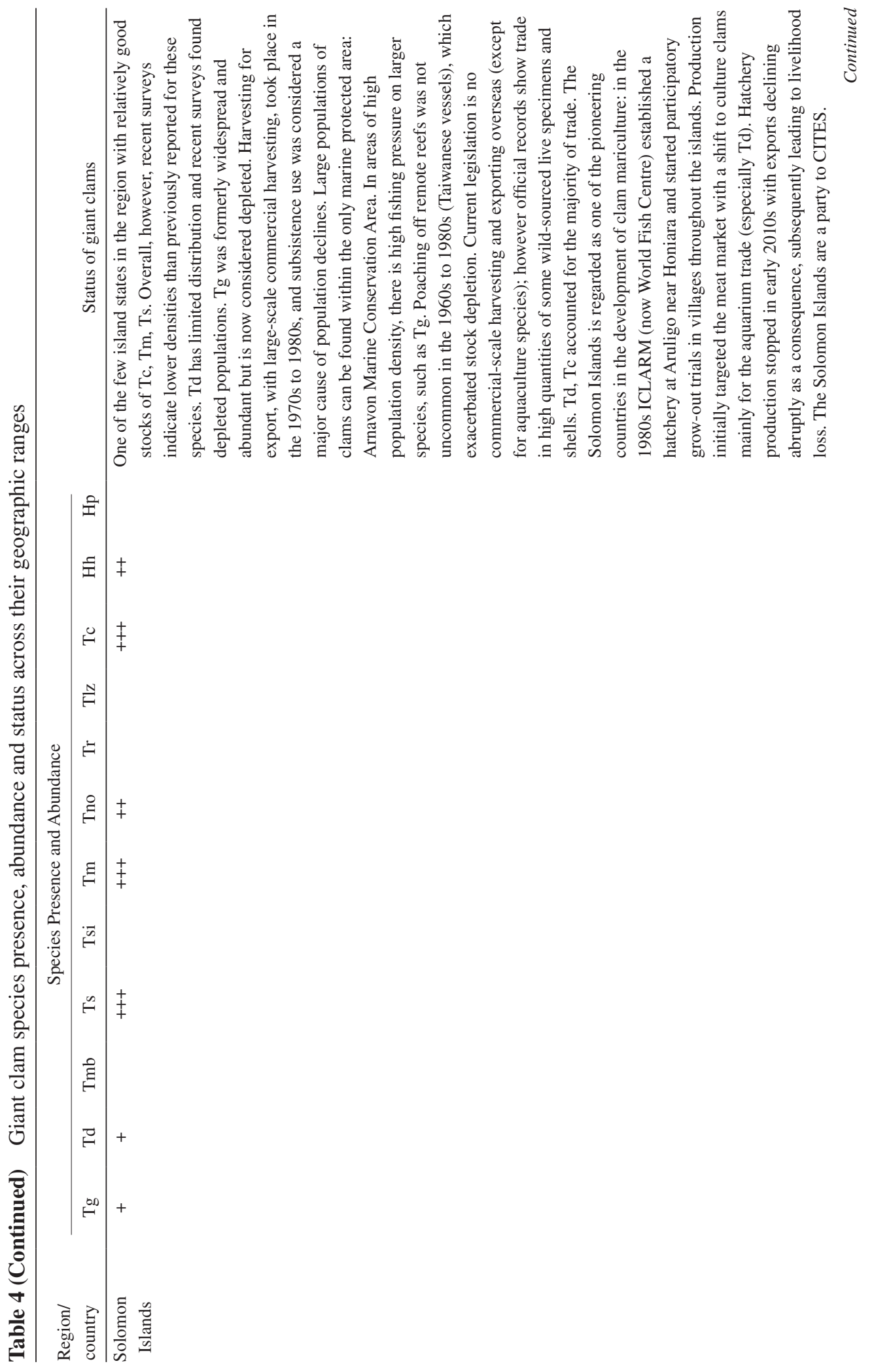




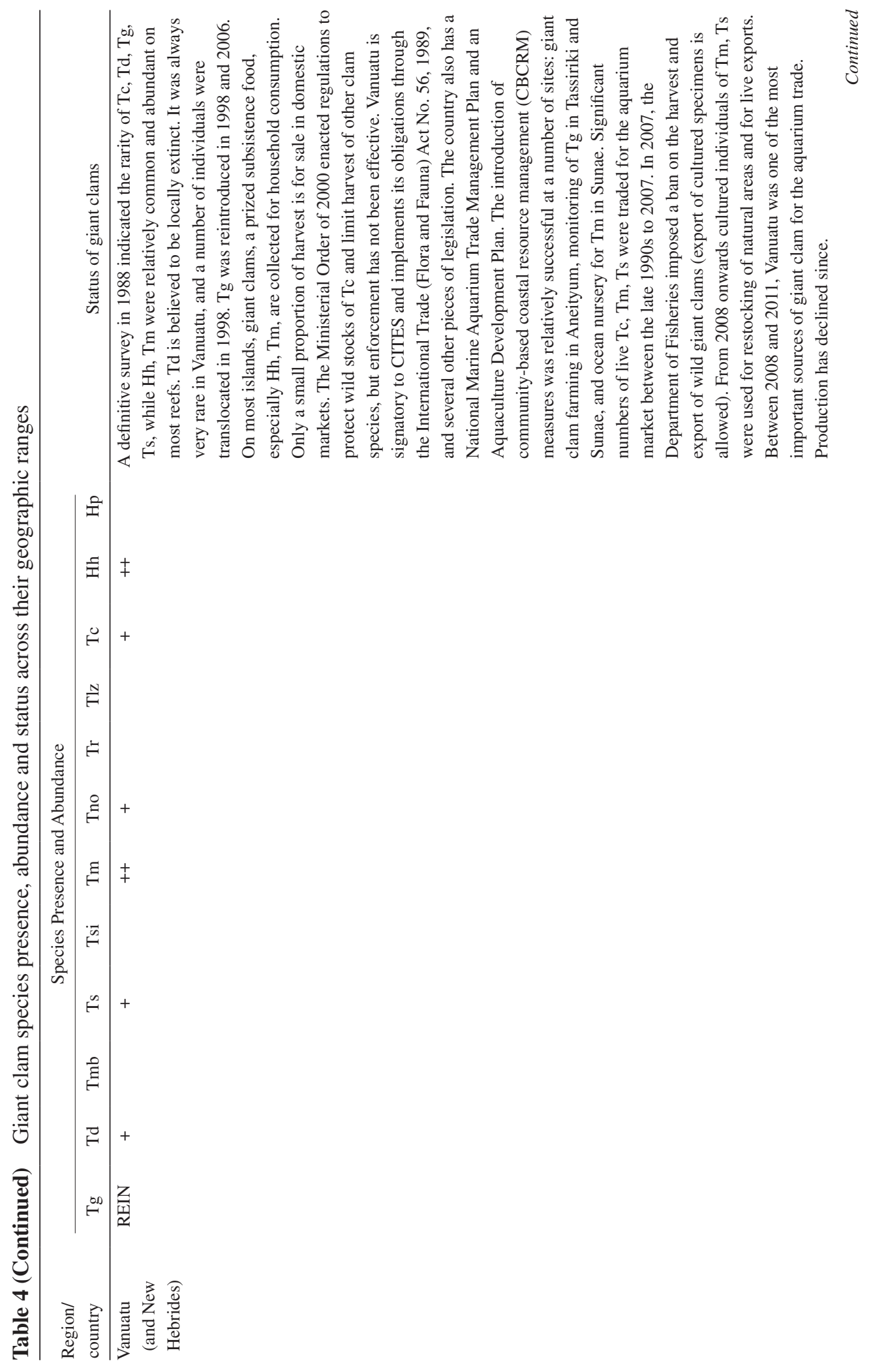




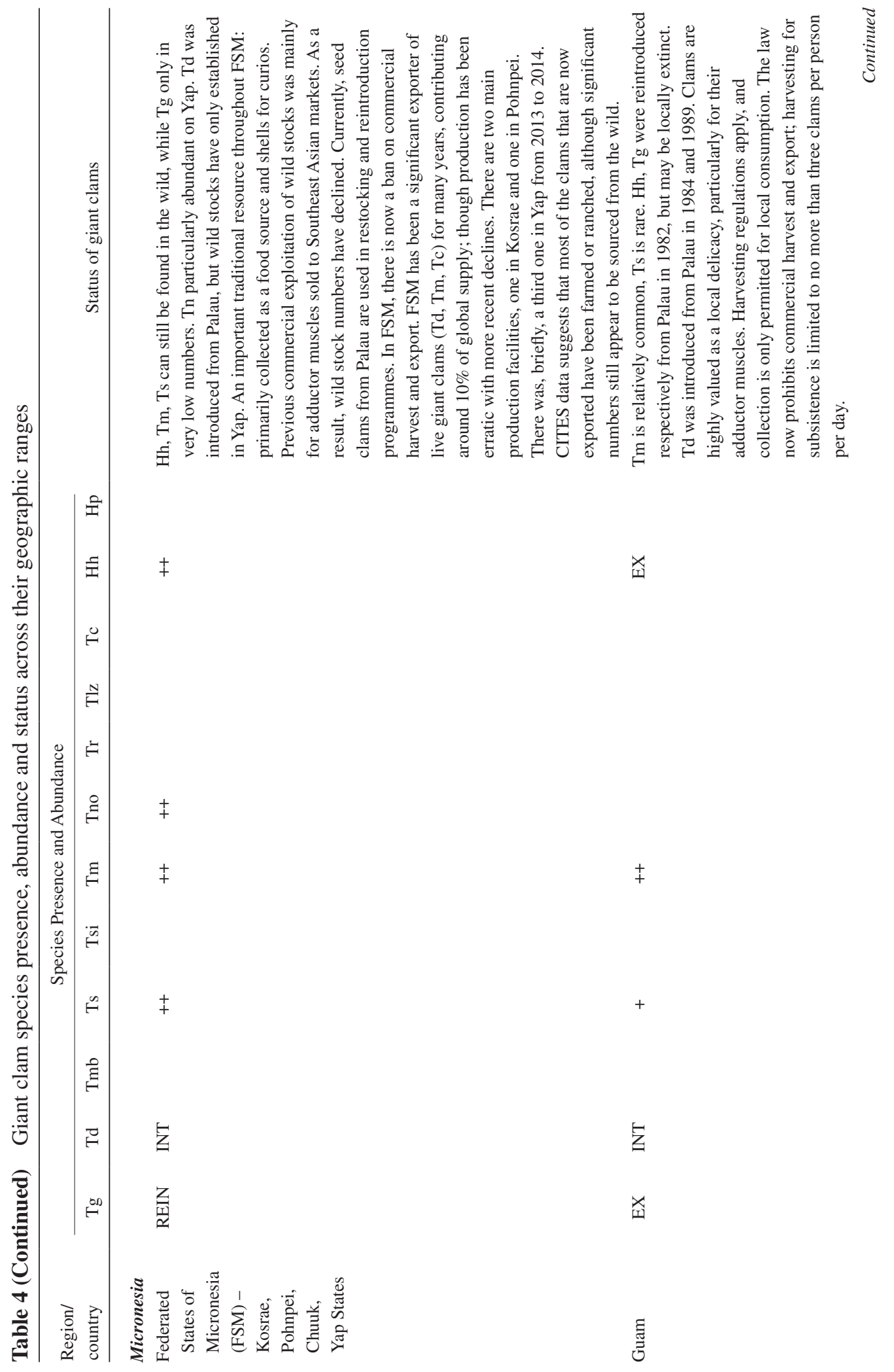


GIANT CLAMS (BIVALVIA: CARDIIDAE: TRIDACNINAE)

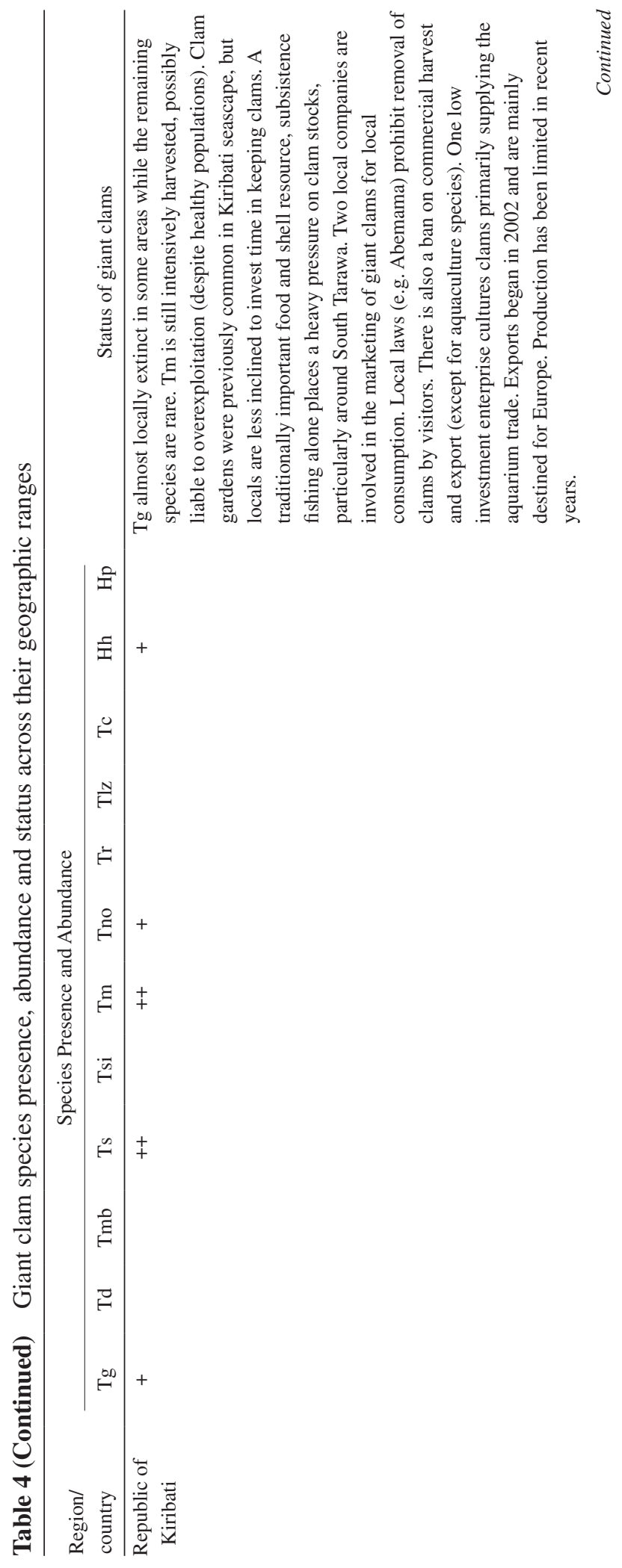




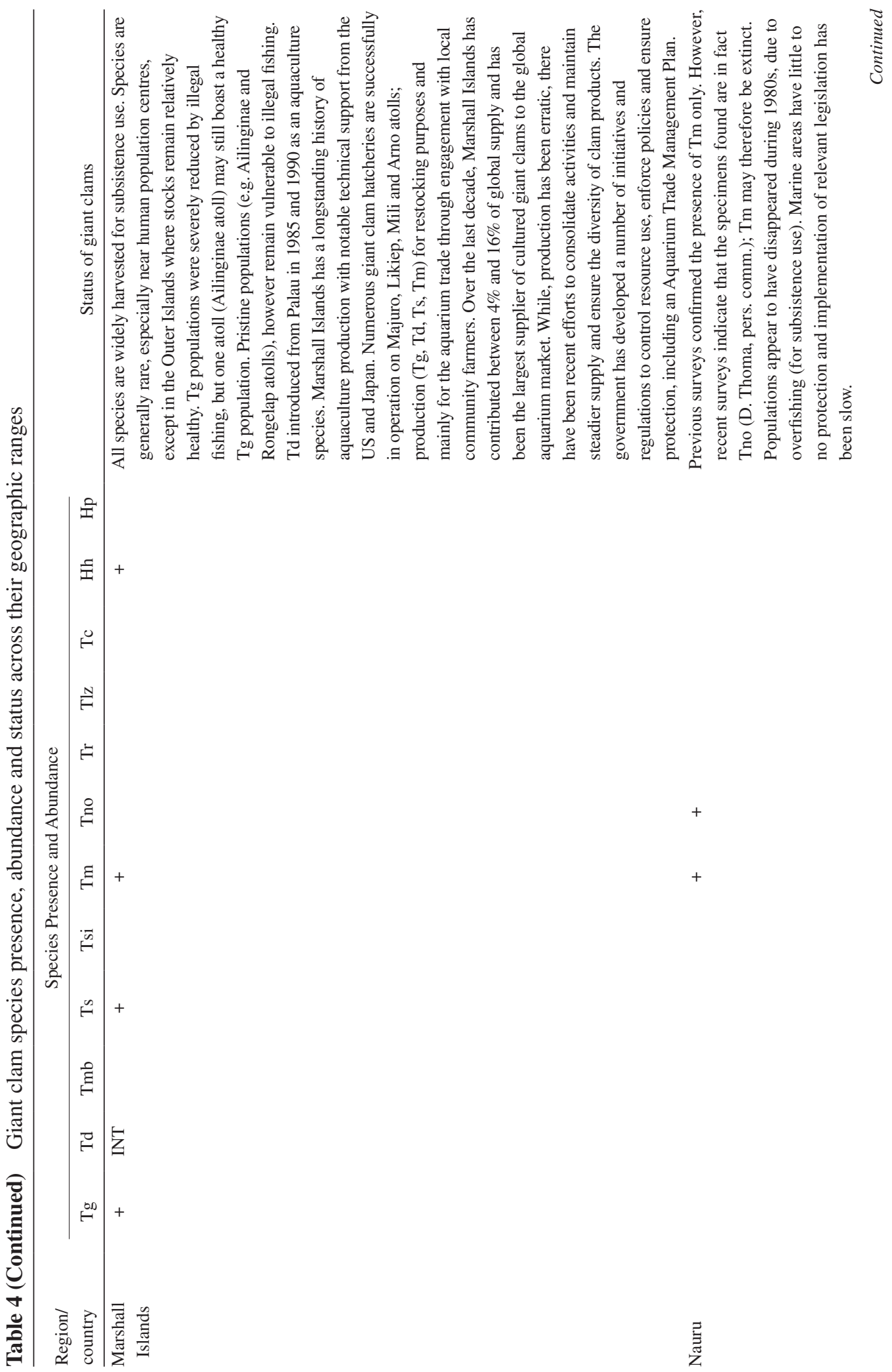




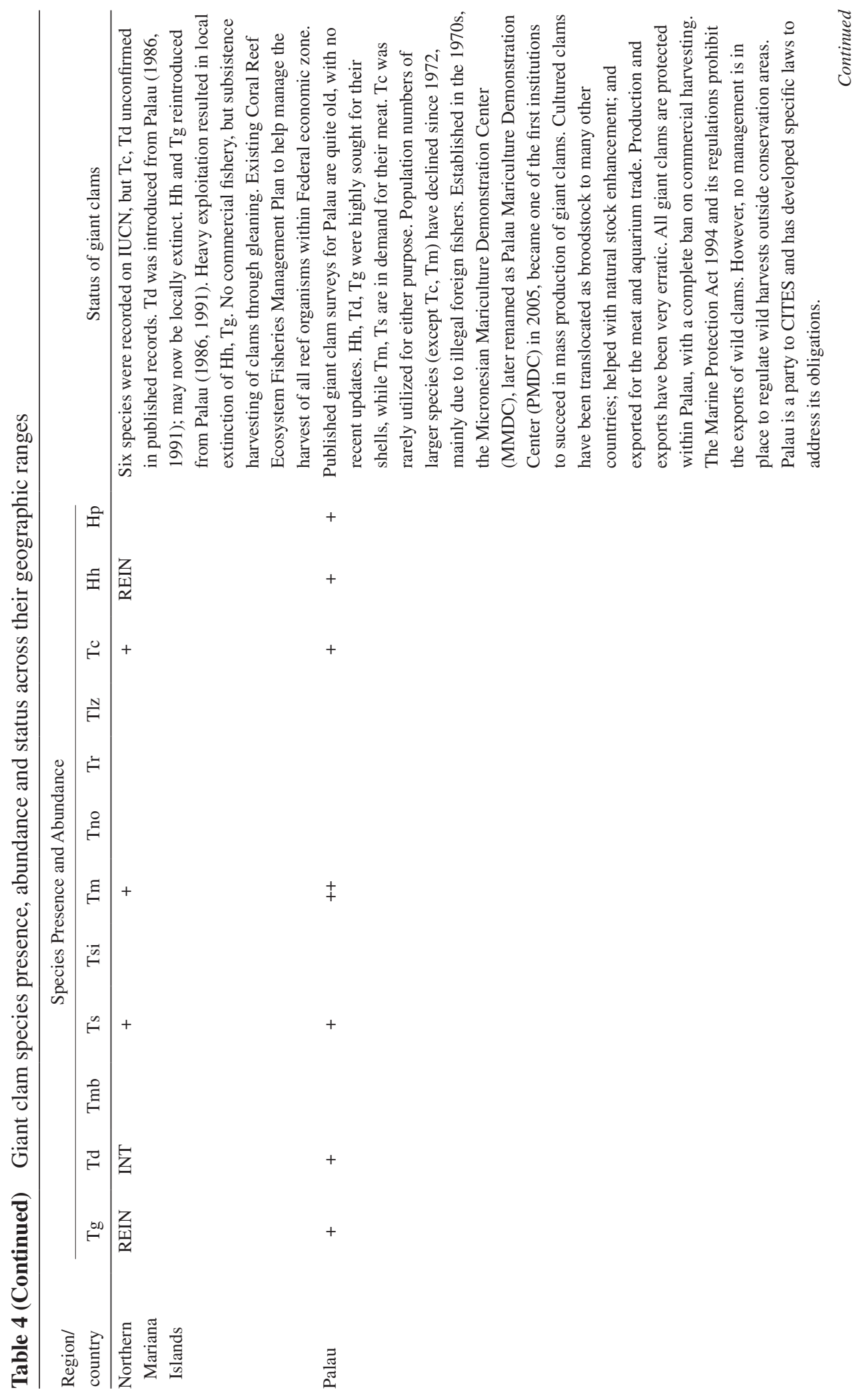


MEI LIN NEO ET AL.

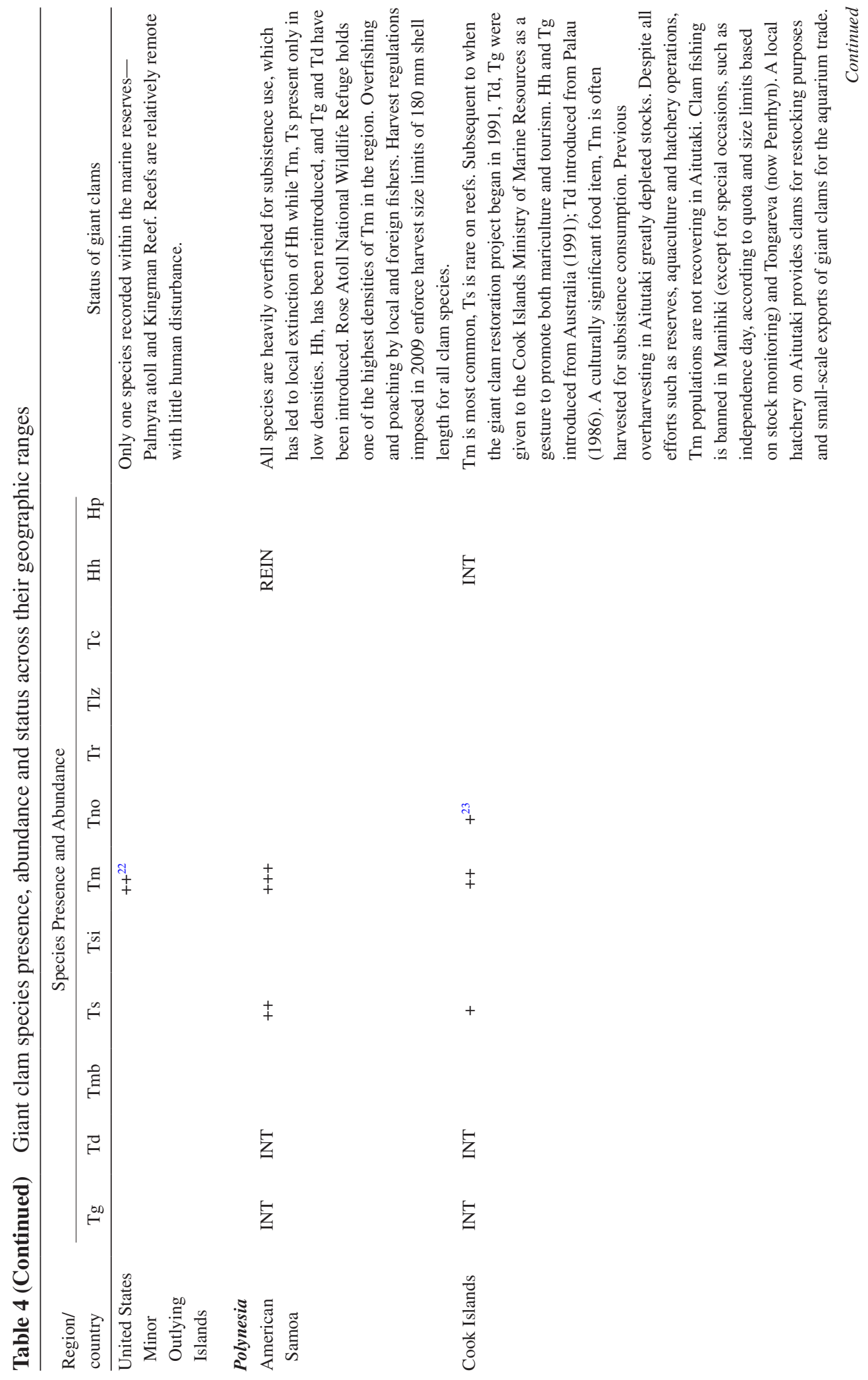




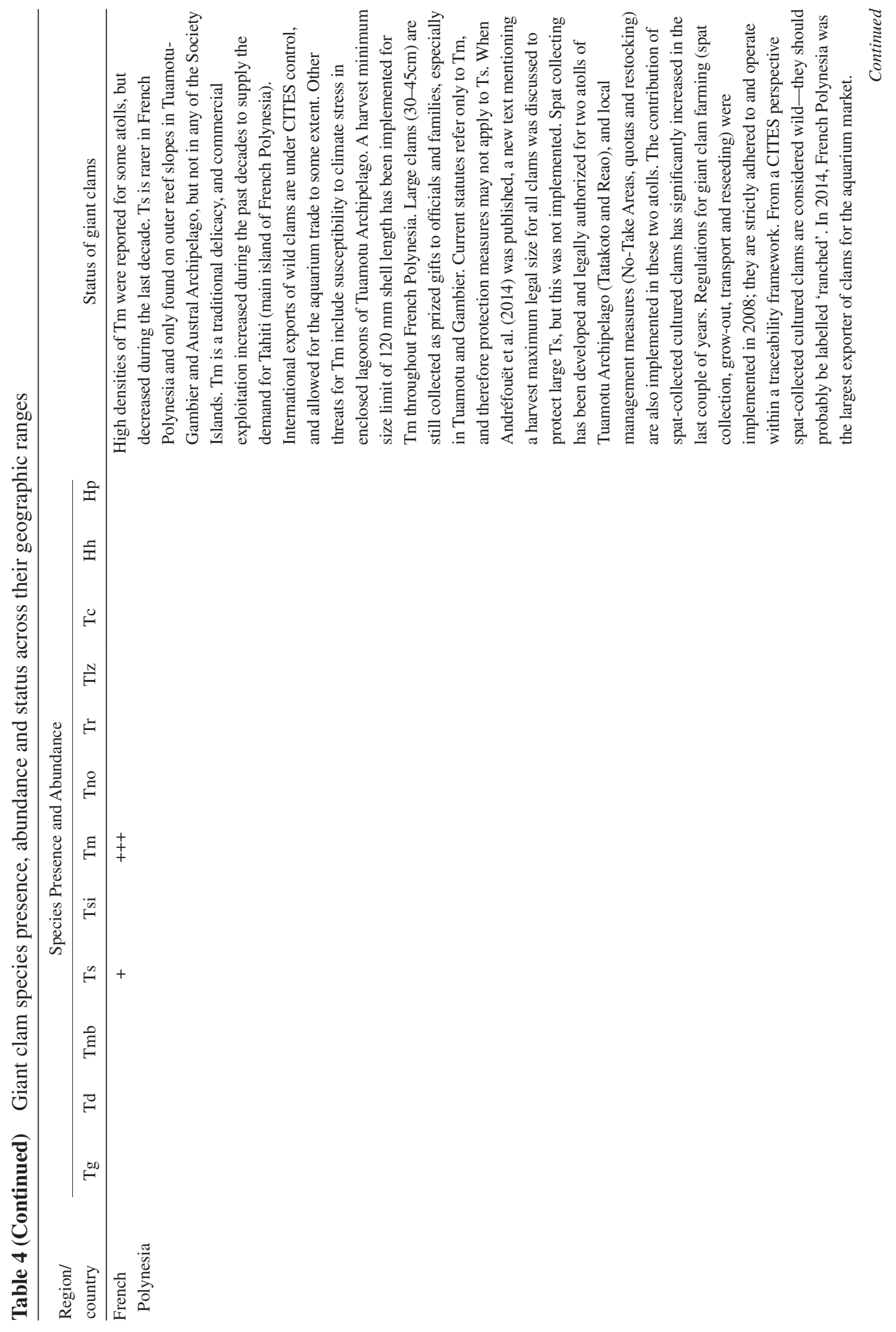


MEI LIN NEO ET AL.

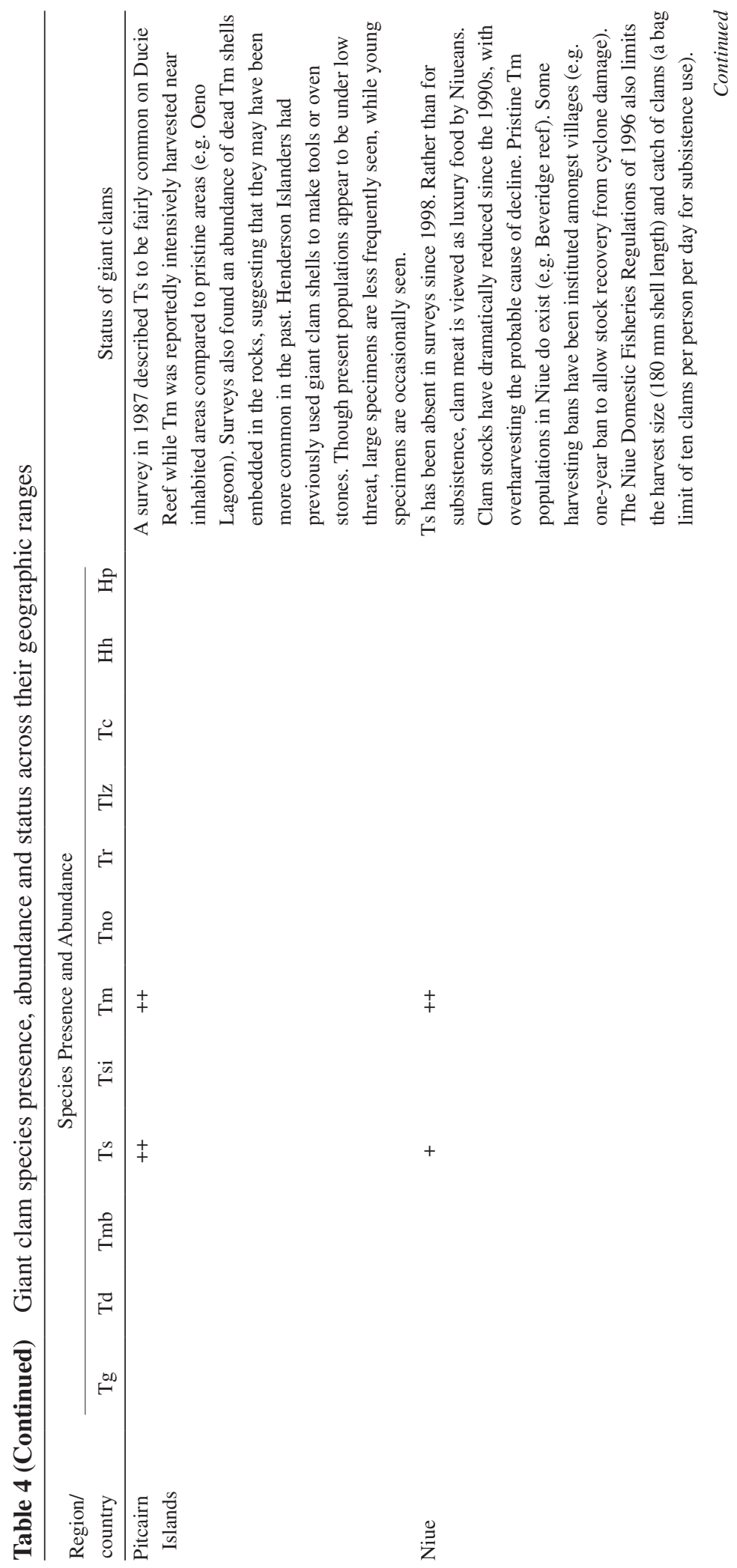




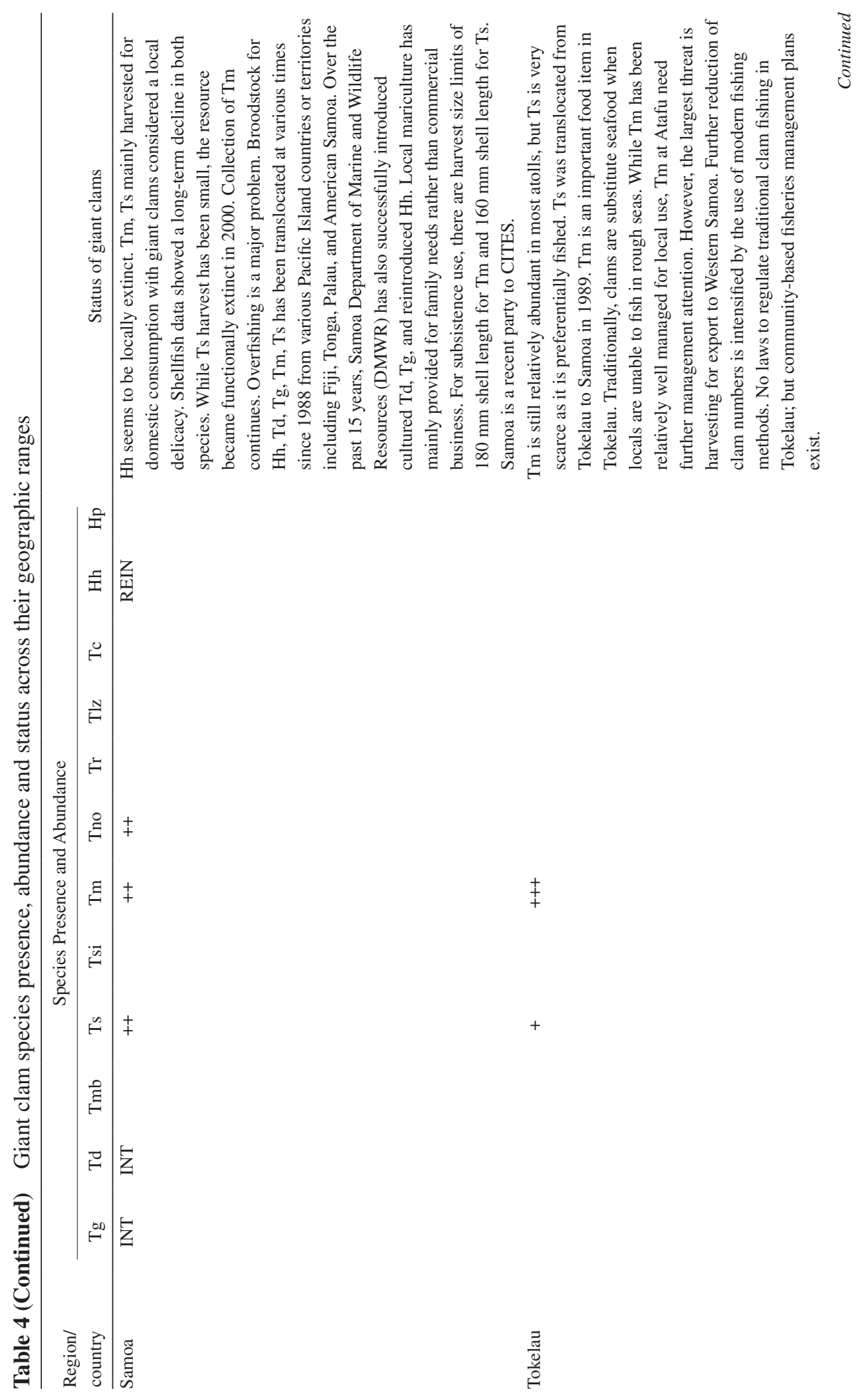


MEI LIN NEO ET AL.

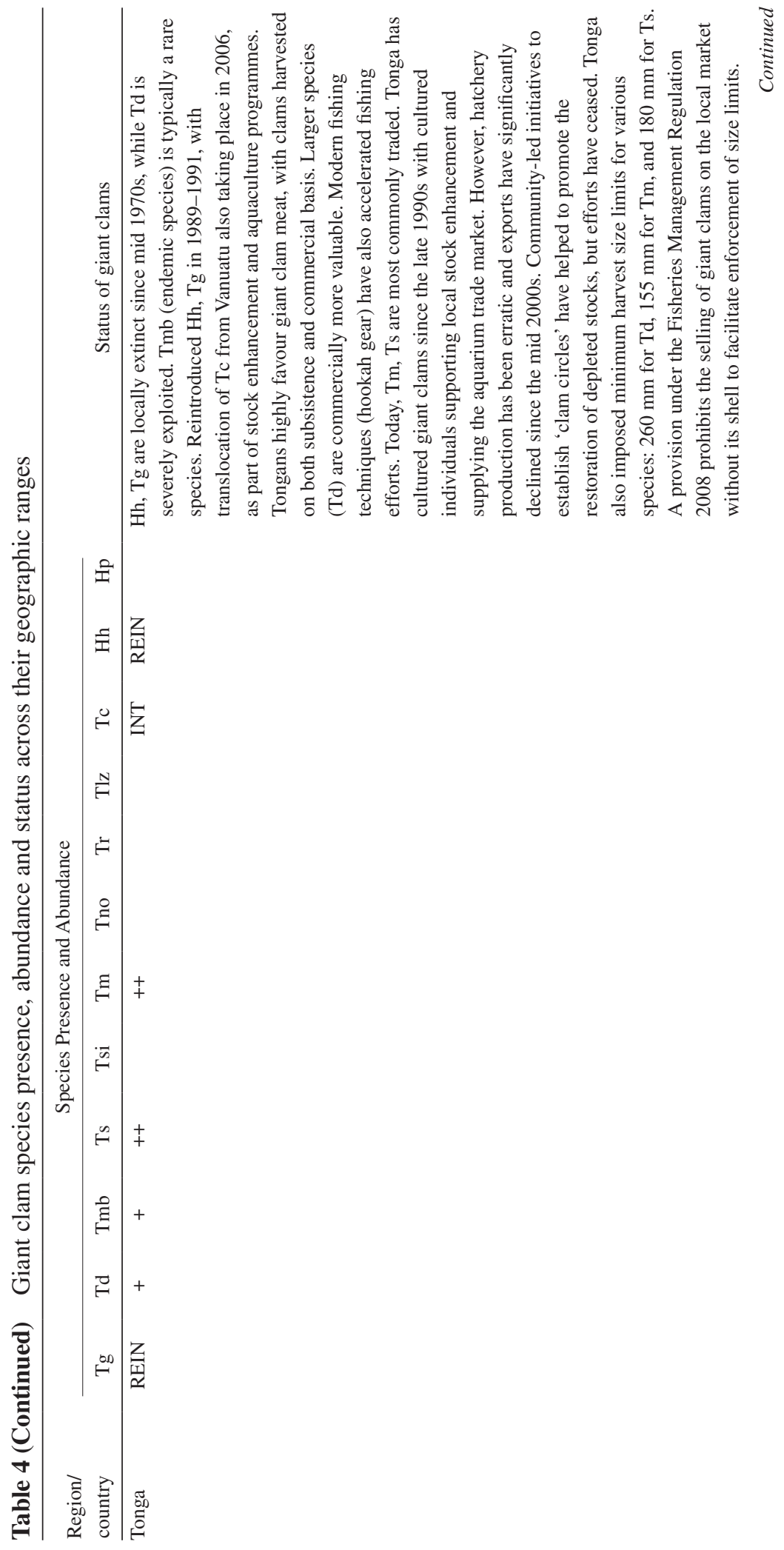


GIANT CLAMS (BIVALVIA: CARDIIDAE: TRIDACNINAE)

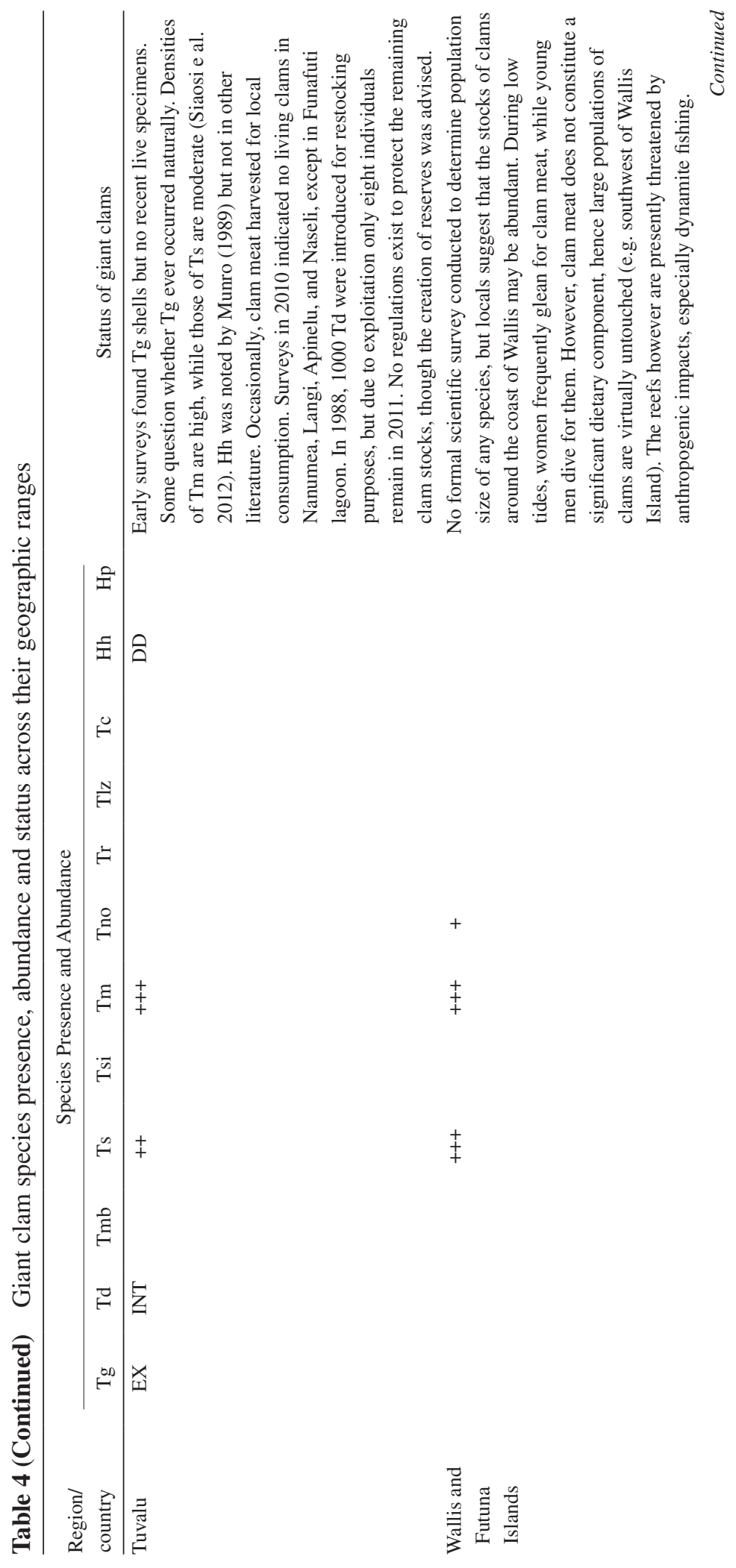




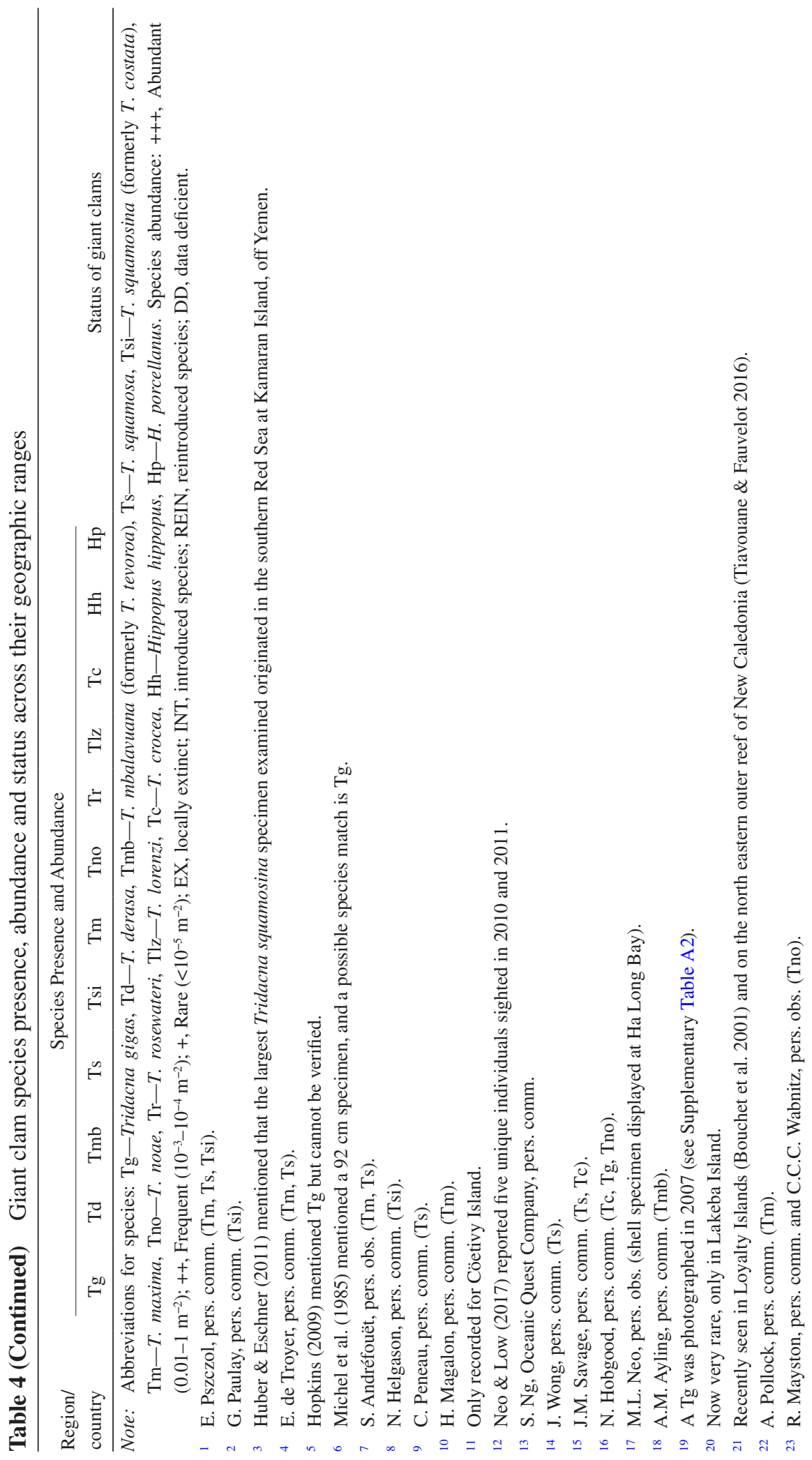




\title{
Species characteristics, distribution, and status
}

\author{
Hippopus hippopus (Linnaeus, 1758)
}

Hippopus hippopus (Figure 2A) has several common names, such as the horse's hoof clam and strawberry clam. Individuals have been reported to grow up to $40 \mathrm{~cm}$ (Poutiers 1998), yet an individual within a marine protected area of the north-eastern lagoon in New Caledonia measured $47 \mathrm{~cm}$ (C. Fauvelot, pers. obs.) and another one at the Bolinao Marine Laboratory, Philippines, reached $50 \mathrm{~cm}$ (Mingoa-Licuanan \& Gomez 2007). Unlike the Tridacna species, the Hippopus species lack hyaline organs (small pinhole eyes) in their mantles, which also do not extend over their shell margins, and they have a narrow byssal orifice with tight-fitting teeth (Rosewater 1965). The thick shells of $H$. hippopus have strong radial ribbing and display reddish blotches in irregular bands. Their mantles usually exhibit green, yellow-brown or grey mottled patterns, and their incurrent siphon bears no guard tentacles. Byssal attachment is present in young individuals, but older ones mostly lie unattached on the substratum (Rosewater 1965). Hippopus hippopus often inhabits shallow, nearshore patches of reef, sandy areas and seagrass beds that can be exposed during low tides. It is occasionally found as deep as $10 \mathrm{~m}$ (S. Andréfouët, pers. obs.). This species is common throughout the Indo-Pacific, except for the Red Sea and Western Indian Ocean (Figure 1). It has been recorded in at least 25 localities, but at ten of these H. hippopus has been reported to be locally extinct (Table 4). Hippopus hippopus is a popular species for local harvesting and consumption (Hviding 1993), as it is traditionally favoured as a delicacy, considered as 'high status food' for use on special occasions, or as a reserve food when times are difficult. The nearshore habitats where $H$. hippopus is found are accessible and the species is free-living (i.e. unattached to the substratum), making it an easy target for reef gleaners (Hviding 1993). Consequently, populations are widely depleted. It is currently listed as a species of 'Lower Risk/Conservation Dependent' under the IUCN Red List of threatened species. Hippopus hippopus has been cultured in Palau, Australia (Orpheus Island Research Station, north Queensland), Malaysia and the Philippines for purposes of translocation to other areas (e.g. from Palau to American Samoa, Yap, the Cook Islands, Samoa and Tonga) or restocking (Table 4). Maricultured H. hippopus specimens in Palau exhibited exceptional hardiness and a short generation time (three years), earning this species the distinction of being the most 'farmer-friendly' of the giant clams (Heslinga 2012, 2013).

\section{Hippopus porcellanus Rosewater, 1982}

Before its formal description, Hippopus porcellanus (Figure 2B), also referred to as the China clam, was already common in the shell trade (Rosewater 1982). Maximum shell length is typically $\sim 40 \mathrm{~cm}$, with the largest specimen recorded at $41.1 \mathrm{~cm}$ (Hutsell et al. 1997). Unlike the elaborate shells of H. hippopus, H. porcellanus has a smoother and thinner shell (Rosewater 1982). This species may be easily mistaken for Tridacna derasa due to its similar shell shape and texture, but the mantles of Hippopus porcellanus are generally grey or brown, lack hyaline organs, and the incurrent siphon has prominent guard tentacles (Rosewater 1982). As with H. hippopus, the mantle does not extend beyond the shell margins, and there is a narrow byssal orifice. Hippopus porcellanus is usually found free-living on intertidal reef flats (Pasaribu 1988), and on the shallow reefs along the edges of lagoons (Dolorosa et al. 2014). This species has only been recorded from the Sulu Archipelago and Palawan (Philippines), Sabah (Malaysia), Sulawesi and Raja Ampat (Indonesia), Palau, and Milne Bay Province (Papua New Guinea) (Table 4, Figure 1). Heavy exploitation, from both subsistence and commercial fishing, has decimated populations of $H$. porcellanus, leading to extirpations (Calumpong \& Cadiz 1993, Dolorosa et al. 2014). Like H. hippopus, it is classified by IUCN as of 'Lower Risk/Conservation Dependent'. The few surveys conducted to date suggest that $H$. porcellanus is rare. Some of the healthiest populations are located within southeast Sulawesi (Indonesia) and the Tubbataha Reef Natural Park (Philippines). At the latter site, 100 individuals of 

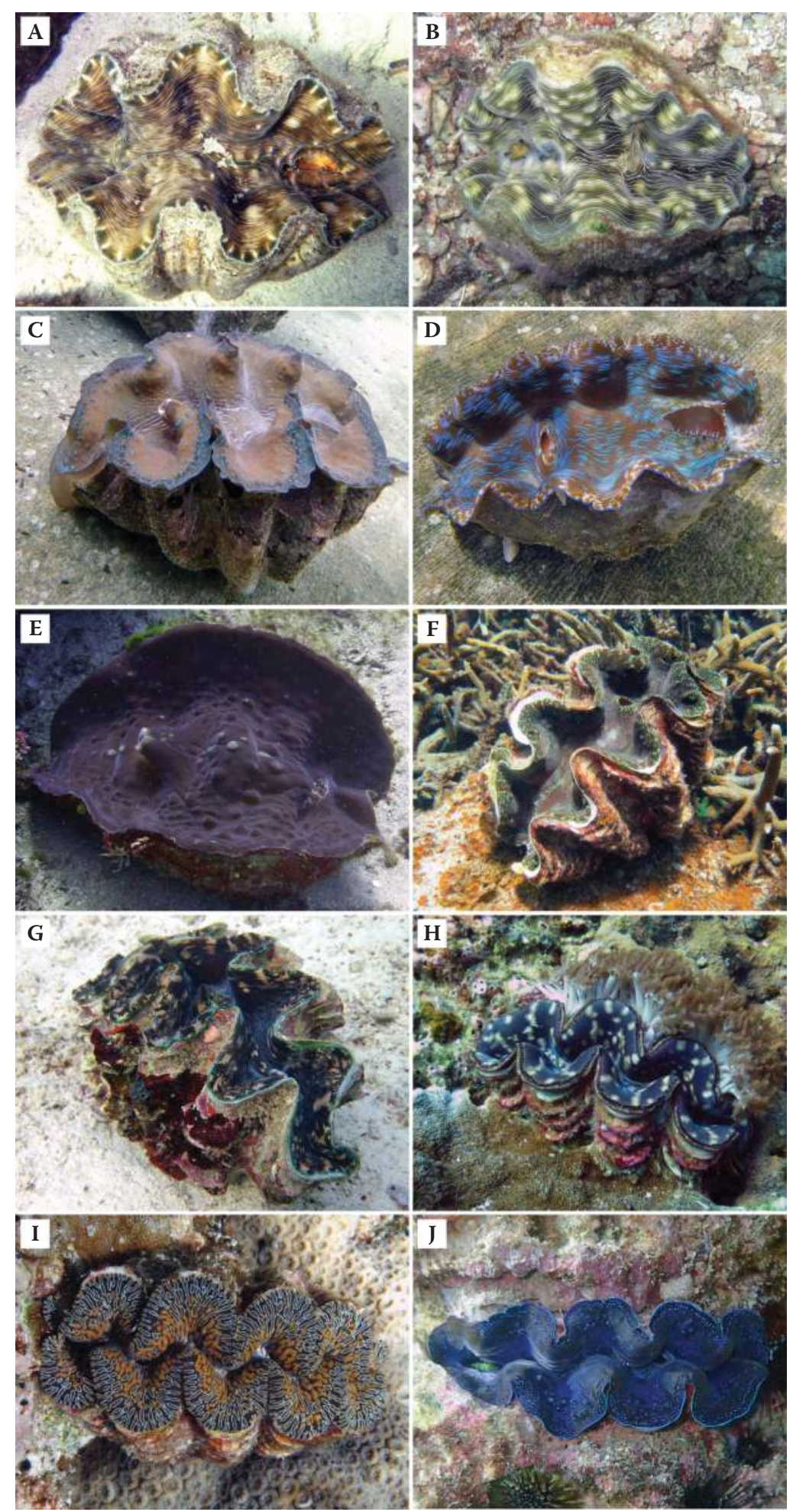

Figure 2 Giant clam species: (A) Hippopus hippopus, (B) H. porcellanus, (C) Tridacna gigas, (D) T. derasa, (E) T. mbalavuana, (F) T. squamosa, (G) T. squamosina, (H) T. maxima, (I) T. noae, (J) T. crocea. 
various sizes (shell length $=8.2-31.3 \mathrm{~cm}$ ) were found tagged and being monitored (Dolorosa et al. 2014). There are few published data on the reproduction of $H$. porcellanus (Alcazar et al. 1987, Calumpong et al. 1993), but 2000 maricultured F1 H. porcellanus individuals were successfully raised to sexual maturity at Palau's Micronesian Mariculture Demonstration Center (MMDC) facility in the mid-1990s (G.A. Heslinga \& T.C. Watson, pers. comm.). At present, the Marine Ecology Research Centre in Malaysia produces H. porcellanus in limited numbers (E.D. Gomez, pers. obs.).

\section{Tridacna gigas (Linnaeus, 1758)}

Tridacna gigas (Figure 2C) is the only truly gigantic giant clam species: the largest individual reported was $137 \mathrm{~cm}$ long (Rosewater 1965), while the heaviest known specimen (106 cm shell length) weighed approximately $500 \mathrm{~kg}$ (Lucas 1994). The species is easily identified by its size and distinctive elongate and triangular projections on the upper shell margins. Mantle colours are mostly dull brown and olive green, and the mantle edge bears numerous iridescent blue-green circles. Unlike the other Tridacna species, the incurrent siphon of T. gigas bears no tentacles. Tridacna gigas typically lives in coral reefs with good light penetration, and is usually free-living on either sand or hard reef substrata (Rosewater 1965). It occurs naturally from Myanmar (Burma) to the Republic of Kiribati (but not the Cook Islands), and the Ryukyus (southern Japan) to Queensland (Australia) (Figure 1). Anecdotal accounts suggest that the historical species range possibly extended to southeast Africa (Kenya: Accordi et al. 2010), Madagascar (Hopkins 2009) and Mauritius (Michel et al. 1985). A living T. gigas individual was observed on the fringing reefs of Tonumea Island, an uninhabited island in the southern Haápai group of Tonga in December 1973 (R.D. Braley, pers. obs.). Records have recently been discovered for Singapore, although no living individuals have been encountered in recent memory (Neo \& Todd 2012a, 2013). Currently, there are at least 31 localities with natural wild populations of T. gigas, but at 26 of them this species is severely depleted, locally extinct or data deficient (Table 4). Globally, the IUCN classifies the conservation status of $T$. gigas as 'Vulnerable'. The Great Barrier Reef (GBR) in Australia is the most extensive area within the natural distribution of T. gigas that still supports relatively undisturbed populations (Braley 1984, 1986, 1987a,b, Table 5) and exhibits evidence of natural recruitment (Braley 1988, Braley \& Muir

Table 5 A 25-year population data set for pristine populations of Tridacna gigas and T. derasa from five sites in the far northern Great Barrier Reef, Australia

\begin{tabular}{lccccc}
\hline \multirow{2}{*}{ Species } & $\begin{array}{c}\text { Site } \\
\text { number }\end{array}$ & $\begin{array}{c}\text { Survey area } \\
\text { (hectares) }\end{array}$ & \multicolumn{2}{c}{ Clam abundance } & Percentage \\
\cline { 4 - 5 } Tridacna gigas & 1 & 0.550 & 136 & 158 & $+16.0 \%$ \\
& 2 & 0.730 & 79 & 61 & $-22.7 \%$ \\
& 3 & 0.561 & 61 & 28 & $-54.0 \%$ \\
Tridacna derasa & 4 & 0.022 & 9 & 5 & $-44.0 \%$ \\
& 5 & 0.120 & 89 & 71 & $-15.7 \%$ \\
& 1 & 0.550 & 29 & 26 & $-10.0 \%$ \\
& 2 & 0.730 & 22 & 26 & $+18.8 \%$ \\
& 3 & 0.561 & 30 & 17 & $-43.3 \%$ \\
& 4 & 0.022 & 6 & 1 & $-83.0 \%$ \\
& 5 & 0.120 & 8 & 2 & $-62.5 \%$ \\
\hline
\end{tabular}

Note: Survey sites: 1-Watson's Bay, Lizard Island, 2-Palfrey-South Channel, Lizard Island, 3-West bommie of Rachel Carson Reef (formerly Northern Escape Reef), 4-Small east bommie of Rachel Carson Reef, 5-Southern end of Michaelmas Cay. (R.D. Braley, unpublished data) 
1995). Samples of these populations have been monitored over a 25 -year period and continue to be monitored today (Table 5). Generally, however, populations of T. gigas are dwindling. Extensive surveys in the Pacific Islands indicate that sometimes the presence of this species is limited to one individual (C.C.C. Wabnitz, pers. obs.). Populations typically face high levels of exploitation pressure and habitat deterioration (Gomez 2015a, Larson 2016). Tridacna gigas remains a valuable coastal resource for both domestic and commercial markets, as it is highly favoured for its meat as food and large shells for the ornament trade. To assist its conservation, T. gigas has been extensively cultivated and reintroduced (albeit in some areas, sometimes limited to a couple of individuals) to Peninsular Malaysia, Sabah, Philippines, Fiji, Northern Mariana Islands, Vanuatu and Tonga, as well as introduced to American Samoa, the Cook Islands, Hawaii (USA) and Samoa (Table 4). The oldest known maricultured T. gigas individual is 34 years old and was produced at Palau's MMDC in 1982. It is now on display at the Waikiki Aquarium in Honolulu (Carlson 2012, Heslinga 2013). Unfortunately, there is little information available regarding the outcomes of restocking in these areas (with a notable exception of the Philippines; Gomez \& Mingoa-Licuanan 2006, Cabaitan \& Conaco 2017).

\section{Tridacna derasa (Röding, 1798)}

The second largest species, Tridacna derasa (Figure 2D), grows up to $60 \mathrm{~cm}$ in shell length. It is known as the smooth giant clam because its valves have almost no ribbing (Lucas 1988). Tridacna derasa has brilliant mantle colours, displaying shades of blue and green with striped patterns. Its incurrent siphon bears relatively inconspicuous guard tentacles (Lucas et al. 1991). Mostly freeliving as adults, this species can be found on reef flats, fore reefs, barrier reefs and in atoll lagoons (S. Andréfouët, pers. obs.) down to depths of $20 \mathrm{~m}$. Tridacna derasa occurs from the Cocos (Keeling) Islands to Tonga, and from China to Queensland (Australia) (Figure 1). Of the 16 localities in which the presence of $T$. derasa has been recorded, in 12 of them wild populations are either severely exploited or locally extinct (Table 4). As with T. gigas, populations of T. derasa on the GBR are virtually undisturbed, and surveys of 57 reefs determined an average density of 4.4 ha $^{-1}$, with the highest density being $30 \mathrm{ha}^{-1}$ (Braley 1986, Table 5). Similar to T. gigas, large T. derasa individuals are also highly valued for their meat and shells as food and curios, respectively. Tridacna derasa is classified as 'Vulnerable' by the IUCN. Tridacna derasa was one of the first giant clam species to be commercially bred, partly owing to its fast growth and durability (Hart et al. 1998) making it better suited for meat production (Heslinga et al. 1984, Leung et al. 1994). Mariculture of this species has been highly successful (e.g. Palau, Marshall Islands, Federated States of Micronesia, the Cook Islands and Solomon Islands). Spats tend to be produced for local enhancement, occasionally for translocation programmes to other countries, for sale 'live' in the aquarium trade and, in Palau, sometimes either as food for local restaurants or export to Japan for sale as sashimi (Table 4). For subsistence and conservation purposes, $T$. derasa has been introduced to island states in Micronesia and Polynesia, and reintroduced to Palau, Indonesia, Malaysia and the Philippines.

\section{Tridacna mbalavuana Ladd, 1934}

Previously described as Tridacna tevoroa, the devil clam has been hypothesized to be a transitional species between Hippopus and Tridacna due to overlapping characters (Schneider \& Ó Foighil 1999). The species has Hippopus-like features, such as the absence of a byssal gape, no extension of the mantle over the shells, and the absence of hyaline organs (Lucas et al. 1991). Tridacna mbalavuana (Figure 2E) also resembles T. derasa in appearance, but is distinguished by its rugose mantle surface, prominent guard tentacles on the incurrent siphon, thinner shell valves, and coloured patches on the shell ribbing. Individuals can normally grow up to $50 \mathrm{~cm}$, with the largest specimen recorded at $56 \mathrm{~cm}$ long (Lucas et al. 1991). Tridacna mbalavuana inhabits relatively deep waters 
( $>20 \mathrm{~m}$ ) compared to other tridacnines, and is apparently intolerant of conditions in shallow water (Lucas et al. 1991). Previously restricted to Fiji and Tonga, this species has been sighted in the Loyalty Islands, New Caledonia (Bouchet et al. 2001), the main island of New Caledonia (Tiavouane \& Fauvelot 2016), and Australia (A.M. Ayling, pers. comm., Newman \& Gomez 2000) (Figure 1). Tridacna mbalavuana is generally rare throughout its known range: Ledua et al. (1993) reported few live specimens (abundance, $N=20,1989$ to 1991) in the eastern Lau group of Fiji, and a slightly higher abundance in Tonga ( $\mathrm{N}=50,1989$ to 1992) (see Supplementary Table A3). In Haápai, Tonga, individuals were seen on live coral habitat at $>30 \mathrm{~m}$ depth in clear water, whilst in the eastern Lau group of Fiji, individuals were never found on live coral habitat, but instead next to rocks on steep slopes (Ledua et al. 1993). Recently, only two living individuals have been reported from New Caledonia, despite exhaustive searches (Tiavouane \& Fauvelot 2016). In Fiji, some T. mbalavuana have been 'accidentally' collected along with T. derasa for commercial exports of its meat (Lewis \& Ledua 1988, Lewis et al. 1988). In Tonga, T. mbalavuana has been harvested for domestic markets either using SCUBA or traditional Pacific Islands fishing methods (Ledua et al. 1993). Even though their preference for deeper water habitats may have offered some protection from harvesting (Lewis \& Ledua 1988, Lucas et al. 1991), the development of SCUBA and hookah gear has facilitated access to previously inaccessible T. mbalavuana stocks. The species is classified as 'Vulnerable' by the IUCN. There is little information regarding the mariculture of T. mbalavuana, but there was a successful spawning in December 1991 at the Tonga Fisheries Hatchery (Ledua et al. 1993).

\section{Tridacna squamosa Lamarck, 1819}

Tridacna squamosa (Figure $2 \mathrm{~F}$ ) is commonly known as the fluted giant clam. The valves have well-defined ribs and folds (the ribs also possess distinct protrusions called scutes). This species typically attains shell lengths of $\sim 40 \mathrm{~cm}$, but Hutsell et al. (1997) recorded an individual with a shell length of $42.9 \mathrm{~cm}$. The mantle of T. squamosa usually exhibits mottled patterns in combinations of yellow, orange, blue, green and brown, and the incurrent siphon bears distinct tentacles. The valves are often coloured (yellow and orange-pink), which makes the species highly valued in the shell trade (Lucas 1988). Juvenile T. squamosa are typically byssally attached to coral rubble, while adults may be byssally attached or free-living. Tridacna squamosa inhabits a wide depth range, from reef flats to reef slopes down to $42 \mathrm{~m}$ (Jantzen et al. 2008), and is usually found in sheltered sites (e.g. wedged between corals) (Rosewater 1965). Globally, T. squamosa is the second most common tridacnine species, present from the Red Sea and eastern Africa in the west to the Pitcairn Islands, southern Japan and Queensland (Australia) in the east (Figure 1). New records for the central Pacific (Australes, Tuamotu and Gambier Archipelagos) have been added recently, although some gaps persist (such as Society Islands, French Polynesia) (Gilbert et al. 2007, Andréfouët et al. 2014). Despite ongoing exploitation, population numbers remain relatively stable across its range, with the exception of Cocos (Keeling) Islands and the Northern Mariana Islands where the species is locally extinct. Tridacna squamosa is classified by the IUCN as of 'Lower Risk/Conservation Dependent'. It is mainly harvested for subsistence use in local island communities and has been reported to be preferred in the shell trade due to its attractive colours, appearance and size. This species has been successfully cultured, mainly for restocking purposes in Indonesia, Malaysia, Philippines, Singapore, Thailand, Fiji, Palau, Federated States of Micronesia, Marshall Islands, Tonga, Vanuatu and Solomon Islands (Table 4), but there have been no reports of the outcomes of these endeavours. Individuals were also translocated from Palau to Guam and Tokelau, and Fiji to Samoa to help with local restocking initiatives (Kinch \& Teitelbaum 2010). Juveniles from culture efforts in Australia, Palau, Federated States of Micronesia, Marshall Islands, Tonga, Vanuatu and Solomon Islands are (or have been) exported for the aquarium trade. As part of its larger research programme, the Darwin Aquaculture Centre (Northern Territory, Australia) also cultures T. squamosa to encourage farming as an economic opportunity for indigenous communities (Darwin Aquaculture Centre, pers. comm.). 


\section{Tridacna squamosina Sturany, 1899}

Tridacna squamosina (Figure $2 \mathrm{G}$ ) was originally collected during the 'Pola' expedition to the Red Sea in the 1890s (Huber \& Eschner 2011). Sturany (1899) first published the results of this expedition, which noted the presence of three Tridacna species in the Red Sea: T. maxima, T. squamosa and a new species: T. elongata var. squamosina. The species was later rediscovered when living individuals were found in the Red Sea in the late 2000s (Richter et al. 2008), the largest recorded being $32 \mathrm{~cm}$ long. The species bears a strong resemblance to T. squamosa, but can be distinguished by its asymmetrical shells, crowded scutes, wider byssal orifice, and deep triangular radial folds (Roa-Quiaoit 2005). Tridacna squamosina strictly inhabits shallow reef areas and seagrass beds ( $\sim 5 \mathrm{~m}$ depth), and is usually weakly byssally attached to the substratum (Roa-Quiaoit 2005). Presently only known from the Red Sea (i.e. Egypt, Israel, Jordan, Saudi Arabia and Yemen), recent anecdotal sightings of T. squamosina in Mozambique suggest that the species may also occur in the Indian Ocean (Table 4, Figure 1). Survey data suggest that live T. squamosina are generally rare. For example, only 13 individuals were identified during extensive surveys along the Jordanian Red Sea coastline (Richter et al. 2008). The current low numbers are postulated to be a result of overharvesting in the Red Sea, where it formed an important diet component of early coastal gatherers (>125,000 years ago) (Richter et al. 2008). As Tridacna exploitation remains prevalent in the Red Sea, T. squamosina is highly vulnerable to extinction. Mariculture of this species may have been carried out in Jordan (Roa-Quiaoit 2005), but the small number of individuals available for broodstock would make any mariculture effort a significant challenge.

\section{Tridacna maxima (Röding, 1798)}

The small giant clam, Tridacna maxima (Figure $2 \mathrm{H}$ ), usually grows up to $\sim 35 \mathrm{~cm}$, with the largest individual collected (from Fanning Island, Republic of Kiribati) measuring $41.7 \mathrm{~cm}$ (Stasek 1965). Tridacna maxima is one of the three boring (sometimes referred to as 'burrowing') Tridacna species; juveniles are usually fully embedded in the reef substratum, but older individuals eventually outgrow the bored concavity and become partially embedded only. In areas characterized by high densities, such as the enclosed lagoons of French Polynesia, some individuals can be found on sand (Van Wynsberge et al. 2016). A persistent characteristic among the boring tridacnines is the tendency to byssally attach to the inside of the borehole. Tridacna maxima is also identified by its close-set scutes on the upper valves, the neat rows of tightly spaced hyaline organs along its mantle margin, and its brilliantly coloured and mottled mantle (usually blue, green and brown). It typically dwells in shallow areas of reefs and lagoons, rarely beyond a depth of $10 \mathrm{~m}$ (the deepest record is $21.2 \mathrm{~m}$ at the Dongsha atoll, South China Sea; M.L. Neo, pers. obs.). With a similar geographic range to T. squamosa, T. maxima is also a cosmopolitan species, but with more variable population densities across its range compared to T. squamosa (Van Wynsberge et al. 2016). Although T. maxima is harvested frequently for either subsistence or commercial purposes, it is still relatively common and hence classified by the IUCN as of 'Lower Risk/Conservation Dependent'. With rapid declines in the populations of larger tridacnine species, T. maxima is increasingly being extracted for local consumption and is likely to become more of a target for fisheries in the future (Van Wynsberge et al. 2016). Due to its attractively coloured mantle patterns it is, together with T. crocea, the most sought-after species for the aquarium trade. With a current ban on exports of wild-caught individuals for most countries within its range, the majority of individuals that enter the aquarium trade are cultured. While the species has been bred mainly for the aquarium trade (Wabnitz et al. 2003), wherever aquaculture and mariculture efforts exist (or were active), e.g. the Cook Islands (Waters et al. 2013), French Polynesia, Federated States of Micronesia, Samoa, Republic of Kiribati, Marshall Islands, Solomon Islands, Fiji, Vanuatu, Tonga, Palau and Taiwan (L.-L. Liu, pers. comm.), they have also contributed to reef restocking efforts (Table 4). 


\section{Tridacna noae (Röding, 1798)}

The largest individual of Tridacna noae (Figure 2I) reported to date, from Kosrae, Micronesia, was 28 $\mathrm{cm}$ long (Borsa et al. 2015b). Tridacna noae cannot be readily identified by its shell traits, but it exhibits a highly distinctive mantle ornamentation including discrete teardrop patches typically bounded by white margins, sparsely distributed hyaline organs along the mantle margin, and the presence of papillae (Penny \& Willan 2014, Su et al. 2014, Borsa et al. 2015a). Nevertheless, the mantle patterns of T. noae vary greatly in appearance among individuals (Borsa et al. 2015b). Because of its generally highly distinct and beautiful mantle, T. noae, long identified by aquarists as 'teardrop maxima', is highly desired for the aquarium trade (Wabnitz \& Fauvelot 2014). The habitats of T. noae are generally similar to those of T. maxima, occupying depths of 1-15 m (Borsa et al. 2015b, Militz et al. 2015). Also a boring species, individuals are often found partially embedded within reef substrata. The known geographic distribution of T. noae extends from the Ryukyus (southern Japan), Taiwan, Southeast Asia, Western Australia and the Pacific Islands as far east as Christmas Island (Borsa et al. 2015b, Neo \& Low 2017, Figure 1). As a newly resurrected species, data on the habitat and distribution of T. noae are scarce, but inferred to be similar to T. maxima due to morphological similarities and habitat preferences. A survey by Militz et al. (2015) determined that almost $42 \%$ of the specimens recorded as T. maxima within the Kavieng Lagoon system, Papua New Guinea, could now be classified as T. noae. Also, re-surveys of the Ningaloo Reef Marine Park revealed the presence of T. noae only, with no signs of T. maxima (Johnson et al. 2016); findings that challenge an earlier survey reporting the presence of (only) T. maxima (Black et al. 2011). Snorkel surveys on the reefs in Yap (Federated States of Micronesia), also identified high abundances of $T$. noae, which would have previously been recorded as T. maxima (C.C.C. Wabnitz, pers. obs.). Moreover, in Nauru, the only species found on the reefs during dedicated reef invertebrate surveys was recently re-identified as T. noae and not T. maxima (D. Thoma, pers. comm.). This inadvertent confusion of the two species highlights two problems: 1) the historical and current densities of T. maxima are likely to be overestimates in several locations, and 2) commercial exploitation that does not differentiate between the two species could interfere with local extinction risk calculations (Borsa et al. 2015b, Militz et al. 2015, Johnson et al. 2016). There have been a number of ex situ attempts to breed T. noae in Taiwan for restocking purposes (Su 2013) and some culture trials for mariculture grow-out and subsequent sale for the aquarium trade in the Federated States of Micronesia (C.C.C. Wabnitz, pers. obs.). Embryology, larval development and feeding ecology of T. noae in Papua New Guinea have recently been described (Southgate et al. 2016, 2017), while successful hatchery production has been reported in Fiji (P. Southgate, pers. comm.).

\section{Tridacna rosewateri Sirenko \& Scarlato, 1991}

The first and only specimens of Tridacna rosewateri were collected from the Saya de Malha Bank (currently administered by Mauritius), Indian Ocean, during a 1984 expedition (Sirenko \& Scarlato 1991). Nine individuals were collected measuring 6.7-19.1 cm shell length. The shell morphology of $T$. rosewateri shares features with both T. maxima (i.e. large byssal orifice) and T. squamosa (i.e. large scutes), but differs from those species in having thinner shell walls, deep triangular valve margin folds, and larger dense scutes on primary radial folds (Sirenko \& Scarlato 1991, Monsecour 2016). Little is known about its habitat, but the T. rosewateri individuals were found among corals (Madrepora sp.) and dense beds of the seagrass Thalassodendron ciliatum (Sirenko \& Scarlato 1991). Tridacna rosewateri is currently classified as 'Vulnerable' by the IUCN. The absence of living individuals makes the validity of $T$. rosewateri as a tridacnine species ambiguous. Benzie \& Williams (1998) criticized the poor description of the species and proposed that it is a junior synonym of T. squamosa, while Newman \& Gomez (2000) and Monsecour (2016) have argued that they could readily distinguish its shells from T. squamosa and concluded that it might be a distinct species endemic to Saya de Malha Banks. 


\section{Tridacna lorenzi Monsecour, 2016}

Tridacna lorenzi is the newest species added to the list of Tridacninae. The species was described from the Cargados Carajos Archipelago (St. Brandon), Mascarene Plateau in the outlying territories of Mauritius (Monsecour 2016). A medium-sized species, ten of the largest type specimens measured between 11.3 and $26.0 \mathrm{~cm}$ shell length. Monsecour (2016) notes that both T. maxima and $T$. rosewateri are likely the closest congeners to $T$. lorenzi on the basis of some overlapping morphological characters. Similar to T. maxima, T. lorenzi has asymmetric shells, a large byssal orifice, and close-set scutes, but differs in the narrow interstices between primary ribs, its triangular valve margins, and the dull-coloured mantle that does not extend beyond the shell margins (Monsecour 2016). Commercially, this species has previously been misidentified as T. rosewateri, since the valve margins of both primary ribs and rib interstices are triangular in both species (Monsecour 2016). Tridacna lorenzi can, however, be distinguished from T. rosewateri by its more asymmetric, more globose, heavier shell valves, and closer-set scutes. The T. lorenzi individuals described by Monsecour (2016) were mostly collected from shallow waters in turbid lagoons of no more than $1 \mathrm{~m}$ depth, free-living on sand and among loose rubble. Distribution data are limited, although Monsecour (2016) suggested that T. lorenzi was locally common and encountered more often than the rarer $T$. squamosa and uncommon T. maxima. Local fishermen reportedly eat the species, and use their shells as saucers or ashtrays. A molecular analysis of T. lorenzi to determine its relationship with congeners has yet to be conducted.

\section{Tridacna crocea Lamarck, 1819}

Of all the tridacnine species, Tridacna crocea (Figure 2J) is the smallest with a maximum size of $\sim 15 \mathrm{~cm}$ (Rosewater 1965). Commonly known as the 'burrowing' or 'boring' giant clam, T. crocea is a rock borer that embeds its entire body into the substratum, leaving only the mantle exposed (Yonge 1936). It appears to be well adapted to low salinity levels, often found in areas that experience freshwater runoff (Hart et al. 1998). As with T. maxima and T. noae, this species byssally attaches to its bored concavity. Tridacna crocea is usually identified by its boring habit, but it also develops well-spaced scutes that become eroded over time within the borehole. The mantles are brightly coloured, exhibiting various shades of blue, green, purple, white and brown (Todd et al. 2009). Tridacna crocea mostly inhabits reef flats in shallow waters of depths no more than $10 \mathrm{~m}$ (Hamner \& Jones 1976, Hamner 1978). The species has a wide distribution (24 localities), ranging from Australia to Japan, east to Palau, and from Vanuatu to the Andaman Islands (Figure 1). It is possibly extinct in Guam and the Northern Mariana Islands (Wells 1997). In most areas, T. crocea is still considered reasonably abundant, probably due to its small size and the difficulty of extracting it from reef substrata. Even though $T$. crocea is one of the most easily accessible tridacnine species, exploitation is limited to domestic consumption. It is a popular delicacy in Okinawa, Japan (Okada 1997). The species was considered widespread in the Solomon Islands (Wells 1997) and was preferentially harvested as a source of food (Hviding 1993). More recent surveys indicate that it is much less common than it used to be in the Solomon Islands (Ramohia 2006). It is classified as of 'Lower Risk/Least Concern' by the IUCN. Mariculture of T. crocea is well established in Okinawa, Japan, where the spats are distributed to local fishermen for culture and release (Okada 1997). There have also been ex situ attempts to culture T. crocea in Brazil (Mies et al. 2012). Due to its bright colours, it is highly prized in the aquarium trade (Wabnitz et al. 2003), and mariculture efforts in Palau, the Marshall Islands and the Federated States of Micronesia, for example, have had some success breeding it (Heslinga 1995, 2013). However, because of its comparatively slow growth and poor early survival rates, it is often regarded as less suitable (not cost-effective) for aquaculture or mariculture operations, in spite of its desirability within the aquarium trade. 


\section{Contemporary threats and challenges}

Throughout their geographic range, representatives of the Tridacninae remain an important and valuable coastal resource to both local fishing communities and commercial markets. The relative abundance, shallow distribution, conspicuous appearance, and sessile nature of giant clams make them easy to harvest with simple fishing gear. During reef gleaning and free-diving (Hviding 1993, Sant 1995), individuals are usually collected opportunistically in areas of low densities, but they can be the main target of fishing trips in areas where densities are high. Their flesh is excised from the shells with knives, wooden sticks or metal stakes (Kinch \& Teitelbaum 2010). SCUBA and improvised diving apparatus such as hookah gear (a simple surface air-feed) are used to reach individuals in deeper waters (Hviding 1993, Ledua et al. 1993, Kinch \& Teitelbaum 2010). Almost all species of the Tridacninae have been exploited for meat as food, fish bait or animal feed, their shells sold to the curio trade, and exported live for the aquarium trade (Heslinga 1995, Sant 1995, Kinch \& Teitelbaum 2010, Neo \& Loh 2014).

Prior to the 1980s, commercial exports of tridacnine adductor muscles to Asian markets and illegal poaching by long-range foreign vessels were responsible for the severe stock reductions occurring in the Indo-Pacific (Pearson 1977, Dawson \& Philipson 1989, Shang et al. 1991, Sant 1995). Even though commercial exploitation of wild stocks is now banned in most countries, either poorly regulated or unregulated subsistence harvesting can still threaten remaining stocks (Tan \& Zulfigar 2003). Large-scale poaching also poses a major and persistent threat for wild populations. Coastal resource authorities from various countries (Australia, Cambodia, Malaysia and the Philippines) have reported an increase in the number of fishing boats harvesting giant clams illegally within the last five years (Krell et al. 2011, Lee 2014, Colbeck 2015, Gomez 2015b). The scale of this harvest is substantial, with almost 20 tonnes of shells reportedly removed from protected areas (Lee 2014). One of the largest Tridacna shell markets today is China. Many of the local fishermen from Tanmen, Hainan, have converted from traditional fishing to the more lucrative tridacnine fishing as their main livelihood (Zhang 2014). Shells of giant clams may have become a substitute for ivory, the import of which is now regulated strictly (Gomez 2015a,b, Cavell 2016, Larson 2016). As the shell craft industry flourishes in Tanmen, large quantities of fossilized giant clam shells have been extracted from the sea beds of Scarborough Shoal, the Spratlys and Paracel Islands (South China Sea) to support the handicraft industry (Zhang 2014, Gomez 2015a,b, Larson 2016). Large shells are carved into sculptures, with medium-sized shells processed into beads for jewellery. It is also thought that giant clam shells are increasingly being used to manufacture nuclei for the Chinese freshwater pearl industry (X. Fan, pers. comm.). Even though recent sources suggest that the local Chinese government has banned the harvesting of dead shells (Master 2016), the intense extraction has devastated large tracts of coral reefs within the South China Sea.

The habitats of tridacnines are also threatened as corals reefs throughout the Indo-Pacific become degraded (Huang 2012, Neo \& Todd 2012b). The pressure of anthropogenic activities threatens the health of reef environments and hence the survival and growth of the tridacnines that live in them. In a global meta-analysis for Tridacna maxima, Van Wynsberge et al. (2016) highlighted that, except for areas with very low human population density ( $<20$ inhabitants ha ${ }^{-1}$ of reef), giant clam densities tended to decrease as human presence increased. Giant clam densities were also strongly dependent on the type of reef (atoll, island, continent) — which is an important natural cofactor. In the northern Red Sea (Egypt), Mekawy \& Madkour (2012) showed that the abundance of T. maxima was higher at sites further away from anthropogenic sources and proposed that the main stressors were tourism, SCUBA diving, water pollution and contaminants, and the drilling for and production of oil. The survival, growth and photosynthetic performance of giant clams is significantly reduced when exposed to high copper concentration (tested at $50 \mu \mathrm{g} \mathrm{L}^{-1}$ ) (Elfwing et al. 2001) and reduced salinities (Eckman et al. 2014). Coastal urbanization also has negative effects on giant clam populations. For example, in Singapore, many of the reefs where giant clams were previously 
found have been buried as a result of large-scale land reclamation projects (Guest et al. 2008, Neo $\&$ Todd 2012a,b). The impacts of sedimentation on tridacnines are not yet well understood, but, in addition to affecting photosynthetic performance, sediment stress has been hypothesized to divert energy away from maximizing photosynthesis (e.g. by transporting inorganic ions to the zooxanthellae) to supporting behavioural responses and increased respiratory demands (Elfwing et al. 2001). A preliminary study by Ang (2014) revealed that juvenile T. squamosa was more susceptible to chronic sedimentation than to acute deposition events.

Climate warming may lead to undesirable effects on giant clams, where extremes in either temperature or ultraviolet irradiation can lead to poor growth, bleaching (the expulsion of photosynthetic symbionts), and increased mortality (Buck et al. 2002, Andréfouët et al. 2013, Junchompoo et al. 2013), particularly near the equator (Chaudhary et al. 2016). The few studies relevant to the impacts of climate change on tridacnines have focused on the effects of thermal stress and bleaching responses (Norton et al. 1995, Blidberg et al. 2000, Buck et al. 2002, Leggat et al. 2003), which have been shown to affect their growth negatively. Warming oceans can also lead to bleaching of both juveniles and broodstock individuals, resulting in the loss of productivity or lower survival of 'grow-out' stocks (Wilkinson \& Buddemeier 1994, Gomez \& Mingoa-Licuanan 1998). In the 2016 global mass coral bleaching event, bleaching incidences among giant clams varied across geographic sites: Tridacna maxima did not bleach in Mauritius (R. Bhagooli, pers. comm.), but those in Singapore (M.L. Neo, pers. obs.), Guam (A. Miller, pers. comm.) and East Tuamotu (S. Andréfouët, pers. obs.) were bleached severely. Interestingly, surveys of giant clam populations at Lizard Island, Australia, showed that the 2016 mass coral bleaching event and cyclones during the previous three years resulted in a much lower mortality rate for T. gigas compared to either T. derasa or T. squamosa, suggesting that $T$. gigas may be best able to survive after major perturbations in the GBR (A.D. Lewis, pers. comm.).

The detrimental effects of ocean acidification have also been demonstrated in juvenile giant clams, with experimental evidence showing that they exhibit negative shell growth (dissolution) (Waters 2008) and lower survival rates (Watson et al. 2012) in acidic conditions ( 600-1000 $\mu$ atm [60.8-101.3 $\mathrm{Pa}] p \mathrm{CO}_{2}$ ). Studies testing the combined effects of increasing temperature and $p \mathrm{CO}_{2}$ (based on climate projections for the end of this century) for 60 days showed that the shells of juvenile Tridacna squamosa were significantly altered with a decrease in calcium and magnesium ions (Armstrong et al. 2014), and lower survival rates (Watson et al. 2012, Watson 2015). Less is known about the effects of climate change stressors on early life-history stages, with only one study conducted to date. Neo et al. (2013b) tested the combined effects of temperature and salinity on T. squamosa fertilization and embryo development, and showed that salinity ( $27 \mathrm{psu}$ and $32 \mathrm{psu}$ ) had no significant effect on survival but mortality increased at the higher of the two temperatures tested $\left(22.5^{\circ} \mathrm{C}\right.$ and $\left.29.5^{\circ} \mathrm{C}\right)$. Climate change could also place additional economic and developmental pressures on giant clam mariculture operations. Increased temperatures in hatcheries can cause problems of algal overgrowth (M.L. Neo, pers. obs.), poor shell precipitation (Schwartzmann et al. 2011), and possibly premature spawning patterns, which are all undesired outcomes for spawning and rearing of juveniles.

Impacts due to the threats outlined above lead to the lowering of tridacnine population densities across their ranges in the wild, which has serious repercussions for their ability to reproduce successfully (Munro 1992). Fertilization success depends on the synchronized spawning of conspecifics (Lucas 1988, Gilbert et al. 2006a), as the trigger for sperm release is dependent on the chemical cues found on the eggs (Munro et al. 1983). Upon detection of the inducer, other neighbouring clams may also release eggs, thus encouraging progressive downstream fertilization. The tendency for tridacnines to aggregate has been attributed to their need to be close to each other to reproduce (Braley 1984, Huang et al. 2007, Soo \& Todd 2012, 2014). Giant clam populations are therefore highly sensitive to stock depletion, where sparse spawning adult populations can lead to lowered (or zero) fertilization rates and consequently reduced or absent recruitment rates (Munro 1992, Tan \& Zulfigar 1999, Neo et al. 2013a). To compound matters, as stocks become more scarce, 
harvesting size tends to decrease, meaning that individuals may be harvested even before reaching reproductive viability, thereby further affecting the availability of mates and limiting fertilization rates (i.e. component Allee effects) (Stephens et al. 1999). This could lead to the functional extinction and eventual collapse of the entire population (Frank \& Brickman 2000, Petersen \& Levitan 2001). Wild stocks may recover via the dispersal of planktonic larvae from other reefs brought in by prevailing currents (Benzie \& Williams 1992a,b, Tan \& Zulfigar 1999, 2001, Neo et al. 2013a). Such recovery, however, may take decades if coral reefs are isolated (due to the short [9-day] pelagic larval duration of giant clams), and/or currents are unfavourable (Yamaguchi 1977). Even in closed lagoons (with high retention rate) and with large stocks the recovery to initial population levels may still take decades. This is the case for Tatakoto Atoll, renowned for supporting the highest clam densities on record (Supplementary Table A3), but now depleted severely after a mass mortality event (Andréfouët et al. 2013). It may be many decades before densities such as those observed in 2004 (Gilbert et al. 2006a, Van Wynsberge 2016) will be witnessed again.

Cryptic species also present another challenge for the management and conservation of remaining tridacnine populations. When cryptic species become confused with contemporary common species, there are implications for commercial giant clam fisheries and their regulation due to the potential for misidentification (e.g. Rosewater 1982, Borsa et al. 2015b, Militz et al. 2015, Monsecour 2016). Additionally, the lack of knowledge regarding these species makes it difficult to implement appropriate conservation measures (Militz et al. 2015, Johnson et al. 2016). Previous systematic research on tridacnines relied heavily on morphological and behavioural characterization (e.g. Rosewater 1982, Lucas et al. 1991). These diagnostic characters can, however, be misleading in that giant clams generally are morphologically plastic and functionally similar (Benzie \& Williams 1998, Neo \& Todd 2011). During the last decade, the global use of genetic tools and breakthroughs in sequencing have led to the discovery of an increasing number of cryptic lineages (Pfenninger \& Schwenk 2007) hidden behind one species name (morphologically close, but genetically divergent). Yet, the conversion of genetically unique lineages into robust and formally named taxonomic entities remains challenging. Considering the recognized variability in tridacnine morphology, they are good candidates for crypticity. In 2008, phylogenetics helped to identify a cryptic Red Sea species: first described as a new species, Tridacna costata (Richter et al. 2008) and later synonymized as T. squamosina (Huber \& Eschner 2011). Subsequently, there has been the rediscovery of T. noae using various genetic markers (Su et al. 2014), and T. noae has turned out to be a widespread cryptic species in the Indo-Pacific (Borsa et al. 2015a,b, Militz et al. 2015, Johnson et al. 2016). Given the ambiguity of morphological characters among cryptic individuals, the growing body of molecular evidence can help reveal deep lineages across taxa and lead to the (re)discovery of species (Wilson \& Kirkendale 2016).

\section{Conservation and management}

\section{Legislation and regulations}

\section{Convention on International Trade in Endangered Species of Wild Fauna and Flora (CITES)}

The Convention on International Trade in Endangered Species of Wild Fauna and Flora (CITES) is recognized internationally as the governing body that oversees the trade exports and imports of selected endangered species. Giant clams are currently listed on Appendix II of CITES, which comprises species that are not necessarily now threatened with extinction, but that may become so unless trade is closely monitored. Tridacna gigas and T. derasa were first listed in 1983, and the other members of the family Tridacnidae (now subfamily Tridacninae) were listed in 1985 on the basis of so-called 'look alike species', i.e. species whose specimens in trade look like those of species listed for conservation reasons (Wells 1997). CITES states that the international trade 
in giant clams (whole or any part of the animal) is permitted only if the relevant export/import certifications are issued. The effectiveness of enforcing CITES is, however, largely dependent on whether the countries involved in the trade are signatories to the Treaty, or if a non-signatory is trading with the signatories (Wells 1997). In the past, countries such as Taiwan and the Maldives were involved heavily in the giant clam trade but were not CITES Parties, which impeded the implementation of CITES legislation (Wells 1997). Even in instances where exporting countries are CITES Parties, the trade data provided may be unreliable. In a number of examples capacity within relevant offices has been reduced, at times resulting in omissions, erroneous data entry (e.g. wrong source code, and submission of number of permits issued instead of actual numbers traded), and failure to submit or significant delays in providing trade statistics to the Secretariat (UNEP-WCMC 2011, C.C.C. Wabnitz, pers. obs.). Various workshops and other initiatives have been conducted to strengthen CITES capacity for countries in Oceania, including non-parties to the Convention (Table 4). Another concern, however, is that the scope of the CITES Treaty does not include localized collection and trade of giant clams within countries (which can be substantial), regardless of their status as a party to the convention. Relatedly, these countries may allow a quota of wild tridacnines to be collected and sold for the aquarium trade, but suppliers will usually collect only specimens with the highest value colours. This can result in genes for colour being reduced or lost from wild populations. Although not well understood, it is likely that mantle colours and their varieties (colour polymorphism) are ecologically important in natural reef settings (Todd et al. 2009).

\section{International Union for Conservation of Nature (IUCN)}

\section{Red List categories of threat}

Nine of the 12 species of Tridacninae are on the IUCN Red List of Threatened Species (Neo \& Todd 2013). Tridacna gigas, T. derasa and T. rosewateri are listed as 'Vulnerable', due to the rate of decline of remaining wild stocks. Tridacna mbalavuana is also listed as 'Vulnerable' on the basis of its small and declining area of occupancy, although it has been suggested that it should be categorized as 'Endangered' (Wells 1997). Hippopus hippopus, H. porcellanus, Tridacna maxima and T. squamosa are listed as 'Lower Risk/Conservation Dependent' due to the decline and disappearance of many populations. Tridacna crocea was initially excluded in the earlier Red Lists due to insufficient data (Wells 1997), but was reinstated in 1996 and listed as 'Lower Risk/Least Concern' (Molluscs Specialist Group 1996). The IUCN Red List of Threatened Species draws attention to species at risk of extinction and promotes their conservation (Collar 1996), and is frequently used to guide the management of resources (Rodrigues et al. 2006). It is, however, important to point out that 1) the global IUCN classifications for tridacnines are outdated as they were last reviewed by Wells $(1996) ; 2$ ) the reported status may not accurately reflect the situation within individual countries, e.g. Neo \& Todd (2013) for Singapore; and 3) recent species, i.e. T. lorenzi, T. noae and T. squamosina, are not yet on the IUCN Red List as their ecology, habitat occupancy and density have not been assessed. Given the decline in tridacnine stocks and their habitat, it is important to produce a definitive update of IUCN classifications for all 12 species, including promoting the use of localized or regional classifications to better represent situations 'on the ground' that are of greater value when planning conservation strategies (Neo \& Todd 2013).

\section{Local mitigation measures}

Regional efforts to initiate cooperation and collaboration among nations towards the management of sustainable giant clam fisheries have been few (e.g. Kinch \& Teitelbaum 2010), but much has been done locally to reduce exploitation. The conservation efforts implemented throughout the IndoPacific are listed in Table 4. The localities of Red Sea, Southeast Africa and the Indian Ocean generally lack specific laws to regulate recreational fishing of giant clams. In East Asia, restoration of impacted populations has begun, but mariculture there (except in Japan) is still in its infancy. In the South China Sea, tridacnines are, unfortunately, within disputed territorial waters, which 
makes agreeing and coordinating ocean governance among the numerous neighbours a substantial challenge. There have been a number of restocking efforts using mariculture in Southeast Asia, but the success of programmes has been variable at each locality (Indonesia, Malaysia, the Philippines, Singapore and Thailand). The management of tridacnine populations is most advanced in Australia and the Pacific Island nations. For example, some coastal communities in the South Pacific have put in place stricter measures to alleviate tridacnine fishing pressures (Table 4), including banning commercial fishing (Fiji, Papua New Guinea, Solomon Islands, Vanuatu, Federated States of Micronesia, Guam, Republic of Kiribati and Palau), setting minimum size limits for subsistence harvesting (French Polynesia, Niue, Samoa and Tonga), imposing harvesting quotas or bag limits (New Caledonia, American Samoa and the Cook Islands), restricting fishing to free diving only and banning the use of mechanical fishing equipment (Chambers 2008, Kinch \& Teitelbaum 2010, Andréfouët et al. 2013). Outcomes of these measures vary among the South Pacific nations as they depend on the degree of exploitation (i.e. a highly exploited population will take a longer recovery time), local enforcement measures and capacity, as well as community willingness to adopt these practices (Munro 1989, Lucas 1997). For instance, some Tongan communities set up giant clam 'circles' (i.e. aggregating adult clams into rings) to facilitate reproduction among individuals, and were able to repopulate nearby reefs with juveniles within ten months (Chesher 1993). Unfortunately, efforts do not appear to have been maintained and stocks in Tonga are severely depleted (C.C.C. Wabnitz, pers. obs.) - it is hoped that the regulation of selling giant clams in their shells to enforce size limits, which is widely respected, will help resolve this issue. In general, surveys throughout the region continue to indicate that populations are under severe stress (K. Pakoa, pers. comm.). Australia, India, China, Mauritius, Taiwan, and Japan have their own national protection acts that include giant clams (Table 4). Within Southeast Asia, it is generally recognized that tridacnines need protection, but only the Philippines, Malaysia and Thailand have national legislation regulating their exploitation (Knight et al. 2010, Gomez 2015a). Illegal fishing by coastal communities, however, remains prevalent in many of these countries, probably because of the traditional importance of giant clams as a coastal resource coupled with the lack of manpower and funding to support long-term monitoring, surveillance and law enforcement.

\section{Mariculture for restocking}

Giant clam breeding was pioneered in the 1970s at the University of Guam Marine Laboratory and the Micronesian Mariculture Demonstration Centre (MMDC) in Palau. It was further complemented by the work of John Lucas in Australia supported by the Australian Centre for International Agricultural Research in the 1980s, and consolidated by the work of ICLARM (now WorldFish) in the Solomon Islands in the late 1980s and early 1990s and, subsequently, supported the extensive research and technical training throughout the Pacific and Southeast Asia (e.g. Heslinga et al. 1984, Heslinga \& Fitt 1987, Heslinga 1991, Copland \& Lucas 1988, Braley 1992, Calumpong 1992, Norton \& Jones 1992, Tisdell 1992, Fitt 1993). Mariculture is being adopted increasingly for mass production of individuals for the aquarium trade (Heslinga et al. 1990, O'Callaghan 1995, Bell et al. 1997, Heslinga 2013) as well as the restocking of rare species (Neo et al. 2009, 2011, Neo \& Todd 2012a, Heslinga 2013) or extirpated populations (Braley \& Muir 1995, Gomez \& Mingoa-Licuanan 2006). Tridacnine mariculture has no apparent deleterious environmental effects (Lucas 1997), but there remains the possibility of inadvertently introducing exotic parasites, diseases and other biota (Newman \& Gomez 2000), especially if broodstocks are imported without appropriate quarantines. Combined with local community farm grow-out operations, such mariculture activities can provide sustainable livelihood opportunities in localities where there are few alternatives (e.g. remote atolls in French Polynesia, remote locations in the Solomon Islands, and outlying islands in the Marshall Islands), as long as projects are conceived and run as sustainable and cost-effective enterprises or projects. In many cases, however, poor survival, limited production, and hatchery expenses result 
in cost-ineffective production and eventual termination of activities. Nevertheless, as of 2016, there were at least 34 functioning giant clam hatcheries in 25 countries, and hundreds of ocean nurseries and reserves (G.A. Heslinga, pers. obs.).

While most giant clam hatcheries operate on some commercial (or semi-commercial) basis, some, generally with the support of foreign aid or other forms of subsidies, also function as a means to support conservation and facilitate sustainable harvesting (Lucas 1997, Heslinga 2012, see Table 4). In general, the success of these initiatives is neither well studied nor well documented (Teitelbaum \& Friedman 2008). Restocking programmes often do not have a set of protocols for fisheries officers and managers to follow, nor do they tend to be accompanied by regular monitoring to ascertain the success of such efforts over time (C.C.C. Wabnitz, pers. obs.). The survivorship of restocked clams varies widely within and among localities, with the main causes of mortality being predators, storms, poaching, and the lack of continuous husbandry (Lucas 1997, Southward et al. 2005, Heslinga 2013). In addition, hatchery-produced juveniles may be less genetically variable, which could increase vulnerability to parasites and diseases (Benzie \& Williams 1996). High mortality rates, coupled with the high costs and intensive labour of rearing giant clams to reach 'escape size' (typically $\sim 25 \mathrm{~mm}$ long, at which point they are less vulnerable to predators), may explain the waning enthusiasm and funding for restocking in some areas, notably Queensland (Australia) and the Solomon Islands, since the late 1980s (Bell 1999, Southward et al. 2005).

Restocking giant clams requires long-term commitment and monitoring, with examples of this mainly occurring in Palau, the Philippines and Japan, where mariculture, domestication and restocking have maintained momentum for over 20 years (Murakoshi 1986, Bell 1999, Gomez \& Mingoa-Licuanan 2006, Heslinga 2013). There are also many examples of maricultured giant clams being shipped around the Indo-Pacific region as juveniles in the 1980s and 1990s, matured in ocean nurseries in the destination countries, and then used as breeding stock in local hatcheries. Firm evidence that restocked clams have produced local juvenile recruitment is either absent of or poorly documented, probably owing in part to the remoteness of the areas under study, and the difficulty and expense of conducting authoritative surveys. Exceptions to this may be found in Yap (Federated States of Micronesia) and the Philippines, where Tridacna derasa and T. gigas, respectively, were restocked (Table 6) and where new recruits have been reported (Cabitan \& Conaco 2017). This is encouraging, as restocking without the creation of new generations will provide few long-term conservation benefits. How to ensure that restocked populations successfully reproduce and recruit is a major challenge for giant clam restoration efforts globally.

\section{Recent conservation approaches}

\section{Biophysical modelling for conservation}

At national and local (archipelago, island, reef) scales, giant clam conservation management has focused on fishing regulations and restocking (see previous sections). Assessing the effectiveness of such conservation efforts for a particular location requires an understanding, and ideally modelling, of processes and factors that influence their distribution and abundance. These include aspects of the species' biology, population dynamics (e.g. size-structure, density, recruitment, mortality), lifehistory traits (e.g. growth-fertility, reproduction and spawning occurrences) (Apte \& Dutta 2010, Black et al. 2011, Yau et al. 2014, Dolorosa et al. 2014, Neo et al. 2013b, 2015b, Menoud et al. 2016, Van Wynsberge et al. 2017), and larval flux (Neo et al. 2013a). Human uses and impacts are also important factors to consider (Van Wynsberge et al. 2015, 2016). Recently, mass mortality in semienclosed atolls due to unusual physical oceanographic conditions has been identified as a key driver of population dynamics (Andréfouët et al. 2013) and climate change is likely to make these events more frequent (Andréfouët et al. 2015). These examples highlight the importance of monitoring physical conditions and their integration into models (Neo et al. 2015b, Van Wynsberge et al. 2017). 
Table 6 An overview of reports of local recruitment after restocking efforts

\begin{tabular}{|c|c|c|c|c|c|}
\hline Locality & $\begin{array}{c}\text { Restocked } \\
\text { species }\end{array}$ & $\begin{array}{c}\text { Restocking } \\
\text { period }\end{array}$ & $\begin{array}{c}\text { Number of } \\
\text { restocked } \\
\text { individuals (life } \\
\text { stage; size range) }\end{array}$ & $\begin{array}{c}\text { Recruitment } \\
\text { monitoring } \\
\text { period }\end{array}$ & Remarks \\
\hline $\begin{array}{l}\text { Yap, Federated } \\
\text { States of } \\
\text { Micronesia }\end{array}$ & $\begin{array}{c}\text { Tridacna } \\
\text { derasa }\end{array}$ & 1984-1991 & $\begin{array}{l}\text { 1984-1989: } \\
8000(8-11 \mathrm{~cm}) \\
\text { 1988-1989: } \\
3500(6-8 \mathrm{~cm}) \\
\text { April 1991: } \\
2000(5-6 \mathrm{~cm}) \\
\text { Nov. } 1991: \\
2000(10 \mathrm{~cm})\end{array}$ & $\begin{array}{r}\text { 1991-2014 } \\
\text { (ongoing) }\end{array}$ & $\begin{array}{l}\text { Tridacna derasa juveniles were } \\
\text { found by local fishermen and } \\
\text { international experts from the } \\
\text { Secretariat of the Pacific } \\
\text { Community (SPC) in the early } \\
\text { 1990s (J.O. Fagolimul \& P. Dor, } \\
\text { pers. comm.) after an extensive } \\
\text { reintroduction program initiated in } \\
\text { the mid-1980s undertaken with } \\
\text { clams cultured at Palau's MMDC } \\
\text { (Price \& Fagolimul 1988, Heslinga } \\
\text { 1991, 1993a,b, 2013, Lindsay 1995, } \\
\text { Teitelbaum \& Friedman 2008). In } \\
\text { 2013-2014, some of these Yapese } \\
\text { T. derasa recruits reached full } \\
\text { maturity and were used with } \\
\text { replicated success as breeding stock } \\
\text { in a local hatchery managed by Mr. } \\
\text { Philip Dor (P. Dor, pers. comm.). } \\
\text { Mr. Dor has successfully produced } \\
\text { commercial numbers (hundreds of } \\
\text { thousands) of macroscopic } \\
\text { T. derasa juveniles in the Yap } \\
\text { hatchery, as verified by international } \\
\text { experts. }\end{array}$ \\
\hline Philippines & $\begin{array}{l}\text { Tridacna } \\
\text { gigas }\end{array}$ & $\begin{array}{l}\text { 1990s to } \\
\text { present- } \\
\text { day }\end{array}$ & $\begin{array}{l}\sim 45,000 \\
(\text { Sub-adults; } \\
>20 \mathrm{~cm})\end{array}$ & $\begin{array}{r}2007-2015 \\
\text { (ongoing) }\end{array}$ & $\begin{array}{l}\text { For }>20 \text { years, the Marine Science } \\
\text { Institute, University of the } \\
\text { Philippines, has been culturing giant } \\
\text { clam species for restoration of } \\
\text { depleted populations in the } \\
\text { Philippines. Several species were } \\
\text { initially restocked, but later efforts } \\
\text { focused on Tridacna gigas (Gomez } \\
\& \text { Mingoa-Licuanan 2006). Recruits } \\
\text { of } T \text {. gigas were first observed in } \\
\text { the vicinity of Bolinao, Pangasinan, } \\
\text { where the broodstock are placed } \\
\text { (Cabitan \& Conaco 2017). } \\
\text { Subsequently, occasional reports } \\
\text { have been received from at least two } \\
\text { other localities where restocking } \\
\text { was carried out. }\end{array}$ \\
\hline
\end{tabular}

Finally, but this has never been attempted, an ecosystem-based characterization including spatiotemporal variation in predation, competition, and food availability, is also likely to influence the accuracy of models simulating the effectiveness of conservation measures.

A pilot fishery-oriented modelling study on what could be the effects of management measures such as no-take areas, rotational closures, fishing quotas, and maximum or minimum catch sizes, 
on giant clam populations was undertaken by Van Wynsberge et al. (2013) for two islands of the Austral Archipelago in French Polynesia (Tubuai and Raivavae). This was the first spatially explicit model of giant clam population dynamics, based on maps of densities and habitat-specific age structure of populations. It was calibrated according to stock data quantified a few years apart, and parameterized and validated using limited local life-history traits and population dynamics data. More recently, the initial model was improved by including spatial patterns of fishing, mass mortality occurrences, size-structure per habitats, and refined population dynamics parameters following two years of surveys during which physical conditions were monitored (Van Wynsberge 2016). This more realistic model has been used to test the effects of conservation measures on Tridacna maxima populations. While such modelling opens new pathways for conservation and research, it requires intensive fieldwork for calibration/validation and substantial computing resources.

The models described above cannot be implemented easily and duplication at new sites needs caution, but staged efforts and priorities can be recommended. An important aspect is spatial variability. Different locations along either a reef or lagoon, for example, can display different tridacnine densities as a result of the combination of a number of biophysical processes, such as those associated with coastal hydrodynamics, climate change and pollution (Zuschin \& Piller 1997, Green \& Craig 1999, Andréfouët et al. 2005, Neo \& Todd 2012b, Ullmann 2013). It is, therefore, desirable to first map the continuum of giant clam density across a reef system together with the clam sizestructure (Andréfouët et al. 2005, 2009, Gilbert et al. 2006b). Ideally, the spatial characterization of density and size-structure should be used to determine where to monitor population dynamics and life traits and, if there is ongoing human exploitation, focal sites should be selected to represent both exploited and refuge areas.

Information about larval dispersal is another critical input for conservation modelling. The priority level for such work is dependent on the degree of closure and isolation of the studied reef, or sets of reefs. In Singapore, for instance, there is a continuum of reefs along the continent and island shores organized in a dense matrix, and understanding larval dispersal of Tridacna squamosa among reefs and (meta-)populations is necessary for the sound management of this species (Neo et al. 2013a). Conversely, the populations of T. maxima in the east Tuamotu archipelago of French Polynesia presents an opposing scenario, where remote and hydrodynamically closed atoll lagoons are more self-recruiting with limited flux from outside compared to open lagoons. While fluxes between atolls may be important for genetics, they are negligible in term of demography and fishery management (Van Wynsberge et al. 2016).

Biophysical modelling for conservation of giant clams is a new, complex and exciting task; however, it requires diverse spatial and temporal information that is difficult and costly to acquire. Nevertheless, population dynamics modelling and connectivity modelling are needed to create a holistic dynamic framework that can be applied to multiple locations, as well as to foster ambitious informative multidisciplinary studies to enhance knowledge for giant clam conservation.

\section{Genetic information and evolutionary relationships for conservation planning}

As molecular genetics techniques become more efficient and cost-effective, it is increasingly common for conservation managers to use genetic data in prioritizing species conservation (e.g. Huang 2012, Neo \& Todd 2012b, Beger et al. 2014, von der Heyden et al. 2014). Fundamentally, genetic data offer insights into genetic diversity, population connectivity, and the evolutionary history of species (Beger et al. 2014). Such information provides the opportunity to investigate cryptic species diversity (discussed earlier in 'Contemporary threats and challenges'), spatial ecological interactions (Selkoe et al. 2008), as well as the evolutionary potential of species (Peijnenburg \& Goetze 2013). The genetic structure of giant clam populations has been of interest since the 1990s, mainly to differentiate populations (e.g. Benzie \& Williams 1992a,b, 1995, Macaranas et al. 1992), although none of these previous studies mentioned the incorporation of genetic information for 
spatial conservation prioritization. Subsequent giant clam population genetic studies have provided opportunities to develop phylogenetically-informed management strategies (e.g. DeBoer et al. 2008, Kochzius \& Nuryanto 2008, Neo \& Todd 2012b).

Another genetic-based conservation approach is the consideration of evolutionary relationships within a clade of target species (Faith 1992, 2007), especially for species that may be at risk of extinction and thus lead to loss of phylogenetic diversity (Huang \& Roy 2013, Curnick et al. 2015). One such platform is the EDGE (Evolutionarily Distinct and Globally Endangered) of Existence programme that converts IUCN threat categories to probabilities of extinction for phylogenetic conservation prioritization (Redding \& Mooers 2006, Mooers et al. 2008). The current programme has applied these metrics to major taxonomic groups such as mammals (Isaac et al. 2007, Safi et al. 2013) and amphibians (Isaac et al. 2012, Safi et al. 2013), but not to invertebrate taxa, with the exception of the Scleractinia (Huang 2012, Huang \& Roy 2013). Given that wild tridacnines today are facing an array of threats, the use of phylogenetic diversity and evolutionary distinctiveness could help to hasten the evaluation of species' extinction risk.

Beyond phylogeny, in principle, larval dispersal and population genetic information can contribute to the design of more effective reserve networks by ensuring that all identified (meta-)populations are represented within them and by protecting source areas (Fogarty \& Botsford 2007). All published studies thus far have used water circulation models and simulation of passive drifters to predict and explain (or not) the spatial patterns in genetic or demographic observations. In Indonesia, DeBoer et al. (2008) found poor agreement between larval dispersal distances of Tridacna crocea inferred from passive larval dispersal modelling and from genetic data. Van Wynsberge (2016) showed that biophysical models are in better agreement with T. maxima genetic observations in New Caledonia if habitat distribution and population densities are taken into account. Reaching an agreement between models and empirical in situ data is also likely largely dependent on enhanced realistic biophysical model forcing, with the necessary future inclusion of larval behaviour, settlement processes, fine-scale coastal hydrodynamics, habitat distribution, and so on (Dumas et al. 2014, Neo et al. 2013a, 2015b, Soo \& Todd 2014, Van Wynsberge 2016). All these represent significant long-term challenges.

\section{The future of giant clams?}

This review synthesizes the current state of knowledge on giant clam taxonomy, distribution and abundance, exploitation and other threats, and conservation issues. In general, there exists a global consensus that tridacnines in many localities are endangered, especially the larger species, Tridacna gigas and T. derasa, where $>50 \%$ of naturally occurring populations are severely depleted, locally extinct, or data deficient. The combination of increased commercial demand (including large-scale illegal fisheries) coupled with advances in fishing techniques, transport and storage have had significant negative impacts. Overharvesting for human use (consumption and materials) is probably the greatest driver of decline. Climate change, pollution, habitat loss and coastal development are additional factors that can deleteriously influence the survival of remaining stocks. As a result of lowered densities, populations are potentially experiencing component Allee effects (i.e. low-density constraints on fertilization efficacy), thus impairing their capacity to reproduce successfully in the wild (Neo et al. 2013a). Furthermore, the genetic diversity of populations may already have been reduced irretrievably in many areas. CITES listings and the IUCN Red List of Threatened categories have helped to raise awareness of the threats giant clams face, regulate trade and mitigate the decline of remnant populations. Local measures such as the enforcement of laws to regulate (or ban) both subsistence and commercial fishing (i.e. South Pacific), as well as mariculture and restocking to help maintain population numbers (i.e. Southeast Asia, Australia and the Pacific) have had some success. There is, however, a lack of standard protocols and regular monitoring to ascertain success 
of these mitigation measures on a local scale. Decades of giant clam research have also contributed to our understanding of their systematics, biology, physiology and ecological significance, which has helped to reinforce the case for protecting these charismatic molluscs (Neo et al. 2015a).

Even though substantial effort and resources have been injected into giant clam conservation since the 1970s, positive results are limited. Successes are generally due to the availability of large sums of financial aid to support the continuity of programmes, strong governance to implement fishery policies, as well as the involvement of local communities to take ownership of their coastal resources and help manage them. Updated data and new conservation approaches such as biophysical modelling and molecular genetic tools will be needed to help resolve fundamental issues such as larval dispersal and connectivity, fishery projections, cryptic species and population genetics. Mariculture also has a complementary role in the conservation of giant clams, as it is capable of producing large numbers of individuals to assist the restoration of depleted populations, and it may relieve some fishing pressures. Collectively, these approaches should help to prevent local extinctions of larger species (e.g. Tridacna gigas and T. derasa) and avoid the population collapse of smaller ones (e.g. T. maxima). Towards these important goals, the following fundamental ecological questions need to be resolved:

- What is the minimum number and density of giant clams (i.e. minimum viable population) needed to ensure that a population remains reproductive and yield genetically diverse progeny in the wild? Sexually mature individuals are becoming rare, and are therefore a limiting factor in reproductive success. These data are also key for restocking endeavours.

- Where and how should aggregations of restocked individuals be spatially arranged on reefs to optimize both fertilization success, survival and dispersal of larvae? Giant clams are broadcast spawners and aggregation is necessary to promote both spawning and fertilization success. However, data such as the minimum distances required between spawning individuals remain limited.

- What is the genetic connectivity, and larval dispersal extent, of wild giant clam populations locally, regionally and globally? An understanding of how populations are related promotes appropriate boundary management among populations. Such data can also contribute towards the maintenance of genetic diversity within regions, and will be especially useful for informing translocation and restocking endeavours.

- What are the phylogenetic relationships among giant clam species? This information is fundamental to the correct identification of species and subsequent planning of speciesspecific policies.

- How might giant clams (both in the wild and mariculture) acclimatize/adapt to anthropogenic threats, such as warming oceans and ocean acidification? There has been some progress on this front, mostly via manipulative experiments, but impacts on wild stocks and mariculture production are poorly understood.

These questions highlight the paucity of essential ecological data available to resource managers trying to improve the success of restocking giant clams, as well as conservation planners designing legislation to ensure sustainable exploitation. In addition to science-based conservation and management, it is critical to engage all stakeholders and increase conservation literacy through education, outreach and capacity building. Emphasizing the ecological benefits of giant clams and the consequences of overexploitation can help bring about changes in attitude and lead to improved fishing practices. Enforcement of existing regulations and the implementation of locally-appropriate new legislation is also crucial if populations are to be protected. 


\section{Acknowledgements}

This review would not have been possible if not for the following who provided so much invaluable information: Steven Ng, Oceanic Quest Company (Brunei), Jessica Savage (Cambodia), Coral Cay Conservation (Cambodia), Yuehuan Zhang, Ziniu Yu and Xubing Fan (China), Allison Miller (Guam), Sundy Ramah and Ranjeet Bhagooli (Mauritius), D. Thoma (Nauru), Keryea Soong, Li-Lian Liu and Hei-Nin Kwong (Taiwan), Jeffrey Low, Jim Wong, Hiu Fung Wong, Denise Cheong and Youna Lyons (Singapore), and Reef Check Foundation (Worldwide). For the image of Tridacna squamosina, we thank Gustav Paulay, Michael Berumen and KAUST (Red Sea), and the research cruise was supported by a KAUST Collaborative Research Grant (URF/1/1389-01-01). Research on giant clam population and mariculture in French Polynesia has been supported by the Direction des Ressources Marines et Minières, under the leadership of Georges Remoissenet. Author C.C.C. Wabnitz would like to acknowledge the financial support from Australia (DFAT) to SPC's FAME division as well as the information provided by her colleagues from the SPC network, particularly John Hambrey, Antoine Teitelbaum, Georges Remoissenet, Ian Bertram and Richard Story. Author A.S.-H. Tan would like to acknowledge the Marine Ecology Research Centre, Sabah for the information provided. Author M.L. Neo would like to acknowledge the National Research Foundation Singapore for supporting her research endeavours at the St. John's Island National Marine Laboratory. This work was partially supported by the National Parks Board's Coastal \& Marine Environment grant number R-154-000-568-490, and the L'Oréal-UNESCO For Women in Science National Fellowship 2015.

\section{References}

Accordi, G., Brilli, M., Carbone, F. \& Voltaggio, M. 2010. The raised coral reef complex of the Kenyan coast: Tridacna gigas U-series dates and geological implications. Journal of African Earth Sciences 58, $97-114$.

Alcazar, S.N. 1986. Observations on predators of giant clams (Bivalvia: Family Tridacnidae). Silliman Journal 33, 54-57.

Alcazar, S.N., Solis, E.P. \& Alcala, A.C. 1987. Serotonin-induced spawning and larval rearing of the china clam Hippopus porcellanus Rosewater (Bivalvia, Tridacnidae). Aquaculture 66, 359-368.

Andréfouët, S., Dutheil, C., Menkes, C.E., Bador, M. \& Lengaigne, M. 2015. Mass mortality events in atoll lagoons: environmental control and increased future vulnerability. Global Change Biology 21, 195-205.

Andréfouët, S., Friedman, K., Gilbert, A. \& Remoissenet, G. 2009. A comparison of two surveys of invertebrates at Pacific Ocean Islands: the giant clam at Raivavae Island, Australes Archipelago, French Polynesia. ICES Journal of Marine Science 66, 1825-1836.

Andréfouët, S., Gilbert, A., Yan, L., Remoissenet, G., Payri, C. \& Chancerelle, Y. 2005. The remarkable population size of the endangered clam Tridacna maxima assessed in Fangatau atoll (Eastern Tuamotu, French Polynesia) using in situ and remote sensing data. ICES Journal of Marine Science 62, 1037-1048.

Andréfouët, S., Van Wynsberge, S., Fauvelot, C., Bruckner, A.W. \& Remoissenet, G. 2014. Significance of new records of Tridacna squamosa Lamarck, 1819, in the Tuamotu and Gambier Archipelagos (French Polynesia). Molluscan Research 34, 277-284.

Andréfouët, S., Van Wynsberge, S., Gaertner-Mazouni, N., Menkes, C., Gilbert, A. \& Remoissenet, G. 2013. Climate variability and massive mortalities challenge giant clam conservation and management efforts in French Polynesia atolls. Biological Conservation 160, 190-199.

Ang, C.F.A. 2014. Responses of juvenile fluted giant clams (Tridacna squamosa) to experimentally enhanced sedimentation. Honours Thesis, National University of Singapore, Singapore.

Apte, D. \& Dutta, S. 2010. Ecological determinants and stochastic fluctuations of Tridacna maxima survival rate in Lakshadweep Archipelago. Systematics and Biodiversity 8, 461-469.

Armstrong, E.J., Watson, S.-A., Calosi, P., Munday, P. \& Stillman, J. 2014. Increased temperature and lowered $\mathrm{pH}$ altered shell mineralogy of the scaled giant clam (Tridacna squamosa). Integrative and Comparative Biology (Society for Integrative and Comparative Biology - Meeting Abstract) 54, E238. 
Asato, S. 1991. The distribution of Tridacna shell adzes in the Southern Ryukyu Islands. In Indo-Pacific Prehistory 1990, P. Bellwood (ed.). Indo-Pacific Prehistory Association Bulletin 10, 1991, 282-291.

Baldo, B.A. \& Uhlenbruck, G. 1975. Quantitative precipitin studies on the specificity of an extract from Tridacna maxima (Röding). Carbohydrate Research 40, 143-151.

Beckvar, N. 1981. Cultivation, spawning and growth of the giant clams Tridacna gigas, Tridacna derasa and Tridacna squamosa in Palau, Caroline Islands. Aquaculture 24, 21-30.

Beger, M., Selkoe, K.A., Treml, E., Barber, P.H., von der Heyden, S., Crandall, E.D., Toonen, R.J. \& Riginos, C. 2014. Evolving coral reef conservation with genetic information. Bulletin of Marine Science 90, 159-185.

Bell, J.D. 1999. Restocking of giant clams: progress, problems and potential. In Stock Enhancement and Sea Ranching. First International Symposium on Stock Enhancement and Sea Ranching, Bergen, Norway, 8-11 September 1997, B.R. Howell et al. (eds). Bergen, Norway. Oxford: Blackwell Science, 437-452.

Bell, J.D., Lane, I., Gervis, M., Soule, S. \& Tafea, H. 1997. Village-based farming of the giant clam, Tridacna gigas (L.), for the aquarium market: initial trials in Solomon Islands. Aquaculture Research 28, 121-128.

Bell, J.D., Rothlisberg, P.C., Munro, J.L., Loneragan, N., Nash, W., Ward, R. \& Andrew, N. 2005. Restocking and stock enhancement of marine invertebrate fisheries. Advances in Marine Biology 49, 1-370.

Benzie, J.A.H. \& Williams, S.T. 1992a. Genetic structure of giant clam (Tridacna maxima) populations from reefs in the Western Coral Sea. Coral Reefs 11, 135-141.

Benzie, J.A.H. \& Williams, S.T. 1992b. No genetic differentiation of giant clam (Tridacna gigas) populations in the Great Barrier Reef, Australia. Marine Biology 113, 373-377.

Benzie, J.A.H. \& Williams, S.T. 1995. Gene flow among giant clam (Tridacna gigas) populations in Pacific does not parallel ocean circulation. Marine Biology 123, 781-787.

Benzie, J.A.H. \& Williams, S.T. 1996. Limitations in the genetic variation of hatchery produced batches of giant clam, Tridacna gigas. Aquaculture 139, 225-241.

Benzie, J.A.H. \& Williams, S.T. 1998. Phylogenetic relationships among giant clam species (Mollusca: Tridacnidae) determined by protein electrophoresis. Marine Biology 132, 123-133.

Black, R., Johnson, M.S., Prince, J., Brearley, A. \& Bond, T. 2011. Evidence of large, local variations in recruitment and mortality in the small giant clam, Tridacna maxima, at Ningaloo Marine Park, Western Australia. Marine and Freshwater Research 62, 1318-1326.

Blidberg, E., Elfwing, T., Plantman, P. \& Tedengren, M. 2000. Water temperature influences on physiological behaviour in three species of giant clams (Tridacnidae). Proceedings 9th International Coral Reef Symposium, Bali, Indonesia, 23-27 October 2000, M.K. Moosa et al. (eds). Jakarta: Indonesian Institute of Sciences, Jakarta: Ministry of Environment, Honolulu, Hawaii: International Society for Reef Studies, 561-565.

Borsa, P., Fauvelot, C., Andréfouët, S., Chai, T.-T., Kubo, H. \& Liu, L.-L. 2015a. On the validity of Noah's giant clam Tridacna noae (Röding, 1798) and its synonymy with Ningaloo giant clam Tridacna ningaloo Penny and Willan, 2014. Raffles Bulletin of Zoology 63, 484-489.

Borsa, P., Fauvelot, C., Tiavouane, J., Grulois, D., Wabnitz, C., Abdon Naguit, M.R. \& Andréfouët, S. 2015 b. Distribution of Noah's giant clam, Tridacna noae. Marine Biodiversity 45, 339-344.

Bouchet, P., Heros, V., Le Goff, A., Lozouet, P. \& Maestrati, P. 2001. Atelier biodiversité Lifou 2000: grottes et récifs coralliens. Rapports de Missions, Science de la Mer, Biologie Marine, No. 26. Institut de recherche pour le développement, Noumea, New Caledonia. Online. http://horizon.documentation.ird. fr/exl-doc/pleins_textes/divers15-06/010031564.pdf (accessed 19 December 2016).

Braley, R.D. 1984. Reproduction in the giant clams Tridacna gigas and T. derasa in situ on the North-Central Great Barrier Reef, Australia, and Papua New Guinea. Coral Reefs 3, 221-227.

Braley, R.D. 1986. Reproduction and recruitment of giant clams and some aspects of their larval and juvenile biology. PhD Thesis, University of New South Wales, Australia.

Braley, R.D. 1987a. Distribution and abundance of the giant clams Tridacna gigas and T. derasa on the Great Barrier Reef. Micronesica 20, 215-223.

Braley, R.D. 1987b. Spatial distribution and population parameters of Tridacna gigas and T. derasa. Micronesica 20, 225-246.

Braley, R.D. 1988. Recruitment of the giant clams Tridacna gigas and T. derasa at four sites on the Great Barrier Reef. In Giant Clams in Asia and the Pacific, J.W. Copland \& J.S. Lucas (eds). ACIAR Monograph No. 9. Canberra: Australian Centre for International Agricultural Research, 73-77. 
Braley, R.D. 1992. The Giant Clam: Hatchery and Nursery Culture Manual. ACIAR Monograph No. 15. Canberra: Australian Centre for International Agricultural Research.

Braley, R.D. 1996. The importance of aquaculture and establishment of reserves for the restocking of giant clams on over-harvested reefs in the Indo-Pacific region. In The Role of Aquaculture in World Fisheries, T.G. Heggberget (ed.). Proceedings of the World Fisheries Congress, Theme 6. New Delhi: Oxford \& IBH Publishing, 136-147.

Braley, R.D. \& Healy, J.M. 1998. Superfamily Tridacnoidea. In Mollusca: The Southern Synthesis, Fauna of Australia. Vol. 5, P.L. Beesley et al. (eds). Melbourne: CSIRO Publishing, Part A, 332-336.

Braley, R.D. \& Muir, F. 1995. The case history of a large natural cohort of the giant clam Tridacna gigas (Fam. Tridacnidae) and the implications for restocking depauperate reefs with maricultured giant clams. Asian Fisheries Science 8, 229-237.

Braley, R.D., Nash, W.J., Lucas, J.S. \& Crawford, C.M. 1988. Comparison of different hatchery and nursery culture methods for the giant clam Tridacna gigas. In Giant Clams in Asia and the Pacific, J.W. Copland \& J.S. Lucas (eds). ACIAR Monograph No. 9. Canberra: Australian Centre for International Agricultural Research, 110-114.

Brown, J.H. \& Muskanofola, M.R. 1985. An investigation of stocks of giant clams (family Tridacnidae) in Java and of their utilization and potential. Aquaculture and Fisheries Management 1, 25-39.

Bruce, A.J. 2000. Biological observations on the commensal shrimp Paranchistus armatus (H. Milne Edwards) (Crustacea: Decapoda: Pontoniinae). Beagle (Records of the Museum and Art Galleries Northern Territory) 16, 91-96.

Bryan, P.G. \& McConnell, D.B. 1976. Status of giant clam stocks (Tridacnidae) on Helen Reef, Palau, Western Caroline Islands, April 1975. Marine Fisheries Review 38, 15-18.

Buck, B.H., Rosenthal, H. \& Saint-Paul, U. 2002. Effect of increased irradiance and thermal stress on the symbiosis of Symbiodinium microadriaticum and Tridacna gigas. Aquatic Living Resources 15, 107-117.

Cabaitan, P.C. \& Conaco, C. 2017. Bringing back the giants: juvenile Tridacna gigas from natural spawning of restocked giant clams. Coral Reefs, doi:10.1007/s00338-017-1558-9

Cabaitan, P.C., Gomez, E.D. \& Aliño, P.M. 2008. Effects of coral transplantation and giant clam restocking on the structure of fish communities on degraded patch reefs. Journal of Experimental Marine Biology and Ecology 357, 85-98.

Calumpong, H.P. 1992. The Giant Clam: An Ocean Culture Manual. ACIAR Monograph No. 16. Canberra: Australian Centre for International Agricultural Research.

Calumpong, H.P., Ablan, M.C., Macaranas, J., Solis-Duran, E., Alcazar, S. \& Abdon-Naguit, R. 1993. Biochemical evidence of self-fertilisation in Hippopus species. In The Biology and Mariculture of Giant Clams: A Workshop Held in Conjunction with the 7th International Coral Reef Symposium 21-26 June 1992, Guam, USA, W.K. Fitt (ed.). ACIAR Proceedings No. 47. Canberra: Australian Centre for International Agricultural Research, 99-110.

Calumpong, H.P. \& Cadiz, P. 1993. Observations on the distribution of giant clams in protected areas. Silliman Journal 36, 107-113.

Calumpong, H.P. \& Solis-Duran, E. 1993. Constraints in restocking Philippine reefs with giant clams. In The Biology and Mariculture of Giant Clams: A Workshop Held in Conjunction with the 7th International Coral Reef Symposium 21-26 June 1992, Guam, USA, W.K. Fitt (ed.). ACIAR Proceedings No. 47. Canberra: Australian Centre for International Agricultural Research, 94-98.

Carlson, B.C. 2012. Waikiki Aquarium's giant clams mark 30-year anniversary. CORAL Magazine 9, 54-60.

Cavell, N. 2016. Blame an ivory ban for China's vanishing giant clams. WIRED, 10 February 2016. Online. http://www.wired.com/2016/02/blame-an-ivory-ban-for-chinas-vanishing-giant-clams/ (accessed 29 February 2016).

Chambers, C.N.L. 2008. Pasua and the politics of environmental management, Tongareva, Cook Islands. Scottish Geographical Journal 124, 192-197.

Chaudhary, C., Saeedi, H. \& Costello, M.J. 2016. Bimodality of latitudinal gradients in marine species richness. Trends in Ecology \& Evolution 31, 670-676.

Chesher, R.H. 1993. Giant clam sanctuaries in the Kingdom of Tonga. Marine Studies of the University of the South Pacific Technical Report Series 95/2. Suva, Fiji: University of the South Pacific. Online. http://www.tellusconsultants.com/chesher-1993-Giant\%20Clam\%20Sanctuaries\%20in\%20the\%20 Kingdom\%20of\%20Tonga.pdf (accessed 19 December 2016). 
Colbeck, R. 2015. Clams to help slam trade shut. Canberra: Australian Fisheries Management Authority. Online. http://www.afma.gov.au/clams-help-slam-trade-shut/ (accessed 26 February 2016).

Collar, N.J. 1996. The reasons for Red Data Books. Oryx 30, 121-130.

Copland, J.W. \& Lucas, J.S. (eds) 1988. Giant Clams in Asia and the Pacific. ACIAR Monograph No. 9. Canberra: Australian Centre for International Agricultural Research.

Cox, L.R. 1941. Lamellibranchs from the White Limestone of Jamaica. Proceedings of the Malacological Society, London 24, 135-144.

Crawford, C.M., Lucas, J.S. \& Munro, J.L. 1987. The mariculture of giant clams. Interdisciplinary Science Reviews 12, 333-340.

Cumming, R.L. 1988. Pyramidellid parasites in giant clam mariculture systems. In Giant Clams in Asia and the Pacific, J.W. Copland \& J.S. Lucas (eds). ACIAR Monograph No. 9. Canberra: Australian Centre for International Agricultural Research, 231-236.

Curnick, D.J., Head, C.E.I., Huang, D., Crabbe, M.J.C., Gollock, M., Hoeksema, B.W., Johnson, K.G., Jones, R., Koldewey, H.J., Obura, D.O., Rosen, B.R., Smith, D.J., Taylor, M.L., Turner, J.R., Wren, S. \& Redding, D.W. 2015. Setting evolutionary-based conservation priorities for a phylogenetically data-poor taxonomic group (Scleractinia). Animal Conservation 18, 303-312.

Dawson, B. 1986. Report on a study of the market for giant clam products in Taiwan, Japan, Hong Kong and Singapore. FFA Report No. 86/37, Honiara, Solomon Islands: Pacific Islands Forum Fisheries Agency. Online. www.spc.int/DigitalLibrary/Doc/FAME/FFA/Reports/FFA_1986_037.pdf (accessed 13 April 2017).

Dawson, R.F. \& Philipson, P.W. 1989. The market for giant clam in Japan, Taiwan, Hong Kong and Singapore. In The Marketing of Marine Products from the South Pacific, P.W. Philipson (ed.). Suva, Fiji: Institute of Pacific Studies of the University of the South Pacific, 90-123.

DeBoer, T.S., Abdon-Naguit, M.R., Erdmann, M.V., Ablan-Lagman, M.C.A., Ambariyanto, Carpenter, K.E., Toha, A.H.A. \& Barber, P.H. 2014. Concordance between phylogeographic and biogeographic boundaries in the Coral Triangle: conservation implications based on comparative analyses of multiple giant clam species. Bulletin of Marine Science 90, 277-300.

DeBoer, T.S., Baker, A.C., Erdmann, M.V., Ambariyanto, Jones, P.R. \& Barber, P.H. 2012. Patterns of Symbiodinium distribution in three giant clam species across the biodiverse Bird's Head region of Indonesia. Marine Ecology Progress Series 444, 117-132.

DeBoer, T.S., Subia, M.D., Ambariyanto, Erdmann, M.V., Kovitvongsa, K. \& Barber, P.H. 2008. Phylogeography and limited genetic connectivity in the endangered boring giant clam across the Coral Triangle. Conservation Biology 22, 1255-1266.

Dolorosa, R.G., Conales, S.F. \& Bundal, N.A. 2014. Shell dimension-live weight relationships, growth and survival of Hippopus porcellanus in Tubbataha Reefs Natural Park, Philippines. Atoll Research Bulletin 604, 1-9.

Dolorosa, R.G. \& Jontila, J.B.S. 2012. Notes on common macrobenthic reef invertebrates of Tubbataha Reefs Natural Park, Philippines. Science Diliman 24, 1-11.

Dumas, P., Fauvelot, C., Andréfouët, S. \& Gilbert, A. 2011. Les benitiers en Nouvelle-Caledonie: Statut des populations, impacts de l'exploitation \& connectivitié. Rapport final d'opération, Programme ZONECO, Avril 2011. Noumea, New Caledonia: Zonéco. Online. http://www.zoneco.nc/documents/les-benitiersde-nouvelle-caledonie-statut-des-populations-impact-de-lexploitation-et (accessed 19 December 2016).

Dumas, P., Tiavouane, J., Senia, J., Willam, A., Dick, L. \& Fauvelot, C. 2014. Evidence of early chemotaxis contributing to active habitat selection by the sessile giant clam Tridacna maxima. Journal of Experimental Marine Biology and Ecology 452, 63-69.

Eckman, W., Vicentuan-Cabaitan, K. \& Todd, P.A. 2014. Observations on the hyposalinity tolerance of fluted giant clam (Tridacna squamosa, Lamarck 1819) larvae. Nature in Singapore 7, 111-116.

Elfwing, T., Plantman, P., Tedengren, M. \& Wijnbladh, E. 2001. Responses to temperature, heavy metal and sediment stress by the giant clam Tridacna squamosa. Marine and Freshwater Behaviour and Physiology 34, 239-248.

Eliata, A., Zahida, F., Wibowo, N.J. \& Panggabean, L.M.G. 2003. Abundance of giant clam in coral reef ecosystem at Pari Island: A population comparison of 2003's to 1984's data. Biota 8, 149-152.

Faith, D.P. 1992. Conservation evaluation and phylogenetic diversity. Biological Conservation 61, 1-10. 
Faith, D.P. 2007. Threatened species and the potential loss of phylogenetic diversity: Conservation scenarios based on estimated extinction probabilities and phylogenetic risk analysis. Conservation Biology 22, 1461-1470.

Fankboner, P.V. 1971. Intracellular digestion of symbiotic zooxanthellae by host amoebocytes in giant clams (Bivalvia: Tridacnidae), with a note on the nutritional role of the hypertrophied siphonal epidermis. Biological Bulletin 141, 222-234.

Fitt, W.K. 1988. Role of zooxanthellae in the mariculture of giant clams. In Giant Clams in Asia and the Pacific, J.W. Copland \& J.S. Lucas (eds). ACIAR Monograph No. 9. Canberra: Australian Centre for International Agricultural Research, 166-169.

Fitt, W.K. (ed.) 1993. The Biology and Mariculture of Giant Clams: A Workshop Held in Conjunction with the 7th International Coral Reef Symposium 21-26 June 1992, Guam, USA. ACIAR Proceedings No. 47. Canberra: Australian Centre for International Agricultural Research.

Fitt, W.K. \& Trench, R.K. 1981. Spawning, development, and acquisition of zooxanthellae by Tridacna squamosa (Mollusca, Bivalvia). Biological Bulletin 161, 213-235.

Fogarty, M.J. \& Botsford, L.W. 2007. Population connectivity and spatial management of marine fisheries. Oceanography 20, 112-123.

Frank, K.T. \& Brickman, D. 2000. Allee effects and compensatory population dynamics within a stock complex. Canadian Journal of Fisheries and Aquatic Sciences 57, 513-517.

Gilbert, A., Andréfouët, S., Yan, L. \& Remoissenet, G. 2006b. The giant clam Tridacna maxima communities of three French Polynesia islands: comparison of their population sizes and structures at early stages of their exploitation. ICES Journal of Marine Science 63, 1573-1589.

Gilbert, A., Planes, S., Andréfouët, S., Friedman, K. \& Remoissenet, G. 2007. First observation of the giant clam Tridacna squamosa in French Polynesia: a species range extension. Coral Reefs 26, 229 only.

Gilbert, A., Remoissenet, G., Yan, L. \& Andréfouët, S. 2006a. Special traits and promises of the giant clam (Tridacna maxima) in French Polynesia. SPC Fisheries Newsletter 118, 44-52.

Gilbert, A., Yan, L., Remoissenet, G., Andréfouët, S., Payri, C. \& Chancerelle, Y. 2005. Extraordinarily high giant clam density under protection in Tatakoto Atoll (eastern Tuamotu Archipelago, French Polynesia). Coral Reefs 24, 495 only.

Gomez, E.D. 2015a. Rehabilitation of biological resources: coral reefs and giant clam populations need to be enhanced for a sustainable marginal sea in the western Pacific. Journal of International Wildlife Law and Policy 18, 120-127.

Gomez, E. 2015b. Destroyed reefs, vanishing giant clams. Inquirer.net, 3 May 2015. Online. http://opinion. inquirer.net/84595/destroyed-reefs-vanishing-giant-clams (accessed 26 February 2016).

Gomez, E.D. \& Mingoa-Licuanan, S.S. 1998. Mortalities of giant clams associated with unusually high temperatures and coral bleaching. Reef Encounter 24, 23 only.

Gomez, E.D. \& Mingoa-Licuanan, S.S. 2006. Achievements and lessons learned in restocking giant clams in Philippines. Fisheries Research 80, 46-52.

Gonzales, B.J., Becira, J.G., Galon, W.M. \& Gonzales, M.M.G. 2014. Protected versus unprotected area with reference to fishes, corals, marine invertebrates, and CPUE in Honda Bay, Palawan. The Palawan Scientist 6, 42-59.

Govan, H. 1992. Predators and predator control. In The Giant Clam: An Ocean Culture Manual, H.P. Calumpong (ed.). ACIAR Monograph No. 16. Canberra: Australian Centre for International Agricultural Research, 41-49.

Green, A. \& Craig, P. 1999. Population size and structure of giant clams at Rose Atoll, an important refuge in the Samoan Archipelago. Coral Reefs 18, 205-211.

Guest, J.R., Todd, P.A., Goh, E., Sivalonganathan, B.S. \& Reddy, K.P. 2008. Can giant clam (Tridacna squamosa) populations be restored on Singapore's heavily impacted coral reefs? Aquatic Conservation: Marine and Freshwater Ecosystems 18, 570-579.

Hambrey Consulting 2013. Market study on exporting cultured giant clams from French Polynesia. Synthesis report. Report commissioned by Agence Francaise de Developpement in partnership with the Secretariat of the Pacific Community and the French Polynesian Ministry of Marine Resources. Strathpeffer, Scotland, UK: Hambrey Consulting.

Hamner, W.M. 1978. Intraspecific competition in Tridacna crocea, a burrowing bivalve. Oecologia 34, 267-281. 
Hamner, W.M. \& Jones, M.S. 1976. Distribution, burrowing, and growth rates of the clam Tridacna crocea on interior reef flats. Oecologia 24, 207-227.

Hart, A.M., Bell, J.D. \& Foyle, T.P. 1998. Growth and survival of the giant clams, Tridacna derasa, T. maxima and T. crocea, at village farms in the Solomon Islands. Aquaculture 165, 203-220.

Harzhauser, M., Mandic, O., Piller, W.E., Reuter, M. \& Kroh, A. 2008. Tracing back the origin of the IndoPacific mollusc fauna: basal Tridacninae from the Oligocene and Miocene of the Sultanate of Oman. Palaeontology 51, 199-213.

Hedley, C. 1921. A revision of the Australian Tridacna. Records of the Australian Museum 13, 163-172.

Herrera, N.D., ter Poorten, J.J., Bieler, R., Mikkelsen, P.M., Strong, E.E., Jablonski, D. \& Steppan, S.J. 2015. Molecular phylogenetics and historical biogeography amid shifting continents in the cockles and giant clams (Bivalvia: Cardiidae). Molecular Phylogenetics and Evolution 93, 94-106.

Heslinga, G.A. 1991. History and current status of the MMDC giant clam project. A Special Report Prepared for: The House of Delegates, Third Olbill Era Kelulau (Palau National Congress). February 10, 1991. Koror, Palau: Micronesian Mariculture Demonstration Center.

Heslinga, G.A. 1993a. Regional yield trials for commercially valuable giant clam species, Phase I. Tridacna gigas and Tridacna derasa. Final Project Report U.S. National Marine Fisheries Service (NOAA/ NMFS NA16DO335-01). Koror, Palau: Micronesian Mariculture Demonstration Center.

Heslinga, G.A. 1993b. Regional yield trials for commercially valuable giant clam species, Phase II. Hippopus hippopus and Tridacna derasa. U.S. National Marine Fisheries Service (NOAA/NMFS NA16FDO335-02). Koror, Palau: Micronesian Mariculture Demonstration Center.

Heslinga, G.A. 1995. Clams to cash: how to make and sell giant clam shell products. Publication No. 125, Waimanalo, Hawaii: Center for Tropical and Subtropical Aquaculture (Hawaii). Online. http://www. ctsa.org/files/publications/CTSA_1256316728628558255081.pdf (accessed 19 December 2016).

Heslinga, G.A. 2012. The origin and future of farming giant clams. CORAL Magazine 9, 38-52.

Heslinga, G.A. 2013. Saving Giants (eBook): Cultivation and Conservation of Tridacnid Clams. KailuaKona, Hawaii: Indo-Pacific Sea Farms. http://www.blurb.com/ebooks/374835-saving-giants (accessed 20 July 2016).

Heslinga, G.A. \& Fitt, W.K. 1987. The domestication of reef-dwelling clams. BioScience 37, 332-339.

Heslinga, G.A., Perron, F.E. \& Orak, O. 1984. Mass culture of giant clams (f. Tridacnidae) in Palau. Aquaculture 39, 197-215.

Heslinga, G.A., Watson, T.C. \& Isamu, T. 1990. Giant Clam Farming. Honolulu, Hawaii: Pacific Fisheries Development Foundation (NMFS/NOAA).

Hester, F.J. \& Jones, E.C. 1974. A survey of giant clams, Tridacnidae, on Helen Reef, a Western Pacific atoll. Marine Fisheries Review 36, 17-22.

Hirschberger, W. 1980. Tridacnid clam stocks on Helen Reef, Palau, Western Caroline Islands. Marine Fisheries Review 42, 8-15.

Hopkins, A. 2009. Marine invertebrates as indicators of reef health: a study of the reefs in the region of Andavadoaka, South West Madagascar. MSc Dissertation, Imperial College London, UK.

Huang, D. 2012. Threatened reef corals of the world. PLOS ONE 7, e34459. doi:10.1371/journal.pone.0034459

Huang, D. \& Roy, K. 2013. Anthropogenic extinction threats and future loss of evolutionary history in reef corals. Ecology and Evolution 3, 1184-1193.

Huang, D., Todd, P.A. \& Guest, J.R. 2007. Movement and aggregation in the fluted giant clam (Tridacna squamosa L.). Journal of Experimental Marine Biology and Ecology 342, 269-281.

Huber, M. 2010. Compendium of Bivalves. A Full-Color Guide to 3,300 of the World's Marine Bivalves. A Status on Bivalvia after 250 Years of Research. Hackenheim: Conchbooks.

Huber, M. \& Eschner, A. 2011. Tridacna (Chametrachea) costata Roa-Quiaoit, Kochzius, Jantzen, Al-Zibdah and Richter from the Red Sea, a junior synonym of Tridacna squamosina Sturany, 1899 (Bivalvia, Tridacnidae). Annalen des Naturhistorischen Museums in Wien B 112, 153-162.

Huelsken, T., Keyse, J., Liggins, L., Penny, S., Treml, E.A. \& Riginos, C. 2013. A novel widespread cryptic species and phylogeographic patterns within several giant clam species (Cardiidae: Tridacna) from the Indo-Pacific Ocean. PLoS ONE 8, e80858. doi:10.1371/journal.pone.0080858

Hutsell, K.C., Hutsell, L.L. \& Pisor, D.L. 1997. Registry of World Record Size Shell. San Diego, California: Snail's Pace Productions. 
Hviding, E. 1993. The rural context of giant clam mariculture in Solomon Islands: an anthropological study. ICLARM Technical Report 39. Manila, Philippines: International Center for Living Aquatic Resources Management. Online. http://pdf.usaid.gov/pdf_docs/Pnabq793.pdf (accessed 19 December 2016).

Isaac, N.J.B., Redding, D.W., Meredith, H.M. \& Safi, K. 2012. Phylogenetically-informed priorities for amphibian conservation. PLoS ONE 7, e43912. doi:10.1371/journal.pone.0043912

Isaac, N.J.B., Turvey, S.T., Collen, B., Waterman, C. \& Baillie, J.E.M. 2007. Mammals on the EDGE: Conservation priorities based on threat and phylogeny. PLOS ONE 2, e296. doi:10.1371/journal. pone.0000296

Jameson, S.C. 1976. Early life of the giant clam Tridacna crocea Lamarck, Tridacna maxima (Röding), and Hippopus hippopus (Linnaeus). Pacific Science 30, 219-233.

Jantzen, C., Wild, C., El-Zibdah, M., Roa-Quiaoit, H.A., Haacke, C. \& Richter, C. 2008. Photosynthetic performance of giant clams, Tridacna maxima and T. squamosa, Red Sea. Marine Biology 155, 211-221.

Johnson, M.S., Prince, J., Brearley, A., Rosser, N.L. \& Black, R. 2016. Is Tridacna maxima (Bivalvia: Tridacnidae) at Ningaloo Reef, Western Australia? Molluscan Research 36, 264-270.

Juinio, M.A.R., Meñez, L.A.B., Villanoy, C.L. \& Gomez, E.D. 1989. Status of giant clam resources of the Philippines. Journal of Molluscan Studies 55, 431-440.

Junchompoo, C., Sinrapasan, N., Penpian, C. \& Patsorn, P. 2013. Changing seawater temperature effects on giant clams bleaching, Mannai Island, Rayong Province, Thailand. KURENAI 2013-03, Proceedings of the Design Symposium on Conservation of Ecosystem (2013) (The 12th SEASTAR2000 workshop), Bangkok, Thailand, 71-76. doi:10.13140/2.1.1906.5600

Keen, A.M. 1969. Superfamily Tridacnacea Lamarck, 1819. In Treatise on Invertebrate Paleontology, Part N, Mollusca 6, Bivalvia, Vol. 2, R.C. Moore (ed.). Boulder, Colorado: Geological Society of America and Lawrence, Kansas: University of Kansas, N594-N595.

Keys, J.L. \& Healy, J.M. 2000. Relevance of sperm ultrastructure to the classification of giant clams (Mollusca, Cardioidea, Cardiidae, Tridacninae). In The Evolutionary Biology of the Bivalvia, E.M. Harper et al. (eds). Geological Society Special Publication No. 177. London: Geological Society, 191-205.

Kinch, J. 2001. Clam harvesting, the Convention on the International Trade in Endangered Species (CITES) and conservation in Milne Bay Province, Papua New Guinea. SPC Fisheries Newsletter 99, 24-36.

Kinch, J. 2002. Giant clams: their status and trade in Milne Bay Province, Papua New Guinea. TRAFFIC Bulletin 19, 1-9.

Kinch, J. \& Teitelbaum, A. 2010. Proceedings of the Regional Workshop on the Management of Sustainable Fisheries for Giant Clams (Tridacnidae) and CITES Capacity Building (4-7 August 2009, Nadi, Fiji). Noumea, New Caledonia: Secretariat of the Pacific Community.

Klumpp, D.W. \& Griffiths, C.L. 1994. Contributions of phototrophic and heterotrophic nutrition to the metabolic and growth requirements of four species of giant clam (Tridacnidae). Marine Progress Ecology Series 115, 103-115.

Knight, R., Watson, K., Dill, J., Moore, P. \& Miller, K. 2010. A Toolkit for Protecting the Environment and Natural Resources in Kuraburi. Bangkok, Thailand: IUCN Thailand Programme and IUCN Regional Environmental Law Programme, Asia.

Kochzius, M. \& Nuryanto, A. 2008. Strong genetic population structure in the boring giant clam, Tridacna crocea, across the Indo-Malay Archipelago: implications related to evolutionary processes and connectivity. Molecular Ecology 17, 3775-3787.

Krell, B., Skopal, M. \& Ferber, P. 2011. Koh Rong Samloem and Koh Kon Marine Environmental Assessment: Report on Marine Resources and Habitats. Koh Rong Samloen, Mittapheap District, Cambodia: Marine Conservation Cambodia. Online. http://www.marineconservationcambodia.org/marine-reef-research/ file/16-koh-rong-samloem-koh-rong-marine-assessment-2011-for-fiacd (accessed 19 December 2016).

Kubo, H. \& Iwai, K. 2007. On two sympatric species within Tridacna "maxima". Annual Report Okinawa Fisheries Oceanography Research Centre 68, 205-210.

Ladd, H.S. 1934. Geology of Viti Levu, Fiji. Bulletin of the Bernice P. Bishop Museum 119, 1-263.

Lai, L.T.-A. 2015. A large baroque Tridacna gigas (giant clam) pearl. Gems and Gemology, The Quarterly Journal of the Gemological Institute of America L, 247 only.

Lamarck, J.B. De 1809. Philosophie Zoologique. Volumes 1 and 2. Paris: Dentu.

Larson, C. 2016. Shell trade pushes giant clams to the brink. Science 351, 323-324. 
Ledua, E., Manu, N. \& Braley, R.D. 1993. Distribution, habitat and culture of the recently described giant clam Tridacna tevoroa in Fiji and Tonga. In The Biology and Mariculture of Giant Clams: A Workshop Held in Conjunction with the 7th International Coral Reef Symposium 21-26 June 1992, Guam, USA, W.K. Fitt (ed.). ACIAR Proceedings No. 47. Canberra: Australian Centre for International Agricultural Research, 147-153.

Lee, S. 2014. Twenty tonnes of giant clams seized from Vietnamese fishermen. The Star Online, 14 April 2014. Online. http://www.thestar.com.my/news/nation/2014/04/14/crime-cops-clam/ (accessed 26 February 2016).

Leggat, W., Buck, B.H., Grice, A. \& Yellowlees, D. 2003. The impact of bleaching on the metabolic contribution of dinoflagellate symbionts to their giant clam host. Plant, Cell and Environment 26, 1951-1961.

Leung, P.S., Shang, Y.C., Wanitprapha, K. \& Tian, X. 1994. Production economics of giant clam (Tridacna species) culture systems in the U.S.-affiliated Pacific Islands. Publication No. 114, Waimanalo, Hawaii: Center for Tropical and Subtropical Aquaculture. Online. http://www.ctsa.org/files/publications/ CTSA_1146316812008666376521.pdf (accessed 19 December 2016).

Lewis, A.D. \& Ledua, E. 1988. A possible new species of Tridacna (Tridacnidae: Mollusca) from Fiji. In Giant Clams in Asia and the Pacific, J.W. Copland \& J.S. Lucas (eds). Canberra: Australian Centre for International Agricultural Research, 82-84.

Lewis, A.D., Adams, T.J.H. \& Ledua, E. 1988. Fiji's giant clam stocks - a review of their distribution, abundance, exploitation and management. In Giant Clams in Asia and the Pacific, J.W. Copland \& J.S. Lucas (eds). Canberra: Australian Centre for International Agricultural Research, 66-72.

Lindsay, S. 1995. Giant Clams Reseeding Programs: Do They Work and Do They Use Limited Resources Wisely? Using Yap State, Federated States of Micronesia as a Model. Joint FFA/SPC Workshop on the Management of South Pacific Inshore Fisheries, Noumea, New Caledonia, 26 June-7 July 1995. Noumea, New Caledonia: South Pacific Commission.

Lizano, A.M.D. \& Santos, M.D. 2014. Updates on the status of giant clams Tridacna spp. and Hippopus hippopus in the Philippines using mitochondrial CO1 and 16S rRNA genes. Phillipine Science Letters 7, $187-200$.

Lucas, J.S. 1988. Giant clams: description, distribution and life history. In Giant Clams in Asia and the Pacific, J.W. Copland \& J.S. Lucas (eds). Canberra: Australian Centre for International Agricultural Research, 21-32.

Lucas, J.S. 1994. The biology, exploitation, and mariculture of giant clams (Tridacnidae). Reviews in Fisheries Science 2, 181-223.

Lucas, J.S. 1997. Giant clams: mariculture for sustainable exploitation. In Conservation and the Use of Wildlife Resources, M. Bolton (ed.). London: Chapman and Hall, 77-95.

Lucas, J.S. 2014. Giant clams. Current Biology 24, R183-R184.

Lucas, J.S., Ledua, E. \& Braley, R.D. 1990. A new species of giant clam (Tridacnidae) from Fiji and Tonga. ACIAR Working Paper No. 23. Canberra: Australian Centre for International Agricultural Research.

Lucas, J.S., Ledua, E. \& Braley, R.D. 1991. Tridacna tevoroa Lucas, Ledua and Braley: A recently described species of giant clam (Bivalvia: Tridacnidae) from Fiji and Tonga. Nautilus 105, 92-103.

Maboloc, E.A. \& Mingoa-Licuanan, S.S. 2011. Feeding aggregation of Spratelloides delicatulus on giant clams' gametes. Coral Reefs 30, 167 only.

Macaranas, J.M., Ablan, C.A., Pante, M.J.R., Benzie, J.A.H. \& Williams, S.T. 1992. Genetic structure of giant clam (Tridacna derasa) populations from reefs in the Indo-Pacific. Marine Biology 113, 231-238.

Maruyama, T. \& Heslinga, G.A. 1997. Fecal discharge of zooxanthellae in the giant clam Tridacna derasa, with reference to their in situ growth rate. Marine Biology 127, 473-477.

Maruyama, T., Ishikura, M., Yamazaki, S. \& Kanai, S. 1998. Molecular phylogeny of zooxanthellate bivalves. Biological Bulletin 195, 70-77.

Master, F. 2016. South China Sea reefs "decimated" as giant clams harvested in bulk. Thomson Reuters, 27 June 2016. http://www.reuters.com/article/us-china-clams-idUSKCNOZD30F (accessed 12 July 2016).

McKenna S.A., Baillon N., Blaffart H. \& Abrusci G. 2008. Une évaluation rapide de la biodiversité marine des récifs coralliens du Mont Panié, Province Nord, Nouvelle Calédonie. Bulletin PER d'évaluation biologique $\mathrm{N}^{\circ} 42$. Arlington, Virginia: Conservation International.

McLean, R.A. 1947. A revision of the Pelecypod family Tridacnidae. Notulae Naturae of The Academy of Natural Sciences of Philadelphia 195, 1-7. 
Mekawy, M.S. \& Madkour, H.A. 2012. Studies on the Indo-Pacific Tridacnidae (Tridacna maxima) from the Northern Red Sea, Egypt. International Journal of Geosciences 3, 1089-1095.

Menoud, M., Van Wynsberge, S., Le Moullac, G., Levy, P., Andréfouët, S., Remoissenet, G. \& GaertnerMazouni, N. 2016. Identifying robust proxies of gonad maturation for the protandrous hermaphrodite Tridacna maxima (Röding, 1798, Bivalvia) from individual to population scale. Journal of Shellfish Research 35, 51-61.

Michel, C., Coowar, M. \& Takoor, S. 1985. Marine Molluscs of Mauritius. Gland, Switzerland: WWF and IUCN.

Mies, M., Braga, F., Scozzafave, M.S., de Lemos D.E.L. \& Sumida, P.Y.G. 2012. Early development, survival and growth rates of the giant clam Tridacna crocea (Bivalvia: Tridacnidae). Brazilian Journal of Oceanography 60, 127-133.

Militz, T.A., Kinch, J. \& Southgate, P.C. 2015. Population demographics of Tridacna noae (Röding, 1798) in New Ireland, Papua New Guinea. Journal of Shellfish Research 34, 329-335.

Mingoa-Licuanan, S.S. \& Gomez, E.D. 2007. Giant Clam Hatchery, Ocean Nursery and Stock Enhancement. Iloilo, Philippines: Aquaculture Department, Southeast Asian Fisheries Development Center.

Molluscs Specialist Group, 1996. Tridacna crocea. In IUCN Red List of Threatened Species. Version 2012.2. Cambridge, UK: IUCN Global Species Programme Red List Unit. Online. http://www.iucnredlist.org (accessed 14 July 2016).

Monsecour, K. 2016. A new species of giant clam (Bivalvia: Cardiidae) from the Western Indian Ocean. Conchylia 46, 69-77.

Mooers, A.Ø., Faith, D.P. \& Maddison, W.P. 2008. Converting endangered species categories to probabilities of extinction for phylogenetic conservation prioritisation. PLOS ONE 3, e3700. doi:10.1371/journal. pone. 0003700

Morton, B. 1978. The diurnal rhythm and the processes of feeding and digestion in Tridacna crocea (Bivalvia : Tridacnidae). Journal of Zoology, London 185, 371-388.

Morton, B. 2000. The biology and functional morphology of Fragum erugatum (Bivalvia: Cardiidae) from Shark Bay, Western Australia: the significance of its relationship with entrained zooxanthellae. Journal of Zoology, London 251, 39-52.

Morton, B. \& Morton, J. 1983. The Seashore Ecology of Hong Kong. Hong Kong: Hong Kong University Press.

Munro, J.L. 1988. Status of Giant Clam Stocks in the Central Gilbert Islands Group, Republic of Kiribati. Workshop on Pacific Inshore Fishery Resources, Noumea, New Caledonia, 14-25 March 1988. SPC/ Inshore Fish Res/BP54. Noumea, New Caledonia: South Pacific Commission.

Munro, J.L. 1989. Fisheries for giant clams (Tridacnidae: Bivalvia) and prospects for stock enhancement. In Marine Invertebrate Fisheries: Their Assessment and Management, J.F. Caddy (ed.). New York: Wiley, 541-558.

Munro, J.L. 1992. Chapter 13 - Giant clams. FFA Report 92/75. Honiara, Solomon Islands: Pacific Islands Forum Fisheries Agency. Online. http://www.spc.int/DigitalLibrary/Doc/FAME/Reports/Munro_93_ GiantClams.pdf (accessed 19 December 2016).

Munro, J.L. \& Heslinga, G.A. 1983. Prospects for the commercial cultivation of giant clams (Bivalvia: Tridacnidae). Proceedings of the Annual Gulf Caribbean Fisheries Institute 35, 122-134.

Munro, P.E., Beard, J.H. \& Lacanienta, E. 1983. Investigations on the substance which causes sperm release in Tridacnid clams. Comparative Biochemistry and Physiology 74C, 219-223.

Murakoshi, M. 1986. Farming of the boring giant clam, Tridacna crocea Lamarck. Galaxea 5, 239-254.

Neo, M.L., Eckman, W., Vicentuan-Cabaitan, K., Teo, S.L.-M. \& Todd, P.A. 2015a. The ecological significance of giant clams in coral reef ecosystems. Biological Conservation 181, 111-123.

Neo, M.L., Erftermeijer, P.L.A., van Beek, J.K.L., van Maren, D.S., Teo, S.L.-M. \& Todd, P.A. 2013 a. Recruitment constraints in Singapore's fluted giant clam (Tridacna squamosa) population - A dispersal model approach. PLoS ONE 8, e58819. doi:10.1371/journal.pone.0058819

Neo, M.L. \& Loh, K.S. 2014. Giant clam shells 'graveyard' at Semakau Landfill. Singapore Biodiversity Records 2014, 248-249.

Neo, M.L. \& Low, J.K.Y. 2017. First observations of Tridacna noae (Röding, 1798) (Bivalvia: Heterodonta: Cardiidae) in Christmas Island (Indian Ocean). Marine Biodiversity, doi:10.1007/s12526-017-0678-3 
Neo, M.L. \& Todd, P.A. 2011. Predator-induced changes in fluted giant clam (Tridacna squamosa) shell morphology. Journal of Experimental Marine Biology and Ecology 397, 21-26.

Neo, M.L. \& Todd, P.A. 2012a. Giant clams (Mollusca: Bivalvia: Tridacninae) in Singapore: history, research and conservation. Raffles Bulletin of Zoology 25, 67-78.

Neo, M.L. \& Todd, P.A. 2012b. Population density and genetic structure of the giant clams Tridacna crocea and T. squamosa on Singapore's reefs. Aquatic Biology 14, 265-275.

Neo, M.L. \& Todd, P.A. 2013. Conservation status reassessment of giant clams (Mollusca: Bivalvia: Tridacninae) in Singapore. Nature in Singapore 6, 125-133.

Neo, M.L., Todd, P.A., Chou, L.M. \& Teo, S.L.-M. 2011. Spawning induction and larval development in the fluted giant clam, Tridacna squamosa (Bivalvia: Tridacnidae). Nature in Singapore 4, 157-161.

Neo, M.L., Todd, P.A., Teo, S.L.-M. \& Chou, L.M. 2009. Can artificial substrates enriched with crustose coralline algae enhance larval settlement and recruitment in the fluted giant clam (Tridacna squamosa)? Hydrobiologia 625, 83-90.

Neo, M.L., Todd, P.A., Teo, S.L.-M. \& Chou, L.M. 2013b. The effects of diet, temperature and salinity on survival of larvae of the fluted giant clam, Tridacna squamosa. Journal of Conchology 41, 369-376.

Neo, M.L., Vicentuan, K., Teo, S.L.M., Erftemeijer, P.L.A. \& Todd, P.A. 2015b. Larval ecology of the fluted giant clam, Tridacna squamosa, and its potential effects on dispersal models. Journal of Experimental Marine Biology and Ecology 469, 76-82.

Newman, W.A. \& Gomez, E.D. 2000. On the status of giant clams, relics of Tethys (Mollusca: Bivalvia: Tridacninae). In Proceedings of the 9th International Coral Reef Symposium, Bali, Indonesia, 23-27 October 2000, Vol. 2, M.K. Moosa et al. (eds). Jakarta: Indonesian Institute of Sciences, Jakarta: Ministry of Environment, Honolulu, Hawaii: International Society for Reef Studies, 927-936.

Norton, J.H. \& Jones, G.W. 1992. The Giant Clam: An Anatomical and Histological Atlas. ACIAR Monograph. Canberra: Australian Centre for International Agricultural Research.

Norton, J.H., Prior, H.C., Baillie, B. \& Yellowlees, D. 1995. Atrophy of the zooxanthellal tubular system in bleached giant clams Tridacna gigas. Journal of Invertebrate Pathology 66, 307-310.

Norton, J.H., Shepherd, M.A., Long, H.M. \& Fitt, W.K. 1992. The zooxanthellal tubular system in the giant clam. Biological Bulletin 183, 503-506.

Nuryanto, A., Duryadi, D., Soedharma, D. \& Blohm, D. 2007. Molecular phylogeny of giant clams based on mitochondrial DNA cytochrome C oxidase I gene. HAYATI Journal of Biosciences 14, 162-166.

O'Callaghan, M. 1995. Village-farmed giant clams - From South Pacific Ocean to you, sustainably. Freshwater and Marine Aquarium 18, 8-10.

Okada, H. 1997. Market Survey of Aquarium Giant Clams in Japan. South Pacific Aquaculture Development Project (Phase II). FAO Fisheries and Aquaculture Department Field Document No. 8. Rome: Food and Agriculture Organization of the United Nations. Online. http://www.fao.org/docrep/005/ac892e/ AC892E00.htm (accessed 19 December 2016).

Oppenheim, P. 1901. Die Priabonaschichten und ihre Fauna im Zusammenhange mit gleichalterigen und analogen Ablagerungen. Palaeontographica 47, 1-348. (In German)

Othman, A.S., Goh, G.H.S. \& Todd, P.A. 2010. The distribution and status of giant clams (family Tridacnidae) -a short review. Raffles Bulletin of Zoology 58, 103-111.

Pasaribu, B.P. 1988. Status of giant clams in Indonesia. In Giant Clams in Asia and the Pacific, J.W. Copland \& J.S. Lucas (eds). Canberra: Australian Centre for International Agricultural Research, 44-46.

Pearson, R.G. 1977. Impact of foreign vessels poaching giant clams. Australian Fisheries 36, 8-11, 23.

Pearson, R.G. \& Munro, J.L. 1991. Growth, mortality and recruitment rates of giant clams, Tridacna gigas and T. derasa, at Michaelmas Reef, central Great Barrier Reef, Australia. Australian Journal of Marine and Freshwater Research 42, 241-262.

Peijnenburg, K.T.C.A. \& Goetze, E. 2013. High evolutionary potential of marine zooplankton. Ecology and Evolution 3, 2765-2781.

Penny, S.S. \& Willan, R.C. 2014. Description of a new species of giant clam (Bivalvia: Tridacnidae) from Ningaloo Reef, Western Australia. Molluscan Research 34, 201-211.

Perron, F.E., Heslinga, G.A. \& Fagolimul, J. 1985. The gastropod Cymatium muricinum, a predator on juvenile tridacnid clams. Aquaculture 48, 211-221.

Petersen, C.W. \& Levitan, D.R. 2001. The Allee effect: a barrier to recovery by exploited species. In Conservation of Exploited Species, J.D. Reynolds et al. (eds). Conservation Biology Series 6. Cambridge: Cambridge University Press, 281-300. 
Pfenninger, M. \& Schwenk, K. 2007. Cryptic animal species are homogeneously distributed among taxa and biogeographical regions. BMC Evolutionary Biology 7, 121 only.

Poutiers, J.M. 1998. Bivalves. Acephala, Lamellibranchia, Pelecypoda. In FAO Species Identification Guide for Fishery Purposes. The Living Marine Resources of the Western Central Pacific. Volume 1. Seaweeds, Corals, Bivalves, and Gastropods, K.E. Carpenter \& V.H. Niem (eds). Rome: Food and Agriculture Organization of the United Nations, 123-362.

Price, C.M. \& Fagolimul, J.O. 1988. Reintroduction of giant clams to Yap State, Federated States of Micronesia. In Giant Clams in Asia and the Pacific, J.W. Copland \& J.S. Lucas (eds). Canberra: Australian Centre for International Agricultural Research, 41-43.

Ramadoss, K. 1983. Giant clam (Tridacna) resources. CMFRI Bulletin 34, 79-81.

Ramohia, P. 2006. Fisheries resources: commercially important macroinvertebrates. In Solomon Islands Marine Assessment: Technical Report on Survey Conducted May 13 to June 17, 2004, A. Green et al. (eds). Arlington, Virginia: The Nature Conservancy, 330-400.

Redding, D.W. \& Mooers, A.Ø. 2006. Incorporating evolutionary measures into conservation prioritisation. Conservation Biology 20, 1670-1678.

Reef Check Foundation 2016. Global reef tracker. Marina del Rey, California: Reef Check Foundation. Online. http://data.reefcheck.us/ (accessed 28 December 2016).

Reese, D.S. 1988. A new engraved Tridacna shell from Kish. Journal of Near Eastern Studies 47, 35-41.

Reese, D.S. \& Sease, C. 1993. Some previously unpublished engraved Tridacna shells. Journal of Near Eastern Studies 52, 109-128.

Reid, R.G.B., Fankboner, P.V. \& Brand, D.G. 1984. Studies on the physiology of the giant clam Tridacna gigas Linné - I. Feeding and digestion. Comparative Biochemistry and Physiology 78A, 95-101.

Ricard, M. \& Salvat, B. 1977. Faeces of Tridacna maxima (Mollusca: Bivalvia), composition and coral reef importance. In Proceedings of the Third International Coral Reef Symposium, Volume 1: Biology, D.L. Taylor (ed.). Miami, Florida: Rosenstiel School of Marine and Atmospheric Science, 495-501.

Richards, R. \& Roga, K. 2004. Barava: land title deeds in fossil shell from the western Solomon Islands. Tuhinga 15, 17-26.

Richter, C., Roa-Quiaoit, H., Jantzen, C., Al-Zibdah, M. \& Kochzius, M. 2008. Collapse of a new living species of giant clam in the Red Sea. Current Biology 18, 1349-1354.

Roa-Quiaoit, H.A.F. 2005. The ecology and culture of giant clams (Tridacnidae) in the Jordanian sector of Gulf of Aqaba, Red Sea. PhD Dissertation, University of Bremen, Germany.

Rodrigues, A.S.L., Pilgrim, J.D., Lamoreux, J.F., Hoffmann, M. \& Brooks, T.M. 2006. The value of the IUCN Red List for conservation. Trends in Ecology \& Evolution 21, 71-76.

Rosewater, J. 1965. The family Tridacnidae in the Indo-Pacific. Indo-Pacific Mollusca 1, 347-396.

Rosewater, J. 1982. A new species of Hippopus (Bivalvia: Tridacnidae). The Nautilus 96, 3-6.

Safi, K., Armour-Marshall, K., Baillie, J.E.M. \& Issac, N.J.B. 2013. Global patterns of evolutionary distinct and globally endangered amphibians and mammals. PLOS ONE 8, e63582. doi:10.1371/journal. pone.0063582

Sant, G. 1995. Marine Invertebrates of the South Pacific: An Examination of the Trade. Cambridge, UK: TRAFFIC International. Online. https://portals.iucn.org/library/sites/library/files/documents/Traf-024. pdf (accessed 19 December 2016).

Schneider, J.A. 1992. Preliminary cladistic analysis of the bivalve family Cardiidae. American Malacological Bulletin 9, 145-155.

Schneider, J.A. 1998. Phylogeny of the Cardiidae (Bivalvia): Phylogenetic relationships and morphological evolution within the subfamilies Clinocardiidae, Lymnocardiidae, Fraginae and Tridacninae. Malacologia 40, 321-373.

Schneider, J.A. \& Ó Foighil, D. 1999. Phylogeny of giant clams (Cardiidae: Tridacninae) based on partial mitochondrial 16S rDNA gene sequences. Molecular Phylogenetics and Evolution 13, 59-66.

Schwartzmann, C., Durrieu, G., Sow, M., Ciret, P., Lazareth, C.E. \& Massabuau, J.-C. 2011. In situ giant clam growth rate behaviour in relation to temperature: a one-year coupled study of high-frequency noninvasive valvometry and sclerochronology. Limnology and Oceanography 56, 1940-1951.

Selin, N.I. \& Latypov, Y.Y. 2011. The size and age structure of Tridacna crocea Lamarck, 1819 (Bivalvia: Tridacnidae) in the coastal area of islands of the Cön Dao Archipelago in the South China Sea. Russian Journal of Marine Biology 37, 376-383. 
Selkoe, K.A., Henzler, C.M. \& Gaines, M.D. 2008. Seascape genetics and the spatial ecology of marine populations. Fish and Fisheries 9, 363-377.

Shang, Y.C., Tisdell, C. \& Leung, P.S. 1991. Report on a Market Survey of Giant Clam Products in Selected Countries. Publication No. 107. Waimanalo, Hawaii: Center for Tropical and Subtropical Aquaculture.

Siaosi, F., Sapatu, M., Lalavanua, W., Pakoa, K., Yeeting, B., Magron, F., Moore, B., Bertram, I. \& Chapman, L. 2012. Climate Change Baseline Assessment - Funafuti Atoll, Tuvalu. July-August 2011. Coastal Fisheries Science and Management Section, Secretariat of the Pacific Community, December 2012. Online. http://www.spc.int/DigitalLibrary/Doc/FAME/Reports/Siaosi_12_Tuvalu_Climate_Change_ Baseline_Monitoring_Report.pdf (accessed 15 March 2017).

Sirenko, B.I. \& Scarlato, O.A. 1991. Tridacna rosewateri sp. n. A new species of giant clam from Indian Ocean. La Conchiglia 22, 4-9.

Soo, P. \& Todd, P.A. 2012. Nocturnal movement and possible geotaxis in the fluted giant clam (Tridacna squamosa). Contributions to Marine Science 2012, 159-162.

Soo, P. \& Todd, P.A. 2014. The behaviour of giant clams (Bivalvia: Cardiidae: Tridacninae). Marine Biology 161, 2699-2717.

Southgate, P.C., Braley, R.D. \& Militz, T.A. 2016. Embryonic and larval development of the giant clam Tridacna noae (Röding, 1798) (Cardiidae: Tridacninae). Journal of Shellfish Research 35, 777-783.

Southgate, P.C., Braley, R.D. \& Militz, T.A. 2017. Ingestion and digestion of micro-algae concentrates by veliger larvae of the giant clam, Tridacna noae. Aquaculture, doi:10.1016/j.aquaculture.2017.02.032

Southward, A.J., Young, C.M. \& Fuiman, L.A. 2005. Restocking initiatives. Advances in Marine Biology 49, $9-41$.

Stasek, C.R. 1962. The form, growth, and evolution of the Tridacnidae (giant clams). Archives de Zoologie Expérimentale et Générale 101, 1-40.

Stasek, C.R. 1965. Behavioural adaptation of the giant clam Tridacna maxima to the presence of grazing fishes. The Veliger 8, 29-35.

Stephens, P.A., Sutherland, W.J. \& Freckleton, R.P. 1999. What is the Allee Effect? Oikos 87, 185-190.

Sturany, R. 1899. Expedition S.M. Schiff "Pola" in das Rothe Meer. Nördliche und südliche Hälfte. 1895/96 und 1897/98. Zoologische Ergebnisse XIV Lamellibranchiaten des Rothen Meeres. Berichte der Commission für oceanographische Forschungen. Sonder druck aus: Denkschriften der mathematischnaturwissenschaftlichen Classe der Kaiserli chen Akademie der Wissenschaften, Wien 69, 255-295.

Su, P.-W. 2013. The reproductive comparison of giant clams Tridacna noae and Tridacna maxima. MSc Thesis, National Sun Yat-Sen University, Taiwan.

Su, Y., Hung, J.-H., Kubo, H. \& Liu, L.-L. 2014. Tridacna noae (Röding, 1798) - a valid giant clam species separated from T. maxima (Röding, 1798) by morphological and genetic data. Raffles Bulletin of Zoology 62, 124-135.

Tan, S.H. \& Zulfigar, Y. 1999. Factors affecting the interchange of Tridacna squamosa larvae and gamete material between Pulau Tioman and Johore Islands in the South China Sea. Proceedings the Tenth Joint Seminar on Marine and Fisheries Sciences, Melaka, Malaysia, 1-3 December 1999. Tokyo: Japan Society for the Promotion of Science and Kuala Lumpur: Vice-Chancellors' Council of National Universities in Malaysia, 288-304.

Tan, S.H. \& Zulfigar, Y. 2001. Factors affecting the dispersal of Tridacna squamosa larvae and gamete material in the Tioman Archipelago, The South China Sea. Phuket Marine Biological Center Special Publication 25, 349-356.

Tan, S.H. \& Zulfigar, Y. 2003. Status of giant clam in Malaysia. SPC Trochus Information Bulletin 10, 9-10.

Teitelbaum, A. \& Friedman, K. 2008. Successes and failures in reintroducting giant clams in the Indo-Pacific region. SPC Trochus Information Bulletin 14, 19-26.

Tiavouane, J. \& Fauvelot, C. 2016. First record of the Devil Clam, Tridacna mbalavuana Ladd 1934, in New Caledonia. Marine Biodiversity, doi:10.1007/s12526-016-0506-1

Tisdell, C. (ed.) 1992. Giant Clams in the Sustainable Development of the South Pacific: Socioeconomic Issues in Mariculture and Conservation. ACIAR Monograph No. 18. Canberra: Australian Centre for International Agricultural Research.

Todd, P.A., Lee, J.H. \& Chou, L.M. 2009. Polymorphism and crypsis in the boring giant clam (Tridacna crocea): potential strategies against visual predators. Hydrobiologia 635, 37-43.

Trench, R.K., Wethey, D.S. \& Porter, J.W. 1981. Observations on the symbiosis with zooxanthellae among the Tridacnidae (Mollusca, Bivalvia). Biological Bulletin 161, 180-198. 
Ullmann, J. 2013. Population status of giant clams (Mollusca: Tridacnidae) in the northern Red Sea, Egypt. Zoology in the Middle East 59, 253-260.

UNEP-WCMC 2011. Review of Oceanian Species/Country Combinations Subject to Long-Standing Import Suspensions. Cambridge: UNEP World Conservation Monitoring Centre. Online. http://ec.europa.eu/ environment/cites/pdf/reports/Review_Oceanian_species.pdf (accessed 19 December 2016).

Van Wynsberge, S. 2016. Approche comparée, intégrée et spatialisée pour la gestion d'une ressource emblématique exploitée en Polynésie française et en Nouvelle-Calédonie: le cas du bénitier (Tridacna maxima). PhD Thesis, Université de la Polynésie française, IRD Centre de Nouméa, Papeete, Nouméa, New Caledonia.

Van Wynsberge, S., Andréfouët, S., Gaertner-Mazouni, N. \& Remoissenet, G. 2015. Conservation and resource management in small tropical islands: trade-offs between planning unit size, data redundancy and data loss. Ocean \& Coastal Management 116, 37-43.

Van Wynsberge, S., Andréfouët, S., Gaertner-Mazouni, N., Wabnitz, C.C.C., Gilbert, A., Remoissenet, G., Payri, C. \& Fauvelot, C. 2016. Drivers of density for the exploited giant clam Tridacna maxima: a metaanalysis. Fish and Fisheries 17, 567-584.

Van Wynsberge, S., Andréfouët, S., Gaertner-Mazouni, N., Wabnitz, C.C.C., Menoud, M., Le Moullac, G., Levy, P., Gilbert, A. \& Remoissenet, G. 2017. Growth, survival and reproduction of the giant clam Tridacna maxima (Röding 1798, Bivalvia) in two contrasting lagoons in French Polynesia. PLoS ONE 12, e0170565. doi:101317/journal.pone.0170565

Van Wynsberge, S., Andréfouët, S., Gilbert, A., Stein, A. \& Remoissenet, G. 2013. Best management strategies for sustainable giant clam fishery in French Polynesia Islands: Answers from a spatial modeling approach. PLoS ONE 8, e64641. doi:10.1371/journal.pone.0064641

Vicentuan-Cabaitan, K., Neo, M.L., Eckman, W., Teo, S.L.-M. \& Todd, P.A. 2014. Giant clam shells host a multitude of epibionts. Bulletin of Marine Science 90, 795-796.

von der Heyden, S., Beger, M., Toonen, R.J., van Herwerden, L., Juinio-Meñez, M.A., Ravago-Gotanco, R., Fauvelot, C. \& Bernardi, G. 2014. The application of genetics to marine management and conservation: examples from the Indo-Pacific. Bulletin of Marine Science 90, 123-158.

Wabnitz, C.C.C. \& Fauvelot, C. 2014. Tridacna noae is back. SPC Fisheries Newsletter 145, 30 only.

Wabnitz, C., Taylor, M., Green, E. \& Razak, T. 2003. From Ocean to Aquarium: The Global Trade in Marine Ornamental Species. Cambridge, UK: UNEP World Conservation Monitoring Centre. Online. http:// wedocs.unep.org//handle/20.500.11822/8341 (accessed 19 December 2016).

Waters, C.G. 2008. Biological responses of juvenile Tridacna maxima (Mollusca:Bivalvia) to increased $\mathrm{pCO}_{2}$ and ocean acidification. MSc Thesis, The Evergreen State College, Olympia, Washington, USA.

Waters, C.G., Story, R. \& Costello, M.J. 2013. A methodology for recruiting a giant clam, Tridacna maxima, directly to natural substrata: a first step in reversing functional extinctions? Biological Conservation 160, 19-24.

Watson, S.-A. 2015. Giant clams and rising $\mathrm{CO}_{2}$ : light may ameliorate effects of ocean acidification on a solarpowered animal. PLoS ONE 10, e0128405. doi:10.1371/journal.pone.0128405

Watson, S.-A., Southgate, P.C., Miller, G.M., Moorhead, J.A. \& Knauer, J. 2012. Ocean acidification and warming reduce juvenile survival of the fluted giant clam, Tridacna squamosa. Molluscan Research 32, 177-180.

Wells, S. 1996. The IUCN Red List of Threatened Species 1996. Cambridge, UK: IUCN Global Species Programme Red List Unit. Online. http://www.iucnredlist.org/ (accessed 28 July 2016).

Wells, S. 1997. Giant Clams: Status, Trade and Mariculture, and the Roles of CITES Management. Gland, Switzerland and Cambridge, UK: IUCN. Online. https://portals.iucn.org/library/sites/library/files/documents/1997-076.pdf (accessed 19 December 2016).

Wells, S.M., Pyle, R.M. \& Collins, N.M. 1983. The IUCN Invertebrate Red Data Book. Gland, Switzerland and Cambridge, UK: International Union for the Conservation of Nature and Natural Resources.

Wilkinson, C.R. \& Buddemeier, R.W. 1994. Global Climate Change and Coral Reefs: Implications for People and Reefs. Report of the UN EP-IOC-ASPEI-IUCN Global Task Team on the Implications of Climate Change on Coral Reefs. Gland, Switzerland: International Union for Conservation of Nature and Natural Resources.

Wilson, N.G. \& Kirkendale, L.A. 2016. Putting the 'Indo' back into the Indo-Pacific: resolving marine phylogeographic gaps. Invertebrate Systematics 30, 86-94. 


\section{MEI LIN NEO ET AL.}

Yamaguchi, M. 1977. Conservation and cultivation of giant clams in the tropical Pacific. Biological Conservation 11, 13-20.

Yau, A.J., Lenihan, H.S. \& Kendall, B.E. 2014. Fishery management priorities vary with self-recruitment in sedentary marine populations. Ecological Applications 24, 1490-1504.

Yonge, C.M. 1936. Mode of life, feeding, digestion and symbiosis with zooxanthellae in the Tridacnidae. Great Barrier Reef Expedition 1928-29, 283-321.

Yonge, C.M. 1982. Functional morphology and evolution in the Tridacnidae (Mollusca: Bivalvia: Cardiacea). Records of the Australian Museum 33, 735-777.

Zhang, H. 2014. Chinese fishermen in troubled waters. The Diplomat October 23, 2014. Online. http:// thediplomat.com/2014/10/chinese-fishermen-in-troubled-waters/ (accessed 26 February 2016).

Zuschin, M. \& Piller, W.E. 1997. Bivalve distribution on coral carpets in the Northern Bay of Safaga (Red Sea, Egypt) and its relation to environmental parameters. Facies 37, 183-194. 


\section{Appendix A: Supplementary materials}

Table A1 List of localities with giant clams (in alphabetical order)

\begin{tabular}{|c|c|c|c|c|}
\hline Locality & Locality & Citations & $\begin{array}{l}\text { Was data useful } \\
\text { for review? }\end{array}$ & $\begin{array}{l}\text { Was data } \\
\text { extracted? }\end{array}$ \\
\hline \multirow[t]{8}{*}{ American Samoa } & Rose Atoll & Radtke (1985) & Y (survey data) & Y (Table A3) \\
\hline & - & Bell (1993) & $\mathrm{Y}$ & \\
\hline & - & Nagaoka (1993) & $\mathrm{Y}$ & \\
\hline & Rose Atoll & Green \& Craig (1999) & Y (survey data) & Y (Table A3) \\
\hline & - & Green (2002) & $\mathrm{Y}$ & \\
\hline & - & Kelty \& Kuartei (2004) & $\mathrm{Y}$ & \\
\hline & - & Craig (2009) & $\mathrm{Y}$ & \\
\hline & - & Reef Check $(1997,2003)$ & Y (survey data) & Y (Table A4) \\
\hline \multirow[t]{15}{*}{ Australia } & $\begin{array}{l}\text { One Tree Island, Capricorn } \\
\text { Group, QL }\end{array}$ & McMichael (1974) & Y (survey data) & Y (Table A3) \\
\hline & $\begin{array}{l}\text { Orpheus Island, Palm Island } \\
\text { Group, QL }\end{array}$ & Hamner \& Jones (1976) & Y (survey data) & Y (Table A3) \\
\hline & $\begin{array}{l}\text { Great Barrier Reef (North \& } \\
\text { South) }\end{array}$ & Braley $(1987 a, b)$ & Y (survey data) & Y (Table A3) \\
\hline & $\begin{array}{l}\text { Lizard Island, Great Barrier } \\
\text { Reef }\end{array}$ & Alder \& Braley (1989) & $\mathrm{Y}$ & \\
\hline & $\begin{array}{l}\text { Michaelmas Reef, Great } \\
\text { Barrier Reef }\end{array}$ & Pearson \& Munro (1991) & Y (survey data) & Y (Table A3) \\
\hline & $\begin{array}{l}\text { Lizard Island, Great Barrier } \\
\text { Reef }\end{array}$ & Braley \& Muir (1995) & $\begin{array}{l}\text { Y (insufficient } \\
\text { data) }\end{array}$ & \\
\hline & $\begin{array}{l}\text { Montebello Islands, } \\
\text { Western Australia }\end{array}$ & Wells et al. (2000) & $\mathrm{Y}$ & \\
\hline & $\begin{array}{l}\text { Mermaid Reef, Cartier } \\
\text { Reef, and Ashmore Reef }\end{array}$ & Rees et al. (2003) & Y (survey data) & Y (Table A3) \\
\hline & $\begin{array}{l}\text { Heron Island, southern } \\
\text { Great Barrier Reef }\end{array}$ & Strotz et al. (2010) & $\mathrm{Y}$ & \\
\hline & Ningaloo Marine Park, WA & Black et al. (2011) & Y (survey data) & Y (Table A3) \\
\hline & $\begin{array}{l}\text { Solitary Islands Marine } \\
\text { Park, NSW }\end{array}$ & Smith (2011) & $\mathrm{Y}$ & \\
\hline & Ningaloo Marine Park, WA & Penny \& Willan (2014) & $\mathrm{Y}$ & \\
\hline & Western Australia & Borsa et al. (2015) & Y (DNA) & \\
\hline & Ningaloo Marine Park, WA & Johnson et al. (2016) & Y (survey data) & Y (Table A3) \\
\hline & - & Reef Check (1997-2014) & Y (survey data) & Y (Table A4) \\
\hline British Indian Ocean & Chagos Archipelago & Sheppard (1984) & $\mathrm{Y}$ & \\
\hline Territory & $\begin{array}{l}\text { Chagos Archipelago } \\
\text { (Salomon and Peros } \\
\text { Banhos atolls) }\end{array}$ & $\begin{array}{l}\text { Chagos Conservation } \\
\text { Trust (FaceBook) (2014) }\end{array}$ & $\mathrm{Y}$ & \\
\hline Brunei & - & Reef Check & & \\
\hline \multirow[t]{5}{*}{ Cambodia } & - & Vibol (N.D.) & Y (survey data) & Y (Table A3) \\
\hline & Koh Rong & Chou (2000) & Y (exploitation) & \\
\hline & - & Chou et al. (2002) & Y (survey data) & Y (Table A3) \\
\hline & - & Kim et al. (2004) & Y (survey data) & Y (Table A3) \\
\hline & - & Van Bochove et al. (2011) & Y (survey data) & Y (Table A3) \\
\hline
\end{tabular}


Table A1 (Continued) List of localities with giant clams (in alphabetical order)

\begin{tabular}{|c|c|c|c|c|}
\hline Locality & Locality & Citations & $\begin{array}{l}\text { Was data useful } \\
\text { for review? }\end{array}$ & $\begin{array}{l}\text { Was data } \\
\text { extracted? }\end{array}$ \\
\hline \multirow[t]{3}{*}{$\begin{array}{l}\text { Cambodia } \\
\text { (Continued) }\end{array}$} & $\begin{array}{l}\text { Song Saa Private Island, } \\
\text { Koh Rong Archipelago }\end{array}$ & Savage et al. (2013) & Y (survey data) & Y (Table A3) \\
\hline & $\begin{array}{c}\text { Koh Rong and Koh Koun, } \\
\text { Koh Rong Archipelago }\end{array}$ & Thorne et al. (2015) & Y (survey data) & Y (Table A3) \\
\hline & - & $\begin{array}{l}\text { Reef Check }(1998,2001, \\
\text { 2003, 2009-2010) }\end{array}$ & Y (survey data) & Y (Table A4) \\
\hline $\begin{array}{l}\text { Cargados Carajos } \\
\text { Archipelago }\end{array}$ & - & Monsecour (2016) & Y (exploitation) & $\mathrm{Y}$ \\
\hline \multirow[t]{6}{*}{ China } & Hainan Islands & Hutchings \& Wu (1987) & $\mathrm{Y}$ & \\
\hline & Hainan Islands & Fiege et al. (1994) & $\mathrm{Y}$ & \\
\hline & - & Qi (2004) & $\mathrm{Y}$ & \\
\hline & Sanya waters & Tadashi et al. (2008) & $\mathrm{Y}$ & \\
\hline & - & Liu (2013) & $\mathrm{Y}$ & \\
\hline & - & Reef Check $(2000,2002)$ & Y (survey data) & Y (Table A4) \\
\hline \multirow[t]{8}{*}{ Christmas Island } & Flying Fish Cove & Andrews et al. (1900) & $\mathrm{Y}$ & \\
\hline & - & Tomlin (1934) & $\mathrm{Y}$ & \\
\hline & - & $\begin{array}{l}\text { Wells \& Slack-Smith } \\
\text { (2000) }\end{array}$ & $\mathrm{Y}$ & \\
\hline & - & Gilligan et al. (2008) & Y (survey data) & Y (Table A3) \\
\hline & - & Hourston (2010) & Y (survey data) & Y (Table A3) \\
\hline & - & Huber (2010) & $\mathrm{Y}$ & \\
\hline & - & Tan \& Low (2014) & $\mathrm{Y}$ & \\
\hline & - & Reef Check (2003-2007) & Y (survey data) & Y (Table A4) \\
\hline Cocos (Keeling) & - & Gibson-Hill (1946) & $\mathrm{Y}$ & \\
\hline \multirow[t]{11}{*}{ Islands } & - & Abbott (1950) & $\mathrm{Y}$ & \\
\hline & - & Maes (1967) & $\mathrm{Y}$ & \\
\hline & - & Wells (1994) & $\mathrm{Y}$ & \\
\hline & - & Hender et al. (2001) & Y (survey data) & Y (Table A3) \\
\hline & - & $\begin{array}{l}\text { Australian Government } \\
\text { (2005) }\end{array}$ & Y (survey data) & Y (Table A3) \\
\hline & - & Hourston (2010) & Y (survey data) & Y (Table A3) \\
\hline & - & Huber (2010) & $\mathrm{Y}$ & \\
\hline & - & $\begin{array}{l}\text { Bellchambers \& Evans } \\
\text { (2013) }\end{array}$ & Y (survey data) & Y (Table A3) \\
\hline & - & Tan \& Low (2014) & $\mathrm{Y}$ & \\
\hline & - & Evans et al. (2016) & Y (survey data) & Y (Table A3) \\
\hline & - & $\begin{array}{l}\text { Reef Check (1997-1999, } \\
\text { 2001-2005, 2007-2008) }\end{array}$ & Y (survey data) & Y (Table A4) \\
\hline Comoros & $\begin{array}{l}\text { Nioumachouoi site; } \\
\text { Ouenefou reef }\end{array}$ & Bigot et al. (2000) & $\mathrm{Y}$ & \\
\hline \multirow[t]{3}{*}{ Cook Islands } & - & Paulay (1987) & $\mathrm{Y}$ & \\
\hline & $\begin{array}{l}\text { Aitutaki Lagoon, Manihiki } \\
\text { Lagoon, Suwarrow Lagoon, } \\
\text { and Penrhyn Lagoon }\end{array}$ & Sims \& Howard (1988) & Y (survey data) & Y (Table A3) \\
\hline & - & $\begin{array}{l}\text { Tisdell \& Wittenberg } \\
\text { (1992) }\end{array}$ & $\mathrm{Y}$ & \\
\hline
\end{tabular}


Table A1 (Continued) List of localities with giant clams (in alphabetical order)

\begin{tabular}{|c|c|c|c|c|}
\hline Locality & Locality & Citations & $\begin{array}{l}\text { Was data useful } \\
\text { for review? }\end{array}$ & $\begin{array}{l}\text { Was data } \\
\text { extracted? }\end{array}$ \\
\hline \multirow{3}{*}{$\begin{array}{l}\text { Cook Islands } \\
\text { (Continued) }\end{array}$} & Tongareva Lagoon & Chambers (2007) & Y (survey data) & Y (Table A3) \\
\hline & Tongareva Lagoon & Chambers (2008) & $\begin{array}{l}\text { Y (insufficient } \\
\text { data) }\end{array}$ & \\
\hline & - & Reef Check (2005) & $\mathrm{Y}$ & Y (Table A4) \\
\hline \multirow[t]{2}{*}{ Djibouti } & - & Pilcher \& Djama (2000) & Y (survey data) & Y (Table A3) \\
\hline & - & PERSGA (2010) & Y (survey data) & Y (Table A3) \\
\hline \multirow[t]{2}{*}{ East Timor } & Dili & Flickr & $\mathrm{Y}$ & \\
\hline & - & Reef Check $(2004,2008)$ & Y (survey data) & Y (Table A4) \\
\hline \multirow[t]{8}{*}{ Egypt } & $\begin{array}{l}\text { Northern Bay of Safaga, } \\
\text { Red Sea }\end{array}$ & Zuschin \& Pillar (1997) & Y (survey data) & Y (Table A3) \\
\hline & Northern Red Sea & Kilada et al. (1998) & Y (survey data) & Y (Table A3) \\
\hline & Northern Red Sea & Ullmann (2013) & Y (survey data) & Y (Table A3) \\
\hline & Egyptian Red Sea & Mekawy (2014) & $\mathrm{Y}$ & \\
\hline & Red Sea area & Richter et al. (2008) & Y (survey data) & Y (Table A3) \\
\hline & Red Sea area & Huber \& Eschner (2011) & $\mathrm{Y}$ & \\
\hline & Northern Red Sea & $\begin{array}{l}\text { Mekawy \& Madkour } \\
\text { (2012) }\end{array}$ & $\mathrm{Y}$ & \\
\hline & - & $\begin{array}{l}\text { Reef Check (1997, } \\
\text { 2000-2015) }\end{array}$ & Y (survey data) & Y (Table A4) \\
\hline Eritrea & - & Reef Check (2000) & Y (survey data) & Y (Table A4) \\
\hline \multirow{4}{*}{$\begin{array}{l}\text { Federated States of } \\
\text { Micronesia }\end{array}$} & Yap State & Price \& Fagolimul (1988) & $\mathrm{Y}$ & \\
\hline & - & Smith (1992) & $\mathrm{Y}$ & \\
\hline & $\begin{array}{l}\text { Kosrae, part of the Caroline } \\
\text { Islands }\end{array}$ & Borsa et al. (2015) & $\mathrm{Y}$ & \\
\hline & - & Reef Check (2000-2008) & Y (survey data) & Y (Table A4) \\
\hline \multirow[t]{10}{*}{ Fiji } & - & Lewis et al. (1988) & $\mathrm{Y}$ & \\
\hline & Eastern islands (Lau) & Lewis \& Ledua (1988) & $\mathrm{Y}$ & \\
\hline & Eastern islands (Lau) & Lucas et al. (1991) & $\mathrm{Y}$ & \\
\hline & Eastern islands (Lau) & Vuki et al. (1992) & $\mathrm{Y}$ & \\
\hline & - & $\begin{array}{l}\text { Tacconi \& Tisdell (1992) } \\
\text { Chapter } 13\end{array}$ & $\mathrm{Y}$ & \\
\hline & - & $\begin{array}{l}\text { Tisdell \& Wittenberg } \\
\text { (1992) }\end{array}$ & $\mathrm{Y}$ & \\
\hline & Eastern islands (Lau) & Ledua et al. (1993) & Y (survey data) & Y (Table A3) \\
\hline & Southwest Viti Levu Island & Seeto et al. (2012) & Y (exploitation) & \\
\hline & Viti-Levu & Borsa et al. (2015) & $\mathrm{Y}$ & \\
\hline & - & $\begin{array}{l}\text { Reef Check (1997, } \\
\text { 1999-2011) }\end{array}$ & Y (survey data) & Y (Table A4) \\
\hline \multirow[t]{5}{*}{ French Polynesia } & Takapoto Atoll & Jaubert (1977) & $\mathrm{Y}$ & \\
\hline & Takapoto Atoll & Richard (1977) & Y (survey data) & Y (Table A3) \\
\hline & Bora Bora Lagoon & Planes et al. (1993) & $\mathrm{Y}$ & \\
\hline & $\begin{array}{l}\text { Moorea, Takapoto, and } \\
\text { Anaa }\end{array}$ & Laurent (2001) & Y (survey data) & Y (Table A3) \\
\hline & $\begin{array}{l}\text { Tatakoto Atoll, Eastern } \\
\text { Tuamotu }\end{array}$ & Gilbert et al. (2005) & Y (survey data) & Y (Table A3) \\
\hline
\end{tabular}


Table A1 (Continued) List of localities with giant clams (in alphabetical order)

\begin{tabular}{|c|c|c|c|c|}
\hline Locality & Locality & Citations & $\begin{array}{l}\text { Was data useful } \\
\text { for review? }\end{array}$ & $\begin{array}{l}\text { Was data } \\
\text { extracted? }\end{array}$ \\
\hline \multirow[t]{11}{*}{$\begin{array}{l}\text { French Polynesia } \\
\text { (Continued) }\end{array}$} & $\begin{array}{l}\text { Fangatau Atoll, Eastern } \\
\text { Tuamotu }\end{array}$ & Andréfouët et al. (2005) & Y (survey data) & Y (Table A3) \\
\hline & Tubuai, Austral Islands & Larrue (2006) & $\mathrm{Y}$ & \\
\hline & $\begin{array}{l}\text { Reao, Pukarua, and } \\
\text { Raivavae }\end{array}$ & Gilbert et al. (2006a) & Y (survey data) & Y (Table A3) \\
\hline & $\begin{array}{l}\text { Fangatau Atoll, Tatakoto } \\
\text { Atoll, and Tubuai }\end{array}$ & Gilbert et al. (2006b) & Y (survey data) & Y (Table A3) \\
\hline & Tubuai, Austral Islands & Newman \& Gomez (2007) & $\mathrm{Y}$ & \\
\hline & - & Gilbert et al. (2007) & $\mathrm{Y}$ & \\
\hline & Raivavae Island & Andréfouët et al. (2009) & Y (survey data) & Y (Table A3) \\
\hline & Tatakoto Atoll & Andréfouët et al. (2013) & Y (survey data) & Y (Table A3) \\
\hline & - & $\begin{array}{l}\text { Van Wynsberge et al. } \\
\text { (2013) }\end{array}$ & Y (survey data) & Y (Table A3) \\
\hline & $\begin{array}{l}\text { Tuamotu and Gambier } \\
\text { Archipelago }\end{array}$ & Andréfouët et al. (2014) & $\mathrm{Y}$ & \\
\hline & - & Reef Check (1999-2014) & Y (survey data) & Y (Table A4) \\
\hline \multirow[t]{6}{*}{ Guam } & - & Stojkovich (1977) & $\mathrm{Y}$ & \\
\hline & - & Munro (1989) & $\mathrm{Y}$ & \\
\hline & - & $\begin{array}{l}\text { Hensley \& Sherwood } \\
\text { (1993) }\end{array}$ & $\mathrm{Y}$ & \\
\hline & - & Anonymous (1994) & $\mathrm{Y}$ & \\
\hline & - & Paulay (2003) & $\mathrm{Y}$ & \\
\hline & - & $\begin{array}{l}\text { Reef Check (1998-1999, } \\
\text { 2001, 2004) }\end{array}$ & Y (survey data) & Y (Table A4) \\
\hline \multirow[t]{2}{*}{ Hong Kong } & Mirs Bay & Morton \& Morton (1983) & $\mathrm{Y}$ & \\
\hline & - & $\begin{array}{l}\text { Reef Check (2003, 2006, } \\
\text { 2011) }\end{array}$ & Y (survey data) & Y (Table A4) \\
\hline \multirow[t]{8}{*}{ India } & $\begin{array}{l}\text { Andaman and Nicobar } \\
\text { Islands }\end{array}$ & Rosewater (1965) & $\mathrm{Y}$ & \\
\hline & Kavaratti Atoll & $\begin{array}{l}\text { Namboodiri \& Sivadas } \\
\text { (1979) }\end{array}$ & $\mathrm{Y}$ & \\
\hline & $\begin{array}{l}\text { Andaman and Nicobar } \\
\text { Islands }\end{array}$ & Ramadoss (1983) & Y (survey data) & Y (Table A3) \\
\hline & Lakshadweep & George et al. (1986) & $\mathrm{Y}$ & \\
\hline & Lakshadweep & Apte \& Dutta (2010) & $\mathrm{Y}$ & \\
\hline & Lakshadweep & Apte et al. (2010) & Y (survey data) & Y (Table A3) \\
\hline & Lakshadweep & Bijukumar et al. (2015) & Y (legislation) & \\
\hline & - & Reef Check (1998) & Y (survey data) & Y (Table A4) \\
\hline \multirow[t]{6}{*}{ Indonesia } & Karimun Java & $\begin{array}{l}\text { Brown \& Muskanofola } \\
\text { (1985) }\end{array}$ & Y (survey data) & Y (Table A3) \\
\hline & - & Pasaribu (1988) & $\mathrm{Y}$ & \\
\hline & Karimunjawa Islands & Pringgenies et al. (1995) & $\mathrm{Y}$ & \\
\hline & Gulf of Tomini, Sulawesi & Wells (2001) & $\mathrm{Y}$ & \\
\hline & $\begin{array}{l}\text { Rajah Ampat Islands, Papua } \\
\text { Province }\end{array}$ & Wells (2002) & Y & \\
\hline & Pari Island & Eliata et al. (2003) & Y (survey data) & Y (Table A3) \\
\hline
\end{tabular}


Table A1 (Continued) List of localities with giant clams (in alphabetical order)

\begin{tabular}{|c|c|c|c|c|}
\hline Locality & Locality & Citations & $\begin{array}{l}\text { Was data useful } \\
\text { for review? }\end{array}$ & $\begin{array}{l}\text { Was data } \\
\text { extracted? }\end{array}$ \\
\hline \multirow[t]{8}{*}{$\begin{array}{l}\text { Indonesia } \\
\text { (Continued) }\end{array}$} & $\begin{array}{l}\text { Anambas and Natuna } \\
\text { Islands }\end{array}$ & Tan \& Kastoro (2004) & $\mathrm{Y}$ & \\
\hline & Pari Island & Panggabean (2007) & $\mathrm{Y}$ & \\
\hline & $\begin{array}{l}\text { Seribu Islands and Manado } \\
\text { waters }\end{array}$ & Yusuf et al. (2009) & Y (survey data) & Y (Table A3) \\
\hline & $\begin{array}{l}\text { Kei Kecil, Southeast } \\
\text { Maluku }\end{array}$ & Kusnadi et al. (2008) & $\mathrm{Y}$ & \\
\hline & $\begin{array}{l}\text { Kei Kecil, Southeast } \\
\text { Maluku }\end{array}$ & Hernawan (2010) & Y (survey data) & Y (Table A3) \\
\hline & $\begin{array}{c}\text { Savu Sea, East Nusa } \\
\text { Tenggara Province }\end{array}$ & Naguit et al. (2012) & Y (survey data) & Y (Table A3) \\
\hline & $\begin{array}{l}\text { Bunaken, Manado and Alor } \\
\text { Archipelago, Savu Sea and } \\
\text { Doi Island }\end{array}$ & Borsa et al. (2015) & Y & \\
\hline & - & Reef Check (1997-2014) & Y (survey data) & Y (Table A4) \\
\hline \multirow[t]{2}{*}{ Israel } & Eilat (southernmost Israel) & Flickr & $\mathrm{Y}$ & \\
\hline & - & $\begin{array}{l}\text { Reef Check (1997-1998, } \\
\text { 2001) }\end{array}$ & Y (survey data) & Y (Table A4) \\
\hline \multirow[t]{6}{*}{ Japan } & - & Hirase (1954) & $\mathrm{Y}$ & \\
\hline & Okinawa & Kanno et al. (1976) & $\mathrm{Y}$ & \\
\hline & Okinawa & Okada (1997) & $\mathrm{Y}$ & \\
\hline & Ogasawara National Park & Fujiwara et al. (2000) & $\mathrm{Y}$ & \\
\hline & $\begin{array}{l}\text { Okinawa and Ishigaki } \\
\text { Islands }\end{array}$ & Kubo \& Iwai (2007) & $\mathrm{Y}$ & \\
\hline & - & $\begin{array}{l}\text { Reef Check (1997-2012, } \\
\text { 2014) }\end{array}$ & Y (survey data) & Y (Table A4) \\
\hline \multirow[t]{5}{*}{ Jordan } & Northern Gulf of Aqaba & Roa-Quaoit (2005) & Y (survey data) & Y (Table A3) \\
\hline & $\begin{array}{l}\text { Jordanian coast of Gulf of } \\
\text { Aqaba }\end{array}$ & Al-Horani et al. (2006) & Y (survey data) & $\begin{array}{l}\text { Cannot be easily } \\
\text { retrieved }\end{array}$ \\
\hline & Red Sea area & Richter et al. (2008) & Y (survey data) & Y (Table A3) \\
\hline & Red Sea area & Huber \& Eschner (2011) & $\mathrm{Y}$ & \\
\hline & - & Reef Check (2007) & Y (survey data) & Y (Table A4) \\
\hline \multirow[t]{4}{*}{ Kenya } & - & Evans et al. (1977) & Y (exploitation) & \\
\hline & Kenyan coastline & Accordi et al. (2010) & $\mathrm{Y}$ & \\
\hline & - & Anam \& Mostarda (2012) & $\mathrm{Y}$ & \\
\hline & - & Reef Check (2003-2004) & Y (survey data) & Y (Table A4) \\
\hline \multirow[t]{2}{*}{ La Réunion } & - & Flickr & $\mathrm{Y}$ & \\
\hline & - & Reef Check (2003-2013) & Y (survey data) & Y (Table A4) \\
\hline \multirow[t]{5}{*}{ Madagascar } & Northwest Madagascar & Wells (2003) & $\mathrm{Y}$ & \\
\hline & Andavadoaka region & Harding et al. (2006) & Y (survey data) & Y (Table A3) \\
\hline & Andavadoaka region & Nadon et al. (2007) & Y (survey data) & Y (Table A3) \\
\hline & Northern Madagascar & $\begin{array}{l}\text { Harding \& } \\
\text { Randriamanantsoa } \\
\text { (2008) }\end{array}$ & Y (survey data) & Y (Table A3) \\
\hline & Southwest Madagascar & $\begin{array}{l}\text { Barnes \& Rawlinson } \\
\text { (2009) }\end{array}$ & Y & \\
\hline
\end{tabular}


Table A1 (Continued) List of localities with giant clams (in alphabetical order)

\begin{tabular}{|c|c|c|c|c|}
\hline Locality & Locality & Citations & $\begin{array}{l}\text { Was data useful } \\
\text { for review? }\end{array}$ & $\begin{array}{l}\text { Was data } \\
\text { extracted? }\end{array}$ \\
\hline Madagascar & Andavadoaka region & Hopkins (2009) & Y (survey data) & Y (Table A3) \\
\hline (Continued) & - & $\begin{array}{l}\text { Reef Check (2001, } \\
\text { 2003-2005, 2007, } \\
\text { 2009-2011) }\end{array}$ & Y (survey data) & Y (Table A4) \\
\hline \multirow[t]{7}{*}{ Malaysia } & Pulau Redang & $\begin{array}{l}\text { Mohamed-Pauzi et al. } \\
\text { (1994) }\end{array}$ & $\mathrm{Y}$ & \\
\hline & Pulau Tioman & Tan et al. (1998) & Y (survey data) & Y (Table A3) \\
\hline & Johore Islands & Zulfigar \& Tan (2000) & $\mathrm{Y}$ & \\
\hline & Johore Islands & Tan \& Zulfigar (2001) & $\mathrm{Y}$ & \\
\hline & - & Tan \& Zulfigar (2003) & $\mathrm{Y}$ & \\
\hline & $\begin{array}{l}\text { Tun Sakaran Marine Park, } \\
\text { East Sabah }\end{array}$ & Montagne et al. (2013) & Y (survey data) & Y (Table A3) \\
\hline & - & $\begin{array}{l}\text { Reef Check (1997-2000, } \\
\text { 2003-2012, 2014) }\end{array}$ & Y (survey data) & Y (Table A4) \\
\hline \multirow[t]{3}{*}{ Maldives } & - & Basker (1991) & Y (survey data) & $\mathrm{Y}$ \\
\hline & Baa Atoll & Andréfouët et al. (2012) & $\mathrm{Y}$ & \\
\hline & - & $\begin{array}{l}\text { Reef Check (1997, 2001, } \\
\text { 2005-2014) }\end{array}$ & Y (survey data) & Y (Table A4) \\
\hline \multirow[t]{4}{*}{ Marshall Islands } & Rongelap Island & Pinca \& Beger (2002) & Y (survey data) & Y (Table A3) \\
\hline & Mili Atoll, Rongelap Atoll & Beger \& Pinca (2003) & Y (survey data) & $\begin{array}{l}\text { Cannot be easily } \\
\text { retrieved }\end{array}$ \\
\hline & - & $\begin{array}{l}\text { Beger et al. (2008) [http:// } \\
\text { www.nras-conservation. } \\
\text { org/publications.html] }\end{array}$ & $\mathrm{Y}$ & \\
\hline & - & Reef Check (2002) & Y (survey data) & Y (Table A4) \\
\hline \multirow[t]{3}{*}{ Mauritius } & - & Michel et al. (1985) & $\mathrm{Y}$ & \\
\hline & Rodrigues Island & Oliver et al. (2004) & $\mathrm{Y}$ & \\
\hline & - & Reef Check (1999-2003) & Y (survey data) & Y (Table A4) \\
\hline \multirow[t]{2}{*}{ Mayotte } & Mayotte & $\begin{array}{l}\text { Jana Around the World } \\
\text { (2010) }\end{array}$ & $\mathrm{Y}$ & \\
\hline & - & $\begin{array}{l}\text { Reef Check (2003-2007, } \\
\text { 2009-2010, 2014) }\end{array}$ & Y (survey data) & Y (Table A4) \\
\hline \multirow[t]{3}{*}{ Mozambique } & Quirimba Archipelago & Barnes et al. (1998) & $\mathrm{Y}$ & \\
\hline & - & ReefBuilders.com (2015) & $\mathrm{Y}$ & \\
\hline & - & $\begin{array}{l}\text { Reef Check (1997, } \\
\text { 2000-2002) }\end{array}$ & Y (survey data) & Y (Table A4) \\
\hline \multirow[t]{2}{*}{ Myanmar } & - & Wells (1997) & $\mathrm{Y}$ & \\
\hline & - & $\begin{array}{l}\text { Reef Check (2001, } \\
\text { 2003-2005, 2013) }\end{array}$ & Y (survey data) & Y (Table A4) \\
\hline \multirow[t]{3}{*}{ Nauru } & - & Jacob (2000) & $\mathrm{Y}$ & \\
\hline & - & South \& Skelton (2000) & $\mathrm{Y}$ & \\
\hline & - & Chin et al. (2011) & $\mathrm{Y}$ & \\
\hline \multirow[t]{2}{*}{ New Caledonia } & $\begin{array}{l}\text { North Province (Kone, } \\
\text { Koumac, Touho, } \\
\text { Hienghène) }\end{array}$ & Virly (2004) & Y (survey data) & Y (Table A3) \\
\hline & $\begin{array}{l}\text { North Eastern Lagoon } \\
\text { (Poeubo to Hienghène) }\end{array}$ & McKenna et al. (2006) & $\mathrm{Y}$ (survey data) & Y (Table A3) \\
\hline
\end{tabular}


Table A1 (Continued) List of localities with giant clams (in alphabetical order)

\begin{tabular}{|c|c|c|c|c|}
\hline Locality & Locality & Citations & $\begin{array}{l}\text { Was data useful } \\
\text { for review? }\end{array}$ & $\begin{array}{l}\text { Was data } \\
\text { extracted? }\end{array}$ \\
\hline \multirow{15}{*}{$\begin{array}{l}\text { New Caledonia } \\
\text { (Continued) }\end{array}$} & Poum & Vieux (2009) & Y (survey data) & Y (Table A3) \\
\hline & Corne Sud & Wantiez et al. (2007a) & Y (survey data) & Y (Table A3) \\
\hline & Ile des Pins & Wantiez et al. (2007b) & Y (survey data) & Y (Table A3) \\
\hline & Bourail & Wantiez et al. (2007c) & Y (survey data) & Y (Table A3) \\
\hline & Grand Lagon Nord & Wantiez et al. (2008a) & Y (survey data) & Y (Table A3) \\
\hline & Merlet & Wantiez et al. (2008b) & Y (survey data) & Y (Table A3) \\
\hline & $\begin{array}{l}\text { Ducos Island, Bay of Saint } \\
\text { Vincent }\end{array}$ & Aubert et al. (2009) & $\mathrm{Y}$ & \\
\hline & New Caledonia (50 sites) & Purcell et al. (2009) & Y (survey data) & Y (Table A3) \\
\hline & Noumea & Chin et al. (2011) & $\mathrm{Y}$ & \\
\hline & New Caledonia & Dumas et al. (2011) & Y (survey data) & Y (Table A3) \\
\hline & Ioro reef & Schwartzmann et al. (2011) & $\mathrm{Y}$ & \\
\hline & - & Dumas et al. (2013) & Y (survey data) & Y (Table A3) \\
\hline & and Loyalty Islands & Borsa et al. (2015) & $\mathrm{Y}$ & \\
\hline & $\begin{array}{l}\text { Northeastern coast of New } \\
\text { Caledonia }\end{array}$ & $\begin{array}{l}\text { Tiavouane \& Fauvelot } \\
\text { (2016) }\end{array}$ & Y (DNA) & \\
\hline & - & $\begin{array}{l}\text { Reef Check (1997-1998, } \\
\text { 2001, 2003-2011) }\end{array}$ & Y (survey data) & Y (Table A4) \\
\hline \multirow[t]{3}{*}{ Niue } & - & Dalzell et al. (1993) & Y (survey data) & Y (Table A3) \\
\hline & - & Vieux et al. (2004) & $\mathrm{Y}$ & \\
\hline & - & Kronen et al. (2008) & Y (survey data) & Y (Table A3) \\
\hline \multirow{2}{*}{$\begin{array}{l}\text { Northern Mariana } \\
\text { Islands }\end{array}$} & Saipan Island & Flickr & $\mathrm{Y}$ & \\
\hline & Maug Island & Flickr & $\mathrm{Y}$ & \\
\hline \multirow[t]{6}{*}{ Palau } & $\begin{array}{l}\text { South of Kokor, Western } \\
\text { Caroline Islands }\end{array}$ & Hardy \& Hardy (1969) & Y (survey data) & Y (Table A3) \\
\hline & $\begin{array}{l}\text { Helen Reef, Western } \\
\text { Caroline Islands }\end{array}$ & Hester \& Jones (1974) & Y (survey data) & Y (Table A3) \\
\hline & $\begin{array}{l}\text { Helen Reef, Western } \\
\text { Caroline Islands }\end{array}$ & $\begin{array}{l}\text { Bryan \& McConnell } \\
\text { (1976) }\end{array}$ & Y (survey data) & Y (Table A3) \\
\hline & $\begin{array}{l}\text { Helen Reef, Western } \\
\text { Caroline Islands }\end{array}$ & Hirshberger (1980) & Y (survey data) & Y (Table A3) \\
\hline & - & Isamu (2008) & $\begin{array}{l}\text { Y (insufficient } \\
\text { data) }\end{array}$ & \\
\hline & - & $\begin{array}{l}\text { Reef Check (1997, } \\
\text { 2000-2003, 2006) }\end{array}$ & Y (survey data) & Y (Table A4) \\
\hline \multirow[t]{8}{*}{ Papua New Guinea } & Milne Bay Province & Kinch (2001) & Y (survey data) & Y (Table A3) \\
\hline & Milne Bay Province & Kinch (2002) & Y (survey data) & Y (Table A3) \\
\hline & Milne Bay Province & Wells \& Kinch (2003) & $\mathrm{Y}$ & \\
\hline & Milne Bay Province & $\begin{array}{l}\text { Miller \& Sweatman } \\
\text { (2004) }\end{array}$ & $\mathrm{Y}$ & \\
\hline & - & $\begin{array}{l}\text { Berzunza-Sanchez et al. } \\
\text { (2013) }\end{array}$ & Y (history) & \\
\hline & Madang and Kavieng & Borsa et al. (2015) & $\mathrm{Y}$ & \\
\hline & Kavieng, New Ireland & Militz et al. (2015) & Y (survey data) & Y (Table A3) \\
\hline & - & $\begin{array}{l}\text { Reef Check (1998-2000, } \\
\text { 2002, 2004, 2008-2009) }\end{array}$ & Y (survey data) & Y (Table A4) \\
\hline
\end{tabular}


Table A1 (Continued) List of localities with giant clams (in alphabetical order)

\begin{tabular}{|c|c|c|c|c|}
\hline Locality & Locality & Citations & $\begin{array}{l}\text { Was data useful } \\
\text { for review? }\end{array}$ & $\begin{array}{l}\text { Was data } \\
\text { extracted? }\end{array}$ \\
\hline \multirow[t]{24}{*}{ Philippines } & Sulu Archipelago & Rosewater (1982) & $\mathrm{Y}$ & \\
\hline & South-Central Philippines & Alcala (1986) & Y (survey data) & Y (Table A3) \\
\hline & - & Alcala \& Alcazar (1987) & $\begin{array}{l}\text { Y (insufficient } \\
\text { data) }\end{array}$ & \\
\hline & $\begin{array}{l}\text { Sulu Archipelago and } \\
\text { Southern Palawan }\end{array}$ & Villanoy et al. (1988) & $\mathrm{Y}$ & \\
\hline & - & Gomez \& Alcala (1988) & Y (survey data) & $\begin{array}{l}\text { see Juinio et al. } \\
\text { (1989) }\end{array}$ \\
\hline & - & Juinio et al. (1989) & Y (survey data) & Y (Table A3) \\
\hline & - & $\begin{array}{l}\text { Calumpong \& Cadiz } \\
\text { (1993) }\end{array}$ & Y (survey data) & Y (Table A3) \\
\hline & - & Gomez et al. (2000) & $\begin{array}{l}\text { Y (insufficient } \\
\text { data) }\end{array}$ & \\
\hline & - & Calumpong et al. (2002) & $\mathrm{Y}$ & \\
\hline & $\begin{array}{l}\text { Tubbataha Reefs Natural } \\
\text { Park }\end{array}$ & $\begin{array}{l}\text { Dolorosa \& Schoppe } \\
\text { (2005) }\end{array}$ & Y (survey data) & Y (Table A3) \\
\hline & - & $\begin{array}{l}\text { Gomez \& Mingoa- } \\
\text { Licuanan (2006) }\end{array}$ & $\begin{array}{l}\text { Y (insufficient } \\
\text { data) }\end{array}$ & \\
\hline & $\begin{array}{l}\text { Caniogan Marine Sanctuary, } \\
\text { NW Philippines }\end{array}$ & Cabaitan et al. (2008) & $\begin{array}{l}\text { Y (insufficient } \\
\text { data) }\end{array}$ & \\
\hline & Bolinao Reef System & Dizon et al. (2008) & $\begin{array}{l}\text { Y (insufficient } \\
\text { data) }\end{array}$ & \\
\hline & $\begin{array}{l}\text { Tubbataha Reefs Natural } \\
\text { Park }\end{array}$ & Dolorosa (2010) & Y (survey data) & Y (Table A3) \\
\hline & $\begin{array}{l}\text { Tubbataha Reefs Natural } \\
\text { Park }\end{array}$ & Dolorosa \& Jontila (2012) & Y (survey data) & $\mathrm{Y}$ \\
\hline & $\begin{array}{l}\text { Island of Hadji Panglima } \\
\text { Tahil, Sulu }\end{array}$ & Tabugo et al. (2013) & $\mathrm{Y}$ & \\
\hline & $\begin{array}{l}\text { Tubbataha Reefs Natural } \\
\text { Park }\end{array}$ & Dolorosa et al. (2014) & Y & \\
\hline & Sibulan, Negos, Philippines & Borsa et al. (2015) & Y (DNA) & \\
\hline & $\begin{array}{l}\text { Sabang Reef Fish } \\
\text { Sanctuary, Honda Bay }\end{array}$ & Gonzales et al. (2014a) & Y (survey data) & Y (Table A3) \\
\hline & $\begin{array}{l}\text { Apulit Island, West Sulu } \\
\text { Sea, Palawan }\end{array}$ & Gonzales et al. (2014a) & Y (survey data) & Y (Table A3) \\
\hline & $\begin{array}{l}\text { Apulit Island, Taytay Bay, } \\
\text { Palawan }\end{array}$ & Gonzales et al. (2014b) & Y (survey data) & Y (Table A3) \\
\hline & $\begin{array}{l}\text { Tubbataha Reefs Natural } \\
\text { Park }\end{array}$ & Dolorosa et al. (2015) & $\mathrm{Y}$ & \\
\hline & $\begin{array}{l}\text { Tubbataha Reefs Natural } \\
\text { Park }\end{array}$ & Conales et al. (2015) & Y (survey data) & Y (Table A3) \\
\hline & - & $\begin{array}{l}\text { Reef Check (1997-2008, } \\
\text { 2010-2014) }\end{array}$ & Y (survey data) & Y (Table A4) \\
\hline \multirow[t]{2}{*}{ Pitcairn Islands } & - & Paulay (1989) & $\mathrm{Y}$ & \\
\hline & Oeno Atoll & Irving \& Dawson (2013) & Y (survey data) & Y (Table A3) \\
\hline \multirow[t]{2}{*}{ Republic of Kiribati } & Fanning Atoll & Kay (1970) & $\mathrm{Y}$ & \\
\hline & - & Taniera (1988) & $\mathrm{Y}$ & \\
\hline
\end{tabular}


Table A1 (Continued) List of localities with giant clams (in alphabetical order)

\begin{tabular}{|c|c|c|c|c|}
\hline Locality & Locality & Citations & $\begin{array}{l}\text { Was data useful } \\
\text { for review? }\end{array}$ & $\begin{array}{l}\text { Was data } \\
\text { extracted? }\end{array}$ \\
\hline \multirow{8}{*}{$\begin{array}{l}\text { Republic of Kiribati } \\
\text { (Continued) }\end{array}$} & Central Gilbert Islands & Munro (1988) & Y (survey data) & Y (Table A3) \\
\hline & $\begin{array}{l}\text { Caroline Atoll (formerly } \\
\text { Gilbert Islands) }\end{array}$ & Kepler \& Kepler (1994) & Y (survey data) & Y (Table A3) \\
\hline & Gilbert Islands & Thomas (2001) & $\mathrm{Y}$ & \\
\hline & Northern Line Islands & Sandin et al. (2008) & Y (survey data) & Y (Table A3) \\
\hline & Millenium Atoll & Barott et al. (2010) & Y (survey data) & Y (Table A3) \\
\hline & Northern Line Islands & Williams et al. (2013) & $\mathrm{Y}$ & \\
\hline & $\begin{array}{l}\text { Kiritimati, Northern Line } \\
\text { Islands }\end{array}$ & Borsa et al. (2015) & $\mathrm{Y}$ & \\
\hline & - & Thomas (2014) & $\mathrm{Y}$ (history) & \\
\hline \multirow[t]{7}{*}{ Samoa } & - & Zann (1989) & $\mathrm{Y}$ & \\
\hline & Upolu, Western Samoa & Zann (1991) & $\mathrm{Y}$ & \\
\hline & Western Samoa & $\begin{array}{l}\text { Tacconi \& Tisdell (1992) } \\
\text { Chapter } 13\end{array}$ & $\mathrm{Y}$ & \\
\hline & - & $\begin{array}{l}\text { Tisdell \& Wittenberg } \\
\text { (1992) }\end{array}$ & $\mathrm{Y}$ & \\
\hline & - & South \& Skelton (2000) & $\mathrm{Y}$ & \\
\hline & - & Tiitii et al. (2014) & $\mathrm{Y}$ & \\
\hline & - & Flickr & $\mathrm{Y}$ & \\
\hline \multirow[t]{4}{*}{ Saudi Arabia } & Jeddah & Hughes (1977) & $\mathrm{Y}$ & \\
\hline & Jeddah & Bodoy (1984) & Y (survey data) & Y (Table A3) \\
\hline & - & PERSGA (2010) & Y (survey data) & Y (Table A3) \\
\hline & - & $\begin{array}{l}\text { Reef Check } \\
\quad(1999,2008-2009)\end{array}$ & Y (survey data) & Y (Table A4) \\
\hline $\begin{array}{l}\text { Saya de Malha } \\
\text { Banks (currently } \\
\text { administered by } \\
\text { Mauritius) }\end{array}$ & - & Sirenko \& Scarlato (1991) & $\mathrm{Y}$ & \\
\hline \multirow[t]{5}{*}{ Seychelles } & Mahe & Taylor (1968) & $\mathrm{Y}$ & \\
\hline & Seychelle Islands & Selin et al. (1992) & Y (survey data) & Y (Table A3) \\
\hline & Aride Island Beach & Agombar et al. (2003) & Y (survey data) & Y (Table A3) \\
\hline & Silhouette Island & Gerlach \& Gerlach (2004) & $\mathrm{Y}$ & \\
\hline & - & Reef Check $(1997,2001)$ & Y (survey data) & Y (Table A4) \\
\hline \multirow[t]{7}{*}{ Singapore } & Singapore & $\begin{array}{l}\text { Courtois de Vicose \& } \\
\text { Chou (1999) }\end{array}$ & $\begin{array}{l}\text { Y (insufficient } \\
\text { data) }\end{array}$ & \\
\hline & Southern Islands & Guest et al. (2008) & Y (survey data) & Y (Table A3) \\
\hline & - & Todd \& Guest (2008) & $\begin{array}{l}\text { Y (insufficient } \\
\text { data) }\end{array}$ & \\
\hline & - & Soo et al. (2010) & $\begin{array}{l}\text { Y (insufficient } \\
\text { data) }\end{array}$ & \\
\hline & Southern Islands & Neo \& Todd $(2012 \mathrm{a}, \mathrm{b})$ & Y (survey data) & Y (Table A3) \\
\hline & - & Neo et al. (2013) & $\begin{array}{l}\text { Y (insufficient } \\
\text { data) }\end{array}$ & \\
\hline & - & Neo \& Todd (2013) & Y (survey data) & Y (Table A3) \\
\hline
\end{tabular}


Table A1 (Continued) List of localities with giant clams (in alphabetical order)

\begin{tabular}{|c|c|c|c|c|}
\hline Locality & Locality & Citations & $\begin{array}{l}\text { Was data useful } \\
\text { for review? }\end{array}$ & $\begin{array}{l}\text { Was data } \\
\text { extracted? }\end{array}$ \\
\hline \multirow[t]{9}{*}{ Solomon Islands } & - & Govan et al. (1988) & $\mathrm{Y}$ & \\
\hline & - & Skewes (1990) & $\begin{array}{l}\text { Y (insufficient } \\
\text { data) }\end{array}$ & \\
\hline & - & Bell et al. (1997) & $\begin{array}{l}\text { Y (insufficient } \\
\text { data) }\end{array}$ & \\
\hline & - & Bell (1999) & $\begin{array}{l}\text { Y (insufficient } \\
\text { data) }\end{array}$ & \\
\hline & $\begin{array}{l}\text { Arnavon Marine } \\
\text { Conservation Area }\end{array}$ & Lovell et al. (2004) & $\mathrm{Y}$ & \\
\hline & - & Ramohia (2006) & Y (survey data) & Y (Table A3) \\
\hline & Bellona (Mungiki) Island & Thaman et al. (2011) & $\mathrm{Y}$ & \\
\hline & - & Borsa et al. (2015) & Y (DNA) & \\
\hline & - & Reef Check (2005-2012) & Y (survey data) & Y (Table A4) \\
\hline \multirow[t]{2}{*}{ Somalia } & - & Sommer et al. (1996) & $\mathrm{Y}$ & \\
\hline & - & $\begin{array}{l}\text { Pilcher \& Alsuhaibany } \\
\text { (2000) }\end{array}$ & $\mathrm{Y}$ & \\
\hline South Africa & - & $\begin{array}{l}\text { Reef Check (2000-2002, } \\
\text { 2005) }\end{array}$ & Y (survey data) & Y (Table A4) \\
\hline \multirow[t]{10}{*}{ South China Sea } & $\begin{array}{l}\text { Xisha Islands (Paracel } \\
\text { Islands) }\end{array}$ & Zhuang (1978) & $\mathrm{Y}$ & \\
\hline & $\begin{array}{l}\text { Xisha (Paracel Islands) and } \\
\text { Nansha Islands (Spratly } \\
\text { Islands) }\end{array}$ & Bernard et al. (1993) & $\mathrm{Y}$ & \\
\hline & $\begin{array}{l}\text { Xisha Islands (Paracel } \\
\text { Islands) }\end{array}$ & Pan \& Lan (1998) & $\mathrm{Y}$ & \\
\hline & $\begin{array}{l}\text { Pulau Layang Layang } \\
\text { (Swallow Reef) (Malaysia) }\end{array}$ & Sahari et al. (2002) & Y (survey data) & Y (Table A3) \\
\hline & North Spratly Islands & Van Long et al. (2008) & Y (survey data) & Y (Table A3) \\
\hline & $\begin{array}{l}\text { North Danger Reef and } \\
\text { Jackson Atoll }\end{array}$ & Calumpong et al. (2008) & $\mathrm{Y}$ & \\
\hline & $\begin{array}{l}\text { North Danger Reef and } \\
\text { Trident Shoal }\end{array}$ & Lasola \& Hoang (2008) & Y (survey data) & Y (Table A3) \\
\hline & $\begin{array}{l}\text { North Danger Reef and } \\
\text { Jackson Atoll }\end{array}$ & $\begin{array}{l}\text { Calumpong \& } \\
\text { Macansantos (2008) }\end{array}$ & Y (survey data) & Y (Table A3) \\
\hline & $\begin{array}{l}\text { Dongsha Atoll (Pratas } \\
\text { Islands) (Taiwan) }\end{array}$ & Borsa et al. (2015) & $\mathrm{Y}$ & \\
\hline & $\begin{array}{l}\text { Taiping Island (Itu Aba } \\
\text { Island, Spratly group) }\end{array}$ & $\begin{array}{l}\text { A Frontier in the South } \\
\text { China Sea: Biodiversity } \\
\text { of Taiping Island, } \\
\text { Nansha Islands (2014) }\end{array}$ & $\mathrm{Y}$ & \\
\hline Sri Lanka & - & Reef Check (2003) & Y (survey data) & Y (Table A4) \\
\hline \multirow[t]{3}{*}{ Sudan } & $\begin{array}{l}\text { Harvey reef, Baraja reef, } \\
\text { Lighthouse reef, Mersa } \\
\text { Towartit }\end{array}$ & Taylor \& Reid (1984) & $\mathrm{Y}$ & \\
\hline & Sanganeb Atoll & CBD Report (N.D.) & $\mathrm{Y}$ & \\
\hline & - & Reef Check $(2004,2009)$ & Y (survey data) & Y (Table A4) \\
\hline
\end{tabular}


Table A1 (Continued) List of localities with giant clams (in alphabetical order)

\begin{tabular}{|c|c|c|c|c|}
\hline Locality & Locality & Citations & $\begin{array}{l}\text { Was data useful } \\
\text { for review? }\end{array}$ & $\begin{array}{l}\text { Was data } \\
\text { extracted? }\end{array}$ \\
\hline \multirow[t]{5}{*}{ Taiwan } & - & Wu (1999) & $\mathrm{Y}$ & \\
\hline & $\begin{array}{l}\text { Northern and Southern } \\
\text { Taiwan, Orchid Island, } \\
\text { Green Island, } \\
\text { Hsiaoliuchiu, Penghu }\end{array}$ & Tang (2005) & $\mathrm{Y}$ & \\
\hline & Gueishan Island & Huang et al. (2013) & $\mathrm{Y}$ & \\
\hline & $\begin{array}{l}\text { Northern and Southern } \\
\text { Taiwan, Orchid Island, } \\
\text { Green Island, } \\
\text { Hsiaoliuchiu, Penghu }\end{array}$ & Su et al. (2014) & $\mathrm{Y}$ & \\
\hline & - & $\begin{array}{l}\text { Reef Check (1998, } \\
\text { 2008-2010) }\end{array}$ & Y (survey data) & Y (Table A4) \\
\hline \multirow[t]{4}{*}{ Tanzania } & Zanzibar & Gossling et al. (2004) & Y & \\
\hline & Chumbe Island & Daniels (2004) & Y (survey data) & Y (Table A3) \\
\hline & $\begin{array}{l}\text { Kilwa Island, southern } \\
\text { Swahili coast }\end{array}$ & Nakamura (2013) & Y & \\
\hline & - & $\begin{array}{l}\text { Reef Check (1997-1998, } \\
\text { 2003-2008) }\end{array}$ & Y (survey data) & Y (Table A4) \\
\hline \multirow[t]{8}{*}{ Thailand } & $\begin{array}{l}\text { Lee-Pae Island, Andaman } \\
\text { Seas }\end{array}$ & $\begin{array}{l}\text { Chantrapornsyl et al. } \\
\text { (1996) }\end{array}$ & Y (survey data) & Y (Table A3) \\
\hline & Surin Islands & Kittiwattanawong (1997) & $\mathrm{Y}$ & \\
\hline & $\begin{array}{l}\text { Surin Islands, Andaman Sea } \\
\text { and Racha Yai Island, } \\
\text { Phuket }\end{array}$ & Kittiwattanawong (2001) & Y & \\
\hline & $\begin{array}{l}\text { Andaman Seas, Gulf of } \\
\text { Thailand }\end{array}$ & $\begin{array}{l}\text { Kittiwattanawong et al. } \\
\text { (2001) }\end{array}$ & Y & \\
\hline & Surin Islands & Koh et al. (2003) & Y (survey data) & Y (Table A3) \\
\hline & Surin Islands & Loh et al. (2004) & Y (survey data) & Y (Table A3) \\
\hline & $\begin{array}{l}\text { Mannai Island, Rayong } \\
\text { province }\end{array}$ & Junchompoo et al. (2013) & Y (survey data) & Y (Table A3) \\
\hline & - & $\begin{array}{l}\text { Reef Check (1998-2001, } \\
\text { 2003-2015) }\end{array}$ & Y (survey data) & Y (Table A4) \\
\hline \multirow[t]{3}{*}{ Tokelau } & - & Braley (1989) & Y (survey data) & Y (Table A3) \\
\hline & - & $\begin{array}{l}\text { Tisdell \& Wittenberg } \\
\text { (1992) }\end{array}$ & Y & \\
\hline & - & Vieux et al. (2004) & $\mathrm{Y}$ & \\
\hline \multirow[t]{7}{*}{ Tonga } & - & $\begin{array}{l}\text { Langi \& Hesitoni ‘Aloua } \\
\text { (1988) }\end{array}$ & Y (survey data) & Y (Table A3) \\
\hline & Ha'apai, Vava'u Islands & Lucas et al. (1991) & $\mathrm{Y}$ & \\
\hline & - & $\begin{array}{l}\text { Tacconi \& Tisdell (1992) } \\
\text { Chapter } 13\end{array}$ & $\mathrm{Y}$ & \\
\hline & - & $\begin{array}{l}\text { Tisdell \& Wittenberg } \\
\text { (1992) }\end{array}$ & Y & \\
\hline & - & Chesher (1993): p. 31 & Y (survey data) & Y (Table A3) \\
\hline & Ha'apai, Vava'u Islands & Ledua et al. (1993) & Y (survey data) & Y (Table A3) \\
\hline & - & Sone \& Loto'ahea (1995) & $\mathrm{Y}$ & \\
\hline
\end{tabular}


Table A1 (Continued) List of localities with giant clams (in alphabetical order)

\begin{tabular}{|c|c|c|c|c|}
\hline Locality & Locality & Citations & $\begin{array}{l}\text { Was data useful } \\
\text { for review? }\end{array}$ & $\begin{array}{l}\text { Was data } \\
\text { extracted? }\end{array}$ \\
\hline \multirow[t]{3}{*}{$\overline{\text { Tonga (Continued) }}$} & Tongatapu Island & Tu'avao et al. (1995) & Y (survey data) & Y (Table A3) \\
\hline & - & Salvat (2000) & Y & \\
\hline & - & Reef Check $(2002,2013)$ & Y (survey data) & Y (Table A4) \\
\hline \multirow[t]{6}{*}{ Tuvalu } & $\begin{array}{l}\text { Nukufetau, Nukulaelae, } \\
\text { Funafuti }\end{array}$ & Braley (1988) & Y (survey data) & Y (Table A3) \\
\hline & Nanumea, Nui & Langi (1990) & Y (survey data) & Y (Table A3) \\
\hline & - & Lovell et al. (2004) & $\mathrm{Y}$ & \\
\hline & - & Sauni et al. (2008) & Y (survey data) & Y (Table A3) \\
\hline & - & Job \& Ceccarelli (2012) & Y (survey data) & Y (Table A3) \\
\hline & Funafuti & Siaosi et al. (2012) & Y (survey data) & Y (Table A3) \\
\hline United States Minor & Palmyra Atoll & Flickr & $\mathrm{Y}$ & \\
\hline Outlying Islands & $\begin{array}{l}\text { Kingman Reef National } \\
\text { Wildlife Refuge }\end{array}$ & Flickr & $\mathrm{Y}$ & \\
\hline \multirow[t]{6}{*}{ Vanuatu } & - & Zann \& Ayling (1988) & Y (survey data) & Y (Table A3) \\
\hline & - & Bell \& Amos (1993) & Y (survey data) & $\begin{array}{l}\text { Y [same as Zann } \\
\text { \& Ayling (1988)] }\end{array}$ \\
\hline & - & Lovell et al. (2004) & $\mathrm{Y}$ & \\
\hline & - & Nimoho et al. (2013) & Y (survey data) & Y (Table A3) \\
\hline & Efate & Borsa et al. (2015) & $\mathrm{Y}$ & \\
\hline & - & $\begin{array}{l}\text { Reef Check (2004, 2008, } \\
\text { 2011-2012) }\end{array}$ & Y (survey data) & Y (Table A4) \\
\hline \multirow[t]{11}{*}{ Viet Nam } & An Thoi Archipelago & Latypov (2000) & $\mathrm{Y}$ & \\
\hline & Central Viet Nam & Latypov (2001) & $\mathrm{Y}$ & \\
\hline & Mju and Moon Islands & Latypov (2006) & Y (survey data) & Y (Table A3) \\
\hline & Con Dao Islands & Selin \& Latypov (2011) & Y (survey data) & Y (Table A3) \\
\hline & $\begin{array}{l}\text { Gulf of Siam and South Viet } \\
\text { Nam }\end{array}$ & Latypov \& Selin (2011) & Y (survey data) & Y (Table A3) \\
\hline & Ku Lao Cham Islands & Latypov \& Selin (2012a) & $\mathrm{Y}$ & \\
\hline & Cam Ranh Bay & Latypov \& Selin (2012b) & Y (survey data) & Y (Table A3) \\
\hline & - & Latypov (2013) & Y (survey data) & Y (Table A3) \\
\hline & Khanh Hoa Province & Latypov \& Selin (2013) & Y (survey data) & $\mathrm{Y}$ \\
\hline & - & Long \& Vo (2013) & Y (survey data) & $\begin{array}{l}\text { Cannot be easily } \\
\text { retrieved }\end{array}$ \\
\hline & - & Reef Check (1998-2006) & Y (survey data) & Y (Table A4) \\
\hline \multirow{2}{*}{$\begin{array}{l}\text { Wallis and Futuna } \\
\text { Islands }\end{array}$} & Wallis Island & Pollock (1992) & $\mathrm{Y}$ & \\
\hline & Wallis Island & Borsa et al. (2015) & $\mathrm{Y}$ & \\
\hline \multirow[t]{3}{*}{ Yemen } & - & PERSGA (2010) & Y (survey data) & Y (Table A3) \\
\hline & Kamaran Island & Huber \& Eschner (2011) & $\mathrm{Y}$ & \\
\hline & - & $\begin{array}{l}\text { Reef Check }(1999,2001 \text {, } \\
\text { 2008) }\end{array}$ & Y (survey data) & Y (Table A4) \\
\hline
\end{tabular}

Note: Full reference list in Appendix B. 
Table A2 Checklist of giant clam species

\begin{tabular}{|c|c|c|c|}
\hline Recorded localities & Species & Localities & Reference(s) \\
\hline \multicolumn{4}{|l|}{ Red Sea } \\
\hline \multirow[t]{2}{*}{ Djibouti } & $\mathrm{TM}$ & Djibouti & PERSGA (2010) \\
\hline & TS & Djibouti & PERSGA (2010) \\
\hline \multirow[t]{7}{*}{ Egypt } & TM & Egypt & $\begin{array}{l}\text { Wells et al. (1983); PERSGA (2010); } \\
\text { Mekawy \& Madkour (2012); Mekawy } \\
\text { (2014) }\end{array}$ \\
\hline & & $\begin{array}{l}\text { Coral carpets, Northern Bay of } \\
\text { Safaga }\end{array}$ & Zuschin \& Pillar (1997) \\
\hline & & Gulf of Aqaba & $\begin{array}{l}\text { Kilada (1998); Zuschin \& Stachowitsch } \\
\text { (2007) }\end{array}$ \\
\hline & & Abu Sauatir, Northern Red Sea & Ullmann (2013) \\
\hline & TS & Egypt & Wells et al. (1983); PERSA (2010) \\
\hline & & Gulf of Aqaba & Kilada (1998) \\
\hline & $\begin{array}{l}\text { TSI (previously } \\
\text { TCO) }\end{array}$ & $\begin{array}{l}\text { Sinai coast, western Gulf of } \\
\text { Aqaba; Northern Red Sea, } \\
\text { Egyptian mainland }\end{array}$ & $\begin{array}{l}\text { Richter et al. (2008); Huber \& Eschner } \\
\text { (2011) }\end{array}$ \\
\hline Eritrea & Tridacna spp. & No data & Reef Check \\
\hline \multirow[t]{3}{*}{ Israel } & $\mathrm{TM}$ & $\begin{array}{l}\text { Eilat (southernmost of Israel, } \\
\text { Red Sea) }\end{array}$ & Flickr Eduardo Pszczol (2006) \\
\hline & TS & $\begin{array}{l}\text { Eilat (southernmost of Israel, } \\
\text { Red Sea) }\end{array}$ & Flickr Eduardo Pszczol (2005) \\
\hline & $\begin{array}{l}\text { TSI (previously } \\
\text { TCO) }\end{array}$ & $\begin{array}{l}\text { Eilat (southernmost of Israel, } \\
\text { Red Sea) }\end{array}$ & Flickr Eduardo Pszczol (2006) \\
\hline \multirow[t]{4}{*}{ Jordan } & $\mathrm{TM}$ & Jordanian coast of Gulf of Aqaba & Roa-Quiaoit (2005); PERSGA (2010) \\
\hline & TS & Jordanian coast of Gulf of Aqaba & Roa-Quiaoit (2005); PERSGA (2010) \\
\hline & $\begin{array}{l}\text { TSI (previously } \\
\text { TCO) }\end{array}$ & Jordanian Red Sea coast & $\begin{array}{l}\text { Richter et al. (2008); Huber \& Eschner } \\
\text { (2011) }\end{array}$ \\
\hline & Tridacna spp. & Jordanian coast of Gulf of Aqaba & Al-Horani et al. (2006) \\
\hline \multirow[t]{5}{*}{ Saudi Arabia } & $\mathrm{TM}$ & Jeddah & Hughes (1977); Bodoy (1984) \\
\hline & & Saudi Arabia & $\begin{array}{l}\text { Wells et al. (1983); Munro (1989); } \\
\text { PERSGA (2010) }\end{array}$ \\
\hline & TS & Jeddah & Hughes (1977) \\
\hline & & Saudi Arabia & Wells et al. (1983); PERSGA (2010) \\
\hline & $\begin{array}{l}\text { TSI (previously } \\
\text { TCO) }\end{array}$ & Aqaba, Tabouk & Flickr Magnus Franklin (2010) \\
\hline \multirow[t]{5}{*}{ Sudan } & $\mathrm{TM}$ & Harvey reef, Towartit & Taylor \& Reid (1984) \\
\hline & & Baraja (patch reef) & Taylor \& Reid (1984) \\
\hline & & Sudan & PERSGA (2010) \\
\hline & TS & Harvey reef, Towartit & Taylor \& Reid (1984) \\
\hline & & Sudan & PERSGA (2010) \\
\hline \multirow[t]{3}{*}{ Yemen } & $\mathrm{TM}$ & Yemen & PERSGA (2010) \\
\hline & TS & Yemen & PERSGA (2010) \\
\hline & $\begin{array}{l}\text { TSI (previously } \\
\text { TCO) }\end{array}$ & Kamaran Island & Huber \& Eschner (2011) \\
\hline
\end{tabular}


Table A2 (Continued) Checklist of giant clam species

\begin{tabular}{|c|c|c|c|}
\hline Recorded localities & Species & Localities & Reference(s) \\
\hline \multicolumn{4}{|l|}{ South-East Africa } \\
\hline \multirow[t]{3}{*}{ Comoros } & $\mathrm{TM}$ & Itsandra Plongee & Flickr Eric de Troyer \\
\hline & TS & Itsandra Plongee & Flickr Eric de Troyer \\
\hline & Tridacna spp. & $\begin{array}{l}\text { Nioumachouoi site and Ouenefou } \\
\text { reef }\end{array}$ & Wilkinson (2000) \\
\hline \multirow[t]{3}{*}{ Kenya } & TG? & Kenya & Accordi et al. (2010) \\
\hline & $\mathrm{TM}$ & Kenya & $\begin{array}{l}\text { Evans et al. (1977); Wells et al. (1983); } \\
\text { Anam \& Mostarda (2012) }\end{array}$ \\
\hline & $\mathrm{TS}$ & Kenya & $\begin{array}{l}\text { Wells et al. (1983); Anam \& Mostarda } \\
\text { (2012) }\end{array}$ \\
\hline \multirow[t]{7}{*}{ Madagascar } & TG? & Andavadoaka region & Hopkins (2009) \\
\hline & $\mathrm{TM}$ & Madagascar & $\begin{array}{l}\text { Wells et al. (1983); Wells (2003), } \\
\text { C. Gough (BlueVentures), pers. comm. }\end{array}$ \\
\hline & TS & Madagascar & $\begin{array}{l}\text { Wells et al. (1983); Wells (2003), } \\
\text { C. Gough (BlueVentures), pers. comm. }\end{array}$ \\
\hline & & Northern Madagascar & Harding \& Randriamanantsoa (2008) \\
\hline & & Southwestern Madagascar & Barnes \& Rawlinson (2009) \\
\hline & Tridacna spp. & Andavadoaka region & Harding et al. (2006) \\
\hline & Giant clams & Andavadoaka region & Nadon et al. (2007) \\
\hline \multirow[t]{4}{*}{ Mauritius } & TG? & $\begin{array}{l}\text { Mauritius (Text: "specimen } 92 \mathrm{~cm} \\
\text { long") }\end{array}$ & Michel et al. (1985) \\
\hline & $\mathrm{TM}$ & Mauritius & Wells et al. (1983); Michel et al. (1985) \\
\hline & & Rodrigues Island & Oliver et al. (2004) \\
\hline & TS & Mauritius & Wells et al. (1983); Michel et al. (1985) \\
\hline \multirow[t]{2}{*}{ Mayotte } & TM & Mayotte & $\begin{array}{l}\text { Blog: Jana around the world; } \\
\text { S. Andréfouët, pers. obs. }\end{array}$ \\
\hline & $\mathrm{TS}$ & Mayotte & $\begin{array}{l}\text { Blog: Jana around the world; } \\
\text { S. Andréfouët, pers. obs. }\end{array}$ \\
\hline \multirow[t]{9}{*}{ Mozambique } & TM & Mozambique & Wells et al. (1983) \\
\hline & & Azura Benguerra Island & Unknown \\
\hline & TS & Mozambique & Wells et al. (1983) \\
\hline & & Quirimba Archipelago & Barnes et al. (1998) \\
\hline & & Paindane Coral Garden & P. Southwood, pers. comm. (2009) \\
\hline & $\begin{array}{l}\text { TSI (previously } \\
\text { TCO) }\end{array}$ & Bazurato Island & Flickr Mark van Malsen (2008) \\
\hline & & Creche, Southern Mozambique & C. Lindeque, pers. comm. (2012) \\
\hline & & Inhambane Province & Flickr Vera \& Gordon (2012) \\
\hline & & Mozambique & $\begin{array}{l}\text { ReefBuilders.com (2015), N. Helgason, } \\
\text { pers. comm. (2015) }\end{array}$ \\
\hline La Réunion & TS & La Réunion & Flickr Cedric Peneau (2014) \\
\hline \multirow[t]{7}{*}{ Seychelles } & $\mathrm{TC}$ & Coetivy Island & Selin et al. (1992) \\
\hline & TM & Mahe & Taylor (1968); Selin et al. (1992) \\
\hline & & Seychelles & Wells et al. (1983) \\
\hline & & Aride Island Beach & Agombar et al. (2003) \\
\hline & & Silhouette Island & Gerlach \& Gerlach (2004) \\
\hline & TS & Mahe & Taylor (1968) \\
\hline & & Seychelles & Wells et al. (1983) \\
\hline
\end{tabular}


Table A2 (Continued) Checklist of giant clam species

\begin{tabular}{|c|c|c|c|}
\hline Recorded localities & Species & Localities & Reference(s) \\
\hline \multirow{2}{*}{\multicolumn{2}{|c|}{$\begin{array}{l}\text { Seychelles } \\
\text { (Continued) }\end{array}$}} & Aride Island Beach & Agombar et al. (2003) \\
\hline & & Silhouette Island & Gerlach \& Gerlach (2004) \\
\hline \multirow[t]{3}{*}{ Somalia } & TM & Somalia & Sommer et al. (1996) \\
\hline & $\mathrm{TS}$ & Somalia & Sommer et al. (1996) \\
\hline & Tridacna spp. & Somalia & Pilcher \& Alsuhaibany (2000) \\
\hline \multirow[t]{2}{*}{ South Africa } & $\mathrm{TM}$ & South Africa & Wells et al. (1983); Munro (1989) \\
\hline & TS & South Africa & Munro (1989) \\
\hline \multirow[t]{4}{*}{ Tanzania } & $\mathrm{TM}$ & Kilwa Island & Nakamura (2013) \\
\hline & & Chumbe Island & Daniels (2004) \\
\hline & TS & Zanzibar & Gossling et al. (2004) \\
\hline & & Chumbe Island & Daniels (2004) \\
\hline \multicolumn{4}{|l|}{ Indian Ocean } \\
\hline \multirow{3}{*}{$\begin{array}{l}\text { Cargados Carajos } \\
\text { Archipelago }\end{array}$} & TLZ & Cargados Carajos Archipelago & Monsecour (2016) \\
\hline & TM & Cargados Carajos Archipelago & Monsecour (2016) \\
\hline & TS & Cargados Carajos Archipelago & Monsecour (2016) \\
\hline \multirow[t]{6}{*}{ Christmas Island } & $\mathrm{TC}$ & Christmas Island & Sources found in Tan \& Low (2014) \\
\hline & $\mathrm{TD}$ & Christmas Island & Sources found in Tan \& Low (2014) \\
\hline & TG & Christmas Island (EXTINCT) & $\begin{array}{l}\text { Andrews et al. (1900); Tomlin (1934); } \\
\text { Wells \& Slack-Smith (2000); Hourston } \\
\text { (2010) }\end{array}$ \\
\hline & $\mathrm{TM}$ & Christmas Island & $\begin{array}{l}\text { Tomlin (1934); Wells \& Slack-Smith } \\
\text { (2000); Hourston (2010) }\end{array}$ \\
\hline & TNO & Christmas Island & Neo \& Low (2017) \\
\hline & $\mathrm{TS}$ & Christmas Island & $\begin{array}{l}\text { Wells \& Slack-Smith (2000); Hourston } \\
\text { (2010) }\end{array}$ \\
\hline \multirow{5}{*}{$\begin{array}{l}\text { Cocos (Keeling) } \\
\text { Islands (Australia } \\
\text { Territory) }\end{array}$} & $\mathrm{TC}$ & Cocos (Keeling) Islands & Abbott (1950) \\
\hline & $\mathrm{TD}$ & Cocos (Keeling) Islands & $\begin{array}{c}\text { Maes (1967); Wells et al. (1983); Munro } \\
\text { (1989); Wells (1994); Hourston (2010) }\end{array}$ \\
\hline & TG & $\begin{array}{l}\text { Cocos (Keeling) Islands } \\
(\text { EXTINCT) }\end{array}$ & $\begin{array}{l}\text { Wells (1994); Hender et al. (2001); } \\
\text { Hourston (2010) }\end{array}$ \\
\hline & $\mathrm{TM}$ & Cocos (Keeling) Islands & $\begin{array}{l}\text { Maes (1967); Wells (1994); Australian } \\
\text { Government (2005); Hourston (2010); } \\
\text { Bellchambers \& Evans (2013); Evans } \\
\text { et al. (2016) }\end{array}$ \\
\hline & TS & $\begin{array}{l}\text { Cocos (Keeling) Islands } \\
(\text { EXTINCT) }\end{array}$ & Gibson-Hill (1946) \\
\hline \multirow[t]{2}{*}{$\begin{array}{l}\text { British Indian } \\
\text { Ocean Territory }\end{array}$} & $\mathrm{TM}$ & Chagos Archipelago & $\begin{array}{l}\text { Wells et al. (1983); Sheppard (1984); } \\
\text { Chagos Conservation Trust (2014) }\end{array}$ \\
\hline & $\mathrm{TS}$ & Chagos Archipelago & $\begin{array}{l}\text { Wells et al. (1983); Sheppard (1984); } \\
\text { Chagos Conservation Trust (2014) }\end{array}$ \\
\hline \multirow[t]{6}{*}{ India } & $\mathrm{HH}$ & Andaman Islands & Rosewater (1965) \\
\hline & & Nicobar Islands & Rosewater (1965) \\
\hline & $\mathrm{TC}$ & Kavaratti & Namboodiri \& Sivadas (1979) \\
\hline & & Andaman Islands & Ramadoss (1983) \\
\hline & & Nicobar Islands & Ramadoss (1983) \\
\hline & TG & Andaman and Nicobar Islands & Apte et al. (2010) \\
\hline
\end{tabular}


Table A2 (Continued) Checklist of giant clam species

\begin{tabular}{|c|c|c|c|}
\hline Recorded localities & Species & Localities & Reference(s) \\
\hline \multirow[t]{7}{*}{ India (Continued) } & TM & Andaman Islands & $\begin{array}{l}\text { Ramadoss (1983); Wells et al. (1983); } \\
\text { Munro (1989) }\end{array}$ \\
\hline & & Nicobar Islands & Ramadoss (1983); Munro (1989) \\
\hline & & Laccadives & Munro (1989) \\
\hline & & Lakshadweep Archipelago & $\begin{array}{l}\text { George et al. (1986); Apte \& Dutta } \\
\text { (2010); Apte et al. (2010) }\end{array}$ \\
\hline & TS & Andaman Islands & Ramadoss (1983); Munro (1989) \\
\hline & & Nicobar Islands & Ramadoss (1983); Munro (1989) \\
\hline & & Laccadives & Munro (1989) \\
\hline \multirow[t]{6}{*}{ Maldives } & $\mathrm{TM}$ & Maldives & Wells et al. (1983) \\
\hline & & Central and northern atolls & Basker (1991) \\
\hline & & Baa Atoll & Andréfouët et al. (2012) \\
\hline & TS & Maldives & Wells et al. (1983) \\
\hline & & Central and northern atolls & Basker (1991) \\
\hline & & Baa Atoll & Andréfouët et al. (2012) \\
\hline $\begin{array}{l}\text { Saya de Malha } \\
\text { Bank }\end{array}$ & TR & Saya de Malha Bank & Sirenko \& Scarlato (1991) \\
\hline \multirow[t]{2}{*}{ Sri Lanka } & $\mathrm{TM}$ & Sri Lanka & Wells et al. (1983); Munro (1989) \\
\hline & TS & Sri Lanka & Munro (1989) \\
\hline \multicolumn{4}{|l|}{ East Asia } \\
\hline \multirow[t]{8}{*}{ China } & $\mathrm{TC}$ & Sanya & Qi (2004) \\
\hline & & Xincun & Qi (2004) \\
\hline & $\mathrm{TM}$ & China & Wells et al. (1983) \\
\hline & TS & $\begin{array}{l}\text { Hainan Island (Shalao, } \\
\text { Xiaodonghai, Xizhou Islet, } \\
\text { Dongzhou Islet, Yezhu Island) }\end{array}$ & Fiege et al. (1994) \\
\hline & & Sanya & Qi (2004) \\
\hline & & Xincun & Qi (2004) \\
\hline & Tridacna spp. & Lunya Bay, Hainan Island & Hutchings \& Wu (1987) \\
\hline & & Sanya waters & Tadashi et al. (2008) \\
\hline Hong Kong & $\mathrm{TM}$ & Mirs Bay & Morton \& Morton (1983) \\
\hline \multirow[t]{13}{*}{ Japan } & $\mathrm{HH}$ & Ryukyu & Hirase (1954); Wells et al. (1983) \\
\hline & & Okinawa & Bernard et al. (1993); Okada (1997) \\
\hline & $\mathrm{TC}$ & Amami-oshima & $\begin{array}{l}\text { Hirase (1954); Miklos Kazmer, pers. } \\
\text { comm. (2015) }\end{array}$ \\
\hline & & Ishigaki & Kanno et al. (1976) \\
\hline & & Ryukyu & Wells et al. (1983); Munro (1989) \\
\hline & & Okinawa & Bernard et al. (1993); Okada (1997) \\
\hline & & Sesoko Island, Okinawa & Flickr Jin-Yao Ong (2013) \\
\hline & TG & Yaeyama, Ryukyu & Hirase (1954); Wells et al. (1983) \\
\hline & $\mathrm{TM}$ & Amami-oshima & Hirase (1954) \\
\hline & & Ishigaki & Kanno et al. (1976) \\
\hline & & Japan & Wells et al. (1983) \\
\hline & & Ryukyu (EXTINCT) & Munro (1989) \\
\hline & & Okinawa & Bernard et al. (1993); Okada (1997) \\
\hline
\end{tabular}


Table A2 (Continued) Checklist of giant clam species

\begin{tabular}{|c|c|c|c|}
\hline Recorded localities & Species & Localities & Reference(s) \\
\hline \multirow[t]{8}{*}{ Japan (Continued) } & & $\begin{array}{l}\text { Ogasawara National Park (Chichi } \\
\text { and Haha Islands) }\end{array}$ & Fujiwara et al. (2000) \\
\hline & & Tokashiki-son, Okinawa & Flickr Nemo's great uncle (2009) \\
\hline & & Clothesline, Okinawa & Flickr chino1138 (2012) \\
\hline & TNO & Okinawa and Ishigaki Islands & Kubo \& Iwai (2007) \\
\hline & TS & Ryukyu & Hirase (1954); Munro (1989) \\
\hline & & Ishigaki & Kanno et al. (1976) \\
\hline & & Japan & Wells et al. (1983) \\
\hline & & Okinawa & Bernard et al. (1993); Okada (1997) \\
\hline \multirow[t]{19}{*}{ Taiwan } & $\mathrm{HH}$ & EXTINCT & Bernard et al. (1993); Munro (1989) \\
\hline & & Hengchun, Lanyu & Wu (1999) \\
\hline & $\mathrm{TC}$ & Taiwan & Bernard et al. (1993) \\
\hline & & Hengchun, Lanyu & Wu (1999) \\
\hline & & Gueishan Island & Huang et al. (2013) \\
\hline & TD & EXTINCT & Bernard et al. (1993) \\
\hline & & Hengchun, Lanyu & Wu (1999) \\
\hline & TG & EXTINCT & Bernard et al. (1993); Munro (1989) \\
\hline & & Hengchun, Lanyu & Wu (1999) \\
\hline & & Gueishan Island & Huang et al. (2013) \\
\hline & $\mathrm{TM}$ & Taiwan & Wells et al. (1983); Bernard et al. (1993) \\
\hline & & $\begin{array}{l}\text { Taipei, Suao, Daikanko, } \\
\text { Kaohsiung, Shaoliuchiu, } \\
\text { Penghu, Hengchun, Lanyu }\end{array}$ & Wu (1999) \\
\hline & & Gueishan Island & Huang et al. (2013) \\
\hline & & Lamay Island & Flickr Dennis Wong (2013) \\
\hline & & Lanyu, Orchid Island & Flickr Blowing Puffer Fish (2015) \\
\hline & TNO & $\begin{array}{l}\text { Northern and Southern Taiwan, } \\
\text { Orchid Island, Green Island, } \\
\text { Hsiaoliuchiu, Penghu }\end{array}$ & Tang (2005); Su et al. (2014) \\
\hline & TS & Taiwan & Bernard et al. (1993) \\
\hline & & Hengchun, Lanyu & Wu (1999) \\
\hline & & Green Island & $\begin{array}{l}\text { Flickr Michael Huang (2007); Flickr } \\
\text { rcmlee99 (2015) }\end{array}$ \\
\hline \multirow[t]{9}{*}{ South China Sea } & $\mathrm{HH}$ & Xisha Islands (Paracel Islands) & $\begin{array}{l}\text { Zhuang (1978); Pan \& Lan (1998); } \\
\text { Qi (2004) }\end{array}$ \\
\hline & & $\begin{array}{l}\text { Xisha (Paracel Islands) and } \\
\text { Nansha Islands (Spratly Islands) }\end{array}$ & Bernard et al. (1993); Liu (2013) \\
\hline & & $\begin{array}{l}\text { Pulau Layang Layang (Swallow } \\
\text { Reef) }\end{array}$ & Sahari et al. (2002) \\
\hline & & $\begin{array}{l}\text { North Danger Reef (Spratly } \\
\text { Islands) }\end{array}$ & $\begin{array}{l}\text { Calumpong et al. (2008); Calumpong \& } \\
\text { Macansantos (2008) }\end{array}$ \\
\hline & & Jackson Atoll (Spratly Islands) & Calumpong et al. (2008) \\
\hline & & Taiping Island (Itu Aba Island) & A Frontier in the SCS (2014) \\
\hline & $\mathrm{TC}$ & Xisha Islands (Paracel Islands) & Zhuang (1978); Qi (2004) \\
\hline & & Nansha Islands (Spratly Islands) & Bernard et al. (1993); Liu (2013) \\
\hline & & $\begin{array}{l}\text { Pulau Layang Layang (Swallow } \\
\text { Reef) }\end{array}$ & Sahari et al. (2002) \\
\hline
\end{tabular}


Table A2 (Continued) Checklist of giant clam species

\begin{tabular}{|c|c|c|c|}
\hline Recorded localities & Species & Localities & Reference(s) \\
\hline \multirow{25}{*}{$\begin{array}{l}\text { South China Sea } \\
\text { (Continued) }\end{array}$} & & North Spratly Islands & Van Long et al. (2008) \\
\hline & & $\begin{array}{l}\text { North Danger Reef (Spratly } \\
\text { Islands) }\end{array}$ & $\begin{array}{l}\text { Calumpong et al. (2008); Lasola \& } \\
\text { Hoang (2008); Calumpong \& } \\
\text { Macansantos (2008) }\end{array}$ \\
\hline & & Jackson Atoll (Spratly Islands) & $\begin{array}{l}\text { Calumpong et al. (2008); Calumpong \& } \\
\text { Macansantos (2008) }\end{array}$ \\
\hline & & Trident Shoal (Spratly Islands) & Lasola \& Hoang (2008) \\
\hline & & Taiping Island (Itu Aba Island) & A Frontier in the SCS (2014) \\
\hline & $\mathrm{TD}$ & Xisha Islands (Paracel Islands) & Zhuang (1978); Qi (2004) \\
\hline & & $\begin{array}{l}\text { Xisha (Paracel Islands) and } \\
\text { Nansha Islands (Spratly Islands) }\end{array}$ & Bernard et al. (1993); Liu (2013) \\
\hline & TG & Xisha Islands (Paracel Islands) & Zhuang (1978); Qi (2004) \\
\hline & & $\begin{array}{l}\text { Xisha (Paracel Islands) and } \\
\text { Nansha Islands (Spratly Islands) }\end{array}$ & Bernard et al. (1993); Liu (2013) \\
\hline & & $\begin{array}{l}\text { Pulau Layang Layang (Swallow } \\
\text { Reef) }\end{array}$ & Sahari et al. (2002) \\
\hline & $\mathrm{TM}$ & Xisha Islands (Paracel Islands) & Zhuang (1978); Qi (2004) \\
\hline & & $\begin{array}{l}\text { Xisha (Paracel Islands) and } \\
\text { Nansha Islands (Spratly Islands) }\end{array}$ & Bernard et al. (1993); Liu (2013) \\
\hline & & $\begin{array}{l}\text { Pulau Layang Layang (Swallow } \\
\text { Reef) }\end{array}$ & Sahari et al. (2002) \\
\hline & & $\begin{array}{l}\text { North Danger Reef (Spratly } \\
\text { Islands) }\end{array}$ & $\begin{array}{l}\text { Calumpong et al. (2008); Calumpong \& } \\
\text { Macansantos (2008) }\end{array}$ \\
\hline & & Jackson Atoll (Spratly Islands) & $\begin{array}{l}\text { Calumpong et al. (2008); Calumpong \& } \\
\text { Macansantos (2008) }\end{array}$ \\
\hline & & Taiping Island (Itu Aba Island) & A Frontier in the SCS (2014) \\
\hline & TNO & Dongsha Atoll (Pratas Islands) & Borsa et al. (2015) \\
\hline & TS & Xisha Islands (Paracel Islands) & Zhuang (1978); Qi (2004) \\
\hline & & $\begin{array}{l}\text { Xisha (Paracel Islands) and } \\
\text { Nansha Islands (Spratly Islands) }\end{array}$ & Bernard et al. (1993); Liu (2013) \\
\hline & & $\begin{array}{l}\text { Pulau Layang Layang (Swallow } \\
\text { Reef) }\end{array}$ & Sahari et al. (2002) \\
\hline & & North Spratly Islands & Van Long et al. (2008) \\
\hline & & $\begin{array}{l}\text { North Danger Reef (Spratly } \\
\text { Islands) }\end{array}$ & $\begin{array}{l}\text { Calumpong et al. (2008); Lasola \& } \\
\text { Hoang (2008); Calumpong \& } \\
\text { Macansantos (2008) }\end{array}$ \\
\hline & & Jackson Atoll (Spratly Islands) & $\begin{array}{l}\text { Calumpong et al. (2008); Calumpong \& } \\
\text { Macansantos (2008) }\end{array}$ \\
\hline & & Trident Shoal (Spratly Islands) & Lasola \& Hoang (2008) \\
\hline & & Taiping Island (Itu Aba Island) & A Frontier in the SCS (2014) \\
\hline \multicolumn{4}{|l|}{ South-East Asia } \\
\hline Brunei & Tridacna spp. & No data & Reef Check \\
\hline \multirow[t]{2}{*}{ Cambodia } & TG? & $\begin{array}{l}\text { Song Saa Private Island, Koh } \\
\text { Rong Archipelago }\end{array}$ & Savage et al. (2013) \\
\hline & & $\begin{array}{l}\text { Koh Rong and Koh Koun, Koh } \\
\text { Rong Archipelago }\end{array}$ & Thorne et al. (2015) \\
\hline
\end{tabular}


GIANT CLAMS (BIVALVIA: CARDIIDAE: TRIDACNINAE)

Table A2 (Continued) Checklist of giant clam species

\begin{tabular}{|c|c|c|c|}
\hline Recorded localities & Species & Localities & Reference(s) \\
\hline \multirow[t]{7}{*}{$\begin{array}{l}\text { Cambodia } \\
\text { (Continued) }\end{array}$} & TC & $\begin{array}{l}\text { Song Saa Private Island, Koh } \\
\text { Rong Archipelago }\end{array}$ & J.M. Savage, pers. comm. \\
\hline & TS & $\begin{array}{l}\text { Song Saa Private Island, Koh } \\
\text { Rong Archipelago }\end{array}$ & J. Wong, pers. comm. \\
\hline & Tridacna spp. & Cambodia & Chou et al. (2002) \\
\hline & & Koh Kong & Vibol (N.D.); Kim et al. (2004) \\
\hline & & Koh Sdach & Vibol (N.D.); Kim et al. (2004) \\
\hline & & Koh Rong & $\begin{array}{l}\text { Vibol (N.D.); Kim et al. (2004); } \\
\text { Van Bochove et al. (2011) }\end{array}$ \\
\hline & & Koh Tang & Vibol (N.D.); Kim et al. (2004) \\
\hline \multirow[t]{3}{*}{ East Timor } & $\mathrm{TC}$ & Dili Rock & Flickr Nick Hobgood (2006) \\
\hline & TG & Dili Rock & Flickr Nick Hobgood (2006) \\
\hline & TNO & Dili Rock & Flickr Nick Hobgood (2006) \\
\hline \multirow[t]{24}{*}{ Indonesia } & $\mathrm{HH}$ & Indonesia & $\begin{array}{l}\text { Wells et al. (1983); Pasaribu (1988); } \\
\text { Munro (1989) }\end{array}$ \\
\hline & & Karimun Jawa, Central Indonesia & Brown \& Muskanofola (1985) \\
\hline & & Genting Island & Pringgenies et al. (1995) \\
\hline & & Gulf of Tomini, Sulawesi & Wells (2001) \\
\hline & & $\begin{array}{l}\text { Rajah Ampat Islands, Papua } \\
\text { Province }\end{array}$ & $\begin{array}{l}\text { Wells (2002); Flickr Raja Ampat } \\
\text { Biodiversity (2013) }\end{array}$ \\
\hline & & Pari Island & Eliata et al. (2003); Panggabean (2007) \\
\hline & & $\begin{array}{l}\text { Kei Kecil waters, Southeast } \\
\text { Maluku }\end{array}$ & Kusnadi et al. (2008); Hernawan (2010) \\
\hline & & $\begin{array}{l}\text { Savu Sea, East Nusa Tenggara } \\
\text { Province }\end{array}$ & Naguit et al. (2012) \\
\hline & $\mathrm{HP}$ & Northeastern Indonesia & $\begin{array}{l}\text { Wells et al. (1983); Pasaribu (1988); } \\
\text { Munro (1989) }\end{array}$ \\
\hline & & Seruni Island & Pringgenies et al. (1995) \\
\hline & & Gulf of Tomini, Sulawesi & Wells (2001) \\
\hline & & $\begin{array}{l}\text { Rajah Ampat Islands, Papua } \\
\text { Province }\end{array}$ & Wells (2002) \\
\hline & $\mathrm{TC}$ & Indonesia & $\begin{array}{l}\text { Wells et al. (1983); Pasaribu (1988); } \\
\text { Munro (1989) }\end{array}$ \\
\hline & & Karimun Jawa, Central Indonesia & Brown \& Muskanofola (1985) \\
\hline & & Genting Island & Pringgenies et al. (1995) \\
\hline & & Seruni Island & Pringgenies et al. (1995) \\
\hline & & Sambangan Island & Pringgenies et al. (1995) \\
\hline & & Gulf of Tomini, Sulawesi & Wells (2001) \\
\hline & & $\begin{array}{l}\text { Rajah Ampat Islands, Papua } \\
\text { Province }\end{array}$ & Wells (2002) \\
\hline & & Pari Island & Eliata et al. (2003) \\
\hline & & Seribu Islands & Yusuf et al. (2009) \\
\hline & & Manado waters & Yusuf et al. (2009) \\
\hline & & $\begin{array}{l}\text { Kei Kecil waters, Southeast } \\
\text { Maluku }\end{array}$ & Kusnadi et al. (2008); Hernawan (2010) \\
\hline & & $\begin{array}{l}\text { Savu Sea, East Nusa Tenggara } \\
\text { Province }\end{array}$ & Naguit et al. (2012) \\
\hline
\end{tabular}


MEI LIN NEO ET AL.

Table A2 (Continued) Checklist of giant clam species

\begin{tabular}{|c|c|c|c|}
\hline Recorded localities & Species & Localities & Reference(s) \\
\hline \multirow{34}{*}{$\begin{array}{l}\text { Indonesia } \\
\text { (Continued) }\end{array}$} & \multirow[t]{6}{*}{ TD } & Irian Jaya & Wells et al. (1983) \\
\hline & & Indonesia & $\begin{array}{l}\text { Wells et al. (1983); Pasaribu (1988); } \\
\text { Munro (1989) }\end{array}$ \\
\hline & & Karimun Jawa, Central Indonesia & Brown \& Muskanofola (1985) \\
\hline & & $\begin{array}{l}\text { Rajah Ampat Islands, Papua } \\
\text { Province }\end{array}$ & Wells (2002) \\
\hline & & $\begin{array}{l}\text { Kei Kecil waters, Southeast } \\
\text { Maluku }\end{array}$ & Hernawan (2010) \\
\hline & & Komodo & Flickr yudas_net (2009) \\
\hline & \multirow[t]{9}{*}{$\mathrm{TG}$} & Indonesia & $\begin{array}{l}\text { Wells et al. (1983); Pasaribu (1988); } \\
\text { Munro (1989) }\end{array}$ \\
\hline & & Karimun Jawa, Central Indonesia & Brown \& Muskanofola (1985) \\
\hline & & Gulf of Tomini, Sulawesi & Wells (2001) \\
\hline & & $\begin{array}{l}\text { Rajah Ampat Islands, Papua } \\
\text { Province }\end{array}$ & Wells (2002) \\
\hline & & Bunaken, Manado waters & $\begin{array}{l}\text { Yusuf et al. (2009); Flickr Matt Kieffer } \\
\text { (2010) }\end{array}$ \\
\hline & & $\begin{array}{l}\text { Kei Kecil waters, Southeast } \\
\text { Maluku }\end{array}$ & Kusnadi et al. (2008); Hernawan (2010) \\
\hline & & Kri Island, Irian Jaya & Flickr Eric Cheng (2004) \\
\hline & & Current City, Komodo & Flickr Maximilian Hand (2008) \\
\hline & & West Papua & Flickr Paul Cowell (2011) \\
\hline & \multirow[t]{14}{*}{$\mathrm{TM}$} & Indonesia & $\begin{array}{l}\text { Wells et al. (1983); Pasaribu (1988); } \\
\text { Munro (1989) }\end{array}$ \\
\hline & & Karimun Jawa, Central Indonesia & Brown \& Muskanofola (1985) \\
\hline & & Genting Island & Pringgenies et al. (1995) \\
\hline & & Seruni Island & Pringgenies et al. (1995) \\
\hline & & Sambangan Island & Pringgenies et al. (1995) \\
\hline & & Gulf of Tomini, Sulawesi & Wells (2001) \\
\hline & & $\begin{array}{l}\text { Rajah Ampat Islands, Papua } \\
\text { Province }\end{array}$ & Wells (2002) \\
\hline & & Pari Island & Eliata et al. (2003) \\
\hline & & Anambas and Natuna Islands & $\begin{array}{l}\text { Tan \& Kastoro (2004); Flickr Fauzan } \\
\text { Rizki (2015) }\end{array}$ \\
\hline & & Seribu Islands & Yusuf et al. (2009) \\
\hline & & Manado waters & Yusuf et al. (2009) \\
\hline & & $\begin{array}{l}\text { Kei Kecil waters, Southeast } \\
\text { Maluku }\end{array}$ & Hernawan (2010) \\
\hline & & $\begin{array}{l}\text { Savu Sea, East Nusa Tenggara } \\
\text { Province }\end{array}$ & Naguit et al. (2012) \\
\hline & & $\begin{array}{l}\text { Komodo National Park, East } \\
\text { Nusa Tenggara }\end{array}$ & Flickr Nick Hobgood (2006) \\
\hline & \multirow[t]{2}{*}{ TNO } & Bunaken and Alor Archipelago & Borsa et al. (2015) \\
\hline & & Doi Island, Molucca Sea & Borsa et al. (2015) \\
\hline & \multirow[t]{3}{*}{$\mathrm{TS}$} & Indonesia & $\begin{array}{l}\text { Wells et al. (1983); Pasaribu (1988); } \\
\text { Munro (1989) }\end{array}$ \\
\hline & & Karimun Jawa, Central Indonesia & Brown \& Muskanofola (1985) \\
\hline & & Gulf of Tomini, Sulawesi & Wells (2001) \\
\hline
\end{tabular}


GIANT CLAMS (BIVALVIA: CARDIIDAE: TRIDACNINAE)

Table A2 (Continued) Checklist of giant clam species

\begin{tabular}{|c|c|c|c|}
\hline Recorded localities & Species & Localities & Reference(s) \\
\hline \multirow[t]{11}{*}{$\begin{array}{l}\text { Indonesia } \\
\text { (Continued) }\end{array}$} & & $\begin{array}{l}\text { Rajah Ampat Islands, Papua } \\
\text { Province }\end{array}$ & Wells (2002) \\
\hline & & Pari Island & Eliata et al. (2003) \\
\hline & & Seribu Islands & Yusuf et al. (2009) \\
\hline & & Manado waters & Yusuf et al. (2009) \\
\hline & & $\begin{array}{l}\text { Kei Kecil waters, Southeast } \\
\text { Maluku }\end{array}$ & Kusnadi et al. (2008); Hernawan (2010) \\
\hline & & $\begin{array}{l}\text { Savu Sea, East Nusa Tenggara } \\
\text { Province }\end{array}$ & Naguit et al. (2012) \\
\hline & & Wakatobi & Flickr Richard Johnson (2007) \\
\hline & & Aceh & Flickr iderq_shai (2010) \\
\hline & & Komodo & Flickr Brandon (2011) \\
\hline & & Cenderawasih Bay & Flickr lcn2012a (2012) \\
\hline & & West Papua & Flickr Sailendivers (2012) \\
\hline \multirow[t]{25}{*}{ Malaysia } & $\mathrm{HP}$ & Sabah, East Malaysia & Tan \& Zulfigar $(2001,2003)$ \\
\hline & $\mathrm{HH}$ & North Borneo & Wells et al. (1983) \\
\hline & & Malaysia & $\begin{array}{l}\text { Munro (1989); Tan \& Zulfigar (2001, } \\
\text { 2003) }\end{array}$ \\
\hline & & Johore Islands & Zulfigar \& Tan (2000) \\
\hline & $\mathrm{TC}$ & $\begin{array}{l}\text { Western coast of the Malay } \\
\text { Peninsula }\end{array}$ & Wells et al. (1983) \\
\hline & & North Borneo & Wells et al. (1983) \\
\hline & & Malaysia & $\begin{array}{l}\text { Munro (1989); Tan \& Zulfigar (2001, } \\
\text { 2003) }\end{array}$ \\
\hline & & Pulau Redang (Terengganu) & Mohamed-Pauzi et al. (1994) \\
\hline & & Pulau Tioman (Pahang) & Tan et al. (1998) \\
\hline & & Johore Islands & Zulfigar \& Tan (2000) \\
\hline & TD & Sabah, East Malaysia & Tan \& Zulfigar (2003) \\
\hline & TG & Malaysia & $\begin{array}{l}\text { Munro (1989); Tan \& Zulfigar (2001, } \\
\text { 2003) }\end{array}$ \\
\hline & & Pulau Redang (Terengganu) & Mohamed-Pauzi et al. (1994) \\
\hline & & Pulau Tioman (Pahang) & Tan et al. (1998) \\
\hline & $\mathrm{TM}$ & Malaysia & $\begin{array}{l}\text { Wells et al. (1983); Munro (1989); } \\
\text { Tan \& Zulfigar (2001, 2003) }\end{array}$ \\
\hline & & North Borneo & Wells et al. (1983) \\
\hline & & Pulau Redang (Terengganu) & Mohamed-Pauzi et al. (1994) \\
\hline & & Pulau Tioman (Pahang) & Tan et al. (1998) \\
\hline & & Johore Islands & Zulfigar \& Tan (2000) \\
\hline & $\mathrm{TS}$ & Malaysia & $\begin{array}{l}\text { Wells et al. (1983); Munro (1989); } \\
\text { Tan \& Zulfigar (2001, 2003) }\end{array}$ \\
\hline & & North Borneo & Wells et al. (1983) \\
\hline & & Pulau Redang (Terengganu) & Mohamed-Pauzi et al. (1994) \\
\hline & & Pulau Tioman (Pahang) & Tan et al. (1998) \\
\hline & & Johore Islands & Zulfigar \& Tan (2000) \\
\hline & Tridacna spp. & $\begin{array}{l}\text { Tun Sakaran Marine Park, East } \\
\text { Sabah }\end{array}$ & Montagne et al. (2013) \\
\hline
\end{tabular}


MEI LIN NEO ET AL.

Table A2 (Continued) Checklist of giant clam species

\begin{tabular}{|c|c|c|c|}
\hline Recorded localities & Species & Localities & Reference(s) \\
\hline \multirow[t]{4}{*}{ Myanmar (Burma) } & $\mathrm{HH}$ & Burma & Munro (1989); Wells (1997) \\
\hline & TG & Burma & Munro (1989) \\
\hline & $\mathrm{TM}$ & Burma & Munro (1989) \\
\hline & TS & Burma & Munro (1989) \\
\hline \multirow[t]{24}{*}{ Philippines } & $\mathrm{HH}$ & Philippines & $\begin{array}{l}\text { Wells et al. (1983); Gomez \& Alcala } \\
\text { (1988); Juinio et al. (1989); Munro } \\
\text { (1989) }\end{array}$ \\
\hline & & Central Visayas & Alcala (1986) \\
\hline & & Palawan & Alcala (1986) \\
\hline & & Cagayan & Alcala (1986) \\
\hline & & $\begin{array}{l}\text { Sulu Archipelago and Southern } \\
\text { Palawan }\end{array}$ & Villanoy et al. (1988) \\
\hline & & Tubbataha & $\begin{array}{l}\text { Dolorosa \& Schoppe (2005); Dolorosa } \\
\text { (2010); Dolorosa et al. (2015) }\end{array}$ \\
\hline & & Hadji Panglima Tahil, Sulu & Tabugo et al. (2013) \\
\hline & HP & $\begin{array}{l}\text { Sulu Archipelago, Southern } \\
\text { Philippines }\end{array}$ & $\begin{array}{l}\text { Rosewater (1982); Wells et al. (1983); } \\
\text { Gomez \& Alcala (1988); Juinio et al. } \\
\text { (1989); Munro (1989) }\end{array}$ \\
\hline & & Cagayan & Alcala (1986) \\
\hline & & Tubbataha & $\begin{array}{l}\text { Calumpong \& Cadiz (1993); Dolorosa } \\
\text { (2010); Dolorosa \& Jontila (2012); } \\
\text { Dolorosa et al. (2014, 2015) }\end{array}$ \\
\hline & & $\begin{array}{l}\text { Sulu Archipelago and Southern } \\
\text { Palawan }\end{array}$ & Villanoy et al. (1988) \\
\hline & $\mathrm{TC}$ & Philippines & $\begin{array}{l}\text { Wells et al. (1983); Gomez \& Alcala } \\
\text { (1988); Juinio et al. (1989); Munro } \\
\text { (1989) }\end{array}$ \\
\hline & & Central Visayas & Alcala (1986) \\
\hline & & Western Visayas & Alcala (1986) \\
\hline & & Palawan & Alcala (1986) \\
\hline & & Cagayan & $\begin{array}{l}\text { Alcala (1986); Calumpong \& Cadiz } \\
\text { (1993) }\end{array}$ \\
\hline & & Tubbataha & $\begin{array}{l}\text { Calumpong \& Cadiz (1993); Dolorosa } \\
\text { \& Schoppe (2005); Dolorosa (2010); } \\
\text { Dolorosa \& Jontila (2012); Gonzales } \\
\text { et al. (2014b); Dolorosa et al. (2015); } \\
\text { Conales et al. (2015) }\end{array}$ \\
\hline & & Sumilon Island & Calumpong \& Cadiz (1993) \\
\hline & & Balicasag Island & Calumpong \& Cadiz (1993) \\
\hline & & Pamilacan Island & Calumpong \& Cadiz (1993) \\
\hline & & Bolisong, Negros Oriental & Calumpong et al. (2002) \\
\hline & TD & Philippines & $\begin{array}{l}\text { Wells et al. (1983); Gomez \& Alcala } \\
\text { (1988); Juinio et al. (1989); Munro } \\
\text { (1989) }\end{array}$ \\
\hline & & Palawan & Alcala (1986) \\
\hline & & Cagayan & Alcala (1986) \\
\hline
\end{tabular}


GIANT CLAMS (BIVALVIA: CARDIIDAE: TRIDACNINAE)

Table A2 (Continued) Checklist of giant clam species

\begin{tabular}{|c|c|c|c|}
\hline Recorded localities & Species & Localities & Reference(s) \\
\hline \multirow{28}{*}{$\begin{array}{l}\text { Philippines } \\
\text { (Continued) }\end{array}$} & & Tubbataha & Dolorosa et al. $(2010,2015)$ \\
\hline & & $\begin{array}{l}\text { Sabang Reef Fish Sanctuary, } \\
\text { Honda Bay, Palawan }\end{array}$ & Gonzales et al. (2014a) \\
\hline & TG & Philippines & $\begin{array}{l}\text { Wells et al. (1983); Gomez \& Alcala } \\
\text { (1988); Juinio et al. (1989); Munro } \\
\text { (1989) }\end{array}$ \\
\hline & & Palawan & Alcala (1986) \\
\hline & & Cagayan & Alcala (1986) \\
\hline & & $\begin{array}{l}\text { Sulu Archipelago and Southern } \\
\text { Palawan }\end{array}$ & Villanoy et al. (1988) \\
\hline & & $\begin{array}{l}\text { Sabang Reef Fish Sanctuary, } \\
\text { Honda Bay, Palawan }\end{array}$ & Gonzales et al. (2014a) \\
\hline & & Tubbataha & Dolorosa et al. (2015) \\
\hline & $\mathrm{TM}$ & Philippines & $\begin{array}{l}\text { Wells et al. (1983); Gomez \& Alcala } \\
\text { (1988); Junio et al. (1989); Munro } \\
\text { (1989) }\end{array}$ \\
\hline & & Central Visayas & Alcala (1986) \\
\hline & & Western Visayas & Alcala (1986) \\
\hline & & Palawan & Alcala (1986) \\
\hline & & Cagayan & $\begin{array}{l}\text { Alcala (1986); Calumpong \& Cadiz } \\
\text { (1993) }\end{array}$ \\
\hline & & Tubbataha & $\begin{array}{l}\text { Calumpong \& Cadiz (1993); Dolorosa } \\
\text { \& Schoppe (2005); Dolorosa (2010); } \\
\text { Dolorosa \& Jontila (2012); Dolorosa } \\
\text { et al. (2015) }\end{array}$ \\
\hline & & Sumilon Island & Calumpong \& Cadiz (1993) \\
\hline & & Apo Island & Calumpong et al. (2002) \\
\hline & TNO & $\begin{array}{l}\text { Sibulan, Negros (Lizano \& } \\
\text { Santos, 2014) }\end{array}$ & Borsa et al. (2015) \\
\hline & $\mathrm{TS}$ & Philippines & $\begin{array}{l}\text { Wells et al. (1983); Gomez \& Alcala } \\
\text { (1988); Juinio et al. (1989); Munro } \\
\text { (1989) }\end{array}$ \\
\hline & & Central Visayas & Alcala (1986) \\
\hline & & Western Visayas & Alcala (1986) \\
\hline & & Palawan & Alcala (1986) \\
\hline & & Cagayan & Alcala (1986) \\
\hline & & $\begin{array}{l}\text { Sulu Archipelago and Southern } \\
\text { Palawan }\end{array}$ & Villanoy et al. (1988) \\
\hline & & Tubbataha & $\begin{array}{l}\text { Calumpong \& Cadiz (1993); Dolorosa } \\
\text { \& Schoppe (2005); Dolorosa (2010); } \\
\text { Dolorosa \& Jontila (2012); Dolorosa } \\
\text { et al. (2015) }\end{array}$ \\
\hline & & Bolisong, Negros Oriental & Calumpong et al. (2002) \\
\hline & & Apo Island & Calumpong et al. (2002) \\
\hline & & Hadji Panglima Tahil, Sulu & Tabugo et al. (2013) \\
\hline & & $\begin{array}{l}\text { Sabang Reef Fish Sanctuary, } \\
\text { Honda Bay, Palawan }\end{array}$ & Gonzales et al. (2014a) \\
\hline
\end{tabular}


Table A2 (Continued) Checklist of giant clam species

\begin{tabular}{|c|c|c|c|}
\hline Recorded localities & Species & Localities & Reference(s) \\
\hline \multirow[t]{5}{*}{ Singapore } & $\mathrm{HH}$ & Singapore & $\begin{array}{l}\text { Wells et al. (1983); Munro (1989); Neo } \\
\text { \& Todd (2012a,b, 2013) }\end{array}$ \\
\hline & $\mathrm{TC}$ & Singapore & $\begin{array}{l}\text { Wells et al. (1983); Munro (1989); Guest } \\
\text { et al. (2008); Neo \& Todd (2012a,b, } \\
\text { 2013) }\end{array}$ \\
\hline & TG & Singapore & Neo \& Todd (2012a,b, 2013) \\
\hline & $\mathrm{TM}$ & Singapore & $\begin{array}{l}\text { Munro (1989); Guest et al. (2008); Neo } \\
\text { \& Todd (2012a,b, 2013) }\end{array}$ \\
\hline & TS & Singapore & $\begin{array}{l}\text { Munro (1989); Guest et al. (2008); Neo } \\
\text { \& Todd (2012a,b, 2013) }\end{array}$ \\
\hline \multirow[t]{16}{*}{ Thailand } & $\mathrm{TC}$ & Thailand & Wells et al. (1983); Munro (1989) \\
\hline & & Lee-Pae Island & Chantrapornsyl et al. (1996) \\
\hline & & Surin Islands & Koh et al. (2003); Loh et al. (2004) \\
\hline & & Mannai Island, Rayong Province & Junchompoo et al. (2013) \\
\hline & TG & Thailand & Munro (1989) \\
\hline & & EXTINCT & Kittiwattanawong (2001) \\
\hline & $\mathrm{TM}$ & Thailand & Wells et al. (1983); Munro (1989) \\
\hline & & Lee-Pae Island & Chantrapornsyl et al. (1996) \\
\hline & & Surin Islands & $\begin{array}{l}\text { Kittiwattanawong (1997); Koh et al. } \\
\text { (2003) }\end{array}$ \\
\hline & & Phuket Islands & Kittiwattanawong (1997) \\
\hline & & Adang Rawii Islands & Kittiwattanawong (1997) \\
\hline & $\mathrm{TS}$ & Thailand & Wells et al. (1983); Munro (1989) \\
\hline & & Lee-Pae Island & Chantrapornsyl et al. (1996) \\
\hline & & Surin Islands & $\begin{array}{l}\text { Kittiwattanawong et al. (2001); Koh } \\
\text { et al. (2003) }\end{array}$ \\
\hline & & Gulf of Thailand & Kittiwattanawong et al. (2001) \\
\hline & & Mannai Island, Rayong Province & Junchompoo et al. (2013) \\
\hline \multirow[t]{15}{*}{ Viet Nam } & $\mathrm{TC}$ & $\begin{array}{l}\text { An Thoi Archipelago, South } \\
\text { China Sea }\end{array}$ & Latypov (2000) \\
\hline & & Mju Island & Latypov (2006) \\
\hline & & $\begin{array}{l}\text { Hon Bay Canh Island and Hon } \\
\text { Cau Island, Con Dao }\end{array}$ & Latypov \& Selin (2011) \\
\hline & & Con Dao Archipelago & Selin \& Latypov (2011) \\
\hline & & Khanh Hoa Province & Latypov \& Selin (2013) \\
\hline & & Giang Bo Reef & Latypov (2013) \\
\hline & & Re Island & Latypov (2013) \\
\hline & & Bath Long Vi Reef & Latypov (2013) \\
\hline & TG & Ha Long Bay (shells) & M.L. Neo, pers. obs. (2014) \\
\hline & $\mathrm{TM}$ & Cham Islands, Central Viet Nam & Latypov (2001) \\
\hline & & Tho Chau, Con Dao, Thu Islands & Latypov \& Selin (2011) \\
\hline & & Ku Lao Cham Islands & Latypov \& Selin (2012a) \\
\hline & & Hon Nai Island, Cam Ranh Bay & Latypov \& Selin (2012b) \\
\hline & TS & $\begin{array}{l}\text { An Thoi Archipelago, South } \\
\text { China Sea }\end{array}$ & Latypov (2000) \\
\hline & & Tho Chau, Con Dao, Thu Islands & Latypov \& Selin (2011) \\
\hline
\end{tabular}


GIANT CLAMS (BIVALVIA: CARDIIDAE: TRIDACNINAE)

Table A2 (Continued) Checklist of giant clam species

\begin{tabular}{|c|c|c|c|}
\hline Recorded localities & Species & Localities & Reference(s) \\
\hline \multirow{4}{*}{$\begin{array}{l}\text { Viet Nam } \\
\text { (Continued) }\end{array}$} & & Khanh Hoa Province & Latypov \& Selin (2013) \\
\hline & & Giang Bo Reef & Latypov (2013) \\
\hline & & Re Island & Latypov (2013) \\
\hline & & Bath Long Vi Reef & Latypov (2013) \\
\hline \multicolumn{4}{|l|}{ Australia } \\
\hline \multirow[t]{27}{*}{ Australia } & $\mathrm{HH}$ & Western Australia & Wells et al. (1983); Rees et al. (2003) \\
\hline & & Queensland & Wells et al. (1983) \\
\hline & & Australia & Munro (1989) \\
\hline & $\mathrm{TC}$ & $\begin{array}{l}\text { Orpheus Island, Palm Island } \\
\text { Group, Queensland }\end{array}$ & Hamner \& Jones (1976) \\
\hline & & Great Barrier Reef, Queensland & Wells et al. (1983) \\
\hline & & Australia & Munro (1989) \\
\hline & & Western Australia & Rees et al. (2003) \\
\hline & TD & Australia & Wells et al. (1983); Munro (1989) \\
\hline & & Great Barrier Reef, Queensland & $\begin{array}{l}\text { Braley (1987a,b); Alder \& Braley } \\
\text { (1989); Pearson \& Munro (1991) }\end{array}$ \\
\hline & & Western Australia & Rees et al. (2003) \\
\hline & TG & Western Australia & Wells et al. (1983); Rees et al. (2003) \\
\hline & & Great Barrier Reef, Queensland & $\begin{array}{l}\text { Wells et al. (1983); Braley (1987a,b); } \\
\text { Alder \& Braley (1989); Pearson \& } \\
\text { Munro (1991) }\end{array}$ \\
\hline & & Australia & Munro (1989) \\
\hline & & $\begin{array}{l}\text { Heron Island, southern Great } \\
\text { Barrier Reef }\end{array}$ & Strotz et al. (2010) \\
\hline & $\mathrm{TM}$ & One Tree Island, Queensland & McMichael (1974) \\
\hline & & Australia & Wells et al. (1983); Munro (1989) \\
\hline & & $\begin{array}{l}\text { Lord Howe Island, New South } \\
\text { Wales }\end{array}$ & Wells et al. (1983) \\
\hline & & Western Australia & Rees et al. (2003) \\
\hline & & $\begin{array}{l}\text { Montebello Islands, Western } \\
\text { Australia }\end{array}$ & Wells et al. (2000) \\
\hline & & $\begin{array}{l}\text { Solitary Islands Marine Park, } \\
\text { northern New South Wales }\end{array}$ & Smith (2011) \\
\hline & $\begin{array}{l}\text { TMB } \\
\text { (previously TT) }\end{array}$ & No data & Newman \& Gomez (2000) \\
\hline & TNI (now TNO) & $\begin{array}{l}\text { Five Finger Reef, south of Coral } \\
\text { Bay, WA }\end{array}$ & $\begin{array}{l}\text { Penny \& Willan (2014); Borsa et al. } \\
\text { (2015) }\end{array}$ \\
\hline & TNO & $\begin{array}{l}\text { Western Australia (Huelsken } \\
\text { et al., 2013) }\end{array}$ & Borsa et al. (2015) \\
\hline & & Ningaloo Marine Park, WA & Black et al. (2011); Johnson et al. (2016) \\
\hline & TS & Australia & Wells et al. (1983); Munro (1989) \\
\hline & & $\begin{array}{l}\text { Montebello Islands, Western } \\
\text { Australia }\end{array}$ & Wells et al. (2000) \\
\hline & & Western Australia & Rees et al. (2003) \\
\hline
\end{tabular}


Table A2 (Continued) Checklist of giant clam species

\begin{tabular}{|c|c|c|c|}
\hline Recorded localities & Species & Localities & Reference(s) \\
\hline \multicolumn{4}{|l|}{ Pacific Ocean } \\
\hline \multicolumn{4}{|l|}{ Melanesia } \\
\hline \multirow[t]{27}{*}{ Fiji } & $\mathrm{HH}$ & EXTINCT & $\begin{array}{l}\text { Wells et al. (1983); Munro (1989); } \\
\text { Tisdell \& Wittenberg (1992); Seeto } \\
\text { et al. (2012) }\end{array}$ \\
\hline & $\mathrm{TC}$ & Lakeba Island & Vuki et al. (1992) \\
\hline & & Cicia Island & Vuki et al. (1992) \\
\hline & TD & Fiji & $\begin{array}{l}\text { Lewis et al. (1988); Munro (1989); } \\
\text { Tacconi \& Tisdell (1992b); Tisdell \& } \\
\text { Wittenberg (1992) }\end{array}$ \\
\hline & & Lakeba Island & Vuki et al. (1992) \\
\hline & & Tuvuca Island & Vuki et al. (1992) \\
\hline & & Cicia Island & Vuki et al. (1992) \\
\hline & & Balavu Island & Vuki et al. (1992) \\
\hline & & Ono Island & Flickr avipoodle (2010) \\
\hline & TG & EXTINCT & $\begin{array}{l}\text { Lewis et al. (1988); Munro (1989); } \\
\text { Tisdell \& Wittenberg (1992) }\end{array}$ \\
\hline & & Fiji & Flickr Jex207 (2007) \\
\hline & $\mathrm{TM}$ & Fiji & $\begin{array}{l}\text { Wells et al. (1983); Lewis et al. (1988); } \\
\text { Munro (1989); Tacconi \& Tisdell } \\
\text { (1992b); Tisdell \& Wittenberg (1992) }\end{array}$ \\
\hline & & Lakeba Island & Vuki et al. (1992) \\
\hline & & Tuvuca Island & Vuki et al. (1992) \\
\hline & & Cicia Island & Vuki et al. (1992) \\
\hline & & Balavu Island & Vuki et al. (1992) \\
\hline & TNO & Moon Reef, Viti Levu & Borsa et al. (2015) \\
\hline & & Bega Lagoon Resort & $\begin{array}{l}\text { Flickr CrashDiver (2010); Flickr } \\
\text { scuba_dot_com (2014) }\end{array}$ \\
\hline & $\mathrm{TS}$ & Fiji & $\begin{array}{l}\text { Wells et al. (1983); Lewis et al. (1988); } \\
\text { Munro (1989); Tacconi \& Tisdell } \\
\text { (1992b); Tisdell \& Wittenberg (1992) }\end{array}$ \\
\hline & & Lakeba Island & Vuki et al. (1992) \\
\hline & & Tuvuca Island & Vuki et al. (1992) \\
\hline & & Cicia Island & Vuki et al. (1992) \\
\hline & & Balavu Island & Vuki et al. (1992) \\
\hline & & Wakaya, Koro Sea & Flickr Paul \& Jill (2011) \\
\hline & $\begin{array}{l}\text { TMB } \\
\text { (previously TT) }\end{array}$ & Eastern Islands (Lau) & $\begin{array}{l}\text { Lewis \& Ledua (1988); Lucas et al. } \\
\text { (1991); Ledua et al. (1993) }\end{array}$ \\
\hline & & Fiji & Tacconi \& Tisdell (1992b) \\
\hline & & Matokana & Ledua et al. (1993) \\
\hline \multirow[t]{4}{*}{ New Caledonia } & $\mathrm{HH}$ & New Caledonia & $\begin{array}{l}\text { Wells et al. (1983); Munro (1989); } \\
\text { Dumas et al. (2011, 2013) }\end{array}$ \\
\hline & & $\begin{array}{l}\text { North Eastern Lagoon (Poeubo to } \\
\text { Hienghène) }\end{array}$ & McKenna et al. (2006) \\
\hline & & Bourail & Wantiez et al. (2007c) \\
\hline & & Grand Lagon Nord & Wantiez et al. (2008a) \\
\hline
\end{tabular}


GIANT CLAMS (BIVALVIA: CARDIIDAE: TRIDACNINAE)

Table A2 (Continued) Checklist of giant clam species

\begin{tabular}{|c|c|c|c|}
\hline Recorded localities & Species & Localities & Reference(s) \\
\hline \multirow[t]{35}{*}{$\begin{array}{l}\text { New Caledonia } \\
\text { (Continued) }\end{array}$} & & $\begin{array}{l}\text { Ducos Island, Bay of Saint } \\
\text { Vincent }\end{array}$ & Aubert et al. (2009) \\
\hline & & Ioro Reef & Schwartzmann et al. (2011) \\
\hline & $\mathrm{TC}$ & $\begin{array}{l}\text { North Eastern Lagoon (Poeubo to } \\
\text { Hienghène) }\end{array}$ & McKenna et al. (2006) \\
\hline & & Poum & Vieux (2009) \\
\hline & & Bourail & Wantiez et al. (2007c) \\
\hline & & Grand Lagon Nord & Wantiez et al. (2008a) \\
\hline & & Merlet & Wantiez et al. (2008b) \\
\hline & & New Caledonia & Dumas et al. (2011) \\
\hline & $\mathrm{TD}$ & New Caledonia & $\begin{array}{l}\text { Wells et al. (1983); Munro (1989); } \\
\text { Purcell et al. (2009); Dumas et al. } \\
\text { (2011) }\end{array}$ \\
\hline & & $\begin{array}{l}\text { North Eastern Lagoon (Poeubo to } \\
\text { Hienghène) }\end{array}$ & McKenna et al. (2006) \\
\hline & & Corne Sud & Wantiez et al. (2007a) \\
\hline & & Ile des Pins & Wantiez et al. (2007b) \\
\hline & & Bourail & Wantiez et al. (2007c) \\
\hline & & Grand Lagon Nord & Wantiez et al. (2008a) \\
\hline & & Merlet & Wantiez et al. (2008b) \\
\hline & TG & FOSSIL TG FOUND / EXTINCT & Munro (1989) \\
\hline & $\mathrm{TM}$ & New Caledonia & $\begin{array}{l}\text { Wells et al. (1983); Munro (1989); } \\
\text { Purcell et al. (2009); Dumas et al. } \\
(2011,2013)\end{array}$ \\
\hline & & $\begin{array}{l}\text { North Eastern Lagoon (Poeubo to } \\
\text { Hienghène) }\end{array}$ & McKenna et al. (2006) \\
\hline & & Poum & Vieux (2009) \\
\hline & & Corne Sud & Wantiez et al. (2007a) \\
\hline & & Ile des Pins & Wantiez et al. (2007b) \\
\hline & & Bourail & Wantiez et al. (2007c) \\
\hline & & Grand Lagon Nord & Wantiez et al. (2008a) \\
\hline & & Merlet & Wantiez et al. (2008b) \\
\hline & $\begin{array}{l}\text { TMB } \\
\text { (previously TT) }\end{array}$ & Loyalty Islands & $\begin{array}{l}\text { Bouchet et al. (2001); Tiavouane \& } \\
\text { Fauvelot (2016) }\end{array}$ \\
\hline & TNO & Loyalty Islands & Borsa et al. (2015) \\
\hline & & Hienghene, northeastern coast & Borsa et al. (2015) \\
\hline & TS & New Caledonia & $\begin{array}{l}\text { Wells et al. (1983); Munro (1989); } \\
\text { Purcell et al. (2009); Dumas et al. } \\
(2011,2013)\end{array}$ \\
\hline & & $\begin{array}{l}\text { North Eastern Lagoon (Poeubo to } \\
\text { Hienghène) }\end{array}$ & McKenna et al. (2006) \\
\hline & & Poum & Vieux (2009) \\
\hline & & Corne Sud & Wantiez et al. (2007a) \\
\hline & & Ile des Pins & Wantiez et al. (2007b) \\
\hline & & Bourail & Wantiez et al. (2007c) \\
\hline & & Grand Lagon Nord & Wantiez et al. (2008a) \\
\hline & & Merlet & Wantiez et al. (2008b) \\
\hline
\end{tabular}


Table A2 (Continued) Checklist of giant clam species

\begin{tabular}{|c|c|c|c|}
\hline Recorded localities & Species & Localities & Reference(s) \\
\hline \multirow[t]{14}{*}{ Papua New Guinea } & $\mathrm{HH}$ & PNG & Wells et al. (1983); Munro (1989) \\
\hline & & Milne Bay Province & $\begin{array}{l}\text { Kinch }(2001,2002) \text {; Wells \& Kinch } \\
\text { (2003) }\end{array}$ \\
\hline & $\mathrm{HP}$ & Milne Bay Province & Kinch $(2001,2002)$ \\
\hline & $\mathrm{TC}$ & PNG & Wells et al. (1983) \\
\hline & & Milne Bay Province & $\begin{array}{l}\text { Kinch }(2001,2002) \text {; Wells \& Kinch } \\
\text { (2003) }\end{array}$ \\
\hline & TD & PNG & Wells et al. (1983); Munro (1989) \\
\hline & & Milne Bay Province & Kinch (2002); Wells \& Kinch (2003) \\
\hline & TG & PNG & Wells et al. (1983); Munro (1989) \\
\hline & & Milne Bay Province & $\begin{array}{l}\text { Kinch }(2001,2002) \text {; Wells \& Kinch } \\
\text { (2003) }\end{array}$ \\
\hline & $\mathrm{TM}$ & PNG & Wells et al. (1983); Munro (1989) \\
\hline & & Milne Bay Province & $\begin{array}{l}\text { Kinch }(2001,2002) \text {; Wells \& Kinch } \\
\text { (2003) }\end{array}$ \\
\hline & TNO & Madang Province, Kavieng & Borsa et al. (2015) \\
\hline & TS & PNG & Wells et al. (1983); Munro (1989) \\
\hline & & Milne Bay Province & $\begin{array}{l}\text { Kinch }(2001,2002) \text {; Wells \& Kinch } \\
\text { (2003) }\end{array}$ \\
\hline \multirow[t]{16}{*}{ Solomon Islands } & $\mathrm{HH}$ & Solomon Islands & $\begin{array}{l}\text { Wells et al. (1983); Govan et al. (1988); } \\
\text { Munro (1989); Ramohia (2006) }\end{array}$ \\
\hline & & Bellona (Mungiki) Island & Thaman et al. (2011) \\
\hline & $\mathrm{TC}$ & Solomon Islands & $\begin{array}{l}\text { Wells et al. (1983); Govan et al. (1988); } \\
\text { Munro (1989); Ramohia (2006) }\end{array}$ \\
\hline & & Bellona (Mungiki) Island & Thaman et al. (2011) \\
\hline & $\mathrm{TD}$ & Solomon Islands & $\begin{array}{l}\text { Govan et al. (1988); Munro (1989); } \\
\text { Ramohia (2006) }\end{array}$ \\
\hline & & Bellona (Mungiki) Island & Thaman et al. (2011) \\
\hline & TG & Solomon Islands & $\begin{array}{l}\text { Wells et al. (1983); Govan et al. (1988); } \\
\text { Munro (1989); Ramohia (2006); Flickr } \\
\text { Artefacque (2014) }\end{array}$ \\
\hline & & Bellona (Mungiki) Island & Thaman et al. (2011) \\
\hline & & Arnavon Island & Flickr LMMA Network (2006) \\
\hline & $\mathrm{TM}$ & Solomon Islands & $\begin{array}{l}\text { Wells et al. (1983); Govan et al. (1988); } \\
\text { Munro (1989); Ramohia (2006) }\end{array}$ \\
\hline & & Bellona (Mungiki) Island & Thaman et al. (2011) \\
\hline & & Gizo & Flickr Shea Pletz (2011) \\
\hline & TNO & $\begin{array}{l}\text { Solomon Islands (Huelsken et al., } \\
\text { 2013) }\end{array}$ & Borsa et al. (2015) \\
\hline & TS & Solomon Islands & $\begin{array}{l}\text { Govan et al. (1988); Munro (1989); } \\
\text { Ramohia (2006) }\end{array}$ \\
\hline & & Bellona (Mungiki) Island & Thaman et al. (2011) \\
\hline & & $\begin{array}{l}\text { Bulo Island, off SE Gatokae } \\
\text { Island, Mbatuna }\end{array}$ & Flickr Jose B (2015) \\
\hline \multirow[t]{2}{*}{$\begin{array}{l}\text { Vanuatu (and New } \\
\text { Hebrides) }\end{array}$} & $\mathrm{HH}$ & Vanuatu (and New Hebrides) & $\begin{array}{l}\text { Wells et al. (1983); Munro (1989); Zann } \\
\text { \& Ayling (1988); Bell \& Amos (1993) }\end{array}$ \\
\hline & $\mathrm{TC}$ & Vanuatu & $\begin{array}{l}\text { Zann \& Ayling (1988); Bell \& Amos } \\
\text { (1993) }\end{array}$ \\
\hline
\end{tabular}


Table A2 (Continued) Checklist of giant clam species

\begin{tabular}{|c|c|c|c|}
\hline Recorded localities & Species & Localities & Reference(s) \\
\hline \multirow{5}{*}{$\begin{array}{l}\text { Vanuatu (and New } \\
\text { Hebrides) } \\
\text { (Continued) }\end{array}$} & $\mathrm{TD}$ & EXTINCT & Munro (1989); Bell \& Amos (1993) \\
\hline & TG & EXTINCT & $\begin{array}{l}\text { Wells et al. (1983); Munro (1989); Bell } \\
\text { \& Amos (1993) }\end{array}$ \\
\hline & $\mathrm{TM}$ & Vanuatu (and New Hebrides) & $\begin{array}{l}\text { Wells et al. (1983); Munro (1989); Zann } \\
\text { \& Ayling (1988); Bell \& Amos (1993) }\end{array}$ \\
\hline & TNO & Efate & Borsa et al. (2015) \\
\hline & $\mathrm{TS}$ & Vanuatu & $\begin{array}{l}\text { Munro (1989); Zann \& Ayling (1988); } \\
\text { Bell \& Amos (1993) }\end{array}$ \\
\hline \multicolumn{4}{|l|}{ Micronesia } \\
\hline \multirow[t]{7}{*}{$\begin{array}{l}\text { Federated States of } \\
\text { Micronesia (FSM) }\end{array}$} & $\mathrm{HH}$ & $\begin{array}{l}\text { LOW NUMBERS } \\
\text { (REINTRODUCTION) }\end{array}$ & Munro (1989); Smith (1992) \\
\hline & $\mathrm{TD}$ & $\begin{array}{l}\text { NO WILD STOCKS } \\
\text { (INTRODUCTION) }\end{array}$ & Munro (1989); Smith (1992) \\
\hline & TG & $\begin{array}{l}\text { Lamotrek and West Fayu Atolls } \\
\text { (relict) }\end{array}$ & $\begin{array}{l}\text { Price \& Fagolimul (1988); Munro } \\
\text { (1989) }\end{array}$ \\
\hline & & FSM & Smith (1992) \\
\hline & $\mathrm{TM}$ & FSM & Munro (1989); Smith (1992) \\
\hline & TNO & Kosrae, part of the Caroline Islands & Borsa et al. (2015) \\
\hline & $\mathrm{TS}$ & FSM & Munro (1989); Smith (1992) \\
\hline \multirow[t]{7}{*}{ Guam } & $\mathrm{HH}$ & EXTINCT & $\begin{array}{l}\text { Munro (1989); Anonymous (1994); } \\
\text { Paulay (2003) }\end{array}$ \\
\hline & TD & INTRODUCED FROM PALAU & $\begin{array}{l}\text { Wells et al. (1983); Anonymous (1994); } \\
\text { Paulay (2003) }\end{array}$ \\
\hline & TG & EXTINCT & $\begin{array}{l}\text { Munro (1989); Anonymous (1994); } \\
\text { Paulay (2003) }\end{array}$ \\
\hline & $\mathrm{TM}$ & Guam & $\begin{array}{l}\text { Munro (1989); Stojkovich (1977); } \\
\text { Anonymous (1994); Paulay (2003) }\end{array}$ \\
\hline & & Mariana Islands & $\begin{array}{l}\text { Flickr NOAA Photo Library, David } \\
\text { Burdick (2010) }\end{array}$ \\
\hline & $\mathrm{TS}$ & Guam & Anonymous (1994); Paulay (2003) \\
\hline & & Cocos West Island & Flickr GingrichCrew (2011) \\
\hline \multirow[t]{10}{*}{ Republic of Kiribati } & $\mathrm{HH}$ & Gilbert Islands & $\begin{array}{l}\text { Wells et al. (1983); Munro (1988, 1989); } \\
\text { Thomas (2001) }\end{array}$ \\
\hline & & Kiribati Islands & Taniera (1988); Thomas (2014) \\
\hline & TG & Gilbert Islands & $\begin{array}{l}\text { Wells et al. (1983); Munro (1988, 1989); } \\
\text { Thomas (2001) }\end{array}$ \\
\hline & & Kiribati Islands & Taniera (1988); Thomas (2014) \\
\hline & $\mathrm{TM}$ & Fanning Island & Kay (1970) \\
\hline & & Gilbert Islands & $\begin{array}{l}\text { Wells et al. (1983); Munro (1988, 1989); } \\
\text { Kepler \& Kepler (1994); Thomas } \\
\text { (2001) }\end{array}$ \\
\hline & & Northern Line Islands & $\begin{array}{l}\text { Kay (1970); Wells et al. (1983); Munro } \\
\text { (1989); Sandin et al. (2008); Williams } \\
\text { et al. (2013) }\end{array}$ \\
\hline & & Phoenix Islands & Munro (1989) \\
\hline & & Kiribati Islands & Taniera (1988); Thomas (2014) \\
\hline & & Millennium Atoll Lagoon & Barott et al. (2010) \\
\hline
\end{tabular}


Table A2 (Continued) Checklist of giant clam species

\begin{tabular}{|c|c|c|c|}
\hline Recorded localities & Species & Localities & Reference(s) \\
\hline \multirow{3}{*}{$\begin{array}{l}\text { Republic of Kiribati } \\
\text { (Continued) }\end{array}$} & TNO & Kiritimati, Northern Line Islands & Borsa et al. (2015) \\
\hline & TS & Gilbert Islands & $\begin{array}{l}\text { Wells et al. (1983); Munro (1988,t } \\
\text { 1989); Thomas (2001) }\end{array}$ \\
\hline & & Kiribati Islands & Taniera (1988) \\
\hline \multirow[t]{21}{*}{ Marshall Islands } & $\mathrm{HH}$ & Marshall Islands & $\begin{array}{l}\text { Wells et al. (1983); Munro (1989); Pinca } \\
\text { \& Beger (2002) }\end{array}$ \\
\hline & & Rongelap Atoll & Pinca \& Beger (2003) \\
\hline & & Namu Atoll & Beger et al. (2008) \\
\hline & $\mathrm{TD}$ & INTRODUCED FROM PALAU & Munro (1989); Pinca \& Beger (2002) \\
\hline & & Mili Atoll & Pinca \& Beger (2003) \\
\hline & & Rongelap Atoll & Pinca \& Beger (2003) \\
\hline & & Arno Atoll & Beger et al. (2008) \\
\hline & TG & Marshall Islands & $\begin{array}{l}\text { Wells et al. (1983); Munro (1989); Pinca } \\
\text { \& Beger (2002) }\end{array}$ \\
\hline & & Mili Atoll & Pinca \& Beger (2003) \\
\hline & & Rongelap Atoll & Pinca \& Beger (2003) \\
\hline & & Namu Atoll & Beger et al. (2008) \\
\hline & $\mathrm{TM}$ & Marshall Islands & $\begin{array}{l}\text { Wells et al. (1983); Munro (1989); Pinca } \\
\text { \& Beger (2002) }\end{array}$ \\
\hline & & Mili Atoll & Pinca \& Beger (2003) \\
\hline & & Rongelap Atoll & Pinca \& Beger (2003) \\
\hline & & Namu Atoll & Beger et al. (2008) \\
\hline & & Majuro Atoll & Beger et al. (2008) \\
\hline & TS & Marshall Islands & $\begin{array}{l}\text { Wells et al. (1983); Munro (1989); Pinca } \\
\text { \& Beger (2002) }\end{array}$ \\
\hline & & Mili Atoll & Pinca \& Beger (2003) \\
\hline & & Rongelap Atoll & Pinca \& Beger (2003) \\
\hline & & Namu Atoll & Beger et al. (2008) \\
\hline & & Majuro Atoll & Beger et al. (2008) \\
\hline Nauru & $\mathrm{TM}$ & LOCALLY EXTINCT & Jacob (2000); South \& Skelton (2000) \\
\hline \multirow{8}{*}{$\begin{array}{l}\text { Northern Mariana } \\
\text { Islands }\end{array}$} & $\mathrm{HH}$ & LOCALLY EXTINCT & Munro (1989) \\
\hline & $\mathrm{TC}$ & POSSIBLY EXTINCT & IUCN Red List \\
\hline & $\mathrm{TD}$ & POSSIBLY EXTINCT & IUCN Red List \\
\hline & TG & LOCALLY EXTINCT & Munro (1989) \\
\hline & $\mathrm{TM}$ & Mariana Islands & Wells et al. (1983); Munro (1989) \\
\hline & & $\begin{array}{l}\text { Maug Island, Marianas Trench } \\
\text { Marine National Monument }\end{array}$ & Flickr lucidlou (2007) \\
\hline & & Saipan Island & Flickr Chris (2008) \\
\hline & TS & Mariana Islands & Wells et al. (1983) \\
\hline \multirow[t]{5}{*}{ Palau } & $\mathrm{HH}$ & Caroline Islands & $\begin{array}{l}\text { Hardy \& Hardy (1969); Hester \& Jones } \\
\text { (1974); Bryan \& McConnell (1976); } \\
\text { Hirshberger (1980); Wells et al. (1983) }\end{array}$ \\
\hline & & Palau & Wells et al. (1983); Munro (1989) \\
\hline & $\mathrm{HP}$ & Palau & Munro (1989) \\
\hline & $\mathrm{TC}$ & Caroline Islands & $\begin{array}{l}\text { Hardy \& Hardy (1969); Hester \& Jones } \\
\text { (1974); Wells et al. (1983) }\end{array}$ \\
\hline & & Palau & Munro (1989) \\
\hline
\end{tabular}


Table A2 (Continued) Checklist of giant clam species

\begin{tabular}{|c|c|c|c|}
\hline Recorded localities & Species & Localities & Reference(s) \\
\hline \multirow[t]{8}{*}{ Palau (Continued) } & \multirow[t]{2}{*}{$\mathrm{TD}$} & Caroline Islands & $\begin{array}{l}\text { Hardy \& Hardy (1969); Hester \& Jones } \\
\text { (1974); Bryan \& McConnell (1976); } \\
\text { Hirshberger (1980); Wells et al. (1983) }\end{array}$ \\
\hline & & Palau & Munro (1989) \\
\hline & \multirow[t]{2}{*}{ TG } & Caroline Islands & $\begin{array}{l}\text { Hardy \& Hardy (1969); Hester \& Jones } \\
\text { (1974); Bryan \& McConnell (1976); } \\
\text { Hirshberger (1980); Wells et al. (1983) }\end{array}$ \\
\hline & & Palau & Munro (1989) \\
\hline & \multirow[t]{2}{*}{$\mathrm{TM}$} & Caroline Islands & $\begin{array}{l}\text { Hardy \& Hardy (1969); Hester \& Jones } \\
\text { (1974); Bryan \& McConnell (1976); } \\
\text { Hirshberger (1980); Wells et al. (1983) }\end{array}$ \\
\hline & & Palau & Munro (1989) \\
\hline & \multirow[t]{2}{*}{$\mathrm{TS}$} & Caroline Islands & $\begin{array}{l}\text { Hardy \& Hardy (1969); Hester \& Jones } \\
\text { (1974); Bryan \& McConnell (1976); } \\
\text { Hirshberger (1980); Wells et al. (1983) }\end{array}$ \\
\hline & & Palau & Munro (1989) \\
\hline $\begin{array}{l}\text { United States Minor } \\
\text { Outlying Islands }\end{array}$ & $\mathrm{TM}$ & Wake Island & Wells et al. (1983) \\
\hline \multicolumn{4}{|l|}{ Polynesia } \\
\hline \multirow[t]{5}{*}{ American Samoa } & $\mathrm{HH}$ & $\begin{array}{l}\text { LOCALLY EXTINCT and } \\
\text { REINTRODUCED }\end{array}$ & Nagaoka (1993); Craig (2009) \\
\hline & $\mathrm{TD}$ & INTRODUCED & Bell (1993) \\
\hline & TG & INTRODUCED & Bell (1993) \\
\hline & $\mathrm{TM}$ & Rose Atoll & $\begin{array}{l}\text { Radtke (1985); Munro (1989); Green \& } \\
\text { Craig (1999); Craig (2009) }\end{array}$ \\
\hline & TS & American Samoa & Munro (1989); Craig (2009) \\
\hline \multirow[t]{11}{*}{ Cook Islands } & $\mathrm{TD}$ & INTRODUCED FROM PALAU & $\begin{array}{l}\text { Munro (1989); Tisdell \& Wittenberg } \\
\text { (1992) }\end{array}$ \\
\hline & TG & INTRODUCED & $\begin{array}{l}\text { Flickr Richard Mayston (2008); Flickr } \\
\text { RDPixelShop (2011) }\end{array}$ \\
\hline & \multirow[t]{6}{*}{$\mathrm{TM}$} & Cook Islands & $\begin{array}{l}\text { Munro (1989); Tisdell \& Wittenberg } \\
\text { (1992) }\end{array}$ \\
\hline & & Suwarrow Atoll & Sims \& Howard (1988) \\
\hline & & Manihiki Atoll & Sims \& Howard (1988) \\
\hline & & Penrhyn Atoll & Sims \& Howard (1988) \\
\hline & & Aitutaki & Paulay (1987); Sims \& Howard (1988) \\
\hline & & Tongareva Lagoon & Chambers (2007) \\
\hline & TNO & Rarotonga & Flickr Richard Mayston (2008) \\
\hline & \multirow[t]{2}{*}{$\mathrm{TS}$} & Cook Islands & $\begin{array}{l}\text { Paulay (1987); Tisdell \& Wittenberg } \\
\text { (1992) }\end{array}$ \\
\hline & & Aitutaki (RARE) & Sims \& Howard (1988); Munro (1989) \\
\hline \multirow[t]{5}{*}{ French Polynesia } & \multirow[t]{5}{*}{$\mathrm{TM}$} & Takapoto Atoll & $\begin{array}{l}\text { Jaubert (1977); Richard (1977); Laurent } \\
\text { (2001) }\end{array}$ \\
\hline & & Tuamotu & Wells et al. (1983) \\
\hline & & Polynesie Francaise & Munro (1989) \\
\hline & & Bora Bora Island & Planes et al. (1993) \\
\hline & & Moorea & Laurent (2001) \\
\hline
\end{tabular}


Table A2 (Continued) Checklist of giant clam species

\begin{tabular}{|c|c|c|c|}
\hline Recorded localities & Species & Localities & Reference(s) \\
\hline \multirow{10}{*}{$\begin{array}{l}\text { French Polynesia } \\
\text { (Continued) }\end{array}$} & & Anaa & Laurent (2001) \\
\hline & & Tatakoto Atoll & $\begin{array}{l}\text { Gilbert et al. (2005, 2006b); Andréfouët } \\
\text { et al. (2013) }\end{array}$ \\
\hline & & Fangatau Atoll & $\begin{array}{l}\text { Andréfouët et al. (2005); Gilbert et al. } \\
\text { (2006b) }\end{array}$ \\
\hline & & Reao & Gilbert et al. (2006a) \\
\hline & & Pukarua & Gilbert et al. (2006a) \\
\hline & & Raivavae & $\begin{array}{l}\text { Gilbert et al. (2006a); Andréfouët et al. } \\
\text { (2009); Van Wynsberge et al. (2013) }\end{array}$ \\
\hline & & Tubuai, Austral Islands & $\begin{array}{l}\text { Larrue (2006); Gilbert et al. (2006b); } \\
\text { Van Wynsberge et al. (2013) }\end{array}$ \\
\hline & $\mathrm{TS}$ & Tuamotu & Wells et al. (1983); Andréfouët et al. (2014) \\
\hline & & Tubuai, Austral Islands & $\begin{array}{l}\text { Gilbert et al. (2007); Newman \& Gomez } \\
\text { (2007) }\end{array}$ \\
\hline & & Gambier & Andréfouët et al. (2014) \\
\hline \multirow[t]{6}{*}{ Pitcairn Islands } & $\mathrm{TM}$ & Henderson Island & Wells et al. (1983); Paulay et al. (1989) \\
\hline & & Oeno Lagoon & $\begin{array}{l}\text { Paulay et al. (1989); Irving \& Dawson } \\
\text { (2013) }\end{array}$ \\
\hline & & Pitcairn Islands & Palomares et al. (2011) \\
\hline & $\mathrm{TS}$ & Ducie Atoll & Paulay et al. (1989) \\
\hline & & Henderson Island & Paulay et al. (1989) \\
\hline & & Pitcairn Islands & Palomares et al. (2011) \\
\hline \multirow[t]{3}{*}{ Niue } & $\mathrm{TM}$ & Niue & Dalzell et al. (1993); Kronen et al. (2008) \\
\hline & $\mathrm{TS}$ & LOCALLY EXTINCT & $\begin{array}{l}\text { Dalzell et al. (1993); absent in Kronen } \\
\text { et al. (2008) surveys }\end{array}$ \\
\hline & & Niue & $\begin{array}{l}\text { Flickr orbitonline (2009); Flickr Sam \& } \\
\text { Fanny (2012) }\end{array}$ \\
\hline \multirow[t]{8}{*}{ Samoa } & $\mathrm{HH}$ & LOCALLY EXTINCT & $\begin{array}{l}\text { Munro (1989); Zann (1991); Tacconi \& } \\
\text { Tisdell (1992b); South \& Skelton } \\
\text { (2000) }\end{array}$ \\
\hline & & REINTRODUCED & Flickr Richard Mayston (2015) \\
\hline & $\mathrm{TD}$ & INTRODUCED & Fisheries Newsletter (2014) \\
\hline & TG & INTRODUCED & Fisheries Newsletter (2014) \\
\hline & TM & Samoa & $\begin{array}{l}\text { Wells et al. (1983); Munro (1989); Zann } \\
\text { (1989); Tisdell \& Wittenberg (1992) }\end{array}$ \\
\hline & & Upolu, Western Samoa & Zann (1991); Tacconi \& Tisdell (1992b) \\
\hline & $\mathrm{TS}$ & Samoa & $\begin{array}{l}\text { Wells et al. (1983); Munro (1989); Zann } \\
\text { (1989); Tisdell \& Wittenberg (1992) }\end{array}$ \\
\hline & & Upolu, Western Samoa & Zann (1991); Tacconi \& Tisdell (1992b) \\
\hline \multirow[t]{6}{*}{ Tokelau } & $\mathrm{TM}$ & Tokelau & $\begin{array}{l}\text { Munro (1989); Tisdell \& Wittenberg } \\
\text { (1992) }\end{array}$ \\
\hline & & Fakaofo & Braley (1989) \\
\hline & & Nukunonu & Braley (1989) \\
\hline & & Atafu & Braley (1989) \\
\hline & TS & Fakaofo & Braley (1989) \\
\hline & & Nukunonu & Braley (1989) \\
\hline
\end{tabular}


GIANT CLAMS (BIVALVIA: CARDIIDAE: TRIDACNINAE)

Table A2 (Continued) Checklist of giant clam species

\begin{tabular}{|c|c|c|c|}
\hline Recorded localities & Species & Localities & Reference(s) \\
\hline \multirow[t]{14}{*}{ Tonga } & $\mathrm{HH}$ & LOCALLY EXTINCT & $\begin{array}{l}\text { Wells et al. (1983); Langi \& Hesitoni } \\
\text { 'Aloua (1988); Munro (1989); Tacconi } \\
\text { \& Tisdell (1992b); Loto'ahea \& Sone } \\
\text { (1995); Salvat (2000) }\end{array}$ \\
\hline & & Vava'u (EXTINCT) & Chesher (1993) \\
\hline & TG & LOCALLY EXTINCT & Salvat (2000) \\
\hline & TD & Tonga & $\begin{array}{l}\text { Langi \& Hesitoni 'Aloua (1988); Munro } \\
\text { (1989); Tacconi \& Tisdell (1992b); } \\
\text { Tisdell \& Wittenberg (1992); Loto'ahea } \\
\text { \& Sone (1995) }\end{array}$ \\
\hline & & Vava'u & Chesher (1993) \\
\hline & & Tongatapu Island & Tu'avao et al. (1995) \\
\hline & TM & Tonga & $\begin{array}{l}\text { Wells et al. (1983); Langi \& Hesitoni } \\
\text { ‘Aloua (1988); Munro (1989); Tacconi } \\
\text { \& Tisdell (1992b); Tisdell \& } \\
\text { Wittenberg (1992); Loto'ahea \& Sone } \\
\text { (1995) }\end{array}$ \\
\hline & & Vava'u & Chesher (1993) \\
\hline & & Tongatapu Island & Tu'avao et al. (1995) \\
\hline & $\mathrm{TS}$ & Tonga & $\begin{array}{l}\text { Wells et al. (1983); Langi \& Hesitoni } \\
\text { ‘Aloua (1988); Munro (1989); Tacconi } \\
\text { \& Tisdell (1992b); Tisdell \& } \\
\text { Wittenberg (1992); Loto'ahea \& Sone } \\
\text { (1995) }\end{array}$ \\
\hline & & Vava'u & Chesher (1993) \\
\hline & & Tongatapu Island & Tu'avao et al. (1995) \\
\hline & $\begin{array}{l}\text { TMB } \\
\text { (previously TT) }\end{array}$ & Vava'u and Ha' apai Islands & Lucas et al. (1991) \\
\hline & & Main islands of Tonga & $\begin{array}{l}\text { Tacconi \& Tisdell (1992b); Ledua et al. } \\
\text { (1993) }\end{array}$ \\
\hline \multirow[t]{14}{*}{ Tuvalu } & $\mathrm{HH}$ & Tuvalu & Munro (1989) \\
\hline & TD & INTRODUCED & Job \& Ceccarelli (2012) \\
\hline & TG & Tuvalu & $\begin{array}{l}\text { Munro (1989); Tacconi \& Tisdell } \\
\text { (1992a); Sauni et al. (2008) }\end{array}$ \\
\hline & $\mathrm{TM}$ & Ellice Islands & Wells et al. (1983) \\
\hline & & Nukufetau & Braley (1988); Sauni et al. (2008) \\
\hline & & Funafuti & $\begin{array}{l}\text { Braley (1988); Sauni et al. (2008); Job } \\
\text { \& Ceccarelli (2012); Siaosi et al. } \\
\text { (2012) }\end{array}$ \\
\hline & & Nukulaelae & Braley (1988); Job \& Ceccarelli (2012) \\
\hline & & Tuvalu & Munro (1989) \\
\hline & & Nanumea & Langi (1990) \\
\hline & & Nui & Langi (1990) \\
\hline & & Niutao & Sauni et al. (2008) \\
\hline & & Vaitupu & Sauni et al. (2008) \\
\hline & TS & Ellice Islands & Wells et al. (1983) \\
\hline & & Nukufetau & Braley (1988); Sauni et al. (2008) \\
\hline
\end{tabular}

Continued 


\section{MEI LIN NEO ET AL.}

Table A2 (Continued) Checklist of giant clam species

\begin{tabular}{|c|c|c|c|}
\hline Recorded localities & Species & Localities & Reference(s) \\
\hline \multirow[t]{2}{*}{ Tuvalu (Continued) } & & Funafuti & $\begin{array}{l}\text { Braley (1988); Sauni et al. (2008); Job } \\
\text { \& Ceccarelli (2012); Siaosi et al. } \\
\text { (2012) }\end{array}$ \\
\hline & & Tuvalu & Munro (1989) \\
\hline \multirow{3}{*}{$\begin{array}{l}\text { Wallis and Futuna } \\
\text { Islands }\end{array}$} & $\mathrm{TM}$ & Wallis and Futuna & Pollock (1992) \\
\hline & TNO & Wallis Island & Borsa et al. (2015) \\
\hline & TS & Wallis and Futuna & Pollock (1992) \\
\hline
\end{tabular}

Note: Full reference list found in Appendix B. Tg-Tridacna gigas; Td-T. derasa; Tmb-T. mbalavuana (previously T. tevoroa); Ts-T. squamosa; Tsi-T. squamosina (previously T. costata); Tr-T. rosewateri; Tm-T. maxima; $\mathrm{Tlz}-T$. lorenzi; Tno-T. noae; Tc-T. crocea $\mathrm{Hh}-$ Hippopus hippopus; $\mathrm{Hp}-H$. porcellanus. 
GIANT CLAMS (BIVALVIA: CARDIIDAE: TRIDACNINAE)

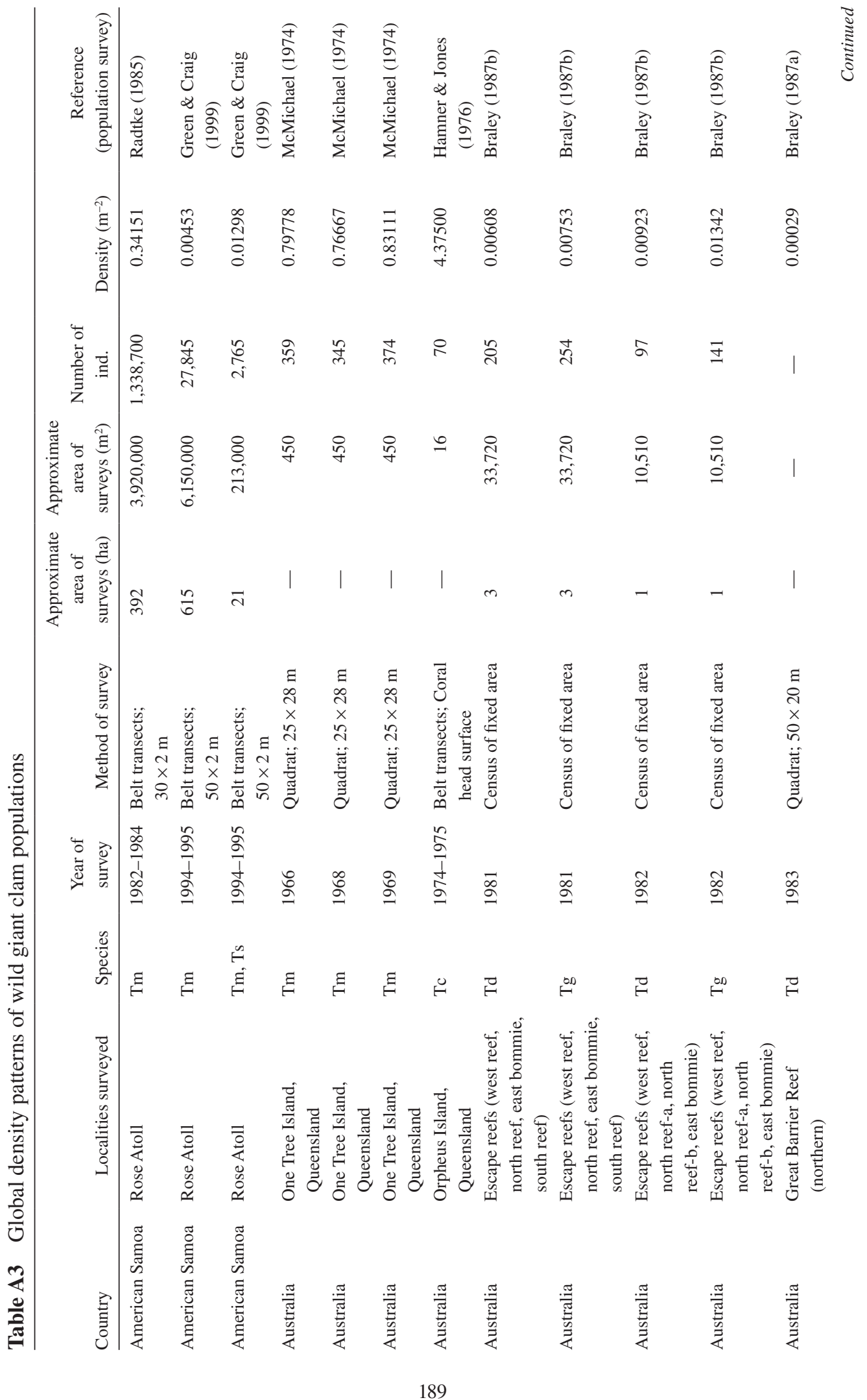




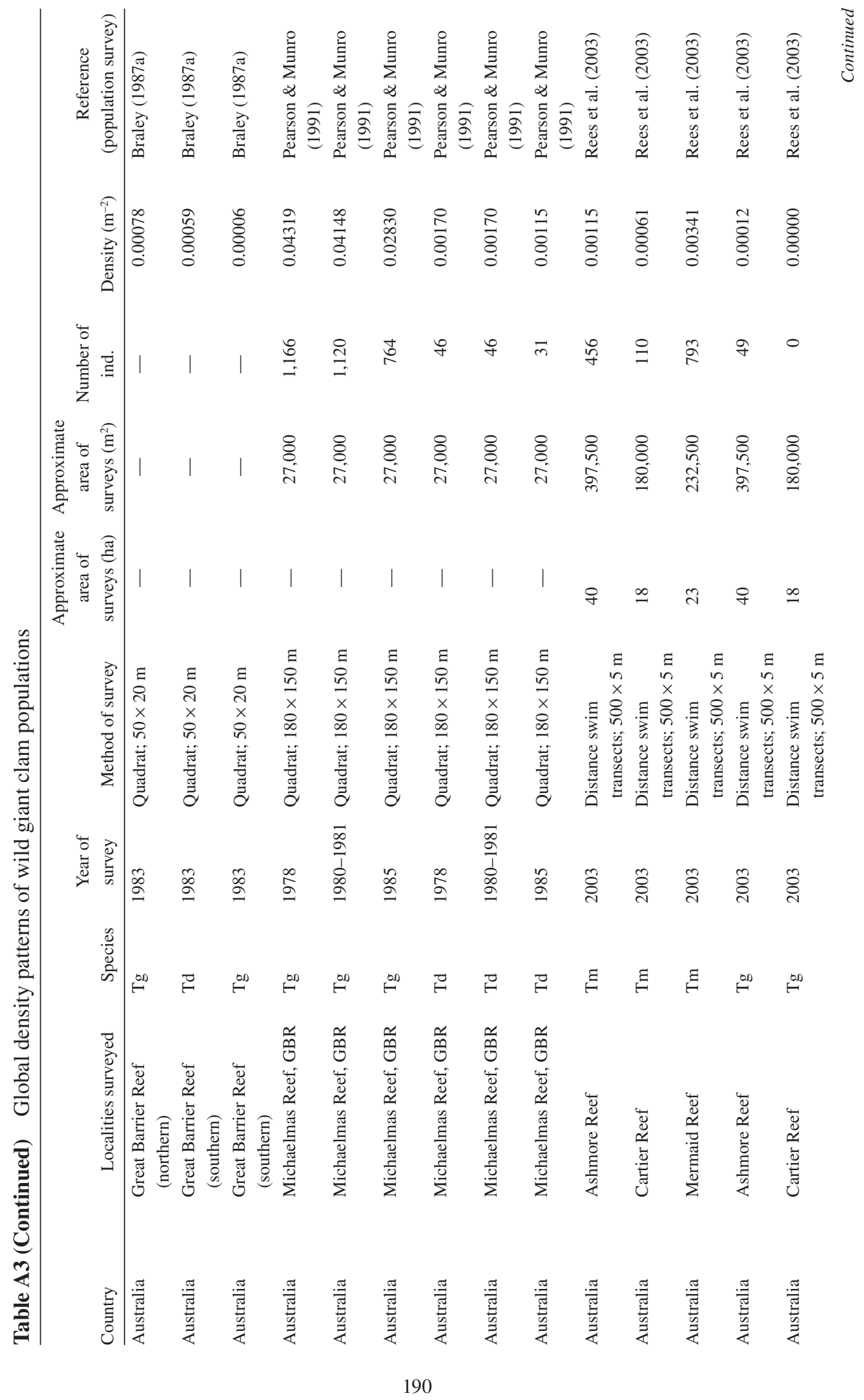




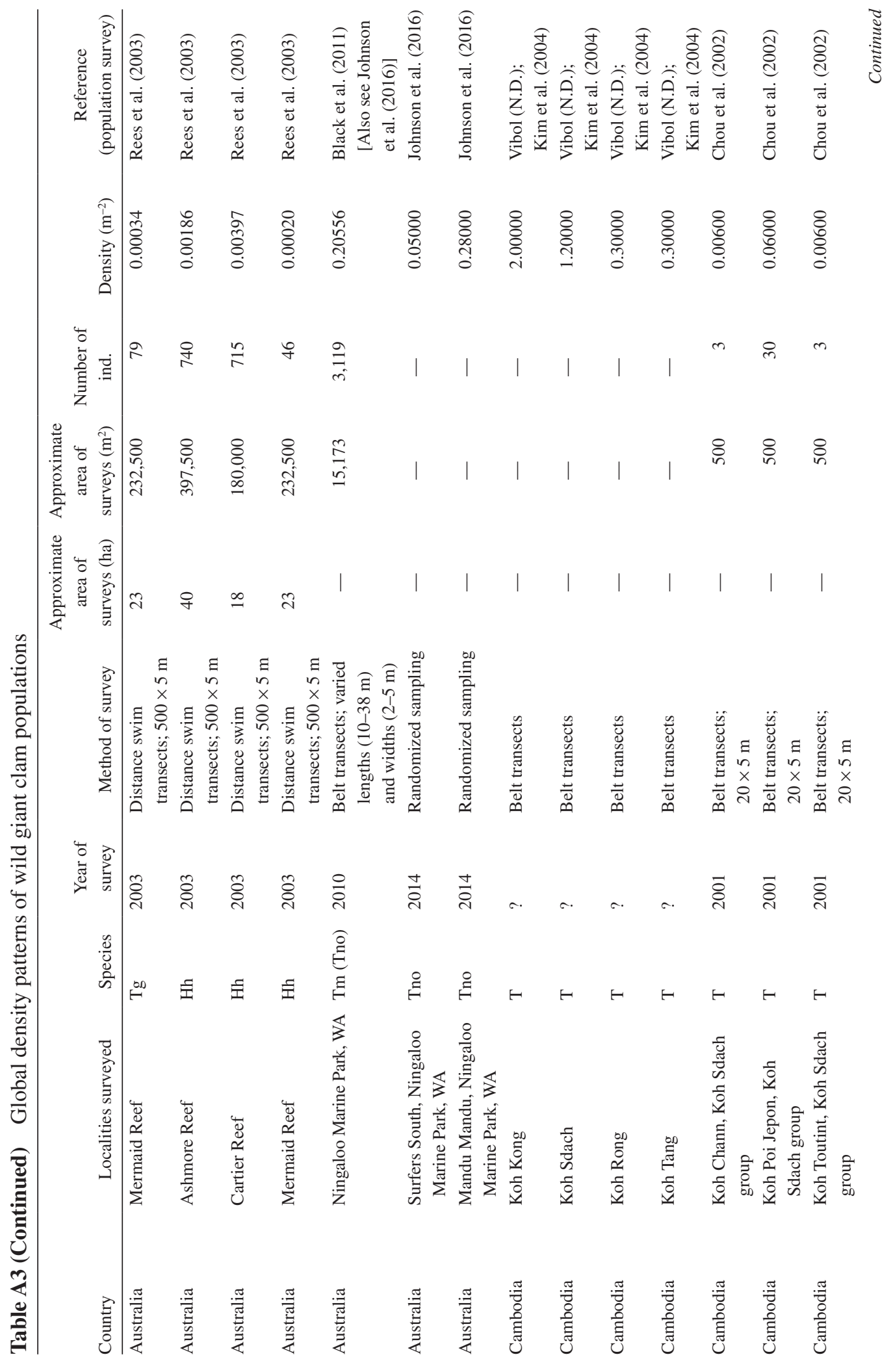


MEI LIN NEO ET AL.

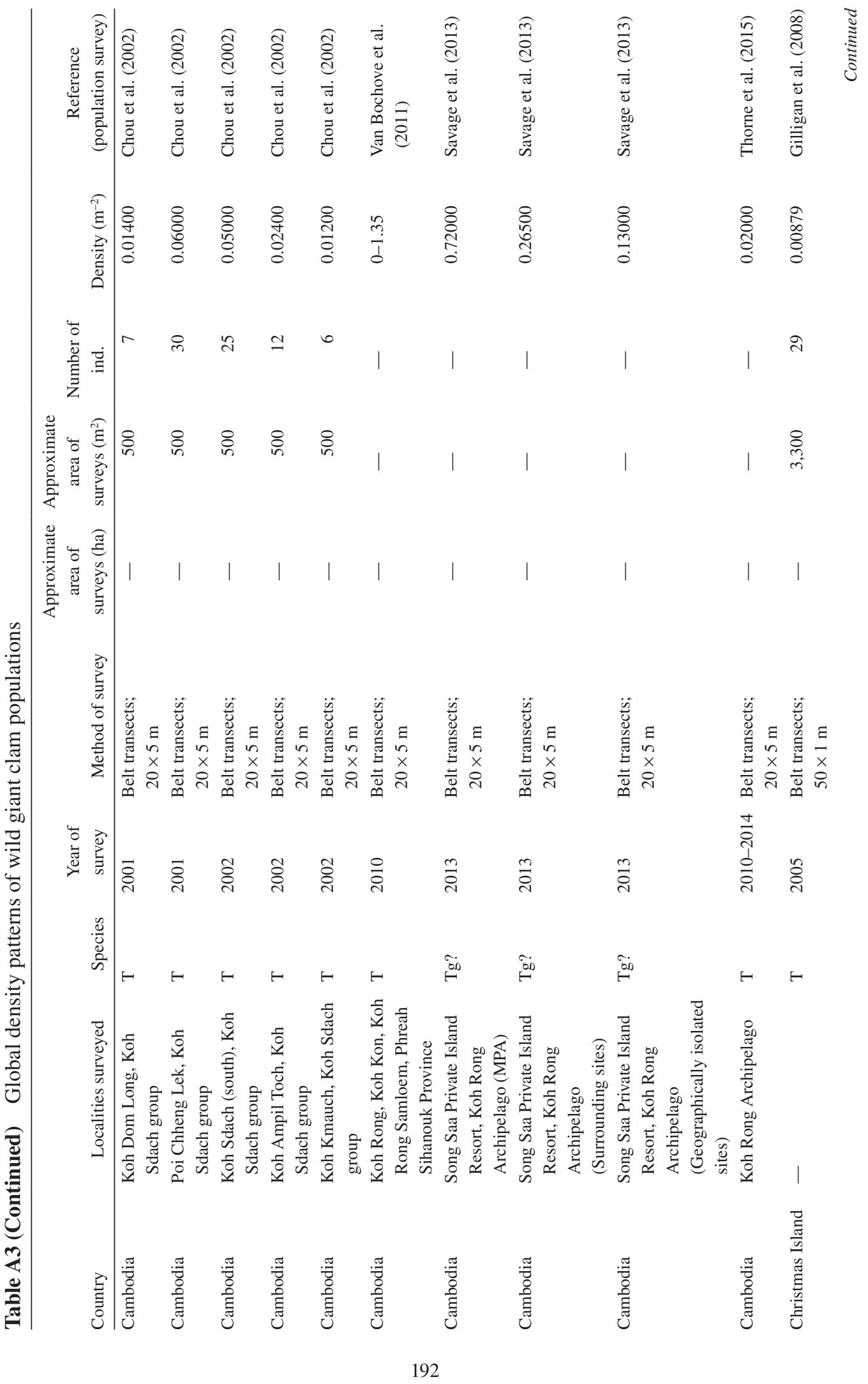


GIANT CLAMS (BIVALVIA: CARDIIDAE: TRIDACNINAE)

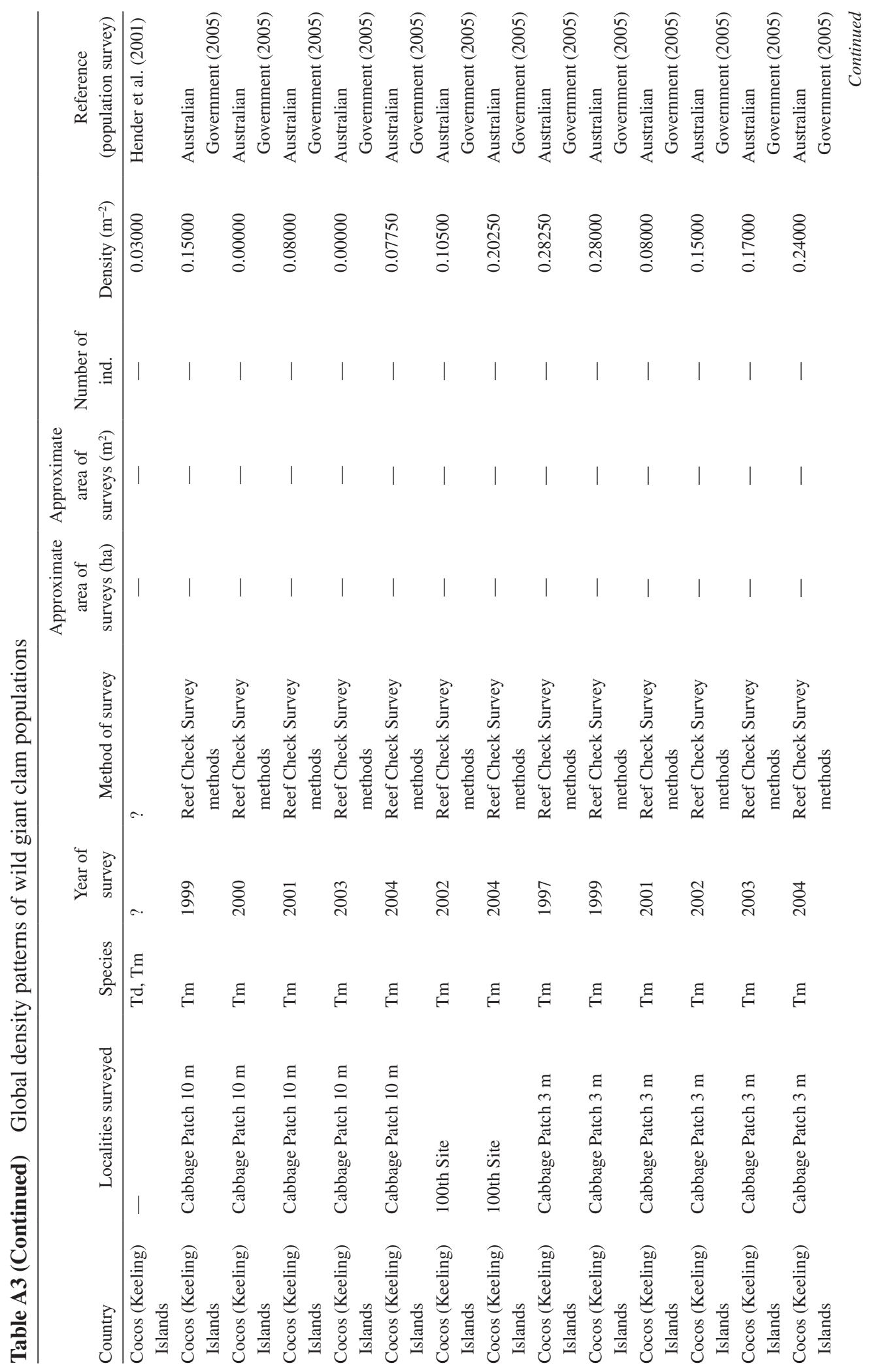


MEI LIN NEO ET AL.

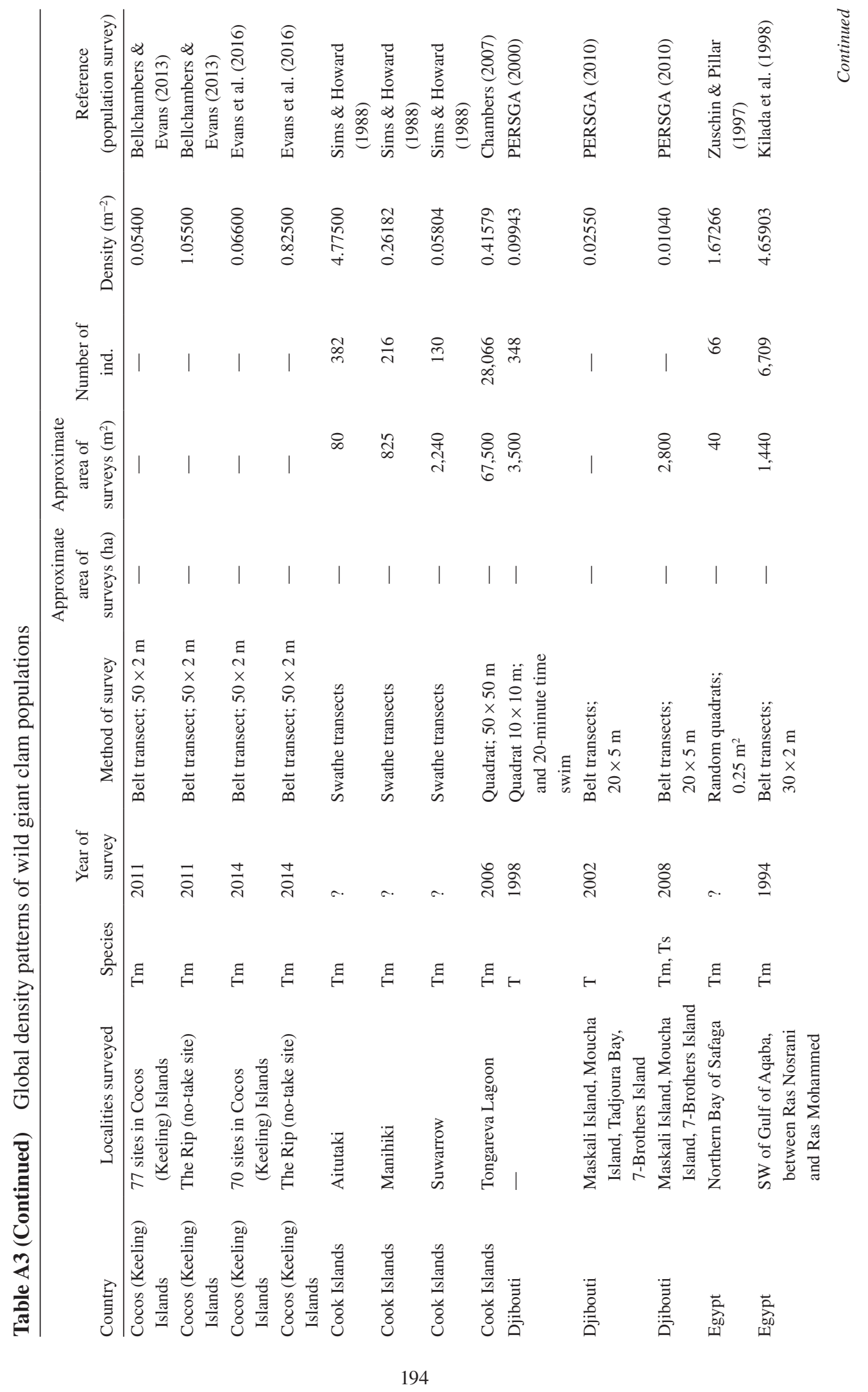


GIANT CLAMS (BIVALVIA: CARDIIDAE: TRIDACNINAE)

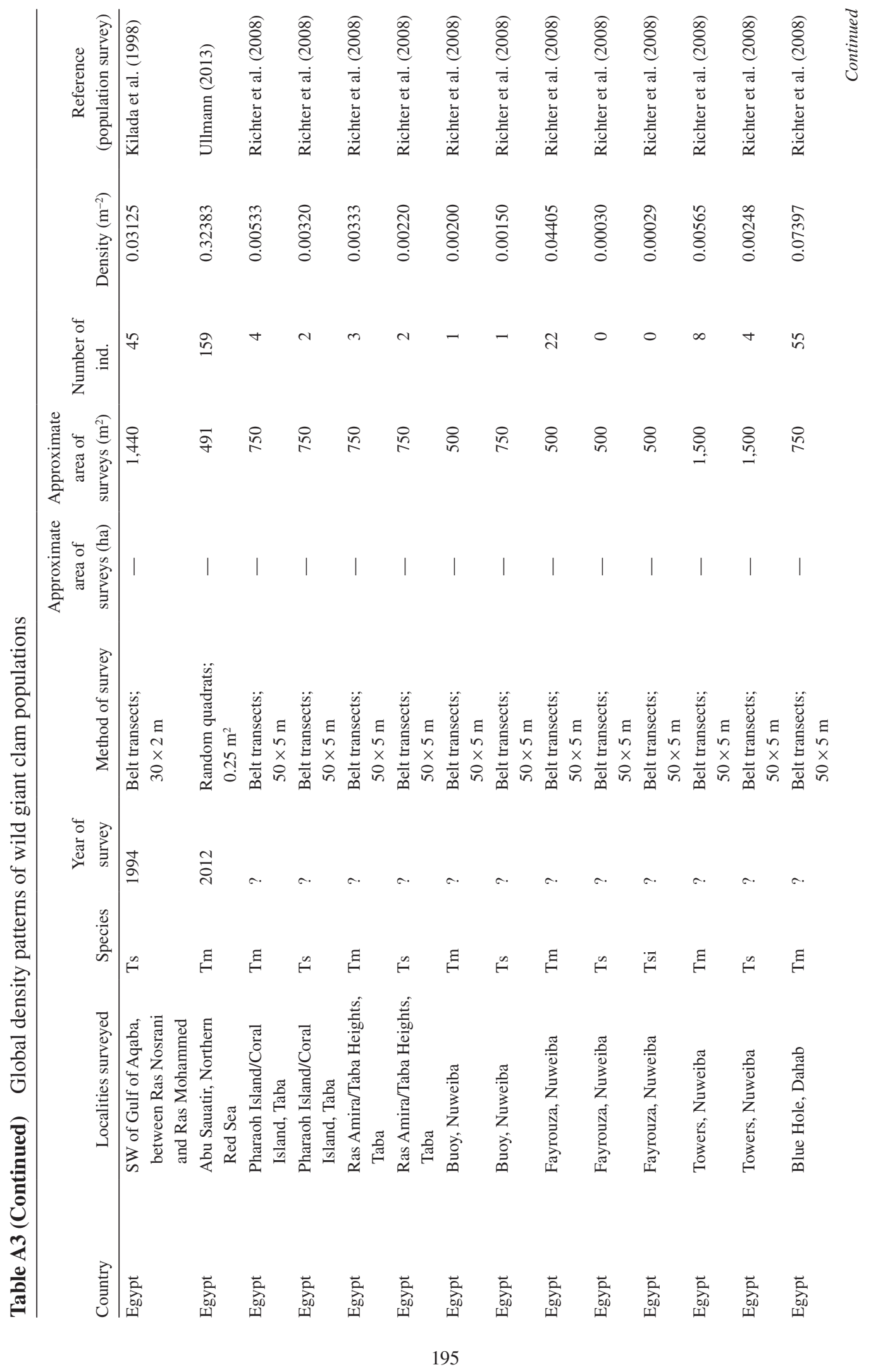


MEI LIN NEO ET AL.

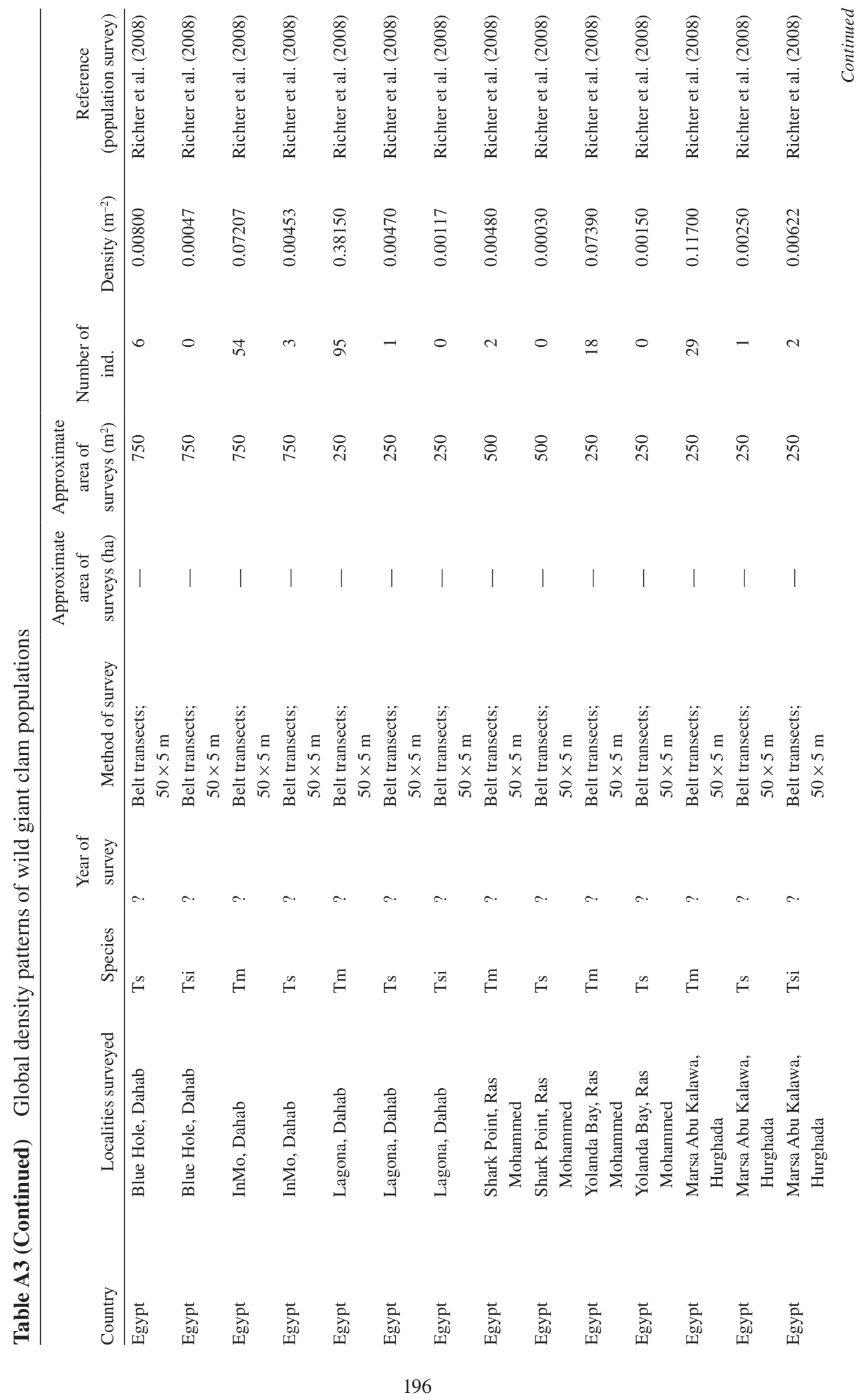


GIANT CLAMS (BIVALVIA: CARDIIDAE: TRIDACNINAE)

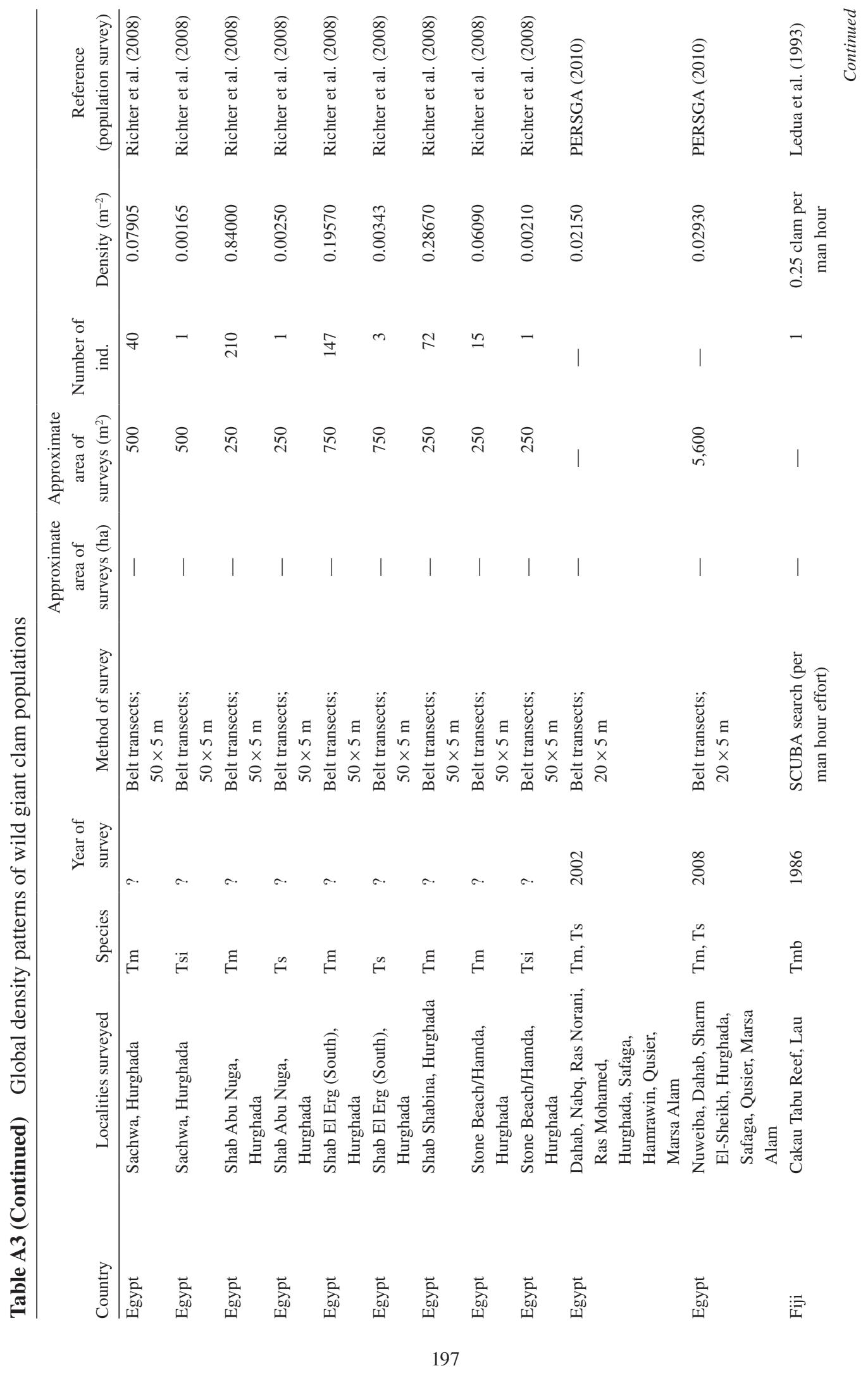


MEI LIN NEO ET AL.

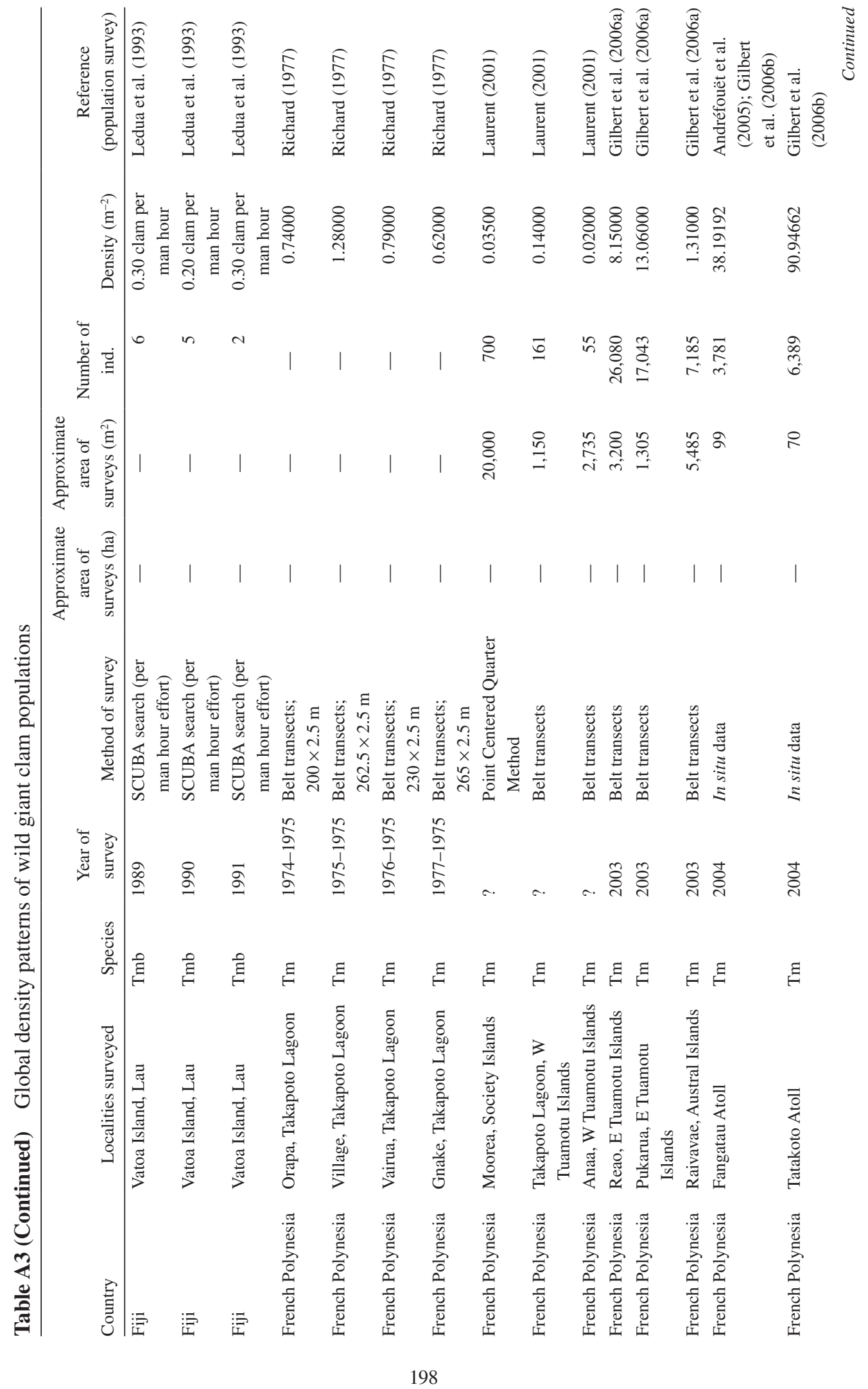


GIANT CLAMS (BIVALVIA: CARDIIDAE: TRIDACNINAE)

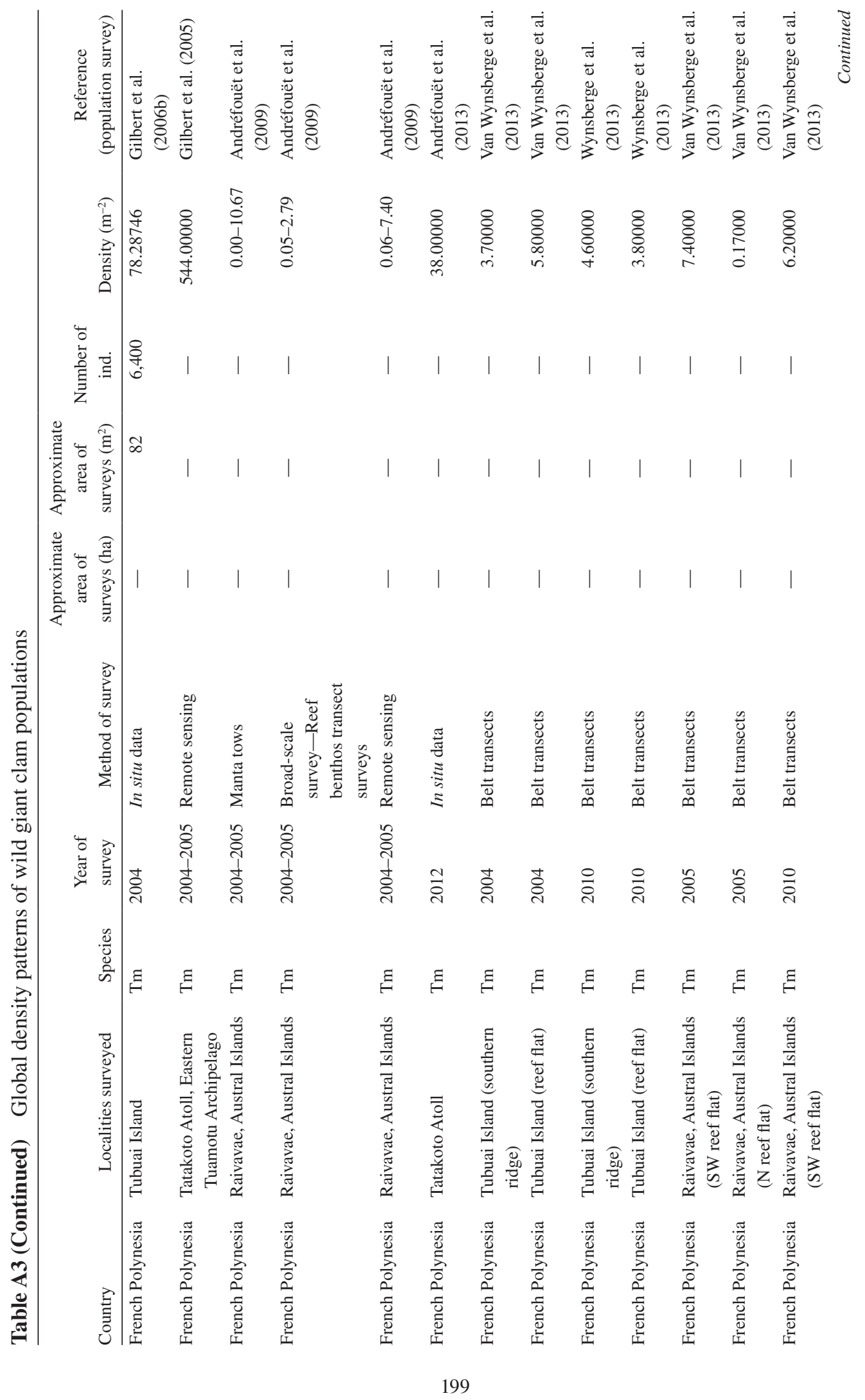


MEI LIN NEO ET AL.

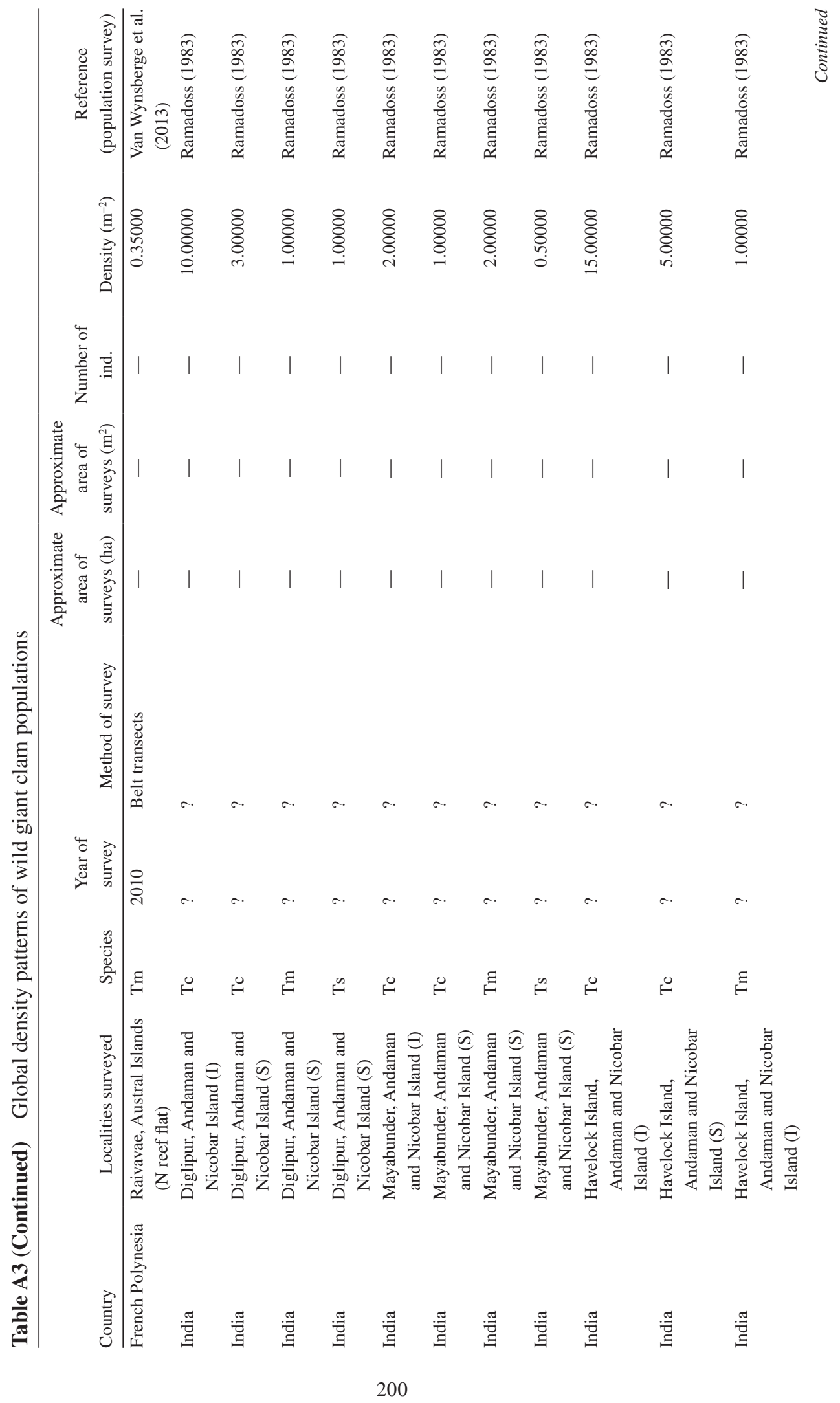


GIANT CLAMS (BIVALVIA: CARDIIDAE: TRIDACNINAE)

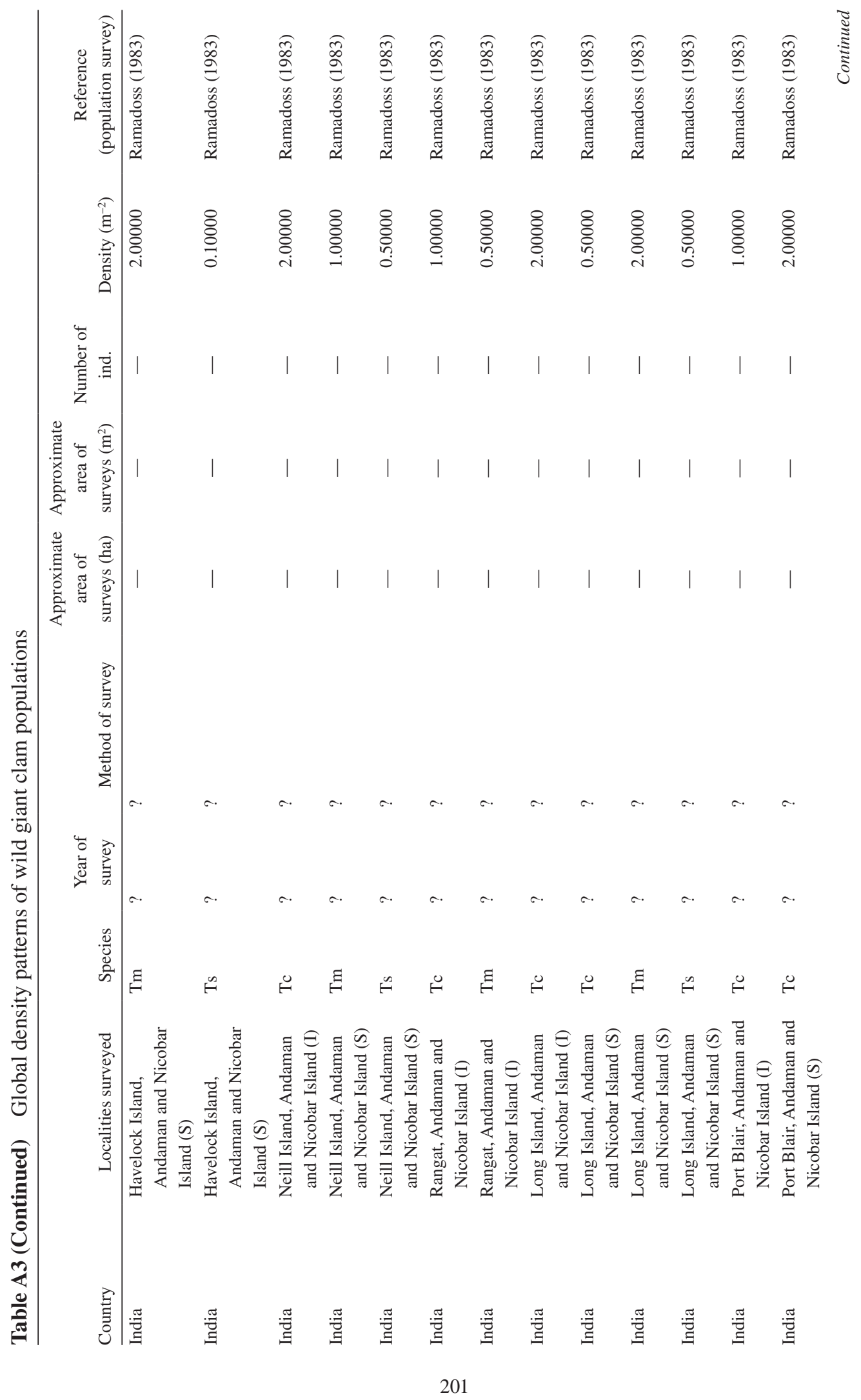


MEI LIN NEO ET AL.

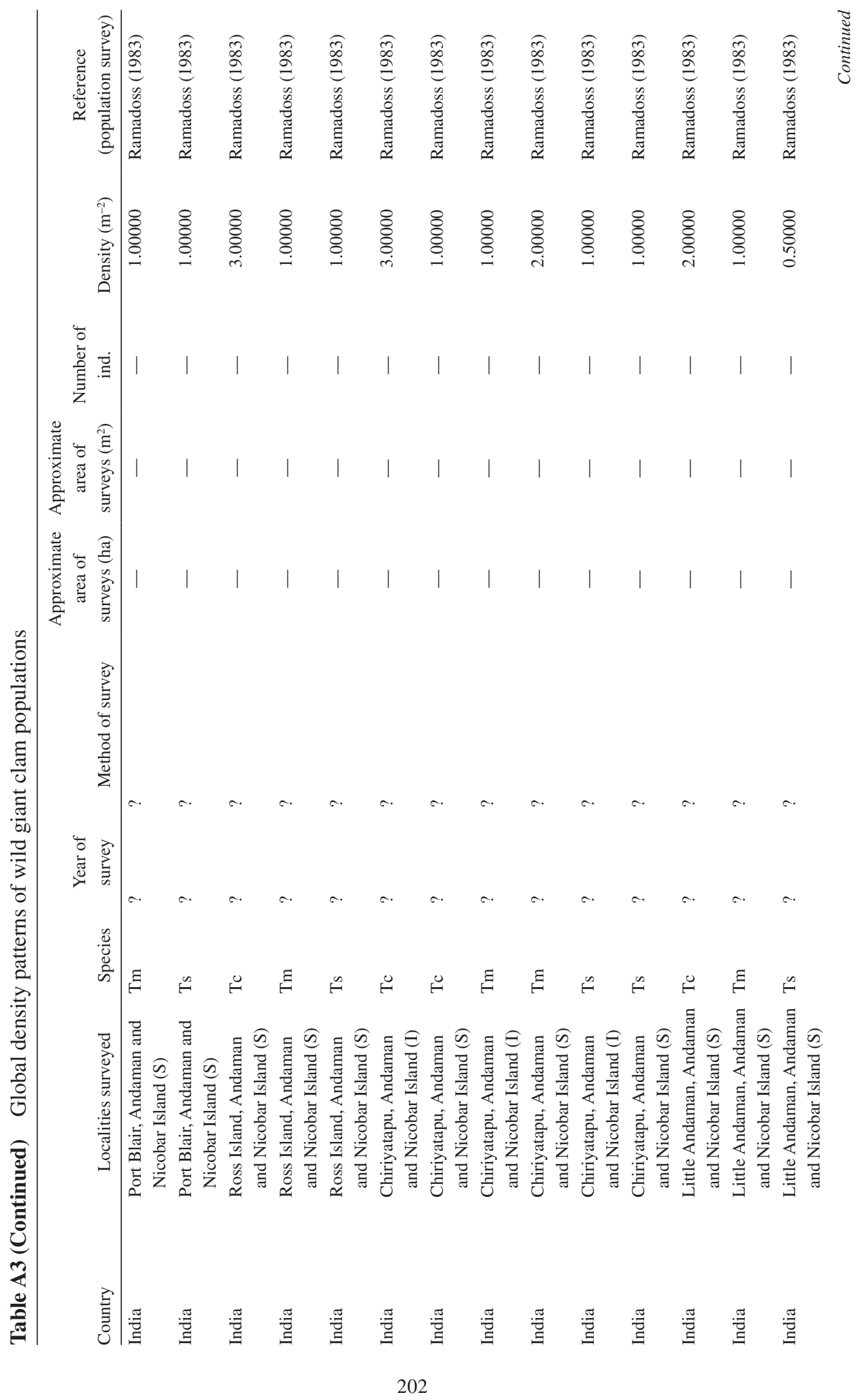


GIANT CLAMS (BIVALVIA: CARDIIDAE: TRIDACNINAE)

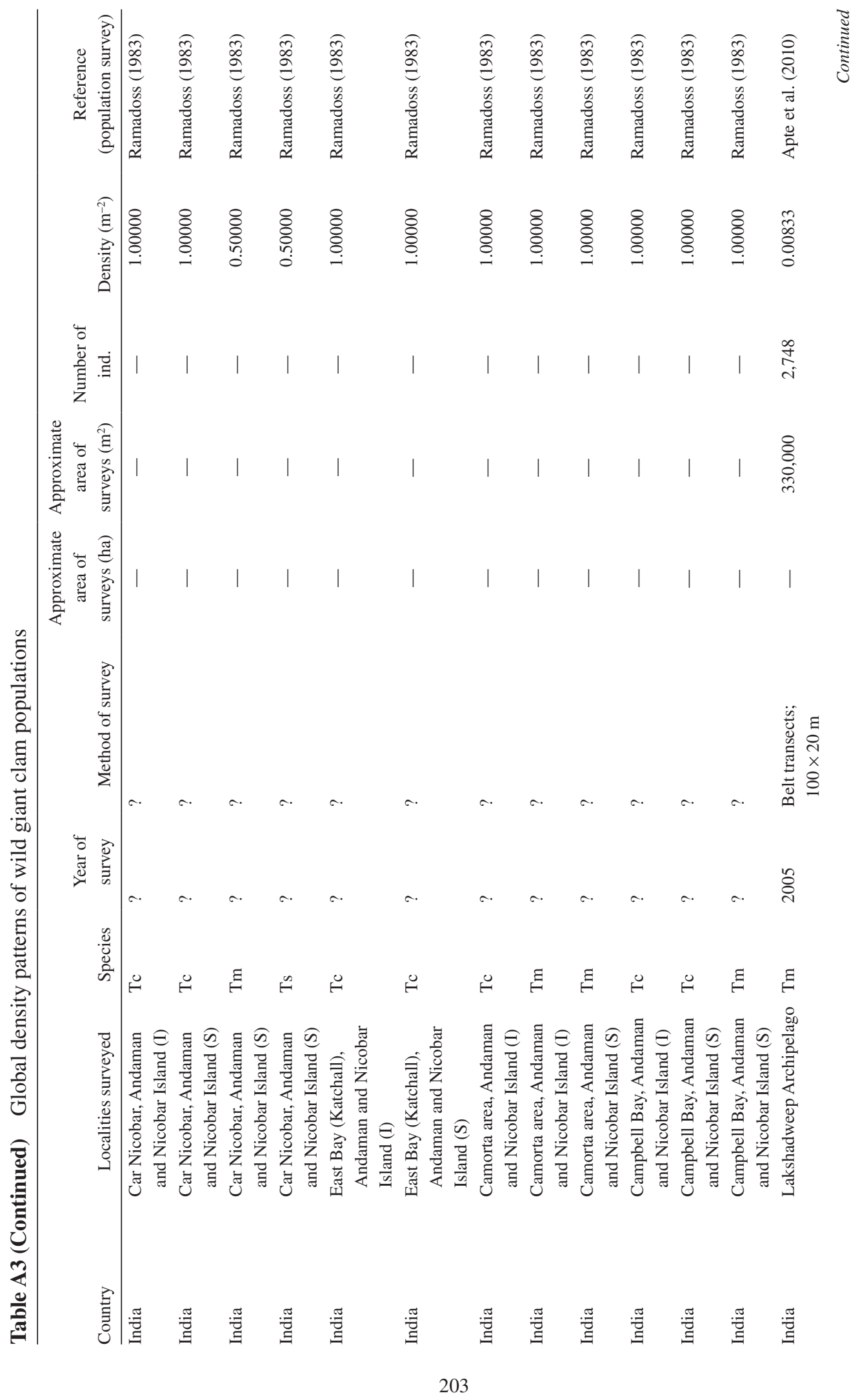


MEI LIN NEO ET AL.

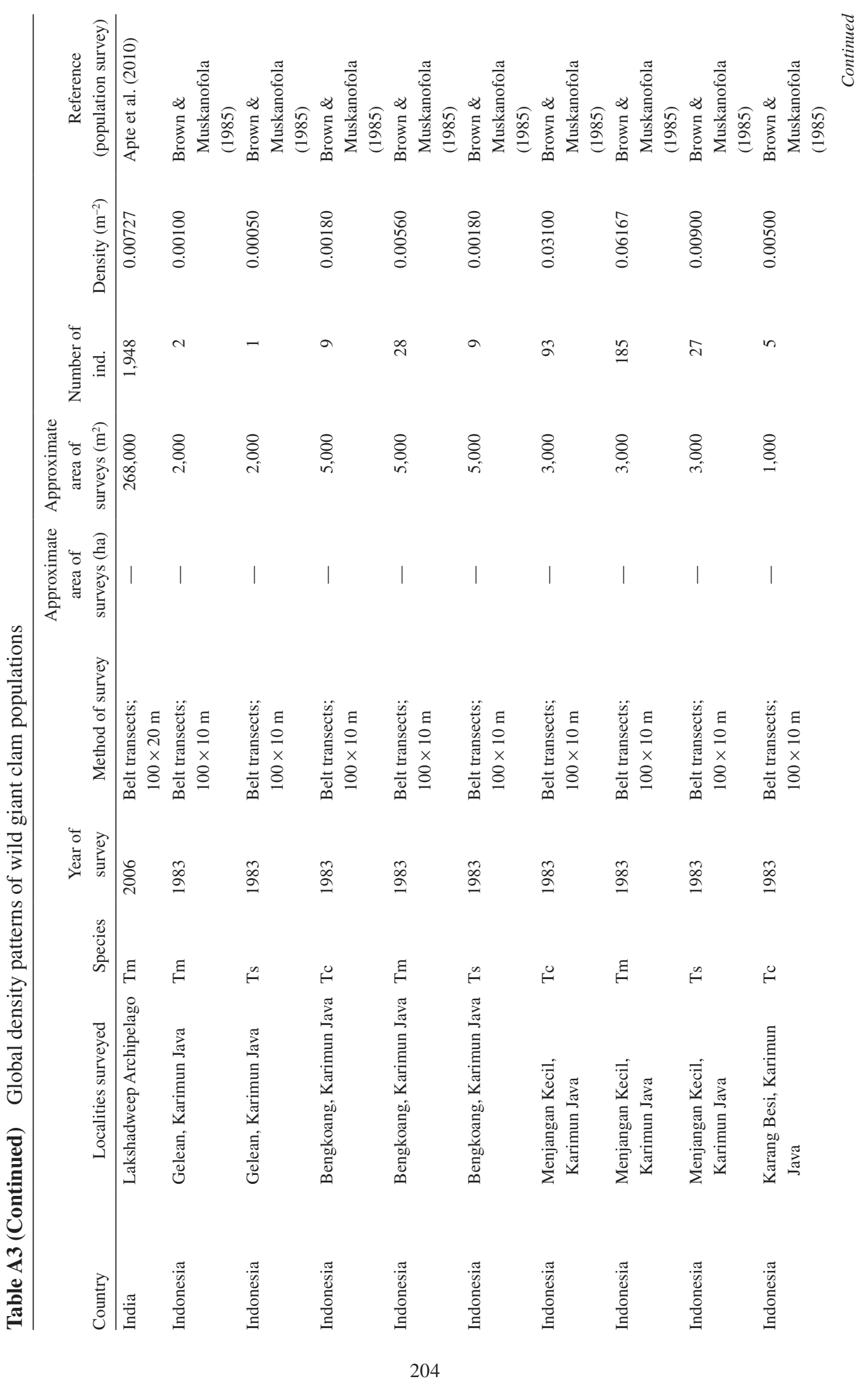


GIANT CLAMS (BIVALVIA: CARDIIDAE: TRIDACNINAE)

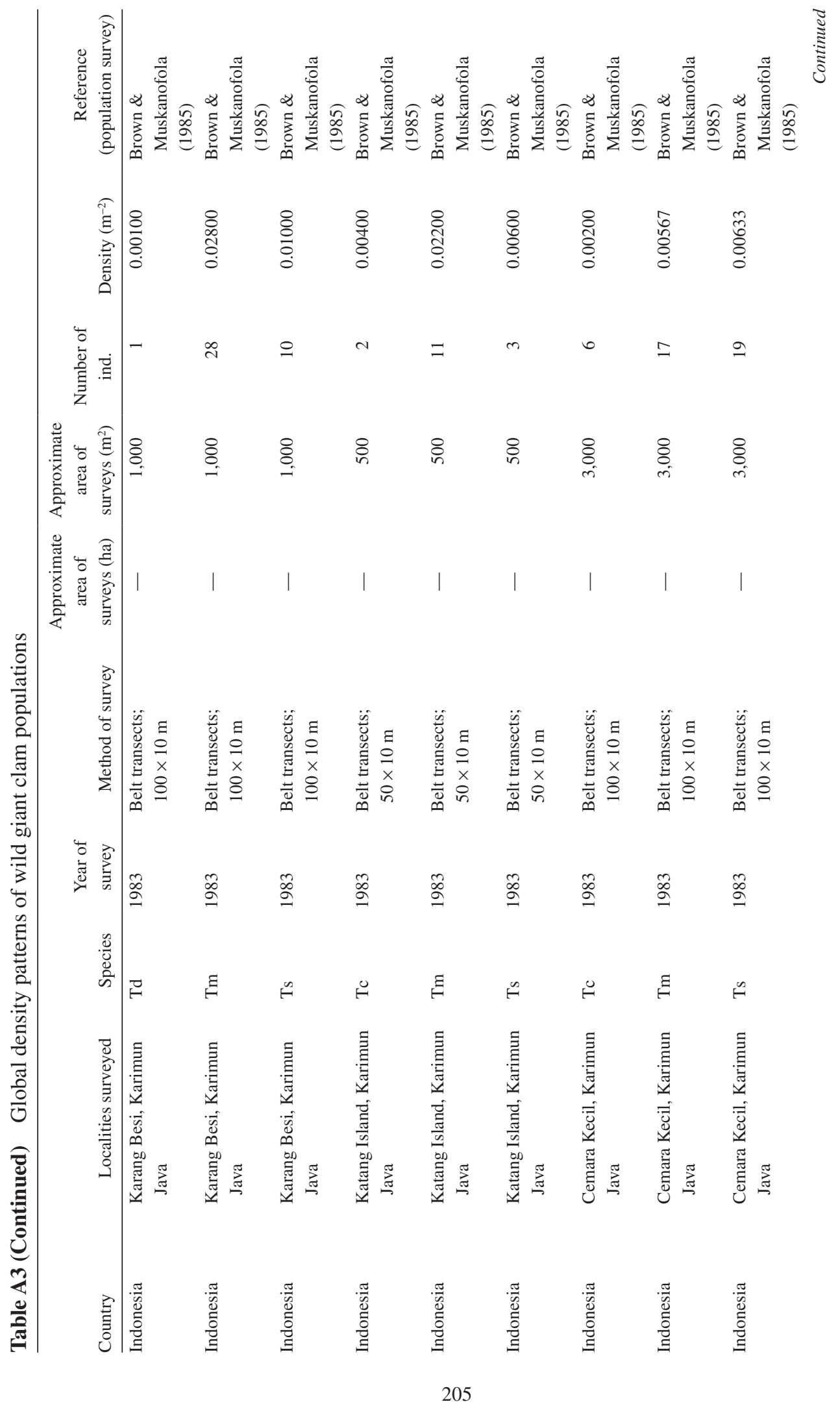


MEI LIN NEO ET AL.

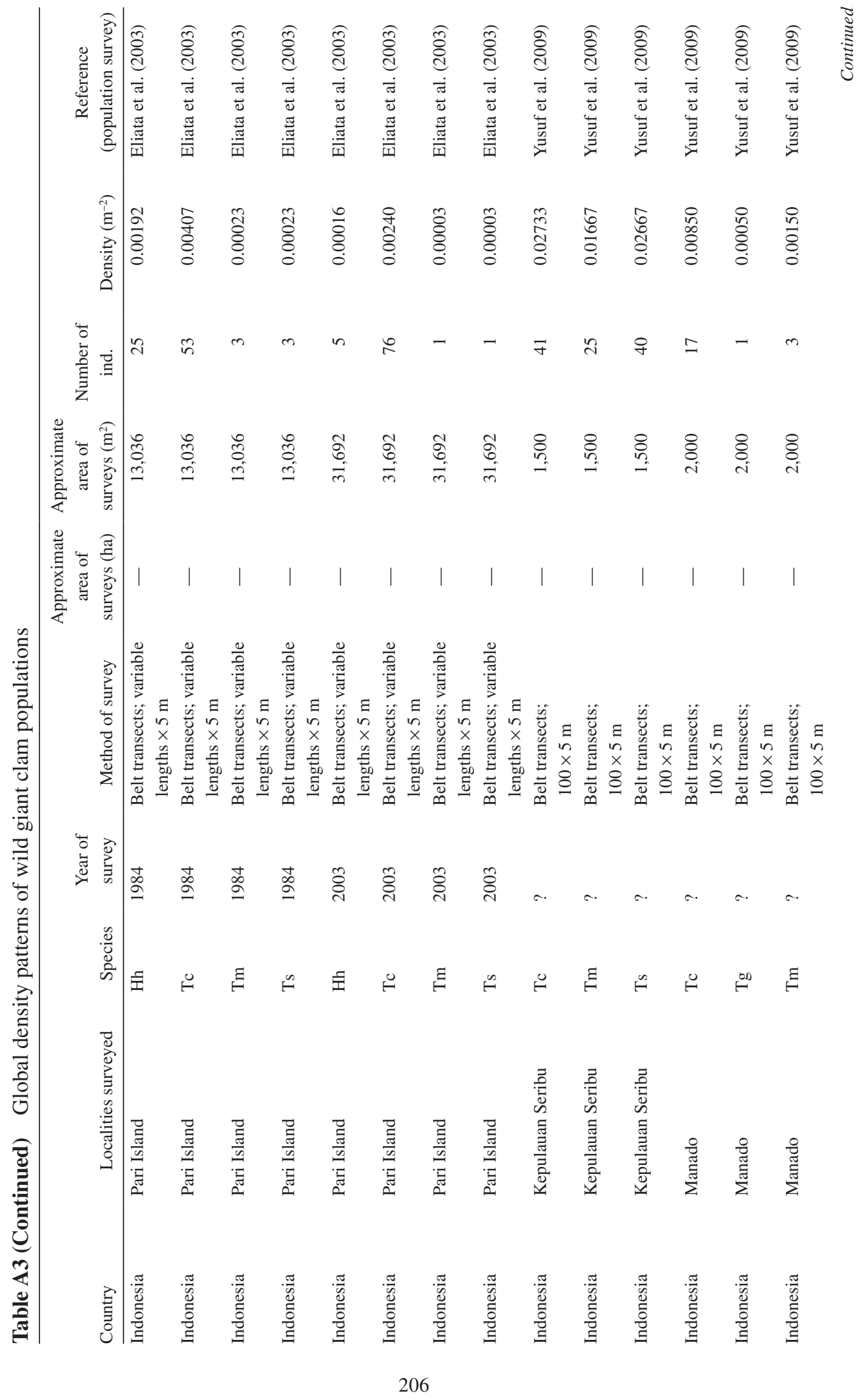


GIANT CLAMS (BIVALVIA: CARDIIDAE: TRIDACNINAE)

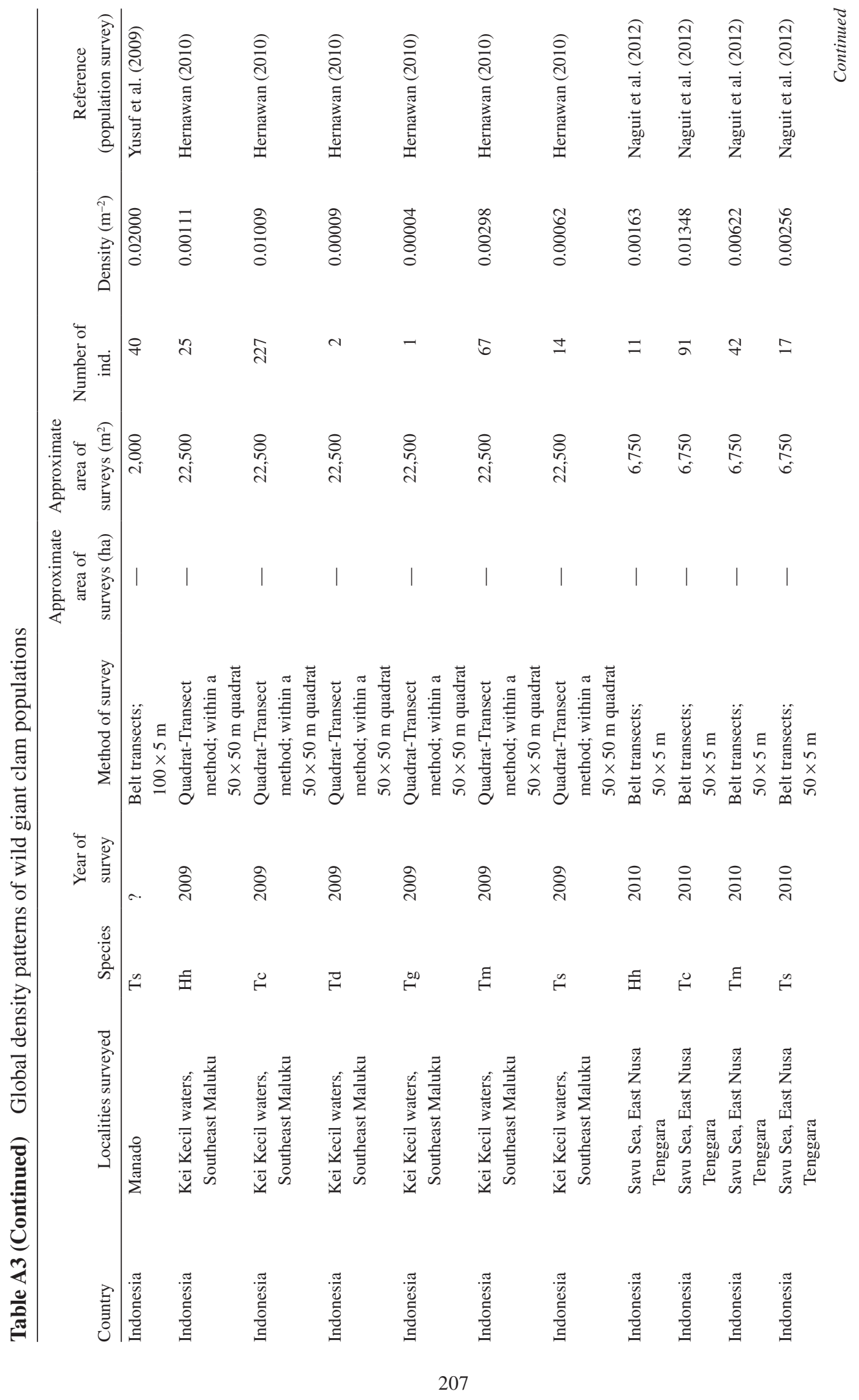


MEI LIN NEO ET AL.

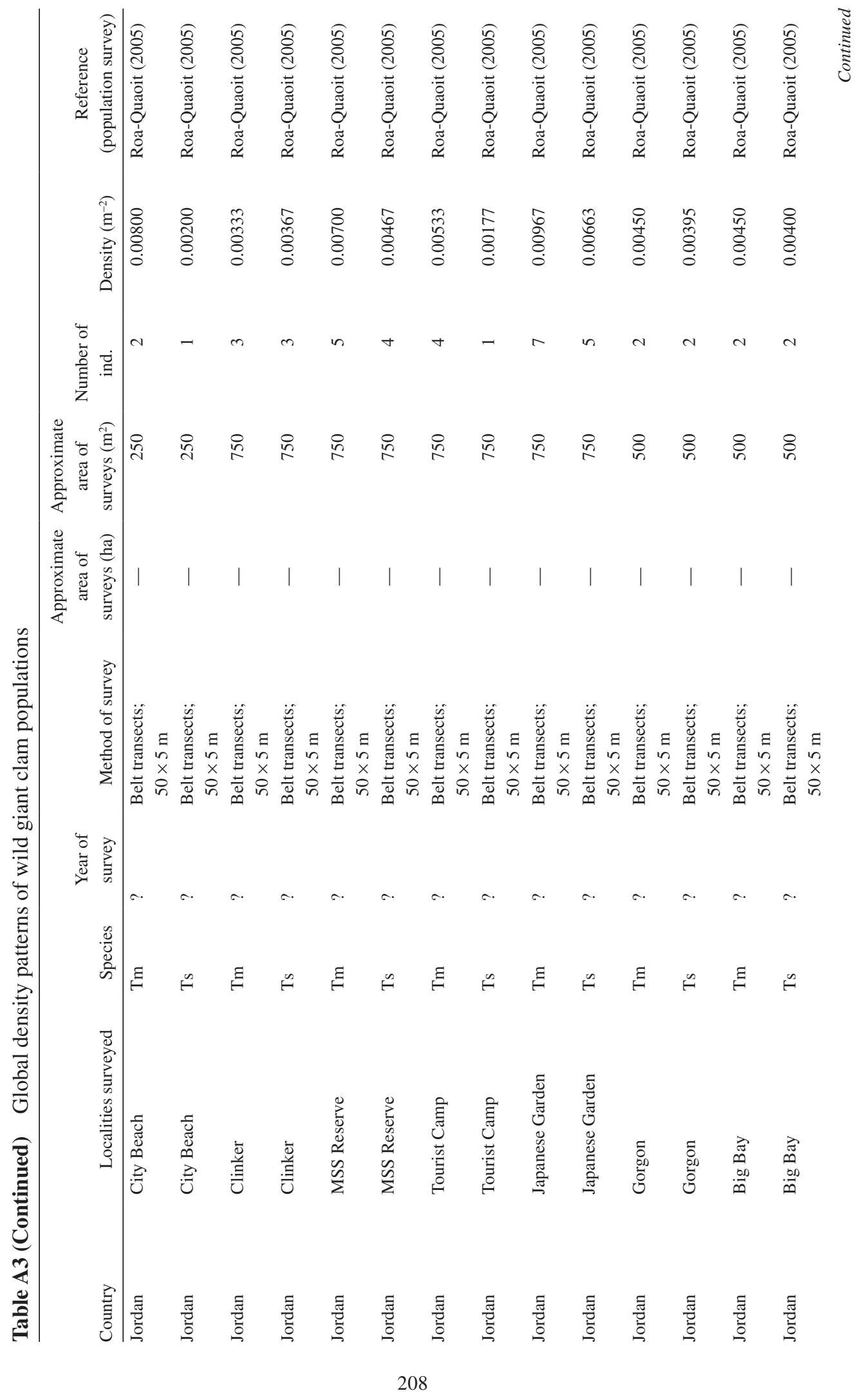


GIANT CLAMS (BIVALVIA: CARDIIDAE: TRIDACNINAE)

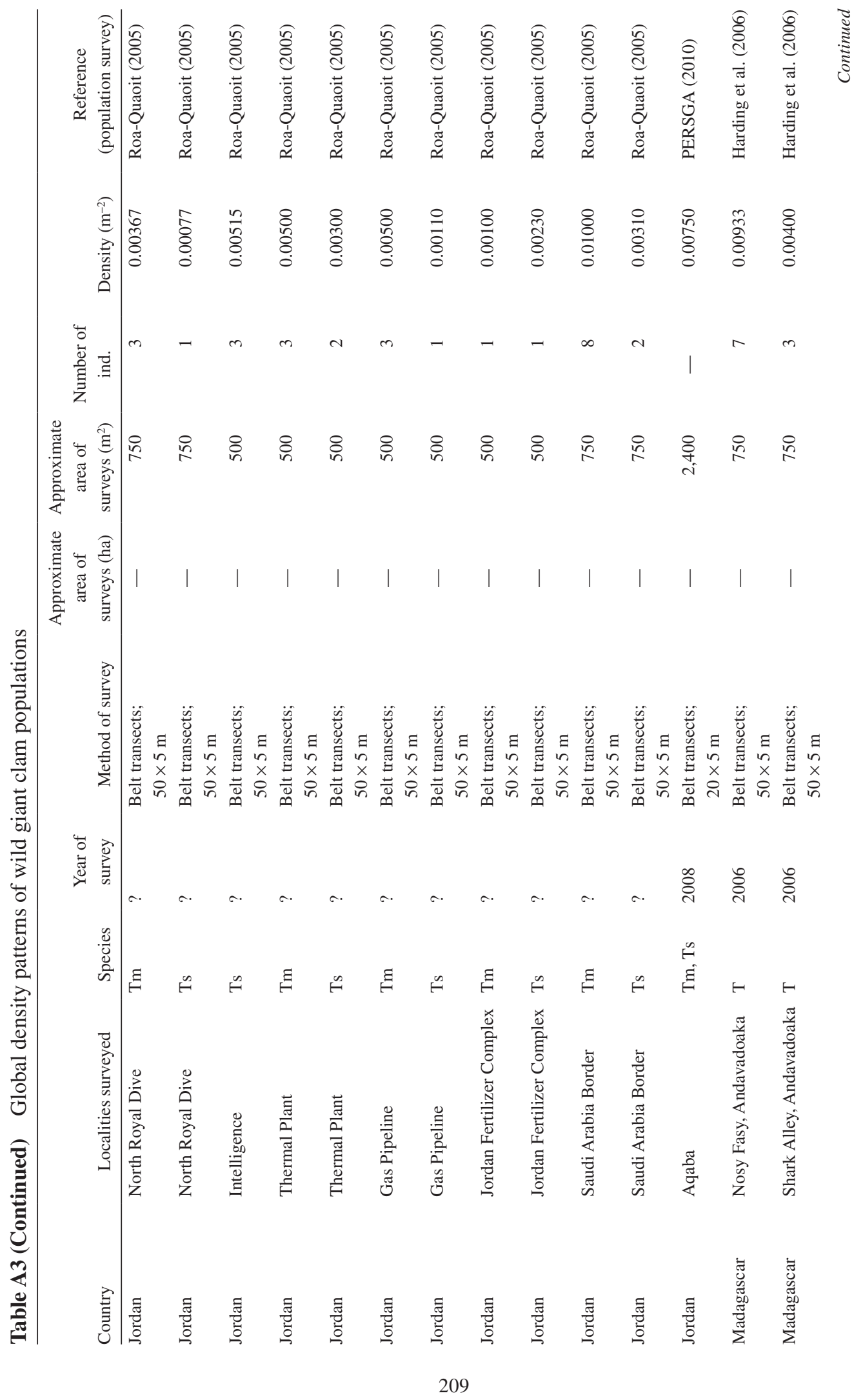




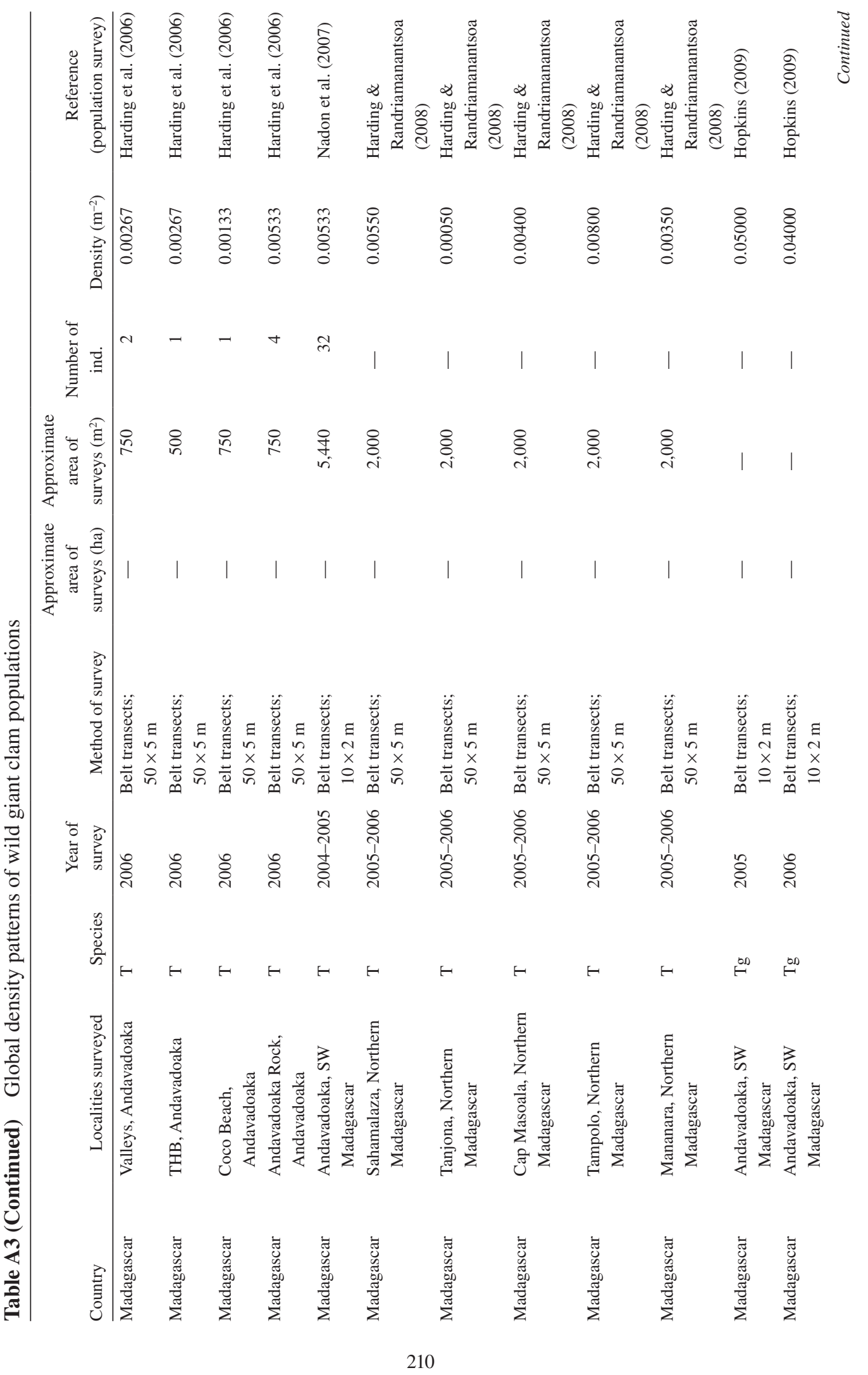




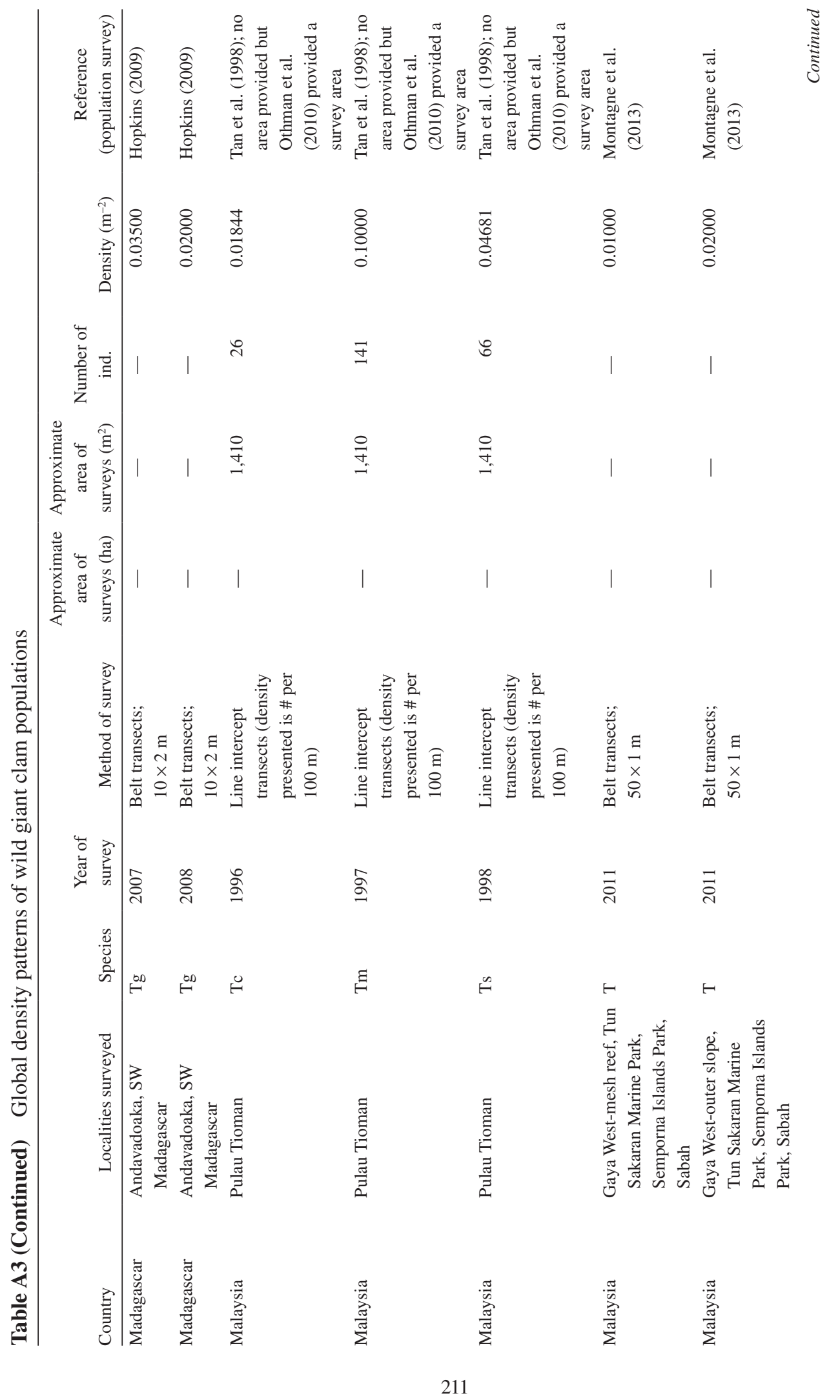


MEI LIN NEO ET AL.

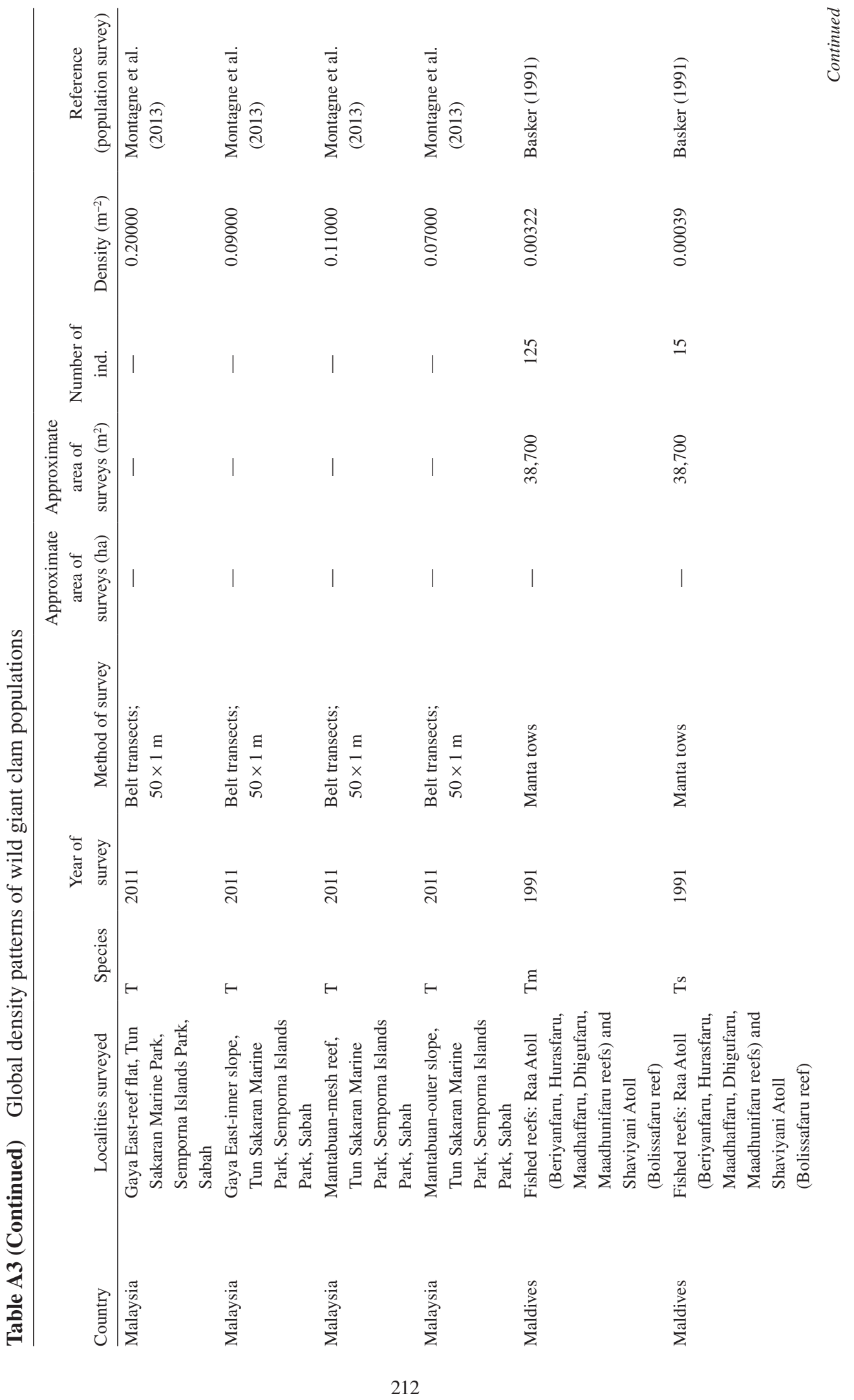


GIANT CLAMS (BIVALVIA: CARDIIDAE: TRIDACNINAE)

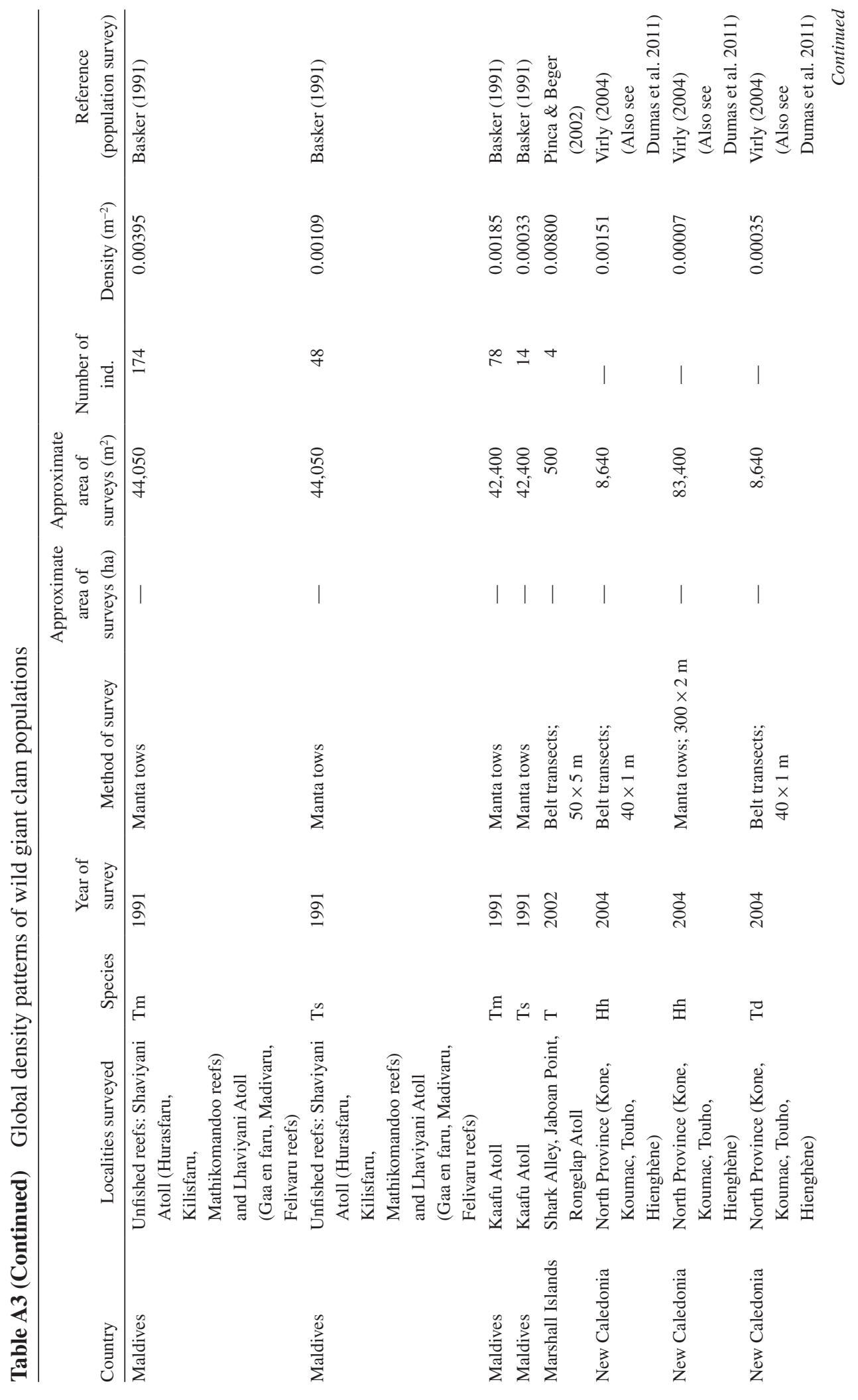




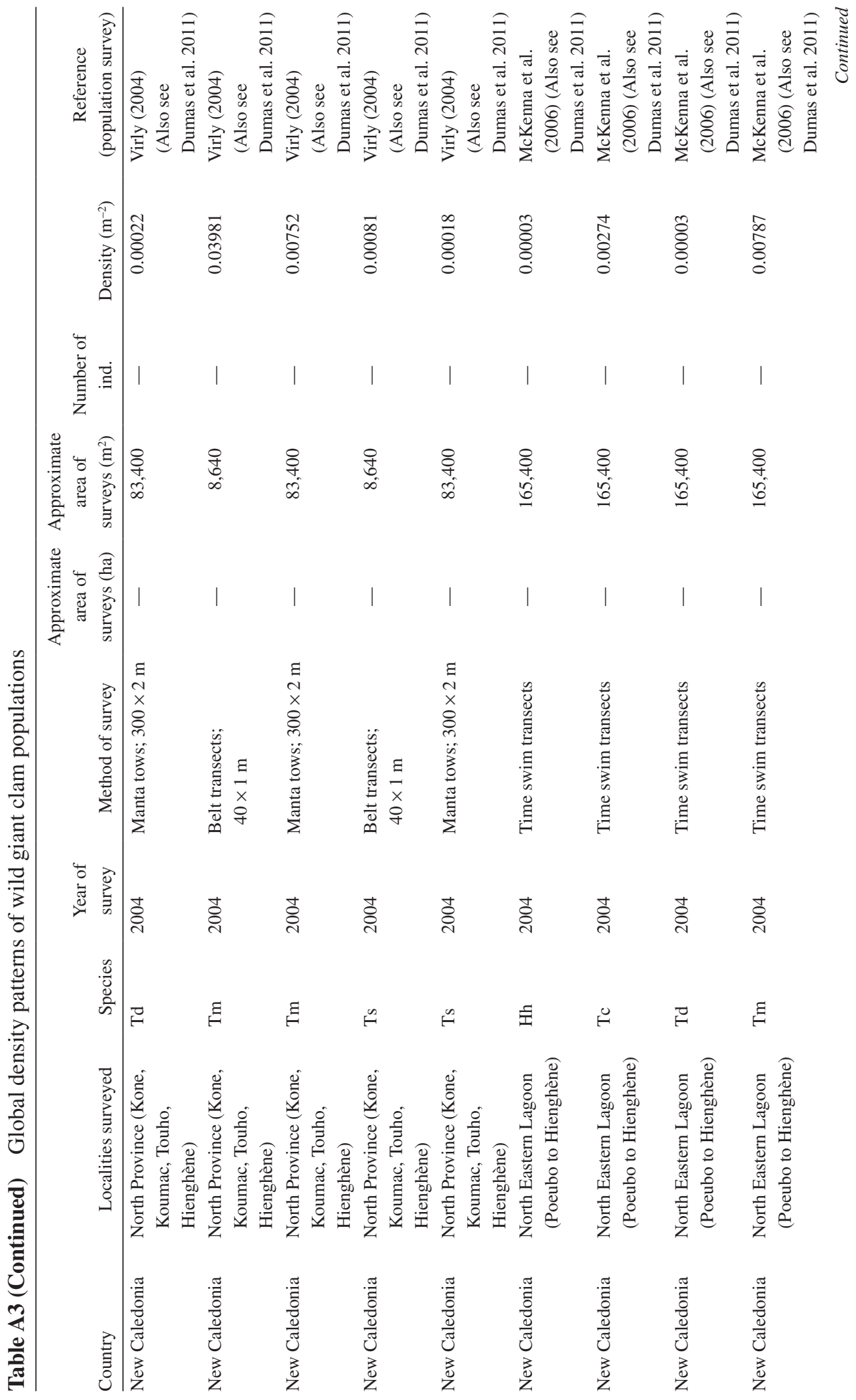




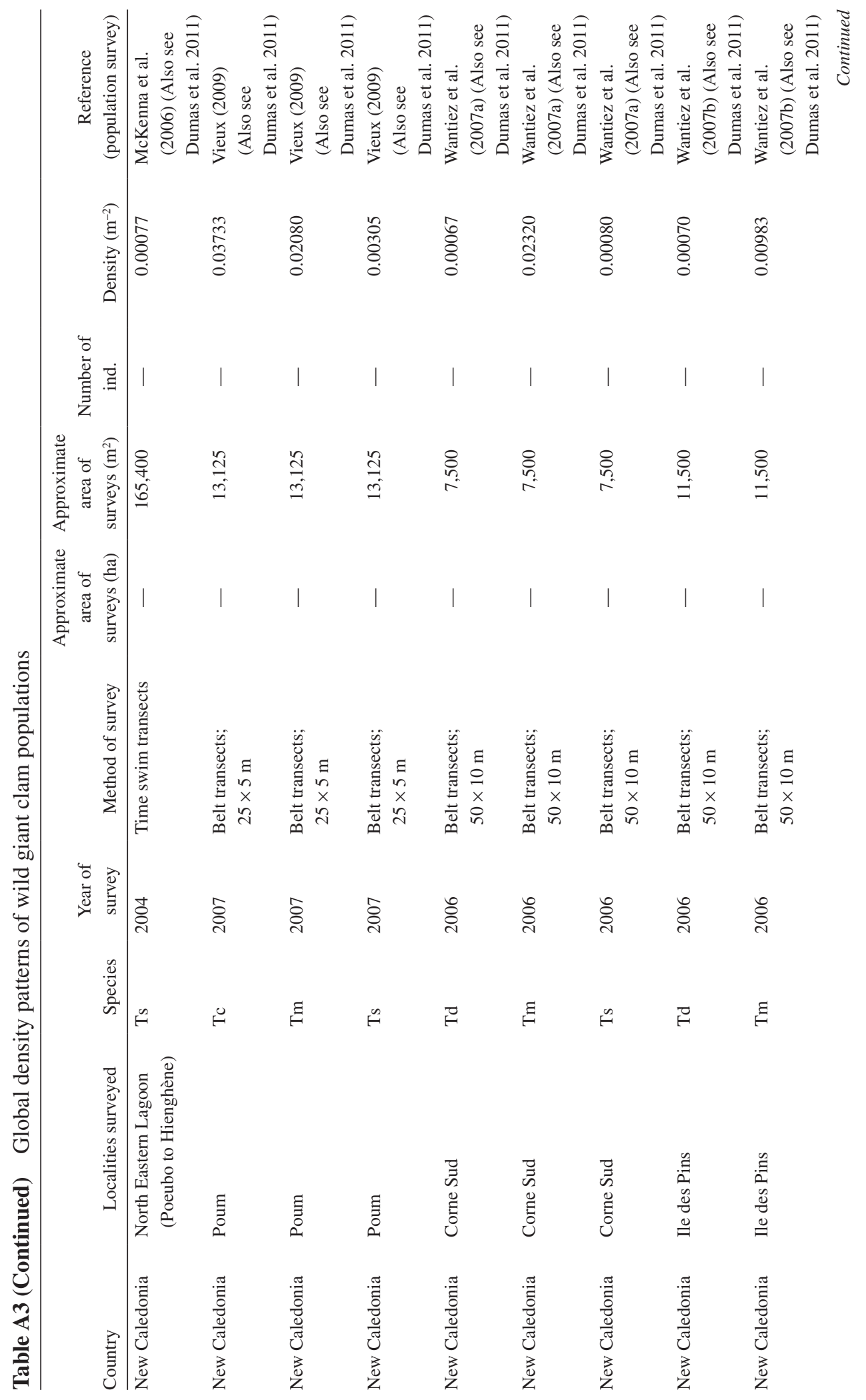




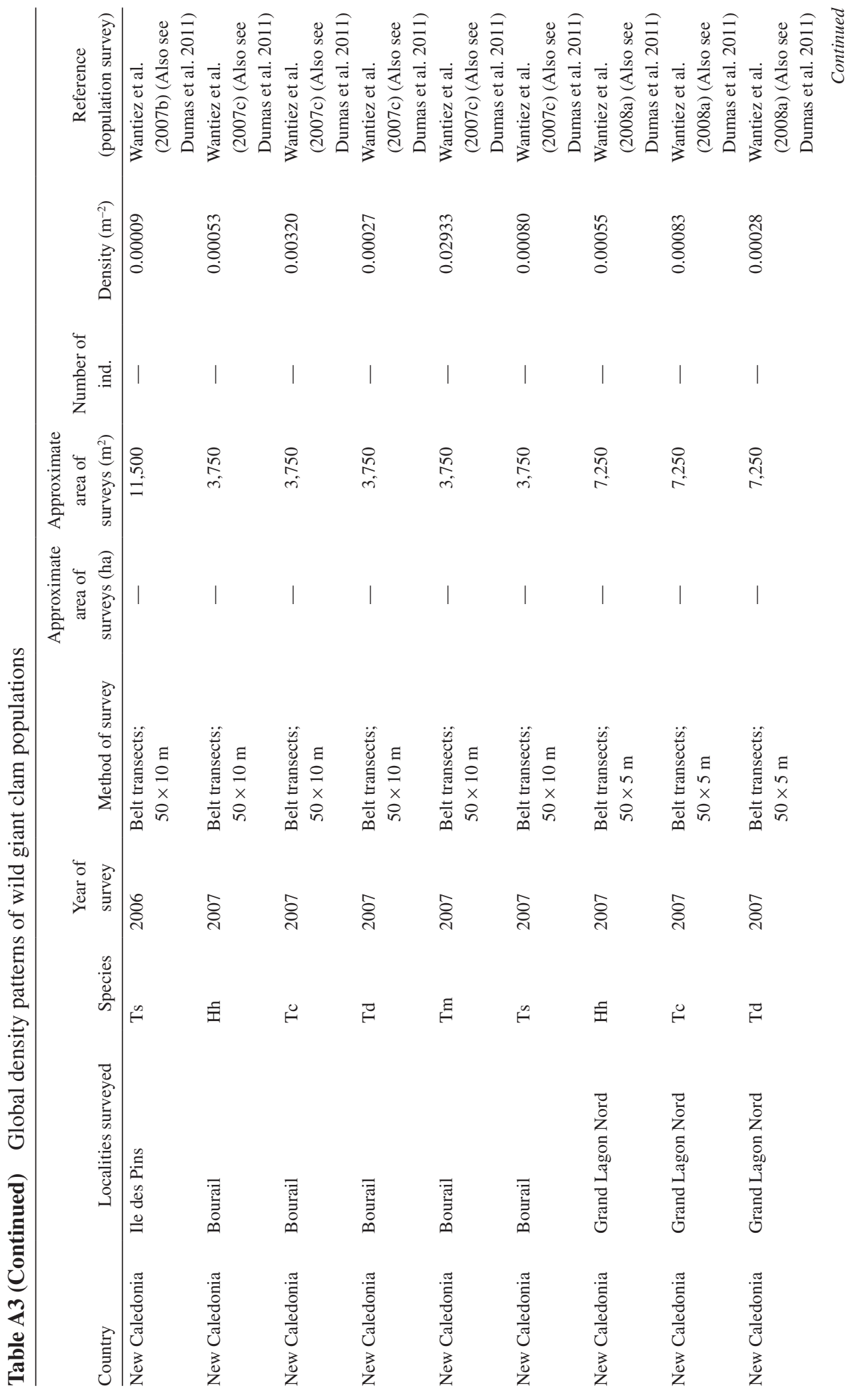




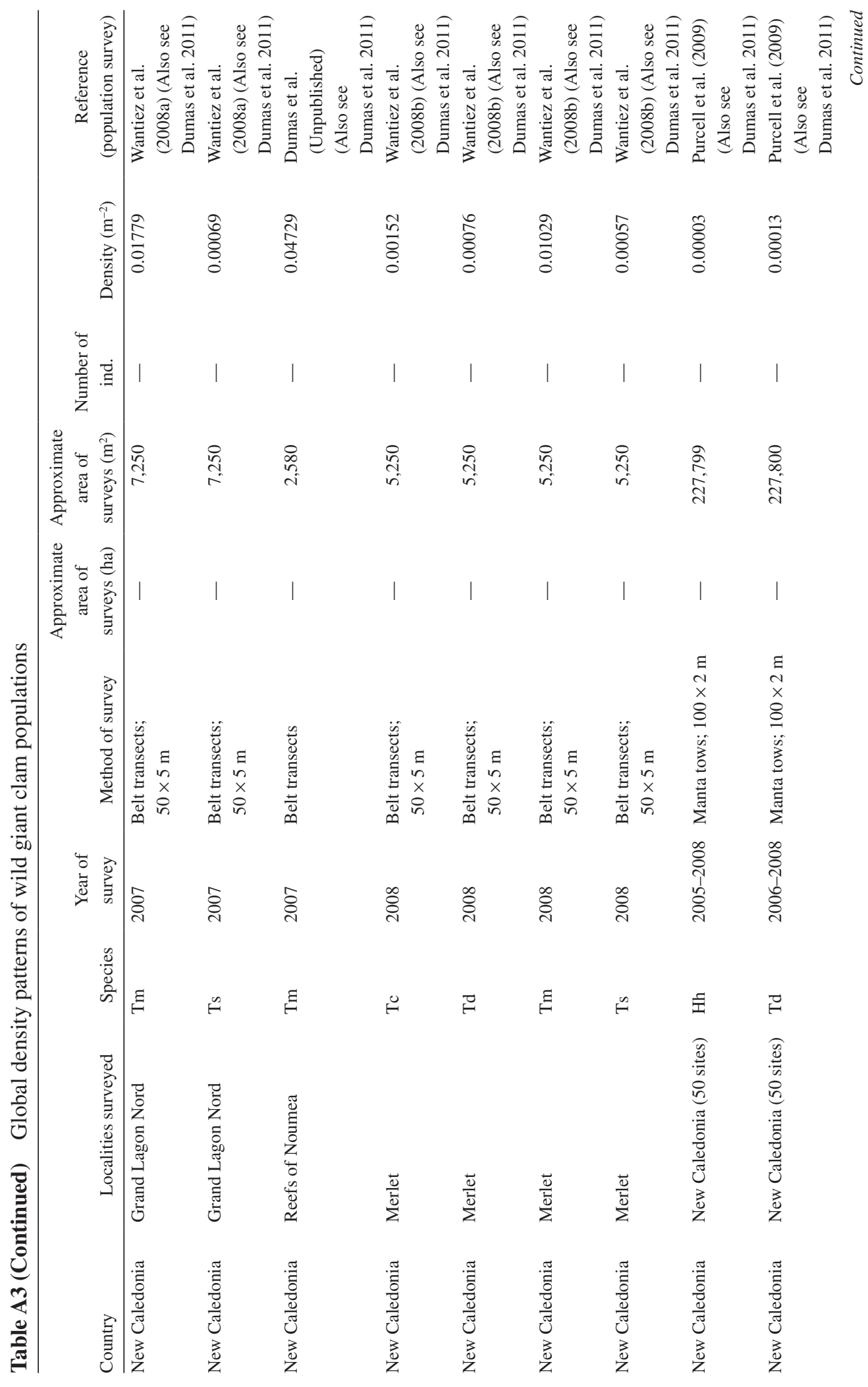




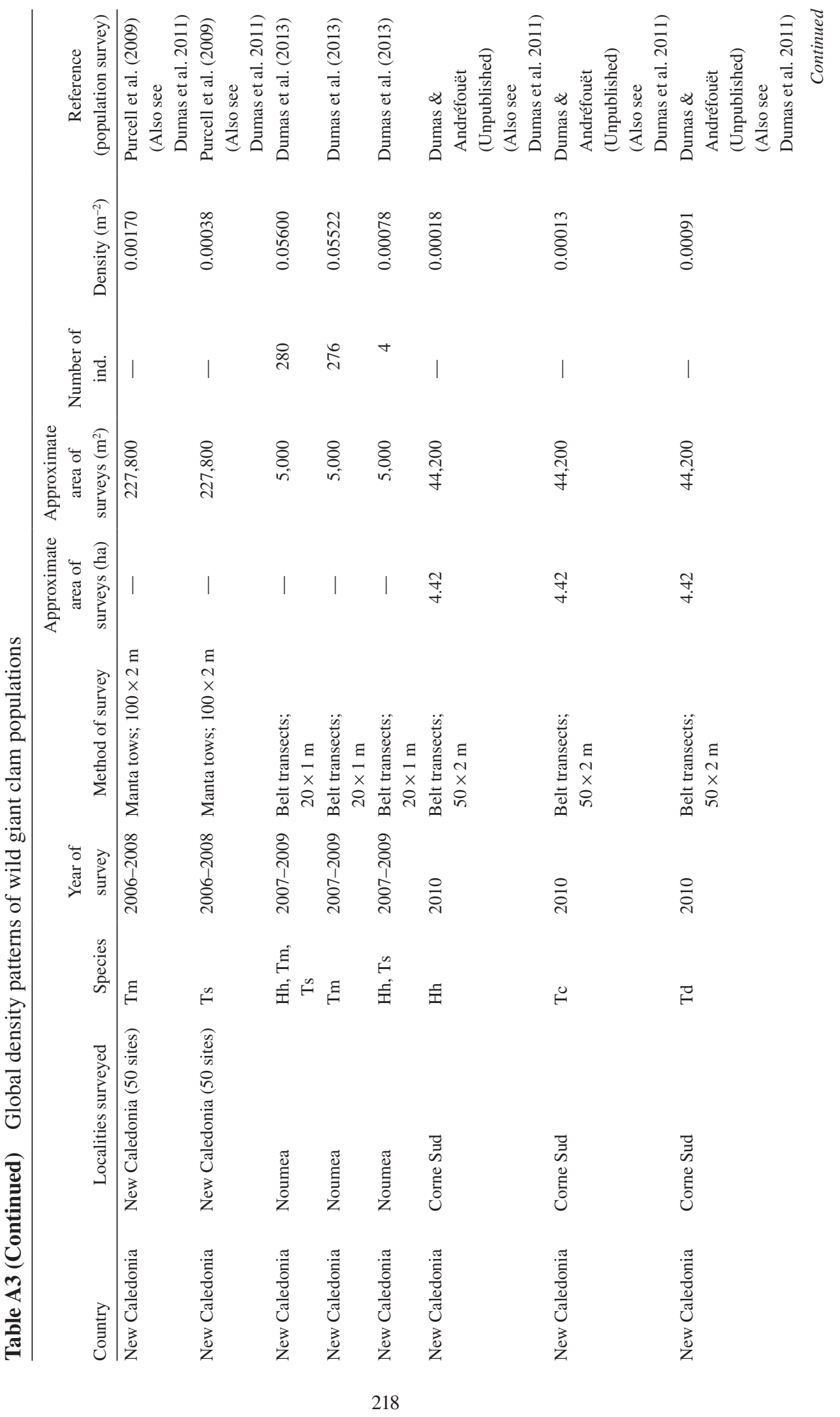


GIANT CLAMS (BIVALVIA: CARDIIDAE: TRIDACNINAE)

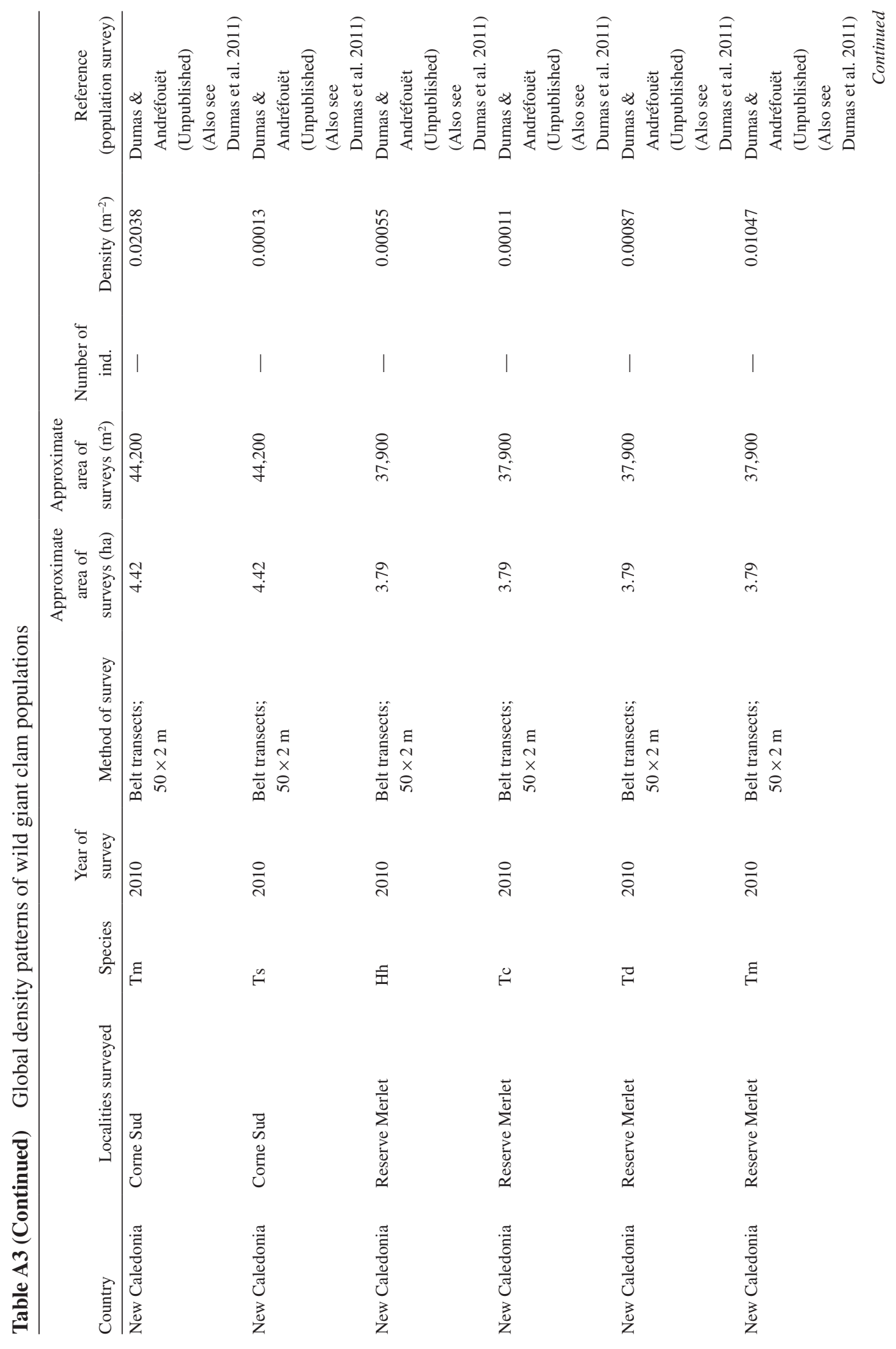


MEI LIN NEO ET AL.

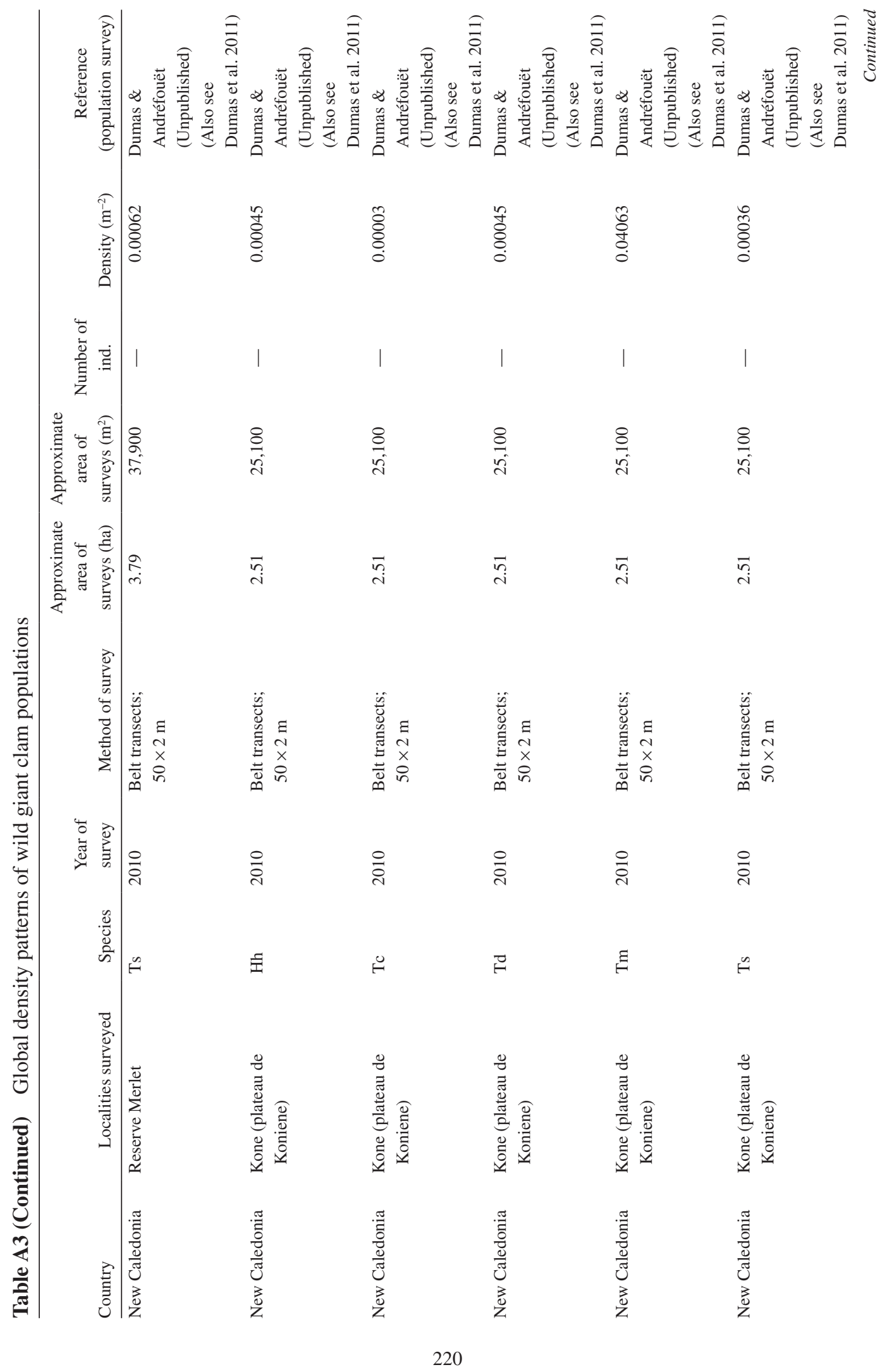


GIANT CLAMS (BIVALVIA: CARDIIDAE: TRIDACNINAE)

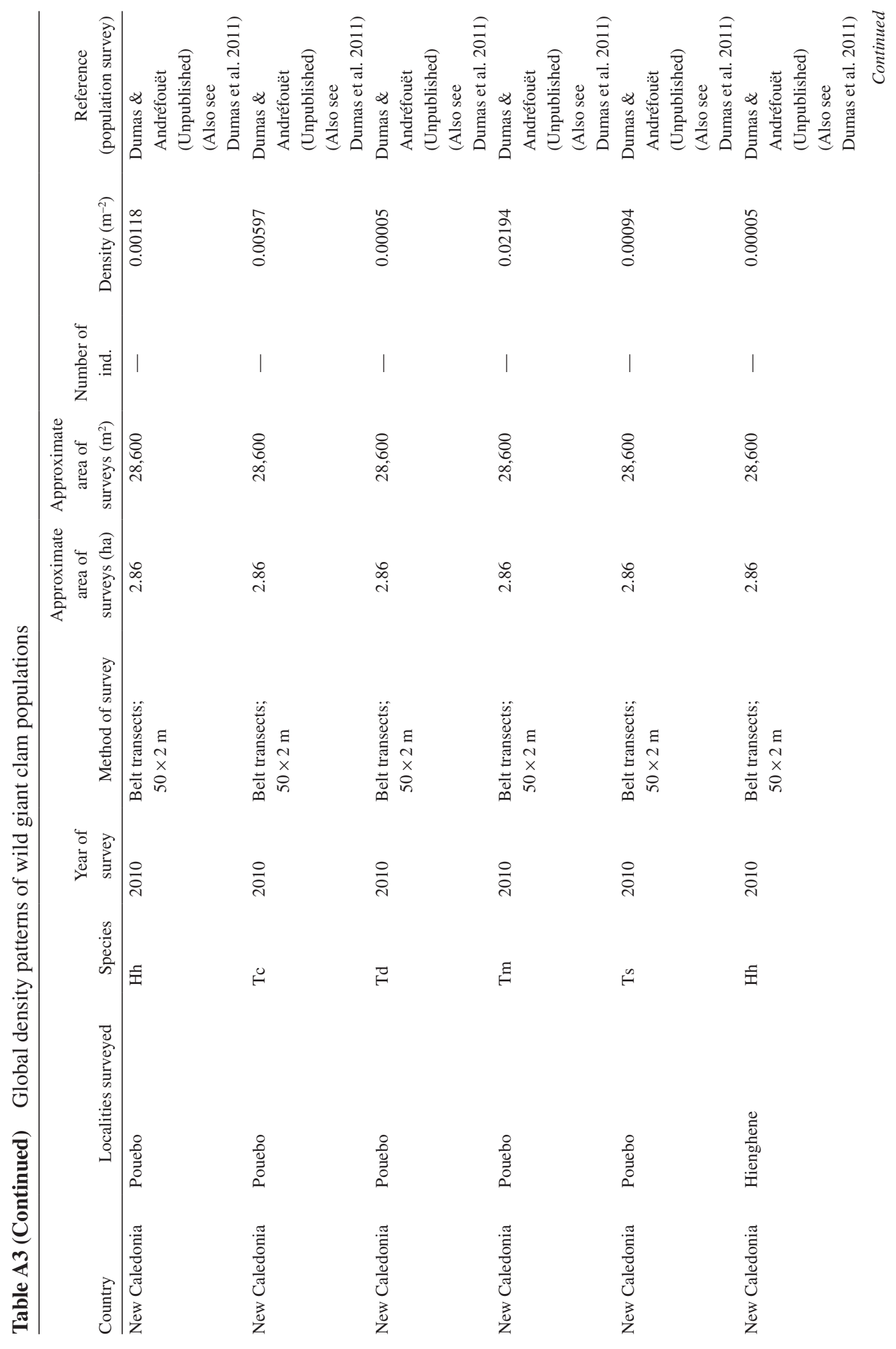


MEI LIN NEO ET AL.

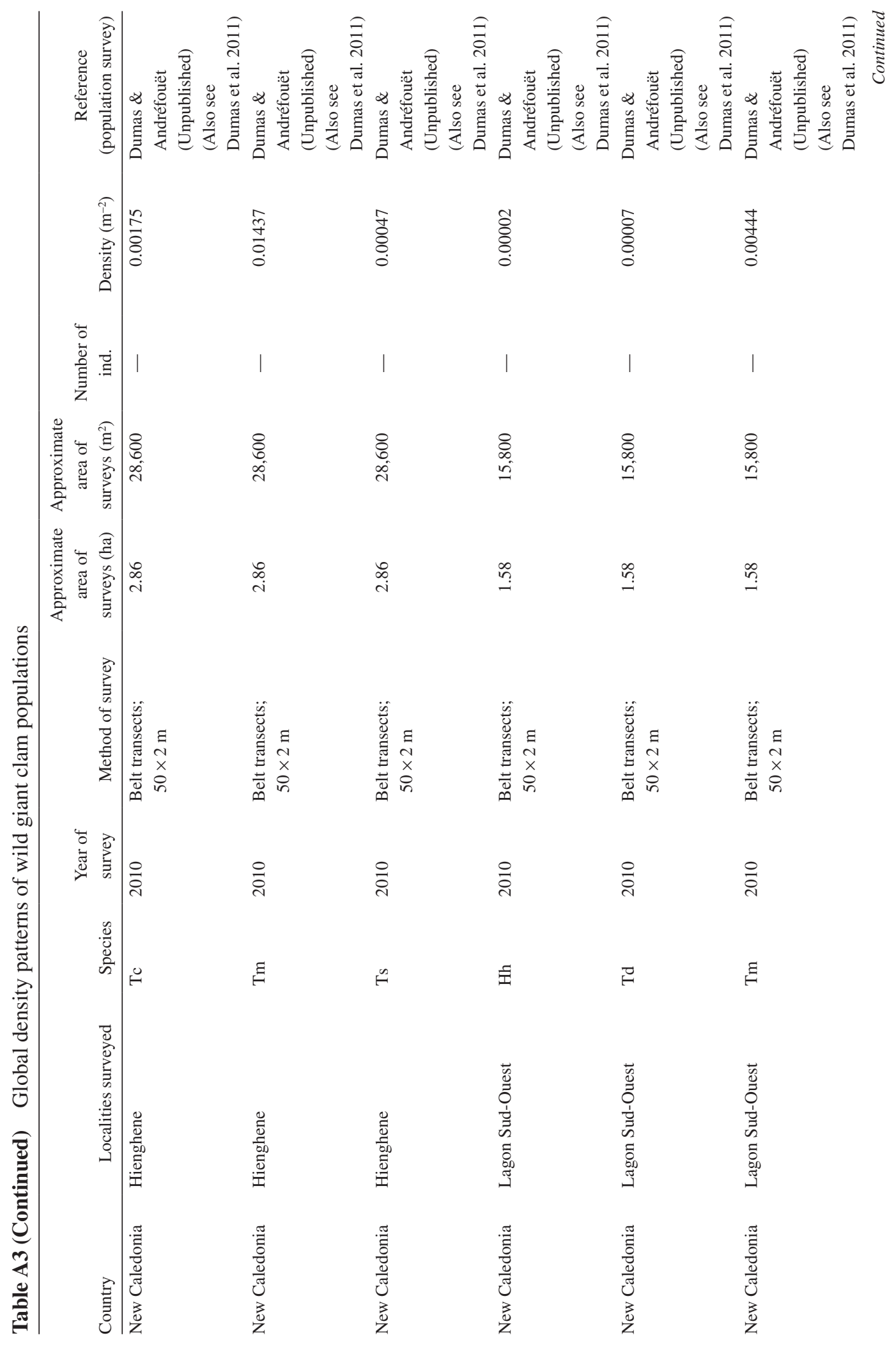


GIANT CLAMS (BIVALVIA: CARDIIDAE: TRIDACNINAE)

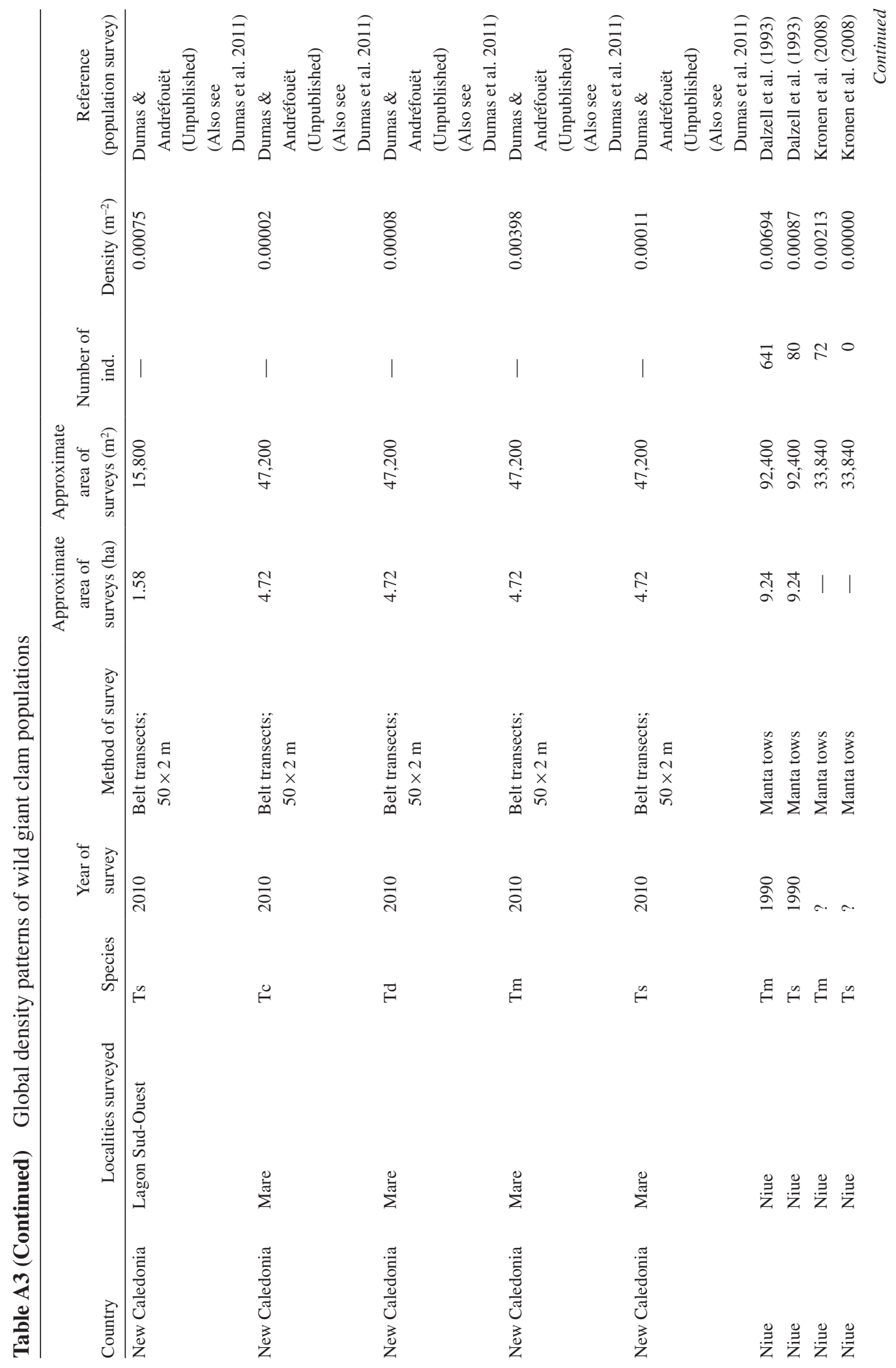


MEI LIN NEO ET AL.

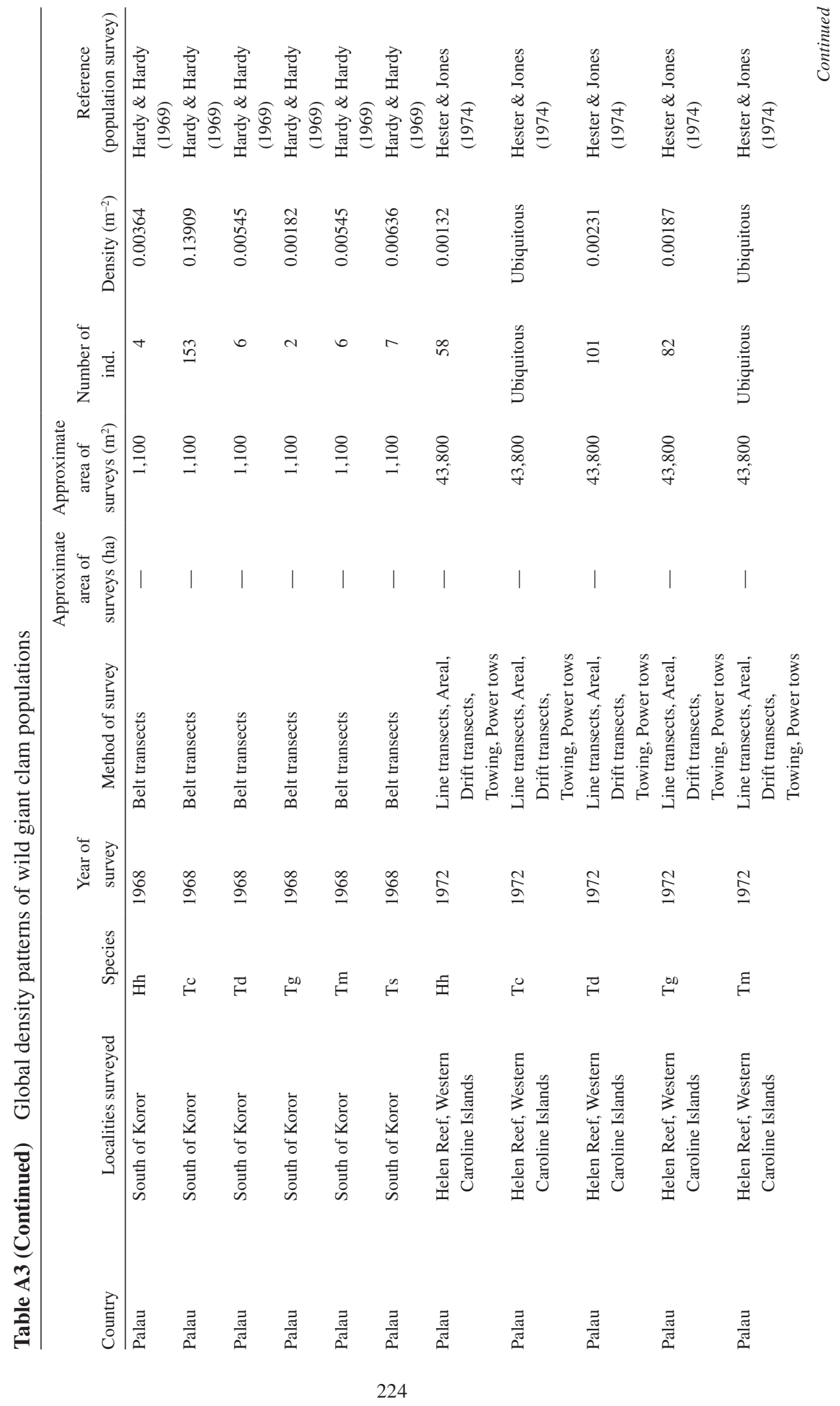


GIANT CLAMS (BIVALVIA: CARDIIDAE: TRIDACNINAE)

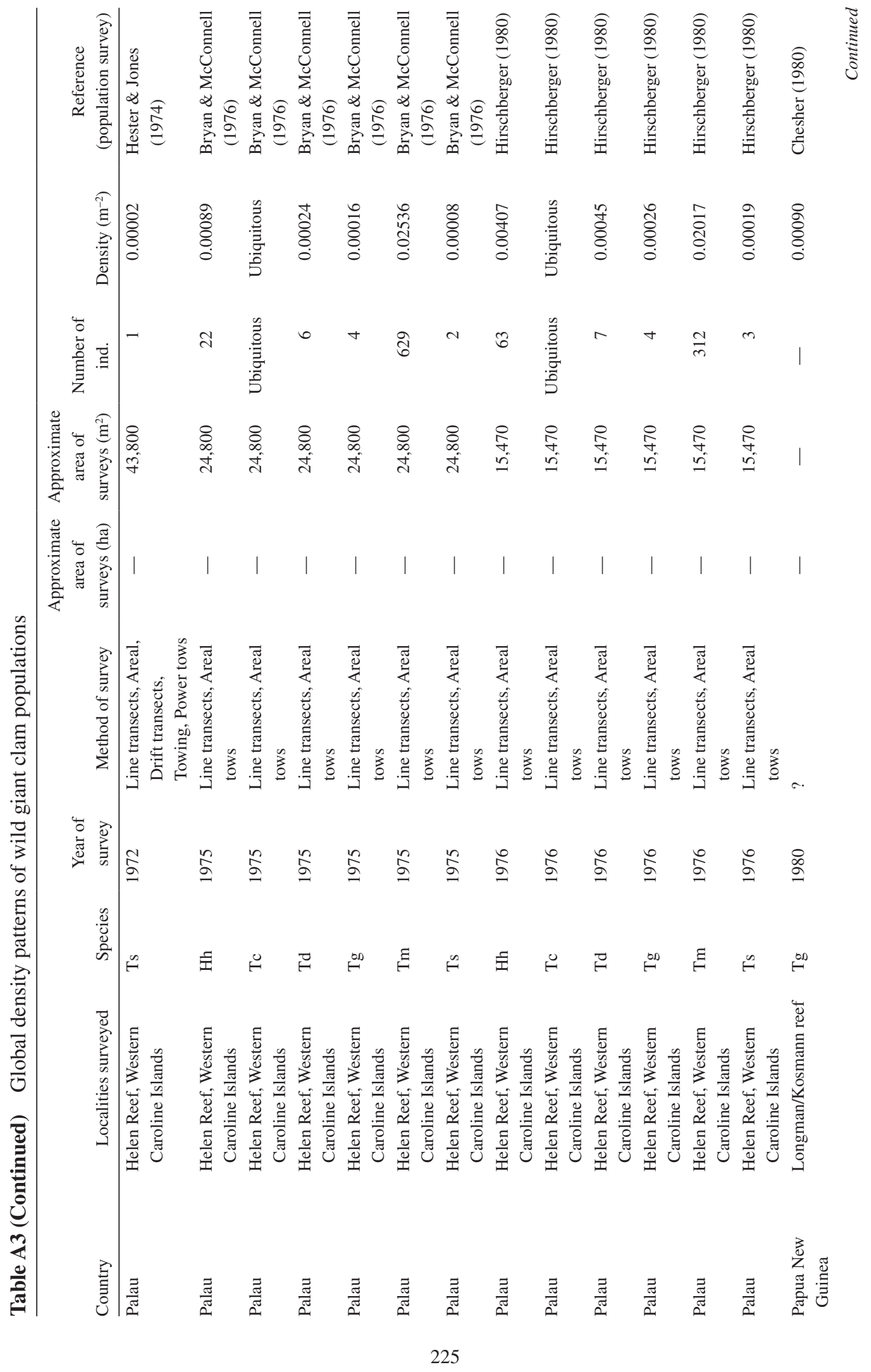


MEI LIN NEO ET AL.

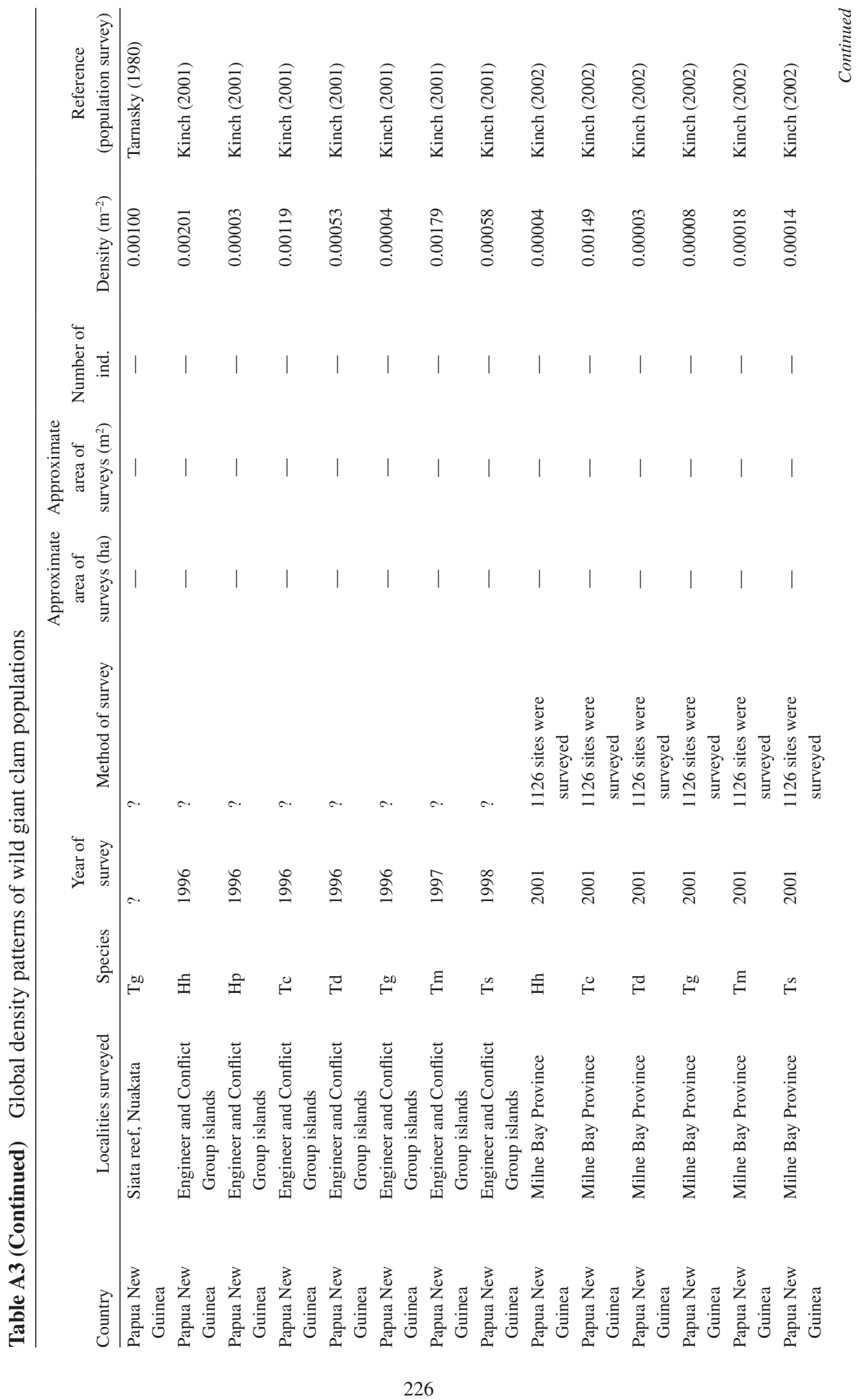


GIANT CLAMS (BIVALVIA: CARDIIDAE: TRIDACNINAE)

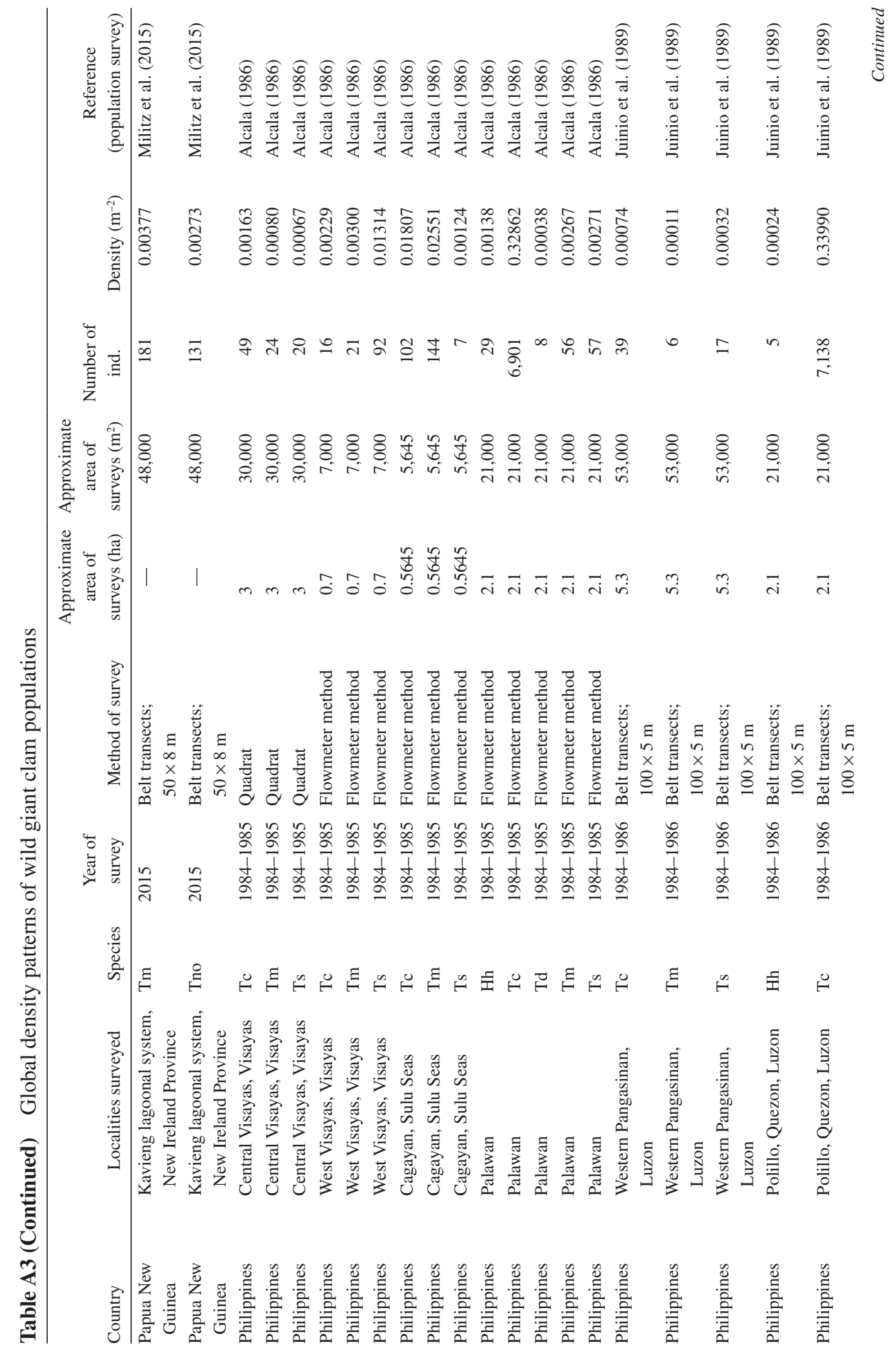




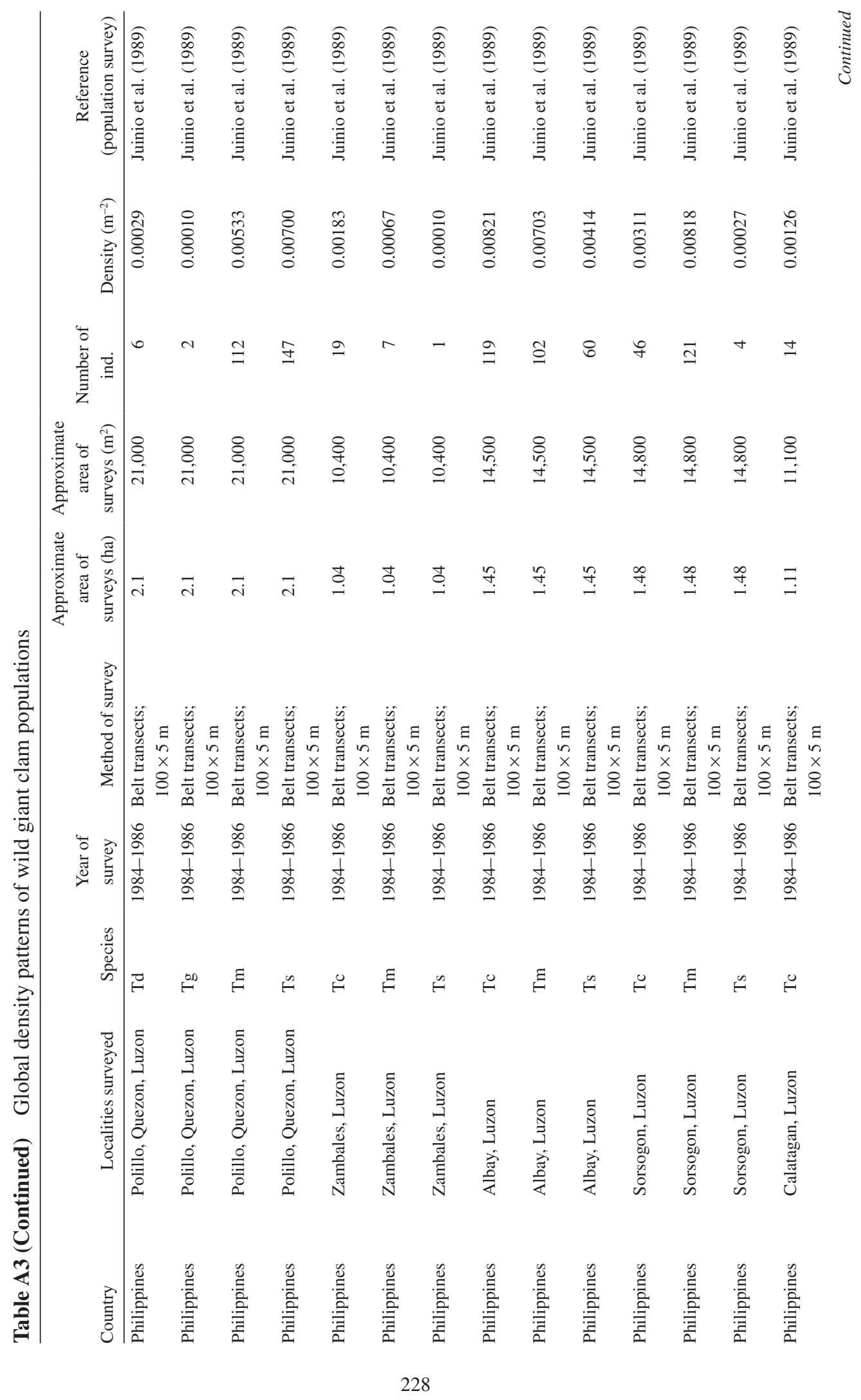




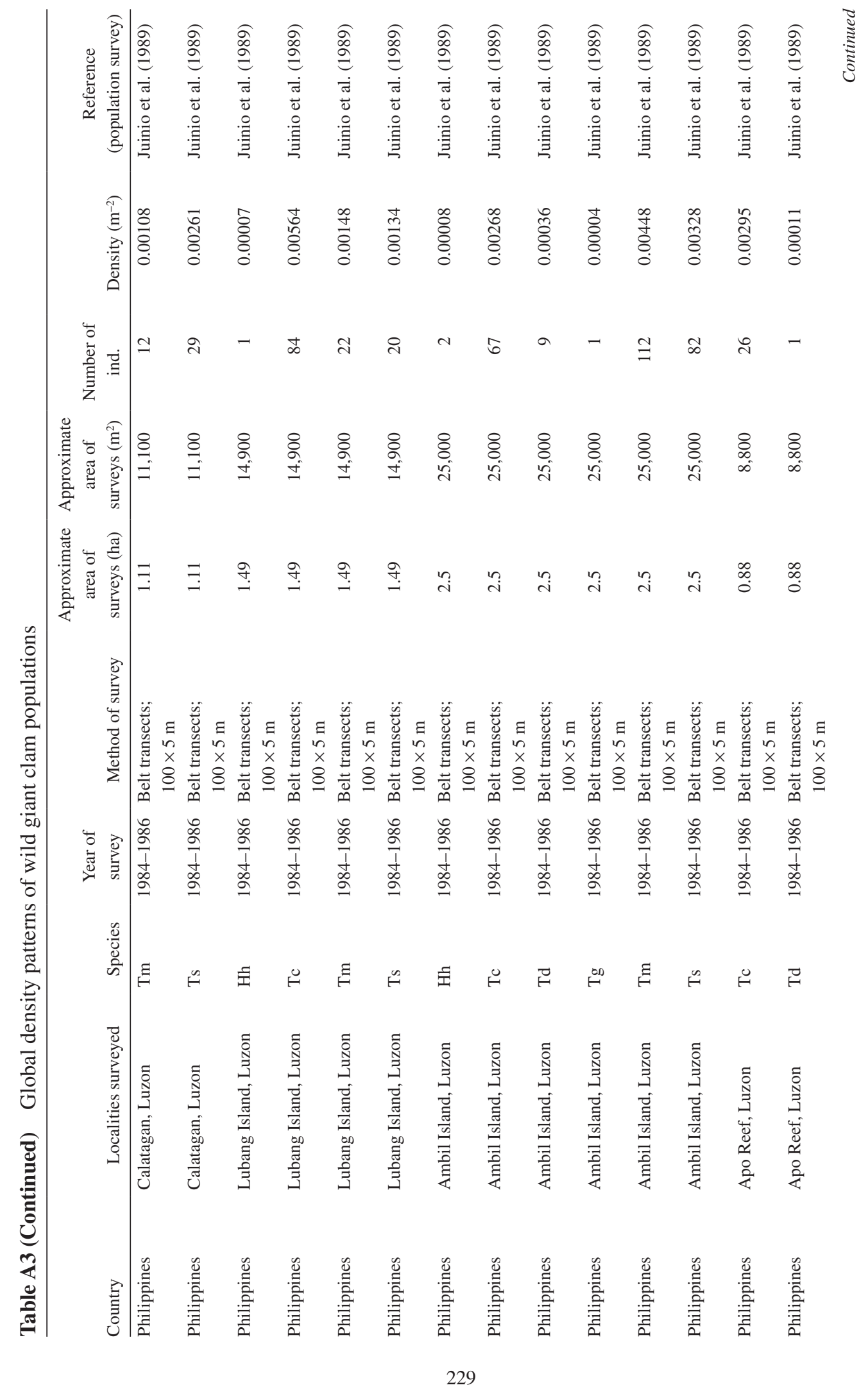




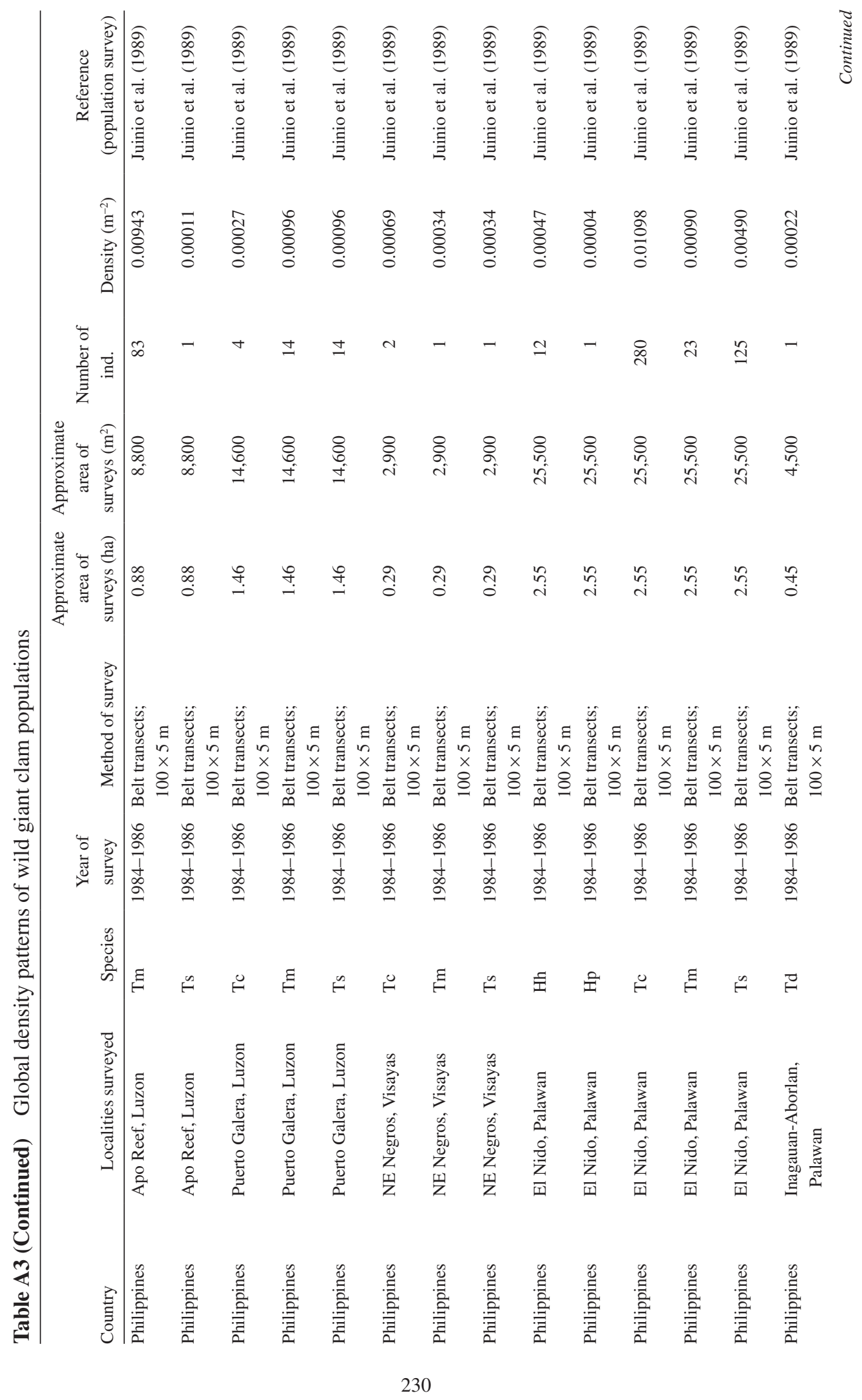




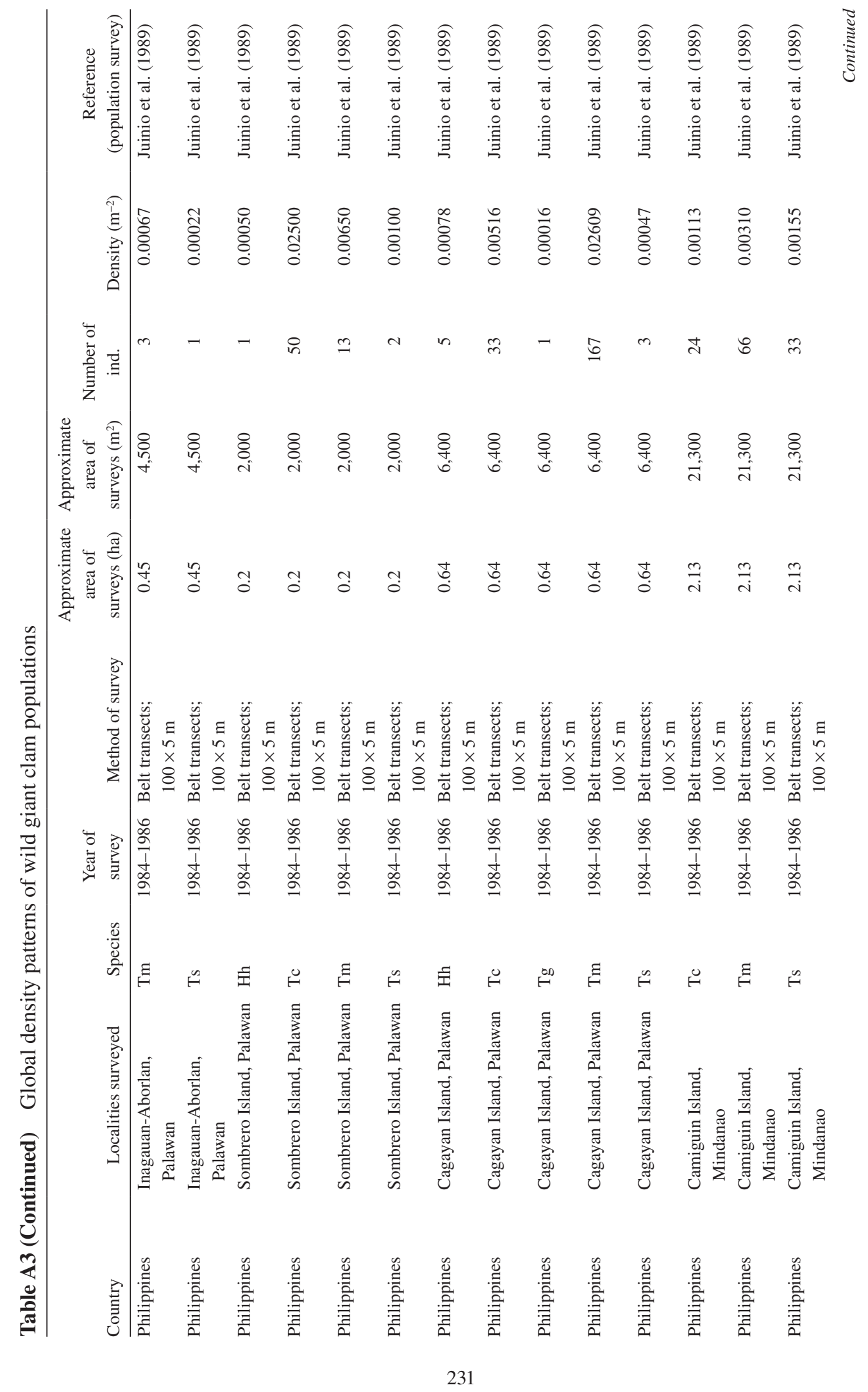


MEI LIN NEO ET AL.

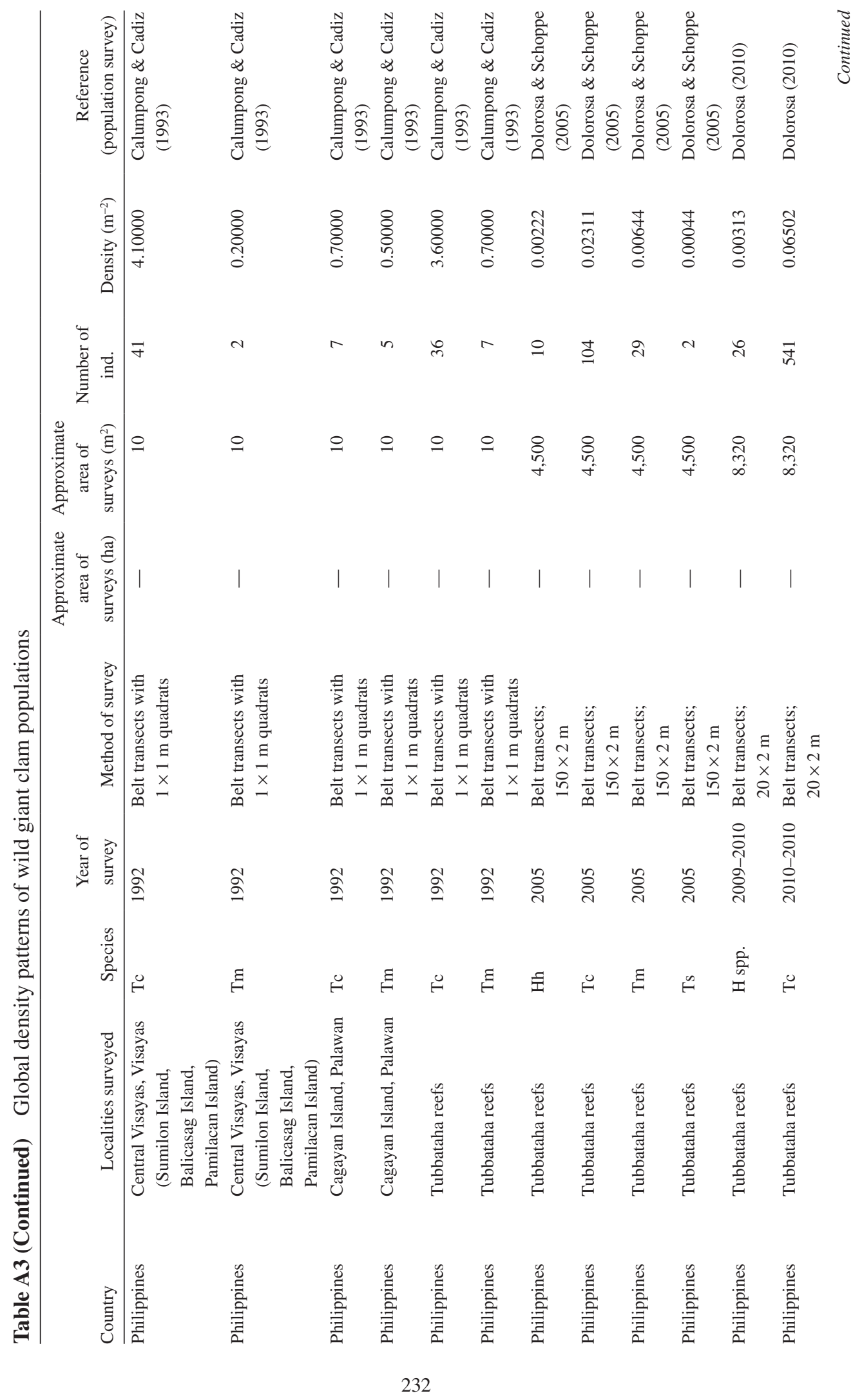


GIANT CLAMS (BIVALVIA: CARDIIDAE: TRIDACNINAE)

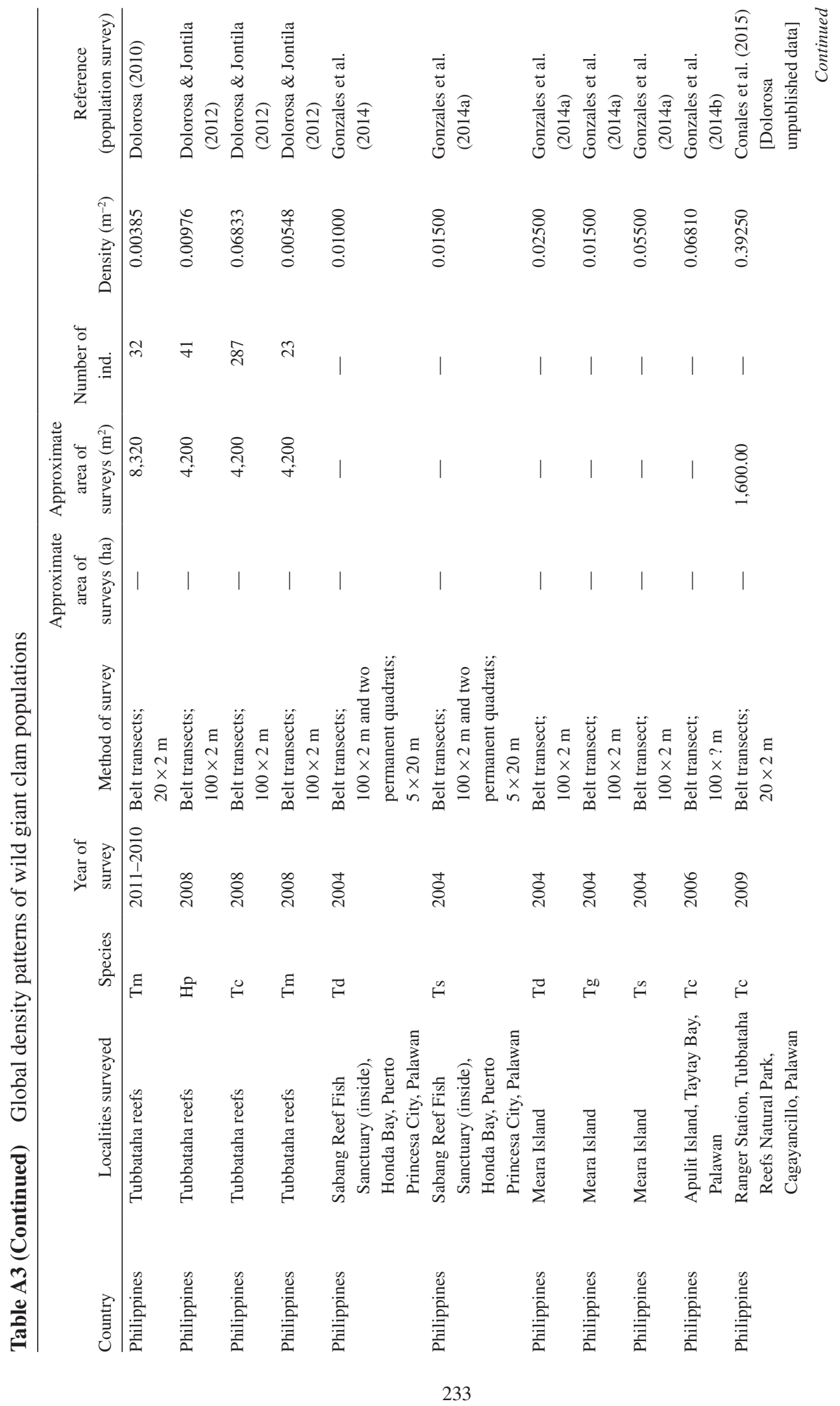


MEI LIN NEO ET AL.

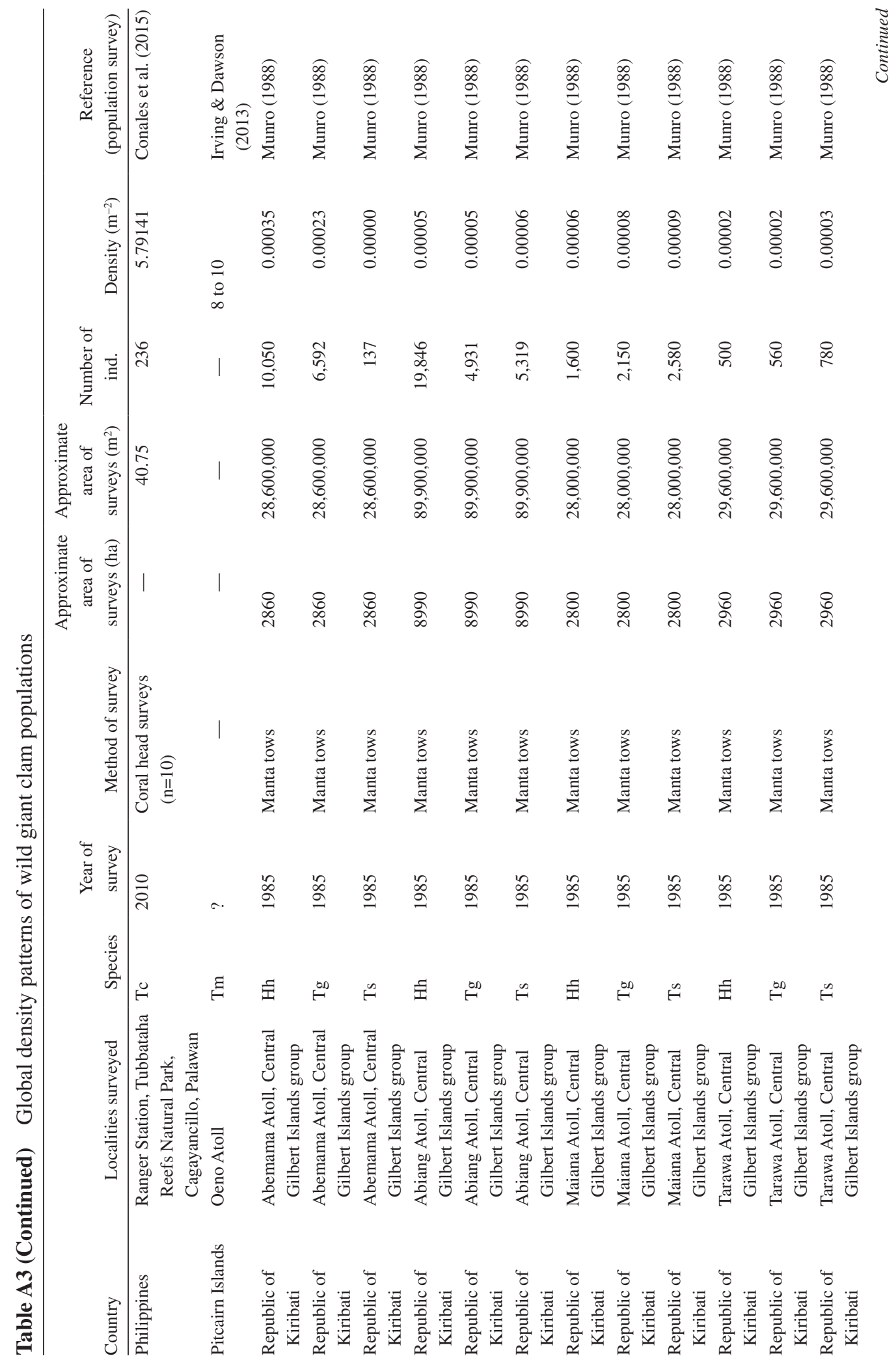


GIANT CLAMS (BIVALVIA: CARDIIDAE: TRIDACNINAE)

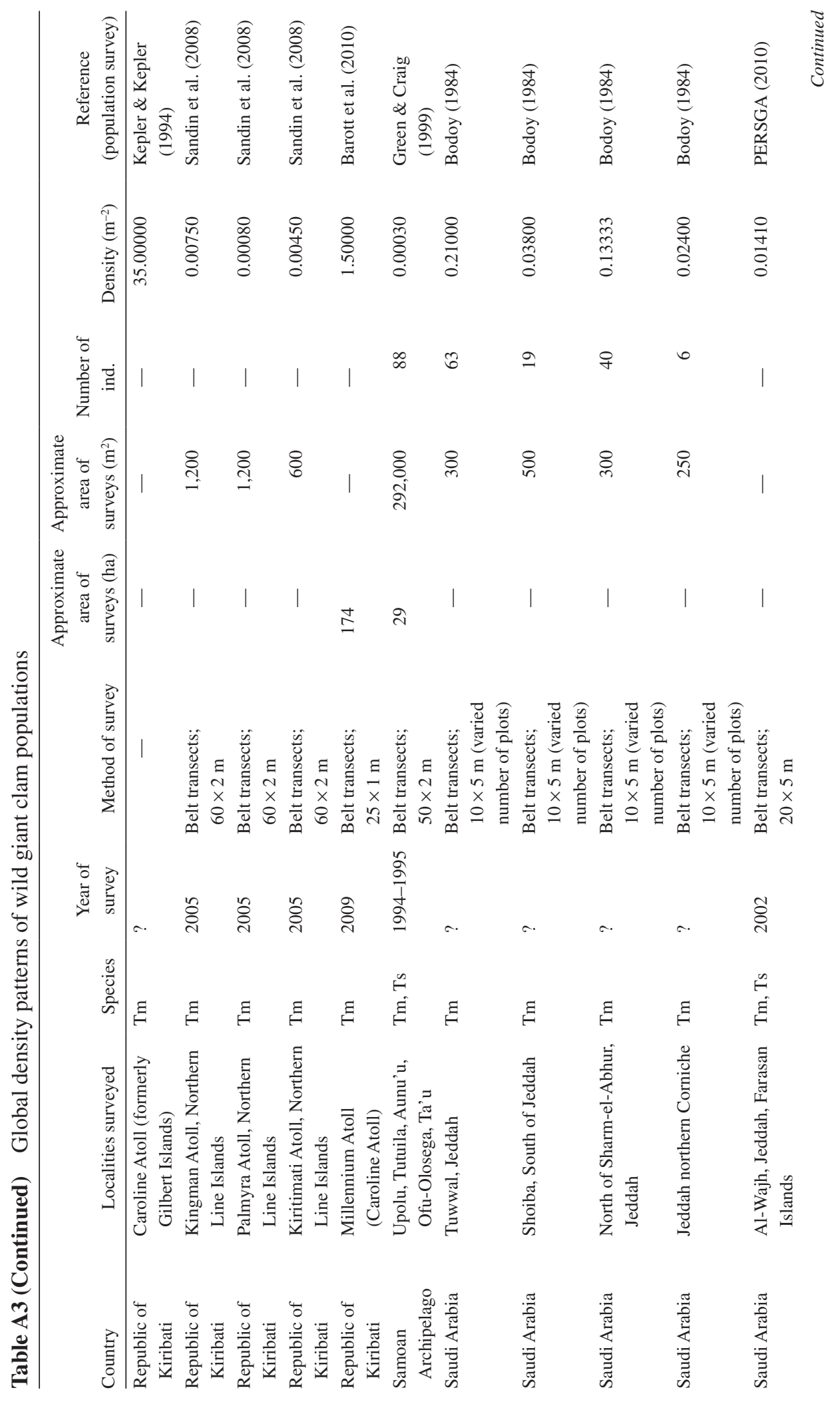


MEI LIN NEO ET AL.

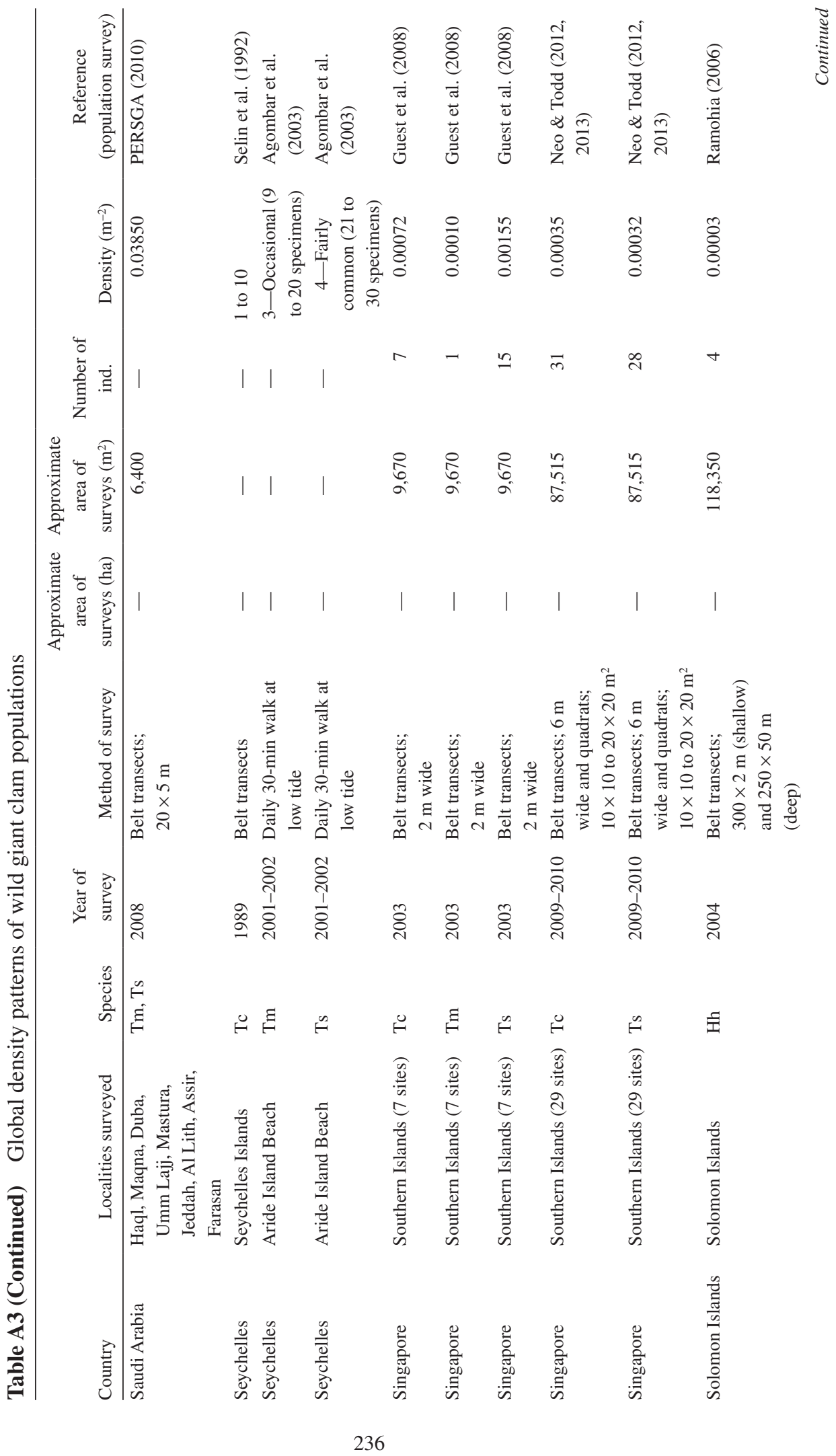


GIANT CLAMS (BIVALVIA: CARDIIDAE: TRIDACNINAE)

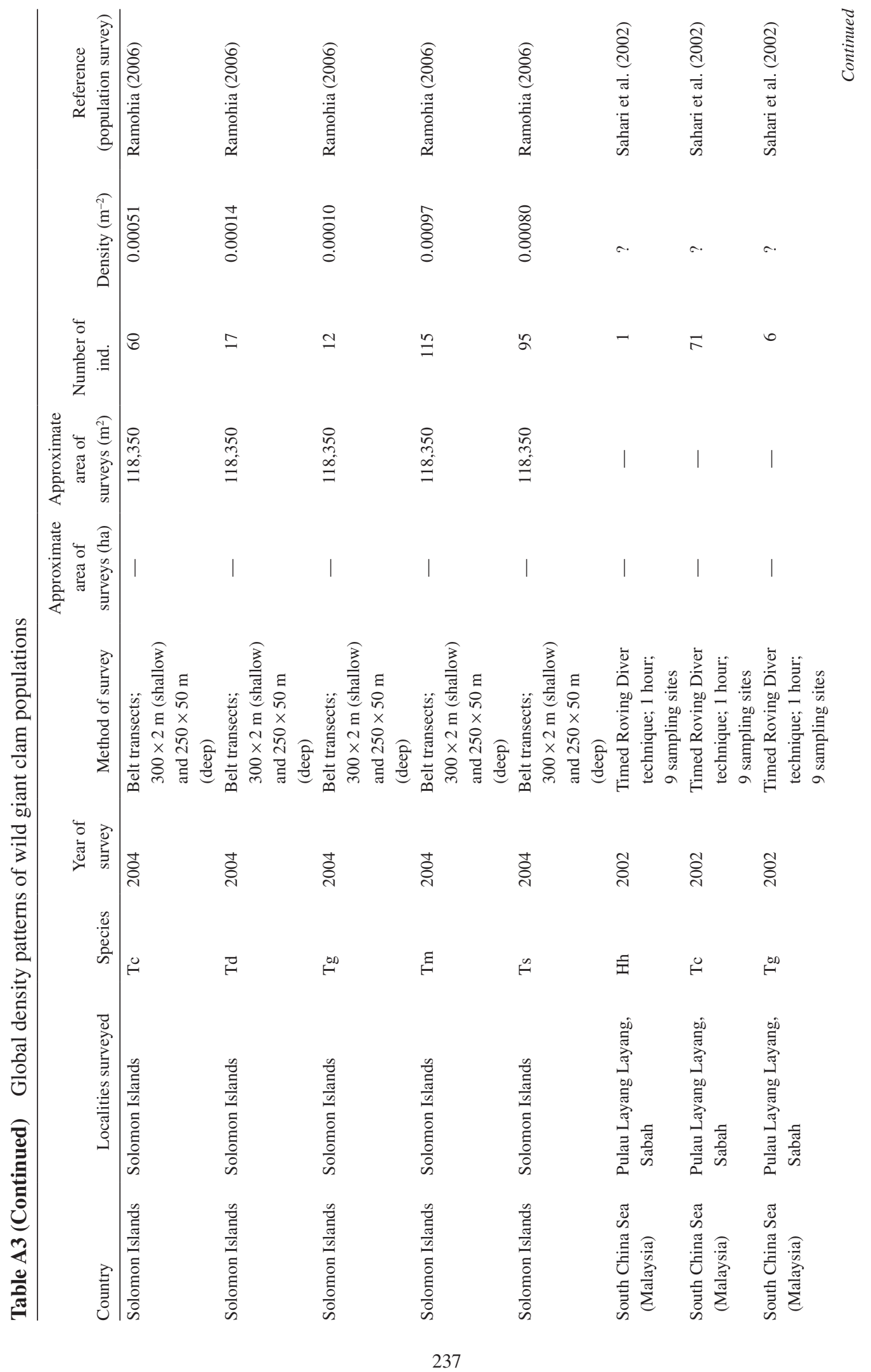


MEI LIN NEO ET AL.

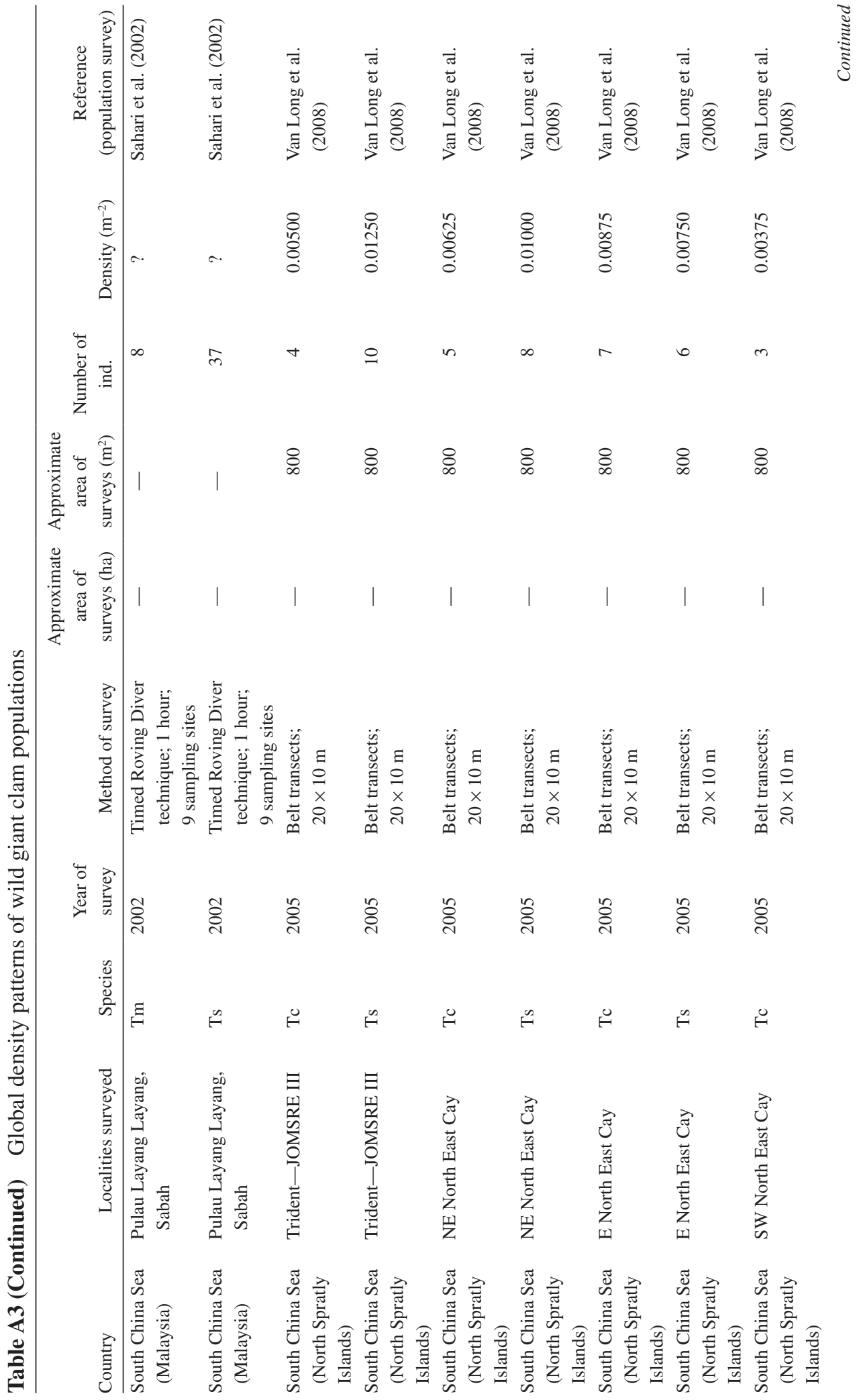


GIANT CLAMS (BIVALVIA: CARDIIDAE: TRIDACNINAE)

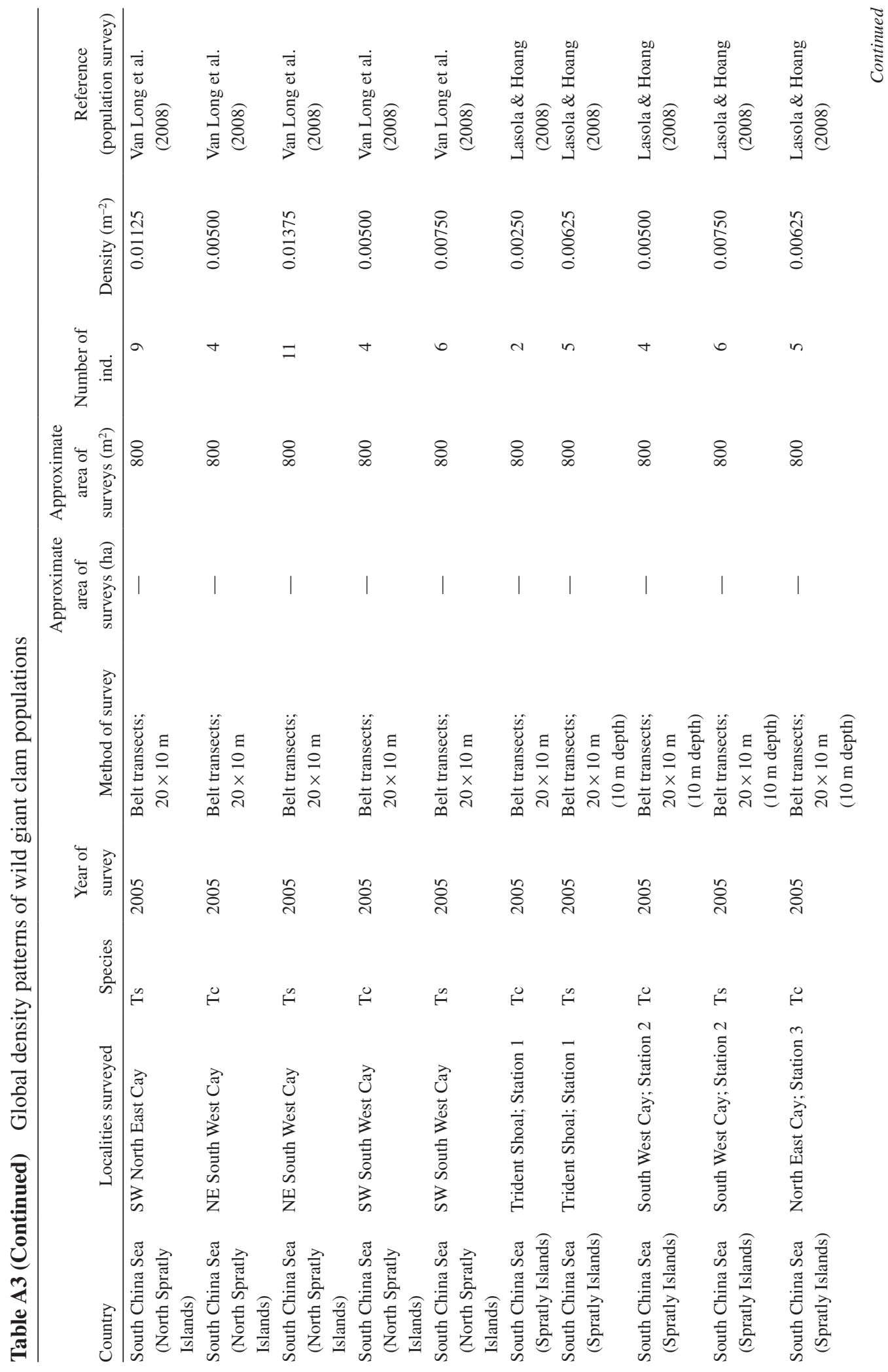


MEI LIN NEO ET AL.

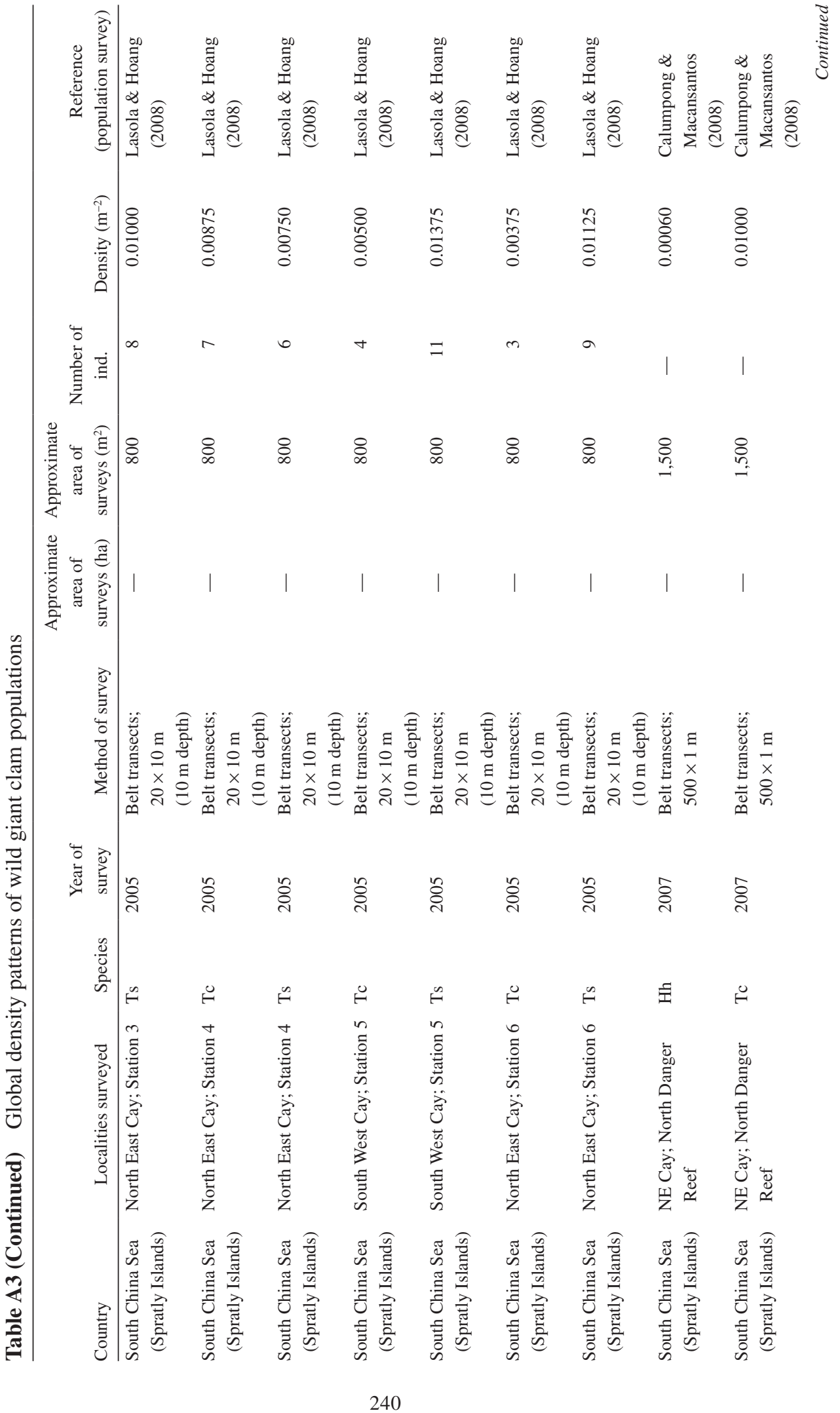


GIANT CLAMS (BIVALVIA: CARDIIDAE: TRIDACNINAE)

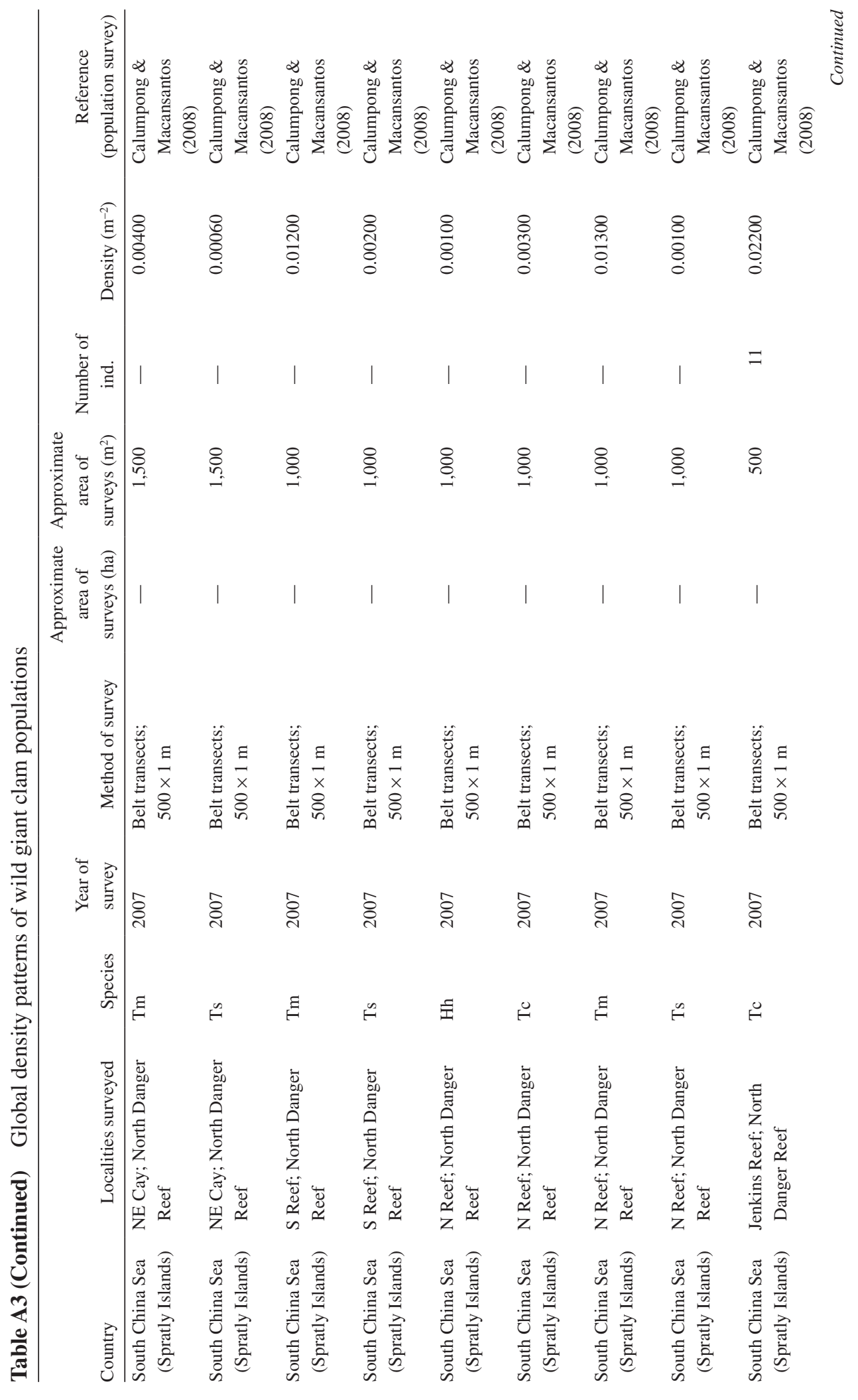


MEI LIN NEO ET AL.

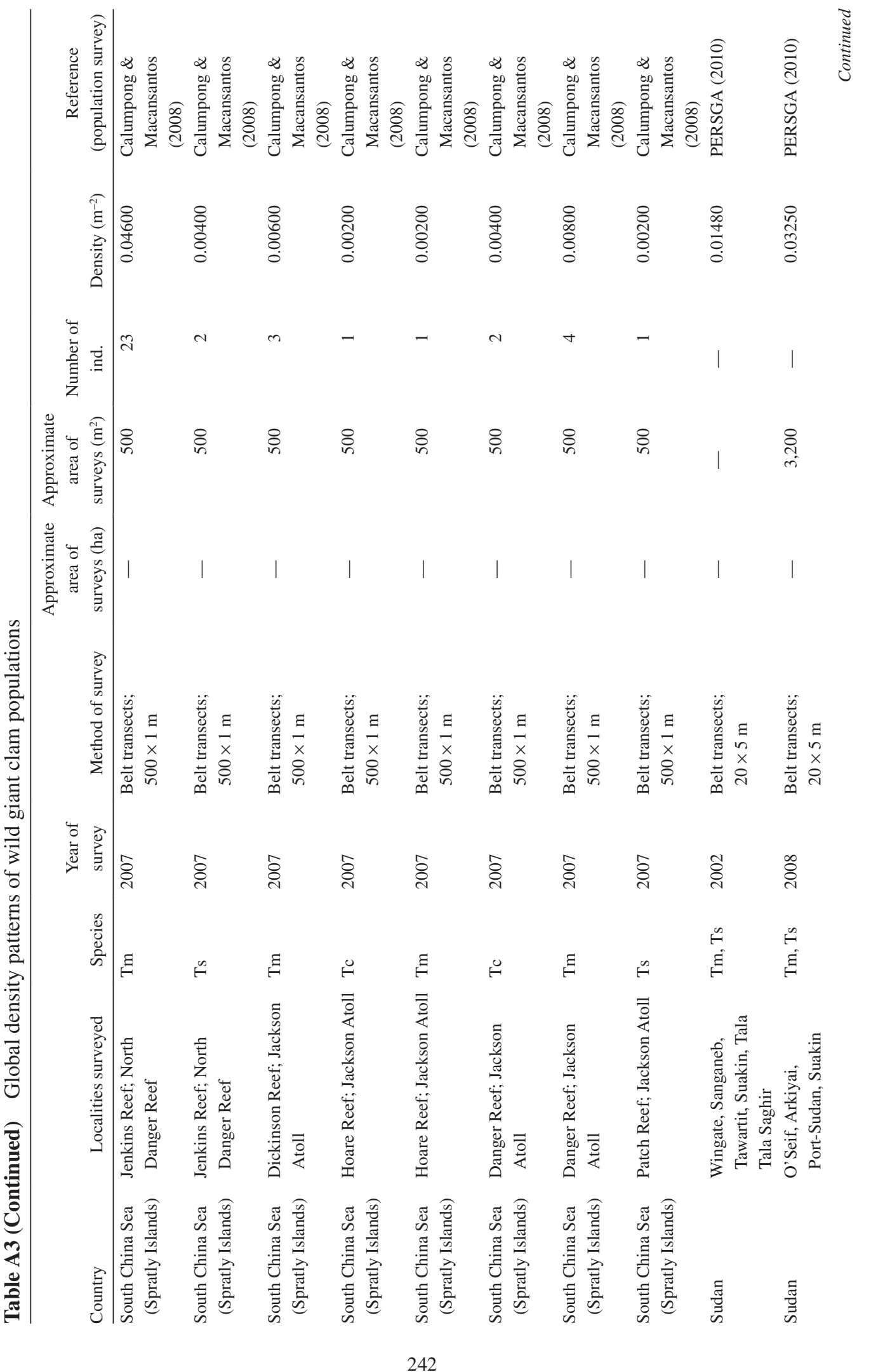


GIANT CLAMS (BIVALVIA: CARDIIDAE: TRIDACNINAE)

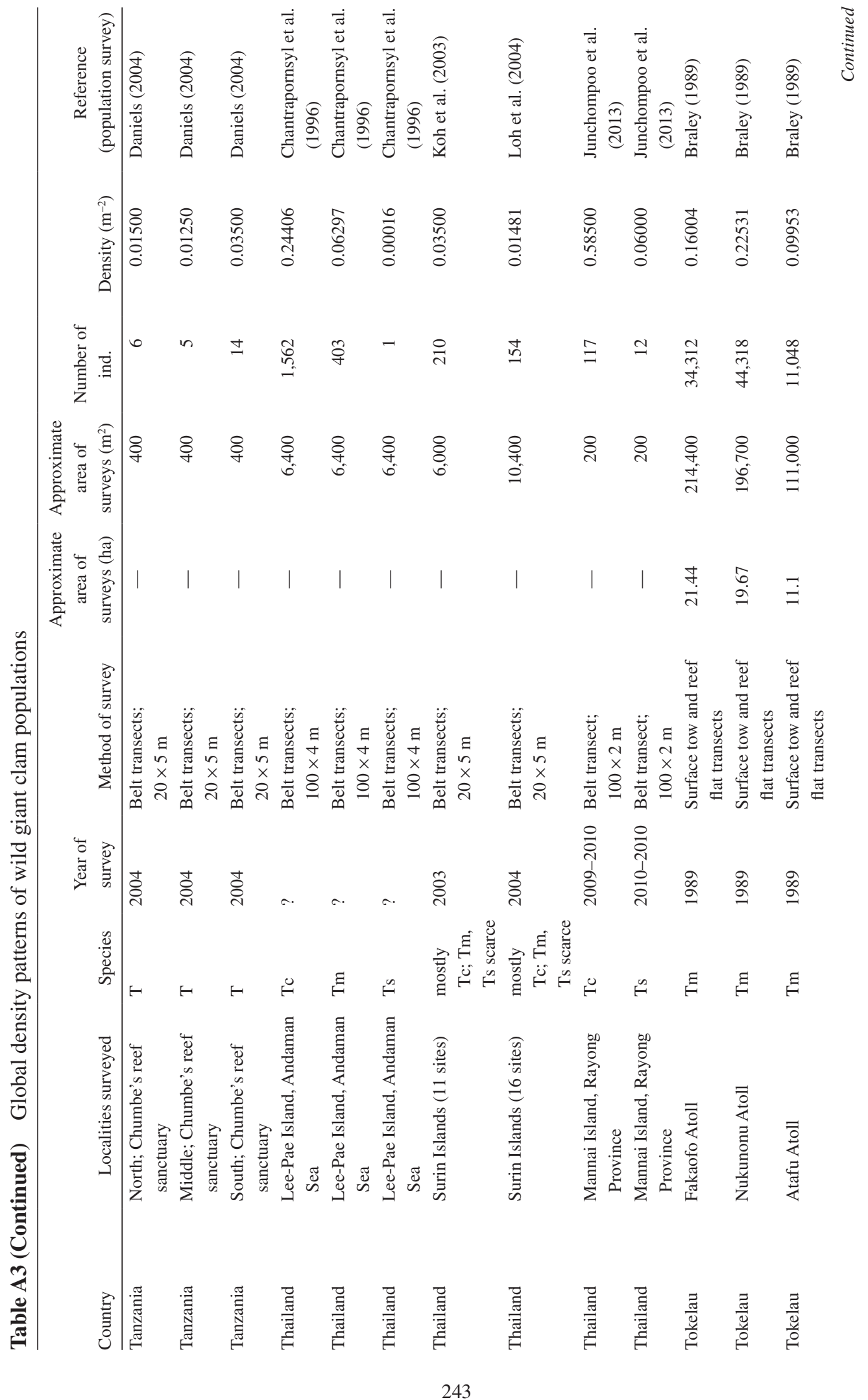




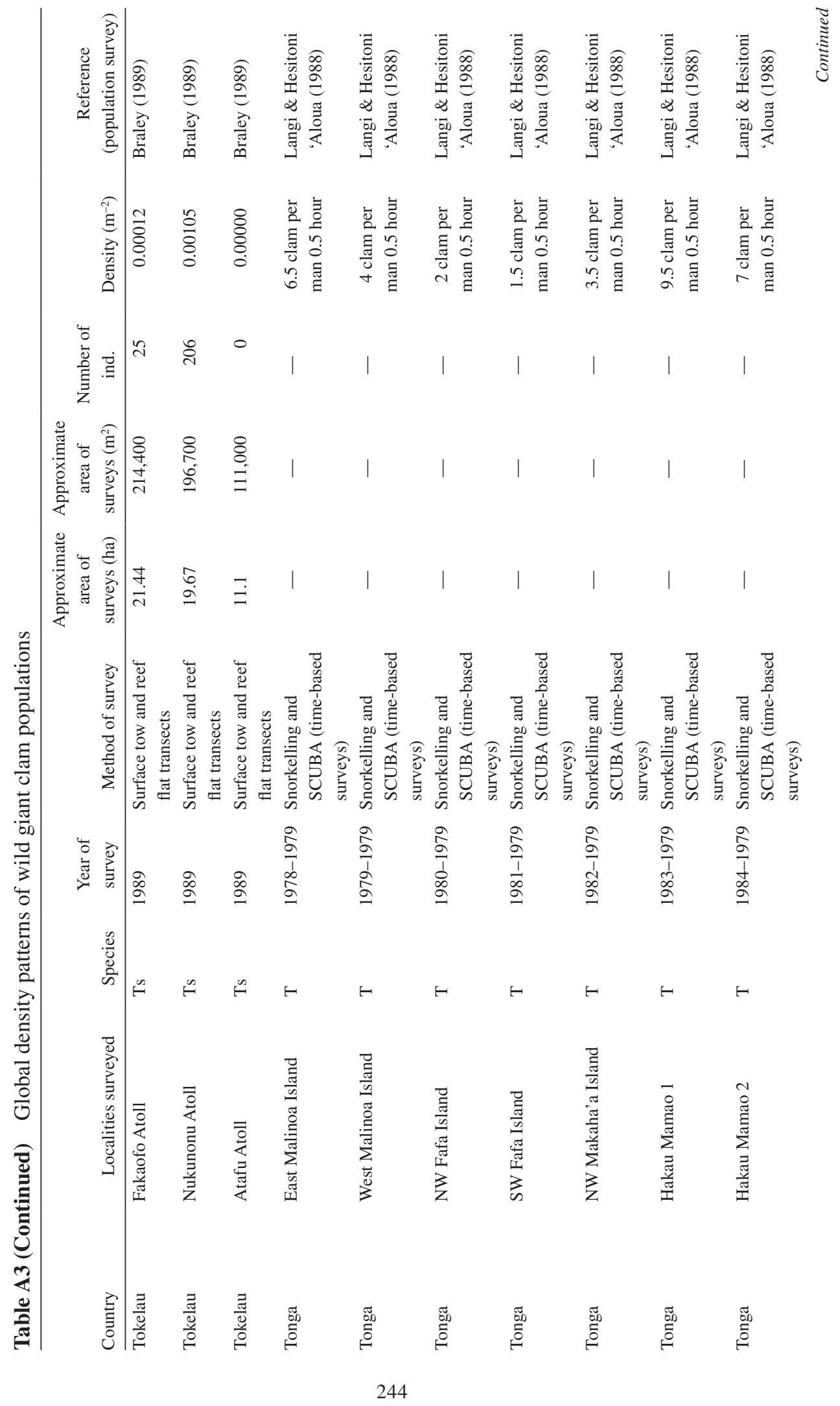


GIANT CLAMS (BIVALVIA: CARDIIDAE: TRIDACNINAE)

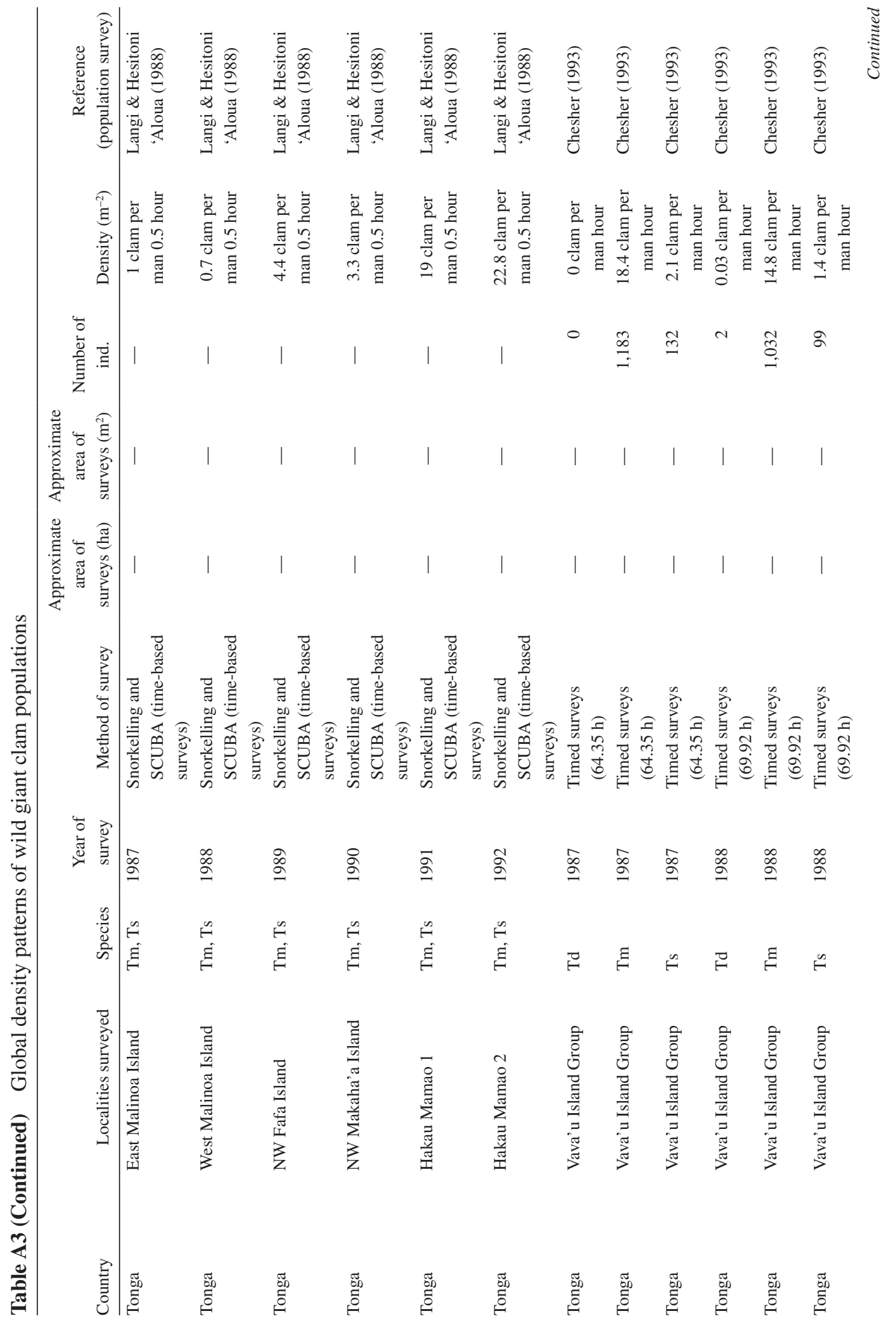




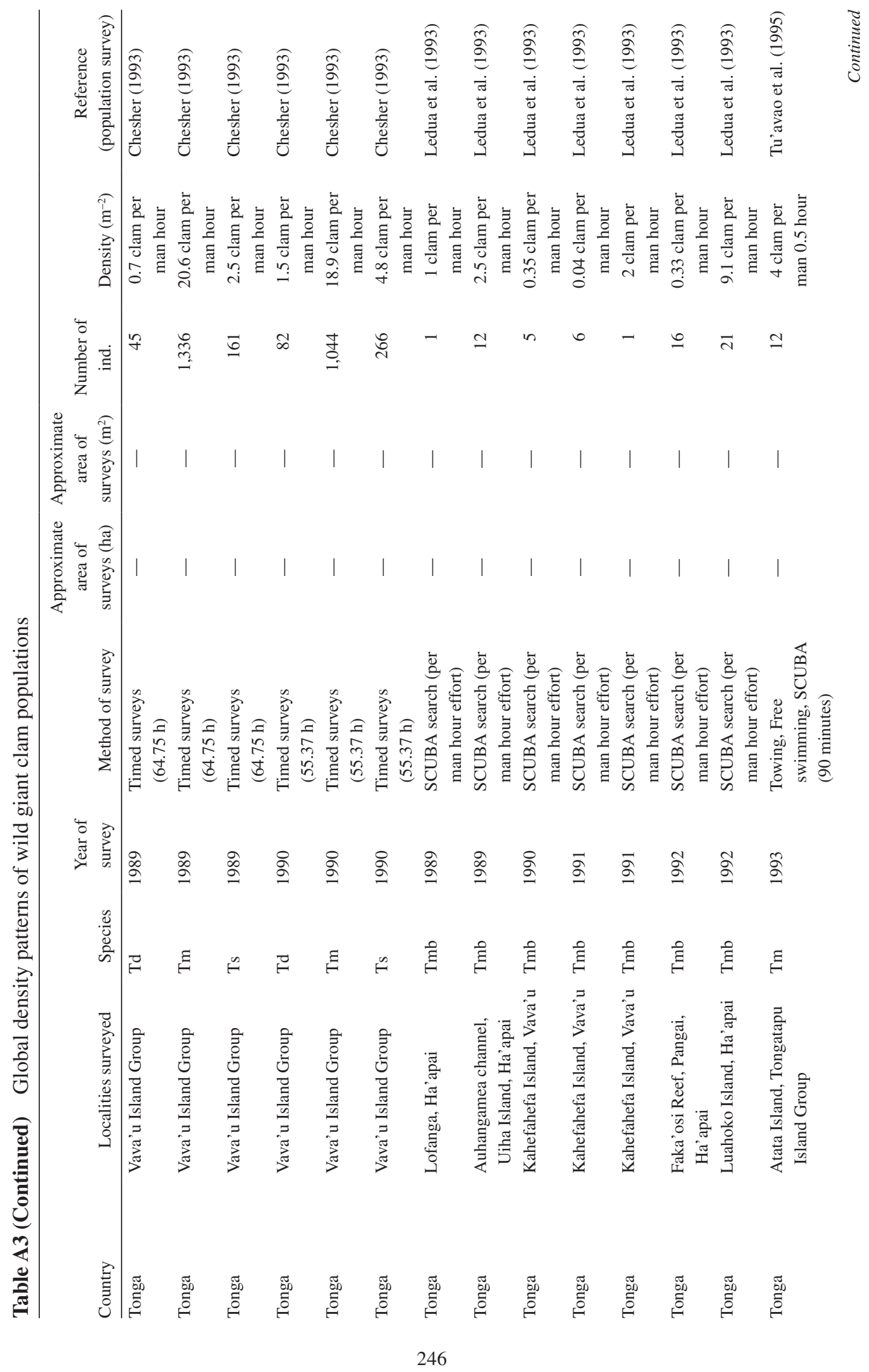




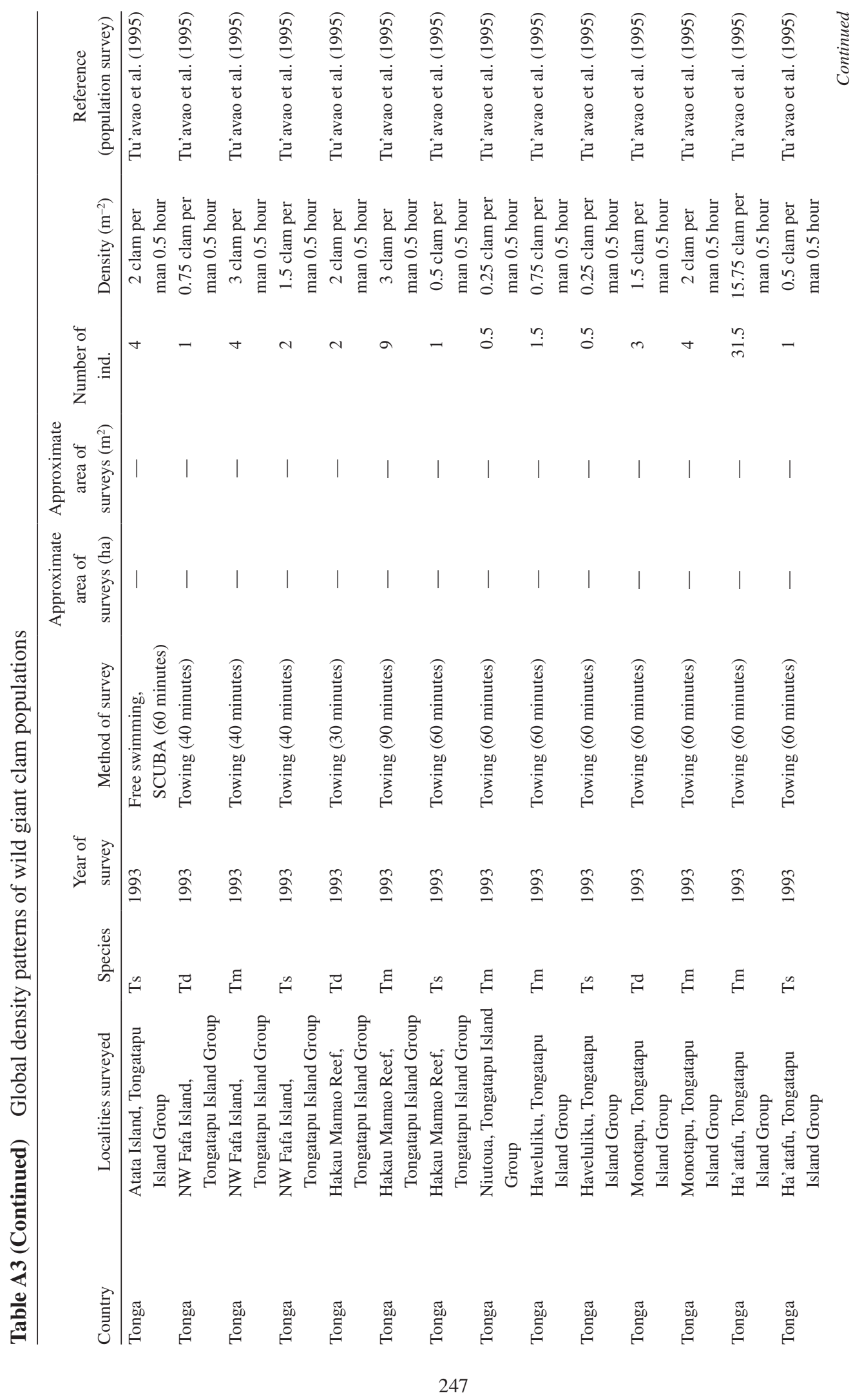


MEI LIN NEO ET AL.

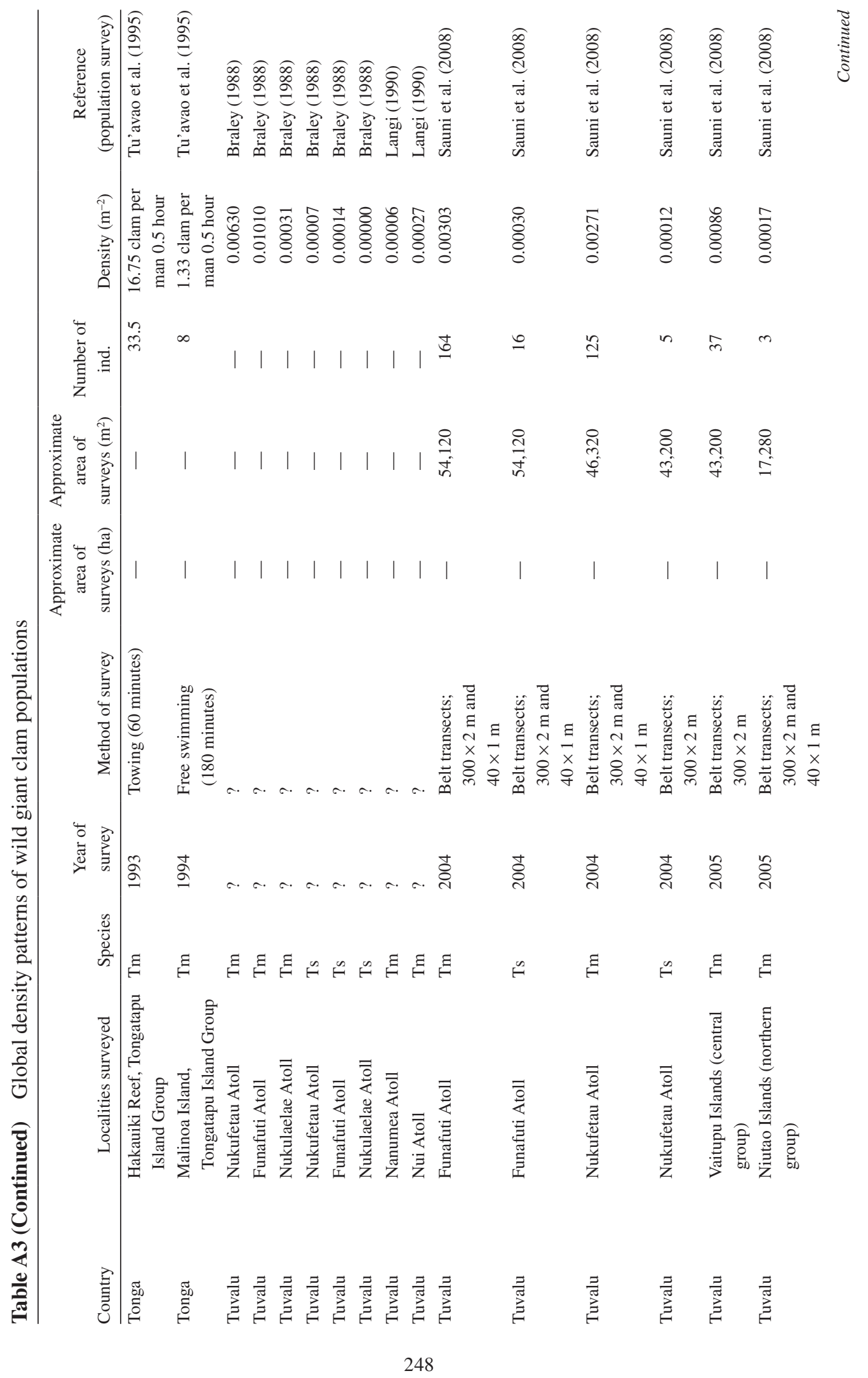




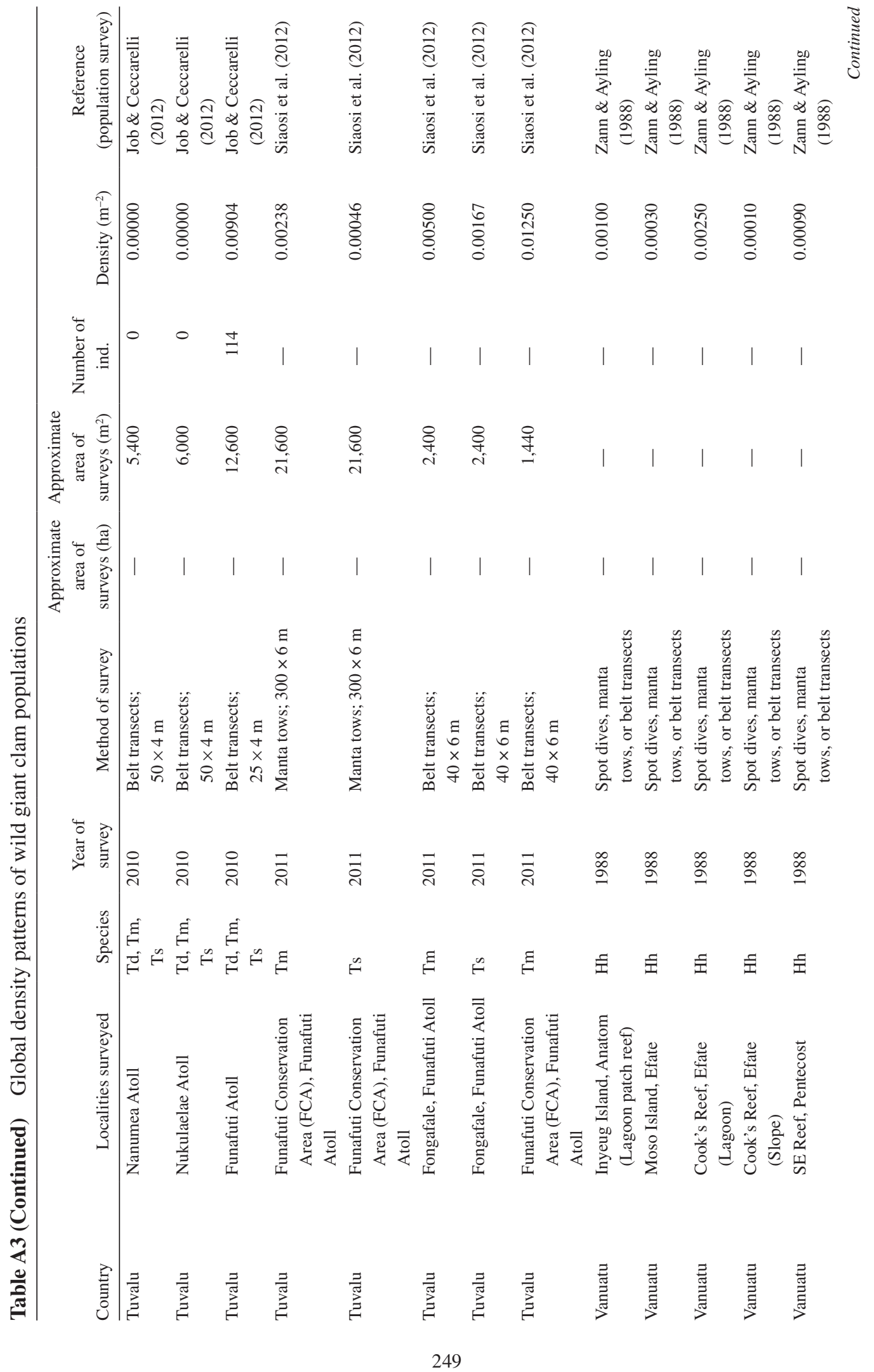




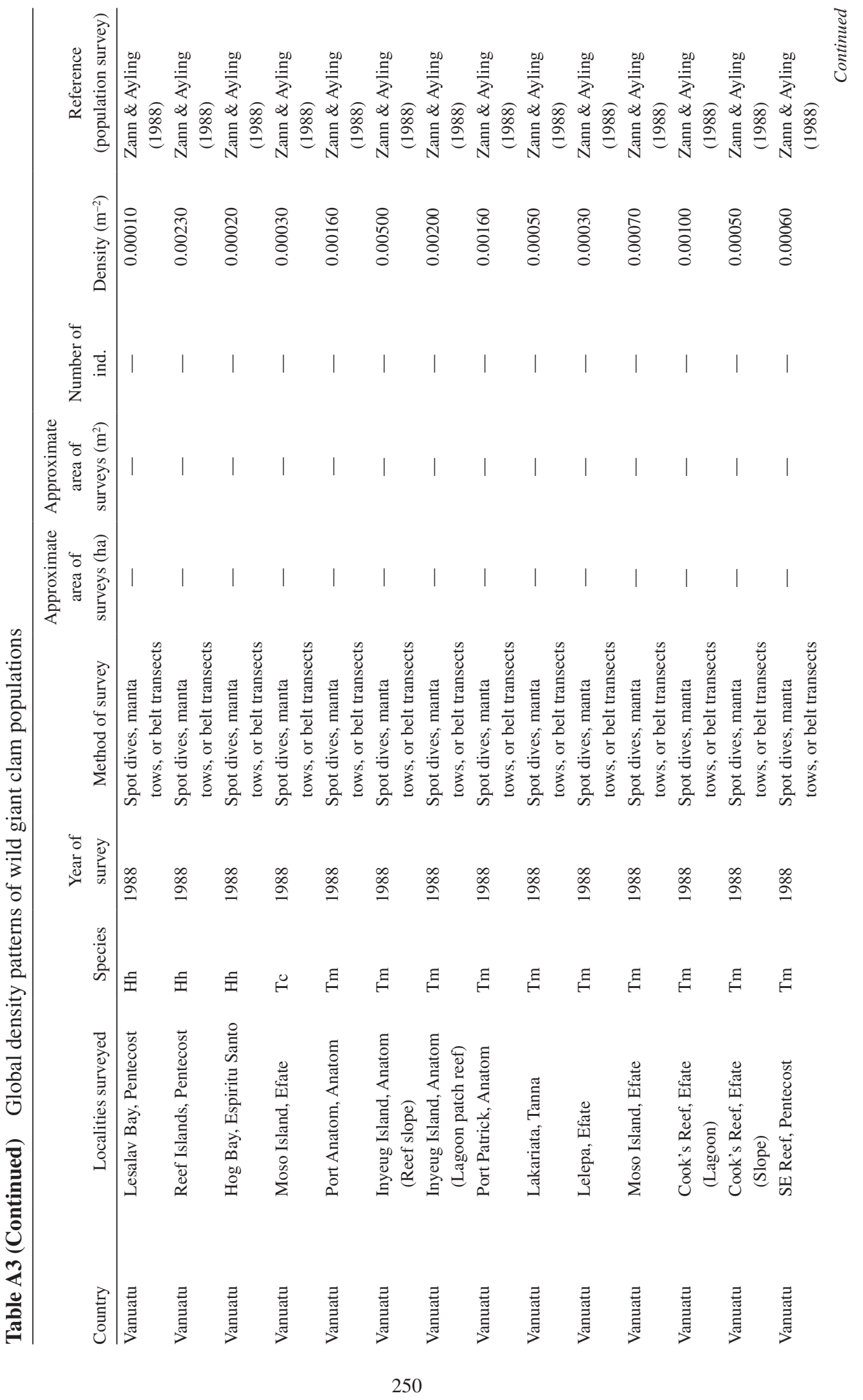


GIANT CLAMS (BIVALVIA: CARDIIDAE: TRIDACNINAE)

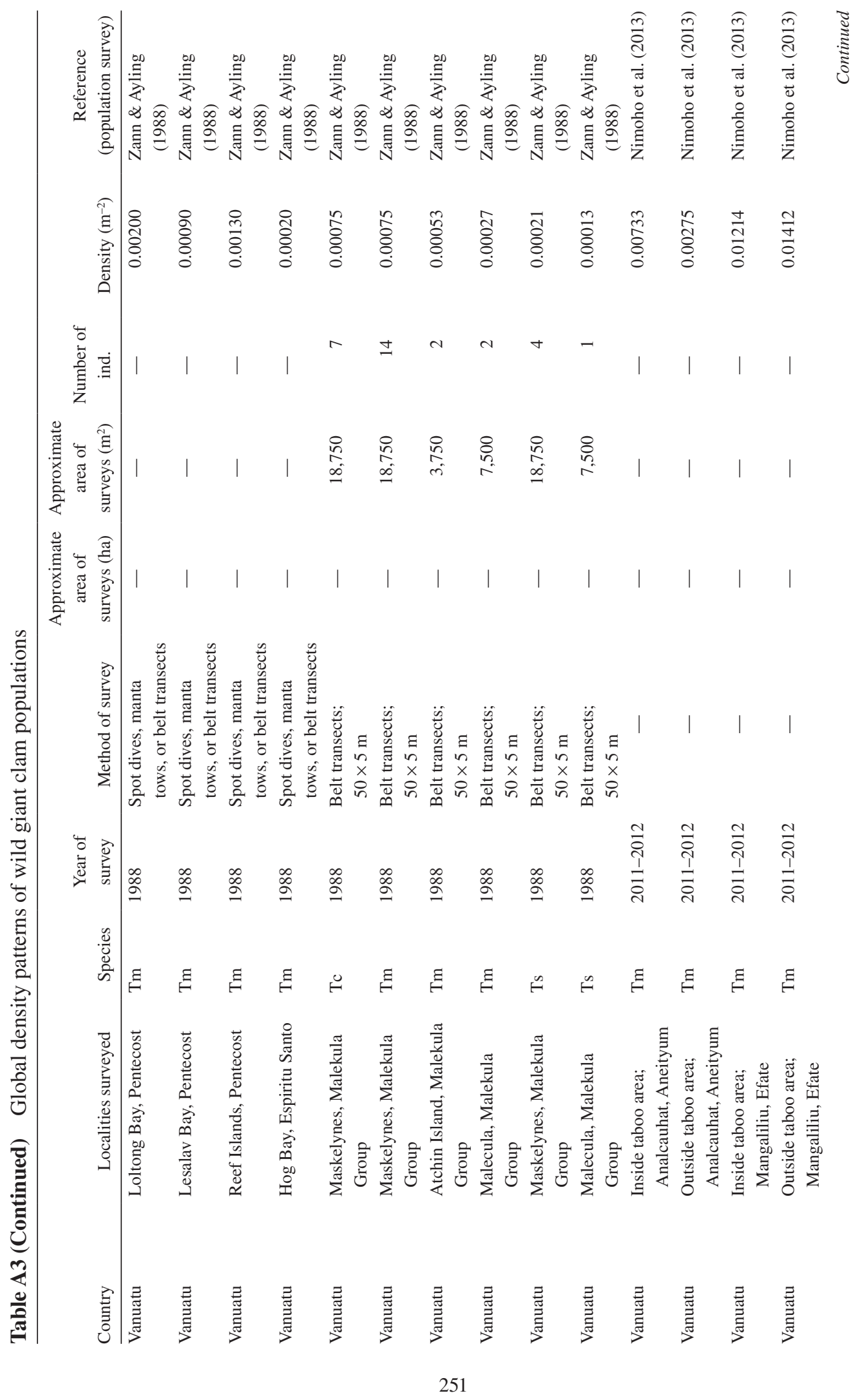




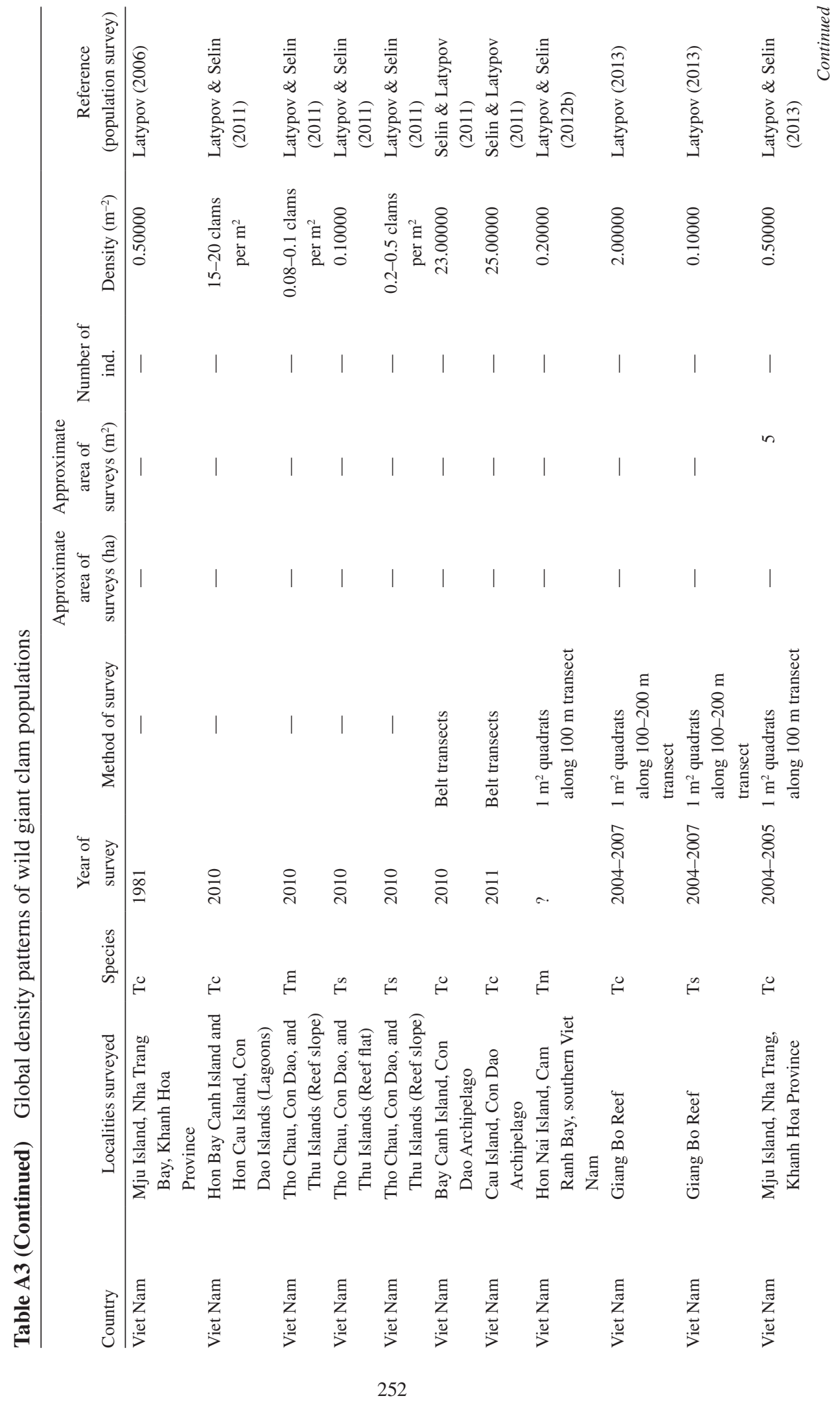




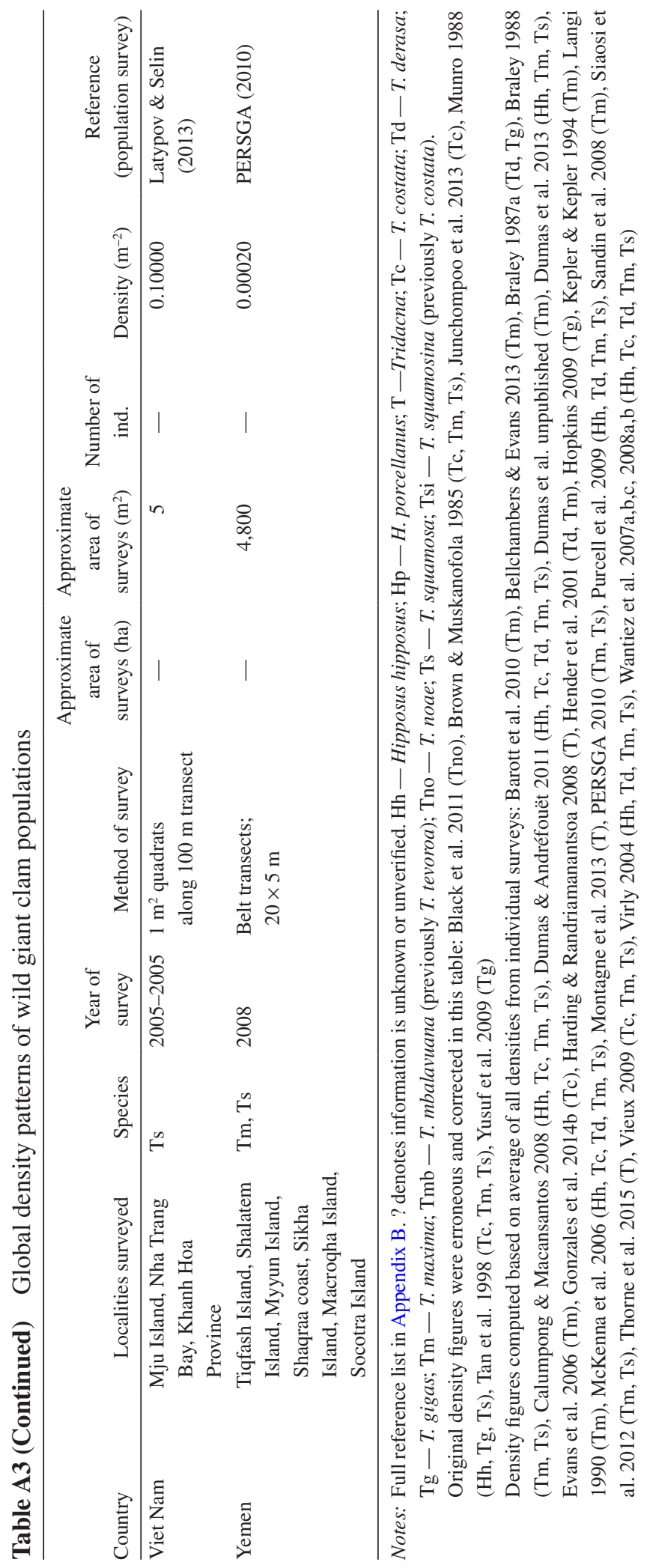


MEI LIN NEO ET AL.

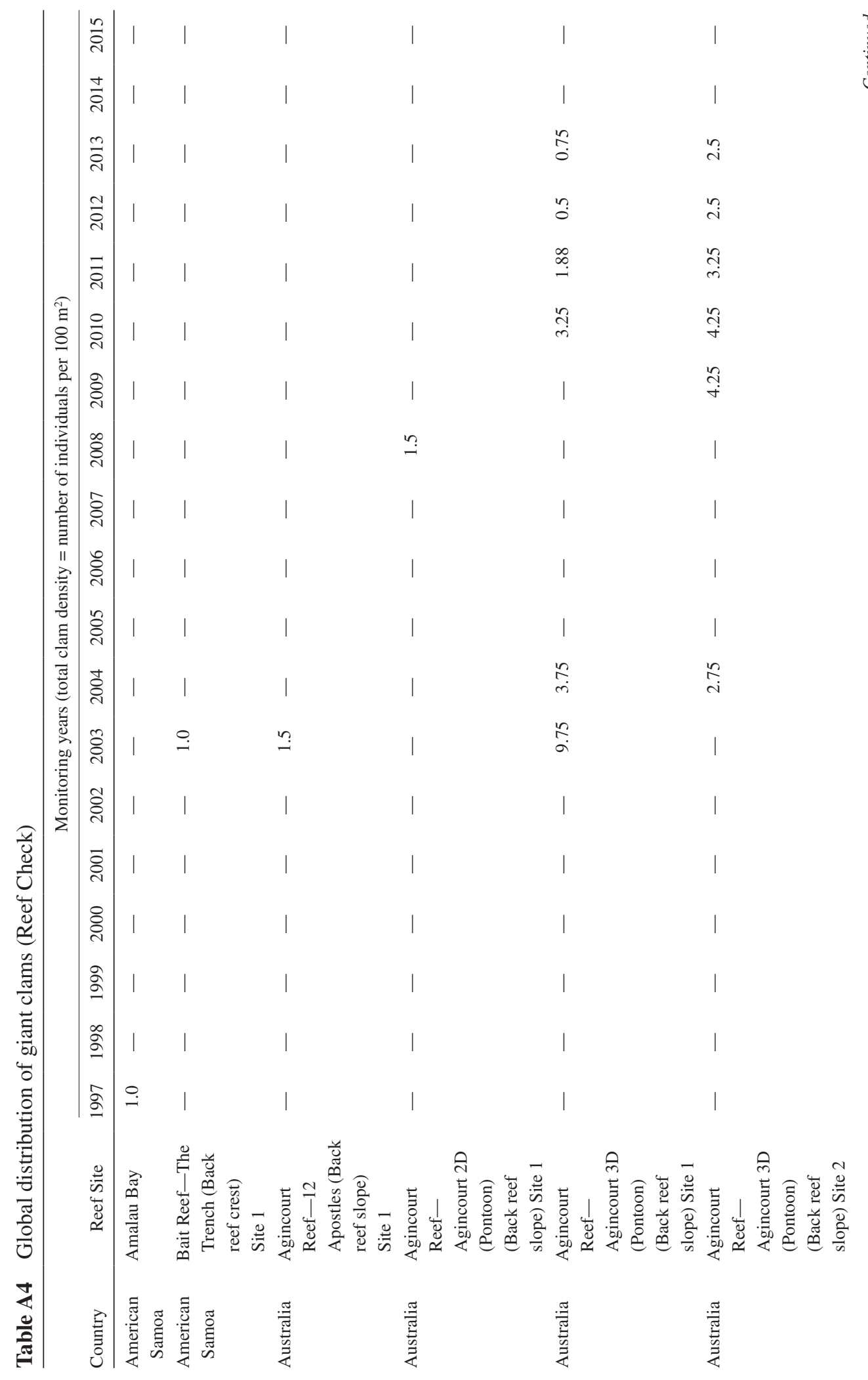


GIANT CLAMS (BIVALVIA: CARDIIDAE: TRIDACNINAE)

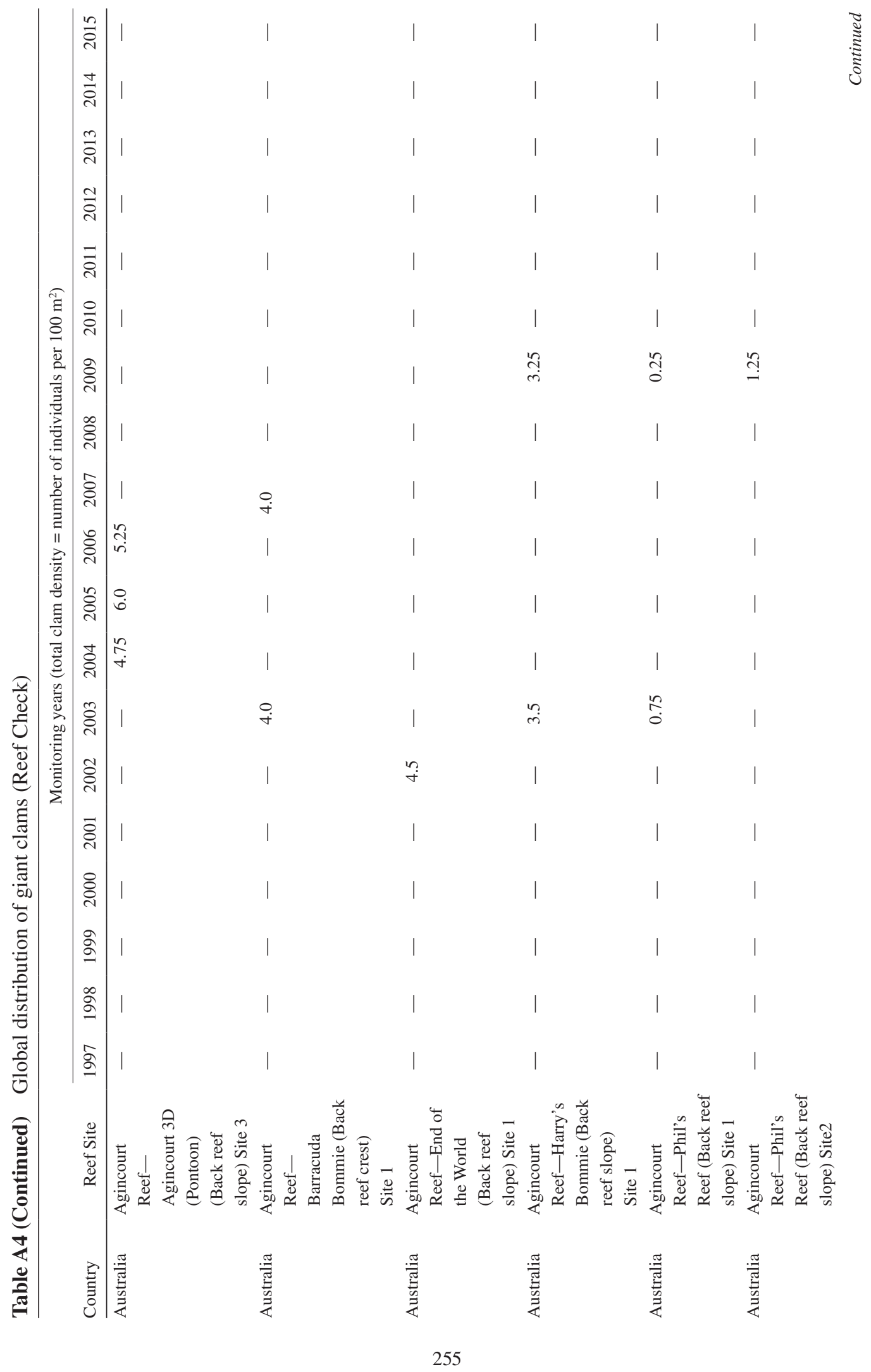


MEI LIN NEO ET AL.

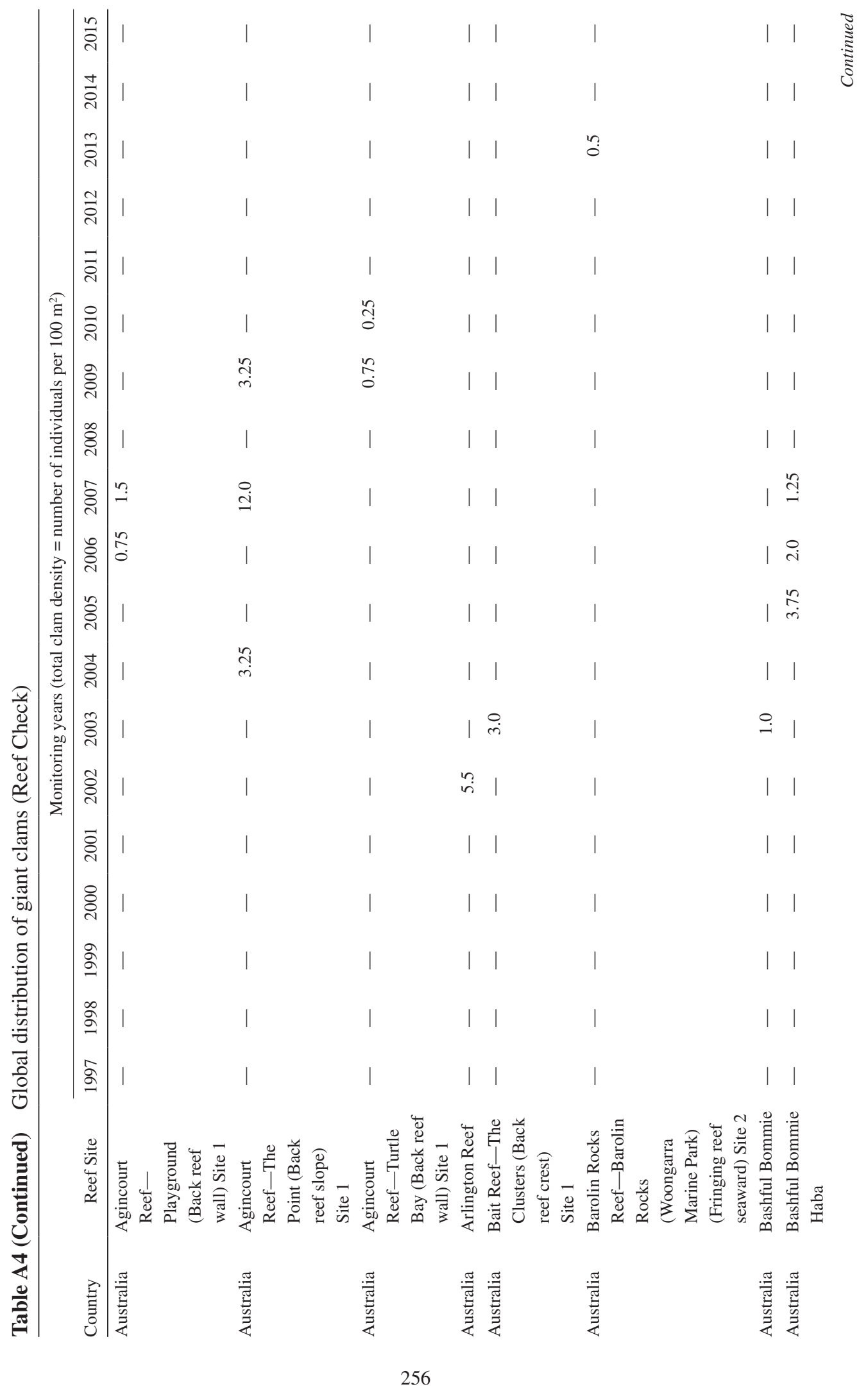


GIANT CLAMS (BIVALVIA: CARDIIDAE: TRIDACNINAE)

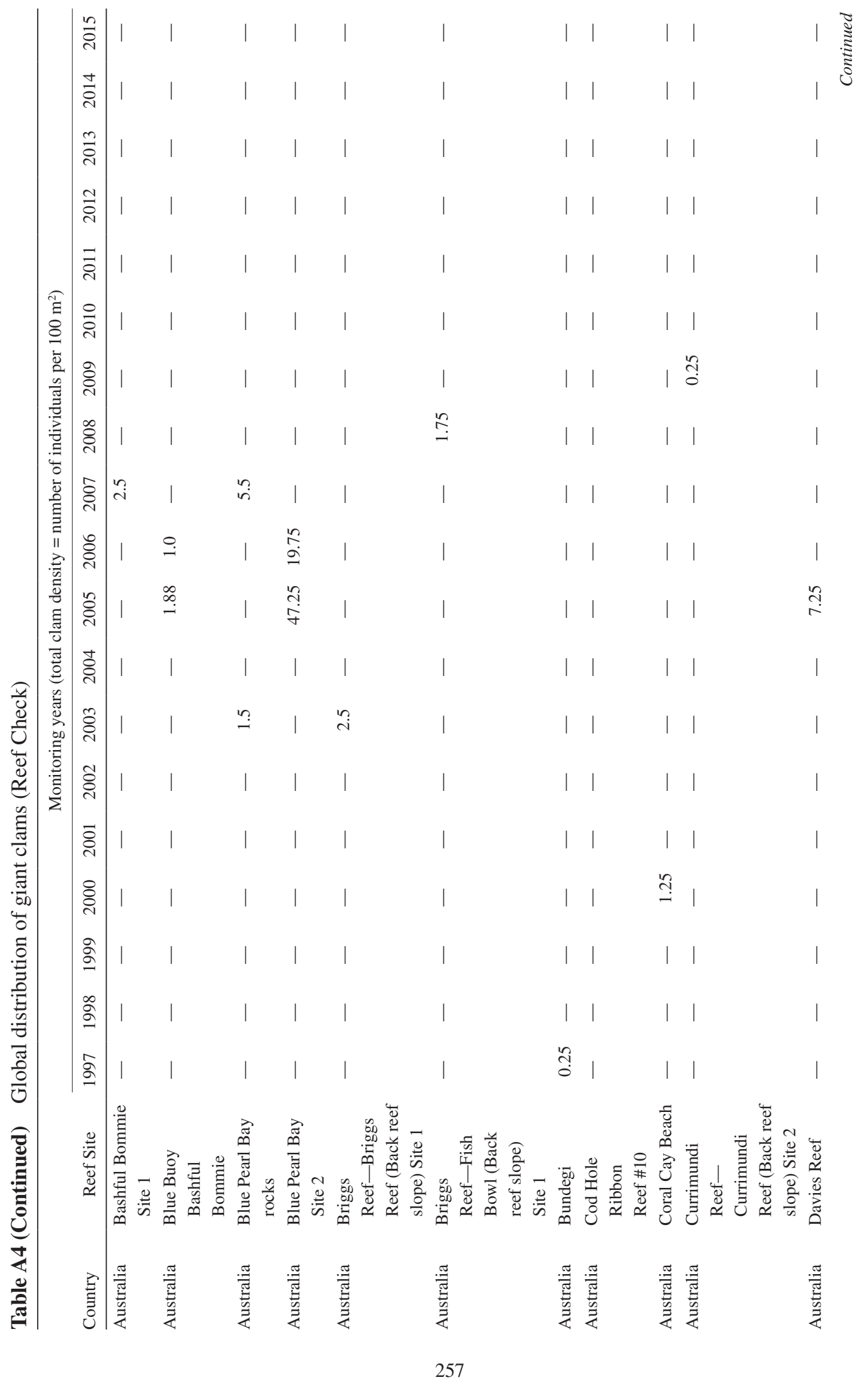


MEI LIN NEO ET AL.

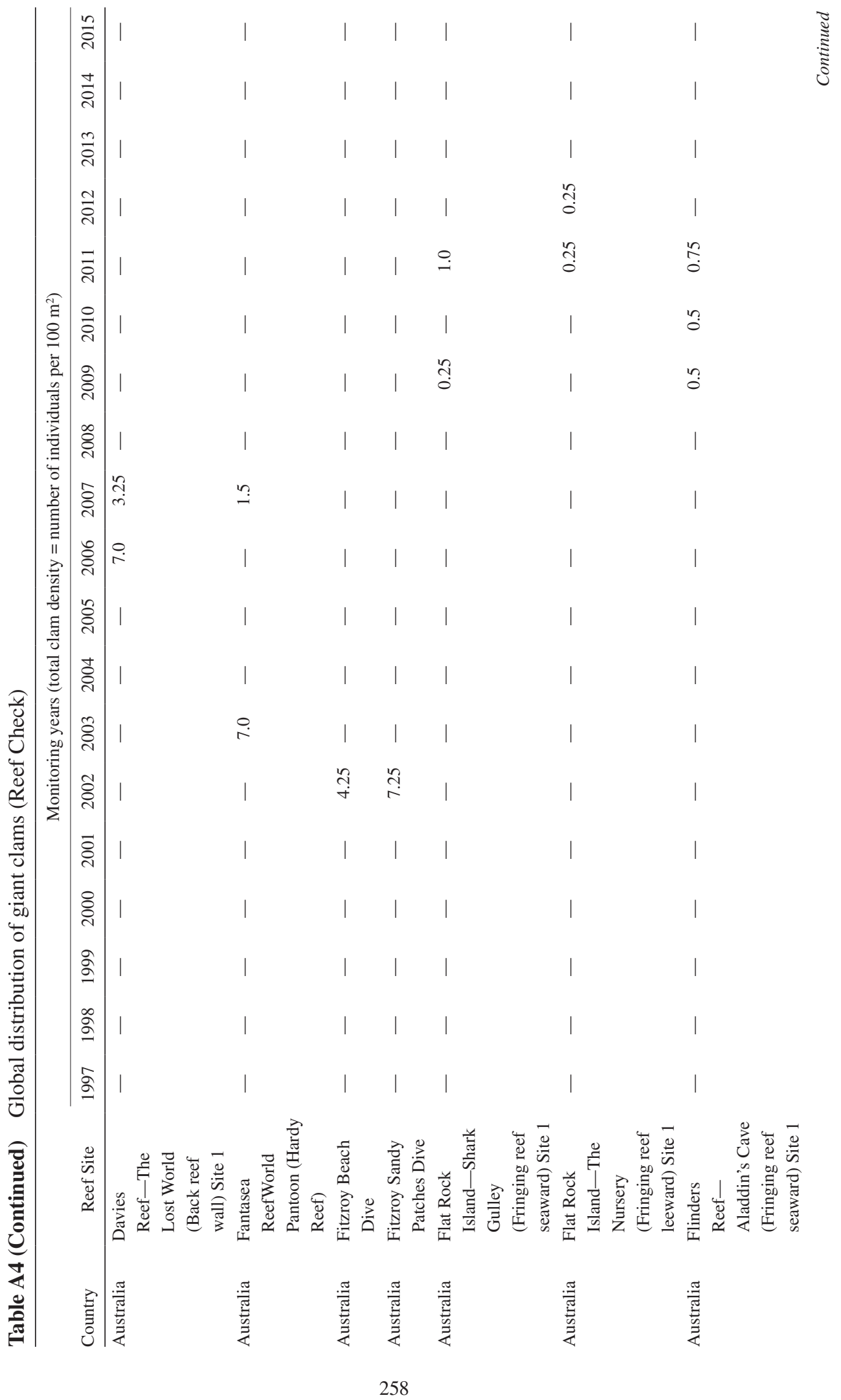


GIANT CLAMS (BIVALVIA: CARDIIDAE: TRIDACNINAE)

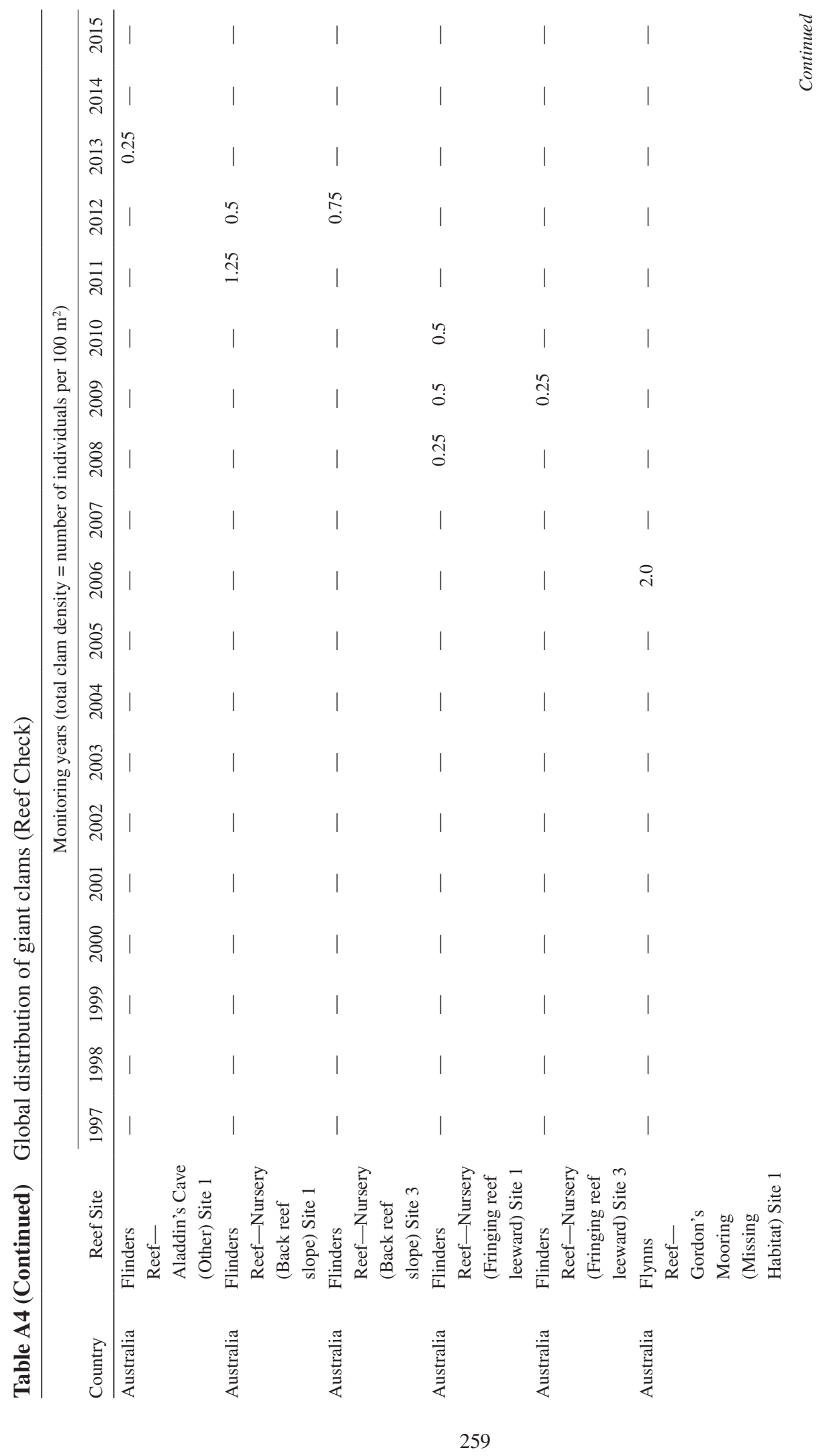


MEI LIN NEO ET AL.

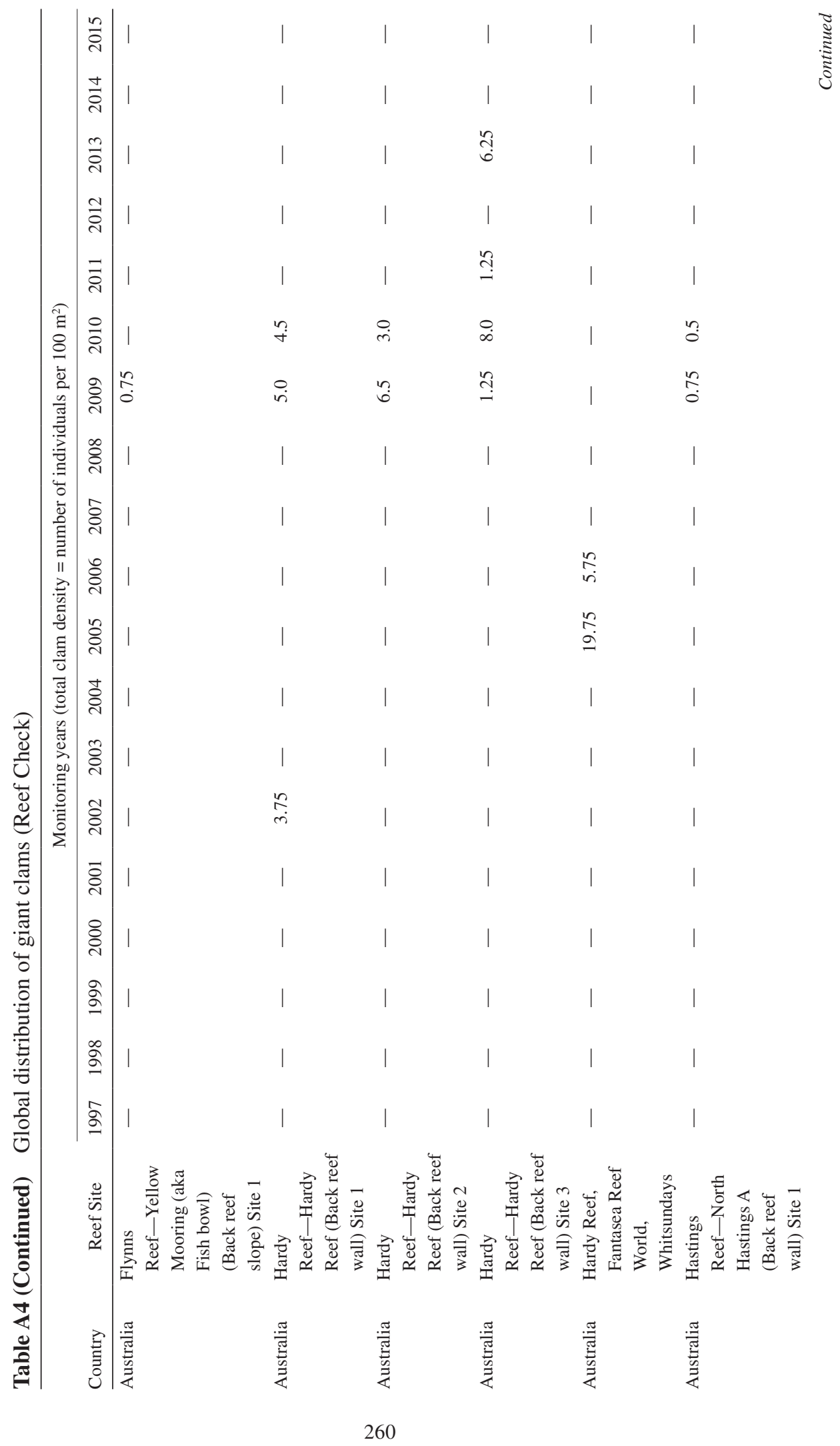


GIANT CLAMS (BIVALVIA: CARDIIDAE: TRIDACNINAE)

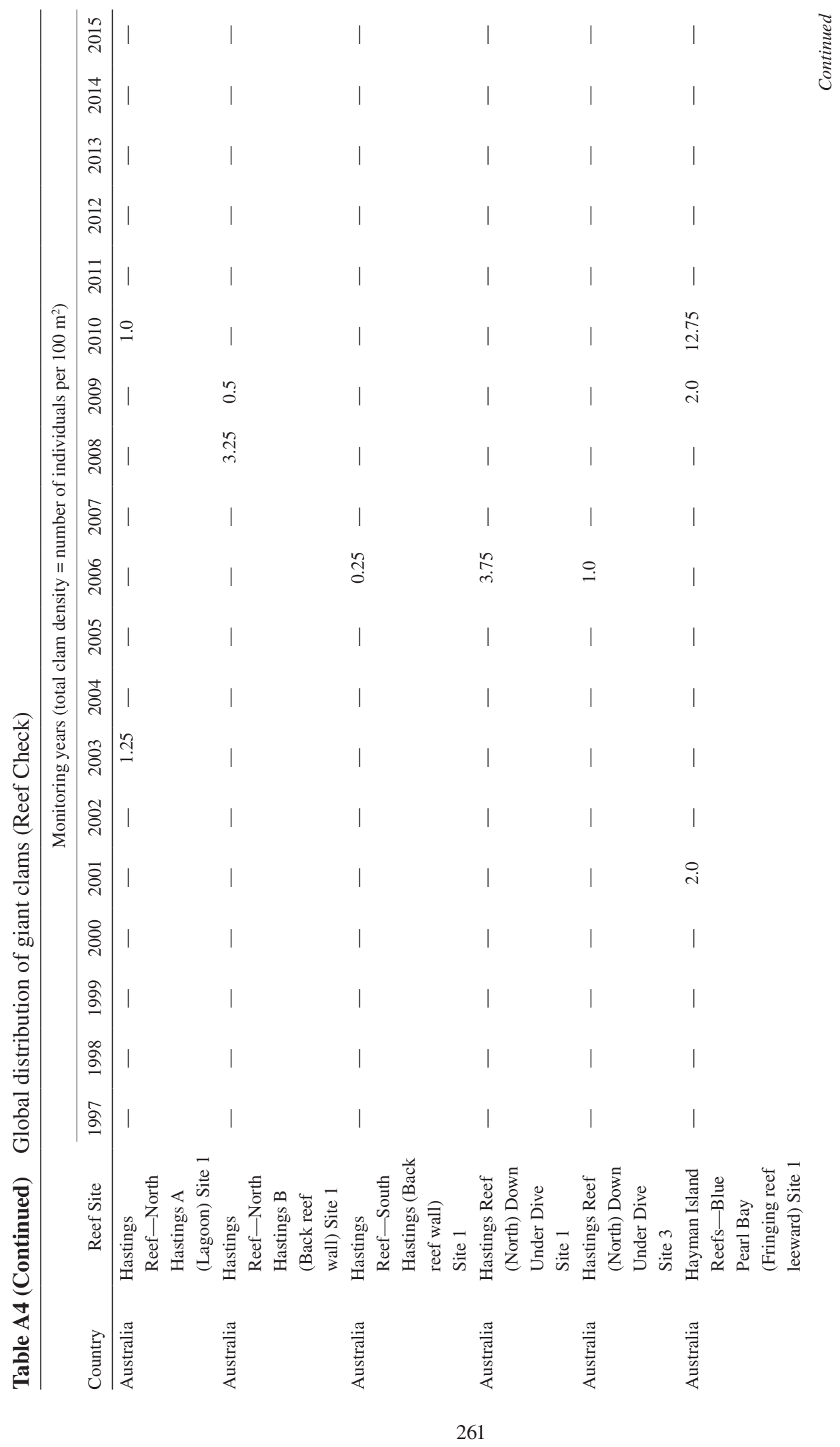


MEI LIN NEO ET AL.

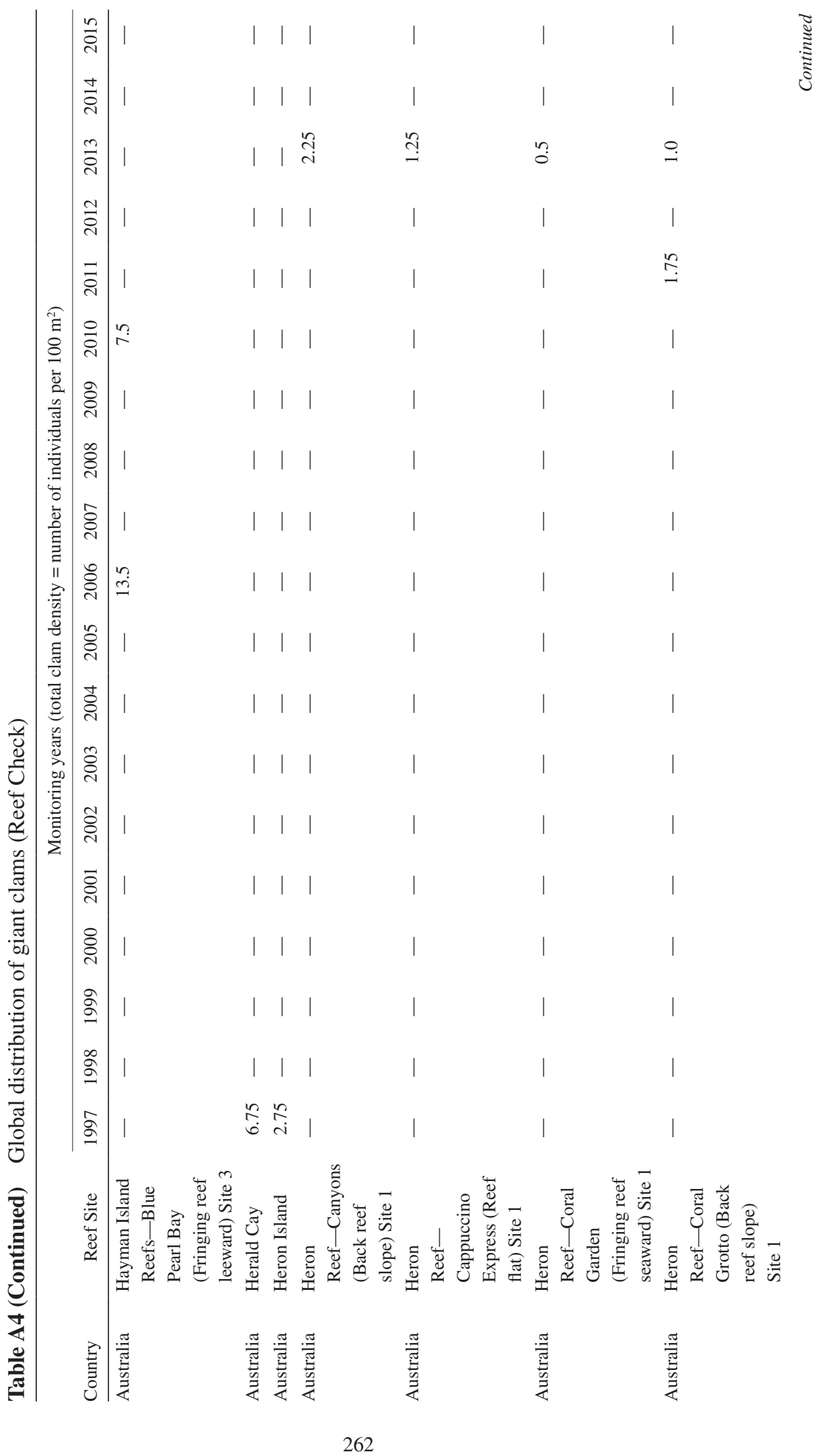


GIANT CLAMS (BIVALVIA: CARDIIDAE: TRIDACNINAE)

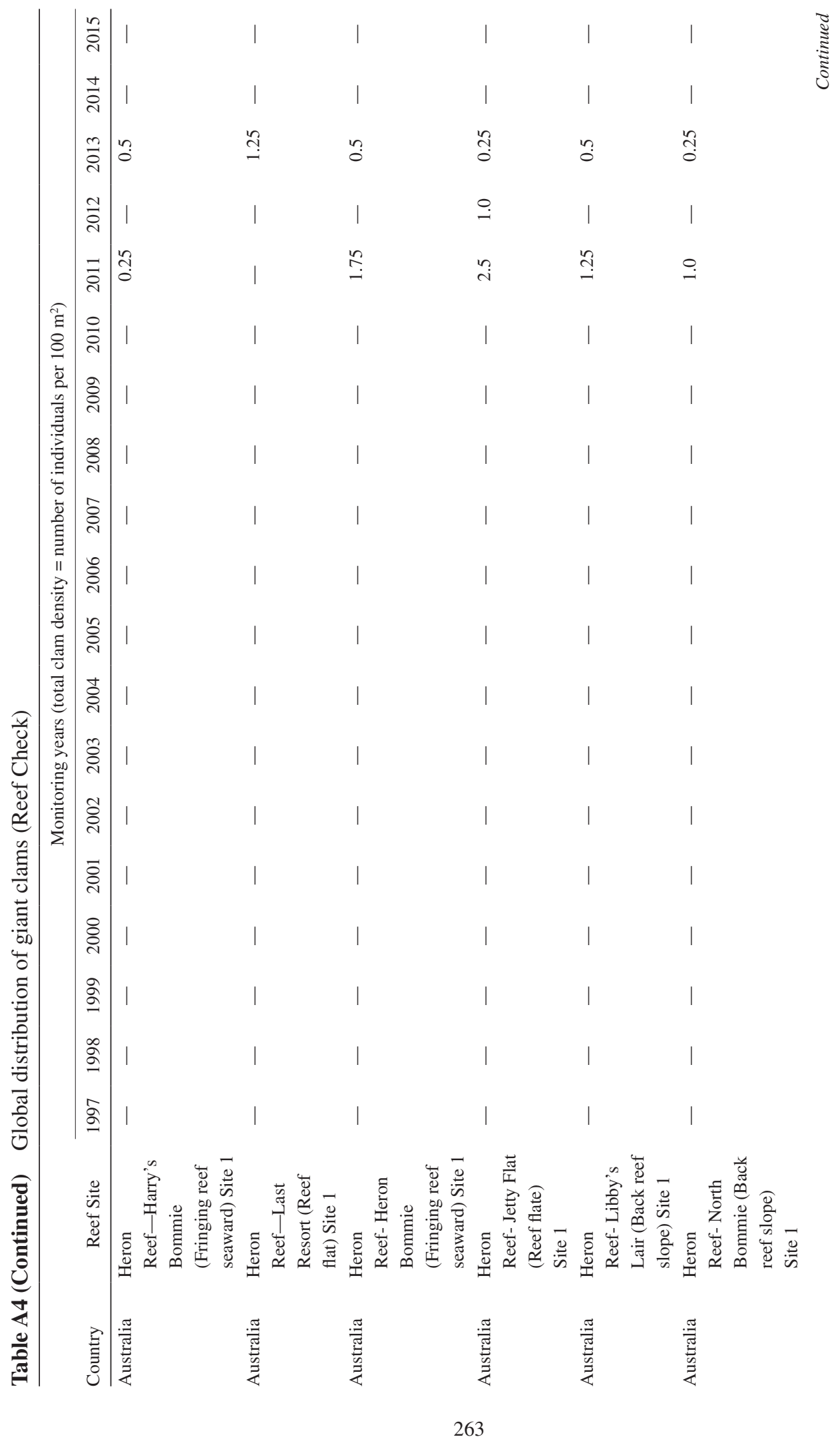


MEI LIN NEO ET AL.

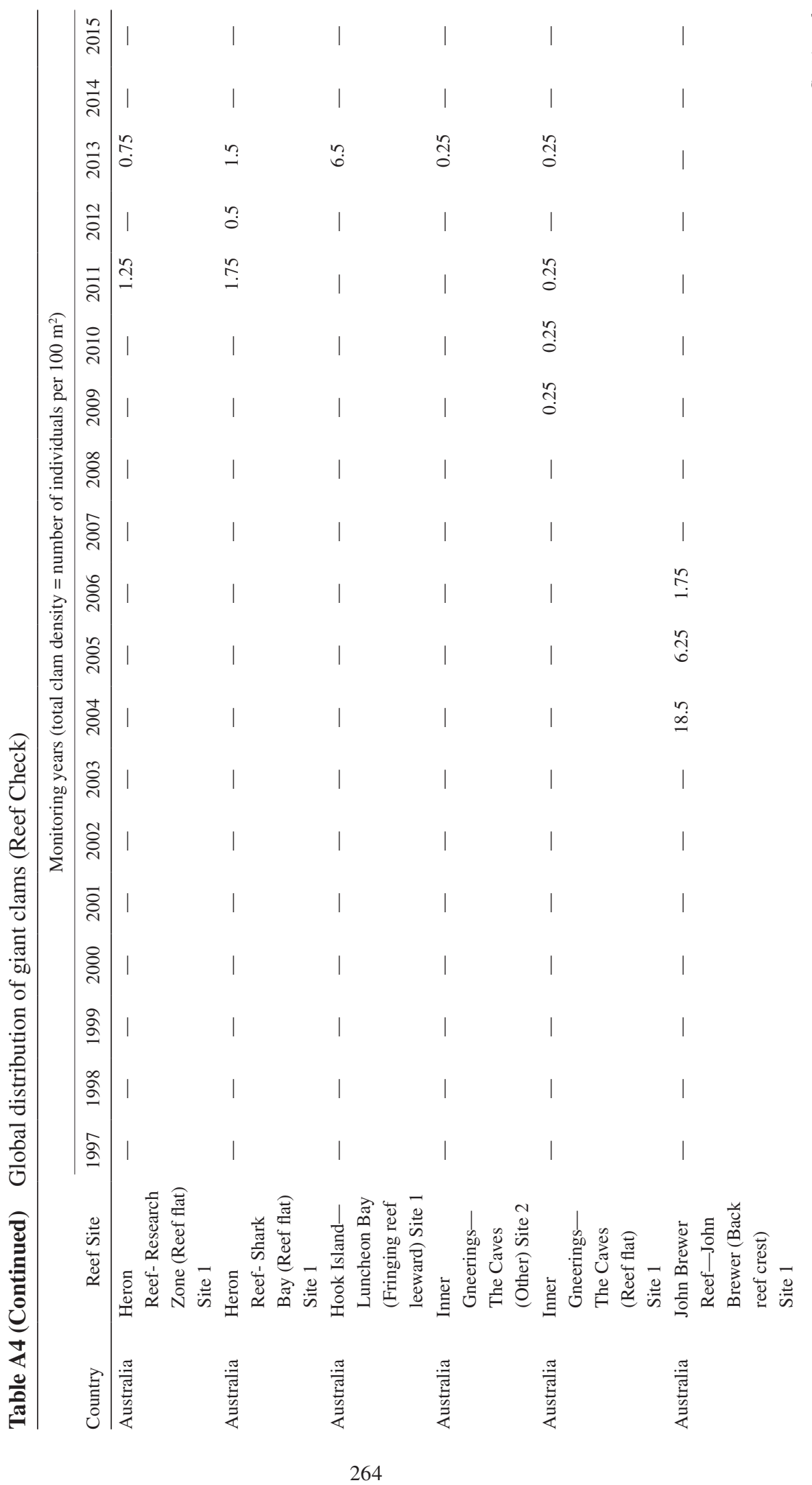


GIANT CLAMS (BIVALVIA: CARDIIDAE: TRIDACNINAE)

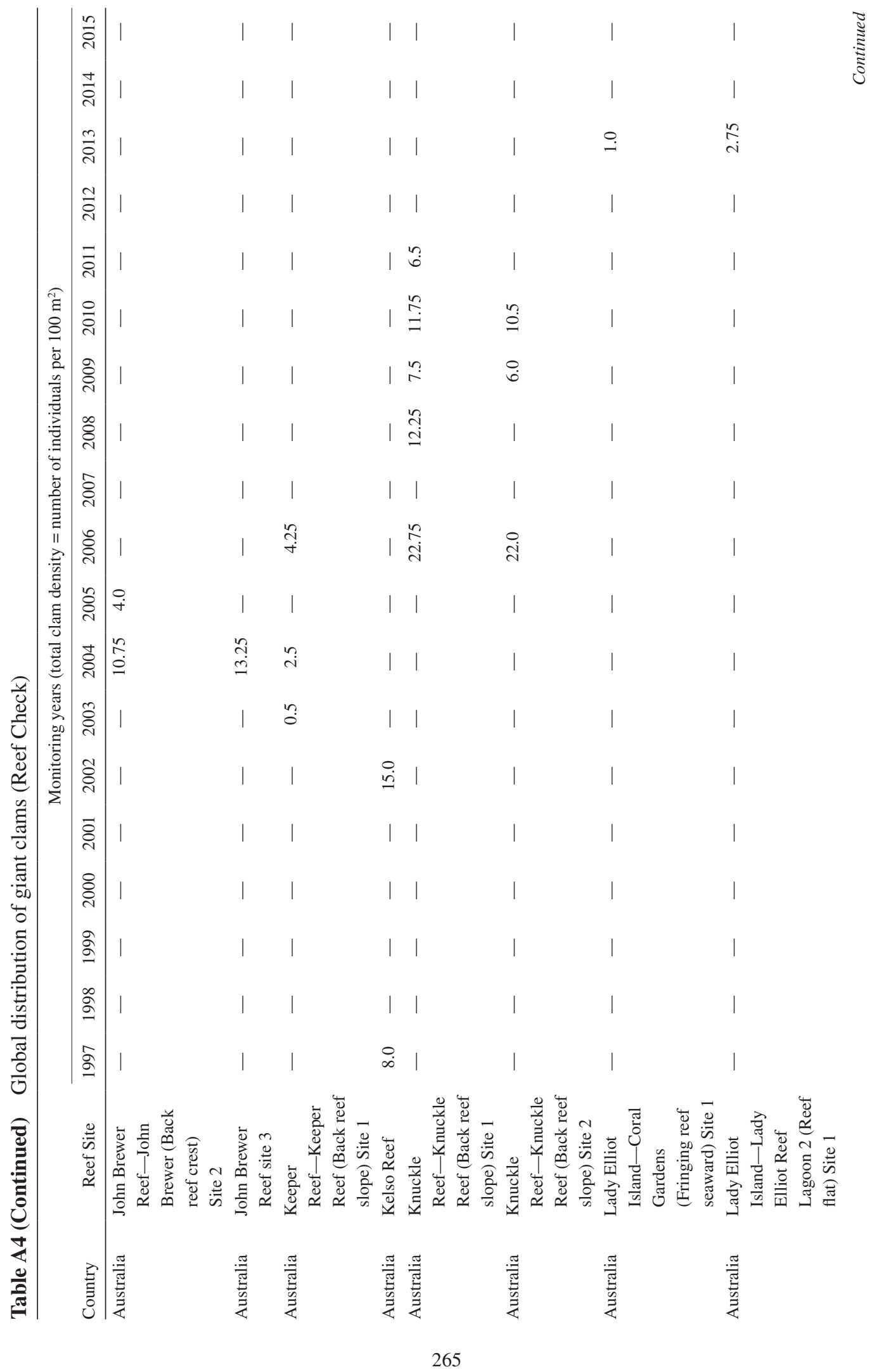


MEI LIN NEO ET AL.

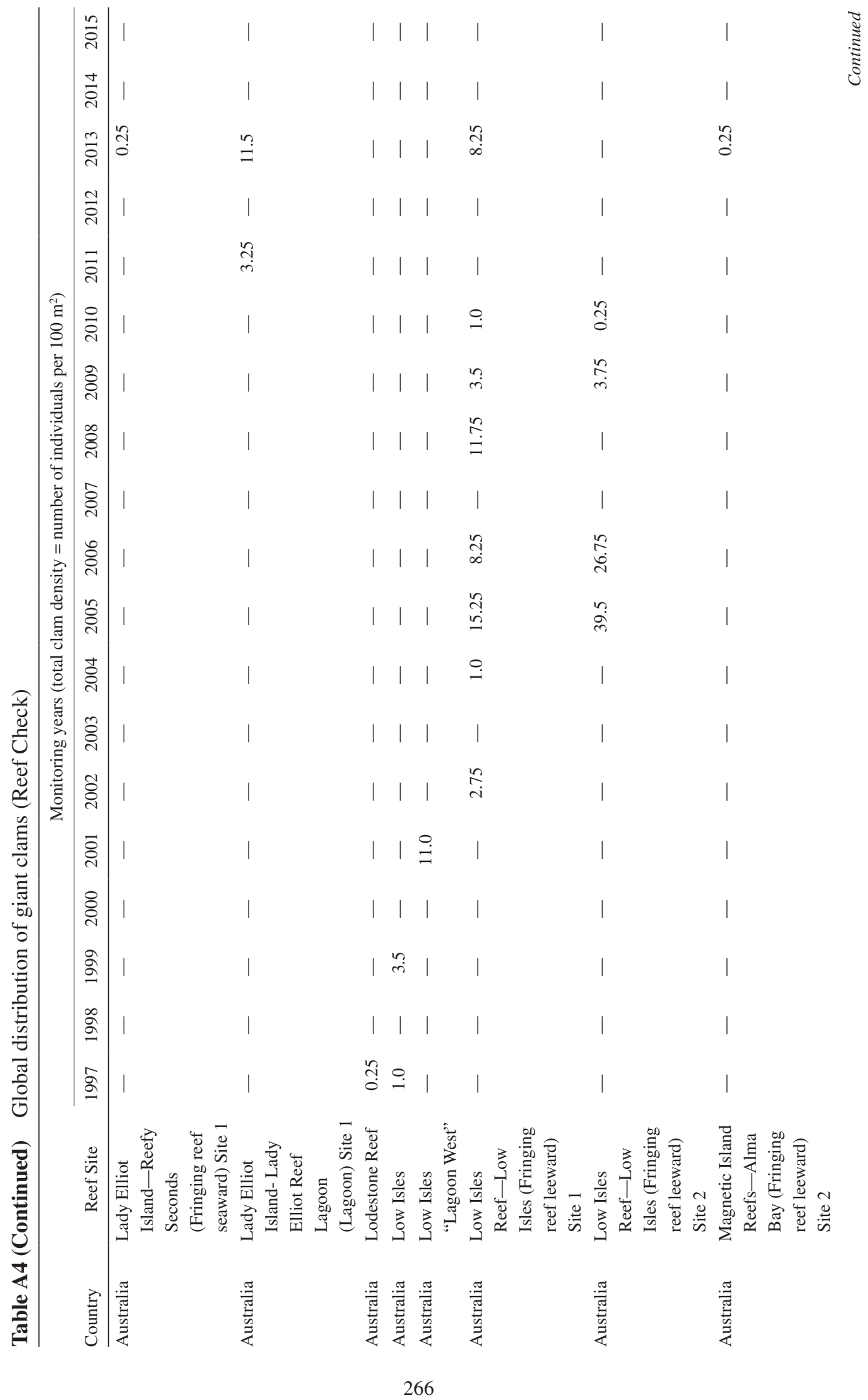


GIANT CLAMS (BIVALVIA: CARDIIDAE: TRIDACNINAE)

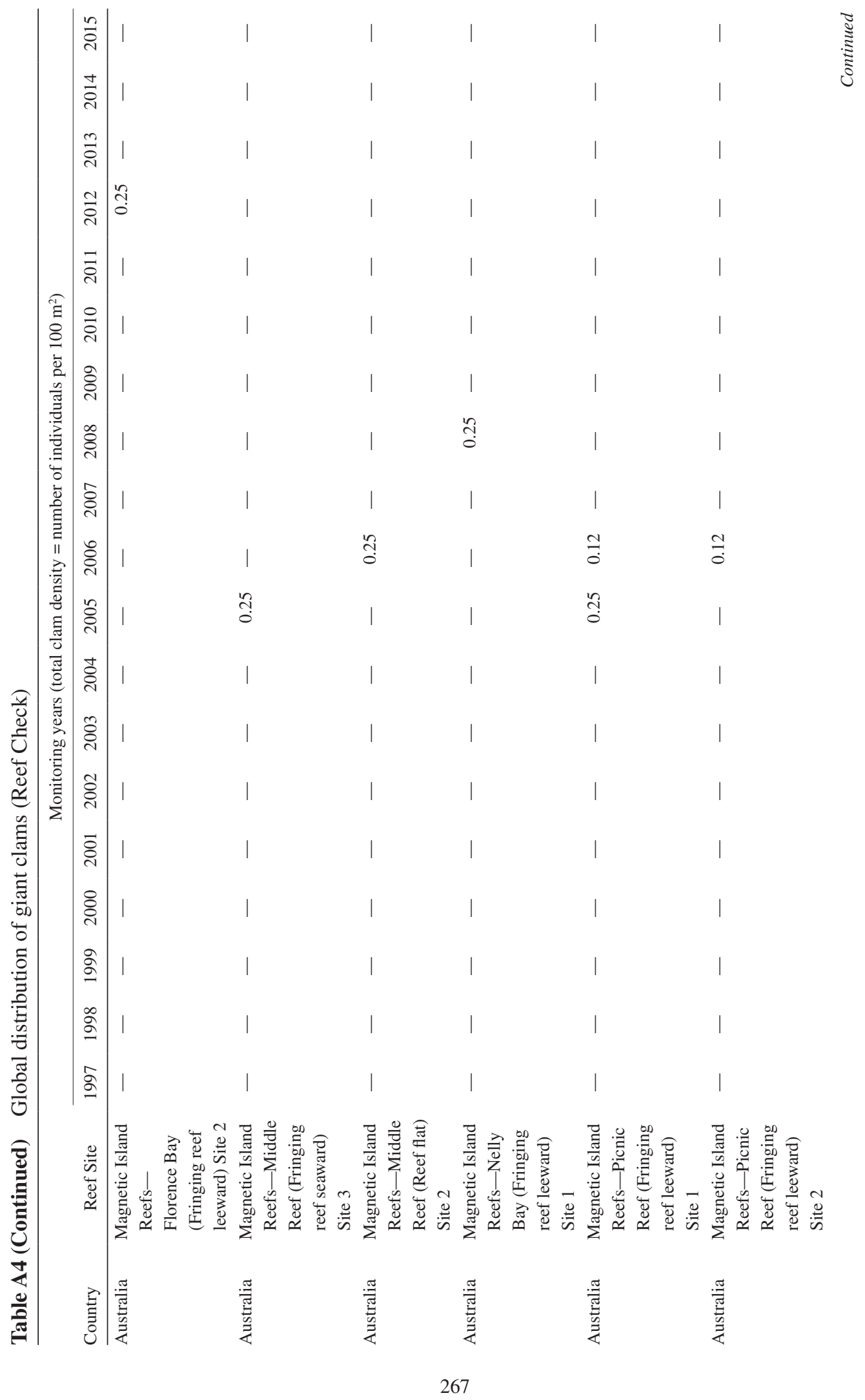


MEI LIN NEO ET AL.

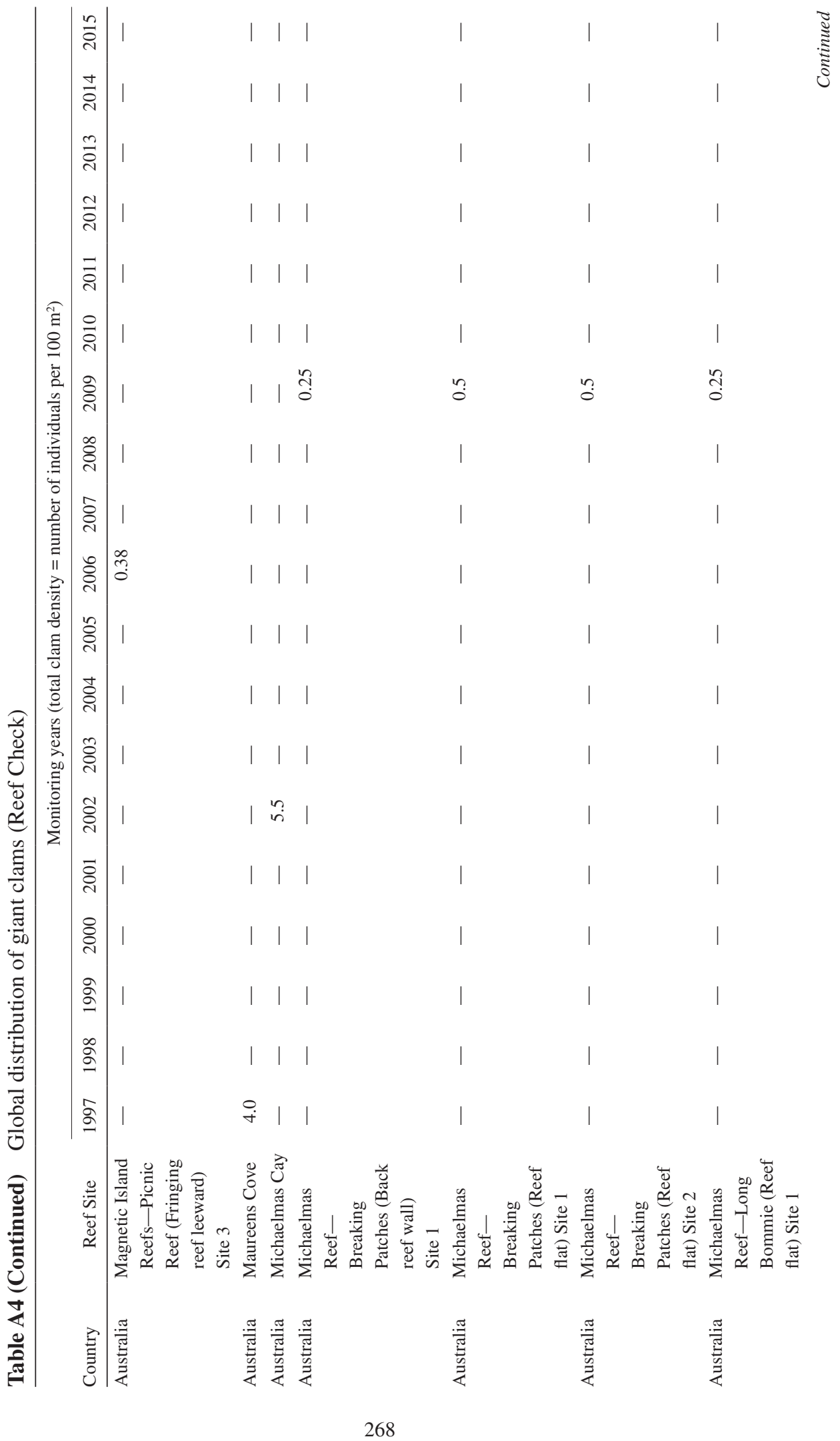


GIANT CLAMS (BIVALVIA: CARDIIDAE: TRIDACNINAE)

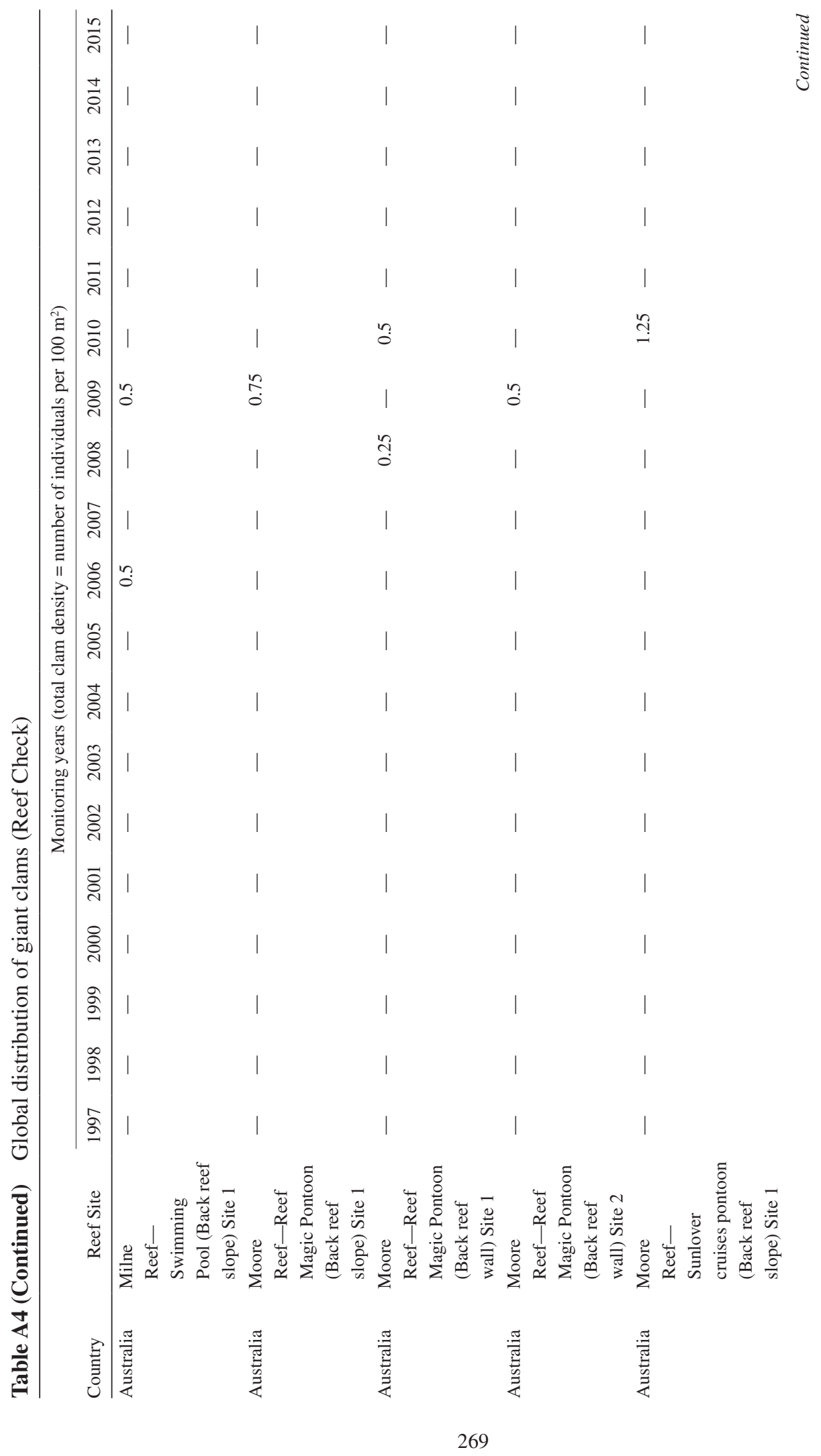


MEI LIN NEO ET AL.

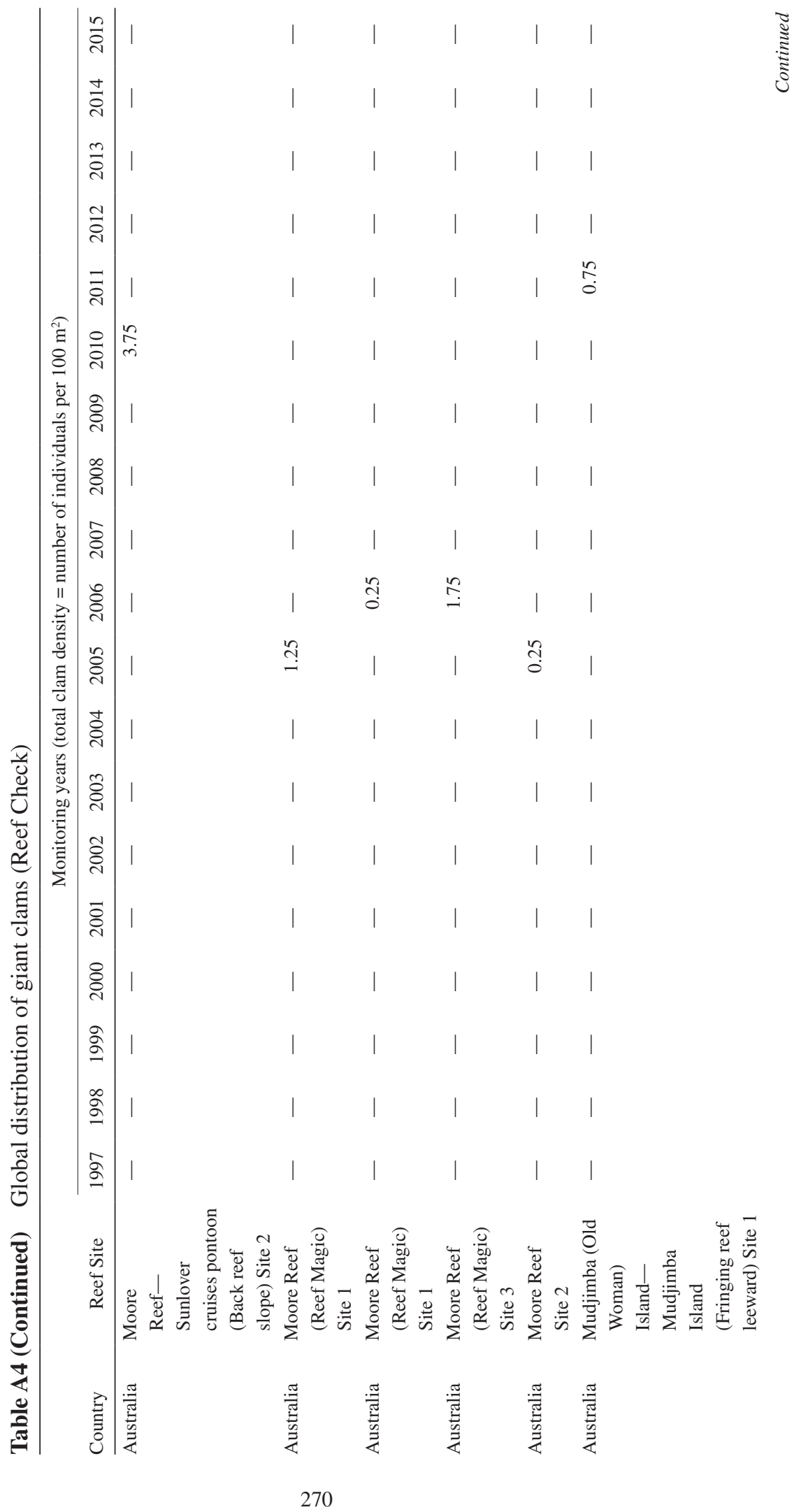


GIANT CLAMS (BIVALVIA: CARDIIDAE: TRIDACNINAE)

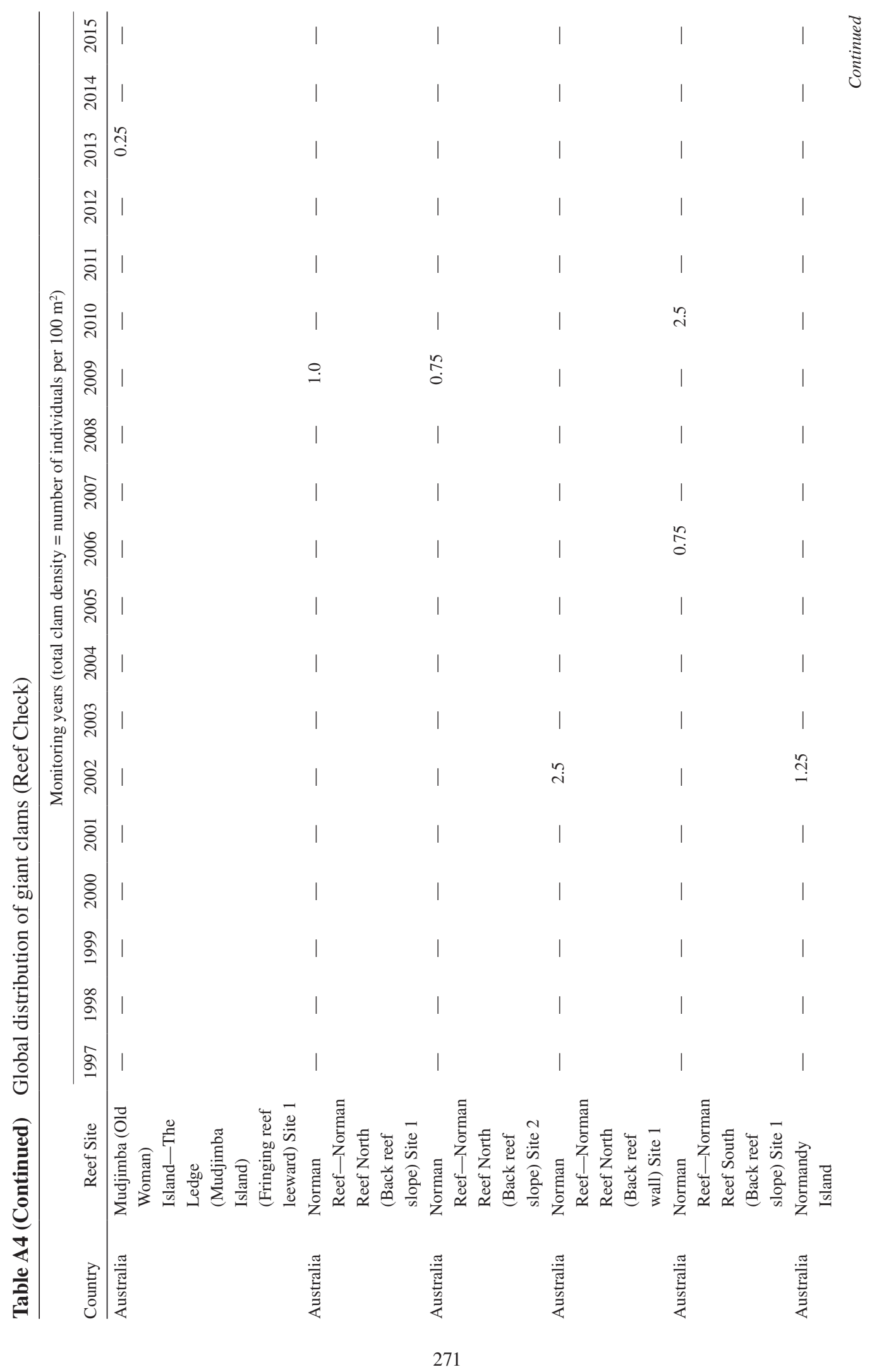


MEI LIN NEO ET AL.

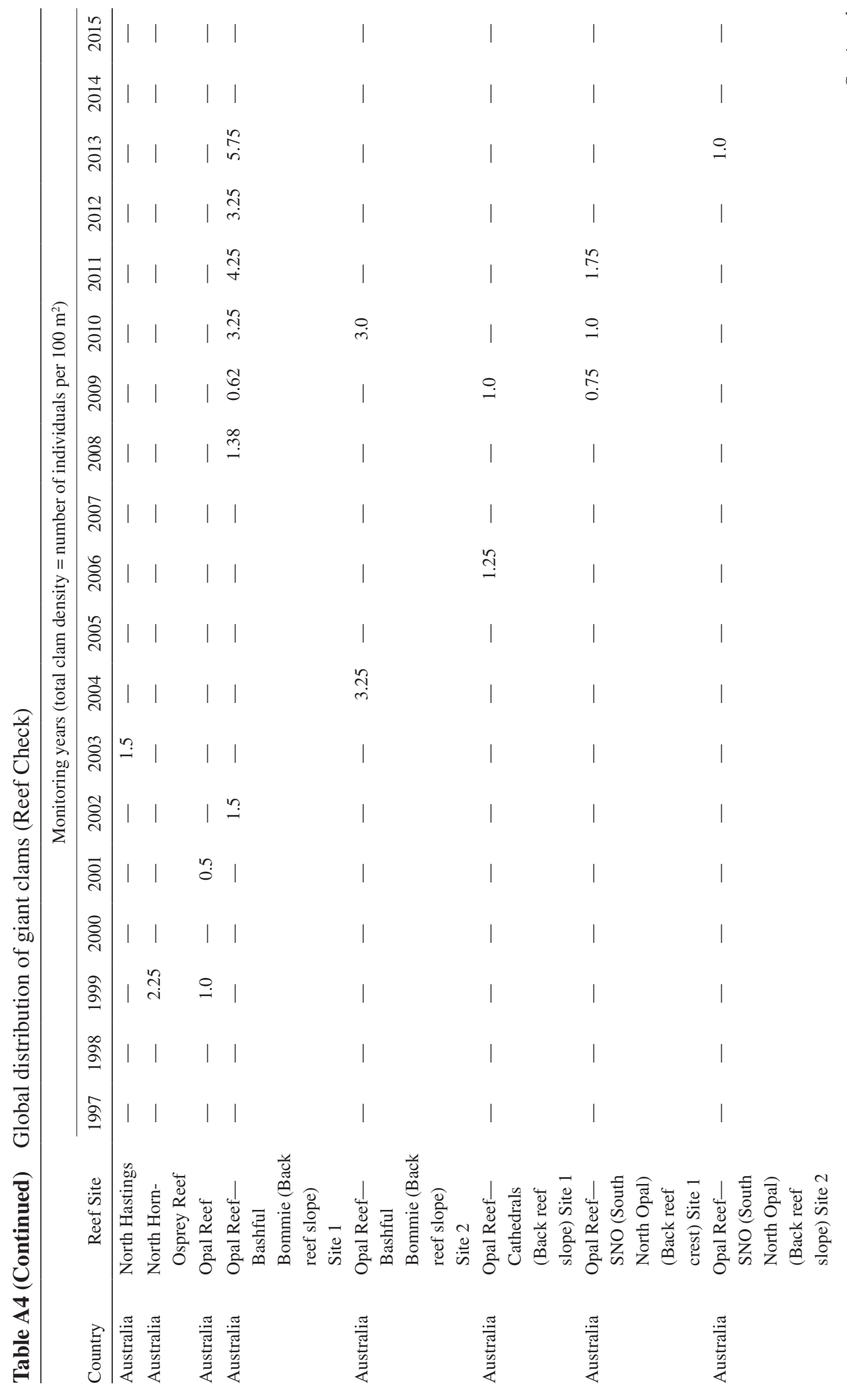


GIANT CLAMS (BIVALVIA: CARDIIDAE: TRIDACNINAE)

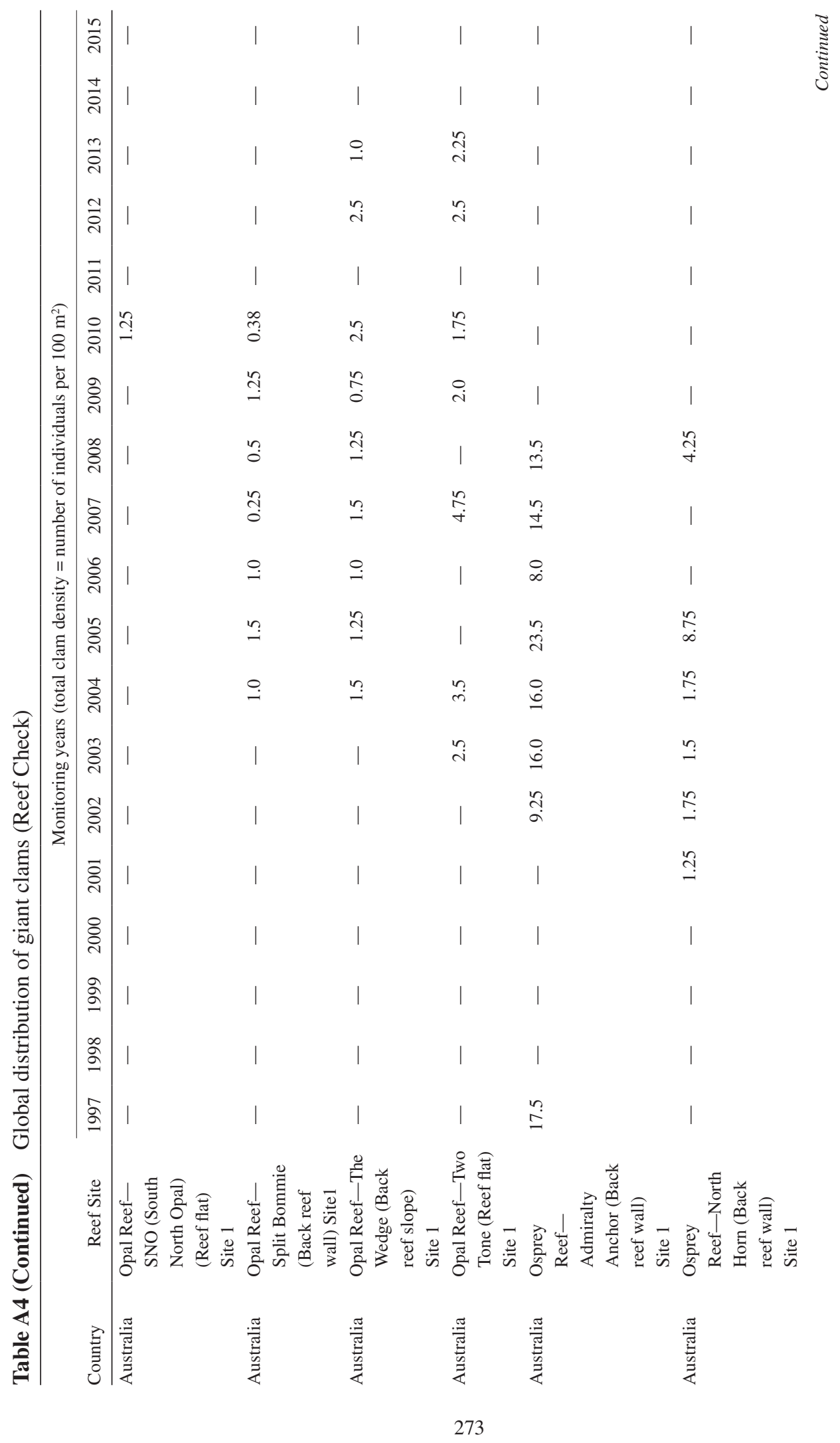


MEI LIN NEO ET AL.

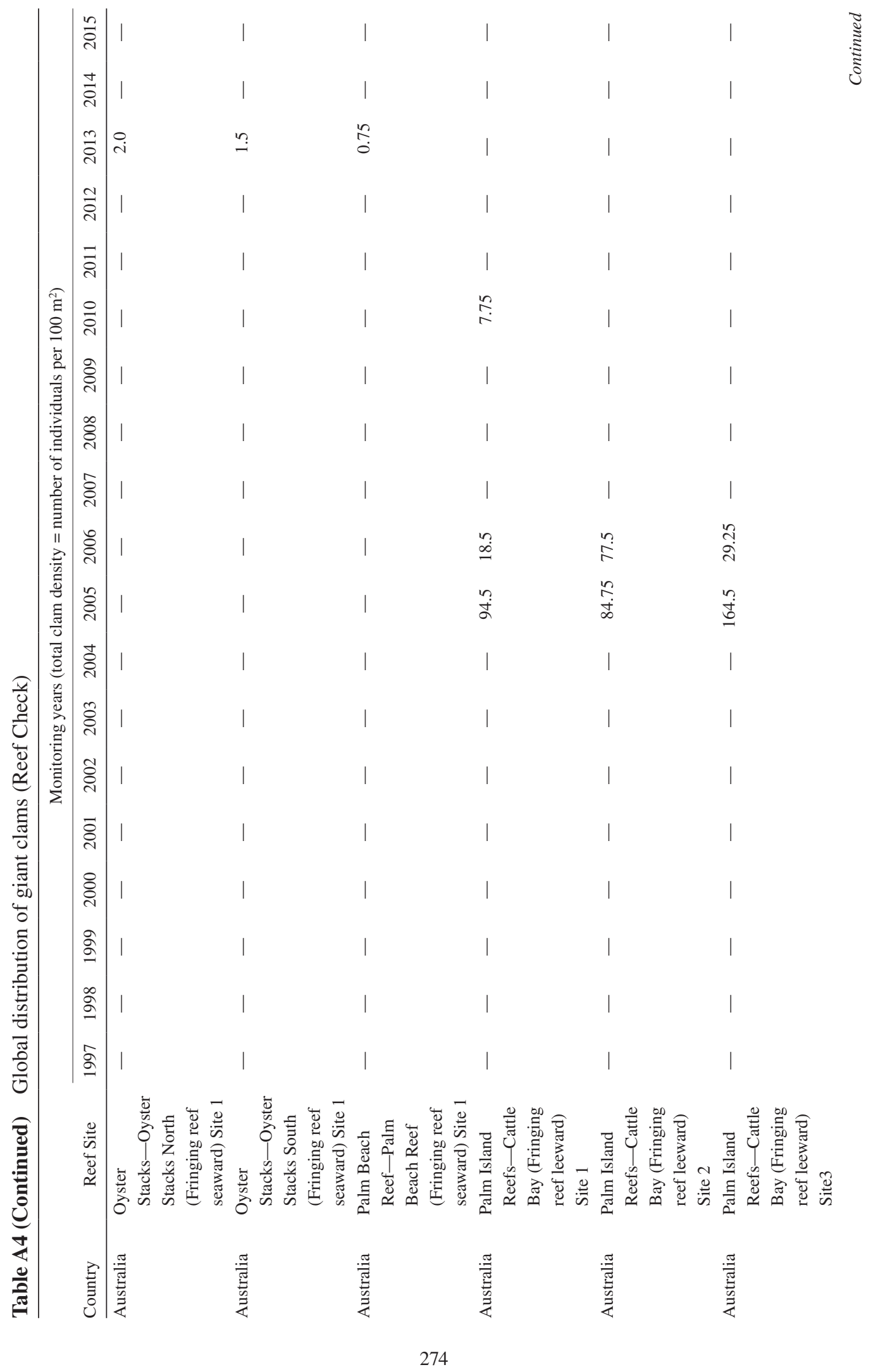


GIANT CLAMS (BIVALVIA: CARDIIDAE: TRIDACNINAE)

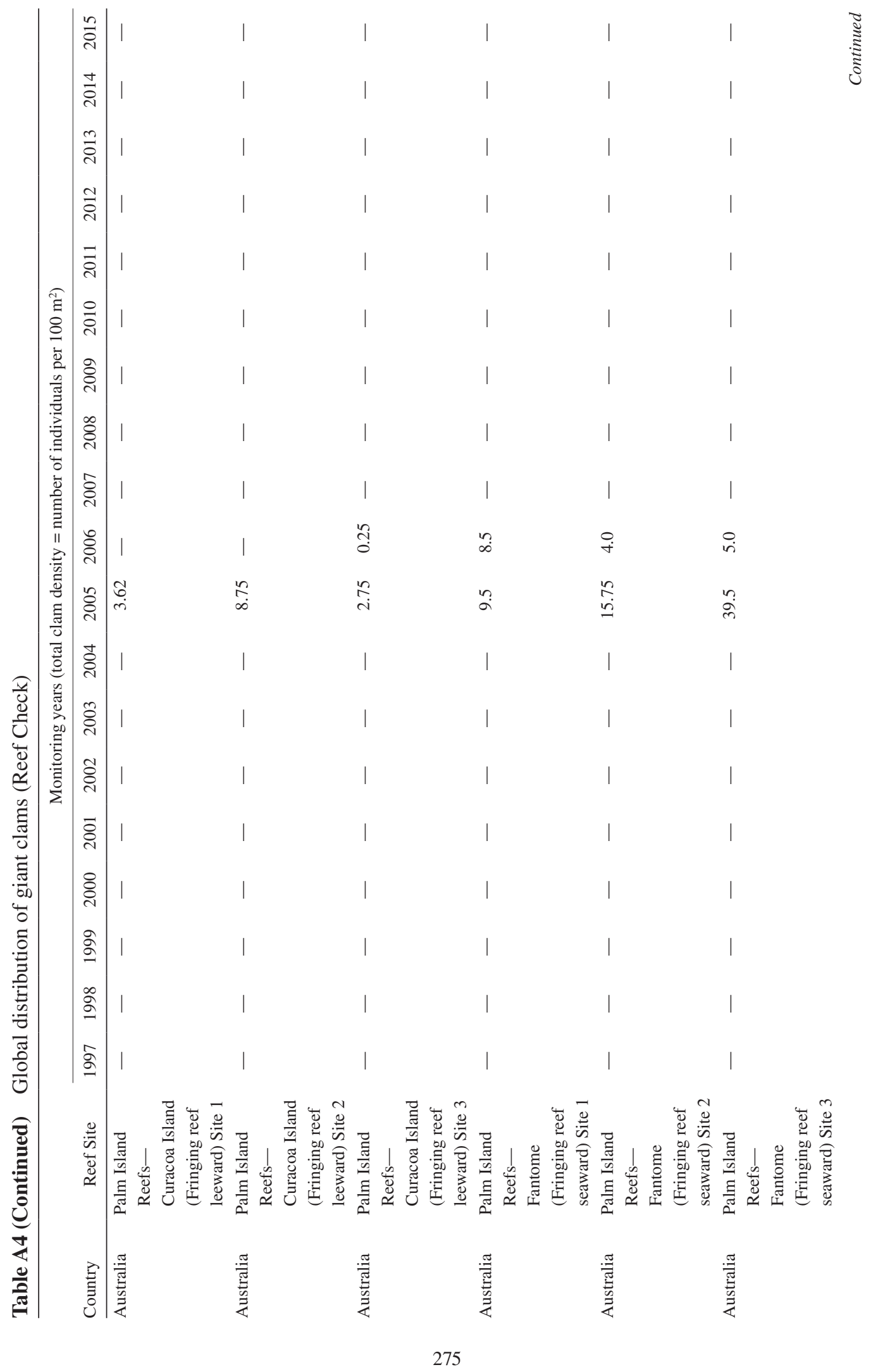


MEI LIN NEO ET AL.

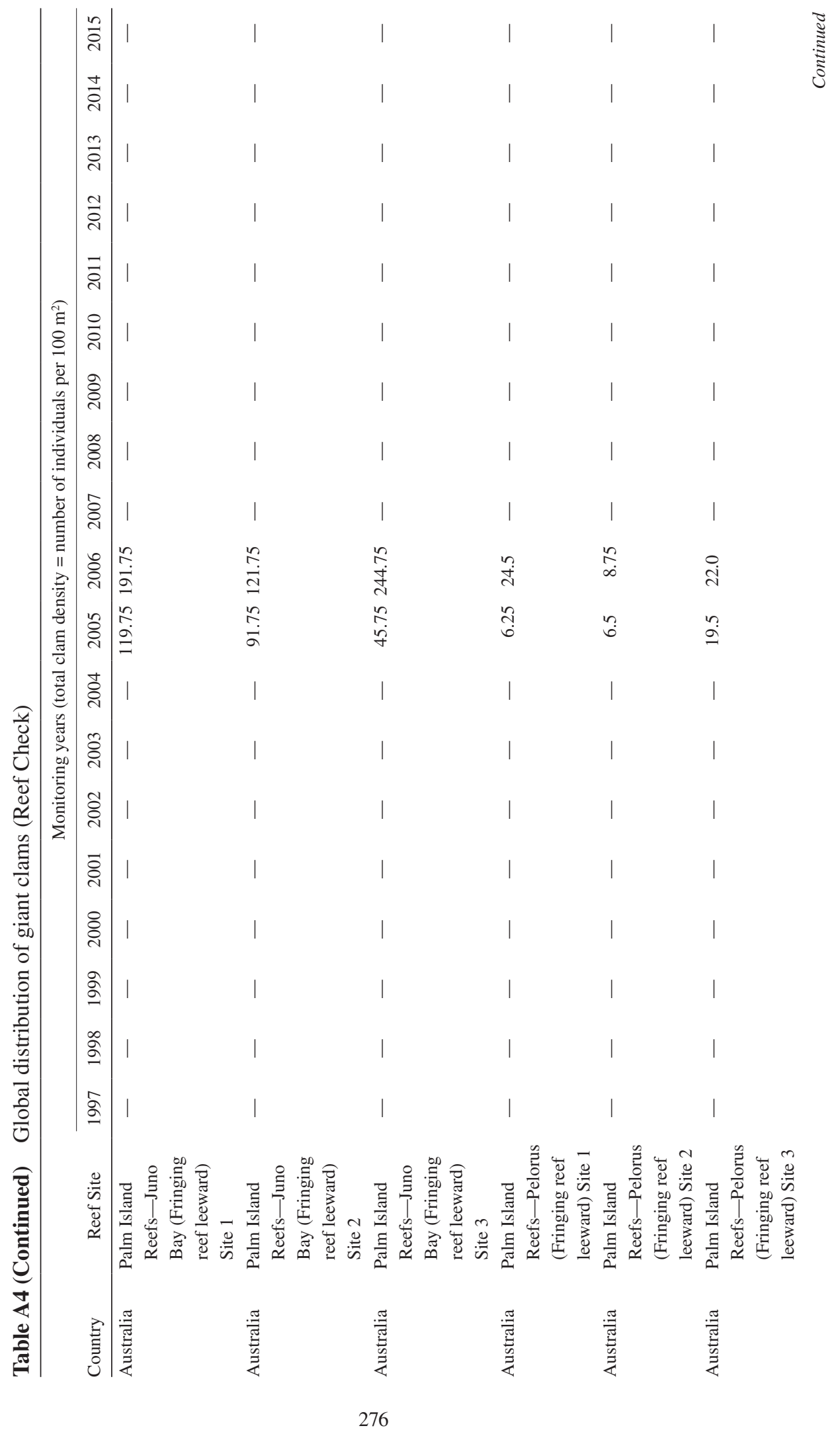


GIANT CLAMS (BIVALVIA: CARDIIDAE: TRIDACNINAE)

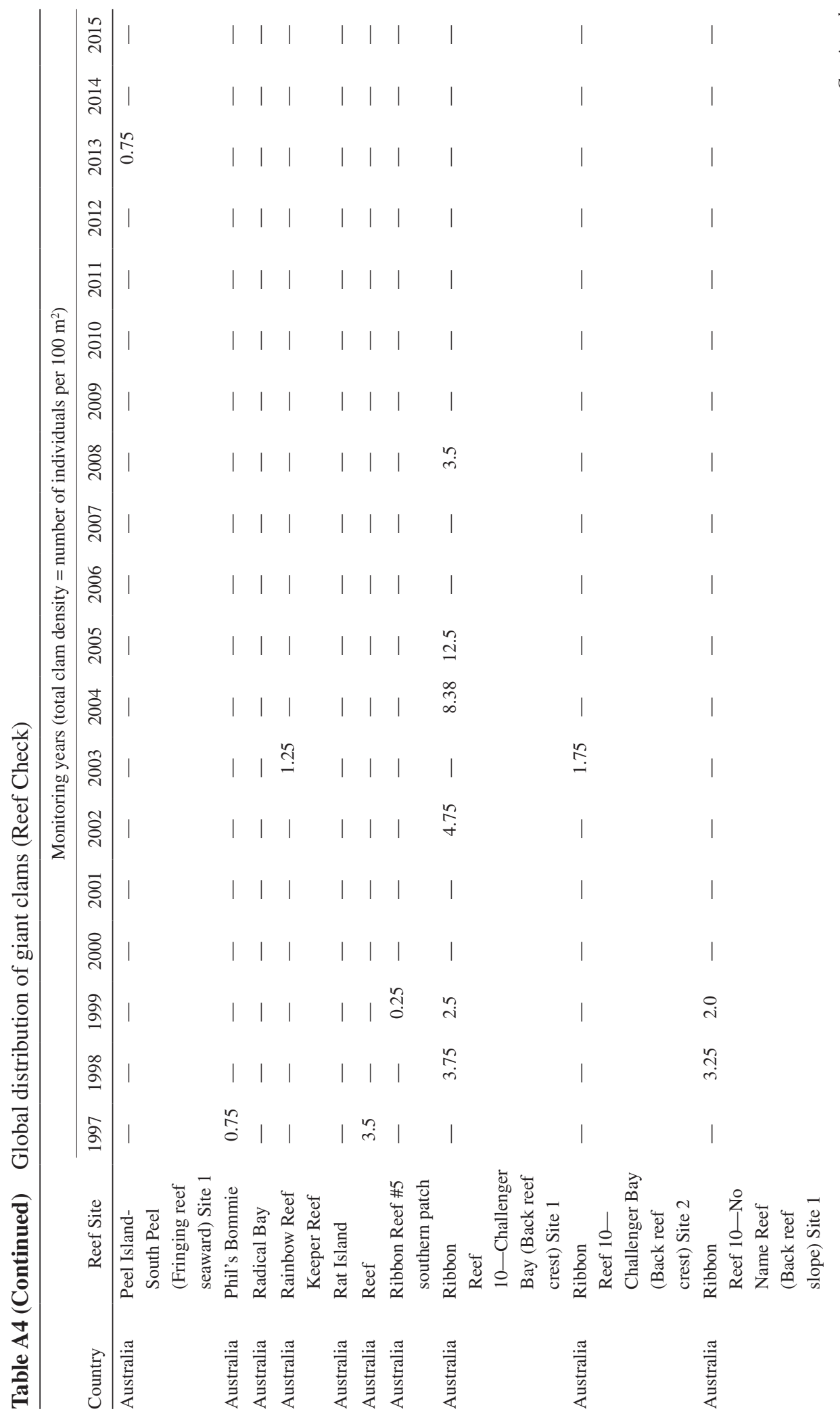


MEI LIN NEO ET AL.

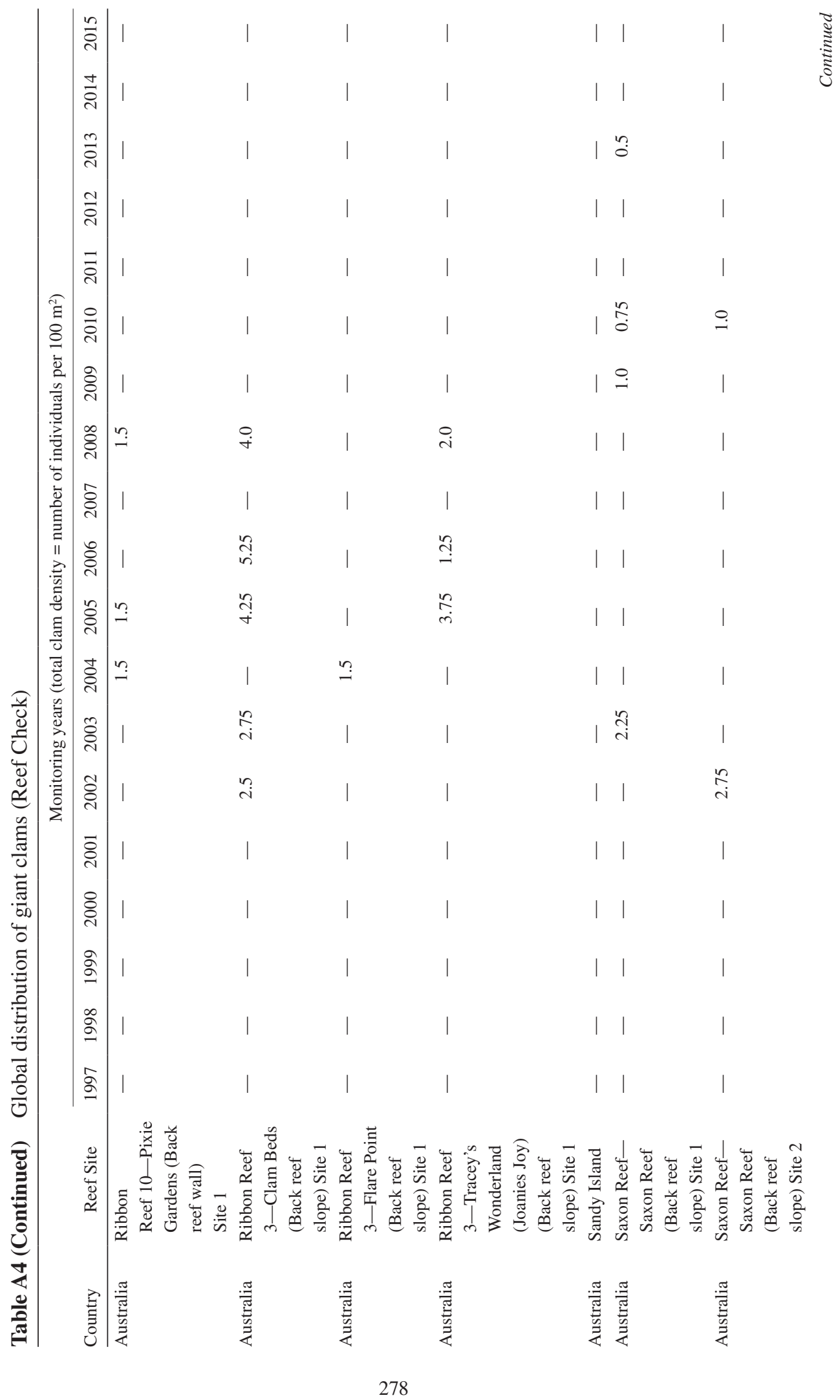


GIANT CLAMS (BIVALVIA: CARDIIDAE: TRIDACNINAE)

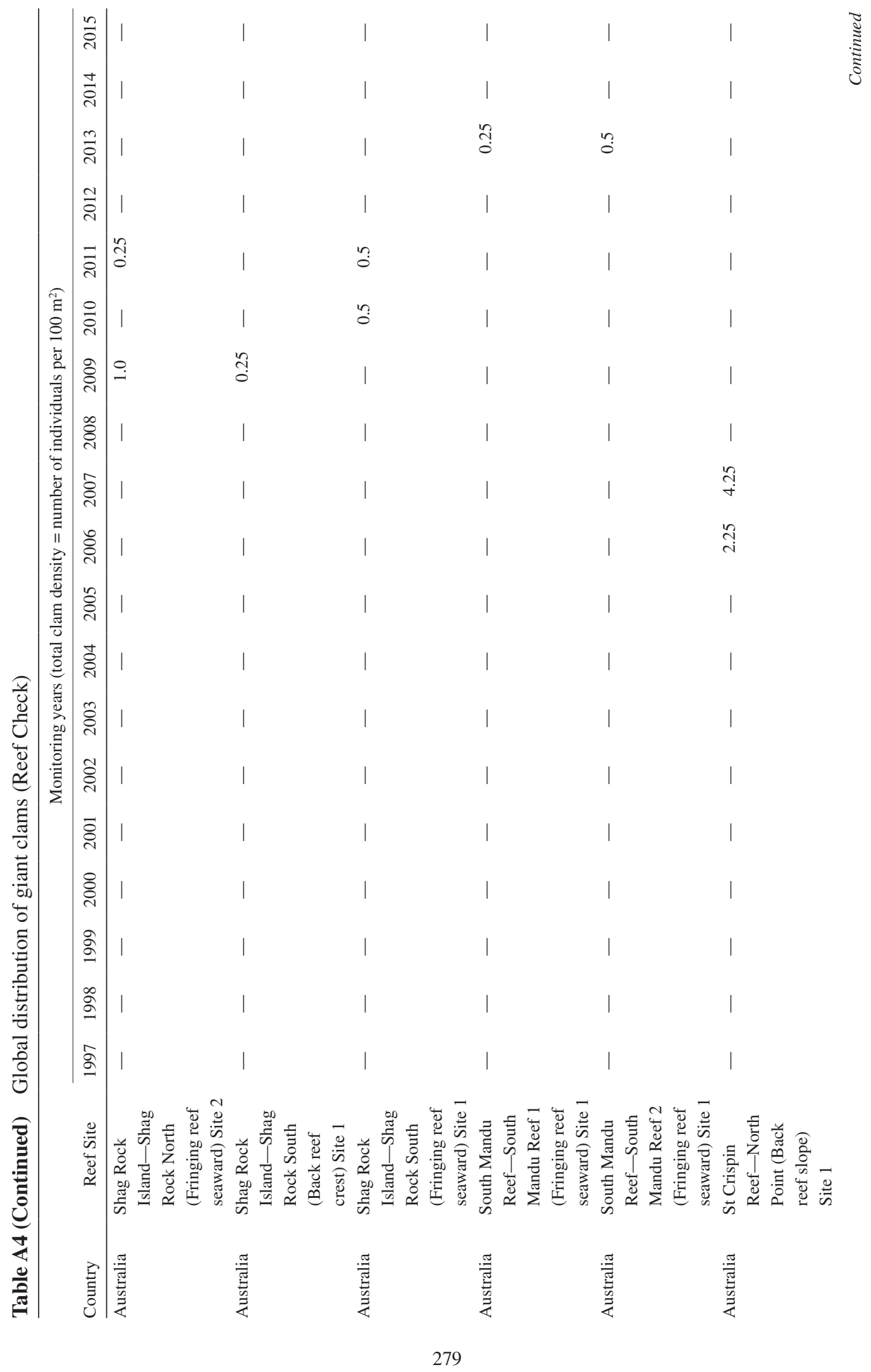


MEI LIN NEO ET AL.

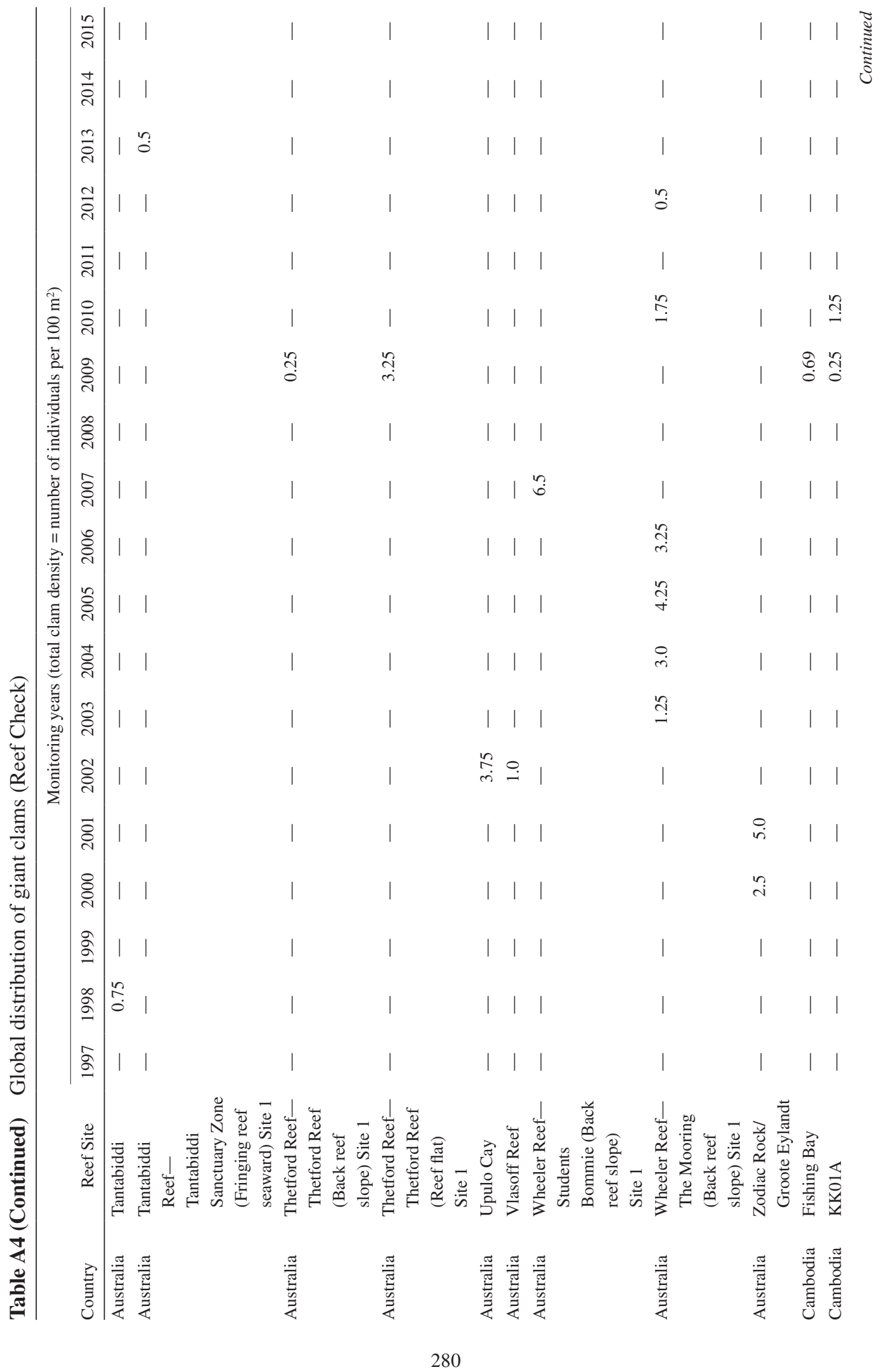


GIANT CLAMS (BIVALVIA: CARDIIDAE: TRIDACNINAE)

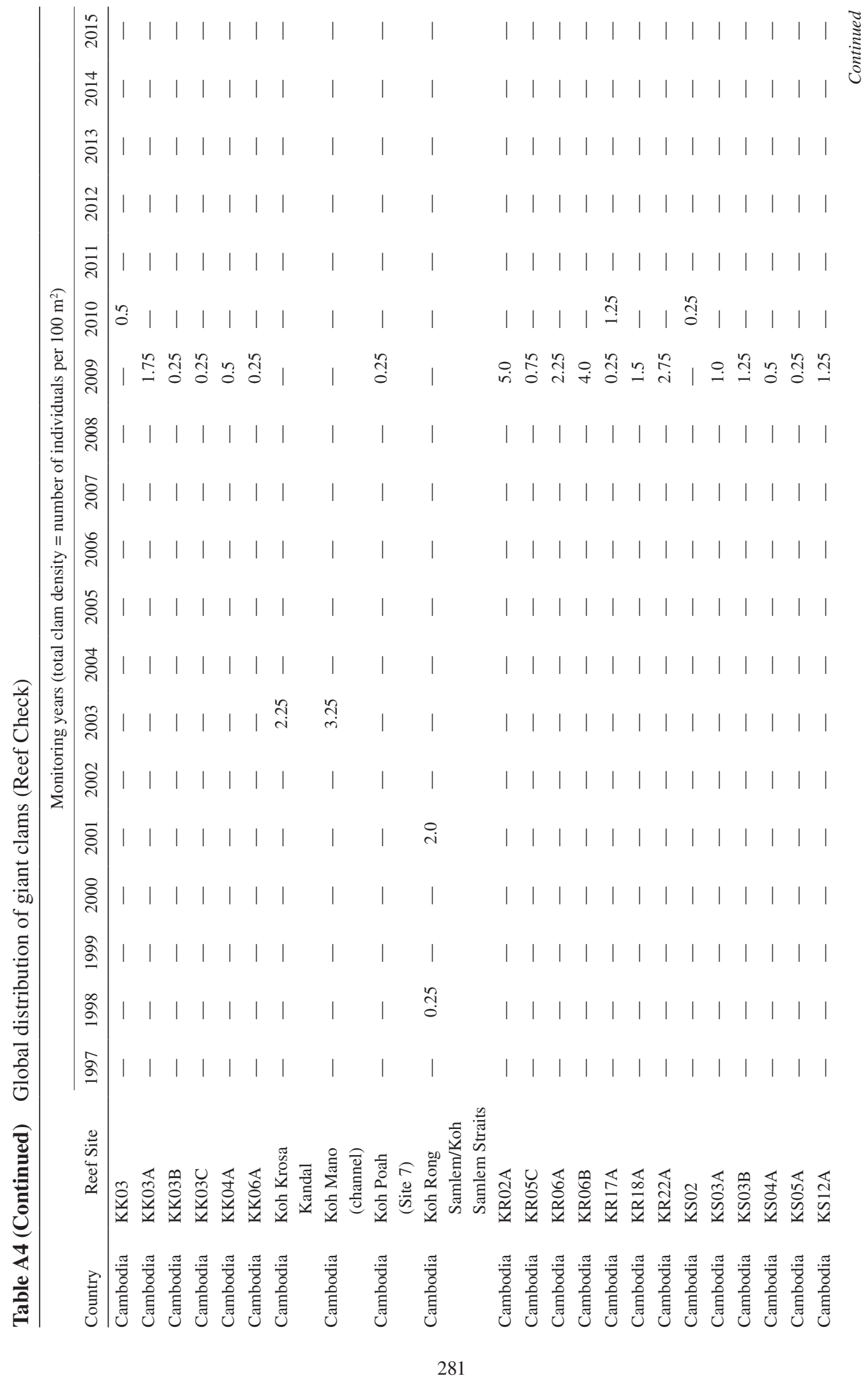


MEI LIN NEO ET AL.

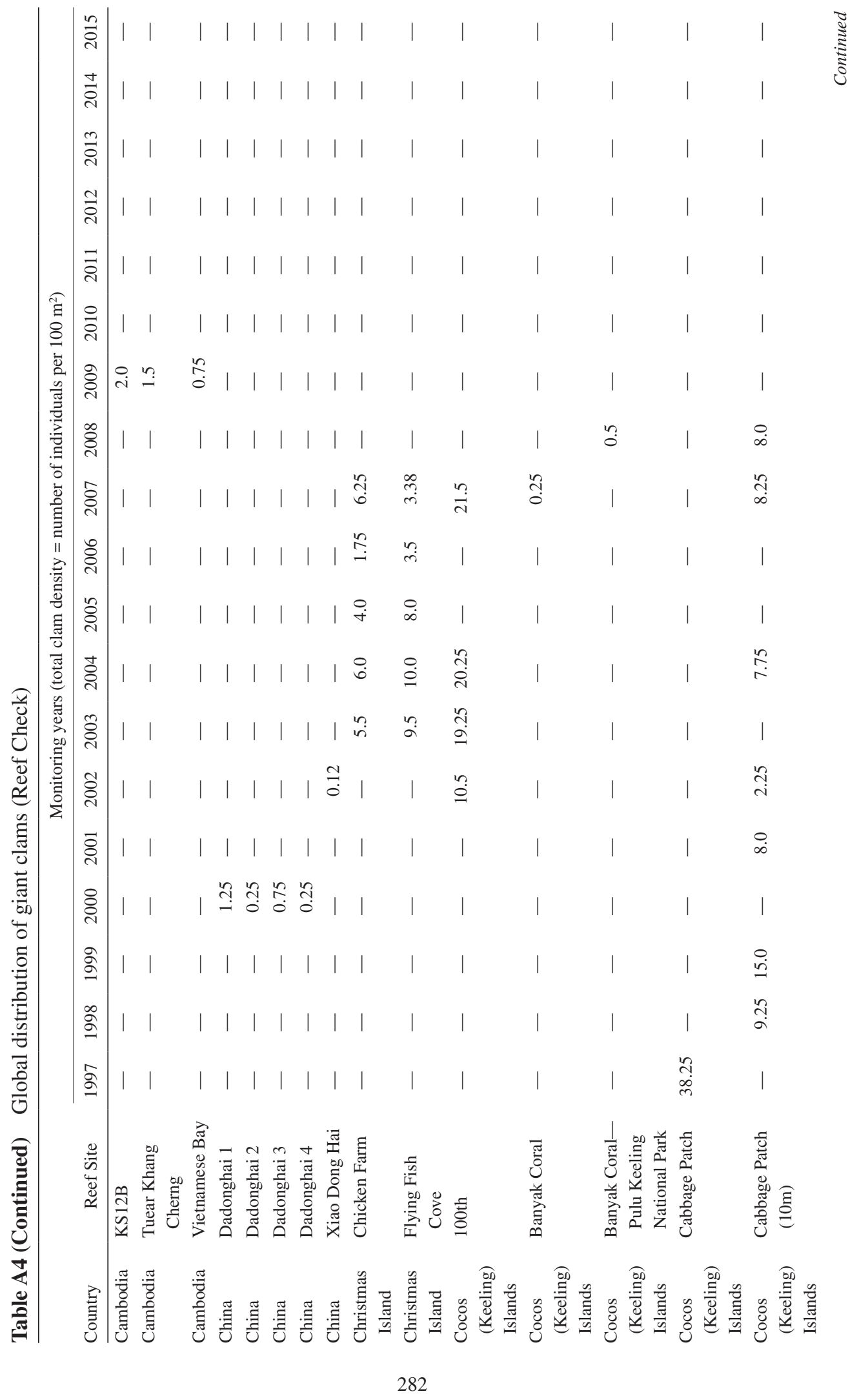


GIANT CLAMS (BIVALVIA: CARDIIDAE: TRIDACNINAE)

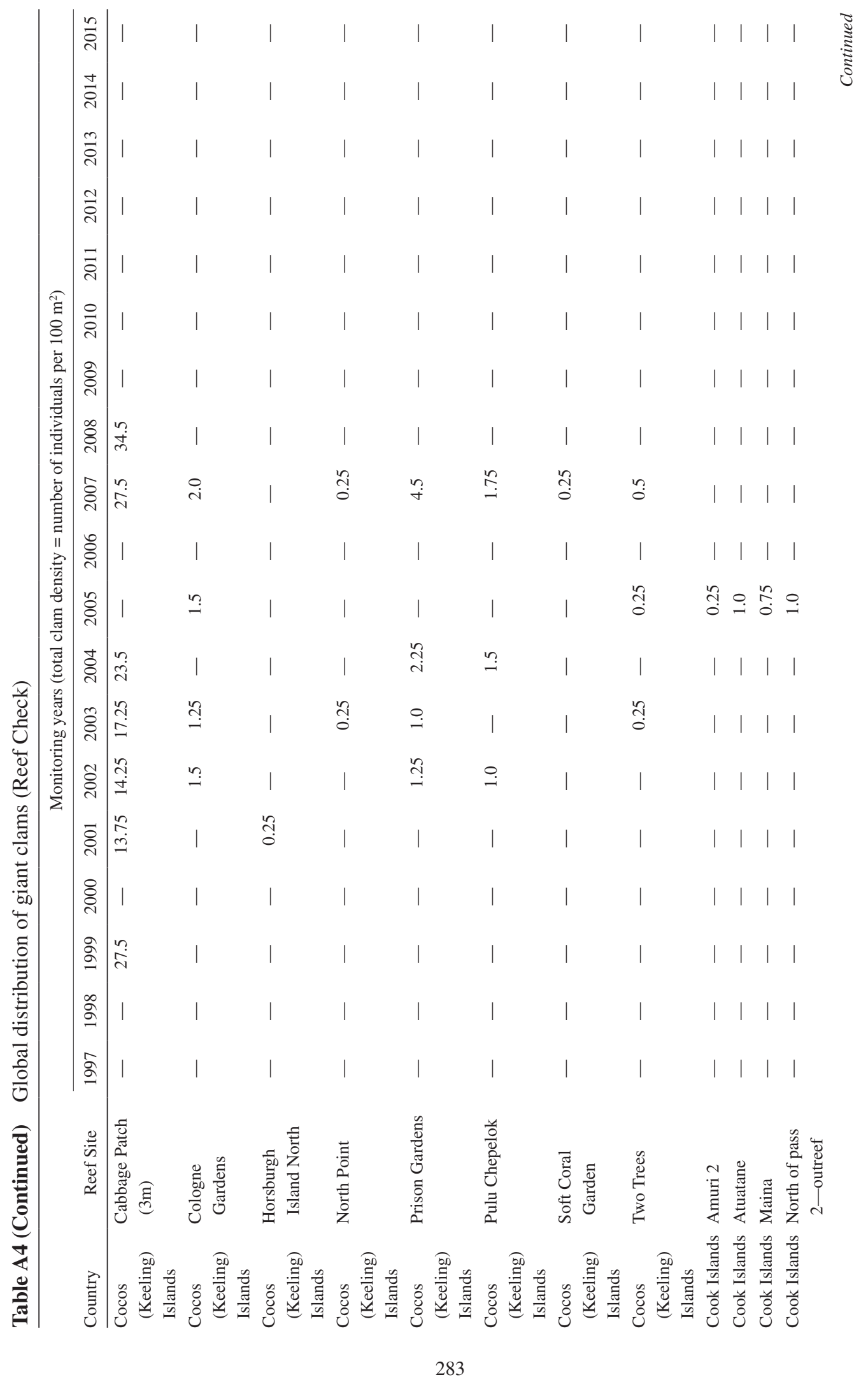


MEI LIN NEO ET AL.

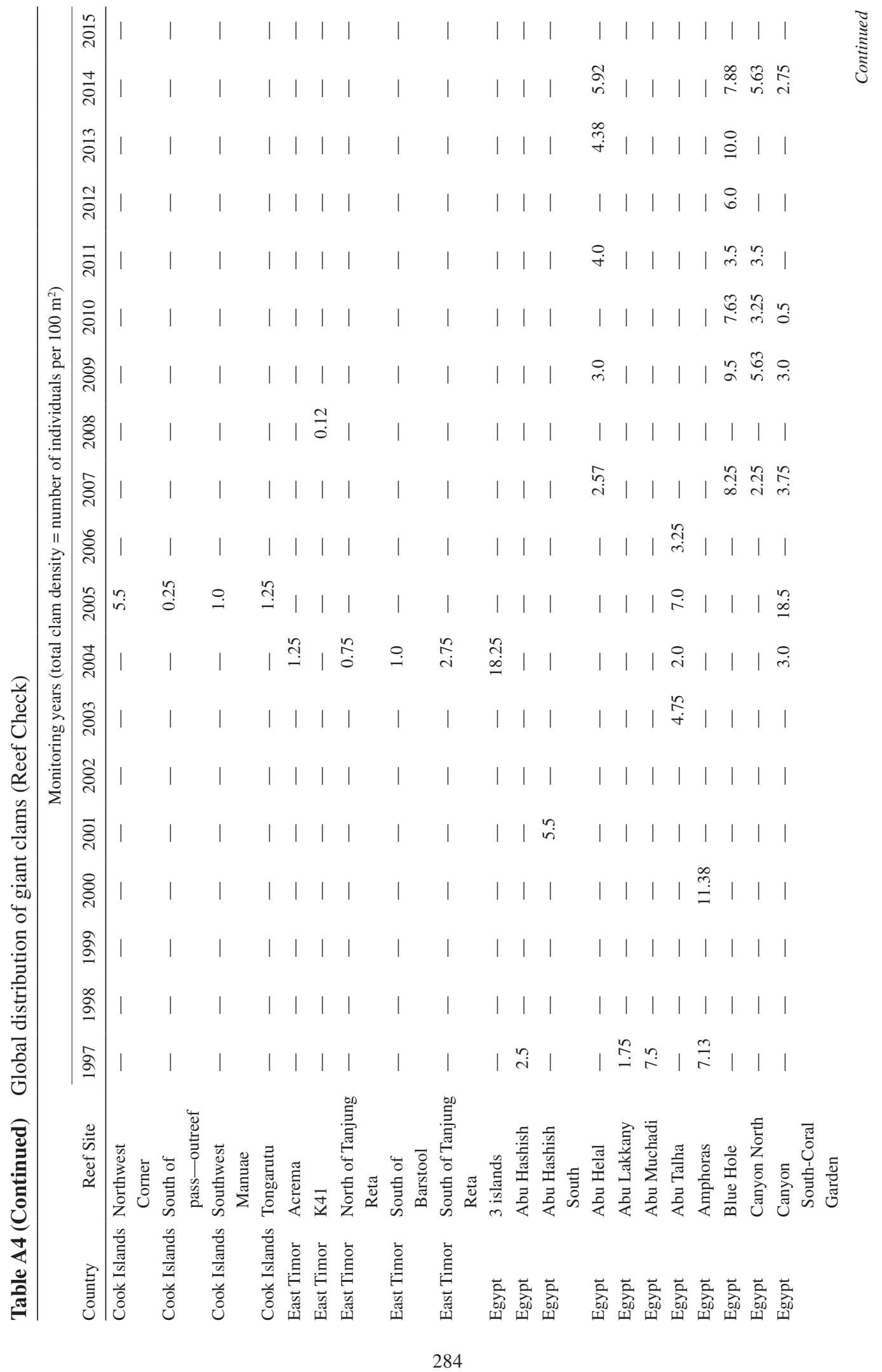


GIANT CLAMS (BIVALVIA: CARDIIDAE: TRIDACNINAE)

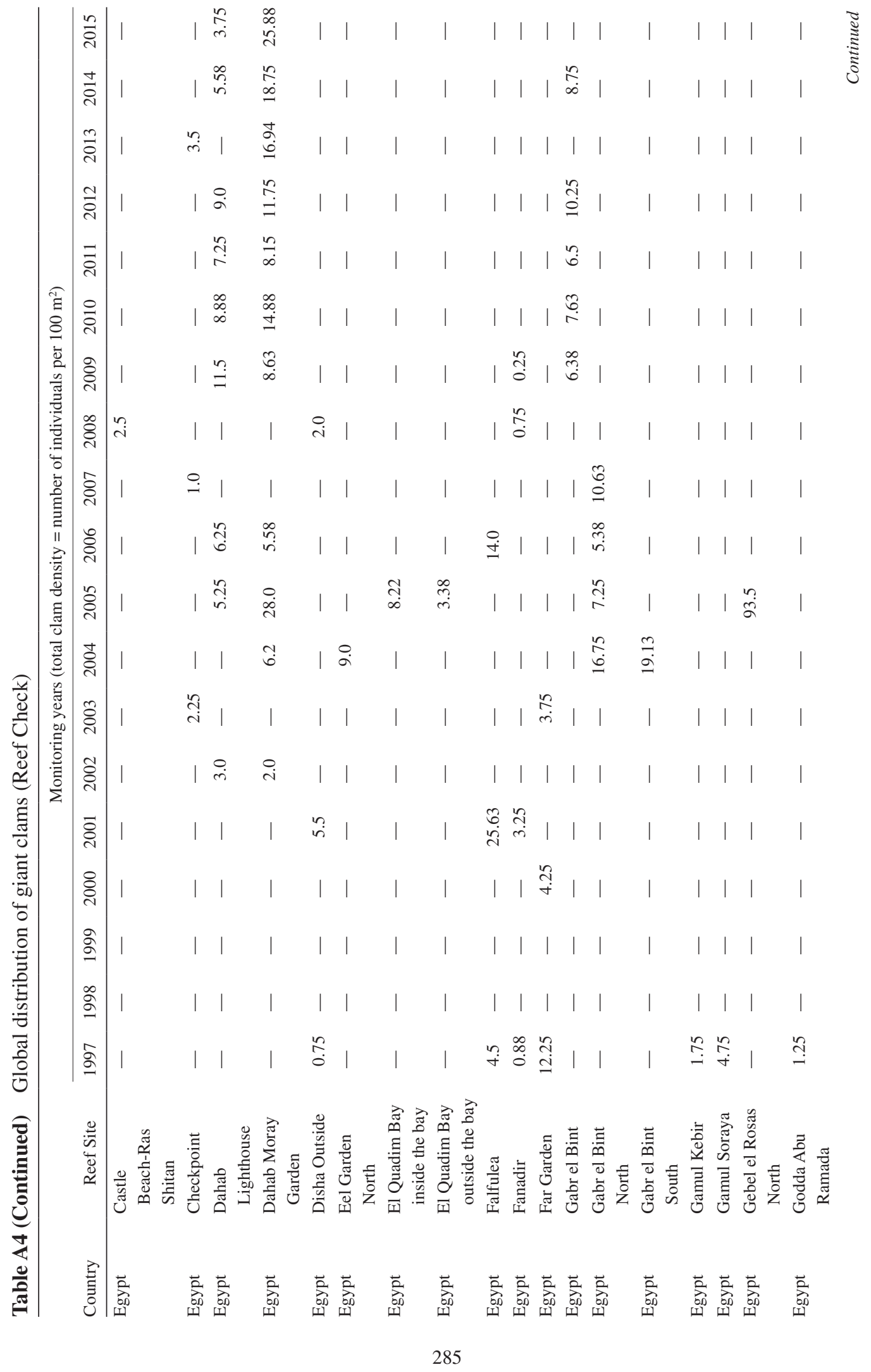


MEI LIN NEO ET AL.

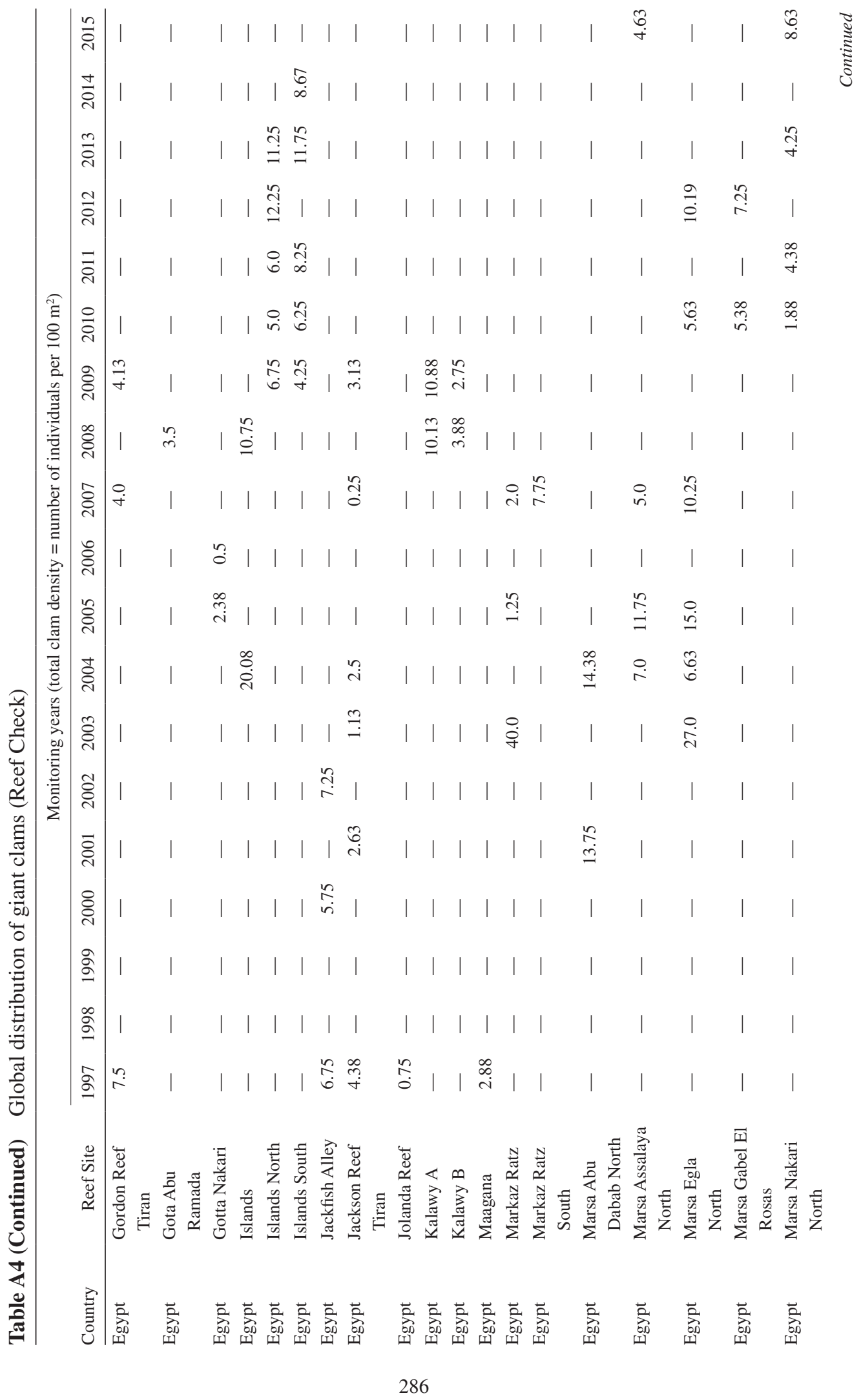


GIANT CLAMS (BIVALVIA: CARDIIDAE: TRIDACNINAE)

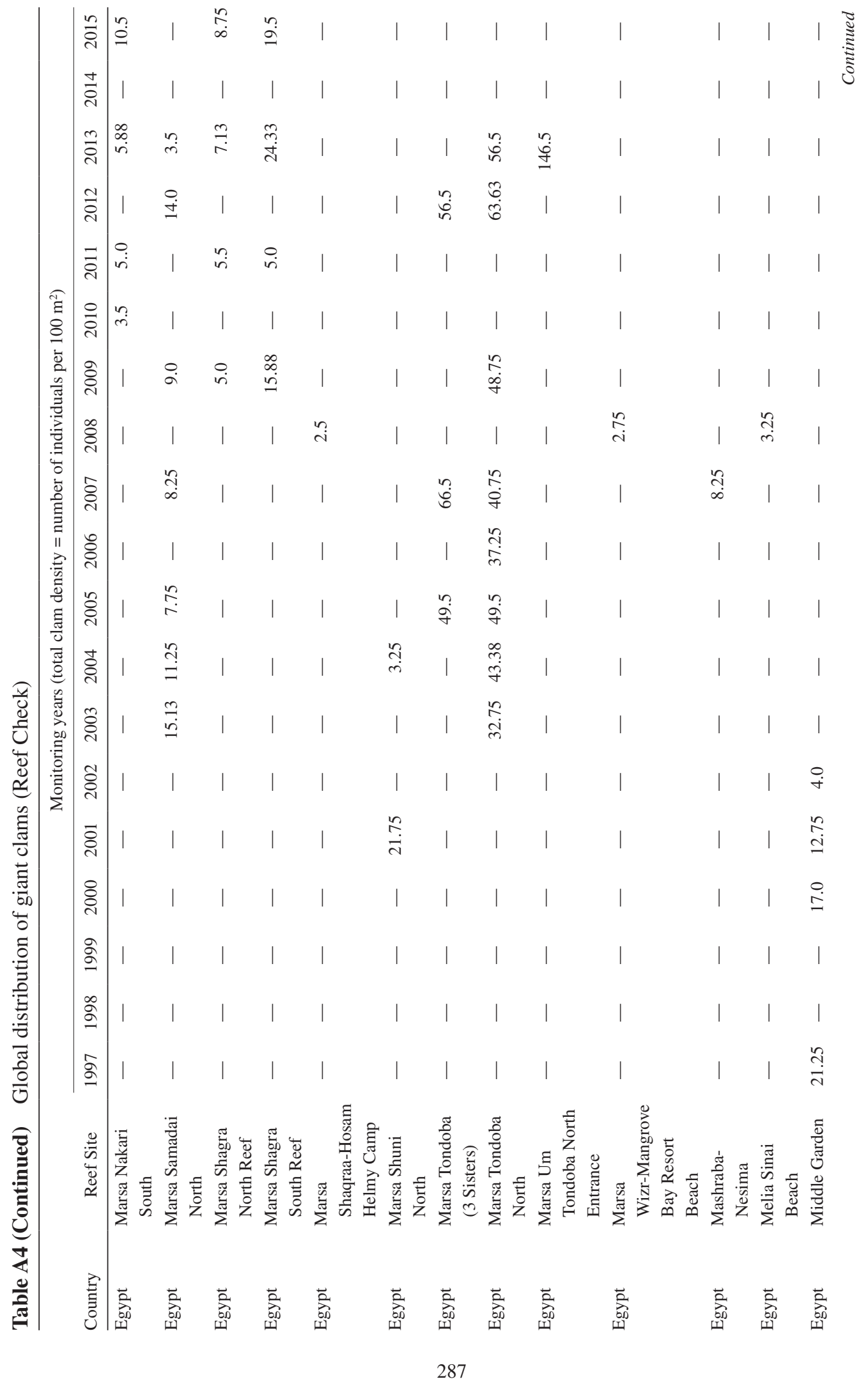


MEI LIN NEO ET AL.

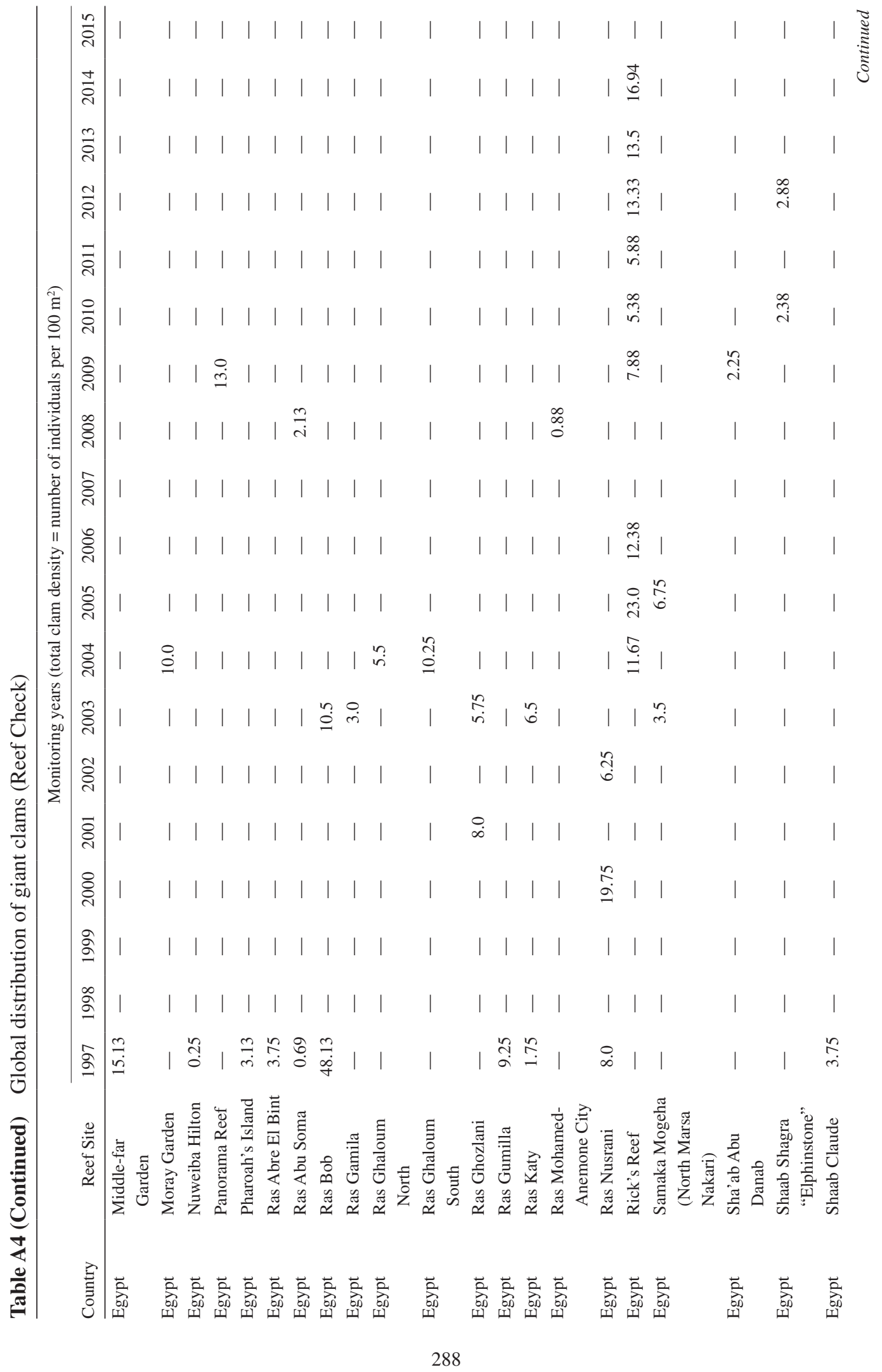


GIANT CLAMS (BIVALVIA: CARDIIDAE: TRIDACNINAE)

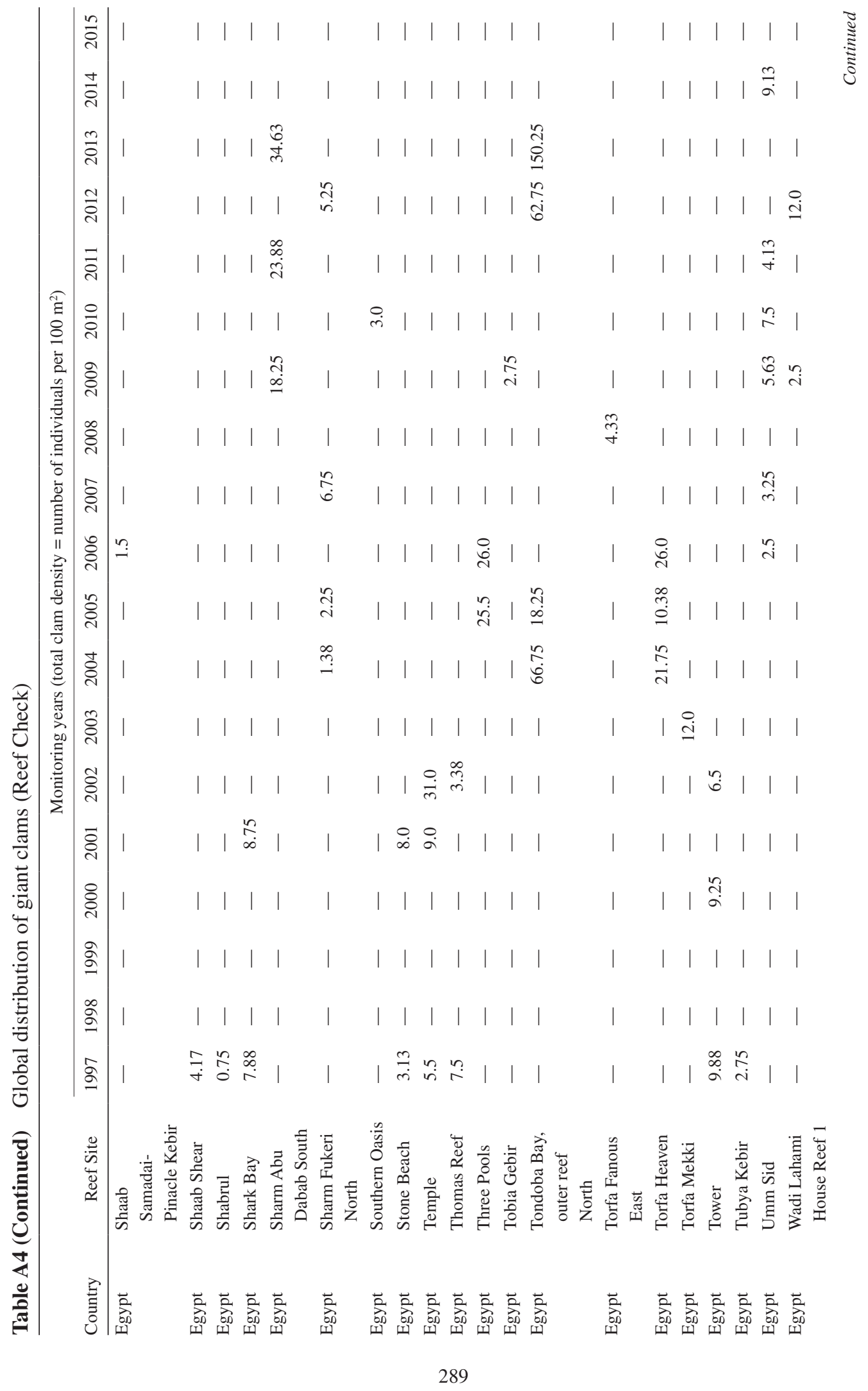


MEI LIN NEO ET AL.

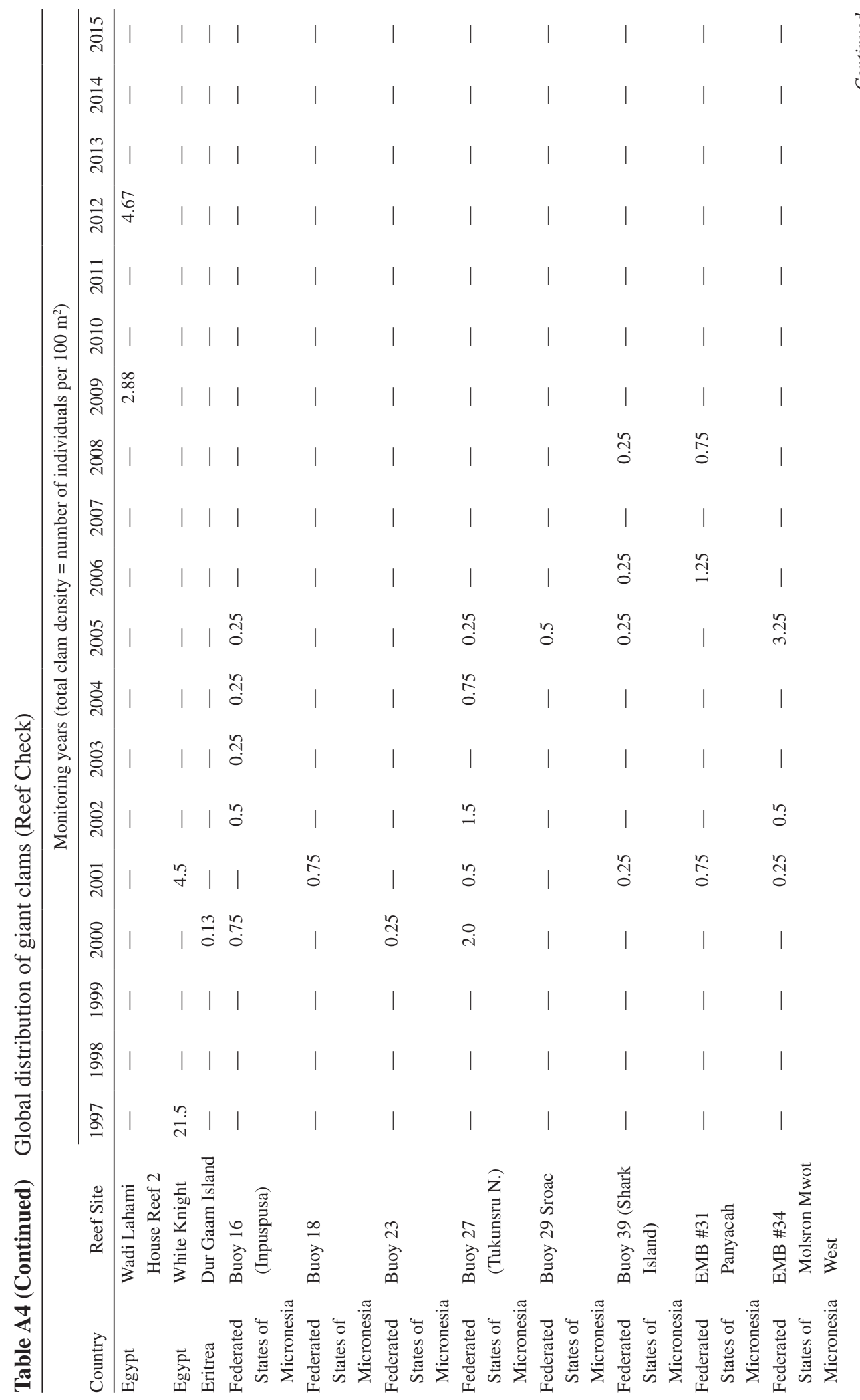


GIANT CLAMS (BIVALVIA: CARDIIDAE: TRIDACNINAE)

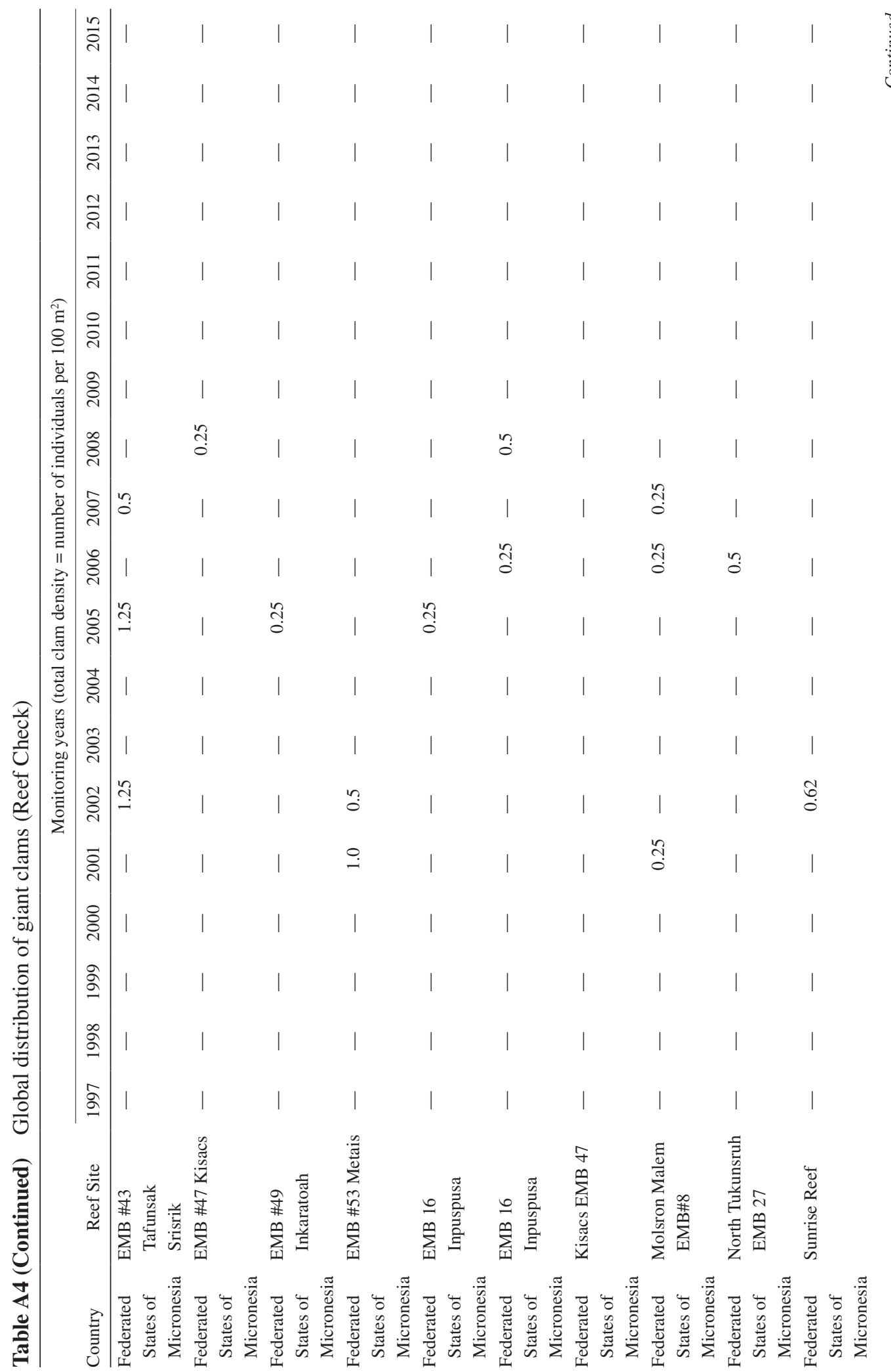


MEI LIN NEO ET AL.

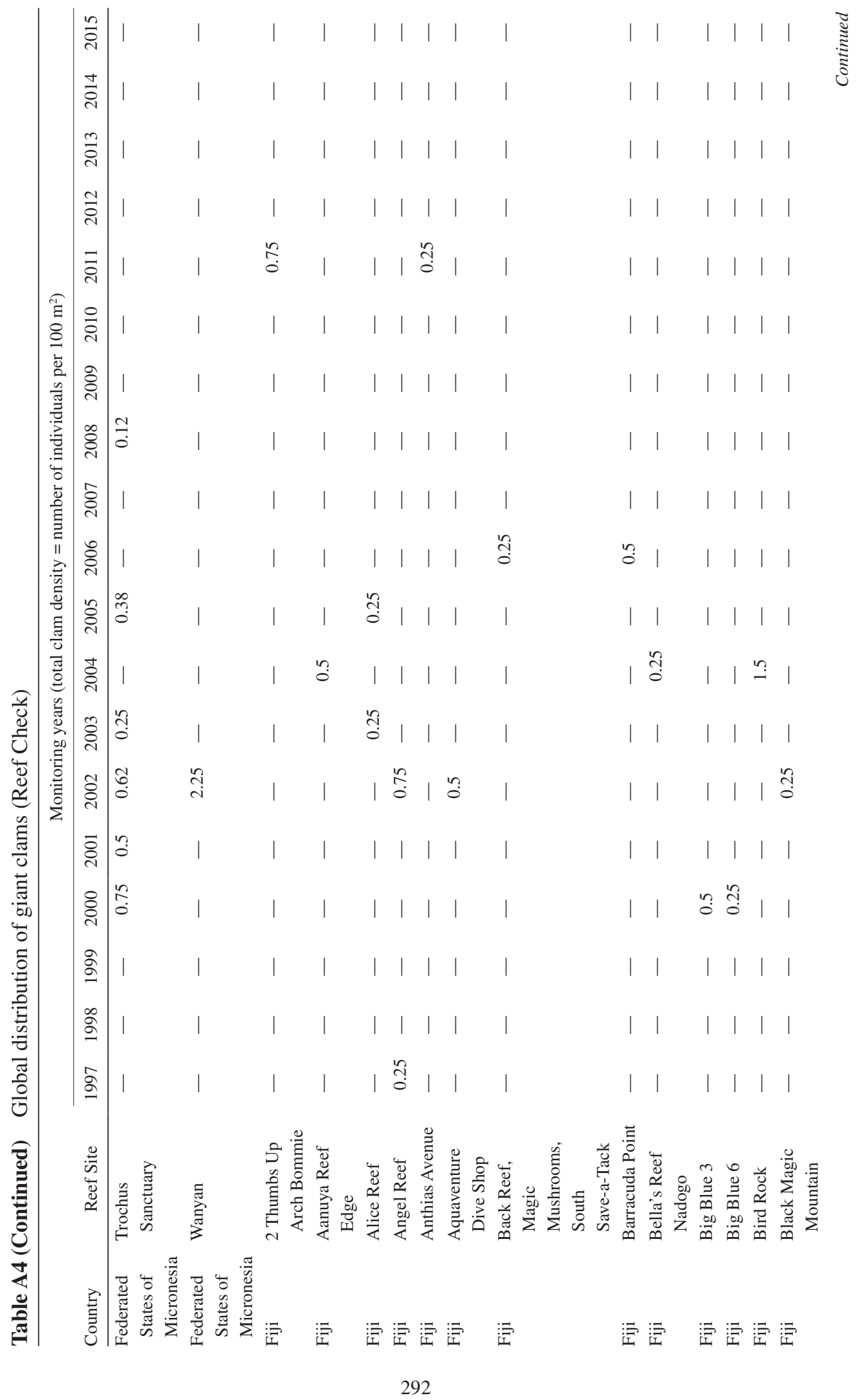


GIANT CLAMS (BIVALVIA: CARDIIDAE: TRIDACNINAE)

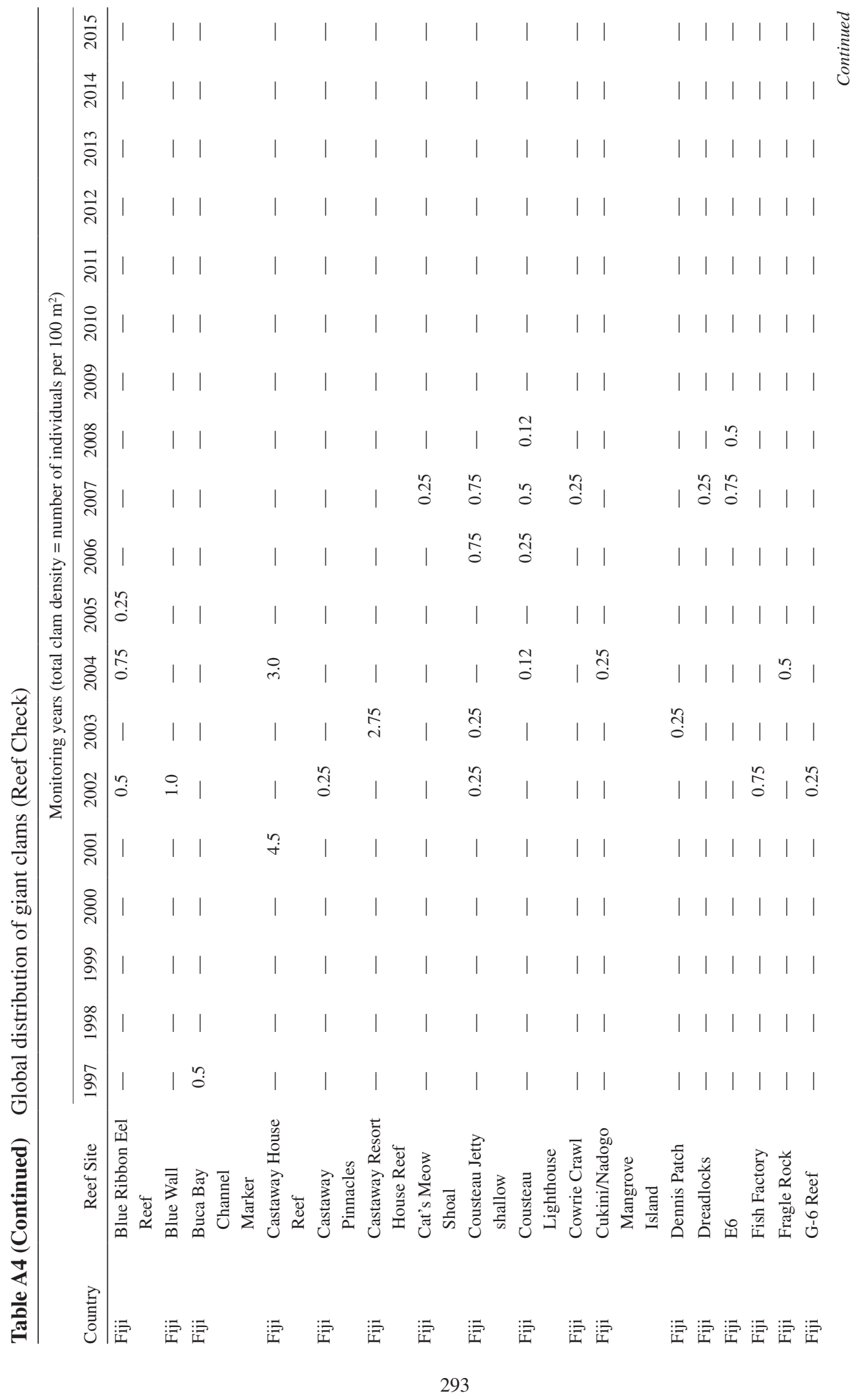


MEI LIN NEO ET AL.

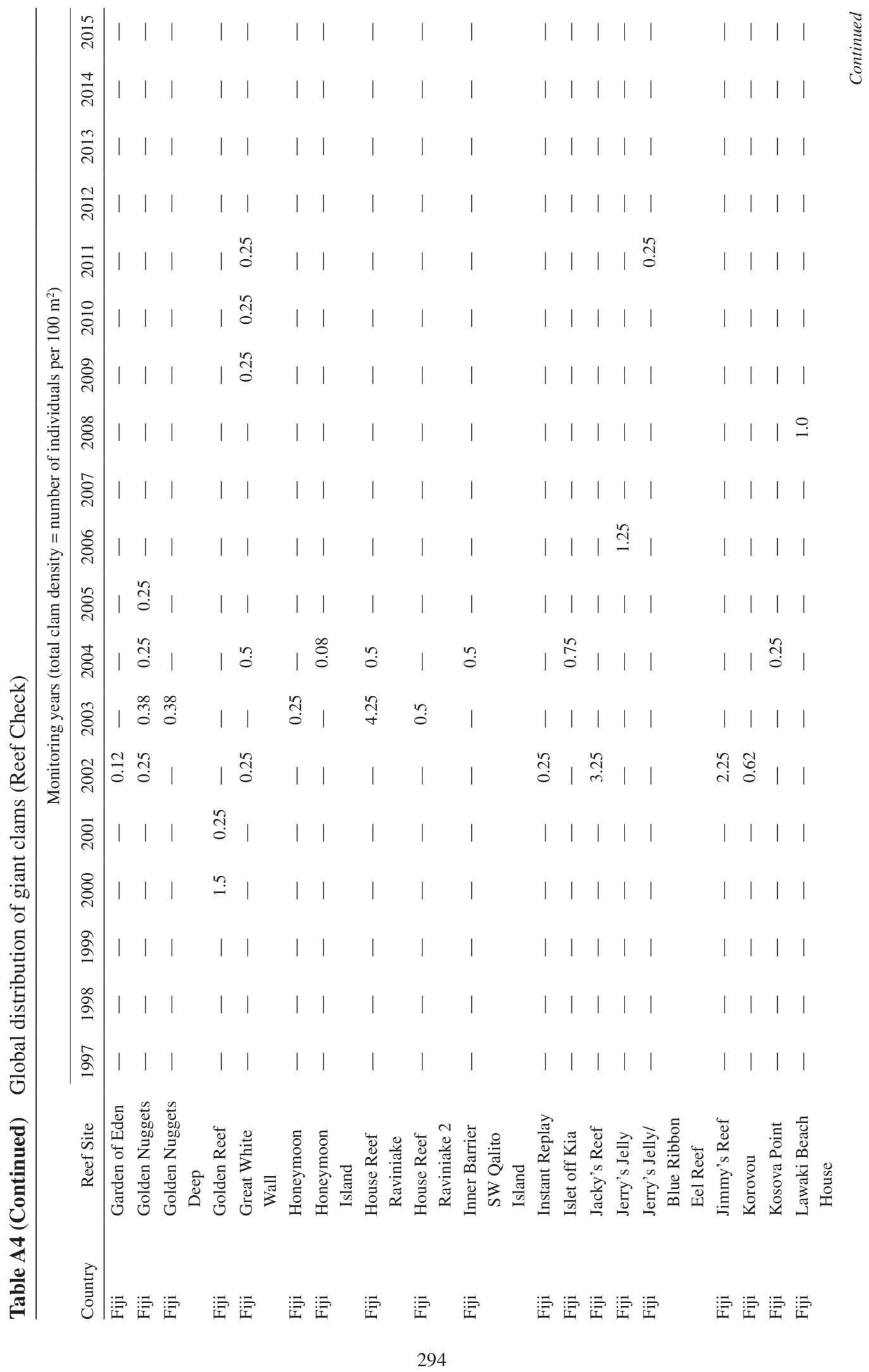


GIANT CLAMS (BIVALVIA: CARDIIDAE: TRIDACNINAE)

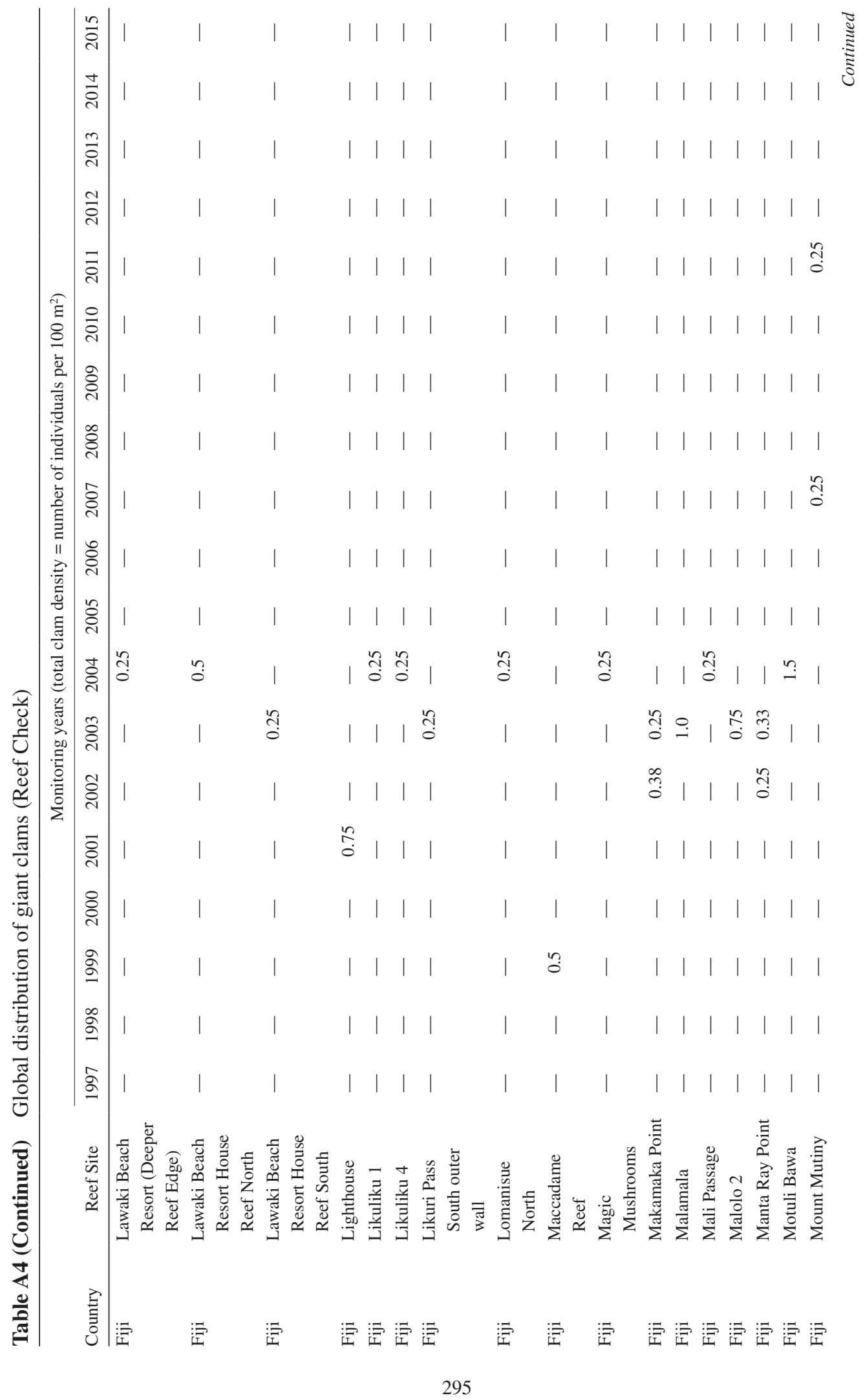


MEI LIN NEO ET AL.

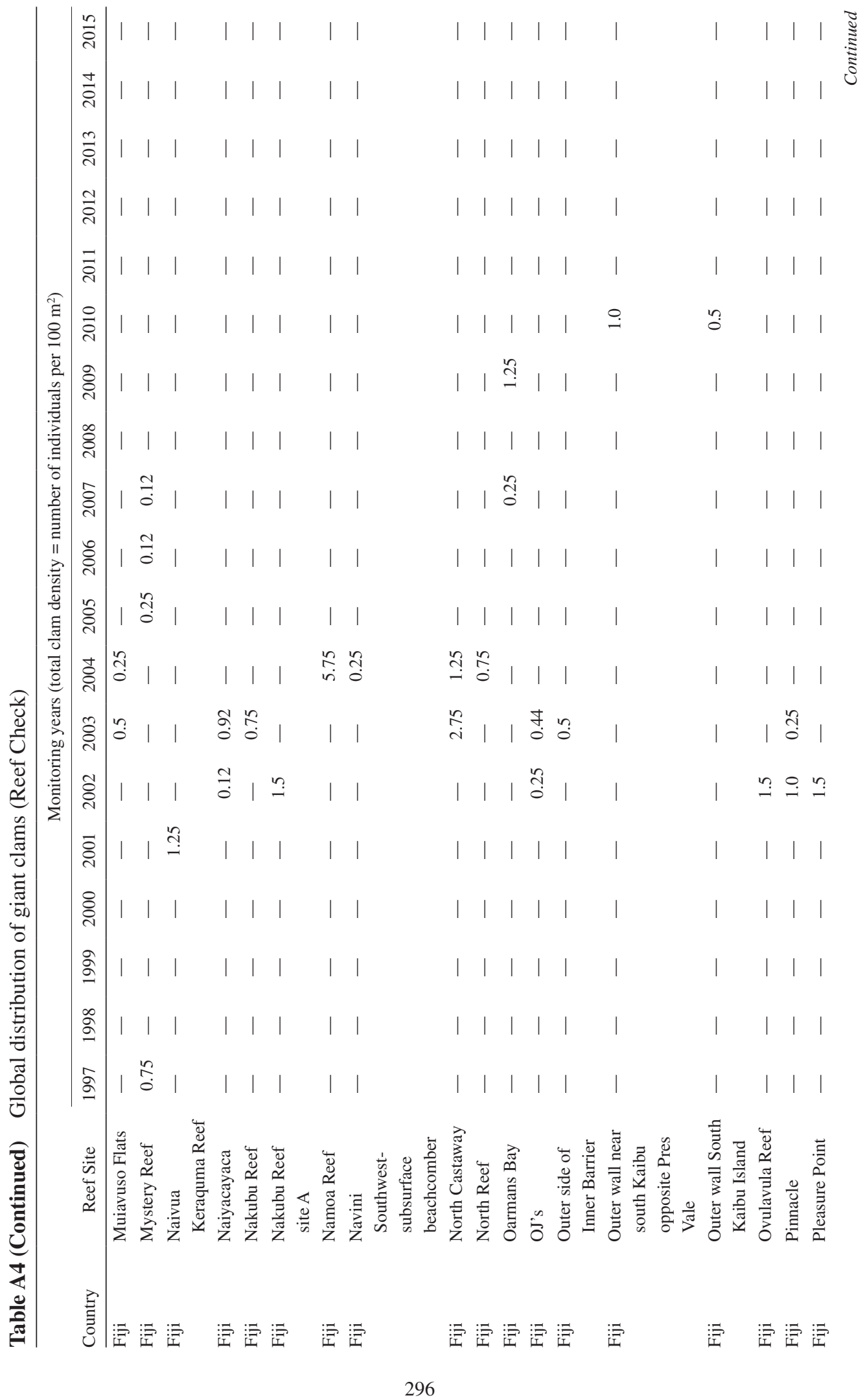


GIANT CLAMS (BIVALVIA: CARDIIDAE: TRIDACNINAE)

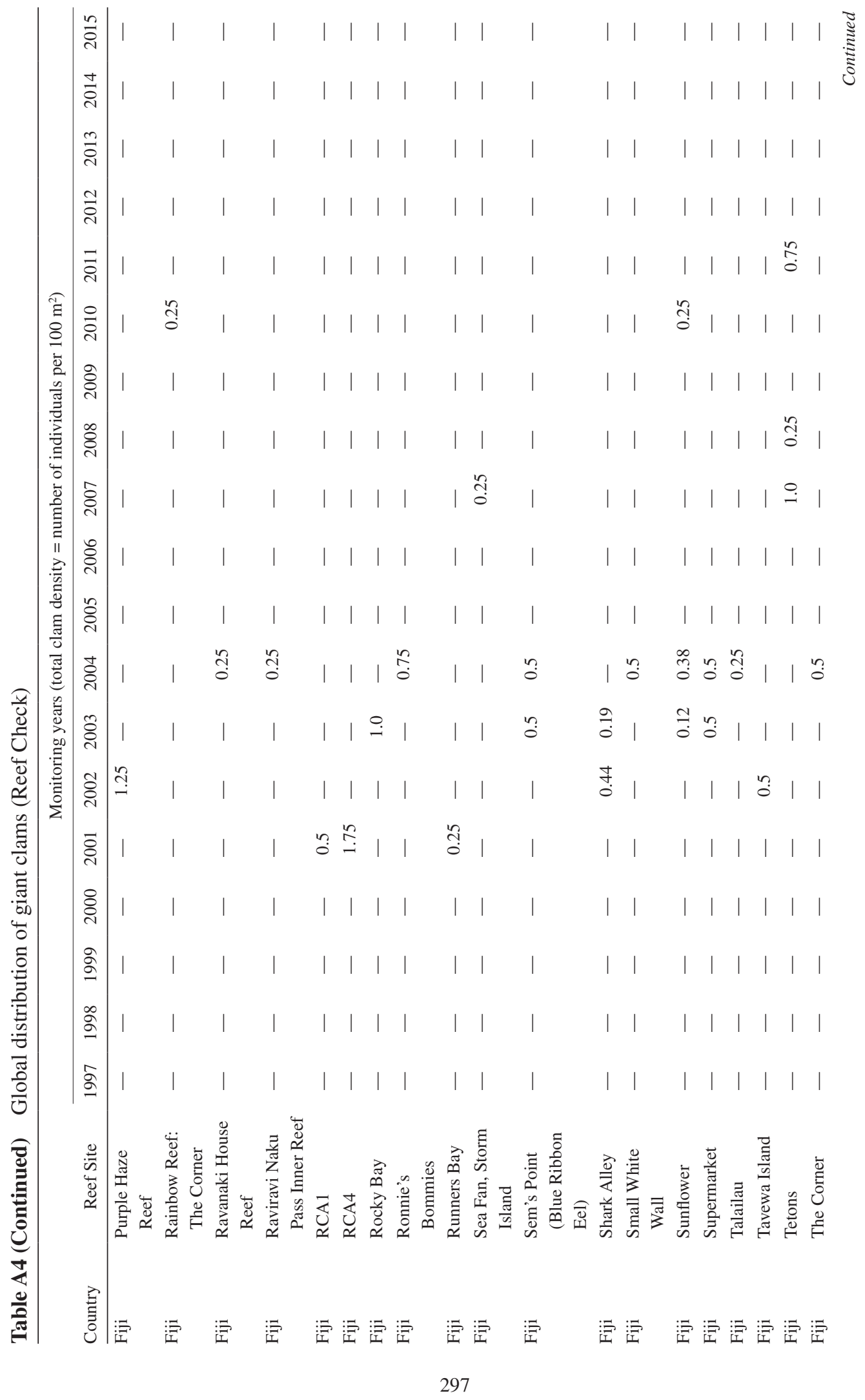


MEI LIN NEO ET AL.

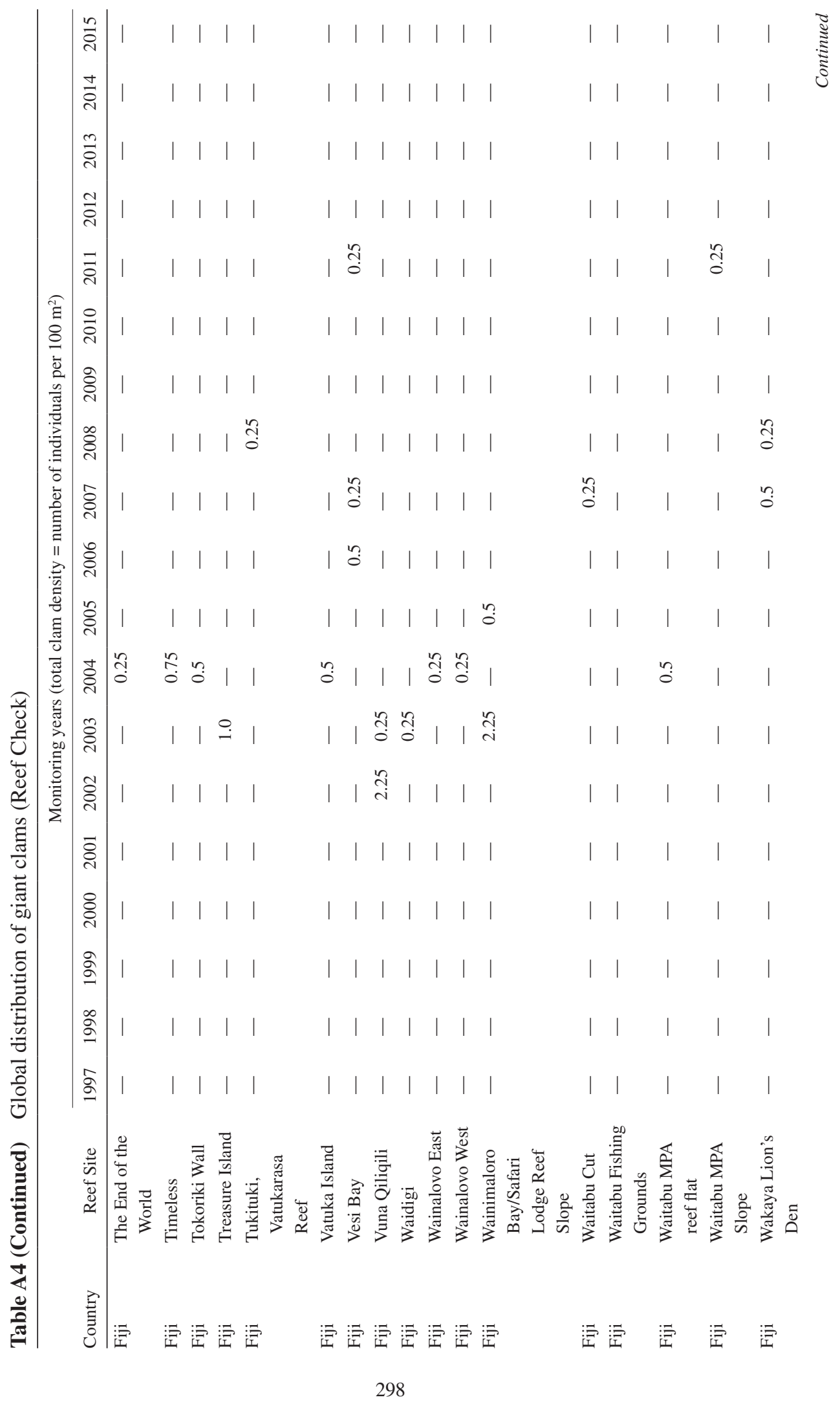


GIANT CLAMS (BIVALVIA: CARDIIDAE: TRIDACNINAE)

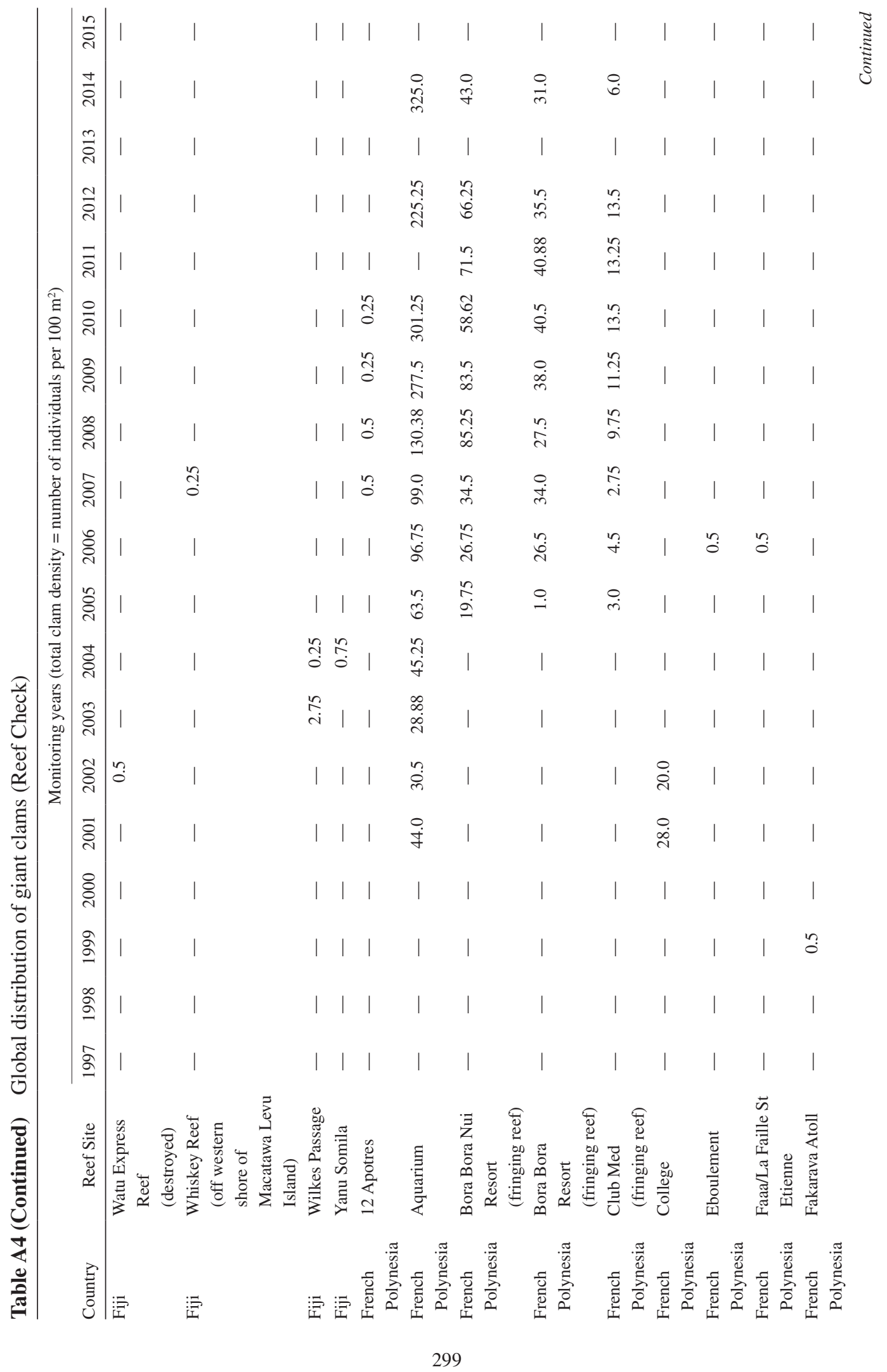


MEI LIN NEO ET AL.

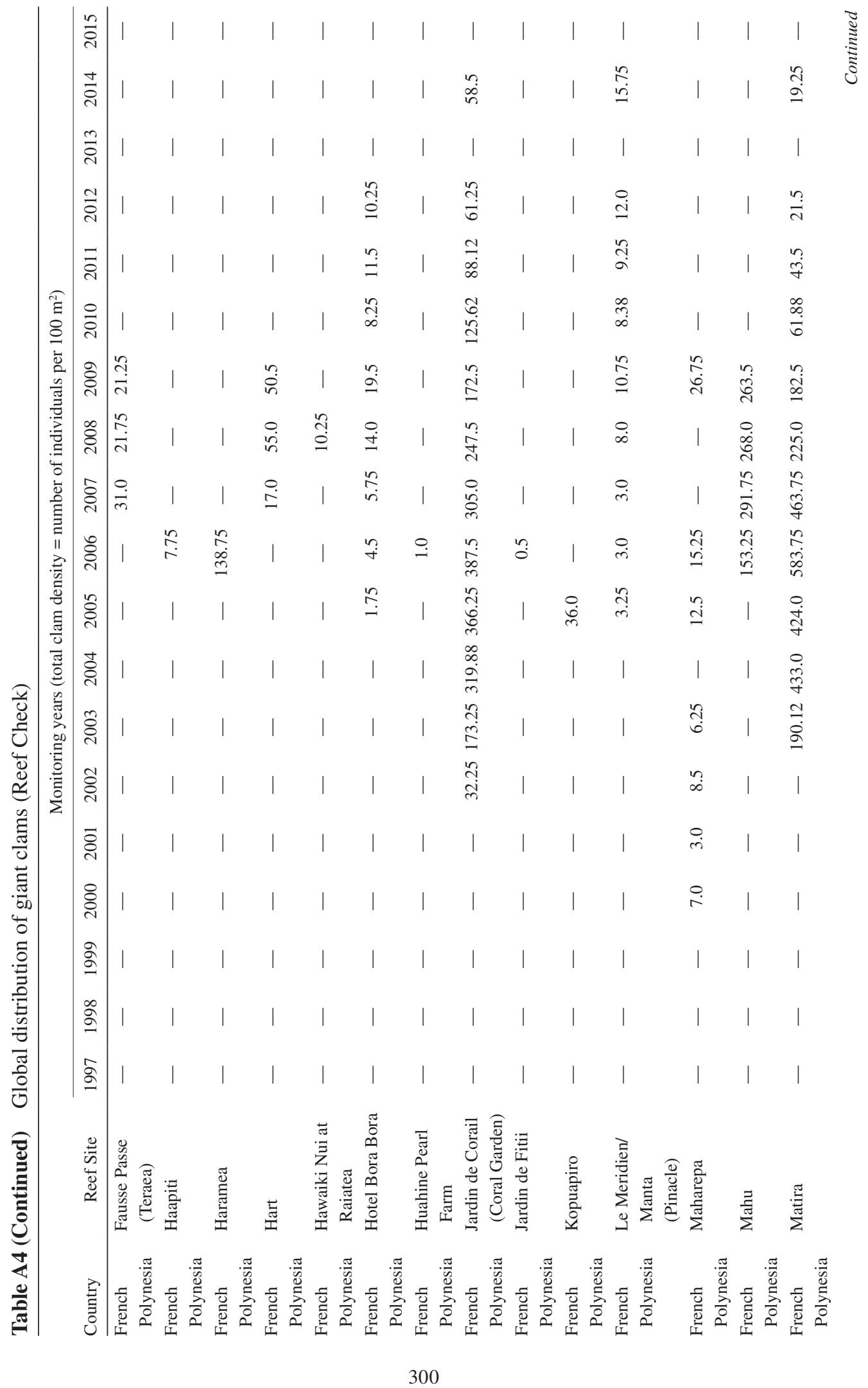


GIANT CLAMS (BIVALVIA: CARDIIDAE: TRIDACNINAE)

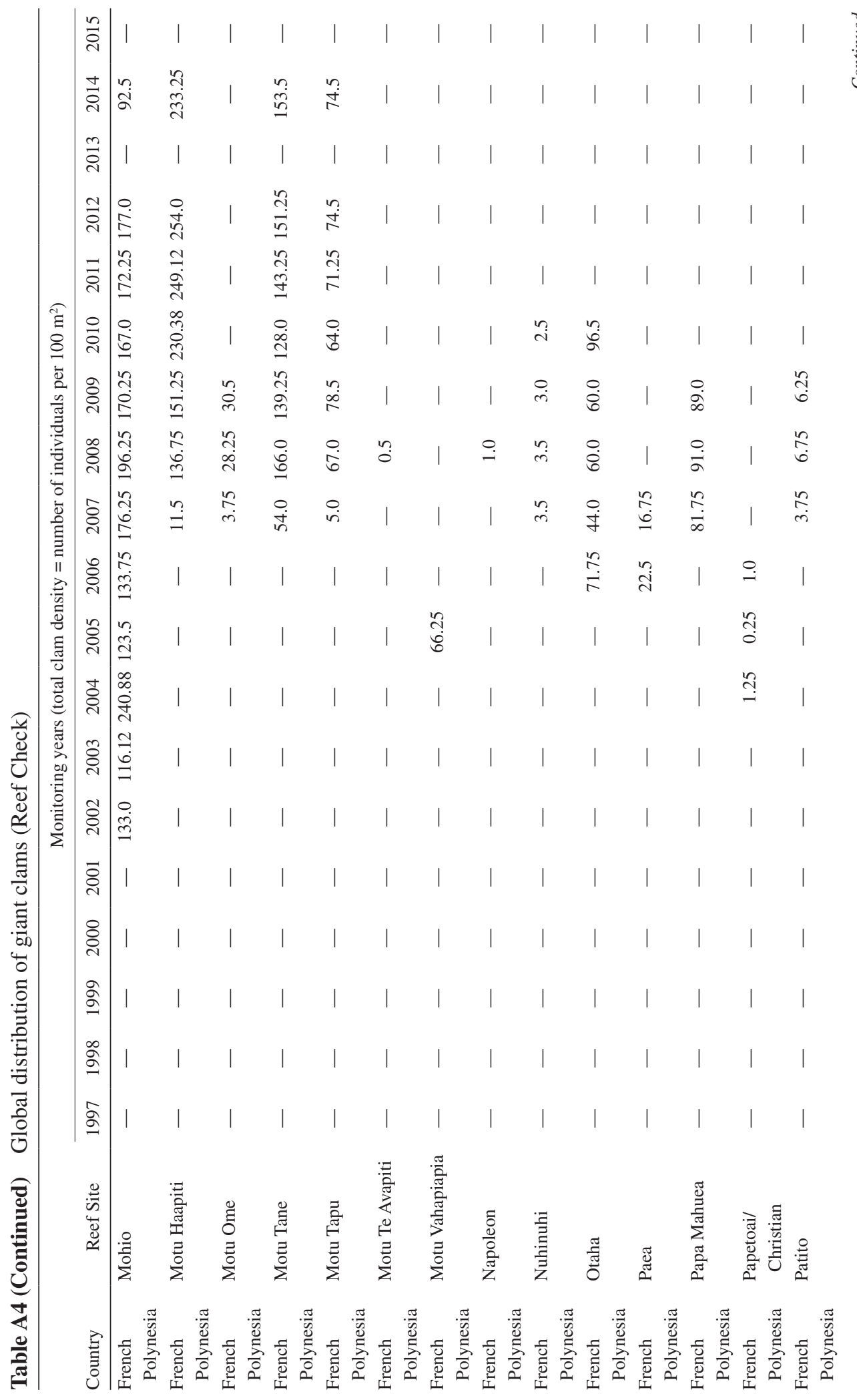


MEI LIN NEO ET AL.

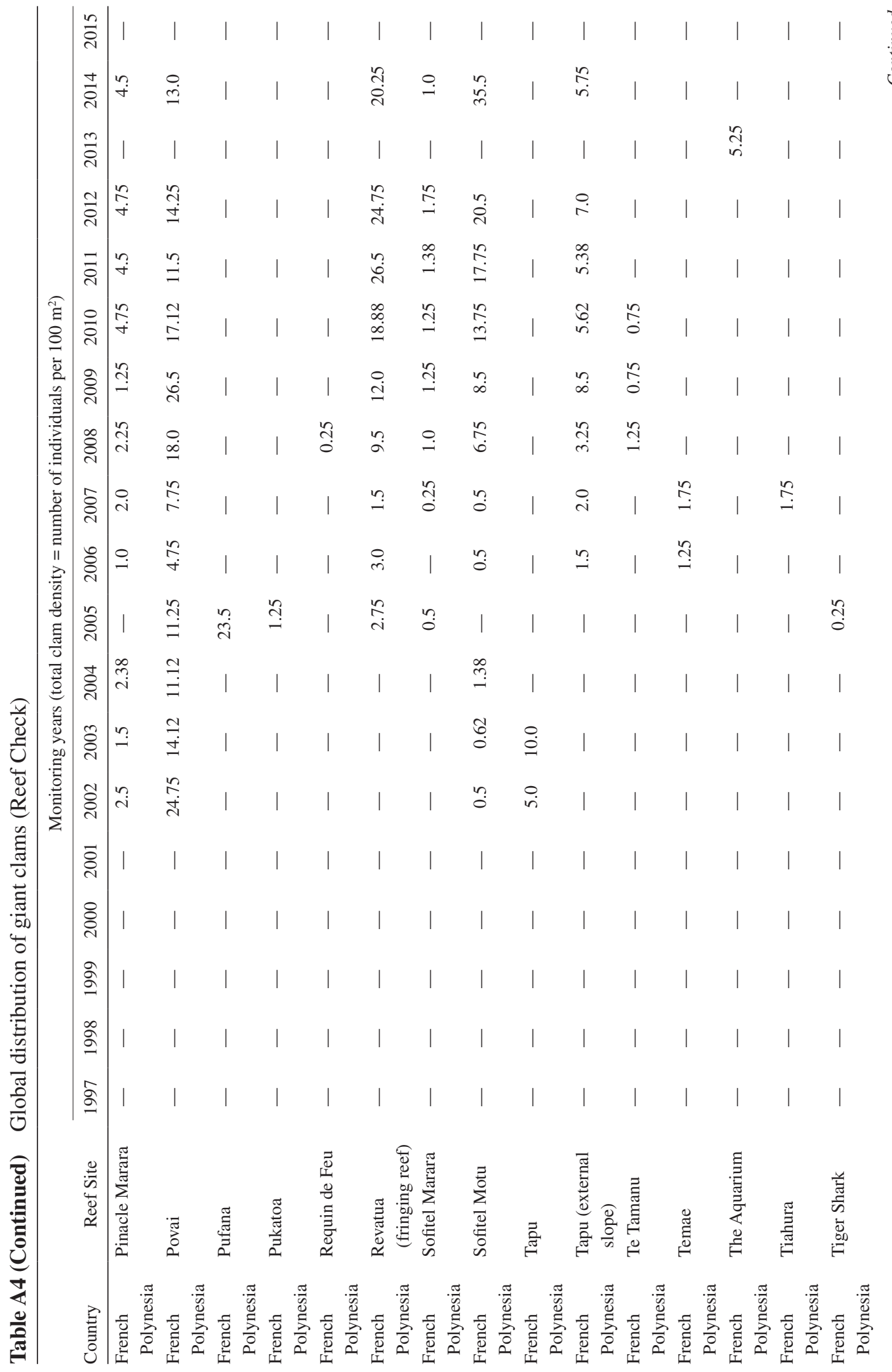


GIANT CLAMS (BIVALVIA: CARDIIDAE: TRIDACNINAE)

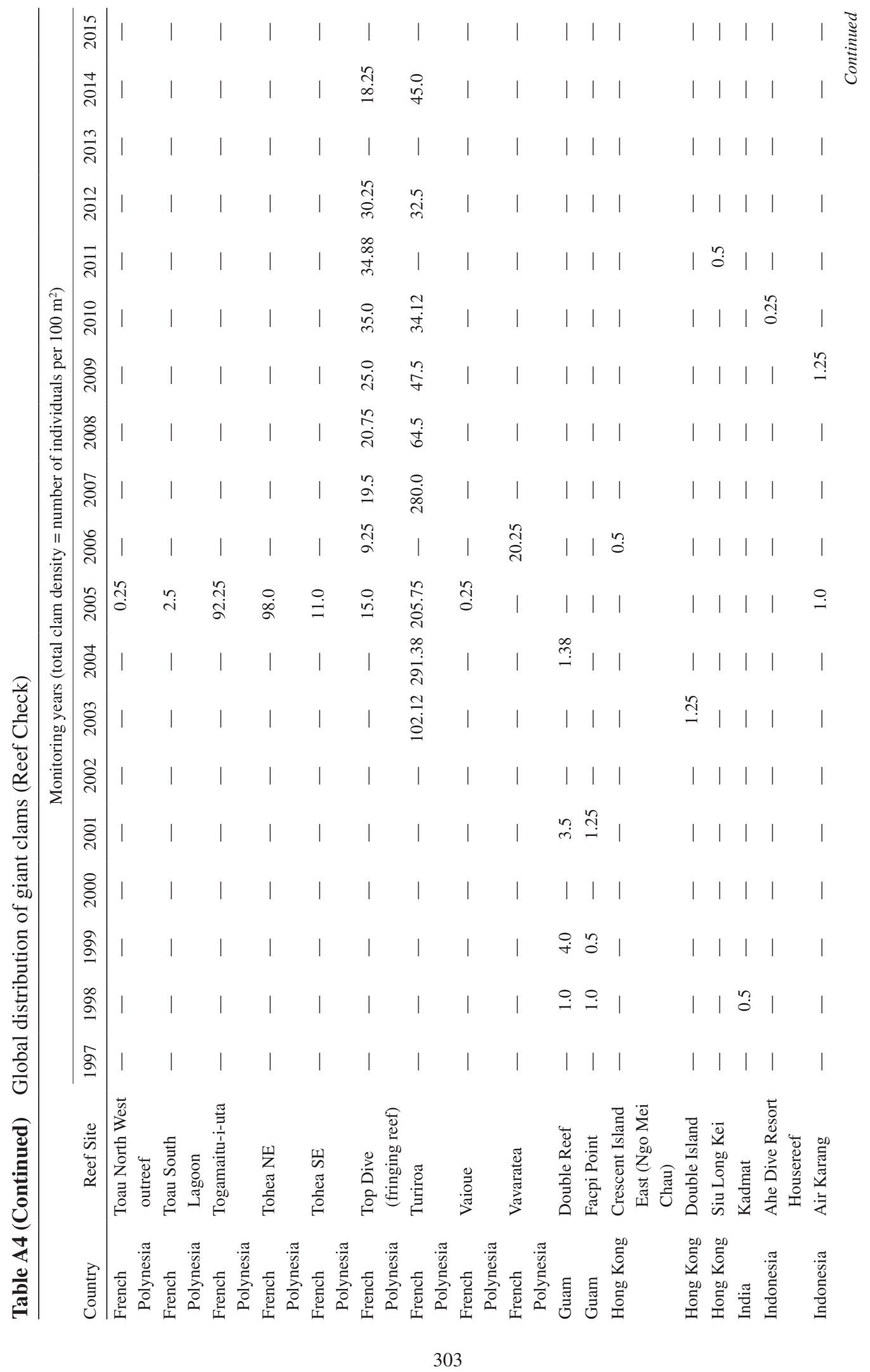


MEI LIN NEO ET AL.

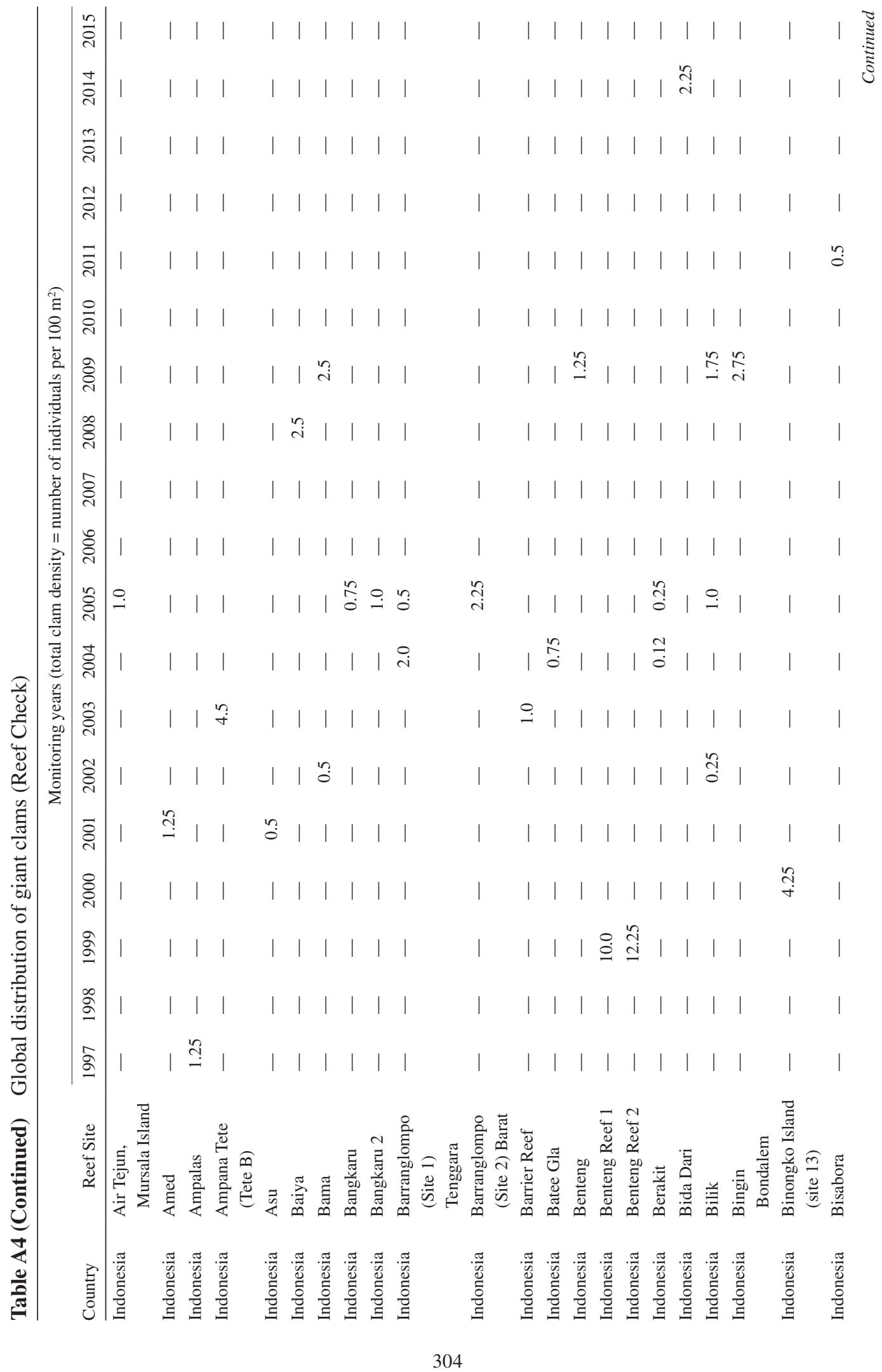


GIANT CLAMS (BIVALVIA: CARDIIDAE: TRIDACNINAE)

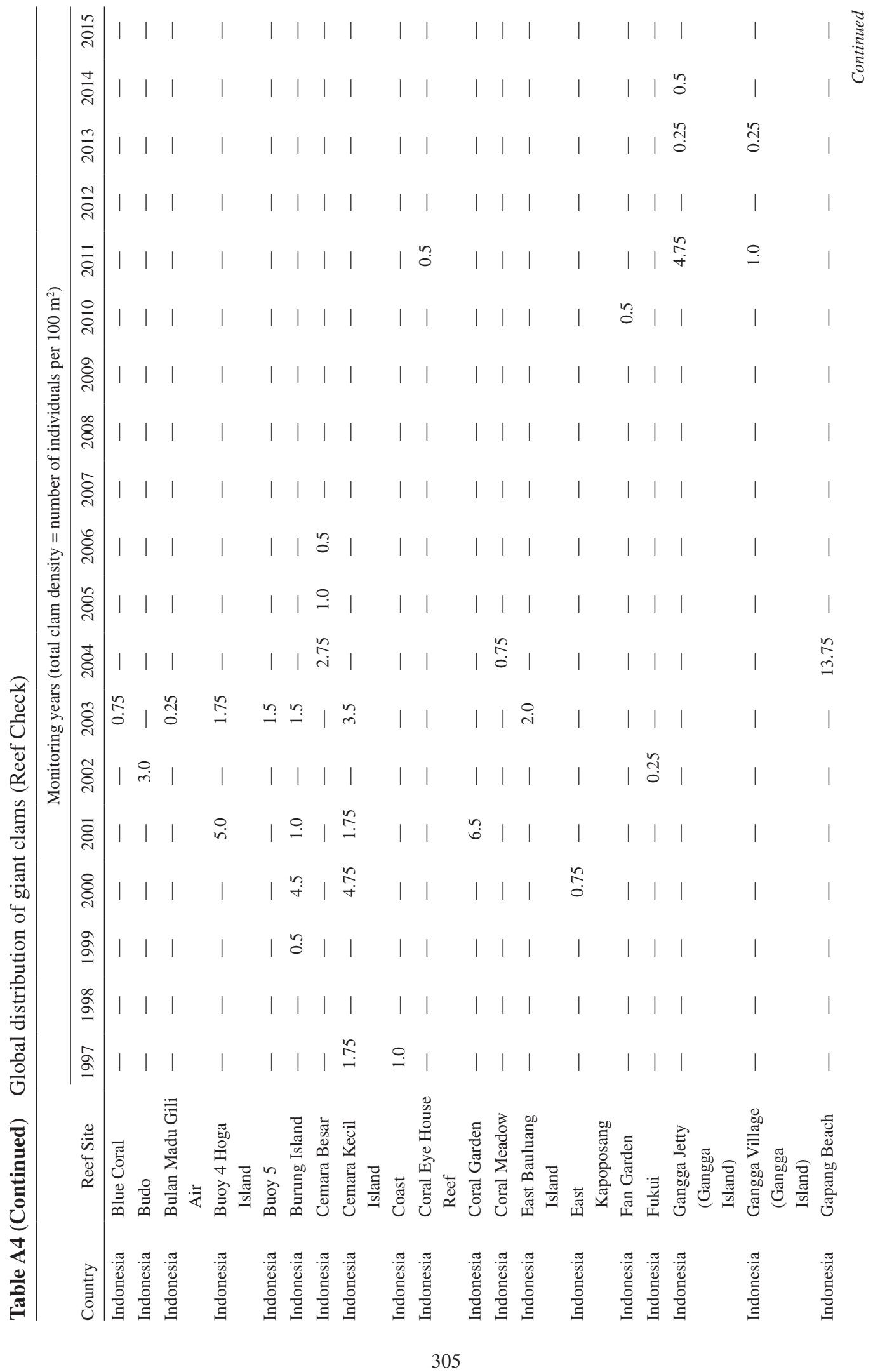


MEI LIN NEO ET AL.

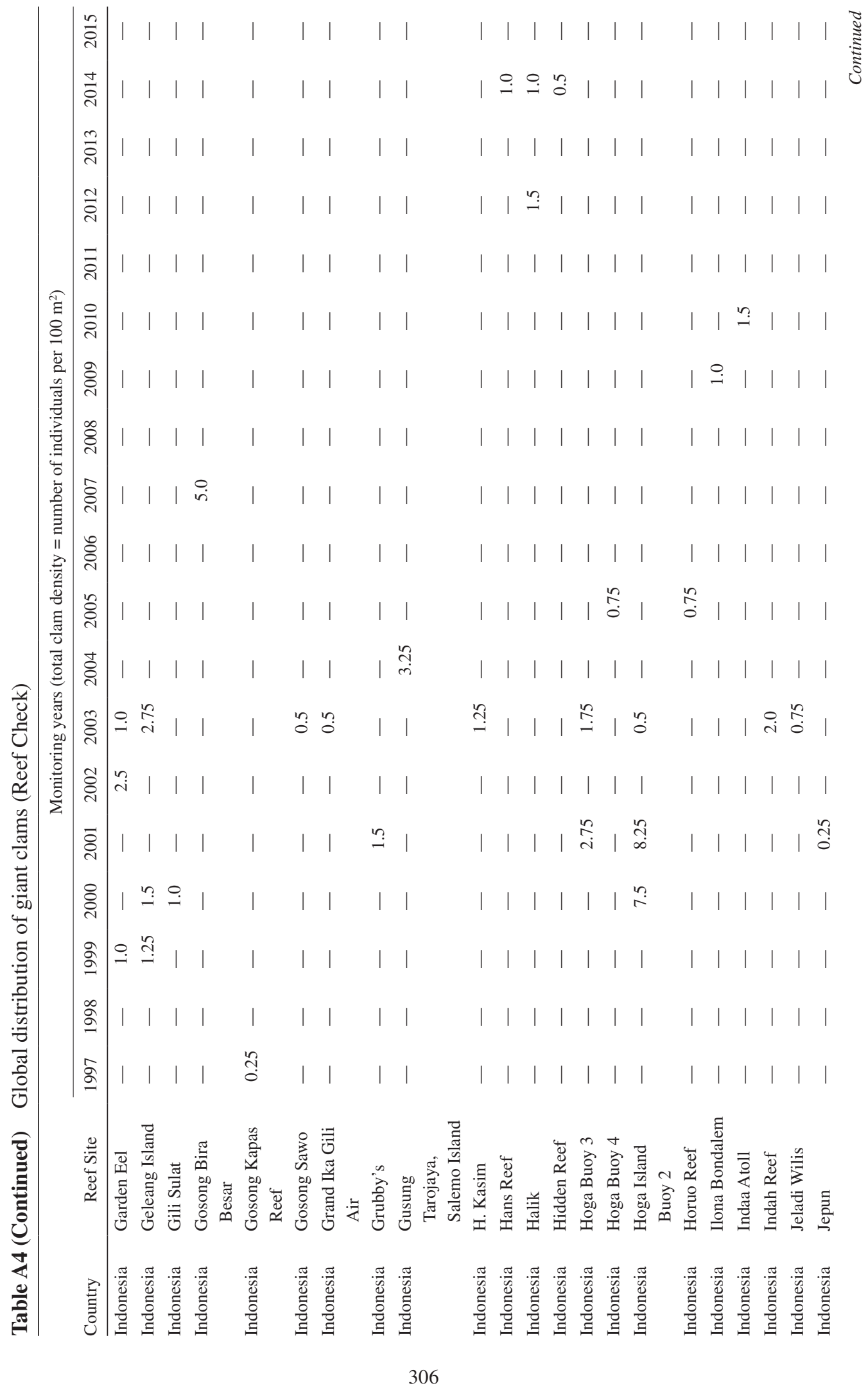


GIANT CLAMS (BIVALVIA: CARDIIDAE: TRIDACNINAE)

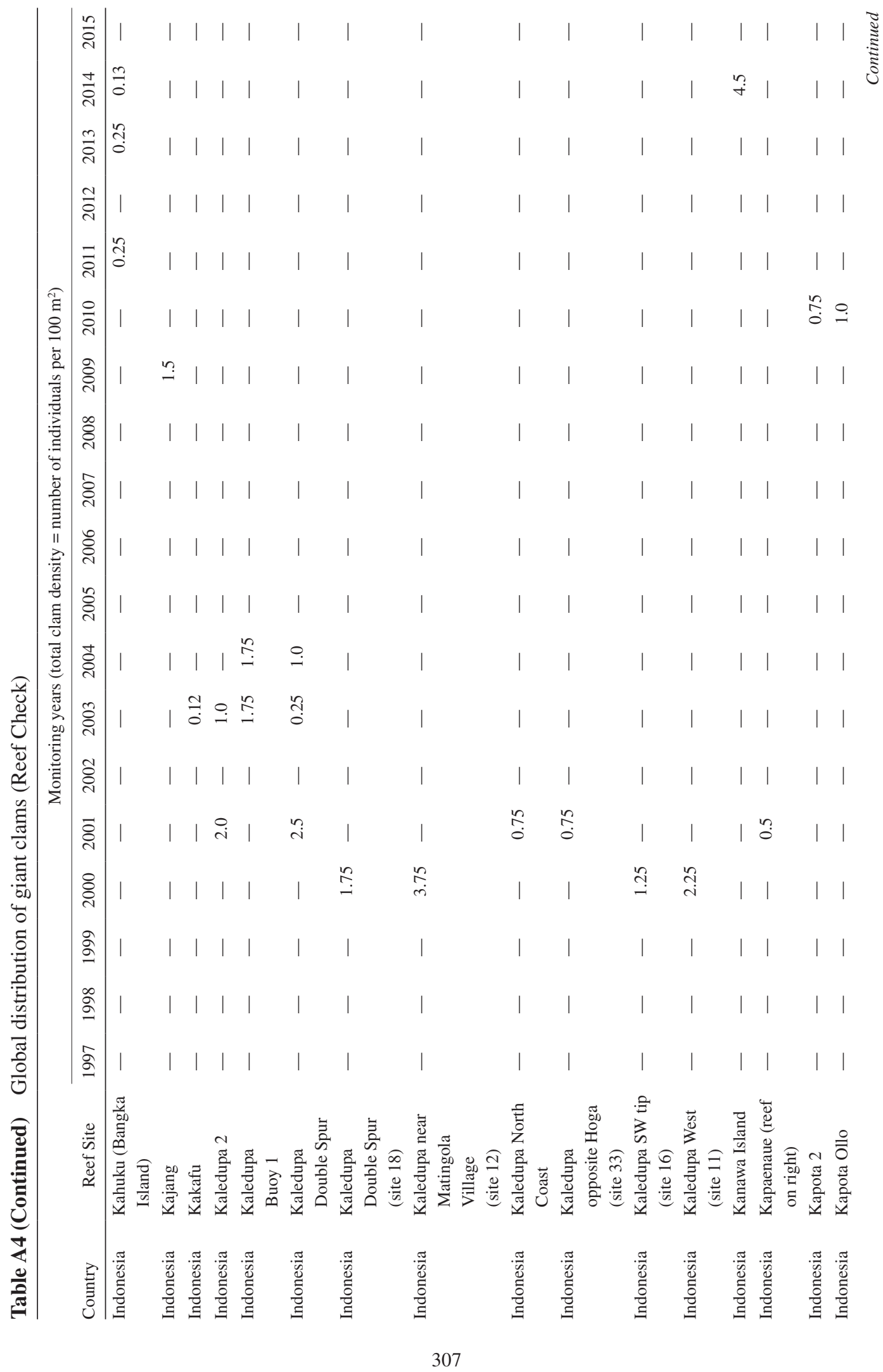


MEI LIN NEO ET AL.

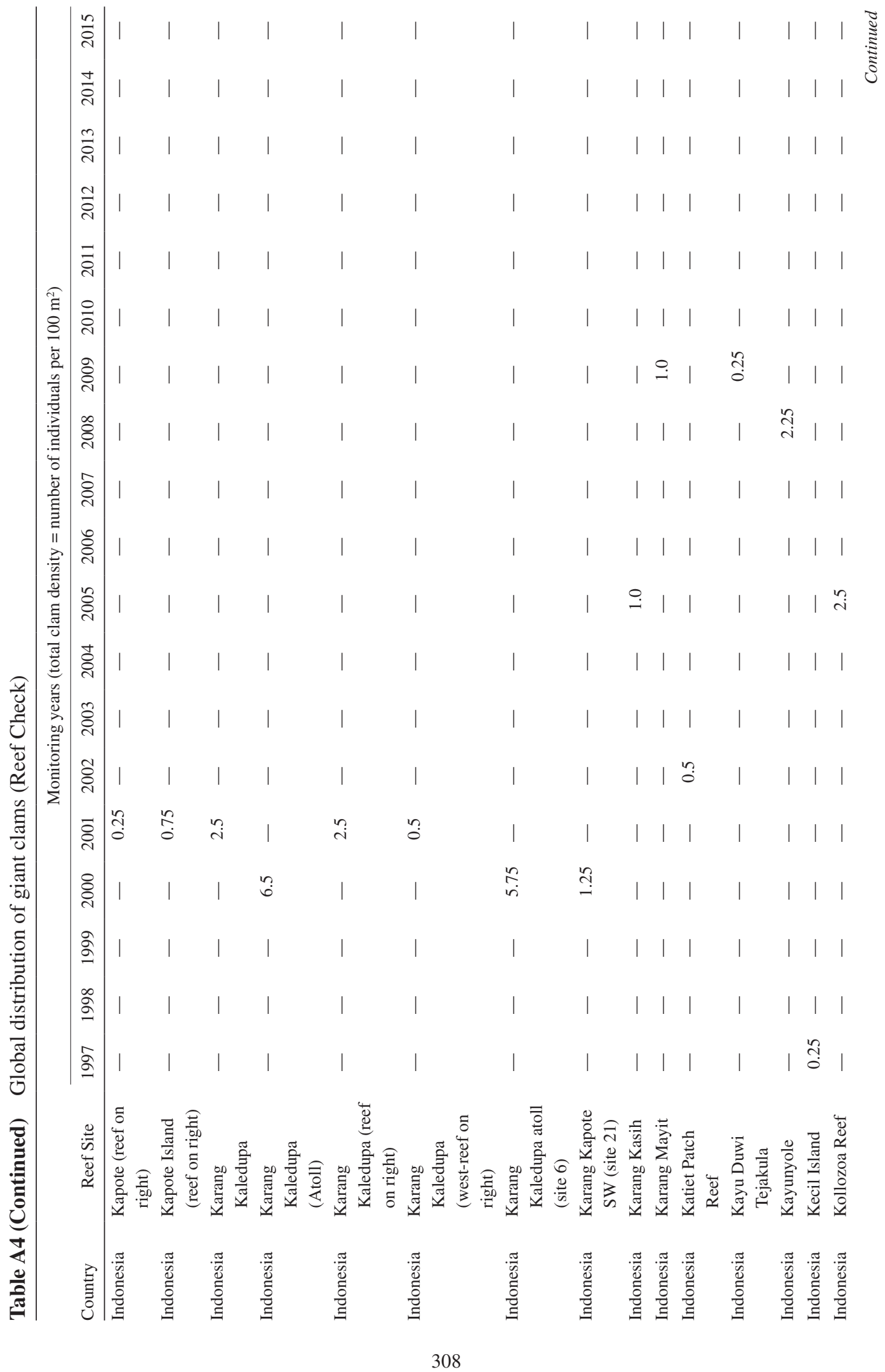


GIANT CLAMS (BIVALVIA: CARDIIDAE: TRIDACNINAE)

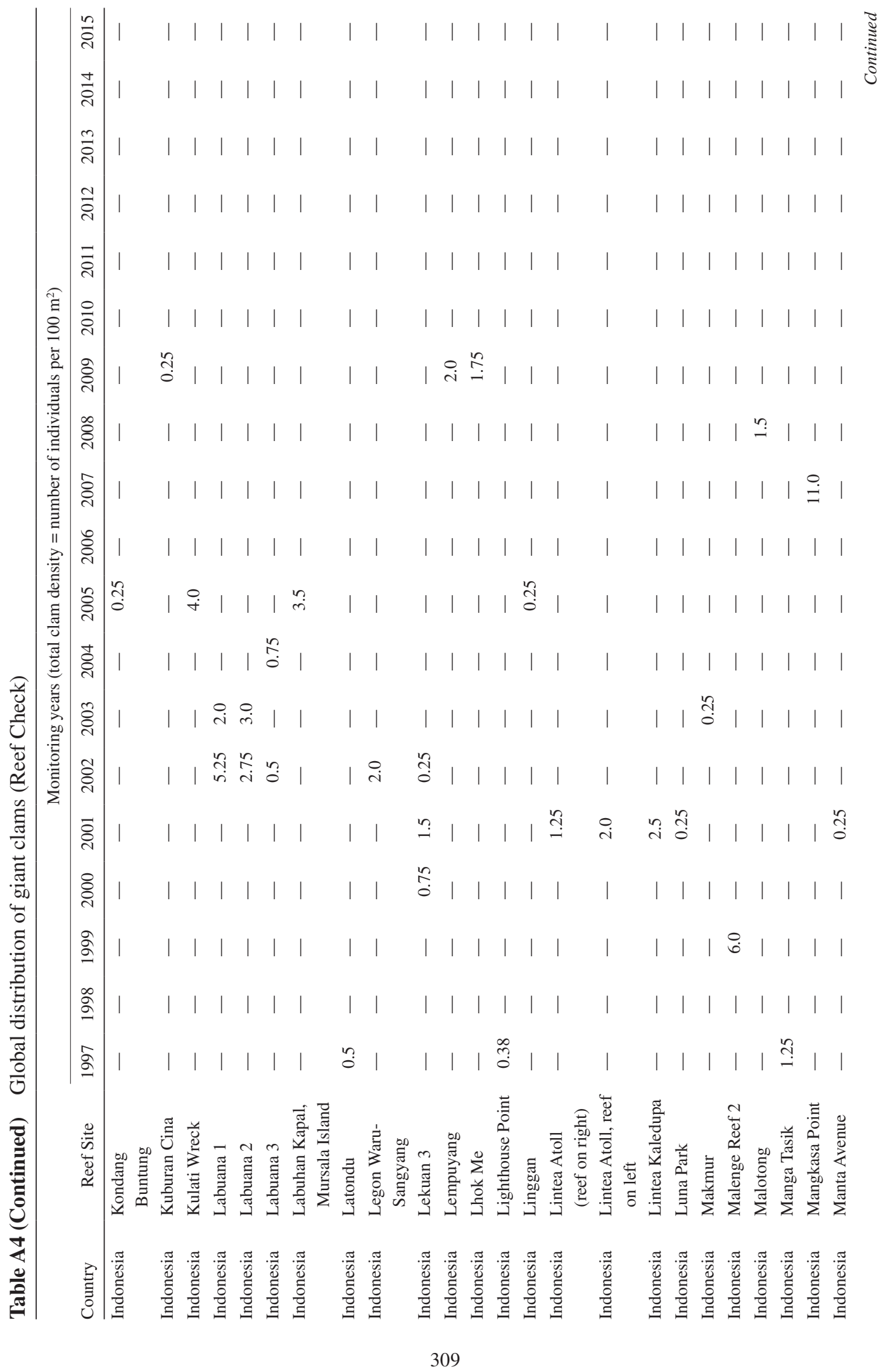


MEI LIN NEO ET AL.

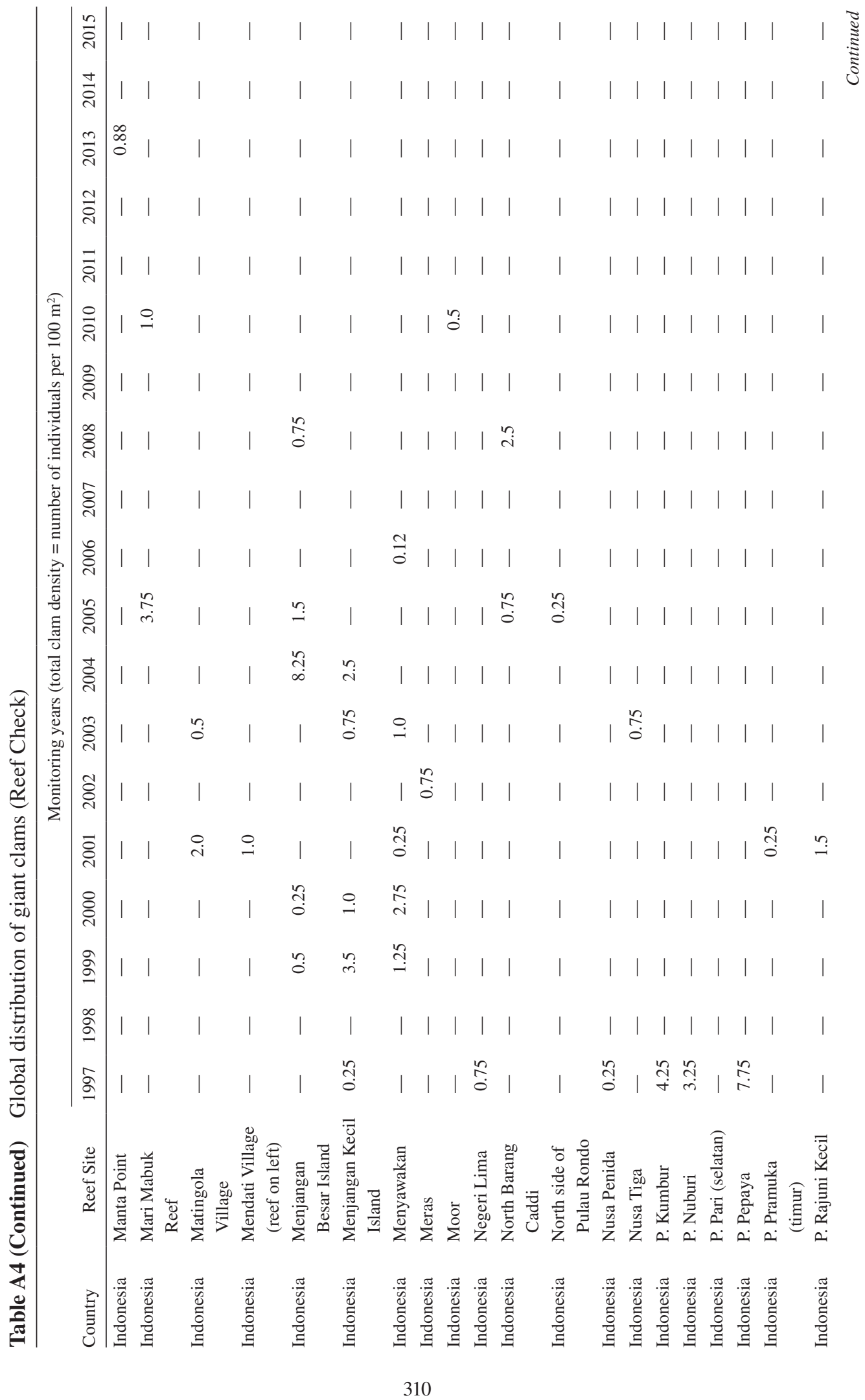


GIANT CLAMS (BIVALVIA: CARDIIDAE: TRIDACNINAE)

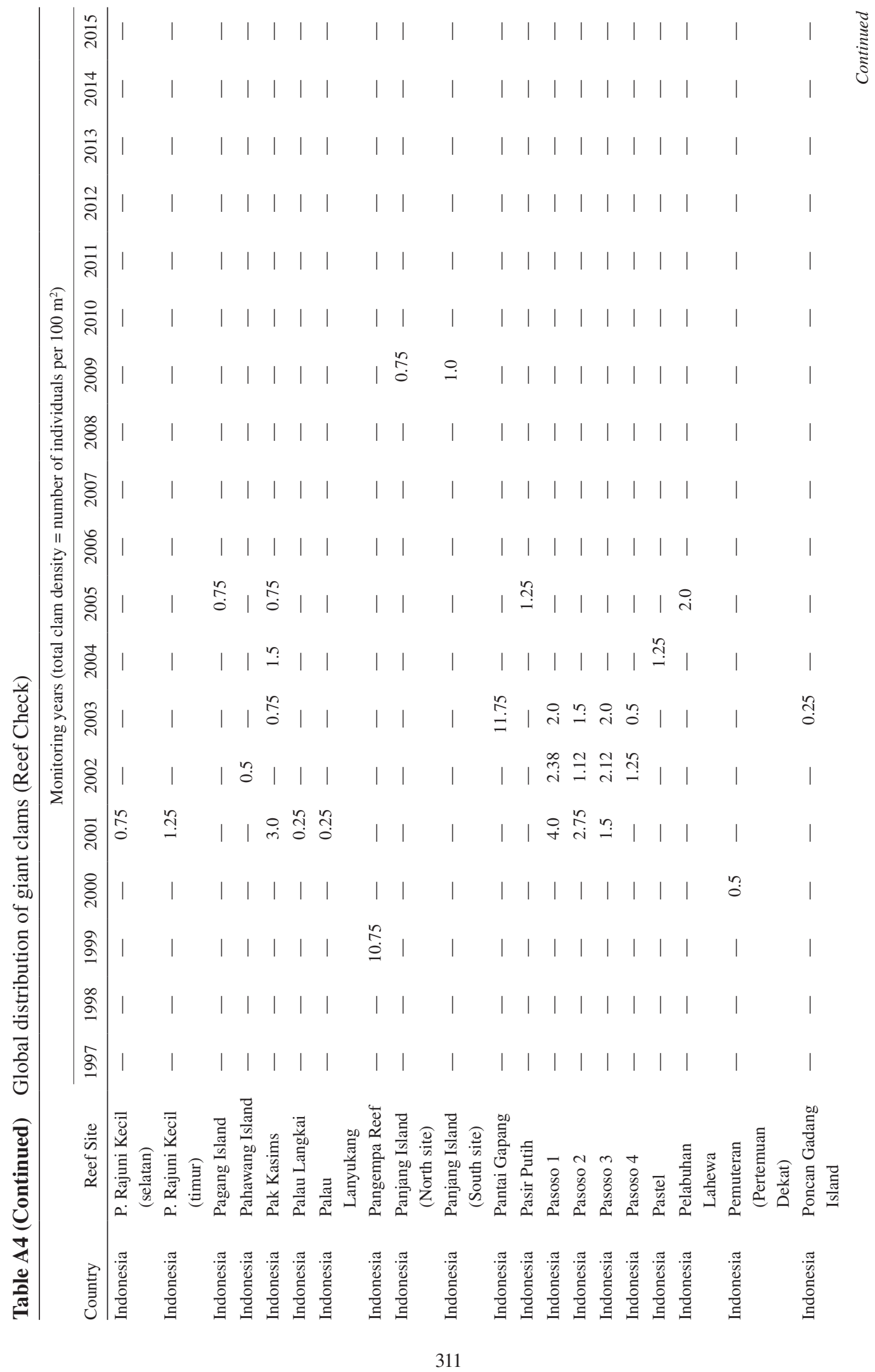


MEI LIN NEO ET AL.

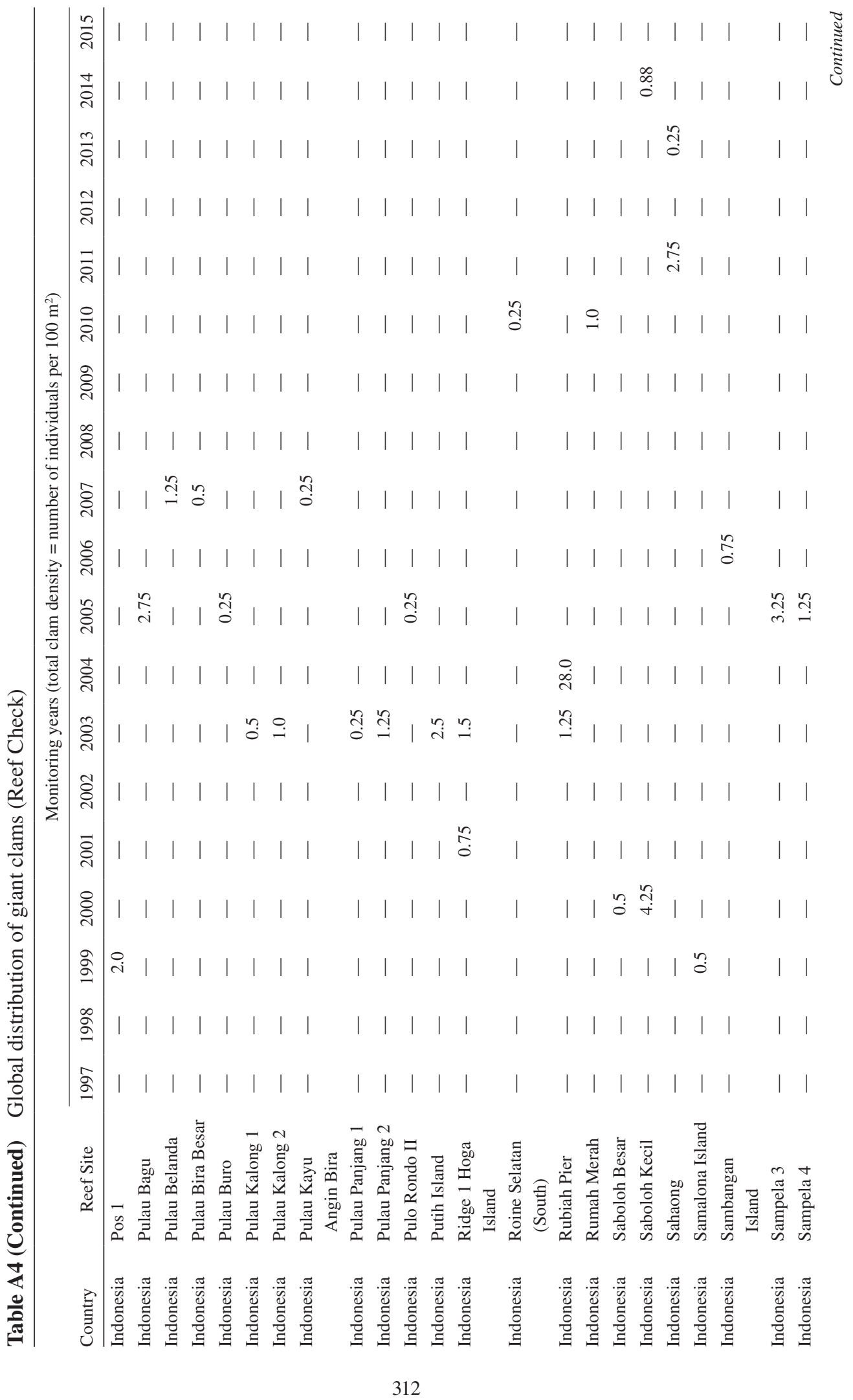


GIANT CLAMS (BIVALVIA: CARDIIDAE: TRIDACNINAE)

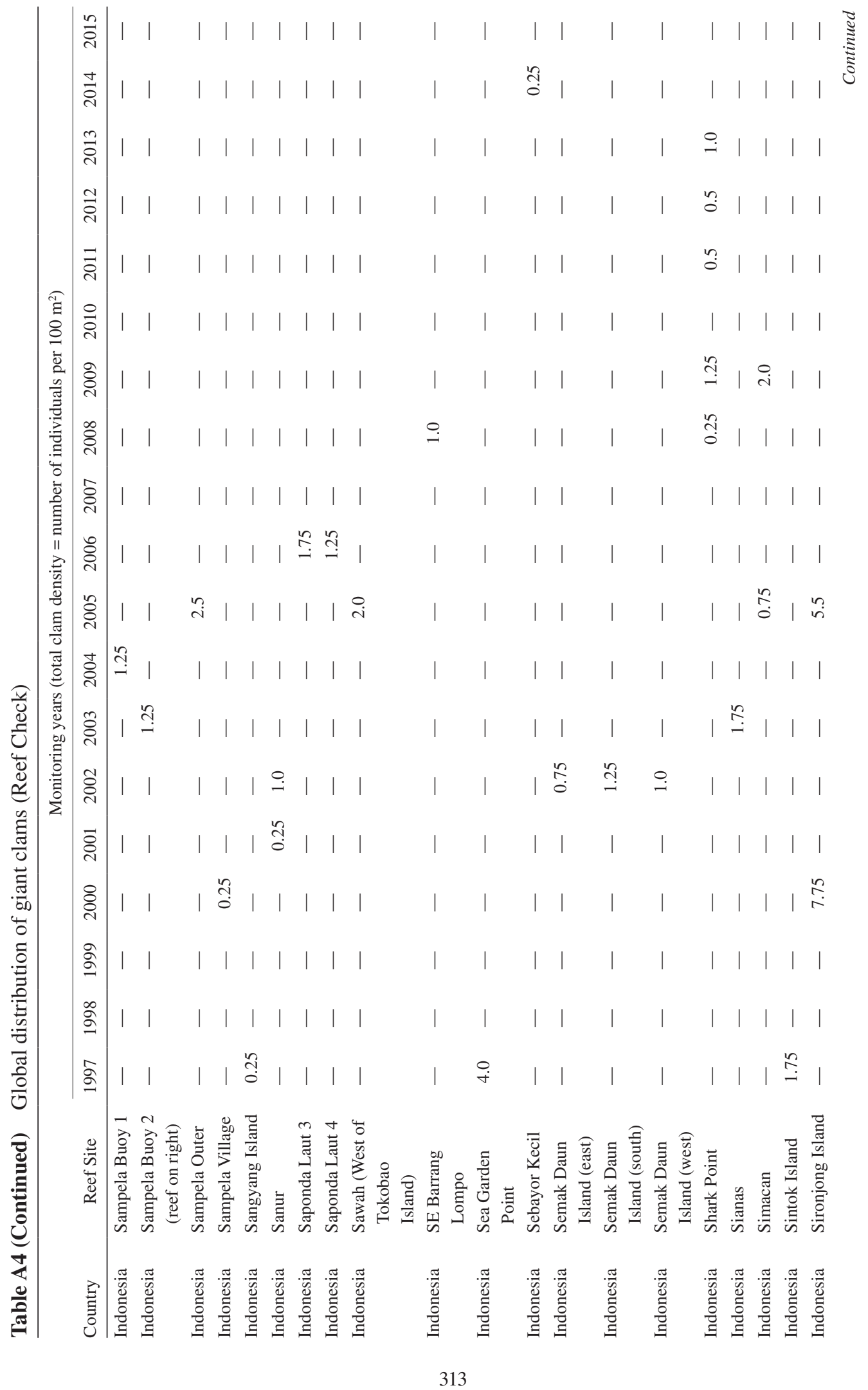


MEI LIN NEO ET AL.

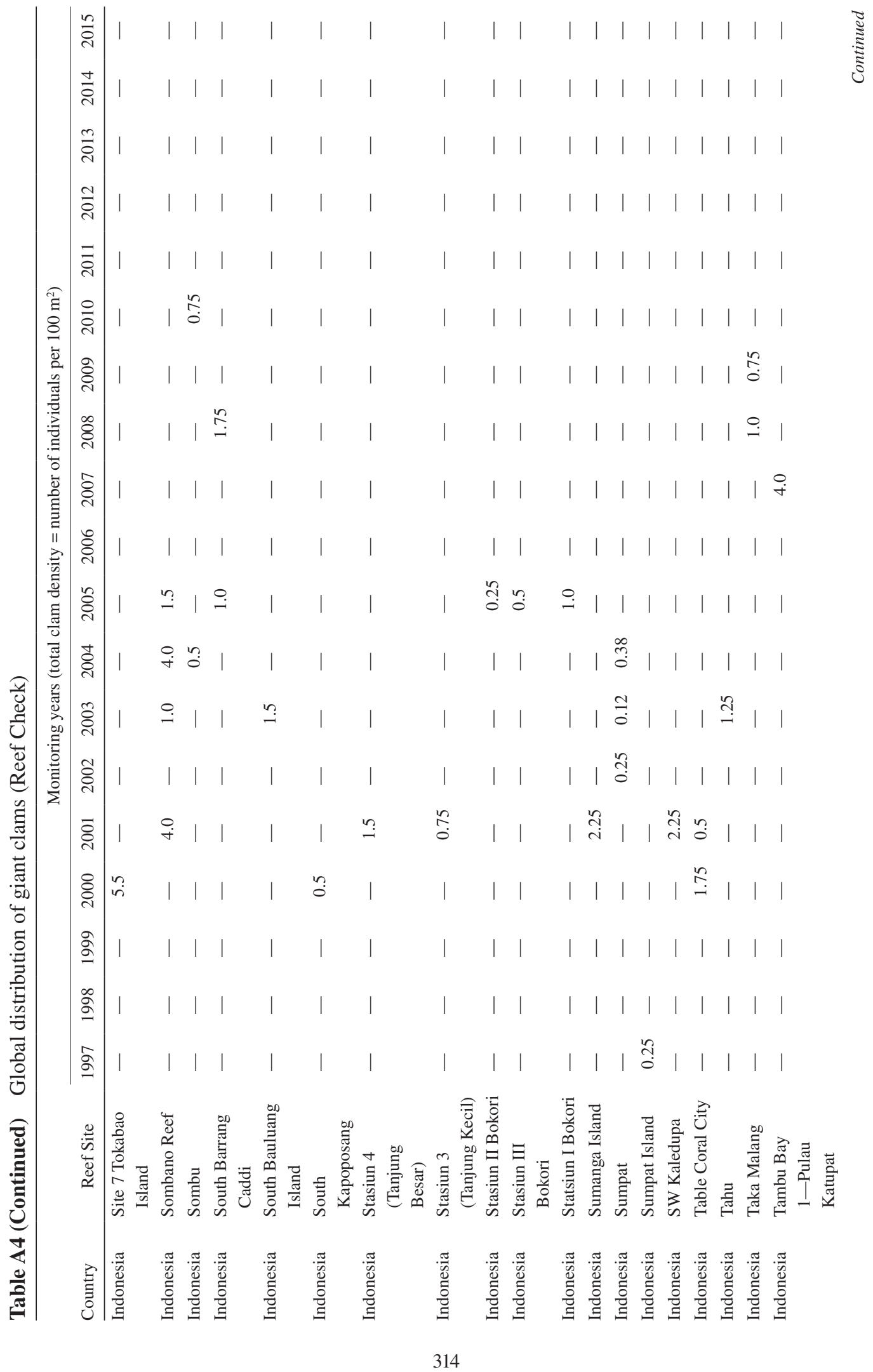


GIANT CLAMS (BIVALVIA: CARDIIDAE: TRIDACNINAE)

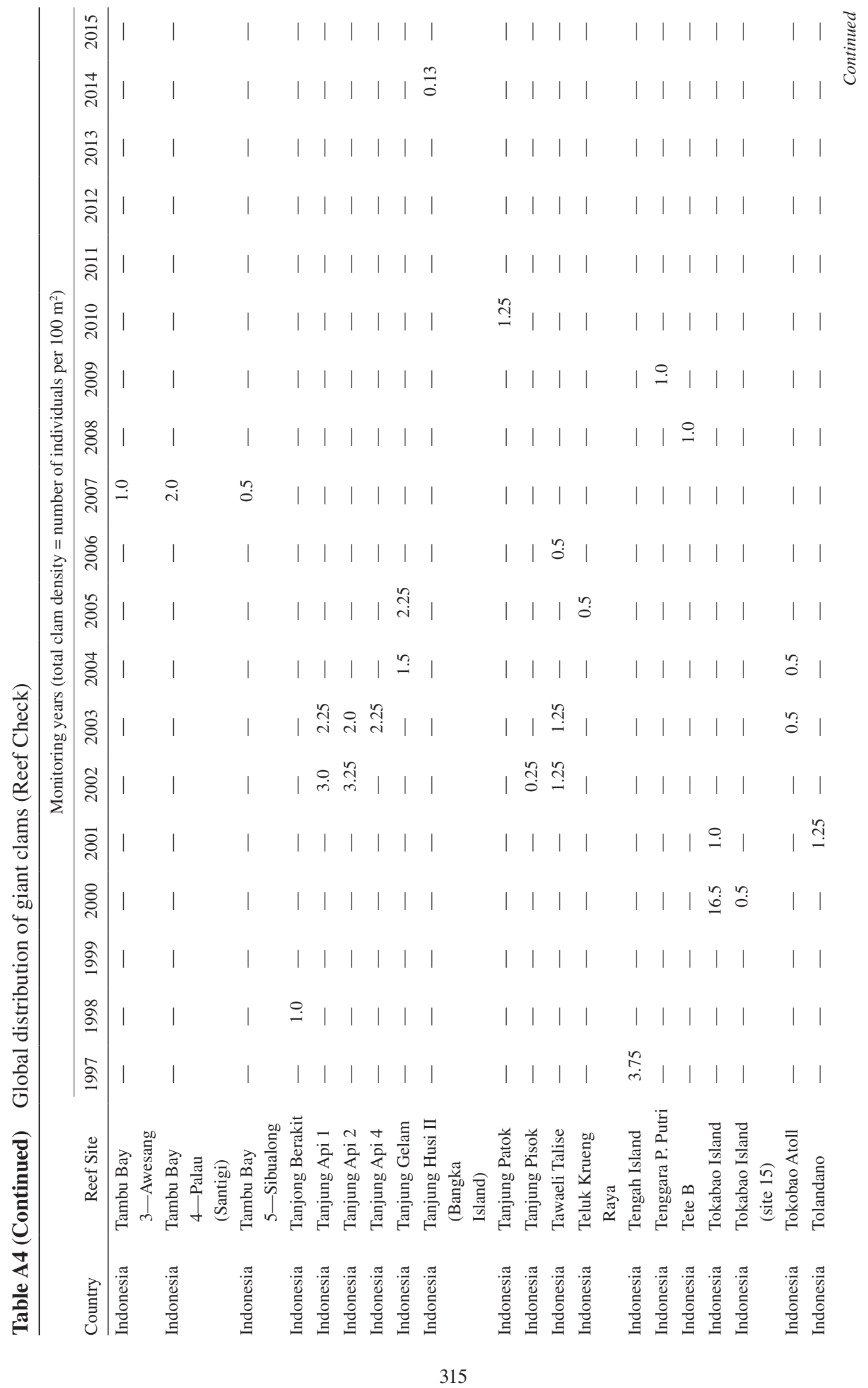


MEI LIN NEO ET AL.

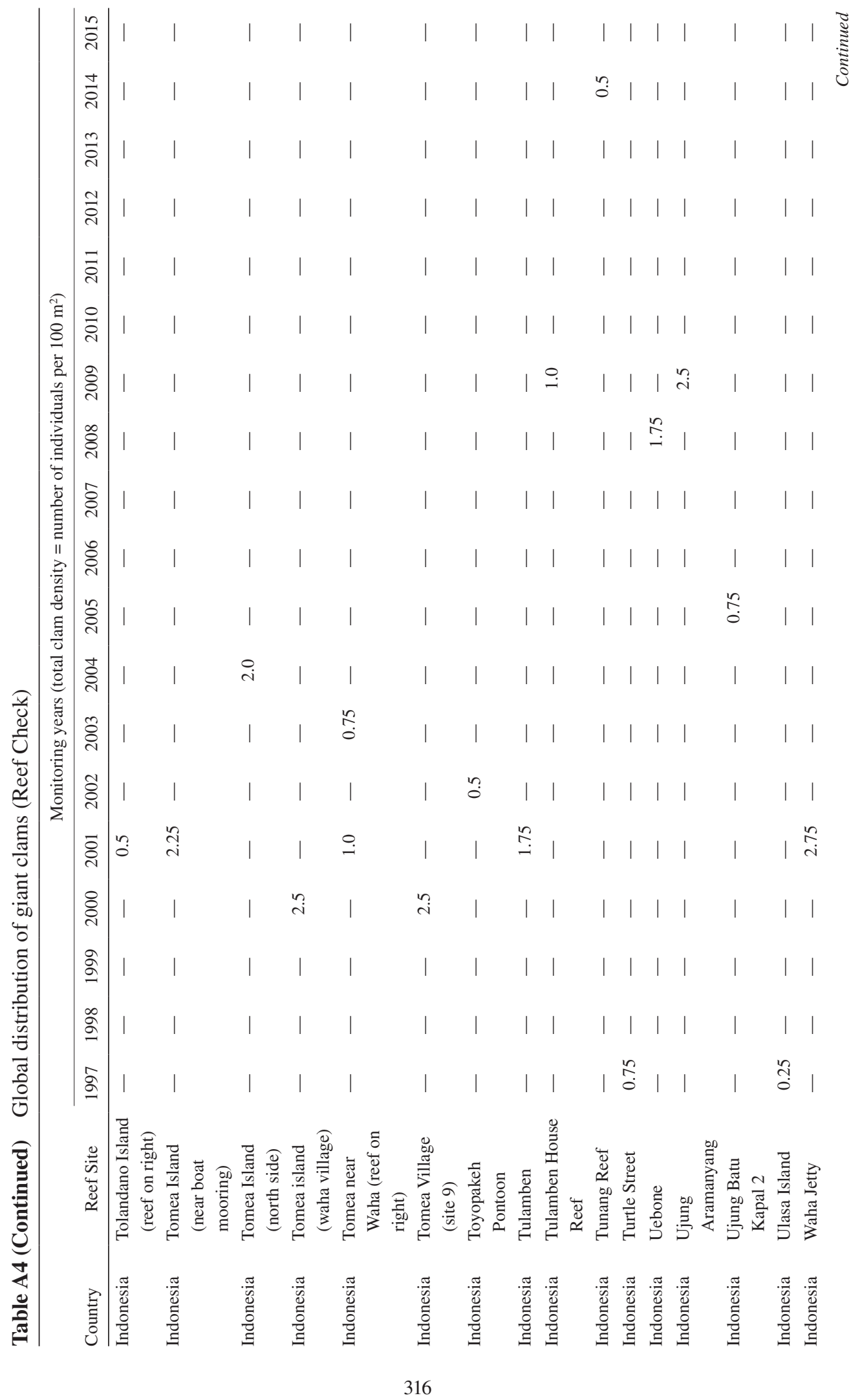


GIANT CLAMS (BIVALVIA: CARDIIDAE: TRIDACNINAE)

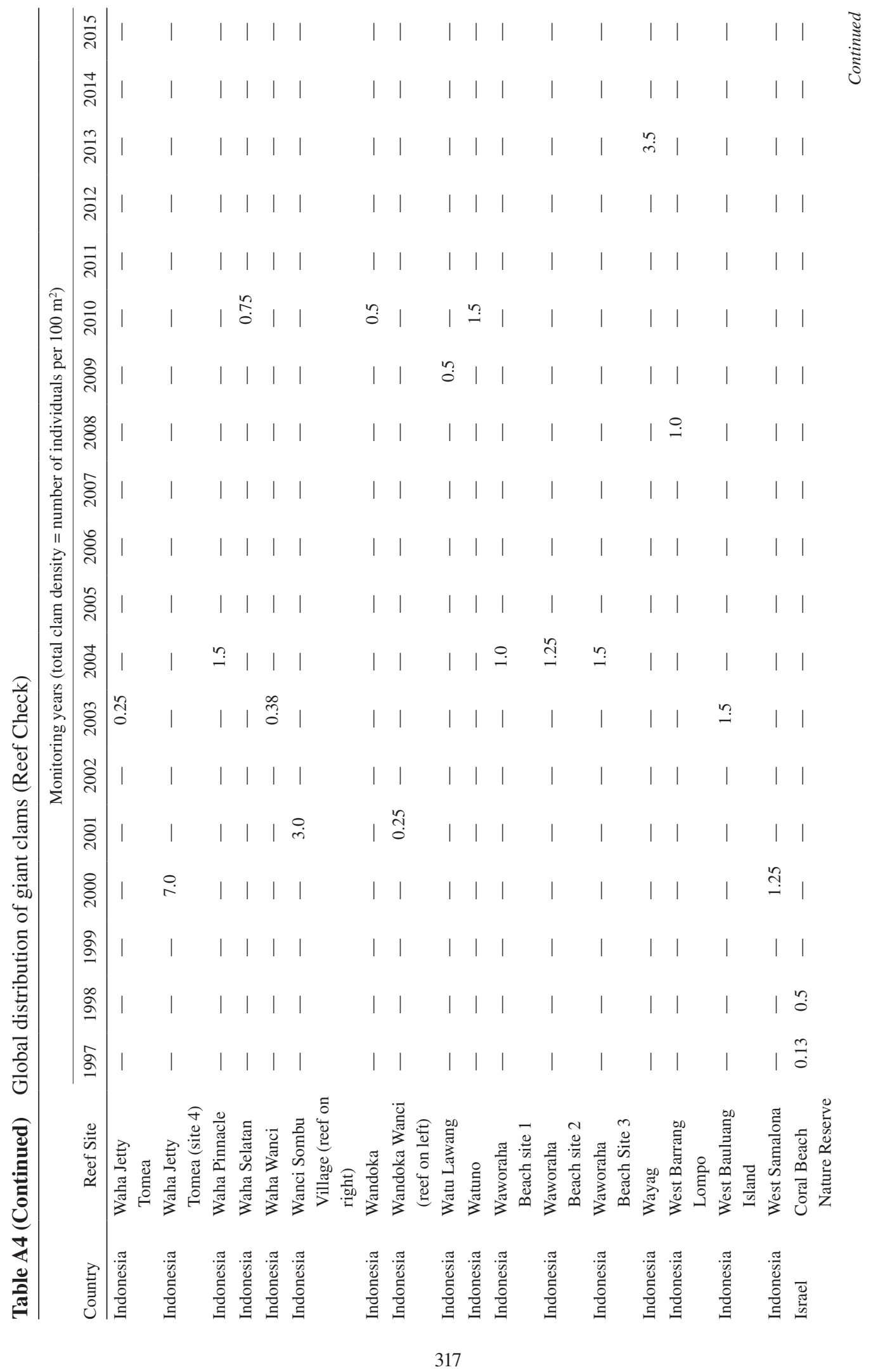


MEI LIN NEO ET AL.

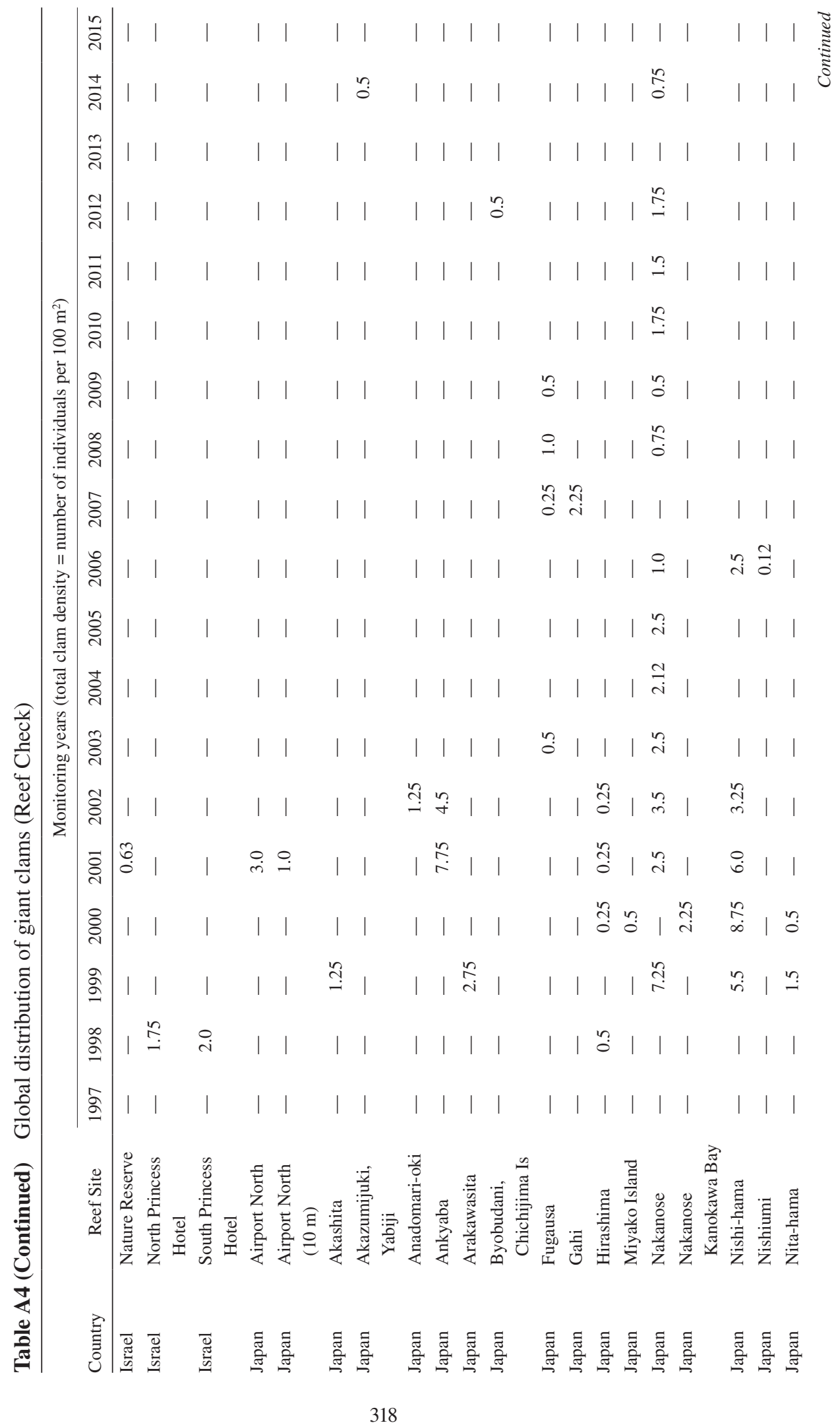


GIANT CLAMS (BIVALVIA: CARDIIDAE: TRIDACNINAE)

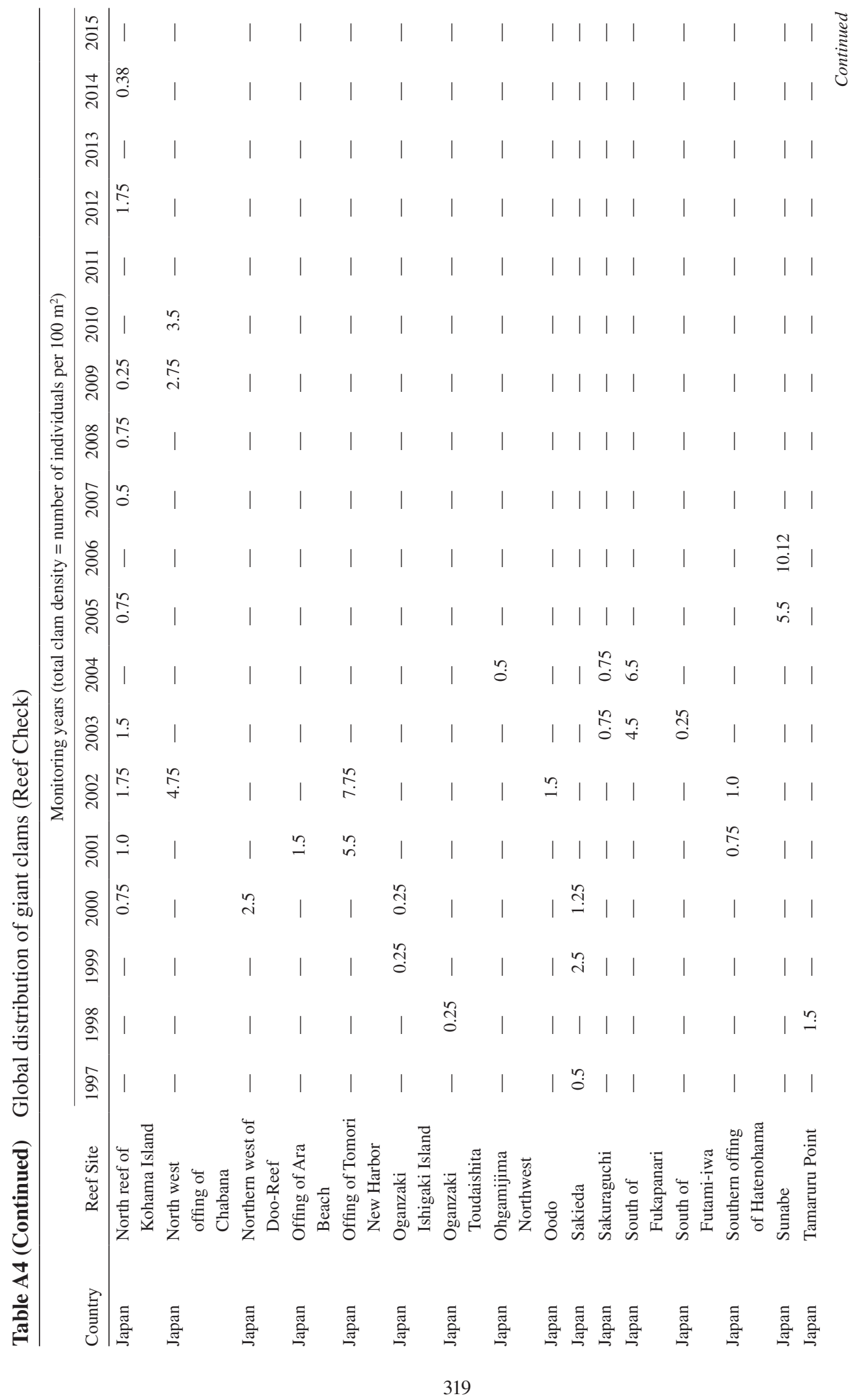


MEI LIN NEO ET AL.

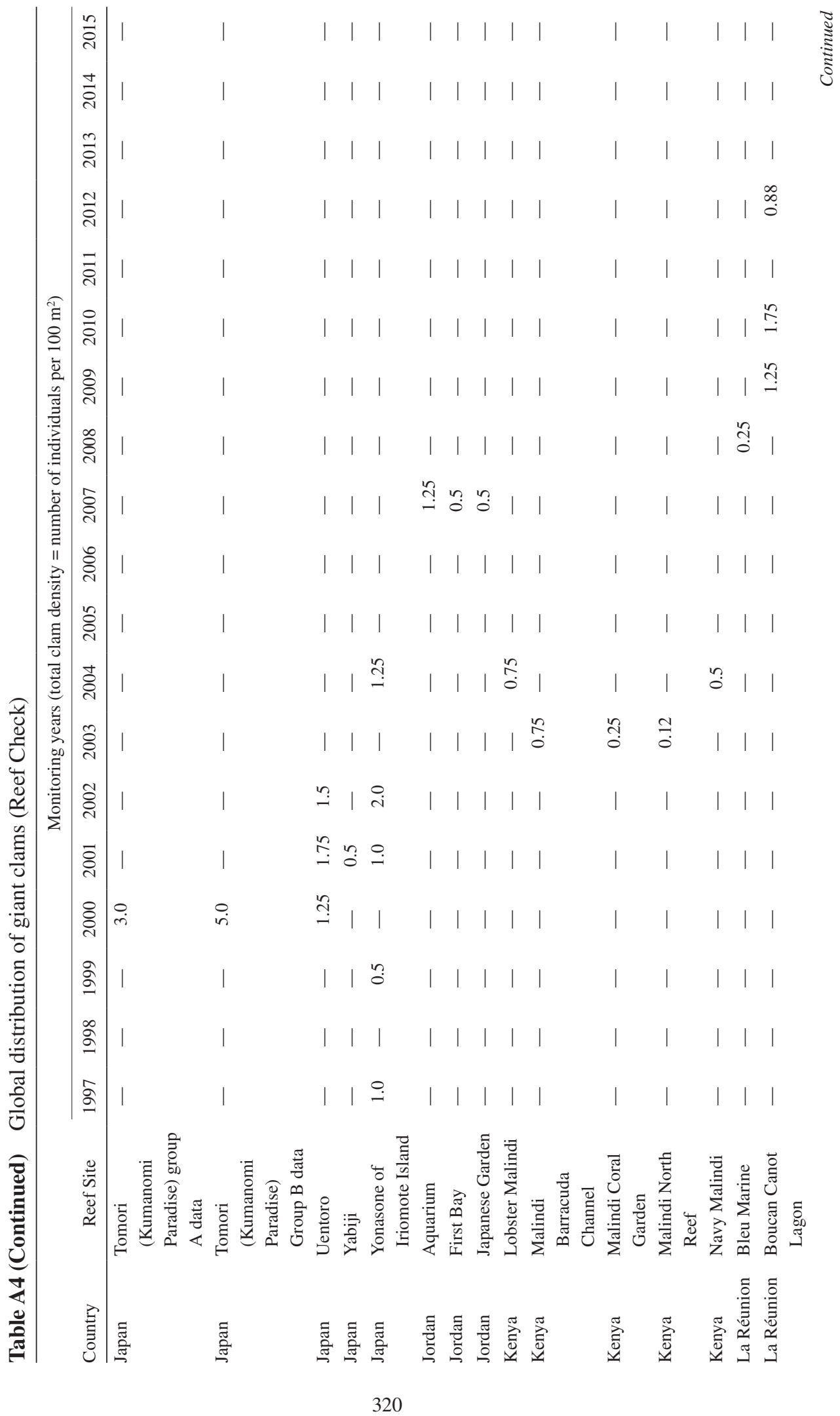


GIANT CLAMS (BIVALVIA: CARDIIDAE: TRIDACNINAE)

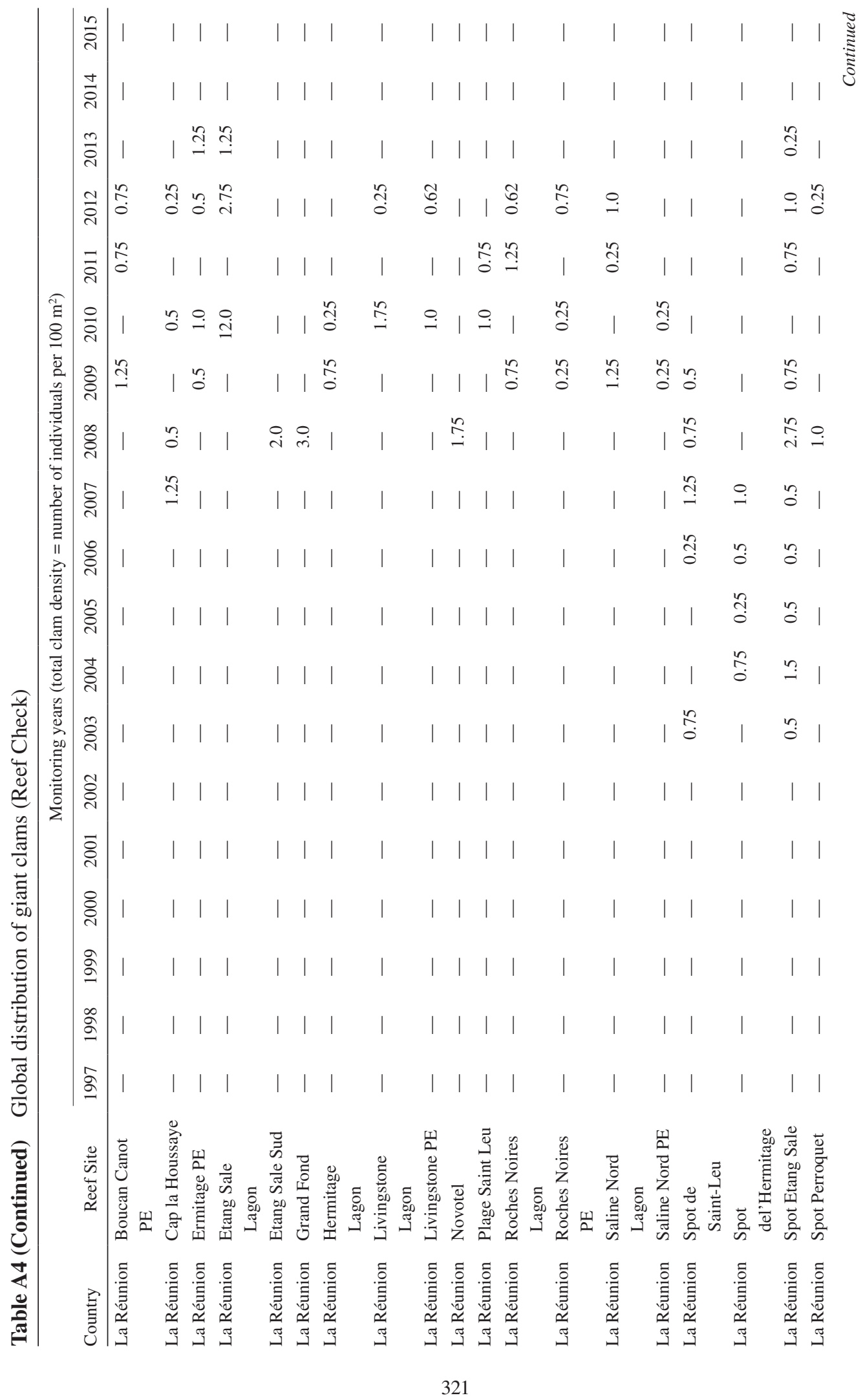


MEI LIN NEO ET AL.

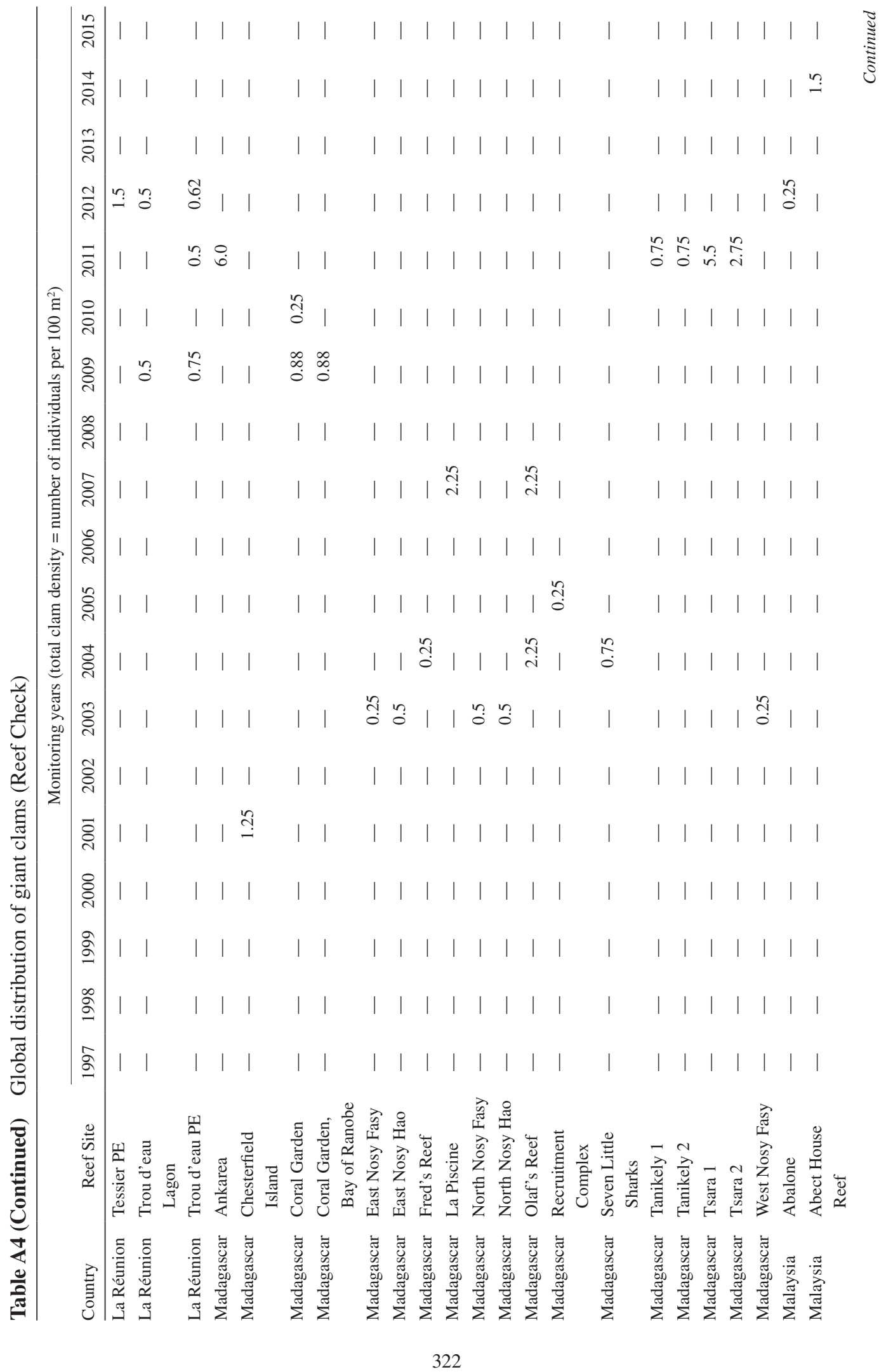




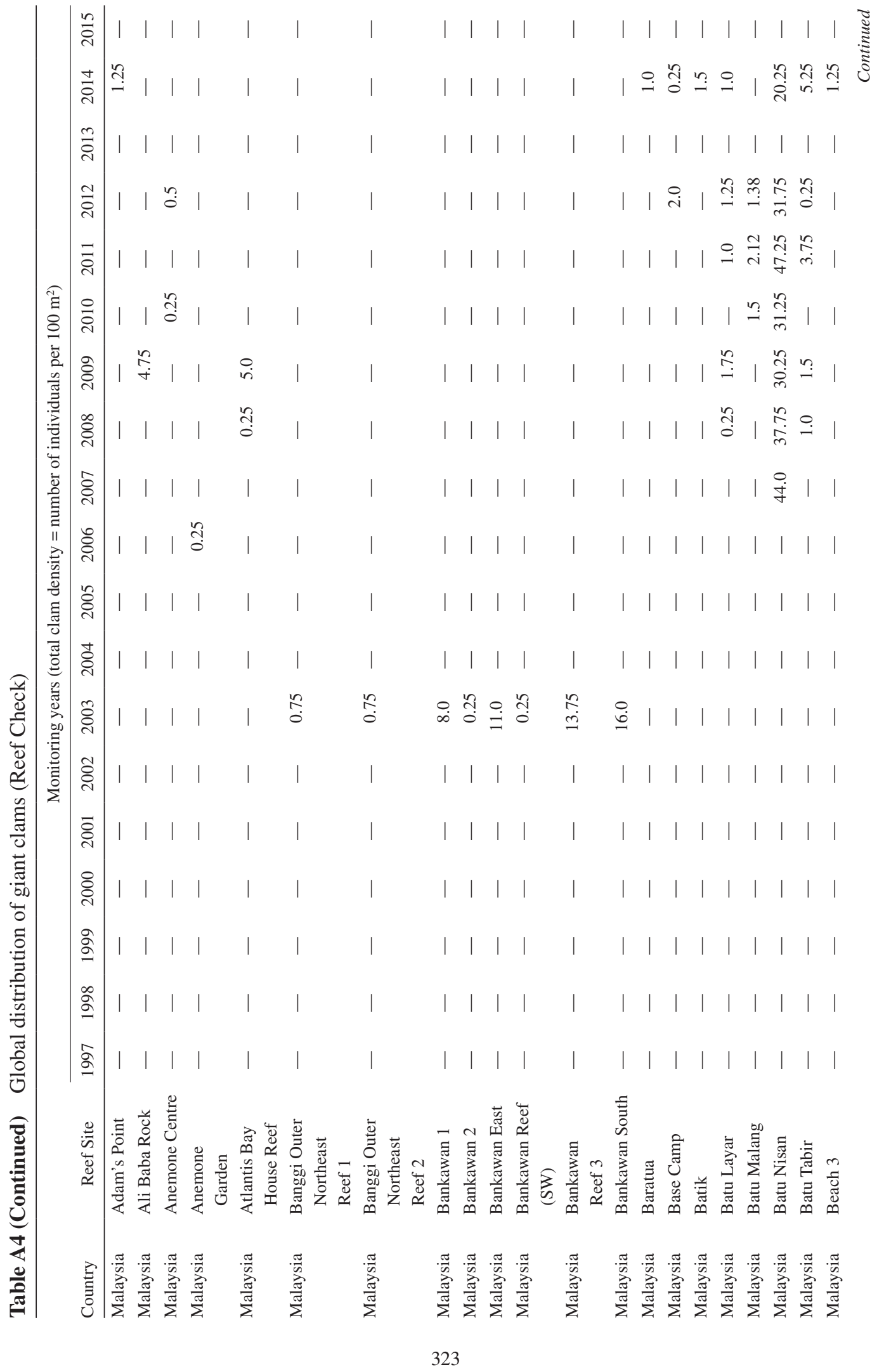


MEI LIN NEO ET AL.

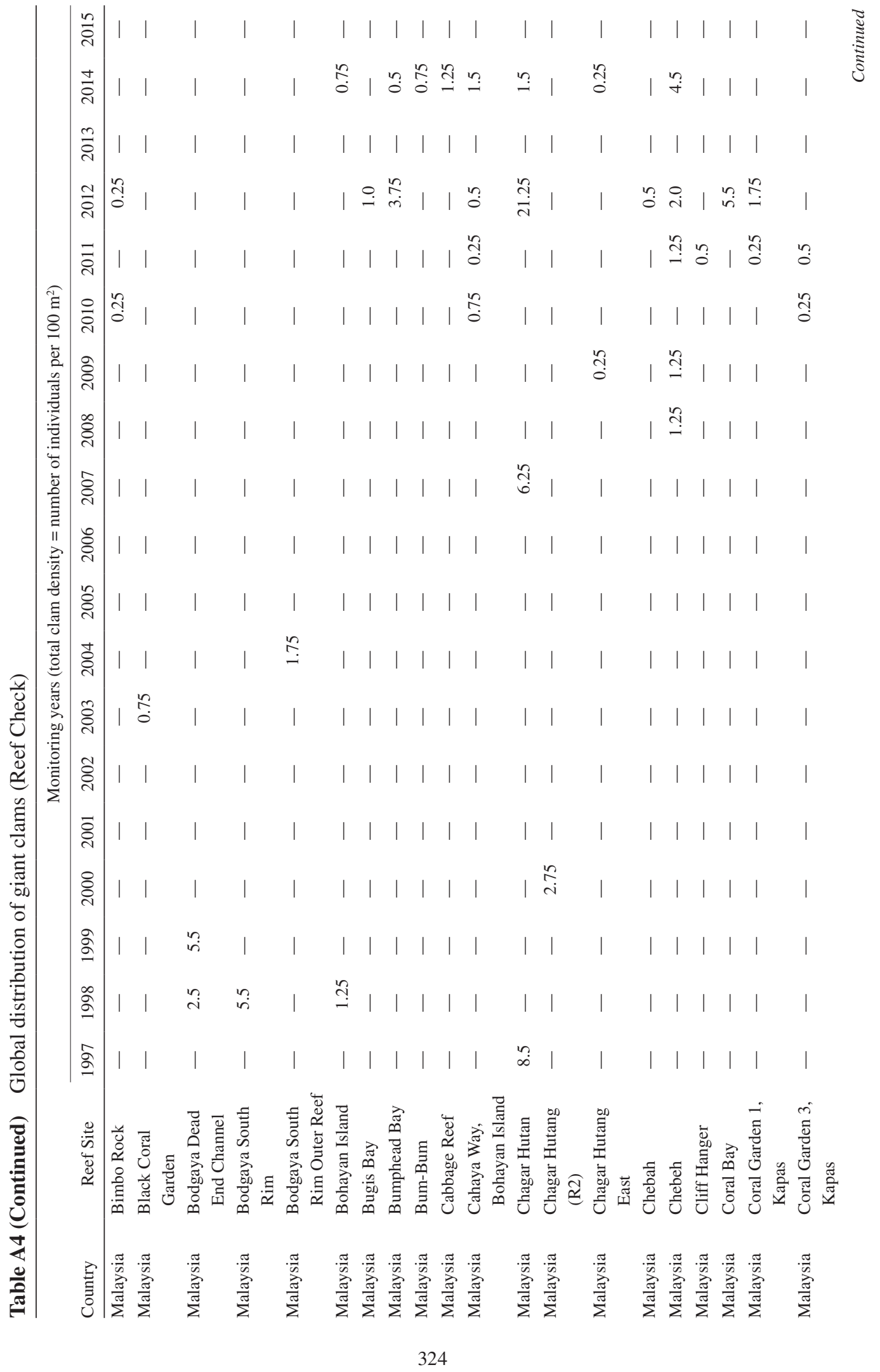


GIANT CLAMS (BIVALVIA: CARDIIDAE: TRIDACNINAE)

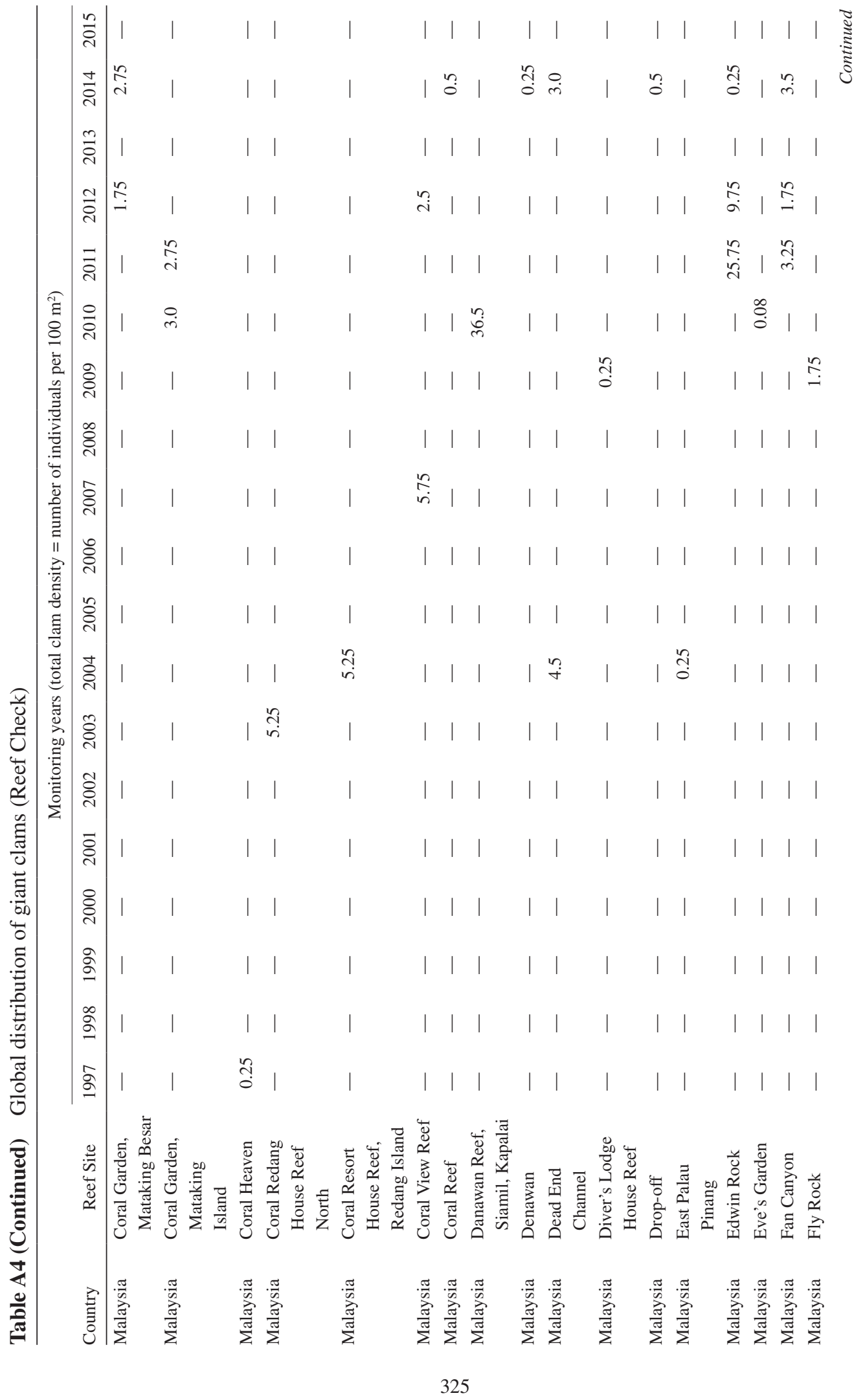


MEI LIN NEO ET AL.

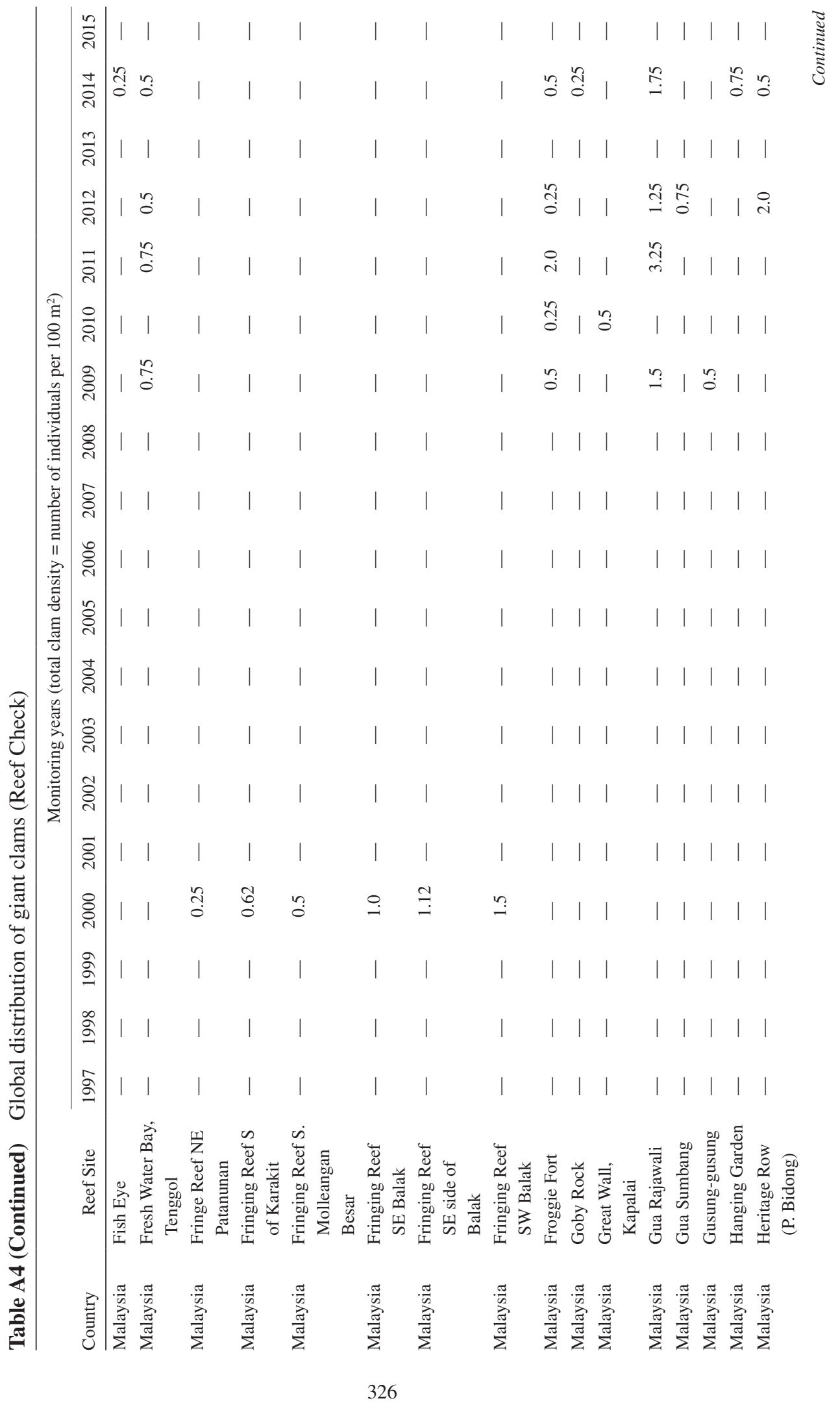


GIANT CLAMS (BIVALVIA: CARDIIDAE: TRIDACNINAE)

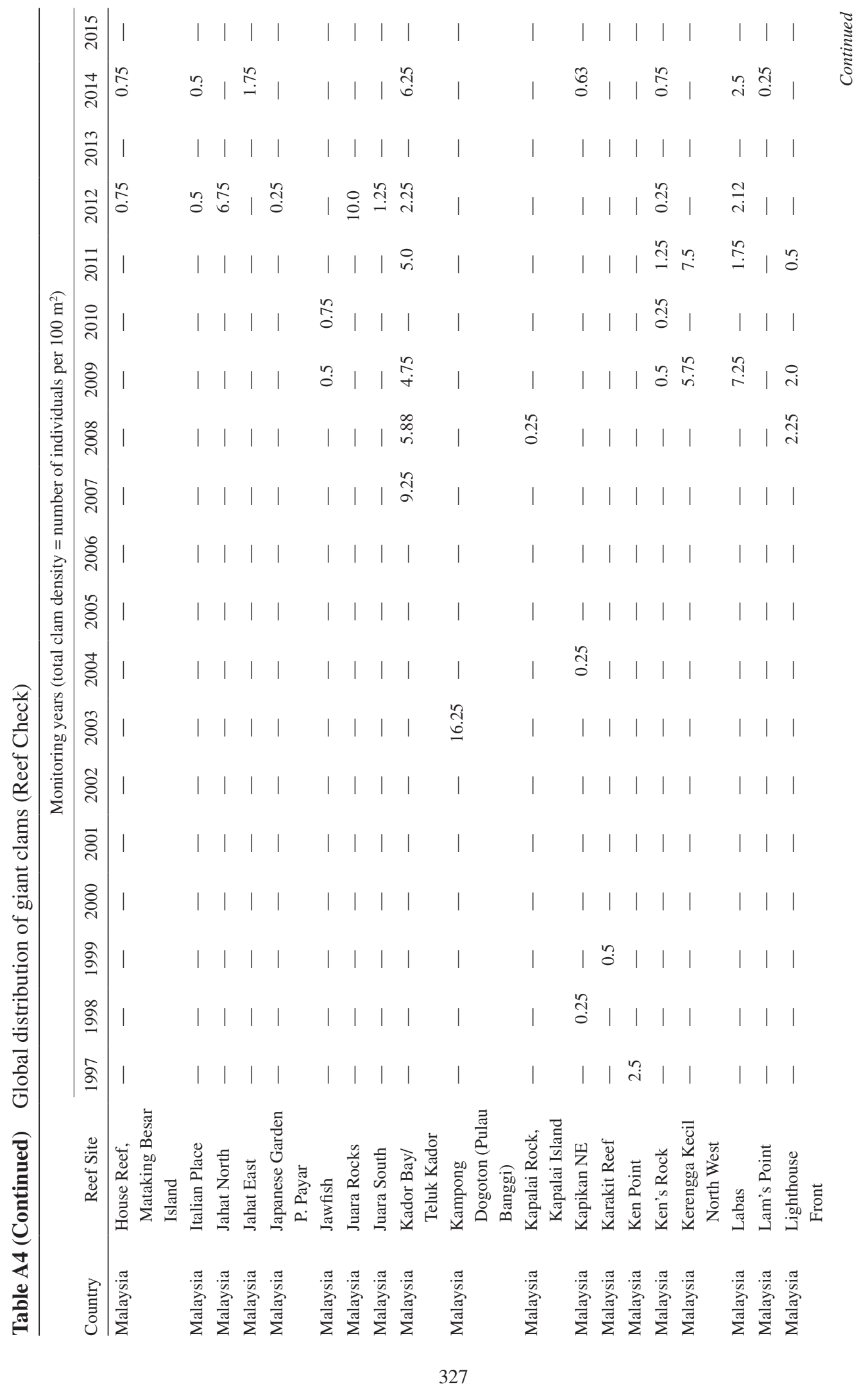


MEI LIN NEO ET AL.

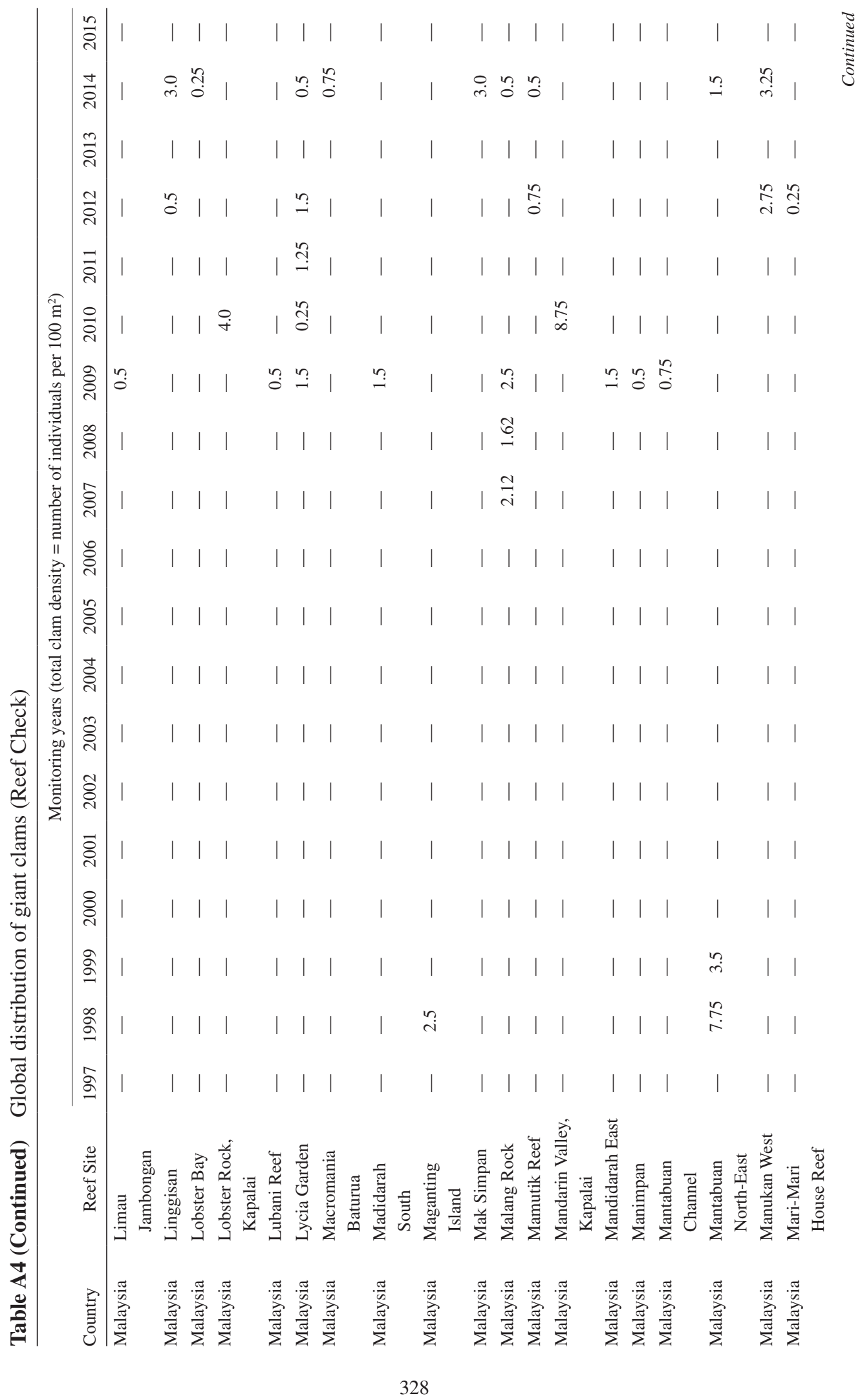


GIANT CLAMS (BIVALVIA: CARDIIDAE: TRIDACNINAE)

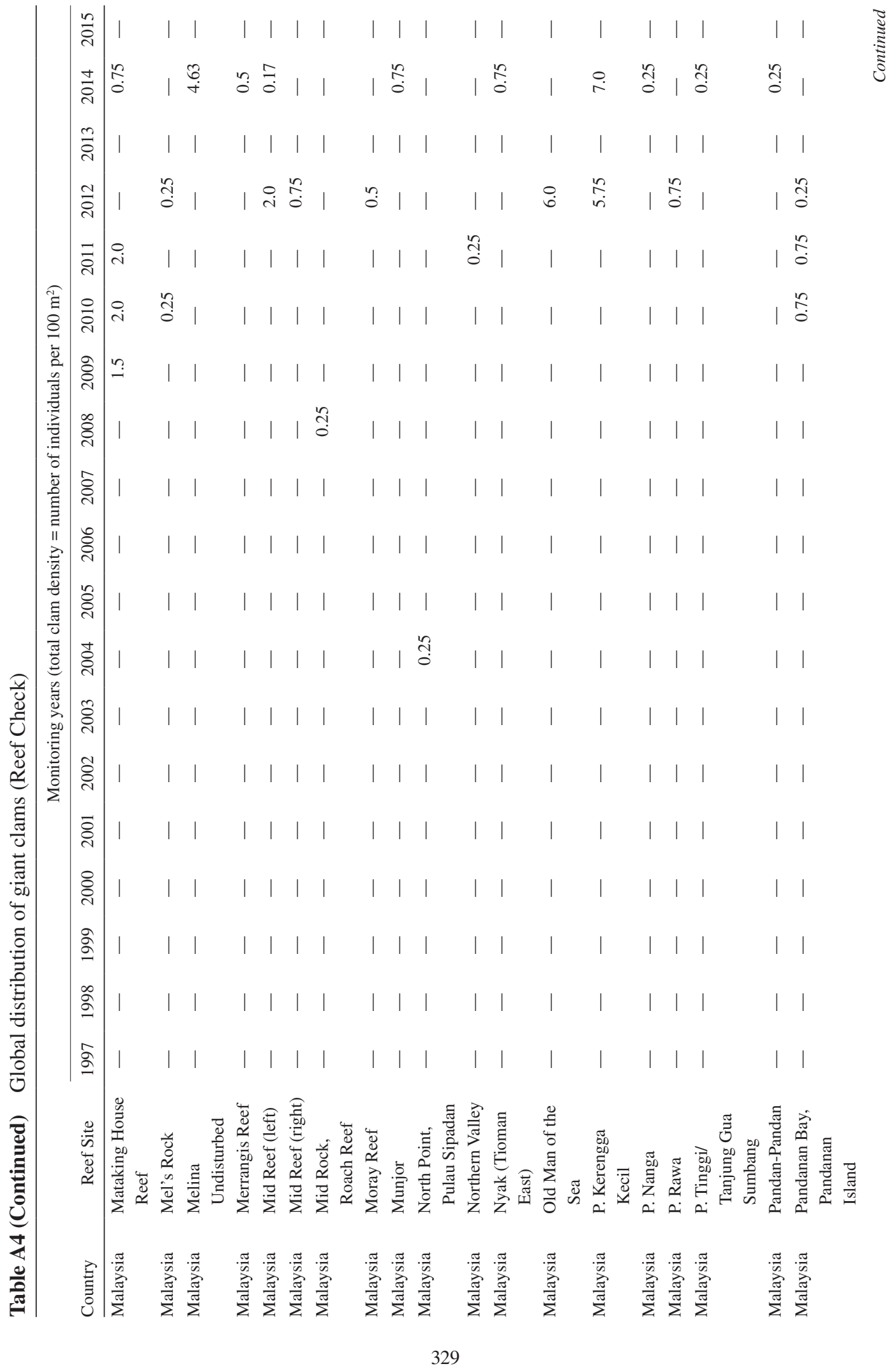


MEI LIN NEO ET AL.

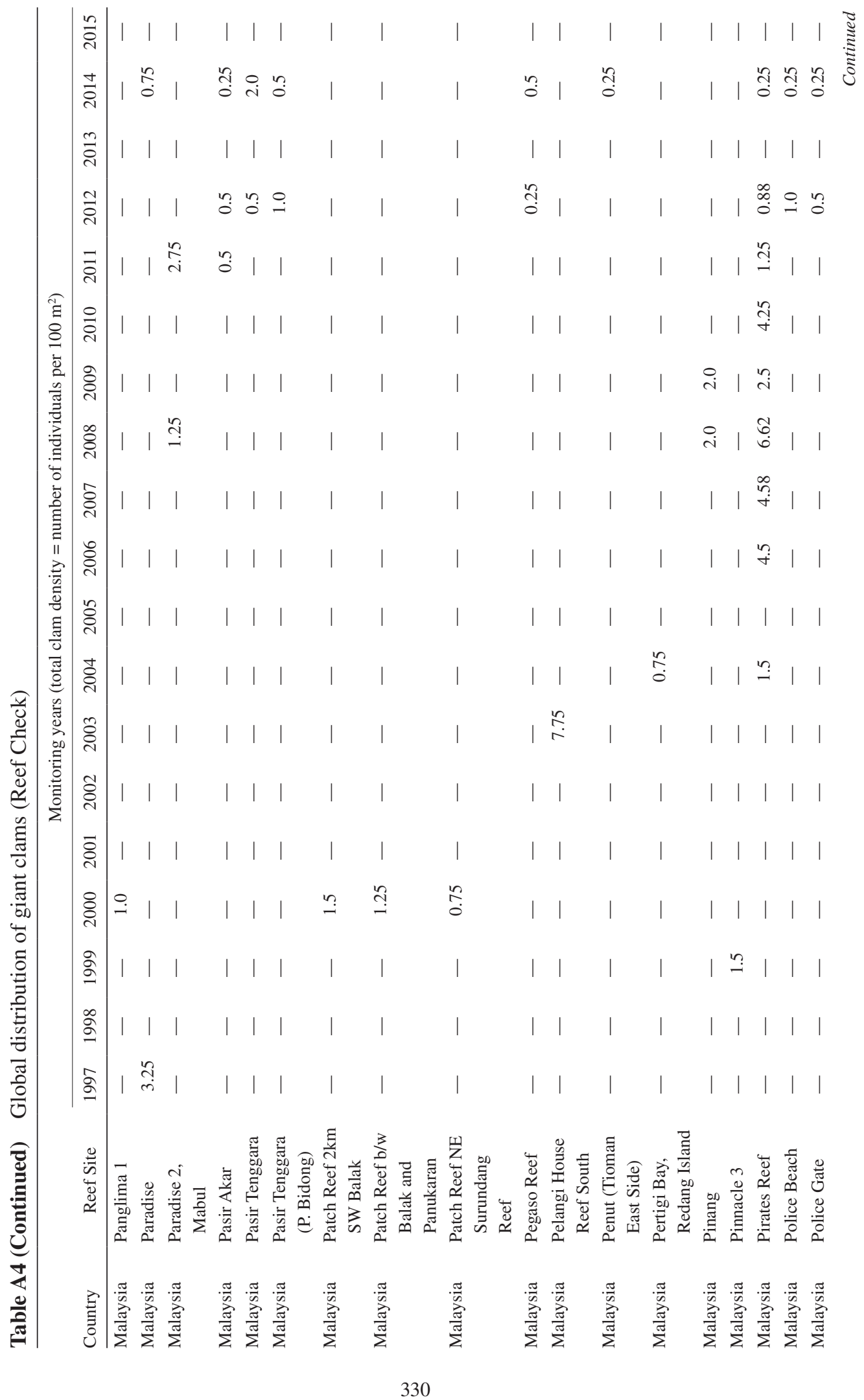


GIANT CLAMS (BIVALVIA: CARDIIDAE: TRIDACNINAE)

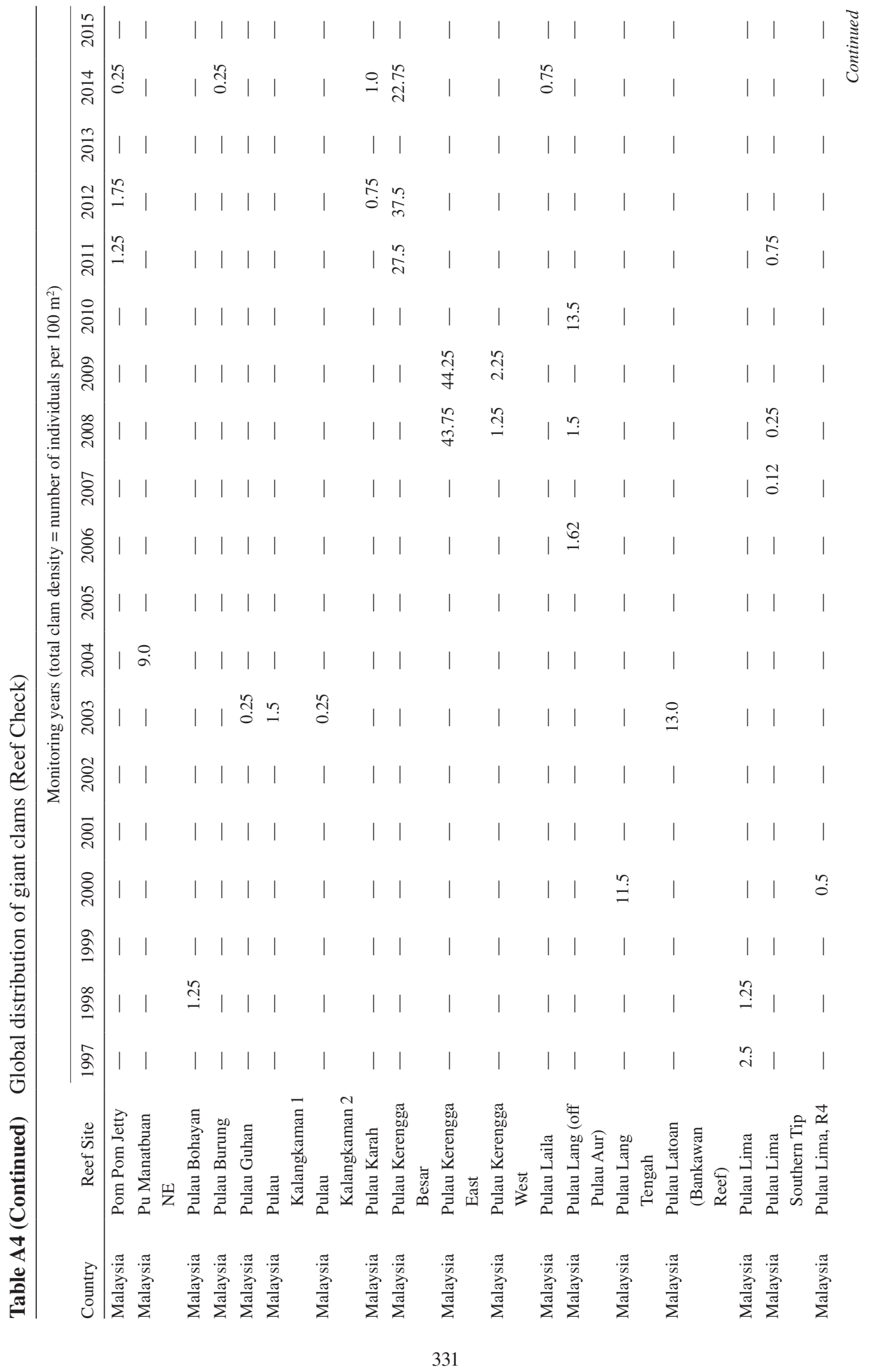


MEI LIN NEO ET AL.

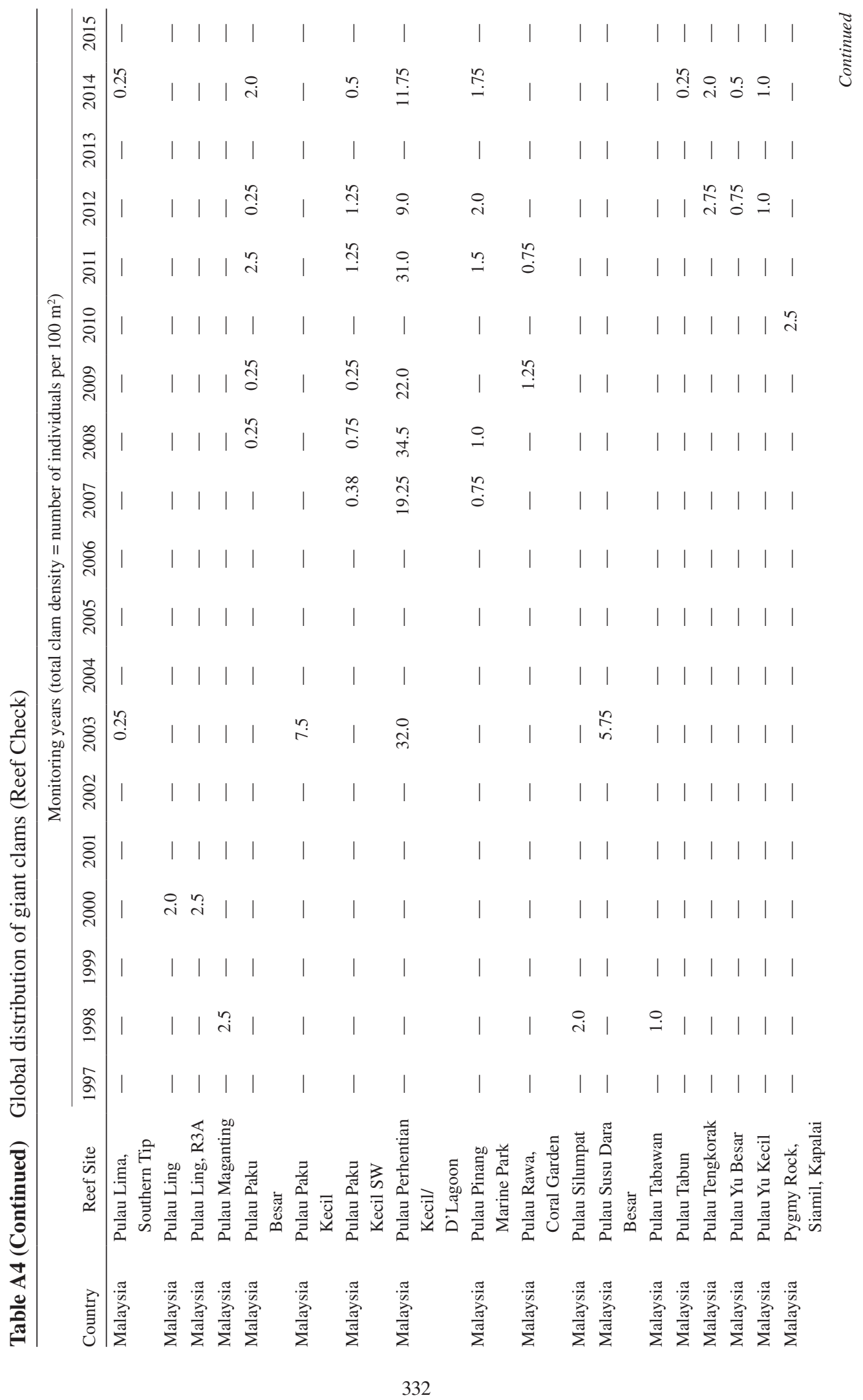




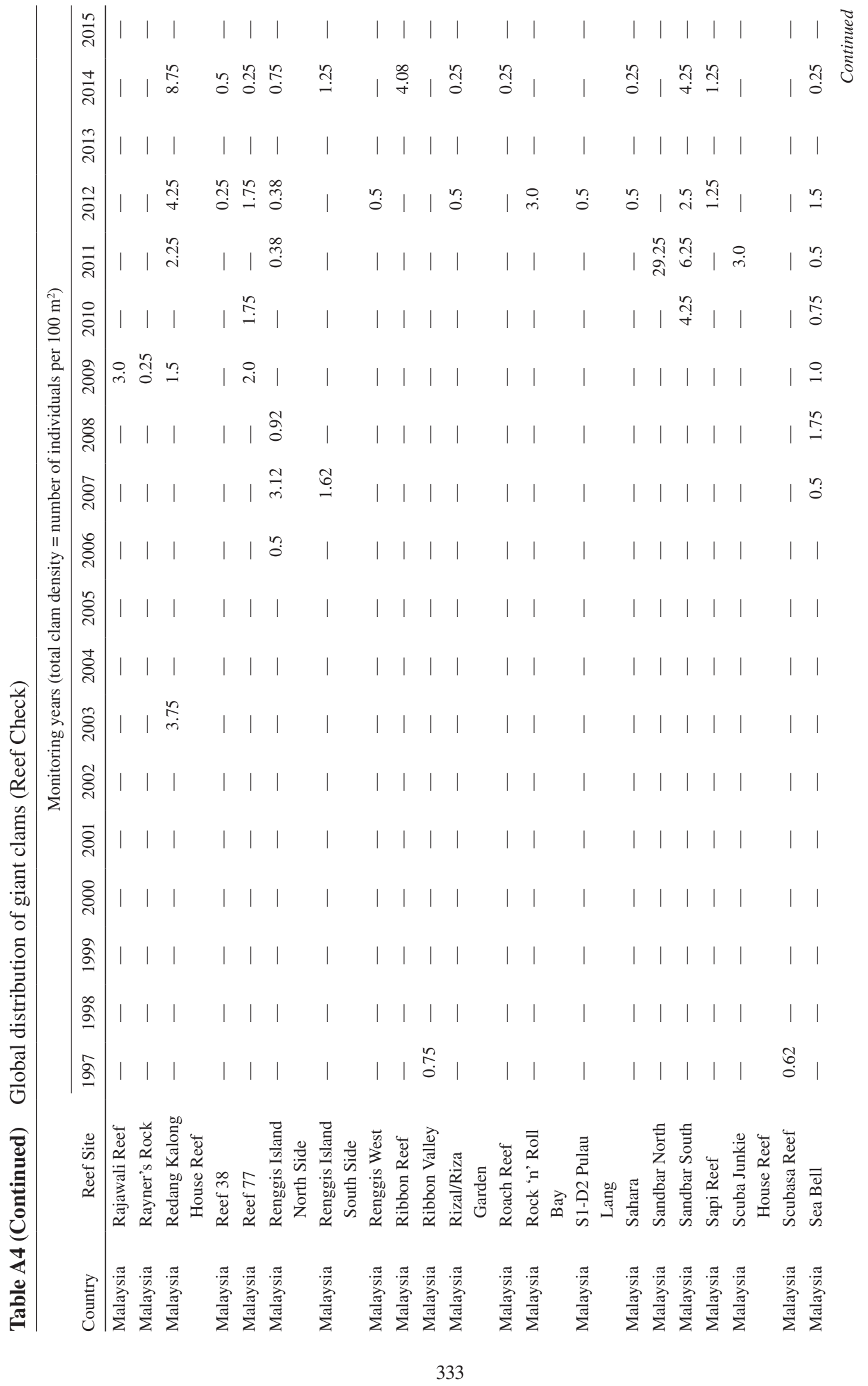


MEI LIN NEO ET AL.

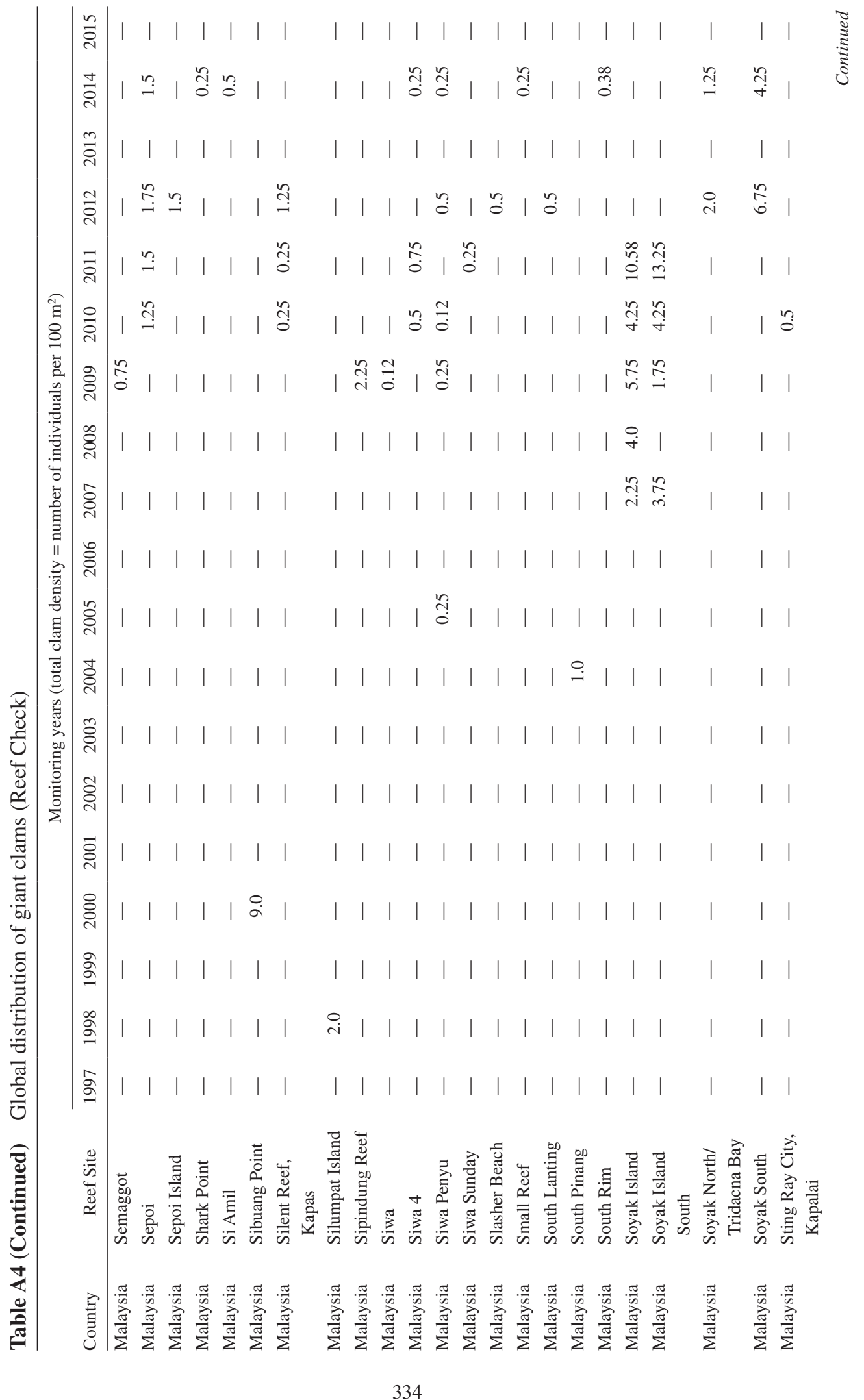


GIANT CLAMS (BIVALVIA: CARDIIDAE: TRIDACNINAE)

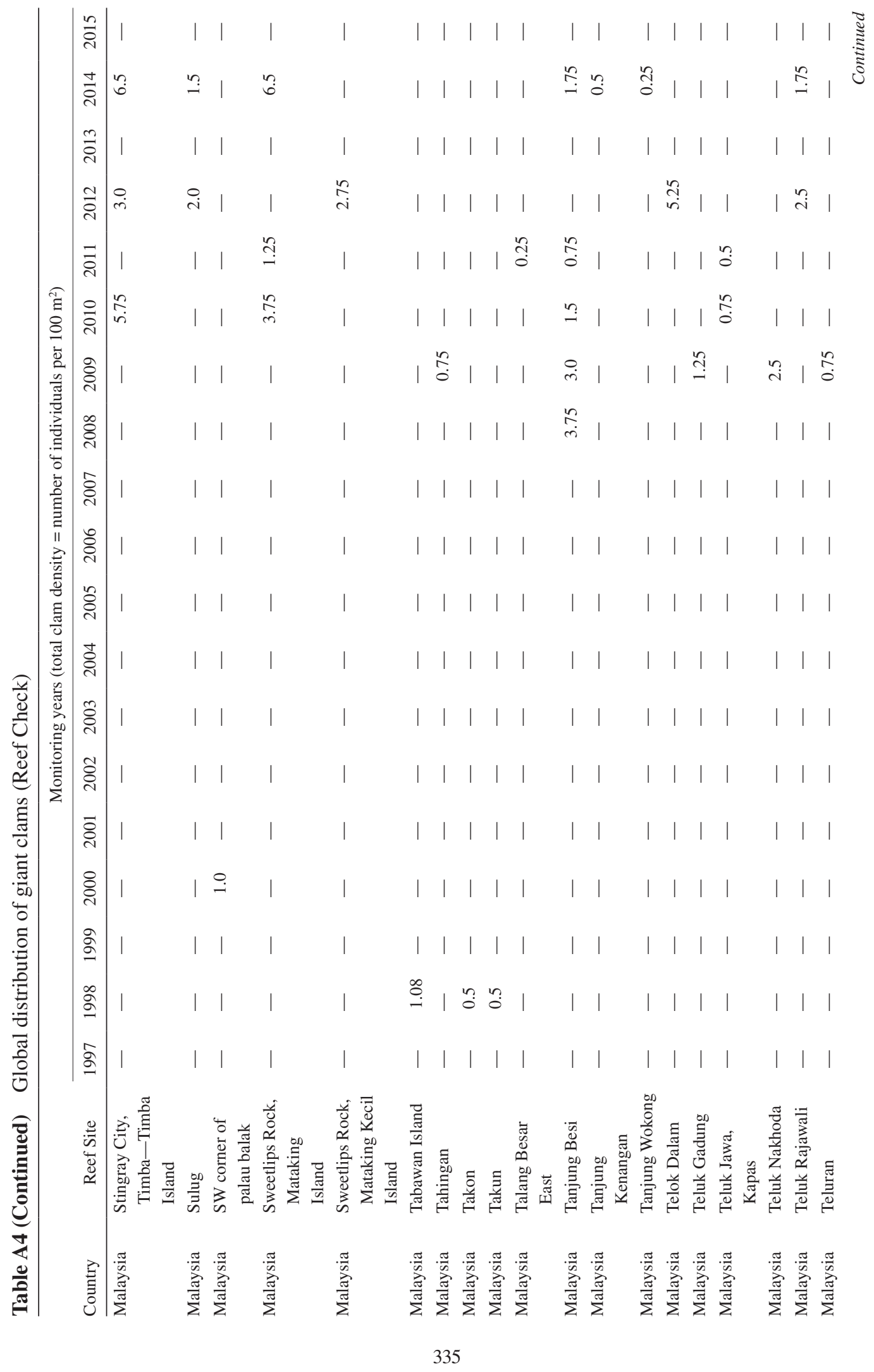


MEI LIN NEO ET AL.

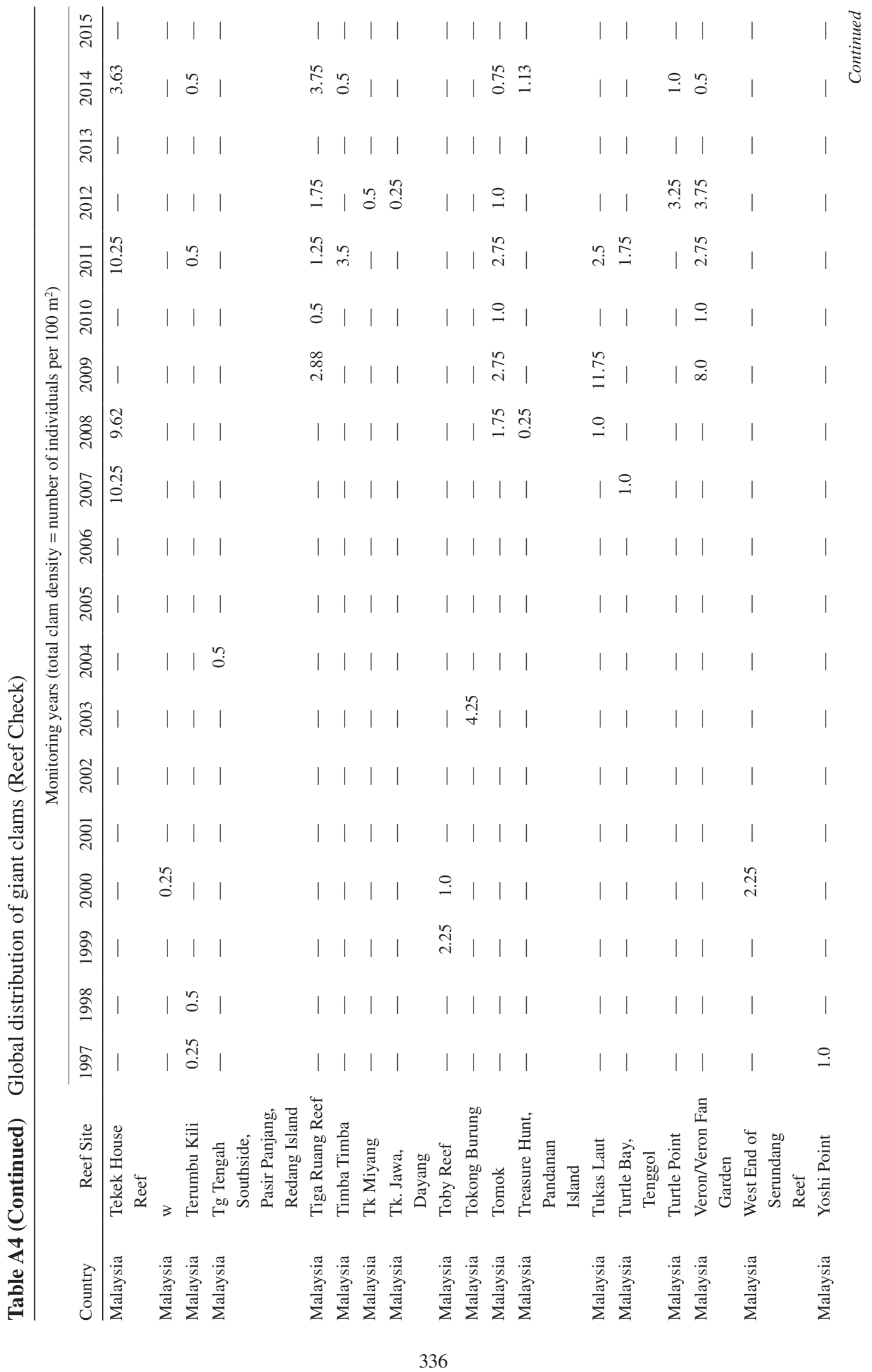


GIANT CLAMS (BIVALVIA: CARDIIDAE: TRIDACNINAE)

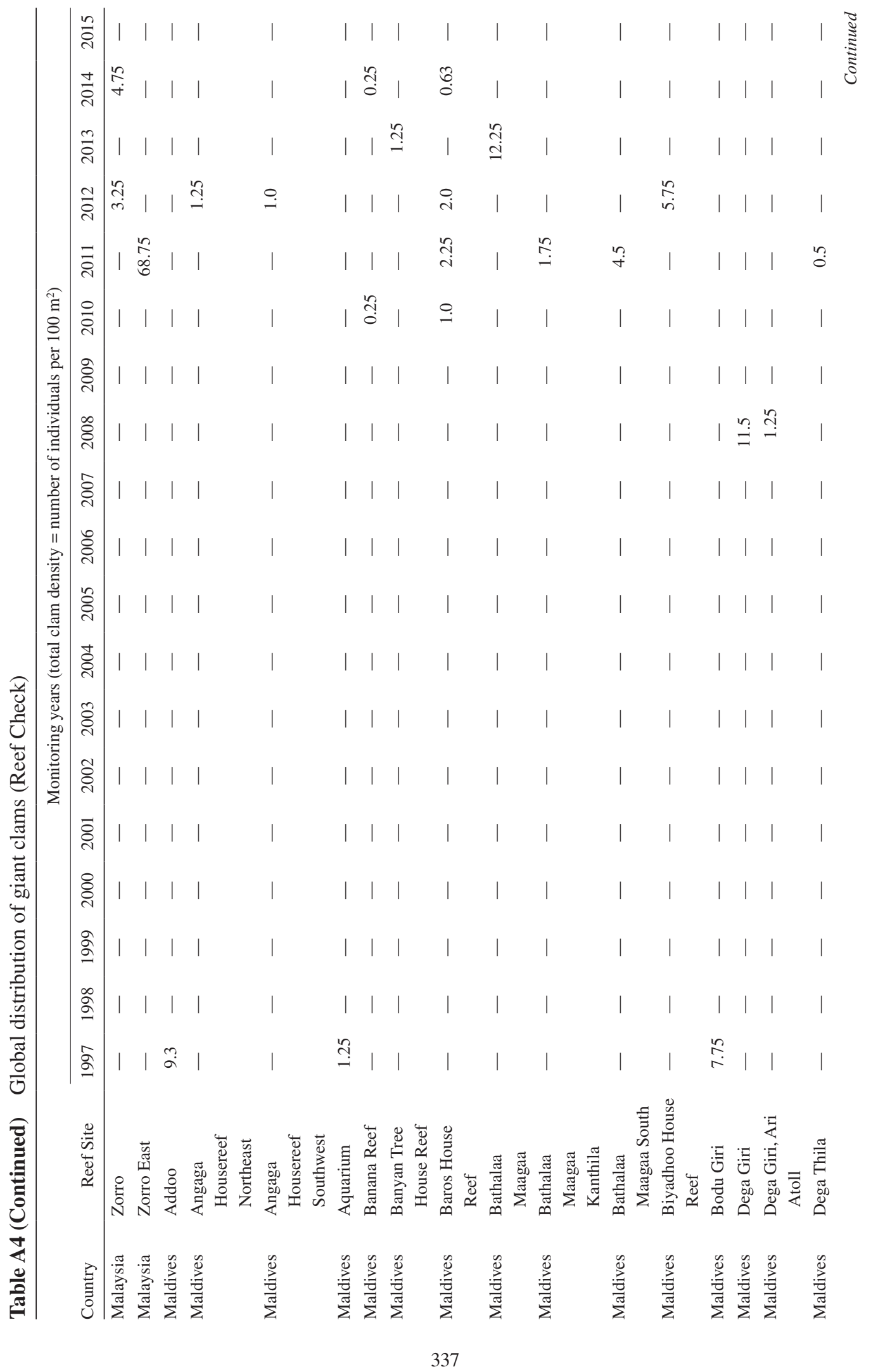


MEI LIN NEO ET AL.

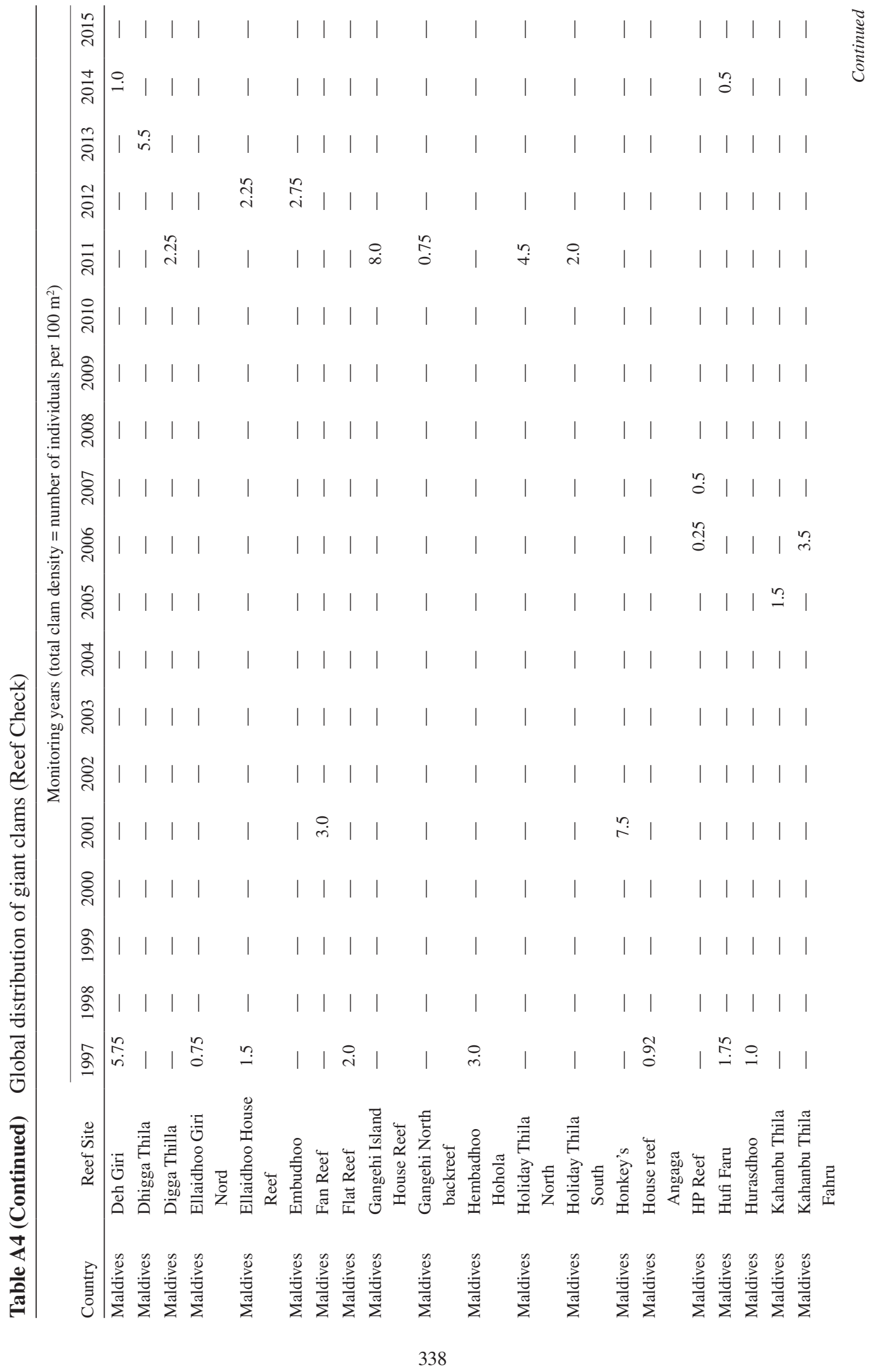


GIANT CLAMS (BIVALVIA: CARDIIDAE: TRIDACNINAE)

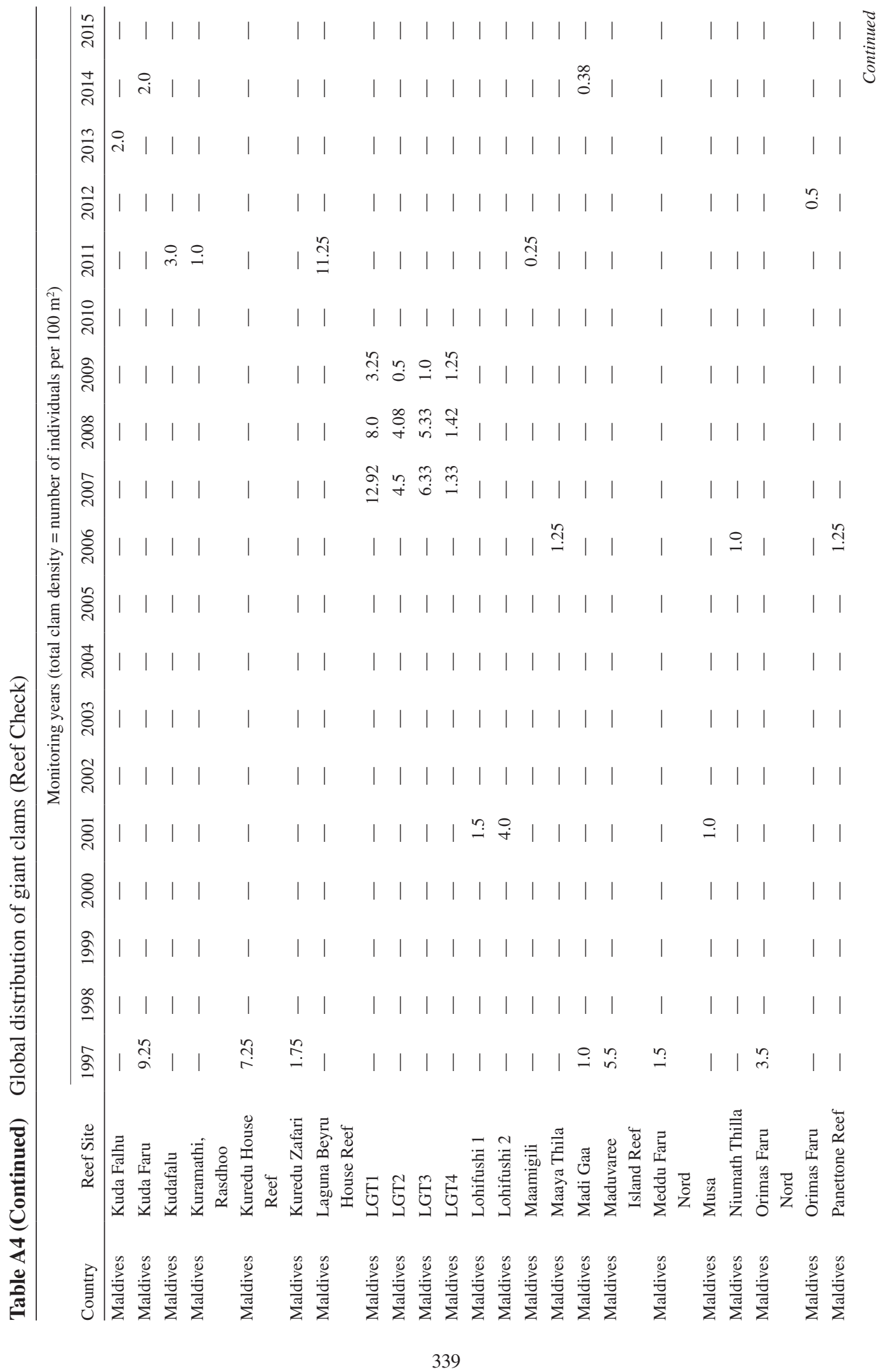


MEI LIN NEO ET AL.

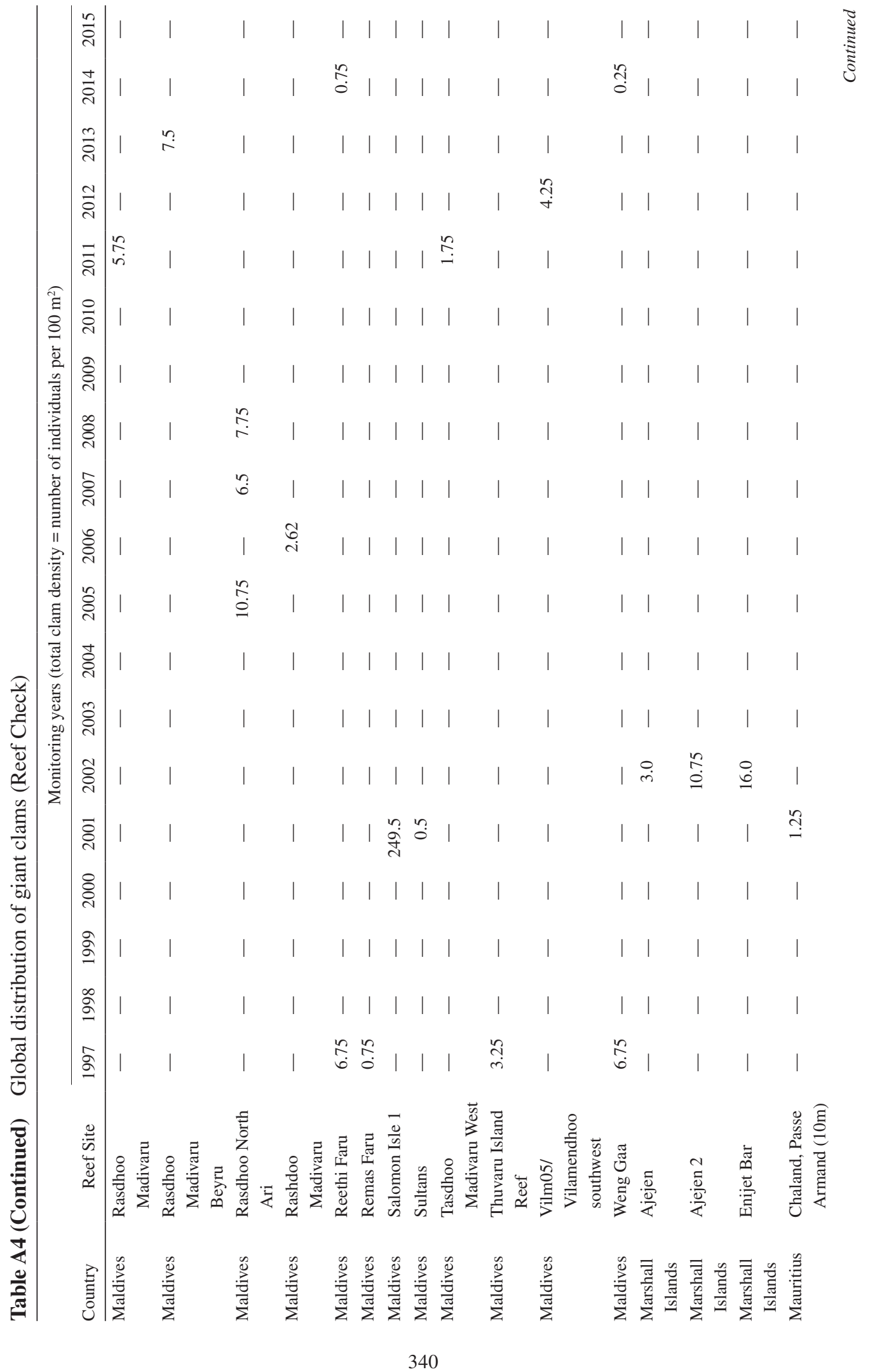


GIANT CLAMS (BIVALVIA: CARDIIDAE: TRIDACNINAE)

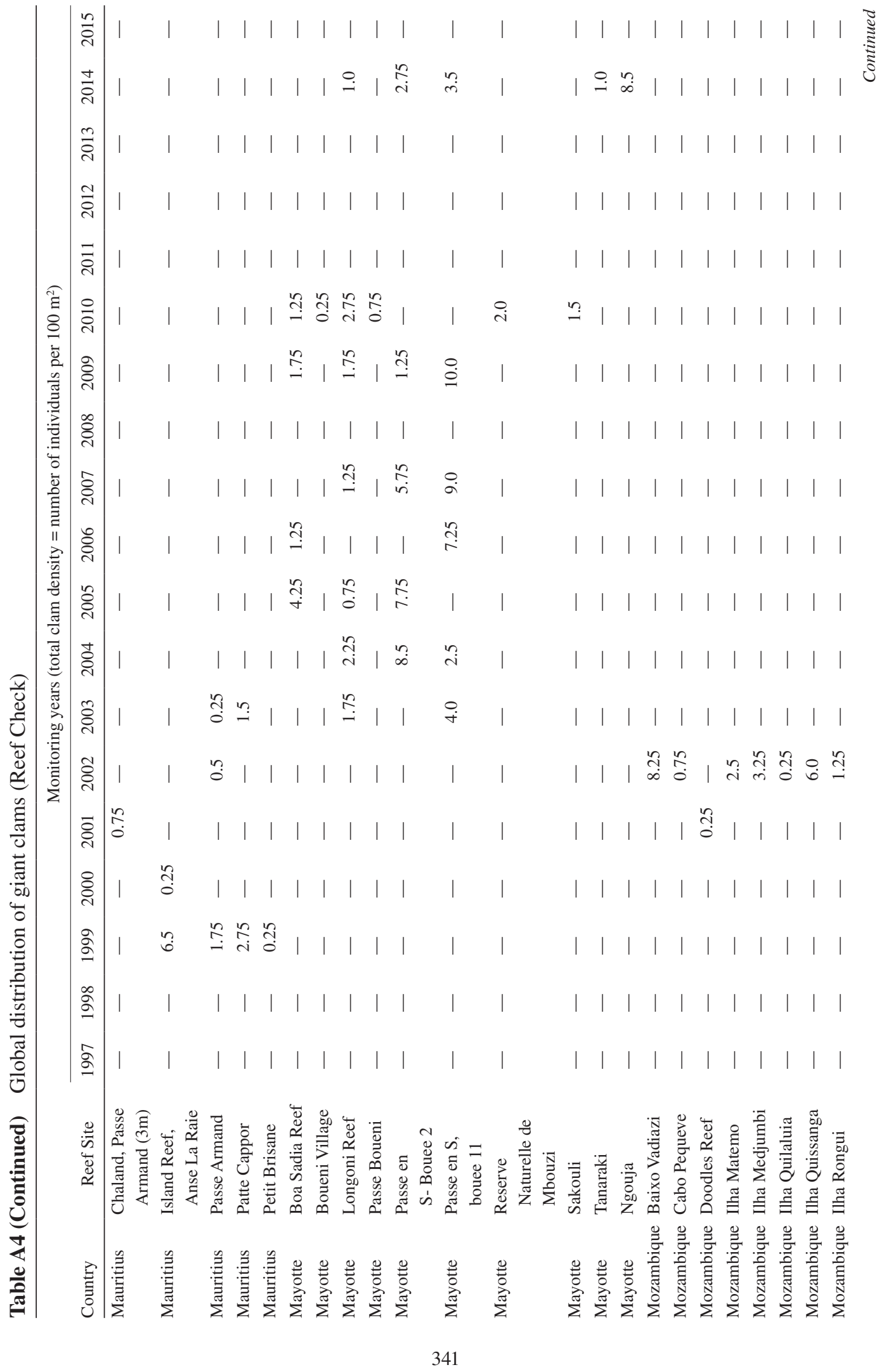


MEI LIN NEO ET AL.

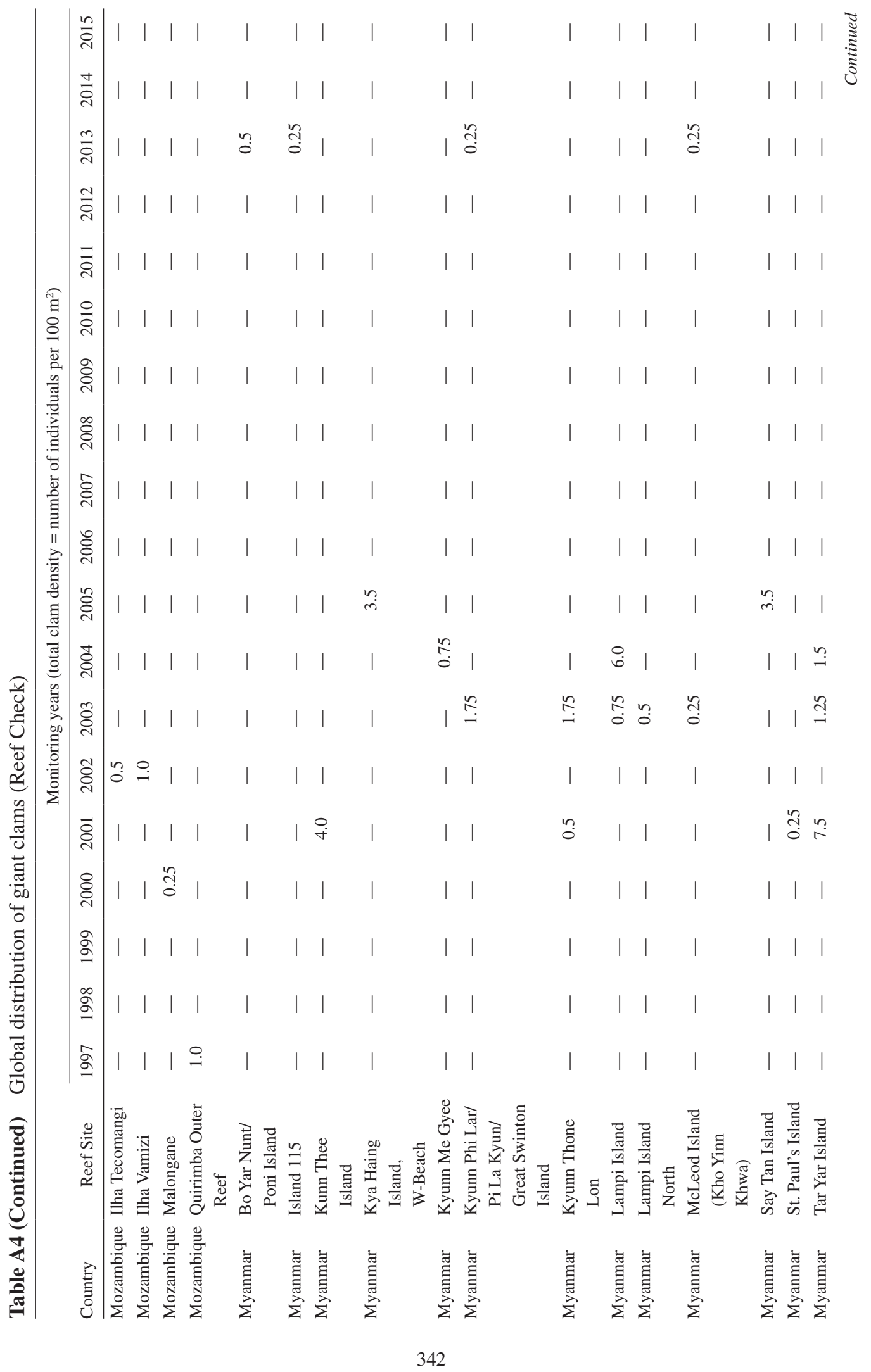


GIANT CLAMS (BIVALVIA: CARDIIDAE: TRIDACNINAE)

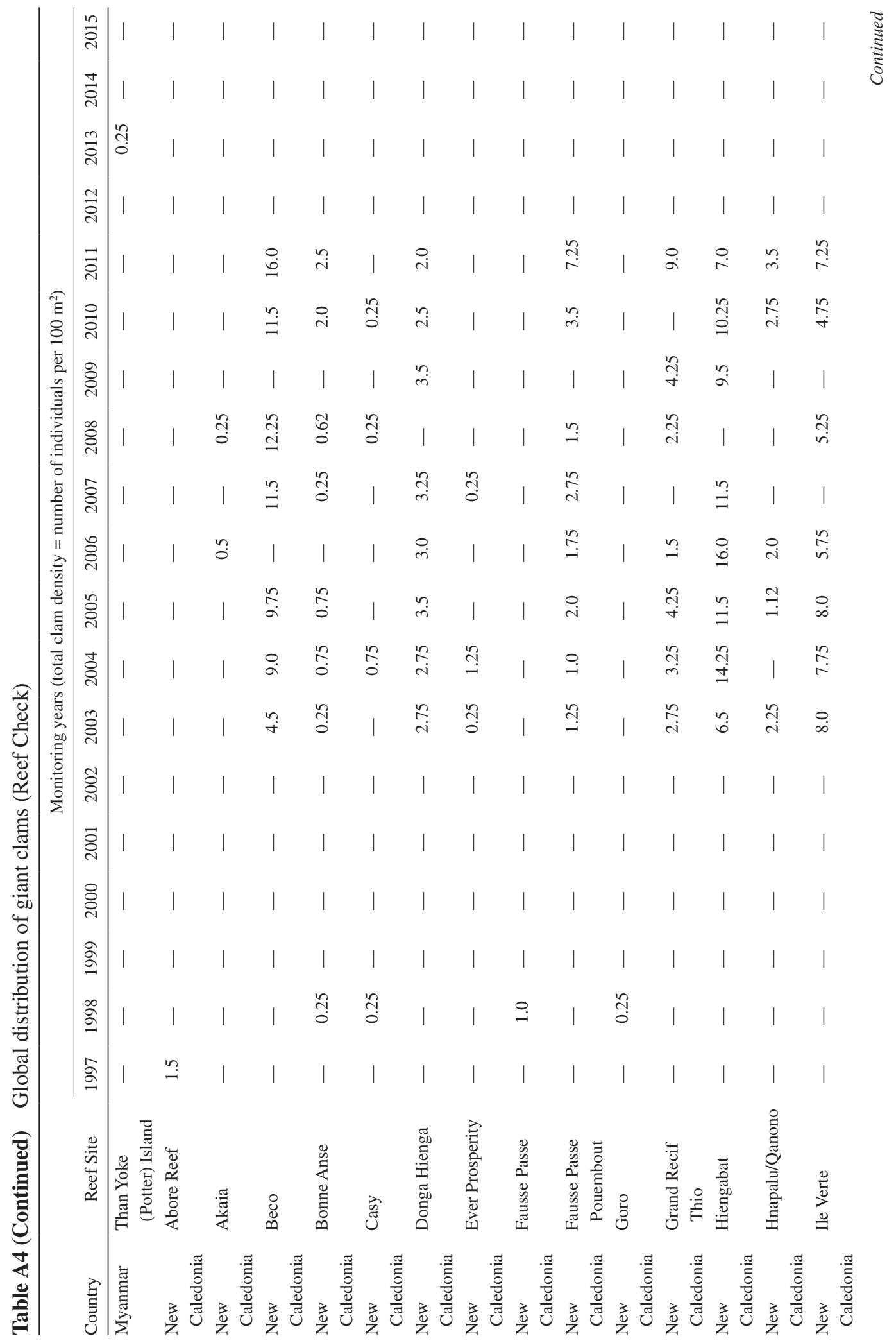


MEI LIN NEO ET AL.

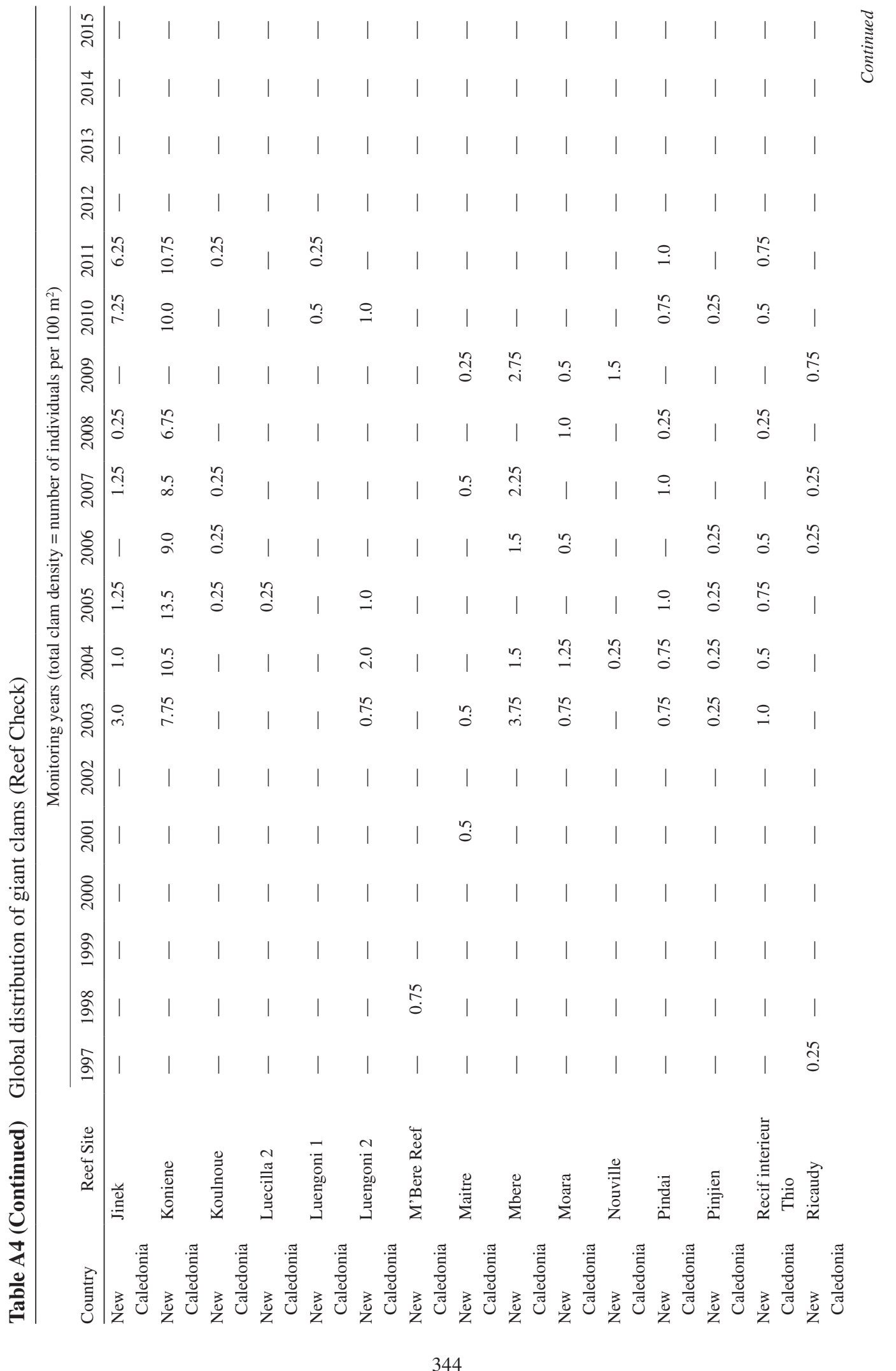


GIANT CLAMS (BIVALVIA: CARDIIDAE: TRIDACNINAE)

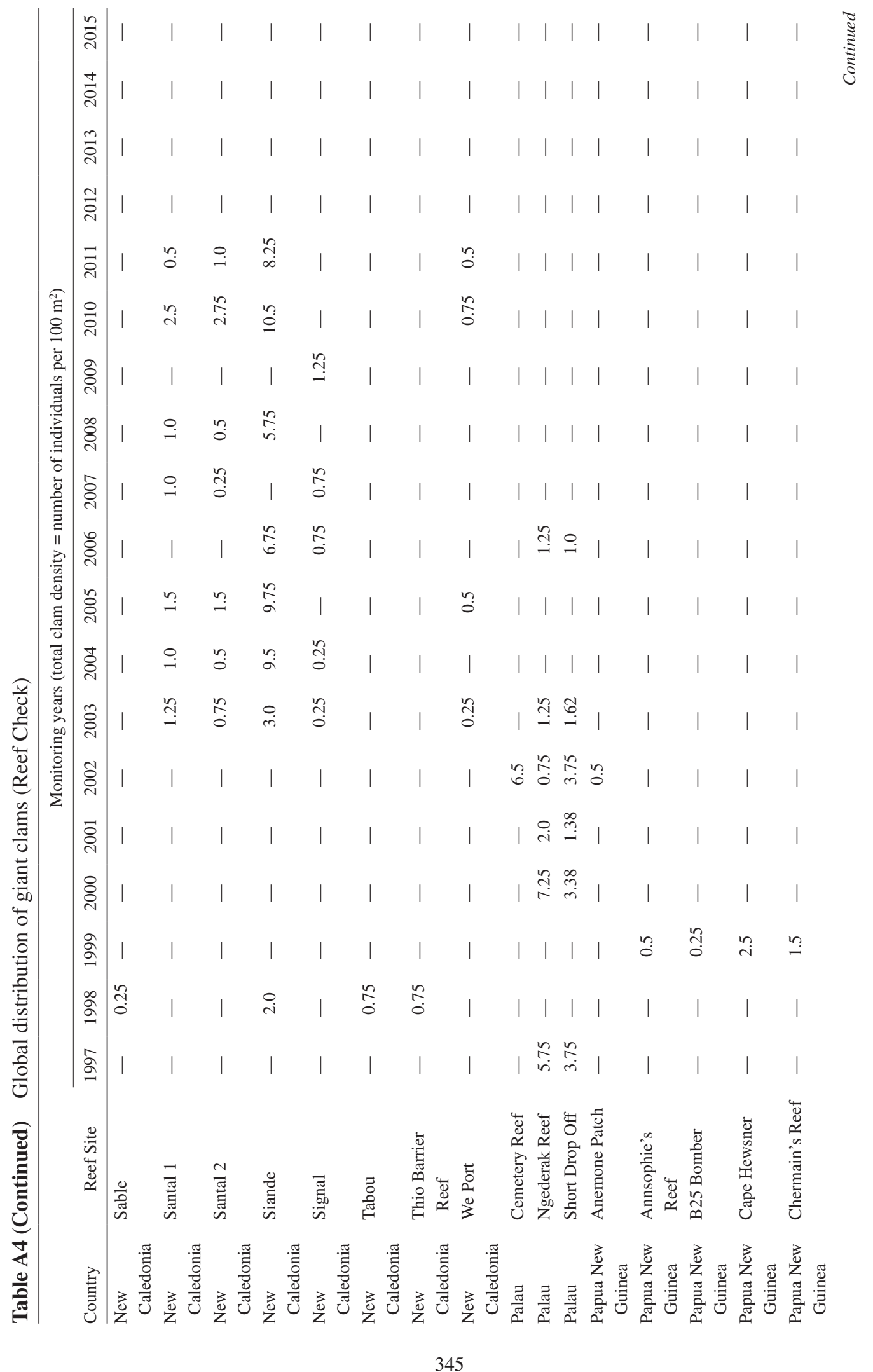


MEI LIN NEO ET AL.

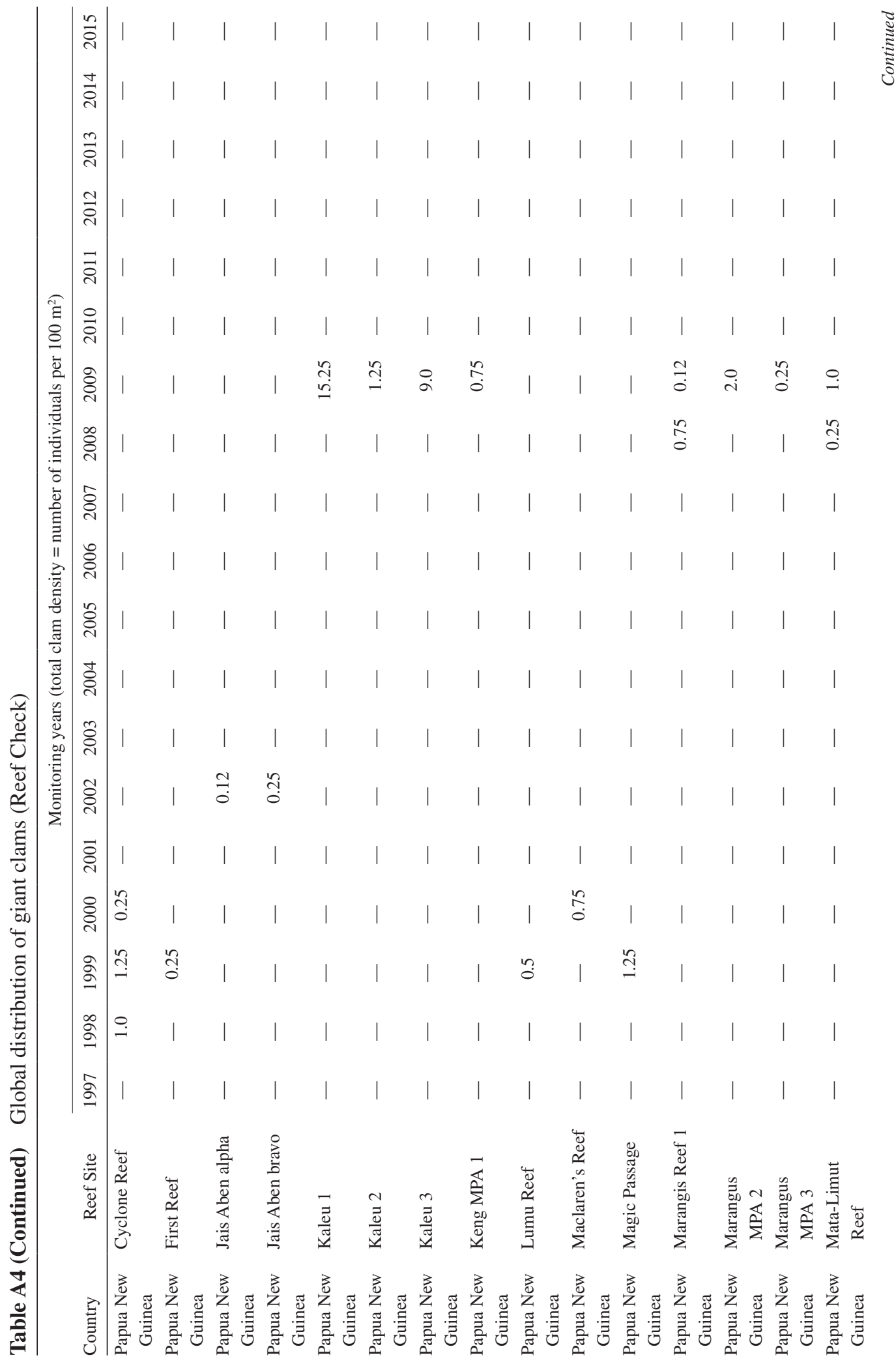


GIANT CLAMS (BIVALVIA: CARDIIDAE: TRIDACNINAE)

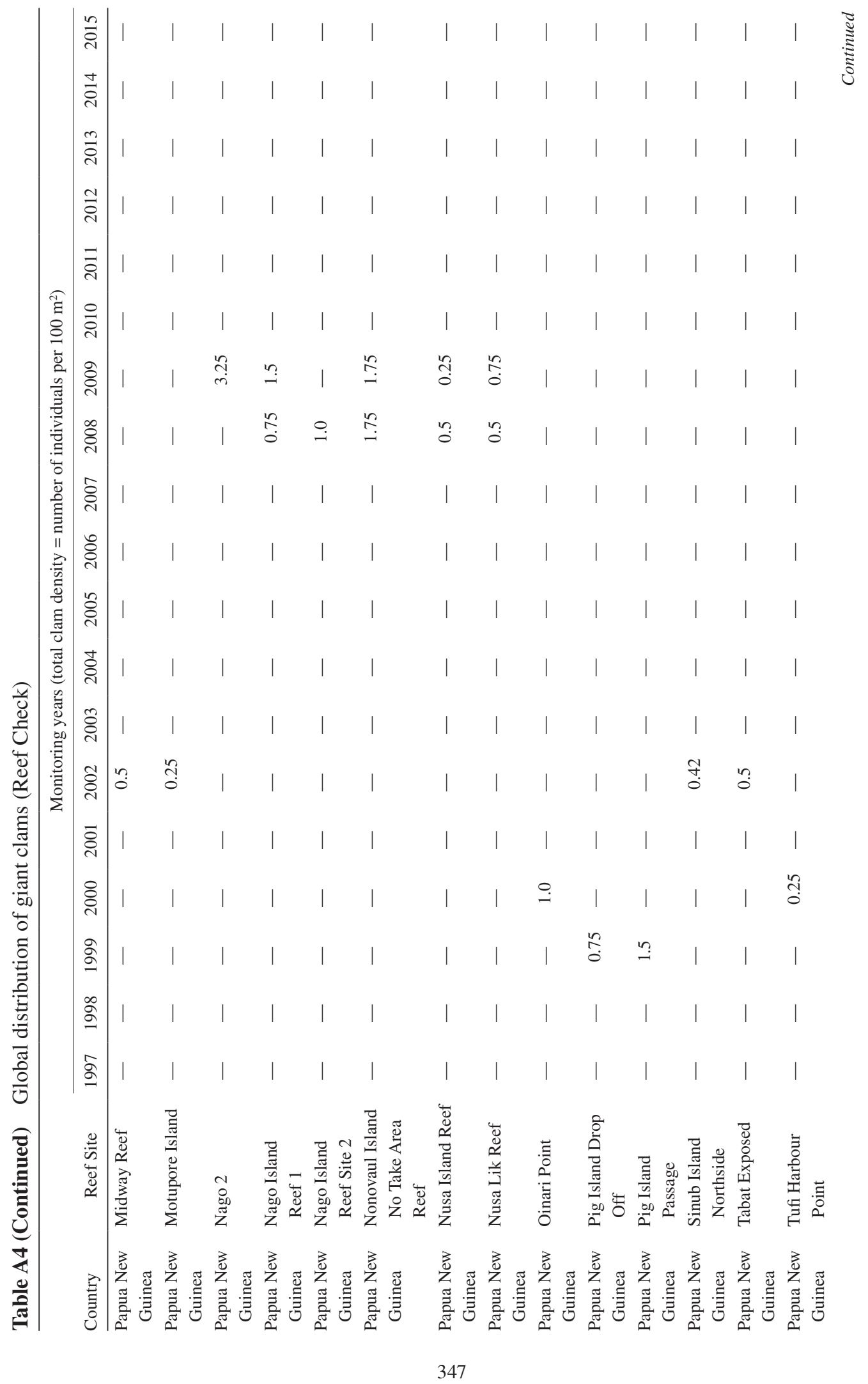


MEI LIN NEO ET AL.

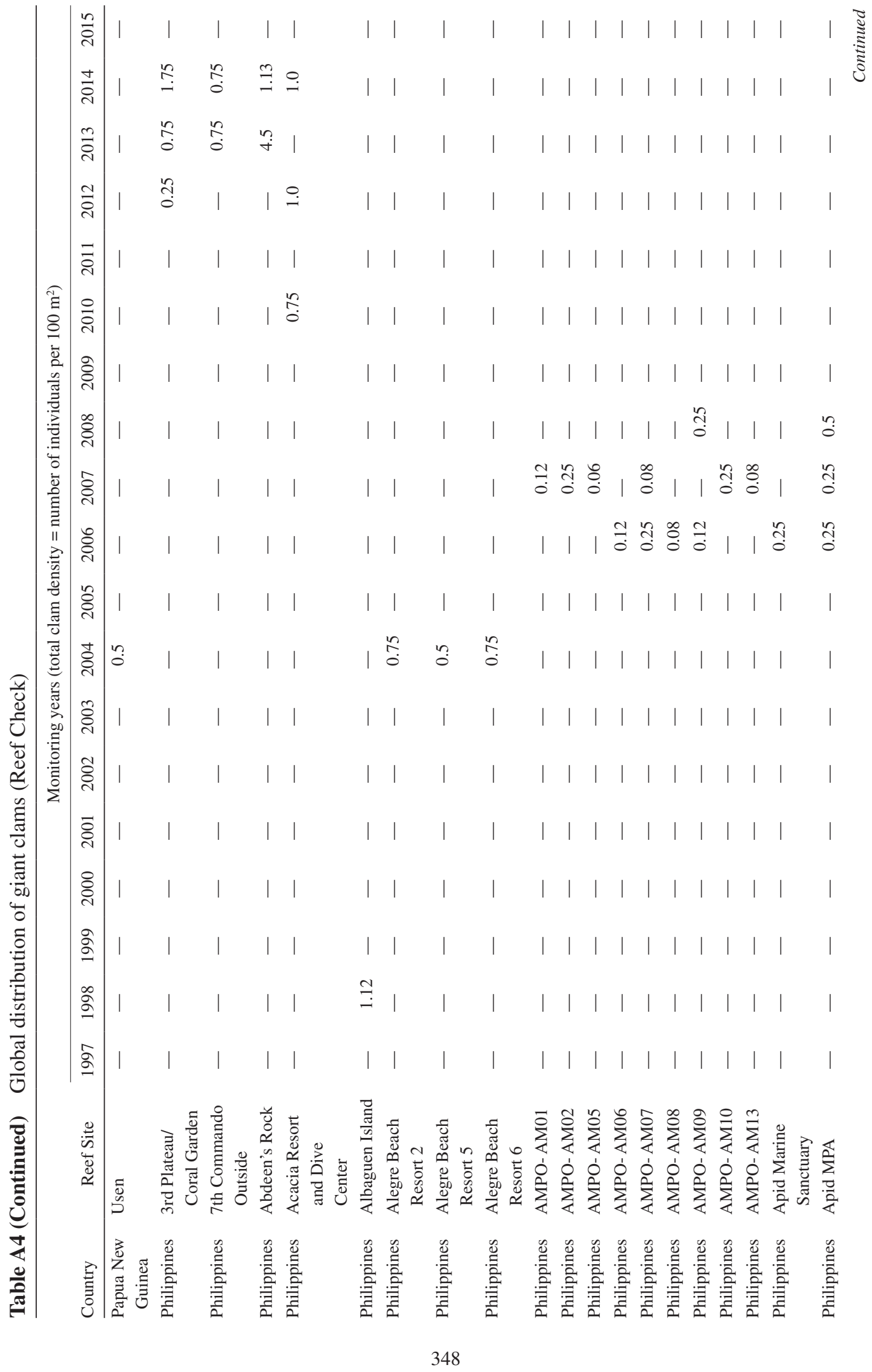


GIANT CLAMS (BIVALVIA: CARDIIDAE: TRIDACNINAE)

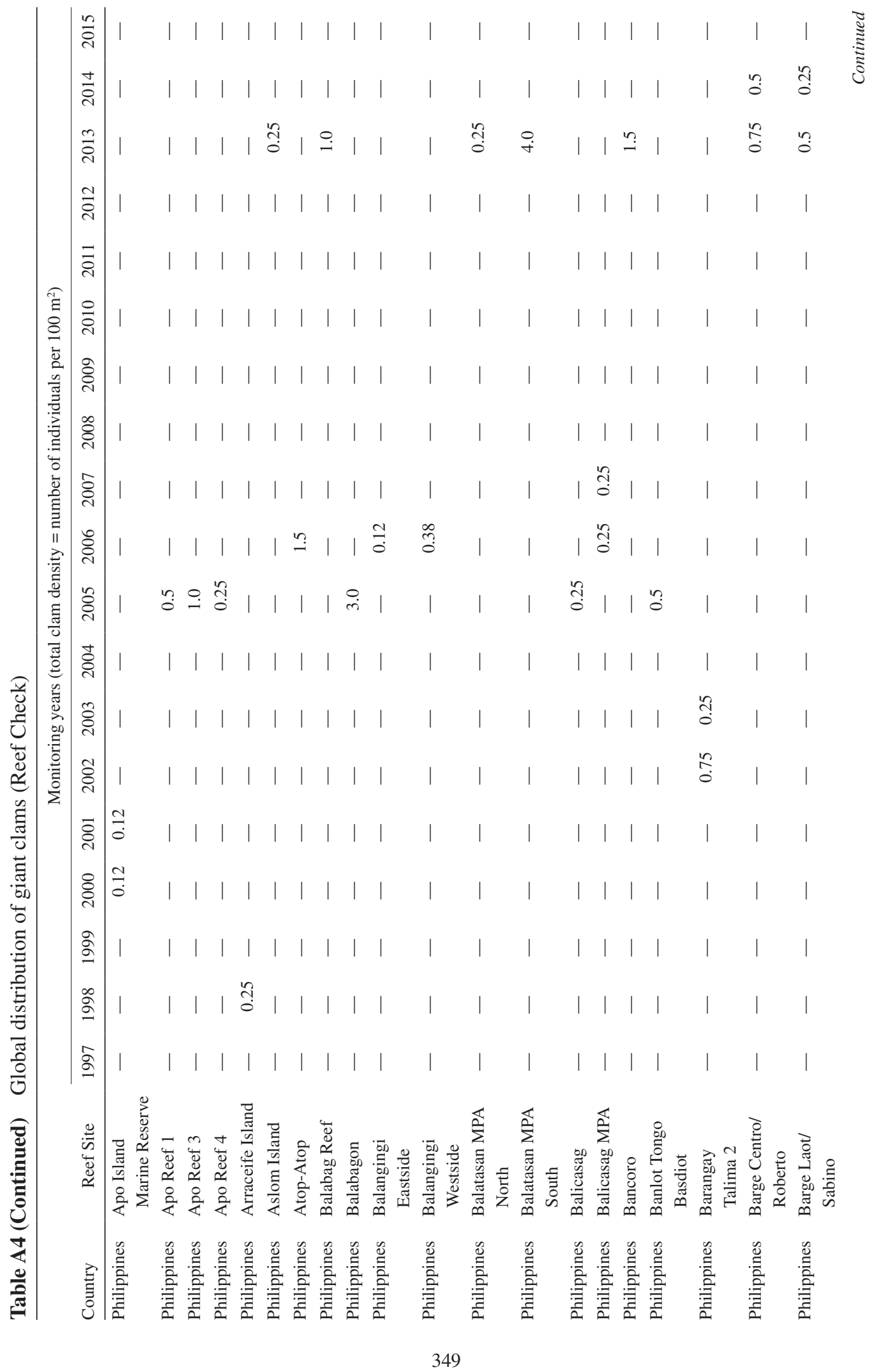


MEI LIN NEO ET AL.

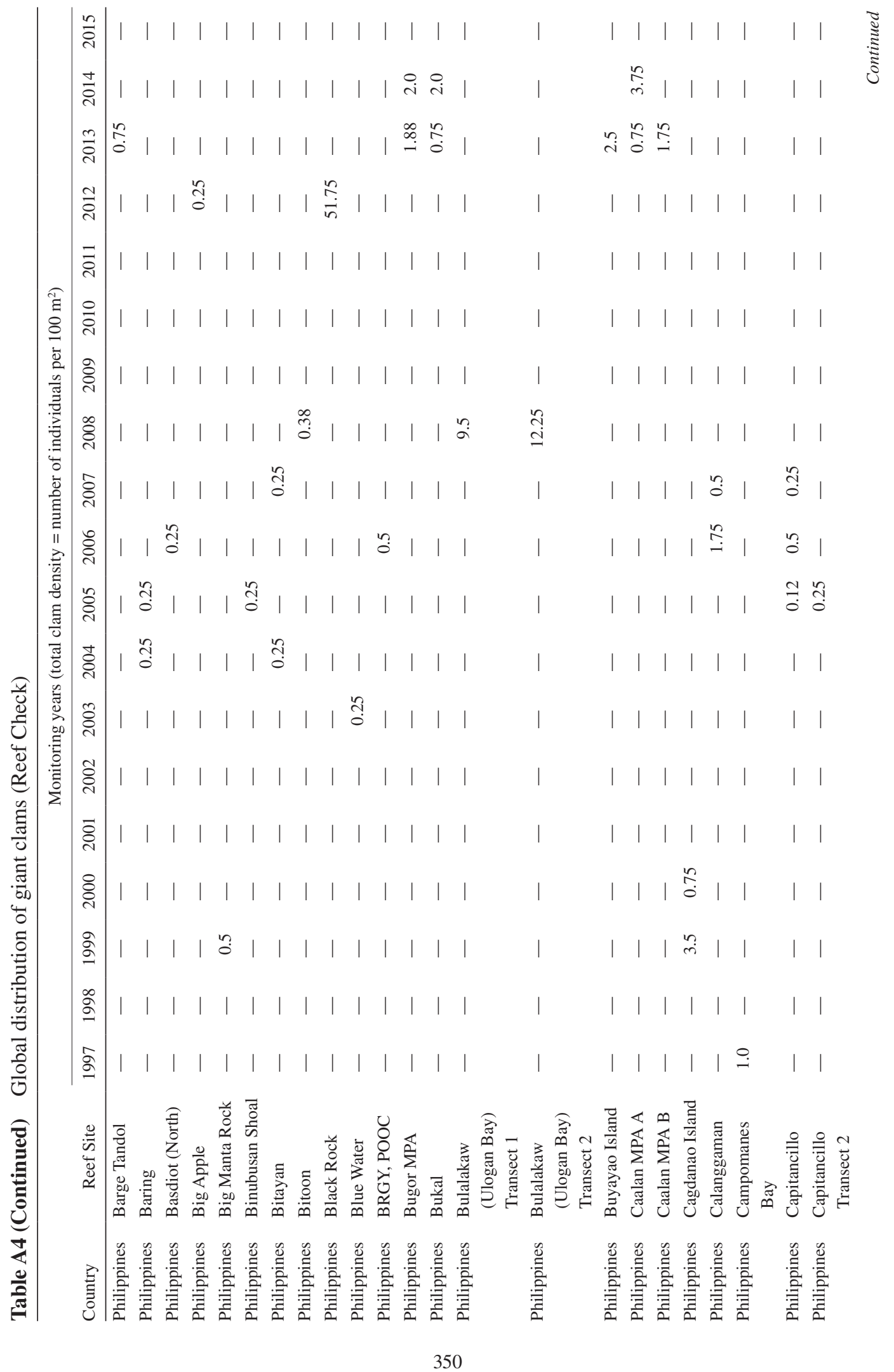


GIANT CLAMS (BIVALVIA: CARDIIDAE: TRIDACNINAE)

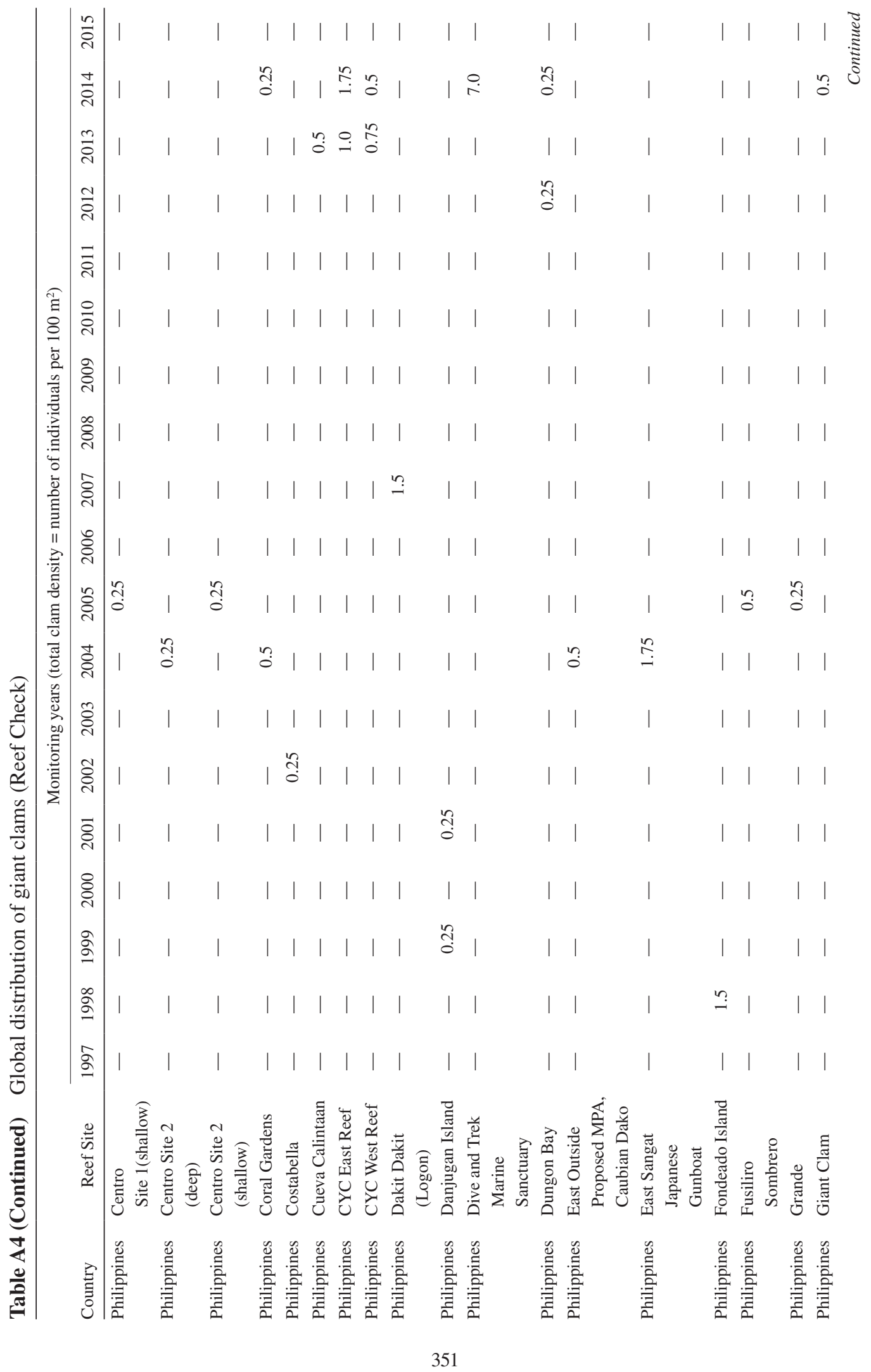


MEI LIN NEO ET AL.

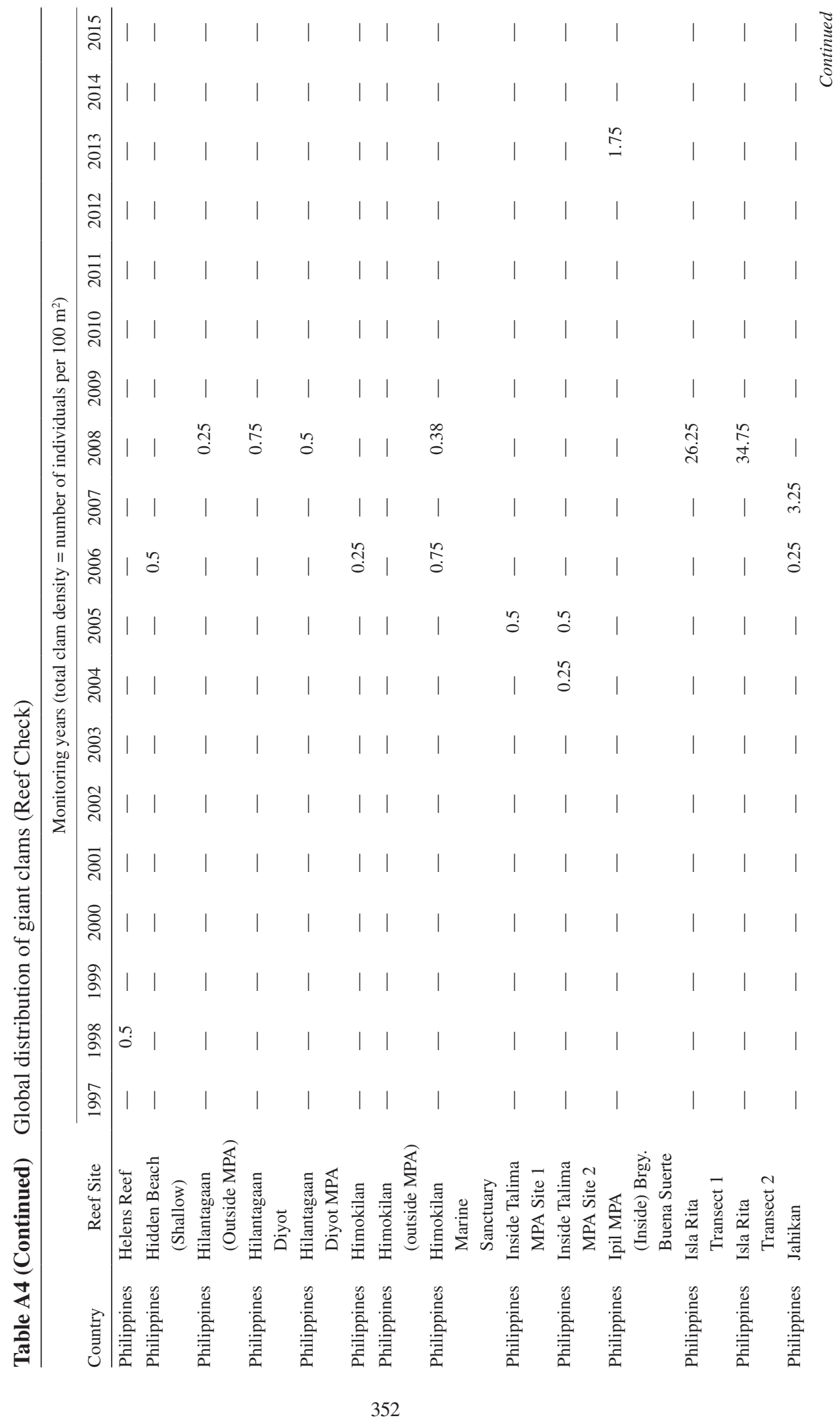


GIANT CLAMS (BIVALVIA: CARDIIDAE: TRIDACNINAE)

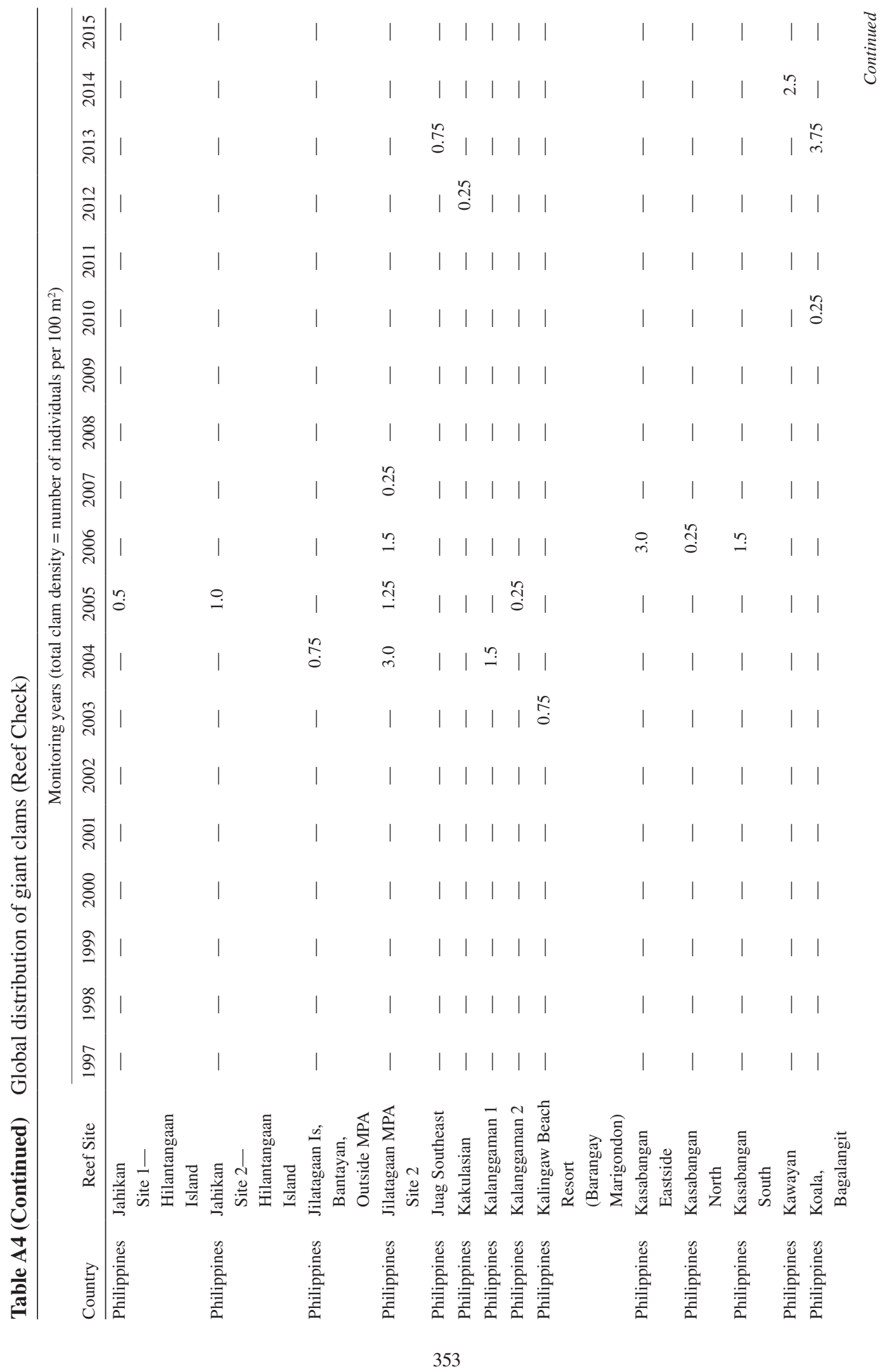


MEI LIN NEO ET AL.

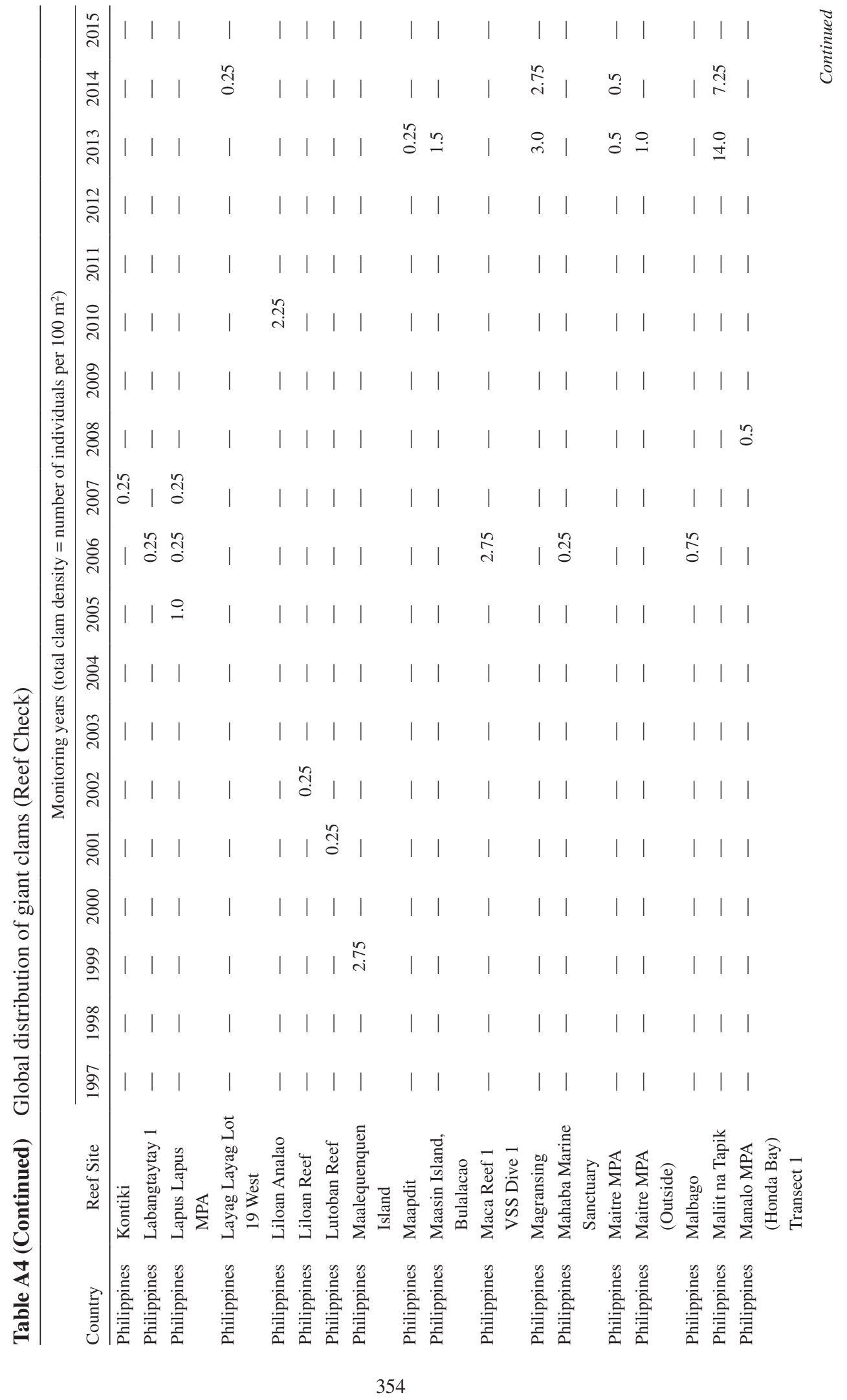


GIANT CLAMS (BIVALVIA: CARDIIDAE: TRIDACNINAE)

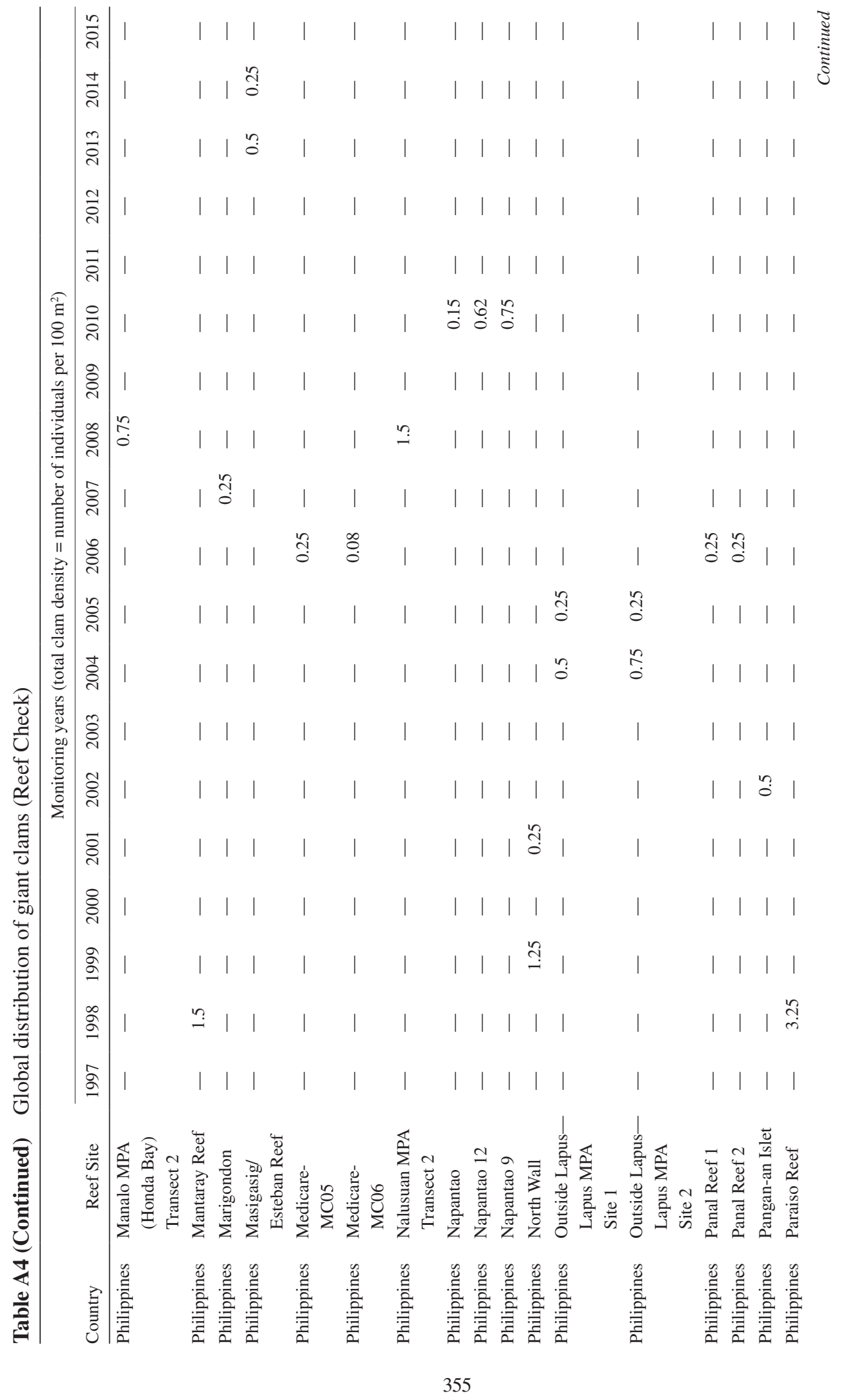


MEI LIN NEO ET AL.

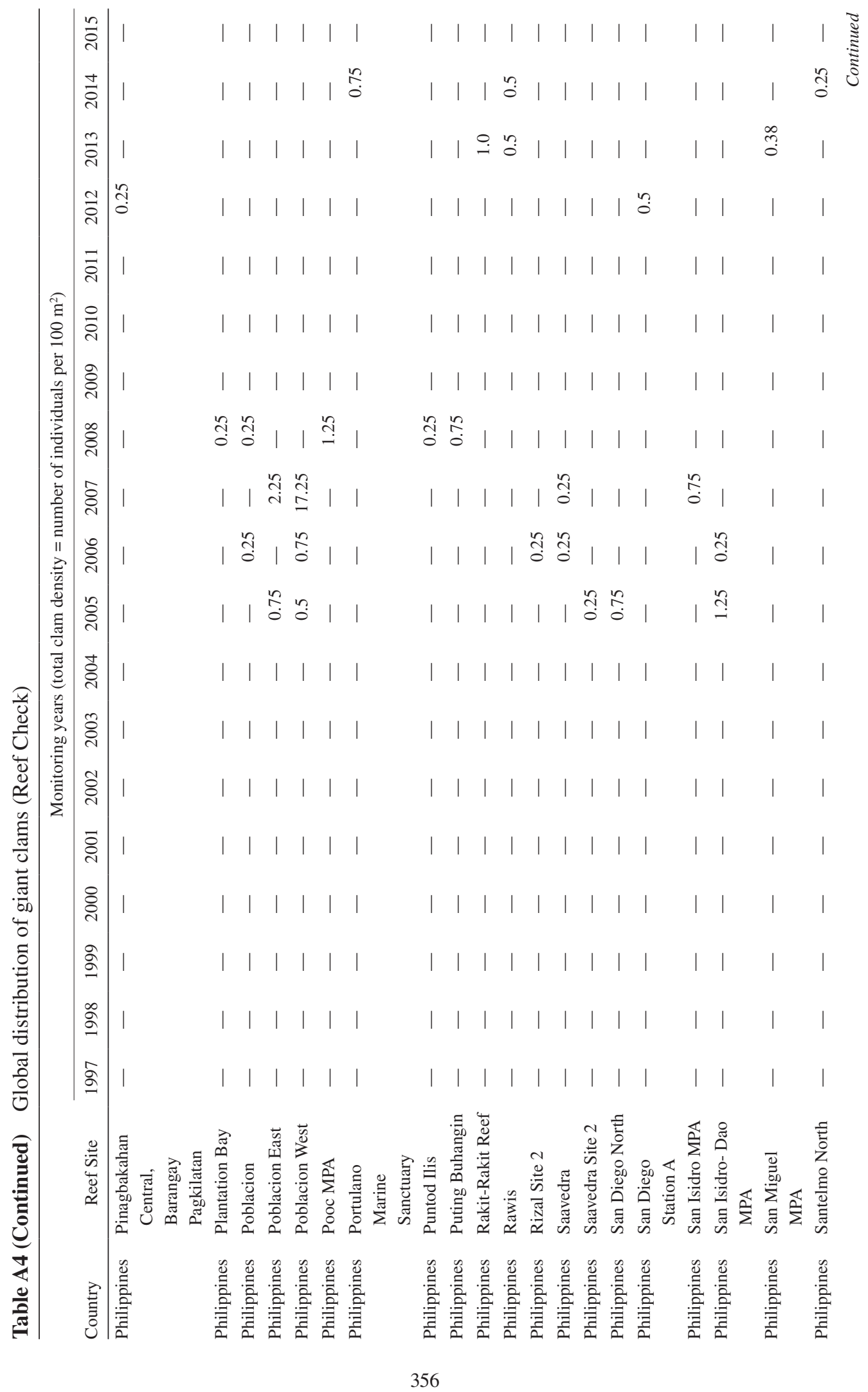


GIANT CLAMS (BIVALVIA: CARDIIDAE: TRIDACNINAE)

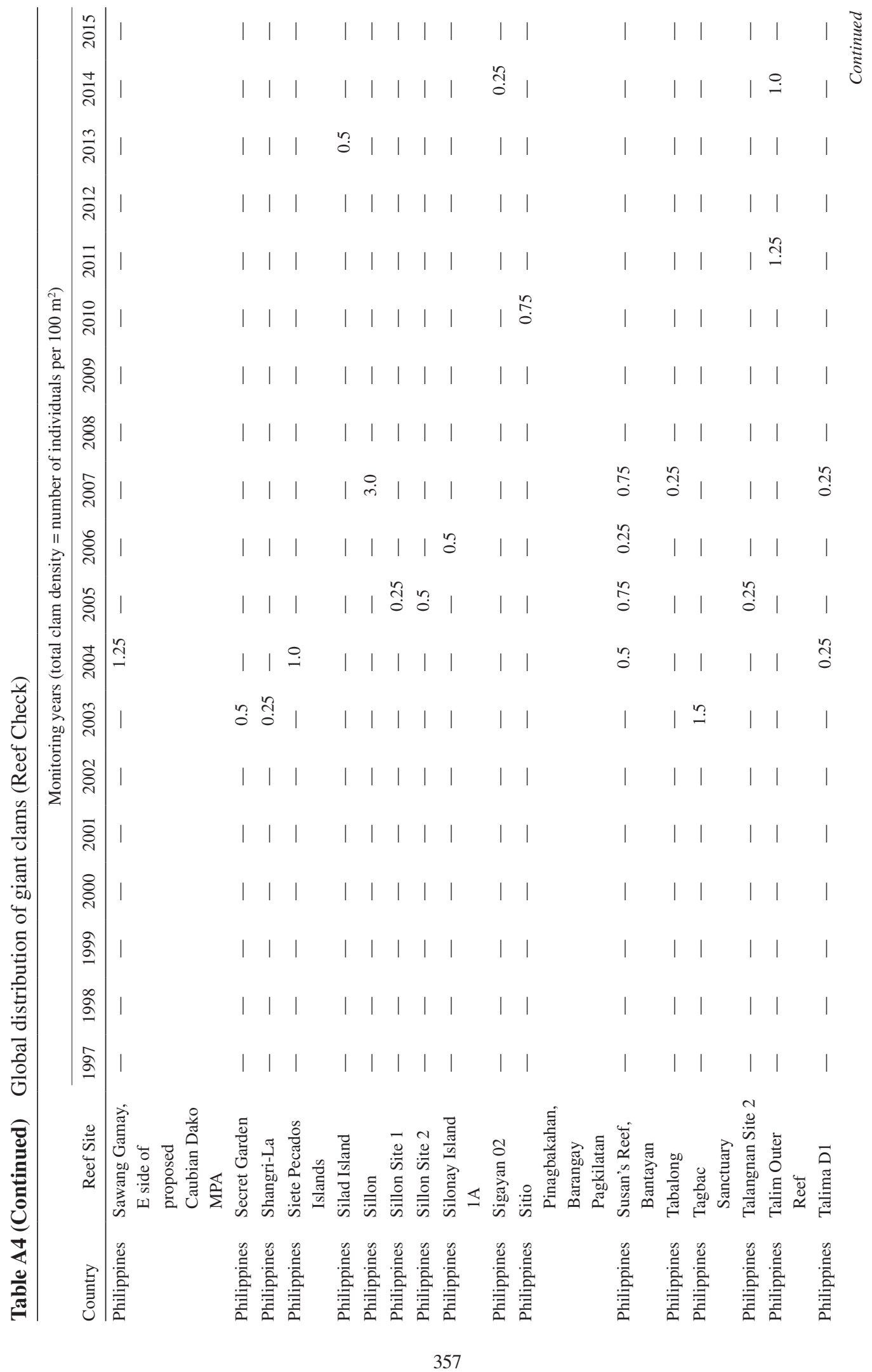


MEI LIN NEO ET AL.

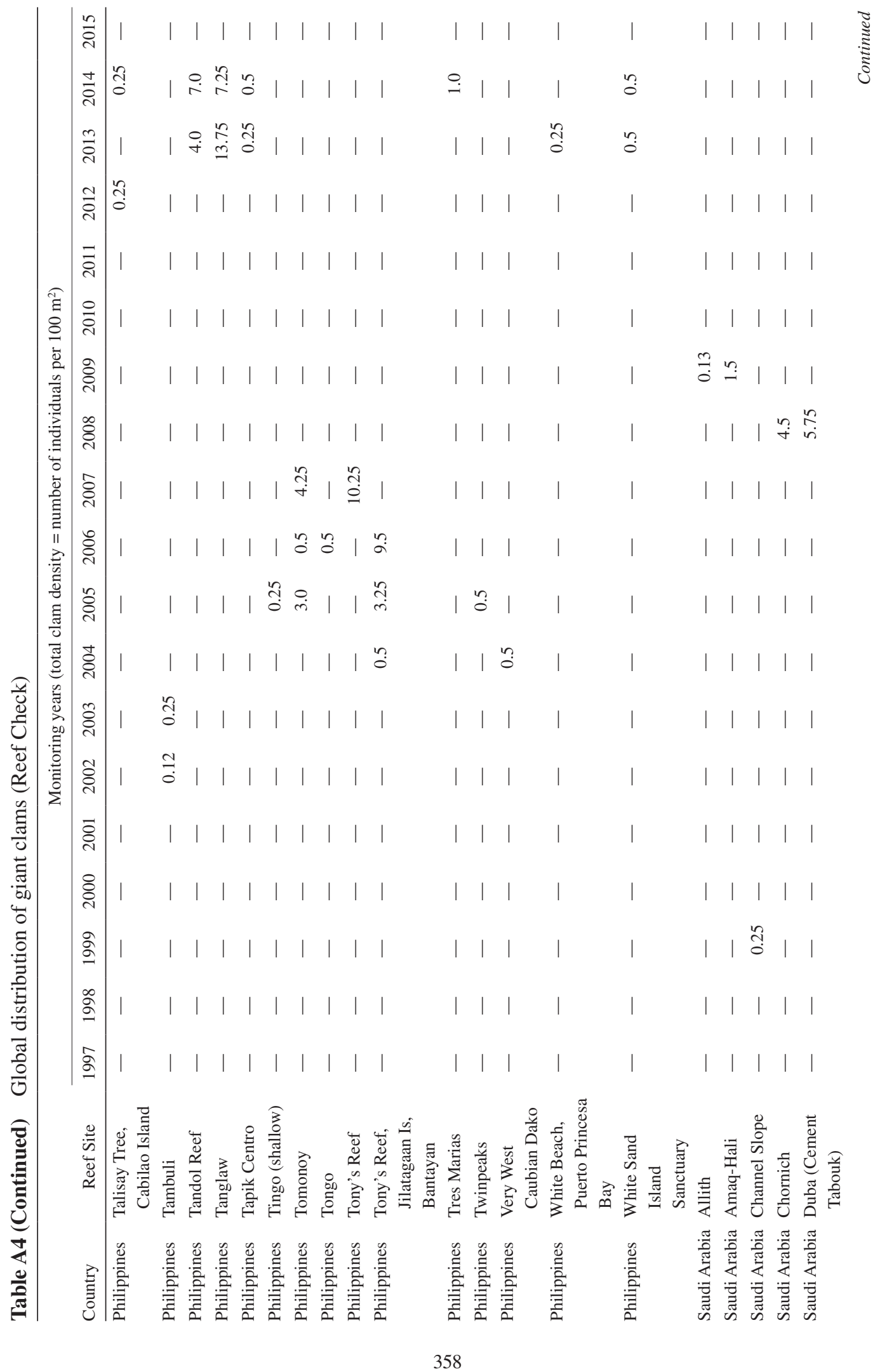


GIANT CLAMS (BIVALVIA: CARDIIDAE: TRIDACNINAE)

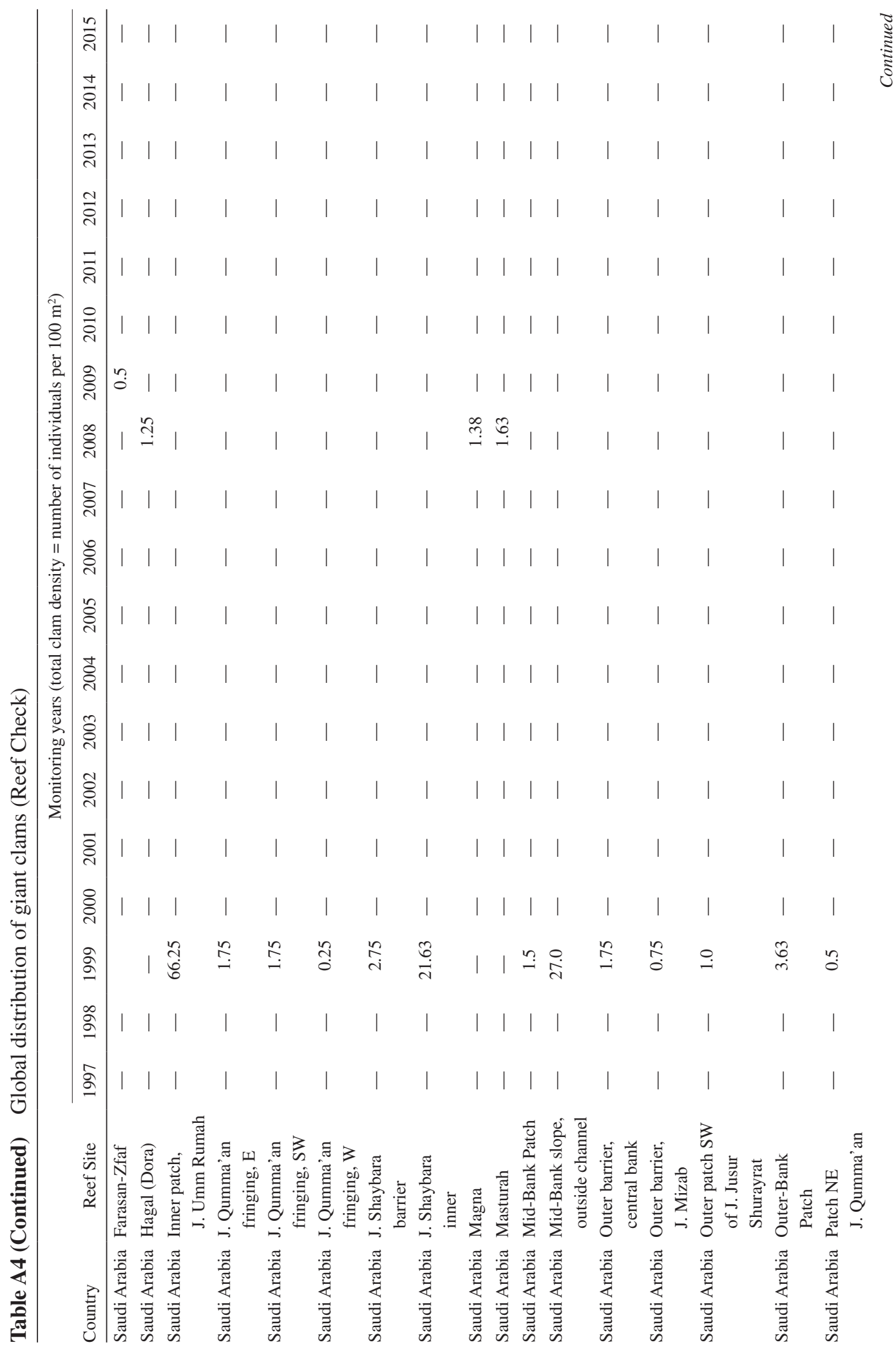


MEI LIN NEO ET AL.

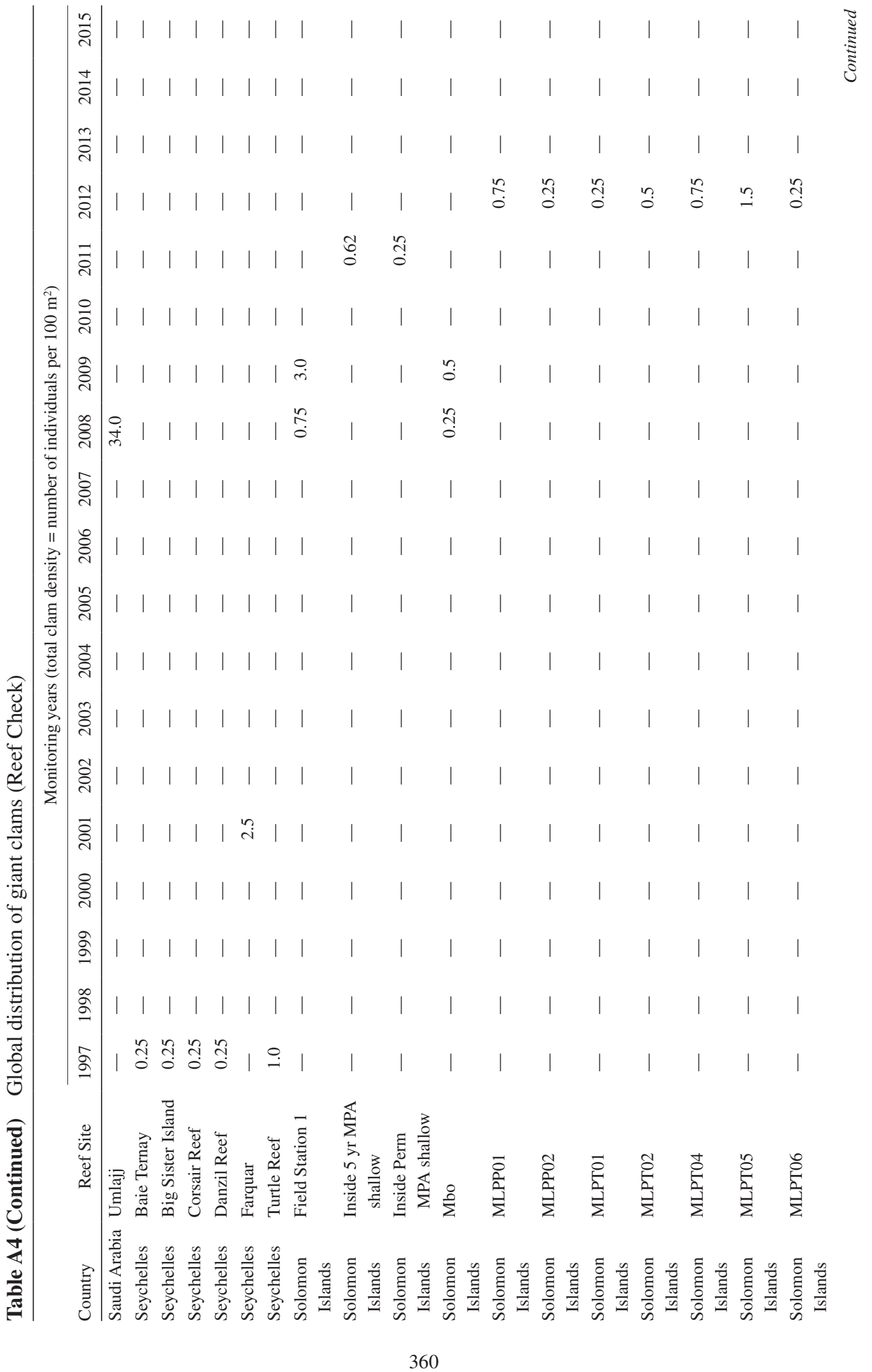


GIANT CLAMS (BIVALVIA: CARDIIDAE: TRIDACNINAE)

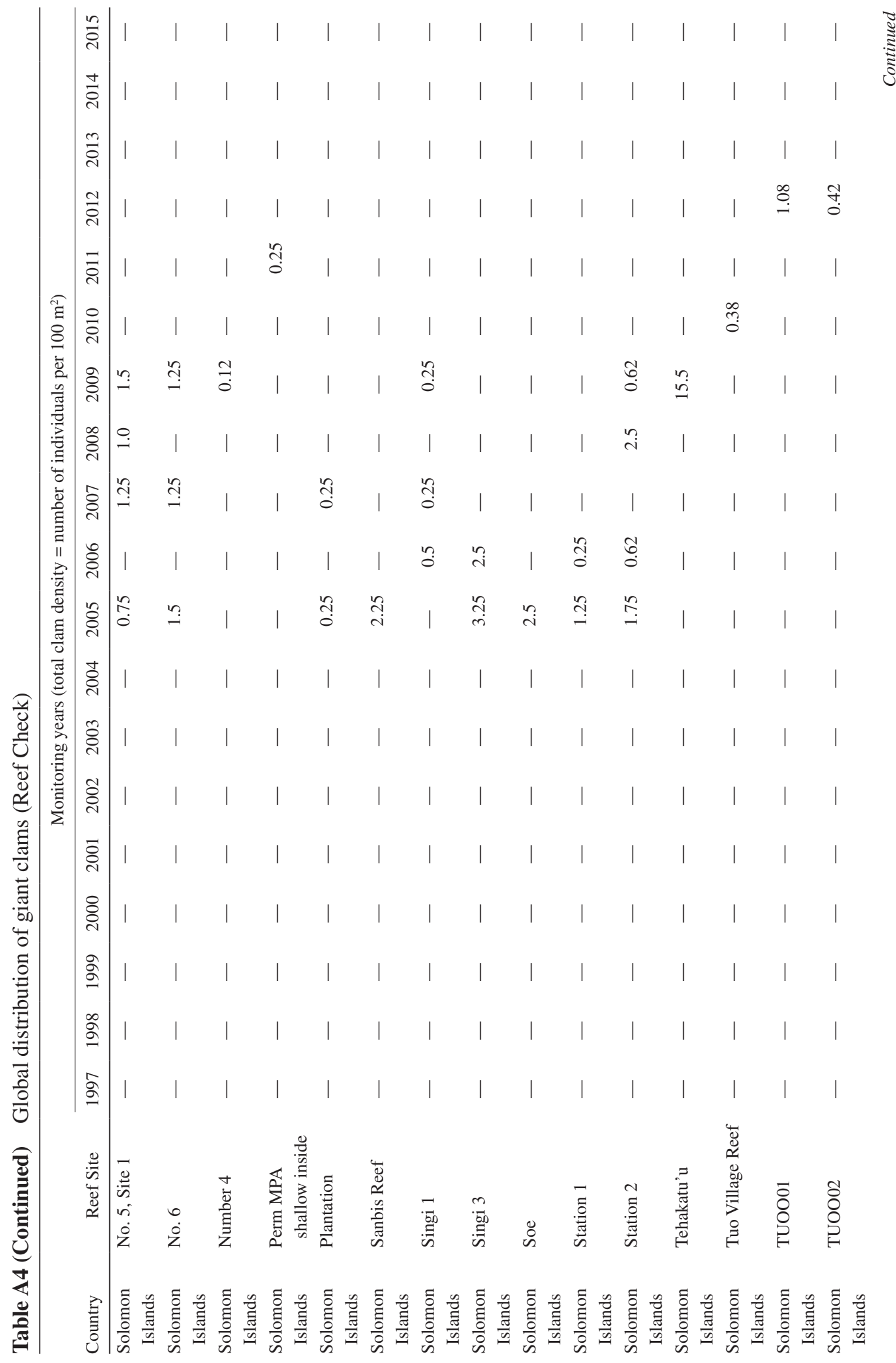


MEI LIN NEO ET AL.

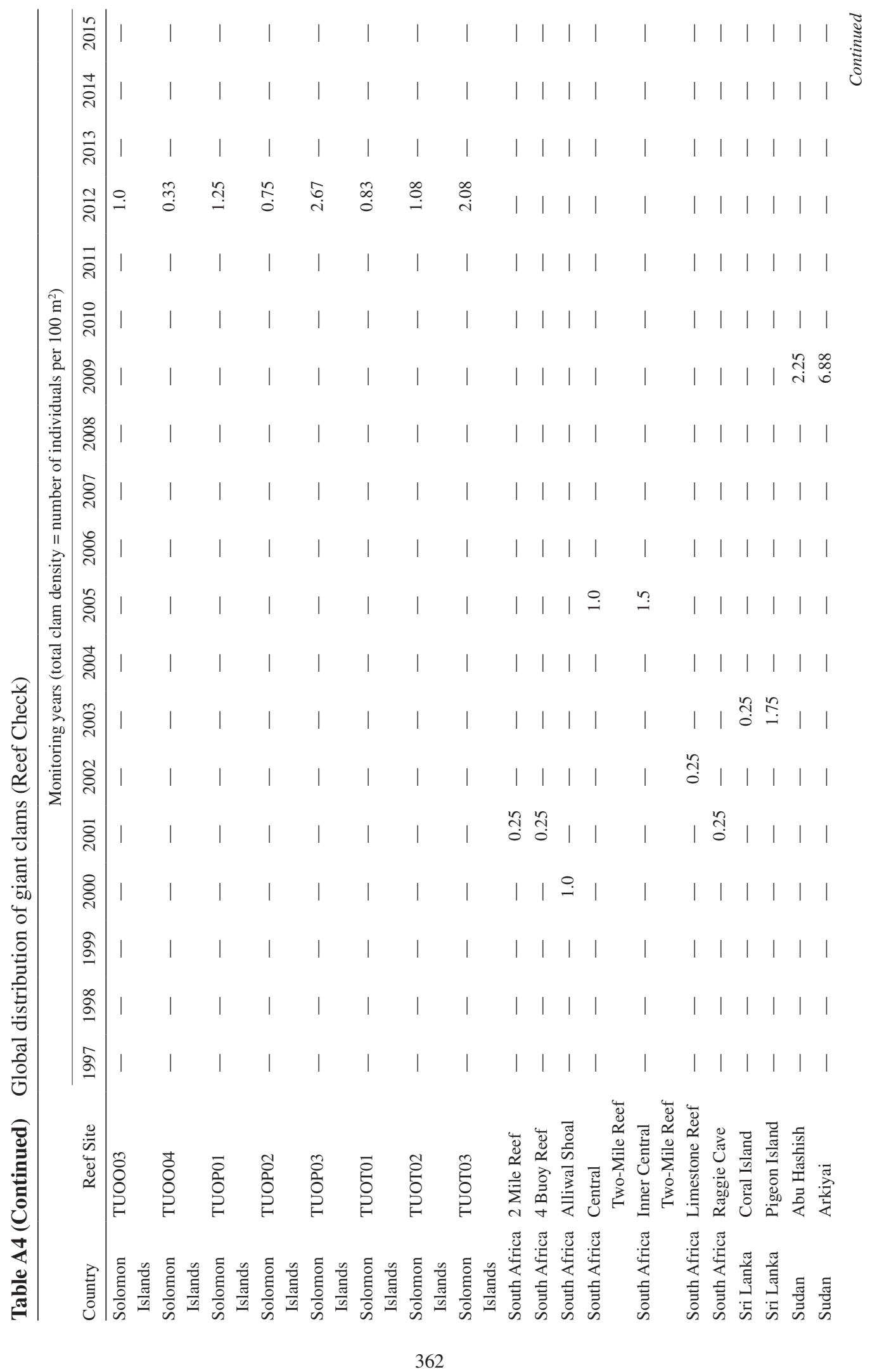


GIANT CLAMS (BIVALVIA: CARDIIDAE: TRIDACNINAE)

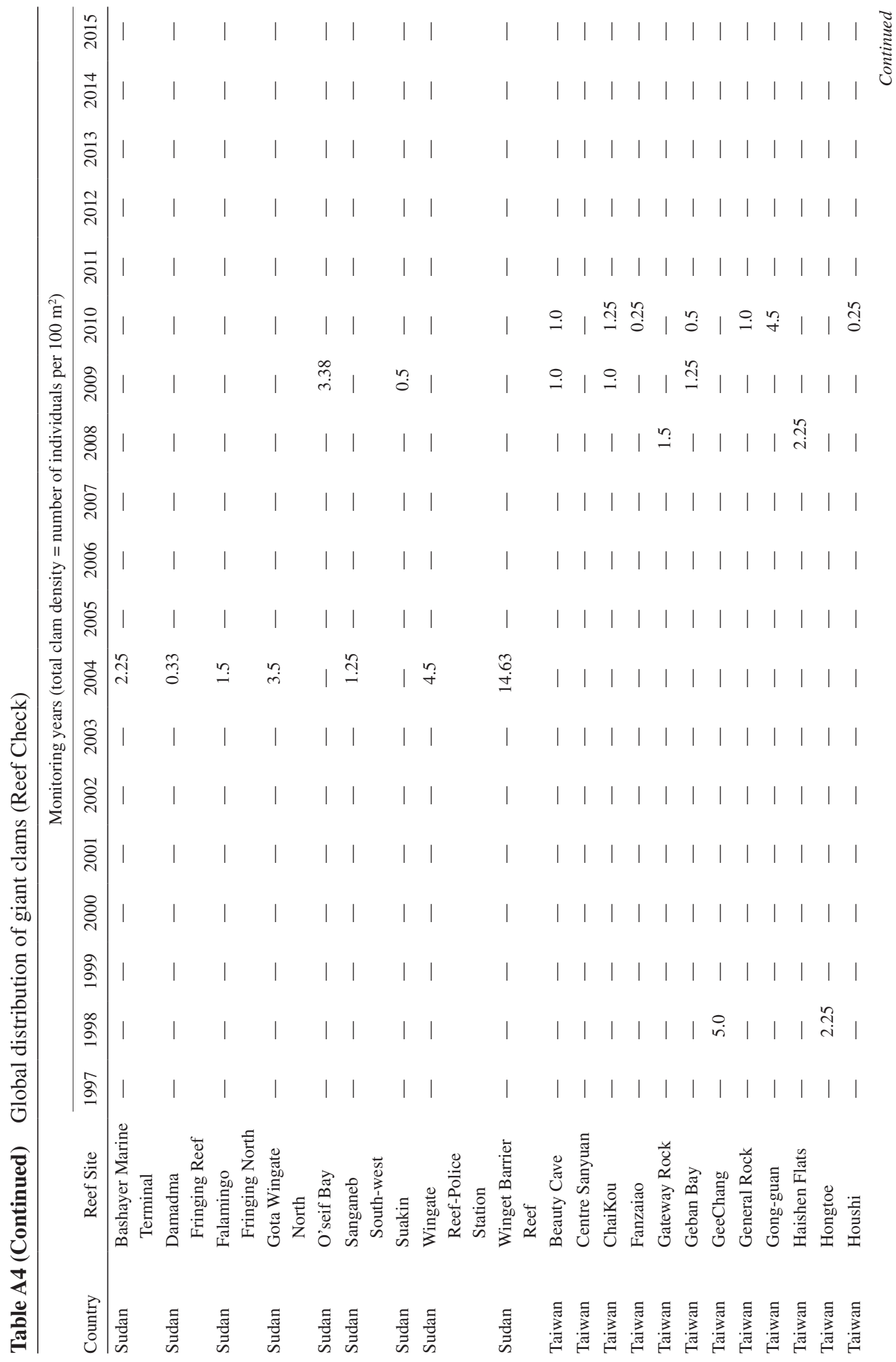


MEI LIN NEO ET AL.

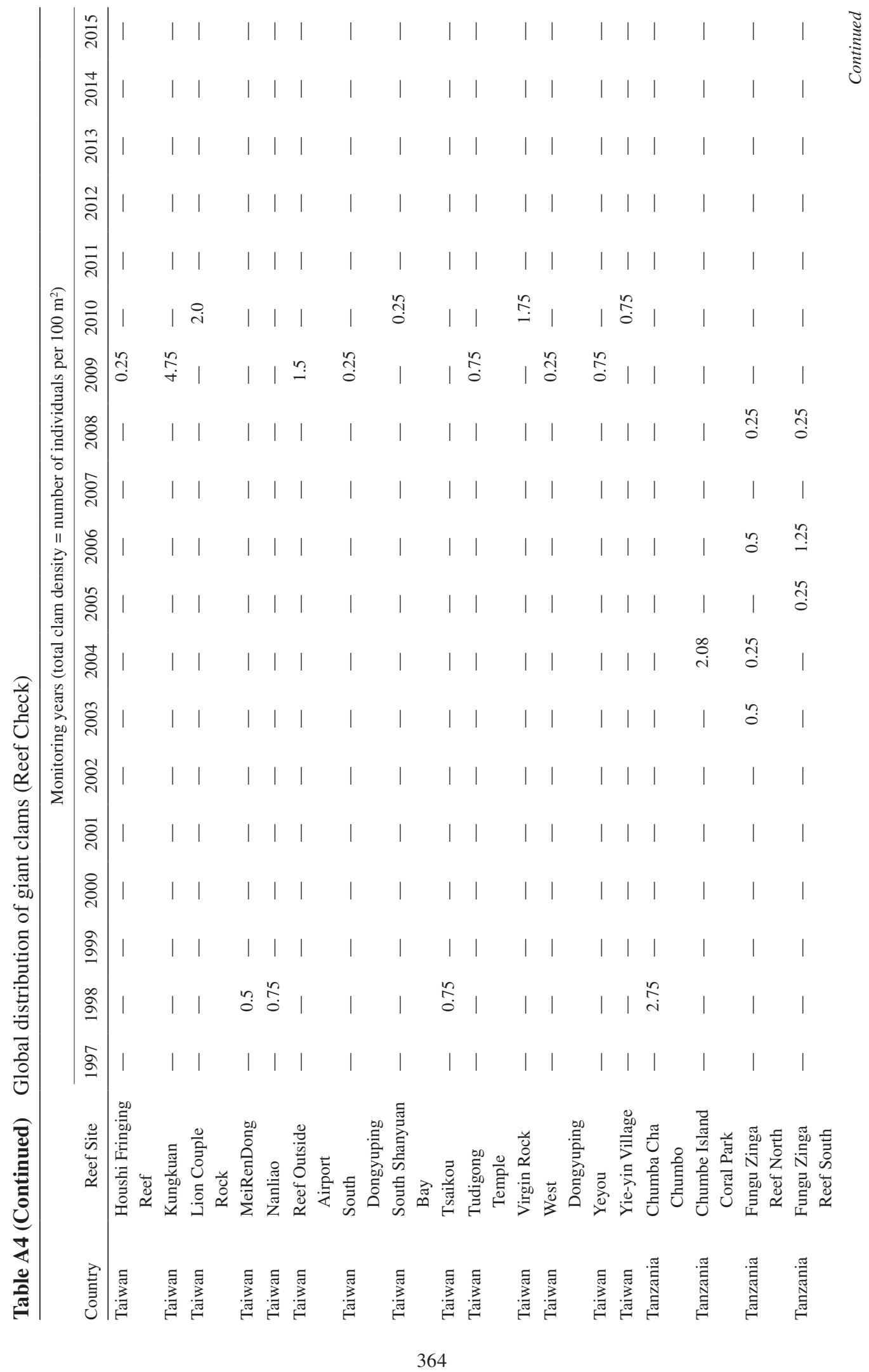


GIANT CLAMS (BIVALVIA: CARDIIDAE: TRIDACNINAE)

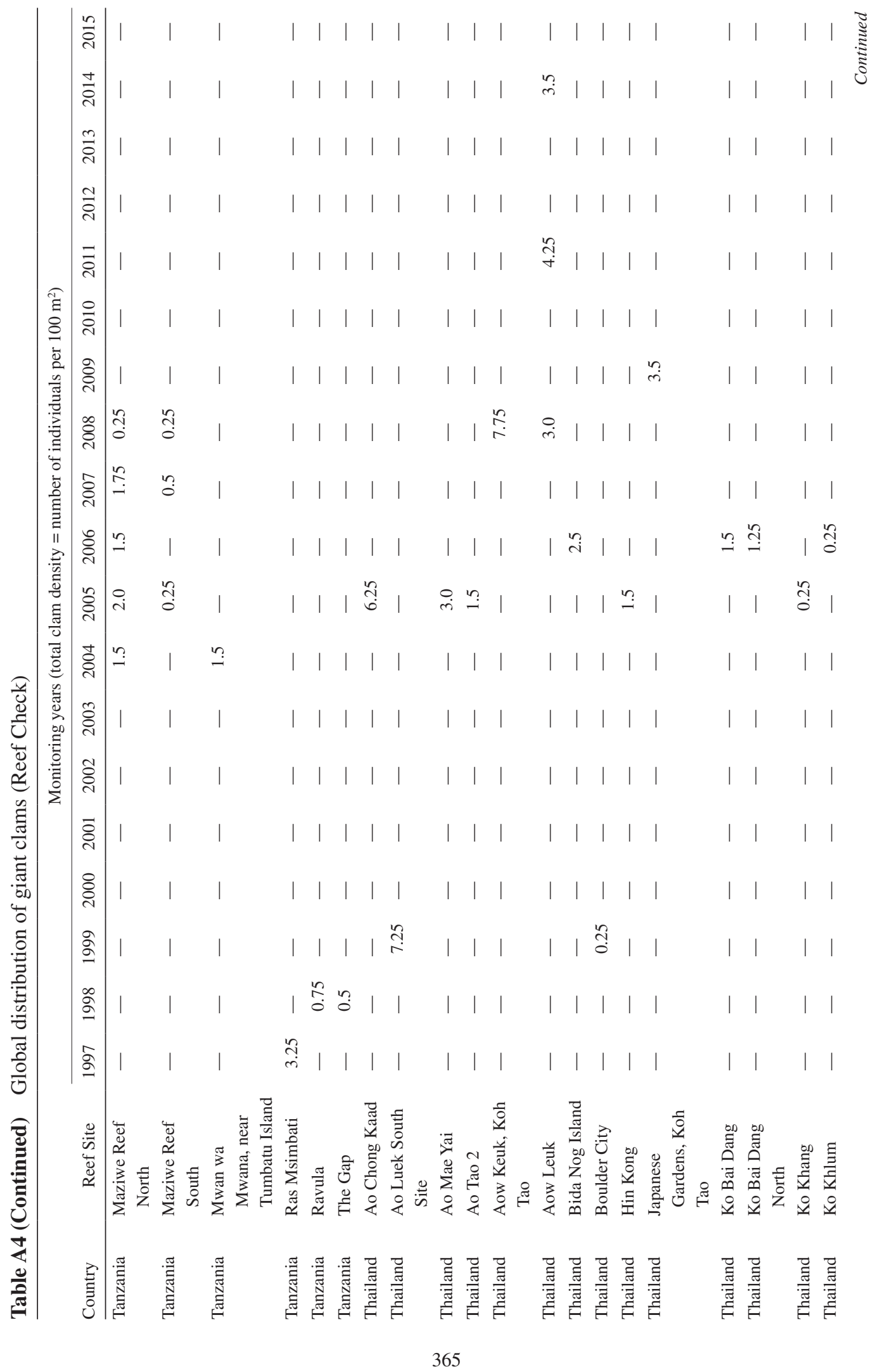


MEI LIN NEO ET AL.

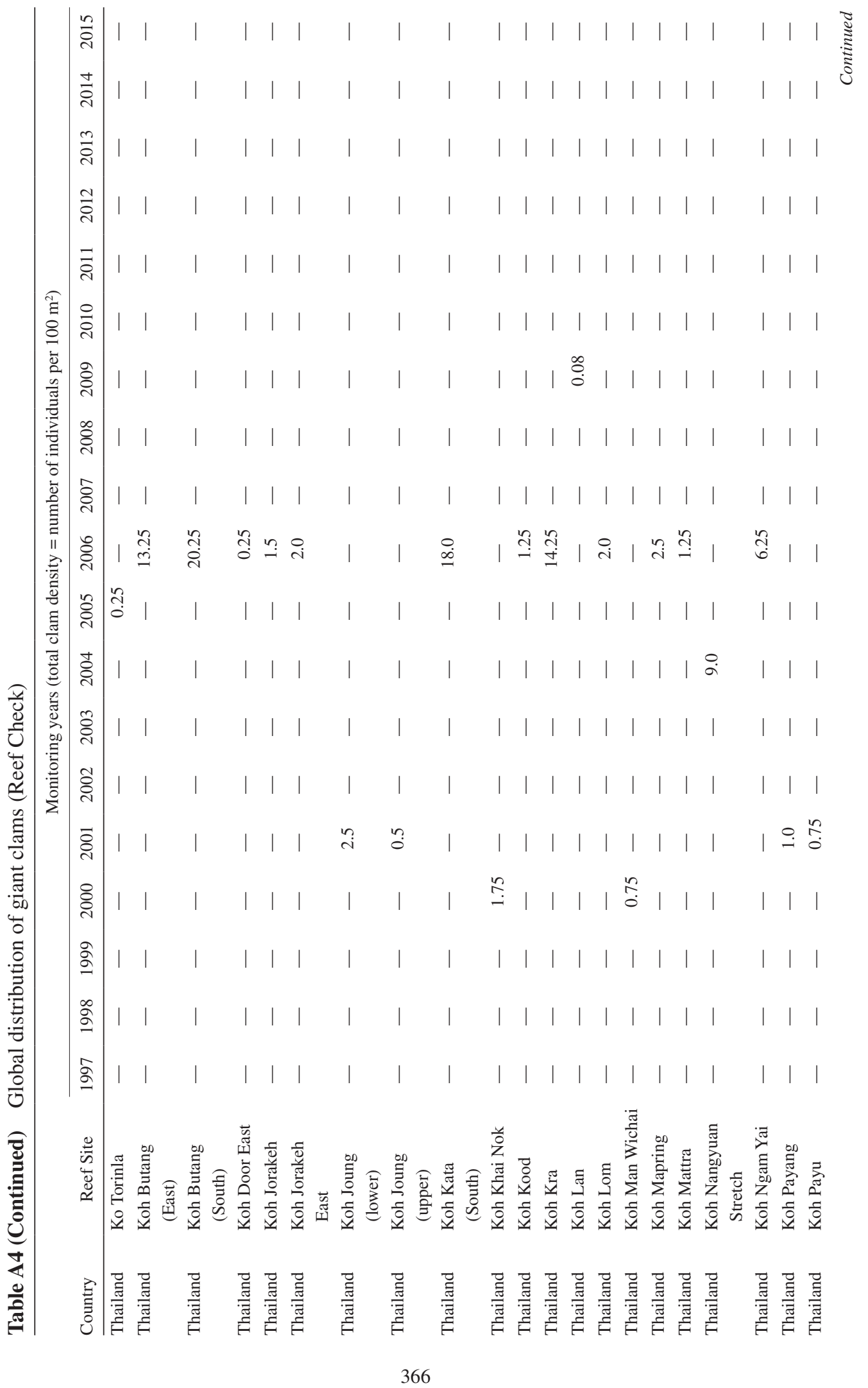


GIANT CLAMS (BIVALVIA: CARDIIDAE: TRIDACNINAE)

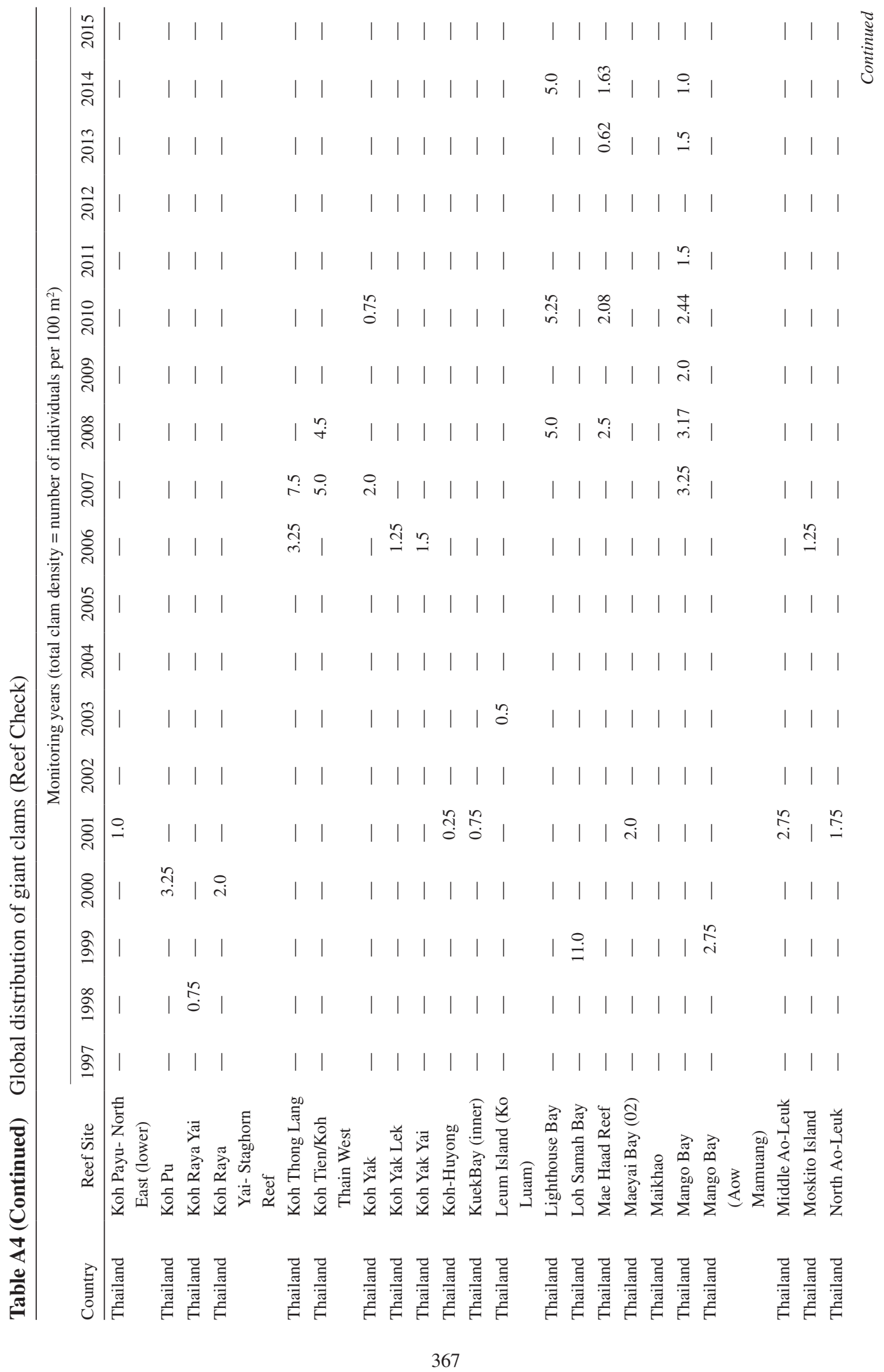


MEI LIN NEO ET AL.

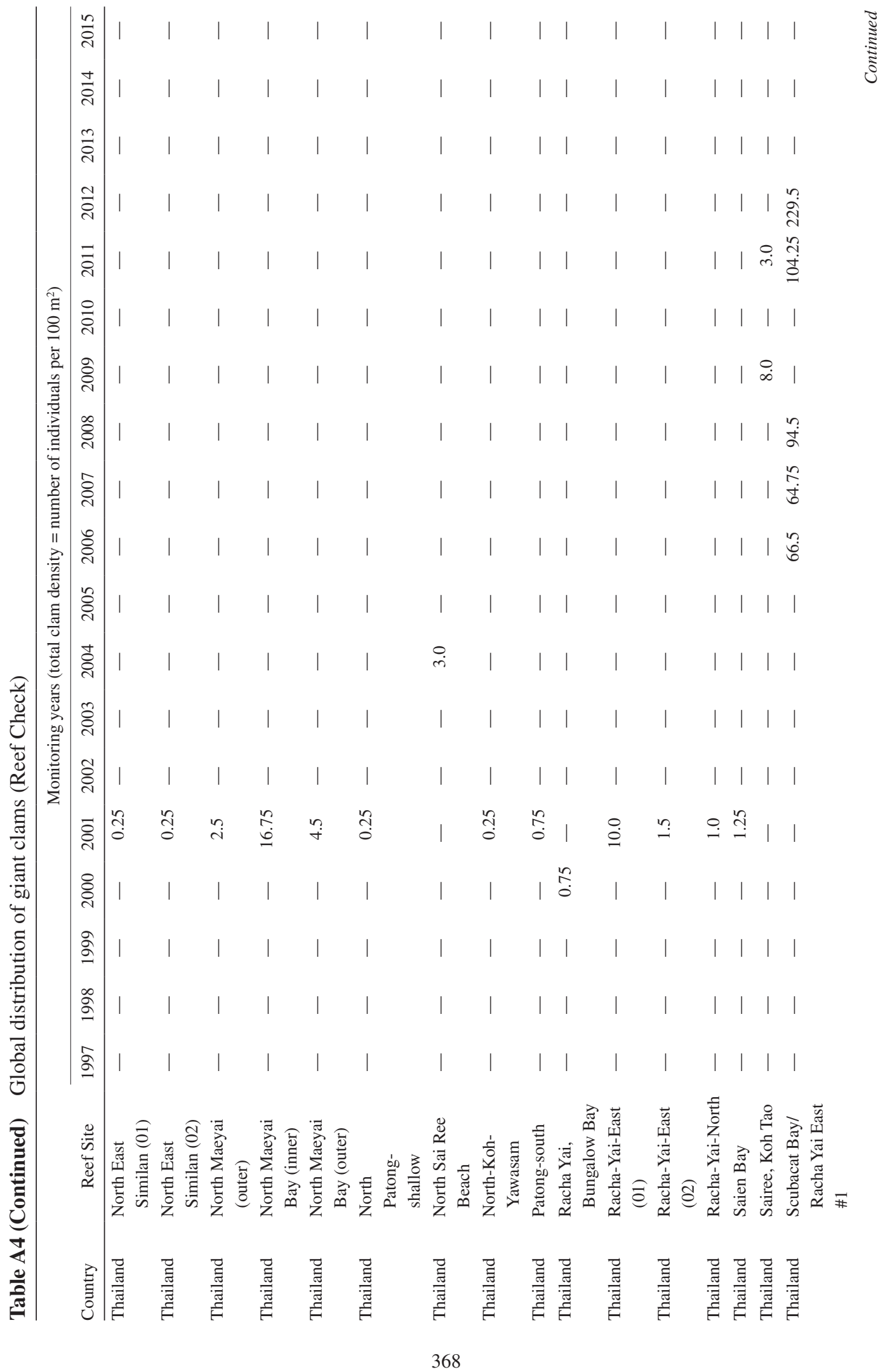


GIANT CLAMS (BIVALVIA: CARDIIDAE: TRIDACNINAE)

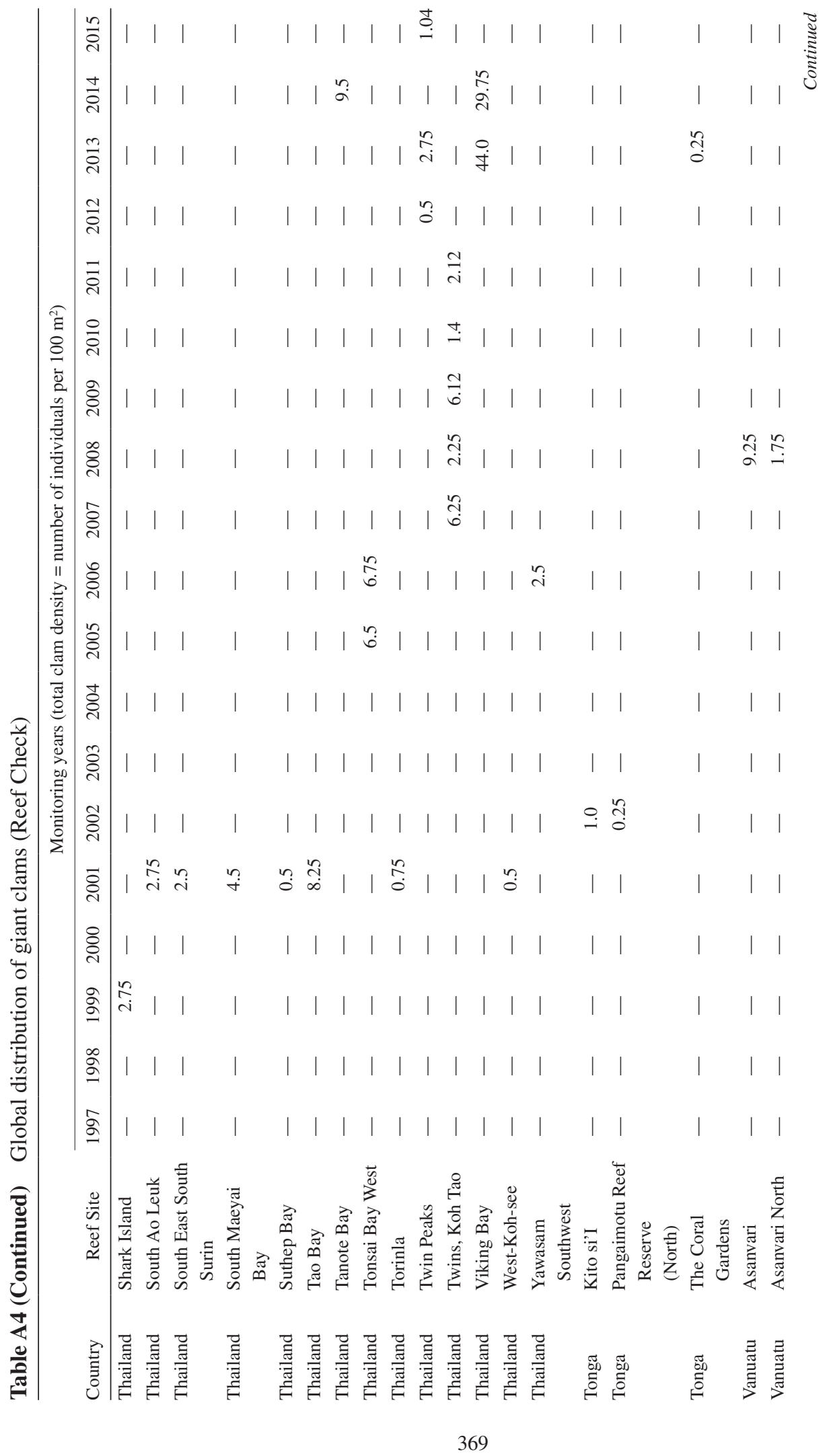


MEI LIN NEO ET AL.

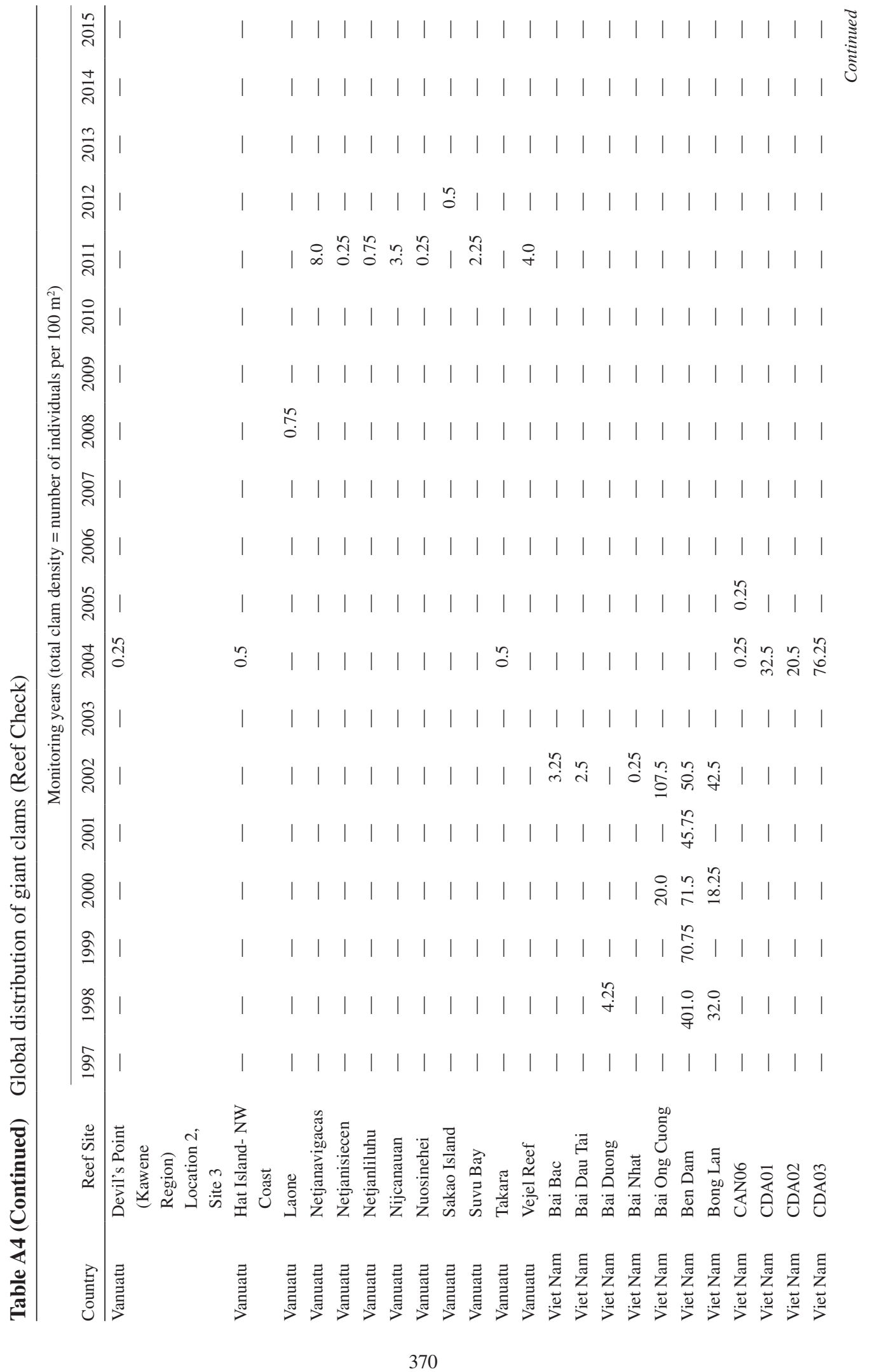


GIANT CLAMS (BIVALVIA: CARDIIDAE: TRIDACNINAE)

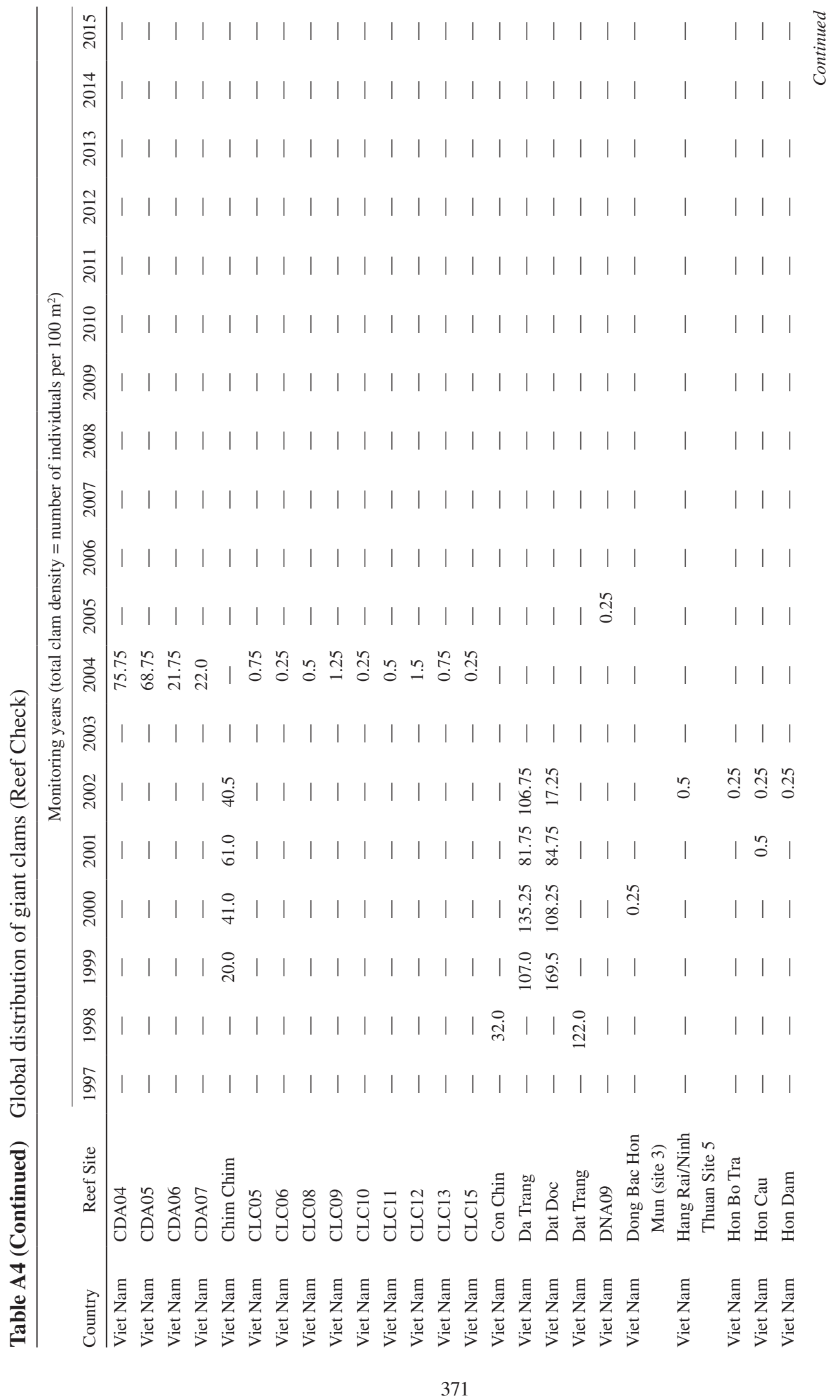


MEI LIN NEO ET AL.

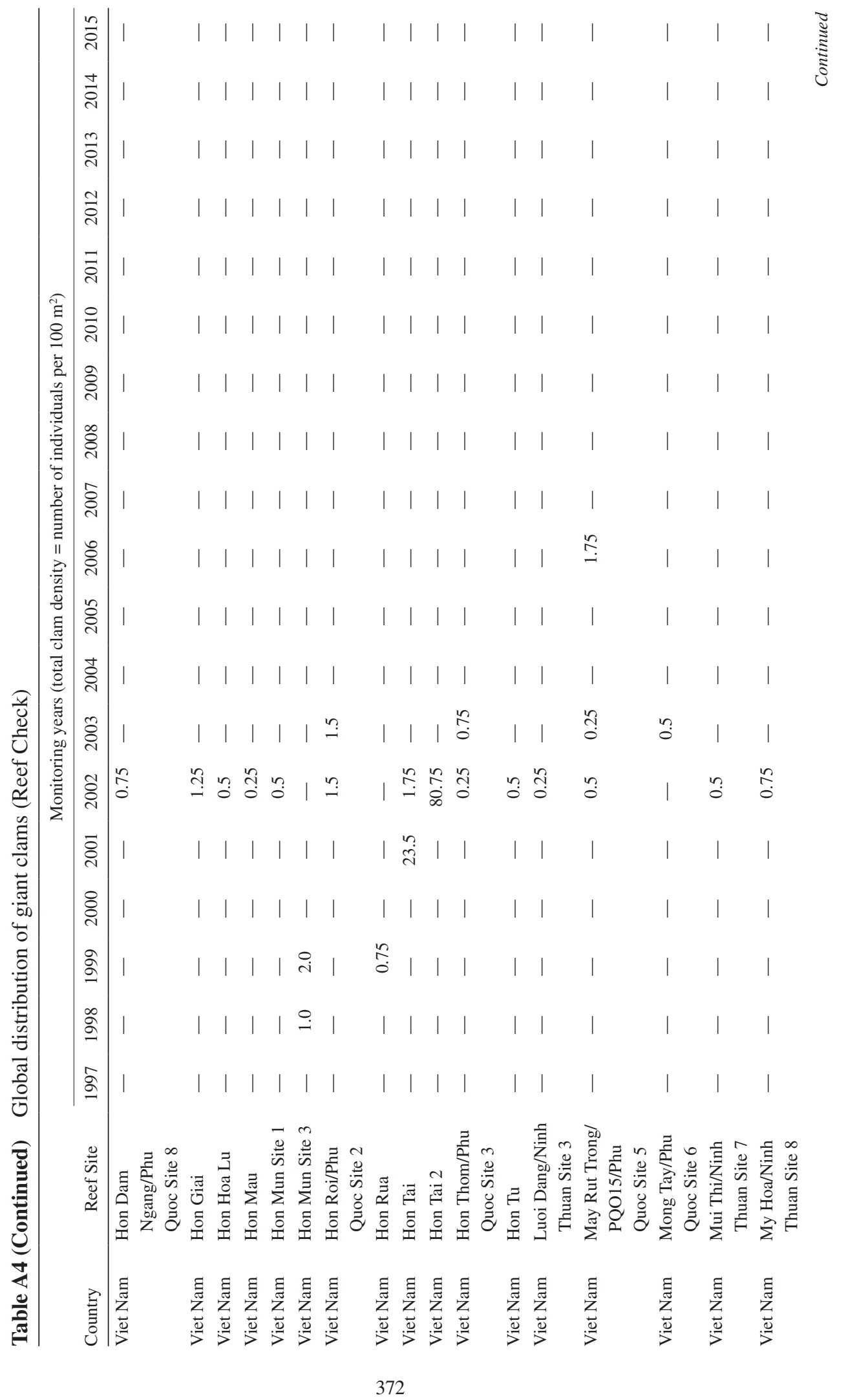


GIANT CLAMS (BIVALVIA: CARDIIDAE: TRIDACNINAE)

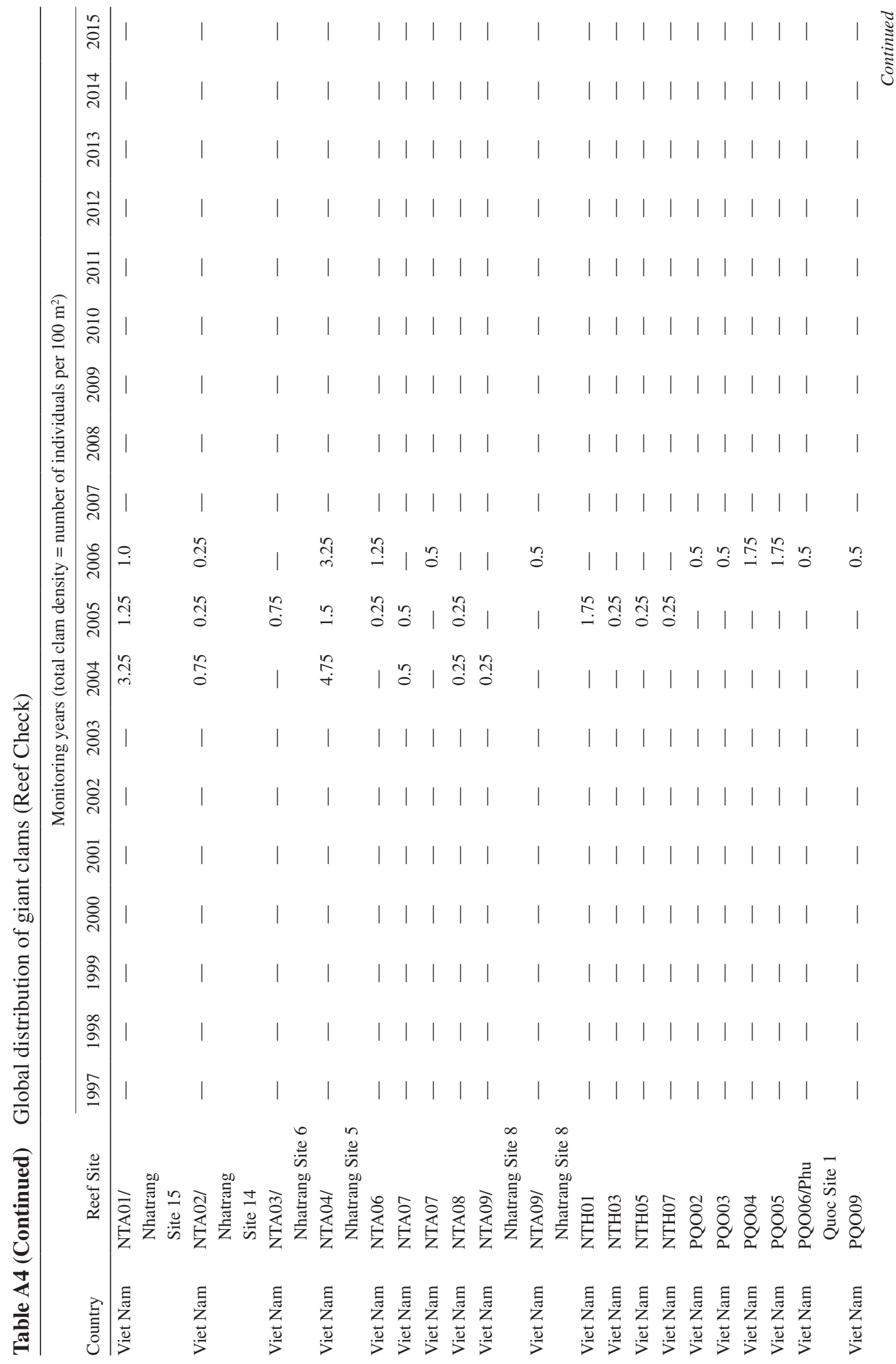


MEI LIN NEO ET AL.

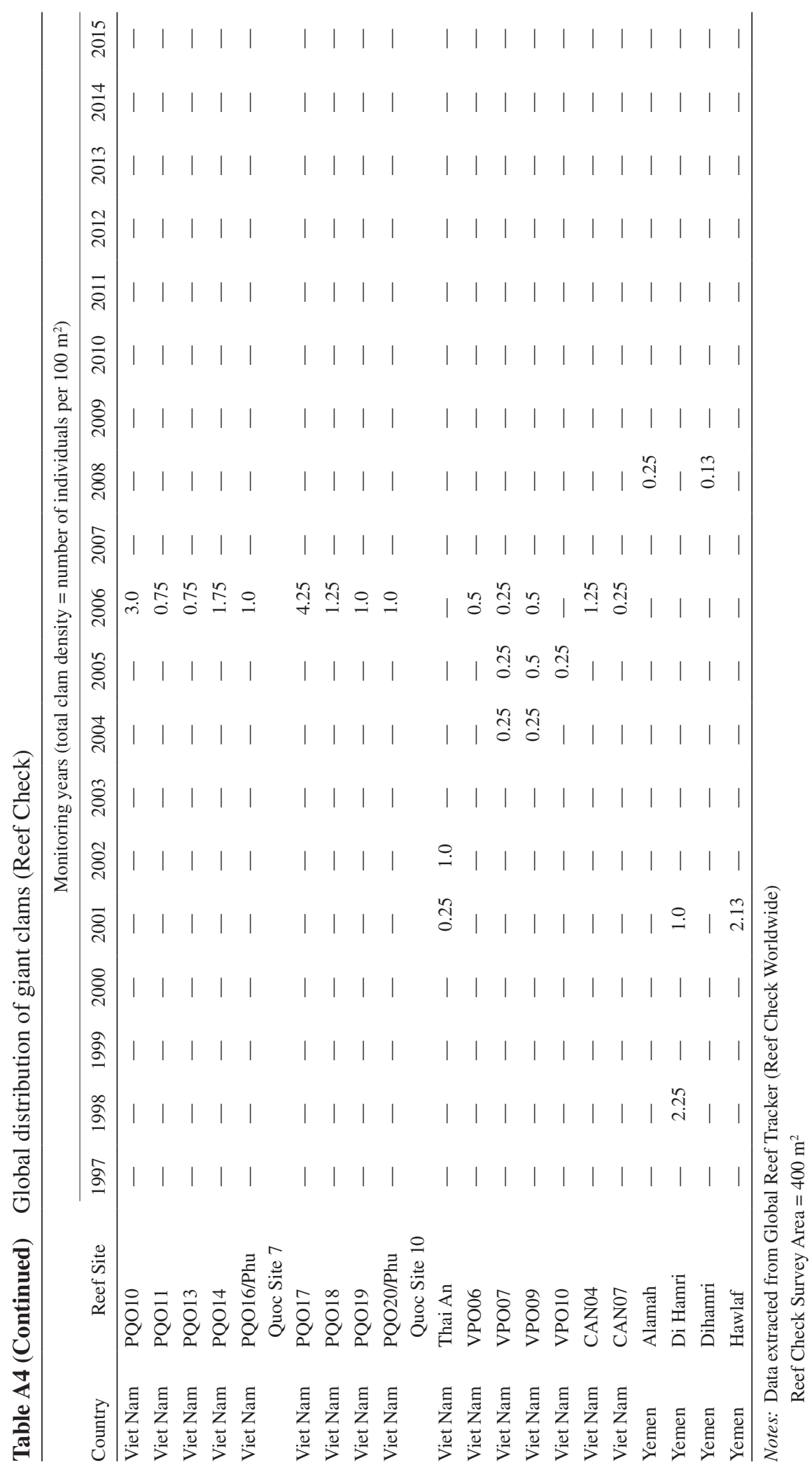




\section{Appendix B: Full list of literature reviewed}

Refer to Tables A1-A3 for list of localities and species, respectively.

Abbott, R.T. 1950. The molluscan Fauna of the Cocos-Keeling Islands, Indian Ocean. Bulletin of Raffles Musuem 22, 68-98.

Accordi, G., Brilli, M., Carbone, F. \& Voltaggio, M. 2010. The raised coral reef complex of the Kenyan coast: Tridacna gigas U-series dates and geological implications. Journal of African Earth Sciences $\mathbf{5 8}, 97-114$.

Agombar, J.S., Dugdale, H.L. \& Hawkswell, N.J. 2003. Species list and relative abundance of marine molluscs collected on Aride Island beach between March 2001 and February 2002. Phelsuma 11, 29-38.

Al-Horani, F.A., Al-Rousan, S.A., Al-Zibdeh, M. \& Khalaf, M.A. 2006. The status of coral reefs on the Jordanian coast of the Gulf of Aqaba, Red Sea. Zoology in the Middle East 38, 99-110.

Alcala, A.C. 1986. Distribution and abundance of giant clams (Family Tridacnidae) in the South-Central Philippines. Silliman Journal 33, 1-9.

Alder, J. \& Braley, R.D. 1989. Serious mortality in populations of giant clams on reefs surrounding Lizard Island, Great Barrier Reef. Australian Journal of Marine and Freshwater Research 40, 205-213.

Anam, R. \& Mostarda, E. 2012. Field Identification Guide to the Living Marine Resources of Kenya. FAO Species Identification Guide for Fishery Purposes. Rome, Food and Agriculture Organization of the United Nations (FAO).

Andréfouët, S., Friedman, K., Gilbert, A. \& Remoissenet, G. 2009. A comparison of two surveys of invertebrates at Pacific Ocean Islands: the giant clam at Raivavae Island, Australes Archipelago, French Polynesia. ICES Journal of Marine Science 66, 1825-1836.

Andréfouët, S., Gilbert, A., Yan, L., Remoissenet, G., Payri, C. \& Chancerelle, Y. 2005. The remarkable population size of the endangered clam Tridacna maxima assessed in Fangatau atoll (Eastern Tuamotu, French Polynesia) using in situ and remote sensing data. ICES Journal of Marine Science 62, 1037-1048.

Andréfouët, S., Menou, J-L. \& Naeem, S. 2012. Macro-invertebrate communities of Baa Atoll, Republic of Maldives. In Biodiversity, Resources and Conservation of Baa Atoll (Republic of Maldives): A UNESCO Man and Biosphere Reserve, S. Andréfouët (ed.). Atoll Research Bulletin No. 590, 125-142.

Andréfouët, S., Van Wynsberge, S., Fauvelot, C., Bruckner, A.W. \& Remoissenet, G. 2014. Significance of new records of Tridacna squamosa Lamarck, 1819, in the Tuamotu and Gambier Archipelagos (French Polynesia). Molluscan Research 34, 277-284.

Andréfouët, S., Van Wynsberge, S., Gaertner-Mazouni, N., Menkes, C., Gilbert, A. \& Remoissenet, G. 2013. Climate variability and massive mortalities challenge giant clam conservation and management efforts in French Polynesia atolls. Biological Conservation 160, 190-199.

Andrews, C.W., Smith, E.A., Bernard, H.M., Kirkpatrick, R. \& Chapman, F.C. 1900. On the marine fauna of Christmas Island (Indian Ocean). Proceedings of the Zoological Society of London 69, 115-140.

Anonymous 1994. Hima (Giant Clams). Sport Fish \& Wildlife Restoration.

Apte, D. \& Dutta, S. 2010. Ecological determinants and stochastic fluctuations of Tridacna maxima survival rate in Lakshadweep Archipelago. Systematics and Biodiversity 8, 461-469.

Apte, D., Dutta, S. \& Babu, I. 2010. Monitoring densities of the giant clam Tridacna maxima in Lakshadweep Archipelago. Marine Biodiversity Records 3, e78 (9 pages).

Aubert, A., Lazareth, C.E., Cabioch, G., Boucher, H., Yamada, T., Iryu, Y. \& Farman, R. 2009. The tropical giant clam Hippopus hippopus shell, a new archive of environmental conditions as revealed by sclerochronological and $\delta^{18} \mathrm{O}$ profiles. Coral Reefs 28, 989-998.

Australian Government 2005. Status of the coral reefs at the Cocos (Keeling) Islands: a report on the status of the marine community at Cocos (Keeling) Islands, East Indian Ocean, 1997-2005. Canberra: Department of the Environment and Heritage. Online. http://www.environment.gov.au/resource/statuscoral-reefs-cocos-keeling-islands-indian-ocean (accessed 13 April 2017).

Barnes, D.K.A. \& Rawlinson, K.A. 2009. Traditional coastal invertebrate fisheries in south-western Madagascar. Journal of the Marine Biological Association of the United Kingdom 89, 1589-1596.

Barnes, D.K.A., Corrie, A., Whittington, M., Carvalho, M.A. \& Gell, F. 1998. Coastal shellfish resource use in the Quirimba Archipelago, Mozambique. Journal of Shellfish Research 17, 51-58. 
Barott, K.L., Caselle, J.E., Dinsdale, E.A., Friedlander, A.M., Maragos, J.E., Obura, D., Rohwer, F.L., Sandin, S.A., Smith, J.E. \& Zgliczynski, B. 2010. The lagoon at Caroline/Millennium Atoll, Republic of Kiribati: natural history of a nearly pristine ecosystem. PLOS ONE 5, e10950. doi:10.1371/journal.pone.0010950

Basker, J.R. 1991. Giant Clams in the Maldives - A stock assessment and study of their potential for culture. Madras, India: Bay of Bengal Programme, Reef Fish Research \& Resources Survey. Online. http:// www.fao.org/3/a-ae451e.pdf (accessed 13 April 2017).

Beger, M. \& Pinca, S. 2003. Coral reef biodiversity community-based assessment and conservation planning in the Marshall Islands: Baseline surveys, capacity building and natural protection and management of coral reefs of the atolls of Rongelap and Mili. Final Report: Project 2002-0317-008. Natural Resources Assessment Surveys Team and Majuro, Republic of the Marshall Islands: College of the Marshall Islands. Online. http://www.nras-conservation.org/nraslibrary/NFWF_finalreport2003.pdf (accessed 13 April 2017).

Beger, M., Jacobson, D., Pinca, S., Richards, Z.T., Hess, D., Harris, F., Page, C., Peterson, E.L. \& Baker, N. 2008. The state of coral reef ecosystems of the Republic of the Marshall Islands. In The State of Coral Reef Ecosystems of the United States and Pacific Freely Associated States, J.E. Waddell \& A. Clarke (eds). NOAA: Silver Spring, Maryland, USA, 330-361.

Bell, L.A.J. \& Amos, M.J. 1993. Republic of Vanuatu Fisheries Resources Profiles. FFA Report 93/49. Honiara, Solomon Islands: Pacific Islands Forum Fisheries Agency. Online. www.spc.int/DigitalLibrary/Doc/ FAME/FFA/Reports/FFA_1993_049.pdf (accessed 13 April 2017).

Bell, L.A.J. 1993. Giant Clam Project American Samoa. FFA Report 93/06. Honiara, Solomon Islands: Pacific Islands Forum Fisheries Agency. Online. www.spc.int/DigitalLibrary/Doc/FAME/FFA/Reports/ FFA_1993_006.pdf (accessed 13 April 2017).

Bellchambers, L.M. \& Evans, S.N. 2013. A Summary of the Department of Fisheries, Western Australia Invertebrate Research at Cocos (Keeling) Islands 2006-2011. Fisheries Research Report No. 239. North Beach, Western Australia: Department of Fisheries, Western Australia. Online. http://www.fish.wa.gov. au/Documents/research_reports/frr239.pdf (accessed 13 April 2017).

Bernard, F.R., Cai, Y-Y. \& Morton, B. 1993. Catalogue of the Living Marine Bivalve Molluscs of China. Hong Kong: Hong Kong University Press.

Berzunza-Sanzhez, M.M., Cabrera, M.C.C. \& Pandolfi, J.M. 2013. Historical patterns of resource exploitation and the status of Papua New Guinea coral reefs. Pacific Science 67, 425-440.

Bigot, L., Charpy, L., Maharavo, J., Abdou Rabi, F., Paupiah, N., Aumeeruddy, R., Villedieu, C. \& Lieutaud, A. 2000. 5. Status of coral reefs of the Southern Indian Ocean: The Indian Ocean Commission node for Comoros, Madagascar, Mauritius, Reunion and Seychelles. In Status of Coral Reefs of the World: 2000, C. Wilkinson (ed.). Cape Ferguson, Queensland: Australian Institute of Marine Science, 77-93.

Bijukumar, A., Ravinesh, R., Arathi, A.R. \& Idreesbabu, K.K. 2015. On the molluscan fauna of Lakshadweep included in various schedules of wildlife (protection) act of India. Journal of Threatened Taxa 7, $7253-7268$.

Black, R., Johnson, M.S., Prince, J., Brearley, A. \& Bond, T. 2011. Evidence of large, local variations in recruitment and mortality in the small giant clam, Tridacna maxima, at Ningaloo Marine Park, Western Australia. Marine and Freshwater Research 62, 1318-1326.

Bodoy, A. 1984. Assessment of human impact on giant clams (Tridacna maxima) near Jeddah, Saudi Arabia. Proceedings of the Symposium on Coral Reef Environment of the Red Sea, Jeddah 1984, 472-490.

Borsa, P., Fauvelot, C., Tiavouane, J., Grulois, D., Wabnitz, C., Abdon Naguit, M.R. \& Andréfouët, S. 2015. Distribution of Noah's giant clam, Tridacna noae. Marine Biodiversity 45, 339-344.

Bouchet, P., Heros, V., Le Goff, A., Lozouet, P. \& Maestrati, P. 2001. Atelier biodiversité Lifou 2000, grottes et récifs coralliens. Rapport de mission, IRD, Noumea, New Caledonia.

Braley, R.D. 1987a. Distribution and abundance of the giant clams Tridacna gigas and T. derasa on the Great Barrier Reef. Micronesica 20, 215-223.

Braley, R.D. 1987b. Spatial distribution and population parameters of Tridacna gigas and T. derasa. Micronesica 20, 225-246.

Braley, R.D. 1988. The Status of Giant Clams Stocks and Potential for Clam Mariculture in Tuvalu. Suva, Fiji: South Pacific Aquaculture Development Project, Food and Agriculture Organization of the United Nations. 
Braley, R.D. 1989. A Giant Clam Stock Survey and Preliminary Investigation of Pearl Oyster Resources in the Tokelau Islands. Suva, Fiji: South Pacific Aquaculture Development Project, Food and Agriculture Organization of the United Nations.

Brown, J.H. \& Muskanofola, M.R. 1985. An investigation of stocks of giant clams (family Tridacnidae) in Java and of their utilization and potential. Aquaculture and Fisheries Management 1, 25-39.

Bryan, P.G. \& McConnell, D.B. 1976. Status of giant clam stocks (Tridacnidae) on Helen Reef, Palau, Western Caroline Islands, April 1975. Marine Fisheries Review 38, 15-18.

Calumpong, H.P. \& Cadiz, P. 1993. Observations on the distribution of giant clams in protected areas. Silliman Journal 36, 107-116.

Calumpong, H.P. \& Macansantos, A.D. 2008. Distribution and abundance of giant clams in the Spratlys, South China Sea. In Proceedings of the Conference on the Results of the Philippines-Vietnam Joint Oceanographic and Marine Scientific Research Expedition in the South China Sea (JOMSRE-SCS I to IV), 26-29 March 2008, Ha Long City, Vietnam, A.C. Alcala (ed.). Pasay City, Republic of the Philippines. Technical Cooperation Council of the Philippines of the Department of Foreign Affairs, 55-59.

Calumpong, H.P., Apao, A.B., Lucañas, J.R. \& Estacion, J.S. 2002. Community-based giant clam restocking - hope for biodiversity conservation. Proceedings 9th International Coral Reef Symposium, Bali, Indonesia 23-27 October 2000, Volume 2, Moosa et al. (eds). Jakarta: Indonesian Institute of Sciences, Jakarta: Ministry of Environment, Honolulu, Hawaii: International Society for Reef Studies pp. 101-110.

Chambers, C.N.L. 2007. Pasua (Tridacna maxima) size and abundance in Tongareva Lagoon, Cook Islands. SPC Trochus Information Bulletin 13, 7-12.

Chantrapornsyl, S., Kittiwattanawong, K. \& Adulyanukosol, K. 1996. Distribution and abundance of giant clam around Lee-Pae Island, the Andaman Sea, Thailand. Phuket Marine Biological Center Special Publication 16, 195-200.

Chesher, R.H. 1993. Giant clam sanctuaries in the Kingdom of Tonga. Marine Studies of the University of the South Pacific Technical Report Series 95/2. Suva, Fiji: University of the South Pacific. Online. http://www.tellusconsultants.com/chesher-1993-Giant\%20Clam\%20Sanctuaries\%20in\%20the\%20 Kingdom\%20of\%20Tonga.pdf (accessed 19 December 2016).

Chin, A., Lison De Loma, T., Reytar, K., Planes, S., Gerhardt, K., Clua, E., Burke, L. \& Wilkinson, C. 2011. Status of Coral Reefs of the Pacific and Outlook: 2011. Global Coral Reef Monitoring Network. Online. http://www.icriforum.org/sites/default/files/Pacific-Coral-Reefs-2011.pdf (accessed 12 April 2017).

Conales, S.F., Bundal, N.A. \& Dolorosa, R.G. 2015. High densities of Tridacna crocea in exposed massive corals proximate the Ranger Station of Tubbataha Reefs Natural Park, Cagayancillo, Palawan, Philippines. The Palawan Scientist 7, 36-39.

Craig, P. (ed.) 2009. Natural History Guide to American Samoa. Pago Pago, American Samoa: National Park of American Samoa, 3rd edition. Online. https://www.nps.gov/npsa/learn/education/upload/ NatHistGuideAS09.pdf (accessed 12 April 2017).

Dalzell, P., Lindsay, S.R. \& Patiale, H. 1993. Fisheries resources survey of the island of Niue. Inshore Fisheries Research Project, Technical Document No. 3. Noumea, New Caledonia: South Pacific Commission. Online. http://www.spc.int/DigitalLibrary/Doc/FAME/Reports/Dalzell_93_Niue.pdf (accessed 12 April 2017).

Daniels, C. 2004. Marine Science Report - Update report for DFMR, October 2004. Chumbe Island, Tanzania: Chumbe Island Coral Park Pte Ltd.

Dolorosa, R.G. \& Jontila, J.B.S. 2012. Notes on common macrobenthic reef invertebrates of Tubbataha Reefs Natural Park, Philippines. Science Diliman 24, 1-11.

Dolorosa, R.G. \& Schoppe, S. 2005. Focal benthic mollusks (Mollusca: Bivalvia and Gastropoda) of selected sites in Tubbataha Reef National Marine Park, Palawan, Philippines. Science Diliman 17, 1-10.

Dolorosa, R.G. 2010. Conservation status and trends of reef invertebrates in Tubbataha Reefs with emphasis on molluscs and sea cucumbers. Unpublished Technical Report. Online. http://tubbatahareef.org/downloads/research_reports/conservation_status_and_trends_of_reef_invertebrates_in_tubbataha_reefs_ with_emphasis_on_molluscs_and_sea_cucumbers.pdf (accessed 12 April 2017).

Dolorosa, R.G., Conales, S.F. \& Bundal, N.A. 2014. Shell dimension-live weight relationships, growth and survival of Hippopus porcellanus in Tubbataha Reefs Natural Park, Philippines. Atoll Research Bulletin 604, 1-9. 
Dolorosa, R.G., Picardal, R.M. \& Conales, S.F., Jr 2015. Bivalves and gastropods of Tubbataha Reefs Natural Park, Philippines. Check List 11, 1506. doi:10.15560/11.1.1506

Dumas, P., Fauvelot, C., Andréfouët, S. \& Gilbert, A. 2011. Les benitiers en Nouvelle-Caledonie: Statut des populations, impacts de l'exploitation \& connectivitié. Rapport final d'opération, Programme ZONECO, Avril 2011. Noumea, New Caledonia: Institut de Recherche pour le Développement (NouvelleCalédonie); Saint-Denis, Réunion: Université de la Réunion

Dumas, P., Jimenez, H., Peignon, C., Wantiez, L. \& Adjeroud, M. 2013. Small-scale habitat structure modulates the effects of no-take marine reserves for coral reef macroinvetebrates. PLOS ONE 8, e58998. doi:10.1371/journal.pone.0058998

Eliata, A., Zahida, F., Wibowo, N.J. \& Panggabean, L.M.G. 2003. Abundance of giant clam in coral reef ecosystem at Pari Island: a population comparison of 2003's to 1984's data. Biota 8, 149-152.

Evans, S.M., Knowles, G., Pye-Smith, C. \& Scott, R. 1977. Conserving shells in Kenya. Oryx 13, 480-485.

Evans, S.N., Konzewitsch, N. \& Bellchambers, L.M. 2016. An update of the Department of Fisheries, Western Australia, Invertebrate and Reef Health Research and Monitoring at Cocos (Keeling) Islands. Fisheries Research Report No. 272, Department of Fisheries, Western Australia.

Fiege, D., Neumann, V. \& Li, J. 1994. Observations on coral reefs of Hainan Island, South China Sea. Marine Pollution Bulletin 29, 84-89.

Fijiwara, S., Shibuno, T., Mito, K., Nakai, T., Sasaki, Y., Dai, C-F. \& Chen, G. 2000. 8. Status of coral reefs of East and North Asia: China, Japan and Taiwan. In Status of Coral Reefs of the World: 2000, C. Wilkinson (ed.). Cape Ferguson, Queensland: Australian Institute of Marine Science, 131-140.

George, K.C., Thomas, P.A., Appukuttan, K.K. \& Gopakumar, G. 1986. Ancillary living marine resources of Lakshadweep. Marine Fisheries Information Service: Special Issue on Lakshadweep, No. 68, 46-50.

Gerlach, G. \& Gerlach, R. 2004. Species list of marine molluscs on Silhouette Island. Phelsuma 12, 12-23.

Gilbert, A., Andréfouët, S., Yan, L. \& Remoissenet, G. 2006. The giant clam Tridacna maxima communities of three French Polynesia islands: comparison of their population sizes and structures at early stages of their exploitation. ICES Journal of Marine Science 63, 1573-1589.

Gilbert, A., Planes, S., Andréfouët, S., Friedman, K. \& Remoissenet, G. 2007. First observation of the giant clam Tridacna squamosa in French Polynesia: a species range extension. Coral Reefs 26, 229 only.

Gilbert, A., Remoissenet, G., Yan, L. \& Andréfouët, S. 2006. Special traits and promises of the giant clam (Tridacna maxima) in French Polynesia. SPC Fisheries Newsletter No. 118, 44-52.

Gilbert, A., Yan, L., Remoissenet, G., Andréfouët, S., Payri, C. \& Chancerelle, Y. 2005. Extraordinarily high giant clam density under protection in Tatakoto Atoll (eastern Tuamotu Archipelago, French Polynesia). Coral Reefs 24, 495 only.

Gilligan, J., Hender, J., Hobbs, J.P., Neilson, J. \& McDonald, C. 2008. Coral reef surveys and stock size estimates of shallow water $(0-20 \mathrm{~m})$ marine resources at Christmas Island, Indian Ocean. Unpublished Report to Parks Australia North (Technical Report).

Gomez, E.D. \& Alcala, A.C. 1988. Giant clams in the Philippines. In Giant Clams in Asia and the Pacific, J.W. Copland \& J.S. Lucas (eds). Canberra: Australian Centre for International Agricultural Research, 51-53.

Gonzales, B.J., Becira, J.G., Galon, W.M. \& Gonzales, M.M.G. 2014a. Protected versus unprotected area with reference to fishes, corals, marine invertebrates, and CPUE in Honda Bay, Palawan. The Palawan Scientist 6, 42-59.

Gonzales, B.J., Dolorosa, R.G., Pagliawan, H.B. \& Gonzales, M.M.G. 2014b. Marine resource assessment for sustainable management of Apulit Island, West Sulu Sea, Palawan, Philippines. IJFAS 2, 130-136.

Gössling, S., Kunkel, T., Schumacher, K. \& Zilger, M. 2004. Use of molluscs, fish, and other marine taxa by tourism in Zanzibar, Tanzania. Biodiversity and Conservation 13, 2623-2639.

Govan, H., Nichols, P.V. \& Tafea, H. 1988. Giant clam resource investigations in Solomon Islands. In Giant Clams in Asia and the Pacific, J.W. Copland \& J.S. Lucas (eds). Canberra: Australian Centre for International Agricultural Research, 54-57.

Green, A. \& Craig, P. 1999. Population size and structure of giant clams at Rose Atoll, an important refuge in the Samoan Archipelago. Coral Reefs 18, 205-211.

Guest, J.R., Todd, P.A., Goh, E., Sivalonganathan, B.S. \& Reddy, K.P. 2008. Can giant clam (Tridacna squamosa) populations be restored on Singapore's heavily impacted coral reefs? Aquatic Conservation: Marine and Freshwater Ecosystems 18, 570-579.

Hamner, W.M. \& Jones, M.S. 1976. Distribution, burrowing, and growth rates of the clam Tridacna crocea on interior reef flats. Oecologia 24, 207-227. 
Harding, S. \& Randriamanantsoa, B. 2008. Coral reef monitoring in marine reserves of Northern Madagascar. In Ten Years After Bleaching - Facing the Consequences of Climate Change in the Indian Ocean, D.O. Obura et al. (eds). CORDIO Status Report 2008. Mombasa, Kenya: Coastal Oceans Research and Development in the Indian Ocean/Sida-SAREC, 93-106.

Harding, S., Randriamanantsoa, B., Hardy, T. \& Curd, A. 2006. Coral reef monitoring and biodiversity assessment to support the planning of a proposed MPA at Andavadoaka. Unpublished Technical Report.

Hardy, J.T. \& Hardy, S.A. 1969. Ecology of Tridacna in Palau. Pacific Science 23, 467-472.

Hender, J., McDonald, C.A. \& Gilligan, J.J. 2001. Baseline surveys of the marine environments and stock size estimates of marine resources of the south Cocos (Keeling) Atoll (0-15m), eastern Indian Ocean. Unpublished report to the Fisheries Resources Research Fund, Barton, Australia.

Hensley, R.A. \& Sherwood, T.S. 1993. An overview of Guam's inshore fisheries. Marine Fisheries Review $\mathbf{5 5}, 129-138$.

Hernawan, U.E. 2010. Study on giant clams (Cardiidae) population in Kei Kecil waters, Southeast-Maluku. Widyariset 13, 101-108.

Hester, F.J. \& Jones, E.C. 1974. A survey of giant clams, Tridacnidae, on Helen Reef, a Western Pacific atoll. Marine Fisheries Review 36, 17-22.

Hirase, S. 1954. An Illustrated Handbook of Shells in Natural Colours from the Japanese Islands and adjacent territory. Tokyo: Maruzen Co. Ltd.

Hirschberger, W. 1980. Tridacnid clam stocks on Helen Reef, Palau, Western Caroline Islands. Marine Fisheries Review 42, 8-15.

Hopkins, A. 2009. Marine invertebrates as indicators of reef health: a study of the reefs in the region of Andavadoaka, South West Madagascar. MSc Dissertation, Imperial College London, UK.

Hourston, M. 2010. Review of exploitation of marine resources of the Australian Indian Ocean Territories: the implications of biogeographic isolation for tropical island fisheries. Fisheries Research Report No. 208. Perth: Department of Fisheries, Western Australia.

Huang, C.W., Hsiung, T.W., Lin, S.M. \& Wu, W.L. 2013. Molluscan fauna of Gueishan Island, Taiwan. ZooKeys 261, 1-13.

Huber, M. \& Eschner, A. 2011. Tridacna (Chametrachea) costata Roa-Quiaoit, Kochzius, Jantzen, Al-Zibdah and Richter from the Red Sea, a junior synonym of Tridacna squamosina Sturany, 1899 (Bivalvia, Tridacnidae). Annalen des Naturhistorischen Museums in Wien B 112, 153-162.

Huber, M. 2010. Compendium of Bivalves. A Full-Color Guide to 3,300 of the World's Marine Bivalves. A Status on Bivalvia after 250 years of Research. Hackenheim: Conchbooks.

Hughes, R.N. 1977. The biota of reef-flats and limestone cliffs near Jeddah, Saudi Arabia. Journal of Natural History 11, 77-96.

Irving, R. \& Dawson, T. 2013. 22 Coral reefs of the Pitcairn Islands. In Coral Reefs of the United Kingdom Overseas Territories, C.R.C. Sheppard (ed.). Dordrecht, Netherlands: Springer, 299-318.

Jacob, P. 2000. The Status of Marine Resources and Coral Reefs of Nauru. Unpublished Status Report, Global Coral Reef Monitoring Network, 1-10.

Jaubert, J. 1977. Light, metabolism, and the distribution of Tridacna maxima in a South Pacific atoll: Takapoto (French Polynesia). Proceedings 3rd International Coral Reef Symposium, Rosenstiel School of Marine and Atmospheric Science, University of Miami, Miami, Florida, USA, May, 1977, 489-494.

Job, S. \& Ceccarelli, D. 2012. Tuvalu Marine Life: an Alofa Tuvalu Project with the Tuvalu Fisheries Department and Funafuti, Nanumea, Nukulaelae Kaupules. Scientific Report, December 2012. Paris: Alofa Tuvalu. Online. http://alofatuvalu.tv/US/05_a_tuvalu/05_page_tml/livret4light.pdf (accessed 12 April 2017).

Johnson, M.S.,Prince, J., Brearley, A., Rosser, N.L.\& Black, R. 2016. Is Tridacnamaxima (Bivalvia: Tridacnidae) at Ningaloo Reef, Western Australia? Molluscan Research, doi:10.1080/13235818.2016.1181141

Juinio, M.A.R., Meñez, L.A.B., Villanoy, C.L. \& Gomez, E.D. 1989. Status of giant clam resources of the Philippines. Journal of Molluscan Studies 55, 431-440.

Junchompoo, C., Sinrapasan, N., Penpain, C. \& Patsorn, P. 2013. Changing seawater temperature effects on giant clams bleaching, Mannai Island, Rayong province, Thailand. Kurenai 2013-03, 71-76.

Kanno, K., Kotaki, Y. \& Yasumoto, T. 1976. Distribution of toxins in molluscs associated with coral reefs. Bulletin of the Japanese Society of Scientific Fisheries 42, 1395-1398.

Kay, E.A. 1970. The littoral marine mollusks of Fanning Island. In Fanning Island Expedition, January 1970, K.E. Chave (ed.). Honolulu: Hawaii Institute of Geophysics, University of Hawaii, 111-133. 
Kepler, A.K. \& Kepler, C.B. 1994. Part I. History, physiography, botany and isle descriptions. Atoll Research Bulletin 397, 1-225.

Kilada, R., Zakaria, S. \& Farghalli, M.E. 1998. Distribution and abundance of the giant clam Tridacna maxima (Bivalvia: Tridacnidae) in the Northern Red Sea. Bulletin of the National Institute of Oceanography and Fisheries 24, 221-240.

Kinch, J. 2001. Clam harvesting, the Convention on the International Trade in Endangered Species (CITES) and conservation in Milne Bay Province, Papua New Guinea. SPC Fisheries Newsletter 99, 24-36.

Kinch, J. 2002. Giant clams: their status and trade in Milne Bay Province, Papua New Guinea. TRAFFIC Bulletin 19, 1-9.

Kittiwattanawong, K. 1997. Genetic structure of giant clam, Tridacna maxima in the Andaman Sea, Thailand. Phuket Marine Biological Center Special Publication 17, 109-114.

Kittiwattanawong, K. 2001. Records of extinct Tridacna gigas in Thailand. Phuket Marine Biological Center Special Publication 25, 461-463.

Kittiwattanawong, K., Nugranad, J. \& Srisawat, T. 2001. High genetic divergence of Tridacna squamosa living at the west and the east coasts of Thailand. Phuket Marine Biological Center Special Publication 25, 343-347.

Koh, L.L., Tun, K.P.P. \& Chou, L.M. 2003. The status of coral reefs of Surin Islands, Thailand based on surveys in December 2003. REST Technical Report No. 5. Singapore: National University of Singapore.

Kronen, M., Fisk, D., Pinca, S., Magron, F., Friedman, K., Boblin, P., Awira, R. \& Chapman, L. 2008. Niue country report: profile and results from in-country survey work (May to June 2005). Noumea, New Caledonia: Pacific Regional Oceanic and Coastal Fisheries Development Programme. Online. http:// www.spc.int/DigitalLibrary/Doc/FAME/Reports/PROCFish/PROCFish_2008_NiueReport.pdf (accessed 12 April 2017).

Kubo, H. \& Iwai, K. 2007. On two sympatric species within Tridacna "maxima". Annual Report Okinawa Fisheries Oceanography Research Centre 68, 205-210.

Kusnadi, A., Triandiza, T. \& Hernawan, U.E. 2008. Inventarisasi Jenis dan Potensi Moluska Padang Lamun di Kepulauan Kei Kecil, Maluku Tenggara. Biodiversitas 9, 30-34.

Langi, V. \& Hesitoni 'Aloua 1988. Status of giant clams in Tonga. In Giant Clams in Asia and the Pacific, J.W. Copland \& J.S. Lucas (eds). Canberra: Australian Centre for International Agricultural Research, $58-59$.

Langi, V. 1990. Marine resource survey of Nanumea and Nui Islands, Tuvalu: (giant clam, commercial species, bêche-de-mer, pearl oysters and trochus). Canberra: Australian Centre for International Agricultural Research, and Suva, Fiji: Ministry of Primary Industries.

Larrue, S. 2006. Giant clam fishing on the islands of Tubuai, Austral Islands group: between local portrayals, economic necessity and ecological realities. SPC Traditional Marine Resource Management and Knowledge Information Bulletin 19, 3-10.

Lasola, N. \& Hoang, X.B. 2008. Assessment of commercially important macro-invertebrates in the Spratly Group of Islands. In Proceedings of the Conference on the Results of the Philippines-Vietnam Joint Oceanographic and Marine Scientific Research Expedition in the South China Sea (JOMSRE-SCS I to IV), 26-29 March 2008, Ha Long City, Vietnam, A.C. Alcala (ed.). Pasay City, Republic of the Philippines: Technical Cooperation Council of the Philippines of the Department of Foreign Affairs, $51-54$.

Latypov, Y.Y. \& Selin, N.I. 2011. Current status of coral reefs of islands in the Gulf of Siam and Southern Vietnam. Russian Journal of Marine Biology 37, 255-262.

Latypov, Y.Y. \& Selin, N.I. 2012a. Changes of reef community near Ku Lao Cham Islands (South China Sea) after Sangshen Typhoon. American Journal of Climate Change 1, 41-47.

Latypov, Y.Y. \& Selin, N.I. 2012b. The composition and structure of a protected coral reef in Cam Ranh Bay in the South China Sea. Russian Journal of Marine Biology 38, 112-121.

Latypov, Y.Y. \& Selin, N.I. 2013. Some data on spatio-temporal stability and variability of coral reefs in Khanh Hoa Province (Vietnam). Environment, Ecology \& Management 2, 1-16.

Latypov, Y.Y. 2000. Macrobenthos communities on reefs of the An Thoi Archipelago of the South China Sea. Russian Journal of Marine Biology 26, 18-26.

Latypov, Y.Y. 2001. Communities of coral reefs of central Vietnam. Russian Journal of Marine Biology 27, 197-200. 
Latypov, Y.Y. 2006. Changes in the composition and structure of coral communities of Mju and Moon Islands, Nha Trang Bay, South China Sea. Russian Journal of Marine Biology 32, 269-275.

Latypov, Y.Y. 2013. Barrier and platform reefs of the Vietnamese coast of the South China Sea. International Journal of Marine Science 3, 23-32.

Laurent, V. 2001. Etude de stocks, relations biométriques et structure des populations de bénitiers, Tridacna maxima, dans trois lagons de Polynésie francaise (Moorea, Takapoto et Anaa). Report. Rennes: École nationale supérieure agronomique de Rennes.

Ledua, E., Manu, N. \& Braley, R. 1993. Distribution, habitat and culture of the recently described giant clam Tridacna tevoroa in Fiji and Tonga. In The Biology and Mariculture of Giant Clams: A Workshop Held in Conjunction with the 7th International Coral Reef Symposium 21-26 June 1992, Guam, USA, W.K. Fitt (ed.). ACIAR Proceedings No. 47. Canberra: Australian Centre for International Agricultural Research, 147-153.

Lewis, A.D. \& Ledua, E. 1988. A possible new species of Tridacna (Tridacnidae: Mollusca) from Fiji. In Giant Clams in Asia and the Pacific, J.W. Copland \& J.S. Lucas (eds). Canberra: Australian Centre for International Agricultural Research, 82-84.

Lewis, A.D., Adams, T.J.H. \& Ledua, E. 1988. Fiji's giant clam stocks - A review of their distribution, abundance, exploitation and management. In Giant Clams in Asia and the Pacific, J.W. Copland \& J.S. Lucas (eds). Canberra: Australian Centre for International Agricultural Research, 66-72.

Liu, J.Y. 2013. Status of marine biodiversity of the China Seas. PLOS ONE 8, e50719. doi:10.1371/journal. pone.0050719

Loh, T.L., Chaipichit, S., Songploy, S. \& Chou, L.M. 2004. The status of coral reefs of Surin Islands, Thailand, based on surveys in December 2004. REST Technical Report No. 7. Singapore: National University of Singapore.

Long, N.V. \& Vo, T.S. 2013. Degradation trend of coral reefs in the coastal waters of Vietnam. Galaxea Special Issue 15, 79-83. doi:10.3755/galaxea.15.79

Lovell, E., Sykes, H., Deiye, M., Wantiez, L., Garrigue, C., Virly, S., Samuelu, J., Solofa, A., Poulasi, T., Pakoa, K., Sabetian, A., Afzal, D., Hughes, A. \& Sulu, R. 2004. 12. Status of coral reefs in the south west Pacific: Fiji, Nauru, New Caledonia, Samoa, Solomon Islands, Tuvalu and Vanuatu. In Status of Coral Reefs of the World: 2004, Volume 2, C. Wilkinson (ed.). Townsville, Queensland: Australian Institute of Marine Sciences, 337-361.

Lucas, J.S., Ledua, E. \& Braley, R.D. 1991. Tridacna tevoroa Lucas, Ledua and Braley: a recently described species of giant clam (Bivalvia: Tridacnidae) from Fiji and Tonga. Nautilus 105, 92-103.

Maes, V.O. 1967. The littoral marine mollusks of Cocos-Keeling Islands (Indian Ocean). Proceedings of the Academy of Natural Sciences of Philadelphia 119, 93-217.

McKenna S.A., Baillon N., Blaffart H., \& Abrusci G. 2006. Une évaluation rapide de la biodiversité marine des récifs coralliens du Mont Panié, Province Nord, Nouvelle Calédonie. Bulletin PER d'évaluation biologique $\mathrm{N}^{\circ} 42$.

McMichael, D.F. 1974. Growth rate, population size and mantle coloration in the small giant clam Tridacna maxima (Röding), at One Tree Island, Capricorn Group, Queensland. Proceedings 2nd International Coral Reef Symposium, Brisbane, October 1974. Brisbane: The Great Barrier Reef Committee, 241-254.

Mekawy, M.S. \& Madkour, H.A. 2012. Studies on the Indo-Pacific Tridacnidae (Tridacna maxima) from the Northern Red Sea, Egypt. International Journal of Geosciences 3, 1089-1095.

Mekawy, M.S. 2014. Environmental factors controlling the distribution patterns and abundance of sclerobionts on the shells of Tridacna maxima from the Egyptian Red Sea coast. Arabian Journal of Geosciences 7, 3085-3092.

Michel, C. 1985. Marine molluscs of Mauritius. Gland, Switzerland: WWF and IUCN.

Militz, T.A., Kinch, J. \& Southgate, P.C. 2015. Population demographics of Tridacna noae (Röding, 1798) in New Ireland, Papua New Guinea. Journal of Shellfish Research 34, 329-335.

Miller, I. \& Sweatman, H. 2004. 11. Status of coral reefs in Australia and Papua New Guinea in 2004. In Status of Coral Reefs of the World: 2004, Volume 2, C. Wilkinson (ed.). Townsville, Queensland: Australian Institute of Marine Sciences, 303-335.

Mohamed-Pauzi, A., Mohd. Adib, H., Ahmad, A. \& Abdul-Aziz, Y. 1994. A preliminary survey of giant clams in Malaysia. Proceedings of Fisheries Research Conference, Department of Fisheries, Malaysia IV, 487-493. 
Monsecour, K. 2016. A new species of giant clam (Bivalvia: Cardiidae) from the Western Indian Ocean. Conchylia 46, 69-77.

Montagne, A., Naim, O., Tourrand, C., Pierson, B. \& Menier, D. 2013. Status of coral reef communities on two carbonate platforms (Tun Sakaran Marine Park, East Sabah, Malaysia). Journal of Ecosystems 2013, 1-15.

Morton, B. \& Morton, J.E. 1983. The Sea Shore Ecology of Hong Kong. Hong Kong: Hong Kong University Press.

Munro, J.L. 1988. Status of Giant Clam Stocks in the Central Gilbert Islands Group, Republic of Kiribati. Workshop on Pacific inshore fishery resources, Noumea, New Caledonia, 14-25 March 1988. SPC/ Inshore Fish Res/BP54. Noumea, New Caledonia: South Pacific Commission.

Munro, J.L. 1989. 24 Fisheries for giant clams (Tridacnidae: Bivalvia) and prospects for stock enhancement. In Marine Invertebrate Fisheries: Their Assessment and Management, J.F. Caddy (ed.). New York: Wiley, 541-558.

Nadon, M.O., Griffiths, D., Doherty, E. \& Harris, A. 2007. The status of coral reefs in the remote region of Andavadoaka, Southwest Madagascar. Western Indian Ocean Journal of Marine Science 6, 207-218.

Nagaoka, L. 1993. Chapter 13 Faunal assemblages from the To'aga site. In The To'aga Site. Three Millennia of Polynesian Occupation in the Manu'a Islands, American Samoa, P.V. Kirch \& T.L. Hunt (eds). Contributions of the University of California Archaeological Research Facility, Berkeley, Number 51. Online. http://digitalassets.lib.berkeley.edu/anthpubs/ucb/text/arf051-014.pdf (accessed 12 April 2017).

Naguit, M.R.A., Tisera, W.L. \& Calumpong, H.P. 2012. Ecology and genetic structure of giant clams around Savu Sea, East Nusa Tenggara Province, Indonesia. Asian Journal of Biodiversity 3, 174-194.

Nakamura, Y. 2013. Coastal resource use and management on Kilwa Island, southern Swahili Coast, Tanzania. AWER Procedia Advances in Applied Sciences 2013, 364-370.

Namboodiri, P.N. \& Sivadas, P. 1979. Zonation of molluscan assemblage at Kavaratti Atoll (Laccadives). Mahasagar-Bulletin of the National Institute of Oceanography 12, 239-246.

Neo, M.L. \& Todd, P.A. 2012a. Population density and genetic structure of the giant clams Tridacna crocea and T. squamosa on Singapore's reefs. Aquatic Biology 14, 265-275.

Neo, M.L. \& Todd, P.A. 2012b. Giant clams (Mollusca: Bivalvia: Tridacninae) in Singapore: history, research and conservation. Raffles Bulletin of Zoology 25, 67-78.

Neo, M.L. \& Todd, P.A. 2013. Conservation status reassessment of giant clams (Mollusca: Bivalvia: Tridacninae) in Singapore. Nature in Singapore 6, 125-133.

Newman, W. \& Gomez, E. 2007. The significance of the giant clam Tridacna squamosa at Tubuai, Austral Islands, French Polynesia. Coral Reefs 26, 909.

Nimoho, G., Seko, A., Iinuma, M., Nishiyama, K. \& Wakisaka, T. 2013. A baseline survey of coastal villages in Vanuatu. SPC Traditional Marine Resource Management and Knowledge Information Bulletin 32, 3-84.

Okada, H. 1997. Market survey of aquarium giant clams in Japan. South Pacific Aquaculture Development Project (Phase II). FAO Fisheries and Aquaculture Department Field Document No. 8. Rome: Food and Agriculture Organization of the United Nations. Online. http://www.fao.org/docrep/005/ac892e/ AC892E00.htm (accessed 19 December 2016).

Oliver, P.G., Holmes, A.M., Killeen, I.J., Light, J.M. \& Wood, H. 2004. Annotated checklist of the marine Bivalvia of Rodrigues. Journal of Natural History 38, 3229-3272.

Pan, H-Z. \& Lan, X. 1998. Molluscs from Xisha Islands. Acta Palaeontologica Sinica 37, 121-132.

Panggabean, L.M.G. 2007. Karakteristik Pertumbuhan Kima Pasir, Hippopus hippopus yang dibesarkan di Pulau Pari. Oseanologi dan Limnologi di Indonesia 33, 469-480.

Pasaribu, B.P. 1988. Status of giant clams in Indonesia. In Giant Clams in Asia and the Pacific, J.W. Copland \& J.S. Lucas (eds). Canberra: Australian Centre for International Agricultural Research, 44-46.

Paulay, G. 1987. Biology of Cook Islands' bivalves, Part I. Heterodont families. Atoll Bulletin Research No. 298. Washington, DC: The Smithsonian Institution. doi:10.5479/si.00775630.298.1

Paulay, G. 1989. Marine invertebrates of the Pitcairn Islands: Species composition and biogeography of corals, molluscs, and echinoderms. Atoll Research Bulletin No. 326. Washington, DC: The Smithsonian Institution. doi:10.5479/si.00775630.326.1

Paulay, G. 2003. Marine bivalvia (Mollusca) of Guam. Micronesia 35-36, 218-243. 
Pearson, R.G. \& Munro, J.L. 1991. Growth, mortality and recruitment rates of giant clams, Tridacna gigas and T. derasa, at Michaelmas Reef, central Great Barrier Reef, Australia. Australian Journal of Marine and Freshwater Research 42, 241-262.

Penny, S.S. \& Willan, R.C. 2014. Description of a new species of giant clam (Bivalvia: Tridacnidae) from Ningaloo Reef, Western Australia. Molluscan Research 34, 201-211.

PERSGA 2010. The Status of Coral Reefs in the Red Sea and Gulf of Aden: 2009. PERSGA Technical Series Number 16, Jeddah. Saudi Arabia: The Regional Organization for the Conservation of the Environment in the Red Sea and Gulf of Aden.

Pilcher, N. \& Alsuhaibany, A. 2000. 2. Regional status of coral reefs in the Red Sea and the Gulf of Aden. In Status of Coral Reefs of the World: 2000, C. Wilkinson (ed.). Townsville, Queensland: Australian Institute of Marine Sciences, 35-54.

Pilcher, N.J. \& Djama, N. 2000. Status of coral reefs in Djibouti-2000. PERSGA Technical Series Report, Jeddah, Saudi Arabia: The Regional Organization for the Conservation of the Environment in the Red Sea and Gulf of Aden.

Pinca, S. \& Beger, M. (eds) 2002. Coral reef biodiversity community-based assessment and conservation planning in the Marshall Islands: Baseline surveys, capacity building and natural protection and management of coral reefs of the atoll of Rongelap. Majuro, Marshall Islands: College of the Marshall Islands. Online. http://www.nras-conservation.org/nraslibrary/ReportRong2002full.pdf (accessed 12 April 2017).

Planes, S., Chauvet, C., Baldwin, J., Bonvallot, J., Fontaine-Vernaudon, Y., Gabrie, C., Holthus, P., Payri, C. \& Galzin, R. 1993. Impact of tourism-related fishing on Tridacna maxima (Mollusca, Bivalvia) stocks in Bora-Bora Lagoon (French Polynesia). Atoll Research Bulletin No. 385. Washington, DC: The Smithsonian Institution. doi:10.5479/si.00775630.385.1

Pollock, N.J. 1992. Giant clams in Wallis: Prospects for development. In Giant Clams in the Sustainable Development of the South Pacific: Socioeconomic Issues in Mariculture and Conservation, C. Tisdell (ed.). ACIAR Monograph No. 18, 65-79.

Price, C.M. \& Fagolimul, J.O. 1988. Reintroduction of giant clams to Yap State, Federated States of Micronesia. In Giant Clams in Asia and the Pacific, J.W. Copland \& J.S. Lucas (eds). Canberra: Australian Centre for International Agricultural Research, 41-43.

Pringgenies, D., Suprihatin, J. \& Lazo, L. 1995. Spatial and size distribution of giant clams in the Karumunjawa Islands, Indonesia. Phuket Marine Biological Center Special Publication 15, 133-135.

Purcell, S.W., Gossuin, H. \& Agudo, N.S. 2009. Status and management of the sea cucumber fishery of La Grande Terre, New Caledonia. Final report for ZoNéCo project, 2006-2008. Penang, Malaysia: WorldFish Center.

Qi, Z. (ed.) 2004. Seashells of China. Beijing: China Ocean Press.

Radtke, R. 1985. Population dynamics of the giant clam, Tridacna maxima, at Rose Atoll. Honolulu: Hawaii Institute of Marine Biology, University of Hawaii.

Ramadoss, K. 1983. Giant clam (Tridacna) resources. CMFRI Bulletin 34, 79-81.

Ramohia, P. 2006. Fisheries resources: Commercially important macroinvertebrates. In Solomon Islands Marine Assessment: Technical report of survey conducted May 13 to June 17, 2004, A. Green et al. (eds). TNC Pacific Island Countries Report No. 1/06. South Brisbane, Queensland: The Nature Conservancy, 330-400.

Rees, M., Colquhoun, J., Smith, L. \& Heyward, A. 2003. Surveys of Trochus, Holothuria, Giant Clams and the Coral Communities at Ashmore Reef, Cartier Reef and Mermaid Reef, Northwestern Australia: 2003. Unpublished report. Townsville, Queensland: Australian Institute of Marine Science.

Richard, G. 1977. Quantitative balance and production of Tridacna maxima in the Takapoto Lagoon (French Polynesia). Proceedings of the 3rd International Coral Reef Symposium, Rosenstiel School of Marine and Atmospheric Science, University of Miami, Miami, Florida, USA, May 1977, 599-605.

Richter, C., Roa-Quiaoit, H., Jantzen, C., Al-Zibdah, M. \& Kochzius, M. 2008. Collapse of a new living species of giant clam in the Red Sea. Current Biology 18, 1349-1354.

Roa-Quiaoit, H.A.F. 2005. The ecology and culture of giant clams (Tridacnidae) in the Jordanian sector of Gulf of Aqaba, Red Sea. PhD Dissertation, University of Bremen, Germany.

Rosewater, J. 1965. The family Tridacnidae in the Indo-Pacific. Indo-Pacific Mollusca 1, 347-396.

Rosewater, J. 1982. A new species of Hippopus (Bivalvia: Tridacnidae). The Nautilus 96, 3-6.

Sahari, A., Ilias, Z., Sulong, N. \& Ibrahim, K. 2002. Giant clam species and distribution at Pulau Layang Layang, Sabah. Marine Biodiversity of Pulau Layang Layang Malaysia, 25-28. 
Salvat, B. 2000. 11. Status of southeast and central Pacific coral reefs in 'Polynesia Mana Node': Cook Islands, French Polynesia, Kiribati, Niue, Tokelau, Wallis and Futuna. In Status of Coral Reefs of the World: 2000, C. Wilkinson (ed.). Townsville, Queensland: Australian Institute of Marine Sciences, 181-198.

Sandin, S.A., Smith, J.E., DeMartini, E.E., Dinsdale, E.A., Donner, S.D., Friedlander, A.M., Konotchick, T., Malay, M., Maragos, J.E., Obura, D., Pantos, O., Paulay, G., Richie, M., Rohwer, F., Schroeder, R.E., Walsh, S., Jackson, J.B.C., Knowlton, N. \& Sala, E. 2008. Baselines and degradation of coral reefs in Northern Line Islands. PLoS ONE 3, e1548. doi:10.1371./journal.pone.0001548

Sauni, S., Kronen, M., Pinca, S., Sauni, L., Friedman, K., Chapman, L. \& Magron, F. 2008. Tuvalu country report: Profiles and results from survey work at Funafuti, Nukufetau, Vaitupu and Niutao (OctoberNovember 2004 and March-April 2005). Noumea, New Caledonia: Pacific Regional Oceanic and Coastal Fisheries Development Programme.

Savage, J.M., Osborne, P.E. \& Hudson, M.D. 2013. Abundance and diversity of marine flora and fauna of protected and unprotected reefs of the Koh Rong Archipelago, Cambodia. Cambodian Journal of Natural History 2013, 83-94.

Schwartzmann, C., Durrieu, G., Sow, M., Ciret, P., Lazareth, C.E. \& Massabuau, J.-C. 2011. In situ giant clam growth rate behaviour in relation to temperature: a one-year coupled study of high-frequency noninvasive valvometry and sclerochronology. Limnology and Oceanography 56, 1940-1951.

Seeto, J., Nunn, P.D. \& Sanjana, S. 2012. Human-mediated prehistoric marine extinction in the tropical Pacific? Understanding the presence of Hippopus hippopus (Linn. 1758) in ancient shell middens on the Rove Peninsula, Southwest Viti Levu Island, Fiji. Geoarchaeology, An International Journal 27, 2-17.

Selin, N.I. \& Latypov, Y.Y. 2011. The size and age structure of Tridacna crocea Lamarck, 1819 (Bivalvia: Tridacnidae) in the coastal area of islands of the Cön Dao Archipelago in the South China Sea. Russian Journal of Marine Biology 37, 376-383.

Selin, N.I., Latypov, Y.Y., Malyutin, A.N. \& Bolshakova, L.N. 1992. Chapter 4: Species composition and abundance of corals and other invertebrates on the reefs of the Seychelles Islands. Atoll Research Bulletin No. 368. Washington, DC: The Smithsonian Institution. doi:10.5479/si.00775630.368.1

Sheppard, A.L.S. 1984. The molluscan fauna of Chagos (Indian Ocean) and an analysis of its broad distribution patterns. Coral Reefs 3, 43-50.

Siaosi, F., Sapatu, M., Lalavanua, W., Pakoa, K., Yeeting, B., Magron, F., Moore, B., Bertram, I. \& Chapman, L. 2012. Climate Change Baseline Assessment: Funafuti Atoll, Tuvalu July-August 2011. Noumea, New Caledonia: Coastal Fisheries Science and Management Section, Secretariat of the Pacific Community. Online. http://www.spc.int/DigitalLibrary/Doc/FAME/Reports/Siaosi_12_Tuvalu_Climate_Change_ Baseline_Monitoring_Report.pdf (accessed 15 March 2017).

Sims, N.A. \& Howard NT-A-K. 1988. Indigeneous tridacnid clam populations and the introduction of Tridacna derasa in the Cook Islands. In Giant Clams in Asia and the Pacific, J.W. Copland \& J.S. Lucas (eds). Canberra: Australian Centre for International Agricultural Research, 34-40.

Sirenko, B.I. \& Scarlato, O.A. 1991. Tridacna rosewateri sp. n. A new species of giant clam from Indian Ocean. La Conchiglia 22, 4-9.

Smith, A.J. 1992. Federated States of Micronesia Marine Resources Profiles. FFA Report 92/17. Honiara, Solomon Islands: Pacific Islands Forum Fisheries Agency. Online. www.spc.int/DigitalLibrary/Doc/ FAME/FFA/Reports/FFA_1992_017.pdf (accessed 13 April 2017).

Smith, S.D.A. 2011. Growth and population dynamics of the giant clam Tridacna maxima (Röding) at its southern limit of distribution in coastal, subtropical eastern Australia. Molluscan Research 31, 37-41.

Sommer, C., Schneider, W. \& Poutiers, J.M. 1996. FAO Species Identification Field Guide for Fishery Purposes. The Living Marine Resources of Somalia. Rome: Food and Agriculture Organization.

Sone, S. \& Loto'ahea, T. 1995. Ocean culture of giant clam in Tonga. Joint FFA/SPC workshop on the management of South Pacific Inshore Fisheries, Noumea, New Caledonia, 26 June-7 July 1995. SPC/Inshore Fish Mgmt/BP8. Noumea, New Caledonia: South Pacific Commission.

South, R. \& Skelton, P. 2000. 10. Status of coral reefs in the Southwest Pacific: Fiji, Nauru, New Caledonia, Samoa, Solomon Islands, Tuvalu and Vanuatu. In Status of Coral Reefs of the World: 2000, C. Wilkinson (ed.). Townsville, Queensland: Australian Institute of Marine Sciences, 159-180.

Stojkovich, J.O. 1977. Survey and species inventory of representative pristine marine communities of Guam. University of Guam Marine Laboratory, Technical Report No. 40, October 1977. Mangilao, Guam: University of Guam. 
Strotz, L.C., Mamo, B.L., Topper, T.P. \& Bagnato, C. 2010. The highest southern latitude record of a living Tridacna gigas. Malacologia 53, 155-159.

Su, Y., Hung, J.-H., Kubo, H. \& Liu, L.-L. 2014. Tridacna noae (Röding, 1798) - a valid giant clam species separated from T. maxima (Röding, 1798) by morphological and genetic data. Raffles Bulletin of Zoology 62, 124-135.

Tabugo, S.R.M., Pattuinan, J.O., Sespene, N.J.J. \& Jamasali, A.J. 2013. Some economically important bivalves and gastropods found in the Island of Hadji Panglima Tahil, in the province of Sulu, Philippines. International Research Journal of Biological Sciences 2, 30-36.

Tacconi, L. \& Tisdell, C. 1992. Domestic markets and demand for giant clam meat in the South Pacific Islands: Fiji, Tonga and Western Samoa. In Giant Clams in the Sustainable Development of the South Pacific: Socioeconomic Issues in Mariculture and Conservation, C. Tisdell (ed.). ACIAR Monograph No. 18. Canberra: Australian Centre for International Agricultural Research, 205-222.

Tadashi, K., Dai, C.F., Park, H-S., Huang, H. \& Ang, P.O. 2008. 10. Status of coral reefs in East and North Asia (China, Hong Kong, Taiwan, South Korea and Japan). In Status of Coral Reefs of the World: 2008, C. Wilkinson (ed.). Townsville, Australia: Global Coral Reef Monitoring Network and Reef and Rainforest Research Centre, 145-158.

Tan, S.H. \& Zulfigar, Y. 2001. Factors affecting the dispersal Tridacna squamosa larvae and gamete material in the Tioman Archipelago, The South China Sea. Phuket Marine Biological Center Special Publication 25, 349-356.

Tan, S.-H. \& Zulfigar, Y. 2003. Status of giant clam in Malaysia. SPC Trochus Information Bulletin 10, 9-10.

Tan, K.S. \& Kastoro, W.W. 2004. A small collection of gastropods and bivalves from the Anambas and Natuna Islands, South China Sea. Raffles Bulletin of Zoology 11, 47-54.

Tan, S.H., Yasin, Z.B., Salleh, I.B. \& Yusof, A.A. 1998. Status of giant clams in Pulau Tioman, Malaysia. Malayan Nature Journal 52, 205-216.

Tan, S.-K. \& Low, M.E.Y. 2014. Checklist of the Mollusca of Cocos (Keeling)/Christmas Island ecoregion. Raffles Bulletin of Zoology 30, 313-375.

Tang, Y.C. 2005. The systematic status of Tridacna maxima (Bivalvia: Tridacnidae) based on morphological and molecular evidence. MSc Dissertation, National Taiwan Ocean University, Taiwan.

Taniera, T. 1988. Status of giant clams in Kiribati. In Giant Clams in Asia and the Pacific, J.W. Copland \& J.S. Lucas (eds). Canberra: Australian Centre for International Agricultural Research, 47-48.

Taylor, J.D. \& Reid, D.G. 1984. The abundance and trophic classification of molluscs upon coral reefs in the Sudanese Red Sea. Journal of Natural History 18, 175-209.

Taylor, J.D. 1968. Coral reef and associated invertebrate communities (mainly molluscan) around Mahé, Seychelles. Philosophical Transactions of the Royal Society of London, Series B, Biological Sciences 254, 129-206.

Thaman, R.R., Puia, T., Tongabaea, W., Namona, A. \& Fong, T. 2011. Marine biodiversity and ethnobiodiversity of Bellona (Mungiki) Island, Solomon Islands. Singapore Journal of Tropical Geography 31, 70-84.

Thomas, F.R. 2001. Mollusk habitats and fisheries in Kiribati: an assessment from the Gilbert Islands. Pacific Science 55, 77-97.

Thomas, F.R. 2014. Shellfish gathering and conservation on low coral islands: Kiribati perspecitives. The Journal of Island and Coastal Archaeology 9, 203-218.

Thorne, B.V., Mulligan, B., Mag Aoidh, R. \& Longhurst, K. 2015. Current status of coral reef health around the Koh Rong Archipelago, Cambodia. Cambodian Journal of Natural History 2015, 98-113.

Tiavouane, J. \& Fauvelot, C. 2016. First record of the Devil Clam, Tridacna mbalavuana Ladd 1934, in New Caledonia. Marine Biodiversity, doi:10.1007/s12526-016-0506-1

Tiitii, U., Roebeck, U. \& Gomez, R.G. 2014. Samoa aquaculture section team fully involved in giant clam farming. Fisheries Newsletter 145, 29.

Tisdell, C. \& Wittenberg, R. 1992. The market for giant clam meat in New Zealand: results of interviews with Pacific Island immigrants. In Giant Clams in the Sustainable Development of the South Pacific: Socioeconomic Issues in Mariculture and Conservation, C. Tisdell (ed.). ACIAR Monograph No. 18. Canberra: Australian Centre for International Agricultural Research, 258-274.

Tomlin, J.R. 1934. The marine mollusca of Christmas Island, Indian Ocean. Bulletin of Raffles Museum $\mathbf{9}$, 74-84. 
Tu'avao, T., Loto'ahea, T., Udagawa, K. \& Sone, S. 1995. Results of the field surveys on giant clam stock in the Tongatapu Island Group. Fisheries Research Bulletin of Tonga 3, 1-10.

Ullmann, J. 2013. Population status of giant clams (Mollusca: Tridacnidae) in the northern Red Sea, Egypt. Zoology in the Middle East 59, 253-260.

Van Long, N., Hoang, P.K., Ben, H.X. \& Stockwell, B. 2008. Status of the marine biodiversity in the Northern Spratly Islands, South China Sea. In Proceedings of the Conference on the Results of the PhilippinesVietnam Joint Oceanographic and Marine Scientific Research Expedition in the South China Sea (JOMSRE-SCS I to IV), 26-29 March 2008, Ha Long City, Vietnam, A.C. Alcala (ed.). Pasay City, Republic of the Philippines: Technical Cooperation Council of the Philippines of the Department of Foreign Affairs, 11-19.

Van Wynsberge, S., Andréfouët, S., Gilbert, A., Stein, A. \& Remoissenet, G. 2013. Best management strategies for sustainable giant clam fishery in French Polynesia Islands: answers from a spatial modelling approach. PLoS ONE 8, e64641. doi:10.1371/journal.pone.0064641

Vieux, C. 2009. Assessment of targeted invertebrate species of the northwestern lagoon of Grande-Terre (Poum to Koumac). In A Rapid Marine Biodiversity Assessment of the Coral Reefs of the Northwest Lagoon, between Yandé and Koumac, Province Nord, New Caledonia, S.A. McKenna \& J. Spaggiari (eds). RAP Bulletin of Biological Assessment 53. Arlington, Virginia: Conservation International, 41-46.

Vieux, C., Aubanel, A., Axford, J., Chancerelle, Y., Fisk, D., Holland, P., Juncker, M., Kirata, T., Kronen, M., Osenberg, C., Pasisi, B., Power, M., Salvat, B., Shima, J. \& Vavia, V. 2004. 13. A century of change in coral reef status in southeast and central Pacific: Polynesia Mana Node, Cook Islands, French Polynesia, Kiribati, Niue, Tokelau, Tonga, Wallis and Futuna. In Status of Coral Reefs of the World: 2004, Volume 2, C. Wilkinson (ed.). Townsville, Queensland: Australian Government and Australian Institute of Marine Sciences, 363-380.

Villanoy, C.L., Juinio, A.R. \& Meñez, L.A. 1988. Fishing mortality rates of giant clams (family Tridacnidae) from the Sulu Archipelago and Southern Palawan, Philippines. Coral Reefs 7, 1-5.

Virly, S. 2004. Etude préliminaire relative à la ressource en bénitier en Province Nord: Statut écologique et halieutique. Koohne, New Caledonia: Service de l'Environnement de la Province Nord.

Vuki, V., Tisdell, C. \& Tacconi, L. 1992. Giant clams, socioeconomics and village life in the Lau group, Fiji: prospects for farming Tridacnids. In Giant Clams in the Sustainable Development of the South Pacific: Socioeconomic Issues in Mariculture and Conservation, C. Tisdell (ed.). ACIAR Monograph No. 18. Canberra: Australian Centre for International Agricultural Research, 17-37.

Wantiez, L., Bouilleret, F., Clément, G. \& Virly, S. 2007a. Communautés biologiques et habitat corallien de la Corne Sud. Etat initial. Unpublished report. Noumea, New Caledonia: Province Sud de la NouvelleCalédonie, Université de la Nouvelle-Calédonie. doi:10.13140/RG.2.1.1871.9768

Wantiez, L., Bouilleret, F., Clément, G. \& Virly, S. 2007b. Communautés biologiques et habitats coralliens de l'île des Pins. Etat initial. Unpublished report. Noumea, New Caledonia: Province Sud de la NouvelleCalédonie, Université de la Nouvelle-Calédonie. doi:10.13140/RG.2.1.3444.8400

Wantiez, L., Bouilleret, F., Clément, G. \& Virly, S. 2007c. Communautés biologiques et habitats coralliens de Bourail. Etat inital. Unpublished report. Noumea, New Caledonia: Province Sud de la NouvelleCalédonie, Université de la Nouvelle-Calédonie. doi:10.13140/RG.2.1.2920.5522

Wantiez, L., Bouilleret, F., le Mouellic, S. \& Virly, S. 2008a. Communautés biologiques et habitats coralliens du Grand Lagon Nord. Etat initial. Unpublished report. Noumea, New Caledonia: Province Nord de la Nouvelle-Calédonie, Aquarium des Lagons. doi:10.13140/RG.2.1.3313.7686

Wantiez, L., Sarramégna, S. \& Virly, S. 2008b. Communautés biologiques et habitats coralliens de la réserve intégrale Merlet. Etat inital. Unpublished report. Noumea, New Caledonia: Province Sud de la NouvelleCalédonie, Aquarium des lagons. doi:10.13140/RG.2.1.4362.3441

Wells, F.E. \& Kinch, J.P. 2003. Chapter 3 Molluscs of Milne Bay Province, Papua New Guinea. In A Rapid Marine Biodiversity Assessment of Milne Bay Province, Papua New Guinea - Survey II (2000), G.R. Allen et al. (eds). RAP Bulletin of Biological Assessment 29. Washington, DC: Conservation International, 39-45.

Wells, F.E. \& Slack-Smith, S.M. 2000. Molluscs of Christmas Island. In Survey of the Marine Fauna of the Montebello Islands, Western Australia and Christmas Island, Indian Ocean, P.F. Berry \& F.E. Wells (eds). Records of the Western Australian Museum Supplement No. 59, 103-115. Online. http://museum. wa.gov.au/research/records-supplements/records/molluscs-christmas-island (accessed 13 April 2017). 
Wells, F.E. 1994. Chapter 12 Marine molluscs of the Cocos (Keeling) Islands. Atoll Research Bulletin No. 410. Washington, DC: The Smithsonian Institution. doi:10.5479/si.00775630.410.1

Wells, F.E. 2001. Chapter 3 Molluscs of the Gulf of Tomini, Sulawesi, Indonesia. In A Marine Rapid Assessment of the Togean and Banggai Islands, Sulawesi, Indonesia, G.R. Allen \& S.A. McKenna (eds). RAP Bulletin of Biological Assessment 20. Washington, DC: Conservation International, 38-43.

Wells, F.E. 2002. Chapter 2 Molluscs of Rajah Ampat Islands, Papua Province, Indonesia. In A Marine Rapid Assessment of the Rajah Ampat Islands, Papua Province, Indonesia, S.A. McKenna et al. (eds). RAP Bulletin of Biological Assessment 22. Washington, DC: Conservation International, 37-45.

Wells, S.M., Pyle, R.M. \& Collins, N.M. 1983. The IUCN Invertebrate Red Data Book. Gland, Switzerland: International Union for Conservation of Nature.

Williams, G.J., Smith, J.E., Conklin, E.J., Gove, J.M., Sala, E. \& Sandin, S.A. 2013. Benthic communities at two remote Pacific coral reefs: effects of reef habitat, depth, and wave energy gradients on spatial patterns. PeerJ 1, e81. doi:10.7717/peerj.81

Wu, W.-L. 1999. The list of Taiwan bivalve fauna. Quarterly Journal of the Taiwan Musuem 33, 55-208.

Yusuf, C., Ambariyanto \& Hartati, R. 2009. Abundance of Tridacna (family Tridacnidae) at Seribu Islands and Manado waters, Indonesia. Ilmu Kelautan 14, 150-154.

Zann, L.P. \& Ayling, A.M. 1988. Status of giant clams in Vanuatu. In Giant Clams in Asia and the Pacific, J.W. Copland \& J.S. Lucas (eds). Canberra: Australian Centre for International Agricultural Research, 60-63.

Zann, L.P. 1989. A preliminary check list of the major species of fishes and other marine organisms in Western Samoa. FAO/UNDP SAM/89/002 Field Report No. 1.

Zann, L.P. 1991. The inshore resources of Upolu, Western Samoa: Coastal inventory and fisheries database. FAO/UNDP SAM/89/002 Field Report No. 5.

Zhuang, Q. 1978. The Tridacnids of the Xisha Islands, Guangdong Province, China. Studia Marina Sinica 12, 133-139.

Zulfigar, Y. \& Tan, A.S.-H. 2000. Quantitative and qualitative effects of light on the distribution of giant clams at the Johore Islands in South China Sea. Phuket Marine Biological Center Special Publication 21, 113-118.

Zuschin, M. \& Piller, W.E. 1997. Bivalve distribution on coral carpets in the Northern Bay of Safaga (Red Sea, Egypt) and its relation to environmental parameters. Facies 37, 183-194.

Zuschin, M. \& Stachowitsch, M. 2007. The distribution of molluscan assemblages and their postmortem fate on coral reefs in the Gulf of Aqaba (northern Red Sea). Marine Biology 151, 2217-2230. 


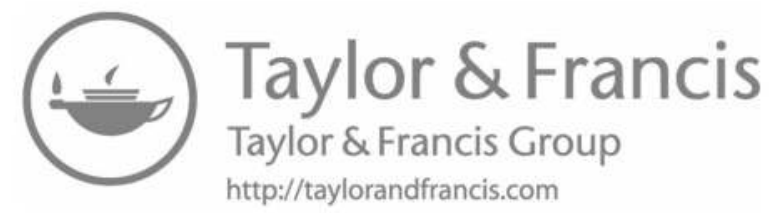


Oceanography and Marine Biology: An Annual Review, 2017, 55, 389-420

(C) S. J. Hawkins, D. J. Hughes, I. P. Smith, A. C. Dale, L. B. Firth, and A. J. Evans, Editors

Taylor \& Francis

\title{
HOW ANTHROPOGENIC ACTIVITIES AFFECT THE ESTABLISHMENT AND SPREAD OF NON-INDIGENOUS SPECIES POST-ARRIVAL
}

\author{
EMMA L. JOHNSTON ${ }^{1,2 *}$, KATHERINE A. DAFFORN ${ }^{1,2}$, \\ GRAEME F. CLARK ${ }^{1}$, MARC RIUS ${ }^{3,4} \&$ OLIVER FLOERL ${ }^{5}$ \\ ${ }^{1}$ Evolution \& Ecology Research Centre, School of Biological, Earth and Environmental \\ Sciences, University of New South Wales, Sydney, New South Wales 2052, Australia \\ ${ }^{2}$ Sydney Institute of Marine Science, Mosman, New South Wales 2088, Australia \\ ${ }^{3}$ Ocean and Earth Science, University of Southampton, National Oceanography \\ Centre, European Way, Southampton, SO14 3ZH, United Kingdom \\ ${ }^{4}$ Department of Zoology, University of Johannesburg, \\ Auckland Park, 2006, Johannesburg, South Africa \\ ${ }^{5}$ Cawthron Institute, Nelson 7010, New Zealand \\ *Corresponding author: Emma L. Johnston \\ e-mail: e.johnston@unsw.edu.au, tel: +61 293851825
}

When humans transport a species to a location outside its native range, multiple biotic and abiotic factors influence its post-arrival establishment and spread. Abiotic factors such as disturbance and environmental conditions determine the suitability of the new environment for an invader, as well as influence resource availability and ecological succession. Biotic processes such as competition, facilitation, predation and disease can either limit or promote invasion, as can emergent communitylevel traits such as species diversity. Synergies arise when the abiotic and biotic factors controlling invasion success are themselves influenced by anthropogenic activities, such as those associated with coastal urbanization and industrialization. Here we present a review of the major anthropogenic activities that affect the success of non-indigenous species (NIS) post-arrival. We prioritize the factors in terms of their ecological and evolutionary importance, and present potential management actions to reduce NIS success post-arrival. Evidence-based management has the potential to mitigate anthropogenic activities that enhance invasion success. High priority management actions include: 1) the removal, or containment, of legacy contaminants and reduction of new inputs to reduce the competitive advantage that some invaders have in contaminated environments, 2) the redesign of artificial structures to reduce colonization by NIS through eco-engineering, selection of construction materials and the 'seeding' of structures with native species to provide a priority advantage, 3) the management of dominant regional transport pathways to ensure that the risk of transporting NIS via our increasingly complex transport networks is minimized and 4) the protection and maintenance of biotic resilience in the form of intact living habitats and endemic diversity. Further research is required to advance our understanding of the role of anthropogenic activities in driving post-arrival success of NIS. Such work is vital for developing responsive and mechanistic management plans and ultimately for reducing the impacts of marine invasive species. 


\section{Introduction}

The invasion of natural ecosystems by non-indigenous species (NIS) is one of the greatest threats to native biodiversity (Wilcove et al. 1998, Butchart et al. 2010). Although only a small proportion of NIS artificially transported to new regions establish, spread and cause impacts (Williamson et al. 1986, Suarez et al. 2005, Blackburn et al. 2011), successful invasions have had a wide range of effects on native biota. The post-arrival establishment of NIS is strongly influenced by a number of biotic and abiotic factors (Theoharides \& Dukes 2007, Forrest et al. 2009). For example, ecological interactions such as competition, facilitation, predation or disease and environmental factors such as temperature and salinity may produce synergies that allow ecological dominance of NIS (Castilla et al. 2004). Species traits, such as predatory avoidance or growth rate, can sometimes be linked to the success of NIS over natives (Van Kleunen et al. 2010, McKnight et al. 2016). Abiotic influences such as disturbance can regulate resource availability, which may in turn affect invasibility (Davis et al. 2000, Airoldi \& Bulleri 2011). Therefore, understanding biotic and abiotic factors that govern the survival and success of NIS and their populations post-arrival is key. In addition, it is important to have a good understanding of major anthropogenic factors that interact with these factors and ultimately shape the success of NIS post-arrival. In particular, anthropogenic factors associated with urbanization and industrialization are key for improving our understanding of postarrival NIS success (Figure 1). Anthropogenic activities on land and in the ocean change physicochemical parameters of marine habitats, such as water and sediment quality, directly influencing NIS. However, many NIS have wide tolerances to environmental conditions (Dukes \& Mooney 1999, Sorte et al. 2010, Zerebecki \& Sorte 2011, Rius et al. 2014b) and to highly toxic chemicals

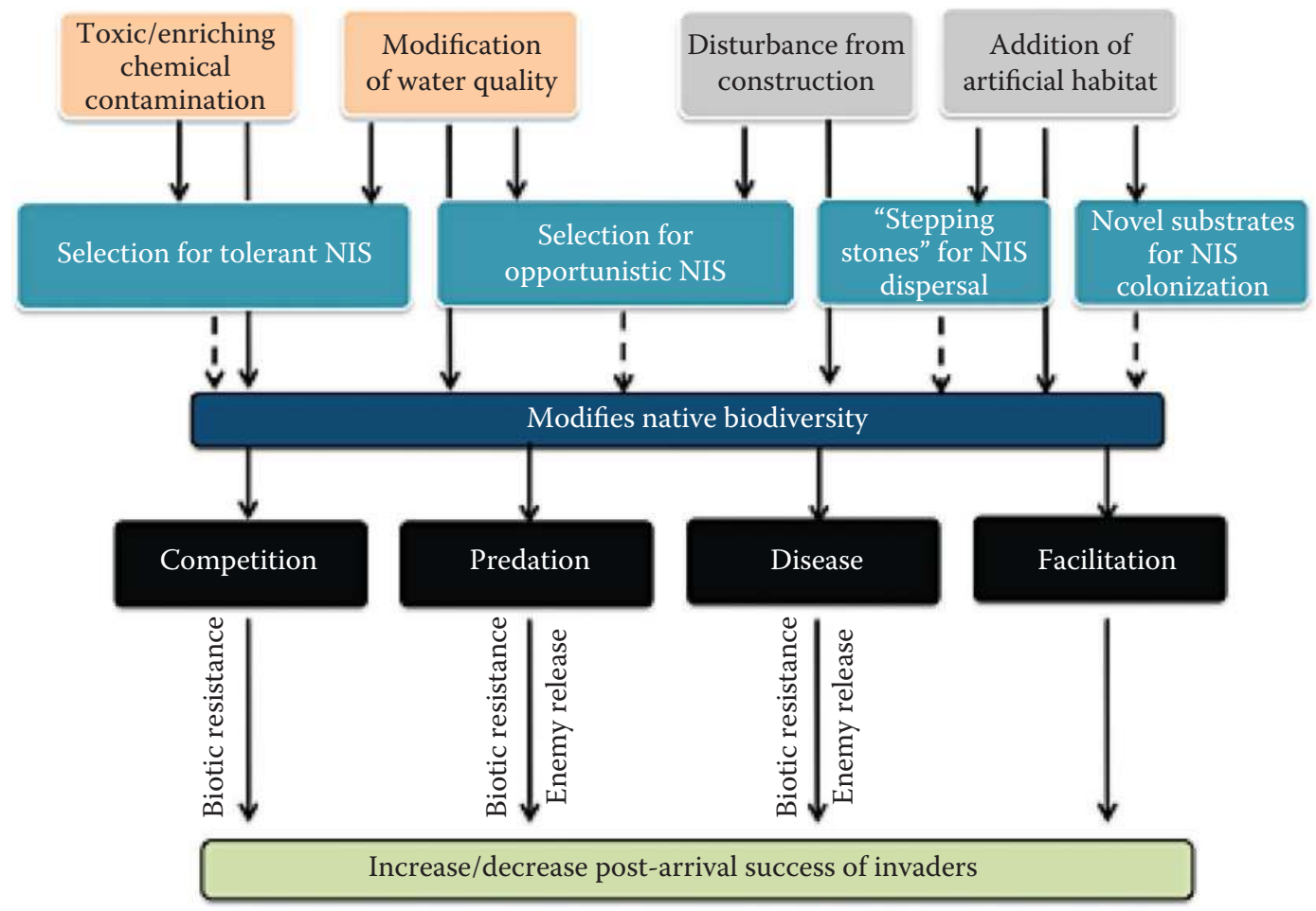

Figure 1 Chemical (orange) and physical (grey) disturbances from human activities that influence the postarrival success of invaders. Effects of disturbance on NIS can be direct (dark green) or indirect (blue), and can affect associated biotic processes (black). Direct interactions are illustrated by an unbroken line; indirect interactions are illustrated by a broken line. 
such as copper biocides (Prentis et al. 2008, Piola et al. 2009). Hence, anthropogenic activities that promote extreme environmental conditions might provide a post-arrival advantage for NIS.

The global increase in anthropogenic activities has resulted in previously-undisturbed marine and estuarine environments being transformed into habitats with artificial features such as pontoons, jetties, breakwaters, boating marinas and commercial ports (Dugan et al. 2011). The physical characteristics of artificial structures tend to differ markedly from that of natural systems (Airoldi et al. 2005, 2009, Airoldi \& Beck 2007), creating environmental novelty and newly available artificial habitat (Glasby \& Connell 1999). Urban sprawl into our waterways and the construction of vessel infrastructure also results in hydrological modifications that reduce flow and increase silt, nutrient and contaminant retention (Johnston et al. 2011, Rivero et al. 2013).

Human-assisted regional translocation of species can increase connectivity, overcoming barriers to natural dispersal and facilitating the post-establishment spread of NIS, with patterns and rates of spread being very different from those achieved via natural dispersal (Buchan \& Padilla 1999, Ruiz \& Carlton 2003). Intraregional transport increases propagule pressure of NIS (Zabin et al. 2014). Such transport patterns are likely to increase the frequency of propagule arrival, which is correlated with NIS success in both theoretical (Leung et al. 2004) and experimental studies (Clark \& Johnston 2009, Hedge et al. 2012).

Vectors that initially transport a species beyond its native range have been the focus of NIS science and management for decades (Carlton 1985, Ruiz et al. 1997, Hewitt \& Campbell 2008, Davidson et al. 2010). After a marine non-indigenous species has arrived, less attention and resources are allocated to its management as removal or control is automatically deemed too expensive or logistically impossible. If we pay more attention to the factors affecting NIS success postarrival in a new region we can identify the biotic and abiotic conditions that will be important for the likelihood of a species' establishment and spread. For example, more information is needed to understand how human activities influence species traits that promote biological invasions. Such factors may be more amenable to management and more effective than attempts at direct eradication via physical removal or chemical/biological control.

In this paper, we explore the anthropogenic factors that influence the successful establishment and spread of introduced species in the marine environment, post-arrival (Figure 1). We first provide an overview of the major anthropogenic influences to marine environments and describe how they may affect NIS. We separate these factors into four major categories of change: chemical and physical changes to environments, changes to connectivity and changes to the biological aspects of recipient environments. Finally, we highlight areas in which there is potential for effective management of NIS post-arrival.

\section{Chemical alteration of recipient environments}

\section{Contamination and changes to water quality}

The intense and extensive development by humans across the planet has subjected much of the world's biological diversity to frequent chemical changes, which are often concentrated in urban and industrial areas (Grimm et al. 2008). Human activity is reliant on access to freshwater and trade such that it becomes concentrated around waterways. These activities inevitably release contaminants into water bodies and result in other modifications to physico-chemical conditions. As a consequence, estuaries in particular have been highly impacted by chemical change related to agriculture, industrialization and urbanization, with almost all estuaries suffering some degree of impact (Lotze et al. 2006). An example is fertilizer runoff into waterways; fertilizer use is already responsible for the eutrophication and formation of 'deadzones' in many of the world's coastal waterways (Rabalais et al. 2010); global nitrogen and phosphorous effluent is predicted to increase between 150-180\% between the years 2000-2150 (Marchal et al. 2011, Alexandratos \& 


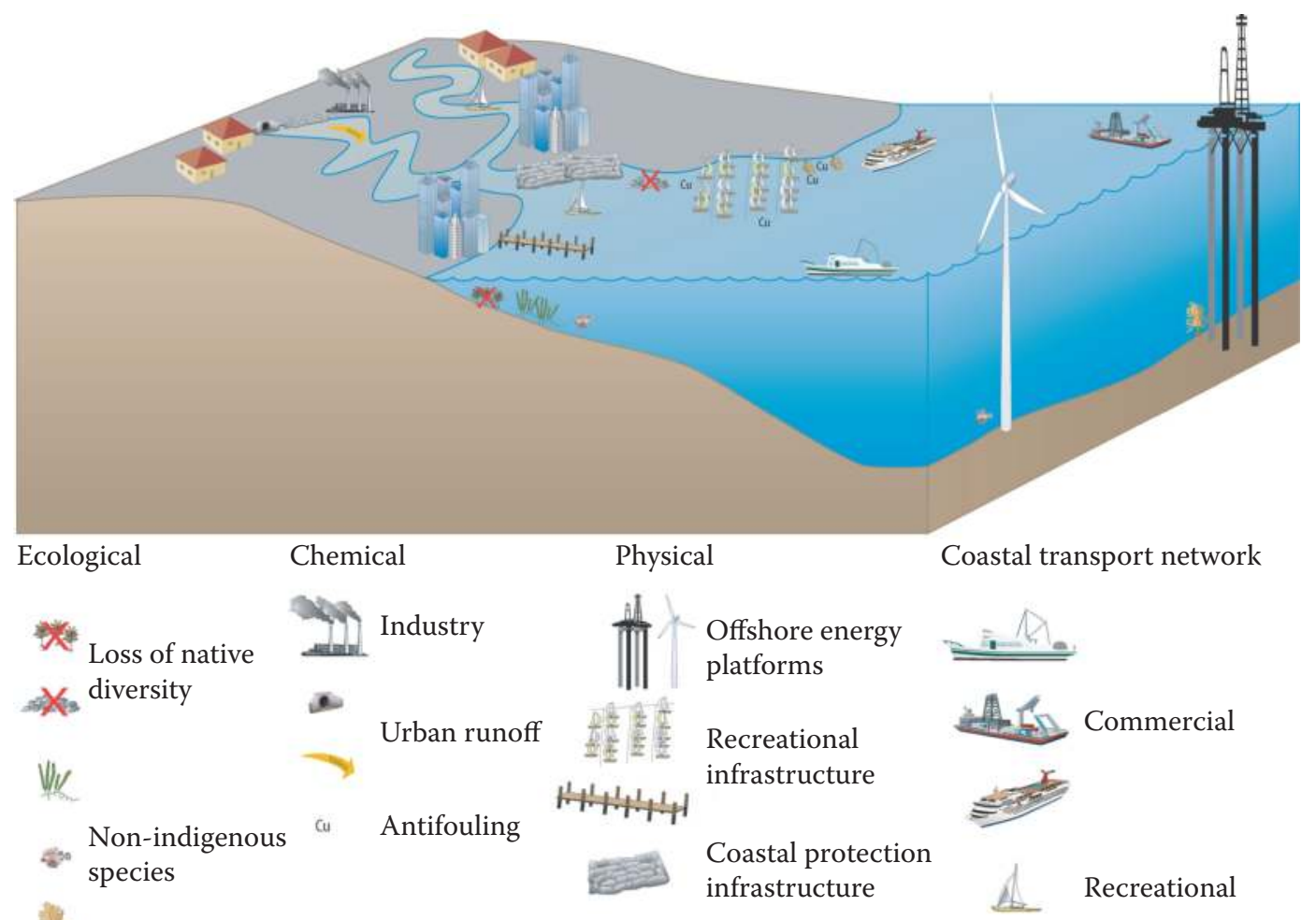

Figure 2 Anthropogenic factors influencing the establishment and spread of NIS include chemical and physical alterations of habitat, which interact with ecological traits and processes, as well as coastal transport networks. The introduction of chemicals from industrial and urban runoff and vessel antifouling paint may facilitate metal-tolerant NIS and reduce native biodiversity. Increasing coastal development adds novel habitat such as recreational infrastructure (e.g. marinas and jetties) and coastal protection infrastructure (e.g. sea walls) for colonization by NIS, and creates stepping-stones for their spread. These structures are linked by busy coastal transport networks, such as commercial and recreational vessel movements or aquaculture operations, which can act as vectors for NIS for inter- and intraregional spread.

Bruinsma 2012). Important chemical stressors include toxic contaminants (e.g. metals) (Birch 2000, Rodríguez-Obeso et al. 2007, Burton \& Johnston 2010) and enriching contaminants (e.g. nutrients) (Statham 2012) (Figure 2).

Chemical stressors that are released into waterways impact the ecological composition and function of important habitats (Johnston \& Roberts 2009, Burton \& Johnston 2010). Metals are known to have toxic effects on aquatic taxa, including increased mortality (Trannum et al. 2004, MartínezLladó et al. 2007), reduced reproductive potential (Alquezar et al. 2006, Simpson \& Spadaro 2011) and other sublethal effects (Fleeger et al. 2003). Nutrients such as dissolved nitrogen and phosphorus can also have community-wide effects, with high levels resulting in a community composed of very high densities of a few tolerant opportunistic species (Pearson \& Rosenberg 1978). However, in contrast to toxic contaminants, such nutrients initially have an enriching effect, increasing the richness and abundance of primary producers with consequences at higher trophic levels (Tewfik et al. 2005, Smith et al. 2006, Elser et al. 2007, McKinley \& Johnston 2010, Clark et al. 2015).

Environmental suitability is now acknowledged as a strong predictor of invasion success, and consideration of the role of chemical parameters has generally emphasized natural environmental variables such as dissolved oxygen (DO), $\mathrm{pH}$, salinity and temperature (Williamson et al. 1986, Blackburn \& Duncan 2001). There has been less consideration of how anthropogenic modifications 
to environmental conditions may influence the establishment and spread of NIS. Locations where NIS are often introduced are low flow, high retention sites (naturally or by construction) (Floerl \& Inglis 2003, Rivero et al. 2013) and therefore also locations of high contaminant retention (Dafforn et al. 2008, Johnston et al. 2011). Where the transport process for NIS is environmentally stressful (e.g. copper-coated vessel hull), it is likely that selection for environmentally tolerant (particularly to copper) NIS will take place (McKenzie et al 2012). This will lead to greater success of NIS in anthropogenically-modified habitats.

\section{Toxic and enriching contaminants aid post-arrival success of NIS}

The addition of toxic contaminants is perhaps the least intuitive reason for increasing NIS success, but is the area in which we have the strongest experimental and mensurative data to support the hypothesis. The mechanism is relatively simple and relies on selection for toxicant tolerance in NIS (Piola \& Johnston 2009, McKenzie et al. 2012). Elevated concentrations of metals, for example, are highly toxic to many marine organisms (Hall et al. 1998), but some organisms have evolved effective detoxification and avoidance mechanisms and are considered to be superior in their ability to withstand exposures to these toxicants (Johnston 2011).

The majority of marine NIS are transported in ballast water or as hull-fouling organisms (Ruiz et al. 1997, 2000, Hewitt 2002, Godwin 2003, Clarke Murray et al. 2011) and both of these transport mechanisms are highly contaminated with metals (Alzieu et al. 1986, Claisse \& Alzieu 1993, Schiff et al. 2004, Warnken et al. 2004, Piola et al. 2009, Dafforn et al. 2011). Hulls are contaminated because they are often coated in toxic antifouling paints containing metal-based biocides, and ballast water tanks are sometimes antifouled and often corroding internally (Tamburri et al. 2005). The transport process may therefore select for metal tolerance, and the major contaminants in ports and harbours are metals (Piola et al. 2009). Metal tolerance has now been observed in a wide range of marine organisms including polychaetes, bryozoans, algae, amphipods and barnacles (reviewed by Johnston 2011, Pineda et al. 2012). Hence, shipping selects for metal-tolerant species, then delivers them to metal-contaminated locations (Piola \& Johnston 2008a). This gives NIS arrivals a competitive advantage over local native species that may not have developed tolerance. However, it should be noted that native species can also adapt or become tolerant and there is potential for toxicant tolerance to be a useful risk-identifier for predicting future NIS (Dafforn et al. 2009a). Some studies have observed that assemblages switch from native-dominated to NIS-dominated when exposed to a small strip of antifouling paint (Piola \& Johnston 2008a) - an effect as relevant in small marinas as it is in large working ports (Dafforn et al. 2009a). Interestingly, large-scale surveys of selected NIS are now finding that these species possess higher tolerance to metals in more polluted environments than in pristine habitats (Clark et al., unpublished data), and it would appear that NIS have the ability to lose tolerance (which can be costly to fitness) when spreading from contaminated to clean systems (Piola \& Johnston 2006).

The addition of nutrients to a system is an example of the addition of resources, and is therefore more readily understood as a mechanism for increasing the success of NIS (Davis et al. 2000). Many high-impact NIS are 'weedy' (reviewed by Sutherland 2004) with an 'r-type' life-history strategy (Ruiz \& Hewitt 2002, Hänfling et al. 2011) so they are therefore capable of dominating in high-resource environments. This has been demonstrated for land-based weeds (Grime 1977, Dukes 2001) - more research is required for marine species, but disturbance that renews resources is certainly a facilitator (Clark \& Johnston 2009, 2011, Airoldi \& Bulleri 2011). Humans elevate nutrients in nearshore areas via run-off from agricultural and urbanized areas and through the release of sewage (Figure 2). Nutrients may be limiting in marine systems and hence anthropogenically-modified waterways may be more productive than natural systems (Nixon et al. 1986, 2001). Productivity increases may result from large changes in community composition (Duarte 1995). Productivity increases will occur up until thresholds are exceeded and excessive eutrophication 
takes place, reducing water quality and causing oxygen depletion as has happened in much of the Baltic Sea (Carstensen et al. 2014). Thresholds and tipping points will differ for each habitat and each NIS and are therefore difficult to predict without extensive monitoring. Up until such tipping points are reached, the system is increasingly susceptible to fast-growing weedy species that are able to rapidly take advantage of excess primary and secondary food sources (Clark et al. 2015). Non-indigenous species are often considered 'weedy' species and examples of this are the fastgrowing invasive Caulerpa macroalgal species (Williams \& Smith 2007) and harmful microalgae, which have a tendency to bloom in high-nutrient conditions (Hallegraeff \& Gollasch 2006).

\section{Changes in water quality and hydrological regimes}

Due to a paucity of empirical studies, it is difficult to generalize the response of NIS to anthropogenic modifications of water quality per se. Where our activities push these parameters beyond natural realms of variability, we might expect that modifications will benefit species with wide environmental tolerances. Species that benefit are unlikely to be the resident native species that have evolved under historical conditions and will be disadvantaged by changed environmental or biological regimes. Water quality modifications may also be of concern if they represent a change in natural habitat or a uniformity of conditions that, as a result, drives biotic homogenization (McKinney \& Lockwood 1999). Anthropogenic modifications of hydrological regimes will likely increase in the future as inland waterway transport is predicted to rise and there will be a greater need for expansion and new canal developments to support this trade (Galil et al. 2007, 2015). These modifications in hydrological regimes are likely to occur together with an increase in available suitable habitat for colonization by NIS. Increasing drought will drive water extractions from river sources, with associated impacts further downstream in estuaries. The interaction of water-usage practices and climate change anomalies has the potential to create invasion windows. For example, the co-occurrence of increased freshwater extraction and increased drought severity is thought to have created saline conditions in San Francisco estuary that benefitted a non-indigenous zooplankton species (Winder et al. 2011). Anthropogenic activities and associated stressors tend to be a common problem and may establish a particular set of conditions that are replicated in harbours around the globe (Halpern et al. 2008, Knights et al. 2013, Pearson et al. 2016). NIS are transported from multiple locations, but it is possible that these locations may have similar water quality conditions because they are busy ports or marinas, usually characterized by low flow, high turbidity, low DO and high nutrient conditions. These situations can create environments that suit a set of species representing 'harbour-tolerant' conditions as described in Floerl et al. (2009a).

Regime shifts associated with climate change may lead to the exacerbation of hydrological regime change and impacts on water quality (Delpla et al. 2009, Whitehead et al. 2009). It is inherently difficult to make predictions in complex ecological systems, but climate change will change the nature of basic chemical interactions. Increasing temperature and $\mathrm{pH}$ both have the potential to increase the availability of toxic contaminants (Schiedek et al. 2007, Sokolova \& Lannig 2008, Nikinmaa 2013) as does increasing storm activity, which resuspends contaminated sediments (Eggleton \& Thomas 2004). With temperature increases, we might also expect increases in primary productivity and an increased frequency of eutrophic events and hypoxia (Rabalais et al. 2009, Moss et al. 2011, O’Neil et al. 2012).

\section{Physical alteration of recipient environments}

\section{Estuarine, coastal and offshore development}

The estuarine environment faces increasing pressure from encroaching urban and industrial developments (Figure 2). Historically, the majority of human settlement has occurred within $100 \mathrm{~km}$ of 
the coast (Bulleri 2006, Firth et al. 2016) and, despite these areas being at most risk from climate change events, this trend continues (McGranahan et al. 2007). World population growth is projected to increase from 7.2 to 9.6 billion in 2050 (Gerland et al. 2014) and resource demand will result in increased exploitation of the marine environment. For example, some areas of Europe have lost $50-80 \%$ of coastal wetlands and seagrasses to development to support urban activities (reviewed by Airoldi \& Beck 2007). Anthropogenic habitat modification also extends beyond the coastal zone as world population growth has driven the search for new energy sources off shore (Asif \& Muneer 2007). The discovery of new oil and gas reserves, such as those in the Arctic region, will result in the continued construction of near and offshore production platforms (Asif \& Muneer 2007). Over 7500 offshore oil and gas platforms had been constructed worldwide as of 2003 (Hamzah 2003, Parente et al. 2006). Similarly, renewable energy is moving off shore with the construction of marine wind farms (Kennedy 2005, Punt et al. 2009). To exploit renewable energy sources, several thousand turbines will be constructed in wind farm clusters along the European Atlantic coast (Kennedy 2005) and, presumably, other global locations (Firth et al. 2016). Offshore energy platforms may appear relatively isolated, but they are linked to coastal areas by vessel movements (e.g. maintenance) and therefore can act as sinks or sources of NIS propagules (Yeo et al. 2009, Sammarco et al. 2010, Adams et al. 2014). Furthermore, the decommissioning of offshore installations may remove the structures that support NIS or leave behind permanent structures for NIS that are no longer maintained or monitored (Schroeder \& Love 2004, Page et al. 2006, Macreadie et al. 2011). Underwater pipelines have received less attention in relation to their potential impacts, but they connect offshore energy infrastructure with coastal zones and introduce other novel structures to the marine environment that may be colonized by NIS or facilitate their spread (Feary et al. 2011).

Habitat modification often involves the addition of structures that may increase or replace existing natural habitat (Glasby \& Connell 1999). Common structures added to coastal zones include sea walls, break walls and groynes constructed to protect urban coastal zones and maritime vessels (Mineur et al. 2012). Marinas and ports are often protected by break walls and infrastructure within these areas includes pilings and pontoons to support vessel berthing. Furthermore, vessel transport is supported by hydrological modifications including the construction of canals and other waterways. Similarly, offshore energy platforms, while built above the waterline, require extensive underwater scaffolding (Wilson \& Elliott 2009). Comparisons of artificial structures and natural habitats have revealed distinct differences in the assemblages able to colonize and persist on them (Connell \& Glasby 1999, Glasby 1999a, Glasby \& Connell 1999, Atilla et al. 2003, Chapman \& Bulleri 2003, Bulleri \& Chapman 2004, 2010, Firth et al. 2016). Differences between anthropogenic and natural hard-substratum habitats arise due to their physical characteristics, including substratum composition and microhabitats (Anderson \& Underwood 1994, Glasby 2000, Chapman \& Bulleri 2003, Chapman 2011, Firth et al. 2013, 2014, Browne \& Chapman 2014), age (Perkol-Finkel et al. 2005, Pinn et al. 2005, Burt et al. 2011), orientation or incline (Connell 1999, Glasby \& Connell 2001, Saunders \& Connell 2001, Knott et al. 2004, Langhamer et al. 2009, Chapman \& Underwood 2011, Firth et al. 2015), predation levels (Clynick et al. 2007, Nydam \& Stachowicz 2007), illumination levels (Glasby 1999b, Shafer 1999, Marzinelli et al. 2011, Davies et al. 2014), disturbance levels (Airoldi \& Bulleri 2011) and movement (Holloway \& Connell 2002, Perkol-Finkel et al. 2008, Shenkar et al. 2008, Dafforn et al. 2009b). The increasing transformation of natural to urbanized coastlines has promoted the establishment and spread of NIS (Bulleri \& Airoldi 2005, Bulleri et al. 2006, Airoldi et al. 2015).

\section{Artificial structures aid establishment and dispersal of NIS}

The addition of artificial structures in close proximity may provide 'stepping stones' for NIS (Glasby \& Connell 1999, Coutts \& Forrest 2007) (Figure 2), providing 'corridors' for their spread and dispersal (Bulleri \& Airoldi 2005, Airoldi et al. 2015). Propagules released from one structure have 
a higher chance of making it to other structures where the presence of NIS is often higher than in surrounding natural habitats (often sedimentary, Airoldi et al. 2015). The large amount of artificial structures in ports and harbours provides suitable habitat in close proximity to key vectors, such as commercial and recreational vessels (Bulleri \& Airoldi 2005) (Figure 2). Some invasive fouling NIS exhibit preferences for shallow floating artificial structures (Lambert \& Lambert 1998, Glasby et al. 2007, Dafforn et al. 2009b), potentially because they present a similar surface to a vessel hull with respect to movement and depth (Neves et al. 2007). Such artificial habitats unprecedentedly provide downward-facing surfaces, which are uncommon in natural ecosystems (Miller \& Etter 2008). Thus, certain species that were present in low abundance in nature are now thriving in these new environments. Research on larval phototaxis and geotaxis of ascidians (arguably one of the most important marine groups in terms of NIS) (Zhan et al. 2015), found that some globally-distributed species show settlement preference for downward surfaces (Svane \& Dolmer 1995, Rius et al. 2010). In addition, studies have shown that recruitment of fouling species are enhanced within proximity to a pier (Hedge \& Johnston 2012) and shading (Miller \& Etter 2008). Moreover, the design of ports and marinas can disrupt tidal flushing and result in vastly local increased recruitment rates (Floerl \& Inglis 2003, Johnston et al. 2011, Toh et al. 2016), but also increase regional connectivity by creating a network of substrata away from initial invader entry points (Knights et al., 2016). As a result, the characteristics of marinas increase retention of NIS propagules and provide a substratum for their establishment (Vaselli et al. 2008). This effect has been so strong that association with artificial structures has been used as a criterion for classifying species as non-indigenous (Chapman \& Carlton 1991). Even temporary or removable infrastructure, such as slow-moving barges and drilling rigs, can cause changes to the local habitat. During their period of operation, these floating structures provide a hard substratum for colonization of NIS, often surrounded by soft-sediment habitats (Sheehy \& Vik 2010). Invasive corals of the genus Tubastraea have, in recent years, colonized an ever-increasing proportion of oil-production infrastructure off the coasts of Brazil and southern USA (Sammarco et al. 2010, 2012, 2014, Costa et al. 2014). Hydrological modifications have also been implicated in the spread of NIS. For example, canals and waterways provide links between distant areas that would otherwise be isolated (Galil et al. 2007, Bishop et al. 2017). The increased addition of artificial structures into coastal areas and hydrological modifications that link isolated waterways provide NIS with 'stepping stones', networks and 'dispersal corridors', respectively (Glasby \& Connell 1999, Bulleri \& Airoldi 2005, Coutts \& Forrest 2007).

The increasing intensity of storms and rising sea levels associated with climate change are likely to increase the need for artificial coastal defences to be constructed on a global scale (Nicholls \& Mimura 1998, Moschella et al. 2005, FitzGerald et al. 2008). At the same time, climate change has created environmental conditions that have facilitated significant range expansion of various species (Barry et al. 1995, Hawkins et al. 2009, Ling et al. 2009, Mieszkowska et al. 2014, Rius et al. 2014a). Therefore, increased connectivity from networks of hard structures, together with climate change, may additively enhance the spread of NIS by providing habitat for colonization in areas opened up by warming temperatures (Ware et al. 2014, Firth et al. 2016). In addition to warming, there is a growing number of studies reporting more frequent extreme weather conditions (e.g. significantly larger differences between minimum and maximum seawater conditions, Wernberg et al. 2011, 2012, 2013), which facilitates the success of species with broader thermal ranges (Rius et al. 2014a).

In addition to increasing energy demands over the next decades, an increased demand for protein will result in a considerable expansion of the global aquaculture industry (FAO 2012). This will involve the construction of larger and denser aggregations of fin and shellfish farms in coastal regions that provide extensive artificial habitats to NIS (Fitridge et al. 2012). Another example is the Norwegian salmon farming industry that currently operates $\sim 700$ coastal farms, each comprising approximately $50,000 \mathrm{~m}^{2}$ of artificial habitat (Bloecher et al. 2015), and is predicted to grow fivefold by 2050 (Olafsen 2012). Aquaculture facilities are a major vector of NIS (Voisin et al. 2005, Fitridge et al. 2012, Aldred \& Clare 2014), not only because they intentionally introduce NIS to be 


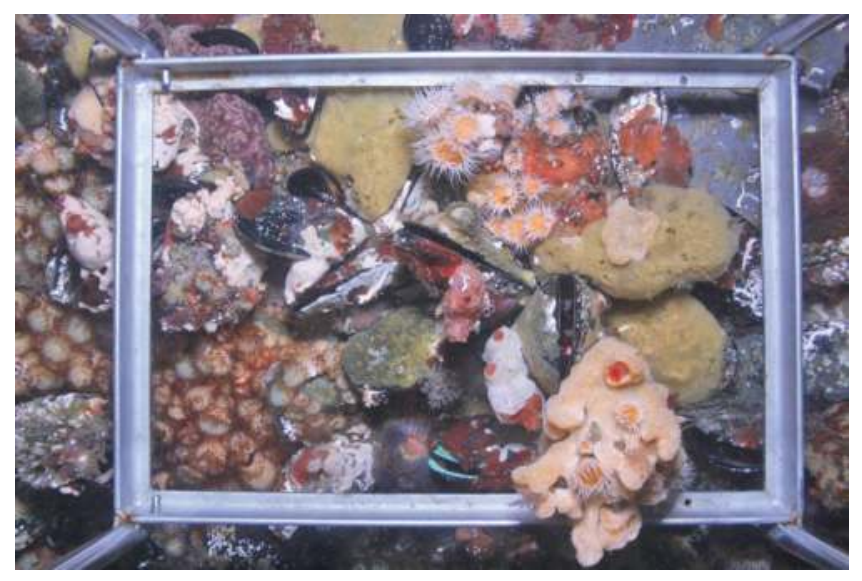

Figure 3 Extensive fouling of a salmon farm pontoon supports a diverse community of non-indigenous species, including the invasive ascidian, Didemnum vexillum. The development of dense aquaculture farming regions can facilitate the human-assisted spread of NIS and disease pathogens via the provision of steppingstone habitats and a complex transport network. (Photo: Javier Atalah, Cawthron Institute)

farmed, but because they unintentionally transport associated organisms that may establish and spread in the new range (Rosa et al. 2013, Woodin et al. 2014, Grosholz et al. 2015) (Figure 3). Once the farmed or associated species grow, they release propagules that will settle both in the aquaculture facilities and elsewhere. After the initial introduction in the 1970s of the Mediterranean mussel, Mytilus galloprovincialis, for farming in South Africa, this species spread more than $2000 \mathrm{~km}$, where it now dominates extensive sections of the rocky intertidal zone (Rius et al. 2011). In addition, the presence of aquaculture facilities has provided new artificial substrata where other NIS that coexist with the farmed NIS can thrive (Rius et al. 2011). Research has shown that such coexistence can allow persistence over long periods, which means that aquaculture facilities act as incubators for multiple NIS. Another problem associated with aquaculture facilities is the accidental release of the non-indigenous farmed stock (Schröder \& De Leaniz 2011), such as the case of fish farms in Chile (Soto et al. 2001, 2006, Soto \& Norambuena 2004). Finally, the development of dense aquaculture farming regions can facilitate the human-assisted spread of NIS and disease pathogens via the provision of stepping-stone habitats for natural dispersal and a complex transport network (Murray et al. 2002, Morrisey et al. 2011) (Figure 4).

\section{Connectivity: coastal transport networks}

\section{Commercial and recreational vectors}

Once established, the spread of marine NIS is often facilitated through the presence of extensive transport networks associated with coastal shipping, boating and aquaculture. Urbanized coastlines are characterized by the presence of commercial ports, boating marinas, ferry terminals and other infrastructure that are associated with a wide range of vectors, including merchant ships, cruise liners, naval vessels, car and passenger ferries, water taxis, recreational yachts, dredges, barges and others (Figure 2). Movements of these vectors occur at local (e.g. car ferries, water taxis, service vessels), regional or national scales (e.g. merchant or recreational vessels). Domestic transport networks can be complex. For example, New Zealand's recreational vessel network comprises $>500$ distinct voyage routes among 36 of the country's main marina facilities, and involves $>8000$ marina-to-marina voyages per year. In addition, there are $~ 7200$ annual movements of large commercial vessels between New Zealand's commercial ports that occur via $>300$ voyage routes (Floerl 


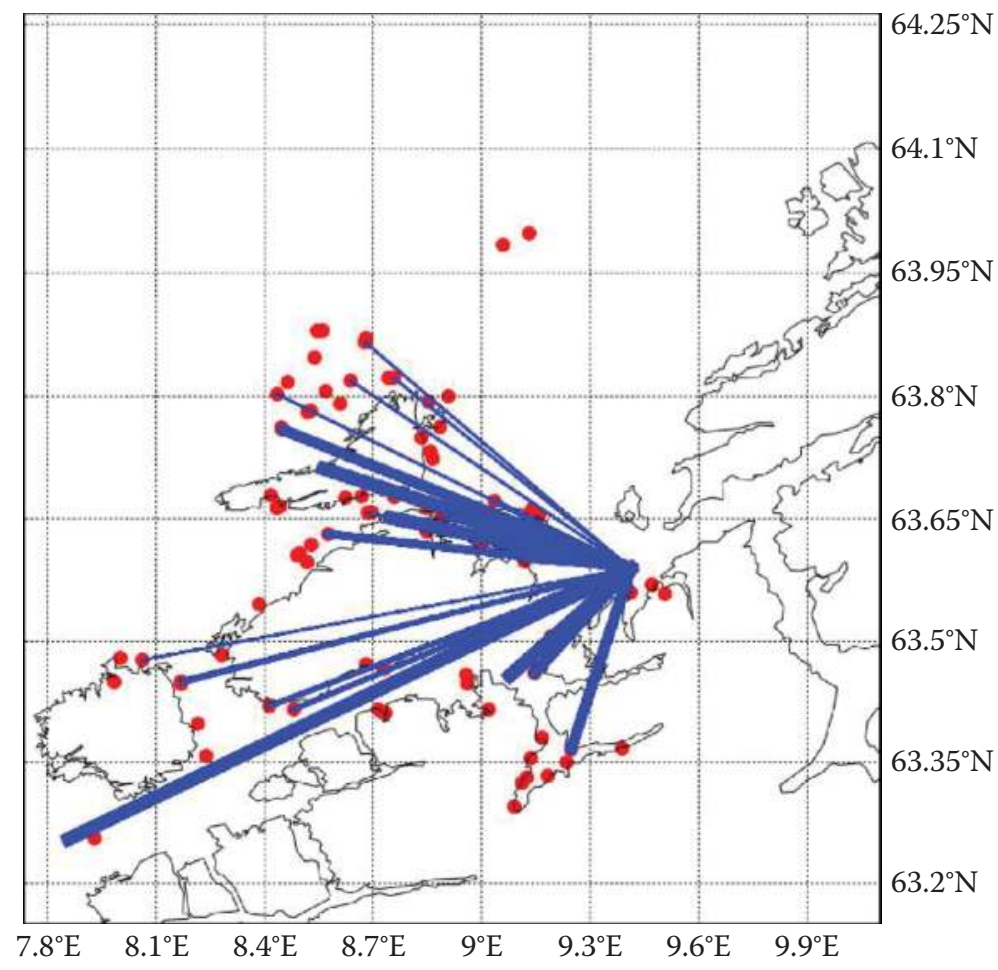

Figure 4 Annual 'connectivity' of a single Norwegian salmon farm in a network of 90 salmon farms on the coast of mid-Norway. The thickness of blue lines indicates the strength of connectivity. Vessel movements were tracked using automatic identification system (AIS) data (Floerl unpublished data).

et al. 2009a, Hayden et al. 2009). Many recreational, cruise, aquaculture and fishing vessels also regularly move between coastal centres and a wide range of relatively pristine natural coastal environments (Wasson et al. 2001, Gust et al. 2008, Zabin et al. 2014). For example, in 2013, a subset of 90 commercial salmon farms along the coast of Trøndelag, Norway, was visited by a total of 204 different vessels, including well-boats and feed, cleaning and service vessels (Figure 3). Individual farms received up to 400 visits from up to 57 different vessels, and farm-to-farm voyages of contractor vessels connected individual farms with up to 20 other farms (Floerl 2014). Human-assisted translocation can overcome barriers to natural dispersal and result in patterns and rates of spread very different from those achieved via natural dispersal (Buchan \& Padilla 1999, Ruiz \& Carlton 2003, Seebens et al. 2013) (Figure 4).

\section{Coastal transport networks facilitate transport of NIS at local, regional and domestic scales}

Transport of NIS via movements of vessels and other mobile submerged infrastructure predominantly occurs via biofouling on submerged surfaces or in internal ballast water (Drake \& Lodge 2007, Hewitt \& Campbell 2008). International conventions and guidelines to regulate shipping pathways are in development or already operational (IMO 2005, 2011b), but the domestic risk associated with both of these transportation modes remains largely unmanaged by most coastal nations. For example, Simkanin et al. (2009) established that approximately 27\% ( 6 million metric tons) of ballast water discharged at commercial ports on the west coast of the USA originates from other west coast ports, which can facilitate the translocation of organisms among regional ports. Similarly, domestic vessel 
movements in the USA and New Zealand (to name two examples) are likely to transport biofouling species between ports or from ports to remote natural environments (Floerl et al. 2009b, Zabin et al. 2014). Dispersal of biofouling species can be facilitated by all types of vessels and mobile infrastructure. The greatest risk is often attributed to vessels that spend extended periods (weeks to months) at their destinations, such as many recreational vessels, towed barges and inactive commercial vessels (Apte et al. 2000, Davidson et al. 2008, Floerl \& Coutts 2009). However, Schimanski (2015) recently showed that the export of recruits from a local larval pool via vessel movements can occur following residency periods of a single day. Recreational vessels are implicated in the domestic spread of NIS in North America (Wasson et al. 2001, Davidson et al. 2008, Clarke Murray et al. 2011, Zabin et al. 2014), Europe (Fletcher \& Farrell 1999, Dupont et al. 2010) and New Zealand (Goldstien et al. 2010). There is also evidence of commercial vessels acting as domestic transport vectors. For example, the translocation of a dumb barge from New Zealand's North Island to the South Island has facilitated the dispersal of the invasive ascidian, Didemnum vexillum, from its probable founder population into the heart of the country's aquaculture growing region $500 \mathrm{~km}$ further south, where it established highly prolific populations (Coutts \& Forrest 2007, Forrest et al. 2013). Regional movements of leased marina pontoons and transfers of aquaculture stock between growing regions have also been identified as potential dispersal vectors of NIS (Forrest \& Blakemore 2006, Gust et al. 2008).

The spread of NIS is determined by myriad factors that are not all well understood and that are likely to differ between species and environmental contexts. For example, there are known relationships between propagule pressure and colonization success (Hedge \& Johnston 2012) and between aspects (size, gene pool, etc.) of founder populations and longer-term persistence (Simberloff \& Gibbons 2004). The modes of anthropogenic transport described above can enhance the postestablishment success of marine NIS in several ways. First, they can facilitate the establishment of further regional satellite populations whose cumulative spread and impact can be greater and far more difficult to manage than that of a single invasive population (Moody \& Mack 1988). Second, some elements of coastal transport networks, such as container vessel movements, involve repeat voyages or loops (Kaluza et al. 2010). These can facilitate recurring introductions of propagules to established NIS populations, which may enhance resilience and adaptive capacity of such populations to disturbance or environmental change (Carlton \& Hodder 1995, Prentis et al. 2008, Hedge et al. 2012). Third, repeat introductions can also help small populations overcome Allee effects and become self-sustaining (Drake \& Lodge 2006) thereby increasing invasion risk. Finally, the transport of biofouling species on vessels can select for individuals that are particularly robust (e.g. environmentally tolerant, Piola \& Johnston 2008a). Vessels with particular voyage profiles, such as frequent short-distance voyages, may facilitate transport of recruits that are able to produce viable offspring for release in vessels' future destinations (Schimanski 2015).

There is mounting evidence that both recreational vessels and commercial shipping allow the translocation of genotypes around the world. Many studies show little genetic differentiation among distant populations found within a species' introduced range (Tepolt et al. 2009, Rius et al. 2012, Ordóñez et al. 2013), indicating the presence of population connectivity both at regional and global scales. Although genetic bottlenecks can have deleterious effects on recently-established introduced populations (Roman \& Darling 2007), the majority of marine genetic studies support the idea that introduced populations have high levels of genetic diversity as a result of recurrent introductions from multiple and diverse sources (Rius et al. 2015). Human-assisted global reshuffling of genotypes may have evolutionary consequences for species and assemblages in both introduced and native ranges (Olden et al. 2004, Hudson et al. 2016). Human activities fundamentally alter evolutionary trajectories that have been shaped by millions of years. For example, both artificial transport of species and climate change facilitate contacts of previously isolated genotypes, which unprecedentedly increases hybridization rates (Rius \& Darling 2014, Vallejo-Marin \& Hiscock, 2016). However, more research is needed to understand how human activities are affecting species ranges of both native and NIS. 


\section{Ecological, physiological and genetic alteration of recipient environments}

When a NIS interacts with the receiving community, a gradient of possible outcomes can be expected. The first one is ecological dominance by the NIS, in which the absence of natural competitors and predators (the so-called 'enemy release hypothesis', Keane \& Crawley 2002) facilitates NIS success. Another possibility is that a NIS becomes established in the new area but that the receiving community limits its success (i.e. biotic containment, Stachowicz et al. 2002a, Levine et al. 2004, Simkanin et al. 2013). Finally, biotic resistance or the ability of resident species to resist newcomers may prevent the establishment of NIS. Human activities have the potential to modify each of these processes and thereby influence the success of NIS post-arrival.

\section{Loss of species diversity and changes in community interactions}

One of the most studied but debated forms of community-level biotic resistance is that attributable to species diversity (Elton 1958). Species diversity is thought to affect biotic resistance through two main mechanisms: the sampling effect and species complementarity. The sampling effect refers to the probability that a community will contain one or more dominant species (e.g. superior competitors or predators) that are particularly effective in repelling invaders (Huston 1997). Dominant species may create habitat for many subordinate species, which increases species diversity and inhibits the establishment of new arrivals. Species complementarity, or resource partitioning, refers to differential resource use between species (Schoener 1974, Tilman 1997). A higher number of species can often utilize a larger proportion of the resource base, which reduces invasibility by leaving fewer unused resources available to invaders (Davis et al. 2000).

Experimental studies have shown that diverse communities can 'overyield', where they are more productive and use more resources than would be expected by the sum of component species (Hector et al. 2002). Species complementarity can also occur temporally, when diversity buffers the effects of temporary species loss (Levine 2000). This was observed in a marine system where the primary space-occupiers (colonial ascidians) underwent boom-and-bust cycles at different times of the year, and diverse communities tended to contain species in each boom-phase (Stachowicz et al. 1999). These experimental studies demonstrate effects of species diversity on invasibility at local scales, but there is debate over its importance at larger scales (Fridley et al. 2007, Clark \& Johnston 2011, Clark et al. 2013).

Competition between species within trophic levels is an important process in many marine communities (Branch 1984), and represents a key form of biotic resistance. Classic ecological theory identifies three main types of competition (interference, exploitative and apparent), which include both direct and indirect mechanisms (Fellers 1987). Examples of these in hard-substratum marine systems are overgrowth interactions between neighbours (interference, Russ 1982) and competition for resources such as food and space (exploitative, Buss 1990), both of which can act to resist postestablishment invasion (Kimbro et al. 2013). Apparent competition is that mediated by a predator or herbivore and is more difficult to study, but has been implicated as a mechanism influencing the invasion success of some terrestrial plants (Dangremond et al. 2010, Combs et al. 2011).

The importance of competition shaping community composition is context-dependent (Firth et al. 2009, Klein et al. 2011) and is regulated by resources and stress levels (McQuaid et al. 2015), so is variable across space and time. It is less important in early successional or highly disturbed communities where resources are abundant, but becomes increasingly important as communities develop and resources become scarce (Parrish \& Bazzaz 1982, Dohn et al. 2013). The degree of niche partitioning also influences the importance of competition, since divergent resource use between species diminishes the frequency and/or intensity of competitive interactions. There is some evidence for latitudinal trends in the intensity of competition (Barnes 2002), which may contribute 
to differences in the invasibility of latitudinal regions (Freestone \& Osman 2011, Freestone et al. 2011, 2013).

Increased disturbance, for example by human activities that chemically or physically alter the environment, typically increases species turnover and the amount of available resources (Davis et al. 2000, Clark \& Johnston 2005) (Figure 1). This reduces the importance of competition in structuring communities, and advantages species with r-selected traits and/or tolerance to disturbance. Many NIS are relatively successful in disturbed environments by their virtue of high dispersal (particularly in association with human transport vectors), rapid reproduction and wide environmental tolerance (Piola \& Johnston 2008b) (Figure 1). Byers (2002) argued that anthropogenic disturbances create environmental conditions that favour NIS, removing the advantages of pre-adaptation that would normally be held by natives.

The loss of native species or a reduction in their abundance can compromise species interactions that would otherwise provide biotic resistance. Fewer species reduces the scope for species complementarity and the probability that communities will contain dominant taxa (i.e. the sampling effect). Stress that reduces the fitness of native species may weaken biotic resistance by decreasing the intensity of competition, or by altering the outcome of competitive interactions (Liancourt et al. 2005). Conversely, positive interactions (facilitation) between invaders can exacerbate their impacts, spread and subsequent invasions - a phenomenon known as 'invasional meltdown' (Simberloff \& Von Holle 1999, Grosholz 2005) (Figure 1). An example in hard-substratum marine fauna is when habitat-forming invaders (e.g. the colonial bryozoan, Watersipora subtorquata) provide secondary substratum for other invaders (Floerl et al. 2004), sometimes on antifouling-painted surfaces that would otherwise be uninhabitable by non-tolerant invaders. Facilitative interactions can also occur between native and NIS. Most evidence of this comes from studies on terrestrial and freshwater ecosystems, but some marine examples exist (see review by Rodriguez 2006). Facilitative effects are often transitory (Holloway \& Keough 2002) or dependent on environmental conditions (Maestre et al. 2009, Rius \& McQuaid 2009, Holmgren \& Scheffer 2010). Overall positive and negative ecological interactions affect levels of biodiversity, which ultimately influence the success of NIS.

Impacts of human activities on biotic resistance are spatially variable, as some habitats are dominated by taxa that are particularly susceptible to environmental change. For example, areas with more stable environments (e.g. subtidal reefs or deep-sea sediments) are more likely to contain species less able to adapt to or tolerate change, relative to areas with fluctuating conditions (e.g. tidal rock pools or shallow estuaries) (Levin \& Lubchenco 2008). Change in biotic resistance may also be temporally variable, as species can approach their physiological limits during seasonal extremes (Durrant et al. 2013). These fluctuations in natural stress might interact with human stressors to create periods of heightened vulnerability to invasion.

\section{Loss of top-down control or 'enemy release'}

Predation or herbivory is a third type of ecological interaction that, in the context of biological invasions, is referred to as top-down control (McEnvoy \& Coombs 1999). Non-indigenous marine invertebrates can be prey for some native fish or grazing invertebrates (e.g. echinoderms), and likewise non-indigenous fish can be prey for larger native fish or higher-order predators. The importance of this to marine bioinvasions is difficult to gauge since predation rates on many lower trophic levels are not often well understood. Some evidence exists from studies that describe predation of early life-history stages of marine epifaunal taxa (both native and/or NIS) as a key determinant of the development of benthic communities (Osman \& Whitlatch 1995, 2004, Rius et al. 2014b). Softbodied marine invertebrates (e.g. solitary and colonial ascidians) may be more prone to predation than those with hard outer shells, so the susceptibility of invertebrate invaders to top-down control can be influenced by their morphology (Lavender et al. 2014), the natural predators present (e.g. specialist versus generalist) and other competitors (Russ 1980, 1982, Osman \& Whitlatch 2004). 
Chemical defences can also inhibit predation upon fish (Snyder \& Burgess 2007) and marine invertebrates (Bakus 1981, Pawlik 1993, Teo \& Ryland 1994), and herbivory upon algae (Steinberg 1986, Hay \& Fenical 1988), providing some invaders with relative immunity to top-down control (Lagesa et al. 2006, Enge et al. Chapter 6 in this volume).

The 'enemy release hypothesis' refers to situations when the invader has partial or complete immunity from predation in its new range, and can lead to the proliferation and dominance of the invader (Keane \& Crawley 2002) (Figure 1). Most examples of the enemy release hypothesis come from terrestrial studies (Colautti et al. 2004, Liu \& Stiling 2006), but there is some evidence from the marine environment (Torchin et al. 2003, Blakeslee et al. 2009, 2012). A laboratory study compared the preference of a sea urchin for feeding upon native versus exotic ascidians, and found that the urchin preferred the native prey (Simoncini \& Miller 2007). Another study found that even though Hawaiian herbivores grazed introduced algae in preference to native algae, the intensity of herbivory was lower there than in the invaders' native range (Vermeij et al. 2009). Field studies have highlighted that besides a relative immunity to predation, invaded communities dominated by NIS may benefit native predators by providing previously unavailable resources (Branch \& Steffani 2004, Rius et al. 2009). Torchin et al. (2003) highlighted the importance of escape from parasites in the success of some exotic marine invertebrates, since parasites are known to reduce growth, survival and natality (Torchin et al. 2002). For example, infection of the native mussel, Perna perna, in South Africa by trematodes was found to reduce growth and adductor muscle strength, and increase water loss compared to the uninfected non-indigenous mussel, Mytilus galloprovincialis (CalvoUgarteburu \& McQuaid 1998). While not top-down control, this appears to be another important form of enemy release in marine systems. Enemy release can accelerate invasion events that were initiated or facilitated by the anthropogenic factors mentioned in other sections of this chapter.

\section{Managing anthropogenic factors to reduce the establishment and spread of NIS}

Our existing insights of how humans can influence the post-arrival success of NIS by altering physical, chemical and biological parameters of the environment, or by facilitating dispersal, provide us with a wide range of options for reducing invasion risk. These are briefly discussed here and summarized in Table 1.

Ecological interactions, such as biotic resistance or containment, occur across and within trophic groups, as well as at multiple levels of biological organization and life-history stages (Kimbro et al. 2013). Human activities can impair biotic resistance to post-establishment spread of NIS by reducing the types, extent or magnitude of species diversity, community interactions and top-down control (Figure 1). At local or regional scales, for example, diversity loss can result from anthropogenic stressors such as contamination providing an advantage to non-indigenous species (Piola \& Johnston 2008b). Physical modifications of habitats due to increasing coastal development can result in species removal and the loss of native species that might otherwise provide a barrier to invasion (Dafforn et al. 2015). Fishing practices that remove apex predators can reduce top-down control on marine communities and might also facilitate invasion at lower trophic levels (Baum \& Worm 2009, reviewed by Johnson et al. 2011). At larger scales, human-induced climate change is modifying natural ranges of species (Ling et al. 2009) and may be increasing the rate of biotic homogenization (Stachowicz et al. 2002b, Olden et al. 2004).

The way we manage and conserve the diversity and integrity of native species assemblages will affect their ability to repel NIS now and in the future. Specifically, it will be important to conserve the native attributes of systems such that natural mechanisms of biotic resistance can operate most efficiently. For example, conserving native diversity will facilitate synergistic mechanisms of biotic resistance (e.g. species complementarity and indirect interactions) that would be virtually 
Table 1 Summary of mechanisms for establishment and spread of NIS, likely impacts and suggestions for effective management

\begin{tabular}{|c|c|c|}
\hline $\begin{array}{l}\text { Establishment and/or } \\
\text { dispersal vector }\end{array}$ & Likely impacts & Management suggestions \\
\hline $\begin{array}{l}\text { Reduced biotic } \\
\text { resistance }\end{array}$ & $\begin{array}{l}\text { Changes in species diversity, } \\
\text { competitive interactions and } \\
\text { top-down control }\end{array}$ & $\begin{array}{l}\text { - Conserve native biodiversity (e.g. with marine sanctuaries) } \\
\text { - Understand interactions between stressors } \\
\text { - Protect natural predators for top-down control } \\
\text { - Monitor key native species }\end{array}$ \\
\hline $\begin{array}{l}\text { Contamination, } \\
\text { eutrophication and } \\
\text { changes to water } \\
\text { quality }\end{array}$ & $\begin{array}{l}\text { Selection for tolerant species, } \\
\text { selection for fast-growing } \\
\text { species, freeing of resources } \\
\text { for NIS }\end{array}$ & $\begin{array}{l}\text { - Improve flushing in marinas to reduce water retention } \\
\text { - Use of non-toxic antifouling paints } \\
\text { - Remediate contaminated sediments to avoid } \\
\text { resuspension of toxicants } \\
\text { - Manage storm water runoff }\end{array}$ \\
\hline $\begin{array}{l}\text { Addition of artificial } \\
\text { structures }\end{array}$ & $\begin{array}{l}\text { Introduction of artificial hard } \\
\text { substratum, invasion stepping } \\
\text { stone }\end{array}$ & $\begin{array}{l}\text { - Shift from hard defence structures to natural coastal } \\
\text { protection } \\
\text { - Design structures to conserve natural habitat complexity } \\
\text { and reduced shading } \\
\text { - Use fixed rather than floating structures }\end{array}$ \\
\hline $\begin{array}{l}\text { Commercial and } \\
\text { recreational transport } \\
\text { networks }\end{array}$ & $\begin{array}{l}\text { Translocation of NIS via } \\
\text { fouling on hulls or equipment, } \\
\text { and in ballast water }\end{array}$ & $\begin{array}{l}\text { - Pathway management } \\
\text { - Domestic ballast water management } \\
\text { - Improved ability for hull treatment }\end{array}$ \\
\hline
\end{tabular}

impossible to artificially engineer. Reducing the input of contaminants to receiving environments and removing historical legacies of toxicants would go some way to support native species resistance (Piola et al. 2009). For example, there has been evidence of macrofaunal recovery following the ban on tributyltin in antifouling paints (Smith et al. 2008, Langston et al. 2015). Similarly, the removal of organic contaminants associated with a fish farm resulted in positive changes to native ecological structure and function over time (Macleod et al. 2008). Broad conservation of processes that maintain strong ecological interactions will provide the most comprehensive protection against a wide range of possible scenarios.

The increased addition of artificial structures to coastal environments aids the establishment and dispersal of NIS. Where artificial structures are used for protection and defence (e.g. groynes, breakwaters, sea walls), the establishment of natural coastal protection would reduce these risks. For example, the addition of buffer zones for the landward extension of coastal vegetation (e.g. mangroves) would provide more natural protection from storms and storm surges (Hoang Tri et al. 1998, Kelly \& Adger 2000, Costanza et al. 2008). Where coastal defence structures are needed, improving the design of artificial structures would go some way to reducing post-arrival success of NIS if structures matched the complexity of natural habitats (Atilla et al. 2005), shading was reduced to encourage native algal assemblage growth (Dafforn et al. 2012) and developments such as ports and marinas were designed to improve flushing and reduce retention rate for invasive propagules (Floerl \& Inglis 2003, Vaselli et al. 2008). Future management strategies should take into account the potential for shallow moving structures to enhance invader dominance, and strongly consider using fixed structures to reduce opportunities for invaders (Dafforn et al. 2009b).

Physical changes that increase connectivity of habitats are a primary cause for invader spread. Canals have been implicated in invader spread (e.g. Suez and Panama canals) linking regions that would have otherwise been isolated by a natural barrier. The design of locks and weirs within such canals, combined with effective water or hull treatment technology, could help to reduce the transport of viable species between naturally isolated waterbodies (Galil et al. 2007, 2015). Upstream hydrological modifications should take into consideration the potential for changes to environmental conditions downstream that might enhance abiotic conditions for invaders (Winder et al. 2011). 
A reduction in the risk of post-establishment spread via human transport mechanisms can also be achieved via the development and implementation of effective pathway management measures. Such initiatives may involve the setting of hygiene requirements or movement restrictions for vessels or infrastructure (e.g. aquaculture equipment) of particular types or origin to minimize their risk of translocating NIS (see discussions in Sinner et al. 2013, Inglis et al. 2014). One recent example of such measures is the Craft Risk Management Standard developed by the New Zealand government to limit the arrival and spread of non-indigenous biofouling species via overseas vessels (MPI 2014). Similar regional efforts are required to control domestic spread, and are being developed by several New Zealand regional jurisdictions (Sinner et al. 2013). To be effective and feasible, such measures need to be evidence-based and underpinned by effective prevention, inspection/surveillance and treatment technologies, industry codes of practice, incentivized schemes and educational measures (Floerl et al. 2016).

Longer-term international strategies for reducing risk include the implementation of widelyadopted, best-practice ballast water treatment and hull maintenance regimes that reduce biofouling (Hewitt \& Campbell 2007, Tamelander et al. 2010) (Figure 5) and the development of more effective risk-based screening tools for border clearance. Genetic tools, including environmental DNA, are providing improved strategies for early detection, which can enable a faster and more effective detection and response to species invasions (Jerde et al. 2011, Zaiko et al. 2016). A sustained reduction in the overall per-vector risk of facilitating species transfers will be associated with long-term benefits for biosecurity (Drake and Lodge 2004). This is reflected in current international measures made for commercial ships (e.g. IMO 2011a) but needs to be better and more effectively implemented at domestic scales and across the range of anthropogenic transport mechanisms (Williams et al. 2013).

Multiple stressors (biological, chemical or physical) can impose additive or synergistic effects on ecosystems. Ameliorating as many stressors as possible will bolster the ability of ecosystems to deal with the remainder, and identifying important interactions between stressors may also help in prioritizing their management (Crain et al. 2008). Marine protected areas (MPAs), where certain human activities are restricted or forbidden, are one such tool with which to conserve the natural attributes of systems, and thereby biotic resistance. MPAs harbour natural predators that impose top-down control (Shears \& Babcock 2002), and have the potential to conserve diversity and strong competitors within trophic levels to minimize excess resource availability (Baskett et al. 2007). Further understanding of species interactions most important to biotic resistance would be

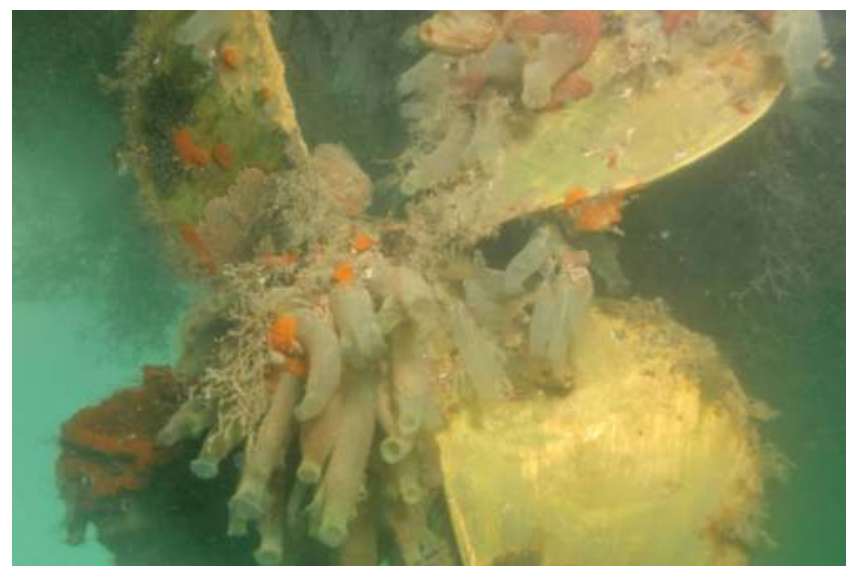

Figure 5 Propeller of a domestic vessel fouled by the invasive ascidian, Ciona robusta. Longer-term strategies for reducing invasion risk include the implementation of widely-adopted, best-practice hull maintenance regimes that reduce fouling. (Photo: Javier Atalah, Cawthron Institute) 
useful, allowing us to monitor key species and predict when and where biotic resistance is likely to be compromised.

Much research has focused on the vectors that initially transport a species beyond its native range (Carlton 1985, Ruiz et al. 1997, Hewitt \& Campbell 2008, Davidson et al. 2010). However, it is clear that human activities have the potential to increase invader success through multiple stages of the invasion process (Williamson et al. 1986, Piola et al. 2009). Anthropogenic activities that increase the survival, establishment, proliferation and secondary spread of marine NIS post-arrival in a new region require greater management attention and research focus if we are to prevent the gradual homogenization of the world's coastal biota.

\section{Acknowledgements}

This research was supported by the Australian Research Council through an Australian Research Fellowship awarded to Johnston and a Linkage Grant (LP140100753) awarded to Dafforn and Johnston. This is SIMS publication number 195. Floerl's time was in part supported by SINTEF Fisheries and Aquaculture and by the National Institute of Water and Atmospheric Research under Coasts and Oceans Research Programme 6, Marine Biosecurity (2015/16 SCI). We thank a reviewer for constructive criticisms and Steve Hawkins, Louise Firth and Hanna Schuster for inviting us to submit this review.

\section{References}

Adams, T.P., Miller, R.G., Aleynik, D. \& Burrows, M.T. 2014. Offshore marine renewable energy devices as stepping stones across biogeographical boundaries. Journal of Applied Ecology 51, 330-338.

Airoldi, L., Abbiati, M., Beck, M.W., Hawkins, S.J., Jonsson, P.R., Martin, D., Moschella, P. S., Sundelof, A., Thompson, R.C. \& Aberg, P. 2005. An ecological perspective on the deployment and design of lowcrested and other hard coastal defence structures. Coastal Engineering 52, 1073-1087.

Airoldi, L. \& Beck, M.W. 2007. Loss, status and trends for coastal marine habitats of Europe. Oceanography and Marine Biology: An Annual Review 45, 345-405.

Airoldi, L. \& Bulleri, F. 2011. Anthropogenic disturbance can determine the magnitude of opportunistic species responses on marine urban infrastructures. PLOS ONE 6, e22985.

Airoldi, L., Connell, S.D. \& Beck, M.W. 2009. The loss of natural habitats and the addition of artificial substrata. In Marine Hard Bottom Communities, M. Wahl (ed.). Berlin: Springer, 269-280.

Airoldi, L., Turon, X., Perkol-Finkel, S. \& Rius, M. 2015. Corridors for aliens but not for natives: effects of marine urban sprawl at a regional scale. Diversity and Distributions 21, 755-768.

Aldred, N. \& Clare, A.S. 2014. Mini-review: impact and dynamics of surface fouling by solitary and compound ascidians. Biofouling 30, 259-270.

Alexandratos, N. \& Bruinsma, J. 2012. World agriculture towards 2030/2050: the 2012 revision. ESA Working paper Rome, FAO.

Alquezar, R., Markich, S.J. \& Booth, D.J. 2006. Effects of metals on condition and reproductive output of the smooth toadfish in Sydney estuaries, south-eastern Australia. Environmental Pollution 142, 116-122.

Alzieu, C.L., Sanjuan, J., Deltreil, J.P. \& Borel, M. 1986. Tin contamination in Arcachon Bay: effects on oyster shell anomalies. Marine Pollution Bulletin 17, 494-498.

Anderson, M.J. \& Underwood, A.J. 1994. Effects of substratum on the recruitment and development of an intertidal estuarine fouling assemblage. Journal of Experimental Marine Biology and Ecology 184, 217-236.

Apte, S., Holland, B., Godwin, L. \& Gardner, J. 2000. Jumping ship: a stepping stone event mediating transfer of a non-indigenous species via a potentially unsuitable environment. Biological Invasions 2, 75-79.

Asif, M. \& Muneer, T. 2007. Energy supply, its demand and security issues for developed and emerging economies. Renewable and Sustainable Energy Reviews 11, 1388-1413.

Atilla, N., Fleeger, J.W. \& Finelli, C.M. 2005. Effects of habitat complexity and hydrodynamics on the abundance and diversity of small invertebrates colonizing artificial substrates. Journal of Marine Research 63, 1151-1172. 
Atilla, N., Wetzel, M.A. \& Fleeger, J.W. 2003. Abundance and colonization potential of artificial hard substrate-associated meiofauna. Journal of Experimental Marine Biology and Ecology 287, 273-287.

Bakus, G.J. 1981. Chemical defense mechanisms on the Great Barrier reef, Australia. Science 211, 497-499.

Barnes, D.K.A. 2002. Polarization of competition increases with latitude. Proceedings of the Royal Society of London B: Biological Sciences 269, 2061-2069.

Barry, J.P., Baxter, C.H., Sagarin, R.D. \& Gilman, S.E. 1995. Climate-related, long-term faunal changes in a California rocky intertidal community. Science 267, 672-675.

Baskett, M.L., Micheli, F. \& Levin, S.A. 2007. Designing marine reserves for interacting species: insights from theory. Biological Conservation 137, 163-179.

Baum, J.K. \& Worm, B. 2009. Cascading top-down effects of changing oceanic predator abundances. Journal of Animal Ecology 78, 699-714.

Birch, G.F. 2000. Marine pollution in Australia, with special emphasis on central New South Wales estuaries and adjacent continental margin. International Journal of Environment and Pollution 13, 573-607.

Bishop, M.J., Mayer-Pinto, M., Airoldi, L., Firth, L.B., Morris, R.L., Loke, L.H.L., Hawkins, S.J., Naylor, L.A., Coleman, R.A., Chee, S.Y. \& Dafforn, K.A. 2017. Effects of ocean sprawl on ecological connectivity: impacts and solutions. Journal of Experimental Marine Biology and Ecology. https://doi. org/10.1016/j.jembe.2017.01.021

Blackburn, T.M. \& Duncan, R.P. 2001. Determinants of establishment success in introduced birds. Nature 414, 195-197.

Blackburn, T.M., Pyšek, P., Bacher, S., Carlton, J.T., Duncan, R.P., Jarosik, V., Wilson, J.R.U. \& Richardson, D.M. 2011. A proposed unified framework for biological invasions. Trends in Ecology \& Evolution 26, 333-339.

Blakeslee, A.M., Altman, I., Miller, A.W., Byers, J.E., Hamer, C.E. \& Ruiz, G.M. 2012. Parasites and invasions: a biogeographic examination of parasites and hosts in native and introduced ranges. Journal of Biogeography 39, 609-622.

Blakeslee, A.M., Keogh, C.L., Byers, J.E., Lafferty, A.M.K.K.D. \& Torchin, M.E. 2009. Differential escape from parasites by two competing introduced crabs. Marine Ecology Progress Series 393, 83-96.

Bloecher, N., Floerl, O. \& Sunde, L.M. 2015. Amplified recruitment pressure of biofouling organisms in commercial salmon farms: potential causes and implications for farm management. Biofouling 31, 163-172.

Branch, G. 1984. Competition between marine organisms: ecological and evolutionary implications. Oceanography and Marine Biology: An Annual Review 22, 429-593.

Branch, G.M. \& Steffani, C.N. 2004. Can we predict the effects of alien species? A case-history of the invasion of South Africa by Mytilus galloprovincialis (Lamarck). Journal of Experimental Marine Biology and Ecology 300, 189-215.

Browne, M. \& Chapman, M. 2014. Mitigating against the loss of species by adding artificial intertidal pools to existing seawalls. Marine Ecology Progress Series 497, 119-129.

Buchan, L.A.J. \& Padilla, D.K. 1999. Estimating the probability of long-distance overland dispersal of invading aquatic species. Ecological Applications 9, 254-265.

Bulleri, F. 2006. Is it time for urban ecology to include the marine realm? Trends in Ecology \& Evolution 21, 658-659.

Bulleri, F., Abbiati, M. \& Airoldi, L. 2006. The colonisation of human-made structures by the invasive alga Codium fragile ssp. tomentosoides in the north Adriatic Sea (NE Mediterranean). Hydrobiologia 555, 263-269.

Bulleri, F. \& Airoldi, L. 2005. Artificial marine structures facilitate the spread of a non-indigenous green alga, Codium fragile ssp. tomentosoides, in the north Adriatic Sea. Journal of Applied Ecology 42, 1063-1072.

Bulleri, F. \& Chapman, M.G. 2004. Intertidal assemblages on artificial and natural habitats in marinas on the north-west coast of Italy. Marine Biology 145, 381-391.

Bulleri, F. \& Chapman, M.G. 2010. The introduction of coastal infrastructures as a driver of change in marine environments. Journal of Applied Ecology 47, 26-35.

Burt, J., Bartholomew, A. \& Sale, P.F. 2011. Benthic development on large-scale engineered reefs: a comparison of communities among breakwaters of different age and natural reefs. Ecological Engineering 37, 191-198. 


\section{ANTHROPOGENIC ACTIVITIES AFFECT POST-ARRIVAL SUCCESS OF NIS}

Burton, G.A. \& Johnston, E.L. 2010. Assessing contaminated sediments in the context of multiple stressors. Environmental Toxicology and Chemistry 29, 2625-2643.

Buss, L.W. 1990. Competition within and between encrusting clonal invertebrates. Trends in Ecology \& Evolution 5, 352-356.

Butchart, S.H.M., Walpole, M., Collen, B., van Strien, A., Scharlemann, J.P.W., Almond, R.E.A., Baillie, J.E.M., Bomhard, B., Brown, C., Bruno, J., Carpenter, K.E., Carr, G.M., Chanson, J., Chenery, A.M., Csirke, J., Davidson, N.C., Dentener, F., Foster, M., Galli, A., Galloway, J.N., Genovesi, P., Gregory, R.D., Hockings, M., Kapos, V., Lamarque, J.F., Leverington, F., Loh, J., McGeoch, M.A., McRae, L., Minasyan, A., Morcillo, M.H., Oldfield, T.E.E., Pauly, D., Quader, S., Revenga, C., Sauer, J.R., Skolnik, B., Spear, D., Stanwell-Smith, D., Stuart, S.N., Symes, A., Tierney, M., Tyrrell, T.D., Vie, J.C. \& Watson, R. 2010. Global biodiversity: indicators of recent declines. Science 328, 1164-1168.

Byers, J.E. 2002. Impact of non-indigenous species on natives enhanced by anthropogenic alteration of selection regimes. Oikos 97, 449-458.

Calvo-Ugarteburu, G. \& McQuaid, C. 1998. Parasitism and invasive species: effects of digenetic trematodes on mussels. Marine Ecology Progress Series 169, 149-163.

Carlton, J.T. 1985. Transoceanic and interoceanic dispersal of coastal marine organisms; the biology of ballast water. Oceanography and Marine Biology: An Annual Review 23, 313-373.

Carlton, J.T. \& Hodder, J. 1995. Biogeography and dispersal of coastal marine organisms: experimental studies on a replica of a 16th-century sailing vessel. Marine Biology 121, 721-730.

Carstensen, J., Conley, D., Bonsdorff, E., Gustafsson, B., Hietanen, S., Janas, U., Jilbert, T., Maximov, A., Norkko, A., Norkko, J., Reed, D., Slomp, C., Timmermann, K. \& Voss, M. 2014. Hypoxia in the Baltic Sea: biogeochemical cycles, benthic fauna, and management. Ambio 43, 26-36.

Castilla, J.C., Guiñez, R., Caro, A.U. \& Ortiz, V. 2004. Invasion of a rocky intertidal shore by the tunicate Pyura praeputialis in the Bay of Antofagasta, Chile. Proceedings of the National Academy of Sciences of the United States of America 101, 8517-8524.

Chapman, J.W. \& Carlton, J.T. 1991. A test of criteria for introduced species: the global invasion by the isopod Synidotea laevidorsalis (Miers, 1881). Journal of Crustacean Biology 11, 386-400.

Chapman, M.G. 2011. Restoring intertidal boulder-fields as habitat for "specialist" and "generalist" animals. Restoration Ecology 20, 277-285.

Chapman, M.G. \& Bulleri, F. 2003. Intertidal seawalls - new features of landscape in intertidal environments. Landscape and Urban Planning 62, 159-172.

Chapman, M.G. \& Underwood, A.J. 2011. Evaluation of ecological engineering of 'armoured' shorelines to improve their value as habitat. Journal of Experimental Marine Biology and Ecology 400, 302-313.

Claisse, D. \& Alzieu, C. 1993. Copper contamination as a result of antifouling paint regulations? Marine Pollution Bulletin 26, 395-397.

Clark, G.F. \& Johnston, E.L. 2005. Manipulating larval supply in the field: a controlled study of marine invasibility. Marine Ecology Progress Series 298, 9-19.

Clark, G.F. \& Johnston, E.L. 2009. Propagule pressure and disturbance interact to overcome biotic resistance of marine invertebrate communities. Oikos 118, 1679-1686.

Clark, G.F. \& Johnston, E.L. 2011. Temporal change in the diversity-invasibility relationship in the presence of a disturbance regime. Ecology Letters 14, 52-57.

Clark, G.F., Johnston, E.L. \& Leung, B. 2013. Intrinsic time dependence in the diversity-invasibility relationship. Ecology 94, 25-31.

Clark, G.F., Kelaher, B.P., Dafforn, K.A., Coleman, M.A., Knott, N.A., Marzinelli, E.M. \& Johnston, E.L. 2015. What does impacted look like? High diversity and abundance of epibiota in modified estuaries. Environmental Pollution 196, 12-20.

Clarke Murray, C., Pakhomov, E.A. \& Therriault, T.W. 2011. Recreational boating: a large unregulated vector transporting marine invasive species. Diversity and Distributions 17, 1161-1172.

Clynick, B.G., Chapman, M.G. \& Underwood, A.J. 2007. Effects of epibiota on assemblages of fish associated with urban structures. Marine Ecology Progress Series 332, 201-210.

Colautti, R.I., Ricciardi, A., Grigorovich, I.A. \& MacIsaac, H.J. 2004. Is invasion success explained by the enemy release hypothesis? Ecology Letters 7, 721-733. 
Combs, J.K., Reichard, S.H., Groom, M.J., Wilderman, D.L. \& Camp, P.A. 2011. Invasive competitor and native seed predators contribute to rarity of the narrow endemic Astragalus sinuatus Piper. Ecological Applications 21, 2498-2509.

Connell, S.D. 1999. Effects of surface orientation on the cover of epibiota. Biofouling 14, 219-226.

Connell, S.D. \& Glasby, T.M. 1999. Do urban structures influence local abundance and diversity of subtidal epibiota? A case study from Sydney Harbour, Australia. Marine Environmental Research 47, 373-387.

Costa, T.J.F., Pinheiro, H.T., Teixeira, J.B., Mazzei, E.F., Bueno, L., Hora, M.S.C., Joyeux, J.-C., CarvalhoFilho, A., Amado-Filho, G., Sampaio, C.L.S. \& Rocha, L.A. 2014. Expansion of an invasive coral species over Abrolhos Bank, Southwestern Atlantic. Marine Pollution Bulletin 85, 252-253.

Costanza, R., Pérez-Maqueo, O., Martinez, M.L., Sutton, P., Anderson, S.J. \& Mulder, K. 2008. The value of coastal wetlands for hurricane protection. AMBIO: A Journal of the Human Environment 37, 241-248.

Coutts, A.D.M. \& Forrest, B.M. 2007. Development and application of tools for incursion response: Lessons learned from the management of the fouling pest Didemnum vexillum. Journal of Experimental Marine Biology and Ecology 342, 154-162.

Crain, C.M., Kroeker, K. \& Halpern, B.S. 2008. Interactive and cumulative effects of multiple human stressors in marine systems. Ecology Letters 11, 1304-1315.

Dafforn, K.A., Glasby, T.M., Airoldi, L., Rivero, N.K., Mayer-Pinto, M. \& Johnston, E.L. 2015. Marine urbanisation: an ecological framework for designing multifunctional artificial structures. Frontiers in Ecology and the Environment 13, 82-90.

Dafforn, K.A., Glasby, T.M. \& Johnston, E.L. 2008. Differential effects of tributyltin and copper anti-foulants on recruitment of non-indigenous species. Biofouling 24, 23-33.

Dafforn, K.A., Glasby, T.M. \& Johnston, E.L. 2009a. Links between estuarine condition and spatial distributions of marine invaders. Diversity and Distributions 15, 807-821.

Dafforn, K.A., Glasby, T.M. \& Johnston, E.L. 2012. Comparing the invasibility of experimental "reefs" with field observations of natural reefs and artificial structures. PLOS ONE 7, e38124.

Dafforn, K.A., Johnston, E.L. \& Glasby, T.M. 2009b. Shallow moving structures promote marine invader dominance. Biofouling 25, 277-287.

Dafforn, K.A., Lewis, J.A. \& Johnston, E.L. 2011. Antifouling strategies: history and regulation, ecological impacts and mitigation. Marine Pollution Bulletin 62, 453-465.

Dangremond, E.M., Pardini, E.A. \& Knight, T.M. 2010. Apparent competition with an invasive plant hastens the extinction of an endangered lupine. Ecology 91, 2261-2271.

Davidson, I.C., McCann, L.D., Fofonoff, P.W., Sytsma, M.D. \& Ruiz, G.M. 2008. The potential for hullmediated species transfers by obsolete ships on their final voyages. Diversity and Distributions 14, 518-529.

Davidson, I.C., Zabin, C.J., Chang, A.L., Brown, C.W., Sytsma, M.D. \& Ruiz, G.M. 2010. Recreational boats as potential vectors of marine organisms at an invasion hotspot. Aquatic Biology 11, 179-191.

Davies, T.W., Duffy, J.P., Bennie, J. \& Gaston, K.J. 2014. The nature, extent, and ecological implications of marine light pollution. Frontiers in Ecology and the Environment 12, 347-355.

Davis, M.A., Grime, J.P. \& Thompson, K. 2000. Fluctuating resources in plant communities: a general theory of invasibility. Journal of Ecology 88, 528-534.

Delpla, I., Jung, A.-V., Baures, E., Clement, M. \& Thomas, O. 2009. Impacts of climate change on surface water quality in relation to drinking water production. Environment International 35:1225-1233.

Dohn, J., Dembélé, F., Karembé, M., Moustakas, A., Amévor, K.A. \& Hanan, N.P. 2013. Tree effects on grass growth in savannas: competition, facilitation and the stress-gradient hypothesis. Journal of Ecology 101, 202-209.

Drake, J.M. \& Lodge, D.M. 2004. Global hot spots of biological invasions: evaluating options for ballast-water management. Proceedings of the Royal Society of London B: Biological Sciences 271, 575-580.

Drake, J.M. \& Lodge, D.M. 2006. Allee effects, propagule pressure and the probability of establishment: risk analysis for biological invasions. Biological Invasions 8, 365-375.

Drake, J.M. \& Lodge, D.M. 2007. Hull fouling is a risk factor for intercontinental species exchange in aquatic ecosystems. Aquatic Invasions 2, 121-131.

Duarte, C.M. 1995. Submerged aquatic vegetation in relation to different nutrient regimes. Ophelia 41, 87-112.

Dugan, J.E., Airoldi, L., Chapman, M.G., Walker, S.J. \& Schlacher, T. 2011. Estuarine and coastal structures: environmental effects, a focus on shore and nearshore structures. In Treatise on Estuarine and Coastal Science Vol 8, E. Wolanski \& D. McLusky (eds). Waltham: Academic Press, 17-41. 


\section{ANTHROPOGENIC ACTIVITIES AFFECT POST-ARRIVAL SUCCESS OF NIS}

Dukes, J.S. 2001. Biodiversity and invasibility in grassland microcosms. Oecologia 126, 563-568.

Dukes, J.S. \& Mooney, H.M. 1999. Does global change increase the success of biological invaders? Trends in Ecology \& Evolution 14, 135-139.

Dupont, L., Viard, F., Davis, M.H., Nishikawa, T. \& Bishop, J.D.D. 2010. Pathways of spread of the introduced ascidian Styela clava (Tunicata) in Northern Europe, as revealed by microsatellite markers. Biological Invasions 12, 2707-2721.

Durrant, H.M.S., Clark, G.F., Dworjanyn, S.A., Byrne, M. \& Johnston, E.L. 2013. Seasonal variation in the effects of ocean warming and acidification on a native bryozoan, Celleporaria nodulosa. Marine Biology 160, 1903-1911.

Eggleton, J. \& Thomas, K.V. 2004. A review of factors affecting the release and bioavailability of contaminants during sediment disturbance events. Environment International 30, 973-980.

Elser, J.J., Bracken, M.E., Cleland, E.E., Gruner, D.S., Harpole, W.S., Hillebrand, H., Ngai, J.T., Seabloom, E.W., Shurin, J.B. \& Smith, J.E. 2007. Global analysis of nitrogen and phosphorus limitation of primary producers in freshwater, marine and terrestrial ecosystems. Ecology Letters 10, 1135-1142.

Elton, C.S. 1958. The Ecology of Invasions by Animals and Plants. London: Methuen.

FAO. 2012. The state of world fisheries and aquaculture. Food and Agriculture Organization of the United Nations, Rome.

Feary, D.A., Burt, J.A. \& Bartholomew, A. 2011. Artificial marine habitats in the Arabian Gulf: review of current use, benefits and management implications. Ocean \& Coastal Management 54, 742-749.

Fellers, J.H. 1987. Interference and exploitation in a guild of woodland ants. Ecology 68, 1466-1478.

Firth, L.B., Crowe, T.P., Moore, P., Thompson, R.C. \& Hawkins, S.J. 2009. Predicting impacts of climateinduced range expansion: an experimental framework and a test involving key grazers on temperate rocky shores. Global Change Biology 15, 1413-1422.

Firth, L., Knights, A., Thompson, R., Mieszkowska, N., Bridger, D., Evans, A., Moore, P., O'Connor, N., Sheehan, E. \& Hawkins, S. 2016. Ocean sprawl: challenges and opportunities for biodiversity management in a changing world. Oceanography and Marine Biology: An Annual Review 54, 193-269.

Firth, L.B., Schofield, M., White, F.J., Skov, M.W. \& Hawkins, S.J. 2014. Biodiversity in intertidal rock pools: informing engineering criteria for artificial habitat enhancement in the built environment. Marine Environmental Research 102, 122-130.

Firth, L.B., Thompson, R.C., White, F.J., Schofield, M., Skov, M.W., Hoggart, S.P.G., Jackson, J., Knights, A.M. \& Hawkins, S.J. 2013. The importance of water-retaining features for biodiversity on artificial intertidal coastal defence structures. Diversity and Distributions 19, 1275-1283.

Firth, L.B., White, F.J., Schofield, M., Hanley, M.E., Burrows, M.T., Thompson, R.C., Skov, M.W., Evans, A.J., Moore, P.J. \& Hawkins, S.J. 2015. Facing the future: the importance of substratum features for ecological engineering of artificial habitats in the rocky intertidal. Marine and Freshwater Research 67, 131-143.

Fitridge, I., Dempster, T., Guenther, J. \& de Nys, R. 2012. The impact and control of biofouling in marine aquaculture: a review. Biofouling 28, 649-669.

FitzGerald, D.M., Fenster, M.S., Argow, B.A. \& Buynevich, I.V. 2008. Coastal impacts due to sea-level rise. Annual Review of Earth and Planetary Sciences 36, 601-647.

Fleeger, J.W., Carman, K.R. \& Nisbet, R.M. 2003. Indirect effects of contaminants in aquatic ecosystems. Science of the Total Environment 317, 207-233.

Fletcher, R.L. \& Farrell, P. 1999. Introduced brown algae in the North East Atlantic, with particular respect to Undaria pinnatifida (Harvey) Suringar. Helgolander Meeresuntersuchungen 52, 259-275.

Floerl, O. 2014. Challenges and opportunities for understanding and managing biofouling in marine aquaculture. International Congress for Marine Corrosion and Fouling, Singapore.

Floerl, O. \& Coutts, A. 2009. Potential ramifications of the global economic crisis on human-mediated dispersal of marine non-indigenous species. Marine Pollution Bulletin 58, 1595-1598.

Floerl, O. \& Inglis, G.J. 2003. Boat harbour design can exacerbate hull fouling. Austral Ecology 28, 116-127.

Floerl, O., Inglis, G., Dey, K.L. \& Smith, A. 2009a. The importance of transport hubs in stepping-stone invasions. Journal of Applied Ecology 46, 37-45.

Floerl, O., Inglis, G.J. \& Diettrich, J. 2016. Incorporating human behaviour into the risk-release relationship for invasion vectors: why targeting only the worst offenders can fail to reduce spread. Journal of Applied Ecology 53, 742-750. 
Floerl, O., Inglis, G.J. \& Gordon, D.P. 2009b. Patterns of taxonomic diversity and relatedness among native and non-indigenous bryozoans. Diversity and Distributions 15, 438-449.

Floerl, O., Pool, T.K. \& Inglis, G.J. 2004. Positive interactions between nonidigenous species facilitate transport by human vectors. Ecological Applications 14, 1724-1736.

Forrest, B. \& Blakemore, K.A. 2006. Evaluation of treatments to reduce the spread of a marine plant pest with aquaculture transfers. Aquaculture 257, 333-345.

Forrest, B.M., Fletcher, L.M., Atalah, J., Piola, R.F. \& Hopkins, G.A. 2013. Predation limits spread of Didemnum vexillum into natural habitats from refuges on anthropogenic structures. PLoS ONE 8, e82229.

Forrest, B.M., Gardner, J.P.A. \& Taylor, M.D. 2009. Internal borders for managing invasive marine species. Journal of Applied Ecology 46, 46-54.

Freestone, A.L. \& Osman, R.W. 2011. Latitudinal variation in local interactions and regional enrichment shape patterns of marine community diversity. Ecology 92, 208-217.

Freestone, A.L., Osman, R.W., Ruiz, G.M. \& Torchin, M.E. 2011. Stronger predation in the tropics shapes species richness patterns in marine communities. Ecology 92, 983-993.

Freestone, A.L., Ruiz, G.M. \& Torchin, M.E. 2013. Stronger biotic resistance in tropics relative to temperate zone: effects of predation on marine invasion dynamics. Ecology 94, 1370-1377.

Fridley, J.D., Stachowicz, J.J., Naeem, S., Sax, D.F., Seabloom, E.W., Smith, M.D., Stohlgren, T.J., Tilman, D. \& Von Holle, B. 2007. The invasion paradox: reconciling pattern and process in species invasions. Ecology 88, 3-17.

Galil, B., Boero, F., Campbell, M., Carlton, J., Cook, E., Fraschetti, S., Gollasch, S., Hewitt, C., Jelmert, A., Macpherson, E., Marchini, A., McKenzie, C., Minchin, D., Occhipinti-Ambrogi, A., Ojaveer, H., Olenin, S., Piraino, S. \& Ruiz, G. 2015. 'Double trouble': the expansion of the Suez Canal and marine bioinvasions in the Mediterranean Sea. Biological Invasions 17, 973-976.

Galil, B.S., Nehring, S. \& Panov, V. 2007. Waterways as invasion highways - impact of climate change and globalization. In Biological Invasions, W. Nentwig (ed.). Berlin Heidelberg: Springer-Verlag, 59-74.

Gerland, P., Raftery, A.E., Ševčíková, H., Li, N., Gu, D., Spoorenberg, T., Alkema, L., Fosdick, B.K., Chunn, J. \& Lalic, N. 2014. World population stabilization unlikely this century. Science 346, 234-237.

Glasby, T.M. 1999a. Differences between subtidal epibiota on pier pilings and rocky reefs at marinas in Sydney, Australia. Estuarine, Coastal and Shelf Science 48, 281-290.

Glasby, T.M. 1999b. Effects of shading on subtidal epibiotic assemblages. Journal of Experimental Marine Biology and Ecology 234, 275-290.

Glasby, T.M. 2000. Surface composition and orientation interact to affect subtidal epibiota. Journal of Experimental Marine Biology and Ecology 248, 177-190.

Glasby, T.M. \& Connell, S.D. 1999. Urban structures as marine habitats. Ambio 28, 595-598.

Glasby, T.M. \& Connell, S.D. 2001. Orientation and position of substrata have large effects on epibiotic assemblages. Marine Ecology Progress Series 214, 127-135.

Glasby, T.M., Connell, S.D., Holloway, M.G. \& Hewitt, C.L. 2007. Nonindigenous biota on artificial structures: could habitat creation facilitate biological invasions? Marine Biology 151, 887-895.

Godwin, L.S. 2003. Hull fouling of maritime vessels as a pathway for marine species invasions to the Hawaiian Islands. Biofouling 19, 123-131.

Goldstien, S.J., Schiel, D.R. \& Gemmell, N.J. 2010. Regional connectivity and coastal expansion: differentiating pre-border and post-border vectors for the invasive tunicate Styela clava. Molecular Ecology 19, $874-885$.

Grime, J.P. 1977. Evidence for existence of 3 primary strategies in plants and its relevance to ecological and evolutionary theory. American Naturalist 111, 1169-1194.

Grimm, N.B., Foster, D., Groffman, P., Grove, J.M., Hopkinson, C.S., Nadelhoffer, K.J., Pataki, D.E. \& Peters, D.P.C. 2008. The changing landscape: ecosystem responses to urbanization and pollution across climatic and societal gradients. Frontiers in Ecology and the Environment 6, 264-272.

Grosholz, E.D. 2005. Recent biological invasion may hasten invasional meltdown by accelerating historical introductions. Proceedings of the National Academy of Sciences of the United States of America 102, 1088-1091.

Grosholz, E.D., Crafton, R.E., Fontana, R.E., Pasari, J.R., Williams, S.L. \& Zabin, C.J. 2015. Aquaculture as a vector for marine invasions in California. Biological Invasions 17, 1471-1484.

Gust, N., Inglis, G., Floerl, O., Peacock, L., Denny, C. \& Forrest, B. 2008. Assessment of population management options for Styela clava. NIWA, Christchurch. 
Hall, L. W., Scott, M.C. \& Killen, W.D. 1998. Ecological risk assessment of copper and cadmium in surface waters of Chesapeake Bay watershed. Environmental Toxicology and Chemistry 17, 1172-1189.

Hallegraeff, G. \& Gollasch, S. 2006. Anthropogenic introductions of microalgae. In Ecology of Harmful Algae, E. Granéli \& J. Turner (eds). Berlin Heidelberg: Springer, 379-390.

Halpern, B.S., Walbridge, S., Selkoe, K.A., Kappel, C.V., Micheli, F., D’Agrosa, C., Bruno, J.F., Casey, K.S., Ebert, C., Fox, H.E., Fujita, R., Heinemann, D., Lenihan, H.S., Madin, E.M.P., Perry, M.T., Selig, E.R., Spalding, M., Steneck, R. \& Watson, R. 2008. A global map of human impact on marine ecosystems. Science 319, 948-952.

Hamzah, B.A. 2003. International rules on decommissioning of offshore installations: some observations. Marine Policy 27, 339-348.

Hänfling, B., Edwards, F. \& Gherardi, F. 2011. Invasive alien Crustacea: dispersal, establishment, impact and control. BioControl 56, 573-595.

Hawkins, S., Sugden, H., Mieszkowska, N., Moore, P., Poloczanska, E., Leaper, R., Herbert, R. J., Genner, M., Moschella, P. \& Thompson, R. 2009. Consequences of climate-driven biodiversity changes for ecosystem functioning of North European rocky shores. Marine Ecology Progress Series 396, 245-259.

Hay, M.E. \& Fenical, W. 1988. Marine plant-herbivore interactions: the ecology of chemical defense. Annual Review of Ecology and Systematics 19, 111-145.

Hayden, B.J., Unwin, M., Roulston, H., Peacock, L., Floerl, O., Kospartov, M. \& Seaward, K. 2009. Evaluation of vessel movements from the 24 ports and marinas surveyed through the port baseline survey programmes, ZBS2000-04 and ZBS2005-19 (ZBS2005-13). MPI Technical Paper No: 2014/04. Ministry of Primary Industries, Wellington.

Hector, A., Bazeley-White, E., Loreau, M., Otway, S. \& Schmid, B. 2002. Overyielding in grassland communities: testing the sampling effect hypothesis with replicated biodiversity experiments. Ecology Letters 5, 502-511.

Hedge, L.H. \& Johnston, E.L. 2012. Propagule pressure determines recruitment from a commercial shipping pier. Biofouling 28, 73-85.

Hedge, L.H., O'Connor, W.A. \& Johnston, E.L. 2012. Manipulating the intrinsic parameters of propagule pressure: implications for bio-invasion. Ecosphere 3, 1-13 Art48.

Hewitt, C. L. 2002. Distribution and biodiversity of Australian tropical marine bioinvasions. Pacific Science 56, 213-222.

Hewitt, C.L. \& Campbell, M.L. 2007. Mechanisms for the prevention of marine bioinvasions for better biosecurity. Marine Pollution Bulletin 55, 395-401.

Hewitt, C.L. \& Campbell, M.L. 2008. Assessment of relative contribution of vectors to the introduction and translocation of marine invasive species. Report for the Department of Agriculture, Fisheries and Forestry Australia, University of Tasmania

Hoang Tri, N., Adger, W.N. \& Kelly, P.M. 1998. Natural resource management in mitigating climate impacts: the example of mangrove restoration in Vietnam. Global Environmental Change 8, 49-61.

Holloway, M.G. \& Connell, S.D. 2002. Why do floating structures create novel habitats for subtidal epibiota? Marine Ecology Progress Series 235, 43-52.

Holloway, M.G. \& Keough, M.J. 2002. An introduced polychaete affects recruitment and larval abundance of sessile invertebrates. Ecological Applications 12, 1803-1823.

Holmgren, M. \& Scheffer, M. 2010. Strong facilitation in mild environments: the stress gradient hypothesis revisited. Journal of Ecology 98, 1269-1275.

Hudson, J., Viard, F., Roby, C. \& Rius, M. 2016. Anthropogenic transport of species across native ranges: unpredictable genetic and evolutionary consequences. Biology Letters 12, 20160620.

Huston, M.A. 1997. Hidden treatments in ecological experiments: re-evaluating the ecosystem function of biodiversity. Oecologia 108, 449-460.

IMO. 2005. International convention on the control and management of ship's ballast water and sediments. International Maritime Organization, London.

IMO. 2011a. Guidelines for the control and management of ship's biofouling to minimize the transfer of invasive aquatic species (Annex 26, Resolution MEPC.207(62)) (http://www.imo.org/blast/blastDataHelper. asp?data_id=30766). International Maritime Organization, London.

IMO. 2011b. Guidelines for the control and management of ship's biofouling to minimize the transfer of invasive aquatic species (Annex 26, Resolution MEPC.207(62)) (http://www.imo.org/blast/blastDataHelper. asp?data_id=30766). International Maritime Organization, London. 
Inglis, G., Morrisey, D., Woods, C., Sinner, J. \& Newton, M. 2014. Managing the domestic spread of harmful marine organisms. Part A - Operational tools for management. Report prepared for New Zealand Ministry for Primary Industries. National Institute of Water and Atmospheric Research. Christchurch, $166 \mathrm{p}$.

Jerde, C.L., Mahon, A.R., Chadderton, W.L. \& Lodge, D.M. 2011. "Sight-unseen" detection of rare aquatic species using environmental DNA. Conservation Letters 4, 150-157.

Johnson, C.R., Banks, S.C., Barrett, N.S., Cazassus, F., Dunstan, P.K., Edgar, G.J., Frusher, S.D., Gardner, C., Haddon, M., Helidoniotis, F., Hill, K.L., Holbrook, N.J., Hosie, G.W., Last, P.R., Ling, S.D., MelbourneThomas, J., Miller, K., Pecl, G.T., Richardson, A.J., Ridgway, K.R., Rintoul, S.R., Ritz, D.A., Ross, D.J., Sanderson, J.C., Shepherd, S.A., Slotwinski, A., Swadling, K.M. \& Taw, N. 2011. Climate change cascades: shifts in oceanography, species' ranges and subtidal marine community dynamics in eastern Tasmania. Journal of Experimental Marine Biology and Ecology 400, 17-32.

Johnston, E. 2011. Tolerance to contaminants: evidence from chronically-exposed populations of aquatic organisms. In Tolerance to Environmental Contaminants, C. Amiard-Triquet et al. (eds). Boca Raton: CRC Press, Boca Raton, 25-46.

Johnston, E.L., Marzinelli, E.M., Wood, C.A., Speranza, D. \& Bishop, J.D.D. 2011. Bearing the burden of boat harbours: heavy contaminant and fouling loads in a native habitat-forming alga. Marine Pollution Bulletin 62, 2137-2144.

Johnston, E.L. \& Roberts, D.A. 2009. Contaminants reduce the richness and evenness of marine communities: a review and meta-analysis. Environmental Pollution 157, 1745-1752.

Kaluza, P., Kolzsch, A., Gastner, M.T. \& Blasius, B. 2010. The complex network of global cargo ship movements. Journal of the Royal Society Interface 7, 1093-1103.

Keane, R.M. \& Crawley, M.J. 2002. Exotic plant invasions and the enemy release hypothesis. Trends in Ecology \& Evolution 17, 164-170.

Kelly, P.M. \& Adger, W.N. 2000. Theory and practice in assessing vulnerability to climate change and facilitating adaptation. Climatic Change 47, 325-352.

Kennedy, S. 2005. Wind power planning: assessing long-term costs and benefits. Energy Policy 33, 1661-1675.

Kimbro, D.L., Cheng, B.S. \& Grosholz, E.D. 2013. Biotic resistance in marine environments. Ecology Letters 16, 821-833.

Klein, J.C., Underwood, A.J. \& Chapman, M.G. 2011. Urban structures provide new insights into interactions among grazers and habitat. Ecological Applications 21, 427-438.

Knights, A.M., Firth, L.B., Thompson, R.C., Yunnie, A.L.E., Hiscock, K. \& Hawkins, S.J. 2016. Plymouth - a World Harbour through the ages. Regional Studies in Marine Science 8, 297-307.

Knights, A.M., Koss, R.S. \& Robinson, L.A. 2013. Identifying common pressure pathways from a complex network of human activities to support ecosystem-based management. Ecological Applications 23, $755-765$.

Knott, N.A., Underwood, A.J., Chapman, M.G. \& Glasby, T.M. 2004. Epibiota on vertical and on horizontal surfaces on natural reefs and on artificial structures. Journal of the Marine Biological Association of the United Kingdom 84, 1117-1130.

Lagesa, B.G., Fleurya, B.G., Ferreira, C.E.L. \& Pereira, R.C. 2006. Chemical defense of an exotic coral as invasion strategy. Journal of Experimental Marine Biology and Ecology 328, 127-135.

Lambert, C.C. \& Lambert, G. 1998. Non-indigenous ascidians in southern California harbors and marinas. Marine Biology 130, 675-688.

Langhamer, O., Wilhelmsson, D. \& Engström, J. 2009. Artificial reef effect and fouling impacts on offshore wave power foundations and buoys - a pilot study. Estuarine, Coastal and Shelf Science 82, 426-432.

Langston, W., Pope, N., Davey, M., Langston, K., O’Hara, S., Gibbs, P. \& Pascoe, P. 2015. Recovery from TBT pollution in English Channel environments: a problem solved? Marine Pollution Bulletin 95, 551-564.

Lavender, J.T., Dafforn, K.A. \& Johnston, E.L. 2014. Meso-predators: a confounding variable in consumer exclusion studies. Journal of Experimental Marine Biology and Ecology 456, 26-33.

Leung, B., Drake, J.M. \& Lodge, D.M. 2004. Predicting invasions: Propagule pressure and the gravity of allee effects. Ecology 85, 1651-1660.

Levin, S.A. \& Lubchenco, J. 2008. Resilience, robustness, and marine ecosystem-based management. Bioscience 58, 27-32.

Levine, J.M. 2000. Species diversity and biological invasions: relating local process to community pattern. Science 288, 852-854. 
Levine, J.M., Adler, P.B. \& Yelenik, S.G. 2004. A meta-analysis of biotic resistance to exotic plant invasions. Ecology Letters 7, 975-989.

Liancourt, P., Callaway, R.M. \& Michalet, R. 2005. Stress tolerance and competitive-response ability determine the outcome of biotic interactions. Ecology 86, 1611-1618.

Ling, S.D., Johnson, C.R., Ridgway, K., Hobday, A.J. \& Haddon, M. 2009. Climate-driven range extension of a sea urchin: inferring future trends by analysis of recent population dynamics. Global Change Biology 15, 719-731.

Liu, H. \& Stiling, P. 2006. Testing the enemy release hypothesis: a review and meta-analysis. Biological Invasions 8, 1535-1545.

Lotze, H.K., Lenihan, H.S., Bourque, B.J., Bradbury, R.H., Cooke, R.G., Kay, M.C., Kidwell, S.M., Kirby, M.X., Peterson, C.H. \& Jackson, J.B.C. 2006. Depletion, degradation, and recovery potential of estuaries and coastal seas. Science 312, 1806-1809.

Macleod, C.K., Moltschaniwskyj, N.A. \& Crawford, C.M. 2008. Ecological and functional changes associated with long-term recovery from organic enrichment. Marine Ecology Progress Series 365, 17-24.

Macreadie, P.I., Fowler, A.M. \& Booth, D.J. 2011. Rigs-to-reefs: will the deep sea benefit from artificial habitat? Frontiers in Ecology and the Environment 9, 455-461.

Maestre, F.T., Callaway, R.M., Valladares, F. \& Lortie, C.J. 2009. Refining the stress-gradient hypothesis for competition and facilitation in plant communities. Journal of Ecology 97, 199-205.

Marchal, V., Dellink, R., Van Vuuren, D., Clapp, C., Chateau, J., Magné, B. \& van Vliet, J. 2011. OECD environmental outlook to 2050. Organization for Economic Co-operation and Development.

Martínez-Lladó, X., Gibert, O., Martí, V., Díez, S., Romo, J., Bayona, J.M. \& de Pablo, J. 2007. Distribution of polycyclic aromatic hydrocarbons (PAHs) and tributyltin (TBT) in Barcelona harbour sediments and their impact on benthic communities. Environmental Pollution 149, 104-113.

Marzinelli, E.M., Underwood, A.J. \& Coleman, R.A. 2011. Modified habitats influence kelp epibiota via direct and indirect effects. PLOS ONE 6, e21936.

McEnvoy, P.B. \& Coombs, E.M. 1999. Biological control of plant invaders: regional patterns, field experiments, and structured population models. Ecological Applications 9, 387-401.

McGranahan, G., Balk, D. \& Anderson, B. 2007. The rising tide: assessing the risks of climate change and human settlements in low elevation coastal zones. Environment and Urbanization 19, 17-37.

McKenzie, L.A., Johnston, E.L. \& Brooks, R. 2012. Using clones and copper to resolve the genetic architecture of metal tolerance in a marine invader. Ecology and Evolution 2, 1319-1329.

McKinley, A. \& Johnston, E.L. 2010. Impacts of contaminant sources on marine fish abundance and species richness: a review and meta-analysis of evidence from the field. Marine Ecology Progress Series 420, 175-191.

McKinney, M.L. \& Lockwood, J.L. 1999. Biotic homogenization: a few winners replacing many losers in the next mass extinction. Trends in Ecology \& Evolution 14, 450-453.

McKnight, E., García-Berthou, E., Srean, P. \& Rius, M. 2016. Global meta-analysis of native and nonindigenous trophic traits in aquatic ecosystems. Global Change Biology, doi:10.1111/gcb.13524

McQuaid, C.D., Porri, F., Nicastro, K. \& Zardi, G. 2015. Simple, scale-dependent patterns emerge from very complex effects: an example from the intertidal mussels Mytilus galloprovincialis and Perna perna. Oceanography and Marine Biology: An Annual Review 53, 127-156.

Mieszkowska, N., Sugden, H., Firth, L.B. \& Hawkins, S.J. 2014. The role of sustained observations in tracking impacts of environmental change on marine biodiversity and ecosystems. Philosophical Transactions of the Royal Society of London A: Mathematical, Physical and Engineering Sciences 372, 20130339.

Miller, R.J. \& Etter, R.J. 2008. Shading facilitates sessile invertebrate dominance in the rocky subtidal Gulf of Maine. Ecology 89, 452-462.

Mineur, F., Cook, E.J., Minchin, D., Bohn, K., MacLeod, A. \& Maggs, C. 2012. Changing coasts: marine aliens and artificial structures. Oceanography and Marine Biology: An Annual Review 50, 189-234.

Moody, M.E. \& Mack, R.N. 1988. Controlling the spread of plant invasions: the importance of nascent foci. Journal of Applied Ecology 25, 1009-1021.

Morrisey, D., Plew, D. \& Seaward, K. 2011. Aquaculture Readiness Data: Phase II. MAF Technical Paper 58.

Moschella, P.S., Abbiati, M., Åberg, P., Airoldi, L., Anderson, J.M., Bacchiocchi, F., Bulleri, F., Dinesen, G.E., Frost, M., Gacia, E., Granhag, L., Jonsson, P.R., Satta, M.P., Sundelöf, A., Thompson, R.C. \& Hawkins, S.J. 2005. Low-crested coastal defence structures as artificial habitats for marine life: using ecological criteria in design. Coastal Engineering 52, 1053-1071. 
Moss, B., Kosten, S., Meerhof, M., Battarbee, R., Jeppesen, E., Mazzeo, N., Havens, K., Lacerot, G., Liu, Z. \& De Meester, L. 2011. Allied attack: climate change and eutrophication. Inland Waters 1, 101-105.

MPI. 2014. Craft risk management standard: biofouling on vessels arriving to New Zealand. Ministry for Primary Industries, Wellington, New Zealand.

Murray, A.G., Smith, R.J. \& Stagg, R.M. 2002. Shipping and the spread of infectious salmon anemia in Scottish aquaculture. Emerging Infectious Diseases 8, 1-5.

Neo, M.L. \& Low, J.K.Y. 2017. First observations of Tridacna noae (Röding, 1798) (Bivalvia: Heterodonta: Cardiidae) in Christmas Island (Indian Ocean). Marine Biodiversity, doi:10.1007/s12526-017-0678-3

Neves, C.S., Rocha, R.M., Pitombo, F.B. \& Roper, J.J. 2007. Use of artificial substrata by introduced and cryptogenic marine species in Paranagua Bay, southern Brazil. Biofouling 23, 319-330.

Nicholls, R.J. \& Mimura, N. 1998. Regional issues raised by sea-level rise and their policy implications. Climate Research 11, 5-18.

Nikinmaa, M. 2013. Climate change and ocean acidification - interactions with aquatic toxicology. Aquatic Toxicology 126, 365-372.

Nixon, S., Buckley, B., Granger, S. \& Bintz, J. 2001. Responses of very shallow marine ecosystems to nutrient enrichment. Human and Ecological Risk Assessment: An International Journal 7, 1457-1481.

Nixon, S., Oviatt, C., Frithsen, J. \& Sullivan, B. 1986. Nutrients and the productivity of estuarine and coastal marine ecosystems. Journal of the Limnological Society of Southern Africa 12, 43-71.

Nydam, M. \& Stachowicz, J.J. 2007. Predator effects on fouling community development. Marine Ecology Progress Series 337, 93-101.

O'Neil, J., Davis, T.W., Burford, M.A. \& Gobler, C. 2012. The rise of harmful cyanobacteria blooms: the potential roles of eutrophication and climate change. Harmful Algae 14, 313-334.

Olafsen, T. 2012. Value created from productive oceans in 2050. Report for the Royal Norwegian Society of Sciences and Letters (DKNVS) and the Norwegian Academy of Technological Sciences (NTVA), Trondheim.

Olden, J.D., Poff, N.L., Douglas, M.R., Douglas, M.E. \& Fausch, K.D. 2004. Ecological and evolutionary consequences of biotic homogenization. Trends in Ecology \& Evolution 19, 18-24.

Ordóñez, V., Pascual, M., Rius, M. \& Turon, X. 2013. Mixed but not admixed: a spatial analysis of genetic variation of an invasive ascidian on natural and artificial substrates. Marine Biology 160, 1645-1660.

Osman, R. \& Whitlatch, R. 1995. Predation on early ontogenetic life stages and its effect on recruitment into a marine epifaunal community. Oceanographic Literature Review 9, 772.

Osman, R.W. \& Whitlatch, R.B. 2004. The control of the development of a marine benthic community by predation on recruits. Journal of Experimental Marine Biology and Ecology 311, 117-145.

Page, H.M., Dugan, J.E., Culver, C.S. \& Hoesterey, J.C. 2006. Exotic invertebrate species on offshore oil platforms. Marine Ecology Progress Series 325, 101-107.

Parente, V., Ferreira, D., dos Santos, E.M. \& Luczynski, E. 2006. Offshore decommissioning issues: deductibility and transferability. Energy Policy 34, 1992-2001.

Parrish, J.A.D. \& Bazzaz, F.A. 1982. Responses of plants from three successional communities to a nutrient gradient. Journal of Ecology 70, 233-248.

Pawlik, J.R. 1993. Marine invertebrate chemical defenses. Chemical Reviews 93, 1911-1922.

Pearson, S., Windupranata, W., Pranowo, S.W., Putri, A., Ma, Y., Vila-Concejo, A., Fernández, E., Méndez, G., Banks, J., Knights, A.M. \& Firth, L.B. 2016. Conflicts in some of the World Harbours: what needs to happen next? Maritime Studies 15: 10-33.

Pearson, T.H. \& Rosenberg, R. 1978. Macrobenthic succession in relation to organic enrichment and pollution of the marine environment. Oceanography and Marine Biology: An Annual Review 16, 229-311.

Perkol-Finkel, S., Shashar, N., Barneah, O., Ben-David-Zaslow, R., Oren, U., Reichart, T., Yacobovich, T., Yahel, G., Yahel, R. \& Benayahu, Y. 2005. Fouling reefal communities on artificial reefs: does age matter? Biofouling 21, 127-140.

Perkol-Finkel, S., Zilman, G., Sella, I., Miloh, T. \& Benayahu, Y. 2008. Floating and fixed artificial habitats: spatial and temporal patterns of benthic communities in a coral reef environment. Estuarine, Coastal and Shelf Science 77, 491-500.

Pineda, M.C., McQuaid, C.D., Turon, X., López-Legentil, S., Ordóñez, V. \& Rius, M. 2012. Tough adults, frail babies: an analysis of stress sensitivity across early life-history stages of widely introduced marine invertebrates. PLOS ONE 7, e46672. 


\section{ANTHROPOGENIC ACTIVITIES AFFECT POST-ARRIVAL SUCCESS OF NIS}

Pinn, E.H., Mitchell, K. \& Corkill, J. 2005. The assemblages of groynes in relation to substratum age, aspect and microhabitat. Estuarine, Coastal and Shelf Science 62, 271-282.

Piola, R.F., Dafforn, K.A. \& Johnston, E.L. 2009. The influence of antifouling practices on marine invasions: a mini-review. Biofouling 25, 633-644.

Piola, R.F. \& Johnston, E.L. 2006. Differential tolerance to metals among populations of the introduced bryozoan Bugula neritina. Marine Biology 148, 997-1010.

Piola, R.F. \& Johnston, E.L. 2008a. Pollution reduces native diversity and increases invader dominance in marine hard-substrate communities. Diversity and Distributions 14, 329-342.

Piola, R.F. \& Johnston, E.L. 2008b. The potential for translocation of marine species via small-scale disruptions to antifouling surfaces. Biofouling 24, 145-155.

Piola, R.F. \& Johnston, E.L. 2009. Comparing differential tolerance of native and non-indigenous marine species to metal pollution using novel assay techniques. Environmental Pollution 157, 2853-2864.

Prentis, P.J., Wilson, J.R.U., Dormontt, E.E., Richardson, D.M. \& Lowe, A.J. 2008. Adaptive evolution in invasive species. Trends in Plant Science 13, 288-294.

Punt, M.J., Groeneveld, R.A., van Ierland, E.C. \& Stel, J.H. 2009. Spatial planning of offshore wind farms: a windfall to marine environmental protection? Ecological Economics 69, 93-103.

Rabalais, N., Diaz, R., Levin, L., Turner, R., Gilbert, D. \& Zhang, J. 2010. Dynamics and distribution of natural and human-caused hypoxia. Biogeosciences 7, 585-619.

Rabalais, N.N., Turner, R.E., Díaz, R.J. \& Justić, D. 2009. Global change and eutrophication of coastal waters. ICES Journal of Marine Science: Journal du Conseil 66, 1528-1537.

Rius, M., Branch, G.M., Griffiths, C.L. \& Turon, X. 2010. Larval settlement behaviour in six gregarious ascidians in relation to adult distribution. Marine Ecology Progress Series 418, 151-163.

Rius, M., Clusella-Trullas, S., McQuaid, C.D., Navarro, R.A., Griffiths, C.L., Matthee, C.A., von der Heyden, S. \& Turon, X. 2014a. Range expansions across ecoregions: interactions of climate change, physiology and genetic diversity. Global Ecology and Biogeography 23, 76-88.

Rius, M. \& Darling, J.A. 2014. How important is intraspecific genetic admixture to the success of colonising populations? Trends in Ecology \& Evolution 29, 233-242.

Rius, M., Heasman, K.G. \& McQuaid, C.D. 2011. Long-term coexistence of non-indigenous species in aquaculture facilities. Marine Pollution Bulletin 62, 2395-2403.

Rius, M. \& McQuaid, C.D. 2009. Facilitation and competition between invasive and indigenous mussels over a gradient of physical stress. Basic and Applied Ecology 10, 607-613.

Rius, M., Pineda, M.C. \& Turon, X. 2009. Population dynamics and life cycle of the introduced ascidian Microcosmus squamiger in the Mediterranean Sea. Biological Invasions 11, 2181-2194.

Rius, M., Potter, E.E., Aguirre, J.D. \& Stachowicz, J.J. 2014b. Mechanisms of biotic resistance across complex life cycles. Journal of Animal Ecology 83, 296-305.

Rius, M., Turon, X., Bernardi, G., Volckaert, F.A. \& Viard, F. 2015. Marine invasion genetics: from spatiotemporal patterns to evolutionary outcomes. Biological Invasions 17, 869-885.

Rius, M., Turon, X., Ordóñez, V. \& Pascual, M. 2012. Tracking invasion histories in the sea: facing complex scenarios using multilocus data. PLoS ONE 7, e35815.

Rivero, N.K., Dafforn, K.A., Coleman, M.A. \& Johnston, E.L. 2013. Environmental and ecological changes associated with a marina. Biofouling 29, 803-815.

Rodriguez, L.F. 2006. Can invasive species facilitate native species? Evidence of how, when, and why these impacts occur. Biological Invasions 8, 927-939.

Rodríguez-Obeso, O., Alvarez-Guerra, M., Andrés, A., Viguri, J., DelValls, T., Riba, I. \& Martín-Díaz, M. 2007. Monitoring and managing sediment quality and impact assessment in Spain in the past 10 years. Trends in Analytical Chemistry 26, 252-260.

Roman, J. \& Darling, J.A. 2007. Paradox lost: genetic diversity and the success of aquatic invasions. Trends in Ecology \& Evolution 22, 454-464.

Rosa, M., Holohan, B., Shumway, S., Bullard, S., Wikfors, G., Morton, S. \& Getchis, T. 2013. Biofouling ascidians on aquaculture gear as potential vectors of harmful algal introductions. Harmful Algae 23, $1-7$.

Ruiz, G. \& Carlton, J. 2003. Invasive Species - Vectors and Management Strategies. Washington, DC: Island Press. 
Ruiz, G.M., Carlton, J.T., Grosholz, E.D. \& Hines, A.H. 1997. Global invasions of marine and estuarine habitats by non-indigenous species: mechanisms, extent, and consequences. American Zoologist 37, 621-632.

Ruiz, G.M., Fofonoff, P.W., Carlton, J.T., Wonham, M.J. \& Hines, A.H. 2000. Invasion of coastal marine communities in North America: apparent patterns, processes and biases. Annual Review of Ecology and Systematics 31, 481-531.

Ruiz, G.M. \& Hewitt, C.L. 2002. Toward understanding patterns of coastal marine invasions: a prospectus. In Invasive Aquatic Species of Europe. Distribution, Impacts and Management, E. Leppäkoski et al. (eds). Dordrecht: Springer, 529-547.

Russ, G.R. 1980. Effects of predation by fishes, competition, and the structural complexity of the substratum on the establishment of a marine epifaunal community. Journal of Experimental Marine Biology and Ecology 42, 55-69.

Russ, G.R. 1982. Overgrowth in a marine epifaunal community: competitive hierarchies and competitive networks. Oecologia 53, 12-19.

Sammarco, P.W., Brazeau, D.A. \& Sinclair, J. 2012. Genetic connectivity in scleractinian corals across the northern Gulf of Mexico: oil/gas platforms, and relationship to the Flower Garden Banks. PLoS ONE 7, e30144.

Sammarco, P.W., Porter, S.A. \& Cairns, S.D. 2010. A new coral species introduced into the Atlantic Ocean Tubastraea micranthus (Ehrenberg 1834)(Cnidaria, Anthozoa, Scleractinia): an invasive threat. Aquatic Invasions 5, 131-140.

Sammarco, P.W., Porter, S.A., Sinclair, J. \& Genazzio, M. 2014. Population expansion of a new invasive coral species, Tubastraea micranthus, in the northern Gulf of Mexico. Marine Ecology Progress Series 495, $161-173$.

Saunders, R.J. \& Connell, S.D. 2001. Interactive effects of shade and surface orientation on the recruitment of spirorbid polychaetes. Austral Ecology 26, 109-115.

Schiedek, D., Sundelin, B., Readman, J.W. \& Macdonald, R.W. 2007. Interactions between climate change and contaminants. Marine Pollution Bulletin 54, 1845-1856.

Schiff, K., Diehl, D. \& Valkirs, A. 2004. Copper emissions from antifouling paint on recreational vessels. Marine Pollution Bulletin 48, 371-377.

Schimanski, K.B. 2015. The importance of selective filters on vessel biofouling invasion processes. $\mathrm{PhD}$ thesis, University of Canterbury, New Zealand.

Schoener, T.W. 1974. Resource partitioning in ecological communities. Science 185, 27-39.

Schröder, V. \& De Leaniz, C.G. 2011. Discrimination between farmed and free-living invasive salmonids in Chilean Patagonia using stable isotope analysis. Biological Invasions 13, 203-213.

Schroeder, D.M. \& Love, M.S. 2004. Ecological and political issues surrounding decommissioning of offshore oil facilities in the Southern California Bight. Ocean \& Coastal Management 47, 21-48.

Seebens, H., Gastner, M.T. \& Blasius, B. 2013. The risk of marine bioinvasion caused by global shipping. Ecology Letters 16, 782-790.

Shafer, D.J. 1999. The effects of dock shading on the seagrass Halodule wrightii in Perdido Bay, Alabama. Estuaries 22, 936-943.

Shears, N.T. \& Babcock, R.C. 2002. Marine reserves demonstrate top-down control of community structure on temperate reefs. Oecologia 132, 131-142.

Sheehy, D.J. \& Vik, S.F. 2010. The role of constructed reefs in non-indigenous species introductions and range expansions. Ecological Engineering 36, 1-11.

Shenkar, N., Zeldman, Y. \& Loya, Y. 2008. Ascidian recruitment patterns on an artificial reef in Eilat (Red Sea). Biofouling 24, 119-128.

Simberloff, D. \& Gibbons, L. 2004. Now you see them, now you don't - population crashes of established introduced species. Biological Invasions 6, 161-172.

Simberloff, D. \& Von Holle, B. 1999. Positive interactions of nonindigenous species: invasional meltdown? Biological Invasions 1, 21-32.

Simkanin, C., Davidson, I., Falkner, M., Sytsma, M. \& Ruiz, G. 2009. Intra-coastal ballast water flux and the potential for secondary spread of non-native species on the US West Coast. Marine Pollution Bulletin 58, 366-374. 


\section{ANTHROPOGENIC ACTIVITIES AFFECT POST-ARRIVAL SUCCESS OF NIS}

Simkanin, C., Dower, J.F., Filip, N., Jamieson, G. \& Therriault, T.W. 2013. Biotic resistance to the infiltration of natural benthic habitats: examining the role of predation in the distribution of the invasive ascidian Botrylloides violaceus. Journal of Experimental Marine Biology and Ecology 439, 76-83.

Simoncini, M. \& Miller, R.J. 2007. Feeding preference of Strongylocentrotus droebachiensis (Echinoidea) for a dominant native ascidian, Aplidium glabrum, relative to the invasive ascidian Botrylloides violaceus. Journal of Experimental Marine Biology and Ecology 342, 93-98.

Simpson, S.L. \& Spadaro, D.A. 2011. Performance and sensitivity of rapid sublethal sediment toxicity tests with the amphipod Melita plumulosa and copepod Nitocra spinipes. Environmental Toxicology and Chemistry 30, 2326-2334.

Sinner, J., Forrest, B.M., Newton, M., Hopkins, G.A., Inglis, G., Woods, C. \& Morrisey, D. 2013. Managing the domestic spread of harmful marine organisms, Part B: statutory framework and analysis of options. Report prepared for New Zealand Ministry for Primary Industries. Cawthron Institute report No. 2442. Nelson, 73 p.

Smith, R., Bolam, S., Rees, H. \& Mason, C. 2008. Macrofaunal recovery following TBT ban. Environmental Monitoring and Assessment 136, 245-256.

Smith, V.H., Joye, S.B. \& Howarth R.W. 2006. Eutrophication of freshwater and marine ecosystems. Limnology and Oceanography 51, 351-355.

Snyder, D.B. \& Burgess, G.H. 2007. The Indo-Pacific red lionfish, Pterois volitans (Pisces: Scorpaenidae), new to Bahamian ichthyofauna. Coral Reefs 26, 175.

Sokolova, I.M. \& Lannig, G. 2008. Interactive effects of metal pollution and temperature on metabolism in aquatic ectotherms: implications of global climate change. Climate Research 37, 181-201.

Sorte, C.J.B., Williams, S.L. \& Zerebecki, R.A. 2010. Ocean warming increases threat of invasive species in a marine fouling community. Ecology 91, 2198-2204.

Soto, D., Arismendi, I., Gonzalez, J., Sanzana, J., Jara, F., Jara, C., Guzman, E. \& Lara, A. 2006. Southern Chile, trout and salmon country: invasion patterns and threats for native species. Revista Chilena de Historia Natural 79, 97-117.

Soto, D., Jara, F. \& Moreno, C. 2001. Escaped salmon in the inner seas, southern Chile: facing ecological and social conflicts. Ecological Applications 11, 1750-1762.

Soto, D. \& Norambuena, F. 2004. Evaluation of salmon farming effects on marine systems in the inner seas of southern Chile: a large-scale mensurative experiment. Journal of Applied Ichthyology 20, 493-501.

Stachowicz, J.J., Fried, H., Osman, R.W. \& Whitlach, R.B. 2002a. Biodiversity, invasion resistance, and marine ecosystem function: reconciling pattern and process. Ecology 83, 2575-2590.

Stachowicz, J.J., Terwin, J.R., Whitlatch, R.B. \& Osman, R.W. 2002b. Linking climate change and biological invasions: ocean warming facilitates nonindigenous species invasions. Proceedings of the National Academy of Sciences of the United States of America 99, 15497-15500.

Stachowicz, J.J., Whitlatch, R.B. \& Osman, R.W. 1999. Species diversity and invasion resistance in a marine ecosystem. Science 286, 1577-1579.

Statham, P.J. 2012. Nutrients in estuaries - an overview and the potential impacts of climate change. Science of the Total Environment 434, 213-227.

Steinberg, P.D. 1986. Chemical defenses and the susceptibility of tropical marine brown algae to herbivores. Oecologia 69, 628-630.

Suarez, A.V., Holway, D.A. \& Ward, P.S. 2005. The role of opportunity in the unintentional introduction of nonnative ants. Proceedings of the National Academy of Sciences of the United States of America 102, 17032-17035.

Sutherland, S. 2004. What makes a weed a weed: life history traits of native and exotic plants in the USA. Oecologia 141, 24-39.

Svane, I. \& Dolmer, P. 1995. Perception of light at settlement: a comparative study of two invertebrate larvae, a scyphozoan planula and a simple ascidian tadpole. Journal of Experimental Marine Biology and Ecology 187, 51-61.

Tamburri, M.N., Ruiz, G.M., Apple, R., Altshuller, D., Fellbeck, H. \& Hurley, W.L. 2005. Evaluations of a ballast water treatment to stop invasive species and tank corrosion. Discussion. Transactions-Society of Naval Architects and Marine Engineers 113, 558-568. 
Tamelander, J., Riddering, L., Haag, F., Matheickal, J. \& No, G.M.S. 2010. Guidelines for development of a national ballast water management strategy, GloBallast Partnerships Project Coordination Unit, International Maritime Organization.

Teo, S.L.M. \& Ryland, J.S. 1994. Toxicity and palatability of some British ascidians. Marine Biology 120, 297-303.

Tepolt, C., Darling, J., Bagley, M., Geller, J., Blum, M. \& Grosholz, E. 2009. European green crabs (Carcinus maenas) in the northeastern Pacific: genetic evidence for high population connectivity and current-mediated expansion from a single introduced source population. Diversity and Distributions 15, 997-1009.

Tewfik, A., Rasmussen, J. \& McCann, K.S. 2005. Anthropogenic enrichment alters a marine benthic foodweb. Ecology 86, 2726-2736.

Theoharides, K.A. \& Dukes, J.S. 2007. Plant invasion across space and time: factors affecting nonindigenous species success during four stages of invasion. New Phytologist 176, 256-273.

Tilman, D. 1997. Community invasibility, recruitment limitation, and grassland biodiversity. Ecology 78, 81-92.

Toh, K.B., Ng, C.S.L., Wu, B., Toh, T.C., Cheo, P.R., Tun, K. \& Chou, L.M. 2016. Spatial variability of epibiotic assemblages on marina pontoons in Singapore. Urban Ecosystems, doi:10.1007/s11252-016-0589-2

Torchin, M.E., Lafferty, K.D., Dobson, A.P., McKenzie, V.J. \& Kuris, A.M. 2003. Introduced species and their missing parasites. Nature 421, 628-630.

Torchin, M., Lafferty, K. \& Kuris, A. 2002. Parasites and marine invasions. Parasitology 124, 137-151.

Trannum, H.C., Olsgard, F., Skei, J.M., Indrehus, J., Overas, S. \& Eriksen, J. 2004. Effects of copper, cadmium and contaminated harbour sediments on recolonisation of soft-bottom communities. Journal of Experimental Marine Biology and Ecology 310, 87-114.

Vallejo-Marín, M. \& Hiscock, S.J. 2016. Hybridization and hybrid speciation under global change. The New Phytologist 211, 1170-1187.

Van Kleunen, M., Weber, E. \& Fischer, M. 2010. A meta-analysis of trait differences between invasive and non-invasive plant species. Ecology Letters 13, 235-245.

Vaselli, S., Bulleri, F. \& Benedetti-Cecchi, L. 2008. Hard coastal-defence structures as habitats for native and exotic rocky-bottom species. Marine Environmental Research 66, 395-403.

Vermeij, M.J.A., Smith, T.B., Dailer, M.L. \& Smith, C.M. 2009. Release from native herbivores facilitates the persistence of invasive marine algae: a biogeographical comparison of the relative contribution of nutrients and herbivory to invasion success. Biological Invasions 11, 1463-1474.

Voisin, M., Engel, C.R. \& Viard, F. 2005. Differential shuffling of native genetic diversity across introduced regions in a brown alga: aquaculture vs. maritime traffic effects. Proceedings of the National Academy of Sciences of the United States of America 102, 5432-5437.

Ware, C., Berge, J., Sundet, J.H., Kirkpatrick, J.B., Coutts, A.D.M., Jelmert, A., Olsen, S.M., Floerl, O., Wisz, M.S. \& Alsos, I.G. 2014. Climate change, non-indigenous species and shipping: assessing the risk of species introduction to a high-Arctic archipelago. Diversity and Distributions 20, 10-19.

Warnken, J., Dunn, R.J.K. \& Teasdale, P.R. 2004. Investigation of recreational boats as a source of copper at anchorage sites using time-integrated diffusive gradients in thin film and sediment measurements. Marine Pollution Bulletin 49, 833-843.

Wasson, K., Zabin, C.J., Bedinger, L., Diaz, M.C. \& Pearse, J.S. 2001. Biological invasions of estuaries without international shipping: the importance of intraregional transport. Biological Conservation 102, $143-153$.

Wernberg, T., Russell, B.D., Moore, P.J., Ling, S.D., Smale, D.A., Campbell, A., Coleman, M.A., Steinberg, P.D., Kendrick, G.A. \& Connell, S.D. 2011. Impacts of climate change in a global hotspot for temperate marine biodiversity and ocean warming. Journal of Experimental Marine Biology and Ecology 400, $7-16$.

Wernberg, T., Smale, D.A. \& Thomsen, M.S. 2012. A decade of climate change experiments on marine organisms: procedures, patterns and problems. Global Change Biology 18, 1491-1498.

Wernberg, T., Smale, D.A., Tuya, F., Thomsen, M.S., Langlois, T.J., de Bettignies, T., Bennett, S. \& Rousseaux, C.S. 2013. An extreme climatic event alters marine ecosystem structure in a global biodiversity hotspot. Nature Climate Change 3, 78-82.

Whitehead, P., Wilby, R., Battarbee, R., Kernan, M. \& Wade, A.J. 2009. A review of the potential impacts of climate change on surface water quality. Hydrological Sciences Journal 54, 101-123. 
Wilcove, D.S., Rothstein, D., Jason, D., Phillips, A. \& Losos, E. 1998. Quantifying threats to imperiled species in the United States. Bioscience 48, 607-615.

Williams, S.L., Davidson, I.C., Pasari, J.R., Ashton, G.V., Carlton, J.T., Crafton, R.E., Fontana, R.E., Grosholz, E.D., Miller, A.W., Ruiz, G.M. \& Zabin, C.J. 2013. Managing multiple vectors for marine invasions in an increasingly connected world. BioScience 63, 952-966.

Williams, S.L. \& Smith, J.E. 2007. A global review of the distribution, taxonomy, and impacts of introduced seaweeds. Annual Review of Ecology, Evolution, and Systematics 38, 327-359.

Williamson, M.H., Brown, K.C., Holdgate, M.W., Kornberg, H., Southwood, R. \& Mollison, D. 1986. The analysis and modelling of British invasions. Philosophical Transactions of the Royal Society of London 314, 505-522.

Wilson, J.C. \& Elliott, M. 2009. The habitat-creation potential of offshore wind farms. Wind Energy 12, 203-212.

Winder, M., Jassby, A.D. \& Mac Nally, R. 2011. Synergies between climate anomalies and hydrological modifications facilitate estuarine biotic invasions. Ecology Letters 14, 749-757.

Woodin, S.A., Wethey, D.S. \& Dubois, S.F. 2014. Population structure and spread of the polychaete Diopatra biscayensis along the French Atlantic coast: human-assisted transport by-passes larval dispersal. Marine Environmental Research 102, 110-121.

Yeo, D.C., Ahyong, S.T., Lodge, D.M., Ng, P.K., Naruse, T. \& Lane, D.J. 2009. Semisubmersible oil platforms: understudied and potentially major vectors of biofouling-mediated invasions. Biofouling 26, 179-186.

Zabin, C.J., Ashton, G.V., Brown, C.W., Davidson, I.C., Sytsma, M.D. \& Ruiz, G.M. 2014. Small boats provide connectivity for nonindigenous marine species between a highly invaded international port and nearby coastal harbors Management of Biological Invasions 5, 97-112.

Zaiko, A., Schimanski, K., Pochon, X., Hopkins, G.A., Goldstien, S., Floerl, O. \& Wood, S.A. 2016. Metabarcoding improves detection of eukaryotes from early biofouling communities: implications for pest monitoring and pathway management. Biofouling 32, 671-684.

Zerebecki, R.A. \& Sorte, C.J.B. 2011. Temperature tolerance and stress proteins as mechanisms of invasive species success. PloS one 6, e14806.

Zhan, A., Briski, E., Bock, D.G., Ghabooli, S. \& MacIsaac, H.J. 2015. Ascidians as models for studying invasion success. Marine Biology 162, 2449-2470. 


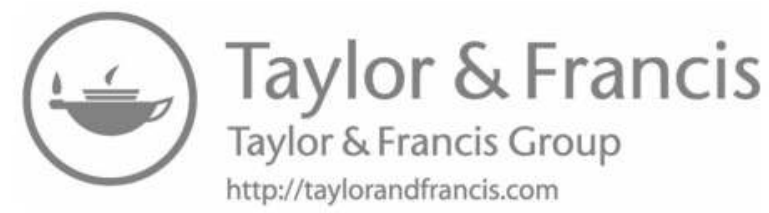




\title{
A REVIEW OF HERBIVORE EFFECTS ON SEAWEED INVASIONS
}

\author{
SWANTJE ENGE ${ }^{1,2}$, JOSEFIN SAGERMAN $^{3}$, SOFIA A. WIKSTRÖM ${ }^{3}$ \& HENRIK PAVIA ${ }^{4}$ \\ ${ }^{1}$ Department of Plant and Environmental Sciences, \\ University of Copenhagen, 1871 Frederiksberg, Denmark \\ ${ }^{2}$ Institute for Chemistry and Biology of the Marine Environment, \\ University of Oldenburg, 26382 Wilhelmshaven, Germany \\ ${ }^{3}$ Baltic Sea Centre, Stockholm University, 10691 Stockholm, Sweden \\ ${ }^{4}$ Department of Marine Sciences-Tjärnö, University of Gothenburg, 45296 Strömstad, Sweden \\ *Corresponding author: Henrik Pavia \\ e-mail: henrik.pavia@marine.gu.se
}

\begin{abstract}
Almost 300 non-native seaweeds are identified worldwide and an increasing number of these are classified as invasive with potential negative effects on the diversity and functioning of native ecosystems. Marine herbivores affect seaweed biomass and community structure in marine habitats across the globe. Consequently, herbivore-seaweed interactions are expected to be important for the establishment and invasion success of non-native seaweeds. To synthesize current knowledge of consumer effects on non-native seaweeds, we performed a meta-analysis on feeding preferences of native herbivores for non-native versus native seaweeds. Data were included from 35 studies, published from 1992-2015 and comprising 18 non-native seaweeds. Results showed that overall, native herbivores tended to prefer to feed on native rather than non-native seaweeds. Preferences were, however, variable across studies with significant differences between taxonomic and functional groups of seaweeds. In particular, filamentous red non-native seaweeds were of low palatability to native herbivores. No general feeding preferences were apparent between natives and non-natives for brown and green seaweeds, or for leathery and corticated seaweeds. In addition, we reviewed the existing studies on the effects of consumers on the performance of native and non-native seaweeds in invaded communities. This indicated that non-native seaweeds performed better than their native competitors in the presence of grazers, but in many cases had superior competitive abilities also in the absence of herbivory. To achieve a comprehensive evaluation of consumers' role in seaweed invasion success, future research should have a larger focus on manipulative community experiments, ideally on time scales that include seasonal changes and complete life cycles of the seaweeds.
\end{abstract}

\section{Introduction}

At any time, several thousand marine species are shuffled between biogeographical regions of the world's oceans (Johnson \& Chapman 2007). Some of these species establish in their new communities and become widespread and abundant, being deemed invasive, with significant impacts on community composition and ecosystem properties (Williamson \& Fitter 1996). The global number of non-indigenous seaweeds has reached more than 270 species (Williams \& Smith 2007), many of them reported to negatively affect native seaweed communities in terms of cover, density and biodiversity (Schaffelke \& Hewitt 2007, Engelen et al. 2015, Maggi et al. 2015). Identification of the 
factors that control establishment and invasion success of non-native species is a key challenge in invasion ecology and important for risk assessment and management of non-indigenous seaweeds.

Herbivores have large influence on the abundance and community structure of both terrestrial and marine primary producers across ecosystems (e.g. Lubchenco \& Gaines 1981, Hawkins \& Hartnoll 1983, Hawkins et al. 1992, Hay \& Steinberg 1992, Burkepile \& Hay 2008, Poore et al. 2012). Consequently, herbivore-plant interactions have long been suggested to be crucial also for the outcome of plant invasions. On the one hand, herbivores are recognized to contribute to biotic resistance against the establishment and proliferation of non-native plants (Elton 1958, Maron \& Vila 2001). On the other hand, herbivore foraging has been suggested to drive invasions, when native herbivores preferably consume native over the non-native plant species. The latter argument forms the basis for the enemy release hypothesis (ERH), which states that non-native species become invasive since they escape the regulation of their co-evolved enemies in their native range and are less affected by enemies compared to the native competitors in their new range (Darwin 1859, Elton 1958, Keane \& Crawley 2002). The reduced negative impact of herbivores is expected to give the non-native species a competitive advantage over the native plants in the community, leading to dominance and a biological invasion (Keane \& Crawley 2002).

The concepts of biotic resistance and enemy release originate from terrestrial plant systems; the findings from these systems have been summarized in several reviews and meta-analyses (Colautti et al. 2004, Levine et al. 2004, Liu \& Stiling 2006, Parker et al. 2006, Chun et al. 2010). Recently, Kimbro et al. (2013) published a meta-analysis on biotic resistance in marine environments, indicating negative effects of consumers on non-native marine primary producers. Seaweeds were only represented by seven studies in their analysis and seaweed data were analyzed together with data on a non-native salt marsh grass. Thus, a comprehensive quantitative synthesis of research on herbivore effects on non-native seaweeds is still lacking.

Seaweed communities are strongly dominated by generalist herbivores (Hawkins \& Hartnoll 1983, Hawkins et al. 1992, Hay \& Fenical 1992), which are more likely than specialists to include newly encountered species into their diet. Accordingly, generalist consumers have been suggested to counteract invasions by providing biotic resistance instead of facilitating invasions through enemy release (Parker \& Hay 2005, Parker et al. 2006). There are, however, mechanisms by which non-native plants can escape generalist herbivores in their new range, especially by means of chemical defences (Wikström et al. 2006, Verhoeven et al. 2009, Forslund et al. 2010, Schaffner et al. 2011, Enge et al. 2012, Nylund et al. 2012). Seaweeds are known to be rich in secondary metabolites (Hay \& Fenical 1992) and there is an increasing number of examples where potent chemical defences against native herbivores have been demonstrated in non-native seaweeds (Lemee et al. 1996, Lyons et al. 2007, Nylund et al. 2011, Enge et al. 2012). It is not known, however, if low palatability to generalist herbivores is a common trait of non-native seaweeds or if this trait is important for invasion success in seaweed communities.

The aim of this study was to review and synthesize current findings of consumer effects on nonnative seaweeds. As part of the predictions of the ERH, we specifically explored via a meta-analysis whether non-native seaweeds are less palatable than native species, and thus generally experience a reduced impact by herbivores compared to native competitors. We further examined if there are differences among 1) seaweed taxonomic groups, 2) seaweed functional groups, 3) herbivore groups or 4) regions. Furthermore, we reviewed and summarized the literature that assessed the effects of herbivory on the competitive outcome between non-native and native seaweeds in a community.

\section{Material and methods}

\section{Literature search and data extraction}

Relevant studies for the meta-analysis were identified in the online database ISI Web of Science in August 2015, with no restrictions on publication year, using the following combination of search terms: ((introduced OR invasive OR non-native OR exotic OR alien OR non-indigenous) AND 
(seaweed* OR alga* OR macroalga*) AND (herbivor* OR consum* OR *graz* OR enem* OR prefer*)). In order to retrieve studies that tested non-native seaweeds but without specifying the species as non-native in the title or abstract, we performed an additional search for all non-native seaweeds listed in Williamson \& Smith (2007) using the search terms: (('algal species name') AND (enem* OR herbivor* OR consum* OR graz*)). To determine if the seaweeds in these studies were non-native, we compared the study region with the reported natural distribution of the species. We further included three as yet non-peer-reviewed datasets (S.A. Wikström unpublished, K. Hill unpublished, S. Jakobsson unpublished). All titles and abstracts of the search results were screened for studies assessing feeding preferences or herbivore damage on non-native compared to native seaweeds, as well as for studies examining seaweed performances and competitive relationships between the non-native and native seaweeds in the presence and absence of herbivory. To be included in the final dataset, the studies had to meet the following criteria: 1) the investigated seaweed was non-native to the study region while the seaweeds used for comparison and the herbivores were native to the study region; 2) the study assessed herbivore preference, damage or their effects on both non-native and native seaweed performance under laboratory or field conditions in two- or multiple-species experiments using living algal material; 3) the experimental design included proper controls and presented all necessary measures for calculating the effect size. We excluded data of epifaunal abundances on non-native compared to native seaweeds because abundance may reflect habitat choice rather than food preference (e.g. work on refuges from predation: Duffy \& Hay 1991, Enge et al. 2013). We also excluded data from no-choice feeding experiments since consumption in a no-choice situation can be confounded by compensatory feeding (Cruz-Rivera \& Hay 2000). Furthermore, studies using gut content analysis of herbivores collected in the field were excluded because it was not possible to relate gut content to the availability of seaweeds in the field. Finally, studies where herbivores were preconditioned on one of the experimental seaweeds by either being specifically collected from or fed with only that seaweed prior to the experiments were also excluded.

For the retained studies the following data were compiled (see Table 1): seaweed species name, taxonomic and functional group, the study region and its corresponding climate region, the origin of the non-native seaweeds, herbivore species identity and phylum, as well as the experiment type (i.e. two- or multiple-choice). Mean values and measures of dispersion were extracted from figures using the WebPlotDigitizer software (Rohatgi 2015) or directly from text, tables or original datasets. All retrieved studies on herbivore feeding preference reported consumption or relative growth of the seaweeds as the response variable, which were either presented already corrected for autogenic changes of the seaweeds or together with the means of controls for autogenic changes. In the latter case, the consumption or relative growth data were corrected for the autogenic changes before values were entered into the database. To obtain a reference value for the native seaweeds in multiple-choice experiments, we calculated the average consumption of all native seaweeds and used their pooled variance as a measure of variability, which assumes the means of the populations to differ but their variances to be the same.

\section{Meta-analysis}

Hedges' $d$ standardized mean difference (Hedges \& Olkin 1985) was used as the effect size measure and was calculated as the difference between non-native and native seaweeds: $d=\left[\left(\bar{X}_{N N}-\bar{X}_{N}\right) / s\right]$, where $\bar{X}_{N N}$ corresponds to the mean consumption of the non-native seaweed and $\bar{X}_{N}$ to the mean consumption of the native species, $s$ designates their pooled standard deviations and $\mathrm{J}$ is the smallsample-size bias correction factor. Positive Hedges' $d$ values thereby reflect herbivore preference for the non-native seaweeds, while negative values reflect herbivore preference for the native seaweeds.

Many publications reported data of several independently performed two- or multiple-choice experiments using different native seaweed species and/or different herbivores, which resulted in up to 16 data entries from one study and for one non-native seaweed. To balance the influence of studies in the analyses and to decrease possible non-independence of these multiple entries, we 


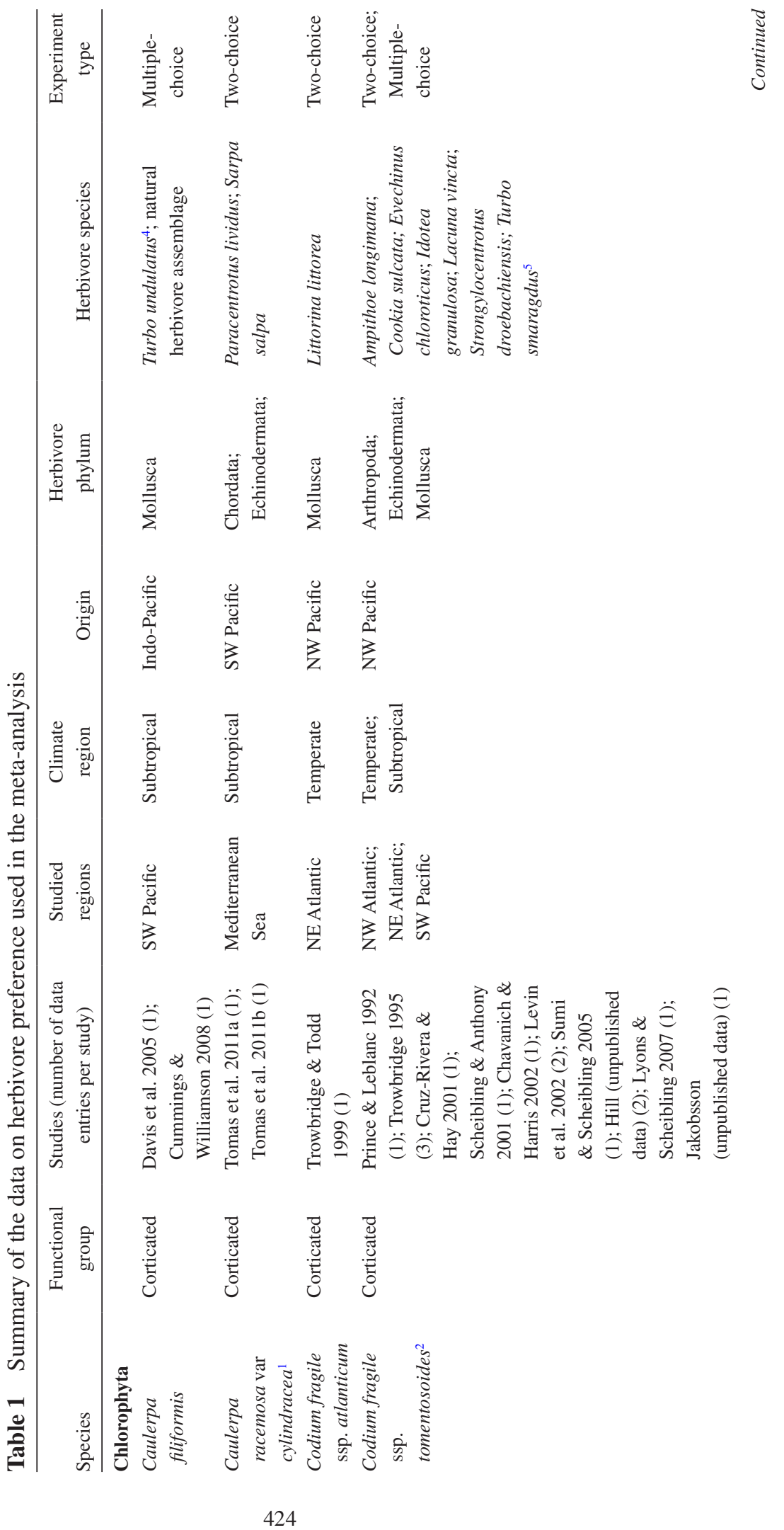




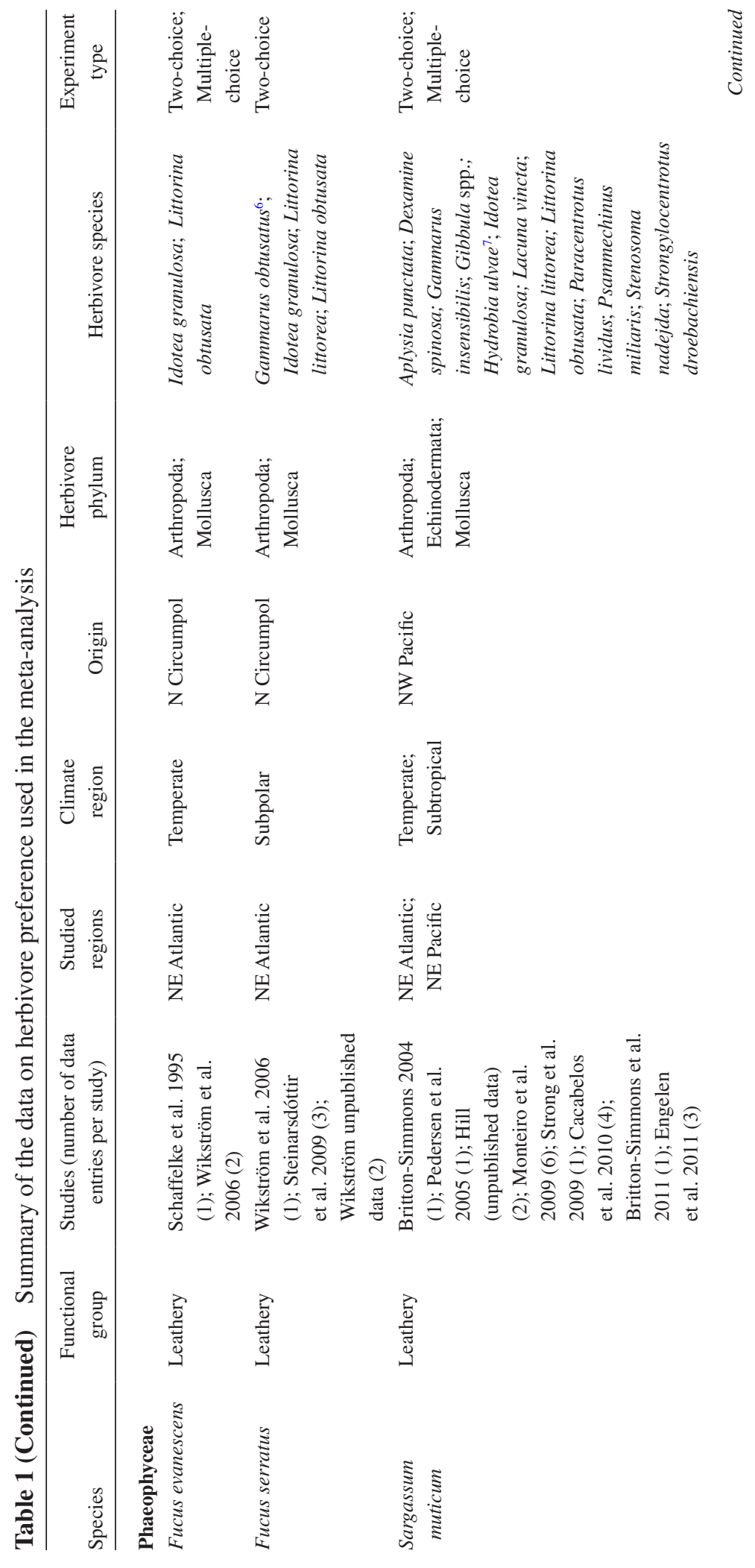


SWANTJE ENGE, JOSEFIN SAGERMAN, SOFIA A. WIKSTRÖM \& HENRIK PAVIA

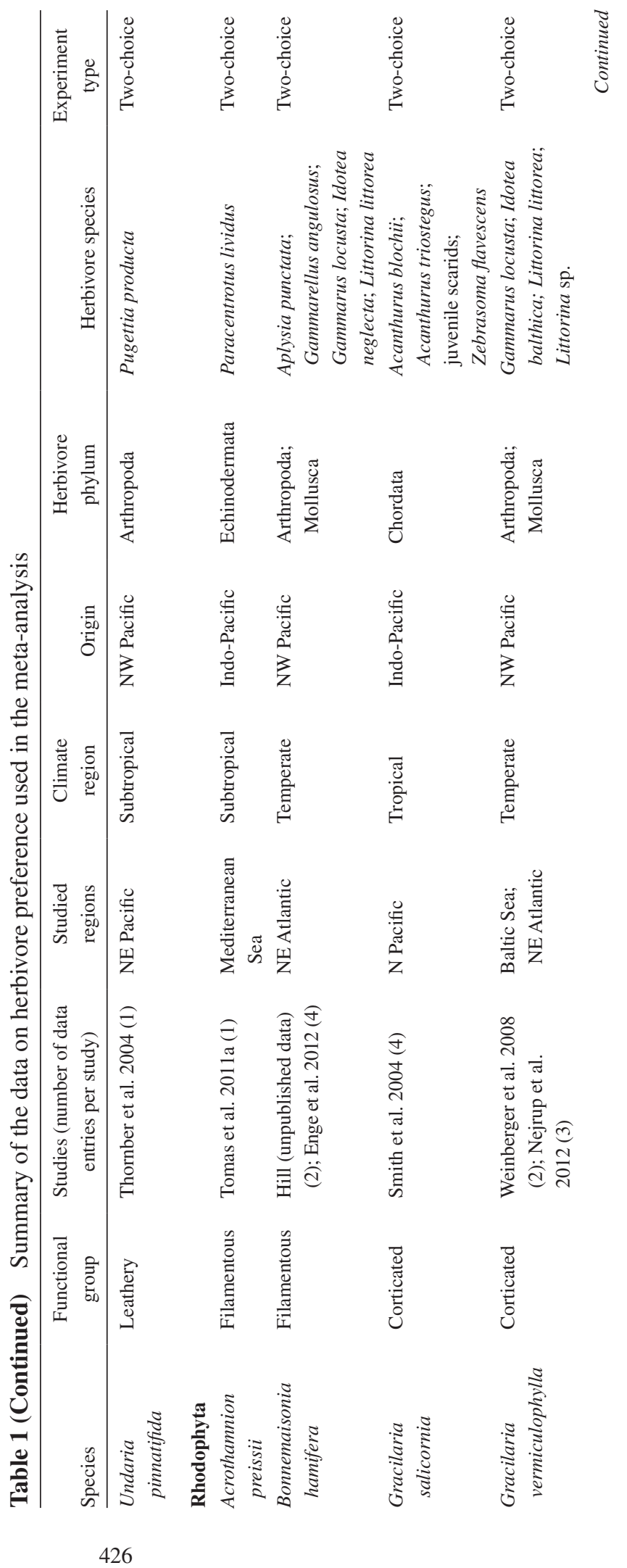




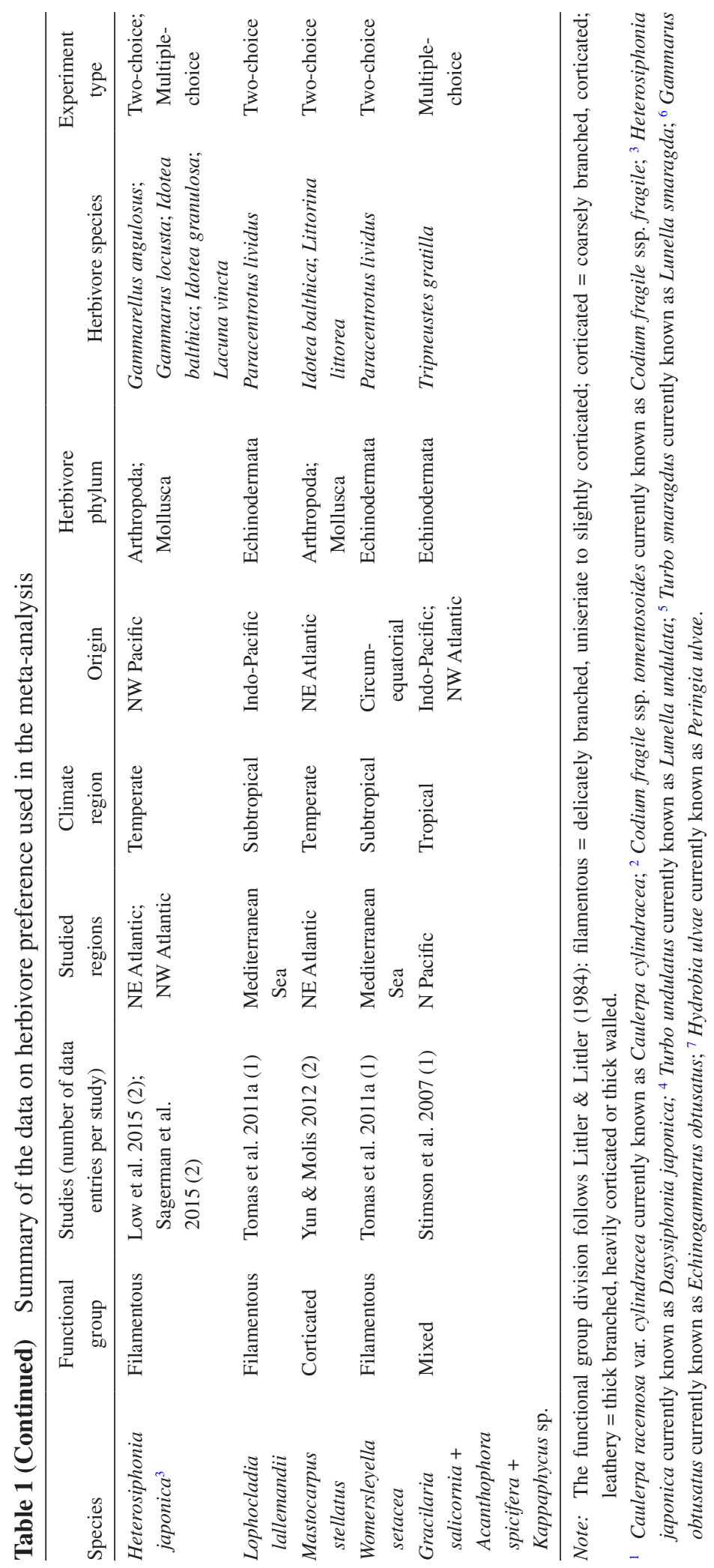


calculated a study-specific mean effect size for each herbivore species and non-native species across all experiments testing different combinations with native seaweeds in a study. In this way, we kept the resolution between the non-native seaweed and herbivore species, but reduced the problem of overweighing and consequent false precision estimates (Rothstein et al. 2013). We also calculated a study-specific mean effect size when experiments were repeatedly performed at different times during the year. In both cases, the study-specific mean effects were estimated using a fixed-effects model, which assumes the results of the different experiments in one study to vary only because of random sampling error. This procedure reduced the number of entries in the dataset with a factor of up to five for some publications and in total from 145 to 74 entries.

The meta-analysis on consumer preference for non-native versus native seaweeds was conducted using the metafor-package in R (Viechtbauer 2010) and the OpenMee software (Dietz et al. 2016). The weighted overall mean effect of herbivore preference for non-native or native seaweeds was calculated by a random-effects model using the restricted maximum-likelihood estimator for residual heterogeneity. Bootstrapped $95 \%$ confidence intervals were calculated for the overall mean effect size generated from 4999 iterations. To check the robustness of the meta-analysis outcome, we calculated the fail-safe number with the weighted method of Rosenberg (2005), which represents the number of additional studies with no effect needed to change the result of the meta-analysis from significant to non-significant. Publication bias was further examined with a funnel-plot and the rank correlation test for funnel plot asymmetry (Begg \& Mazumdar 1994). The influence of outliers on the overall mean effects size was tested by evaluating the change of the overall effect when one study at a time was left out of the analysis. Since hypothesis-driven research tends to favour large effect sizes in support of the hypothesis in earlier publications, we examined temporal trends in the data with a cumulative meta-analysis sorted by publication year (Jennions \& Møller 2002).

We used meta-regression with mixed-effects models and with a restricted maximum-likelihood estimator for residual heterogeneity to assess if the predefined covariables explained any of the observed heterogeneity and to explore their influence on consumer preference as well as differences between subgroups. Specifically, we tested how much of the observed heterogeneity the non-native seaweed itself accounted for, if there were differences in consumer preferences among phyla or functional groups of the non-native species, and if the climate region of the study site, herbivore phylum and experiment type influenced the study outcome. Origin and study region as covariables were omitted from these analyses since subgroups were often only represented by one or two species and few data entries in some of the subgroups, which were considered insufficient for a valid interpretation.

Only five studies that tested for consumer effects on the performance of non-native and native seaweeds on a community scale were identified, too few to perform a formal meta-analysis. However, findings of the few existing studies were summarized and discussed.

\section{Results}

The literature search identified 35 studies published from 1992-2015 that examined feeding preferences of native herbivores for non-native compared to native seaweeds. These studies addressed in total 18 non-native seaweed taxa: four green algae (Chlorophyta), four brown algae (Phaeophyceae) and ten red algae (Rhodophyta) (Table 1). This is comparable with the taxonomic composition of all registered non-native seaweeds reported by Williams \& Smith (2007): of 276 taxa, 45 were green algae, 66 brown algae and 165 red algae. Accordingly, between 6-9\% of all non-native seaweeds in each of the taxonomic groups were covered by our meta-analysis. All comparisons were made between non-native seaweeds and native seaweeds with the exception of one study with five data entries where the palatability of non-native seaweeds was compared to a seagrass species. By far the most intensively studied seaweeds in the context of feeding preference of herbivores were Codium fragile ssp. tomentosoides (currently accepted name Codium fragile ssp. fragile) and Sargassum muticum, which also resulted in the highest number of entries for these species in the meta-analysis 
(Table 1). More than two thirds of the non-native seaweeds included in the meta-analysis have their original distribution in the north-west Pacific and Indo-Pacific, whereas the most intensively studied region of introduction was the north-east Atlantic (Table 1). Isopods and amphipods (Arthropoda), gastropods (Mollusca), sea urchins (Echinodermata) and herbivorous fish (Chordata) constituted the majority of the tested herbivores in the studies (Table 1).

\section{Meta-analysis of consumer preference}

The weighted overall mean effect was estimated to be -0.528 with a bootstrapped $95 \% \mathrm{CI}=$ $(-0.872,-0.187)$. This effect was significantly different from zero $(p=0.002$, Figure 1$)$ and showed

(A) Chlorophyta

Caulerpa filiformis $(\mathrm{n}=2)$

Caulerpa racemosa var cylindracea ${ }^{1}(\mathrm{n}=2)$

Codium fragile ssp. atlanticum $(\mathrm{n}=1)$

Codium fragile ssp. tomentosoides $^{2}(\mathrm{n}=14)$

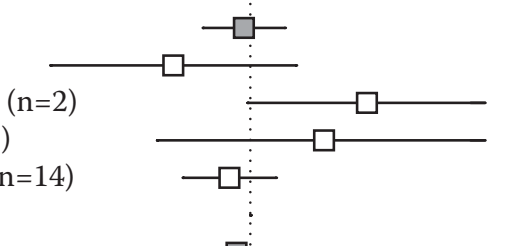

\section{Phaeophyceae}

Fucus evanescens $(\mathrm{n}=4)$

Fucus serratus $(\mathrm{n}=5)$

Sargassum muticum $(\mathrm{n}=19)$

Undaria pinnatifida $(\mathrm{n}=1)$

\section{Rhodophyta}

Acrothamnion preissii $(\mathrm{n}=1)$

Bonnemaisonia hamifera $(\mathrm{n}=6)$

Heterosiphonia japonica $^{3}(\mathrm{n}=5)$

Gracilaria salicornia $(\mathrm{n}=4)$

Gracilaria vermiculophylla $(\mathrm{n}=5)$

Lophocladia lallemandii $(\mathrm{n}=1)$

Mastocarpus stellatus $(\mathrm{n}=2)$

Womersleyella setacea $(\mathrm{n}=1)$

G. salicornia + Acanthophora spicifera

+ Kappaphycus sp. $(\mathrm{n}=1)$

\section{Overall mean}

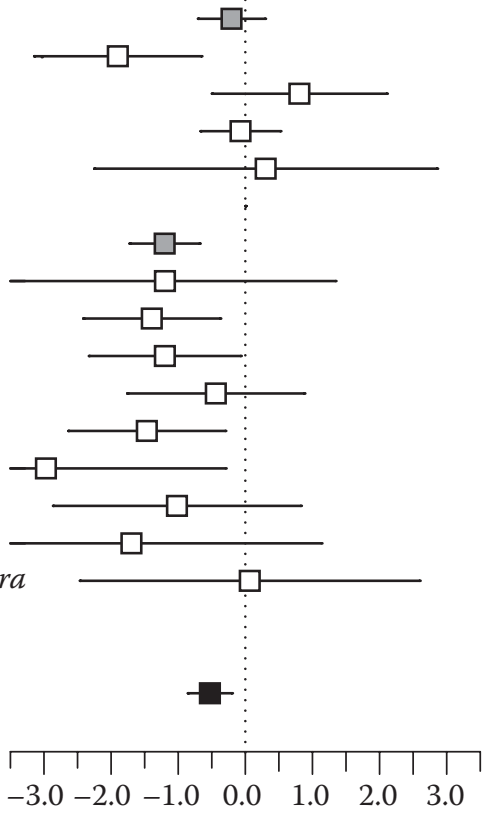

Hedges' $d$ standardized mean difference

\begin{tabular}{lcccc} 
(B) Co-variable & $\mathbf{Q}_{\mathbf{M}}$ & $\mathbf{Q}_{\mathbf{E}}$ & $\mathbf{I}^{\mathbf{2}}$ & $\mathbf{R}^{\mathbf{2}}$ \\
\hline Species & $31.27^{* *}$ & $466^{* * * * *}$ & 92.33 & 17.53 \\
Phylum & $9.34^{* * *}$ & $725^{* * * * *}$ & 92.95 & 11.72
\end{tabular}

Figure 1 (A) Forest plot of the estimated effect sizes (Hedges' $d$ standardized mean difference) grouped by each non-native species (open squares) and by the phylum of the non-native species (grey squares). The black square indicates the overall mean effect size of feeding preferences. Error bars represent $95 \%$ confidence intervals. The numbers in brackets describe the number of dataset entries for each species. (B) The results of the meta-regression with the non-native seaweed or phylum of the non-native species as an explanatory variable in a random-effects model; $* \mathrm{p}<0.5 ; * * \mathrm{p}<0.01 ; * * * \mathrm{p}<0.001 .{ }^{1}$ Currently accepted name Caulerpa cylindracea $;{ }^{2}$ Currently accepted name Codium fragile ssp. fragile; ${ }^{3}$ Currently accepted name Dasysiphonia japonica. 
that non-native seaweeds were on average less preferred by native herbivores compared to native seaweeds. The results of the different studies were, however, highly heterogeneous (residual heterogeneity among studies: $\mathrm{Q}_{1,74}=909.67, \mathrm{p}<0.001, \mathrm{I}^{2}=93.8 \%$ ). Including the predefined covariables in the model showed that the identity of the non-native seaweed, taxonomic and functional groups as well as the experiment type explained significant amounts of the observed heterogeneity (Figures 1 and 2). Residual heterogeneity was always high indicating that there may be other moderators not embraced by our analysis that influenced the outcome.

Grouping the non-native species by their taxonomic group revealed that only non-native red seaweeds were of low palatability to native herbivores, while the non-native green and brown seaweeds did not differ significantly in palatability compared to native seaweeds (Figure 1). Grouping according to functional groups suggested that only non-native filamentous seaweeds were less preferred, whereas the palatability of corticated or leathery non-native seaweeds did not differ from native counterparts (Figure 2). Due to the dataset structure, functional and taxonomic group were highly confounded: all green algae were corticated, all brown algae were leathery macrophytes and all filamentous algae were red seaweeds (Table 1). However, when functional groups were separately

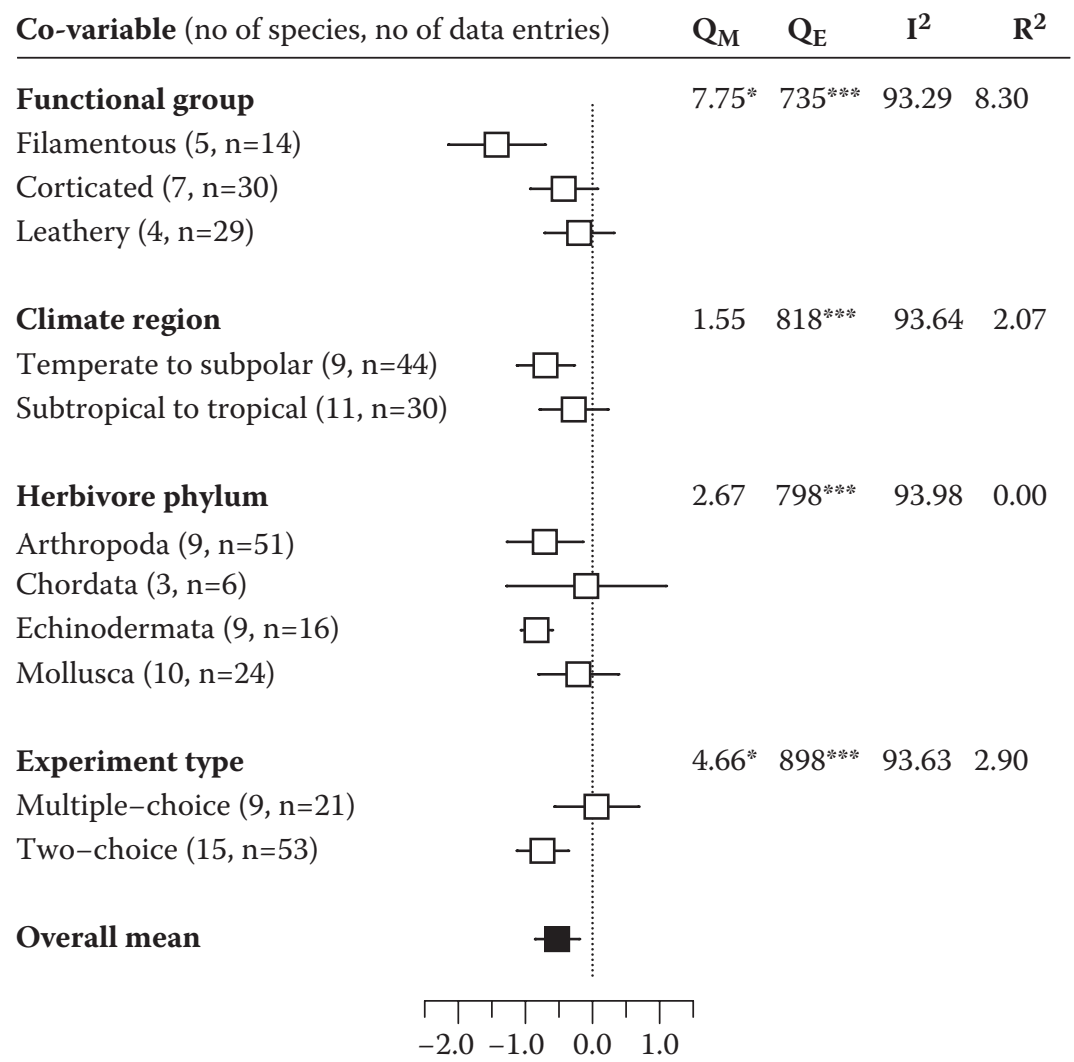

Hedges' $d$ standardized mean difference

Figure 2 Forest plot of the estimated effect sizes (Hedges' $d$ standardized mean difference) grouped by explanatory variables (open squares). The black square indicates the overall mean effect size of the dataset. Error bars represent $95 \%$ confidence intervals. The numbers in brackets describe the number of non-native species and the number of dataset entries represented by each subgroup. The statistics of the meta-regression of a random-effects model using functional group of the non-native seaweed, climate region and experiment type as an explanatory variable are displayed to the right; $* \mathrm{p}<0.5 ; * * \mathrm{p}<0.01 ; * * * \mathrm{p}<0.001$. 
tested for non-native red seaweeds, only filamentous seaweeds were again significantly less preferred $\left(\mathrm{Z}_{\text {filamentous }}=-4.28, \mathrm{p}<0.001 ; \mathrm{Z}_{\text {corticated }}=-1.80, \mathrm{p}=0.07\right)$.

Analysis of the herbivore grouping revealed that arthropods and echinoderms found non-native seaweeds less palatable than native seaweeds, whereas molluscs and fish did not show any preference (Figure 2). Furthermore, herbivores from temperate to subpolar regions significantly preferred native seaweeds to non-native seaweeds, but herbivores from tropical or subtropical regions did not show a preference (Figure 2).

The experiment type had a significant influence on the effect size. In contrast to the two-choice experiments, the multiple-choice experiments, in which consumption of the non-native seaweed was compared to the averaged consumption of all native seaweeds, did not detect an overall significant feeding preference for native or non-native seaweeds (Figure 2).

\section{Sensitivity analysis, publication bias and temporal trends}

There was no indication that the results obtained from the meta-analysis lacked robustness. Exclusion of any data entry in the meta-analysis always resulted in similar overall mean effect size and confidence intervals (results not shown), which indicated that there were no serious outliers present. The cumulative meta-analysis by publication year showed that from the eighth data entry (2001), the overall mean effect size was constantly negative, oscillating between -0.628 and -0.302 , though the $95 \%$ confidence interval included zero over some periods (Figure 3). Furthermore, Rosenberg's fail-safe number was sufficiently large (4219) to conclude that the observed outcome was a reliable estimate of the overall effect size. Additionally, the funnel plot and rank correlation test for funnel plot asymmetry gave no indication that publication bias affected the observed outcome (rank correlation test, Kendall's $\mathrm{T}=0.098, \mathrm{p}=0.2196$, Figure 4).

\section{Review of community studies}

Our literature search identified nine studies that examined adult performance of non-native seaweeds in the presence and absence of consumers. Only five reported effects on cover or biomass for both the non-native species and native seaweeds. These studies included one green, two brown and two red algal taxa and are summarized in Table 2 . All taxa were also covered by the meta-analysis of feeding preference.

In the presence of herbivores, the filamentous red alga Bonnemaisonia hamifera reached higher cover and its biomass increased in short-term community experiments under laboratory conditions. In the absence of herbivores, B. hamifera was an inferior competitor compared to the native red seaweeds in the community and decreased in abundance (Enge et al. 2013, Sagerman et al. 2014). In contrast, the filamentous red alga Heterosiphonia japonica (currently accepted name Dasysiphonia japonica) dominated the community independent of herbivore presence due to its extreme growth rate (Sagerman et al. 2014). Compared to six native species, the leathery brown alga Sargassum muticum was the only seaweed that could maintain clear positive growth in the presence of herbivores in a short-term laboratory community experiment, but was also a superior competitor in the absence of herbivores (Engelen et al. 2011). Grazing had no effect on the cover of the corticated green alga Codium fragile ssp. tomentosoides (currently accepted name Codium fragile ssp. fragile) in a 13-week field experiment, while the native competitor Laminaria longicruris (currently accepted name Saccharina longicruris) could not persist and cover of turf algae strongly decreased under natural sea urchin densities. But again, Codium fragile ssp. tomentosoides had superior competitive abilities compared to Laminaria longicruris even in the absence of herbivores (Sumi \& Scheibling 2005). On sea urchin barrens, grazing could not prevent canopy development of the leathery brown Undaria pinnatifida over a 30-month period, while the native canopy species did not exceed more than $0.7 \%$ cover (Valentine \& Johnson 2005). In addition, the native canopy species showed inferior 


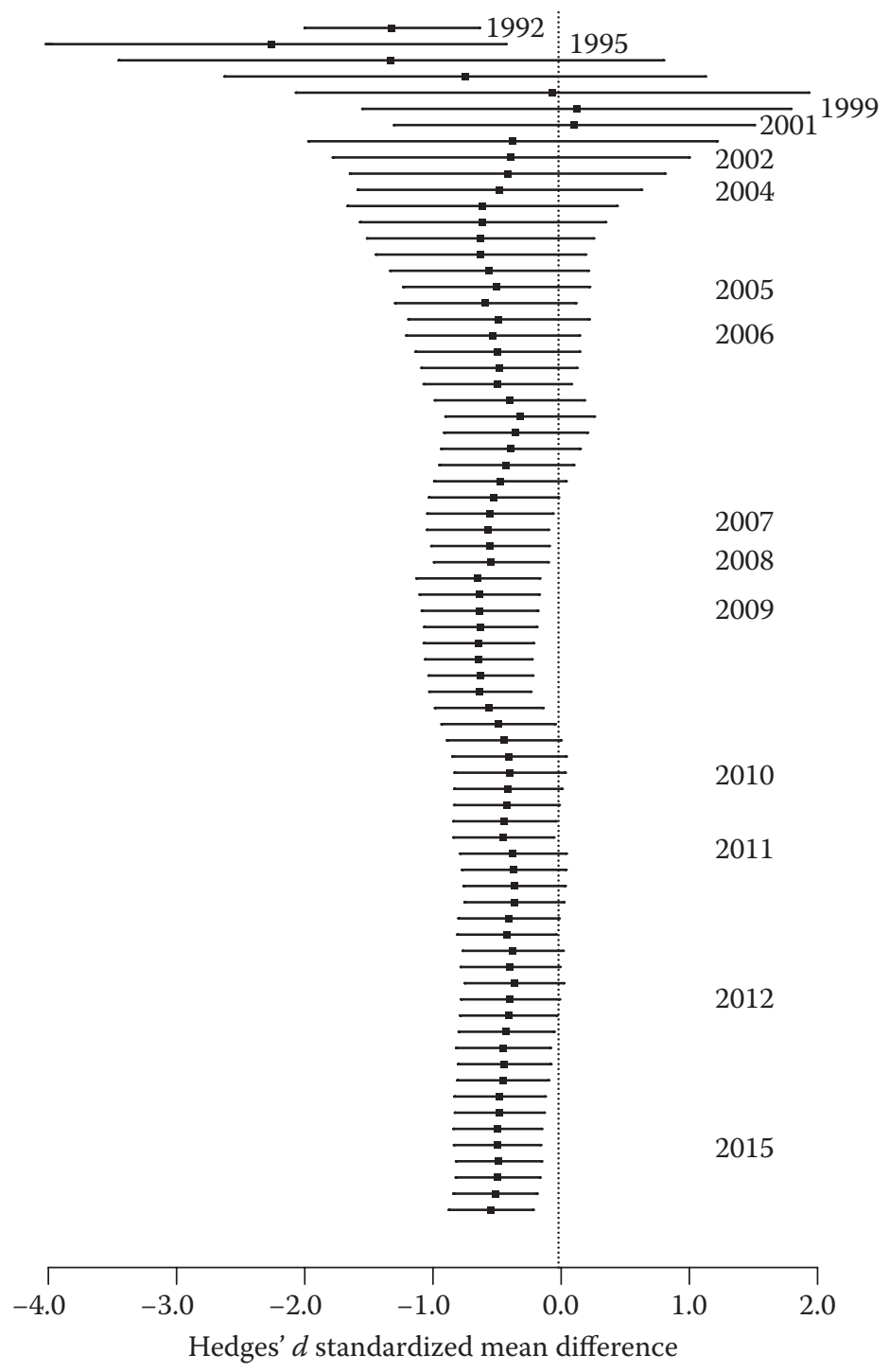

Figure 3 Forest plot of the cumulative meta-analysis of herbivore feeding preference between native and non-native seaweeds, ordered by publication year. Each data point represents the change of the estimated overall mean effect size (Hedges' $d$ standardized mean difference) by adding the next newest entry into the meta-analysis. The dotted line indicates the absence of a significant effect. Error bars represent $95 \%$ confidence intervals.

competitive abilities compared to U. pinnatifida in the absence of herbivores (Valentine \& Johnson 2005).

\section{Discussion}

Our meta-analysis showed that overall, non-native seaweeds tend to be less palatable than native seaweeds to herbivores in the new community. However, the meta-analysis also revealed considerable variability among the results of different studies. This variability could largely be explained by the identity of the seaweed taxon, indicating that the relative palatability of native compared 


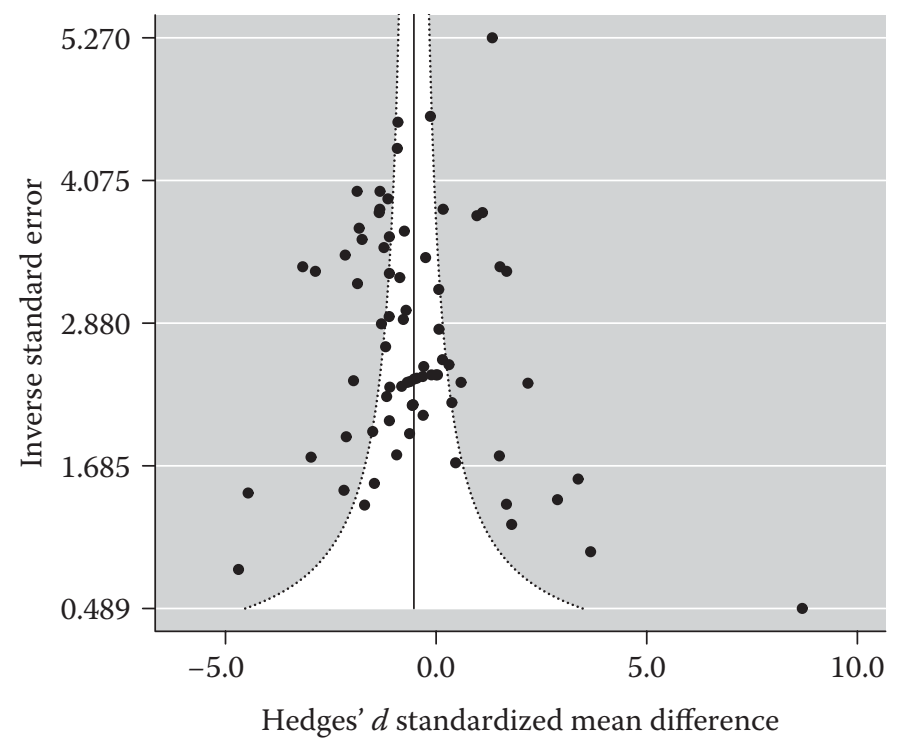

Figure 4 Funnel plot for the meta-analysis of feeding preferences using a random-effects model. Each data entry is represented by a circle showing the relation of the effect size (Hedges' $d$ standardized mean difference) to its inversed standard error. The black line indicates the estimated overall mean effect and the white region represents the region in which $95 \%$ of the studies are expected to lie in the absence of biases and heterogeneity.

Table 2 Summary of community studies on herbivore effects on non-indigenous seaweeds

\begin{tabular}{|c|c|c|c|c|}
\hline Species & $\begin{array}{l}\text { Taxonomic } \\
\text { group }\end{array}$ & $\begin{array}{l}\text { Functional } \\
\text { group }\end{array}$ & Studies & Method \\
\hline $\begin{array}{l}\text { Codium fragile ssp. } \\
\text { tomentosoides }^{1}\end{array}$ & Chlorophyta & Corticated & Sumi \& Scheibling 2005 & Field experiment \\
\hline Sargassum muticum & Phaeophyceae & Leathery & Engelen et al. 2011 & Laboratory experiment \\
\hline Undaria pinnatifida & Phaeophyceae & Leathery & Valentine \& Johnson 2005 & Field experiment \\
\hline Bonnemaisonia hamifera & Rhodophyta & Filamentous & $\begin{array}{l}\text { Enge et al. 2013, Sagerman et al. } \\
2014\end{array}$ & Laboratory experiment \\
\hline Heterosiphonia japonica ${ }^{2}$ & Rhodophyta & Filamentous & Sagerman et al. 2014 & Laboratory experiment \\
\hline
\end{tabular}

Note: The Functional group classification follows Littler \& Littler (1984): filamentous = delicately branched, uniseriate to slightly corticated; corticated $=$ coarsely branched, corticated; leathery $=$ thick branched, heavily corticated or thick walled.

1 currently accepted name Codium fragile ssp. fragile

2 currently accepted name Dasysiphonia japonica

to non-native seaweeds differs between the groups of red, brown and green seaweeds. It was only for reds, but not for the brown and green seaweeds, that the meta-analysis demonstrated an overall difference in herbivore preference between native and non-native species. Furthermore, the metaanalysis revealed that filamentous non-native species, which were all red seaweeds in our analysis, tended to be of low palatability to native herbivores.

Feeding preference of herbivores is positively correlated to the nutritional quality and the shelter provided by the seaweed, and seaweeds can in turn deter herbivores by structural and chemical defences (Lubchenco \& Gaines 1981, Hay \& Fenical 1992). The low herbivore preference for nonnative filamentous algae is an unexpected result because filamentous algae are commonly regarded to be palatable and highly susceptible to most consumers (Littler \& Littler 1980, Steneck \& Watling 
1982, Littler et al. 1983). Consequently, this group could be expected to face a higher degree of consumptive biotic resistance in new regions, compared to non-native seaweeds from other functional groups. Our result matches recent findings suggesting that leathery and foliose algae are more susceptible to herbivores than filamentous or corticated algae (Poore et al. 2012), which indicates that structural traits, such as tissue toughness, is far from always a determining factor for food choice of herbivores and that feeding preferences are driven by other seaweed traits.

The presence of chemical defences can explain low palatability of certain seaweeds to marine herbivores (Hay \& Fenical 1992, Pavia et al. 2012). Accordingly, it has been postulated that chemical defences can protect non-native seaweeds, as well as vascular plants, from being attacked by native herbivores in a new region, either by comparatively high defence concentrations or by molecular structures that are evolutionarily novel to the native herbivores (Cappuccino \& Arnason 2006, Wikström et al. 2006, Verhoeven et al. 2009, Enge et al. 2012). Red seaweeds in particular produce an immense diversity and high quantities of often halogenated secondary metabolites, which have been frequently demonstrated to possess effective antimicrobial (Persson et al. 2011, Nylund et al. 2013), antifouling (Dworjanyn et al. 2006), allelopathic (Svensson et al. 2013) and antiherbivore activities (Kladi et al. 2005, Cabrita et al. 2010, Enge et al. 2012). The diversity of chemical defence compounds in red algae may explain why non-native red seaweeds showed especially low palatability in our meta-analysis.

The establishment of a specific chemical basis for a low preference of potential native consumers for an introduced organism is, however, a demanding task and marine examples are still rare. Evidence for chemical defences against native herbivores has so far only been provided for a few non-native seaweed species. The green algae, Caulerpa taxifolia and C. racemosa, produce caulerpenyne with effects on sea urchins (Amade \& Lemée 1998, Dumay et al. 2002). Codium fragile ssp. fragile (=Codium fragile ssp. tomentosoides) possesses wound-activated defences involving dimethylsulfoniopropionate (DMSP), which deters native sea urchins (Lyons et al. 2007). The arctic brown alga, Fucus evanescens ${ }^{*}$, contains significantly higher concentrations of phlorotannins (polyphenolic defence compounds) than native fucoids in its new range, deterring native isopods and molluscs (Wikström et al. 2006, Forslund et al. 2010). The highly invasive red alga, Gracilaria vermiculophylla, produces prostaglandins, hydroxylated fatty acids and arachidonic acid-derived lactones on wounding, which provides resistance against native isopods and molluscs (Nylund et al. 2011, Hammann et al. 2016). Another red seaweed, the filamentous Bonnemaisonia hamifera, produces volatile brominated compounds that provide defence against native isopods, gammarids and ophistobranch consumers (Enge et al. 2012). These examples show that chemical defence can explain the low palatability of some non-native seaweeds, but further studies are needed before it can be concluded that chemical defence is a common trait of low-preferred non-native seaweeds (especially of the filamentous red algae).

Notably, two of the species for which chemical defences have been characterized (Caulerpa racemosa and Codium fragile ssp. tomentosoides) were not consistently of low preference to native herbivores in our meta-analysis. In both cases, the chemical defence compound was only documented to be active against one herbivore species, while multiple herbivores were tested in the feeding preference experiments. A specific chemical defence is usually not effective against all herbivore species, since herbivores can adapt to and/or circumvent the effects of secondary metabolites (Sotka, 2005). Furthermore, concentrations and the effectiveness of the chemical defence compounds can vary between seaweed and herbivore populations (Pavia et al. 2003, Sotka 2005), which makes it

\footnotetext{
Fucus evanescens may have expanded its range naturally, but available evidence suggests that the spread of this species to southern Scandinavia and the British Isles was aided by human transport. It exhibits a disjunct distribution with new occurrences that were discovered in harbours in the beginning of the 20th century, making introduction from shipping plausible. Thus, we chose to include Fucus evanescens in the definition of a non-native species that we used in the literature search, i.e. a species that has been translocated to a new range by humans.
} 
important that the palatability of non-native species introduced into several regions are tested with a set of the native herbivores that are relevant in the new regions.

Herbivore preference can be a first indicator for plant performance and competitive ability, but cannot be directly translated into community composition and population dynamics under natural conditions. We found that studies using long-term community experiments assessing the effects of consumers on non-native seaweeds in interaction with native seaweeds are essentially lacking. The few existing studies included in our review showed that performance of non-native seaweeds can be increased, equal or reduced in the presence of herbivores. To date, the most rigorous example of a successful seaweed invasion based on chemical defence concerns the filamentous red alga Bonnemaisonia hamifera (Figure 5). The documented chemical defence (1,1,3,3-tetrabromo2-heptanone) provides this relatively poor competitor (in the absence of native herbivores), with a strong competitive advantage in its new range in the presence of native herbivores (Enge et al. 2013, Sagerman et al. 2014). In addition, the same brominated compound inhibits the recruitment of native algal competitors (Svensson et al. 2013) and reduces bacterial load (Nylund et al. 2008). Thus, the multiple ecological benefits of this compound outweigh the cost of its production for the invader in the new range (Nylund et al. 2013). In some of the other studies the non-native seaweeds often performed better than their native competitors in the presence of herbivores, but the non-native species were superior competitors also in the absence of herbivores. Thus, the extent to which low herbivore preference contributes to invasion success of non-native seaweeds remains elusive. There is a need for more studies on the effects of herbivores on non-native seaweed populations, ideally experiments that include seasonal changes and complete life cycles of the seaweed and grazers. This is a challenging task in marine environments with species with complex life cycles.

In conclusion, the results of our meta-analysis show that low palatability does not seem to be a universal trait among non-native seaweeds and only certain seaweeds escape native herbivores in

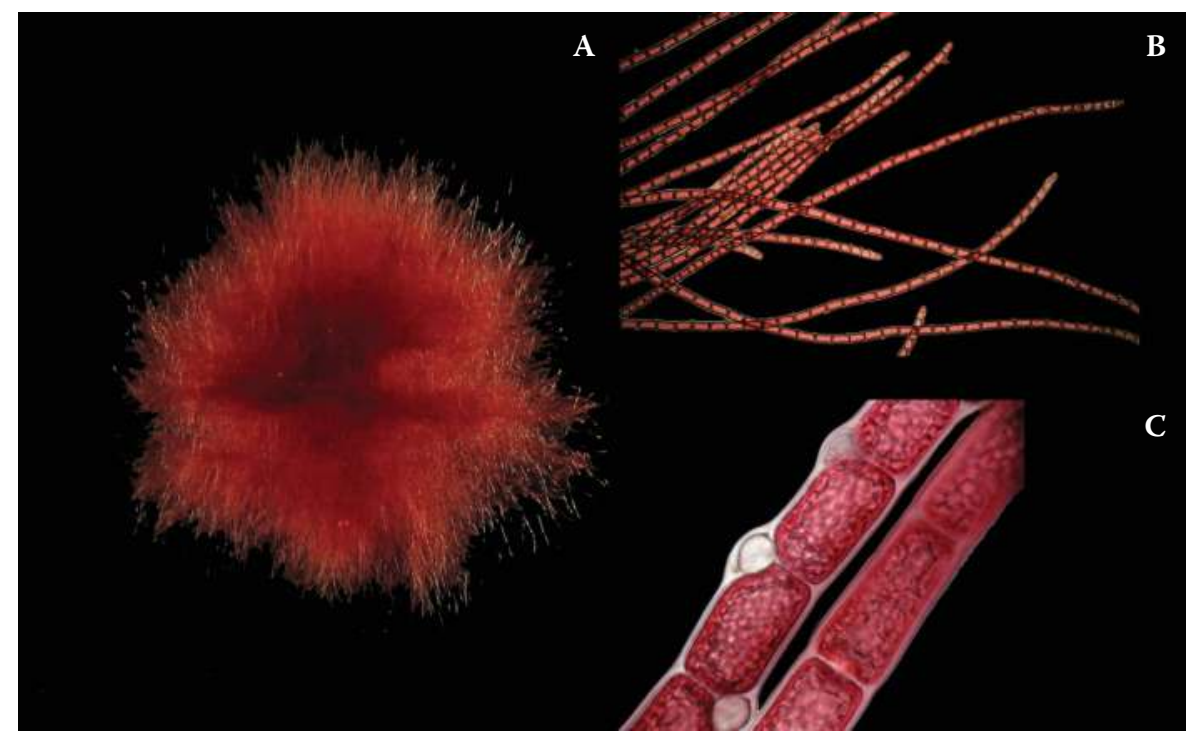

Figure 5 The invasive filamentous red seaweed Bonnemaisonia hamifera, which produces a potent chemical defence (1,1,3,3-tetrabromo-2-heptanone) that makes it unpalatable to native herbivores in the north Atlantic, thereby providing it with a strong competitive advantage over native seaweeds in its new range. (A) Tetrasporophytic phase, growing as small turfs, which consist of numerous sparsely branched filaments (B). Filaments are one cell-layer thick and have numerous gland cells, containing chemical defences, located between the vegetative cells (C). (From Nylund et al. 2008.) 
their new range. Accordingly, the prediction of the enemy release hypothesis that introduced species are less attacked by herbivores than their native counterparts in the new range (Keane \& Crawley 2002), does not hold for all non-native seaweeds. Interestingly, we found that non-native filamentous red seaweeds tend to be especially less palatable to herbivores. This is an important finding considering the majority of seaweed introductions are filamentous or corticated red algae (Williams $\&$ Smith 2007). Due to their morphology, these species can often be cryptic or less apparent compared to larger brown and green seaweeds. Probably, therefore, they are less frequently studied and often overlooked in their community impacts, even though effects on biodiversity and ecosystem processes have been proven (Schaffelke \& Hewitt 2007, Sagerman et al. 2014). The low preference for many non-native filamentous red algae indicates that low impact of herbivores may contribute to invasion success in this group. However, to assess if consumers play a crucial role in seaweed invasions, future research should focus on examining consumer impacts on competitive interactions between non-native and native seaweeds.

\section{Acknowledgements}

This work was supported by the Swedish Research Council through grant no. 621-2011-5630 to H.P., by a grant from the Swedish Research Council Formas to S.A.W., and by the Linnaeus Centre for Marine Evolutionary Biology (http://www.cemeb.science.gu.se/). S.A.W. was partly financed by the Baltic Eye project. Stephen Hawkins and Ally Evans provided comments that improved the manuscript and Gunilla Toth and Göran Nylund helped with the editing.

\section{References}

Amade, P. \& Lemée, R. 1998. Chemical defence of the mediterranean alga Caulerpa taxifolia: variations in caulerpenyne production. Aquatic Toxicology 43, 287-300.

Begg, C.B. \& Mazumdar, M. 1994. Operating characteristics of a rank correlation test for publication bias. Biometrics 50, 1088-1101.

Britton-Simmons, K.H. 2004. Direct and indirect effects of the introduced alga Sargassum muticum on benthic, subtidal communities of Washington State, USA. Marine Ecology Progress Series 277, 61-78.

Britton-Simmons, K.H., Pister, B., Sánchez, I. \& Okamoto, D. 2011. Response of a native, herbivorous snail to the introduced seaweed Sargassum muticum. Hydrobiologia 661, 187-196.

Burkepile, D.E. \& Hay, M.E. 2008. Herbivore species richness and feeding complementarity affect community structure and function on a coral reef. Proceedings of the National Academy of Science USA 105, 16201-16206.

Cabrita, M.T., Vale, C. \& Rauter, A.P. 2010. Halogenated compounds from marine algae. Marine Drugs 8 , 2301-2317.

Cacabelos, E., Olabarria, C., Incera, M. \& Troncoso, J.S. 2010. Do grazers prefer invasive seaweeds? Journal of Experimental Marine Biology and Ecology 393, 182-187.

Cappuccino, N. \& Arnason, J.T. 2006. Novel chemistry of invasive exotic plants. Biology Letters 2, 189-193.

Chavanich, S. \& Harris, L.G. 2002. The influence of macroalgae on seasonal abundance and feeding preference of a subtidal snail, Launa vincta (Montagu) (Littorinidae) in the Gulf of Maine. Journal of Molluscan Studies 68, 73-78.

Chun, Y.J., van Kleunen, M. \& Dawson, W. 2010. The role of enemy release, tolerance and resistance in plant invasions: linking damage to performance. Ecology Letters 13, 937-946.

Colautti, R.I., Ricciardi, A., Grigorovich, I.A. \& MacIsaac, H.J. 2004. Is invasion success explained by the enemy release hypothesis? Ecology Letters 7, 721-733.

Cruz-Rivera, E. \& Hay, M.E. 2000. Can quantity replace quality? Food choice, compensatory feeding, and fitness of marine mesograzers. Ecology 81, 201-219.

Cruz-Rivera, E. \& Hay, M. 2001. Macroalgal traits and the feeding and fitness of an herbivorous amphipod: the roles of selectivity, mixing, and compensation. Marine Ecology Progress Series 218, 249-266. 
Cummings, D.O. \& Williamson, J.E. 2008. The role of herbivory and fouling on the invasive green alga Caulerpa filiformis in temperate Australian waters. Marine and Freshwater Research 59, 279-290.

Darwin, C. 1859. On the Origin of Species by Means of Natural Selection, or, the Preservation of Favoured Races in the Struggle for Life. London: J. Murray.

Davis, A.R., Benkendorff, K. \& Ward, D.W. 2005. Responses of common SE Australian herbivores to three suspected invasive Caulerpa spp.. Marine Biology 146, 859-868.

Dietz, G., Dahabreh, I.J., Gurevitch J, Lajeunesse, M.J., Schmid, C.H., Trikalinos, T.A. \& Wallace, B.C. 2016. OpenMEE: Software for Ecological and Evolutionary Meta-analysis (Computer program). Available at (http://www.cebm.brown.edu/open_mee)

Duffy, J.E. \& Hay, M.E. 1991. Food and shelter as determinants of food choice by an herbivorous marine amphipod. Ecology 72, 1286-1298.

Dumay, O., Pergent, G., Pergent-Martini, C. \& Amade, P. 2002. Variations in caulerpenyne contents in Caulerpa taxifolia and Caulerpa racemosa. Journal of Chemical Ecology 28, 343-352.

Dworjanyn, S.A., de Nys, R. \& Steinberg, P.D. 2006. Chemically mediated antifouling in the red alga Delisea pulchra. Marine Ecology Progress Series 318, 153-163.

Elton, C.S. 1958. The Ecology of Invasions by Animals and Plants. London: Springer.

Enge, S., Nylund, G.M., Harder, T. \& Pavia, H. 2012. An exotic chemical weapon explains low herbivore damage in an invasive alga. Ecology 93, 2736-2745.

Enge, S., Nylund, G.M \& Pavia, H. 2013. Native generalist herbivores promote invasion of a chemically defended seaweed via refuge-mediated apparent competition. Ecology Letters 16, 487-492.

Engelen, A.H., Henriques, N., Monteiro, C. \& Santos, R. 2011. Mesograzers prefer mostly native seaweeds over the invasive brown seaweed Sargassum muticum. Hydrobiologia 669, 157-165.

Engelen, A.H., Serebryakova, A., Ang, P., Britton-Simmons, K., Mineur, F., Pedersen, M.F., Arenas, F., Fernández, C., Steen, H., Svenson, R., Pavia, H., Toth, G., Viard, F. \& Santos, R. 2015. Circumglobal invasion by the brown seaweed Sargassum muticum. Oceanography and Marine Biology: An Annual Review 53, 81-126.

Forslund, H., Wikström, S. \& Pavia, H. 2010. Higher resistance to herbivory in introduced compared to native populations of a seaweed. Oecologia 164, 833-840.

Hammann, M., Rempt, M., Pohnert, G., Wang, G., Boo, S.M. \& Weinberger, F. 2016. Increased potential for wound activated production of Prostaglandin E2 and related toxic compounds in non-native populations of Gracilaria vermiculophylla. Harmful Algae 51, 81-88.

Hawkins, S.J. \& Hartnoll, R.G. 1983. Grazing of intertidal algae by marine-invertebrates. Oceanography and Marine Biology: An Annual Review 21, 195-282.

Hawkins, S.J., Hartnoll, R.G., Kain, J.M. \& Norton, T.A. 1992. Plant-animal interactions on hard substrata in the north-east Atlantic. In Plant-Animal Interactions in the Marine Benthos, D.M. John et al. (eds). Oxford: Clarendon Press, 1-32.

Hay, M.E. \& Fenical W. 1992. Chemical mediation of seaweed-herbivore interactions. In Plant-Animal Interactions in the Marine Benthos, D.M. John et al. (eds). Oxford: Clarendon Press, 319-338.

Hay, M.E. \& Steinberg, P.D. 1992. The chemical ecology of plant-herbivore interactions in marine versus terrestrial communities. In Herbivores: Their Interactions with Secondary Metabolites, Evolutionary and Ecological Processes, G. Rosenthal \& M. Berenbaum (eds). San Diego, USA: Academic Press, 371-413.

Hedges, L.V. \& Olkin, I. 1985. Statistical methods for meta-analysis. Orlando: Academic Press.

Jennions, M.D. \& Møller, A.P. 2002. Relationships fade with time: a meta-analysis of temporal trends in publication in ecology and evolution. Proceedings of the Royal Society of London B: Biological Sciences 269, 43-48.

Johnson, C.R. \& Chapman, A.R.O. 2007. Seaweed invasions: introduction and scope. Botanica Marina 50, 321-325.

Keane, R. \& Crawley, M.J. 2002. Exotic plant invasions and the enemy release hypothesis. Trends in Ecology \& Evolution 17, 164-170.

Kimbro, D.L., Cheng, B.S. \& Grosholz, E.D. 2013. Biotic resistance in marine environments. Ecology Letters 16, 821-833.

Kladi, M., Vagias, C. \& Roussis, V. 2005. Volatile halogenated metabolites from marine red algae. Phytochemistry Reviews 3, 337-366. 
Lemee, R., Boudouresque, C., Gobert, J., Malestroit, P., Mari, X., Meinesz, A., Menager, V. \& Ruitton, S. 1996. Feeding behaviour of Paracentrotus lividus in the presence of Caulerpa taxifolia introduced in the Mediterranean Sea. Oceanologica Acta 19, 245-253.

Levin, P.S., Coyer, J.A., Petrik, R. \& Good, T.P. 2002. Community-wide effects of noninigenous species on temperate rocky reefs. Ecology 83, 3182-3193.

Levine, J.M., Adler, P.B. \& Yelenik, S.G. 2004. A meta-analysis of biotic resistance to exotic plant invasions. Ecology Letters 7, 975-989.

Littler, M.M. \& Littler, D.S. 1980. The evolution of thallus form and survival strategies in benthic marine macroalgae: field and laboratory tests of a functional form model. American Naturalist 116, 25-44.

Littler, M.M. \& Littler, D.S. 1984. Relationships between macroalgal functional form groups and substrata stability in a subtropical rocky-intertidal system. Journal of Experimental Marine Biology and Ecology 74, 13-34.

Littler, M.M., Taylor, P.R. \& Littler, D.S. 1983. Algal resistance to herbivory on a Caribbean barrier reef. Coral Reefs 2, 111-118.

Liu, H. \& Stiling, P. 2006. Testing the enemy release hypothesis: a review and meta-analysis. Biological Invasions 8, 1535-1545.

Low, N.H.N., Drouin, A., Marks, C.J. \& Bracken, M.E.S. 2015. Invader traits and community context contribute to the recent invasion success of the macroalga Heterosiphonia japonica on New England rocky reefs. Biological Invasions 17, 257-271.

Lubchenco, J. \& Gaines, S.D. 1981. A unified approach to marine plant-herbivore interactions. I. Populations and communities. Annual Review of Ecology and Systematics 12, 405-437.

Lyons, D.A. \& Scheibling, R.E. 2007. Effect of dietary history and algal traits on feeding rate and food preference in the green sea urchin Strongylocentrotus droebachiensis. Journal of Experimental Marine Biology and Ecology 349, 194-204.

Lyons, D.A., Van Alstyne, K.L. \& Scheibling, R.E. 2007. Anti-grazing activity and seasonal variation of dimethylsulfoniopropionate-associated compounds in the invasive alga Codium fragile ssp. tomentosoides. Marine Biology 153, 179-188.

Maggi, E., Benedetti-Cecchi, L., Castelli, A., Chatzinikolaou, E., Crowe, T.P., Ghedini, G., Kotta, J., Lyons, D.A., Ravaglioli, C., Rilov, G., Rindi, L. \& Bulleri, F. 2015. Ecological impacts of invading seaweeds: a meta-analysis of their effects at different trophic levels. Diversity and Distributions 21, 1-12.

Maron, J.L. \& Vila, M. 2001. When do herbivores affect plant invasion? Evidence for the natural enemies and biotic resistance hypotheses. Oikos 95, 361-373.

Monteiro, C.A., Engelen, A.H. \& Santos, R.O.P. 2009. Macro- and mesoherbivores prefer native seaweeds over the invasive brown seaweed Sargassum muticum: a potential regulating role on invasions. Marine Biology 156, 2505-2515.

Nejrup, L.B., Pedersen, M.F. \& Vinzent, J. 2012. Grazer avoidance may explain the invasiveness of the red alga Gracilaria vermiculophylla in Scandinavian waters. Marine Biology 159, 1703-1712.

Nylund, G.M., Cervin, G., Persson, F., Hermansson, M., Steinberg, P.D. \& Pavia, H. 2008. Seaweed defence against bacteria: a poly-halogenated 2-heptanone from the red alga Bonnemaisonia hamifera inhibits bacterial colonisation at natural surface concentrations. Marine Ecology Progress Series 369, 39-50.

Nylund, G.M., Enge, S. \& Pavia, H. 2013. Cost and benefits of chemical defence in the red alga Bonnemaisonia hamifera. PLOS ONE 8, e61291.

Nylund, G.M., Pereyra, R.T., Wood, H.L., Johannesson, K. \& Pavia, H. 2012. Increased resistance towards generalist herbivory in the new range of a habitat-forming seaweed. Ecosphere 3, 1-13 Art125.

Nylund, G.M., Weinberger, F., Rempt, M. \& Pohnert, G. 2011 Metabolomic assessment of induced and activated chemical defence in the invasive red alga Gracilaria vermiculophylla. PLoS ONE 6, e29359.

Parker, J.D., Burkepile, D.E. \& Hay, M.E. 2006. Opposing effects of native and exotic herbivores on plant invasions. Science 311, 1459-1461.

Parker, J.D. \& Hay, M.E. 2005. Biotic resistance to plant invasions? Native herbivores prefer non-native plants. Ecology Letters 8, 959-967.

Pavia, H., Baumgartner, F., Cervin, G., Enge, S., Kubanek, J., Nylund, G.M., Selander, E., Svensson, J.R. \& Toth, G.B. 2012. Chemical defences against herbivores. In Chemical Ecology in Aquatic Systems, C. Brönmark \& L.-A. Hansson (eds). Oxford: Oxford University Press, 210-235.

Pavia, H., Toth, G.B., Lindgren, A. \& Åberg, P. 2003. Intraspecific variation in the phlorotannin content of the brown alga Ascophyllum nodosum. Phycologia 42, 378-383. 
Pedersen, M.F., Stæhr, P.A., Wernberg, T. \& Thomsen, M.S. 2005. Biomass dynamics of exotic Sargassum muticum and native Halidrys siliquosa in Limfjorden, Denmark - -implications of species replacements on turnover rates. Aquatic Botany 83, 31-47.

Persson, F., Svensson ,R., Nylund, G.M., Fredriksson, J., Pavia, H. \& Hermansson, M. 2011. Ecological role of a seaweed secondary metabolite for a colonizing bacterial community. Biofouling 27, 579-588.

Poore, A.G.B., Campbell, A.H., Coleman, R.A., Edgar, G.J., Jormalainen, V., Reynolds, P.L., Sotka, E.E., Stachowicz, J.J., Taylor, R.B., Vanderklift, M.A. \& Duffy, J.E. 2012. Global patterns in the impact of marine herbivores on benthic primary producers. Ecology Letters 15, 912-922.

Prince, J.S. \& LeBlanc, W.G. 1992. Comparative feeding preference of Strongylocentrotus droebachiensis (Echinoidea) for the invasive seaweed Codium fragile ssp. tomentosoides (Chlorophyceae) and four other seaweeds. Marine Biology 113, 159-163.

Rohatgi, A. 2015. WebPlotDigitalizer. Version 3.10. Austin, Texas. Available at (http://arohatgi.info/ WebPlotDigitizer/app/).

Rosenberg, M.S. 2005. The file-drawer problem revisited: a general weighted method for calculating fail-safe numbers in meta-analysis. Evolution 59, 464-468.

Rothstein, H.R., Lortie, C.J., Stewart, G.B., Koricheva, J. \& Gurevitch, J. 2013. Quality standards for research synthesis. In Handbook of Meta-Analysis in Ecology and Evolution. J. Koricheva et al. (eds). Princeton: Princeton University Press, 323-338.

Sagerman, J., Enge, S., Pavia, H. \& Wikström, S.A. 2014. Divergent ecological strategies determine different impacts on community production by two successful non-native seaweeds. Oecologia 175, 937-946.

Sagerman, J., Enge, S., Pavia, H. \& Wikström, S.A. 2015. Low feeding preference of native herbivores for the successful non-native seaweed Heterosiphonia japonica. Marine Biology 162, 2471-2479.

Schaffelke, B. Evers, D. \& Walhorn, A. 1995. Selective grazing of the isopod Idotea baltica between Fucus evanescens and F. vesiculosus from Kiel Fjord (western Baltic). Marine Biology 124, 215-218.

Schaffelke, B. \& Hewitt, C.L. 2007. Impacts of introduced seaweeds. Botanica Marina 50, 397-417.

Schaffner, U., Ridenour, W.M., Wolf VC, Bassett, T., Muller, C., Muller-Scharer, H., Sutherland, S., Lortie, C.J. \& Callaway, R.M. 2011. Plant invasions, generalist herbivores, and novel defense weapons. Ecology 92, 829-835.

Scheibling, R. \& Anthony, S. 2001. Feeding, growth and reproduction of sea urchins (Strongylocentrotus droebachiensis) on single and mixed diets of kelp (Laminaria spp.) and the invasive alga Codium fragile ssp. tomentosoides. Marine Biology 139, 139-146.

Smith, J.E., Hunter, C.L., Conklin, E.J., Most, R., Sauvage, T., Squair, C. \& Smith, C.M. 2004. Ecology of the invasive red alga Gracilaria salicornia (Rhodophyta) on O'ahu, Hawai'i. Pacific Science 58, 325-343.

Sotka, E.E. 2005. Local adaptation in host use among marine invertebrates. Ecology Letters 8, 448-459.

Steinarsdóttir, M.B., Ingólfsson, A. \& Ólafsson, E. 2009. Trophic relationships on a fucoid shore in southwestern Iceland as revealed by stable isotope analyses, laboratory experiments, field observations and gut analyses. Journal of Sea Research 61, 206-215.

Steneck, R.S. \& Watling, L. 1982. Feeding capabilities and limitation of herbivorous mollusks - a functionalgroup approach. Marine Biology 68, 299-319.

Stimson, J., Cunha, T. \& Philippoff, J. 2007. Food preferences and related behavior of the browsing sea urchin Tripneustes gratilla (Linnaeus) and its potential for use as a biological control agent. Marine Biology 151, 1761-1772.

Strong, J.A., Maggs, C.A. \& Johnson, M.R. 2009. The extent of grazing release from epiphytism for Sargassum muticum (Phaeophyceae) within the invaded range. Journal of the Marine Biological Association of the United Kingdom 89, 303-314.

Sumi, C.B.T. \& Scheibling, R.E. 2005. Role of grazing by sea urchins Strongylocentrotus droebachiensis in regulating the invasive alga Codium fragile ssp. tomentosoides in Nova Scotia. Marine Ecology Progress Series 292, 203-212.

Svensson, J.R., Nylund, G.M., Cervin, G., Toth, G.B. \& Pavia, H. 2013. Novel chemical weapon of an exotic macroalga inhibits recruitment of native competitors in the invaded range. Journal of Ecology 101, $140-148$.

Thornber, C.S., Kinlan, B.P., Graham, M.H. \& Stachowicz, J.J. 2004. Population ecology of the invasive kelp Undaria pinnatifida in California: environmental and biological controls on demography. Marine Ecology Progress Series 268, 69-80. 
Tomas, F., Box, A. \& Terrados, J. 2011a. Effects of invasive seaweeds on feeding preference and performance of a keystone Mediterranean herbivore. Biological Invasions 13, 1559-1570.

Tomas, F., Cebrian, E. \& Ballesteros, E. 2011b. Differential herbivory of invasive algae by native fish in the Mediterranean Sea. Estuarine, Coastal and Shelf Science 92, 27-34.

Trowbridge, C.D. 1995. Establishment of the green alga Codium fragile ssp. tomentosoides on New Zealand rocky shores: current distribution and invertebrate grazers. The Journal of Ecology 83, 949-965.

Trowbridge, C.D. \& Todd, C.D. 1999. The familiar is exotic: I. Codium fragile ssp. atlanticum on Scottish rocky intertidal shores. Botanical Journal of Scotland 51, 139-160.

Valentine, J.P. \& Johnson, C.R. 2005. Persistence of the exotic kelp Undaria pinnatifida does not depend on sea urchin grazing. Marine Ecology Progress Series 285, 43-55.

Verhoeven, K.J.F., Biere, A., Harvey, J.A. \& van der Putten, W.H. 2009. Plant invaders and their novel natural enemies: who is naïve? Ecology Letters 12, 107-117.

Viechtbauer, W. 2010. Conducting meta-analyses in R with the metafor package. Journal of Statistical Software 36, 1-48.

Weinberger, F., Buchholz, B., Karez, R. \& Wahl, M. 2008. The invasive red alga Gracilaria vermiculophylla in the Baltic Sea: adaptation to brackish water may compensate for light limitation. Aquatic Biology $\mathbf{3}$, 251-264.

Wikström, S.A., Steinarsdóttir, M.B., Kautsky, L. \& Pavia, H. 2006. Increased chemical resistance explains low herbivore colonization of introduced seaweed. Oecologia 148, 593-601.

Williams, S.L. \& Smith, J.E. 2007. A global review of the distribution, taxonomy, and impacts of introduced seaweeds. Annual Review of Ecology, Evolution, and Systematics 38, 327-359.

Williamson, M. \& Fitter, A. 1996. The varying success of invaders. Ecology 77, 1661-1666.

Yun, H.Y. \& Molis, M. 2012. Comparing the ability of a non-indigenous and a native seaweed to induce antiherbivory defenses. Marine Biology 159, 1475-1484. 


\section{AUTHOR INDEX}

Page numbers in boldface denote complete articles.

\section{A}

Abbiati, M. See Airoldi, L., 405

See Bulleri, F., 406

See Moschella, P.S., 413

Abbott, R.T., 375

Abdon Naguit, M.R. See Borsa, P., 142, 376

Abdon-Naguit, M.R. See DeBoer, T.S., 144

Abdon-Naguit, R. See Calumpong, H.P., 143

Abdou Rabi, F. See Bigot, L., 376

Abdul-Aziz, Y. See Mohamed-Pauzi, A., 381

Åberg, P. See Moschella, P.S., 413

See Pavia, H., 438

Aberg, P. See Airoldi, L., 405

See Coleman, R.A., 27

Ablan, C.A. See Macaranas, J.M., 148

Ablan, M.C. See Calumpong, H.P., 143

Ablan-Lagman, M.C.A. See DeBoer, T.S., 144

Abrusci G. See McKenna S.A., 148, 381

Accordi, G., 141, 375

Adams, T.J.H. See Lewis, A.D., 148, 381

Adams, T.P., 405

Addessi, L., 49

Adger, W.N. See Hoang Tri, N., 411

See Kelly, P.M., 412

Adjeroud, M. See Dumas, P., 378

See Kayal, M., 30

Adler, P.B. See Levine, J.M., 413, 438

Adulyanukosol, K. See Chantrapornsyl, S., 377

Aeby, G.S. See Kenyon, J.C., 30

Afzal, D. See Lovell, E., 381

Agnetta, D. See Gianguzza, P., 51

Agombar, J.S., 375

Agudo, N.S. See Purcell, S.W., 383

Aguilera, M.A., 26

Aguirre, J.D. See Rius, M., 415

Ahmad, A. See Mohamed-Pauzi, A., 381

Ahyong, S.T. See Yeo, D.C., 419

Aiken, C.M., 74

Airoldi, L., 74, 405

See Bishop, M.J., 406

See Bulleri, F., 406

See Dafforn, K.A., 408

See Dugan, J.E., 408

See Moschella, P.S., 413

Al-Horani, F.A., 375

Al-Rousan, S.A. See Al-Horani, F.A., 375

Al-Zibdah, M. See Richter, C., 151, 383

Al-Zibdeh, M. See Al-Horani, F.A., 375

Alcala, A.C., 375

See Alcazar, S.N., 141

See Gomez, E.D., 378

Alcazar, S. See Calumpong, H.P., 143

Alcazar, S.N., 141

Alcoverro, T. See Vergés, A., 33

Alder, J., 375
Aldred, N., 405

Alexander, S.K., 26

Alexandratos, N., 405

Aleynik, D. See Adams, T.P., 405

Alfaro, A.C., 26

Aliño, P.M. See Cabaitan, P.C., 143

Alkema, L. See Gerland, P., 410

Allen, J.C. See Hanekom, N., 78

Almany, G.R., 75

Almond, R.E.A. See Butchart, S.H.M., 407

Alsos, I.G. See Ware, C., 418

Alsuhaibany, A. See Pilcher, N., 383

Altieri, A.H., 49

Altman, I. See Blakeslee, A.M., 406

Altshuller, D. See Tamburri, M.N., 417

Alvarado, J. See Castilla, J.C., 76

Alvarado, J.L., 75

See Castilla, J.C., 76

Alvarez-Guerra, M. See Rodriguez, L.F., 415

Alzieu, C. See Claisse, D., 407

Alzieu, C.L., 405

Amade, P., 436

See Dumay, O., 437

Amado-Filho, G. See Costa, T.J.F., 408

Amarasekare, P. See Leibold, M.A., 80

Ambariyanto See DeBoer, T.S., 144

See Yusuf, C., 387

Amerongen, H. See Chia, F.-S., 27

Amévor, K.A. See Dohn, J., 408

Amos, M.J. See Bell, L.A.J., 376

Amsler, C.D., 26

Anam, R., 375

Anderson, B. See McGranahan, G., 413

Anderson, J.M. See Moschella, P.S., 413

Anderson, M.J., 26, 405

Anderson, S.J. See Costanza, R., 408

Andréfouët, S., 87-140, 141, 155-374, 375

See Borsa, P., 142, 376

See Dumas, P., 144, 378

See Gilbert, A., 145, 378

See Menoud, M., 149

See Van Wynsberge, S., 153, 386

Andrés, A. See Rodriguez, L.F., 415

Andrew, N. See Bell, J.D., 142

Andrew, N.L. See Underwood, A.J., 84

Andrews, C.W., 375

Ang, C.F.A., 141

Ang, P. See Engelen, A.H., 437

Ang, P.O. See Tadashi, K., 385

Angulo, E. See Berec, L., 75

Anthony, S. See Scheibling, R., 439

Apao, A.B. See Calumpong, H.P., 377

Apple, R. See Tamburri, M.N., 417

Appukuttan, K.K. See George, K.C., 378

Apte, D., 141, 375 


\section{AUTHOR INDEX}

Apte, S., 405

Araki, G.S., 26

Arathi, A.R. See Bijukumar, A., 376

Archibald, S. See Hempson, G.P., 29

Arenas, F. See Coleman, R.A., 27

See Engelen, A.H., 437

Argow, B.A. See FitzGerald, D.M., 409

Arismendi, I. See Soto, D., 417

Armour-Marshall, K. See Safi, K., 151

Armstrong, E.J., 141

Arnason, J.T. See Cappuccino, N., 436

Arnold, K.E. See Littler, M.M., 30

Arrontes, J., 26

See Coleman, R.A., 27

Asato, S., 142

Ashton, G.V. See Williams, S.L., 419 See Zabin, C.J., 419

Asif, M., 405

Asmus, H. See Baird, D., 75

Asmus, R. See Baird, D., 75

Astorga, M.P., 75

Atalah, J. See Forrest, B.M., 410

Atienza, D. See Martin, A., 31

Atilla, N., 405, 406

Attard, C.R.M. See Teske, P.R., 84

Aubanel, A. See Vieux, C., 386

Aubert, A., 375

Aumeeruddy, R. See Bigot, L., 376

Awira, R. See Kronen, M., 380

Axford, J. See Vieux, C., 386

Ayling, A.M. See Zann, L.P., 387

\section{B}

Babcock, R., 75

Babcock, R.C. See Shears, N.T., 416

Babu, I. See Apte, D., 375

Bacchiocchi, F. See Moschella, P.S., 413

Bacher, S. See Blackburn, T.M., 406

Bador, M. See Andréfouët, S., 141

Bagley, M. See Tepolt, C., 418

Bagnato, C. See Strotz, L.C., 385

Bahamonde, N. See Castilla, J.C., 76

Baillie, B. See Norton, J.H., 150

Baillie, J.E.M. See Butchart, S.H.M., 407 See Isaac, N.J.B., 147

See Safi, K., 151

Baillon N. See McKenna S.A., 148, 381

Baine, M., 50 See Pratchett, M.S., 32

Baird, A.H., 26, 75 See Pratchett, M.S., 32

Baird, D., 75

Bak, H.P., 27

Bak, R.P.M., 75

Baker, A.C. See DeBoer, T.S., 144

Baker, N. See Beger, M., 376

Bakus, G.J., 406

Baldo, B.A., 142

Baldwin, J. See Planes, S., 383

Balk, D. See McGranahan, G., 413
Ballesteros, E. See Ling, S.D., 30 See Tomas, F., 440 See Vergés, A., 33

Bally, M. See Garrabou, J., 78

Bally, R., 75

Banks, J. See Pearson, S., 414

Banks, S.C. See Johnson, C.R., 29, 412 See Teske, P.R., 84

Bannerot, S.P. See Iversen, E.S., 51

Barahona, M. See Castilla, J.C., 76

Barber, P.H. See Beger, M., 142 See DeBoer, T.S., 144

Barbour, M.G. See Richardson, D.M., 82

Bardsley, L. See Goss-Custard, J.D., 78

Barkai. A. See Day, R.W., 77

Barker, M.F., 27

Barker, N.P. See Teske, P.R., 84

Barneah, O. See Perkol-Finkel, S., 414

Barnes, D.K.A., 50, 375, 406 See Kuklinski, P., 51

Barott, K.L., 376

Barrett, G. See Underwood, A.J., 52

Barrett, N.S. See Johnson, C.R., 29, 412

Barry, J.P., 406

Bartholomew, A. See Burt, J., 406 See Feary, D.A., 409

Basker, J.R., 376

Baskett, M.L., 406

Bassett, T. See Schaffner, U., 439

Battarbee, R. See Moss, B., 414 See Whitehead, P., 418

Baum, J.K., 406

Baumgartner, F. See Pavia, H., 438

Baures, E. See Delpla, I., 408

Bavestrello, G. See Cerrano, C., 76

Baxter, C.H. See Barry, J.P., 406

Bayne, B.L., 75

Bayona, J.M. See Martínez-Lladó, X., 413

Bazeley-White, E. See Hector, A., 411

Bazzaz, F.A. See Parrish, J.A.D., 414

Beard, J.H. See Munro, J.L., 149

Becira, J.G. See Gonzales, B.J., 145, 378

Beck, M.W. See Airoldi, L., 405

Becker, B.J. See Roy, K., 83

Beckvar, N., 142

Bedinger, L. See Wasson, K., 418

Beger, M., 142, 376

See Pinca, S., 383

See von der Heyden, S., 153

Begg, C.B., 436

Begovic, E. See Roy, K., 83

Beheregaray, L.B. See Teske, P.R., 84

Bell, J.D., 142 See Hart, A.M., 146

Bell, L.A.J., 376

Bellchambers, L.M., 376 See Evans, S.N., 378

Ben, H.X. See Van Long, N., 386

Ben-David-Zaslow, R. See Perkol-Finkel, S., 414

Benayahu, Y. See Perkol-Finkel, S., 414 


\section{AUTHOR INDEX}

Benedetti-Cecchi, L., 27

See Coleman, R.A., 27

See Maggi, E., 438

See Vaselli, S., 418

Bengtsson, J. See Loreau, M., 80

Benhissoune, S. See Teske, P.R., 84

Benkendorff, K. See Davis, A.R., 437 See Liversage, K., 52

Bennett, D.M. See Hillebrand, H., 79

Bennett, S. See Wernberg, T., 418

Bennett, T. See Roni, P., 52

Bennie, J. See Davies, T.W., 408

Benson, A.A., 27

Bensoussan, N. See Garrabou, J., 78

Benzie, J.A.H., 142 See Macaranas, J.M., 148

Berec, L., 75

Berge, J. See Ware, C., 418

Berger, J. See Estes, J.A., 28

Berkley, H.A., 75

Berlow, E.L. See Menge, B.A., 81 See Navarrete, S.A., 81

Bernard, F.R., 376

Bernard, H.M. See Andrews, C.W., 375

Bernardi, G. See Rius, M., 415 See von der Heyden, S., 153

Bernatchez, L. See Veliz, D., 84

Berrios, F. See Ortiz, M., 81

Bertness, M.D., 75

See Altieri, A.H., 49

See Bruno, J.F., 75

See Crain, C.M., 77

Bertocci, I. See Benedetti-Cecchi, L., 27

Bertram, I. See Siaosi, F., 152, 384

Berumen, M.L. See Almany, G.R., 75

Berzunza-Sanzhez, M.M., 376

Bieler, R. See Herrera, N.D., 146

Biere, A. See Verhoeven, K.J.F., 440

Bigot, L., 376

Bijukumar, A., 376

Bintz, J. See Nixon, S., 414

Birch, G.F., 406

Birkelan, C. See Mauzey, K.P., 31

Birkeland, C., 27

Birnie, S.L. See Kyle, R., 79

Bishop, J.D.D. See Dupont, L., 409 See Johnston, E.L., 412

Bishop, M.J., 406

Bitar, G. See Monniot, C., 81

Black, R., 142, 376 See Johnson, M.S., 147, 379

Blackburn, T.M., 406

Blaffart H. See McKenna S.A., 148, 381

Blake, D.B., 27 See Mah, C., 31

Blakemore, K.A. See Forrest, B., 410

Blamey, L.K. See Ling, S.D., 30

Blanchette, C.A. See Menge, B.A., 81

Blasius, B. See Kaluza, P., 412 See Seebens, H., 416

Blidberg, E., 142
Blockley, D.J. See Green, D.S., 51

Bloecher, N., 406

Blohm, D. See Nuryanto, A., 150

Blum, M. See Tepolt, C., 418

Boavida, I. See Branco, P., 50

Boblin, P. See Kronen, M., 380

Bock, D.G. See Zhan, A., 419

Bodoy, A., 376

Boero, F. See Galil, B., 410

Bohn, K. See Mineur, F., 413

Bolam, S. See Smith, R., 417

Bolshakova, L.N. See Selin, N.I., 384

Bomhard, B. See Butchart, S.H.M., 407

Bonaviri, C. See Gianguzza, P., 51

Bond, T. See Black, R., 142, 376

Bond, W.J. See Estes, J.A., 28 See Hempson, G.P., 29

Bone, Q., 75

Bonsdorff, E. See Carstensen, J., 407

Bonuso, N. See Clapham, M.E., 77

Bonvallot, J. See Planes, S., 383

Boo, S.M. See Hammann, M., 437

Booth, D.J. See Alquezar, R., 405 See Macreadie, P.I., 413 See Vergés, A., 33

Borel, M. See Alzieu, C.L., 405

Borsa, P., 142, 376

Bos, A.R. See Mueller, B., 31

Bosserelle, P. See Kayal, M., 30

Botsford, L.W. See Fogarty, M.J., 145

Bottjer, D.J. See Clapham, M.E., 77

Boucher, H. See Aubert, A., 375

Bouchet, P., 142, 376

Boudouresque, C. See Lemee, R., 438

Bouilleret, F. See Wantiez, L., 386

Bourget, E. See Veliz, D., 84

Bourque, B.J. See Lotze, H.K., 413

Bowman, G., 75

Box, A. See Tomas, F., 440

Bracken, M.E. See Elser, J.J., 409

Bracken, M.E.S. See Low, N.H.N., 438

Bradbury, R.H. See Lotze, H.K., 413

Braga, F. See Mies, M., 149

Brahimi-Horn, M.C., 27

Braley, R. See Ledua, E., 381

Braley, R.D., 87-140, 142, 143, 155-374, 376, 377

See Alder, J., 375

See Ledua, E., 148

See Lucas, J.S., 148, 381

See Southgate, P.C., 152

Branch, G., 406

Branch, G.M., 27, 50, 75, 406

See Hanekom, N., 78

See McQuaid, C.D., 81

See Pillay, D., 31

See Rius, M., 82, 415

Branch, M.L. See Branch, G.M., 27

Branco, P., 50

Brand, D.G. See Reid, R.G.B., 151

Brandt, M. See Dee, L.E., 28

Brashares, J.S. See Estes, J.A., 28 


\section{AUTHOR INDEX}

Brazeau, D.A. See Sammarco, P.W., 416

Brearley, A. See Black, R., 142, 376 See Johnson, M.S., 147, 379

Brickman, D. See Frank, K.T., 145

Bridger, D. See Firth, L., 409

Brilli, M. See Accordi, G., 141, 375

Briski, E. See Zhan, A., 419

Britton-Simmons, K. See Engelen, A.H., 437

Britton-Simmons, K.H., 436

Broitman, B.R. See Navarrete, S.A., 81

Brooks, R. See McKenzie, L.A., 413

Brooks, T.M. See Rodrigues, A.S.L., 151

Brown, C. See Butchart, S.H.M., 407

Brown, C.J. See García Molinos, J., 28

Brown, C.W. See Davidson, I.C., 408 See Zabin, C.J., 419

Brown, D.S. See Pompanon, F., 31

Brown, J.H., 75, 143, 377

Brown, K.C. See Williamson, M.H., 419

Browne, M., 406

Bruce, A.J., 143

Bruckner, A.W. See Andréfouët, S., 141, 375

Bruinsma, J. See Alexandratos, N., 405

Brun, E., 27

Bruno, J. See Butchart, S.H.M., 407

Bruno, J.F., 50, 75 See Halpern, B.S., 411

Bryan, P.G., 143, 377

Bryant, J.P. See Coley, P.D., 77

Buchan, L.A.J., 406

Buchholz, B. See Weinberger, F., 440

Buck, B.H., 143 See Leggat, W., 148

Buckley, B. See Nixon, S., 414

Buddemeier, R.W. See Wilkinson, C.R., 153

Bueno, L. See Costa, T.J.F., 408

Bullard, S. See Rosa, M., 415

Bulleri, F., 406

See Airoldi, L., 405

See Chapman, M.G., 407

See Maggi, E., 438

See Moschella, P.S., 413

See Vaselli, S., 418

Bundal, N.A. See Conales, S.F., 377 See Dolorosa, R.G., 144, 377

Burford, M.A. See O'Neil, J., 414

Burgess, G.H. See Snyder, D.B., 417

Burgett, J.M., 27

Burke, L. See Chin, A., 377

Burkepile, D.E., 436 See Parker, J.D., 438

Burrows, M.T. See Adams, T.P., 405

See Firth, L.B., 409

See García Molinos, J., 28

See Griffin, J.N., 29

See Jenkins, S.R., 29

Burt, J., 406

Burt, J.A. See Feary, D.A., 409

Burton, G.A., 407

Buss, L.W., 407

Bustamante, R.H. See Castilla, J.C., 76

Butchart, S.H.M., 407
Butman, C.A. See Pawlik, J.R., 82

Buttemer, W.A. See Knott, N.A., 79

Buynevich, I.V. See FitzGerald, D.M., 409

Byers, J.E., 407

See Blakeslee, A.M., 406

Byrne, M., 1-26, 34

See Dartnall, A.J., 28

See Durrant, H.M.S., 409

See Hart, M.W., 29

See Kamya, P.Z., 30

See Marshall, D.J., 80

See Martinez, A.S., 31

See Uthicke, S., 33

C

Cabaitan, P.C., 143

Caballes, C.F. See Pratchett, M.S., 32

Cabioch, G. See Aubert, A., 375

Cabral, H.N. See Rius, M., 82

Cabrera, M.C.C. See Berzunza-Sanzhez, M.M., 376

Cabrita, M.T., 436

Cacabelos, E., 436

Cadiz, P. See Calumpong, H.P., 143, 377

Cadotte, M.W. See Hillebrand, H., 79

Cafaro, P., 75

Cai, Y-Y. See Bernard, F.R., 376

Cairns, S.D. See Sammarco, P.W., 416

Caldow, R.W. See Goss-Custard, J.D., 78

Callaway, R.M. See Liancourt, P., 413 See Maestre, F.T., 413

See Schaffner, U., 439

Calosi, P. See Armstrong, E.J., 141

Calumpong, H.P., 143, 377 See Naguit, M.R.A., 382

Calvo-Ugarteburu, G., 407

Camaño, A. See Castilla, J.C., 76

Camara, M. See Kuussaari, M., 79

Camp, P.A. See Combs, J.K., 408

Campbell, A. See Wernberg, T., 418

Campbell, A.H. See Poore, A.G.B., 31, 439 See Vergés, A., 33

Campbell, M. See Galil, B., 410

Campbell, M.L. See Hewitt, C. L., 411

Campbell, S.J. See Baird, A.H., 26

Campos, B. See Ramorino, L., 82

Campos, L. See Ortiz, M., 81

Campos, M.A. See Castilla, J.C., 76

Cancino, J. See Paine, R.T., 82

Cappuccino, N., 436

Carbone, F. See Accordi, G., 141, 375

Carlson, B.C., 143

Carlton, J. See Galil, B., 410 See Ruiz, G., 415

Carlton, J.T., 75, 407 See Blackburn, T.M., 406 See Chapman, J.W., 407

See Ruiz, G.M., 416

See Williams, S.L., 419

Carman, K.R. See Fleeger, J.W., 409

Caro, A.U., 75

See Castilla, J.C., 76, 407 


\section{AUTHOR INDEX}

Carpenter, K.E. See Butchart, S.H.M., 407 See DeBoer, T.S., 144

Carpenter, S.R. See Estes, J.A., 28

Carr, G.M. See Butchart, S.H.M., 407

Carré, C. See Bone, Q., 75

Carstensen, J., 407

Carvalho, M.A. See Barnes, D.K.A., 375

Carvalho-Filho, A. See Costa, T.J.F., 408

Caselle, J.E. See Barott, K.L., 376

Casey, K.S. See Halpern, B.S., 411

Castelli, A. See Maggi, E., 438

Castilla, J. See Goss-Custard, J.D., 78

Castilla, J.C., 55-74, 75, 76, 407

See Alvarado, J.L., 75

See Astorga, M.P., 75

See Caro, A.U., 75

See Cerda, M., 76

See Clarke, M., 77

See Gelcich, S., 78

See Guiñez, R., 78

See Manríquez, P.H., 80

See Navarrete, S.A., 81

See Pacheco, C.J., 82

See Paine, R.T., 82

Castro, J. See Coleman, R.A., 27

Castro, M. See Goss-Custard, J.D., 78

Cavell, N., 143

Cazassus, F. See Johnson, C.R., 29, 412

Cebrian, E. See Ling, S.D., 30

See Tomas, F., 440

See Vergés, A., 33

Ceccarelli, D. See Job, S., 379

Cerda, M., 76 See Castilla, J.C., 76

Cerrano, C., 76 See Garrabou, J., 78

Cervin, G. See Nylund, G.M., 438

See Pavia, H., 438

See Svensson, J.R., 439

Chadderton, W.L. See Jerde, C.L., 412

Chafer, C.J., 76

Chai, T.-T. See Borsa, P., 142

Chaipichit, S. See Loh, T.L., 381

Chambers, C.N.L., 143, 377

Chancerelle, Y. See Andréfouët, S., 141, 375

See Gilbert, A., 145, 378

See Kayal, M., 30

See Vieux, C., 386

Chang, A.L. See Davidson, I.C., 408

Chang, P. See Bone, Q., 75

Chanson, J. See Butchart, S.H.M., 407

Chantrapornsyl, S., 377

Chapin, F.S. See Coley, P.D., 77

Chapman, A.R.O. See Johnson, C.R., 437

Chapman, F.C. See Andrews, C.W., 375

Chapman, J.W., 407

Chapman, L See Siaosi, F., 152

Chapman, L. See Kronen, M., 380

See Sauni, S., 384

See Siaosi, F., 384

Chapman, M. See Browne, M., 406
Chapman, M.G., 27, 35-49, 50, 77, 407

See Bulleri, F., 406

See Clynick, B.G., 407

See Cruz Motta, J.J., 50

See Dugan, J.E., 408

See Grayson, J.E., 51

See Green, D.S., 51

See Klein, J.C., 412

See Knott, N.A., 412

See Monteiro, S.M., 81

See Smoothey, A.F., 52

Charpy, L. See Bigot, L., 376

Chase, J.M. See Leibold, M.A., 80

Chateau, J. See Marchal, V., 413

Chatzinikolaou, E. See Maggi, E., 438

Chaudhary, C., 143

Chauvet, C. See Planes, S., 383

Chavanich, S., 436

Chee, S.Y. See Bishop, M.J., 406

Chemello, R. See Gianguzza, P., 51

Chen, B.Y., 27

Chen, C.P. See Chen, B.Y., 27

Chen, G. See Fijiwara, S., 378

Chenery, A.M. See Butchart, S.H.M., 407

Cheng, B.S. See Kimbro, D.L., 412, 437

Cheo, P.R. See Toh, K.B., 418

Chesher, R.H., 27, 143, 377

Chevaldonné, P. See Garrabou, J., 78

Chia, F.-S., 27

See Birkeland, C., 27

See Levitan, D.R., 80

Chin, A., 377

Choat, J.H., 27

Choi, D.R, 50

Chou, L.M., 50

See Koh, L.L., 380

See Loh, T.L., 381

See Neo, M.L., 150

See Todd, P.A., 152

See Toh, K.B., 418

Chun, Y.J., 436

Chunco, A.J., 77

Chunn, J. See Gerland, P., 410

Cigliano, M. See Garrabou, J., 78

Cinner, J. See Gelcich, S., 78

Ciret, P. See Schwartzmann, C., 151, 384

Claisse, D., 407

Clapham, M.E., 77

Clapp, C. See Marchal, V., 413

Clare, A.S. See Aldred, N., 405

Clark, G.F., 389-405, 407 See Durrant, H.M.S., 409

Clarke Murray, C., 407

Clarke, A. See Barnes, D.K.A., 50

Clarke, K.R. See Chapman, M.G., 50

Clarke, M., 77 See Castilla, J.C., 76

Cledón, M. See Farias, N.E., 28

Cleland, E.E. See Elser, J.J., 409

Clément, G. See Wantiez, L., 386

Clement, M. See Delpla, I., 408

Clemente, S. See Ling, S.D., 30 


\section{AUTHOR INDEX}

Clua, E. See Chin, A., 377

Clusella-Trullas, S. See Rius, M., 82, 415

Clutton-Brock, T. See Courchamp, F., 77

Clynick, B.G., 407

Coen, L.D. See Williams, A.H., 33

Colautti, R.I., 407, 436

Colbeck, R., 144

Cole, V.J., 77 See Liversage, K., 52

Coleman, M.A. See Clark, G.F., 407 See Rivero, N.K., 415

See Vergés, A., 33

See Wernberg, T., 418

Coleman, N., 27

Coleman, R.A., 1-26, 27, 34

See Bishop, M.J., 406

See Liversage, K., 52

See Martinez, A.S., 31

See Marzinelli, E.M., 413

See Poore, A.G.B., 31, 439

Coley, P.D., 77

Collar, N.J., 144

Collen, B. See Butchart, S.H.M., 407 See Isaac, N.J.B., 147

Collins J. See Dartnall, A.J., 28

Collins, A.G. See Castilla, J.C., 76 See Roy, K., 83

Collins, N.M. See Wells, S., 153 See Wells, S.M., 387

Colquhoun, J. See Rees, M., 383

Colyvan, M. See Justus, J., 79

Coma, R. See Garrabou, J., 78 See Gili, J.-M., 78 See Ribes, M., 82

Combs, J.K., 408

Conaco, C. See Cabaitan, P.C., 143

Conales, S.F., 377 See Dolorosa, R.G., 144, 377

Conales, S.F., Jr. See Dolorosa, R.G., 378

Conklin, E.J. See Smith, J.E., 439 See Williams, G.J., 387

Conley, D. See Carstensen, J., 407

Connell, J.H., 50, 77

Connell, S.D., 408

See Airoldi, L., 405

See Glasby, T.M., 410

See Holloway, M.G., 411

See Ling, S.D., 30

See Saunders, R.J., 416

See Wernberg, T., 418

Connolly, S.R., 77

Cook, E. See Galil, B., 410

Cook, E.J. See Mineur, F., 413

Cooke, G.M. See Teske, P.R., 84

Cooke, R.G. See Lotze, H.K., 413

Coombs, E.M. See McEnvoy, P.B., 413

Coowar, M. See Michel, C., 149

Copland, J.W., 144

Corkill, J. See Pinn, E.H., 415

Corrie, A. See Barnes, D.K.A., 375

Costa, T.J.F., 408

Costanza, R., 408
Costello, M.J., 87-140, 155-374

See Chaudhary, C., 143

See Waters, C.G., 153

Courchamp, F., 77

See Berec, L., 75

Coutts, A. See Floerl, O., 409

Coutts, A.D.M., 408 See Ware, C., 418

Cowles, D.L. See Morgan, M.B., 31

Cox, L.R., 144

Coyer, J.A. See Levin, P.S., 438

Crabbe, M.J.C. See Curnick, D.J., 144

Crafton, R.E. See Grosholz, E.D., 410 See Williams, S.L., 419

Craig, P., 377 See Green, A., 145, 378

Crain, C.M., 77, 408

Crandall, E.D. See Beger, M., 142

Crawford, C.M., 144

See Braley, R.D., 143

See Macleod, C.K., 413

Crawley, M.J. See Keane, R., 437 See Keane, R.M., 412

Cronon, W., 77

Crooks, J.A., 77

Crowe, T.P. See Farrell, E.D., 77 See Firth, L.B., 409

See Green, D.S., 51

See Griffin, J.N., 29

See Maggi, E., 438

Crump, R.G., 27, 28 See Emson, R.H., 28

Crutsinger, G.M., 77

Cruz Motta, J.J., 50

Cruz-Rivera, E., 436 See Paul, V.J., 31

Cryer, M., 50

Csirke, J. See Butchart, S.H.M., 407

Cubit, J. See Lubchenco, J., 30

Culver, C.S. See Page, H.M., 414

Cumming, R.L., 144

Cummings, D.O., 437

Cunha, T. See Stimson, J., 439

Curd, A. See Harding, S., 379

Curnick, D.J., 144

Currie, V. See Dayton, P.K., 28

D

D’Agrosa, C. See Halpern, B.S., 411

Dafforn, K.A., 389-405, 408

See Bishop, M.J., 406

See Clark, G.F., 407

See Lavender, J.T., 412

See Piola, R.F., 415

See Rivero, N.K., 415

Dahabreh, I.J. See Dietz, G., 437

Dai, C-F. See Fijiwara, S., 378

Dai, C.F. See Tadashi, K., 385

Dailer, M.L. See Vermeij, M.J.A., 418

Dalby, J.E.J., 77

Dalzell, P., 377 


\section{AUTHOR INDEX}

Dangremond, E.M., 408

Daniels, C., 377

Dankers, N. See van de Koppel, J., 84

Darling, J. See Tepolt, C., 418

Darling, J.A. See Rius, M., 82, 415 See Roman, J., 415

Dartnall, A.J., 28

See Hart, M.W., 29

See Keough, M.J., 30

Darwin, C., 437

Davenport, J. See Lehane, C., 80

Davey, M. See Langston, W., 412

Davidson, I. See Simkanin, C., 416

Davidson, I.C., 408

See Williams, S.L., 419

See Zabin, C.J., 419

Davidson, J. See LeBlanc, N., 80

Davidson, N.C. See Butchart, S.H.M., 407

Davies, T.W., 408

Davis, A.R., 437 See Knott, N.A., 79

Davis, M.A., 408

Davis, M.H. See Dupont, L., 409

Davis, T.W. See O’Neil, J., 414

Dawson, B., 144

Dawson, J., 28

Dawson, R.F., 144

Dawson, T. See Irving, R., 379

Dawson, W. See Chun, Y.J., 436

Day, R.W., 77

Dayton, P.K., 28, 50, 77 See Mauzey, K.P., 31

de Bettignies, T. See Wernberg, T., 418

de Jong, I. See Bak, R.P.M., 75

De Leaniz, C.G. See Schröder, V., 416

de Lemos D.E.L. See Mies, M., 149

de Loma, T.L. See Kayal, M., 30

De Meester, L. See Moss, B., 414

de Nys, R. See Dworjanyn, S.A., 437

See Hawkins, S.J., 409

de Pablo, J. See Martínez-Lladó, X., 413

De'ath, G., 28

Deagle, B.E. See Pompanon, F., 31

DeBoer, T.S., 144

Decho, A.W., 28

Dee, L.E., 28

Defeo, O. See Castilla, J.C., 76

Degnan, B.M. See Walker, S.J., 53

Deiye, M. See Lovell, E., 381

Delgado, A. See Castilla, J.C., 76

Delgado, A.P. See Manríquez, P.H., 80

Della Santina, P. See Coleman, R.A., 27

Dellink, R. See Marchal, V., 413

Delpla, I., 408

Deltreil, J.P. See Alzieu, C.L., 405

DelValls, T. See Rodriguez, L.F., 415

DeMartini, E.E. See Sandin, S.A., 384

Dembélé, F. See Dohn, J., 408

Dempster, T. See Hawkins, S.J., 409

Dendrinos, P. See Vergés, A., 33

Denley, E.J. See Underwood, A.J., 33

Denny, C. See Gust, N., 410
Dentener, F. See Butchart, S.H.M., 407

Desqueyroux-Faúndez, R. See Castilla, J.C., 76

Dethier, M.N. See Steneck, R.S., 32, 83

Dey, K.L See Floerl, O., 409

Dias, G.M. See Rius, M., 83 See Vieira, E.A., 84

Diaz, D. See Garrabou, J., 78

Diaz, M.C. See Wasson, K., 418

Diaz, R. See Rabalais, N., 415

Díaz, R.J. See Rabalais, N.N., 415

Dick, L. See Dumas, P., 144

Diehl, D. See Schiff, K., 416

Dierschke, V. See Goss-Custard, J.D., 78

Diettrich, J. See Floerl, O., 409

Dietz, G., 437

Díez, S. See Martínez-Lladó, X., 413

Dill, J. See Knight, R., 147

Dinesen, G.E. See Moschella, P.S., 413

Dinsdale, E.A. See Barott, K.L., 376 See Sandin, S.A., 384

Djama, N. See Pilcher, N., 383

Dobson, A.P. See Reed, J.M., 82 See Torchin, M.E., 418

Doherty, E. See Nadon, M.O., 382

Dohn, J., 408

Dolecal, R.E., 28

Dolmer, P. See Svane, I., 417

Dolorosa, R.G., 144, 377, 378 See Conales, S.F., 377

See Gonzales, B.J., 378

Donahue, M.J., 77

Donlan, C.J. See Gelcich, S., 78

Donner, S.D. See Sandin, S.A., 384

Dormontt, E.E. See Prentis, P.J., 415

Dornbos, S.Q. See Clapham, M.E., 77

dos Santos, E.M. See Parente, V., 414

Douglas, M., 50

Douglas, M.E. See Olden, J.D., 414

Douglas, M.R. See Olden, J.D., 414

Dower, J.F. See Simkanin, C., 417

Downes, B.J., 51

Downing, J.A., 77

Drake, J.M., 408 See Leung, B., 412

Driscoll, M.J.L. See Kimmerer, R.W., 51

Drouin, A. See Low, N.H.N., 438

Duarte, C. See Manríquez, P.H., 80

Duarte, C.M., 408

Duarte, L.F.L. See Vieira, E.A., 84

Dubois, P. See Hennebert, E., 29

Dubois, S.F. See Woodin, S.A., 419

Duchesne, P. See Veliz, D., 84

Duffy, J.E., 28, 437 See Poore, A.G.B., 439

Duffy, J.P. See Davies, T.W., 408

Dugan, J.E., 408 See Page, H.M., 414

Dugdale, H.L. See Agombar, J.S., 375

Dukes, J.S., 409 See Theoharides, K.A., 418

Dumas, P., 144, 378

Dumay, O., 437 


\section{AUTHOR INDEX}

Duncan, R.P. See Blackburn, T.M., 406

Dunn, R.J.K. See Warnken, J., 418

Dunstan, P.K. See Johnson, C.R., 29, 412

Dupont, L., 409

Durán, L.R. See Castilla, J.C., 76

Durell, S.E. See Goss-Custard, J.D., 78

Durrant, H.M.S., 409

Durrieu, G. See Schwartzmann, C., 151, 384

Duryadi, D. See Nuryanto, A., 150

Dutheil, C. See Andréfouët, S., 141

Dutil, C. See Himmelman, J.H., 29

Dutta, S. See Apte, D., 141, 375

Duyverman, H., 28

Dworjanyn, S.A., 437

See Durrant, H.M.S., 409

See Kamya, P.Z., 30

\section{$\mathbf{E}$}

Ebert, C. See Halpern, B.S., 411

Eckman, W., 144 See Neo, M.L., 149

See Vicentuan-Cabaitan, K., 153

Edgar, G.J. See Johnson, C.R., 29, 412 See Poore, A.G.B., 31, 439

Edwards, F. See Hänfling, B., 411

Eggleton, J., 409

Eichhorn, G. See Goss-Custard, J.D., 78

El-Zibdah, M. See Jantzen, C., 147

Elfwing, T., 144 See Blidberg, E., 142

Eliata, A., 144, 378

Elliott, J.K. See Rogers, T.L., 52

Elliott, M. See Wilson, J.C., 419

Ellis, R.P. See Hempson, G.P., 29

Elser, J.J., 409

Elton, C.S., 409, 437

Emlet, R.B. See Marshall, D.J., 80

Emmett Duffy, J. See Poore, A.G.B., 31

Emparanza, E.J.M., 51

Emson, R.H., 28 See Crump, R.G., 28

Enge, S., 421-436, 437 See Nylund, G.M., 438

See Pavia, H., 438

See Sagerman, J., 439

Engel, C.R. See Voisin, M., 418

Engelen, A.H., 437 See Monteiro, C.A., 438

Engle, J.M. See Roy, K., 83

Engström, J. See Langhamer, O., 412

Ens, B.J. See Goss-Custard, J.D., 78

Erdmann, M.V. See DeBoer, T.S., 144

Erftemeijer, P.L.A. See Neo, M.L., 149, 150

Eriksen, J. See Trannum, H.C., 418

Eriksson, B.K., 77

Erlandsson, J., 77

Eschner, A. See Huber, M., 146, 379

Essington, T.E. See Estes, J.A., 28

Estacion, J.S. See Calumpong, H.P., 377

Estes, J.A., 28

Etter, R.J. See Miller, R.J., 413
Evans, A. See Firth, L., 409

Evans, A.J. See Firth, L.B., 409

Evans, S.M., 378

Evans, S.N., 378

See Bellchambers, L.M., 376

Evers, D. See Schaffelke, B., 439

Exo, K.M. See Goss-Custard, J.D., 78

Eylers, J.P., 28

\section{F}

F. Pantoja, J. See Poore, A.B., 31

Fadeev, V.I. See Levin, V.S., 30

Fagolimul, J. See Perron, F.E., 150

Fagolimul, J.O. See Price, C.M., 151, 383

Fairweather, P.G., 77

Faith, D.P., 144, 145

See Mooers, A.Ø., 149

Falkner, M. See Simkanin, C., 416

Fankboner, P.V., 145

See Reid, R.G.B., 151

Farghalli, M.E. See Kilada, R., 380

Farias, N.E., 28

Farman, R. See Aubert, A., 375

Farrell, E.D., 77

Farrell, P. See Fletcher, R.L., 409

Faulkner, K. See von der Meden, C.E.O., 84

Fausch, K.D. See Olden, J.D., 414

Fauvelot, C., 87-140, 155-374

See Andréfouët, S., 141, 375

See Borsa, P., 142, 376

See Dumas, P., 144, 378

See Tiavouane, J., 152, 385

See Van Wynsberge, S., 153

See von der Heyden, S., 153

See Wabnitz, C.C.C., 153

Feary, D.A., 409

See Vergés, A., 33

Fellbeck, H. See Tamburri, M.N., 417

Fellers, J.H., 409

Fenical, W. See Hay, M.E., 411, 437

Fenster, M.S. See FitzGerald, D.M., 409

Ferber, P. See Krell, B., 147

Fernández, C. See Engelen, A.H., 437

Fernández, E. See Pearson, S., 414

Ferns, P.N. See Goss-Custard, J.D., 78

Ferreira, C.E.L. See Lagesa, B.G., 412

Ferreira, D. See Parente, V., 414

Ferreira, M.T. See Branco, P., 50

Feuda, R., 28

Fiala-Médioni, A., 78

Fiege, D., 378

Field, C.E. See Benson, A.A., 27

Field, J.G. See Newell, R.C., 81

Fielding, P.J., 78

See Kyle, R., 79

Figueira, W. See Vergés, A., 33

Fijiwara, S., 378

Filip, N. See Simkanin, C., 417

Finelli, C.M. See Atilla, N., 405

Firth, L., 409 


\section{AUTHOR INDEX}

Firth, L.B., 409

See Bishop, M.J., 406

See Mieszkowska, N., 413

See Pearson, S., 414

Fischer, M. See Van Kleunen, M., 418

Fisk, D. See Kronen, M., 380 See Vieux, C., 386

Fitt, W.K., 145 See Heslinga, G.A., 146 See Norton, J.H., 150

Fitter, A. See Williamson, M., 440

FitzGerald, D.M., 409

Flammang, P. See Hennebert, E., 29

Fleeger, J.W., 409 See Atilla, N., 405, 406

Fletcher, L., 78

Fletcher, L.M. See Forrest, B.M., 410

Fletcher, R.L., 409

Fleurya, B.G. See Lagesa, B.G., 412

Flinn, M.V., 78

Floerl, O., 389-405, 409, 410

See Bloecher, N., 406

See Gust, N., 410

See Hayden, B.J., 411

See Ware, C., 418

See Zaiko, A., 419

Fofonoff, P.W. See Davidson, I.C., 408 See Ruiz, G.M., 416

Fogarty, M.J., 145

Foltz, D. See Mah, C., 30, 31

Fong, T. See Thaman, R.R., 385

Fontaine-Vernaudon, Y. See Planes, S., 383

Fontana, R.E. See Grosholz, E.D., 410 See Williams, S.L., 419

Forbes, A.T. See Fielding, P.J, 78

Forrest, B., 410 See Gust, N., 410

Forrest, B.M., 410 See Coutts, A.D.M., 408 See Sinner, J., 417

Forslund, H., 437

Fosdick, B.K. See Gerland, P., 410

Foster, D. See Grimm, N.B., 410

Foster, M. See Butchart, S.H.M., 407

Fowler, A.M. See Macreadie, P.I., 413

Fox, H.E. See Halpern, B.S., 411

Fox, J.W., 78

Foyle, T.P. See Hart, A.M., 146

Fraiser, M.L. See Clapham, M.E., 77

Frank, K.T., 145

Fraschetti, S. See Galil, B., 410

Freckleton, R.P. See Stephens, P.A., 152

Fredriksson, J. See Persson, F., 439

Freeman, J. See Kilfoyle, A.K., 51

Freestone, A.L., 410

Fridley, J.D., 410

Fried, H. See Stachowicz, J.J., 417

Friedlander, A.M. See Barott, K.L., 376 See Sandin, S.A., 384

Friedman, K. See Andréfouët, S., 141, 375 See Gilbert, A., 145, 378

See Kronen, M., 380
See Sauni, S., 384

See Teitelbaum, A., 152

Frithsen, J. See Nixon, S., 414

Frost, M. See Moschella, P.S., 413

Frost, N.J. See Johnson, M.P., 29

Frusher, S.D. See Johnson, C.R., 29, 412

Fuentes-Grunewald, C. See Teske, P.R., 84

Fuiman, L.A. See Southward, A.J., 152

Fujita, D., 28 See Ling, S.D., 30

Fujita, R. See Halpern, B.S., 411

G

Gabrie, C. See Planes, S., 383

Gacia, E. See Moschella, P.S., 413

Gaertner-Mazouni, N. See Andréfouët, S., 141, 375 See Menoud, M., 149

See Van Wynsberge, S., 153

Gaimard, A. See Quoy, J., 82

Gaines, M.D. See Selkoe, K.A., 152

Gaines, S. See Kinlan, B.P., 79

Gaines, S.D. See Kinlan, B.P., 79 See Lubchenco, J., 30, 80, 438

Gale, A.S., 28

Galil, B., 410

Galli, A. See Butchart, S.H.M., 407

Galloway, J.N. See Butchart, S.H.M., 407

Galon, W.M. See Gonzales, B.J., 145, 378

Galzin, R. See Planes, S., 383

Gambi, M.C. See Garrabou, J., 78

Garbary, D.J. See Jenkins, S.R., 29

García Molinos, J., 28

García-Berthou, E. See McKnight, E., 413

Gardner, C. See Johnson, C.R., 29, 412

Gardner, J. See Apte, S., 405

Gardner, J.P.A. See Forrest, B.M., 410

Gargallo, L. See Castilla, J.C., 76

Garrabou, J., 78 See Ling, S.D., 30

Garrigue, C. See Lovell, E., 381

Gascoigne, J., 78

Gastner, M.T. See Kaluza, P., 412 See Seebens, H., 416

Gaston, K.J., 51 See Davies, T.W., 408

Gaymer, C.F., 28 See Himmelman, J.H., 29

Geary, D.C. See Flinn, M.V., 78

Gelcich, S., 78

Gell, F. See Barnes, D.K.A., 375

Geller, J. See Tepolt, C., 418

Geller, J.B. See Carlton, J.T., 75

Gemmell, N.J. See Goldstien, S.J., 410

Genazzio, M. See Sammarco, P.W., 416

Genner, M. See Hawkins, S., 411

Genovesi, P. See Butchart, S.H.M., 407

Geoffroy, S. See Kayal, M., 30

George, K.C., 378

Gerard, V.A., 28

Gerhardt, K. See Chin, A., 377

Gerlach, G., 378 


\section{AUTHOR INDEX}

Gerlach, R. See Gerlach, G., 378

Gerland, P., 410

Gerrodette, T. See Dayton, P.K., 28

Gervis, M. See Bell, J.D., 142

Getchis, T. See Rosa, M., 415

Ghabooli, S. See Zhan, A., 419

Ghedini, G. See Maggi, E., 438

Gherardi, F. See Hänfling, B., 411

Gianguzza, P., 51

Gibbons, L. See Simberloff, D., 416

Gibbs, P. See Langston, W., 412

Gibert, O. See Martínez-Lladó, X., 413

Giddins, R. See Johnson, C.R., 29

Giese, A.C. See Araki, G.S., 26

Gilbert, A., 145, 378

See Andréfouët, S., 141, 375

See Dumas, P., 378

See Dumas, P., 144

See Van Wynsberge, S., 153, 386

Gilbert, D. See Rabalais, N., 415

Gili, J.-M., 78

Gili, J.M. See Ribes, M., 82

Gill, J.A. See Goss-Custard, J.D., 78

Gilligan, J., 378

Gilligan, J.J. See Hender, J., 379

Gilman, S.E. See Barry, J.P., 406

Ginsberg, R.N. See Choi, D.R, 50

Glaister, A. See Downes, B.J., 51

Glasby, T.M., 410

See Connell, S.D., 408

See Dafforn, K.A., 408

See Knott, N.A., 412

Gobert, J. See Lemee, R., 438

Gobler, C. See O'Neil, J., 414

Godoy, N. See Gelcich, S., 78

Godwin, L. See Apte, S., 405

Godwin, L.S., 410

Goetze, E. See Peijnenburg, K.T.C.A., 150

Goh, E. See Guest, J.R., 145, 378

Goh, G.H.S. See Othman, A.S., 150

Goldstien, S. See Zaiko, A., 419

Goldstien, S.J., 410

Gollasch, S. See Galil, B., 410

See Hallegraeff, G., 411

Gollock, M. See Curnick, D.J., 144

Gomez, E., 145

See Newman, W., 382

Gomez, E.D., 87-140, 145, 155-374, 378

See Cabaitan, P.C., 143

See Juinio, M.A.R., 147, 379

See Mingoa-Licuanan, S.S., 149

See Newman, W.A., 150

Gomez, R.G. See Tiitii, U., 385

Gonzales, B.J., 145, 378

Gonzales, M.M.G. See Gonzales, B.J., 145, 378

Gonzalez, A. See Leibold, M.A., 80

González, J. See Ortiz, M., 81

Gonzalez, J. See Soto, D., 417

Good, T.P. See Levin, P.S., 438

Gopakumar, G. See George, K.C., 378

Gordon, D.P. See Floerl, O., 410

Goss-Custard, J.D., 78
Gössling, S., 378

Gossuin, H. See Purcell, S.W., 383

Govan, H., 145, 378

Gove, J.M. See Williams, G.J., 387

Graba-Landry, A. See Kamya, P.Z., 30

Grace, R.V., 28

Graf, G. See Mueller, B., 31

Graham, M.H. See Thornber, C.S., 439

Granger, S. See Nixon, S., 414

Granhag, L. See Moschella, P.S., 413

Grant, C.C. See Hempson, G.P., 29

Grayson, J.E., 51

Green, A., 145, 378

Green, D.S., 51

Green, E. See Wabnitz, C.C.C., 153

Greenstone, M.H. See Symondson, W.O.C., 83

Gregory, R.D. See Butchart, S.H.M., 407

Grenfell, B. See Courchamp, F., 77

Grice, A. See Leggat, W., 148

Griffin, J.N., 29

Griffiths, C.L. See Bally, R., 75

See Hughes, R.N., 79

See Klumpp, D.W., 147

See Monniot, C., 81

See Newell, R.C., 81

See Rius, M., 82, 415

See Robinson, T.B., 83

See Wright, A., 85

Griffiths, D. See Nadon, M.O., 382

Grigorovich, I.A. See Colautti, R.I., 407, 436

Grime, J.P., 410

See Davis, M.A., 408

See Loreau, M., 80

Grimm, N.B., 410

Groeneveld, R.A. See Punt, M.J., 415

Groffman, P. See Grimm, N.B., 410

Groom, M.J. See Combs, J.K., 408

Grosberg, R.K., 78

Grosholz, E. See Bertness, M.D., 75

See Tepolt, C., 418

Grosholz, E.D., 410

See Kimbro, D.L., 412, 437

See Ruiz, G.M., 416

See Williams, S.L., 419

Grove, J.M. See Grimm, N.B., 410

Grulois, D. See Borsa, P., 142, 376

Gruner, D.S. See Elser, J.J., 409

Gu, D. See Gerland, P., 410

Guenther, J. See Hawkins, S.J., 409

Guest, J.R., 145, 146, 378

Guglielmino, M.L. See Brahimi-Horn, M.C., 27

Guiler, E.R., 78

Guiñez, R., 78

See Astorga, M.P., 75

See Castilla, J.C., 76, 407

Guiñez, R. See Alvarado, J.L., 75 See Caro, A.U., 75

Gumanao, G.S. See Mueller, B., 31

Gupta, A.S. See Vergés, A., 33

Gurevitch, J. See Dietz, G., 437 See Rothstein, H.R., 439

Gust, N., 410 


\section{AUTHOR INDEX}

Gustafsson, B. See Carstensen, J., 407

Gutiérrez, J.L., 78

Gutow, L. See Poore, A.B., 31

Guzman, E. See Soto, D., 417

\section{H}

Haacke, C. See Jantzen, C., 147

Haag, F. See Tamelander, J., 418

Hacker, S.D. See Steneck, R.S., 83

Haddon, M. See Johnson, C.R., 29, 412 See Ling, S.D., 413

Haesaerts, D. See Hennebert, E., 29

Hagen, W. See Wessels, H., 33

Halford, A.R. See Keesing, J.K., 30

Hall, L. W., 411

Hallegraeff, G., 411

Halpern, B.S., 411

See Crain, C.M., 408

See García Molinos, J., 28

Hambrey Consulting, 145

Hamer, C.E. See Blakeslee, A.M., 406

Hammann, M., 437

Hamner, W.M., 145, 146, 378

Hamzah, B.A., 411

Hanan, N.P. See Dohn, J., 408

Hanekom, N., 78

Hänfling, B., 411

Hanley, M.E. See Firth, L.B., 409 See Johnson, M.P., 29

Hanski, I. See Kuussaari, M., 79

Hanson, K. See Roni, P., 52

Harder, T. See Enge, S., 437

Harding, S., 379

Harding, S.P. See Hawkins, S.J., 29

Hardy, J.T., 379

Hardy, S.A. See Hardy, J.T., 379

Hardy, T. See Harding, S., 379

Harley, C.D.G., 78

Harmelin, J.G. See Garrabou, J., 78

Harpole, W.S. See Elser, J.J., 409

Harris, A. See Nadon, M.O., 382

Harris, F. See Beger, M., 376

Harris, J.M. See Hanekom, N., 78

Harris, L.G. See Chavanich, S., 436

Hart, A.M., 146

Hart, M.W., 29 See Dartnall, A.J., 28

Hartati, R. See Yusuf, C., 387

Hartnoll, R.G. See Coleman, R.A., 27 See Hawkins, S.J., 29, 51, 78, 437

Harvey, H. See Downing, J.A., 77

Harvey, J.A. See Verhoeven, K.J.F., 440

Harvey, N. See Bowman, G., 75

Harzhauser, M., 146

Havens, K. See Moss, B., 414

Hawkins, S., 411 See Firth, L., 409

Hawkins, S.J., 29, 51, 78, 409, 437

See Airoldi, L., 405

See Bishop, M.J., 406

See Coleman, R.A., 27
See Firth, L.B., 409

See Griffin, J.N., 29

See Jenkins, S.R., 29

See Johnson, M.P., 29

See Mieszkowska, N., 413

See Moschella, P.S., 413

See Norton, T.A., 31

Hawkswell, N.J. See Agombar, J.S., 375

Hay, M. See Cruz-Rivera, E., 436

Hay, M.E., 29, 411, 437

See Burkepile, D.E., 436

See Cruz-Rivera, E., 436

See Duffy, J.E., 28, 437

See Parker, J.D., 438

See Stachowicz, J.J., 83

See Vergés, A., 33

Hayden, B.J., 411

Hayward, B.W., 78

Head, C.E.I. See Curnick, D.J., 144

Healy, J.M. See Braley, R.D., 143

See Keys, J.L., 147

Heasman, K.G., 78

See Rius, M., 415

Hecht, T. See Heasman, K.G., 78

Heck, K.L. See Vergés, A., 33

Hector, A., 411 See Loreau, M., 80

Hedge, L.H., 411

Hedges, L.V., 437

Hedley, C., 146

Heinemann, D. See Halpern, B.S., 411

Helidoniotis, F. See Johnson, C.R., 29, 412

Heller, C., 78

Hempson, G.P., 29

Hender, J., 379 See Gilligan, J., 378

Henderson, J.A., 29

Hennebert, E., 29

Henriques, N. See Engelen, A.H., 437

Hensley, R.A., 379

Henzler, C.M. See Selkoe, K.A., 152

Herbert, R. J. See Hawkins, S., 411

Herdiana, Y. See Baird, A.H., 26

Hereu, B. See Ling, S.D., 30

Herman, P.M.J. See van de Koppel, J., 84

Hermansson, M. See Nylund, G.M., 438 See Persson, F., 439

Hermosillo, B. See Ortiz, M., 81

Hernández, J.C. See Ling, S.D., 30

Hernawan, U.E., 379

See Kusnadi, A., 380

Heros, V. See Bouchet, P., 142, 376

Herrera, N.D., 146

Hesitoni 'Aloua See Langi, V., 380

Heslinga, G.A., 87-140, 146, 155-374

See Maruyama, T., 148

See Munro, J.L., 149

See Perron, F.E., 150

Hess, D. See Beger, M., 376

Hester, F.J., 146, 379

Hewitt, C. L., 411

Hewitt, C. See Galil, B., 410 


\section{AUTHOR INDEX}

Hewitt, C.L. See Glasby, T.M., 410

See Ruiz, G.M., 416

See Schaffelke, B., 439

Heyward, A. See Rees, M., 383

Hietanen, S. See Carstensen, J., 407

Hill, A.S. See Hawkins, S.J., 29

Hill, K.L. See Johnson, C.R., 29, 412

Hillebrand, H., 79 See Elser, J.J., 409

Hily, C. See Le Hir, M., 51

Himmelman, J.H., 29 See Gaymer, C.F., 28

Hines, A.H. See Ruiz, G.M., 416

Hirase, S., 379

Hirschberger, W., 146, 379

Hiscock, S.J. See Vallejo-Marín, M., 84, 418

Hoang Tri, N., 411

Hoang, P.K. See Van Long, N., 386

Hoang, X.B. See Lasola, N., 380

Hobbs, J.P. See Gilligan, J., 378

Hobday, A.J. See Ling, S.D., 413

Hockey, P.A. See Goss-Custard, J.D., 78

Hockings, M. See Butchart, S.H.M., 407

Hodder, J. See Carlton, J.T., 407

Hoeksema, B.W. See Curnick, D.J., 144

Hoesterey, J.C. See Page, H.M., 414

Hoey, A.S. See Baird, A.H., 26

Hoffmann, M. See Rodrigues, A.S.L., 151

Hoggart, S.P.G. See Firth, L.B., 409

Holbrook, N.J. See Johnson, C.R., 29, 412

Holdgate, M.W. See Williamson, M.H., 419

Holland, B. See Apte, S., 405

Holland, P. See Vieux, C., 386

Holloway, M.G., 411 See Glasby, T.M., 410

Holmes, A.M. See Oliver, P.G., 382

Holmgren, M., 411

Holohan, B. See Rosa, M., 415

Holt, R.D. See Estes, J.A., 28 See Leibold, M.A., 80

Holt, R.D.C. See Estes, J.A., 28

Holthus, P. See Planes, S., 383

Holway, D.A. See Suarez, A.V., 417

Holyoak, M. See Leibold, M.A., 80

Hoope, M.F. See Leibold, M.A., 80

Hooper, D.U. See Loreau, M., 80

Hooper, J.N.A. See Walker, S.J., 53

Hopkins, A., 146, 379

Hopkins, G.A. See Forrest, B.M., 410 See Sinner, J., 417

See Zaiko, A., 419

Hopkinson, C.S. See Grimm, N.B., 410

Hora, M.S.C. See Costa, T.J.F., 408

Hosie, G.W. See Johnson, C.R., 29, 412

Hourston, M., 379

Howard NT-A-K. See Sims, N.A., 384

Howarth R.W. See Smith, V.H., 417

Hsiung, T.W. See Huang, C.W., 379

Huang, C.W., 379

Huang, D., 146

See Curnick, D.J., 144

Huang, H. See Tadashi, K., 385
Huber, M., 146, 379

Hudson, J., 411

Hudson, M.D. See Savage, J.M., 384

Huelsken, T., 146

Hughes, A. See Lovell, E., 381

Hughes, R.N., 79, 379

Hughes, T.P. See Baird, A.H., 75

Hung, J.-H. See Su, Y., 152

Hung, J.H. See Su, Y., 385

Hunter, C.L. See Smith, J.E., 439

Huntly, N., 29

Hurley, W.L. See Tamburri, M.N., 417

Huston, M.A., 411 See Loreau, M., 80

Hutchinson, S. See Hawkins, S.J., 29

Hutsell, K.C., 146

Hutsell, L.L. See Hutsell, K.C., 146

Huusko, A. See Koljonen, S., 51

Hviding, E., 147

\section{I}

Ibrahim, K. See Sahari, A., 383

Idreesbabu, K.K. See Bijukumar, A., 376

Iinuma, M. See Nimoho, G., 382

Ilias, Z. See Sahari, A., 383

Incera, M. See Cacabelos, E., 436

Inchausti, P. See Loreau, M., 80

Indrehus, J. See Trannum, H.C., 418

Inglis, G., 412

See Floerl, O., 409

See Gust, N., 410

See Sinner, J., 417

Inglis, G.J. See Floerl, O., 409, 410

Ingólfsson, A. See Jenkins, S.R., 29

See Steinarsdóttir, M.B., 439

Iribarne, O.O. See Gutiérrez, J.L., 78

Irving, R., 379

Iryu, Y. See Aubert, A., 375

Isaac, N.J.B., 147

See Safi, K., 151

Isamu, T. See Heslinga, G.A., 146

Ishikura, M. See Maruyama, T., 148

Iversen, E.S., 51

Ivin, V.V. See Levin, V.S., 30

Iwai, K. See Kubo, H., 147, 380

\section{J}

Jablonski, D. See Herrera, N.D., 146

Jackson, A.C., 29

Jackson, J. See Firth, L.B., 409

Jackson, J.B.C. See Lotze, H.K., 413 See Sandin, S.A., 384

Jacob, P., 379

Jacobson, D. See Beger, M., 376

Jamasali, A.J. See Tabugo, S.R.M., 385

James, R.L., 51

Jameson, S.C., 147

Jamieson, G. See Simkanin, C., 417

Janas, U. See Carstensen, J., 407 


\section{AUTHOR INDEX}

Jangoux, M., 29

See Hennebert, E., 29

Jantzen, C., 147

See Richter, C., 151, 383

Jara, C. See Soto, D., 417

Jara, F. See Soto, D., 417

Jara, H.F. See Moreno, C.A., 81

Jara, M.E. See Castilla, J.C., 76 See Manríquez, P.H., 80

Jarman, S.N. See Pompanon, F., 31

Jarosik, V. See Blackburn, T.M., 406

Jason, D. See Wilcove, D.S., 419

Jassby, A.D. See Winder, M., 419

Jaubert, J., 379

Jelmert, A. See Galil, B., 410

See Ware, C., 418

Jenkins, S.R., 29

See Coleman, R.A., 27

See Griffin, J.N., 29

Jennions, M.D., 437

Jensen, K.R. See Gianguzza, P., 51

Jeppesen, E. See Moss, B., 414

Jerde, C.L., 412

Jerez, G. See Castilla, J.C., 76

Jernakoff, P. See Underwood, A.J., 33, 52

Jilbert, T. See Carstensen, J., 407

Jimenez, H. See Dumas, P., 378

Job, S., 379

Joenje, M. See Bak, R.P.M., 75

Jofré Madariaga, D. See Poore, A.B., 31

Johannesson, K. See Nylund, G.M., 438

John, D.M. See Lieberman, M., 51

Johnson, C.H., 79

Johnson, C.R., 29, 412, 437

See Ling, S.D., 30, 413

See Trowbridge, C.D., 440

Johnson, K.G. See Curnick, D.J., 144

Johnson, L.E. See Ling, S.D., 30

Johnson, M.P., 29

Johnson, M.R. See Strong, J.A., 439

Johnson, M.S., 147, 379

See Black, R., 142, 376

Johnston, E., 412

Johnston, E.L, 389-405

See Burton, G.A., 407

See Rivero, N.K., 415

Johnston, E.L., 412

See Clark, G.F., 407

See Dafforn, K.A., 408

See Durrant, H.M.S., 409

See Hedge, L.H., 411

See McKenzie, L.A., 413

See McKinley, A., 413

See Piola, R.F., 415

Johnstone, I. See Goss-Custard, J.D., 78

Jones, C.G., 79

See Gutiérrez, J.L., 78

See Lawton, J.H., 80

See Wright, J.P., 85

Jones, E.C. See Hester, F.J., 146, 379

Jones, G.P. See Almany, G.R., 75

Jones, G.W. See Norton, J.H., 150
Jones, M.S. See Hamner, W.M., 146, 378

Jones, P.R. See DeBoer, T.S., 144

Jones, R. See Curnick, D.J., 144

Jonsson, P.R. See Airoldi, L., 405

See Moschella, P.S., 413

Jontila, J.B.S. See Dolorosa, R.G., 144, 377

Jordaan, T. See Porri, F., 82

Jordan, L.K.B. See Kilfoyle, A.K., 51

Jordan, W.R., 79

Jormalainen, V. See Poore, A.G.B., 31, 439

Joye, S.B. See Smith, V.H., 417

Joyeux, J.-C. See Costa, T.J.F., 408

Juinio, A.R. See Villanoy, C.L., 386

Juinio, M.A.R., 147, 379

Juinio-Meñez, M.A. See von der Heyden, S., 153

Junchompoo, C., 147, 379

Juncker, M. See Vieux, C., 386

Jung, A.-V. See Delpla, I., 408

Justic, D. See Rabalais, N.N., 415

Justus, J., 79

K

Kaehler, S. See Rius, M., 82

Kain, J.M. See Hawkins, S.J., 29, 437

Kalejta-Summers, B. See Goss-Custard, J.D., 78

Kaluza, P., 412

Kamermans, P. See Troost, K., 84

Kamya, P.Z., 30

Kanai, S. See Maruyama, T., 148

Kangas, M., 51

Kanno, K., 379

Kapos, V. See Butchart, S.H.M., 407

Kappel, C.V. See Halpern, B.S., 411

Karamanlidis, A.A. See Vergés, A., 33

Karembé, M. See Dohn, J., 408

Karez, R. See Weinberger, F., 440

Karsten, U. See Wessels, H., 33

Kastoro, W.W. See Tan, K.S., 385

Katoh, M. See Kurihara, T., 51

Katz, E., 79

Kautsky, L. See Wikström, S.A., 440

Kay, E.A., 379

Kay, M.C. See Lotze, H.K., 413

Kayal, M., 30

Keane, R., 437

Keane, R.M., 412

Keen, A.M., 147

Keesing, J. See Babcock, R., 75

Keesing, J.K., 30

Keever, C.C. See Hart, M.W., 29

Kelaher, B.P. See Clark, G.F., 407

Keller, B.D. See Dayton, P.K., 28

Keller, L.F., 79

Kelly, P.M., 412

See Hoang Tri, N., 411

Kendall, B.E. See Berkley, H.A., 75 See Yau, A.J., 154

Kendrick, G.A. See Wernberg, T., 418

Kennedy, S., 412

Kennelly, S.J. See Kingsford, M.J., 79

Kennish, R., 30 


\section{AUTHOR INDEX}

Kenyon, J.C., 30

Keough, M.J., 30, 79

See Holloway, M.G., 411

See Marshall, D.J., 80

Kepler, A.K., 380

Kepler, C.B. See Kepler, A.K., 380

Kernan, M. See Whitehead, P., 418

Kersting, D.K. See Garrabou, J., 78

Keys, J.L., 147

Keyse, J. See Huelsken, T., 146

Khalaf, M.A. See Al-Horani, F.A., 375

Kidwell, S.M. See Lotze, H.K., 413

Kiessling, W. See García Molinos, J., 28

Kilada, R., 380

Kilfoyle, A.K., 51

Killeen, I.J. See Oliver, P.G., 382

Killen, W.D. See Hall, L. W., 411

Kimbro, D.L., 412, 437

Kimmerer, R.W., 51

Kinch, J., 147, 380 See Militz, T.A., 149, 381

Kinch, J.P. See Well, F.E., 386

King, A. See Keough, M.J., 79

Kingsford, M.J., 79 See Underwood, A.J., 84

Kinlan, B.P., 79 See Thornber, C.S., 439

Kirata, T. See Vieux, C., 386

Kirby, M.X. See Lotze, H.K., 413

Kirkendale, L.A. See Wilson, N.G., 154

Kirkpatrick, J.B. See Ware, C., 418

Kirkpatrick, R. See Andrews, C.W., 375

Kittiwattanawong, K., 380 See Chantrapornsyl, S., 377

Kizilkaya, Z. See Vergés, A., 33

Kladi, M., 437

Klein, J.C., 412

Klumpp, D.W., 79, 147 See Stuart, V., 83

Knapp, A.K. See Smith, M.D., 83

Knauer, J. See Watson, S.-A., 153

Knight, R., 147

Knight, T.M. See Dangremond, E.M., 408

Knights, A. See Firth, L., 409

Knights, A.M., 412 See Firth, L.B., 409

See Pearson, S., 414

Knott, N.A., 79, 412 See Clark, G.F., 407

Knowles, G. See Evans, S.M., 378

Knowlton, N. See Sandin, S.A., 384

Kobayashi, M. See Kurihara, T., 51

Kochzius, M., 147 See Richter, C., 151, 383

Koh, L.L., 380

Koldewey, H.J. See Curnick, D.J., 144

Koljonen, S., 51

Kolzsch, A. See Kaluza, P., 412

Kong, I. See Castilla, J.C., 76

Konotchick, T. See Sandin, S.A., 384

Konzewitsch, N. See Evans, S.N., 378

Koricheva, J. See Rothstein, H.R., 439
Kornberg, H. See Williamson, M.H., 419

Kospartov, M. See Hayden, B.J., 411

Koss, R.S. See Knights, A.M., 412

Kosten, S. See Moss, B., 414

Kosuge, T. See Kurihara, T., 51

Kotaki, Y. See Kanno, K., 379

Kott, P., 79

Kotta, J. See Maggi, E., 438

Kovačič, M., 51

Kovitvongsa, K. See DeBoer, T.S., 144

Krell, B., 147

Kristensen, J.H., 30

Kroeker, K. See Crain, C.M., 408

Kroh, A. See Harzhauser, M., 146

Kronen, M., 380 See Sauni, S., 384

See Vieux, C., 386

Krug, P.J. See Marshall, D.J., 80

Kruger, F.J. See Hempson, G.P., 29

Kruger, L.M. See Hempson, G.P., 29

Kubanek, J. See Pavia, H., 438

Kubo, H., 147, 380

See Borsa, P., 142

See Su, Y., 152, 385

Kuklinski, P., 51

Kunkel, T. See Gössling, S., 378

Kupriyanova, E.K. See Marshall, D.J., 80

Kurihara, T., 30, 51

Kuris, A. See Torchin, M., 418

Kuris, A.M. See Torchin, M.E., 418

Kusnadi, A., 380

Kuussaari, M., 79

Kyle, R., 79

Kyriakides, M.A. See Hawkins, S.J., 29

L

LaBarbera, M. See Sherrard, K.M., 83

Laboute, P. See Monniot, C., 81

Lacanienta, E. See Munro, J.L., 149

Lacerot, G. See Moss, B., 414

Ladd, H.S., 147

Lafargue, F., 79

Lafferty, A.M.K.K.D. See Blakeslee, A.M., 406

Lafferty, K. See Torchin, M., 418

Lafferty, K.D. See Torchin, M.E., 418

Lagesa, B.G., 412

Lagos, N.A. See Castilla, J.C., 76 See Manríquez, P.H., 80

Lai, L.T.-A., 147

Lajeunesse, M.J. See Dietz, G., 437

Lake, P.S. See Douglas, M., 50

See Downes, B.J., 51

Lalavanua, W. See Siaosi, F., 152, 384

Lalic, N. See Gerland, P., 410

Lamarck, J.B. De, 147

Lamarque, J.F. See Butchart, S.H.M., 407

Lambert, C.C., 412

Lambert, G., 79

See Lambert, C.C., 412

Lambrechts, D.Y.M. See Bak, R.P.M., 75 


\section{AUTHOR INDEX}

Lamoreux, J.F. See Rodrigues, A.S.L., 151

Lan, X. See Pan, H-Z., 382

Landry, T. See LeBlanc, N., 80

Lane, D.J. See Yeo, D.C., 419

Lane, I. See Bell, J.D., 142

Langhamer, O., 412

Langi, V., 380

Langlois, T. See Vergés, A., 33

Langlois, T.J. See Wernberg, T., 418

Langston, K. See Langston, W., 412

Langston, W., 412

Lannig, G. See Sokolova, I.M., 417

Lara, A. See Soto, D., 417

Lardies, M.A. See Manríquez, P.H., 80

Largier, J. See Castilla, J.C., 76

Larrue, S., 380

Larson, C., 147

Lasiak, T., 80

Lasiak, T.A. See Majiza, V.N., 80

Lasola, N., 380

Last, P.R. See Johnson, C.R., 29, 412

Latypov, Y.Y., 380, 381

See Selin, N.I., 151, 384

Laughlin, R.A., 30

Laurent, V., 381

Lauzon-Guay, J.-S. See Scheibling, R., 32

Lavender, J.T., 412

Law, R. See Leibold, M.A., 80

Lawrence, J.M., 30

Lawton, J.H., 80

See Jones, C.G., 79

Laxton, J.H., 30

Lazareth, C.E. See Aubert, A., 375 See Schwartzmann, C., 151, 384

Lazo, L. See Pringgenies, D., 383

Le Goff, A. See Bouchet, P., 142, 376

Le Hir, M., 51

le Mouellic, S. See Wantiez, L., 386

Le Moullac, G. See Menoud, M., 149 See Van Wynsberge, S., 153

Leaper, R. See Hawkins, S., 411

LeBlanc, N., 80

LeBlanc, W.G. See Prince, J.S., 439

Ledoux, J.B. See Garrabou, J., 78

Ledua, E., 148, 381

See Lewis, A.D., 148, 381

See Lucas, J.S., 148, 381

Lee, J.H. See Todd, P.A., 152

Lee, S., 148

Leggat, W., 148

Lehane, C., 80 See Barnes, D.K.A., 50

Leibold, M.A., 80

Leiva, A. See Castilla, J.C., 76

Lejeusne, C. See Garrabou, J., 78

Lemee, R., 438

Lemée, R. See Amade, P., 436

Lengaigne, M. See Andréfouët, S., 141

Lenihan, H.S. See Halpern, B.S., 411

See Lotze, H.K., 413

See Yau, A.J., 154
Leonard, G.H., 30 See Bertness, M.D., 75

Lester, S.E. See Kinlan, B.P., 79

Leung, B., 412

Leung, P.S., 148 See Shang, Y.C., 152

Leverington, F. See Butchart, S.H.M., 407

Levin, L. See Rabalais, N., 415

Levin, P.S., 438

Levin, S.A., 412 See Baskett, M.L., 406

Levin, V.S., 30

Levine, J.M., 412, 413, 438

Levins, R., 80

Levitan, D.R., 80 See Petersen, C.W., 150

Levy, P. See Menoud, M., 149 See Van Wynsberge, S., 153

Lewis, A.D., 148, 381

Lewis, J.A. See Dafforn, K.A., 408

Li, J. See Fiege, D., 378

Li, N. See Gerland, P., 410

Liancourt, P., 413

Lieberman, D. See Lieberman, M., 51

Lieberman, M., 51

Lieutaud, A. See Bigot, L., 376

Liggins, L. See Huelsken, T., 146

Light, J.M. See Oliver, P.G., 382

Lin, S.M. See Huang, C.W., 379

Linares, C. See Garrabou, J., 78

Lindberg, D.R. See Castilla, J.C., 76

Lindgren, A. See Pavia, H., 438

Lindsay, J.R. See McQuaid, C.D., 81

Lindsay, S., 148

Lindsay, S.R. See Dalzell, P., 377

Ling, S.D., 30, 413

See Johnson, C.R., 29, 412

See Wernberg, T., 418

Lipcius, R.N. See Gascoigne, J., 78

Lison De Loma, T. See Chin, A., 377

Littler, D.S. See Littler, M.M., 30, 51, 438

Littler, M.M., 30, 51, 438

Liu, H., 413, 438

Liu, J.Y., 381

Liu, L.-L. See Borsa, P., 142 See Su, Y., 152

Liu, L.L. See Su, Y., 385

Liu, Z. See Moss, B., 414

Liversage, K., 51, 52

Lizano, A.M.D., 148

Locke, A., 80

Lockwood, J.L. See McKinney, M.L., 413

Lodge, D.M. See Drake, J.M., 408

See Jerde, C.L., 412

See Leung, B., 412

See Yeo, D.C., 419

Logan, R.I. See Brahimi-Horn, M.C., 27

Loh, J. See Butchart, S.H.M., 407

Loh, K.S. See Neo, M.L., 149

Loh, T.L., 381

Loke, L.H.L. See Bishop, M.J., 406

Londoño-Cruz, E., 52 


\section{AUTHOR INDEX}

Loneragan, N. See Bell, J.D., 142

Long, H.M. See Norton, J.H., 150

Long, J.D. See Dolecal, R.E., 28

Long, N.V., 381

Longhurst, K. See Thorne, B.V., 385

Loo, L.-O., 80

López-Legentil, S. See Pineda, M.C., 414

Loreau, M., 80

See Hector, A., 411

See Leibold, M.A., 80

Lortie, C.J. See Maestre, F.T., 413

See Rothstein, H.R., 439

See Schaffner, U., 439

Losos, E. See Wilcove, D.S., 419

Loto'ahea, T. See Sone, S., 384

See Tu'avao, T., 386

Lotze, H.K., 413

Loughman, Z.J., 52

Louhi, A. See Koljonen, S., 51

Love, M.S. See Schroeder, D.M., 416

Lovell, E., 381

Low, J.K.Y. See Neo, M.L., 149, 414

Low, M.E.Y. See Tan, S.K., 385

Low, N.H.N., 438

Lowe, A.J. See Prentis, P.J., 415

Loya, Y. See Shenkar, N., 416

Lozouet, P. See Bouchet, P., 142, 376

Lubchenco, J., 30, 80, 438

See Levin, S.A., 412

Lucañas, J.R. See Calumpong, H.P., 377

Lucas, J.S., 148, 381

See Braley, R.D., 143

See Copland, J.W., 144

See Crawford, C.M., 144

See Henderson, J.A., 29

See Keesing, J.K., 30

Luczynski, E. See Parente, V., 414

Lyons, D.A., 438

See Maggi, E., 438

\section{M}

Ma, Y. See Pearson, S., 414

Maboloc, E.A., 148

Mac Nally, R. See Winder, M., 419

Macansantos, A.D. See Calumpong, H.P., 377

Macaranas, J. See Calumpong, H.P., 143

Macaranas, J.M., 148

Macdonald, R.W. See Schiedek, D., 416

MacIsaac, H.J. See Colautti, R.I., 407, 436 See Zhan, A., 419

Mack, R.N. See Moody, M.E., 413

MacLeod, A. See Mineur, F., 413

Macleod, C.K., 413

Macpherson, E. See Galil, B., 410

Macreadie, P.I., 413

Maddison, W.P. See Mooers, A.Ø., 149

Madin, E.M.P. See Halpern, B.S., 411

Madkour, H.A. See Mekawy, M.S., 149, 381

Maes, V.O., 381

Maestrati, P. See Bouchet, P., 142, 376

Maestre, F.T., 413
Mag Aoidh, R. See Thorne, B.V., 385

Maggi, E., 438

See Benedetti-Cecchi, L., 27

Maggs, C. See Mineur, F., 413

Maggs, C.A. See Strong, J.A., 439

Magné, B. See Marchal, V., 413

Magron, F. See Kronen, M., 380

See Sauni, S., 384

See Siaosi, F., 152, 384

Maguire, L. See Justus, J., 79

Mah, C., 30, 31

Maharavo, J. See Bigot, L., 376

Mahon, A.R. See Jerde, C.L., 412

Majiza, V.N., 80

Mäki-Petäys, A. See Koljonen, S., 51

Malay, M. See Sandin, S.A., 384

Malestroit, P. See Lemee, R., 438

Malyutin, A.N. See Selin, N.I., 384

Mamo, B.L. See Strotz, L.C., 385

Mandic, O. See Harzhauser, M., 146

Manley, N.L. See Norton, T.A., 31

Manríquez, P. See Castilla, J.C., 76

Manríquez, P.H., 55-74, 80 See Castilla, J.C., 76

Manu, N. See Ledua, E., 148, 381

Manzur, T. See Castilla, J.C., 76

Maragos, J.E. See Barott, K.L., 376 See Sandin, S.A., 384

Marchal, V., 413

Marchini, A. See Galil, B., 410

Mardones, M.L. See Manríquez, P.H., 80

Marenco, P.J. See Clapham, M.E., 77

Mari, X. See Lemee, R., 438

Markich, S.J. See Alquezar, R., 405

Marks, C.J. See Low, N.H.N., 438

Maron, J.L., 438

Marquet, P. See Alvarado, J.L., 75

Marquis, R.J. See Estes, J.A., 28

Marschal, C. See Garrabou, J., 78

Marshall, D.J., 80 See Rius, M., 83

Martí, V. See Martínez-Lladó, X., 413

Martin, A., 31

Martin, D. See Airoldi, L., 405

Martin, R.B., 31

Martín-Díaz, M. See Rodriguez, L.F., 415

Martinez, A.S., 1-26, 31, 34

Martinez, M.L. See Costanza, R., 408

Martínez-Lladó, X., 413

Maruyama, T., 148

Marzinelli, E.M., 413

See Clark, G.F., 407

See Johnston, E.L., 412

See Vergés, A., 33

Masero, J.A. See Goss-Custard, J.D., 78

Mason, C. See Smith, R., 417

Massabuau, J.-C. See Schwartzmann, C., 151, 384

Master, F., 148

Matheickal, J. See Tamelander, J., 418

Matthee, C.A. See Rius, M., 82, 415

Maurer, B.A. See Brown, J.H., 75

Mauzey, K.P., 31 


\section{AUTHOR INDEX}

Maximov, A. See Carstensen, J., 407

Mayer-Pinto, M. See Bishop, M.J., 406 See Dafforn, K.A., 408

Mazumdar, M. See Begg, C.B., 436

Mazzei, E.F. See Costa, T.J.F., 408

Mazzeo, N. See Moss, B., 414

McCann, K.S. See Tewfik, A., 418

McCann, L.D. See Davidson, I.C., 408

McClusky, C.F. See Teske, P.R., 84

McConnell, D.B. See Bryan, P.G., 143, 377

McDonald, C. See Gilligan, J., 378

McDonald, C.A. See Hender, J., 379

McEnvoy, P.B., 413

McGeoch, M.A. See Butchart, S.H.M., 407

McGranahan, G., 413

McGuinness, K.A., 52

McKenna S.A., 148, 381

McKenzie, C. See Galil, B., 410

McKenzie, L.A., 413

McKenzie, V.J. See Torchin, M.E., 418

McKinley, A., 413

McKinney, M.L., 413

McKnight, E., 413

McLean, R.A., 148

McMichael, D.F., 381

McNiven, M. See LeBlanc, N., 80

McQuaid, C. See Calvo-Ugarteburu, G., 407

McQuaid, C.D., 55-74, 81, 413

See Cole, V.J., 77

See Erlandsson, J., 77

See Heasman, K.G., 78

See Liversage, K., 52

See Pineda, M.C., 414

See Porri, F., 82

See Rius, M., 82, 415

See Robinson, T.B., 83

See Teske, P.R., 84

See von der Meden, C.E.O., 84

McRae, L. See Butchart, S.H.M., 407

Meerhof, M. See Moss, B., 414

Meinesz, A. See Lemee, R., 438

Mekawy, M.S., 149, 381

Melbourne-Thomas, J. See Johnson, C.R., 29, 412

Mena, O. See Ramírez, M.E., 82

Menager, V. See Lemee, R., 438

Méndez, G. See Pearson, S., 414

Meñez, L.A. See Villanoy, C.L., 386

Meñez, L.A.B. See Juinio, M.A.R., 147, 379

Menge, B.A., 31, 52, 81 See Lubchenco, J., 80

Menier, D. See Montagne, A., 382

Menkes, C. See Andréfouët, S., 141, 375

Menkes, C.E. See Andréfouët, S., 141

Menou, J-L. See Andréfouët, S., 375

Menoud, M., 149 See Van Wynsberge, S., 153

Meredith, H.M. See Isaac, N.J.B., 147

Meretta, P.E. See Farias, N.E., 28

Metaxas, A. See Scheibling, R.E., 32

Meyer, C.P. See Castilla, J.C., 76

Michalet, R. See Liancourt, P., 413
Michel, C., 149, 381

Micheli, F. See Baskett, M.L., 406 See Halpern, B.S., 411

Michonneau, F. See Kayal, M., 30

Mies, M., 149

Mieszkowska, N., 413

See Firth, L., 409

See Hawkins, S., 411

Mikkelsen, P.M. See Herrera, N.D., 146

Militz, T.A., 149, 381

See Southgate, P.C., 152

Millar, R.H., 81

Miller, A.W. See Blakeslee, A.M., 406 See Williams, S.L., 419

Miller, G.M. See Watson, S.-A., 153

Miller, I., 381

Miller, K. See Johnson, C.R., 29, 412 See Knight, R., 147

Miller, R.G. See Adams, T.P., 405

Miller, R.J., 413

See Simoncini, M., 417

Miloh, T. See Perkol-Finkel, S., 414

Mimura, N. See Nicholls, R.J., 414

Minasyan, A. See Butchart, S.H.M., 407

Minchin, D. See Galil, B., 410 See Mineur, F., 413

Mineur, F., 413 See Engelen, A.H., 437

Mingoa-Licuanan, S.S., 149 See Gomez, E.D., 145 See Maboloc, E.A., 148

Mitarai, S. See Berkley, H.A., 75

Mitchell, K. See Pinn, E.H., 415

Mito, K. See Fijiwara, S., 378

Mito, K.-I. See Kurihara, T., 51

Mizerek, T. See Vergés, A., 33

Mohamed-Pauzi, A., 381

Mohd. Adib, H. See Mohamed-Pauzi, A., 381

Molis, M. See Yun, H.Y., 440

Møller, A.P. See Jennions, M.D., 437

Mollison, D. See Williamson, M.H., 419

Moltschaniwskyj, N.A. See Macleod, C.K., 413

Monniot, C., 81 See Monniot, F., 81

Monniot, F., 81 See Monniot, C., 81

Monsecour, K., 149, 382

Montagne, A., 382

Monteiro, C. See Engelen, A.H., 437

Monteiro, C.A., 438

Monteiro, S.M., 81

Moody, M.E., 413

Mooers, A.Ø., 149 See Redding, D.W., 151

Mooney, H.M. See Dukes, J.S., 409

Moore, B. See Siaosi, F., 152, 384

Moore, P. See Firth, L., 409

See Firth, L.B., 409

See Hawkins, S., 411

See Jenkins, S.R., 29

See Knight, R., 147 


\section{AUTHOR INDEX}

Moore, P.J. See Firth, L.B., 409

See García Molinos, J., 28 See Wernberg, T., 418

Moorhead, J.A. See Watson, S.-A., 153

Moran, P.J. See Brahimi-Horn, M.C., 27 See De'ath, G., 28

Morcillo, M.H. See Butchart, S.H.M., 407

Moreira, F. See Goss-Custard, J.D., 78

Moreno, C. See Soto, D., 417

Moreno, C.A., 81

Morgan, M.B., 31

Morley, M.S. See Hayward, B.W., 78

Morley, S. See Roni, P., 52

Morris, R.L. See Bishop, M.J., 406

Morrisey, D., 413

See Inglis, G., 412

See Sinner, J., 417

Morton, B., 149, 382 See Bernard, F.R., 376

Morton, J. See Morton, B., 149

Morton, J.E. See Morton, B., 382

Morton, S. See Rosa, M., 415

Moschella, P. S. See Airoldi, L., 405

Moschella, P. See Hawkins, S., 411

Moschella, P.S., 413

Mosley, M.W. J. See Johnson, M.P., 29

Moss, B., 414

Most, R. See Smith, J.E., 439

Mostarda, E. See Anam, R., 375

Mouquet, N. See Leibold, M.A., 80

Moustakas, A. See Dohn, J., 408

Moxley, C. See Hempson, G.P., 29

Mueller, B., 31

Muir, F. See Braley, R.D., 143

Mulder, K. See Costanza, R., 408

Muller, C. See Schaffner, U., 439

Muller-Scharer, H. See Schaffner, U., 439

Mulligan, B. See Thorne, B.V., 385

Mumby, P.J. See Vergés, A., 33

Munday, P. See Armstrong, E.J., 141

Muneer, T. See Asif, M., 405

Munro, J.L., 149, 382

See Bell, J.D., 142

See Crawford, C.M., 144

See Pearson, R.G., 150, 383

Muotka, T. See Koljonen, S., 51

Murakoshi, M., 149

Murphy, R.J. See Jackson, A.C., 29

Murray, A.G., 414

Murray, S.N. See Smith, J.R., 83

Muskanofola, M.R. See Brown, J.H., 143, 377

\section{$\mathbf{N}$}

Nadelhoffer, K.J. See Grimm, N.B., 410

Nadon, M.O., 382

Naeem, S. See Andréfouët, S., 375

See Fridley, J.D., 410

See Loreau, M., 80

Nagaoka, L., 382

Nagarajan, R.V. See Goss-Custard, J.D., 78
Naguit, M.R.A., 382

Naim, O. See Montagne, A., 382

Nakai, T. See Fijiwara, S., 378

Nakamura, Y., 382 See Vergés, A., 33

Namboodiri, P.N., 382

Namona, A. See Thaman, R.R., 385

Naruse, T. See Yeo, D.C., 419

Nash, W. See Bell, J.D., 142

Nash, W.J. See Braley, R.D., 143

Navarrete, S.A., 81

See Aguilera, M.A., 26

See Aiken, C.M., 74

See Castilla, J.C., 76

See Menge, B.A., 81

Navarro, J.M. See Manríquez, P.H., 80

Navarro, R.A. See Rius, M., 82, 415

Naylor, L.A. See Bishop, M.J., 406

Nehring, S. See Galil, B., 410

Neill, P.E. See Castilla, J.C., 76

Neilson, J. See Gilligan, J., 378

Nejrup, L.B., 438

Neo, M.L., 87-140, 149, 150, 155-374, 382, 414

See Vicentuan-Cabaitan, K., 153

Neumann, V. See Fiege, D., 378

Neves, C.S. See Neo, M.L., 414

Newell, R.C., 81 See Seiderer, L.J., 83

Newman, W., 382

Newman, W.A., 150

Newton, M. See Inglis, G., 412

See Sinner, J., 417

Ng, C.S.L. See Toh, K.B., 418

Ng, P.K. See Yeo, D.C., 419

Ngai, J.T. See Elser, J.J., 409

Nicastro, K. See McQuaid, C.D., 413

Nicholls, R.J., 414

Nichols, D. See Barker, M.F., 27

Nichols, P.V. See Govan, H., 378

Nieuwland, G. See Bak, R.P.M., 75

Nikinmaa, M., 414

Nilsson, M.-C., 81

Nimoho, G., 382

Nisbet, R.M. See Fleeger, J.W., 409

Nishikawa, T. See Dupont, L., 409

Nishiyama, K. See Nimoho, G., 382

Nixon, S., 414

No, G.M.S. See Tamelander, J., 418

Noel, L. See Griffin, J.N., 29

Norambuena, F. See Soto, D., 417

Norderhaug, K.M. See Ling, S.D., 30

Norkko, A. See Carstensen, J., 407

Norkko, J. See Carstensen, J., 407

Norton, J.H., 150

Norton, T.A., 31

See Hawkins, S.J., 29, 437

Nugranad, J. See Kittiwattanawong, K., 380

Nunn, P.D. See Seeto, J., 384

Nuryanto, A., 150

See Kochzius, M., 147

Nydam, M., 414 


\section{AUTHOR INDEX}

Nylund, G.M., 438

See Enge, S., 437

See Pavia, H., 438

See Persson, F., 439

See Svensson, J.R., 439

\section{O}

Ó Foighil, D. See Schneider, J.A., 151

O'Callaghan, M., 150

O’Connor, N. See Firth, L., 409

O'Connor, N.J. See Wolcott, D.L, 33

O'Connor, W.A. See Hedge, L.H., 411

O'Hara, S. See Langston, W., 412

O'Loughlin, P.M., 31

O'Neil, J., 414

Obura, D. See Barott, K.L., 376 See Sandin, S.A., 384

Obura, D.O. See Curnick, D.J., 144

Occhipinti-Ambrogi, A. See Galil, B., 410

Ojaveer, H. See Galil, B., 410

Okada, H., 150, 382

Okamoto, D. See Britton-Simmons, K.H., 436

Oksanen, L. See Estes, J.A., 28

Oksanen, T. See Estes, J.A., 28

Olabarria, C. See Cacabelos, E., 436

Olafsen, T., 414

Ólafsson, E. See Steinarsdóttir, M.B., 439

Olden, J.D., 414

Oldewage, W.H., 81

Oldfield, T.E.E. See Butchart, S.H.M., 407

Olenin, S. See Galil, B., 410

Olff, H. See Eriksson, B.K., 77

Oliva, D. See Castilla, J.C., 76

Oliver, P.G., 382

Olkin, I. See Hedges, L.V., 437

Olmstead, P. See Roni, P., 52

Olsen, S.M. See Ware, C., 418

Olsgard, F. See Trannum, H.C., 418

Olson, R.R. See Johnson, C.R., 29

Oppenheim, P., 150

Orak, O. See Heslinga, G.A., 146

Ordóñez, V., 414

See Pineda, M.C., 414

See Rius, M., 415

Ordoñez, V. See Rius, M., 83

Oren, U. See Perkol-Finkel, S., 414

Orth, R.J., 31

Ortiz, M., 81

Ortiz, V. See Caro, A.U., 75

See Castilla, J.C., 76, 407

See Clarke, M., 77

See Manríquez, P.H., 80

Osborne, P.E. See Savage, J.M., 384

Osenberg, C. See Vieux, C., 386

Osman, R., 414

Osman, R.W., 52, 414

See Freestone, A.L., 410

See Stachowicz, J.J., 417

Othman, A.S., 150

Otway, N.M., 81

See Smith, K.A., 52
Otway, S. See Hector, A., 411

Overas, S. See Trannum, H.C., 418

Oviatt, C. See Nixon, S., 414

Owen-Smith, N. See Hempson, G.P., 29

Owens, I.P. See Goss-Custard, J.D., 78

\section{$\mathbf{P}$}

Pacheco, C. See Alvarado, J.L., 75

See Castilla, J.C., 76

See Goss-Custard, J.D., 78

Pacheco, C.J., 82

Padilla, D.K. See Buchan, L.A.J., 406

Page, C. See Beger, M., 376

Page, H.M., 414

Page, M. See Teske, P.R., 84

Pagliawan, H.B. See Gonzales, B.J., 378

Paine, R.T., 31, 82 See Estes, J.A., 28

Pakhomov, E.A. See Clarke Murray, C., 407

Pakoa, K. See Lovell, E., 381

See Siaosi, F., 152, 384

Pal, P. See Erlandsson, J., 77

Palmer, A.N.S., 52

Pan, H-Z., 382

Pandolfi, J.M. See Berzunza-Sanzhez, M.M., 376 See García Molinos, J., 28

Panetta, F.D. See Richardson, D.M., 82

Panggabean, L.M.G., 382 See Eliata, A., 144, 378

Panov, V. See Galil, B., 410

Pante, M.J.R. See Macaranas, J.M., 148

Pantos, O. See Sandin, S.A., 384

Pardini, E.A. See Dangremond, E.M., 408

Parente, V., 414

Park, H-S. See Tadashi, K., 385

Parker, J.D., 438

Parrish, J.A.D., 414

Pasari, J.R. See Grosholz, E.D., 410 See Williams, S.L., 419

Pasaribu, B.P., 150, 382

Pascoe, P. See Langston, W., 412

Pascual, M. See Ordóñez, V., 414 See Rius, M., 83, 415

Pasisi, B. See Vieux, C., 386

Pataki, D.E. See Grimm, N.B., 410

Patiale, H. See Dalzell, P., 377

Patsorn, P. See Junchompoo, C., 147, 379

Patton, J.S. See Benson, A.A., 27

Pattuinan, J.O. See Tabugo, S.R.M., 385

Patzner, R.A. See Kovačič, M., 51

Paul, V.J., 31

Paula, J. See Coleman, R.A., 27

Paulay, G., 382 See Sandin, S.A., 384

Pauly, D. See Butchart, S.H.M., 407

Paupiah, N. See Bigot, L., 376

Pavia, H., 421-436, 438

See Enge, S., 437

See Engelen, A.H., 437

See Forslund, H., 437

See Nylund, G.M., 438 


\section{AUTHOR INDEX}

See Persson, F., 439

See Sagerman, J., 439

See Svensson, J.R., 439

See Wikström, S.A., 440

Pawlik, J.R., 82, 414

See Toonen, R.J., 84

Payri, C. See Andréfouët, S., 141, 375

See Gilbert, A., 145, 378

See Planes, S., 383

See Van Wynsberge, S., 153

Peacock, L. See Gust, N., 410

See Hayden, B.J., 411

Pearse, J.S. See Wasson, K., 418

Pearson, B. See Kyle, R., 79

Pearson, R.G., 150, 383

Pearson, S., 414

Pearson, T.H., 414

Pecl, G.T. See Johnson, C.R., 29, 412

Pedersen, M.F., 439

See Engelen, A.H., 437

See Nejrup, L.B., 438

Peel, M.J. S. See Hempson, G.P., 29

Peignon, C. See Dumas, P., 378

Peijnenburg, K.T.C.A., 150

Penchaszadeh, P. See Martin, A., 31

Penin, L. See Kayal, M., 30

Penny, S. See Huelsken, T., 146

Penny, S.S., 150, 383

Penpain, C. See Junchompoo, C., 379

Penpian, C. See Junchompoo, C., 147

Pereira, R.C. See Lagesa, B.G., 412

Pereyra, R.T. See Nylund, G.M., 438

Pérez, T. See Garrabou, J., 78

Perez-Hurtado, A. See Goss-Custard, J.D., 78

Pérez-Maqueo, O. See Costanza, R., 408

Pérez-Matus, A. See Ling, S.D., 30

Pérez-Portela, R. See Wright, A., 85

Pergent, G. See Dumay, O., 437

Pergent-Martini, C. See Dumay, O., 437

Perkol-Finkel, S., 414

See Airoldi, L., 74, 405

Perron, F.E., 150

See Heslinga, G.A., 146

Perry, M.T. See Halpern, B.S., 411

Persson, F., 439

See Nylund, G.M., 438

Pérusse, M. See Downing, J.A., 77

Pess, G.R. See Roni, P., 52

Peters, D.P.C. See Grimm, N.B., 410

Petersen, C.W., 150

Petersen, J.K., 82

Peterson, C.H. See Lotze, H.K., 413

Peterson, E.L. See Beger, M., 376

Petrik, R. See Levin, P.S., 438

Pettifor, R.A. See Goss-Custard, J.D., 78

Pfenninger, M., 151

Philippoff, J. See Stimson, J., 439

Philipson, P.W. See Dawson, R.F., 144

Phillips, A. See Wilcove, D.S., 419

Phillips, N.W., 31

Phillips, T.E. See McQuaid, C.D., 81

Picardal, R.M. See Dolorosa, R.G., 378
Piersma, T. See Eriksson, B.K., 77

Pierson, B. See Montagne, A., 382

Piggott, M.P. See Teske, P.R., 84

Pikitch, E.K. See Estes, J.A., 28

Pilcher, N., 383

Pilgrim, J.D. See Rodrigues, A.S.L., 151

Pillay, D., 31

See Dawson, J., 28

Piller, W.E. See Harzhauser, M., 146 See Zuschin, M., 154, 387

Pinca, S., 383

See Beger, M., 376

See Kronen, M., 380

See Sauni, S., 384

Pineda, J. See Tapia, F.J., 83

Pineda, M.C., 414 See Rius, M., 415

Pinheiro, A. See Branco, P., 50

Pinheiro, H.T. See Costa, T.J.F., 408

Pinn, E.H., 415

Pino, C. See Castilla, J.C., 76

Pinto, R. See Alvarado, J.L., 75

Piola, R.F., 415 See Forrest, B.M., 410

Piraino, S. See Galil, B., 410

Pisor, D.L. See Hutsell, K.C., 146

Pister, B. See Britton-Simmons, K.H., 436

Pitcher, G.C. See Heasman, K.G., 78

Pitombo, F.B. See Neo, M.L., 414

Planes, S., 383 See Almany, G.R., 75

See Chin, A., 377

See Gilbert, A., 145, 378

See Kayal, M., 30

Plantman, P. See Blidberg, E., 142 See Elfwing, T., 144

Plew, D. See Morrisey, D., 413

Pochon, X. See Zaiko, A., 419

Poff, N.L. See Olden, J.D., 414

Pohnert, G. See Hammann, M., 437 See Nylund, G.M., 438

Polanowski, A., 31

Pollock, N.J., 383

Poloczanska, E. See Hawkins, S., 411

Poloczanska, E.S. See García Molinos, J., 28

Pompanon, F., 31

Pool, T.K. See Floerl, O., 410

Poore, A.B., 31

Poore, A.G.B., 31, 439 See Vergés, A., 33

Pope, N. See Langston, W., 412

Porri, F., 82 See McQuaid, C.D., 413

See von der Meden, C.E.O., 84

Porter, J.W., 31 See Trench, R.K., 153

Porter, S.A. See Sammarco, P.W., 416

Potter, E.E. See Rius, M., 83, 415

Poulasi, T. See Lovell, E., 381

Poutiers, J.M., 151

See Sommer, C., 384 


\section{AUTHOR INDEX}

Power, M. See Vieux, C., 386

Power, M.E. See Estes, J.A., 28

Powers, C.M. See Clapham, M.E., 77

Pranowo, S.W. See Pearson, S., 414

Pratchett, M.S., 32 See Baird, A.H., 26

Prentis, P.J., 415

Prestedge, G.K., 32

Price, C.M., 151, 383

Prince, J. See Black, R., 142, 376 See Johnson, M.S., 147, 379

Prince, J.S., 439

Pringgenies, D., 383

Prior, H.C. See Norton, J.H., 150

Pruss, S.B. See Clapham, M.E., 77

Puia, T. See Thaman, R.R., 385

Punt, M.J., 415

Purcell, S.W., 383

Putri, A. See Pearson, S., 414

Pye-Smith, C. See Evans, S.M., 378

Pyle, R.M. See Wells, S., 153 See Wells, S.M., 387

Pyšek, P. See Blackburn, T.M., 406 See Richardson, D.M., 82

\section{Q}

Qi, Z., 383

Quader, S. See Butchart, S.H.M., 407

Quinn, G.P. See Keough, M.J., 79

Quinn, J.F. See Grosberg, R.K., 78

Quinn, T.P. See Kilfoyle, A.K., 51

Quoy, J., 82

\section{$\mathbf{R}$}

Rabalais, N., 415

Rabalais, N.N., 415

Radic, D. See Castilla, J.C., 76

Radtke, R., 383

Raffaelli, D. See Loreau, M., 80

Raftery, A.E. See Gerland, P., 410

Raimondi, P.T. See Keough, M.J., 79

Ramadoss, K., 151, 383

Ramírez, M.E., 82

Ramohia, P., 151, 383

Ramorino, L., 82

Randløv, A., 82

Randriamanantsoa, B. See Harding, S., 379

Rasmussen, J. See Tewfik, A., 418

Rassweiler, A. See Ling, S.D., 30

Rauter, A.P. See Cabrita, M.T., 436

Ravaglioli, C. See Maggi, E., 438

Ravago-Gotanco, R. See von der Heyden, S., 153

Ravinesh, R. See Bijukumar, A., 376

Rawlinson, K.A. See Barnes, D.K.A., 375

Razak, T. See Wabnitz, C.C.C., 153

Readman, J.W. See Schiedek, D., 416

Redding, D.W., 151

See Curnick, D.J., 144

See Isaac, N.J.B., 147

Reddy, K.P. See Guest, J.R., 145, 378
Reed, D. See Carstensen, J., 407

Reed, J.M., 82

Rees, H. See Smith, R., 417

Rees, M., 383

Reese, D.S., 151

Regan, H. See Justus, J., 79

Reichard, S.H. See Combs, J.K., 408

Reichart, T. See Perkol-Finkel, S., 414

Reid, D.G. See Taylor, J.D., 385

Reid, R.G.B., 151

Rejmánek, M., See Richardson, D.M., 82

Remoissenet, G. See Andréfouët, S., 141, 375 See Gilbert, A., 145, 378

See Menoud, M., 149

See Van Wynsberge, S., 153, 386

Rempt, M. See Hammann, M., 437 See Nylund, G.M., 438

Reuter, M. See Harzhauser, M., 146

Revenga, C. See Butchart, S.H.M., 407

Reynolds, P.L. See Poore, A.G.B., 31, 439

Reytar, K. See Chin, A., 377

Riba, I. See Rodriguez, L.F., 415

Ribes, M., 82 See Garrabou, J., 78

Ricard, M., 151

Ricciardi, A. See Colautti, R.I., 407, 436

Richard, G., 383

Richards, R., 151

Richards, Z.T. See Beger, M., 376

Richardson, A.J. See García Molinos, J., 28 See Johnson, C.R., 29, 412

Richardson, D.M., 82 See Blackburn, T.M., 406 See Prentis, P.J., 415

Richie, M. See Sandin, S.A., 384

Richter, C., 151, 383 See Jantzen, C., 147

Riddering, L. See Tamelander, J., 418

Ridenour, W.M. See Schaffner, U., 439

Ridgway, K. See Ling, S.D., 413

Ridgway, K.R. See Johnson, C.R., 29, 412

Rietkerk, M. See van de Koppel, J., 84

Riginos, C. See Beger, M., 142 See Huelsken, T., 146

Riisgård, H.U. See Petersen, J.K., 82 See Randløv, A., 82

Rilov, G. See Maggi, E., 438

Rindi, L. See Maggi, E., 438

Rintoul, S.R. See Johnson, C.R., 29, 412

Ripple, W.J. See Estes, J.A., 28

Ritz, D.A. See Johnson, C.R., 29, 412

Rius, M., 55-74, 82, 83, 389-405, 415

See Airoldi, L., 74, 405

See Hudson, J., 411

See McKnight, E., 413

See Ordóñez, V., 414

See Pineda, M.C., 414

See Robinson, T.B., 83

See Teske, P.R., 84

Rivera-Posada, J.A. See Pratchett, M.S., 32

Rivero, N.K., 415

See Dafforn, K.A., 408 


\section{AUTHOR INDEX}

Roa-Quiaoit, H. See Richter, C., 151, 383

Roa-Quiaoit, H.A. See Jantzen, C., 147

Roa-Quiaoit, H.A.F., 151, 383

Roberts, D.A. See Johnston, E.L., 412

Robertson, W.D. See Kyle, R., 79

Robey, J. See von der Meden, C.E.O., 84

Robinson, L.A. See Knights, A.M., 412

Robinson, S.M.C. See Sloan, N.A., 32

Robinson, T.B., 83

Roby, C. See Hudson, J., 411

Rocha, L.A. See Costa, T.J.F., 408

Rocha, R.M. See Neo, M.L., 414

Rochon, Y. See Downing, J.A., 77

Rodrigues, A.S.L., 151

Rodriguez, F. See Ortiz, M., 81

Rodriguez, L.F., 415

Rodríguez-Obeso, O. See Rodriguez, L.F., 415

Roebeck, U. See Tiitii, U., 385

Roga, K. See Richards, R., 151

Rogers, D. See Goss-Custard, J.D., 78

Rogers, T.L., 52

Rohatgi, A., 439

Rohwer, F. See Sandin, S.A., 384

Rohwer, F.L. See Barott, K.L., 376

Roman, J., 415

Romano, J.C. See Garrabou, J., 78

Romo, J. See Martínez-Lladó, X., 413

Roni, P., 52

Roper, J.J. See Neo, M.L., 414

Rosa, M., 415

Rosen, B.R. See Curnick, D.J., 144

Rosenberg, M.S., 439

Rosenberg, R. See Loo, L.-O., 80 See Pearson, T.H., 414

Rosenthal, H. See Buck, B.H., 143

Rosenthal, R. See Dayton, P.K., 28

Rosewater, J., 151, 383

Ross, D.J. See Johnson, C.R., 29, 412

Rosser, N.L. See Johnson, M.S., 147, 379

Rossi, F. See Cruz Motta, J.J., 50

Rosson, A. See Castilla, J.C., 76

Rothery, P. See Barnes, D.K.A., 50

Rothlisberg, P.C. See Bell, J.D., 142

Rothstein, D. See Wilcove, D.S., 419

Rothstein, H.R., 439

Roughan, M. See Vergés, A., 33

Roughgarden, J. See Connolly, S.R., 77

Roulston, H. See Hayden, B.J., 411

Rousseaux, C.S. See Wernberg, T., 418

Roussis, V. See Kladi, M., 437

Rowe, F.W.E. See O'Loughlin, P.M., 31

Roy, K., 83 See Huang, D., 146

Rozbaczylo, N. See Castilla, J.C., 76

Ruitton, S. See Lemee, R., 438

Ruiz, G., 415

See Galil, B., 410

See Simkanin, C., 416

Ruiz, G.M., 416

See Blakeslee, A.M., 406

See Davidson, I.C., 408

See Freestone, A.L., 410
See Tamburri, M.N., 417

See Williams, S.L., 419

See Zabin, C.J., 419

Russ, G.R., 416

Russell, B.D. See Wernberg, T., 418

Ryland, J.S. See Teo, S.L.M., 418

\section{$\mathbf{S}$}

Sabetian, A. See Lovell, E., 381

Saccheri, I. See Kuussaari, M., 79

Saeedi, H. See Chaudhary, C., 143

Safi, K., 151

See Isaac, N.J.B., 147

Sagarin, R.D. See Barry, J.P., 406

Sagerman, J., 421-436, 439

Sahari, A., 383

Saint-Paul, U. See Buck, B.H., 143

Sala, E. See Ling, S.D., 30

See Sandin, S.A., 384

See Vergés, A., 33

See Williams, G.J., 387

Sale, P.F. See Burt, J., 406

See Roy, K., 83

Salleh, I.B. See Tan, S.H., 385

Salomon, A.K. See Ling, S.D., 30

Salvat, B., 384

See Ricard, M., 151

See Vieux, C., 386

Sammarco, P.W., 416

Sampaio, C.L.S. See Costa, T.J.F., 408

Samuelu, J. See Lovell, E., 381

Sánchez, I. See Britton-Simmons, K.H., 436

Sanders, N.J. See Crutsinger, G.M., 77

Sanderson, J.C. See Johnson, C.R., 29, 412

Sandin, S.A., 384

See Barott, K.L., 376

See Estes, J.A., 28

See Williams, G.J., 387

Sandoval-Castillo, J. See Teske, P.R., 84

Sanford, E. See Menge, B.A., 31

Sanjana, S. See Seeto, J., 384

Sanjuan, J. See Alzieu, C.L., 405

Sant, G., 151

Santelices, B. See Castilla, J.C., 76

Santos, J.M. See Branco, P., 50

Santos, M.D. See Lizano, A.M.D., 148

Santos, R. See Engelen, A.H., 437

Santos, R.O.P. See Monteiro, C.A., 438

Sanzana, J. See Soto, D., 417

Sapatu, M. See Siaosi, F., 152, 384

Sarà, M., 83

Sarramégna, S. See Wantiez, L., 386

Sasaki, M. See Teske, P.R., 84

Sasaki, Y. See Fijiwara, S., 378

Satta, M.P. See Moschella, P.S., 413

Sauer, J.R. See Butchart, S.H.M., 407

Saunders, R.J., 416

Sauni, L. See Sauni, S., 384

Sauni, S., 384

Sauvage, T. See Smith, J.E., 439

Savage, J.M., 384 


\section{AUTHOR INDEX}

Sax, D.F. See Fridley, J.D., 410

Scarlato, O.A. See Sirenko, B.I., 152, 384

Schaffelke, B., 439 See Uthicke, S., 33

Schaffner, U., 439

Scharlemann, J.P.W. See Butchart, S.H.M., 407

Scheffer, M. See Estes, J.A., 28 See Holmgren, M., 411

Scheibling, R., 32, 439

Scheibling, R.E., 32 See Ling, S.D., 30 See Lyons, D.A., 438 See Sumi, C.B.T., 439

Scheiffarth, G. See Goss-Custard, J.D., 78

Schenk, T.J. See Pratchett, M.S., 32

Schiedek, D., 416

Schiel, D.R. See Goldstien, S.J., 410

Schiff, K., 416

Schimanski, K. See Zaiko, A., 419

Schimanski, K.B., 416

Schlacher, T. See Dugan, J.E., 408

Schleyer, M. See Monniot, C., 81

Schliewen, U. See Kovačič, M., 51

Schmid, B. See Hector, A., 411 See Loreau, M., 80

Schmid, C.H. See Dietz, G., 437

Schneider, J.A., 151

Schneider, W. See Sommer, C., 384

Schoeman, D.S. See García Molinos, J., 28

Schoener, T.W., 83, 416 See Estes, J.A., 28

Schofield, M. See Firth, L.B., 409

Schoppe, S. See Dolorosa, R.G., 377

Schreiber, E.S.G. See Downes, B.J., 51

Schröder, V., 416

Schroeder, D.M., 416

Schroeder, R.E. See Sandin, S.A., 384

Schultz, M., 83

Schumacher, K. See Gössling, S., 378

Schwartzmann, C., 151, 384

Schwenk, K. See Pfenninger, M., 151

Scott, M.C. See Hall, L. W., 411

Scott, R. See Evans, S.M., 378

Scozzafave, M.S. See Mies, M., 149

Seabloom, E.W. See Elser, J.J., 409 See Fridley, J.D., 410

Sease, C. See Reese, D.S., 151

Seaward, K. See Hayden, B.J., 411 See Morrisey, D., 413

Sebens, K.P. See Jenkins, S.R., 29 See Taylor, J.D., 385

Seebens, H., 416

Seeto, J., 384

Seiderer, L.J., 83

Seko, A. See Nimoho, G., 382

Selander, E. See Pavia, H., 438

Selig, E.R. See Halpern, B.S., 411

Selin, N.I., 151, 384 See Latypov, Y.Y., 380

Selkoe, K.A., 152

See Beger, M., 142

See Halpern, B.S., 411
Sella, I. See Perkol-Finkel, S., 414

Senia, J. See Dumas, P., 144

Serebryakova, A. See Engelen, A.H., 437

Serrano, E. See Garrabou, J., 78

Sespene, N.J.J. See Tabugo, S.R.M., 385

Ševèíková, H. See Gerland, P., 410

Sewell, M.A. See Levitan, D.R., 80

Shachak, M. See Jones, C.G., 79

Shafer, D.J., 416

Shang, Y.C., 152

See Leung, P.S., 148

Shashar, N. See Perkol-Finkel, S., 414

Shears, N. See Ling, S.D., 30

Shears, N.T., 416

Sheehan, E. See Firth, L., 409

Sheehy, D.J., 416

Shenkar, N., 416

Shepherd, M.A. See Norton, J.H., 150

Shepherd, S.A., 32

See Johnson, C.R., 29, 412

See Kangas, M., 51

Sheppard, A.L.S., 384

Sherrard, K.M., 83

Sherwood, T.S. See Hensley, R.A., 379

Shibuno, T. See Fijiwara, S., 378

Shima, J. See Vieux, C., 386

Shumway, S. See Rosa, M., 415

Shurin, J.B. See Elser, J.J., 409

See Estes, J.A., 28

See Leibold, M.A., 80

Siaosi, F., 152, 384

Siegel, D.A. See Berkley, H.A., 75

Silliman, B.R. See Altieri, A.H., 49

Simberloff, D., 83, 416

Simkanin, C., 416, 417

Simoncini, M., 417

Simpson, S.L., 417

Sims, N.A., 384

Sinclair, A.R.E. See Estes, J.A., 28

Sinclair, J. See Sammarco, P.W., 416

Sinner, J., 417 See Inglis, G., 412

Sinrapasan, N. See Junchompoo, C., 147, 379

Sirenko, B.I., 152, 384

Sitters, H. See Goss-Custard, J.D., 78

Sivadas, P. See Namboodiri, P.N., 382

Sivalonganathan, B.S. See Guest, J.R., 145, 378

Skalican, K.T. See Loughman, Z.J., 52

Skei, J.M. See Trannum, H.C., 418

Skelton, P. See South, R., 384

Skilleter, G.A. See Walker, S.J., 53

Skolnik, B. See Butchart, S.H.M., 407

Skopal, M. See Krell, B., 147

Skov, M.W. See Firth, L.B., 409

Slack-Smith, S.M. See Wells, F.E., 386

Sloan, N.A., 32

Slomp, C. See Carstensen, J., 407

Slotwinski, A. See Johnson, C.R., 29, 412

Smale, D.A. See Vergés, A., 33

See Wernberg, T., 418

Smit, I.P. J. See Hempson, G.P., 29

Smith, A. See Floerl, O., 409 


\section{AUTHOR INDEX}

Smith, A.B. See Feuda, R., 28

Smith, A.J., 384

Smith, C.M. See Smith, J.E., 439 See Vermeij, M.J.A., 418

Smith, D.J. See Curnick, D.J., 144

Smith, E.A. See Andrews, C.W., 375

Smith, J.E., 439

See Barott, K.L., 376

See Elser, J.J., 409

See Sandin, S.A., 384

See Williams, G.J., 387

See Williams, S.L., 419, 440

Smith, J.R., 83

Smith, K.A., 52

Smith, L. See Rees, M., 383

Smith, M.D., 83 See Fridley, J.D., 410

Smith, R., 417

Smith, R.J. See Murray, A.G., 414

Smith, S.D.A., 384

Smith, T.B. See Vermeij, M.J.A., 418

Smith, V.H., 417

Smoothey, A.F., 52 See Chapman, M.G., 50

Snelgrove, P.V. R. See Jenkins, S.R., 29

Snyder, D.B., 417

Soedharma, D. See Nuryanto, A., 150

Sokolova, I.M., 417

Solis, E.P. See Alcazar, S.N., 141

Solis-Duran, E. See Calumpong, H.P., 143

Solofa, A. See Lovell, E., 381

Sommer, C., 384

Sone, S., 384 See Tu'avao, T., 386

Songploy, S. See Loh, T.L., 381

Soo, P., 152

Sorte, C.J.B., 417 See Zerebecki, R.A., 419

Sotka, E.E., 439 See Poore, A.G.B., 31, 439

Soto, D., 417

Soto, R. See Castilla, J.C., 76

Soulé, M., 83

Soule, M.E. See Estes, J.A., 28

Soule, S. See Bell, J.D., 142

Sousa, W.P., 52, 83

South, R., 384

Southgate, P.C., 152 See Militz, T.A., 149, 381

See Watson, S.-A., 153

Southward, A.J., 152

Southwood, R. See Williamson, M.H., 419

Souza, L. See Crutsinger, G.M., 77

Sow, M. See Schwartzmann, C., 151, 384

Spadaro, D.A. See Simpson, S.L., 417

Spalding, M. See Halpern, B.S., 411

Sparrow, L.G. See Brahimi-Horn, M.C., 27

Spear, D. See Butchart, S.H.M., 407

Speranza, D. See Johnston, E.L., 412

Spiegel, D. See Vergés, A., 33

Spieler, R.E. See Kilfoyle, A.K., 51

Spoorenberg, T. See Gerland, P., 410
Squair, C. See Smith, J.E., 439

Srean, P. See McKnight, E., 413

Srisawat, T. See Kittiwattanawong, K., 380

Stachowicz, J.J., 83, 417

See Bruno, J.F., 75

See Fridley, J.D., 410

See Nydam, M., 414

See Poore, A.G.B., 31, 439

See Rius, M., 415

See Thornber, C.S., 439

Stachowitsch, M. See Zuschin, M., 387

Stagg, R.M. See Murray, A.G., 414

Stæhr, P.A. See Pedersen, M.F., 439

Stanwell-Smith, D. See Butchart, S.H.M., 407

Starczak, V.R. See Pawlik, J.R., 82

Stasek, C.R., 152

Statham, P.J., 417

Steen, H. See Engelen, A.H., 437

Steffani, C.N. See Branch, G.M., 406

Stein, A. See Van Wynsberge, S., 153, 386

Steinarsdóttir, M.B., 439

See Wikström, S.A., 440

Steinberg, P.D., 417

See Dworjanyn, S.A., 437

See Hay, M.E., 437

See Nylund, G.M., 438

See Wernberg, T., 418

Steinman, A.D., 32

Steinwascher, K., 83

Stel, J.H. See Punt, M.J., 415

Steneck, R. See Halpern, B.S., 411

Steneck, R.S., 32, 83, 439

Stephens, P.A., 83, 152

Stephenson, A. See Stephenson, T.A., 83

Stephenson, T.A., 83

Steppan, S.J. See Herrera, N.D., 146

Stevenson, J.P., 32

Stewart, G.B. See Rothstein, H.R., 439

Steyl, C.D. See Van Driel, C.D., 84

Steyn, A. See Pillay, D., 31

Stievenart, C. See Kayal, M., 30

Stiling, P. See Liu, H., 413, 438

Stillman, J. See Armstrong, E.J., 141

Stillman, R.A. See Goss-Custard, J.D., 78

Stimson, J., 439

Stockwell, B. See Van Long, N., 386

Stoelting, M.S. See Williams, A.H., 33

Stohlgren, T.J. See Fridley, J.D., 410

Stojkovich, J.O., 384

Story, R. See Waters, C.G., 153

Strathmann, R.R. See Birkeland, C., 27

Strayer, D.L See Gutiérrez, J.L., 78

Strong, E.E. See Herrera, N.D., 146

Strong, J.A., 439

Strotz, L.C., 385

Stuart, S.N. See Butchart, S.H.M., 407

Stuart, V., 83

Sturany, R., 152

Styan, C.A. See Marshall, D.J., 80

See Teske, P.R., 84

Su, P.-W., 152

Su, Y., 152, 385 


\section{AUTHOR INDEX}

Suarez, A.V., 417

Suárez-Jiménez, R., 55-74

Subia, M.D. See DeBoer, T.S., 144

Suchanek, T.H. See Paine, R.T., 82

Sugden, H. See Hawkins, S., 411 See Mieszkowska, N., 413

Sullivan, B. See Nixon, S., 414

Sulong, N. See Sahari, A., 383

Sulu, R. See Lovell, E., 381

Sumi, C.B.T., 439

Sumida, P.Y.G. See Mies, M., 149

Sunde, L.M. See Bloecher, N., 406

Sundelin, B. See Schiedek, D., 416

Sundelof, A. See Airoldi, L., 405

Sundelöf, A. See Moschella, P.S., 413

Sunderland, K.D. See Symondson, W.O.C., 83

Sundet, J.H. See Ware, C., 418

Suprihatin, J. See Pringgenies, D., 383

Sutherland, J.P. See Menge, B.A., 81 See Moreno, C.A., 81

Sutherland, S., 417 See Schaffner, U., 439

Sutherland, W.J. See Goss-Custard, J.D., 78 See Stephens, P.A., 83, 152

Sutton, D.C. See Johnson, C.R., 29

Sutton, P. See Costanza, R., 408

Svane, I., 417

See Petersen, J.K., 82

Svenson, R. See Engelen, A.H., 437

Svensson, J.R., 439 See Pavia, H., 438

Svensson, R. See Persson, F., 439

Swadling, K.M. See Johnson, C.R., 29, 412

Sweatman, H. See Miller, I., 381

Sweatman, H.P.A. See Pratchett, M.S., 32

Sykes, H. See Lovell, E., 381

Symes, A. See Butchart, S.H.M., 407

Symondson, W.O.C., 83 See Pompanon, F., 31

Syms, C. See Pratchett, M.S., 32

Sytsma, M. See Simkanin, C., 416

Sytsma, M.D. See Davidson, I.C., 408 See Zabin, C.J., 419

\section{T}

Taberlet, P. See Pompanon, F., 31

Tabugo, S.R.M., 385

Tacconi, L., 385 See Vuki, V., 386

Tadashi, K., 385

Tafea, H. See Bell, J.D., 142 See Govan, H., 378

Takoor, S. See Michel, C., 149

Tala, F. See Poore, A.B., 31

Tamburri, M.N., 417

Tamelander, J., 418

Tan S.H., 385

Tan, A.S.H. See Zulfigar, Y., 387

Tan, Aileen Shau-Hwai, 87-140, 155-374

Tan, K.S., 385

Tan, S.H., 152, 385
Tan, S.K., 385

Tang, Y.C., 385

Taniera, T., 385

Tapia, F.J., 83

Tapia-Lewin, S. See Gelcich, S., 78

Taw, N. See Johnson, C.R., 29, 412

Taylor, J.D., 385

Taylor, M. See Wabnitz, C.C.C., 153

Taylor, M.D. See Forrest, B.M., 410

Taylor, M.L. See Curnick, D.J., 144

Taylor, N.D. See Loughman, Z.J., 52

Taylor, P.D. See Kuklinski, P., 51

Taylor, P.R. See Littler, M.M., 438

Taylor, R.B. See Poore, A.G.B., 31, 439

Teasdale, P.R. See Warnken, J., 418

Tedengren, M. See Blidberg, E., 142 See Elfwing, T., 144

Teitelbaum, A., 152 See Kinch, J., 147

Teixeira, J.B. See Costa, T.J.F., 408

Teixido, N. See Garrabou, J., 78

Teo, S.L.-M. See Neo, M.L., 149, 150

See Vicentuan-Cabaitan, K., 153

Teo, S.L.M., 418

Tepolt, C., 418

ter Poorten, J.J. See Herrera, N.D., 146

Terborgh, J. See Estes, J.A., 28

Terrados, J. See Tomas, F., 440

Terwin, J.R. See Stachowicz, J.J., 417

Teske, P.R., 55-74, 84 See Rius, M., 83

Tewfik, A., 418

Thacker, R.W. See Paul, V.J., 31

Thaman, R.R., 385

Theoharides, K.A., 418

Therriault, T.W. See Clarke Murray, C., 407 See Simkanin, C., 417

Thiel, M. See Poore, A.B., 31

Thomas, F.R., 385

Thomas, K.V. See Eggleton, J., 409

Thomas, O. See Delpla, I., 408

Thomas, P.A. See George, K.C., 378

Thomassin, B.A., 32

Thompson, K. See Davis, M.A., 408

Thompson, R. See Firth, L., 409 See Hawkins, S., 411

Thompson, R.C. See Airoldi, L., 405

See Firth, L.B., 409

See Griffin, J.N., 29

See Moschella, P.S., 413

Thomsen, M.S. See Pedersen, M.F., 439 See Wernberg, T., 418

Thornber, C.S., 439

Thorne, B.V., 385

Thorrold, S.R. See Almany, G.R., 75

Thorson, G., 84

Tian, X. See Leung, P.S., 148

Tiavouane, J., 152, 385

See Borsa, P., 142, 376

See Dumas, P., 144

Tierney, M. See Butchart, S.H.M., 407

Tiitii, U., 385 


\section{AUTHOR INDEX}

Tilman, D., 84, 418

See Fridley, J.D., 410

See Leibold, M.A., 80

See Loreau, M., 80

Timmermann, K. See Carstensen, J., 407

Tisdell, C., 152, 385

See Shang, Y.C., 152

See Tacconi, L., 385

See Vuki, V., 386

Tisera, W.L. See Naguit, M.R.A., 382

Todd, C.D., 84

See Trowbridge, C.D., 440

Todd, P.A., 87-140, 146, 152, 155-374

See Eckman, W., 144

See Guest, J.R., 145, 378

See Neo, M.L., 149, 150, 382

See Othman, A.S., 150

See Soo, P., 152

See Vicentuan-Cabaitan, K., 153

Toh, K.B., 418

Toh, T.C. See Toh, K.B., 418

Toha, A.H.A. See DeBoer, T.S., 144

Tokeshi, M. See Londoño-Cruz, E., 52

Tomas, F., 440

See Vergés, A., 33

Tomlin, J.R., 385

Tongabaea, W. See Thaman, R.R., 385

Toonen, R.J., 84

See Beger, M., 142

See von der Heyden, S., 153

Topper, T.P. See Strotz, L.C., 385

Torchin, M., 418

Torchin, M.E., 418

See Blakeslee, A.M., 406

See Freestone, A.L., 410

Torrents, O. See Garrabou, J., 78

Torres, R. See Manríquez, P.H., 80

Toth, G.B. See Pavia, H., 438

See Svensson, J.R., 439

Tourrand, C. See Montagne, A., 382

Town, J.C., 32

Trannum, H.C., 418

Tremblay, R. See LeBlanc, N., 80

Treml, E. See Beger, M., 142

Treml, E.A. See Huelsken, T., 146

Trench, R.K., 153 See Fitt, W.K., 145

Tresca, D.V. See Dayton, P.K., 28

Triandiza, T. See Kusnadi, A., 380

Trikalinos, T.A. See Dietz, G., 437

Triplet, P. See Goss-Custard, J.D., 78

Troncoso, J.S. See Cacabelos, E., 436

Troost, K., 84

Trowbridge, C.D., 440

Tsuchiya, M., 84

Tu'avao, T., 386

Tun, K. See Toh, K.B., 418

Tun, K.P.P. See Koh, L.L., 380

Turner, J.R. See Curnick, D.J., 144

Turner, R. See Rabalais, N., 415

Turner, R.E. See Rabalais, N.N., 415
Turon, X. See Airoldi, L., 74, 405

See Ordóñez, V., 414

See Pineda, M.C., 414

See Rius, M., 82, 83, 415

Turvey, S.T. See Isaac, N.J.B., 147

Tuya, F. See Wernberg, T., 418

Tyree, S., 84

Tyrrell, T.D. See Butchart, S.H.M., 407

$\mathbf{U}$

Udagawa, K. See Tu'avao, T., 386

Udayangani-Fernando, P.U. See Goss-Custard, J.D., 78

Uhlenbruck, G. See Baldo, B.A., 142

Ullmann, J., 153, 386

Underwood, A.J., 33, 52, 84

See Anderson, M.J., 405

See Arrontes, J., 26

See Chapman, M.G., 27, 50, 77, 407

See Clynick, B.G., 407

See Coleman, R.A., 27

See Cruz Motta, J.J., 50

See Jackson, A.C., 29

See James, R.L., 51

See Kingsford, M.J., 79

See Klein, J.C., 412

See Knott, N.A., 412

See Marzinelli, E.M., 413

See McGuinness, K.A., 52

See Monteiro, S.M., 81

Unwin, M. See Hayden, B.J., 411

Uribe, M. See Castilla, J.C., 76

Uthicke, S., 33

V

Vagias, C. See Kladi, M., 437

Valdovinos, C. See Castilla, J.C., 76

Vale, C. See Cabrita, M.T., 436

Valentine, J.P. See Trowbridge, C.D., 440

Valkirs, A. See Schiff, K., 416

Valladares, F. See Maestre, F.T., 413

Vallejo-Marín, M., 84, 418

Van Alstyne, K.L. See Lyons, D.A., 438

van Beek, J.K.L. See Neo, M.L., 149

van de Koppel, J., 84

See Eriksson, B.K., 77

van der Heide, T. See Eriksson, B.K., 77

van der Putten, W.H. See Verhoeven, K.J.F., 440

van der Veer, H.W. See Eriksson, B.K., 77

Van Driel, C.D., 84

van Herwerden, L. See von der Heyden, S., 153

van Ierland, E.C. See Punt, M.J., 415

Van Kleunen, M., 418

van Kleunen, M. See Chun, Y.J., 436

Van Long, N., 386

van Maren, D.S. See Neo, M.L., 149

Van Name, W.G., 84

van Sebille, E. See Teske, P.R., 84

See Vergés, A., 33

Van Slyke, D. See Roni, P., 52 


\section{AUTHOR INDEX}

van Strien, A. See Butchart, S.H.M., 407

Van Tamelen, P.G., 52

van Vliet, J. See Marchal, V., 413

Van Vuuren, D. See Marchal, V., 413

Van Wesenbeeck, B.K. See Altieri, A.H., 49

Van Wynsberge, S., 87-140, 153, 155-374, 386

See Andréfouët, S., 141, 375

See Menoud, M., 149

Vanderklift, M.A. See Poore, A.G.B., 31, 439

Vanmontfrans, J. See Orth, R.J., 31

Varas, M. See Castilla, J.C., 76

Vargas, C.A. See Manríquez, P.H., 80

Varner, G., 84

Vaselli, S., 418 See Benedetti-Cecchi, L., 27

Vavia, V. See Vieux, C., 386

Veliz, D., 84

Vercelloni, J. See Kayal, M., 30

Vergés, A., 33

Verhoeven, K.J.F., 440

Vermeij, M.J.A., 418

Viard, F. See Dupont, L., 409

See Engelen, A.H., 437

See Hudson, J., 411

See Rius, M., 415

See Voisin, M., 418

Vicentuan, K. See Neo, M.L., 150

Vicentuan-Cabaitan, K., 153

See Eckman, W., 144

See Neo, M.L., 149

Vickers, K.J. See Hempson, G.P., 29

Vie, J.C. See Butchart, S.H.M., 407

Viechtbauer, W., 440

Vieira, E.A., 84

Vieux, C., 386

Viguri, J. See Rodriguez, L.F., 415

Vik, S.F. See Sheehy, D.J., 416

Vila, M. See Maron, J.L., 438

Vila-Concejo, A. See Pearson, S., 414

Villanoy, C.L., 386

See Juinio, M.A.R., 147, 379

Villedieu, C. See Bigot, L., 376

Vinzent, J. See Nejrup, L.B., 438

Virly S., 386

See Lovell, E., 381

See Wantiez, L., 386

Virtanen, R. See Estes, J.A., 28

Vitule, J.R.S. See Simberloff, D., 83

Vo, T.S. See Long, N.V., 381

Voisin, M., 418

Volckaert, F.A. See Rius, M., 415

Voltaggio, M. See Accordi, G., 141, 375

von der Heyden, S., 153

See Beger, M., 142

See Rius, M., 82, 415

von der Meden, C.E.O., 84

Von Holle, B. See Fridley, J.D., 410

See Simberloff, D., 416

Voss, M. See Carstensen, J., 407

Vuki, V., 386

\section{W}

Wabnitz, C. See Borsa, P., 142, 376

Wabnitz, C.C.C., 87-140, 153, 155-374 See Van Wynsberge, S., 153

Wade, A.J. See Whitehead, P., 418

Wahl, M. See Lafargue, F., 79 See Weinberger, F., 440

Wakisaka, T. See Nimoho, G., 382

Walbridge, S. See Halpern, B.S., 411

Walhorn, A. See Schaffelke, B., 439

Walker, S.J., 53 See Dugan, J.E., 408

Wallace, B.C. See Dietz, G., 437

Waller, C.L., 53

Waller, D.M. See Keller, L.F., 79

Walls, K. See Teske, P.R., 84

Walpole, M. See Butchart, S.H.M., 407

Walsh, S. See Sandin, S.A., 384

Wang, G. See Hammann, M., 437

Wanitprapha, K. See Leung, P.S., 148

Wantiez, L., 386

See Dumas, P., 378

See Lovell, E., 381

Ward, C.V. See Flinn, M.V., 78

Ward, D.W. See Davis, A.R., 437

Ward, P.S. See Suarez, A.V., 417

Ward, R. See Bell, J.D., 142

Wardle, D.A. See Estes, J.A., 28 See Loreau, M., 80 See Nilsson, M.-C., 81

Ware, C., 418

Warnken, J., 418

Wasson, K., 418

Waterman, C. See Isaac, N.J.B., 147

Waters, C., 87-140, 155-374

Waters, C.G., 153

Waters, J. See Teske, P.R., 84

Waters, J.M. See Teske, P.R., 84

Watling, L. See Steneck, R.S., 32, 439

Watson, D.C. See Hawkins, S.J., 29 See Norton, T.A., 31

Watson, K. See Knight, R., 147

Watson, R. See Butchart, S.H.M., 407 See Halpern, B.S., 411

Watson, S.-A., 153 See Armstrong, E.J., 141

Watson, T.C. See Heslinga, G.A., 146

Weber, E. See Van Kleunen, M., 418

Weerts, K.A. See Fielding, P.J, 78

Weinberger, F., 440 See Hammann, M., 437

See Nylund, G.M., 438

Wells, F.E., 386, 387

Wells, S., 153

Wells, S.M., 387

Wernberg, T., 418

See Pedersen, M.F., 439

See Vergés, A., 33

Wessels, H., 33

West, A.D. See Goss-Custard, J.D., 78 


\section{AUTHOR INDEX}

West, C.J. See Richardson, D.M., 82

Wethey, D.S. See Jenkins, S.R., 29

See Trench, R.K., 153

See Woodin, S.A., 419

Wetzel, M.A. See Atilla, N., 406

White, F.J. See Firth, L.B., 409

Whitehead, P., 418

Whitlach, R.B. See Stachowicz, J.J., 417

Whitlatch, R. See Osman, R., 414

Whitlatch, R.B. See Osman, R.W., 414

Whittington, M. See Barnes, D.K.A., 375

Whittle, G.N. See Cryer, M., 50

Wibowo, N.J. See Eliata, A., 144, 378

Wickens, P.A. See Day, R.W., 77

Wieczorek, S.K., 84

Wiencke, C. See Wessels, H., 33

Wieters, E.A. See Navarrete, S.A., 81

Wijnbladh, E. See Elfwing, T., 144

Wikfors, G. See Rosa, M., 415

Wikström, S. See Forslund, H., 437

Wikström, S.A., 421-436, 440

See Sagerman, J., 439

Wilby, R. See Whitehead, P., 418

Wilcove, D.S., 419

Wild, C. See Jantzen, C., 147

Wilderman, D.L. See Combs, J.K., 408

Wilhelmsson, D. See Langhamer, O., 412

Wilkinson, C. See Chin, A., 377

Wilkinson, C.R., 153

Willam, A. See Dumas, P., 144

Willan, R.C. See Penny, S.S., 150, 383

Williams, A.H., 33

Williams, G.A. See Kennish, R., 30

See Norton, T.A., 31

Williams, G.J., 387

Williams, R. See Cryer, M., 50

Williams, S.L., 419, 440

See Grosholz, E.D., 410

See Sorte, C.J.B., 417

Williams, S.T. See Benzie, J.A.H., 142

See Macaranas, J.M., 148

Williamson, J.E. See Cummings, D.O., 437

Williamson, M., 440

Williamson, M.H., 419

Wilson, C., 33

Wilson, J.C., 419

Wilson, J.R.U. See Blackburn, T.M., 406

See Prentis, P.J., 415

Wilson, N.G., 154

Wilson, S.K. See Vergés, A., 33

Winder, M., 419

Windupranata, W. See Pearson, S., 414

Wisz, M.S. See Ware, C., 418

Witman, J.D. See Dee, L.E., 28

Wittenberg, R. See Tisdell, C., 385

Wolcott, D.L, 33

Wolf, V.C. See Schaffner, U., 439

Wolff, W.J. See Troost, K., 84

Wonham, M.J. See Ruiz, G.M., 416

Wood, C.A. See Johnston, E.L., 412

Wood, H. See Oliver, P.G., 382

Wood, H.L. See Nylund, G.M., 438
Wood, S.A. See Zaiko, A., 419

Woodin, S.A., 419

See Jenkins, S.R., 29

Woods, C. See Inglis, G., 412

See Sinner, J., 417

Woollacott, R.M. See Johnson, C.H., 79

Worm, B. See Baum, J.K., 406

Worrall, D.H. See Goss-Custard, J.D., 78

Wotton, R.S., 33

Wren, S. See Curnick, D.J., 144

Wright, A., 85

Wright, J.P., 85

Wu, B. See Toh, K.B., 418

Wu, W.L., 387

See Huang, C.W., 379

Wulff, J.L., 33

\section{Y}

Yacobovich, T. See Perkol-Finkel, S., 414

Yahel, G. See Perkol-Finkel, S., 414

Yahel, R. See Perkol-Finkel, S., 414

Yamada, S.B. See Menge, B.A., 81

Yamada, T. See Aubert, A., 375

Yamaguchi, M., 33, 154

Yamazaki, S. See Maruyama, T., 148

Yan, L. See Andréfouët, S., 141, 375

See Gilbert, A., 145, 378

Yasin, Z.B. See Tan, S.H., 385

Yasumoto, T. See Kanno, K., 379

Yates, M.G. See Goss-Custard, J.D., 78

Yau, A.J., 154

Yeeting, B. See Siaosi, F., 152, 384

Yelenik, S.G. See Levine, J.M., 413, 438

Yellowlees, D. See Leggat, W., 148 See Norton, J.H., 150

Yeo, D.C., 419

Yodzis, P., 85

Yonge, C.M., 154

Young, C.M., 85

See Southward, A.J., 152

Yun, H.Y., 440

Yusof, A.A. See Tan, S.H., 385

Yusuf, C., 387

\section{$\mathbf{Z}$}

Zabala, M. See Garrabou, J., 78

See Ling, S.D., 30

Zabin, C.J., 419

See Davidson, I.C., 408

See Grosholz, E.D., 410

See Wasson, K., 418

See Williams, S.L., 419

Zahida, F. See Eliata, A., 144, 378

Zaiko, A., 419

Zakaria, S. See Kilada, R., 380

Zann, L.P., 387

Zardi, G. See McQuaid, C.D., 413

Zavala, P. See Castilla, J.C., 76

Zeldman, Y. See Shenkar, N., 416 


\section{AUTHOR INDEX}

Zerebecki, R.A., 419

See Sorte, C.J.B., 417

Zgliczynski, B. See Barott, K.L., 376

Zhan, A., 419

Zhang, H., 154

Zhang, J. See Rabalais, N., 415

Zharikov, Y. See Goss-Custard, J.D., 78

Zhuang, Q., 387
Zilger, M. See Gössling, S., 378

Zilman, G. See Perkol-Finkel, S., 414

Zuberer, F. See Garrabou, J., 78

Zulfigar, Y., 387

See Tan, S.-H., 385

See Tan, S.H., 152

Zuschin, M., 154, 387

Zwarts, L. See Goss-Custard, J.D., 78 


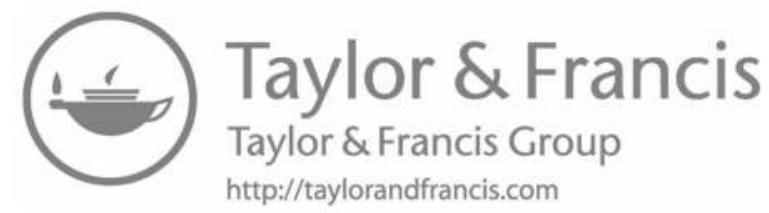




\section{SYSTEMATIC INDEX}

\section{A}

Acanthaster, 20

Acanthaster planci, 7, 16, 17, 18, 19, 25

Acanthasteridae, 7

Acanthophora spicifera, 427, 429

Acanthurus blochii, 426

triostegus, 426

Acrothamnion preissii, 426, 429

Agardhiella, 9

Ampithoe longimana, 424

Annelida, 65

Aplysia punctata, 425, 426

Aquilonastra, 25

anomala, 4, 15, 34

Arthropoda, 424, 425, 426, 427, 429

Asterias, 20, 21 rubens, 17

Asterina anomala, see Aquilonastra anomala gibbosa, 4, 13, 15

miniata, see Patiria miniata

pectinifera, see Patiria pectinifera

phylactica, 4, 15

stellifera, 9, 34

Asterinidae, 4, 9, 12, 15, 18, 21, 34

Asteroidea, 3, 21

Asteropseidae, 10, 18

Astropecten, 21

Austrocochlea porcata, 40, 41, 42

Austromegabalanus psittacus, 69

\section{B}

Bacillariophyceae, 65

Bivalvia, ix, 87

Bonnemaisonia hamifera, 426, 429, 431, 433, 434, 435

Byssocardium, 91

\section{C}

Cabestana, 70 spengleri, 68

Calanoida, 65

Cambarus chasmodactylus, 43

Cardiidae, ix, 87, 90, 91, 92

Caulerpa, 394

cylindracea, 427, 429

filiformis, 424, 429

racemosa, 434

racemosa var. cylindracea, see Caulerpa cylindracea taxifolia, 434

Cellana, 68

tramoserica, 22, 23, 24, 42

Centrostephanus rodgersii, 26

Ceramium, 4, 13

Cerastoderma, 90, 91

Ceratium, 65
Chaetomorpha, 11, 13

Chametrachea, 91, 92

Chlorophyta, 424, 428, 429, 433

Chondracanthus canaliculatus, 37

Chordata, 60, 424, 426, 429

Ciona robusta, 404

Cistina, 15

columbiae, 5

Codium fragile ssp. atlanticum, 424, 429

fragile ssp. fragile, 427, 428, 429, 431, 433, 434

fragile ssp. tomentosoides, see Codium fragile ssp. fragile

Concholepas concholepas, 65, 66, 68, 69, 71

Cookia sulcata, 424

Copepoda, 65

Corallina, 10 officinalis, 4

Coscinasterias, 21 calamaria, 42

Crassostrea gigas, see Magallana gigas

Crossaster papposus, 8, 17

Crustacea, 65

Cryptasterina hystera, 4, 15, 34

pacifica, 4, 34

pentagona, 4, 15, 34

Culcita novaeguineae, 8, 17 schmideliana, 11, 19

Cyanobacteria, 3, 5

Cyclopoida, 65

D

Dactylosaster, 15 cylindricus, 5

Dasysiphonia japonica, 427, 429, 431, 433

Delesseriaceae, 9

Dermasterias imbricata, 10, 19

Dexamine spinosa, 425

Didemnum vexillum, 398, 399

Dinoflagellata, 65

Diodora lineata, 42

Dunaliella primolecta, 66

E

Echinaster, 15, 21

(Othilia) sentus, 7

luzonicus, 5

purpureus, 5

Echinasteridae, 5, 7, 15

Echinodermata, 424, 425, 426, 427, 429

Echinogammarus obtusatus, 427

Ecklonia maxima, 68

Egregia, 9

Enteromorpha, 4, 10, 11

Eurytrochus strangei, 42

Evechinus chloroticus, 424 


\section{SYSTEMATIC INDEX}

\section{F}

Foraminifera, 65

Forcipulatida, 21

Fragiinae, 90

Fragum, 90

Fromia hemiopla, 10

Fucus evanescens, 425, 429, 434

serratus, 425,429

\section{G}

Galeolaria caespitosa, 46

Gammarellus angulosus, 426, 427

Gammarus insensibilis, 425

locusta, 426, 427

obtusatus, see Echinogammarus obtusatus

Gastropoda, 65

Gelidium, 9

Gibbula, 425

Gigartina, 9 canaliculata, see Chondracanthus canaliculatus

Gomophia egyptiaca, 11

Goniasteridae, 5, 8, 10, 15, 18

Gracilaria, 70

salicornia, 426, 427, 429

vermiculophylla, 426, 429, 434

Granaster nutrix, 12, 19

\section{H}

Haematopus fuliginosus, 68 moquini, 68 palliatus pitanay, 68, 69

Halimeda, 7

Hapalochlaena lunulata, 43

Harpacticoida, 65

Heliaster helianthus, 68, 69

Heliocidaris erythrogramma, 42

Hemigrapsus sanguineus, 45

Henricia leviuscula, 7, 17

Heterosiphonia japonica, see Dasysiphonia japonica Hippopus, 90, 91, 123, 126 hippopus, 88, 89, 90, 93, 94, 95, 122, 123, 124, 134, 188,253

porcellanus, 88, 89, 90, 91, 93, 94, 95, 122, 123, 124, $125,134,188,253$

Hormosira, 4

Hydrobia ulvae, see Peringia ulvae

I

Idotea balthica, 426, 427

granulosa, 424, 425, 427

neglecta, 426

Iridea, 9

Ischnochiton, 40 australis, 40, 41, 42, 44, 46

elongatus, 42

fruticosus, 42

smaragdinus, 40, 46

\section{K}

Kappaphycus, 427, 429

$\mathbf{L}$

Lacuna vincta, 424, 425, 427

Laminaria, 4, 9 longicruris, see Saccharina longicruris

Laurencia, 9

Lessonia nigrescens, 67

Linckia, 15, 21

guildingi, 5

laevigata, 6, 16

multifora, 6

Lithophyllum yessoense, 10

Lithothamnia, 10

Littorina, 426

littorea, 424, 425, 426, 427

obtusata, 425

Lophocladia lallemandii, 427, 429

Loricella angasi, 46

Luidia foliolata, 8, 17

Luidiidae, 8

Lunella smaragda, 427

undulata, 427

Lymnocardiinae, 90

\section{M}

Macrocystis pyrifera, 9, 22

Madrepora, 99

Magallana gigas, 39

Marginaster littoralis (nomen dubium), 5, 12

Marthasterias africana, 68 glacialis, 17

Mastocarpus papillatus, 70 stellatus, 427, 429

Mediaster aequalis, 8, 11, 17, 19

Meridiastra calcar, 9, 14, 19, 34 gunnii, 9, 19, 34 medius, 9, 19

Mesophyllum insigne, 8, 17

Meyenaster gelatinosus, 69

Microcladia, 9

Mollusca, 424, 425, 426, 427, 429

Montfortula rugosa, 42

Mytilidae, 65, 66

Mytilus galloprovincialis, 68, 70, 397, 402

\section{$\mathbf{N}$}

Nardoa, 15 variolata, 6

Nectria, 19 multispina, 11

ocellata, 10 saoria, 11

Nematoda, 65

Neoferdina cumingi, 5, 15

Nerita atramentosa, 42 


\section{SYSTEMATIC INDEX}

\section{O}

Octopus mimus, 71

Onithochiton quercinus, 42

Ophidiaster, 15

cribrarius, 6, 34

granifer, 6

hemprichi, 6, 34

robillardi, see Ophidiaster cribrarius squameus, see Ophidiaster hemprichi

Ophidiasteridae, 5, 11, 15, 18, 34

Oreaster, 21

occidentalis, see Pentaceraster cumingi

reticulatus, 11, 13, 16, 18, 21, 22

Oreasteridae, 6, 8, 11, 15, 18, 21, 34

\section{$\mathbf{P}$}

Paracentrotus lividus, 424, 425, 426, 427

Parvulastra, 21

exigua, 4, 14, 15, 16, 22, 23, 24, 34, 41

parvivipara, 4, 15, 34

vivipara, $5,15,34$

Patiria miniata, 9, 13, 19, 22, 34

pectinifera, 10, 14, 23, 34

stellifera, see Asterina stellifera

Patiriella brevispina, see Meridiastra gunnii

calcar, see Meridiastra calcar

exigua, see Parvulastra exigua

obscura, see Cryptasterina pentagona

parvivipara, see Parvulastra parvivipara

pseudoexigua, see Cryptasterina hystera

pseudoexigua pacifica, see Cryptasterina pacifica

pseudoexigua pseudoexigua, see Cryptasterina pentagona

regularis, 10, 13, 20, 21, 23

vivipara, see Parvulastra vivipara

Pentaceraster, 15

cumingi, 6, 15, 16, 34

mammillatus, 6

regulus, 7

Peringia ulvae, 427

Perna canaliculus, 17 perna, 68,402

Persikima, 91

Perumytilus purpuratus, 66, 69, 72

Phaeophyceae, 425, 428, 429, 433

Phataria, 15 unifascialis, 6

Phyllochaetopterus prolifica, 17

Pisaster ochraceus, 20

Porolithon, 7

Porphyra, 9, 11, 19 linearis, 70

pseudolinearis, see Pyropia pseudolinearis

Prionitis, 9

Protoperidinium, 65

Protoreaster, 15

lincki, 7

nodosus, 7, 13, 16, 22

Psammechinus miliaris, 425

Pseudonepanthia troughtoni, 10, 19
Pteraster tesselatus, 8, 17

Pterasteridae, 8

Pugettia producta, 426

Pyropia pseudolinearis, 70

Pyura dalbyi, 62, 63, 71, 73, 74

doppelgangera, 62, 63, 69, 70, 71, 74

haustor, 66

herdmani, 62, 63, 64, 68, 69, 71, 72, 73

praeputialis, 62, 63, 64, 65, 66, 67, 68, 69, 70, 71, 72, 73,74

spinifera, 73

stolonifera, 62, 63, 64, 65, 66, 67, 68, 72, 73

stolonifera species complex (P.s.s.c.), 55, 56, 60, 61, $62,63,64,65,66,67,68,69,70,71,72,73,74$

$\mathbf{R}$

Rhodophyta, 426, 428, 429, 433

Rhodymenia, 9

S

Saccharina longicruris, 431

Sargassum muticum, 425, 428, 429, 431, 433

Sarpa salpa, 424

Scleractinia, 139

Scutus antipodes, 41, 42

Solaster dawsoni, 8, 17

stimpsoni, 8, 17

Solasteridae, 8

Spinulosida, 21

Spyridia, 9

Stenosoma nadejda, 425

Stichaster australis, 8, 17, 70

Stichasteridae, 8, 12, 18

Stomatella impertusa, 41

Strongylocentrotus droebachiensis, 424, 425

Stylasterias forreri, 18

Symbiodinium, 88

Sypharochiton pelliserpentis, 42

\section{$\mathbf{T}$}

Tenguella marginalba, 42

Thalassodendron ciliatum, 129

Tintinnida, 65

Tridacna, 90, 91, 93, 96, 97, 98, 99, 100, 103, 123, 125, $126,128,131,167,168,169,170,172,173,175,253$

costata, see Tridacna squamosina, 87, 90, 92, 93, 122, $133,188,253$

crocea, $88,89,90,91,92,93,94,95,122,124,128$, $130,134,139,188$

derasa, 88, 89, 90, 91, 93, 94, 95, 122, 123, 124, 125, $126,127,132,133,134,136,137,139,140,188$, 253

elongata var. squamosina, see Tridacna squamosina, 128

gigas, $88,89,90,91,93,94,95,122,124,125,126$, $132,133,134,136,137,139,140,188,253$

lorenzi, $87,88,91,92,93,94,95,122,130,134,188$

maxima, 88, 89, 90, 91, 92, 93, 94, 95, 122, 124, 128, $129,130,131,132,134,138,139,140,188,253$ 


\section{SYSTEMATIC INDEX}

mbalavuana, 88, 90, 91, 92, 93, 94, 95, 122, 124, 126, $\mathbf{U}$ $127,134,188,253$

ningaloo, see Tridacna noae, 90, 91, 92

noae, $87,88,90,91,92,93,94,95,122,124,129,130$, $133,134,188,253$

rosewateri, $88,90,91,92,93,94,95,122,129,130$,

$$
134,188
$$

squamosa, $88,89,90,91,92,93,94,95,122,124,127$,

$128,129,130,132,134,138,188,253$

squamosina, $87,88,90,91,92,93,94,95,122,124$,

$128,133,134,188,253$

tevoroa, see Tridacna mbalavuana, 90, 91, 92, 93, 122, $126,188,253$

Tridacnidae, 87, 90, 91, 133

Tridacninae, ix, 87, 88, 90, 91, 131, 133, 134

Tridacnoidea, 91

Tripneustes gratilla, 427

Tubastraea, 396

Tunicata, 55, 60

$\mathbf{U}$

Ulva, 4, 10, 11, 13, 19, 67, 68, 69 lactuca, 37,46

Undaria pinnatifida, 426, 429, 431, 432, 433

V

Valvatida, 21

Venerida, 90

W

Watersipora subtorquata, 401

Womersleyella setacea, 427, 429

$\mathbf{Z}$

Zebrasoma flavescens, 426

Turbo smaragdus, see Lunella smaragda undulatus, see Lunella undulata 


\section{SUBJECT INDEX}

Page numbers in boldface denote tables.

A

abalone fisheries, 26

abiotic factors, boulder-fields, 43-45

abundance, giant clams, 96-122

Acanthasteridae, 7

acidification of ocean, 132

Adelaide (Australia), 70, 73

Africa, 62, see also South Africa

aggregations

amphipods, 67

boulder-fields, 41,46

competition, 66

ecological dominance, 59, 66-73

giant clams, 140

kin aggregation, 58

meeting protein demands, 396

monospecific, 60

predator protection, 59-60

Pyura stolonifera species complex, 60-61, 64, 68-72

self-recruitment, 64

algae, see also seaweed invasions

assemblages structure modification, 21-23, 24

Chlorophyta, 424, 428-429

detritus as energy source, 65

discolouration and scars, 13, 14, 23

dominance, intertidal zone, 57

as food, 19

grazing and predation, 46

metal tolerance, 393

Phaeophyceae, 425-426, 428-429

preference summary, 424-427, 429

Rhodophyta, 426-427, 428-429

rock composition, recruitment, 46

successional sequence dominance, boulder-fields, 37

Algoa Bay, South Africa, 67

Allee effects, 59-60, 72, 133, 139, 399

American Samoa

abundance, presence, and status of giant clams, 116

density patterns, wild giant clams, 189

distribution, giant clams, 254

giant clam species checklist, $\mathbf{1 8 5}$

Hippopus hippopus, 123

localities with giant clams, 155

local mitigation measures, 135

Tridacna gigas, 126

amphipods

aggregations, 67

ecological dominance, 67

grazing and predation, 2, 23, 46

grazing effects of, 2

metal tolerance, 393

seaweed invasions, 429

Andaman Islands, 130

anemones as food, 18-19 annelid larvae, 65

Antarctica, 63

anthropogenic activities

boulder-fields, 35, 43-44

giant clams, 88

illegal harvesting, 131-132

P.s.s.c.-associated species, 71-72

Pyura stolonifera species complex, 62, 71-73

anthropogenic activities affect, NIS post-arrival

artificial structures, 389, 391, 394-397, 403

chemical alteration, 391-394

coastal transport networks, 389, 397-399

commercial vectors, 397-398

community interaction changes, 400-401

connectivity, 397-399, 403

contamination, 391-393

ecological alteration, 400-405

'enemy release', 401-402

environmental tolerance, 390-391, 393

estuarine and coastal development, 394-395

genetic alteration, 400-405

hydrological regimes, 394

introduction, 390-391

management, 389, 402-405

offshore development, 394-395

overview, 389

physical alteration, 394-397

physiological alteration, 400-405

recipient environments, 394-397, 400-405

recreational vectors, 397-398

species diversity loss, 400-401

top-down control, loss of, 401-402

toxic contaminants, 393-394

transport facilitation, 389, 398-399

water quality, 391-394

Antofagasta Bay, see Chile; Pyura stolonifera species complex

arm length, starfish, 19-20

arthropods, 431

artificial structures

anthropogenic activities affect, NIS post-arrival, 389, 391, 394-397, 403

surrogates and reefs, 47-48, 395-397

ascidians, see also Pyura stolonifera species complex

Allee effects, 59

disturbance consequences, 60

dominance, 43, 60, 61

filtration rate, 65-66

as food, 19

obligate herbivores, 17

scales of dispersal, 57

Asterinidae

classification, temporal/spatial fidelity, 4-5, 9-10

current/previous species name, 34

obligate herbivores, 15 


\section{SUBJECT INDEX}

phylogeny and feeding habits, 21

spatial and seasonal changes in diet, 18

Asteroidea database, 3

Asteropseidae, 10, 18

Austral Archipelago, 138

Australasia, 62

Australes, 127

Australia

abundance, presence, and status of giant clams, 107

anthropogenic activity effects, 44,71

bleaching events, 132

boulder-fields, 40-42, 44, 47-48

density patterns, wild giant clams, 189-191

distribution, giant clams, 254-280

general Tridacnines distribution, 93

giant clam conservation, 89

giant clam species checklist, 179

Hippopus hippopus, 123

illegal harvesting, 131

localities with giant clams, 155

local mitigation measures, 135

mariculture and restocking, 136, 139

naturalization of species, 70-71

new giant clam species, 90

non-indigenous species, 70

Pyura stolonifera species complex, 62, 73

restoration, degradation/loss, 47-48

starfish grazing impacts, 22

Tridacna crocea, 130

Tridacna derasa, 126

Tridacna gigas, 125

Tridacna mbalavuana, 127

Tridacna squamosa, 127

azooxanthellates, 90

\section{B}

bait collection, 71

ballast water treatment, 404

Baltic Sea, 394

barnacles

competition, 72

disturbance consequences, 60

grazing effects on, 23

metal tolerance, 393

rock composition, recruitment, 46

scale of dispersal, 57

successional sequence dominance, boulder-fields, 37

bat starfish, 19

benthic assemblages/communities, starfish, 1-2, 21-23

bioengineer species, 61, see also ecological dominance

biofilms

food competitors, 23

newly quarried rocks, 40

obligate herbivores, $15-16$

starfish diet composition, 3, 13-14

starfish grazing impacts, 22-23, 24

biofoam formation, 64,66

biogeography, P.s.s.c., 62-63

biological invasions, P.s.s.c., 69-71

biophysical modelling, 136-138 biota living under boulders, 39-43

biotic factors, boulder-fields, 45-47

bivalves, 23, 60, 66, 67, see also giant clams

bleaching events, 132

blue-ringed octopuses, 43

boating marinas, artificial structures, 391

Bolinao Marine Laboratory, 123

bootstrapped confidence intervals, 428

boring giant clam, see Tridacna crocea

boulder-fields

abiotic and biotic factors, $43-47$

competition, 46

disturbances, 43-44

ecology, biota living under boulders, 39-43

factors, biota diversity and abundance, 43-47

features, boulders and surroundings, 44

future research directions, 48-49

general theories development, 36-39

grazing, 46-47

historical ecological studies, 36-43

introduction, 35-36

microhabitats, 43

overview, 35

position of, 44

post-settlement dispersal, 47

predation, 46-47

recruitment, 45-46

restoration of degradation/loss, 47-48

stress combinations, 45

breakwaters, artificial structures, 391

British Indian Ocean Territory, 155, 169

broadcast fertilizers, 40-41, 59-60

brown algae, 425-426, 428-430

Brunei, 103, 155, 172

bryozoans

boulder-fields, 39-40

dominance, rocky shore species, 60

as food, 19

grazing and predation, 46

metal tolerance, 393

obligate herbivores, 17

Burma, see Myanmar

burrowing giant clam, see Tridacna crocea

C

Cambodia

abundance, presence, and status of giant clams, $\mathbf{1 0 3}$

density patterns, wild giant clams, 191-192

distribution, giant clams, 280-282

giant clam species checklist, 172-173

illegal harvesting, 131

localities with giant clams, 155-156

cannibalism, 66, 72

Cape Banks (Australia), 40, 42

Cardiidae, 90

Cargados Carajos Archipelago

abundance, presence, and status of giant clams, $\mathbf{9 8}$

giant clam species checklist, 169

localities with giant clams, 156

Tridacna lorenzi, 130

Chagos, 100 


\section{SUBJECT INDEX}

chemical alteration, recipient environments, 391-394 anthropogenic activities affect, NIS post-arrival, 391-394

contamination, 391-393

hydrological regimes, 394

toxic contaminants, 393-394

Chile, 70-71, 397, see also Pyura stolonifera species complex

China

abundance, presence, and status of giant clams, 101 distribution, giant clams, 282

giant clam species checklist, $\mathbf{1 7 0}$

illegal harvesting, 131

localities with giant clams, 156

local mitigation measures, 135

Tridacna derasa, 126

China clam, see Hippopus porcellanus

chitons, 41, 44, 46

Chlorophyta, 424, 429

Chordata, see Pyura stolonifera species complex

Christmas Island

abundance, presence, and status of giant clams, 99

density patterns, wild giant clams, 192

distribution, giant clams, 282

giant clam species checklist, 169

localities with giant clams, 156

Tridacna noae, 129

clams, see giant clams

climate changes, 132, 139, 394, 396

coastal development, 394-395

coastal transport networks, 389, 397-399

coastal transport networks, connectivity, 397-399

Cocos (Keeling) Islands

abundance, presence, and status of giant clams, 100

density patterns, wild giant clams, 193-194

distribution, giant clams, 282-283

giant clam species checklist, $\mathbf{1 6 9}$

localities with giant clams, 156

Tridacna derasa, 126

Tridacna squamosa, 127

coelobites, 41

colonization, 47-48, 57

colours, rock composition, 46

commercial vectors, 391, 396-398

communities

interaction changes, recipient environments, 400-401

seaweed invasions, 422, 431

stability and dominant species, 57

structure, Ps.s.c., 66-69

Comoros, 98, 156, 168

compensatory mortality, 58 , see also mass mortality competition, 46, 56-59

connectivity, coastal transport networks, 397-399, 403

conservation

giant clams, 88, 89, 133-139

Pyura stolonifera species complex, 71-72

conspecific attraction, 59, 72

consumer preference meta-analysis, 429-432

contamination, recipient environments, 391-393

Convention on International Trade in Endangered Species of Wild Fauna and Flora (CITES), 133-134, 139
Cook Islands

abundance, presence, and status of giant clams, 116 density patterns, wild giant clams, 194

distribution, giant clams, 283-283

giant clam species checklist, $\mathbf{1 8 5}$

Hippopus hippopus, 123

localities with giant clams, 156-157

local mitigation measures, 135

Tridacna derasa, 126

Tridacna gigas, 126

Tridacna maxima, 128

copepods, 67

coralline algae, 24, see also algae

coral reef communities, 57

Coral Triangle, 93

cordgrass, 39, 45

Corner Inlet (Australia), 70

crabs

anthropogenic activity effects, 43

boulder habitat, 41,45

diet shifts, 18

external factors, diet shifts, 18

plant-animal interactions, 2

post-settlement dispersal, 47

Craft Risk Management Standard, 404

crayfish, 43

crevices, 43

crustacean larvae, 65

cryptic species, 17-18, 90, 133

current/previous species name, starfish, 34

D

Darwin Aquaculture Centre, 127

data

seaweed invasions, 422-423

starfish, 3

'deadzone' formation, 391

decapods, 67

degradation/loss restoration, 47-48

density patterns, giant clams, 189-253

devil clam, 90, see also Tridacna mbalavuana

diatoms, 3, 13, 19, 65

diet composition, see also herbivory

Pyura stolonifera species complex, 65-66

seaweed communities, 422

starfish, 3, 13-14, 24

digestive tract and enzymes, starfish, 2, 13-14, 24-25

disc size, starfish, 19-20

dispersal, ecological dominance, 56-57

distribution, giant clams, 93-94, 254-374

disturbances

boulder-fields biota, 43-44

dominant species, 57

dominant suspension-feeding species, 60

diversity, loss of, 400-401

Djibouti

abundance, presence, and status of giant clams, 96

density patterns, wild giant clams, 194

giant clam species checklist, 167

localities with giant clams, 157 


\section{SUBJECT INDEX}

dominance, see ecological dominance

Dongsha atoll, 128

\section{$\mathbf{E}$}

early life-history stages and settlement, 63-64

East Africa, 89, 127

East Asia, see also specific country

abundance, presence, and status of giant clams, 101-102

giant clams, lack of data, 89

giant clam species checklist, 170-172

local mitigation measures, 134

Eastern Tuamotu, 93, 132

East Timor

abundance, presence, and status of giant clams, $\mathbf{1 0 3}$

distribution, giant clams, 283

giant clam species checklist, 173

localities with giant clams, 157

East Tuamontu, 132

Echinasteridae, 5, 7, 15

echinoderms, 15, 40, 48, 401, 431

ecological alteration, recipient environments, 400-405

ecological dominance, see also Pyura stolonifera species complex

conclusions, 72-74

drivers and consequences, $57-58$

evolutionary implications of, 59-60

future research directions, $72-74$

introduction, 55-56

rocky shore species, 60

seaweed communities, 422

shifting of, 57

theory, 56-59

ecological interactions, 66-69

Ecopath, Ecoism and Loop Analysis, 67

ecosystem engineer species, see ecological dominance Egypt

abundance, presence, and status of giant clams, 96

density patterns, wild giant clams, 194-197

distribution, giant clams, 283-290

giant clam species checklist, 167

illegal harvesting, 131

localities with giant clams, $\mathbf{1 5 7}$

Tridacna squamosina, 128

embryo consumption, 66

endosymbionts, 67

enemy release hypothesis (ERH), 401-402, 422

environmental tolerance, 390-391, 393

Eocene Epoch, 88

ephemeral algae, 58

Equilibrium Theory model, 38

Eritrea

abundance, presence, and status of giant clams, $\mathbf{9 6}$

distribution, giant clams, 290

giant clam species checklist, $\mathbf{1 6 7}$

localities with giant clams, 157

estuarine development, 394-395

Europe, 62

eutrophication, counteracting, 88

Evolutionary Distinct and Globally Endangered (EDGE) of Existence programme, 139 evolutionary history

ecological dominance, rocky shores, 59-60

Pyura stolonifera species complex, 62-63

relationships, conservation planning, 138-139

exploitation, see also anthropogenic activities giant clams, 88

Pyura stolonifera species complex, 71-72

external digestion, starfish, 2

external factors, diet shifts, 18

extinction

giant clams, 89, 91

Hippopus hippopus, 123

Tridacna derasa, 126

Tridacna gigas, 125

Tridacna squamosa, 127

Tridacna squamosina, 128

extra-oral digestion and feeding, 2, 21

F

facultative herbivores, 7-12, 17-19

False Bay (South Africa), 73

Fanning Island, 128

farming, non-indigenous species, 396-397

Federated States of Micronesia

abundance, presence, and status of giant clams, $\mathbf{1 1 2}$

distribution, giant clams, 290-292

giant clam species checklist, $\mathbf{1 8 3}$

localities with giant clams, 157

local mitigation measures, 135

mariculture for restocking, 136, 137

Tridacna crocea, 130

Tridacna derasa, 126

Tridacna maxima, 128

Tridacna noae, 129

Tridacna squamosa, 127

feeding mechanism $v s$. food traits, 2

feeding preferences, see also diet composition

sea urchins, 402

seaweeds, 432-436

feeding structure, starfish, 19-20

fertilization, P.s.s.c., 63-64

fertilizer (chemical) runoff, 391

fidelity to diet, 1

Fiji

abundance, presence, and status of giant clams, 108

density patterns, wild giant clams, 197-198

distribution, giant clams, 292-299

giant clam species checklist, 180

localities with giant clams, 157

local mitigation measures, 135

new giant clam species, 90

Tridacna gigas, 126

Tridacna maxima, 128

Tridacna mbalavuana, 127

Tridacna noae, 129

Tridacna squamosa, 127

filtration

ascidian rate, $65-66,72-73$

counteracting eutrophication, 88

fishery-oriented modelling study, 137-138

Florida, USA, 47 


\section{SUBJECT INDEX}

fluted giant clam, 127

food availability, 1

forbs, microhabitat, 43

Fragiinae, 90

French Polynesia

abundance, presence, and status of giant clams, 117

density patterns, wild giant clams, 198-200

distribution, giant clams, 299-303

general Tridacnines distribution, 93

giant clam species checklist, 185-186

localities with giant clams, 157-158

local mitigation measures, 135

mariculture for restocking, 135

self-recruitment, 138

Tridacna maxima, 128

Tridacna squamosa, 127

funnel plot, 431

Futuna Island, see Wallis and Futuna Islands

future directions and research

boulder-fields, 48-49

ecological dominance, $72-74$

genetic comparisons, 90-91

giant clams, 139-141

grazing by starfish, 24-26

seaweeds, 421

starfish, 24-26

\section{G}

Gambier Archipelagos, 127

gastropods

anthropogenic activity effects, 71

boulder-fields, $40-41$

food competitors, 23

larvae, 65

plant-animal interactions, 2

as predator, 68

seaweed invasions, 429

genetic alteration, recipient environments, 400-405

genetic information, 90, 138-139

giant clams

abundance, presence, and status, 96-122

biophysical modelling, 136-138

challenges, 131-133

conservation, 133-139

Convention on International Trade in Endangered Species of Wild Fauna and Flora (CITES), 133-134, 139

density patterns of, 189-253

distribution of, 93-94, 254-374

evolutionary relationships, conservation planning, 138-139

future directions, 139-141

genetic information, conservation planning, 138-139

geographic distribution, 93-94

Hippopus hippopus, 123, 124

Hippopus porcellanus, 123-125

International Union for Conservation of Nature

(IUCN) Red List, 134, 139

introduction, 88-89

legislation and regulations, 133-135

localities, 155-166 local mitigation measures, 134-135

management, 133-139

mariculture for restocking, 135-136, 139-140

overview, $87-88$

population density, 95

recent conservation approaches, 136-139

shells, human activities, 88-89

species, 167-188

species checklist, 167-188

taxonomy, 90-92

threats, 131-133

Tridacna crocea, 124, 130

Tridacna derasa, 124, 126

Tridacna gigas, 124, 125-126

Tridacna lorenzi, 130

Tridacna maxima, 124, 128

Tridacna mbalavuana, 124, 126-127

Tridacna noae, 124, 129

Tridacna rosewateri, 129

Tridacna squamosa, 124, 127

Tridacna squamosina, 124, 128

giant kelp, see kelp beds

Gondwanaland continent, 62

Goniasteridae

classification, temporal/spatial fidelity, 8, 10-11

obligate herbivores, 15

spatial and seasonal changes in diet, 18

grazing by starfish, see also starfish

algal distribution affects, 21-22

benthic assemblages, effects on, 21-23

biotic factors, boulder-fields biota, 46-47

body metrics, 19-20

classifications, 4-12

current/previous species name, 34

data collection, 3

diet composition, 3, 13-14, 24

digestive tract and enzymes, 2, 24-25

facultative herbivores, 17-19

feeding habits, 21, 24

food competitors, 23-24

future directions, 24-26

herbivores, 2

herbivory categories, 15-21

introduction, 1-3

obligate herbivores, 4-7, 15-17

ontogenetic changes in diet, 7-8, 17-18

overview, 1, 15, 24-26

phylogeny, 21

size of starfish, 25

spatial and seasonal/temporal shifts in diet, 9-12,

18-19

starfish/herbivore interactions, 23-24

terminology, 3

Great Australian Bight, 62

Great Barrier Reef (GBR), 125

green algae

effect on sea urchins, 434

predators feeding on, 19

preference summary, 424, 428-430

successional sequence dominance, boulder-fields, 37

gregariousness, 57, 58, 66, 71-72 


\section{SUBJECT INDEX}

Guam

abundance, presence, and status of giant clams, 112

bleaching events, 132

distribution, giant clams, $\mathbf{3 0 3}$

giant clam species checklist, $\mathbf{1 8 3}$

localities with giant clams, $\mathbf{1 5 8}$

local mitigation measures, 135

Tridacna crocea, 130

Tridacna squamosa, 127

gulls, predation on starfish, 47

\section{H}

habitat, see also boulder-fields

anthropogenic modification, 395

artificial surrogates and reefs, 47-48

boulder-field restoration, 47-48

boulder-fields, 35,49

complexity, species diversity, 38

microhabitats, boulder-fields, 36, 43

position of boulder-fields, 44

P.s.s.c. preference, 62

stepping-stones, 396-397

Habitat Diversity model, 38

harvesting, see anthropogenic activities; specific species Hawaii (USA), 126

Hedges' $d$ standardized mean difference method, 423

herbivory, see also diet composition

Chlorophyta, 424, 429

facultative herbivores, 17-19

grazing preferences, 402

obligate herbivores, $15-17$

overview, 1, 15

Phaeophyceae, 425-426, 429

phylogeny and feeding habits, 21

Rhodophyta, 426-427, 429

seaweed preference, 424-427, 428-436

spatial and seasonal changes in diet, 18-19

starfish body metrics, 19-20

Hippopus hippopus, 95, 123, 124, 134

Hippopus porcellanus, 95, 123-125, 134

historical ecological studies, 36-43

Hong Kong

abundance, presence, and status of giant clams, 101

distribution, giant clams, $\mathbf{3 0 3}$

giant clam species checklist, 170

localities with giant clams, $\mathbf{1 5 8}$

horse's hoof clam, see Hippopus hippopus

hull maintenance, 404

humans, see anthropogenic activities

hydrological regimes, 394

hygiene requirements, 404

\section{I}

inbreeding, 59

India

abundance, presence, and status of giant clams, $\mathbf{1 0 0}$

density patterns, wild giant clams, 200-204

distribution, giant clams, $\mathbf{3 0 3}$

giant clam species checklist, 169-170

localities with giant clams, $\mathbf{1 5 8}$ local mitigation measures, 135

P.s.s.c. extinction, 62

Indian Ocean, see also specific country

abundance, presence, and status of giant clams, 99-100

giant clams, lack of data, 89

giant clam species checklist, 169-170

local mitigation measures, 134

new giant clam species, 90

Tridacna rosewateri, 129

Tridacna squamosina, 128

Indonesia

abundance, presence, and status of giant clams, $\mathbf{1 0 3}$

density patterns, wild giant clams, 204-207

dispersal, conservation modelling, 139

distribution, giant clams, 303-317

giant clam species checklist, 173-175

Hippopus porcellanus, 123

localities with giant clams, 158-159

local mitigation measures, 135

Tridacna derasa, 126

Tridacna squamosa, 127

interactions, starfish/herbivore, 23-24, 25

interbreeding facilitation, 73

Intermediate Disturbance model, 38

International Union for Conservation of Nature (IUCN) Red List, 89, 134, 139

intertidal biomass, Pyura stolonifera species complex, 61 intertidal habitat, see boulder-fields

invasions, P.s.s.c., 69, see also seaweed invasions

invertebrates as food, 19

ISI Web of Science, 422

isopods, 429

Israel

abundance, presence, and status of giant clams, 96

distribution, giant clams, 317-318

giant clam species checklist, 167

localities with giant clams, 159

Tridacna squamosina, 128

Italy, giant clam shells, 89

J

Japan

abundance, presence, and status of giant clams, 101 distribution, giant clams, 318-320

general Tridacnines distribution, 93

giant clam shells, 89

giant clam species checklist, 170-171

localities with giant clams, 159

local mitigation measures, 135

mariculture for restocking, 136

Tridacna crocea, 130

Tridacna derasa, 126

Tridacna gigas, 125

Tridacna noae, 129

Tridacna squamosa, 127

jetties, artificial structures, 391

Jordan

abundance, presence, and status of giant clams, $\mathbf{9 7}$

density patterns, wild giant clams, 208-209

distribution, giant clams, 320 


\section{SUBJECT INDEX}

giant clam species checklist, 167

localities with giant clams, 159

Tridacna squamosina, 128

\section{K}

Kavieng Lagoon system, 129

kelp beds

sea urchin grazing, 2, 26

starfish grazing impacts, 22, 24

Kenya

abundance, presence, and status of giant clams, $\mathbf{9 8}$

distribution, giant clams, 320

giant clam species checklist, 168

localities with giant clams, 159

Tridacna gigas, 125

\section{L}

\section{La Réunion}

abundance, presence, and status of giant clams, 99 distribution, giant clams, 320-322

giant clam species checklist, $\mathbf{1 6 8}$

localities with giant clams, 159

large-scale poaching, giant clams, 131, see also anthropogenic activities

La Rinconada, Chile, 67

larvae

consumption, 65-66

dispersal, conservation modelling, 138-139

solitary ascidians, 70

legislation and regulations, 133-135

life-history stages, P.s.s.c., 63-64

limpets

aggregations, 68

boulder-fields, 41

competitive interactions, $23-24$

grazing effects of, 2,22

Lizard Island, 132

localities, giant clams, 155-166

local mitigation measures, giant clams, 134-135

'Lower Risk/Conservation Dependent' status

Hippopus hippopus, 123, 134

Hippopus porcellanus, 123, 134

Tridacna maxima, 128, 134

Tridacna squamosa, 127, 134

'Lower Risk/Least Concern' status, 130, 134

Low Water Springs level, 61

Luidiidae, $\mathbf{8}$

Lymnocardiinae, 90

\section{M}

macroalgal detritus, energy source, 65

Madagascar

abundance, presence, and status of giant clams, $\mathbf{9 8}$

density patterns, wild giant clams, 209-211

distribution, giant clams, 322

giant clam species checklist, 168

localities with giant clams, 159-160

P.s.s.c. extinction, 62

Tridacna gigas, 125
Malaysia

abundance, presence, and status of giant clams, 104

density patterns, wild giant clams, 211-212, 237-238

distribution, giant clams, 322-337

giant clam species checklist, 175

Hippopus hippopus, 123

Hippopus porcellanus, 123, 125

illegal harvesting, 131

localities with giant clams, 160

local mitigation measures, 135

Tridacna derasa, 126

Tridacna gigas, 126

Tridacna squamosa, 127

Maldives

abundance, presence, and status of giant clams, $\mathbf{1 0 0}$

density patterns, wild giant clams, 212-213

distribution, giant clams, 337-340

giant clam species checklist, 170

localities with giant clams, 160

management, 133-139, 389, 402-405

mariculture for restocking, giant clams, 135-136, 139-140

Marine Ecology Research Centre, 125

Marshall Islands

abundance, presence, and status of giant clams, 114

density patterns, wild giant clams, 213

distribution, giant clams, $\mathbf{3 4 0}$

giant clam species checklist, 184

localities with giant clams, $\mathbf{1 6 0}$

mariculture for restocking, 135

Tridacna crocea, 130

Tridacna derasa, 126

Tridacna maxima, 128

Tridacna squamosa, 127

Mascarene Plateau, 130

mass mortality

dominant suspension-feeding species, 60

Pyura stolonifera species complex, 68

weakening of dominance effect, 57

Mauritius

abundance, presence, and status of giant clams, 98

distribution, giant clams, 340-341

giant clam species checklist, $\mathbf{1 6 8}$

localities with giant clams, $\mathbf{1 6 0}$

local mitigation measures, 135

new giant clam species, 91

Tridacna gigas, 125

Tridacna lorenzi, 130

Tridacna rosewateri, 129

Mayotte

abundance, presence, and status of giant clams, $\mathbf{9 8}$

distribution, giant clams, 341

giant clam species checklist, 168

localities with giant clams, $\mathbf{1 6 0}$

Mediterranean mussels, 397

Melanesia, see also specific country

abundance, presence, and status of giant clams,

\section{8-111}

giant clam species checklist, 180-183

Mesozoic era, 62

meta-analysis, seaweed invasions, 423, 428, 429-436

meta-regression, 428

microhabitats, boulder-fields, 36, 43 


\section{SUBJECT INDEX}

Micronesia, see also specific country

abundance, presence, and status of giant clams,

$$
\text { 112-116 }
$$

giant clam species checklist, 183-185

Tridacna derasa, 126

Tridacna noae, 129

Micronesian Mariculture Demonstration Center (MMDC), 125,135

microsatellite data, 74

Middle East, 89

Miocene Epoch, 91

mobility of herbivores, grazing, 2

molecular methods and tools, 21, 90

molluses

boulder-fields, 40, 49

colonization, 48

diversity, 38

ecological dominance, 65

feeding preferences, 431, 434

grazing and predation, 46

grazing effects of, 2, 23

larvae, 65

undersurfaces of boulders, 40, 46, 49

monopolization, specific resources, 57-59

morphological changes, 18

mortality, compensatory, 58, see also mass mortality

Mozambique

abundance, presence, and status of giant clams, $\mathbf{9 8}$

distribution, giant clams, 341-342

giant clam species checklist, $\mathbf{1 6 8}$

localities with giant clams, 160

multiphasic life cycle, 72

multiple-choice experiments, seaweeds, 431

muricid gastropods as predator, 68

mussels

boulder-field habitat, 39-40, 45

competition for space, 66-67, 72

ecological dominance, 59-60

human exploitation, 71

introduction, South Africa, 70, 397, 402

scale of dispersal, 57

settlement of larvae, 72

Myanmar

abundance, presence, and status of giant clams, 104

distribution, giant clams, 342-343

giant clam species checklist, 176

localities with giant clams, 160

Tridacna gigas, 125

mytilid larvae, 65

\section{$\mathbf{N}$}

names of starfish, current/previous, 34

naturalization of species, 70-71

Nauru

giant clam species checklist, 184

localities with giant clams, 160

Tridacna noae, 129

nemerteans, aggregations, 67

New Caledonia

abundance, presence, and status of giant clams, 109

density patterns, wild giant clams, 213-223 dispersal, conservation modelling, 139

distribution, giant clams, 343-345

giant clam species checklist, 180-181

Hippopus hippopus, 123

localities with giant clams, 160-161

local mitigation measures, 135

Tridacna mbalavuana, 127

New England (USA), 45

New Hebrides, 182-183

newly quarried rocks, 40, 44, 47

newly-settled starfish, 18

New Zealand

ascidian predators, 70

commercial ports, 398-399

Craft Risk Management Standard, 404

non-indigenous species, 70

Pyura stolonifera species complex, 62, 69, 74

starfish grazing impacts, 22

Ningaloo Reef Marine Park, 129

Niue

abundance, presence, and status of giant clams, 118

density patterns, wild giant clams, $\mathbf{2 2 3}$

giant clam species checklist, $\mathbf{1 8 6}$

localities with giant clams, $\mathbf{1 6 1}$

local mitigation measures, 135

non-indigenous species (NIS)

harm caused by introduction, 70

Pyura stolonifera species complex, 73-74

seaweeds, 421-422

non-indigenous species (NIS), anthropogenic activities affect post-arrival

artificial structures, 389, 391, 394-397, 403

chemical alteration, 391-394

coastal transport networks, 389, 397-399

commercial vectors, $397-398$

community interaction changes, 400-401

connectivity, 397-399, 403

contamination, 391-393

ecological alteration, 400-405

'enemy release', 401-402

environmental tolerance, 390-391, 393

estuarine and coastal development, 394-395

genetic alteration, 400-405

hydrological regimes, 394

introduction, 390-391

management, 389, 402-405

offshore development, 394-395

overview, 389

physical alteration, 394-397

physiological alteration, 400-405

recipient environments, 394-397, 400-405

recreational vectors, 397-398

species diversity loss, 400-401

top-down control, loss of, 401-402

toxic contaminants, 393-394

transport facilitation, 389, 398-399

water quality, 391-394

Northern Hemisphere, 62

Northern Mariana Islands

abundance, presence, and status of giant clams, 115

giant clam species checklist, 184

localities with giant clams, 161 


\section{SUBJECT INDEX}

Tridacna crocea, 130

Tridacna gigas, 126

Tridacna squamosa, 127

North Spratly Islands, 238-239

Norway, salmon farming, 396-397

nutrient enrichment, NIS post-arrival, 393-394

nutrient recycling, starfish, 21-23

\section{O}

obligate herbivores, 4-7, 15-17

ocean acidification, 132

octopuses, 43

offshore development, 394-395

Oligocene Epoch, 88

ontogenetic changes in diet, 7-8, 17-18

Ophidiasteridae

current/previous species name, 34

obligate herbivores, 15

spatial and seasonal changes in diet, 18

temporal/spatial fidelity, 5-6, 11

opportunistic feeding, 18-19

Oreasteridae

current/previous species name, 34

obligate herbivores, 15-16

phylogeny and feeding habits, 21

spatial and seasonal changes in diet, 18

temporal/spatial fidelity, $\mathbf{6}-\mathbf{8}, \mathbf{1 1}$

Orpheus Island Research Station, 123

overdispersion

boulder-fields, 38, 40, 44, 46

post-settlement dispersal, 47

overharvesting, 71-72, 139, see also anthropogenic activities

overyield, see productivity increases

oystercatcher as predator, 68

oysters, boulder-fields, 39

\section{$\mathbf{P}$}

Pacific Islands

giant clam conservation, 89

local mitigation measures, 135

mariculture and restocking, 139

mariculture for restocking, 135

Tridacna gigas, 126

Tridacna noae, 129

Pacific Ocean, see also specific country

abundance, presence, and status of giant clams,

108-121

giant clam species checklist, $\mathbf{1 8 0}-\mathbf{1 8 8}$

Palau

abundance, presence, and status of giant clams, 115

density patterns, wild giant clams, 224-225

distribution, giant clams, 345

giant clam species checklist, 184-185

Hippopus hippopus, 123

Hippopus porcellanus, 125

localities with giant clams, 161

local mitigation measures, 135

mariculture for restocking, 135-136

Tridacna crocea, 130
Tridacna derasa, 126

Tridacna maxima, 128

Tridacna squamosa, 127

Palawan (Philippines), 95

Panama Canal, 403

Papua New Guinea

abundance, presence, and status of giant clams, 109

density patterns, wild giant clams, 225-227

distribution, giant clams, 345-348

giant clam species checklist, 182

Hippopus porcellanus, 123

localities with giant clams, 161

local mitigation measures, 135

Tridacna noae, 129

Paracel Islands, 131

Peninsular Malaysia, 126

pentagonal $v s$. stellate body profile, 21

Phaeophyceae, 425-426, 429

Philippines

abundance, presence, and status of giant clams, $\mathbf{1 0 5}$

density patterns, wild giant clams, 227-234

distribution, giant clams, 348-358

giant clam conservation, 89

giant clam species checklist, 176-177

Hippopus hippopus, 123

Hippopus porcellanus, 123, 125

illegal harvesting, 131

localities with giant clams, 162

local mitigation measures, 135

mariculture for restocking, 136, 136, 137

new giant clam species, 90

Tridacna derasa, 126

Tridacna gigas, 126

Tridacna squamosa, 127

photosynthetic dinoflagellate algae, 90

phylogeny and feeding habits, 21

Phylum Chordata, Subphylum Tunicata, see Pyura stolonifera species complex

physical alteration, 394-397

physiological alteration, 400-405

phytoplankton, 65, 72

Pitcairn Islands

abundance, presence, and status of giant clams, $\mathbf{1 1 8}$

density patterns, wild giant clams, 234

general Tridacnines distribution, 93

giant clam species checklist, 186

localities with giant clams, $\mathbf{1 6 2}$

Tridacna squamosa, 127

plant-animal interactions, 2, 23-24

'Pola' expedition, 128

polychaetes

aggregations, 67

boulder-fields, 40

metal tolerance, 393

rock composition, recruitment, 46

polymorphic satellites, 74

Polynesia, see also specific country

abundance, presence, and status of giant clams,

116-121

giant clam species checklist, $\mathbf{1 8 5}-\mathbf{1 8 8}$

Tridacna derasa, 126

pontoons, artificial structures, 391 


\section{SUBJECT INDEX}

population density, giant clams, 95

porcelain crabs, 41

ports, artificial structures, 391, 396, 398

post-settlement dispersal, 47

predation and predators

aggregation protection, 59-60

biotic factors, boulder-fields biota, 46-47

juvenile starfish, 18, 25

loss of top-down control, 401-402

Pyura stolonifera species complex, 66, 68

presence, giant clams, 96-122

previous/current species name, starfish, 34

prey availability, starfish, 18-19

productivity increases, 393-394, 400

prosobranch gastropods, 41

protein demands, 396

P.s.s.c., see Pyura stolonifera species complex

Pterasteridae, 8

Puget Sound, USA, 47

Pyura stolonifera species complex (P.s.s.c.), see also ecological dominance

biogeography of, 62-63

biological invasion, 69-71

community structure, 66-69

conservation of, 71-72

diet, 65-66

early life-history stages and settlement, 63-64

ecological interactions, 66-69

evolutionary history of, 62-63

human exploitation of, 71-72

overview, 56, 60-61

reproductive cycle and fertilization, 63-64

suspension-feeding, 65-66

\section{$\mathbf{R}$}

Random Placement model, 38

rank correlation test, 431

recent conservation approaches, 136-139

recipient environments

anthropogenic activities affect, NIS post-arrival, 394-397, 400-405

community interaction changes, 400-401

'enemy release', 401-402

physical alteration, 394-397

physiological alteration, 400-405

species diversity loss, 400-401

top-down control, loss of, 401-402

recreational vessels, 396, 397-398, 399

recruitment

anthropogenic activity effects, 71

boulder-fields biota, 45-46

limitations and dominant species, 57

Pyura stolonifera species complex, 69

self-recruitment and inbreeding, 59

red algae, see also algae

lack of impact, 70

palatability, 434, 436

preference summary, 425-426, 428-430, 434

successional sequence dominance, 37

red cushion starfish, 18

Red Sea, see also specific country abundance, presence, and status of giant clams, 96-97

giant clam species checklist, 167

illegal harvesting, 131

local mitigation measures, 134

new giant clam species, 90

Tridacna squamosa, 127

Tridacna squamosina, 128

Reef Check surveys, 93, 254-374

regulations, see legislation and regulations

remineralization, 60

reproductive cycle, 63-64

Republic of Kiribati

abundance, presence, and status of giant clams, $\mathbf{1 1 3}$

density patterns, wild giant clams, 234-235

giant clam species checklist, 183-184

localities with giant clams, 162-163

local mitigation measures, 135

Tridacna gigas, 125

Tridacna maxima, 128

resource availability, ecosystem modulation, 57-59

restoration of degradation/loss, boulder-fields, 47-48

restricted maximum-likelihood estimator, 428

Rhodophyta, 426-427, 429

rock composition, boulder-fields, 45-46

rocky shore species, 60, see also ecological dominance Rosenberg's fail-safe number, 431

\section{S}

Sabah (Malaysia), 95, 126

salmon farming, 396-397, 398

Samoa

abundance, presence, and status of giant clams, 119

giant clam species checklist, 186

Hippopus hippopus, 123

localities with giant clams, 163

local mitigation measures, 135

Tridacna gigas, 126

Tridacna maxima, 128

Tridacna squamosa, 127

Samoan Archipelago, 235

San Francisco estuary, 394

Saudi Arabia

abundance, presence, and status of giant clams, $\mathbf{9 7}$

density patterns, wild giant clams, 235-236

distribution, giant clams, 358-360

giant clam species checklist, 167

localities with giant clams, $\mathbf{1 6 3}$

Tridacna squamosina, 128

Saya de Malha Banks

abundance, presence, and status of giant clams, 99

giant clam species checklist, 170

localities with giant clams, $\mathbf{1 6 3}$

new giant clam species, 90

Tridacna rosewateri, 129

Scarborough Shoal, 131

seagrass beds, starfish grazing impacts, 22, 24

sea pens, 19

sea star as predator, 68,70

sea urchins

anthropogenic activity effects, 43-44

competition in assemblages, 46 


\section{SUBJECT INDEX}

feeding preference, 402

grazing effects of, 2, 26

green algae effects on, 434

microhabitats, boulder-fields, 43

obligate herbivores, 16

post-settlement dispersal, 47

seaweed invasions, 429, 431

seaweed invasions

Chlorophyta, 424, 429

communities, 431

consumer preference meta-analysis, 429-432

data extraction, 422-423

discussion, 432-436

herbivore preference summary, 424-427

introduction, 421-422

literature search, 422-423

meta-analysis, 423, 428, 429-436

overview, 421

Phaeophyceae, 425-426, 429

publication bias, 431

results, 428-432

Rhodophyta, 426-427, 429

sensitivity analysis, 431

temporal trends, 431

self-recruitment, 59, 64

sensitivity analysis, seaweed invasions, 431

sessile species, see also giant clams

boulder-field restoration, 47-48

boulder-fields, 40, 47-48

dominance, intertidal zone, 57

grazing effects on, 23

obligate herbivores, 17

restoration, 47-48

settlement, P.s.s.c., 63-64

Seychelles

abundance, presence, and status of giant clams, 99

density patterns, wild giant clams, 236

distribution, giant clams, 360

giant clam species checklist, 168-169

localities with giant clams, 163

Singapore

abundance, presence, and status of giant clams, 105

bleaching events, 132

density patterns, wild giant clams, 236

giant clam species checklist, 178

illegal harvesting, 131-132

localities with giant clams, 163

local mitigation measures, 135

Tridacna gigas, 125

Tridacna squamosa, 127

size

boulders, 37, 39

ecological dominance, 57

grazing, 2

Hippopus porcellanus, 125

limits, local mitigation measures, 135

obligate herbivores, 15

starfish, 17-20

Tridacna derasa, 126

Tridacna gigas, 125

Tridacna lorenzi, 130

Tridacna maxima, 128
Tridacna mbalavuana, 126-127

Tridacna noae, 129

Tridacna rosewateri, 129

Tridacna squamosa, 127

Tridacna squamosina, 128

small giant clam, see Tridacna maxima

small invertebrates ingestion benefits, 16-17

smooth giant clam, see Tridacna derasa

Society Islands, 127

Solasteridae, 8

Solomon Islands

abundance, presence, and status of giant clams, $\mathbf{1 1 0}$

density patterns, wild giant clams, 236-237

distribution, giant clams, 360-362

giant clam species checklist, 182

localities with giant clams, 164

local mitigation measures, 135

mariculture for restocking, 135-136

Tridacna crocea, 130

Tridacna derasa, 126

Tridacna maxima, 128

Tridacna squamosa, 127

Somalia

abundance, presence, and status of giant clams, 97

giant clam species checklist, 169

localities with giant clams, 164

sooty oystercatcher, 68

South Africa

abundance, presence, and status of giant clams, 99

anthropogenic activity effects, 71

boulder-fields, 41,44

chitons, 41

composition, P.s.s.c.-associated communities, 67

distribution, giant clams, 362

general Tridacnines distribution, 93

giant clam species checklist, 169

localities with giant clams, 164

NIS mussel species, 70

non-indigenous mussel species, 70, 397, 402

Pyura stolonifera species complex, 62, 67, 68, 73

starfish grazing impacts, 22

South America, 62, 73

South Asia, 103-106, see also specific country

South China Sea, see also specific country abundance, presence, and status of giant clams, 102 density patterns, wild giant clams, 237-242

giant clam species checklist, 171-172

illegal harvesting, 131

localities with giant clams, $\mathbf{1 6 4}$

local mitigation measures, 134

Tridacna maxima, 128

South-east Africa, see also specific country abundance, presence, and status of giant clams, 98-99 giant clam species checklist, 168-169

local mitigation measures, 134

mariculture and restocking, 139

Tridacna gigas, 125

South-east Asia

giant clam species checklist, 172-179

local mitigation measures, 135

mariculture for restocking, 135

Tridacna noae, 129 


\section{SUBJECT INDEX}

South Pacific, 135, 139

Spain, 69

spatial and temporal/seasonal shifts in diet, 9-12, 18-19

spatially explicit modelling, 138

spatial pattern variability, 38

species-area relationship models, 37-38

species checklist, giant clams, 167-188

species diversity loss, 400-401

species names, starfish, 34

Spinulosida, 21

sponges

boulder-fields, 39

dominance, under boulders, 43

as food, 19

grazing and predation, 46

obligate herbivores, 17

P.s.s.c. competitive superiority over, 66

Spratly Islands, 131, 239-242

Sri Lanka

abundance, presence, and status of giant clams, 100

distribution, giant clams, 362

giant clam species checklist, 170

localities with giant clams, $\mathbf{1 6 4}$

standardized mean difference method, 423

starfish, see also grazing by starfish

boulder-fields, 41

current/previous names, 34

predation by gulls, 47

status, giant clams, 96-122

stellate $v s$. pentagonal body profile, 21

Stichasteridae, 8, 12, 18

stomach extrusion, 18

storms, 71, 396

strawberry clam, see Hippopus hippopus

stress combinations, boulder-fields biota, 45

Subphylum Tunicata, see Pyura stolonifera species complex

successional sequence dominance, boulder-fields, 36-37

Sudan

abundance, presence, and status of giant clams, $\mathbf{9 7}$

density patterns, wild giant clams, 242

distribution, giant clams, 362-363

giant clam species checklist, 167

localities with giant clams, 164

Suez Canal, 403

Sulu Archipelago, 90, 123

sunstar as predator, 68

surroundings, boulder-fields biota, 44

suspension-feeding, 56, 65-66

\section{$\mathbf{T}$}

Taiwan

abundance, presence, and status of giant clams, 102

distribution, giant clams, 363-364

giant clam species checklist, 171

localities with giant clams, 165

local mitigation measures, 135

Tridacna maxima, 128

Tridacna noae, 129

Tanmen, 131
Tanzania

abundance, presence, and status of giant clams, 99

density patterns, wild giant clams, 243

distribution, giant clams, 364-365

giant clam species checklist, 169

localities with giant clams, $\mathbf{1 6 5}$

Tasmania, 26, 70

Tatakoto Atoll, 133

taxonomy, giant clams, 90-92, see also specific species temporal variation and trends, 41, 43, 431

‘tevoro', 90

Thailand

abundance, presence, and status of giant clams, 106 density patterns, wild giant clams, 243

distribution, giant clams, 365-369

giant clam species checklist, 178

localities with giant clams, $\mathbf{1 6 5}$

local mitigation measures, 135

Tridacna squamosa, 127

theories development, 36-39

threats, giant clams, 131-133, 134

Tokelau

abundance, presence, and status of giant clams, 119

density patterns, wild giant clams, 243-244

giant clam species checklist, $\mathbf{1 8 6}$

localities with giant clams, $\mathbf{1 6 5}$

Tridacna squamosa, 127

Tonga

abundance, presence, and status of giant clams, $\mathbf{1 2 0}$

density patterns, wild giant clams, 244-248

distribution, giant clams, $\mathbf{3 6 9}$

giant clam species checklist, 187

Hippopus hippopus, 123

localities with giant clams, 165-166

local mitigation measures, 135

Tridacna derasa, 126

Tridacna gigas, 125-126

Tridacna maxima, 128

Tridacna mbalavuana, 127

Tridacna squamosa, 127

Tonga Fisheries Hatchery, 127

top-down control, loss of, 401-402

toxic contaminants, 393-394

translocation of species, 391

transport facilitation, 389, 398-399

tree topologies, giant clams, 90, 91

Tridacna crocea, 95, 124, 130, 134

Tridacna derasa, 95, 124, 126, 134

Tridacna gigas, 95, 124-126, 134

Tridacna lorenzi, 95, 130

Tridacna maxima, 95, 124, 128, 134

Tridacna mbalavuana, 95, 124, 126-127, 134

Tridacna noae, 95, 124, 129

Tridacna rosewateri, 95, 129, 134

Tridacna squamosa, 95, 124, 127, 134

Tridacna squamosina, 95, 124, 128

Tridacninae, see giant clams

triton shell, as predator, 68

trophic complexity, 57

true cockles, 90

Tuamotu Archipelagos, 127 


\section{SUBJECT INDEX}

Tubbataha Reef Natural Park, 123

tube feet, starfish, 2, 21

tubeworms, 39, 60

Tunicata, see Pyura stolonifera species complex

tunicates, human exploitation, 71

Tuvalu

abundance, presence, and status of giant clams, 121

density patterns, wild giant clams, 248-249

giant clam species checklist, 187-188

localities with giant clams, 166

\section{$\mathbf{U}$}

undersurfaces, boulders, 39-40, 43

United States, 398-399, see also specific state

United States Minor Outlying Islands

abundance, presence, and status of giant clams, 116

giant clam species checklist, $\mathbf{1 8 5}$

localities with giant clams, 166

University of Guam Marine Laboratory, 135

Upper Cretaceous period, 88

upper surfaces, boulders, 39, 43

\section{V}

Valvatida, 21

Vanuatu

abundance, presence, and status of giant clams, 111

density patterns, wild giant clams, 249-251

distribution, giant clams, 369-370

giant clam species checklist, 182-183

localities with giant clams, 166

local mitigation measures, 135

Tridacna crocea, 130

Tridacna gigas, 126

Tridacna maxima, 128

Tridacna squamosa, 127

veliger larvae, 65

Venerida, 90

Viet Nam

abundance, presence, and status of giant clams, 106 density patterns, wild giant clams, 252-253 distribution, giant clams, 370-374

giant clam species checklist, 178-179

localities with giant clams, 166

Viti Kevu (Fiji), 90

'Vulnerable' status

Tridacna derasa, 126, 134

Tridacna gigas, 125, 134

Tridacna mbalavuana, 127, 134

Tridacna rosewateri, 129, 134

W

Waikiki Aquarium (Honolulu), 126

Wallis and Futuna Islands

abundance, presence, and status of giant clams, 121

giant clam species checklist, 188

localities with giant clams, $\mathbf{1 6 6}$

water quality, 391-394

WebPlotDigitizer software, 423

weediness, non-indigenous species, 393-394

Western Australia, 129

West Wind Drift, 63

whelks, 60, 70

wind farm clusters, 395

Y

Yap, see also Federated States of Micronesia

Hippopus hippopus, 123

mariculture for restocking, 136, 137

Tridacna noae, 129

Yemen

abundance, presence, and status of giant clams, 97

density patterns, wild giant clams, 253

distribution, giant clams, 374

giant clam species checklist, 167

localities with giant clams, 166

Tridacna squamosina, 128

$\mathbf{Z}$

zooxanthellates, 90 